
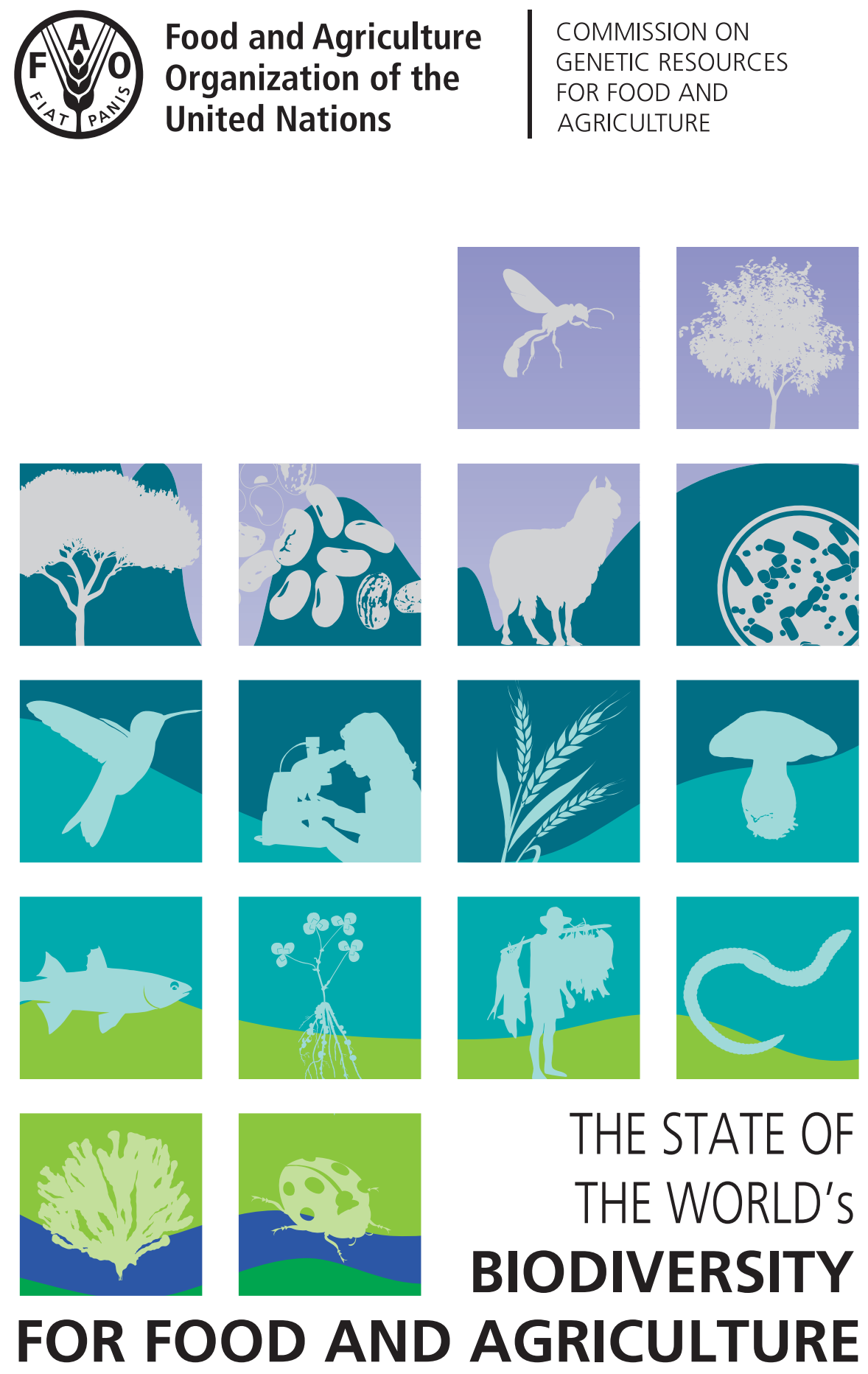

FOR FOOD AND AGRICULTURE 

FAO COMMISSION ON GENETIC RESOURCES FOR FOOD AND AGRICULTURE

ASSESSMENTS • 2019

\section{THE STATE OF}

THE WORLD'S

BIODIVERSITY

FOR FOOD AND AGRICULTURE

COMMISSION ON GENETIC RESOURCES FOR FOOD AND AGRICULTURE FOOD AND AGRICULTURE ORGANIZATION OF THE UNITED NATIONS 


\section{Required citation:}

FAO. 2019. The State of the World's Biodiversity for Food and Agriculture, J. Bélanger \& D. Pilling (eds.). FAO Commission on Genetic Resources for Food and Agriculture Assessments. Rome. 572 pp.

(http://www.fao.org/3/CA3129EN/CA3129EN.pdf)

Licence: CC BY-NC-SA 3.0 IGO.

The designations employed and the presentation of material in this information product do not imply the expression of any opinion whatsoever on the part of the Food and Agriculture Organization of the United Nations (FAO) concerning the legal or development status of any country, territory, city or area or of its authorities, or concerning the delimitation of its frontiers or boundaries. The mention of specific companies or products of manufacturers, whether or not these have been patented, does not imply that these have been endorsed or recommended by FAO in preference to others of a similar nature that are not mentioned.

The views expressed in this information product are those of the author(s) and do not necessarily reflect the views or policies of FAO.

ISBN 978-92-5-131270-4

(C) FAO, 2019

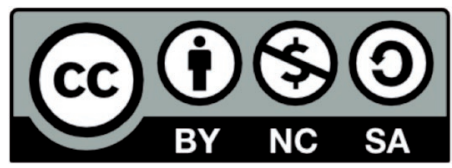

Some rights reserved. This work is made available under the Creative Commons AttributionNonCommercial-ShareAlike 3.0 IGO licence (CC BY-NC-SA 3.0 IGO; https://creativecommons.org/ licenses/by-nc-sa/3.0/igo/legalcode/legalcode).

Under the terms of this licence, this work may be copied, redistributed and adapted for non-commercial purposes, provided that the work is appropriately cited. In any use of this work, there should be no suggestion that FAO endorses any specific organization, products or services. The use of the FAO logo is not permitted. If the work is adapted, then it must be licensed under the same or equivalent Creative Commons licence. If a translation of this work is created, it must include the following disclaimer along with the required citation: "This translation was not created by the Food and Agriculture Organization of the United Nations (FAO). FAO is not responsible for the content or accuracy of this translation. The original [Language] edition shall be the authoritative edition."

Disputes arising under the licence that cannot be settled amicably will be resolved by mediation and arbitration as described in Article 8 of the licence except as otherwise provided herein. The applicable mediation rules will be the mediation rules of the World Intellectual Property Organization http://www.wipo.int/amc/en/mediation/rules and any arbitration will be conducted in accordance with the Arbitration Rules of the United Nations Commission on International Trade Law (UNCITRAL).

Third-party materials. Users wishing to reuse material from this work that is attributed to a third party, such as tables, figures or images, are responsible for determining whether permission is needed for that reuse and for obtaining permission from the copyright holder. The risk of claims resulting from infringement of any third-party-owned component in the work rests solely with the user.

Sales, rights and licensing. FAO information products are available on the FAO website (www.fao.org/publications) and can be purchased through publications-sales@fao.org. Requests for commercial use should be submitted via: www.fao.org/contact-us/licence-request. Queries regarding rights and licensing should be submitted to: copyright@fao.org. 


\section{Contents}

Foreword

xix

Acknowledgements

$x x i$

Abbreviations and acronyms $\quad x x v i$

About this publication $\quad x x x i$

Executive summary xxxvii

\section{Part A Overview}

CHAPTER 1 INTRODUCTION

1.1 Biodiversity and the challenges facing global food and agriculture 3

1.2 What is biodiversity for food and agriculture?

1.3 Biodiversity for food and agriculture and global policy agendas 5

1.4 Assessments of biodiversity for food and agriculture 8

1.5 Key concepts addressed in this report $\quad 10$

\section{CHAPTER 2 ROLES AND IMPORTANCE OF BIODIVERSITY} FOR FOOD AND AGRICULTURE

Key messages 17

$\begin{array}{lll}2.1 & \text { Introduction } & 17\end{array}$

2.2 Ecosystem services 18

$\begin{array}{ll}\text { 2.2.1 Provisioning services } & 19\end{array}$

2.2.2 Regulating and supporting services $\quad 20$

2.2.3 Cultural services $\quad 22$

2.3 Resilience 23

2.3.1 Overview of the contributions of biodiversity for
food and agriculture

2.3.2 Resilience to specific threats 27

2.3.3 Needs and priorities $\quad 34$

2.4 Sustainable intensification $\quad 35$

2.4.1 Overview of the contributions of biodiversity for food and agriculture $\quad 36$

2.4.2 Needs and priorities $\quad 41$

2.5 Livelihoods 41

2.5.1 Overview of the contributions of biodiversity for
food and agriculture

2.5.2 Needs and priorities 48

2.6 Food security and nutrition $\quad 48$

$\begin{array}{lll}2.6 .1 & \text { Availability } & 49\end{array}$

2.6.2 Access 50

2.6.3 Utilization $\quad 51$

2.6.4 Stability 52

2.6.5 Nutrition and food systems 53

2.6.6 Contribution of wild foods $\quad 56$

2.6.7 Needs and priorities $\quad 62$ 


\section{Part B Drivers, status and trends}

\section{CHAPTER 3 DRIVERS OF CHANGE OF BIODIVERSITY FOR FOOD}

AND AGRICULTURE

Key messages $\quad 65$

3.1 Introduction $\quad 65$

3.2 Overview $\quad 69$

$\begin{array}{lll}3.3 & \text { Economic and social drivers } & 69\end{array}$

3.3.1 Population growth and urbanization 70

3.3.2 Markets, trade and value chains $\quad 74$

3.3.3 Changing economic, sociopolitical and cultural factors 76

$\begin{array}{lll}3.4 & \text { Environmental drivers } & 78\end{array}$

$\begin{array}{lll}3.4 .1 & \text { Climate change } & 78\end{array}$

3.4.2 Natural disasters $\quad 83$

$\begin{array}{lll}\text { 3.4.3 Pests, diseases and invasive alien species } & 87\end{array}$

3.5 Advances and innovations in science and technology 93

3.6 Drivers at production-system level 95

3.6.1 Changes in land and water use and management 95

$\begin{array}{ll}\text { 3.6.2 Pollution and external inputs } & 101\end{array}$

$\begin{array}{ll}\text { 3.6.3 Overexploitation and overharvesting } & 104\end{array}$

$\begin{array}{lll}3.7 & \text { Policies } & 107\end{array}$

3.8 Drivers of women's involvement in the management of
biodiversity for food and agriculture

3.9 Drivers of traditional knowledge of biodiversity for $\begin{array}{ll}\text { food and agriculture } & 111\end{array}$

\section{CHAPTER 4 THE STATUS AND TRENDS OF BIODIVERSITY FOR FOOD AND AGRICULTURE}

4.1 Introduction

4.2 Plant, animal, forest and aquatic genetic resources for food and agriculture

4.2.1 Plant genetic resources for food and agriculture 114

4.2.2 Animal genetic resources for food and agriculture 116

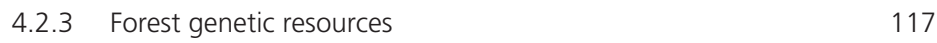

4.2.4 Aquatic genetic resources for food and agriculture 117

$\begin{array}{lll}4.3 & \text { Associated biodiversity } & 119\end{array}$

4.3.1 Associated-biodiversity species managed for

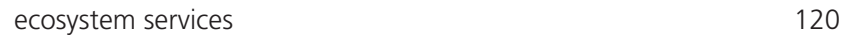

4.3.2 Information and monitoring systems on associated biodiversity 120

$\begin{array}{ll}\text { 4.3.3 Overview of status and trends } & 126\end{array}$

$\begin{array}{ll}\text { 4.3.4 Associated biodiversity for pollination } & 129\end{array}$

4.3.5 Associated biodiversity for pest and disease regulation 134

4.3.6 Associated biodiversity for soil-related ecosystem services $\quad 140$

4.3.7 Associated biodiversity for water-related ecosystem services 148 
4.3.8 Associated biodiversity for natural-hazard regulation 153

4.3.9 Associated biodiversity for habitat provisioning 154

4.3.10 Associated biodiversity for air-quality and climate regulation 157

4.4 Wild foods 160

$\begin{array}{ll}\text { 4.4.1 State of knowledge } & 160\end{array}$

$\begin{array}{ll}\text { 4.4.2 Status and trends } & 161\end{array}$

4.5 Ecosystems of importance to food and agriculture 171

$\begin{array}{lll}4.5 .1 & \text { Wetlands } & 171\end{array}$

4.5.2 Mangroves 172

$\begin{array}{lll}4.5 .3 \text { Seagrasses } & 175\end{array}$

$\begin{array}{lll}4.5 .4 & \text { Coral reefs } & 177\end{array}$

$\begin{array}{lll}4.5 .5 & \text { Forests } & 180\end{array}$

4.5.6 Rangelands 183

$\begin{array}{lll}4.6 & \text { Needs and priorities } & 186\end{array}$

\section{Part C State of management}

\section{CHAPTER 5 THE STATE OF USE OF BIODIVERSITY FOR FOOD}

AND AGRICULTURE 191

Key messages $\quad 191$

$\begin{array}{lll}5.1 & \text { Introduction } & 191\end{array}$

5.2 Overview of management practices and approaches 192

5.3 Ecosystem, landscape and seascape approaches 198

$\begin{array}{ll}\text { 5.3.1 Overview } & 198\end{array}$

5.3.2 Sustainable forest management 201

5.3.3 Ecosystem approach to fisheries and aquaculture 205

5.3.4 Agroecology 208

5.3.5 Landscape and seascape approaches and management 212

5.3.6 Integrated land- and water-use planning 213

$\begin{array}{ll}\text { 5.3.7 Needs and priorities } & 214\end{array}$

$\begin{array}{lll}5.4 & \text { Restoration practices } & 215\end{array}$

$\begin{array}{lll}\text { 5.4.1 Overview } & 215\end{array}$

$\begin{array}{ll}\text { 5.4.2 Status and trends } & 218\end{array}$

$\begin{array}{ll}\text { 5.4.3 Needs and priorities } & 222\end{array}$

5.5 Diversification in production systems 223

$\begin{array}{lll}\text { 5.5.1 Integrated crop-livestock systems } & 224\end{array}$

$\begin{array}{ll}\text { 5.5.2 Home gardens } & 228\end{array}$

5.5.3 Agroforestry 233

$\begin{array}{ll}\text { 5.5.4 Diversification practices in aquaculture } & 241\end{array}$

$\begin{array}{lll}\text { 5.5.5 Needs and priorities } & 248\end{array}$

5.6 Management practices and production approaches 248

$\begin{array}{lll}\text { 5.6.1 Organic agriculture } & 249\end{array}$

5.6.2 Low external input agriculture 251

5.6.3 Management practices to preserve and enhance soil biodiversity 253 
5.6.4 Conservation agriculture 256

5.6.5 Integrated plant nutrient management 259

5.6.6 Integrated pest management 260

$\begin{array}{lll}\text { 5.6.7 Pollination management } & 267\end{array}$

$\begin{array}{lll}\text { 5.6.8 } & \text { Forest-management practices } & 272\end{array}$

$\begin{array}{ll}\text { 5.6.9 Needs and priorities } & 275\end{array}$

5.7 The use of micro-organisms in food processing and agro-industrial processes $\quad 275$

5.7.1 Micro-organisms in food processing 276

5.7.2 Micro-organisms in agro-industrial processes 280

5.8 Rumen microbial diversity 287

$\begin{array}{lll}\text { 5.8.1 Roles and drivers } & 287\end{array}$

$\begin{array}{ll}\text { 5.8.2 Methane emissions } & 289\end{array}$

$\begin{array}{ll}\text { 5.8.3 State of knowledge } & 289\end{array}$

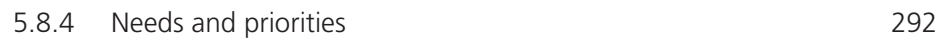

5.9 Genetic improvement 292

5.9.1 Domestication and base broadening 293

5.9.2 Plant, animal, forest and aquatic genetic resources for
food and agriculture 295

$\begin{array}{ll}\text { 5.9.3 Associated biodiversity - overview } & 297\end{array}$

$\begin{array}{lll}5.9 .4 & \text { Pollinators } & 298\end{array}$

5.9.5 Assisted evolution for reef-building corals 301

$\begin{array}{ll}\text { 5.9.6 Needs and priorities } & 304\end{array}$

\section{CHAPTER 6 THE STATE OF CHARACTERIZATION OF BIODIVERSITY FOR} FOOD AND AGRICULTURE

6.1 Introduction 305

6.2 Plant, animal, forest and aquatic genetic resources for food and agriculture $\quad 306$

6.2.1 Plant genetic resources for food and agriculture 306

6.2.2 Animal genetic resources for food and agriculture 307

6.2.3 Forest genetic resources 308

6.2.4 Aquatic genetic resources for food and agriculture 311

6.3 Associated biodiversity $\quad 312$

$\begin{array}{lll}6.3 .1 & \text { Overview } & 313\end{array}$

$\begin{array}{ll}\text { 6.3.2 Country-report analysis } & 314\end{array}$

6.4 Wild foods 318

$\begin{array}{lll}6.4 .1 & \text { Overview } & 318\end{array}$

$\begin{array}{ll}\text { 6.4.2 Country-report analysis } & 321\end{array}$

6.5 Needs and priorities 323 


\section{CHAPTER 7 THE STATE OF CONSERVATION OF BIODIVERSITY FOR FOOD AND AGRICULTURE}

Key messages 325

7.1 Introduction 325

7.2 Plant, animal, forest and aquatic genetic resources for
food and agriculture 326

7.2.1 Plant genetic resources for food and agriculture 326

7.2.2 Animal genetic resources for food and agriculture 329

7.2.3 Forest genetic resources 330

7.2.4 Aquatic genetic resources for food and agriculture 332

7.3 Associated biodiversity 334

7.3.1 In situ conservation 334

7.3.2 Ex situ conservation 344

7.4 Wild foods 354

7.4.1 In situ conservation 354

7.4.2 Ex situ conservation 357

7.5 Roles of protected areas 359

7.5.1 Status and trends 361

7.5.2 Contribution to conservation of wild species used for food 362

7.5.3 Management of biodiversity or food and agriculture
in protected areas

7.5.4 Country-report analysis 367

7.6 Maintenance of traditional knowledge associated with
food and agriculture

$\begin{array}{lll}7.7 & \text { Needs and priorities } & 373\end{array}$

\section{Part D Enabling frameworks}

CHAPTER 8 THE STATE OF POLICIES, INSTITUTIONS AND CAPACITIES 379

Key messages $\quad 379$

8.1 Introduction 379

8.2 Stakeholders 380

8.2.1 Producers and their organizations 380

8.2.2 Suppliers, processors, traders and retailers 386

8.2.3 The public sector 386

8.2.4 The non-governmental sector 387

8.2.5 The general public 388

8.2.6 Regional and international organizations 388

8.3 Cooperation 395

8.3.1 Cooperation at national level 396

8.3.2 Cooperation at international level $\quad 398$

8.3.3 Needs and priorities 403

8.4 Education, training and awareness raising 404

8.4.1 Plant, animal, forest and aquatic genetic resources for
food and agriculture

8.4.2 Associated biodiversity 406 
8.4.3 Needs and priorities $\quad 409$

8.5 Research $\quad \mathbf{4 1 0}$

8.5.1 Institutions involved in research on associated biodiversity 411

$\begin{array}{ll}\text { 8.5.2 Needs and priorities } & 411\end{array}$

8.6 Valuation $\quad 412$

8.6.1 Overview of valuation approaches 413

8.6.2 State of implementation 415

8.6.3 Needs and priorities 418

\begin{tabular}{ll}
8.7 & Incentives \\
\hline & 419
\end{tabular}

$\begin{array}{lll}\text { 8.7.1 Overview } & 419\end{array}$

$\begin{array}{lll}\text { 8.7.2 State of adoption } & 420\end{array}$

8.7.3 Needs and priorities $\quad 424$

8.8 Policy and legal frameworks $\quad 425$

8.8.1 Frameworks at international level $\quad 427$

8.8.2 Frameworks at national level 430

8.8.3 Climate change policy and programmes 437

8.8.4 Frameworks supporting the maintenance of
traditional knowledge

8.8.5 Access and benefit-sharing 439

\section{Part E Conclusions}

CHAPTER 9 NEEDS AND CHALLENGES

9.1 Introduction $\quad 445$

9.2 Drivers of change $\quad 445$

9.3 Status and trends $\quad 446$

9.4 Management 446

9.4.1 State of use 446

9.4.2 State of conservation 449

9.5 Policies, capacities and institutions $\quad 450$

9.6 Towards a more diverse and sustainable future $\quad 451$

$\begin{array}{ll}\text { References } & 453\end{array}$ 


\section{BOXES}

1 The Commission on Genetic Resources for Food and Agriculture

xxxii

PART A

1.1 Biodiversity for food and agriculture, FAO and the Sustainable Development Goals

1.2 Assessing the state of the world's genetic resources for food and agriculture

2.1 Projects and programmes supporting livelihoods by promoting biodiversity for food and agriculture - examples from around the world

2.2 The Second International Conference on Nutrition Framework for Action

2.3 Voluntary Guidelines for Mainstreaming Biodiversity into Policies, Programmes and National and Regional Plans of Action on Nutrition 53

2.4 The Biodiversity for Food and Nutrition Project

2.5 Food-based dietary guidelines as a tool to promote biodiversity

\section{PART B}

3.1 Human-made grasslands as a cultural and ecological asset

3.2 Links between biodiversity, biodiversity loss and disease risk

3.3 Unsustainably managed production systems are a key threat to bird species

4.1 The International Union for Conservation of Nature Red List of Threatened Species ${ }^{\mathrm{TM}}$

4.2 Birds as indicator species

4.3 Monitoring total flying insect biomass over 27 years in protected areas in Germany

4.4 The main functional groups of biological control agents

4.5 The roles of birds in the supply of supporting and regulating ecosystem services

4.6 The Netherlands' soil biological monitoring programme 145

4.7 Páramos - a vital provider of water-regulating services under threat 149

4.8 Trends in the state of habitats in the European Union 156

4.9 Soil carbon assessment initiatives - examples from the United States of America

4.10 FAO global definition of forest

\section{PART C}

5.1 The Convention on Biological Diversity's principles and operational guidelines for the ecosystem approach

5.2 The concept of sustainable forest management

5.3 Application of the ecosystem approach in capture fisheries an example from Panama 
5.4 Ecosystem approach to fisheries management in Saint Lucia 207

5.5 The ten elements of agroecology 209

5.6 The Pacific Ridge to Reef approach - an example of integrated land and water-use planning 213

$\begin{array}{lll}5.7 & \text { Needs and challenges in coral-reef restoration } & 220\end{array}$

5.8 The floating gardens of Bangladesh 224

5.9 Promotion of home gardens for healthy diets in Solomon Islands 230

5.10 Projects and initiatives targeting home gardens - examples from around the world 232

5.11 Policy and legislative frameworks promoting agroforestry examples from around the world 238

5.12 France's Agroforestry Development Plan 2015-2020 239

5.13 Fish polyculture for improved nutrition - an example from Bangladesh 246

5.14 The Voluntary Guidelines for Sustainable Soil Management 254

5.15 Burkina Faso's Operation Manure Pits 256

5.16 Conservation agriculture for climate-smart agriculture 258

5.17 The Save and Grow approach $\quad 260$

5.18 The push-pull approach 263

5.19 Integrated pest management in horticultural production in Almería, Spain 265

5.20 Management of stingless bees in Malaysia 269

5.21 Enhancing pollinator presence in cassava fields in Ghana 271

5.22 Measures or steps typically included in reduced-impact logging 273

5.23 Global research efforts in rumen microbiology 290

5.24 SmartBees: a European project for the conservation of endangered
honey-bee subspecies

6.1 The role of molecular techniques in the characterization of foodprocessing micro-organisms $\quad 315$

6.2 Characterization studies on micro-organisms - examples from Peru 317

6.3 Why undertake genetic data analysis of crop wild relatives and wild food plants?

6.4 Study and development of foods and natural products with potential health benefits in Paraguay 322

7.1 The World Information and Early Warning System on Plant Genetic Resources for Food and Agriculture $\quad 327$

7.2 The Domestic Animal Diversity Information System 330

7.3 Marine sanctuaries and monitoring systems - examples from Jamaica 338

7.4 Marine protected areas in Palau 339

7.5 The traditional Hima rangeland management system in Jordan 340

7.6 Agri-environmental schemes supporting cropland and grassland
biodiversity - examples from Belgium

7.7 Initiatives supporting the in situ conservation of pollinators in the
United States of America

7.8 Selected species-conservation measures in Ireland 343

7.9 Plan of Action for the Conservation of the Nordic Brown Bee 345

7.10 Conservation methods for micro-organisms stored ex situ 348

7.11 Cooperation in the ex situ conservation of micro-organisms 350 
7.12 The culture collection of Mexico's National Genetic Resources Centre

7.13 The Microbial Biodiversity Directorate of the Ethiopian Biodiversity Institute

7.14 Micro-organism conservation for improved agricultural production in India

7.15 The role of Japan's National Agriculture and Food Research Organization Genebank in recovering genetic resources after the earthquake of 2011

7.16 Voluntary Guidelines for the Conservation and Sustainable Use of Crop Wild Relatives and Wild Food Plants

$\begin{array}{ll}7.17 & \text { The IUCN Green List of Protected and Conserved Areas } \\ 7.18 & 367\end{array}$

7.19 The role of geographical indications in the maintenance of biodiversity for food and agriculture

7.20 Maintenance and use of indigenous knowledge - examples from Kenya

7.21 Maintenance and use of traditional practices in the Pacific

7.22 Women's traditional knowledge for improved food and seed security under climate change

7.23 Community forest management and development in Ban Banh, Viet Nam

\section{PART D}

8.1 Governance outcomes promoted by small-scale food providers' organizations

8.2 Community control of a coastal ecosystem - an example from Senegal

8.3 Agroforestry under local control - an example from Costa Rica

8.4 The role of a women's group in promoting sustainable fishing - an example from Ecuador

8.5 Contributions of non-governmental organizations to the sustainable management of biodiversity for food and agriculture examples from the Near East

8.6 Zambia's Biodiversity Community Network

8.7 The Norwegian Genetic Resource Centre and its genetic resources committees

8.8 France's Agricultural Biodiversity Observatory

8.9 The Regional Project for Sustainable Management of Globally Significant Endemic Ruminant Livestock (PROGEBE)

8.10 Appointment of national focal points and participation in the preparation of The State of the World's Biodiversity for Food and Agriculture

8.11 Transfrontier conservation areas in Southern Africa

8.12 Resolution 4/2017. The Commission on Genetic Resources for Food and Agriculture and its contribution to the achievement of the Sustainable Development Goals

8.13 Farmer field schools on integrated pest management experiences from Nepal 
8.15 Participatory workshops with local communities in the development of a Globally Important Agricultural Heritage System in Chile

8.16 Incentive schemes promoting sustainable shrimp aquaculture in Viet Nam 424

8.17 Integrated incentive packages for microwatershed development in Brazil 425

8.18 Integrated incentive packages in Mexico

8.19 Binding and soft-law instruments related to port state measures in the capture-fisheries sector

8.20 Biodiversity and international law

8.21 Brazil's experience in mainstreaming biodiversity into its Food and Nutrition Security Policy

8.22 Voluntary Guidelines to Support the Integration of Genetic Diversity into National Climate Change Adaptation Planning 


\section{TABLES}

1 Overview of country reports and their regional distribution

xxxiv

\section{PART A}

1.1 Production-system classification used in this report

2.1 Biological control of invasive alien species through predation, parasitism and herbivory - examples from the country reports

2.2 Biological control of invasive alien species through resource competition and other antagonistic relationships - examples from the country reports

2.3 Species or varieties that are tolerant or resistant to the effects of invasive alien species - examples from the country reports

2.4 Potential interventions to support positive interactions in food production systems

\section{PART B}

3.1 Drivers of change explored in the country-reporting guidelines

3.2 Reported effects of drivers of change on regulating and supporting ecosystem services, all production systems aggregated

3.3 Number of countries reporting negative, neutral and positive effects of drivers of change on the diversity, availability and knowledge of wild foods

3.4 Reported effects of population growth and urbanization on the provision of regulating and supporting ecosystem services, by production system

3.5 Reported effects of markets, trade and the private sector on the provision of regulating and supporting ecosystem services, by production system

3.6 Reported effects of changing economic, sociopolitical and cultural factors on the provision of regulating and supporting ecosystem services, by production system

3.7 Reported effects of climate change on the provision of regulating and supporting ecosystem services, by production system

3.8 Natural disasters reported to have had a significant effect on biodiversity for food and agriculture and/or on ecosystem services in the past ten years

3.9 Reported effects of natural disasters on the provision of regulating and supporting ecosystem services, by production system

3.10 Reported effects of pests, diseases and invasive alien species on the provision of regulating and supporting ecosystem services, by production system

3.11 Invasive alien species reported by five or more countries as present in one or more production systems 
3.12 Reported effects of advances and innovations in science and technology on the provision of regulating and supporting ecosystem services, by production system

3.13 Reported effects of changes in land and water use and management on the provision of regulating and supporting ecosystem services, by production system

3.14 Reported effects of pollution and external input use on the provision of regulating and supporting ecosystem services, by production system

3.15 Reported effects of overexploitation and overharvesting on the provision of regulating and supporting ecosystem services, by production system

3.16 Reported effects of policies on the provision of regulating and supporting ecosystem services, by production system

4.1 Examples of species and genera reported by countries to be managed for regulating or supporting ecosystem services in production systems

4.2 Species and genera most frequently reported to be managed for multiple supporting and regulating ecosystem services

4.3 Risk status of associated biodiversity for which a significant threat of extinction or loss is reported

4.4 Reported trends in the state of provision of regulating and supporting ecosystem services in production systems

4.5 Examples of associated-biodiversity species or species groups that contribute to pest and disease regulation reported to be under threat 138

4.6 The functions of soil organisms

4.7 Typical numbers of soil organisms in healthy ecosystems

4.8 Summary of regional extent, trends and uncertainties of soilbiodiversity loss presented in the Status of the World's Soil Resources

4.9 Selected examples of wild food species and genera reported by countries

4.10 Global forest area change (1990-2015)

\section{PART C}

5.1 Reported levels of adoption of selected management practices and approaches, all production systems aggregated

5.2 Reported trends in the adoption of selected management practices and approaches, by production system

5.3 Reported ecosystem, landscape and seascape approaches 202

5.4 Restoration measures for wetlands and other aquatic ecosystems 217

5.5 Land area under agroforestry (2008-2010) and trends (2000-2010), by region

5.6 Major benefits and challenges of aquaponic food production

5.7 Indicators of the status of organic agriculture worldwide

5.8 Environmental and other benefits of implementing the three principles of conservation agriculture 
5.9 Examples of integrated pest management measures

5.10 Examples of the roles of associated biodiversity in integrated pest management

6.1 Traits and methods used for characterizing germplasm: percentage of accessions characterized and/or evaluated, by region

6.2 Degree of characterization for the five largest crop collections conserved by 27 reporting countries

6.3 Characters most frequently assessed in 692 evaluations of foresttree genetic variability reported by countries

6.4 Known and estimated number of species of soil organisms and vascular plants

7.1 Associated biodiversity species and genera reported to be conserved in situ, by taxonomic group

7.2 Associated biodiversity species reported to be conserved ex situ, by taxonomic group

7.3 Wild food species and genera reported to be conserved in situ, by taxonomic group

7.4 Wild food species and genera reported to be conserved ex situ, by taxonomic group

7.5 IUCN Protected Area Management Categories

7.6 Number of species in the comprehensively assessed groups of The IUCN Red List with mapped ranges and classified as used for human food 364

7.7 Types of designated area reported to be of particular significance for biodiversity for food and agriculture

\section{PART D}

8.1 Selected regional intergovernmental bodies and multilateral partnerships reported by countries to contribute to initiatives in the management of associated biodiversity

8.2 Examples of associated-biodiversity management activities reported by international organizations

8.3 Examples of practices reported to be promoted through the provision of incentives 


\section{FIGURES}

1 Assignment of countries to regions in this report

XXXV

PART A

1.1 Key developments in the international recognition of the importance of biodiversity for food and agriculture

2.1 Damage and loss to agriculture sectors caused by specific types of abiotic hazard (2006-2016)

2.2 The sustainable livelihoods analytical framework

2.3 Types of wild-food use reported by countries

\section{PART B}

3.1 Reported climate change-related threats to associated biodiversity, (A) by region and (B) by production system

3.2 Global trends in the occurrence of natural disasters - 1980 to 2017

3.3 Invasive alien species reported by countries to be impacting biodiversity for food and agriculture, A) by type of organism and (B) by region

4.1 Regulating and supporting ecosystem services for which associated biodiversity is reported to be managed, by sector of production

4.2 Reported threats to associated biodiversity, by region

4.3 Reported trends in associated biodiversity, by production system

4.4 The soil food web

4.5 Map of the Soil Biodiversity Index

4.6 Map of potential threats to soil biodiversity

4.7 Global risk status of invertebrates in the classes Bivalvia, Holothuroidea, Maxillopoda and Polychaeta

4.8 Global risk status of species included in The IUCN Red List of Threatened Species, by habitat

4.9 Number of wild food species reported, by type and region

4.11 Production systems and environments in which wild food species are present and harvested, by type

4.12 Reported trends in the status of wild food species, by region

4.13 Reported trends in the status of wild food species, by type

4.14 Risk categories of wild foods for which a significant threat of extinction or loss is reported, by region

4.15 Reported threats to wild foods species

4.16 Number of species classified as used for human food on The IUCN Red List of Threatened Species, by type and risk category

4.17 Global distribution of mangroves

4.18 Interconnectivity between coastal ecosystems 
4.20 Global status of reef-building corals 179

4.21 Annual change in forest area (1990-2015) 182

4.22 Global distribution of ruminant livestock production systems 184

4.23 Global grasslands suitable and unsuitable for crop production and share of land use

\section{PART C}

5.1 Perceived impacts on biodiversity for food and agriculture of various management practices and approaches $\quad 197$

5.2 The ten principles that characterize the landscape approach 200

$\begin{array}{lll}5.3 & \text { Legal and policy frameworks on agroecology } & 211\end{array}$

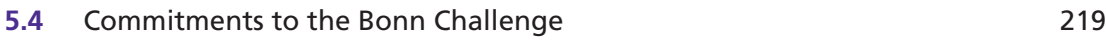

5.5 Livestock and crop integration: from a linear to a circular bioeconomy 225

5.6 An example of an aquaponic system 243

5.7 Rumen microbial fermentation 288

5.8 Motivation for and steps involved in the assisted-evolution
approaches in corals

6.1 Reported progress in the implementation of $(A)$ phenotypic and (B) molecular characterization in livestock species of economic importance $\quad 309$

6.2 Status of characterization or evaluation of associated biodiversity species reported to be conserved ex situ, by region 316

6.3 Wild foods in the FAO/INFOODS Food Composition Database for Biodiversity

6.4 Status of identification and characterization of differences within wild food species reported by countries, by type

7.1 Reported objectives for the in situ conservation of associated biodiversity 336

7.2 Reported actions for the in situ conservation of associated biodiversity 337

7.3 Reported objectives for the ex situ conservation of associated biodiversity 347

7.4 Reported objectives for the in situ conservation of wild foods 357

7.5 Progress of global coverage of protected areas 361

7.6 Geographic distribution of the terrestrial, marine and coastal protected areas of the world 362

7.7 Protected area coverage of species in the comprehensively assessed taxonomic groups of The IUCN Red List with mapped ranges and classified as used for human food

7.8 Protected area coverage of species in the comprehensively assessed taxonomic groups of The IUCN Red List with mapped ranges and classified as threatened and as used for human food

\section{PART D}

8.1 Elements of the TEEBAgriFood Evaluation Framework

8.2 Examples of sources of incentives to support sustainable use and conservation of biodiversity 


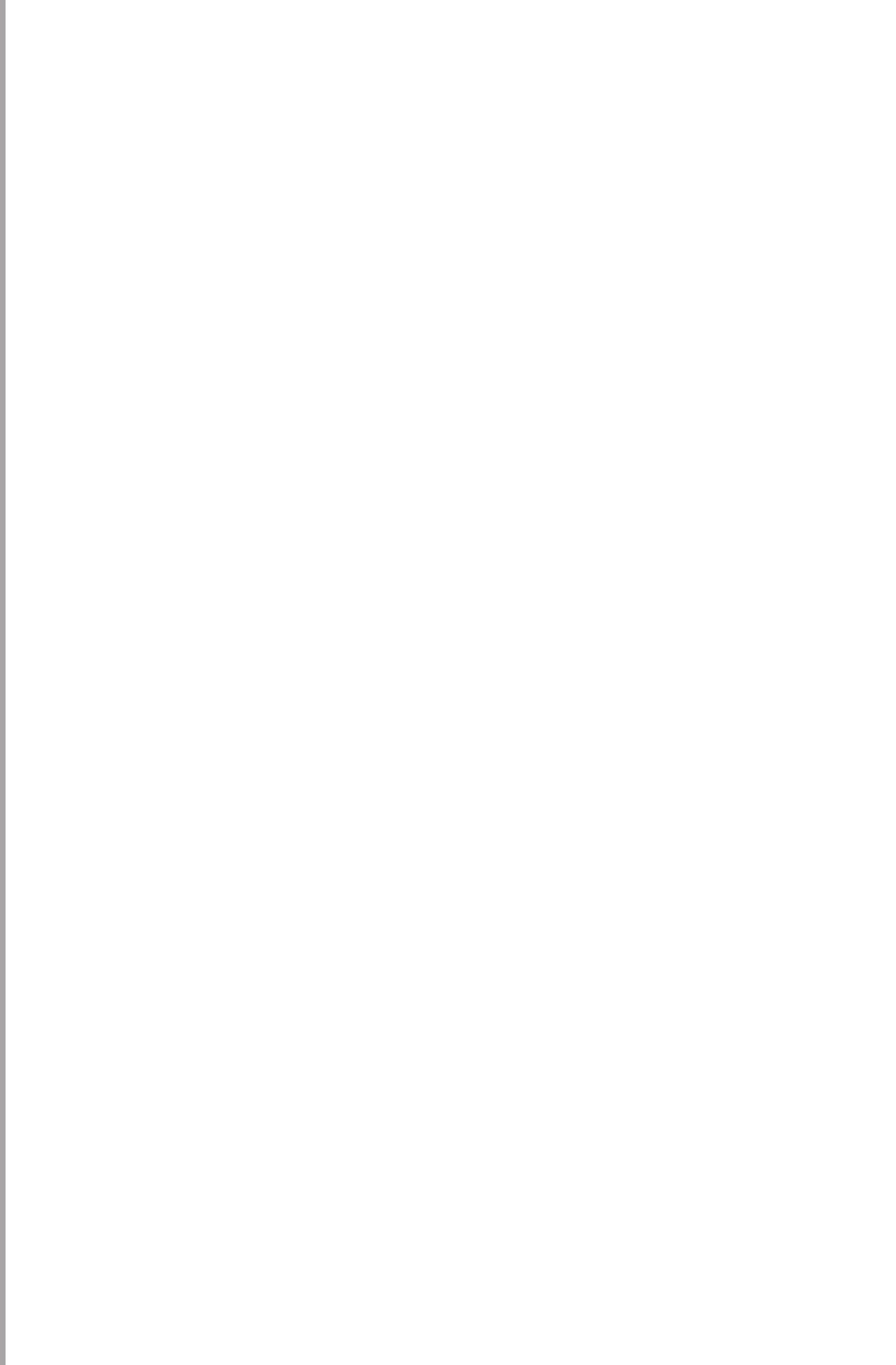




\section{Foreword}

$\mathrm{O}$

ur food and agricultural systems depend in countless ways on the plants, animals and micro-organisms that comprise and surround them. Biodiversity, at every level from genetic, through species to ecosystem, underpins the capacity of farmers, livestock keepers, forest dwellers, fishers and fish farmers to produce food and a range of other goods and services in a vast variety of different biophysical and socio-economic environments. It increases resilience to shocks and stresses, provides opportunities to adapt production systems to emerging challenges and is a key resource in efforts to increase output in a sustainable way. It is vital to efforts to meet the Sustainable Development Goals (SDGs) of the 2030 Agenda.

Over the last two decades, FAO has prepared country-driven global assessments of the genetic resources of crop plants, livestock and forest trees. An assessment covering aquatic genetic resources will shortly be published. What has been missing to date has been an assessment of how biodiversity as a whole contributes to food and agriculture, including "associated biodiversity", the myriad components of biodiversity that support food and agricultural production by providing services such as pollination, pest control, soil formation and maintenance, carbon sequestration, purification and regulation of water supplies, reduction of disasters threats, and the provision of habitat for other beneficial species. The urgency of closing knowledge gaps in this field is underlined by the mounting evidence that the world's biodiversity is under severe threat and by the ever-growing challenges facing food and agriculture, including particularly those related to the impacts of climate change. The publication of The State of the World's Biodiversity for Food and Agriculture is therefore a significant and timely milestone.

Like all the global assessments prepared under the auspices of FAO's Commission on Genetic Resources for Food and Agriculture, a key characteristic of this report is its country-driven nature. Ninety-one countries prepared and submitted reports on the state of their biodiversity for food and agriculture and its management, focusing particularly on associated biodiversity and its role in the supply of supporting and regulating ecosystem services and on wild species that are sources of food. The reporting process provided an opportunity for countries to identify needs and priorities in terms of promoting the sustainable use and conservation of these resources, both at national level and internationally.

Parts of the global report make sombre reading. It is deeply concerning that in so many production systems in so many countries biodiversity for food and agriculture and the ecosystem services it provides are reported to be in decline. The foundations of our food systems are being undermined, often, at least in part, because of the impact of management practices and land-use changes associated with food and agriculture. It is also abundantly clear that the state of knowledge of many components of biodiversity, including in particular invertebrates and micro-organisms, is very inadequate and that this contributes to their neglect. The good news is that many management practices and approaches that rely on the maintenance of abundant and diverse biological communities, or that can otherwise be considered biodiversity friendly, are attracting growing interest and in many cases are becoming more widely adopted. 
The importance of biodiversity and its roles in the food and agriculture sector is increasingly being acknowledged in international policy agendas. This recognition needs to be translated into action. Key tasks include addressing the drivers of biodiversity loss within the food and agriculture sector and beyond, strengthening in situ and ex situ conservation measures, and increasing the uptake of management practices that promote the contributions of biodiversity to sustainable production. Coordinated and collaborative action on the part of the international community is essential. This report will make a valuable contribution to these efforts and to raising awareness of the vital importance of biodiversity to food and agriculture.

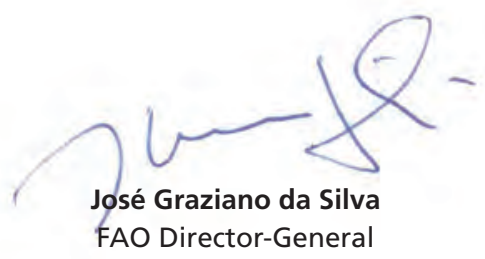




\section{Acknowledgements}

$\mathrm{T}$ he preparation of The State of the World's Biodiversity for Food and Agriculture required the dedication, time and expertise of many individuals, and the collaboration and support of many governments and institutions. The country reports submitted by 91 countries were the primary sources of information. FAO wishes to thank the respective governments and the hundreds of individuals involved, in particular the National Focal Points. Gratitude is also expressed to those who contributed to the preparation of the reports submitted by international organizations. The preparation of the report would not have been possible without the financial and in-kind support of Germany, Norway, Spain and Switzerland.

The report was prepared by FAO. The reporting and preparation process was coordinated by Julie Bélanger, with the assistance of Dafydd Pilling and Kim-Anh Tempelman, in FAO's Secretariat of the Commission on Genetic Resources for Food and Agriculture. The work was facilitated and supported by current and former Secretaries of the Commission, Irene Hoffmann and Linda Collette, and by current and former officers of the Secretariat, Anna Asfaw (seconded by the Government of Germany), Ladina Knapp (seconded by the Government of Switzerland), Dan Leskien, Damiano Luchetti and Miriam Widmer (seconded by the Government of Switzerland). Core contributors to the analysis of the country reports and the drafting, editing and/or finalization of report included Agnès Bernis-Fonteneau, Cordula Hinkes (seconded by the Government of Germany), Manuel Pomar Cloquell, Marcela Portocarrero-Aya, Suzanne Redfern, Vladimir Shlevkov-Pronskiy and Miriam Widmer. The work was further supported by a number of interns, Davide Albeggiani, Poljanka Johnson, Agathe Mansion-Vaquié, Michael Ruggeri, Angus Wilsdon, Lilly Zeitler and Sabrina Zhang. Administrative and secretarial support was provided by Nathalie Bramucci and Cintia Pohl.

The database of country-report data was designed, created and loaded by Enrico Anello, under the supervision of Giorgio Lanzarone of FAO's Information Technology Division. François Fauteux ${ }^{1}$ processed and compiled all taxonomic information contained in the database.

Over 175 individuals contributed to the preparation of the report as authors, contributors and reviewers. Details are provided in the table below, section by section. Significant contributions were provided by staff from many divisions within FAO. The manuscript was further reviewed by David Cooper ${ }^{2}$ (Parts A, B and C), Nigel Dudley, ${ }^{3}$ Toby Hodgkin, ${ }^{4}$ Patrick Mulvany ${ }^{5}$ (Parts A and D) and Mary Taylor ${ }^{6}$ (Parts B and C). All members of the Commission Secretariat also contributed to the reviewing process.

Text boxes were prepared by Peer Berg, ${ }^{7}$ Kaspar Bienefeld,${ }^{8}$ Teresa Borelli, ${ }^{9}$ Martin Brink, ${ }^{10}$ Stuart Butchart, ${ }^{11}$ Georgina Chandler, ${ }^{12}$ Gonzalo Eiriz, ${ }^{13}$ François Fauteux, ${ }^{1}$ Hasan Gezginç, ${ }^{14}$ Linn Fenna Groeneveld, ${ }^{7}$ Kim Holm Boesen, ${ }^{15}$ Danny Hunter, ${ }^{9}$ Mohd Fahimee Bin Jaapar, ${ }^{16}$ Rosliza Jajuli, ${ }^{16}$ Malene Karup Palne, ${ }^{15}$ Amir Kassam, ${ }^{17}$ Patricia Larbouret, ${ }^{18}$ Birgitte Lund, ${ }^{15}$ Tom Moore, ${ }^{19}$ Serge Morand, ${ }^{20}$ Daniela Moura de Oliveira Beltrame, ${ }^{21}$ Christophe Pinard, ${ }^{18}$ Maryam Rahmanian, Ana Islas Ramos, Gamini Samarasinghe, ${ }^{22}$ Florence Tartanac, Emilie Vandecandelaere, Anja Laupstad Vatland, ${ }^{23}$ Pierre Velge ${ }^{24}$ and Victor W. Wasike. ${ }^{25}$ Additional material for the preparation of text boxes was provided by Widegnoma Jean de Dieu Nitiema ${ }^{26}$ and Thembinkosi Gumedze. ${ }^{27}$

The thematic study Biodiversity for food and agriculture and ecosystem services was prepared by Dafydd Pilling. The study Biodiversity for food and agriculture: the perspectives of 
small-scale food providers was prepared by Patrick Mulvany, Bob Brac de la Perrière, Maryam Rahmanian and Angela Cordeiro (International Planning Committee for Food Sovereignty, Agricultural Biodiversity Working Group). The study The contributions of biodiversity for food and agriculture to the resilience of production systems was prepared by Ashley Duval, Dunja Mijatovic and Toby Hodgkin (Platform for Agrobiodiversity Research). The study Contributions of biodiversity to the sustainable intensification of food production was prepared by lan $\mathrm{K}$. Dawson, Simon J. Attwood, Sarah E. Park, Ramni Jamnadass, Wayne Powell, Terry Sunderland, Roeland Kindt, Stepha McMullin, Peter N. Hoebe, John Baddeley, Charles Staver, Vincent Vadez, Sammy Carsan, James M. Roshetko, Ahmed Amri, Eldad Karamura, Deborah Karamura, Paulo van Breugel, Md. Emdad Hossain, Michael Phillips, Ashok Kumar, Jens-Peter B. Lillesø, John Benzie, Gerhard E. Sabastian, Beatrice Ekesa, Walter Ocimati and Lars Graudal (CGIAR). The document entitled Study on the linkages between protected areas and the conservation of biodiversity for food and agriculture was prepared by Natasha Ali, Bárbara Goettsch, James Hardcastle, Sara Oldfield and Yichuan Shi (International Union for Conservation of Nature). See respective studies for authors' individual affiliations.

The layout was designed and implemented by Chiara Caproni.

The draft report was made available for review by members and observers of the Commission. Comments were received from Argentina, Bangladesh, Brazil, Canada, France, Georgia, Germany, Japan, Jordan, Mexico, the Russian Federation, Spain, Sweden, Switzerland, Thailand, Tunisia and the United States of America. The International Union for the Protection of New Varieties of Plants and the Secretariat of the Convention on Biological Diversity also provided comments.

Listing every person by name is not easy and carries with it the risk that someone may be overlooked. Apologies are conveyed to anyone who provided assistance but whose name has been omitted.

\begin{tabular}{|c|c|c|}
\hline \multicolumn{2}{|c|}{ Chapter/section } & $\begin{array}{l}\text { Authors and contributors (alphabetical order) } \\
\text { (affiliations are provided below the table; FAO if not indicated) }\end{array}$ \\
\hline \multicolumn{2}{|c|}{ Entire report } & Julie Bélanger and Dafydd Pilling (eds.) \\
\hline \multicolumn{3}{|c|}{ PART A - OVERVIEW } \\
\hline \multicolumn{3}{|c|}{ Chapter 1. Introduction } \\
\hline \multicolumn{2}{|c|}{ Entire chapter } & $\begin{array}{l}\text { Julie Bélanger, Dafydd Pilling, Kim-Anh Tempelman and Pablo Tittonell, }{ }^{28} \text { with } \\
\text { contributions from Devin Bartley, Paul Boettcher, Stefano Diulgheroff, Simon Funge- } \\
\text { Smith, Bonnie Furman, Jarkko Koskela, Graham Mair, Chikelu Mba and Shawn McGuire }\end{array}$ \\
\hline \multicolumn{3}{|c|}{ Reviewers: Vera Agostini, Frédéric Castell, Anneli Ehlers, ${ }^{29}$ John E. Fa, ${ }^{30}$ Giulia Muir } \\
\hline \multicolumn{3}{|c|}{ Chapter 2. Roles and importance of biodiversity for food and agriculture } \\
\hline 2.2 & Ecosystem services & Dafydd Pilling, drawing on FAO (2019) \\
\hline 2.3 & Resilience & $\begin{array}{l}\text { Agnès Bernis-Fonteneau and Dafydd Pilling, drawing on Duval et al., (2018), with } \\
\text { contributions from Toby Hodgkin, }{ }^{4} \text { Rebeca Koloffon and Sylvie Wabbes-Candotti }\end{array}$ \\
\hline 2.4 & Sustainable intensification & $\begin{array}{l}\text { Agnès Bernis-Fonteneau and Dafydd Pilling, drawing on Dawson et al. (2018a), with } \\
\text { contributions from Pablo Tittonell }{ }^{28}\end{array}$ \\
\hline 2.5 & Livelihoods & $\begin{array}{l}\text { David Colozza and Dafydd Pilling, with contributions from Nigel Dudley }{ }^{3} \text { and Cordula } \\
\text { Hinkes }\end{array}$ \\
\hline 2.6 & Food security and nutrition & $\begin{array}{l}\text { Julie Bélanger, Dafydd Pilling and Lilly Zeitler, with contributions from Vaishali Bansal, }{ }^{31} \text { Agnès } \\
\text { Bernis-Fonteneau, Ruth Charrondiere, Dalia Mattioni, Giulia Muir, Vikas Rawal, }{ }^{31} \text { Florence } \\
\text { Tartanac and Doordarshni Thokchom¹ }\end{array}$ \\
\hline \multicolumn{3}{|c|}{$\begin{array}{l}\text { Reviewers: Simon Attwood, }{ }^{9,32,33} \text { Edmundo Barrios, Caterina Batello, Badi Besbes, Eric Blanchart, }{ }^{34} \text { Paul Boettcher, Teresa Borelli, } \\
\text { David Colozza, Ian Dawson, }{ }^{35,36,37} \text { Ashley Duval, }{ }^{4} \text { John E. Fa, }{ }^{30} \text { Simon Funge-Smith, Bonnie Furman, Nao Furuta, }{ }^{38} \text { Rodolphe Gozlan, }{ }^{20} \\
\text { Danny Hunter, }{ }^{9} \text { Rebeca Koloffon, Jarkko Koskela, Maria Hernandez Lagana, Dunja Mijatovic, }{ }^{4} \text { Avetik Nersisyan, Florence Poulain, } \\
\text { Maryam Rahmanian, Beate Scherf, Nadia Scialabba, Pablo Tittonell, }{ }^{28} \text { Sylvie Wabbes-Candotti and LiesI Wiese }\end{array}$} \\
\hline
\end{tabular}




\section{PART B - DRIVERS, STATUS AND TRENDS}

Chapter 3. Drivers of change of biodiversity for food and agriculture

3.2 Overview

3.3 Economic and social drivers

3.4 Environmental drivers

3.5 Advances and innovations

in science and technology

3.6 Drivers at production

system level

3.7 Policies

3.8 Drivers of women's

involvement in the

management of biodiversity

for food and agriculture

\subsection{Drivers of traditional}

knowledge of biodiversity

for food and agriculture
Julie Bélanger, Toby Hodgkin ${ }^{4}$ and Lilly Zeitler

Marcela Portocarrero-Aya, Pablo Tittone $\|^{28}$ and Lilly Zeitler, with contributions from Julie Bélanger, Agnès Bernis-Fonteneau, David Colozza, Nigel Dudley, ${ }^{3}$ Toby Hodgkin, ${ }^{4}$ Dafydd Pilling, Vladimir Shlevkov-Pronskiy Michael Ruggeri and Kim-Anh Tempelman

Reviewers: Edmundo Barrios, Caterina Batello, Marcio Castro de Souza, David Colozza, Amber Himes-Cornell, Maria Eleonora D'Andrea, Liseth Escobar Aucu, Nicole Franz, Bonnie Furman, Maurizio Furst, Beatrice Grenier, Baogen Gu, Eva Kohlschmid, Regina Laub, Szilvia Lehel, Gregoire Leroy, Dalia Mattioni, Chikelu Mba, Shawn McGuire, Rebecca Metzner, Jamie Morrison, Kwang Suk Oh, Florence Poulain, John Ryder, Nianjun Shen, Ilaria Sisto, Markos Tibbo and Joseph Zelasney

\section{Chapter 4. The status and trends of biodiversity for food and agriculture}

4.2 Plant, animal, forest and aquatic genetic resources for food and agriculture

\subsection{Associated biodiversity}

4.3.1 Associated biodiversity species managed for ecosystem services

4.3.2 Information and monitoring systems on associated biodiversity

4.3.3 Overview of status and trends

4.3.4 Associated biodiversity for pollination

4.3.5 Associated biodiversity for pest and disease regulation

4.3.6 Associated biodiversity for soil-related ecosystem services

4.3.7 Associated biodiversity for water-related ecosystem services

4.3.8 Associated biodiversity for natural-hazard regulation

4.3.9 Associated biodiversity for habitat provisioning

4.3.10 Associated biodiversity for airquality and climate regulation

\subsection{Wild foods}

4.5 Ecosystems of importance to food and agriculture

4.5.1 Wetlands

4.5.2 Mangroves

4.5.3 Seagrasses

4.5.4 Coral reefs

4.5.5 Forests
Dafydd Pilling, drawing on FAO (2010a, 2014a, 2015a, forthcoming), with contributions from Devin Bartley, Roswitha Baumung, Paul Boettcher, Stefano Diulgheroff, Simon

Funge-Smith, Bonnie Furman, Jarkko Koskela, Gregoire Leroy and Chikelu Mba

Julie Bélanger and Kim-Anh Tempelman

Hien $\mathrm{Ngo}^{39}$ and Kim-Anh Tempelman, with contributions from Michael Ruggeri

Vladimir Shlevkov-Pronskiy, with contributions from Markus Knapp ${ }^{40}$ and William Settle Agnès Bernis-Fonteneau and Alberto Orgiazzi, ${ }^{41}$ with contributions from Liesl Wiese

Marcela Portocarrero-Aya, with contributions from Dafydd Pilling

Agnès Bernis-Fonteneau, with contributions from Dafydd Pilling and Michael Ruggeri

Julie Bélanger, with contributions from Natasha Ali, ${ }^{38}$ Bárbara Goettsch, ${ }^{38}$ Poljanka Johnson, Lilly Zeitler and Sabrina Zhang

Marcela Portocarrero-Aya, with contributions from Anne-Maud Courtois, Nigel Dudley, ${ }^{3}$ Dafydd Pilling, Vladimir Shlevkov-Pronskiy and Elaine Springgay

Orjan Jonsson, Jarkko Koskela, Lars Gunnar Marklund, Anssi Pekkarinen, Leticia Pina, Kristina Rodina and Sheila Wertz 


\begin{tabular}{|c|c|c|}
\hline 4.5 .6 & Rangelands & Irene Hoffmann \\
\hline 4.6 & Needs and priorities & Dafydd Pilling and Kim-Anh Tempelman \\
\hline \multicolumn{3}{|c|}{$\begin{array}{l}\text { Reviewers: Vera Agostini, Jose Aguilar Manjarrez, Edn } \\
\text { John E. Fa, }{ }^{30} \text { Kim Friedman, Simon Funge-Smith, Bonn } \\
\text { Moore, }{ }^{19} \text { Anne Mottet, Florence Poulain, Bronwen Por } \\
\text { Oppen, }{ }^{44,45} \text { Lauren Weatherdon }{ }^{46} \text { and Xinhua Yuan }\end{array}$} \\
\hline \multicolumn{3}{|c|}{ PART C - STATE OF MANAGEMENT } \\
\hline \multicolumn{3}{|c|}{ Chapter 5 . The state of use of biodiversity for food and agriculture } \\
\hline 5.2 & $\begin{array}{l}\text { Overview of management } \\
\text { practices and approaches }\end{array}$ & Julie Bélanger and Toby Hodgkin ${ }^{4}$ \\
\hline 5.3 & $\begin{array}{l}\text { Ecosystem, landscape and } \\
\text { seascape approaches }\end{array}$ & \\
\hline 5.3 .1 & Overview & Kim-Anh Tempelman \\
\hline 5.3 .2 & $\begin{array}{l}\text { Sustainable forest } \\
\text { management }\end{array}$ & Jarkko Koskela \\
\hline 5.3 .3 & $\begin{array}{l}\text { Ecosystem approach to } \\
\text { fisheries and aquaculture }\end{array}$ & Marcela Portocarrero-Aya \\
\hline 5.3 .4 & Agroecology & Vladimir Shlevkov-Pronskiy and Pablo Tittonel|28 \\
\hline & $\begin{array}{l}\text { Landscape and seascape } \\
\text { approaches }\end{array}$ & Kim-Anh Tempelman \\
\hline 5.3 .6 & $\begin{array}{l}\text { Integrated land- and water-use } \\
\text { planning }\end{array}$ & \\
\hline 5.3 .7 & Needs and priorities & \\
\hline 5.4 & Restoration practices & Blaise Bodin² and Marcela Portocarrero-Aya \\
\hline 5.5 & $\begin{array}{l}\text { Diversification in } \\
\text { production systems }\end{array}$ & \\
\hline 5.5 .1 & $\begin{array}{l}\text { Integrated crop-livestock } \\
\text { systems }\end{array}$ & Dario Lucantoni and Anne Mottet, with contributions from Dafydd Pilling \\
\hline 5.5 .2 & Home gardens & David Colozza \\
\hline 5.5 .3 & Agroforestry & $\begin{array}{l}\text { Jonathan P. Cornelius, }{ }^{35,56} \text { Jules Bayala, }{ }^{35} \text { Trent Blare, }{ }^{35} \text { Delia Catacutan }{ }^{35} \text { Ann Degrande, }{ }^{35} \\
\text { Roeland Kindt, }{ }^{35} \text { Beria Leimona, }{ }^{35} \text { Sarah-Lan Mathez-Stiefel, }{ }^{35,57} \text { Andrew Miccolis, } \\
\text { Devashree Naik, }{ }^{35} \text { Javed Rizvi, }{ }^{35} \text { James M. Roshetko }{ }^{35} \text { and Leigh Ann Winowiecki }{ }^{35}\end{array}$ \\
\hline 5.5 .4 & $\begin{array}{l}\text { Diversification practices in } \\
\text { aquaculture }\end{array}$ & $\begin{array}{l}\text { Kim-Anh Tempelman, with contributions from Lionel Dabbadie, Simon Funge-Smith, } \\
\text { Alessandro Lovatelli, Dafydd Pilling and Michael Ruggeri }\end{array}$ \\
\hline 5.5 .5 & Needs and priorities & Toby Hodgkin ${ }^{4}$ \\
\hline 5.6 & $\begin{array}{l}\text { Management practices and } \\
\text { production approaches }\end{array}$ & \\
\hline 5.6 .1 & Organic agriculture & Vladimir Shlevkov-Pronskiy, with contributions from Nadia Scialabba and Helga Willer ${ }^{47}$ \\
\hline 5.6 .2 & Low external input agriculture & Vladimir Shlevkov-Pronskiy, with contributions from Dafydd Pilling and Pablo Tittonel|128 \\
\hline 5.6 .3 & $\begin{array}{l}\text { Management practices to } \\
\text { preserve and enhance soil } \\
\text { biodiversity }\end{array}$ & Alberto Orgiazzi ${ }^{41}$ and Miriam Widmer \\
\hline 5.6 .4 & Conservation agriculture & Vladimir Shlevkov-Pronskiy, with contributions from Amir Kassam ${ }^{17}$ \\
\hline 5.6 .5 & $\begin{array}{l}\text { Integrated plant nutrient } \\
\text { management }\end{array}$ & Hugo Fernandez Mena and Debra Turner \\
\hline 5.6 .6 & Integrated pest management & Vladimir Shlevkov-Pronskiy, with contributions from William Settle \\
\hline 5.6 .7 & Pollination management & Hien $\mathrm{Ngo}^{39}$ and Kim-Anh Tempelman \\
\hline 5.6 .8 & Forest-management practices & Jarkko Koskela, with contributions from Jonas Cedergren \\
\hline 5.6 .9 & Needs and priorities & Toby Hodgkin ${ }^{4}$ \\
\hline 5.7 & $\begin{array}{l}\text { The use of micro-organisms } \\
\text { for food processing and } \\
\text { agro-industrial processes }\end{array}$ & $\begin{array}{l}\text { Dafydd Pilling, drawing on Alexandracki et al. (2013) and Chatzipavlidis et al. (2013), } \\
\text { with contributions from Nelson Lima }{ }^{48}\end{array}$ \\
\hline
\end{tabular}




\subsection{Genetic improvement}

5.9.1 Domestication and base broadening

5.9.2 Plant, animal, forest and aquatic genetic resources for food and agriculture

Toby Hodgkin ${ }^{4}$

Dafydd Pilling, drawing on FAO (2010a, 2014a, 2015a, forthcoming), with contributions from Devin Bartley, Paul Boettcher, Stefano Diulgheroff, Simon Funge-Smith, Jarkko Koskela, Chikelu Mba and Arshiya Noorani

5.9.3 Associated biodiversity overview

5.9.4 Pollinators

5.9.5 Assisted evolution for reefbuilding corals

Julie Bélanger, Vladimir Shlevkov-Pronskiy and Miriam Widmer

Yves Le Conte ${ }^{51}$ and Robert J. Paxton ${ }^{52}$

Madeleine J.H. van Oppen, ${ }^{44,45}$ with contributions from Ken Anthony ${ }^{44}$ and Line K. Bay ${ }^{44}$

5.9. Needs and priorities

Toby Hodgkin ${ }^{4}$

Reviewers: Vera Agostini, Elizabeth Bach, ${ }^{53}$ Edmundo Barrios, Roswitha Baumung, Fenton Beed, Kaspar Bienefeld, ${ }^{8}$ Eric Blanchart, ${ }^{34}$ Paul Boettcher, Lucrezia Caon, Jonas Cedergren, Viridiana Alcántara Cervantes, Richard Coe, ${ }^{35}$ Sandra Corsi, Rosa Cuevas Corona,

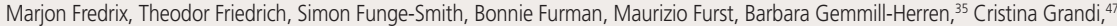
Juan J. Jiménez, ${ }^{54}$ Amir Kassam, ${ }^{17}$ Johannette Klapwijk, ${ }^{40}$ Markus Knapp ${ }^{40}$ Jarkko Koskela, Regina Laub, Szilvia Lehel, Chikelu Mba, Douglas McGuire, Shawn McGuire, Soren Moller, Anne Mottet, Tipparat Pongthanapanich, Maryam Rahmanian, Rosa Rolle, Beate Scherf, llaria Sisto, Carolina Starr, Philip Thornton, ${ }^{43}$ Randolph Thaman, ${ }^{55}$ Pablo Tittonell, ${ }^{28}$ Liesl Wiese and Xinhua Yuan

\section{Chapter 6 . The state of characterization of biodiversity for food and agriculture}

6.2 Plant, animal, forest and aquatic genetic resources for food and agriculture

6.3 Associated biodiversity

6.4 Wild foods

6.5 Needs and priorities
Dafydd Pilling, drawing on FAO (2010a, 2014a, 2015a, forthcoming), with contributions from Devin Bartley, Roswitha Baumung, Paul Boettcher, Stefano Diulgheroff, Simon Funge-Smith, Toby Hodgkin, ${ }^{4}$ Jarkko Koskela, Graham Mair and Chikelu Mba

Julie Bélanger, Dafydd Pilling and Miriam Widmer

Julie Bélanger

Dafydd Pilling and Miriam Widmer

Reviewers: Vera Agostini, Edmundo Barrios, Abram Bicksler, Ruth Charrondière, John E. Fa, ${ }^{30}$ Bonnie Furman, Maurizio Furst, Amber Himes-Cornell, Jarkko Koskela, Regina Laub, Szilvia Lehel, Nelson Lima, ${ }^{48}$ Graham Mair, Sarah Najera Espinosa, Arshiya Noorani, Dave Nowell, Beate Scherf and llaria Sisto

Chapter 7. The state of conservation of biodiversity for food and agriculture

7.2 Plant, animal, forest and aquatic genetic resources for food and agriculture

7.3 Associated biodiversity

\subsection{Wild foods}

7.5 Roles of protected areas

7.6 Maintenance of traditional knowledge associated with food and agriculture

7.7 Needs and priorities
Dafydd Pilling, drawing on FAO (2010a, 2014a, 2015a, forthcoming), with contributions from Devin Bartley, Roswitha Baumung, Paul Boettcher, Stefano Diulgheroff, Simon FungeSmith, Bonnie Furman, Toby Hodgkin, ${ }^{4}$ Jarkko Koskela, Graham Mair and Arshiya Noorani

Julie Bélanger, Dafydd Pilling, Mary Taylor ${ }^{6}$ and Miriam Widmer, with contributions from Toby Hodgkin ${ }^{4}$ and Vladimir Shlevkov-Pronskiy

Julie Bélanger

Natasha Ali, ${ }^{38}$ Bárbara Goettsch ${ }^{38}$ and James Hardcastle, ${ }^{38}$ with contributions from Michael Ruggeri and Kim-Anh Tempelman

Miriam Widmer

Dafydd Pilling

Reviewers: Vera Agostini, Natasha Ali, ${ }^{38}$ Edmundo Barrios, Abram Bicksler, Yoshihide Endo, Bonnie Furman, Amber Himes-Cornell, Maurizio Furst, Jarkko Koskela, Regina Laub, Szilvia Lehel, Graham Mair, Arshiya Noorani, Beate Scherf and Ilaria Sisto

\section{PART D - ENABLING FRAMEWORKS}

Chapter 8. The state of policies, institutions and capacities

8.2 Stakeholders

8.3 Cooperation

8.4 Education, training and awareness raising
Dafydd Pilling and Michael Ruggeri, with contributions from Julie Bélanger, Nigel Dudley, ${ }^{3}$ Miriam Widmer and Angus Wilsdon

Dafydd Pilling, with contributions from Simon Funge-Smith

Dafydd Pilling, drawing on FAO (2010a, 2014a, 2015a, forthcoming), with contributions from Devin Bartley, Paul Boettcher, Nigel Dudley, ${ }^{3}$ Simon Funge-Smith, Bonnie Furman, Shawn McGuire, Arshiya Noorani and Hugo Wilson 

$8.5 \quad$ Research
Cordula Hinkes, with contributions from Nigel Dudley ${ }^{3}$
8.6 Valuation
Cordula Hinkes, with contributions from Nigel Dudley, ${ }^{3}$ Lucy Garrett and Dafydd Pilling
8.7 Incentives
Lucy Garrett, Bernardete Neves and Daniela Ottaviani
8.8 Policy and legal frameworks
8.8.1 Frameworks at international level Dan Leskien
8.8.2 Frameworks at national level
Dafydd Pilling, drawing on FAO (2010a, 2014a, 2015a, forthcoming), with contributions from Devin Bartley, Paul Boettcher, Bonnie Furman, Simon Funge-Smith, Shawn McGuire, Arshiya Noorani and Hugo Wilson
8.8.3 Climate change policy and Donagh Hennessy programmes
8.8.4 Frameworks supporting the maintenance of traditional knowledge
8.8.5 Access and benefit-sharing

\section{Miriam Widmer}
Dan Leskien

Reviewers: Edmundo Barrios, Paul Boettcher, Junning Cai, Stefano Diulgheroff, Simon Funge-Smith, Bonnie Furman, Maurizio Furst, Kathryn Garforth, ${ }^{2}$ Amber Himes-Cornell, Rebeca Koloffon, Regina Laub, Szilvia Lehel, Dan Leskien, Dalia Mattioni, Shawn McGuire, Beate Scherf and Ilaria Sisto

\section{PART E - CONCLUSIONS}

Chapter 9. The way forward

Entire chapter Julie Bélanger, Dafydd Pilling and Kim-Anh Tempelman

Reviewers: Vera Agostini, Edmundo Barrios, Bonnie Furman, Jarkko Koskela, Graham Mair and Beate Scherf

\section{National Research Council, Canada.}

Convention on Biological Diversity.

Equilibrium Research, United Kingdom.

Platform for Agrobiodiversity Research.

5 Centre for Agroecology, Water and Resilience, United Kingdom.

6 University of the Sunshine Coast, Australia.

7 NordGen Farm Animals.

8 Länderinstitut für Bienenkunde Hohen Neuendorf, Germany.

9 Bioversity International.

10 Wageningen University, the Netherlands.

11 BirdLife International.

12 Royal Society for the Protection of Birds, United Kingdom.

13 Ministerio de Agricultura, Alimentación y Medio Ambiente, Spain.

14 Turkish Ministry of Agriculture and Forestry, General Directorate of Agricultural Research and Policies, Turkey.

15 Ministry of Environment and Food of Denmark, The Danish Agricultural Agency, Denmark.

16 Malaysia Agriculture Research and Development Institute, Malaysia.

17 University of Reading, United Kingdom.

18 Ministère de l'agriculture et de l'alimentation, France.

19 National Oceanic and Atmospheric Administration, United States of America.

20 Centre de coopération internationale en recherche agronomique pour le développement, France.

21 Biodiversity for Food and Nutrition Project, Brazil.

22 Plant Genetic Resources Center, Department of Agriculture, Sri Lanka.

23 Brown Bee Network.

24 Secrétariat Général des Affaires Européennes Comité interministériel de l'agriculture et de I'Alimentation, France.

25 Genetic Resources Research Centre, Kenya Agriculture and Livestock Research Organization, Kenya.

26 Ministère de l'Agriculture et de la Sécurité alimentaire, Burkina Faso.
27 National Plant Genetic Resources Centre, Eswatini.

28 Instituto Nacional de Tecnología Agropecuaria, Argentina.

29 Deutsche Gesellschaft für Internationale Zusammenarbeit, Germany.

30 Center for International Forestry Research.

31 Society for Social and Economic Research, India.

32 University of East Anglia, United Kingdom.

33 World Wildlife Fund, Singapore.

34 Institut de Recherche pour le Développement, France.

35 World Agroforestry Centre.

36 Scotland's Rural College, United Kingdom.

37 CGIAR Consortium.

38 International Union for Conservation of Nature.

39 Intergovernmental Science-Policy Platform on Biodiversity and Ecosystem Services.

40 Koppert Biological Systems.

41 European Commission's Joint Research Centre.

42 Pennsylvania State University, United States of America.

43 International Livestock Research Institute.

44 Australian Institute of Marine Science, Australia.

45 University of Melbourne, Australia.

46 UN Environment World Conservation Monitoring Centre.

47 IFOAM - Organics International.

48 European Culture Collections' Organization.

49 AgResearch Limited, New Zealand.

50 New Zealand Agricultural Greenhouse Gas Research Centre, New Zealand.

51 Institut national de la recherche agronomique, UR406 Abeilles \& Environnement, France.

52 Martin-Luther-Universität Halle-Wittenberg and iDiv, Germany.

53 Colorado State University, United States of America.

54 Instituto Pirenaico de Ecología, Consejo Superior de Investigaciones Científicas, Spain.

55 University of the South Pacific, Fiji.

56 James Cook University, Australia.

57 University of Bern, Switzerland. 


\section{Abbreviations and acronyms}

\begin{tabular}{|c|c|}
\hline ABO & Agricultural Biodiversity Observatory (France) \\
\hline ABS & access and benefit-sharing \\
\hline AGRA & Alliance for a Green Revolution in Africa \\
\hline AIDS & acquired immune deficiency syndrome \\
\hline AMBER & Adaptive Management of Barriers in European Rivers \\
\hline AnGR & animal genetic resources for food and agriculture \\
\hline APCRM & Association of Fishermen of the Rural Community Mangagoulack (Senegal) \\
\hline AqGR & aquatic genetic resources for food and agriculture \\
\hline ASEAN & Association of Southeast Asian Nations \\
\hline ASFIS & Aquatic Sciences and Fisheries Information System \\
\hline $\mathrm{AU}$ & African Union \\
\hline BCA & biological control agent \\
\hline BCCM & Belgian Co-ordinated Collections of Micro-organisms \\
\hline BFA & biodiversity for food and agriculture \\
\hline BFN & Biodiversity for Food and Nutrition Project \\
\hline $\mathrm{BGCl}$ & Botanic Gardens Conservation International \\
\hline BINGO & Breeding Invertebrates for Next Generation Biocontrol \\
\hline BIO_SOS & Blodiversity Multi-Source Monitoring System: from Space to Species \\
\hline BISQ & Biological Indicator of Soil Quality (Netherlands) \\
\hline BLUP & best linear unbiased prediction \\
\hline BRC & biological resource centre \\
\hline CABI & Centre for Agriculture and Biosciences International \\
\hline CABRI & Common Access to Biological Resources and Information \\
\hline CAMPFIRE & Communal Areas Management Programme for \\
\hline & Indigenous Resources (Zimbabwe) \\
\hline CBD & Convention on Biological Diversity \\
\hline CEPF & Critical Ecosystem Partnership Fund \\
\hline CIAT & International Center for Tropical Agriculture \\
\hline CIFOR & Center for International Forestry Research \\
\hline CIP & International Potato Center \\
\hline CITES & $\begin{array}{l}\text { Convention on International Trade in Endangered Species of Wild } \\
\text { Fauna and Flora }\end{array}$ \\
\hline CMS & Convention on the Conservation of Migratory Species of Wild Animals \\
\hline COMET & CarbOn Management Evaluation Tool \\
\hline COMIFAC & Commission of Central African Forests \\
\hline CONABIO & Biodiversity Commission (Mexico) \\
\hline COUSSA & Conservation and Sustainable Use of Soil and Water (Mexico) \\
\hline CRP & Conservation Reserve Program (United States of America) \\
\hline CSO & civil society organization \\
\hline CSP & Conservation Stewardship Program (United States of America) \\
\hline CTI-CFF & Coral Triangle Initiative on Coral Reefs, Fisheries and Food Security \\
\hline DAD-IS & Domestic Animal Diversity Information System \\
\hline DIAS & Database on Introductions of Aquatic Species \\
\hline DNA & deoxyribonucleic acid \\
\hline EBA & Endemic Bird Area \\
\hline
\end{tabular}




\begin{tabular}{|c|c|}
\hline EBCC & European Bird Census Council \\
\hline EBI & Ethiopian Biodiversity Institute \\
\hline ECCO & European Culture Collection Organization \\
\hline EMbaRC & European Consortium of Microbial Resource Centres \\
\hline EODHaM & Earth Observation Data for Habitat Monitoring \\
\hline EU & European Union \\
\hline EUR & euro \\
\hline FANTA & Food and Nutrition Technical Assistance III Project \\
\hline FAO & Food and Agriculture Organization of the United Nations \\
\hline FAOSTAT & FAO Statistical Database \\
\hline FBDG & food-based dietary guidelines \\
\hline FGR & forest genetic resources \\
\hline FMNR & farmer-managed natural regeneration \\
\hline FRA & Global Forest Resources Assessment \\
\hline FS & farmer school \\
\hline FSC & Forest Stewardship Council \\
\hline GBRCN & Global Biological Resource Centre Network \\
\hline GDP & gross domestic product \\
\hline GEF & Global Environment Facility \\
\hline GEMStat & Global Water Quality Database and Information System \\
\hline GEMS/Water & Global Environment Monitoring System for Freshwater \\
\hline GIAHS & Globally Important Agricultural Heritage Systems \\
\hline GIS & geographic information system \\
\hline GRC & Global Rumen Census \\
\hline HIV & human immunodeficiency virus \\
\hline IBGE & Brazilian Institute of Geography and Statistics \\
\hline ICCA & Indigenous and Community Conserved Area \\
\hline ICIPE & International Centre of Insect Physiology and Ecology \\
\hline IFF & Intergovernmental Forum on Forests \\
\hline IFOAM & International Federation of Organic Agriculture Movements \\
\hline IMARPE & Marine Institute of Peru \\
\hline IMTA & integrated multitrophic aquaculture \\
\hline INDC & intended national determined contribution \\
\hline INFOODS & International Network of Food Data Systems \\
\hline INIA & National Institute of Agricultural Innovation (Peru) \\
\hline INRA & National Institute for Agricultural Research (France) \\
\hline INTECRAL & $\begin{array}{l}\text { Integrated Eco Technologies and Services for a Sustainable Rural } \\
\text { Rio de Janeiro (Brazil) }\end{array}$ \\
\hline InVest & Integrated Valuation of Ecosystem Services and Tradeoffs \\
\hline IPBES & $\begin{array}{l}\text { Intergovernmental Science-Policy Platform on Biodiversity and } \\
\text { Ecosystem Services }\end{array}$ \\
\hline IPF & Intergovernmental Panel on Forests \\
\hline IPLC & indigenous peoples and local communities \\
\hline IPM & Integrated pest management \\
\hline IPM-FFS & farmer field school on integrated pest management \\
\hline IPNM & integrated plant nutrient management \\
\hline IPOA-IUU & $\begin{array}{l}\text { International Plan of Action to Prevent, Deter and Eliminate Illegal, } \\
\text { Unreported and Unregulated Fishing }\end{array}$ \\
\hline IPPC & International Plant Protection Convention \\
\hline
\end{tabular}




\begin{tabular}{|c|c|}
\hline IPPM & integrated production and pest management \\
\hline IPR & intellectual property rights \\
\hline IPSI & International Partnership for the Satoyama Initiative \\
\hline ISCAAP & $\begin{array}{l}\text { International Standard Statistical Classification of Aquatic Animals } \\
\text { and Plants }\end{array}$ \\
\hline IUCN & International Union for Conservation of Nature \\
\hline IUU & illegal, unreported and unregulated \\
\hline KBA & Key Biodiversity Areas \\
\hline KEEP & Kakamega Environmental and Education Programme (Kenya) \\
\hline KENRIK & Kenya Resource Center for Indigenous Knowledge \\
\hline LEAF & Linking Environment and Farming \\
\hline LEIA & low external input agriculture \\
\hline LER & land equivalent ratio \\
\hline LI-BIRD & Local Initiatives for Biodiversity, Research and Development (Nepal) \\
\hline MARS & $\begin{array}{l}\text { Managing Aquatic ecosystems and water Resources } \\
\text { under multiple Stress }\end{array}$ \\
\hline MasAgro & Sustainable Modernization of Traditional Agriculture (Mexico) \\
\hline MAT & mutually agreed terms \\
\hline MDS & Ministry of Social Development and Hunger Alleviation (Brazil) \\
\hline MEA & Millennium Ecosystem Assessment \\
\hline MERCES & Marine Ecosystems Restoration in Changing European Seas \\
\hline MIRRI & Microbial Resource Research Infrastructure \\
\hline MSDN & Microbial Strain Data Network \\
\hline NAPA & national adaptation programme of action \\
\hline NARO & National Agriculture and Food Research Organization (Japan) \\
\hline NBA & Niger Basin Authority \\
\hline NFP & national forest programme \\
\hline NGO & non-governmental organization \\
\hline NIBIO & Norwegian Institute of Bioeconomy Research \\
\hline NOAA & $\begin{array}{l}\text { National Oceanic and Atmospheric Administration } \\
\text { (United States of America) }\end{array}$ \\
\hline NVS & natural vegetative strips \\
\hline OECD & Organisation for Economic Co-operation and Development \\
\hline PAA & Food Acquisition Programme (Brazil) \\
\hline PAAP & Programme for the Acquisition of Productive Assets (Mexico) \\
\hline PDNA & Post-Disaster Needs Assessment \\
\hline PEFC & Programme for the Endorsement of Forest Certification \\
\hline PELUM & Participatory Ecological Land Use Management Association \\
\hline PERSAGA & $\begin{array}{l}\text { Regional Organization for the Conservation of the Environment of the } \\
\text { Red Sea and Gulf of Aden }\end{array}$ \\
\hline PESA & Strategic Project for Food Security (Mexico) \\
\hline PESAGRO-RIO & Agricultural Research Enterprise of the State of Rio de Janeiro (Brazil) \\
\hline PGRFA & plant genetic resources for food and agriculture \\
\hline $\mathrm{PIC}$ & prior informed consent \\
\hline PLANAPO & National Plan for Agroecology and Organic Production (Brazil) \\
\hline PNAD & National Household Sample Survey (Brazil) \\
\hline PNAE & National School Meals Programme (Brazil) \\
\hline PNAN & National Food and Nutrition Policy (Brazil) \\
\hline
\end{tabular}




\begin{tabular}{|c|c|}
\hline PROGAN & $\begin{array}{l}\text { Sustainable Livestock Production and Management for Livestock and } \\
\text { Beekeeping (Mexico) }\end{array}$ \\
\hline PROGEBE & $\begin{array}{l}\text { Regional Project for Sustainable Management of Globally Significant } \\
\text { Endemic Ruminant Livestock }\end{array}$ \\
\hline PROMAF & $\begin{array}{l}\text { Project of Support for the Productive Chain of Corn and } \\
\text { Bean Producers (Mexico) }\end{array}$ \\
\hline PRONAF & National Programme for Strengthening Family Farming (Brazil) \\
\hline PRONAFOR & National Forest Programme (Mexico) \\
\hline PSM & port state measure \\
\hline PURSN & Sustainable Use of Natural Resources Programme (Mexico) \\
\hline QTL & quantitative trait locus \\
\hline REDD+ & Reducing emissions from deforestation and forest degradation \\
\hline REDESMI & Spanish Micro-organisms Network \\
\hline REFORM & REstoring rivers FOR effective catchment Management \\
\hline RIL & reduced-impact logging \\
\hline RIVM & National Institute for Public Health and the Environment (Netherlands) \\
\hline RNA & ribonucleic acid \\
\hline RSPB & Royal Society for the Protection of Birds \\
\hline SADC & Southern African Development Community \\
\hline SAF & Portuguese and Spanish abbreviation of "agroforestry system" \\
\hline SAGI & Secretariat for Evaluation and Information Management (Brazil) \\
\hline SALT & sloping agricultural land technology \\
\hline SBSTTA & Subsidiary Body on Scientific, Technical and Technological Advice \\
\hline SDG & Sustainable Development Goal \\
\hline SEBRAE & Brazilian Micro and Small Enterprises Support Service \\
\hline SEEA & System of Environmental Economic Accounting \\
\hline SNP & single nucleotide polymorphism \\
\hline SoW & state of the world \\
\hline TEEB & The Economics of Ecosystems and Biodiversity \\
\hline TEEBAgFood & TEEB for Food and Agriculture \\
\hline TEV & total economic value \\
\hline TFCA & transfrontier conservation area \\
\hline TRIPS & Trade-Related Aspects of Intellectual Property Rights \\
\hline UBINIG & Policy Research for Development Alternative (Bangladesh) \\
\hline UKNCC & United Kingdom National Culture Collection \\
\hline UN & United Nations \\
\hline UNALM & National Agrarian University La Molina (Peru) \\
\hline UNCCD & United Nations Convention to Combat Desertification \\
\hline UNCED & United Nations Conference on Environment and Development \\
\hline UN Environment & United Nations Environment Programme \\
\hline UNEP-WCMC & UN Environment World Conservation Monitoring Centre \\
\hline UNESCO & United Nations Educational, Scientific and Cultural Organization \\
\hline UNFCCC & United Nations Framework Convention on Climate Change \\
\hline UNFF & United Nations Forum on Forests \\
\hline UN-REDD & $\begin{array}{l}\text { United Nations Collaborative Programme on Reducing Emissions from } \\
\text { Deforestation and Forest Degradation in Developing Countries }\end{array}$ \\
\hline UPOV & International Union for the Protection of New Varieties of Plants \\
\hline USAID & United States Agency for International Development \\
\hline USD & United States dollar \\
\hline
\end{tabular}


USDA United States Department of Agriculture

WAVES

Wealth Accounting and the Valuation of Ecosystem Services

WFCC

World Federation for Culture Collections

WHC

World Heritage Convention

WIEWS

World Information and Early Warning System on Plant Genetic

Resources for Food and Agriculture

WIPO

World Intellectual Property Organization

WISER

Water bodies in Europe: Integrative Systems to assess Ecological status and Recovery

WTA willingness to accept

WTO World Trade Organization

WTP willingness to pay 


\section{About this publication}

\section{Background}

This report presents the first global assessment of biodiversity for food and agriculture (BFA). It complements other global assessments prepared under the auspices of the Commission on Genetic Resources for Food and Agriculture (see Box 1), which have focused on the state of genetic resources within particular sectors of food and agriculture.

Box 1

The Commission on Genetic Resources for Food and Agriculture

With 178 countries and the European Union as its members, the Commission on Genetic Resources for Food and Agriculture provides a unique intergovernmental forum that specifically addresses biological diversity for food and agriculture. The main objective of the Commission is to ensure the sustainable use and conservation of biodiversity for food and agriculture and the fair and equitable sharing of benefits derived from its use, for present and future generations. The Commission guides the preparation of periodic global assessments of the status and trends of genetic resources and biological diversity for food and agriculture. In response to these assessments, the Commission develops global plans of action, codes of conduct or other policy instruments and monitors their implementation. The Commission raises awareness of the need to conserve and sustainably use biological diversity for food and agriculture and fosters collaboration among countries and other relevant stakeholders to address threats to this biodiversity and promote its sustainable use and conservation.

\section{Scope and contents of the report}

The State of the World's Biodiversity for Food and Agriculture (SoW-BFA) addresses the sustainable use, development and conservation of BFA worldwide. BFA is taken to include the diversity of animals, plants and micro-organisms at the genetic, species and ecosystem levels that sustain structures, functions and processes in and around production systems and provide food and non-food agricultural products.

The report consists of the following five parts.

Part A - Overview: Chapter 1 describes the context for the assessment and presents key concepts and definitions used. Chapter 2 provides an overview of the contributions that BFA makes to the supply of multiple ecosystem services, to livelihoods, to the resilience of production systems, to the sustainable intensification of food and agricultural production, and to food security and nutrition.

Part B - Drivers, status and trends: Chapter 3 discusses the major drivers of change affecting BFA. Chapter 4 presents an analysis of the status and trends of BFA, including a discussion of the state of knowledge in this field.

Part C - State of management: Chapter 5 considers the state of use of BFA, including discussions of landscape, seascape and ecosystem approaches, diversification in production systems, and management practices that utilize BFA or are considered to promote its conservation and sustainable use. This chapter also addresses the roles of micro-organisms in food processing, in agro-industrial practices and in the digestive processes of ruminant 
animals. Finally, it includes a discussion of breeding (genetic improvement) activities for various categories of BFA. Chapters 6 and 7, respectively, address the state of characterization and conservation efforts for BFA.

Part D - Enabling frameworks: Chapter 8 describes the state of policies, institutions and capacities that support the conservation and sustainable use of BFA.

Part E - Conclusions: Chapter 9 presents a discussion of needs and challenges in the management of BFA.

\section{The reporting and preparatory process}

At its Eleventh Regular Session, in 2007, the Commission adopted a number of outputs and milestones to be addressed in its Multi-year Programme of Work, ${ }^{1}$ including the presentation, at its Sixteenth Regular Session, of the SoW-BFA. ${ }^{2}$ The Commission stressed that the preparation of the report should be based on information from country reports and should also draw on thematic studies, reports from international organizations and inputs from other relevant stakeholders, including centres of excellence in developing countries. It further stressed that the report should focus on interactions between sectors and on cross-sectoral matters, taking full advantage of existing information sources, including sectoral assessments. It also suggested that priority be given to information not available in existing sources. At its Sixteenth Regular Session, which was held in 2017, the Commission considered a draft of the SoW-BFA and requested FAO to finalize it, taking into account comments submitted by Members and Observers, by the end of 2018 .

\section{Inputs to the report}

The main sources used to prepare the SoW-BFA were as follows:

\section{Country reports}

In June 2013, FAO invited countries to officially nominate national focal points to lead the preparation of country reports to be submitted to FAO to support the preparation of the SoW-BFA. FAO prepared guidelines to support the development of country reports. The guidelines outlined the suggested content of the report and provided questions to assist countries with their analysis and with the development of each section of the report. The guidelines were made available in all six official FAO languages (Arabic, Chinese, English, French, Russian and Spanish), both in read-only form and as a dynamic version into which countries could enter their responses in order to generate a preformatted country report. ${ }^{3}$

Between March and May 2016, in response to a request by the Commission at its preceding session, FAO organized a series of informal regional consultations at which countries and other stakeholders could share knowledge and information on the state of BFA and discuss needs and priorities with respect to its conservation and sustainable use. The informal regional consultations also served to support national focal points in the finalization of their country reports. As background documentation for each informal regional consultation, FAO prepared a draft regional synthesis report based on the country reports that had thus far been submitted. The regional synthesis reports were subsequently finalized based on feedback received from the participants of the informal regional consultations and on additional country reports received.

By 30 June 2017, the deadline set by the Commission, 91 country reports had been received (see Table 1).

\footnotetext{
CGRFA-11/07/Report, paragraph 90.

CGRFA-14/13/Report, paragraph 14

The dynamic questionnaire was made available in Chinese, English, French, Russian and Spanish.
} 
TABLE 1

Overview of country reports and their regional distribution

\begin{tabular}{|c|c|}
\hline Region & Countries \\
\hline Africa (19) & $\begin{array}{l}\text { Angola, Burkina Faso, Cameroon, Chad, Eswatini, Ethiopia, Gabon, Gambia, Guinea, Kenya, } \\
\text { Mali, Niger, Rwanda, Senegal, Sierra Leone, Togo, United Republic of Tanzania, Zambia, } \\
\text { Zimbabwe }\end{array}$ \\
\hline Asia', $(9)$ & Afghanistan, Bangladesh, Bhutan, China, India, Malaysia, Nepal, Sri Lanka, Viet Nam \\
\hline Europe and Central Asia (23) & $\begin{array}{l}\text { Belgium, Bulgaria, Belarus, Croatia, Denmark, Estonia, Finland, France, }{ }^{3} \text { Georgia, Germany, } \\
\text { Hungary, Ireland, Malta, Netherlands, Norway, Poland, Slovakia, Slovenia, Spain, Sweden, } \\
\text { Switzerland, Turkey, United Kingdom }\end{array}$ \\
\hline $\begin{array}{l}\text { Latin America and the } \\
\text { Caribbean (16) }\end{array}$ & $\begin{array}{l}\text { Argentina, Bahamas, Brazil, Costa Rica, Ecuador, El Salvador, Grenada, Guyana, Jamaica, } \\
\text { Mexico, Nicaragua, Panama, Paraguay, Peru, Saint Lucia, Suriname }\end{array}$ \\
\hline Near East and North Africa (13) & $\begin{array}{l}\text { Algeria, Egypt, Iraq, Jordan, Lebanon, Morocco, Oman, Qatar, Saudi Arabia, Sudan, Syrian } \\
\text { Arab Republic, United Arab Emirates, Yemen }\end{array}$ \\
\hline North America (1) & United States of America \\
\hline Pacific (10) & $\begin{array}{l}\text { Cook Islands, Fiji, Kiribati, Nauru, Niue, Palau, Papua New Guinea, Samoa, Solomon Islands, } \\
\text { Tonga }\end{array}$ \\
\hline \multicolumn{2}{|l|}{ Notes: } \\
\hline \multicolumn{2}{|c|}{$\begin{array}{l}1 \text { The Lao People's Democratic Republic submitted as a country report its National Agro- } \\
2 \text { Action Plan II (2015-2025). Selected information from this report is presented. } \\
3 \text { Selected information from the country report of Japan, submitted in 2018, is presentec } \\
\text { France submitted a draft report. }\end{array}$} \\
\hline
\end{tabular}

\section{Reports from international organizations}

In April 2016, FAO invited 55 international organizations to report on their activities related to the management of BFA and provided them with a standardized questionnaire for the preparation of their reports. Responses were received from the following organizations: Africa Rice Center; African Union - Interafrican Bureau for Animal Resources; African Union Commission, Department of Rural Economy and Agriculture; Bioversity International; Caribbean Agricultural Research and Development Institute; Centre for Agriculture and Biosciences International; Global Crop Diversity Trust; IFOAM Organics International; InterAmerican Institute for Cooperation on Agriculture; International Atomic Energy Agency; International Center for Agricultural Research in the Dry Areas; International Center for Tropical Agriculture; International Centre of Insect Physiology and Ecology; International Food Policy Research Institute; International Fund for Agricultural Development; International Institute of Tropical Agriculture; International Maize and Wheat Improvement Center; International Union for Conservation of Nature; International Rice Research Institute; Pacific Organic and Ethical Trade Community; Secretariat of the Convention on Biological Diversity; Slow Food; Tropical Agricultural Research and Higher Education Center; United Nations Environment Programme - World Conservation Monitoring Centre; World Agroforestry Centre; World Bank. In addition, Oxfam voluntarily provided a report entitled Women's roles in biodiversity management from lessons to practice and impact: scaling up pathways in people's biodiversity management, containing case studies from Peru Viet Nam and Zimbabwe. 




Source: FAO.

\section{Thematic studies}

The following four thematic studies providing in-depth analysis of specific topics relevant to BFA were prepared for the SoW-BFA:

- Biodiversity for food and agriculture: the perspectives of small-scale food providers;

- The contributions of biodiversity for food and agriculture to the resilience of production systems;

- Contributions of biodiversity to the sustainable intensification of food production;

- Biodiversity for food and agriculture and ecosystem services.

\section{Regional synthesis reports}

As described above, the series of informal regional consultations held in 2016 involved the preparation of a regional synthesis report for each region where consultations were held. The contents of these synthesis reports served as source material for the global analysis presented in the SoW-BFA.

\section{State of the world reports}

The subsections of the SoW-BFA that address plant (crop), animal (livestock), forest and aquatic genetic resources draw heavily on the respective global assessments (state of the world reports) published or in preparation under the auspices of the Commission.

\section{Other sources}

In addition to the sources mentioned above, the SoW-BFA draws on a range of literature and data sources. The latter include FAO's statistical database FAOSTAT, ${ }^{4}$ the FAO/INFOODS Food Composition database for biodiversity, ${ }^{5}$ the Domestic Animal Diversity Information System, ${ }^{6}$ the World Information and Early Warning System on Plant Genetic Resources for

\footnotetext{
http://www.fao.org/faostat/en/

5 http://www.fao.org/infoods/infoods/tables-and-databases/faoinfoods-databases/en/

6 http://www.fao.org/dad-is/en/
} 
Food and Agriculture ${ }^{7}$ and The International Union for Conservation of Nature's Red List of Threatened Species. ${ }^{8}$

\section{Regional classification of countries}

The assignment of countries to regions for the purposes of the SoW-BFA follows the regional groupings used in FAO statistics and for election purposes (Figure 1). Seven regions are distinguished: Africa; Asia; Europe and Central Asia; Latin America and the Caribbean; Near East and North Africa; North America; and Pacific. 


\section{Executive summary}

\section{What is biodiversity for food and agriculture?}

Biodiversity is the variety of life at genetic, species and ecosystem levels. Biodiversity for food and agriculture (BFA) is, in turn, the subset of biodiversity that contributes in one way or another to agriculture and food production. It includes the domesticated plants and animals raised in crop, livestock, forest and aquaculture systems, harvested forest and aquatic species, the wild relatives of domesticated species, other wild species harvested for food and other products, and what is known as "associated biodiversity", the vast range of organisms that live in and around food and agricultural production systems, sustaining them and contributing to their output. Agriculture is taken here to include crop and livestock production, forestry, fisheries and aquaculture. ${ }^{1}$

\section{About this report}

The State of the World's Biodiversity for Food and Agriculture provides an assessment of biodiversity for food and agriculture (BFA) and its management worldwide, drawing on information provided in 91 country reports (prepared by over 1300 contributors), 27 reports from international organizations and inputs from over 175 authors and reviewers.

It describes the many contributions that BFA makes to food security and nutrition, livelihoods, the resilience of production systems, the sustainable intensification of food production and the supply of multiple ecosystem services; the major drivers of change affecting BFA; the status and trends of various components of BFA; the state of management of BFA; the state of policies, institutions and capacities that support the sustainable use and conservation of BFA; and needs and challenges in the management of BFA.

\section{Key findings}

\section{Biodiversity is essential to food and agriculture}

Biodiversity for food and agriculture is indispensable to food security, sustainable development and the supply of many vital ecosystem services. Biodiversity makes production systems and livelihoods more resilient to shocks and stresses, including to the effects of climate change. It is a key resource in efforts to increase food production while limiting negative impacts on the environment. It makes multiple contributions to the livelihoods of many people, often reducing the need for food and agricultural producers to rely on costly or environmentally harmful external inputs. The country reports highlight the importance of biodiversity, at genetic, species and ecosystem levels, to efforts to address the challenges posed by diverse and changing production systems. Many emphasize the role of diversification - using multiple species, integrating the use of crop, livestock, forest and aquatic resources, and conserving and managing habitat diversity at landscape or seascape scale - in promoting resilience, improving livelihoods and supporting food security and nutrition.

For the purpose of the country-reporting process, biodiversity for food and agriculture was defined as follows: "...the variety and variability of animals, plants and micro-organisms at the genetic, species and ecosystem levels that sustain the ecosystem structures, functions and processes in and around production systems, and that provide food and nonfood agricultural products." More information on key concepts is provided in Section 1.5. 


\section{Multiple interacting drivers of change are affecting biodiversity for food and agriculture}

While a range of drivers of change are having major negative impacts on biodiversity for food and agriculture and the ecosystem services it delivers, some provide opportunities to promote more sustainable management. Analysis of the country reports and the wider literature indicates that BFA is affected by a variety of drivers operating at a range of levels: major global trends such as changes in climate, international markets and demography give rise to more immediate drivers such as land-use change, pollution and overuse of external inputs, overharvesting and the proliferation of invasive species. Interactions between drivers often exacerbate their effects on BFA. Demographic changes, urbanization, markets, trade and consumer preferences are reported to have a strong influence on food systems, frequently with negative consequences for BFA and the ecosystem services it provides. However, such drivers are also reported to open opportunities to make food systems more sustainable, for example through the development of markets for biodiversityfriendly products. Many of the drivers that have negative impacts on BFA, including overexploitation, overharvesting, pollution, overuse of external inputs, and changes in land and water management, are at least partially caused by inappropriate agricultural practices.

The driver mentioned by the highest number of countries as having negative effects on regulating and supporting ecosystem services is changes in land and water use and management. Loss and degradation of forest and aquatic ecosystems and, in many production systems, transition to intensive production of a reduced number of species, breeds and varieties, remain major drivers of loss of BFA and ecosystem services. Countries report that the maintenance of traditional knowledge related to BFA is negatively affected by the loss of traditional lifestyles as a result of population growth, urbanization and the industrialization of agriculture and food processing, and by overexploitation and overharvesting. Policy measures and advances in science and technology are largely seen by countries as positive drivers that offer ways of reducing the negative effects of other drivers on BFA. They provide critical entry points for interventions supporting sustainable use and conservation. However, policies intended to promote the sustainable management of BFA are often weakly implemented.

\section{Biodiversity for food and agriculture is declining}

Many key components of biodiversity for food and agriculture at genetic, species and ecosystem levels are in decline. Evidence suggests that the proportion of livestock breeds at risk of extinction is increasing, and that, for some crops and in some areas, plant diversity in farmers' fields is decreasing and threats to diversity are increasing. Nearly a third of fish stocks are overfished and a third of freshwater fish species assessed are considered threatened. Countries report that many species that contribute to vital ecosystem services, including pollinators, natural enemies of pests, soil organisms and wild food species, are in decline as a consequence of the destruction and degradation of habitats, overexploitation, pollution and other threats. Key ecosystems that deliver numerous services essential to food and agriculture, including supply of freshwater, protection against hazards and provision of habitat for species such as fish and pollinators, are declining rapidly.

Knowledge of associated biodiversity, in particular micro-organisms and invertebrates, and of its roles in the supply of ecosystem services needs to be improved. While a large amount of information has been accumulated on the characteristics of the domesticated species used in food and agriculture, many information gaps remain, particularly for species, 
varieties and breeds that are not widely used commercially. Information on wild food species is also often limited. Many associated-biodiversity species have never been identified and described, particularly in the case of invertebrates and micro-organisms. Even when they have, their functions within the ecosystem often remain poorly understood. Over 99 percent of bacteria and protist species remain unknown. For several types of associated biodiversity, including soil micro-organisms and those used for food processing, advances in molecular techniques and sequencing technologies are facilitating characterization. Several countries have active programmes for characterizing soil micro-organisms using molecular methods. In many countries, however, gaps in terms of skills, facilities and equipment constrain opportunities to benefit from these developments.

Monitoring programmes for biodiversity for food and agriculture remain limited. Assessment and monitoring of the status and trends of BFA at national, regional and global levels are uneven and often limited. Even in developed regions, where the population trends of many species are well monitored and there are numerous ongoing research projects on the links between biodiversity and food and agriculture, available data often provide only a snapshot of the status of individual species (or groups of species) in particular production systems, habitats or geographical areas. While it is clear that many components of BFA are declining, lack of data often constrains the planning and prioritization of effective remedial measures.

\section{The use of many biodiversity-friendly practices is reported to be increasing}

The sustainable use and conservation of biodiversity for food and agriculture call for approaches in which genetic resources, species and ecosystems are managed in an integrated way in the context of production systems and their surroundings. In particular for many types of associated biodiversity and wild foods, sustainable use and conservation require in situ or on-farm management integrated into strategies at ecosystem or landscape levels. Ex situ conservation should serve as a complementary strategy.

The use of a wide range of management practices and approaches regarded as favourable to the sustainable use and conservation of biodiversity for food and agriculture is reported to be increasing. Eighty percent of reporting countries indicate that one or more of the biodiversity-focused practices on which they were invited to report are being used in one or more types of production system. A much higher proportion of OECD countries than nonOECD countries report the use of these practices. However, it is difficult to fully evaluate the extent to which these approaches are being implemented, because of the variety of scales and contexts involved and the absence of data and appropriate assessment methods. Although countries generally indicate that the impacts of the biodiversity-focused practices on diversity are perceived to be positive, they emphasize the need for more research in this regard, even for practices where research on production issues is well established. Many biodiversity-focused practices are relatively complex and require good understanding of the local ecosystem. They can be knowledge intensive, context specific and provide benefits only in the relatively long term. Many countries note major challenges in up-scaling such practices, and the need to promote them through capacity-development and strengthening policy frameworks.

Although efforts to conserve biodiversity for food and agriculture in situ and ex situ are increasing, levels of coverage and protection are often inadequate. Crop, livestock, forest and aquatic genetic resources are conserved in situ through a variety of approaches, 
including promotion of their sustainable use in production systems and the establishment of protected and other designated areas. However, many species and populations remain inadequately protected. Relatively few in situ conservation programmes are reported to explicitly target associated biodiversity and its roles in the supply of ecosystem services, although such programmes are increasing. Most associated-biodiversity species targeted are conserved through the promotion of biodiversity-friendly production practices, the establishment of protected areas, or policy and legal measures aimed at restricting activities that damage biodiversity. Ex situ conservation efforts for BFA are increasing, in particular for plant genetic resources, although many gaps in coverage remain. Much of the diversity present in minor crops, and in livestock, forest and aquatic species, is also not yet secured ex situ. Although limited, public- and private-sector ex situ conservation initiatives for targeted species of associated biodiversity have been established, with many countries, for instance, holding culture collections of micro-organisms used in agriculture or in agrifood industries. Eight percent of the wild species reported by countries to be used for food are reported to be subject to in situ conservation measures and 13 percent to be conserved ex situ.

\section{Enabling frameworks for the sustainable use and conservation of biodiversity for food and agriculture remain insufficient}

Enabling frameworks for the sustainable use and conservation of biodiversity for food and agriculture urgently need to be established or strengthened. Most countries have put in place legal, policy and institutional frameworks targeting the sustainable use and conservation of biodiversity as a whole. Policies addressing food and agriculture are reported to be increasingly based on ecosystem, landscape and seascape approaches. However, legal and policy measures explicitly targeting wild foods or components of associated biodiversity and their roles in supplying ecosystem services are not widespread. Constraints to the development and implementation of effective policy tools include a lack of awareness among policy-makers and other stakeholders of the importance of BFA, and in particular wild foods and associated biodiversity, to livelihoods and food security. There is a large knowledge gap in terms of how existing policies are affecting these components of biodiversity and the ecosystem services they provide. Diverging interests among stakeholders hamper the development and implementation of laws, policies and regulations, as do shortages of human and financial resources.

Research on food and agricultural systems needs to become more multidisciplinary, more participatory and more focused on interactions between different components of biodiversity for food and agriculture. Improvements to the sustainable use and conservation of BFA are often constrained by a lack of understanding of interactions between sectors (crop and livestock production, forestry, fisheries and aquaculture), between wild and domesticated biodiversity, and between the ecological and socio-economic components of production systems. Cooperation across disciplines, and greater involvement of producers and other stakeholders in research projects, can help to overcome these knowledge gaps.

Improving the management of biodiversity for food and agriculture and enhancing its contributions to ecosystem services call for better multistakeholder, cross-sectoral and international cooperation. Ensuring the sustainable use of BFA requires effective actions by relevant authorities and improved collaboration among a range of stakeholder groups (producers and their organizations, consumers, suppliers and marketers, policy-makers, and national and international governmental and non-governmental organizations) across 
the sectors of food and agriculture and between the food and agriculture sector and the environment/nature-conservation sector. The management of BFA spans international borders and the conventional boundaries between sectors. Frameworks for cooperation at national, regional and international levels in the management of genetic resources are relatively well developed in the individual sectors of food and agriculture. Cross-sectoral cooperation and multistakeholder collaborative activities specifically targeting associated biodiversity and wild foods are less widespread and need to be expanded and strengthened.

\section{What needs to be done?}

Securing and enhancing the multiple roles of BFA will require sustainable use and conservation of the ecosystems, species and genetic diversity that compose it. For this to happen, knowledge of the roles of biodiversity in the ecological processes that underpin food and agricultural production needs to be strengthened, and used to develop management strategies that protect, restore and enhance these processes across a range of scales. Establishing effective policy and outreach measures will be needed to support the uptake of management practices that sustainably use biodiversity to promote food and livelihood security and resilience.

The country-driven process of preparing The State of the World's Biodiversity for Food and Agriculture has led to the identification of numerous gaps, needs and potential actions in the management of BFA. The next step is to take action. Over the years, the Commission on Genetic Resources for Food and Agriculture has overseen the development of global plans of action for genetic resources in the plant, animal and forest sectors. Implementation of these instruments needs to be stepped up. Consideration also needs to be given to how the international community can more effectively promote synergies in the management of all components of biodiversity, across these sectors and others, in the interests of a more sustainable food and agriculture. 

Part A

OVERVIEW 



\section{Chapter 1 Introduction}

\subsection{Biodiversity and the challenges facing global food and agriculture}

Supplying enough safe and nutritious food for a growing world population poses many challenges. Among the most serious is the need to increase food production globally without undermining the capacity of the world's lands and seas to meet the food needs of future generations and to deliver other essential ecosystem services. Despite repeated warnings about the rapid loss of biodiversity (e.g. MEA, 2005a; Steffen et al., 2015) and the mounting evidence of its key role in food security and nutrition (Bommarco, Kleijn and Potts, 2013; Cunningham et al., 2013; Diaz et al., 2011; FAO and PAR, 2011; Pinstrup-Andersen, 2013; Rockström et al., 2017; Sunderland, 2011; Tittonell et al., 2016; Tscharntke et al., 2012), production systems worldwide are becoming ever less diverse in terms of the ecosystems, species and within-species genetic resources they comprise (FAO, forthcoming, 2010a, 2014a, 2015a; Khoury et al., 2014; Macfadyen et al., 2015).

In many parts of the world, biodiverse agricultural landscapes in which cultivated land is interspersed with uncultivated areas such as woodlands, pastures and wetlands have been, or are being, replaced by large areas of monoculture, farmed using large quantities of external inputs such as pesticides, mineral fertilizers and fossil fuels. Livestock production is increasingly becoming geographically separated from crop production, with animals often raised in landless production units, heavily dosed with veterinary drugs and fed on feedstuffs produced elsewhere and transported over long distances (FAO, 2009a, 2015a; Steinfeld et al., eds., 2010). Although high levels of crop and livestock production have been achieved, this has often come at the cost of major disruptions to the integrity of terrestrial and aquatic ecosystems, of declining opportunities for mutually beneficial interactions between sectors, and of the loss of components of biodiversity that provide services such as pollination, pest control and nutrient cycling. Many grasslands are being degraded by excessive or badly managed grazing or being converted for use in crop production or for other purposes (FAO, 2011a). The world's soils and their biodiversity are beset by threats such as erosion, loss of organic carbon, nutrient imbalances, salinization and contamination with pollutants (FAO and ITPS, 2015).

Overfishing threatens marine resources worldwide. Changes in fishing activities by international fleets are exerting particular pressure in the waters of some developing countries, in part because of the use of "flags of convenience" (Ferrel, 2005; Miller and Sumaila, 2014). As of 2015, an estimated 33.1 percent of world fish stocks were being fished at unsustainable levels (FAO, 2018a). Overfishing is also affecting many of the world's lakes and rivers (ibid.).

Over recent decades, growing global demand for fish has increasingly been met by aquaculture. Although fish farming offers opportunities to diversify production through polyculture or through integration with other production activities, it is also becoming increasingly intensified. Some systems use non-native species, which creates the risk of escapes that may harm local biodiversity (Lee and Gordon, 2006; McGinnity et al., 2003). 


\section{PART A}

Forest loss represents a major global threat to biodiversity and the supply of ecosystem services such as habitat provisioning, clean water, soil conservation and protection, and carbon sequestration (FAO, 2018b). Although rates of loss have decreased (and gone into moderate reverse in some regions), global forest area continues to decline, with the early part of this century seeing net losses in sub-Saharan Africa, Latin America and Southeast Asia (ibid.). The main cause of deforestation in these regions is conversion to agriculture, with illegal logging, fires and fuelwood extraction also contributing (ibid.). Remaining forests are threatened by degradation and fragmentation (Haddad et al., 2015).

The food and agriculture sector is a major contributor to greenhouse-gas emissions. For example, livestock production chains are estimated to be responsible for 14.5 percent of anthropogenic greenhouse-gas emissions (FAO, 2017a; Gerber et al., 2013). At the same time, climate change poses enormous threats to food and agriculture, including through its impacts on the species and ecosystems - from soil micro-organisms to coral reefs - that underpin production (FAO, 2015b). Loss of biodiversity in turn threatens the capacity of ecosystems used for food and agriculture to sequester carbon and reduces the options available for modifying production systems in the interests of climate change mitigation and adaptation (Chen et al., 2018; Henry et al., 2009; FAO, 2015b).

As the outcome of the first country-driven global assessment addressing all components of biodiversity of significance to food and agriculture across all sectors, this report, prepared by FAO at the request of its Commission on Genetic Resources for Food and Agriculture, aims to shed light both on the nature of these challenges and on opportunities to address them. It identifies and assesses the contributions that biodiversity makes to the supply of ecosystem services relevant to food and agriculture, to the resilience of production systems, to efforts to intensify production sustainably, to the livelihoods of farmers, livestock keepers, fishers, fish farmers and forest dwellers, and to food security and nutrition. It documents what is known about the status and trends of these components of biodiversity, and identifies and assesses the impacts of major drivers of change affecting them. It also documents the state of adoption of management practices and strategies in food and agriculture that use biodiversity or contribute to its conservation, the state of programmes addressing the characterization and conservation of components of biodiversity relevant to food and agriculture, and the state of policy and institutional frameworks for the management of these resources. It identifies key gaps and needs in terms of knowledge, capacity and resources and pinpoints priority actions that can help to address them.

\subsection{What is biodiversity for food and agriculture?}

Put simply, biodiversity is the variability that exists among living organisms (both within and between species) and the ecosystems of which they are part. In turn, biodiversity for food and agriculture (BFA) is the biodiversity that in one way or another contributes to agriculture and food production (see Section 1.5 for more formal definitions of these terms). It includes not only the domesticated crops and livestock raised by farmers and livestock keepers, the trees planted and harvested by forest dwellers and the aquatic species harvested or raised by fishers and aquaculture practitioners, but also the myriad other species of plants, animals and micro-organisms that underpin production, whether by creating and maintaining healthy soils, pollinating plants, purifying water, providing protection against extreme weather events, enabling ruminant animals to digest fibrous plant materials or delivering any of a range of other vital services. It also includes wild species (beyond the already-noted harvested aquatic species and forest trees) that are harvested for food and for other purposes. Finally, it includes micro-organisms used in food processing and in various agro-industrial processes. 
It is difficult to establish definite boundaries to BFA. Crops and livestock and farmed or wild-harvested trees and aquatic species all clearly contribute directly to food security and livelihoods. In many cases, they also provide other services that support food and agricultural production. For example, a tree or a herbaceous crop plant may help to protect the soil against erosion or to create a favourable microclimate for other components of the production system, a farmed animal may remove weeds or provide manure to fertilize crops, or a filter-feeding mollusc raised in aquaculture may contribute to water purification. Many of the other species that live in and around production systems also make relatively direct and clearly identifiable contributions to food and agriculture, for example the role of bees in pollination or ladybird beetles in removing aphid pests from crop plants. However, the health of a crop, grassland, forest, marine or freshwater production system is influenced by an enormous range of ecological processes, many of which are complex and not well understood. These process operate on a variety of scales, ranging from very local to global, and cross the boundaries between production systems, between the sectors of food and agriculture and between managed and unmanaged ecosystems. To provide a concrete example, a crop plant may benefit from soilmaintaining services provided by earthworms living in the immediate vicinity, from pollination services provided by insects that depend on the biodiversity present in hedgerows or uncultivated areas at the edge of the field, and from climateregulating services provided by distant forest, grassland or ocean biodiversity.

BFA cannot be considered in isolation from the humans that manage production systems. Farmers, livestock keepers, forest dwellers, fish farmers and fishers constantly engage with their environments, shaping them to varying degrees and utilizing components of biodiversity in different combinations to meet their needs. Many domesticated species have been used, developed and maintained by humans for thousands of years.

\subsection{Biodiversity for food and agriculture and global policy agendas}

Over recent decades, the importance of biodiversity to food security and nutrition, rural and coastal livelihoods and sustainable development more generally has gradually been acquiring greater recognition on international agendas (Figure 1.1). 1983 saw the establishment of the Commission on Plant Genetic Resources - an intergovernmental body with a secretariat hosted by FAO - which in 1995 became the Commission on Genetic Resources for Food and Agriculture ${ }^{1}$ and acquired a mandate covering all components of biodiversity of relevance to food and agriculture. Over the years, the Commission has overseen global assessments of genetic resources in the crop, livestock, forest and aquatic sectors and negotiated global plans of action for genetic resources in the first three (FAO, forthcoming, 1997, 2007a, 2007b, 2010a, 2011b, 2014a, 2014b, 2015a).

The adoption of the Convention on Biological Diversity $(C B D)^{2}$ in 1992 established an international legal framework for the conservation and sustainable use of biodiversity, including domesticated and non-domesticated species used for food and agriculture, along with the fair and equitable sharing of the benefits arising from the use of genetic resources. The CBD's programmes on (inter alia) agricultural biodiversity, forest biodiversity, dry and subhumid land biodiversity, inland water ecosystems and marine and coastal biodiversity aim to promote these objectives across a range of ecosystems used for food and agriculture. The Aichi Biodiversity Targets, adopted in 2010 as part of the CBD's Strategic Plan for Biodiversity 2011-2020 (CBD, 2010a), recognize the importance of $B F A$, including the need to reduce or eliminate the loss of forests (Target 5), manage and harvest fish and aquatic

\footnotetext{
http://www.fao.org/cgrfa/en (see also Box 1 in the "About this publication" section).

2 https://www.cbd.int
} 


\section{PART A}

FIGURE 1.1

Key developments in the international recognition of the importance of biodiversity for food and agriculture

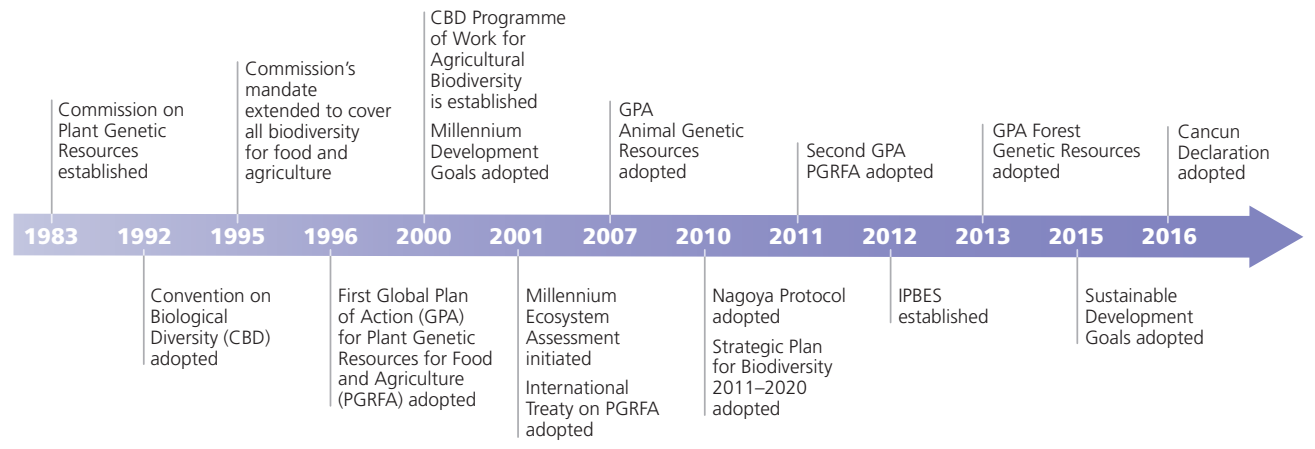

Note: IPBES = Intergovernmental Science-Policy Platform on Biodiversity and Ecosystem Services.

invertebrates and plants sustainably (Target 6), ensure areas under agriculture, aquaculture and forestry are managed sustainably in order to conserve biodiversity (Target 7) and maintain the genetic diversity of cultivated plants and animals and their wild relatives (Target 13 ). Target 18 recognizes the importance of the traditional knowledge, innovations and practices of indigenous and local communities for the conservation and sustainable use of biodiversity. The Nagoya Protocol on Access to Genetic Resources and the Fair and Equitable Sharing of Benefits Arising from their Utilization to the Convention on Biological Diversity, a supplementary agreement to the CBD adopted in 2010, established a legal framework for the implementation of the CBD's objective of fair and equitable sharing of benefits arising from the use of genetic resources.

In 2001, the International Treaty on Plant Genetic Resources for Food and Agriculture, which was negotiated under the aegis of the Commission, established an international legal framework, in harmony with the $\mathrm{CBD}$, for the conservation and sustainable use of plant genetic resources for food and agriculture and the fair and equitable sharing of the benefits arising from their use.
2012 saw the establishment of the Intergovernmental Science-Policy Platform on Biodiversity and Ecosystem Services (IPBES), ${ }^{3}$ an independent intergovernmental body that provides policymakers with objective scientific assessments of the planet's biodiversity and ecosystems, the benefits they provide to people, and the tools and methods available to protect and sustainably use them.

The Sustainable Development Goals, adopted by the United Nations in 2015 (see Box 1.1), include a number of targets related to the conservation and sustainable use of biodiversity in the context of food and agriculture, as did the Millennium Development Goals adopted in 2000.

In December 2016, the high-level ministerial segment of the thirteenth meeting of the Conference of the Parties to the CBD adopted the Cancún Declaration on Mainstreaming the Conservation and Sustainable Use of Biodiversity for Well-being (CBD, 2016a). More than 190 countries committed themselves to working to mainstream biodiversity and "bearing in mind that the agriculture, forestry, fisheries and tourism sectors heavily depend on biodiversity and its components, as well as on the ecosystem functions

\footnotetext{
https://www.ipbes.net
} 
Box 1.1

\section{Biodiversity for food and agriculture, FAO and the Sustainable Development Goals}

FAO is "custodian" UN agency for 21 indicators under Sustainable Development Goals 2, 5, 6, 12, 14 and 15, and a contributing agency for four more. Many of these indicators directly or indirectly measure components of biodiversity for food and agriculture.

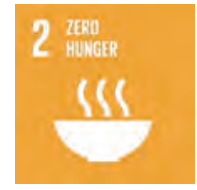

Goal 2 (End hunger, achieve food security and improved nutrition and promote sustainable agriculture) includes a target on ensuring sustainable food production systems and implementing resilient agricultural practices that increase productivity and production, that help maintain ecosystems, that strengthen capacity for adaptation to climate change, extreme weather, drought, flooding and other disasters and that progressively improve land and soil quality (Target 2.4). It also includes a target on maintaining the genetic diversity of seeds, cultivated plants and farmed and domesticated animals and their related wild species, and promoting access to and fair and equitable sharing of benefits arising from the utilization of genetic resources and associated traditional knowledge (Target 2.5). Indicators for these targets include:

- Indicator 2.4.1: Proportion of agricultural area under productive and sustainable agriculture;

- Indicator 2.5.1: Number of plant and animal genetic resources for food and agriculture secured in medium- or long-term conservation facilities; and

- Indicator 2.5.2: Proportion of local breeds, classified as being at risk, not-at-risk or at unknown level of risk of extinction.

Data for Indicators 2.5.1 and 2.5.2 are compiled by FAO through the World Information and Early Warning System on Plant Genetic Resources for Food and Agriculture (WIEWS) ${ }^{1}$ and the Domestic Animal Diversity Information System (DAD-IS), ${ }^{2}$ both of which are managed under the guidance of the Commission on Genetic Resources for Food and Agriculture (see Boxes 7.1 and 7.2 for further information on these systems).

\footnotetext{
http://www.fao.org/wiews/en

http://www.fao.org/dad-is/en
}

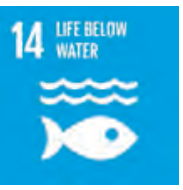

Goal 14 (Conserve and sustainably use the oceans, seas and marine resources) includes targets on the sustainable management and protection of marine and coastal ecosystems, action to promote their restoration in the interest of healthy and productive oceans, and effective regulation of harvesting and overfishing. Indicators for this target include:

- Indicator 14.4.1: Proportion of fish stocks within biologically sustainable levels; and

- Indicator 14.7.1: Sustainable fisheries as a percentage of GDP in small island developing states, least developed countries and all countries.

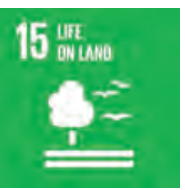

Goal 15 (Sustainably manage forests, combat desertification, halt and reverse land degradation, halt biodiversity loss) includes targets addressing the conservation, restoration and sustainable use of terrestrial and inland freshwater ecosystems and their services, sustainable management of all types of forests and the integration of ecosystem and biodiversity values into national and local planning, development processes and poverty reduction strategies. Indicators for this target include:

- Indicator 15.1.1: Forest area as a percentage of total land area;

- Indicator 15.2.1: Progress towards sustainable forest management; and

- Indicator 15.4.2: Mountain Green Cover Index (a measure of changes in the area of green vegetation in mountain areas [forest, shrubs and pasture land, and cropland]).
Note: For further information, see FAO (2017b) or visit FAO's Sustainable Development Goals web page: http://www.fao.org/sustainable-developmentgoals/en 
and services which biodiversity underpins, and that these sectors also impact on biodiversity in various direct and indirect ways, ... to undertake specific actions for each sector ..."

\subsection{Assessments of biodiversity for food and agriculture}

The growing prominence of biodiversity on international agendas has led to the implementation of a number of global assessments of various components or aspects of biodiversity, including those of relevance to food and agriculture. For example, the Millennium Ecosystem Assessment, ${ }^{4}$ a global effort launched in 2001 to identify the consequences of ecosystem change for human well-being, assessed the state of a range of ecosystem services, ${ }^{5}$ including the supply of food and other agricultural products, and many of the services that underpin production (pollination, pest regulation, erosion control, etc.) (MEA, 2005a). IPBES has prepared global assessments on pollinators, pollination and food production (IPBES, 2016a), on land degradation (IPBES, 2018a) and on biodiversity and ecosystem services (IPBES, forthcoming). Starting in 2001, the CBD's Global Biodiversity Outlook series ${ }^{6}$ has provided periodic reports on the status and trends of global biodiversity and its management. The Economics of Ecosystems and Biodiversity (TEEB) ${ }^{7}$ initiative has prepared a number of publications on the theme of valuating biodiversity and ecosystem services, including an interim report addressing the food and agriculture sector (TEEB, 2015) and a scientific and economic foundation report (TEEB, 2018).

FAO has long conducted regular assessments of food and agriculture (The State of Food and Agriculture), ${ }^{8}$ forests (The State of the World's

\footnotetext{
https://www.millenniumassessment.org/en/Index-2.html See Section 1.5 for further information on this concept. https://www.cbd.int/gbo/default.shtml http://www.teebweb.org

http://www.fao.org/publications/sofa/ the-state-of-food-and-agriculture/en
}

Forests; ${ }^{9}$ Global Forest Resources Assessment) ${ }^{10}$ and fisheries and aquaculture (The State of World Fisheries and Aquaculture), ${ }^{11}$ each of which contributes to knowledge of the state of species and/or ecosystems of relevance to food and agriculture. In 2015, FAO and the Intergovernmental Technical Panel on Soils published Status of the World's Soil Resources, the first major global assessment on soils and related issues (FAO and ITPS, 2015).

The High Level Panel of Experts on Food Security and Nutrition ${ }^{12}$ of the UN Committee on World Food Security has over recent years published a number of reports addressing the significance of particular components of BFA to food security and nutrition: Sustainable fisheries and aquaculture for food security and nutrition (HLPE, 2014a); Sustainable agricultural development for food security and nutrition: what roles for livestock? (HLPE, 2016); Sustainable forestry for food security and nutrition (HLPE, 2017a); and Nutrition and food systems (HLPE, 2017b).

As noted above, the Commission on Genetic Resources for Food and Agriculture has overseen global assessments of genetic resources and their management in the various sectors of food and agriculture (FAO, forthcoming, 1997, 2007a, 2010a, 2015a) (see Box 1.2). These assessments have largely focused on the species, varieties and breeds of plants and animals that are raised or harvested in each sector to provide food and other products (although other roles and uses are discussed). ${ }^{13}$ Other components of BFA received little attention and interactions between sectors were not a major focus.

The State of the World's Biodiversity for Food and Agriculture is intended to complement the sectoral assessments and to fill gaps in terms of scope and focus. It addresses all components of

\footnotetext{
http://www.fao.org/publications/sofo/en

$10 \mathrm{http} / / /$ www.fao.org/forest-resources-assessment/en

http://www.fao.org/fishery/sofia/en

12 http://www.fao.org/cfs/cfs-hlpe/en

13 See Section 1.5 for further discussion of genetic resources in the various sectors of food and agriculture and the scope of the global assessments overseen by the Commission.
} 
Box 1.2

\section{Assessing the state of the world's genetic resources for food and agriculture}

The Commission on Genetic Resources for Food and Agriculture has overseen the preparation of authoritative assessments of the state of the world's genetic resources in the plant (crop), animal (livestock), forest and aquatic sectors.

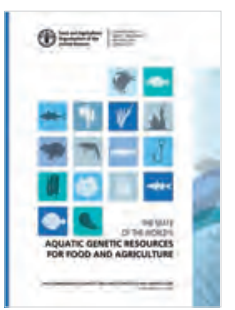

The State of the World's Aquatic Genetic Resources for Food and Agriculture (FAO, forthcoming) focuses on cultured species and their wild relatives, within national jurisdiction. It draws on 92 country reports and five specially commissioned thematic background

studies. The reporting countries are responsible for 96 percent of global aquaculture production. The report sets the context with a review of the state of the world's aquaculture and fisheries and includes overviews of the use and exchange of aquatic genetic resources, the drivers affecting the status of these resources, and the extent of ex situ and in situ conservation efforts targeting them. It also describes the roles of stakeholders in the management of these resources and the levels of activity in research, education, training and extension in this field. It reviews national policies and the levels of regional and global cooperation in the management of aquatic genetic resources. Finally, it assesses needs and challenges in the context of the findings of the analysis of the data provided by countries.

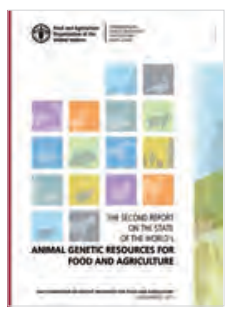

The Second Report on the State of the World's Animal Genetic Resources for Food and Agriculture (FAO, 2015a) provides an update of the global assessment provided in the first report on The State of the World's Animal Genetic Resources for Food and Agriculture, published in

2007. It presents an analysis of the state of livestock diversity, the influence of livestock-sector trends on the management of animal genetic resources, the state of capacity to manage animal genetic resources, including legal and policy frameworks, the state of the art in tools and methods for characterization, genetic improvement, valuation and conservation, and needs and challenges with respect to the future of animal genetic resources management. It draws on 129 country reports, four reports from regional focal points and networks, 15 reports from international organizations and two commissioned thematic studies.

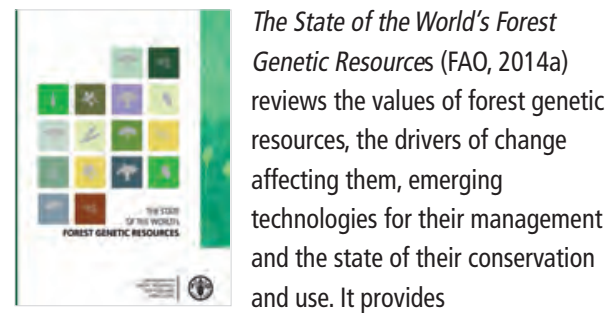

recommendations for the management of these resources, both in terms of innovations in practices and technologies and in terms of increased attention at policy and institutional levels. It draws on information provided by 86 countries, outcomes from regional and subregional consultations, and five commissioned thematic studies.

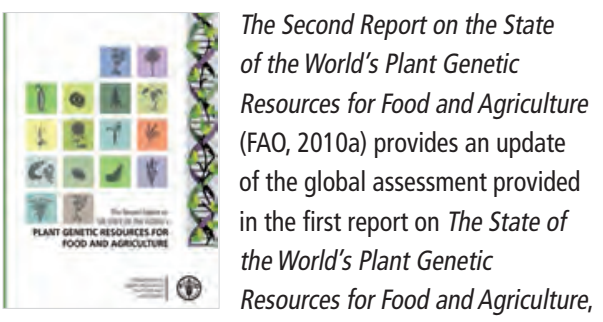
published in 1996. It documents the major achievements in the sector during the preceding decade and identifies gaps and needs requiring urgent attention. It draws on 113 country reports, regional syntheses and eight commissioned thematic studies.

Note: The reports can be viewed at http://www.fao.org/3/a-i4787e.pdf http://www.fao.org/3/a-i3825e.pdf http://www.fao.org/docrep/013/i1500e/i1500e.pdf 
biodiversity across all sectors of food and agriculture, but pays particular attention to the interface between managed and unmanaged biodiversity, cross-sectoral interactions and the roles of components of BFA in the supply of supporting and regulating ecosystem services. ${ }^{14}$

Like the sectoral assessments, the report is the outcome of a country-driven process. The decision to prepare it was taken at the Commission's Eleventh Regular Session in 2007 (FAO, 2007c). Ninety-one countries submitted reports on the state of their BFA and its management, including information on priorities that need to be addressed in order to strengthen the sustainable use and conservation of these resources. A series of informal regional consultations attended by country representatives took place in 2016 and provided an opportunity to share knowledge and information and to discuss needs and priorities.

The broad scope and innovative perspective of the assessment presented challenges in terms of data collection and analysis at all levels. In discussing the preparatory process, the Commission ${ }^{15}$ recognized that findings would be incomplete in a number of areas and requested that gaps in knowledge be assessed and highlighted in the report (FAO, 2013a).

\subsection{Key concepts addressed in this report}

This section provides definitions and short overviews of key concepts addressed in this report.

\section{Biodiversity}

Biological diversity (often referred to as biodiversity) is defined in Article 2 of the CBD as "the variability among living organisms from all sources including, inter alia, terrestrial, marine and other aquatic ecosystems and the ecological complexes of which they are part: this includes diversity within

\footnotetext{
14 See Section 1.5 for further discussion of the various categories of ecosystem services.

15 At its Fourteenth Regular Session, in 2013.
}

species, between species and of ecosystems" (CBD, 1992).

\section{Biodiversity for food and agriculture}

BFA is a subcategory of biodiversity taken for the purposes of this report to correspond to "the variety and variability of animals, plants and micro-organisms at the genetic, species and ecosystem levels that sustain the ecosystem structures, functions and processes in and around production systems, and that provide food and non-food agricultural products" (FAO, 2013b). ${ }^{16}$ Production systems (see below for further discussion of this term) are here taken to include those in the crop, livestock, forest, fishery and aquaculture sectors. BFA includes plant, animal and aquatic genetic resources for food and agriculture, forest genetic resources, associated biodiversity and wild foods (see below for further discussion of these terms). It also includes micro-organisms used for food processing and in agro-industrial processes.

\section{Genetic resources}

Genetic resources are defined under Article 2 of the CBD as "genetic material of actual or potential value". "Genetic material" is in turn defined as "any material of plant, animal, microbial or other origin containing functional units of heredity." Genetic resources can be embodied in living plants, animals or micro-organisms or in stored seeds, semen, oocytes, embryos, somatic cells or isolated DNA (deoxyribonucleic acid). In the context of food and agriculture, the term is often used to refer to the species managed or harvested within a given sector (e.g. plant, animal, forest or aquatic genetic resources for food and agriculture - see below).

\section{Plant genetic resources for \\ food and agriculture}

The term plant genetic resources for food and agriculture refers to genetic material of plant origin of actual or potential value for food and agriculture (FAO, 2010a). This includes farmers' varieties/landraces managed on-farm, improved

\footnotetext{
16 The wording draws on FAO and PAR (2011).
} 
varieties, breeding materials in crop-improvement programmes, accessions conserved ex situ (i.e. in genebanks or other collections) and wild plants that may be related to crops (i.e. crop wild relatives) or those wild species harvested for food.

In agronomy, the term "variety" refers to a plant grouping that is distinguished from any other plant grouping by the expression of certain heritable characteristics that remain unchanged by propagation. ${ }^{17}$ Cultivated varieties can be broadly classified as "modern officially released varieties" or "farmers' varieties" (FAO, 1997). ${ }^{18}$ Modern officially released varieties are the products of breeding by professional plant breeders, mainly working for private companies or publicly funded research institutes (sometimes referred to as the "formal system" or "scientific breeding"). These typically have a high degree of genetic uniformity and breed true (i.e. produce offspring with the same phenotypic traits as their parents). Farmers' varieties, also known as "landraces" or "traditional varieties", are the product of breeding or selection carried out continuously, deliberately or otherwise, by farmers over many generations. Farmers' varieties tend not to be genetically uniform, and contain high levels of genetic diversity.

Crop wild relatives are potential sources of heritable traits for use in crop breeding. Traits from crop wild relatives that confer tolerance to abiotic and biotic stresses and improved nutritional qualities have been successfully incorporated into some elite crop varieties. Advanced biotechnologies (e.g. embryo rescue and protoplast fusion) are

\footnotetext{
17 Definition is based on wording from Article 1 (vi) of the 1991 Act of the International Union for the Protection of New Varieties of Plants (UPOV) Convention (UPOV, 1991), which states that "'variety' means a plant grouping within a single botanical taxon of the lowest known rank, which grouping, irrespective of whether the conditions for the grant of a breeder's right are fully met, can be defined by the expression of the characteristics resulting from a given genotype or combination of genotypes, distinguished from any other plant grouping by the expression of at least one of the said characteristics and considered as a unit with regard to its suitability for being propagated unchanged."

18 It should be noted that "farmers' variety" is an imprecise term and that "varieties" referred to in this way may not meet the requirement that a variety breed true.
}

increasingly being used to circumvent the barriers to cross-breeding that have prevented the introduction of novel alleles from crop wild relatives into cultivated varieties.

\section{Animal genetic resources for food and agriculture}

Animal genetic resources for food and agriculture are genetic resources of animal origin used or potentially used for food and agriculture (FAO, 2007a, 2007b). In line with the scope of previous global assessments (FAO, 2007a, 2015a), the term is used in this report to refer to the genetic resources of domesticated avian and mammalian species used in food and agriculture.

Livestock species generally encompass a number of different subspecific populations referred to as breeds. According to the definition used by FAO, a breed is "either a subspecific group of domestic livestock with definable and identifiable external characteristics that enable it to be separated by visual appraisal from other similarly defined groups within the same species or a group for which geographical and/or cultural separation from phenotypically similar groups has led to acceptance of its separate identity" (FAO, 1999a). Individual breeds, in turn, harbour varying degrees of genetic diversity, and some are more genetically distinct from the species population at large than others. Breeds that have been present in a particular production environment for sufficient time for the effects of natural selection and managed genetic improvement to adapt them to local conditions are referred to as "locally adapted breeds". ${ }^{19}$ Breeds can be subject to breeding programmes to improve their productivity or promote other desirable characteristics. They can be mated with each other to produce cross-bred animals that embody characteristics from both the parent breeds.

\footnotetext{
19 The definition agreed upon by the Commission on Genetic Resources for Food and Agriculture for use in national reporting states that "locally adapted breeds" are "breeds that have been in the country for a sufficient time to be genetically adapted to one or more of the traditional production systems or environments in the country" and that "exotic breeds" are "breeds that are not locally adapted".
} 


\section{PART A}

The wild relatives of domesticated livestock are generally not used in any systematic way in contemporary animal breeding. Some of the wild ancestral species of major domesticated animal species are now extinct, for example the aurochs (Bos primigenius), ancestor of domestic cattle.

\section{Forest genetic resources}

Forest genetic resources are the heritable materials maintained within and among tree and other woody plant species that are of actual or potential economic, environmental, scientific or societal value (FAO, 2014a).

The distribution of genetic diversity within tree species is shaped by the evolutionary history of the species, introgression and hybridization with related species, as well as by forest degradation and fragmentation. Although humans have long utilized tree species, tree genetic improvement efforts were only initiated in the 1930s. Tree breeding is a slow process, as one cycle of testing and selection typically takes decades. Most advanced tree-breeding programmes are only in their third cycle of testing and selection. This means that the gene pools of trees in breeding programmes are still mostly semiwild. Only a few tree species (e.g. various fruit and nut trees) have been domesticated to a level similar to that of agricultural crops.

\section{Aquatic genetic resources for food and agriculture}

Aquatic genetic resources include DNA, genes, chromosomes, tissues, gametes, embryos and other early life history stages, individuals, strains, stocks and communities of organisms, of actual or potential value for food and agriculture. The scope of the assessment undertaken for the report on The State of the World's Aquatic Genetic Resources for Food and Aquaculture is farmed aquatic species and their wild relatives within national jurisdiction (FAO, forthcoming).

Unlike domesticated crop and livestock species, which generally include many breeds, varieties or cultivars, there are few recognized within-species strains among the species used in aquaculture, a sector in which commercial breeding only started in the last century. Subspecific stocks of aquatic species in the wild are recognized. Although some stocks are genetically characterized, it is more usual for a stock to be characterized by its geographic location (e.g. North Atlantic cod).

\section{Associated biodiversity}

Associated biodiversity is a subcategory of BFA. The concept is perhaps most familiar in the crop sector, where the biodiversity of harvested domesticated crop plants is distinguished from "crop-associated biodiversity" - the range of other species that are present in and around the production system and that sustain ecosystem structures, functions and processes (e.g. Lenné and Wood, 2011; Waliyar, Collette and Kenmore, 2002). Examples include pollinators, the predators of crop pests, the vegetation found in hedgerows and at field margins, and the invertebrates and micro-organisms that help to create and maintain the soil and its fertility. In addition to beneficial species such as pollinators, crop associated biodiversity includes the various species that inhibit crop production by acting as weeds or pests.

Equivalent categories of biodiversity can be distinguished in other sectors of food and agriculture. In a livestock production system, for example, the domesticated animals can be distinguished from associated biodiversity such as rangeland plants, the micro-organism and invertebrate communities associated with the soil, and the micro-organisms found in the animals' digestive systems. In a forest ecosystem, trees are surrounded by a multitude of plants, animals and micro-organisms that contribute in various ways to the functioning of the ecosystem. ${ }^{20}$ In capture fisheries, harvested species rely on a range of animals, plants and micro-organisms as sources of food and for services such as water purification and habitat provisioning. They benefit from oxygen provided by aquatic plants and the protection provided by habitats such as kelp forests, seagrass beds and coral reefs. Some species rely on others as

\footnotetext{
The term "forest biodiversity" is used to refer to "the variability among forest-dwelling organisms and the ecological processes of which they are a part. It includes variation at forest ecosystem, species and molecular levels" (FAO, 2014a).
} 
hosts. Aquatic species farmed in extensive systems or raised in culture-based fisheries also interact with these various components of associated biodiversity. Similarly, species raised in aquaculture ponds benefit from a range of services provided by the flora and fauna that surround them, particularly with respect to water purification and nutrient cycling.

Associated biodiversity consists largely of nondomesticated species. Exceptions include the domestic honey bee and some other pollinator species. Various biological control agents (natural enemies used to control pest species) are bred in captivity.

Where ecosystem services (see below) are concerned, associated biodiversity is particularly important to the supply of supporting and regulating services. However, components of associated biodiversity may also be direct sources of food and other products (supply provisioning ecosystem services) or have cultural significance (supply cultural ecosystem services).

\section{Wild foods}

Wild foods are food products obtained from non-domesticated species. They may be harvested (gathered or hunted) from within food and agricultural production systems or from other ecosystems. The group of species that supplies wild foods overlaps to various degrees with those in the above-described "sectoral" categories of genetic resources and with associated biodiversity. For example, capture fisheries are probably the largest single example of the human use of wild foods, and many aquaculture facilities use wildcaught stocks for broodstock or larval grow-out.

\section{Ecosystem services}

As implied in the definition given above, BFA is integral to ecosystem structures, processes and functions in and around production systems. Such structures, processes and functions, both in food and agricultural systems and in ecosystems more generally, give rise in turn to a range of benefits to humans - often referred to as ecosystem services. The Millennium Ecosystem Assessment defined the term simply as "the benefits humans derive from ecosystems" (MEA, 2005a). It identified the following four categories of ecosystem service: provisioning, regulating, supporting and cultural (ibid.). Provisioning services are "the products obtained from ecosystems", i.e. food and raw materials of various kinds. Regulating services are "the benefits obtained from the regulation of ecosystem processes." Examples include regulation of the climate, air and water quality, diseases and natural disasters. Cultural services are "the nonmaterial benefits people obtain from ecosystems through spiritual enrichment, cognitive development, reflection, recreation, and aesthetic experiences". Supporting services are services "that are necessary for the production of all other ecosystem services." Examples include photosynthesis, nutrient cycling and provision of habitat for other species. The distinguishing feature of supporting services is that they have a less direct effect on human welfare. ${ }^{2}$

The slightly different framework used by The Economics of Ecosystems and Biodiversity (TEEB) initiative does not treat supporting services as a separate category, but rather as a subset of the ecological processes that underlie the delivery of other services (TEEB, 2010). However, it distinguishes a separate category, "habitat services", defined as services that "provide living space for resident and migratory species."

In preparing their reports for The State of the World's Biodiversity for Food and Agriculture, countries were invited to focus primarily on regulating and supporting services. A number of questions in the country-reporting guidelines refer specifically to these two categories of ecosystem service.

\section{Conservation}

Conservation of BFA is taken in this report to include all actions implemented with the aim of preventing the loss of diversity in the populations, species and ecosystems that constitute this subset of biodiversity.

\footnotetext{
All the definitions presented in this paragraph are taken from MEA (2005a)
} 
"In situ conservation" is defined under the CBD as "conservation of ecosystems and natural habitats and the maintenance and recovery of viable populations of species in their natural surroundings and, in the case of domesticated or cultivated species, in the surroundings where they have developed their distinctive properties." In the context of BFA, in situ conservation comprises measures that promote the maintenance of biodiversity (including domesticated biodiversity) in and around crop, livestock, forest, aquatic and mixed production systems (or in the case of wild foods and wild relatives of domesticated species also in other habitats).

"Ex situ conservation" is defined under the CBD as "the conservation of components of biological diversity outside their natural habitats." In the context of BFA, ex situ conservation comprises the conservation of relevant components of biodiversity outside their normal habitats in and around production systems. This may involve the maintenance of live organisms at sites such as botanic gardens, aquaria, field genebanks, zoos or rare-breed farms, or storage of seeds, pollen or vegetative plant tissues or cryoconserved materials, such as animal semen or embryos, in genebanks.

\section{Sustainable use}

Sustainable use of the components of biodiversity is one of the three objectives of the $C B D$, which defines the term as follows: "the use of components of biological diversity in a way and at a rate that does not lead to the long-term decline of biological diversity, thereby maintaining its potential to meet the needs and aspirations of present and future generations."

In the case of BFA, "use" is taken in this report to include the various practical activities involved in cultivating or raising domesticated species, the implementation of formal or informal geneticimprovement activities and the domestication of additional wild species, the introduction of domesticated or wild species into new production systems, the management of wild species and their habitats in and around production systems to promote the delivery of ecosystem services, and the harvesting of food and other products from the wild.

Sustainable use and conservation are interrelated in various ways. From one perspective, sustainable use can be seen as an element of conservation. For example, in the case of wild biodiversity, enabling people to use a wild species or ecosystem in a sustainable way may lead to its being protected from more destructive activities. Domesticated biodiversity is to a large degree dependent on use. Individual varieties and breeds of crops, livestock and farmed aquatic species are products of humancontrolled breeding and would cease to exist without ongoing management. In situ conservation of domesticated biodiversity therefore inevitably involves use (unless the targets are feral populations). From another perspective, conservation of BFA can be viewed as a pre-requisite for use. Aside from the obvious point that individual components of BFA cannot be used if they have become extinct, sustainable use of a food and agricultural system, and the genetic resources it contains, may depend on the conservation of neighbouring (or more distant) ecosystems that provide it with essential services.

\section{Production system}

For the purpose of this report, a production system is a category of management unit (farm, livestock holding, forest stand, fishery [in a natural or human-made water body], aquaculture holding, or mixed management unit) that shares common characteristics with respect to the types of species raised or harvested and the types of management practised. The following systems were distinguished in the country-reporting process: grassland-based livestock systems; landless livestock systems; naturally regenerated forests; planted forests; self-recruiting capture fisheries; culture-based fisheries; fed aquaculture; non-fed aquaculture; irrigated crop systems (rice); irrigated crop systems (other); rainfed crop systems; and mixed production systems. See Table 1.1 for further details of this classification system. 
TABLE 1.1

\section{Production-system classification used in this report}

\begin{tabular}{|c|c|}
\hline $\begin{array}{l}\text { Name of the } \\
\text { production system }\end{array}$ & Description \\
\hline $\begin{array}{l}\text { Livestock grassland-based } \\
\text { systems }\end{array}$ & $\begin{array}{l}\text { Systems in which the animals obtain a large proportion of their forage intake by grazing natural or sown pastures, } \\
\text { includes: } \\
\text { - ranching: grassland-based systems in which livestock is kept on privately owned rangeland; } \\
\text { - pastoralist: grassland-based systems in which the livestock keepers move with their herds or flocks in an opportunistic } \\
\text { way on communal land to find feed and water for their animals (either from or not from a fixed home base). }\end{array}$ \\
\hline Livestock landless systems & Systems in which livestock production is separated from the land where the feed given to the animals is produced. \\
\hline $\begin{array}{l}\text { Naturally regenerated } \\
\text { forests }\end{array}$ & $\begin{array}{l}\text { Includes: } \\
\text { - primary: forests of native species, where there are no clearly visible indications of human activities and the } \\
\text { ecological processes are not directly disturbed by humans; } \\
\text { - modified natural: forests of naturally regenerated native species where there are clearly visible indications of } \\
\text { significant human activities; } \\
\text { - semi-natural (assisted natural regeneration): silvicultural practices in natural forest by intensive management } \\
\text { (weeding, fertilizing, thinning, selective logging). }\end{array}$ \\
\hline Planted forests & $\begin{array}{l}\text { Includes: } \\
\text { - semi-natural (planted component): forests of native species, established through planting or seeding, intensively } \\
\text { managed; } \\
\text { - plantations (productive): forests of introduced and/or native species established through planting or seeding } \\
\text { mainly for production of wood or non-wood goods; } \\
\text { - plantations (protective): forests of introduced and/or native species, established through planting or seeding } \\
\text { mainly for provision of services. }\end{array}$ \\
\hline $\begin{array}{l}\text { Self-recruiting capture } \\
\text { fisheries }\end{array}$ & $\begin{array}{l}\text { Includes capture fisheries in marine, coastal and inland areas that can involve: } \\
\text { - natural ecosystems; } \\
\text { - modified ecosystems e.g. reservoirs and rice paddies. }\end{array}$ \\
\hline Culture-based fisheries & $\begin{array}{l}\text { Fisheries based on resources, the recruitment of which originates or is supplemented from cultured stocks (i.e. } \\
\text { populations chosen for culture and not stocks in the same sense as that term is used for capture fisheries) raising } \\
\text { total production beyond the level sustainable through natural processes. }\end{array}$ \\
\hline Fed aquaculture & $\begin{array}{l}\text { The farming of aquatic organisms including fish, molluscs, crustaceans, aquatic plants, crocodiles, alligators, } \\
\text { turtles and amphibians. Farming implies some sort of intervention in the rearing process to enhance production, } \\
\text { such as regular stocking, feeding or protection from predators. Farming also implies individual or corporate } \\
\text { ownership of the stock being cultivated (i.e. the population chosen for culture and not a stock in the same sense } \\
\text { as that term is used for capture fisheries). } \\
\text { Fed aquaculture production utilizes or has the potential to utilize aquafeeds of any type, in contrast to the farming } \\
\text { of filter-feeding invertebrates and aquatic plants that relies exclusively on natural productivity. Also defined as } \\
\text { "farming of aquatic organisms utilizing aquafeeds in contrast to that deriving nutrition directly from nature." }\end{array}$ \\
\hline Non-fed aquaculture & $\begin{array}{l}\text { The farming of aquatic organisms including fish, molluscs, crustaceans and aquatic plants that do not need } \\
\text { supplemental feeding. Farming implies some sort of intervention in the rearing process to enhance production, } \\
\text { such as regular stocking, feeding or protection from predators. Farming also implies individual or corporate } \\
\text { ownership of the stock being cultivated (i.e. the population chosen for culture and not a stock in the same sense } \\
\text { as that term is used for capture fisheries). In non-fed aquaculture systems culture is predominately dependent on } \\
\text { the natural environment for food, e.g. aquatic plants and molluscs. }\end{array}$ \\
\hline Irrigated crops (rice) & Areas where rice is cultivated and purposely provided with water, including land irrigated by controlled flooding. \\
\hline Irrigated crops (other) & Agricultural areas purposely provided with water, including land irrigated by controlled flooding. \\
\hline Rainfed crops & Agricultural practice relying exclusively on rainfall as its source of water. \\
\hline $\begin{array}{l}\text { Mixed production systems } \\
\text { (livestock, crop, forest } \\
\text { and /or aquatic and } \\
\text { fisheries mixed) }\end{array}$ & $\begin{array}{l}\text { Production systems with multiple components. They include: } \\
\text { - crop-livestock: mixed systems in which livestock production is integrated with crop production; } \\
\text { - agropastoralist: livestock-oriented systems that involve some crop production in addition to keeping grazing } \\
\text { livestock on rangelands; they may involve migration with the livestock away from the cropland for part of the } \\
\text { year; in some areas, agropastoral systems emerged from pastoral systems; } \\
\text { - agroforestry-livestock: mixed systems in which livestock production is integrated with the production of trees } \\
\text { and shrubs; } \\
\text { - integrated aquaculture: mixed systems in which aquaculture is integrated with crop and livestock production; } \\
\text { may involve ponds on farms, flooded fields, enrichment of ponds with organic waste, etc.; } \\
\text { - other combinations. }\end{array}$ \\
\hline
\end{tabular}

Source: FAO, 2013b. 



\section{Chapter 2}

\section{Roles and importance of biodiversity for food and agriculture}

\begin{tabular}{|c|c|}
\hline \multicolumn{2}{|l|}{ Key messages } \\
\hline $\begin{array}{l}\text { - Biodiversity for food and agriculture (BFA) - } \\
\text { including domesticated crops and animals, } \\
\text { harvested forest and aquatic species, and the } \\
\text { associated biodiversity found in and around } \\
\text { production systems - is indispensable to food } \\
\text { security, sustainable development and the supply of } \\
\text { many vital ecosystem services. } \\
\text { - BFA helps to make production systems and } \\
\text { livelihoods more resilient to shocks and stresses, } \\
\text { including those associated with climate change. } \\
\text { - BFA is a key resource in efforts to increase food } \\
\text { production while limiting or reducing negative } \\
\text { impacts on the environment. } \\
\text { - BFA contributes in numerous ways to the } \\
\text { livelihoods of many households, particularly } \\
\text { to those that have limited access to external } \\
\text { production inputs or live in marginal areas with } \\
\text { harsh production environments. }\end{array}$ & $\begin{array}{l}\text { - Components of BFA often provide or contribute } \\
\text { to multiple ecosystem services, and this needs } \\
\text { to be built on in their management and in the } \\
\text { management of the production systems where } \\
\text { they are found. } \\
\text { - Many countries emphasize the importance of } \\
\text { genetic diversity as a means of coping with } \\
\text { diverse production environments and adapting } \\
\text { to future challenges. Many also emphasize the } \\
\text { role of diversification - using multiple species } \\
\text { or integrating crop, livestock, forest and aquatic } \\
\text { resources, and conserving and managing habitat } \\
\text { diversity at landscape or seascape scale - } \\
\text { in promoting resilience, improving livelihoods and } \\
\text { supporting food security and nutrition. }\end{array}$ \\
\hline
\end{tabular}

\subsection{Introduction}

This chapter introduces the contributions made by biodiversity for food and agriculture (BFA) to human livelihoods and well-being and to various aspects of sustainable development. The sections of the chapter, respectively, cover the roles of BFA in the supply of ecosystem services, in promoting the resilience of production systems and livelihoods, in providing options for the sustainable intensification of production, in supporting livelihoods and in underpinning food security and nutrition. Each section outlines the concepts involved, describes the mechanisms through which BFA delivers benefits in the respective thematic area, and presents an overview of relevant country-report ${ }^{1}$ responses. The focus of the countryreport analysis presented in this chapter is on what countries regard as the key contributions of BFA in each of the thematic areas covered. ${ }^{2}$ Details

Unless otherwise specified, the term "country reports" in this chapter refers to the country reports prepared as contributions to the preparation of The State of the World's Biodiversity for Food and Agriculture.

2 Countries were specifically invited to report on the contributions of BFA in each of these thematic areas. 


\section{PART A}

of what countries report about specific aspects of BFA management - much of which will be relevant to more than one of the thematic areas - is provided in other chapters of the report, particularly in Chapters 5 and 7.

\subsection{Ecosystem services}

- Diverse biological resources - domesticated and non-domesticated, and at every level from genes to ecosystems - are fundamental to food production and to the supply of many essential non-food products.

- Biodiversity for food and agriculture (BFA) delivers multiple supporting and regulating ecosystem services - including pollination, formation and maintenance of soils, nutrient cycling, climate regulation, maintenance of water supplies, and control of pests and diseases that are vital to production and to human well-being more broadly.

- BFA contributes in many ways to the supply of cultural ecosystem services, i.e. the aesthetic, recreational, inspirational, spiritual and educational benefits that people obtain from contact with nature.

Human well-being and livelihoods depend in countless ways on the Earth's ecosystems and the biodiversity within them. In recent decades, it has become common to describe this dependence in terms of a set of "services" provided by ecosystems. This ecosystem service concept provided the framework for the Millennium Ecosystem Assessment, a major study of the state of the world's ecosystems and their influence on human well-being undertaken between 2001 and 2005. Ecosystem services were defined in this case as "the benefits humans derive from ecosystems" (MEA, 2005a). The concept also underpins The Economics of Ecosystems and Biodiversity (TEEB) initiative, a global study launched in 2007 with the aim of providing a better understanding of the economic value of such services (TEEB, 2010b), and the Intergovernmental Science-Policy Platform on Biodiversity and Ecosystem Services (IPBES), an independent intergovernmental body, established in 2012 to "provide policymakers with objective scientific assessments about the state of knowledge regarding the planet's biodiversity, ecosystems and the benefits they provide to people, as well as the tools and methods to protect and sustainably use these vital natural assets" (IPBES, 2018b).

Exploring the role of BFA in the delivery of ecosystem services was a major objective of The State of the World's Biodiversity for Food and Agriculture (SoW-BFA) reporting process. The country-reporting guidelines focused particularly on "regulating services" 3 and "supporting services", 4 although countries were also invited to report on contributions to "provisioning services" 5 and "cultural services." 6 Provisioning services (and to a lesser degree cultural services) are extensively discussed in the various sectoral global assessments of genetic resources prepared by FAO (FAO, forthcoming, 2010a, 2014a, 2015a).

The country reports include numerous references to the significance of BFA - at every level from landscapes and seascapes to within-species genetic diversity - in the supply of ecosystem services. Examples are presented throughout the report. For instance, Sections 2.5 and 2.6 on the significance of BFA to livelihoods and to food security and nutrition include many references to provisioning services. Section 2.3 on resilience discusses the role of BFA in reducing risks associated with (inter alia) hazards such as natural and human-induced disasters. Sections 2.4 and Chapter 5 feature examples of how ecosystem services such as pollination, pest control and nutrient cycling are mobilized to support sustainable production and integrated into various management strategies. Chapter 4 provides further information on the roles of components of BFA in the supply

\footnotetext{
Defined by MEA (2005a) as the "benefits obtained from the regulation of ecosystem processes."

4 Defined by MEA (2005a) as services "that are necessary for the production of all other ecosystem services."

5 Defined by MEA (2005a) as "the products obtained from ecosystems."

6 Defined by MEA (2005a) as "nonmaterial benefits people obtain from ecosystems through spiritual enrichment, cognitive development, reflection, recreation, and aesthetic experiences."
} 
of ecosystem services, and in particular discusses trends in their supply within the various production system categories considered in this report. Chapter 7 touches on the role of in situ conservation programmes in maintaining the supply of a range of ecosystem services.

This section provides a short introductory overview of the roles of BFA in the delivery of ecosystem services both within and beyond the food and agriculture sector. A more detailed account can be found in the thematic study Biodiversity for food and agriculture and ecosystem services (FAO, 2019), prepared as part of the SoW-BFA process (and as indicated above examples from the country reports can be found throughout the report).

\subsubsection{Provisioning services}

The world's food production depends on its terrestrial and aquatic ecosystems. Approximately 82 percent of the calories in the human food supply are provided by terrestrial plants, 16 percent by terrestrial animals and 1 percent by aquatic animals and plants. The figures for protein supply are 60 percent from terrestrial plants, 33 percent from terrestrial animals and 7 percent from aquatic animals and plants. ${ }^{7}$ Within each of these broad categories, a range of different species - and varieties, breeds and populations within species - are used in food production (see Section 4.2 for further discussion). A wide variety of wild foods, including fruits, leafy vegetables, woody foliage, bulbs and tubers, cereals and grains, nuts and kernels, saps and gums (eaten or used to make drinks), mushrooms, terrestrial invertebrates (insects, snails, etc.), honey, birds' eggs, fish, shellfish and meat from small and large vertebrates (WHO and CBD, 2015), contribute to the diets of large numbers of people, particularly in developing countries (Bharucha and Pretty, 2010). An even wider range of species contribute to the functioning of the ecosystems upon which food production depends.

Global averages mask the fact that certain sectors of food production may be extremely

\footnotetext{
All figures in this paragraph are based on FAOSTAT data for 2013
}

important in specific geographical areas or to particular sections of the population, for example fish in small island developing states and livestock in pastoralist communities. Moreover, in addition to calories and protein, food security and good nutrition require adequate access to vitamins, minerals and essential fatty acids. These nutrients are found in varying quantities in products derived from the various species, varieties and breeds of plants, animals and micro-organisms that are used as sources of food.

Crop, livestock, forest and aquatic production systems and the biodiversity used in and associated with them supply a wide range of non-food products, including fuels (e.g. wood and dung), timber and other construction materials, plant and animal fibres used in the manufacture of textiles, animal hides and skins, various materials used to produce medicines or for biochemical purposes, and ornamental products such as flowers. They are also a source of genetic resources that can be used in plant and animal breeding. They contribute in various ways to the supply of freshwater that can be used domestically, in food and agriculture or in industry (see discussion of water-related services in the following section).

A high degree of diversity among the species, varieties, breeds, populations and ecosystems that supply provisioning services can contribute in a number of ways to increasing the quantity, quality and stability of output and to the efficiency of production. In the case of forests, for example, a study of data from 44 countries found a consistent positive relationship between tree diversity and productivity at landscape, country and ecoregion scales, with on average a 10 percent loss in biodiversity leading to a 3 percent loss in productivity (Liang et al., 2016). Likewise, a large-scale experiment in China comparing forest plots planted with different numbers of tree species found that combining multiple species provided higher levels of productivity: after eight years, 16-species mixtures had accumulated more than twice as much carbon as had monocultures on average (Huang et al., 2018). The contributions of BFA to the resilience of production to shocks and stresses and to efforts to 


\section{PART A}

sustainably increase output are discussed further in Sections 2.3 and 2.4.

\subsubsection{Regulating and supporting services}

\section{Pollination}

An estimated 87.5 percent of all flowering plant species are pollinated by animals (Ollerton, Winfree and Tarrant, 2011). Crops at least partially pollinated by animals account for 35 percent of global food production (Klein et al., 2007) and are particularly significant in the supply of micronutrients for human consumption, for example accounting for more than 90 percent of available vitamin $C$ and more than 70 percent of available vitamin A (Eilers et al., 2011). Bees - including both managed and wild species - are generally the main providers of pollination services. Other insects, birds, bats and some other animals also contribute.

While farmers in intensive systems often rent managed honey bees to pollinate their crops, the majority of farmers rely on bee populations maintained by local beekeepers and on wild pollinators. Moreover, it has been shown that pollination services are enhanced by the presence of wild insects even where honey bees are abundant (Garibaldi et al., 2013). Both higher pollinator density and higher species diversity of pollinator visits to flowers have been found to be associated with higher crop yields (Garibaldi et al., 2016). Species diversity among pollinators can also be important in buffering the supply of pollination services against the effects of fluctuations in the populations of individual species (Kremen, Williams and Thorp, 2002).

\section{Soil-related ecosystem services}

Soil formation and maintenance are inextricably linked to biodiversity. Micro-organisms and invertebrates, in particular, are vital to soil health (Beed et al., 2011; Cock et al., 2011; Schulz et al., 2013). Studies have shown that reducing soil biodiversity can impair various soil processes, including decomposition, nutrient retention and nutrient cycling (Wagg et al., 2014), and reduce resilience to shocks
(Griffiths et al., 2000). Microbial communities can give the soil disease-suppressive qualities that help to protect plants from pathogens (e.g. Schlatter et al., 2017). Plants, including crop and forage plants and forest trees, provide protection against erosion and contribute organic matter (Angers and Caron, 1998). Dung from above-ground animals, including domesticated livestock, can be an important source of nutrients (Graham, Grandy and Thelen, 2009; Ozlu and Kumar, 2018; Sradnick et al., 2013). In some agroecosystems, shade from trees provides protection to earthworm populations and thus promotes improvements to soil structure (Barrios et al., 2018).

\section{Air-quality and climate regulation}

Ecosystems used for food and agriculture and the biodiversity within them can affect the climate at global, continental and local scales. Forests, grasslands and freshwater, marine and coastal ecosystems play key roles in the Earth's carbon cycle and hence in regulating greenhouse-gas concentrations in the atmosphere. In all cases, the uptake and release of carbon depend on complex processes involving an enormous range of interacting species (Beed et al., 2011; Cock et al., 2011; Laffoley and Grimsditch, 2009; Nellemann et al., 2009; Pullin and White, 2011). Because of the complexity involved, the significance of diversity per se can be difficult to evaluate (i.e. whether, and to what extent, diverse biological communities are more effective providers of carbonsequestration services than less diverse ones). Some studies in grasslands have found that more diverse plant communities are better at sequestrating carbon (Fornara and Tilman, 2008; Lange et al., 2015; Steinbeiss et al., 2008). More generally, the health and resilience of ecosystems such as soils and forests - and hence, other things being equal, probably their capacity to sequester carbon - tend to benefit from greater diversity (e.g. Griffiths et al., 2000; Hicks et al., 2014; Loo et al., 2011).

Aside from its contributions to carbon sequestration, studies in various parts of the world have shown that forest vegetation can moderate temperatures and increase rainfall, including in some 
cases influencing rainfall patterns across large swathes of land that are vital to agricultural production at a continental scale (e.g. Alkama and Cescatti, 2016; Macedo and Castello, 2015; Spracklen, Arnold and Taylor, 2012; Wright et al., 2017). Where air quality is concerned, trees and other plants make major contributions to the removal of particulate matter and gaseous pollution from the air (e.g. Nowak et al., 2014).

\section{Natural-hazard regulation}

The frequency of several kinds of extreme weather events is predicted to increase under climate change, and thus one way in which BFA can contribute to reducing the threat posed by natural disasters is via its above-mentioned contributions to climate change mitigation. However, it can also play a more direct protective role (see Section 2.3). For example, a number of coastal ecosystems (mangroves, coral reefs, seagrass meadows, kelp forests, etc.) provide protection against coastal storms and flooding. Forests, wetlands and grasslands regulate water flows and diminish the risk of flooding in downstream areas. Trees and other terrestrial vegetation can provide physical shelter against wind, rain, snow or sun. Vegetation, whether in croplands, forests or grasslands, helps to maintain stable soils and hence reduce hazards such as sand storms and landslides. Grazing animals can be used in certain circumstances to reduce the risk of fires or avalanches (Fabre, Guérin and Bouquet, 2010; Lovreglio, Meddour-Sahar and Leone, 2014; Pecora et al., 2015), although in some ecosystems they can increase fire risk (e.g. Leonard, Kirkpatrick and Marsden-Smedley, 2010). Moreover, although grazing is essential to the maintenance of a healthy plant flora in many ecosystems, overgrazing is a major global driver of soil erosion, soil compaction and related hazards (FAO and ITPS, 2015).

\section{Pest and disease regulation}

Many different components of biodiversity found in and around production systems help to control species that may attack crops, livestock, trees or aquatic species, cause or spread diseases or otherwise disrupt human activities or the supply of ecosystem services. The direct providers of these services (e.g. predators, parasitoids and herbivores that consume pests, disease vectors or weeds) are referred to as biological control agents. These species can include both those that are naturally present in the local area and those introduced deliberately to help control particular problems. The latter approach has to be treated with caution as there have been cases in which species introduced to control pests have themselves caused major problems (e.g. De Clercq, Mason and Babendreier, 2011).

Pest- and disease-regulation services are provided by a wide range of terrestrial and aquatic invertebrates and vertebrates, micro-organisms and plants (the latter may compete with weeds for resources or release substances that are harmful to weeds or repel animal pests - ICIPE, 2015; Lemessa and Wakjira, 2015; Teasdale, 2003). As well as wild species, the providers of pest- and disease-regulation services can include domesticated plants and animals. For example, cover crops can be used to combat weeds, and farmed fish or ducks used to control pests in paddy fields (Halwart and Gupta, 2004; Teo, 2001). Aside from the biological control agents themselves, the supply of pest and disease regulation services depends on the presence of species that provide them with the resources they need to survive, for example shelter, nesting sites and alternative food sources (e.g. Gurr et al., 2017).

The relationship between diversity per se and the provision of this service is again complex. Biological control agents may complement each other's actions in space or time, but there may also be inhibitory effects (e.g. when one control agent preys on another) (Rocca and Messelink, 2017; Finke and Denno, 2004). However, there is evidence that more often than not there is a positive relationship between diversity of biological control agent populations and the supply of pest-control services (Letourneau et al., 2009). Habitat diversity within the agricultural landscape tends to increase the supply of these services (Bianchi, Booij and Tscharntke, 2006; 


\section{PART A}

Bommarco, Kleijn and Potts, 2013; Hooper et al., 2005; Kremen and Miles, 2012; Tscharntke et al., 2005). Diversity among the species, varieties and breeds of crops, livestock or aquatic animals raised in a given area can hinder the spread of diseases and help to reduce the risk of devastating losses (see Section 2.3 for further discussion).

\section{Water-related ecosystem services}

Ecosystems used for food and agriculture affect both the quantity and the quality of water supplies. Healthy soils and vegetation (see above for discussion of the role of biodiversity in maintaining healthy soils), whether in forests, grasslands, wetlands or crop fields, help to regulate the run-off of water into downstream areas. This can both help to reduce the risk of flooding (see above) and to keep streams and rivers flowing during dry periods of the year (TEEB, 2010b). Where water quality is concerned, a range of different physical, chemical and biological processes contribute to removing contaminants (harmful organic and inorganic substances, pathogenic microbes, etc.) from water supplies as they pass through soils or through water bodies such as rivers and lakes. Many different organisms contribute to the process of filtering pollutants before they can enter water bodies, transferring them out of the water (e.g. into bottom sediments or the atmosphere) or degrading them into benign or less-harmful components (Ostroumov, 2010). Water from forested watersheds is generally less contaminated with pollutants than water from non-forested watersheds; many cities deliberately protect forests as part of their water-purification strategies (Dudley and Stolton, 2003). Some ecosystem types, such as tropical mountain cloud forests (Bruijnzeel, 1990), old eucalyptus forests (Kuczera, 1987) and Andean páramos (Postel and Thompson, 2005) (see Box 4.7 in Section 4.3), also increase net water flow.

\section{Habitat provisioning}

Food and agricultural production systems are, on the one hand, major drivers of habitat loss (CBD Secretariat, 2010), but on the other are often significant habitats in their own right. In the case of forestry and fishing, it is clear that many production systems are diverse natural or semi-natural ecosystems that provide habitats for a vast range of species. At the other end of the spectrum, many crop, tree plantation and livestock systems raise only one, or only a very few, domesticated species and have largely been stripped even of semi-natural landscape remnants that would contribute to habitat diversity. However, some crop and livestock systems are very far from being homogeneous in their biological composition. For example, in many parts of the tropics people maintain highly diverse home gardens that serve as sources of food, medicines, ornamental and culturally important plants, fuel, fodder and other products (see Section 5.5 for further information). In places, these gardens serve as refuges for native wild plants that are threatened by habitat loss in the wider landscape (Hemp, 2006; Larios et al., 2013; Webb and Kabir, 2009). For example, coffee plants in home gardens in Ethiopia have been found to be important habitats for a range of rainforest epiphytic species (Hylander and Nemomissa, 2008). Some grasslands used in livestock production are also very biodiverse habitats (FAO, 2014c) (see also Section 4.5.6).

At a landscape scale, crop and livestock farming sometimes add diversity to the "mosaic" of habitat types present. So-called conservation grazing - the intentional use of grazing animals such as cattle, sheep and horses to maintain vegetation in a state that provides suitable habitat for particular kinds of wildlife - has become a widespread practice, particularly in Europe (e.g. Woodland Trust, 2012).

\subsubsection{Cultural services}

Both production systems as a whole and their components (including species, varieties or breeds of crops, livestock, trees and aquatic organisms) can contribute to cultural ecosystem services, i.e. the aesthetic, recreational, inspirational, spiritual and educational benefits that people obtain from contact with ecosystems. Biodiversity has a major influence on the aesthetic appearance of many ecosystems, their capacity to inspire, their suitability for various recreational activities and their educational significance. Some cultural or recreational 
activities depend directly on the presence of particular species (or within-species populations) or a certain level of species diversity, for example various wildlife-watching activities or recreational fishing. In other cases, characteristic species or biological communities add to the particular aesthetic and inspirational qualities of a local landscape.

Many cultural ecosystem services are associated with wild ecosystems. However, food and agricultural production systems and their domesticated and associated biodiversity also contribute to these services. This is the case, for example, for many culinary traditions, which are often linked to local products and may depend on particular local species, varieties or breeds of crops, livestock or aquatic species. The same is true for a variety of non-food products made from wood, plant and animal fibres, skins, feathers, bones or horns. Particular plants and animals, or products obtained from them, are important elements in many cultural and religious events and festivals. Gardening and raising small livestock species such as chickens are widely pursued as leisure activities, and in some places larger-scale hobby farming is popular. Pets and companion animals of various kinds, including aquarium species, are also widely popular. Horses and other animals are used in various sports.

Agricultural, pastoral, wetland and forest landscapes are often valued for their aesthetic qualities, their cultural significance or as sites for recreational activities. A number of traditional agricultural landscapes are recognized as cultural World Heritage Sites, ${ }^{8}$ for instance the Cultural Coffee Landscapes of Colombia, the Rice Terraces of the Philippine Cordilleras and the Lavaux Vineyard Terraces of Switzerland (Mitchell, Rössler and Tricard, 2009), or as Globally Important Agriculture Heritage Sites ${ }^{9}$ (FAO, 2018c). Particular crops, fish, trees or types of livestock may be vital to the "sense of place" associated with a given location. Grazing livestock can play a major role in shaping the local vegetation and hence the character of semi-natural landscapes.

\footnotetext{
http://whc.unesco.org/en/list

9 http://www.fao.org/giahs/en/
}

The biodiversity present in and around food and agricultural systems remains central to the cultures and world views of many indigenous peoples around the world, who often maintain a wealth of traditional knowledge on their use and management. Many studies have demonstrated the contributions that indigenous peoples and other rural communities make to the conservation and use of BFA via their cultural norms and practices (Berkes, Folke and Gadgil, 1995; Gadgil, Berkes and Folke, 1993) (see also Section 8.2).

\subsection{Resilience}

- Biodiversity for food and agriculture (BFA) at intraspecific, species and ecosystem levels can improve the resilience of production systems by decreasing vulnerability to stresses and shocks, reducing their impacts and supporting recovery and adaptation.

- BFA provides options for adapting production systems to the threats posed by climate change and other environmental changes, strengthening disaster prevention, response and rehabilitation measures and combating threats posed by invasive alien species.

- Key priorities for enhancing the contributions of BFA to resilience include ensuring that BFA is conserved and remains available to producers, strengthening research into the relationships between BFA and resilience, and developing management strategies that integrate a range of components of BFA across a range of scales.

Recognition that the capacity of food and agricultural systems to meet the needs of a growing population is vulnerable to various kinds of shocks - and that production systems need to adapt to the effects of (often accelerating) environmental, economic and social trends and drivers of change has led to increasing interest in the concept of resilience. For example, Sustainable Development Goal Target 1.5 reads as follows: "By 2030, build the resilience of the poor and those in vulnerable situations and reduce their exposure and vulnerability to climate-related extreme events and 
other economic, social and environmental shocks and disasters." The concept is also mentioned in several other targets. FAO's Strategic Programme includes the goal of increasing "the resilience of livelihoods to threats and crisis" (Strategic Objective 5) (FAO, 2013c). ${ }^{10}$

One difficulty with providing an overview of the roles of BFA in promoting resilience is that the term is used in different ways in different contexts. The concept emerged in the ecological literature in the 1960s and 1970s to describe the response of ecosystems to disturbances (e.g. Holling, 1973). Resilience is sometimes thought of as the capacity of a system to withstand or recover from shocks. However, in recent years it has increasingly tended to be viewed in a more dynamic way - as the capacity to maintain particular properties (e.g. in the case of an ecosystem to continue supplying particular ecosystem services) in the face of changes of various kinds (e.g. Elmqvist et al., 2003; Folke et al., 2004). Where food and agricultural systems are concerned, these changes will inevitably include changes in management strategies and practices and in broader social, cultural and political structures and processes. The need to take this into account and address the multifaceted nature of resilience in human societies has led to the emergence of the concept of socialecological resilience, which has been applied to a range of production systems in recent years (e.g. Berkes, 2012; Cabel and Oelofse, 2012; Darnhofer et al., 2010; Haider, Quinlan and Peterson, 2012; Kremen and Miles, 2012). Resilience in this sense has been described as the capacity to continually change, adapt and transform, through innovation, in response to external drivers and internal processes (Folke et al., 2010). For example, Darnhofer (2014) proposes that resilience in agricultural systems can be understood in terms of

\footnotetext{
10 This section draws in part on the thematic study The contribution of biodiversity for food and agriculture to the resilience of production systems (Duval, Mijatovic and Hodgkin, 2018) commissioned to support the preparation of The State of the World's Biodiversity for Food and Agriculture. Further discussion and further examples of the contributions of BFA to resilience can be found in this document.
}

three capabilities: buffer capability - the ability of the system to cope with shocks and continue functioning more or less as before; adaptive capability - the ability of the system to adjust to external and internal drivers of change; and transformative capability - the ability to undergo radical changes, for example to transition successfully to a completely different agricultural enterprise or livelihood strategy.

In the context of FAO's Strategic Objective 5 (see above), resilience has been defined as follows: "the ability to prevent and mitigate disasters and crises as well as to anticipate, absorb, accommodate or recover and adapt from them in a timely, efficient and sustainable manner. This includes protecting, restoring and improving livelihoods systems in the face of threats that impact agriculture, nutrition, food security and food safety" (FAO, 2018d).

The diverse interpretations of the resilience concept are reflected in the country reports. Some countries' responses focus on the ecological aspects of resilience, while others also refer to social, economic or cultural aspects. Some countries emphasize resilience to shock events, while others also refer to resilience to more gradual changes.

This section begins by presenting an overview of the ways in which BFA helps to build resilient production systems and livelihoods. It then looks in more detail at the roles of BFA in promoting resilience to a number of specific challenges, namely climate change, disasters and emergencies of various kinds, the threat posed by invasive alien species and food-chain threats such as pest and disease outbreaks. Needs and priorities in terms of strengthening the contributions of BFA to resilience are presented at the end of the section.

\subsubsection{Overview of the contributions of biodiversity for food and agriculture}

Diversity at every level from genetic to ecosystem contributes to the capacity of production systems to cope with shocks and to adapt to change. These contributions involve a variety of different processes operating at every scale from that of the 
individual organism, through the field (or pond or plot of trees), the farm (or holding) and the landscape, to the planet as a whole. Resilience can be conferred not only to the biological components of a system but also to socio-economic components such as a household's livelihood or the food security of a community. It can be enhanced both by the natural properties of unmanaged biodiversity and by human interventions that utilize biodiversity. These many dimensions often overlie each other. The following description focuses on the ways in which resilience can be enhanced at the level of the production system or household.

There are numerous mechanisms through which the characteristics of individual components of BFA or the presence of high levels of diversity can promote resilience. Risk can be reduced, for example, by raising species, breeds or varieties that are well adapted to coping with shocks such as droughts or disease outbreaks or by raising a number of different types of crops, livestock or aquatic organisms so as to increase the likelihood that at least some will survive such events (Hesse et al., 2013). Farmers in the Sahel, for example, tend to hedge against the threat of drought by planting both long- and short-cycle millet varieties (ibid.). Analysis of data from a survey in the Tigray region of Ethiopia showed that maintaining a large number of barley varieties reduced the risk of crop failure, with the effect being particularly marked in areas affected by land degradation (Di Falco and Chavas, 2009).

Production systems that lack diversity can be more vulnerable to severe impacts from shocks such as disease and pest outbreaks than those with more diverse populations. If a single variety is widely grown, a pest or disease to which it lacks resistance can lead to a dramatic fall in production. If livelihoods are heavily dependent on the species in question, the effects can be disastrous. Over the years, this kind of vulnerability has been illustrated in practice on a number of occasions, including the famine caused by potato blight in Ireland in the 1840s, losses in various cereal crops in the United States of America during the twentieth century (Keneni et al., 2012) and losses of taro production in Samoa in the 1990s (Hunter, Pouono and Semisi, 1998; also mentioned in the country report from Samoa).

Aside from biophysical risks such as adverse weather or disease outbreaks, diversifying the species, breeds and varieties raised can also reduce risks associated with economic shocks such as the loss of markets for particular products. Moreover, as discussed further in Section 2.5, some components of BFA such as livestock can serve as stores of wealth that can be drawn upon to cover urgent expenditures or to compensate for loss of income from other activities (on-farm or off-farm).

Another component of BFA that can help households to cope with fluctuations in the supply of food or income-generating opportunities is wild food. A wide range of such foods, including aquatic and non-wood forest products, are often important components of the diet or sources of income during lean seasons of the year or in times of drought or other disaster (see Sections 2.6 and 4.4).

In addition to hedging against the risk of severe production losses or livelihood disruption in the various ways described above, utilizing a diverse range of crop, livestock, aquatic or tree resources can also directly help to reduce vulnerability to stresses and shocks. Many different mechanisms can contribute. For example, integrating intercrops, hedgerows or cover crops, particularly legumes, into a system can (among other benefits) reduce drought stress by helping to conserve water in the soil profile (Buckles, Triomphe and Sain, 1998) and help to replenish depleted soil fertility (Bunch, 1999; Kang, Wilson and Sipkens, 1981; Kaumbutho and Kienzle., 2007; Sanchez, 2000). Crop diversification, including rotation and intercropping and the use of diverse forage plants in pastureland, can reduce pest damage and weed invasions (Altieri, 1999; Chabi-Olaye et al., 2007; Sanderson et al., 2007).

Integrating trees into a crop production system can help to maintain a favourable microclimate for crop growth in the face of harsh conditions in the wider environment, for example keeping temperatures and solar radiation within acceptable levels or preventing excessive fluctuation 


\section{PART A}

in soil moisture levels (e.g. Lin, 2007). Trees and other features such as hedgerows and wildflower banks at field margins can help maintain populations of key suppliers of ecosystem services such as insect pollinators, biological control agents and earthworms (Barrios et al., 2018; IPBES, 2016a; Reed et al., 2017). Trees can also help protect livestock from climatic extremes and provide fodder that can be used when other sources are in short supply (Gregory, 1995; Johnson and Nair, 1985; Wagner et al., 2013). In turn, appropriately managed livestock can contribute to the resilience of crop production. For example, inclusion of a grazed pasture rotation in a cropping system can - through the effects of grazing and dunging - promote the accumulation of soil organic matter, stimulate soil-microbial activity and increase the diversity and density of soil invertebrate macrofauna and hence promote all the resilience-enhancing benefits of healthy and biodiverse soils (Salton et al., 2014). Grazing during a pasture rotation can also help to suppress weeds (Concenço et al., 2015; Salton et al., 2014). As noted in Section 2.2, grazing animals can also be used in the management of fire risk and in the control of pests or invasive species. Specific management strategies and practices involving the use of diverse components of biodiversity that contribute in various ways to resilience are discussed in greater detail in Chapter 5.

Over the longer term, biodiversity increases the range of options that farmers, livestock keepers, forest dwellers, aquaculturists and fishers can draw upon to adapt their livelihoods and production strategies to changing conditions, including in recovering from disasters and other shocks. Aside from providing a range of existing options that can potentially be introduced into a production system (e.g. drought- or disease-resistant species, varieties or breeds), diversity (in this case specifically within-species diversity) also provides the raw material for genetic improvement activities. Well-planned breeding programmes can help adapt populations to the challenges posed by changing production environments (and changing human demands) or enable them to cope better with future extreme events (although in the case of long-lived species, such as trees, breeding programmes operate on timescales longer than those normally associated with the concept of resilience). Crop wild relatives, traditional landraces and locally adapted livestock breeds are an important resource in this respect and their conservation and sustainable use is a key part of overall resilience strategies. Genetic-improvement programmes for various components of BFA are discussed in Section 5.9.

Beyond the level of the farm or holding, resilience can be promoted by conserving or enhancing habitat diversity across the landscape or seascape. For example, efforts can be made to conserve habitats such as coral reefs, mangroves and forests that provide protection against extreme events or to ensure that enough diverse habitat is available to allow sufficient numbers and diversity of ecosystem-service providers such as pollinators to be maintained over the long term in the face of shocks and changing conditions.

Specific examples from the country reports on how BFA contributes to resilience are presented in the sections below on resilience to specific types of threat. To summarize briefly, countries' responses focus mainly on domesticated plants and animals. Several note the significance of species, breeds and varieties that are well adapted to coping with extreme events or report resilience-enhancing roles of diversity at species and variety or breed levels. Although few countries provide detailed information on particular resilience-related benefits provided by associated biodiversity, many mention that resilience is enhanced by the presence of diverse biological communities in and around production systems or by landscapes that consist of mosaics of different types of habitat. Several note that resilience is being reduced as a result of the homogenization of landscapes or seascapes or the loss, degradation or fragmentation of wildlife habitats. Several also mention the roles of wild foods as resources that people can draw upon in times of food shortage. 


\subsubsection{Resilience to specific threats}

\section{Climate change}

The significance of BFA in efforts to cope with the effects of climate change has received increasing attention in recent years. For example, the Resilience Outcome Document of the twenty-third session of the Conference of the Parties to the United Nations Framework Convention on Climate Change in 2017 recognized that "nature is central to climate resilience. The protection, sustainable management and restoration of terrestrial and marine ecosystems are the main elements for adaptation and resilience to a changing climate"11 (UNFCCC, 2017d). FAO has prepared a number of publications in this field, including the Climate smart agriculture sourcebook (FAO, 2013d, 2017c), a review of the economics of plant genetic resource management for adaptation to climate change (Asfaw and Lipper, 2012), a series of studies prepared at the request of the Commission on Genetic Resources for Food and Agriculture on the interactions between climate change and plant, animal, forest, aquatic, invertebrate and micro-organism genetic resources (Beed et al., 2011; Cock et al., 2011; Jarvis et al., 2008; Loo et al., 2011; Pilling and Hoffmann, 2011; Pullin and White, 2011) and Coping with climate change - the roles of genetic resources for food and agriculture (FAO, 2015b), a short book drawing on the sectoral studies.

To summarize briefly (see Section 3.4.1 for further discussion of the effects of climate change on BFA), it is predicted that, over various timescales and with substantial regional variations, crop, livestock, forest and aquatic production will be affected by climate change, for example because of higher temperatures, lower or higher rainfall, greater pressure from pests and diseases, increased occurrence of invasive alien species, more frequent extreme events such as floods and droughts, and (in aquatic environments) lower oxygen levels, greater acidity and higher levels of turbidity or siltation. Many species, breeds or varieties of plants and animals have distinctive

\footnotetext{
11 Emphasis (bold text) is in the original.
}

characteristics that help them to cope with challenges of this kind and hence potentially increase the resilience of production systems to the effects of climate change. As noted above, diversity increases the choices available to producers in their efforts to adapt production systems and to breeders in their efforts to develop better-adapted plant and animal populations. Associated biodiversity contributes both to climate change mitigation (e.g. by promoting carbon sequestration and providing alternatives to fossil fuel-based agricultural practices) and to climate change adaptation (e.g. by buffering against the potential loss or decline of individual species involved in the supply of ecosystem services such as pollination - see for example Christmann and Aw-Hassan, 2012).

Many country-report responses related to the roles of BFA in enhancing resilience note that the roles of BFA are becoming (or are expected to become) increasingly significant in the context of climate change. Aside from these specifically resilience-related responses, countries also note the significance of BFA in climate change adaptation and mitigation in various other parts of their reports. ${ }^{12}$ The following paragraphs discuss the main points raised.

\section{Maintaining, using and developing adapted genetic resources}

A number of countries note the significance of well-adapted species, varieties or breeds in terms of enhancing resilience to climate change. Several specific examples of how such components of BFA have been utilized in adaptation efforts are provided. For example, Papua New Guinea mentions the distribution to farmers of crop accessions identified in ex situ collections as being tolerant to salinity (taro and cassava varieties), drought (cassava, banana and aibika ${ }^{13}$ varieties) and flooding (taro

\footnotetext{
12 The country-reporting guidelines included a question inviting countries to provide information on climate change-related projects and programmes that include explicit references to BFA (see Section 8.8.3 for further information on responses to this question).

13 Aibika (Abelmoschus manihot) is a traditional leafy green vegetable.
} 
and banana varieties). It notes that this activity proved very useful in sustaining food security during the drought that struck the country in 2015 and 2016, ${ }^{14}$ when 40 percent of the population was seriously affected. Panama reports that its criollo livestock breeds have a combination of characteristics that are not found in any introduced breeds, including high fertility rates, longevity, resistance to parasites and diseases and good grazing abilities, including the ability to make use of poorquality pastures. It notes, in particular, the potential of two locally adapted cattle breeds, the Guaymí and the Guabalá, in climate change adaptation. It also mentions, among its climate change adaptation measures, the development of maize varieties and hybrids that are tolerant of drought and diplodia rot (a fungal disease) and that grow well in soils with low nitrogen levels. With regard to choices at species level, Sudan reports that some of its livestock keepers have replaced cattle and sheep with dromedaries and goats, as the latter species are better suited to a climate change-affected environment that is more prone to droughts.

Some countries note the significance of participatory breeding programmes in the context of climate change. For example, Oman mentions that local wheat and barley landraces have been improved through such programmes to obtain varieties that have shorter growing seasons and can be managed more flexibly, especially during years with prolonged periods of extreme heat and limited water availability. Ensuring farmers have access to the adapted germplasm they need is another issue highlighted. Nepal, for example, mentions the role of community-based seed banks in providing farmers with immediate access to locally adapted germplasm that can be used in efforts to cope with climate change.

\section{Diversifying production systems}

A number of countries mention the important role that diversity within production systems plays in climate change adaptation and/or describe measures

\footnotetext{
14 The situation was ongoing at the time the country report was submitted.
}

that are being taken to promote diversity with adaptation-related objectives in mind. Papua New Guinea again provides an example, reporting that a project implemented by the National Agriculture Research Institute using a participatory approach to help communities determine their needs with regard to climate change adaptation included a major component focused on diversifying the use of crop species and varieties with the aim of promoting food supply during times of seasonal shortage or unfavourable weather. The project also introduced new livestock species (ducks and goats), production systems (aquaculture and duck-fish integration) and livestock-management practices.

\section{Conserving and managing habitats and landscape diversity}

Many countries highlight the importance of conserving and managing natural and semi-natural ecosystems that contribute to climate change adaptation and mitigation. The importance of forest ecosystems is mentioned particularly frequently, with countries noting the roles of forests in carbon sequestration and in the supply of a wide range of products and services relevant to climate change adaptation. Several countries note the importance of mangroves, coral reefs and/ or coastal ecosystems more generally in terms of resilience to climate-related disasters. For example, the Bahamas mentions that habitat fragmentation caused by economic development has reduced resilience to hurricanes and storm surges, which are expected to become more severe as a result of climate change. This is reported to be leaving the country more vulnerable to storm damage, erosion and flooding, with impacts on the habitats of economically important species such as fish, crustaceans and honey bees (see the following subsection for further information on the roles of BFA in resilience to climate-related and other disasters). Several countries from the Pacific region mention activities under the Pacific Ridge to Reef Programme. ${ }^{15}$

\footnotetext{
15 http://www.pacific-r2r.org/
} 


\section{Disasters and their impacts}

In all sectors of food and agriculture, production systems and the communities that depend on them are often severely affected by disasters (Doswald and Estrella, 2015; FAO, 2018e), although the relative impacts of specific categories of disaster vary across sectors (see Figure 2.1). One of the striking elements in the material presented in many of the country reports is the domino and/or multiplication effects of most of the disasters reported. For example, countries mention that earthquakes can lead to landslides that in turn cause river obstructions or soil erosion, or that cyclones lead to floods

\section{FIGURE 2.1}

Damage and loss to agriculture sectors caused by specific types of abiotic hazard (2006-2016)
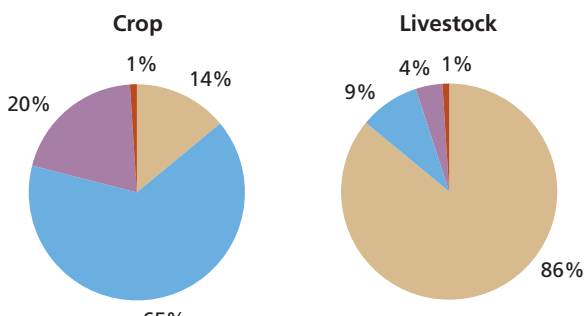

$65 \%$
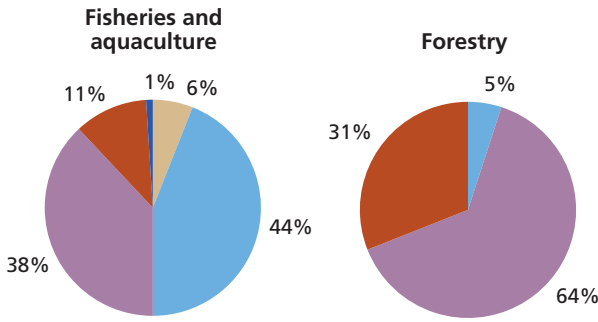

Drought Floods Storms

Earthquakes

Tsunamis

Notes: Based on the review of 74 Post Disaster National Assessments (PDNAs) conducted in 53 developing countries between 2006 and 2016. A PDNA is a system of processes and methods used to assess, plan and mobilize support for the recovery of countries and populations affected by disasters. Typically, the process is owned and led by the respective government and supported by UN Agencies, the European Union and the World Bank.

Source: FAO, 2018e. that in turn lead to pest and disease outbreaks or the spread of invasive alien species. Such chains of events cause losses at production level in all sectors and also in food processing and distribution.

A resilience-focused approach to disaster risk management involves both disaster response and rehabilitation and disaster risk reduction. The following subsections illustrate the relevance of BFA to each.

\section{Disaster response and rehabilitation}

In the immediate aftermath of a disaster, emergency responses prioritize saving lives and ensuring that basic requirements such as water, food and shelter are provided to affected communities. Actions focused on the use of BFA will often not be a priority during the relief phase. It is, however, important to consider them during the initial stages of response and rehabilitation efforts. For example, attention needs to be given to the restoration of ecosystems affected by disasters, as the loss of the protective functions they provide may increase the risk of severe impacts in the event of future disasters. Rehabilitation in production systems often involves the distribution of seeds or animals to allow production to recommence and recover. Care needs to be taken to ensure that the material distributed is well adapted to local conditions and meets the requirements of local people in what will typically be difficult circumstances (e.g. FAO, 2014a, 2015a). However, it is also possible that there may be opportunities to innovate in the interests of reducing future risks. For example, a shorter-cycle variety of black bean (the ICTA Ligero) that can be harvested before the hurricane season has been promoted in Haiti to reduce the risk of losing crops during the hurricane season (Bush, 2018).

The significance of ensuring that appropriate genetic resources are available for distribution during disaster rehabilitation is noted in a number of country reports. For example, the Cook Islands mentions that government response to disasters normally involves providing seeds and seedlings of short-cycle or annual vegetable crops sourced from non-affected areas to provide an immediate 
supply of food while damaged longer-cycle crops, such as bananas, passion fruit and papaya, start to recover. Bangladesh reports that in response to increased soil salinity following cyclones, researchers have screened for salinity-tolerant varieties of rice and other crops, which have then been multiplied and supplied to farmers. The United States of America mentions the Seeds of Success ${ }^{16}$ programme, which helps to re-establish stable native plant communities on land being rehabilitated after disasters such as wildfires. Argentina and Panama highlight the importance of genebanks in supporting producers in recovering genetic resources lost in disasters.

Gathering, hunting and fishing often increase after a disaster as a result of the loss of productive assets or displacement of populations, and can allow people to improve their nutritional intakes and rebuild their livelihoods. For example, in locations near to inland or shallow coastal waters, the low levels of expenditure and limited skills needed in order to take up fishing mean that it is an activity that people can easily fall back on when livestock and crops have been lost (Cattermoul, Brown and Poulain, eds., 2014). In drylands such as those of sub-Saharan Africa, small and fast-growing wild fish can be crucial components of resilience building, as they are highly productive when it rains and if properly processed can be stored for long periods (FAO, 2016a). Fishing and hunting gear are sometimes included in post-disaster emergency supplies in order to help affected people with short-term coping strategies. However, in the long term and if not practised sustainably, their use can seriously damage local ecosystems and make them and related livelihoods less resilient to future disasters (Cattermoul, Brown and Poulain, eds., 2014).

Numerous country reports mention the significance of wild foods to livelihood resilience and food security following disasters. For example, Zimbabwe reports that communities have turned to wild foods for survival following various disasters, noting also the significance of local knowledge

${ }^{16} \mathrm{https}: / /$ www.blm.gov/wo/st/en/prog/more/fish_wildlife_and/ plants/seeds_of_success.htm of wild foods in this regard. It further notes that aside from direct benefits they provide in terms of consumption, non-wood forest products, such as mopane worms, edible stinkbugs and wild fruits, have become important sources of household income as an alternative to traditional crops affected by drought. It notes, however, that between disasters the importance of wild resources is neglected and that little or no conservation or management action is taken to ensure they remain available as a resource for use in potential future emergencies. Section 2.6 provides further examples of the use of wild foods in emergency situations.

Other ways in which BFA can contribute to post-disaster management can include the use of pack animals to deliver food aid to inaccessible areas. There is also interest in the potential roles of micro-organisms in food preservation in post-disaster situations (Beed et al., 2011). See also the discussion of food-chain emergencies below.

\section{Disaster risk reduction}

The term "disaster risk reduction" has been defined as follows: "Disaster risk reduction is aimed at preventing new and reducing existing disaster risk and managing residual risk, all of which contribute to strengthening resilience and therefore to the achievement of sustainable development" (United Nations, 2016). Globally agreed policy on disaster risk reduction is set out in the Sendai Framework for Disaster Risk Reduction 2015-2030, adopted in 2015 (United Nations, 2015a). ${ }^{17}$ The intention is to achieve "substantial reduction of disaster risk and losses in lives, livelihoods and health and in the economic, physical, social, cultural and environmental assets of persons, businesses, communities and countries." In the food and agriculture sector, disaster risk reduction can be viewed as a continuum of actions taken before, during

\footnotetext{
The Sendai Framework was adopted by UN Member States on 18 March 2015 at the Third UN World Conference on Disaster Risk Reduction in Sendai City, Miyagi Prefecture, Japan, and subsequently endorsed by the UN General Assembly.
} 
and after disasters to protect, save, restore and enhance livelihoods.

As described above, BFA helps to make production systems and the supply of the ecosystem services they depend on more resilient to shocks of various kinds. BFA can both reduce the risk of disasters (e.g. by preventing floods) and limit their effects on production systems (e.g. use of trees as shelter against extreme weather or resistant/tolerant crops, livestock or fish to reduce the effects of disease outbreaks). Another link between ecosystem management and disaster risk reduction lies in the fact that ecosystem degradation often reduces economic and livelihood options and can therefore drive people into even more marginal and fragile environments where they are at greater risk from disasters (FAO, 2013e). BFA can help to reduce this effect both by reducing problems such as erosion and loss of soil fertility and by providing people with options for adapting their livelihoods in situ.

Certain ecosystems such as forests are well recognized for their important roles in reducing disaster risk (UN Environment, 2010), and more generally there is growing awareness of the significance of "natural infrastructures" in reducing the threats posed by hazards such as floods, storms and landslides (e.g. Sudmeier-Rieux, 2013). Nonetheless, ecosystem management is still often an overlooked element of disaster risk reduction (Renaud, Sudmeier-Rieux and Estrella, 2013). Too often, development activities disrupt the roles of ecosystems in reducing disaster risk. For example, flood risks can be increased by the loss of floodplain connectivity as a result of the construction of roads or dykes, by the loss of water meadows as a result of river training or by the removal of mangroves.

Several ecosystem processes and structures that help to reduce disaster risk also have associated benefits for food production. For example, floodplains supply sediment-rich seasonal grazing or cropping land (Gugić, Župan and Zupan, 2012) and mangroves provide secure fish nurseries and boost fish production (Kastl, 2014). Measures that enhance the capacity of dryland pastures to supply hazard regulation services will also contribute to the sustainability of grazing resources (Dudley, MacKinnon and Stolton, 2014).

Both species diversity and within-species genetic diversity contribute to the role of ecosystems in disaster risk reduction (see discussion of hazard regulation in Section 2.2). However, the extent and precise nature of the benefits provided are generally not well understood and require more research (Monty, Murti and Furuta, 2016), as do other factors influencing the capacity of ecosystems to supply hazard-regulation services.

A number of country reports identify species or species categories that play particularly significant roles in the supply of hazard-regulation services. In all cases, references are to plants. For example, several reports note the crucial role of mangrove species in coastal protection or mention the importance of riverside or wetland vegetation in flood protection. Some countries refer to the importance of trees and bushes in binding the soil or as windbreaks that reduce the impact of storms. As discussed in more detail in Section 4.3, countries list a number of ecosystems, species, breeds and varieties that are specifically managed to promote hazard regulation. For example, Jordan mentions that the trees Cupressus sempervirens (Mediterranean cypress) and Ceratonia siliqua (carob tree) are planted as part of fire-control efforts. Bhutan notes the contribution of fodder species (e.g. Guatemala grass and Napier grass) in reducing landslide risk.

Several countries mention the benefits of operating mixed systems or of raising a more diverse range of crops or livestock. For example, Nepal mentions that agroforestry is an increasingly important means of promoting resilience to the adverse effects of rainfall variability, shifting weather patterns, reduced water availability and soil erosion. Senegal notes that, in pastoral and agropastoral systems, keeping several species of animals allows flexibility in destocking decisions (a chicken, goat or sheep is sold more easily than a bovine), provides insurance against the effects of droughts and epidemics (which may affect one species but not another) and facilitates the reconstitution of livestock holdings following losses (restocking can start with smaller animals). 


\section{PART A}

TABLE 2.1

\section{Biological control of invasive alien species through predation, parasitism and herbivory - examples from the country reports}

\begin{tabular}{|c|c|c|}
\hline Invasive alien species & Controlling species & Countries reporting \\
\hline \multicolumn{3}{|l|}{ Plants } \\
\hline $\begin{array}{l}\text { Eichhornia crassipes } \\
\text { (water hyacinth) }\end{array}$ & $\begin{array}{l}\text { Neochetina bruchi (chevroned water hyacinth weevil) } \\
\text { Neochetina eichorniae (water hyacinth weevil) }\end{array}$ & $\begin{array}{l}\text { Papua New Guinea } \\
\text { Sudan }\end{array}$ \\
\hline $\begin{array}{l}\text { Mimosa diplotricha } \\
\text { Mimosa invisa (giant sensitive plant) }\end{array}$ & Heteropsylla spinulosa (sensitive plant psyllid) & $\begin{array}{l}\text { Niue } \\
\text { Palau }\end{array}$ \\
\hline Chromolaena odorata (Siam weed) & Cecidochares connexa (a gall fly) & $\begin{array}{l}\text { Palau } \\
\text { Papua New Guinea }\end{array}$ \\
\hline Salvinia molesta (Kariba weed) & Cyrtobagous salviniae (giant salvinia) & Papua New Guinea \\
\hline Pistia stratiotes (water lettuce) & Neohydronomus affinis (water lettuce weevil) & Papua New Guinea \\
\hline Mikania micrantha (bitter vine) & Puccinia spegazzini (a rust fungus) & Papua New Guinea \\
\hline $\begin{array}{l}\text { Sida rhombifolia } \\
\text { (flannel weed broom stick) }\end{array}$ & Calligrapha pantherina (sida leafbeetle) & Papua New Guinea \\
\hline $\begin{array}{l}\text { Impatiens glandulifera } \\
\text { (Himalayan balsam) }\end{array}$ & Rust fungus & United Kingdom \\
\hline $\begin{array}{l}\text { Fallopia japonica } \\
\text { (Japanese knotweed) }\end{array}$ & Aphalara itadori (Japanese knotweed psyllid) & United Kingdom (research ongoing) \\
\hline $\begin{array}{l}\text { Amorpha fruticosa (desert false } \\
\text { indigo) }\end{array}$ & Cattle & $\begin{array}{l}\text { Croatia (reintroduction of grazing cattle } \\
\text { and traditional livestock farming; however, } \\
\text { Amorpha fruticosa is reported to be widely } \\
\text { spread and its eradication considered unlikely) }\end{array}$ \\
\hline \multicolumn{3}{|l|}{ Insects } \\
\hline Tuta absoluta (tomato leafminer) & Bracon concolorans (a parasitic wasp) & Jordan \\
\hline Papuana huebneri (taro beetle) & Metarhizium anisopliae (a fungus) & Kiribati (reported as unsuccessful) \\
\hline \multicolumn{3}{|l|}{ Molluscs } \\
\hline Giant African snail & Flat worm & Solomon Islands \\
\hline \multicolumn{3}{|l|}{ Other } \\
\hline Not specified & $\begin{array}{l}\text { Parasite or predator insects: } \\
\text { Trichogramma evanescens (a wasp) } \\
\text { Bracon hebetor } \\
\text { Podisus maculiventris (spined soldier bug) } \\
\text { Entemopathological nematodes }\end{array}$ & Georgia \\
\hline $\begin{array}{l}\text { Perccottus glenii (Amur sleeper) and } \\
\text { other invasive alien fish species }\end{array}$ & $\begin{array}{l}\text { Silurus glanis (Wels catfish) } \\
\text { Sander lucioperca (pike-perch) }\end{array}$ & $\begin{array}{l}\text { Hungary (effect reported to be insufficient } \\
\text { to slow spread and proliferation or to offset } \\
\text { negative effects on the native fish fauna) }\end{array}$ \\
\hline River weed & Grass carp & Fiji \\
\hline Sciurus carolinensis (grey squirrel) & Martes martes (pine marten) & Ireland \\
\hline
\end{tabular}

Source: Selected from the 91 country reports prepared for The State of the World's Biodiversity for Food and Agriculture.

\section{Invasive alien species}

Invasive alien species are non-native organisms that have been introduced accidently or deliberately into a new location and are causing economic or environmental harm or adversely affecting human health. Worldwide, invasive alien species are considered a major threat to biodiversity, including BFA, in terrestrial, marine and freshwater ecosystems (Chornesky et al., 2005; Keller et al., 2011; MEA, 2005a). For further discussion of the impact 
TABLE 2.2

Biological control of invasive alien species through resource competition and other antagonistic relationships - examples from the country reports

\begin{tabular}{|l|l|l|}
\hline \multicolumn{1}{|c|}{ Invasive alien species } & \multicolumn{1}{c|}{ Controlling species } & Countries reporting \\
\hline Tilapia & Tor putitora (native golden mahaseer) & Nepal (partial success reported) \\
\hline $\begin{array}{l}\text { Ambrosia artemisiifolia (common ragweed } \\
\text { a species that has led to reduced crop yields } \\
\text { in sunflower, maize and wheat production } \\
\text { systems) }\end{array}$ & $\begin{array}{l}\text { Cover crops such as Lolium perenne (perennial ryegrass) } \\
\text { and Medicago sativa (alfalfa) and other plant species } \\
\text { that form dense tufts or groups and compete for light, } \\
\text { moisture and soil nutrients }\end{array}$ & Bulgaria \\
\hline $\begin{array}{l}\text { Fallopia japonica (Japanese knotweed) } \\
\text { Various willow species that compete for light with the }\end{array}$ & France \\
\hline Japanese knotweed & Fiji \\
\hline Plant-parasitic nematodes & Mucuna (a legume cover crop) & Samoa \\
\hline Cyperus aromaticus (Navua sedge) & Tagetes erecta (Mexican marigold) & Jordan \\
\hline
\end{tabular}

Source: Selected from the 91 country reports prepared for The State of the World's Biodiversity for Food and Agriculture.

of invasive alien species on BFA, see Section 3.4.3. Destabilized ecosystems, including systems used for food and agricultural production, tend to be more vulnerable to the spread of invasive alien species (e.g. Chytrý et al., 2008; Marvier, Kareiva and Neubert, 2004). However, there is little evidence to support the hypothesis that highly diverse ecosystems are inherently more resistant to invasive alien species than less-diverse systems (e.g. Keller et al., 2011).

Various species are used as biological control agents to control invasive alien species. However, this strategy can carry some risk and needs to be carefully planned and monitored. It has sometimes had negative effects on native biodiversity. For example, attempts to control giant African snails in the Caribbean using the predatory rosy wolf snail (Euglandina rosea), native to the United States of America, and in the Pacific using the flat worm (Platydemus manokwari), are reported to have led to declines in native endemic snail populations in both regions (Sankaran, 2004).

Countries were invited to provide information on any contribution made by BFA to the management of invasive alien species. The majority of the responses provided relate to the use of specific components of BFA to control specific invasive alien species. A range of different species are reported to provide services of this kind, including predators, herbivores, parasites and parasitoids that feed on invasive alien species (Table 2.1), species that compete with invasive alien species for resources or are otherwise antagonistic to their presence (Table 2.2) and species that are resistant to effects of invasive alien species (Table 2.3). A few countries mention broad control strategies or broad relationships between diversity and the spread of invasive alien species. For example, France states that one means of controlling the proliferation of invasive species in forests is to restore the ecosystem using native species chosen so as to reduce the availability of resources to targeted invasive species. It also notes that native species diversity provides a reserve of resources from which candidates for use in such approaches can be drawn. A few countries note the significance of diversity-based agricultural practices such as multicropping in this context.

\section{Food-chain crises}

Human food chains are affected by a range of shocks including pest and disease outbreaks and food-safety and pollution events (FAO, 2017d). BFA can help increase resilience to many of these threats. Contributions of plant (crop), animal (livestock), aquatic and forest genetic resources to 


\section{PART A}

TABLE 2.3

Species or varieties that are tolerant or resistant to the effects of invasive alien species examples from the country reports

\begin{tabular}{|c|c|c|}
\hline Invasive alien species & Resistant/tolerant species or varieties & Countries reporting \\
\hline $\begin{array}{l}\text { Mycosphaerella fijiensis } \\
\text { (black sigatoka) }\end{array}$ & Resistant cultivars of Musa spp. (banana) & Saint Lucia \\
\hline A new strain of chili anthracnose disease & Resistant and tolerant chili varieties & Fiji \\
\hline $\begin{array}{l}\text { Inter alia, tomato yellow leaf curl virus, } \\
\text { tomato spotted wilt virus and zucchini } \\
\text { mosaic virus }\end{array}$ & Resistant Solanum lycopersicum (tomato) & Jordan \\
\hline $\begin{array}{l}\text { Ascochyta rabiei } \\
\text { (fungus causing Ascochyta blight) }\end{array}$ & Resistant cultivars of Cicer arietinum (chickpea) & Jordan \\
\hline $\begin{array}{l}\text { Chalara fraxinea } \\
\text { (fungus causing ash dieback disease) }\end{array}$ & Less susceptible forest tree types & Norway \\
\hline Cyperus aromaticus (Navua sedge) & Setaria (a pasture species) & Fiji \\
\hline
\end{tabular}

Source: Selected from the 91 country reports prepared for The State of the World's Biodiversity for Food and Agriculture.

pest- and disease-control strategies are discussed in the respective sectoral global assessments (FAO, forthcoming, 2010a, 2014a, 2015a). The significance of associated biodiversity in conferring resilience to the effects of diseases and parasites is noted elsewhere in this chapter, particularly in Section 2.2. The country reports include many references to the roles of associated biodiversity in the control of pests and diseases (see, in particular, Section 4.3). ${ }^{18}$ Management practices involving the use of BFA in controlling pests and diseases are discussed in Section 5.6. Micro-organisms can contribute to the control of some pollution events (see Section 5.7) and can also be used to combat threats to food safety.

\subsubsection{Needs and priorities}

The resilience-related priority most widely identified in the country reports is promoting the conservation and sustainable use of BFA so as to ensure that the resilience-enhancing properties of ecosystems are not undermined and that producers have access to a wide range of options for potential future use. As noted above, a number of countries report that resilience is being threatened

\footnotetext{
18 The country-report questions on these roles did not specifically refer to the concept of resilience.
}

by the loss, degradation or fragmentation of habitats. Several mention the significance of maintaining wildlife corridors to provide connections between larger patches of habitat.

Many countries note that detailed information on relationships between biodiversity and resilience is often lacking. Strengthening research on these relationships is widely mentioned as a priority. A number of countries refer to the need to establish or strengthen policies and programmes that provide support to producers in the implementation of management practices and strategies that help to build resilience. Specific needs identified in this regard include improving training and technology transfer and establishing community-based genebanks. The general significance of participatory and community-based approaches in efforts to improve resilience is also widely noted. Some countries also refer to the importance of awarenessraising among decision-makers on the significance of improving resilience within production systems. While not specifically highlighted in the country reports in the context of resilience, it is important also to note that implementing integrated BFA-management activities at multiple scales that extend beyond farm/holding level can be challenging in that it requires an 
institutional framework that facilitates action at all relevant scales and coordination across them (see Chapters 5 and 8 for further discussion).

The thematic study on resilience prepared as part of the SoW-BFA process (Duval, Mijatovic and Hodgkin, 2018) emphasizes the importance of promoting the conservation and availability of species and genetic diversity in and around production systems, diversifying the use of crops, livestock, forest trees and aquaculture species, and restoring habitats to increase landscape and seascape complexity. It identifies, inter alia, the following priorities for resilience-related research:

- further analyses of the ways in which BFA can optimally contribute to responses to and recovery from stresses and shocks;

- development of management approaches that integrate effects at different scales and that involve diverse components of BFA;

- assessment of the contribution of BFA to resilience of production systems over sufficiently long periods of time to capture medium- and long-term outcomes; and

- more complete analysis and description of the dynamic nature of production systems and development of improved methods for assessing and measuring their resilience.

\subsection{Sustainable intensification}

- Biodiversity for food and agriculture (BFA) can contribute to efforts to increase the output and quality (e.g. nutritional content) of food and other products while using less land, water and other inputs per unit output.

- Appropriate diversification of the species, varieties and breeds present in and around production systems can promote positive interactions that reduce the need for external inputs.

- Well-planned genetic-improvement programmes can produce plant and animal populations that have the characteristics needed to produce efficiently in specific production environments.

- Key priorities for enhancing the contributions of BFA to sustainable intensification include:
- improving knowledge of how existing practices and new approaches can best be combined to promote outcomes that increase productivity in a sustainable way:

- identifying means of adapting sustainable management methods to local agroecological and socio-economic conditions; and

- developing appropriate policy and outreach measures for scaling-up interventions.

The need to ensure the food security and nutrition of a world population predicted to increase to almost 9.8 billion by 2050 (United Nations, 2017a) means that food supplies and their nutritional quality will need to increase substantially over the coming years and decades (Foley et al., 2011). Although strategies such as reducing food waste and promoting dietary changes can potentially contribute, it has been estimated that global food production will need to increase by 50 percent by 2050 (FAO, 2017e). The supply of a range of non-food products will also need to increase substantially (ibid.). The challenge involved is exacerbated by the fact that the food production systems that currently dominate global production have serious negative environmental impacts and are increasingly regarded as unsustainable in a number of respects (FAO, 2017f; Rockström et al., 2009; Steffen et al., 2015; TEEB, 2015). Shortages of land that can be converted to agricultural use without inflicting yet greater damage on the environment (Lambin et al., 2013) mean there is a need to increase the output ${ }^{19}$ of food and other products on land and in water that is already being used for production. ${ }^{20}$

Various approaches to utilizing improved ecological function to increase food production while maintaining the sustainability of production

\footnotetext{
19 This statement refers to terrestrial and aquatic food production systems taken as a whole. There are systems from which output cannot be maintained or increased sustainably.

20 This Section draws on the thematic studies Contributions of biodiversity to the sustainable intensification of food production (Dawson et al., 2018a) and The contribution of biodiversity for food and agriculture to the resilience of production systems (Duval, Mijatovic and Hodgkin, 2018).
} 
systems have been developed (Baulcombe et al., 2009; Struik et al., 2014). These have been variously described as sustainable intensification, ecological intensification, agroecological intensification and eco-functional intensification. The term "sustainable intensification" (often contrasted with "conventional intensification") is used in different ways in different publications (e.g. Garnett et al., 2013; Godfray, 2015; Wezel et al., 2009). ${ }^{21}$ However, the objective in this section is to explore the significance of BFA in efforts to increase the quantity and the nutritional quality of food products using less land, water and other inputs (e.g. inorganic fertilizers and pesticides) per unit output. In keeping with the focus of the report, the discussion largely centres on approaches that involve making more effective use of the functions performed by the biological components of the local agroecosystem and wider landscape (and the interactions and synergies between these components) and thus allow reliance on external inputs to be reduced. A wide range of approaches and management practices can contribute to this kind of biodiversity-focused sustainable intensification (see Chapter 5 for discussion of many of these), including many traditional practices developed by farming, pastoralist, forest and fish-farming communities (Tittonell, 2014).

The focus of this section is largely on the contributions BFA makes to the environmental sustainability of production systems. Social and economic aspects are further discussed in Section 2.5. Practices and approaches that involve mobilizing BFA to promote the maintenance of productivity in the context of shocks and stresses are introduced above in Section 2.3.

While much of the literature on sustainable intensification has focused on crop production

\footnotetext{
${ }^{21}$ A recent assessment of global progress towards the implementation of sustainable intensification (Pretty et al., 2018) took seven management practices into account (integrated pest management, conservation agriculture, integrated crop and biodiversity, pasture and forage, trees, irrigation management and small/patch systems). The authors estimated that 163 million farms (29 percent of the worldwide total) practise some form of sustainable intensification on 453 million hectares of agricultural land (9 percent of the worldwide total)
}

systems (e.g. Attwood et al., 2016; FAO, 2011c), sustainable intensification approaches have also been applied to livestock production (Eisler et al., 2014), mixed systems and (to a much lesser extent) aquaculture (FAO, 2016b, 2016c). Because sustainable intensification as described above involves intervening to promote the productionsupporting functions of ecosystem components, the concept is less applicable to systems, such as capture fisheries, that involve harvesting products from unmanaged ecosystems.

\subsubsection{Overview of the contributions of biodiversity for food and agriculture}

Across all sectors of food and agriculture, biodiversity underpins the supply of multiple ecosystem services that contribute to the productivity and resilience of production systems (see Sections 2.2 and 2.3 and Chapters 4 and 5). Appropriate management of BFA is thus vital to efforts to enhance the supply of these services in the interests of sustainable intensification. Potential interventions to support positive interactions between components of biodiversity in food production systems are listed in Table 2.4 .

\section{Diversification to promote sustainable intensification}

There are many ways in which increasing the diversity of the biological components within production systems can contribute to sustainable intensification. This may involve specific practices (e.g. intercropping), as well as broader integrated approaches such as agroecology (see Section 5.3). Diversification may involve utilizing a wider range of species, varieties or breeds from within a given sector (crops, livestock, forest, aquaculture, etc.), promoting positive interactions or complementarities between species from different sectors within or across production systems (including by diversifying the types of production practised at landscape scale) and/or enhancing the benefits obtained from associated biodiversity such as pollinators and biological control agents. For example, increasing the within- and between-species diversity 
of the crops grown within a production system, both in space and in time, tends to increase the potential for beneficial interactions that, for instance, generate favourable microclimates, promote nutrient cycling or contribute to the control of pests (Altieri et al., 2015a; Attwood et al., 2017a). Crops with different characteristics (e.g. different root lengths, vegetative architectures, or planting and harvesting times) can complement each other in terms of resource use (Brooker et al., 2015). Introducing trees or shrubs can benefit crop yields through improved nutrient cycling and fixation, groundwater recharge and the provision of shade (Binam et al., 2015; Ilstedt et al., 2016). Similarly, livestock can benefit from shade, shelter and/or additional feed supplied by woody species. Livestock in turn can provide manure to fertilize crops and fishponds. Ducks, fish and other aquatic species can contribute to pest control in rice paddies and similar systems. See Section 5.5 for further discussion of the significance of mixed production systems.

Potential measures involving associated biodiversity include increasing the availability of pollinator habitat by planting strips of wild flowers or trees within agricultural landscapes to promote pollinator abundance and diversity, and hence the supply of pollination services (Garibaldi et al., 2013; Klein et al., 2007; Kovács-Hostyánszki et al., 2017), reducing or eliminating the application of pesticides to protect pollinators (Chagnon et al., 2015; EASAC, 2015) and adopting management practices that favour beneficial soil biodiversity (e.g. use of intercrops, rotations, appropriate tillage methods, maintenance of soil cover and the incorporation of crop residues into the soil) (Brooker et al., 2015; FAO, 2003a).

Quantifying the impact of such measures in terms of sustainable intensification can be challenging. The productivity of a system can be measured in various ways based on the relative quantities of various inputs (e.g. energy, fertilizer, water, labour or land), outputs (e.g. food calories or other nutritional measures) and environmental impacts (e.g. greenhouse-gas emissions, biodiversity loss or soil erosion) (Elliott et al., 2013; Notarnicola et al., 2017;
Smith et al., 2017). Such approaches can potentially be used to evaluate the impact of introducing additional biodiversity into a system, although basic measures may not account for more subtle effects such as changes in the nutritional quality of foods.

One widely used method of measuring the effects of including multiple crop species or genotypes in crop-production systems is the "land equivalent ratio" (LER) (Mead and Willey, 1980). The LER is the ratio of the sum of the relative yields of the different components when they are grown together as intercrops to the sum of their yields when grown separately. A value above 1 indicates that having multiple components in the system provides benefits in terms of yield. A value of less than 1 indicates disbenefits in terms of yield. Yu et al. (2015) calculated the LER for annual intercrop systems described in the scientific literature and found an average LER of 1.22 for cereallegume intercrops, i.e. that intercropping tended to have a positive effect on yields (although in a significant minority of cases effects were negative). Nitrogen fertilization was found to lower LERs, suggesting that intercropping systems may be more advantageous where access to inputs is limited, as is the case for many millions of smallholder farmers in low-income countries. It must be recalled, however, that LER is purely a measure of production, and hence does not indicate the overall attractiveness of an intercrop approach to farmers, who also have to consider the labour and other costs involved. Potential additional benefits such as increases in yield stability, reduction of risks and long-term improvements to soil fertility also need to be considered.

Where agroforestry is concerned, Sileshi et al. (2008) conducted a meta-analysis of studies from sub-Saharan Africa on the effect that including woody legumes in the production system had on maize yields and found significant positive responses. An analysis of 40 projects and programmes implemented in the 1990s and 2000s in various countries in Africa that involved practices such as crop improvements, agroforestry, conservation agriculture, integrated pest management and the integration of livestock, fodder crops or 


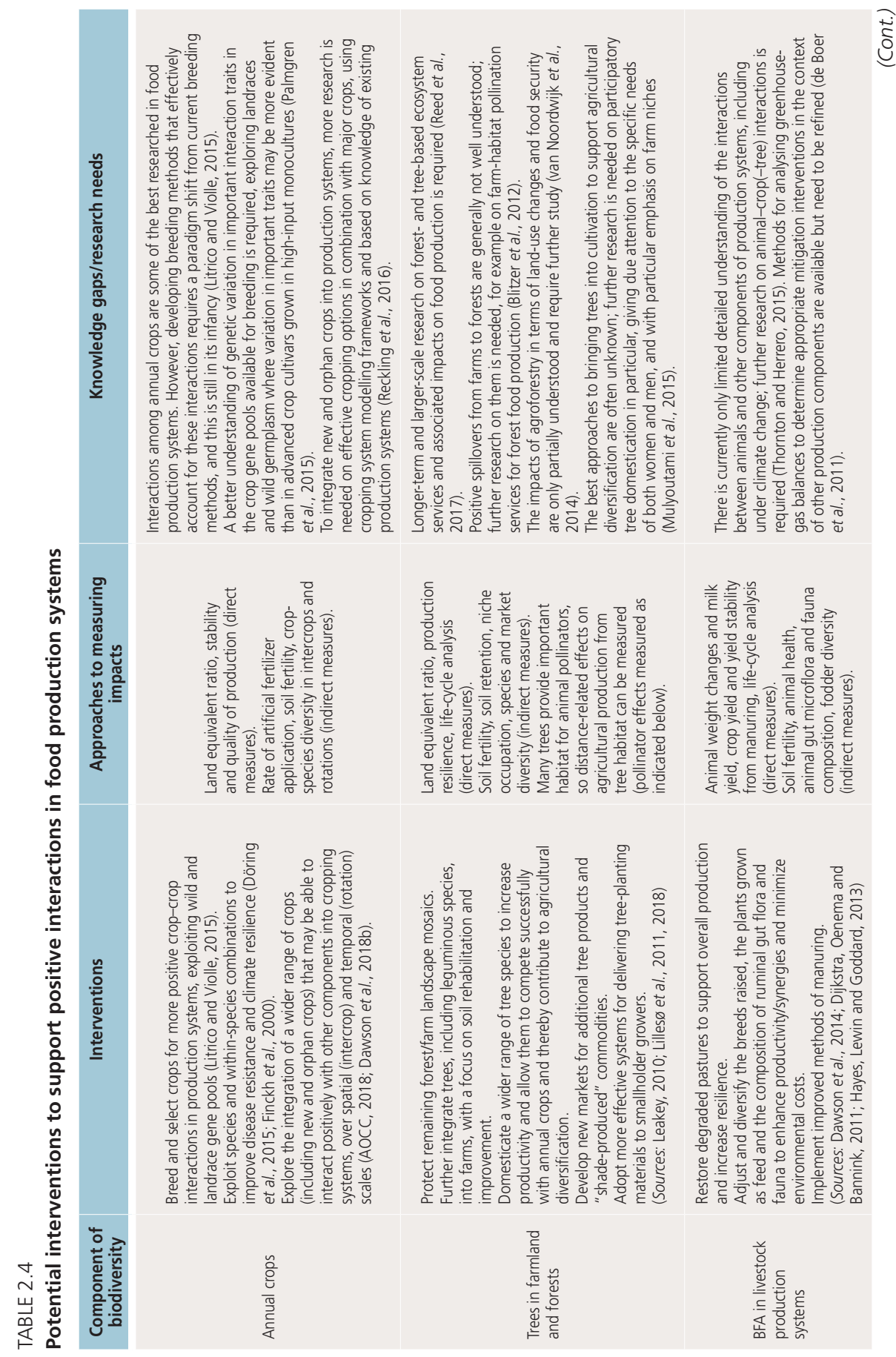



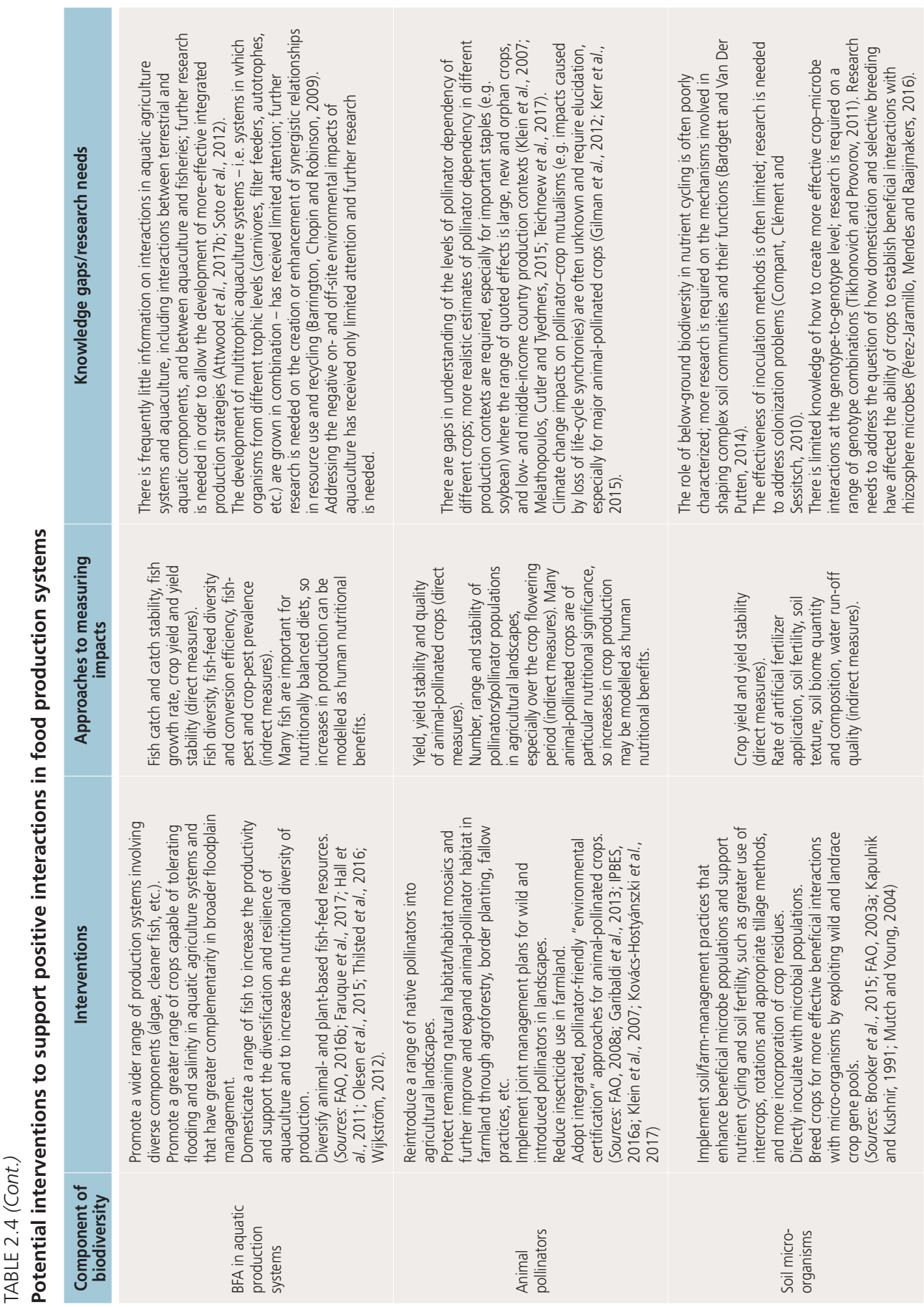

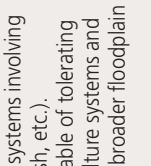

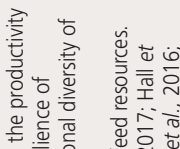

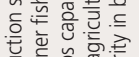

峁离产

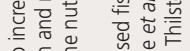

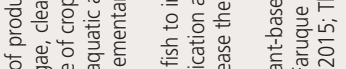

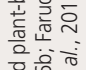

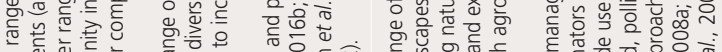

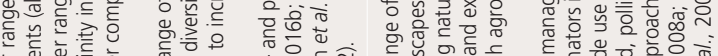

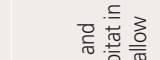

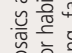

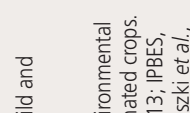

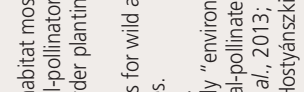

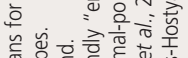

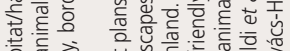

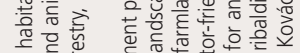

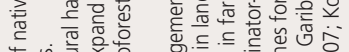

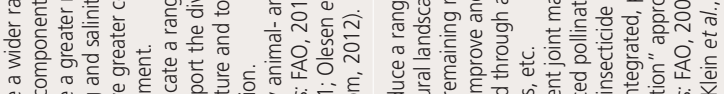
苋品

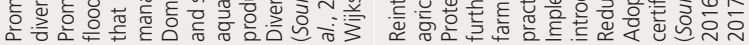

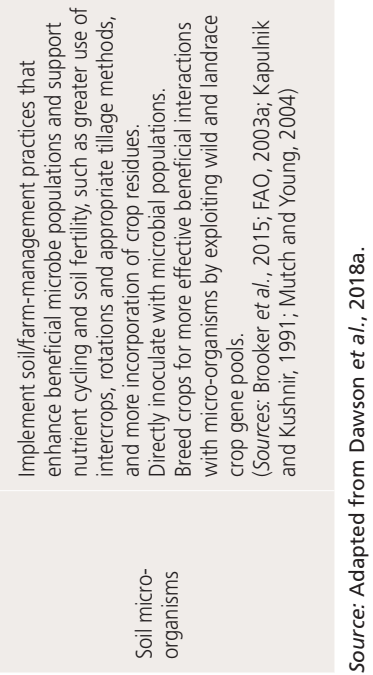


aquaculture into food production systems identified positive results in terms of food outputs and yield increases (Pretty, Toulmin and Williams, 2011). An evaluation of 85 integrated pest management projects implemented in 24 countries in Asia and Africa between 1990 and 2014 (Pretty and Bharucha, 2015) found that they led to a mean yield increase across crops of 41 percent, combined with a decline in pesticide use to 31 percent of the original level. ${ }^{22}$

Potential BFA-based approaches to sustainable intensification in aquaculture include polyculture, i.e. raising multiple species or taxonomic groups (including the use of bioremediation species), shifting to vegetable-based feed, and improving interactions with other production-system components such as crops and livestock (Attwood et al., 2017b). For example, the use of wrasse (Labridae) as cleaner fish has proved to be an effective substitute for the use of chemicals in the control of sea lice in salmon farms (Research Council of Norway, 2010; Skiftesvik et al., 2014).

\section{Genetic improvement to support sustainable intensification}

Genetic-improvement programmes are among the main tools that can be drawn upon to increase the productivity and stability of food and agricultural systems, whether by increasing output, increasing product quality, enabling production to be maintained in harsh conditions or reducing harmful environmental impacts per unit of output. In many cases, however, plants and animals are currently bred for use in production systems that are in one way or another unsustainable, for example polluting, highly dependent on non-renewable resources or vulnerable to being undermined by the negative effects of various drivers of change. Breeding in support of sustainable intensification thus requires adjusting breeding goals so that the outputs are better adapted to systems that meet the overall objectives of the approach.

\footnotetext{
22 Reviews of reported magnitudes of benefits should be interpreted with caution, as they may inadvertently be affected by biases in the literature towards publishing studies that show positive effects.
}

Particularly given the effects of climate change, genetic improvement efforts require access to genes that better enable plants and animals to respond to a range of abiotic and biotic stresses. This requires the maintenance of a diverse portfolio of genetic resources, including crop wild relatives and locally adapted varieties and breeds, which in turn requires effective approaches to the conservation and sustainable use of these resources (Dulloo et al., 2017; FAO, forthcoming, 2010a, 2014a, 2015a; see also Chapters 5 and 7). It also needs to be borne in mind that interactions between the biological components of production systems - including for example those that may influence complementarity in the use of resources - are influenced by their genetics. This means that, for example, it may be possible to improve the performance of crop mixtures by identifying traits that influence such interactions and breeding the components of the mixture so as to optimize complementarity (Litrico and Violle, 2015). Breeding plants for attributes other than yield may be a means of promoting the supply of a wider range of ecosystem services, for example increasing carbon sequestration or water capture.

Realizing the potential contributions of a broad range of genetic resources to breeding programmes that promote sustainable intensification remains challenging. To varying degrees across sectors, there are organizational, technological, knowledgerelated and biological (e.g. the need to conserve genetic diversity in small populations) constraints to the integration of locally adapted populations into genetic improvement strategies. Breeding programmes are discussed in Section 5.9 and in greater detail in the sectoral global assessments of genetic resources (FAO, forthcoming, 2010a, 2014a, 2015a).

\section{Country-report analysis}

The country-reporting guidelines invited countries to provide information on cases in which increasing the amount of BFA in production systems has contributed to an increase in productivity or specifically to sustainable intensification. Responses refer to a range of different biodiversity-based interventions. For example, Argentina reports that studies 
have looked into the potential of sustainable intensification as a means of avoiding agricultural expansion into vulnerable areas. It notes that intensified crop rotations were found to allow improvements in grain yields and in the contribution of crop residues to soil carbon balance. Ethiopia mentions a project in the southwestern part of the country that introduced the use of improved fruit and vegetable varieties, along with practices such as the use of organic manure and integrated pest management, and resulted in a 60 percent increase in crop yields and a 70 percent improvement in nutrition in the areas targeted. It notes that similar activities have been implemented in other parts of the country and that most of the crop varieties involved were developed from landraces at the country's agricultural research centres. Several countries note the significance of breeding programmes that create high-performance varieties, breeds and strains that are resistant to stresses they are likely to encounter or note the importance of existing locally adapted crops or livestock that can function in low external input production systems.

\subsubsection{Needs and priorities}

The country reports emphasize the need to increase research into the potential roles of BFA in sustainable intensification across a range of production systems and to generate, adapt or develop sustainable technologies - including approaches to land management - that meet the needs of producers and their communities. Reported priorities include improving knowledge of how existing practices and new technologies can best be combined to promote sustainable intensification. Several countries note the importance of strengthening genetic-improvement programmes for local breeds and varieties of livestock and crops.

Countries highlight the importance of increasing the availability of financial resources for research on sustainable intensification and for the implementation of sustainable-intensification practices and note the need to promote the involvement of both the public and the private sectors. Several mention the need to develop incentive measures to encourage the adoption of sustainable practices by producers. Raising awareness among policymakers and local communities of the potential significance of sustainable intensification to food security and nutrition - and of the significance of BFA in this regard - is noted as another priority. Some countries also mention the need to monitor and establish indicators for the implementation of sustainable intensification in agriculture.

The thematic study prepared by Dawson et al. (2018a) draws attention to a number of challenges involved in the design and implementation of sustainable intensification strategies and interventions. In addition to the need for greater understanding of the various components of BFA and their interactions, it notes the need to investigate factors influencing levels of adoption, such as the amount of labour, knowledge and time required relative to other practices, as well as potential constraints associated with institutional and governance systems. It further notes the need to determine how to tailor sustainable intensification strategies and interventions to local agroecological conditions and to socio-economic factors such as dietary preferences. The need for interdisciplinary research approaches to all these questions is emphasized. At a more technical level, priority actions identified (largely focused on the crop sector) include the following: greater focus on adaptive-trait breeding for staple crops based on landrace and wild gene pools; support for the diversification of farming systems by focusing on strengthening positive interactions between biological components and promoting greater investment in more nutrient-rich orphan and new crops; and greater attention to spatial planning to maximize positive interactions between components of BFA.

\subsection{Livelihoods}

- Biodiversity for food and agriculture (BFA) is indispensable to livelihoods in countries at all levels of development, providing a wide variety of goods and employment opportunities, contributing to local culture, strengthening food and nutrition security - particularly among marginalized groups and in 
resource-poor areas - and increasing the resilience of production systems to adverse events.

- Actions that need to be taken to support the livelihood-enhancing roles of BFA include:

- better documenting its multiple contributions, including documenting indigenous knowledge related to its use;

- raising awareness of the significance of its livelihood roles; and

- creating appropriate policies in fields such as marketing of sustainably supplied products (e.g. certification schemes) and agro-ecotourism.

According to one widely cited definition, a livelihood "comprises the capabilities, assets (stores, resources, claims and access) and activities required for a means of living; a livelihood is sustainable which can cope with and recover from stress and shocks, maintain or enhance its capabilities and assets, and provide sustainable livelihood opportunities for the next generation; and which contributes net benefits to other livelihoods at the local and global levels and in the short and longterm" (Chambers and Conway, 1991). In this sense, the livelihoods of the world's farmers, livestock keepers, forest-dwellers, fishers and aquaculturists involve drawing on (inter alia) the assets represented by components of BFA and using and combining them in various ways to meet their needs.

\subsubsection{Overview of the contributions of biodiversity for food and agriculture}

According to the so-called sustainable livelihoods approach - a framework developed during the 1990s to analyse livelihoods (particularly the livelihoods of the rural poor) and potential development strategies or interventions (Carney, 1998; Scoones, 1998) - livelihood assets can be grouped into various categories of "capital", typically financial, physical, natural, social and human capitals. Although these categories are not necessarily completely distinct from each other and can be interpreted in various different ways, the framework serves to illustrate the diverse range of assets and activities that make up many livelihoods, and provides a structure within which the livelihood significance of BFA can be discussed. The framework is illustrated in Figure 2.2: a household combines its various categories of assets into a strategy aimed at coping with the various challenges it faces ("the vulnerability context") and achieving desirable "livelihood outcomes".

\section{Financial capital}

"Financial capital" in the livelihoods context refers to the cash assets to which an individual or a household has access. These assets can be used to purchase items that either directly contribute to well-being (e.g. food, medicines and various consumer goods and services) or can be invested in making improvements to the productivity or resilience of livelihood activities (tools, land, seeds, animals, fertilizers, feeds, veterinary medicines, etc.).

Clearly, many products and services derived from biological resources can be sold to obtain cash income. The significance of diversity in this context lies, in part, in the fact that access to a range of different components of BFA (e.g. a range of species, breeds or varieties) can help allow a household to maintain a supply of saleable products in diverse and fluctuating environments and in response to changes in market demand. However, the financial role of BFA is not necessarily restricted to the supply of a steady stream of products that can immediately be converted into cash. Where conventional financial services are unavailable, biological assets can also serve as alternative forms of savings or insurance. This is a well-documented function of livestock, for example (e.g. Ayalew et al., 2003; Ejlertsen, Poole and Marshall, 2012; Moll, 2005). Cash can be "banked" in a herd or flock of animals that can then be sold when need arises. Other resources that may otherwise be of little value such as food waste, crop residues or vegetation from uncultivated rangelands, wastelands, roadsides, etc. can also be converted into savings by feeding them to the animals. If things go well, the flocks and herds will also yield "interest" in the form of offspring, milk, eggs, etc.

\section{Physical capital}

A household's assets will include items that have not yet been, or will never be, converted into cash. 


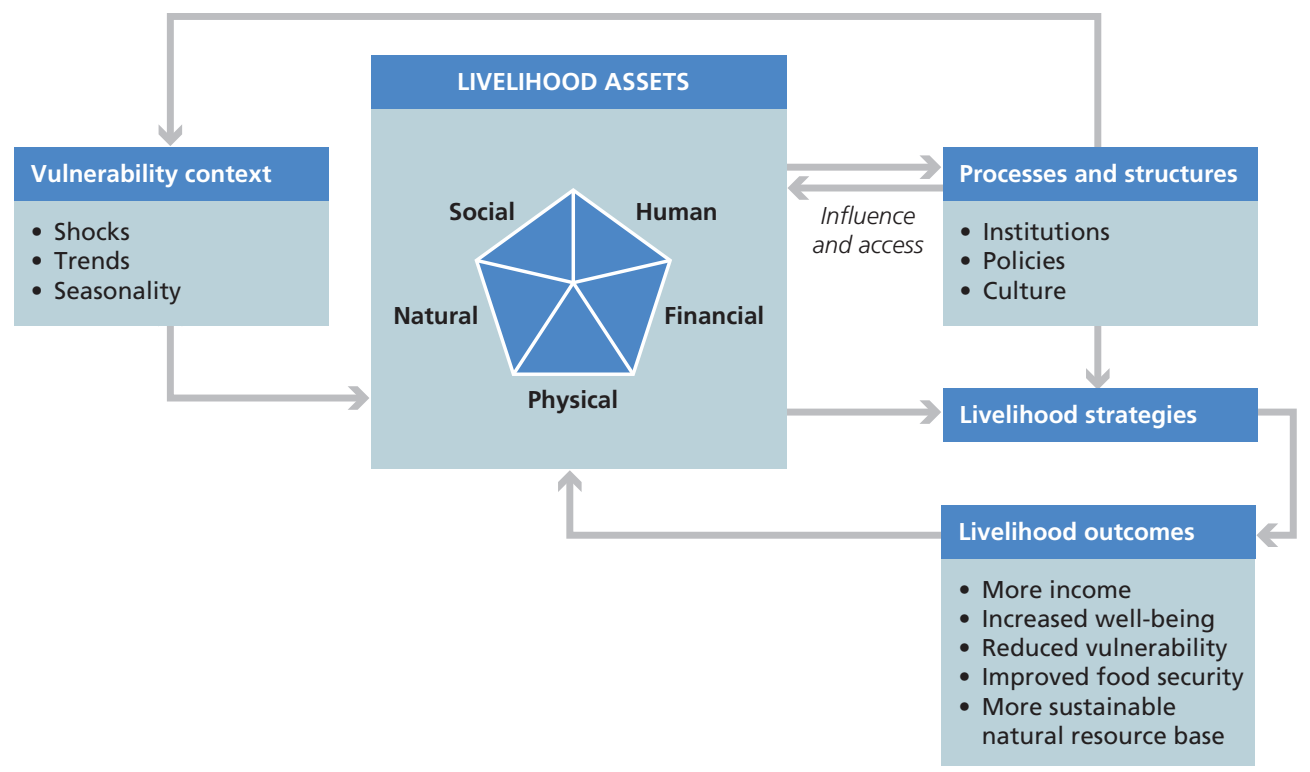

Source: Adapted from FAO (2012a) based on Randolph et al. (2007) and Carney et al. (1999).

As in the case of financial capital, this so-called "physical capital" can serve directly to meet human needs (e.g. crop plants, livestock, forest trees or aquatic species can provide food, transport, shelter, clothing, etc.) and serve as inputs to further livelihood activities (e.g. crops and trees can provide feed for use in animal production, animals can provide draught power for use in crop production, trees can provide timber for use in making tools for various livelihood activities). Again, as in the case of marketed products and services, fulfilling these diverse roles across a range of different production environments requires a range of different species, varieties and breeds.

\section{Natural capital}

"Natural capital" refers to the natural resources and processes that a household (or individual or group) can draw upon. Where BFA is concerned, the boundaries of this category are rather blurry.
In a sense, all the functions of all components of BFA could be included. However, some components of BFA are more "natural" than others in that they have not been domesticated and/or are not actively managed by humans. Moreover, as described above, many types of BFA (crops, livestock, species used in aquaculture, and major harvested tree and aquatic species) are key contributors to the financial and physical assets of large numbers of households. The main focus under this subheading is on BFA falling outside these "sectoral" categories.

As described throughout this chapter and throughout the report, associated biodiversity contributes in many ways to the supply of supporting and regulating ecosystem services that are drawn upon at household level, whether passively or through active use (see in particular Sections 2.2 and 2.4, and Chapter 5). Likewise, wild biodiversity is widely used as source of food and other 


\section{PART A}

products (see in particular Section 2.6). However, while everyone's livelihoods and well-being depend ultimately on ecosystem services and functions, some households are more dependent than others on the services directly provided by their local ecosystems. These may often be households that are not well endowed with other assets. For example, if food is in short supply (e.g. because of a poor harvest), households that have plenty of "financial capital" may be able to buy the food they need despite higher prices, while those that are poorer may have to fall back on harvesting wild foods. Similarly, regulating and supporting services provided by wild biodiversity may be particularly important to poorer households as they often come at little or no direct cost to the beneficiary. For example, wild biological control agents may be particularly important for farmers that are unable to afford purchased pesticides.

However, while some studies have, indeed, indicated that poorer sections of the community tend to be particularly dependent on products obtained from the wild (e.g. Béné et al., 2009; Cavendish, 2000; Jodha, 1992; Shackleton and Shackleton, 2006), it may not be correct to assume that this is a general rule (Vira and Kontoleon, 2012). In some cases, the relationship between the use of particular wild resources and wealth is positive (i.e. wealthier households use more than poorer ones) or U-shaped (i.e. the poorest and the richest use more and those with intermediate levels of wealth use less) (ibid.).

Various factors can influence access to wild resources and capacity to use them. For example, access to other assets may be a prerequisite (Adhikari, Di Falco and Lovett, 2004; Coomes, Barham and Takasaki, 2004; Coulibaly-Lingani et al., 2009). Landowners may find it easier than landless people to access wild resources or may be better able to make use of them, for example using leaf litter gathered in the forest to make compost for use in their crop fields. Livestock owners may have more opportunity to make use of grasslands or other ecosystems that can be grazed or from which forage can be gathered. Access to some wild products may require investment in relatively expensive equipment (e.g. boats for fishing).
Lack of time or knowledge may be constraints and there may be various physical hazards that have to be overcome (rough terrain, dangerous animals, etc.). Particularly where endangered and more valuable resources are concerned, political or social influence may affect access. Changing socio-economic conditions may alter the way in which wild biodiversity is used and valued, for example the high cultural value and therefore economic value that meat or other products from wild animals have acquired among some wealthy people in Africa and Asia (Nasi et al., 2008). There may also be legal, cultural or religious factors that inhibit or promote the use of particular resources, either by the population at large or by particular sections of society.

Another concern that is sometimes raised is that while wild biodiversity is clearly a significant source of income (either regular or as a safety net) for many households, these people often remain poor. In other words, the use of wild biodiversity is not enabling them to break out of the "poverty trap" in which they find themselves and transition to other livelihood activities (Vira and Kontoleon, 2012). Moreover, overuse of wild products is a major problem in many places and has implications both for biodiversity and, in the medium term, for the sustainability of the livelihoods of people relying on these resources. The paradox is that rarity itself can give a species added value and thus promote further exploitation.

\section{Social capital}

"Social capital" in the context of the sustainable livelihoods framework refers to the social connections and bonds that people can draw upon for assistance. BFA can contribute to building social capital via its role in social and cultural life. It can also be the form in which social capital is realized into tangible assets. In pastoralist societies, for example, exchange of livestock via loans and gifts has traditionally been a means of building and maintaining social relationships that can later be drawn upon for help, typically again in the form of loans or gifts of animals (Morton and Meadows, 2000; Potkanski, 1999). More generally, many cultural 
or religious events or activities that help to build social ties involve the use of crops, livestock, forest trees or aquatic organisms or products obtained from them. Sometimes such traditions require the use of specific varieties or breeds within species (FAO, 2007a, 2010a, 2014a, 2015a).

\section{Human capital}

The term "human capital" is used to refer to human capacity to contribute to livelihood activities, i.e. to knowledge, skills, physical strength and so on. As discussed further in Section 2.6, BFA contributes in various ways to human nutrition, and hence to health and capacity to work. Many cultivated and wild plants have medicinal qualities. Moreover, for many households, sales of agricultural, forest or aquatic products are a means of financing expenditures on health and education. For example, among livestock-keeping households, medium-sized animals such as sheep and goats are often sold to finance educational expenses such as school fees (e.g. Otte et al., 2012). Another consideration is that activities that are time consuming or physically exhausting tend to "use up" human capital, i.e. limit people's capacity to do other things. Labour-saving assets can therefore be important. For example, in poorer households in many parts of the world, donkeys often perform essential tasks, such as carrying water and fuelwood, which would otherwise have to be done by people, often by women (Valette, 2014). Raising locally adapted species, varieties and breeds of crops, livestock, trees or fish can be less demanding in terms of labour than raising their exotic counterparts. These labour-sparing characteristics can make locally adapted genetic resources particularly important for women, who often have to spend a lot of time on child-rearing and other domestic activities (FAO, 2012a).

\section{Country-report analysis}

Country reports from all regions, and from countries at all levels of development, provide examples of the positive contributions that BFA makes to livelihoods, including as a direct source of food and income and as a provider of ecosystem services that underpin livelihood activities. Reported roles in food security and nutrition are described in Section 2.6. Chapter 5 includes information on the reported use of BFA in various management activities that underpin livelihoods in food and agriculture. This subsection, therefore, provides a fairly short overview of the main livelihood-related roles of BFA described in the country reports.

Direct contributions of BFA to income generation and employment are highlighted across all sectors of food and agriculture. Even in countries where these sectors make up a relatively small proportion of the national economy, BFA is reported to be key a component of the livelihoods of some local populations, whether directly or indirectly (e.g. by helping to attract tourists). Many countries report on the economic contributions provided by major food and agricultural commodities. ${ }^{23}$ However, the livelihood significance of relatively "overlooked" components of BFA is also widely reported, including those that play multiple roles in household livelihoods and in the wider economy or that are of particular significance to the livelihoods of poorer sections of the population. Several countries report initiatives and programmes aiming to protect and build on the multiple benefits that BFA offers to livelihoods. Box 2.1 presents some examples.

The forest sector is widely reported as a source of employment and of a wide range of wood and non-wood forest products. For example, Bhutan mentions that over 40 species of edible wild vegetables and 350 species of edible mushrooms have been identified in its forests. It notes that as well as making a direct contribution to diets some of these wild species are sold to generate cash income. Similarly, Burkina Faso draws attention to the importance of non-wood forest products in sustaining livelihoods, particularly those of women, who are often responsible for collecting, processing and commercializing such products. Reported examples include shea butter

\footnotetext{
23 Latest national data on production quantities and values for many products are available via FAO's statistical database FAOSTAT at http://www.fao.org/faostat/en/\#home
} 
- extracted from the shea tree (Vitellaria paradoxa) - and soumbala, a traditional aromatic condiment obtained from the seeds of the African locust bean (néré) tree (Parkia biglobosa). The Gambia notes that forests provide about 85 percent of its domestic energy requirements, in the form of fuelwood and charcoal, in addition to providing timber, wild foods, construction materials, medicine and forage for livestock. Sudan mentions that production of gum arabic (a natural gum obtained from acacia trees and used in food production and for various other purposes) makes a substantial contribution to the livelihoods of millions of its poorest people, providing some with up to 50 percent of their total cash incomes. It notes that for smallholders gum arabic represents a diversification strategy that can help to mitigate the effects of crop failure.

Fisheries and coastal ecosystems are reported to be vital to livelihoods in many countries. Fiji, for example, mentions that it has over 70 edible species of shellfish, in addition to finfish, crabs, freshwater mussels and seaweed. It notes that as well as providing a source of products that can be harvested for home consumption, some of these species (e.g. tuna) represent a significant source of paid employment and foreign exchange. India mentions the importance of mangrove ecosystems and their biodiversity in supporting coastal fisheries and hence the livelihoods of local villagers.

The country reports also highlight a range of livelihood contributions provided by livestock. Ethiopia, for example, reports that some 80 percent of smallholders in the country use animal traction to plough their fields. India reports that smallholders and landless rural dwellers manage 75 percent of the country's livestock resources and obtain nearly half of their income from them. Sudan mentions that for pastoralist groups living in areas where there are no banking services livestock are a way to store wealth. It also notes that keeping animals facilitates group solidarity in that those with larger herds may lend animals to those who have fewer resources or have been affected by droughts, epidemics or armed conflicts. Some countries also mention the significance of beekeeping as a source of products such as honey and beeswax for home use or sale.

As illustrated by some of the examples above, many countries note the significance of wild foods to livelihoods, both in terms of food security and nutrition (see Section 2.6) and as a more general source of income. Several provide examples of the livelihood opportunities related to consumer demand for wild foods. Cameroon, for example, mentions that demand for such products from rural dwellers that have moved to urban areas or to other countries increases the prices that can be obtained for them. The popularity of Gnetum spp. (a forest vine eaten as a vegetable) in restaurants throughout the country and abroad is noted as a case in point. Zimbabwe reports that insects, particularly those that can be collected in large numbers, provide both a supplementary source of nutrition for local people and an incomegenerating activity. It notes that commercial harvesting and sale of forest insects is a substantial industry in some parts of the country and drives efforts to conserve trees that provide habitat for the targeted insects. Reports from developed countries generally indicate that wild biodiversity provides only a marginal contribution to national incomes and diets. Several, however, note that it makes a substantial contribution to the livelihoods of some sections of the population or underpins significant niche industries.

Many countries highlight the importance of biodiversity to cultural life - often particularly for indigenous populations - including via roles in traditional ceremonies, cuisine and handicrafts. Several note that aside from their purely cultural significance such traditions often also help to underpin income-generating activities, nutritious diets, the supply of medicinal products or the maintenance of social ties within communities. Niue, for example, mentions that its annual yam and thanksgiving food festivals encourage the utilization of a diverse range of local crop species and varieties and hence help promote a more nutritious diet. Almost all families in the country 
Box 2.1

Projects and programmes supporting livelihoods by promoting biodiversity for food and agriculture - examples from around the world

One Village One Product (Nepal), a project implemented by the Ministry of Agricultural Development, is promoting indigenous food and non-food products derived from local biodiversity - including fabrics and dresses, furnishing and decorations - to enhance the livelihoods of rural villagers.

Árbediehtu (Inherited Knowledge) (Norway), a project established and implemented by the Sámi University College, is documenting the traditional knowledge of the Sámi people on the management of local natural resources, including wild foods, that support their livelihoods. The aim is to integrate this knowledge into the management of local biodiversity.

Research and Innovation in Family Agricultural Production Systems in the Ngäbe Buglé Region (Panama) aims to document local biodiversity for food and agriculture and promote its conservation and sustainable use. Smallholders in the area are custodians of a wide variety of maize, bean, yucca and other vegetables that are well adapted to the local environment. The project has collected local crop cultivars with the aim of breeding them for characteristics such as uniform height and distributing them to family farmers. It has evaluated biofortified varieties for potential introduction in poor rural areas with the aim of improving food security and nutrition. It has also promoted the use of vermicompost in local farming systems and achieved a marked increase in crop yields.

Mainstreaming Agro-biodiversity Conservation and Use in Sri Lankan Agro-ecosystems for Livelihoods and Adaptation to Climate Change (Sri Lanka), a project implemented by the Ministry of Environment and Natural Resources, Bioversity International and the Ministry of Agriculture, is looking at ways in which agrobiodiversity including crops, forest species, livestock and pollinators - can be directly linked to sustainable production practices that can improve the livelihoods of local people while helping to increase resilience to climate change.

Sustainable Livelihoods and Healthy Foods (Tonga) is part of the country's Agriculture Sector Plan and aims to improve farmers' knowledge of, and access to, technology to promote climate-resilient, diversified crop and livestock production and improve product marketing.
Forests Sustainably Managed for Communities, Environment and Shock Resilience (Forest Forces 2014-2018) (Zimbabwe) was established with funding from the European Union and FAO to improve the food security, livelihoods and resilience of vulnerable rural communities through participatory forest management and valorization of forest products to diversify livelihood strategies.

Coral Triangle Initiative on Coral Reefs, Fisheries and Food Security (Indonesia, Malaysia, Papua New Guinea, the Philippines, Solomon Islands and Timor Leste) promotes the conservation of coastal and marine ecosystems. Objectives include protecting the livelihoods of the millions of people that depend on these ecosystems for food and nutrition and income generation.

Mangrove Ecosystems for Climate Change Adaptation and Livelihoods (Fiji, Samoa, Solomon Islands, Vanuatu and Tonga) targets the conservation and management of coastal mangrove ecosystems to reduce the impacts of climate change and improve the livelihoods of local communities. In addition to reducing the negative impacts of natural disasters on livelihoods, one of the project's objectives is to actively seek opportunities to obtain carbon credits for mangrove protection and reforestation in the context of REDD+ and global carbon markets. ${ }^{1}$

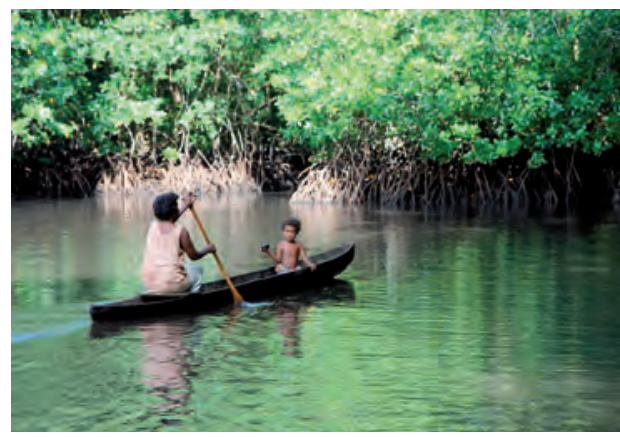

A typical mangrove ecosystem in Solomon Islands. (C) WorldFish Solomon Islands.

Sources: Adapted from the country reports of Malaysia, Nepal, Norway, Panama, Papua New Guinea, Solomon Islands, Sri Lanka, Tonga and Zimbabwe. 1 https://unfecc.int 
are reported to participate in the latter festival, which involves a range of crops and marine species. Products are donated to village pastors and then redistributed in equal proportions to all villagers. The tradition reportedly encourages local people to grow local food species that contribute to healthy diets. Several countries note the importance of micro-organisms in the preparation of traditional foods and drinks that contribute significantly to the livelihoods of local people (see Section 5.7 for examples).

\subsubsection{Needs and priorities}

There is general agreement among reporting countries that the contributions that BFA makes to peoples' livelihoods, whether in terms of income, food security or sociocultural benefits, need to be better documented and researched. Some countries highlight the urgency of recording associated traditional knowledge that may be at risk of being lost. It is also widely recognized that efforts need to be made to ensure that the biological resources that underpin livelihoods are conserved and used sustainably, including wild resources that may be overexploited.

With regard to policies, some concerns are expressed about a lack of awareness of the livelihood significance of BFA among decision-makers and a lack of attention to the need for innovation in small-scale production systems. Some countries mention challenges related to the need to reconcile conflicts between conservation-focused and livelihood-focused policies. Policy areas identified as having potential for further development in support of the livelihood roles of BFA include marketing - including certification schemes (e.g. fair trade, geographic indication or organic production) for products that can fetch premium prices, including in export markets - and agro-ecotourism.

\subsection{Food security and nutrition}

- Biodiversity for food and agriculture (BFA) contributes to food security and nutrition in many ways, including by enabling food to be produced in a wide range of environments, helping to maintain the stability of food supplies through the year and through shocks such as droughts and pest outbreaks, supplying a wide variety of nutritionally diverse foods and contributing to the supply of water and fuel used in food preparation.

- Wild biodiversity is an important source of food for many people, particularly in the poorer regions of the world. It also provides raw material for crop breeding programmes and contributes to the supply of many ecosystem services that support food production.

- Actions that need to be taken to strengthen the contributions of BFA to food security and nutrition include:

- taking steps to maintain and restore ecosystems and habitats of importance to food and agriculture;

- promoting the sustainable use and conservation of relevant species and populations;

- implementing breeding programmes targeting, inter alia, nutrient content and adaptation to environmental stresses and shocks, particularly those associated with climate change; and

- increasing knowledge of how BFA, including wild foods, supports the various dimensions of food security.

Ending food insecurity and malnutrition remains one of the most fundamental challenges facing the world. Recent figures signal a rise in world hunger levels, reversing a long downward trend (FAO et al., 2018). According to the latest estimates, about 821 million people in the world are chronically undernourished, up from 804 million in 2016 (ibid.). Estimates using the Food Insecurity Experience Scale, a more complex and multidimensional measure of food insecurity, show that about 769 million people in the world faced severe food insecurity in 2017. In the same year, nearly 151 million children under five years of age suffered from stunted growth, while 50 million suffered from wasting (a low weight-for-height ratio). Over 38 million children under five were estimated to be overweight and more than 672 million adults to be suffering from obesity (ibid.).

The widely used definition adopted by the 1996 World Food Summit states that food security 
Box 2.2

The Second International Conference on Nutrition Framework for Action

Recent global policy frameworks and commitments recognize the strong link between nutrition and sustainable food systems. In 2014, the Second International Conference on Nutrition (ICN2) called for countries to adopt a common vision for global action to eradicate hunger and end all forms of malnutrition worldwide (FAO and WHO, 2014a). The ensuing ICN2 Framework for Action (FAO and WHO, 2014b) includes a set of 60 recommendations, nine of which are aimed at promoting sustainable food systems and healthy diets. One of these (Recommendation 10) calls for the "the diversification of crops including underutilized traditional crops, more production of fruits and vegetables, and appropriate production of animal-source products as needed, applying sustainable food production and natural resource management practices."

To further reinforce commitments on nutrition, in April 2016 the United Nations proclaimed the UN Decade of Action on Nutrition (2016-2025). The objective of this initiative is to increase investment in nutrition and to implement policies and programmes that improve food security and nutrition within the framework agreed at ICN2. Led by FAO and the World Health Organization, it brings together a wide group of actors, and centres around six action areas, one of which, "Sustainable, resilient food systems for healthy diets", reiterates the importance of diversification. "exists when all people, at all times, have physical, social and economic access to sufficient, safe and nutritious food which meets their dietary needs and food preferences for an active and healthy life" (FAO, 1996a). Over the decades, food security has increasingly come to be recognized as a multifaceted concept (FAO, 2006a). The 2009 World Summit on Food Security identified availability, access, utilization and stability as the four dimensions of food security and also noted that "the nutritional dimension is integral to the concept of food security" (FAO, 2009b).

In 2014, the High Level Panel of Experts on Food Security and Nutrition defined a sustainable food system as a "food system that ensures food security and nutrition for all in such a way that the economic, social and environmental bases to generate food security and nutrition of future generations are not compromised" (HLPE, 2014b). The same year, the Second International Conference on Nutrition Framework of Action featured a set of recommendations aimed at promoting sustainable food systems and healthy diets that included one specifically focused on BFA (Box 2.2).

BFA is essential to all four dimensions of food security, to nutrition and to the sustainability of food systems.

\subsubsection{Availability}

Although food supplies can be stored and transported to address temporary or local shortages, and efforts can be made to reduce food waste, availability is ultimately dependent on production. As noted in Section 2.4, to feed a global population expected to exceed 9 billion in 2050, it has been estimated that food production will need to rise to 50 percent above 2012 levels (FAO, 2017e). The major challenge will be to ensure that the food supply not only meets the energy needs of the population but also provides it with all the nutrients it requires. Production increases will need to be achieved without degrading the natural resources that underpin future production and the supply of other ecosystem services (ibid.) (see Section 2.4 for further discussion).

As discussed in Section 2.2, obtaining food from a wide range of different environments - terrestrial and aquatic, tropical, temperate and boreal, mountain, lowland, forest, steppe, desert and so on - requires a diverse range of plants, animals, bacteria and fungi, both as direct suppliers of food and as suppliers of the supporting and regulating ecosystem services that make food production possible. Increasing 
output will require (along with advances in many other fields) the implementation of wellplanned breeding programmes in crop, tree, livestock and aquatic species. Genetic-improvement programmes have been major contributors to the increases in crop and livestock yields that have occurred over recent decades (Evenson and Gollin, 2003; Peng and Khushg, 2003; Leakey et al., 2009). It may require the domestication of additional food-producing species and increasing the use of underutilized and neglected species. It will certainly require efforts to ensure that the natural resources upon which food production depends, including all categories of BFA, are conserved and that the ecosystem services they provide are nurtured. For example, it has been estimated that about 30 percent of the increase in global production of food crops since the 1960s has come from pollinator-dependent crops (Potts et al., 2016).

Sustainably increasing food output will depend not only on the presence of an appropriate range of well-adapted, food-producing plants and animals and the associated biodiversity that they depend on, but also on how they are managed. As discussed in Sections 2.2 and 2.4 and in Chapter 5, there are many ways in which diversifying the range of species, varieties or breeds within a given field, area of pastureland, forest or aquaculture unit or across the wider landscape/ seascape - or making more effective use of components of associated biodiversity such as pollinators and soil biota - can contribute to increasing food production.

The main themes noted in the country reports in relation to the availability dimension of food security are the significance of access to a wide range of within-species genetic diversity, including for use in breeding programmes, the significance of associated biodiversity and the ecosystem services it provides in supporting food production and the significance of interactions between domesticated components of BFA (e.g. the contributions of livestock to crop production via the supply of manure and draught power). Countries stress the significance both of international exchange of genetic resources and of the use of native species, varieties and breeds whose adaptive characteristics enable them to produce well in local conditions. Where the contributions of associated biodiversity are concerned, Burkina Faso notes that in addition to their vital role as pollinators of crop plants (particularly oilseed crops), bees and other insects help to increase yields of seeds and fruits in forest systems and are also a direct source of honey and other food products such as pollen. Bangladesh likewise mentions the significance of pollination services, noting that a substantial increase in the yield of pollinated crops such as mustard and rapeseed has been achieved through the deployment of beehives. India stresses the significance of associated biodiversity in the delivery of ecosystem services that directly and indirectly support food production, including (in addition to pollination) nutrient cycling and pest regulation. The United Republic of Tanzania mentions that higher yields are obtained from fisheries in mangrove-fringed coastal waters than from fisheries in coastal waters where mangroves are absent.

\subsubsection{Access}

The significance of the "access" dimension of food security lies in the need not only to ensure that sufficient food is available at global or national levels, but that individuals are able to acquire the food and nutrients they need. This means that they have to be able either to produce foods in sufficient quantity, quality (nutrient content) and diversity or to acquire them through purchases or some other kind of social arrangement. This dimension of food security is therefore dependent not only on biophysical aspects of food production, storage, processing and distribution, but also on the broader security of livelihoods at household and individual levels and on economic, social, political and legal factors at community, national and international levels.

As discussed in Section 2.5, food production at household level (or the supply of products and services that can be sold for cash that is used to purchase food) generally requires the use of genetic 
resources that are well adapted to the local environment, particularly in areas where the environment is harsh and when the household is unable to access inputs (fertilizer, pesticides, veterinary medicines, supplementary livestock feed, etc.) that might ameliorate production conditions. The ecosystem services (pest regulation, nutrient cycling, etc.) provided by the associated biodiversity present in and around local production systems are also vital. Again, these may be particularly important for households that are unable to substitute them with purchased inputs. As also noted in Section 2.5, particular components of BFA may also play roles in social and cultural life that help to build ties that can be crucial in obtaining food in times of need.

Wild foods found in the local area are an important source of food for many households. For example, Poverty and Environment Network surveys conducted in selected forest-dependent communities in Asia, Africa and Latin America between 2004 and 2010 found that over 53.5 percent of households consumed at least one type of forest food (Rowland et al., 2017). In traditional riceproduction systems, farm households can access edible aquatic animals such as snails, crabs, crayfish, frogs and fish from their fields (Balzer et al., 2006; Halwart, 2006, 2008; Pingali and Roger, eds., 1995). See Section 2.6.6 for further discussion of the significance of wild foods in food security and nutrition. Wild resources also provide a range of food and non-food products (timber, fuelwood, medicinal products, etc.) that can be sold to obtain cash that can then be used to buy food.

Access to food can also be affected by the practicalities of transport, storage and processing. Problems are particularly likely to arise in remote areas, in emergency situations or in other circumstances where relevant equipment or facilities (trucks, fridges, stoves, etc.) are difficult to access or use. BFA can contribute in various ways to addressing problems of this kind. For example, certain micro-organisms, referred to as "protective cultures", can be used to increase the shelf-life of food and protect it from spoilage by other micro-organisms and reduce the risk of contamination with mycotoxins (Alexandraki et al., 2013; Beed et al., 2011). In many countries, pack and draught animals continue to play an important role in transporting food, particularly in remote and inaccessible locations (FAO, 2015a).

Access can also be an issue in urban areas. For non-food producers, urban or otherwise, income is the main determinant of access. However, the access of urban populations to food is particularly dependent on food outlets, whether retailers, street-food vendors or restaurants. In certain countries, the access of urban populations to food is highly dependent on the decisions of relatively few food traders and supermarkets (IPES-Food, 2017; Lang, Barling and Caraher, 2009; Vorley, 2003). Open "wet" markets are declining as sources of food in low- and middleincome countries and are being replaced by supermarkets (Gómez and Ricketts, 2013). Many places have become "vacuums" of fresh products, which are increasingly being replaced by cheap, processed foods (Hawkes, Chopra and Friel, 2009). Recent food-consumption data show that people are consuming more and more processed foods at the expense of diverse fruits and vegetables (FAO, 2017e). The spatial distribution of food outlets in cities, especially in lower-income areas, can exacerbate this effect (Mozaffarian et al., 2012). Changes in marketing and retailing are also making it more difficult for small-scale producers to directly access growing urban markets (see also Chapter 3).

\subsubsection{Utilization}

"Utilization" refers to the way in which food is used in order to create a state of nutritional well-being (FAO, 2006a). This involves, inter alia, selecting a nutritionally balanced diet and storing, processing and preparing foods safely. A healthy diet will require a range of different foods and hence a range of different plants and (in many cases) animals. Studies have shown that dietary diversity is a good predictor of diet quality, particularly in the case of children's diets (Kennedy et al., 2007; Moursi et al., 2008; Parlesak, Geelhoed and Robertson, 2014; Rah et al., 2010). 
See Section 2.6.5 for further information on the contributions of BFA to nutrition. ${ }^{24}$

Appropriate utilization requires knowledge of foods and how to process, store and prepare them. As discussed in Chapter 3, traditional knowledge related to many components of BFA, including on how to process and cook traditional food products, is being lost. Access to various nonfood inputs, such as clean water and fuel, is also essential. In some circumstances, again particularly in remote areas and for poorer people, these inputs will depend on provisioning (e.g. supply of fuelwood) and regulating (e.g. water purification) ecosystem services supplied by the biodiversity in and around local production systems. Storage can depend on the use of micro-organisms for fermentation (see Section 5.7 for further details).

The country reports provide a number of examples of how BFA helps provide more balanced diets. Burkina Faso, for example, mentions that various crops with specific nutritional and therapeutic virtues are used as dietary supplements, including red and white sorghum, moringa (powdered leaves of Moringa oleifera), soybean and spirulina (certain species of blue-green algae). It further notes the key role of non-wood forest products in the supply of nutritionally balanced diets and also the significance of honey produced by domesticated bees. Nepal mentions that various minor fish and other aquatic species that were once regarded as a "nuisance" are increasingly being recognized for the diversity of their nutrient contents and hence their potential dietary significance. India notes the significance of livestock as a source of products that can help to overcome deficiencies in protein and various vitamins and minerals. A number of countries mention the importance of crop varieties that contain high concentrations of particular nutrients. Some specifically note

\footnotetext{
${ }^{24} \mathrm{FAO}$ and Bioversity International have produced guidelines on assessing biodiverse foods in dietary intake surveys (FAO and Bioversity International, 2017). FAO and USAID's Food and Nutrition Technical Assistance III Project (FANTA), managed by FHI 360 (https://www.fhi360.org), have published a guide to measuring minimum dietary diversity for women (FAO and FHI 360, 2016).
}

the significance of breeding programmes that improve the nutritional quality of staple foods. For example, Zambia mentions vitamin A-rich varieties of maize and sweet potato, and iron- and zinc-rich varieties of beans.

\subsubsection{Stability}

The significance of the "stability" dimension of food security relates to the fact that food security depends on adequate food being available to all individuals at all times, for example with no seasonal shortages or shortages in years when harvests are poor (FAO, 2006a). Diversity is significant to stability, whether at household level or at larger scales, in that the presence of a range of different food-producing species, varieties and breeds that have different life cycles and different adaptive characteristics helps to maintain food supplies through the seasons of the year and through inter-year variations in rainfall, temperature, disease challenge, etc. In the case of food or nonfood products raised or harvested for sale (in this context to obtain cash that can be used for food purchases), diversity can also help to maintain stability of income in the face of market-related risks.

Associated biodiversity contributes to stability by helping to reduce the impacts of disruptive events (floods, droughts, disease and pest outbreaks, etc.) that may affect food production, distribution or storage (see Sections 2.2 and 2.3). Use of micro-organisms in food preservation can help to overcome seasonal variations in food supply. Wild foods can also be important to stability in that access to them potentially serves as a means of maintaining food intakes in the event of shocks that affect food output from domesticated species or otherwise affect access to food (e.g. because of reduced cash income) (Pattanayak and Sills, 2001; Thondhlana and Muchapondwa, 2014).

The country reports provide numerous examples of how BFA contributes to the stability dimension of food security. Several note the significance of diversified production systems in this regard. For example, Kiribati mentions that integrated farming of milkfish, sandfish, sea cucumber and seaweed has proved to be an effective means of securing 
production and income in fluctuating weather conditions, as one or the other of the components of the system is always producing food. India again notes the significance of livestock, which it mentions can act as a buffer against crop failure. Both Zambia and Zimbabwe report that smallholders have responded to persistent drought by adopting more resilient crops such as sorghum, millet, sweet potato and cassava and by diversifying their production systems. Where livestock are concerned, the same two countries mention increasing use of small ruminants as a response to the effects of drought and disease on cattle herds. Further reported examples of the contributions of BFA to the stability of food production are provided in the discussion of resilience in Section 2.3.

\subsubsection{Nutrition and food systems}

Taking a cue from the above-mentioned definition of sustainable food systems, FAO regards food systems as consisting of four functions, roughly corresponding to the four stages of a food supply chain: food production; food handling, storage and processing; food trade and marketing; and consumer demand, food preparation and preferences (FAO, 2017g). The interface between the food system and the consumer (the availability, affordability, convenience and desirability of foods) is referred to as the "food environment" (ibid.).

More generally, recent years have seen growing interest in the links between biodiversity and nutrition (FAO, 2013d). In 2006, the CBD, FAO and Bioversity International jointly established the Cross-cutting Initiative on Biodiversity for Food and Nutrition (CBD, 2006). Further developments have included the formulation of nutrition indicators for biodiversity (FAO, 2008b, 2011d). In 2010, FAO, in collaboration with the International Network of Food Data Systems (INFOODS), published the first version of the FAO/INFOODS Food Composition Database for Biodiversity, with updates published in 2011, 2012, 2016 and 2017 (FAO, 2017h). The current version holds 10156 entries (ibid.). In 2015, the Commission on Genetic Resources for Food and Agriculture adopted Voluntary Guidelines for Mainstreaming Biodiversity into Policies, Programmes and National and Regional Plans of Action on Nutrition (FAO, 2016f) (see Box 2.3).

The background to these developments has been a concern about the fact that, although the proportion of the world population that is

Box 2.3

Voluntary Guidelines for Mainstreaming Biodiversity into Policies, Programmes and National and Regional Plans of Action on Nutrition

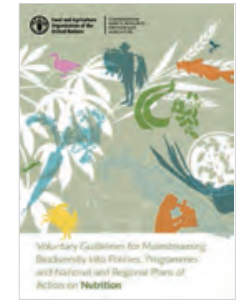

The Voluntary Guidelines fo Mainstreaming Biodiversity into Policies, Programmes and National and Regional Plans of Action on Nutrition (FAO, 2016d) were endorsed by the Commission on Genetic Resources for Food and Agriculture at its Fifteenth Regular Session, in

2015. The objective of the guidelines is "to support countries in the integration of biodiversity into all relevant policies, programmes and national and regional plans of action addressing malnutrition in all its forms, and specifically to promote knowledge, conservation, development and use of varieties, cultivars and breeds of plants and animals used as food, as well as wild, neglected and underutilized species contributing to health and nutrition."

The guidelines provide examples of how mainstreaming could be implemented, in accordance with countries' needs and capabilities. They are divided into three main elements: research; implementation; and awareness. The Commission stressed that implementation of the guidelines should be based on scientific evidence and consistent with relevant international obligations.

Note: The voluntary guidelines can be viewed at http://www.fao.org/3/ai5248e.pdf 
undernourished has declined over recent decades, reductions in food-energy deficits have often not been accompanied by equivalent improvements in other aspects of dietary quality, particularly the intake of micronutrients (FAO, 2015c). Problems of this kind are sometimes exacerbated by a decline in dietary diversity and the replacement of micronutrient-rich local or traditional foods with more mainstream globally traded alternatives (Johns and Eyzaguirre, 2006). The significance of non-mainstream crops - and wild foods - in the diets of (in particular) poor rural people has tended to be overlooked (Heywood, 2013). To some degree, this has been due to the strong attention given in the past decade to agricultural research on staple grains (mainly wheat, maize and rice), to the detriment of other cereals and of pulse, root and oil crops (Khoury and Jarvis, 2014).

Driven in part by the actions of the global food industry (Moodie et al., 2013), many parts of the world are in transition towards a so-called "Western" diet, dominated by high intake of refined carbohydrates, added sugars, fats and (terrestrial) animal-source foods (Popkin, Adair and $\mathrm{Ng}, 2012$ ). This trend has been implicated in the rise of obesity - 39 percent of the world's adult population was overweight as of 2016 (WHO, 2018) cardiovascular disease, diabetes, autoimmune diseases and some cancers (Murray et al., 2013).

It is important to note that changes in diet have been caused not only by changes in supply, but also by changes in demand: urbanization, women's entry into the labour market, higher incomes in some countries and longer hours worked away from home have led to a shift in food demand towards more-convenient, processed foods (Kennedy, Nantel and Shetty, 2004). The challenge is therefore to make diverse, fresh foods more available, affordable and appealing. For this to occur, action needs to be taken not only at production level, for example by increasing agricultural research funds for diverse foods (Khoury and Jarvis, 2014), but also throughout the food system. Relevant measures could include increasing levels of public- and private-sector investment in transport, storage and market development for diverse non-staple foods and taking steps to reduce the transaction costs of smallholder integration into these markets (Pingali, 2015).

Significant intraspecific differences in nutritional content have been documented in most plant-source foods (Burlingame, Charrondiere and Mouille, 2009; FAO, 2013f). These differences are sufficiently large to mean that eating one variety rather than another can make a significant difference in terms of the nutritional adequacy of the diet. They also provide opportunities to breed cultivars that combine higher nutrient content with other desirable characteristics, such as higher productivity or disease resistance. Within-species differences in the nutritional quality of animal products have been relatively little studied, and there are difficulties involved in distinguishing differences caused by genetics from those caused by management factors such as feeding. However, evidence suggests that there are some nutritionally significant differences between products obtained from different breeds (FAO, 2015a).

Where wild and underutilized species are concerned, detailed studies of nutritional significance are not common (Powell et al., 2015). However, evidence from various production systems in various parts of the world indicates that such species make important contributions to local diets. Asian rice fields, for example, harbour a wide range of animals and plants, many of which are important sources of food for local people, often providing essential micronutrients that are not found (or found in limited quantities) in rice, as well as additional sources of protein (Halwart, 2006; Halwart et al., eds., 2016). Traditional rice diets are often deficient in the amino acid lysine, but this can be compensated for by eating fish and other aquatic animals foraged from rice fields. A study of the diets of mothers and children in a small-scale farming system in the East Usambara Mountains of the United Republic of Tanzania found that wild foods, mostly obtained from agricultural land, provided 31 percent of the vitamin A, 19 percent of the iron and 16 percent of the calcium content of the diet, with the contribution being greatest during the wet (more food-scarce) season (Powell et al., 2013). An assessment covering 21 African 
countries (Ickowitz et al., 2014) found a positive relationship between children's dietary diversity and tree cover, an indication of the important contributions that non-wood forest products make to food and nutrition security in the region. A study in a community in rural northeastern
Madagascar showed that removing access to wild meat would induce a 29 percent increase in the number of children suffering from anaemia and a tripling of anaemia cases among children in the poorest households (Golden et al., 2011). Details of a project that has (inter alia) supported the

Box 2.4

The Biodiversity for Food and Nutrition Project

Brazil, Kenya, Sri Lanka and Turkey are home to a vast array of traditional and/or neglected native edible species, both wild and cultivated, that are of enormous nutritional value but are also (like similar resources in most countries) threatened by environmental pressures or lack of use.

The Biodiversity for Food and Nutrition Project ${ }^{1}$ has placed the conservation of this diversity on a much stronger footing by building national capacity to generate nutrition data for 189 underutilized species (primarily plants) across the four countries and to collect information on the sociocultural significance and market value of these species. This evidence base is gradually being made available in national databases and is expanding global knowledge of food biodiversity via the FAO/INFOODS database. ${ }^{2}$

Countries have used the data to strategically target national policies promoting local and indigenous biodiversity for food and nutrition. Actions include promoting diverse, healthy native foods in dietary guidelines (Brazil) (see Box 2.5 and Box 8.21), supporting smallholder farmers in the production of biodiverse foods and linking them to schoolmeals programmes (Kenya), linking with the private sector to create markets for biodiverse foods (Turkey) and prioritizing food biodiversity in relevant national strategies/action plans and in agricultural and nutrition policies (Sri Lanka).

Social and cultural attitudes to these species, which are often perceived as "food for the poor", particularly by younger generations, are also changing thanks to increased awareness of their value. Collaboration with celebrity chefs, food fairs and increased media attention have raised the profile of neglected and underutilized biodiversity and are creating interest among consumers.

Much of the project's experience in promoting the conservation and sustainable use of biodiversity for food and nutrition and mainstreaming it into different sectors is captured

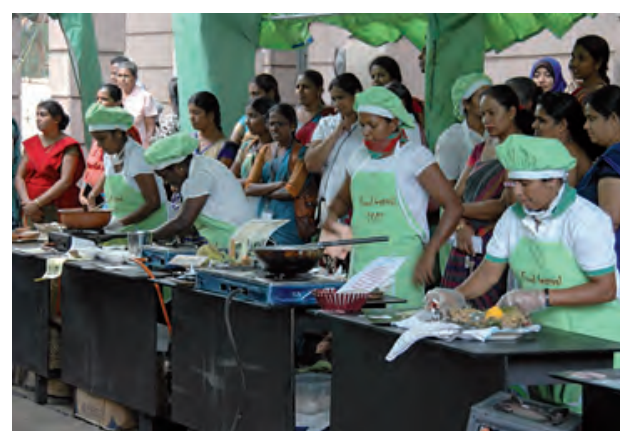

Food festivals and fairs organized in the project countries provide opportunities to raise awareness and promote orphan crops and species. In this gastronomic event in Sri Lanka, women take part in a cooking competition using traditional species. C Bioversity International/D. Hunter.

in an online course ${ }^{3}$ and in a mainstreaming toolkit aimed at policy-makers, academic coordinators, university students, extension workers and others studying or working in nutrition, agriculture, public health or socio-economic development.

For further information, visit the Biodiversity for Food and Nutrition website. ${ }^{4}$

\footnotetext{
The project is funded by the Global Environment Facility and led by Brazil, Kenya, Sri Lanka and Turkey. It is coordinated by Bioversity International with implementation support from FAO and the United Nations Environment Programme. Additional resources were received from the Australian Centre for International Agricultural Research, the Vanguard Charitable Trust and the MacArthur Foundation for the school feeding programme in Kenya and from FAO Kenya for the analysis of the nutritional content of local varieties and species and the development of an updated food composition table that will include local biodiversity. The project contributes to the implementation of the CBD's Cross-Cutting Initiative on Biodiversity for Food and Nutrition.

2 http://www.fao.org/infoods/infoods/tables-and-databases/faoinfoodsdatabases/en

3 http://www.b4fn.org/e-learning

${ }^{4}$ http://www.b4fn.org/

(Cont.)
} 


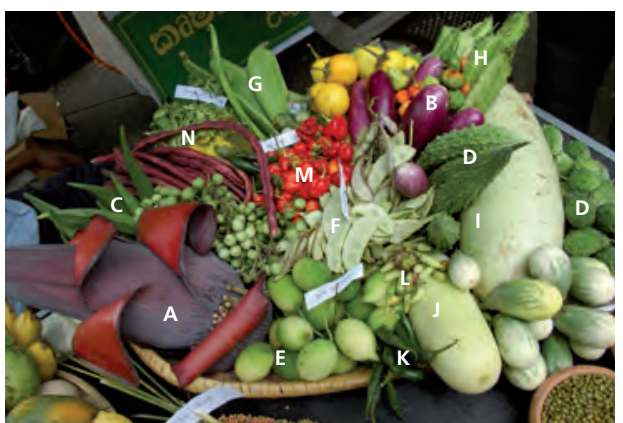

Traditional vegetables

A. Banana flower (Musa spp.)

B. Eggplant (Solanum melongena) - multiple varieties (ela-batu, wam-batu, tib-batu)

C. Yardlong bean (Vigna unguiculata var. sesquipedalis) and okra (Hibiscus esculentus)

D. Bitter gourd and wild bitter gourd (Momordica charantia)

E. Spiny gourd (Mormordica dioica)

F. Hyacinth bean (Lablab purpureus)

G. Sword bean (Canavalia gladiata)

H. Winged bean (Psophocarpus tetragonolobus)

I. Bottle gourd (Lagenaria siceraria)

J. Cooking melon (Cucumis melo)

K. Chilli pepper (Capsicum annuum)

L. Tabasco pepper (Capsicum frutescens)

M.Bonnet pepper (Capsicum chinense)

N. Asamodagam (Trachyspermum roxburghianum)

(c) Bioversity International/D. Hunter.

Source: Provided by Teresa Borelli, Danny Hunter, Daniela Moura de Oliveira Beltrame, Victor W. Wasike, Gamini Samarasinghe and Hasan Gezginç.

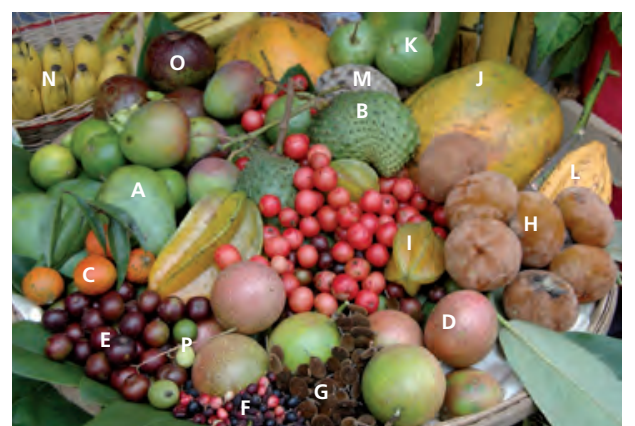

Traditional fruits

A. Mango (Mangifera indica)

B. Soursop (Annona muricata)

C. Mandarin (Citrus reticulata)

D. Passion fruit (Passiflora sp.)

E. Governor's plum (Flacourtia indica)

F. Dan (Syzygium caryophyllatum)

G. Velvet tamarind (Dialium cochinchinense)

H. Velvet apple (Diospyros discolor)

I. Star fruit (Averrhoa carambola)

J. Papaya (Carica papaya)

K. Guava (Psidium guajava)

L. Cacao (Theobroma cacao)

M.Custard apple (Annona squamosa)

N. Banana varieties (Musa spp.)

0. Avocado (Persea americana)

P. Star gooseberry (Phyllanthus acidus)

C Bioversity International/D. Hunter. generation of nutritional data on traditional and/ or neglected species in Brazil, Kenya, Sri Lanka and Turkey are provided in Box 2.4. The contributions that wild foods make to food security and nutrition are explored in greater detail below.

\subsubsection{Contribution of wild foods}

Wild foods ${ }^{25}$ contribute to food security both via direct consumption (on a regular basis or as an emergency measure in times of scarcity) and by being sold to provide income that is reinvested in food purchases (see Section 2.5 for more informa-

\footnotetext{
${ }_{25}$ See Section 1.5 for a definition of this term.
}

tion on the livelihood roles of wild foods). Many wild foods are rich in micronutrients (Bharucha and Pretty, 2010; Grivetti and Ogle, 2000; Grubben and Denton, 2004; Yang and Keding, 2009; van Huis et al., 2013), some containing more than their cultivated counterparts (Kobori and Rodriguez Amaya, 2008; Smith et al., 1996). Eating them can alleviate micronutrient and/or protein deficiencies and thus make diets more nutritious and balanced (Broegaard et al., 2017; Kuyper, Vitta and Dewey, 2013). In addition to regular assessments provided in FAO's reports on The State of the World Fisheries and Aquaculture, several recent publication have reviewed the contributions of wild 
Box 2.5

Food-based dietary guidelines as a tool to promote biodiversity

Food-based dietary guidelines (FBDGs) are a set of evidence-based, easily understood, behaviourally focused messages that constitute a government's recommendation to its population on healthy (and sometimes explicitly sustainable) eating (Gonzalez Fischer and Garnett, 2016).

The Voluntary Guidelines for Mainstreaming Biodiversity into Policies, Programmes and National and Regional Plans of Action on Nutrition (FAO, 2016d - see Box 2.3) recommend the incorporation of biodiversity considerations into FBDGs. There are many potential links between biodiversity and human nutrition, including those related to increasing dietary diversity and quality, improving income, enhancing resilience and promoting the maintenance of genetic resources for future adaptation (Berti and Jones, 2013; Frison, Cherfas and Hodgkin, 2011; Heywood, 2013; Toledo and Burlingame, 2006). However, the practicalities of integrating biodiversity-focused advice into FBDGs can be challenging.

Recommending the consumption of foods produced in ways that conserve and make sustainable use of biodiversity is one approach that can be used to promote biodiversity in FBDGs. For example, Sweden's FBDG recommends choosing eco-friendly products, such as those from sustainable fishing or organic agriculture.' Likewise, Brazil's Dietary Guidelines for the Brazilian Population (Ministry of Health of Brazil, 2016) explicitly promote biodiversity as part of "socially and environmentally sustainable food systems" that provide healthy diets. However, as FBDGs can have a significant influence on public procurement and food-provision programmes, the inclusion of such recommendations often gives rise to opposition from special interest groups.

Most national FBDGs recommend eating a variety of foods (Dwyer, 2012). However, this often refers to eating foods from different food groups, for instance combining rice and beans, or varying the foods within a group, for instance eating apples one day and pears the next. Short and simple messages of this kind comply with the principles of good communication. However they are too general to address the utilization

https://www.livsmedelsverket.se/globalassets/english/food-habits-healthenvironment/dietary-guidelines/kostrad-eng.pdf?id=8140

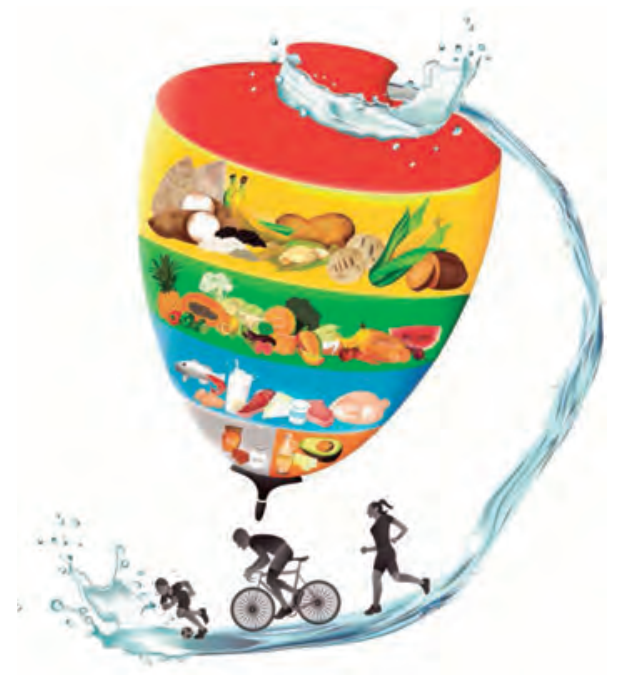

Venezuelan food spinning top.

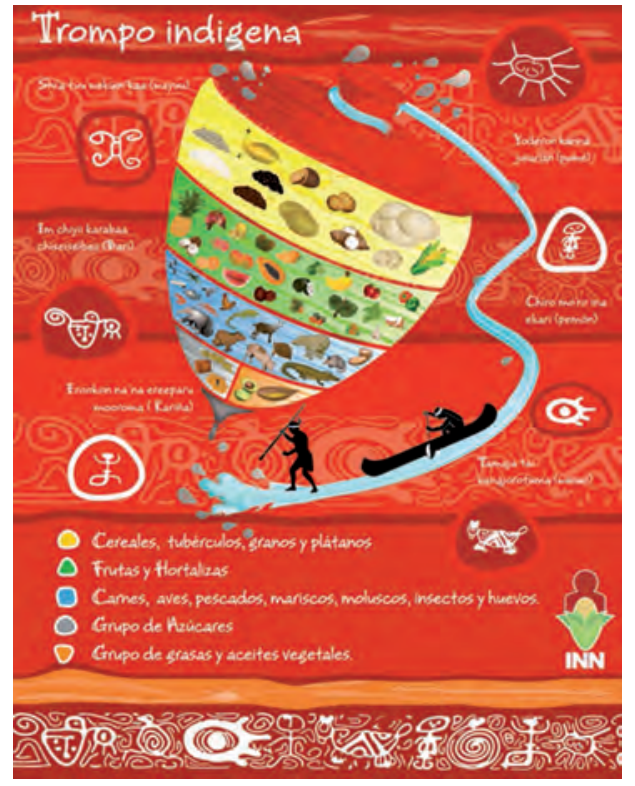

Venezuelan food spinning top for indigenous people.

(Cont.) 


\section{PART A}

Box 2.5 (Cont.)

Food-based dietary guidelines as a tool to promote biodiversity

of "food biodiversity" in the sense of a range of different varieties and breeds of plants and animals, or wild, neglected and underutilized species. Components of biodiversity at these levels are often unique to specific local areas and may have particular significance in the food-production and culinary traditions of specific sections of the population.

Some countries have sought to bridge the gap between national policy and local realities by adapting their national FBDGs for use in different subnational contexts. For example:

- Canada has produced a version of its national food guide adapted for use by First Nations, Inuit and Métis peoples, ${ }^{2}$ which provides advice, inter alia, on how foods such as wild plants and seaweed, bannocks (a type of bread), fish with bones, shellfish and nuts can help provide the nutrients needed by people who do not consume milk products.

- The Bolivarian Republic of Venezuela has adapted its national "food spinning top" for use by indigenous people (see images on preceding page). ${ }^{3}$

- Japan has adapted its national spinning top food guide for each of its prefectures. ${ }^{4}$
Efforts to localize guidance can face a number of challenges and pitfalls. For example, attention needs to be paid to the health of the ecosystems that supply the foods targeted, as success in promoting an individual food may lead to overexploitation to meet demand. There is also a risk that initiatives may be hijacked for commercial purposes. Nonetheless, locally adapted FBDGs have the potential to be an important means of promoting consumption of diverse and underutilized locally available foods. Integrating these efforts with existing initiatives aimed at promoting biodiversity and linking them to the development of cooking skills and gastronomy helps to make them more effective and enjoyable, and also to minimize the above-noted risks associated with promoting single foods.

Source: Provided by Maryam Rahmanian and Ana Islas Ramos.

2 https://www.canada.ca/en/health-canada/services/food-nutrition/canada-foodguide/eating-well-with-canada-food-guide-first-nations-inuit-metis.html

3 http://www.fao.org/nutrition/education/food-dietary-guidelines/regions/ countries/venezuela/en/

4 For example: http://www.pref.hokkaido.lg.jp/hf/kth/kak/tkh/framepage/ dbaransugaido.htm (in Japanese) foods to food security and nutrition (Bioversity International, 2017; WHO and CBD, 2015; HLPE, 2017a, 2014; Vinceti et al., 2013). ${ }^{26}$ All raise concerns about the sustainability of use of wild foods (see Chapter 3 for further discussion).

It is difficult to quantify the global contributions of wild foods to diets. For example, data on wild-food consumption are generally excluded from national statistics (Bharucha and Pretty, 2010; MEA, 2005a). ${ }^{27}$ Other constraints include a lack of information on the nutritional composition of

\footnotetext{
26 In addition, the draft of a first evaluation of the scale and drivers of subsistence and commercial harvesting of wild terrestrial vertebrates for food in tropical and subtropical regions was submitted to CBD SBSTTA 21 (Coad et al., 2017).

27 Sorrenti (2017) provides a systematic review of non-wood forest products in the existing international classification systems used for the collection and dissemination of data on production, trade and economic activities, with the aim ultimately of improving data collection on non-wood forest products.
}

wild foods (Bharucha and Pretty, 2010; Colfer, Sheil and Kishi, 2006; Grivetti and Ogle, 2000; Powell et al., 2015), the variability of nutritional composition within species (Stadlmayr et al., 2013; Toledo and Burlingame, 2006) and inconsistent or incorrect nomenclature in published results (Nesbitt et al., 2010). For further information on the state of knowledge of wild foods, see Section 4.4.

While definitive global data are lacking, estimates are available for specific sectors, regions or types of wild food. Capture fisheries provided a total of 90.9 million tonnes of fish $^{28}$ in 2016 (FAO, 2018a). In 2015, aquatic products supplied 17 percent of the global population's intake of animal protein (nearly half of fish for human consumption

\footnotetext{
28 "Fish" here refers to fish, aquatic crustaceans, aquatic molluscs and other aquatic animals other than mammals and reptiles (it also excludes seaweeds and other aquatic plants).
} 
FIGURE 2.3

\section{Types of wild-food use reported by countries}

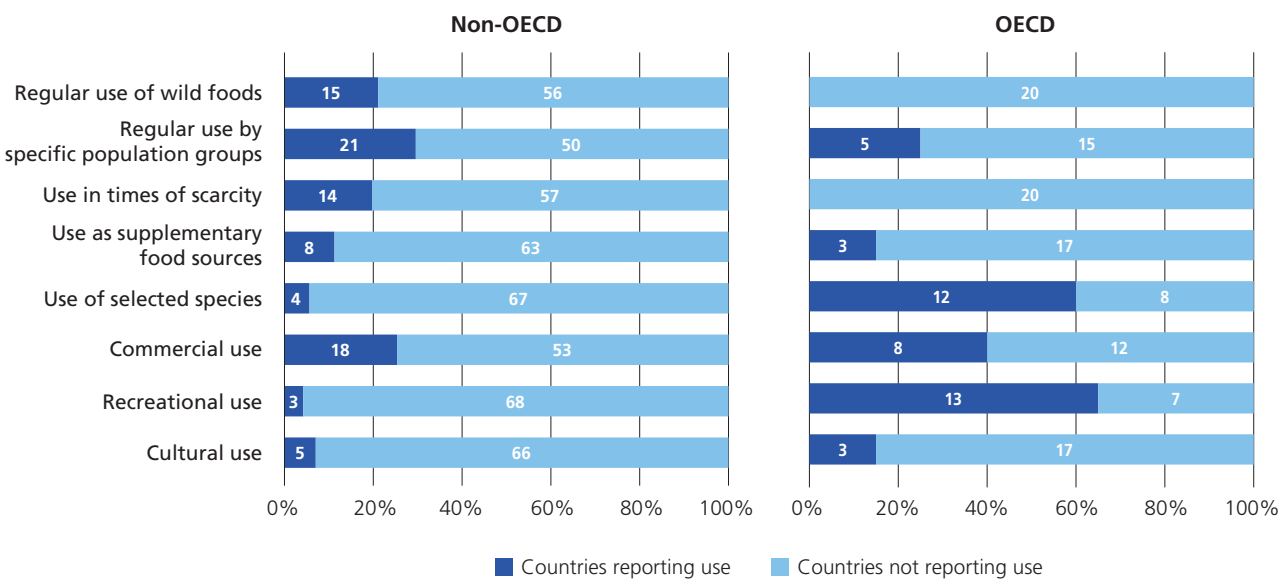

Notes: Values refer to the number of countries. Some countries reported more than one type of use. OECD = Organisation for Economic Co-operation and Development.

Source: Country reports prepared for The State of the World's Biodiversity for Food and Agriculture.

was supplied from capture fisheries) (ibid.). ${ }^{29}$ Wild forest foods contribute to the diets of many millions of people, particularly in terms of micronutrients (Rowland et al., 2017; Sunderland, 2011). Food obtained from forests has been estimated to contribute about 0.6 percent of the global supply of dietary energy (FAO, 2014d). ${ }^{30}$ Recent analysis of data from communities living in or close to forests in 24 countries in Latin America, Africa and Asia revealed that 77 percent of such households

29 These statistics on fish consumption are based on the Food Balance Sheets calculated by the Statistics and Information Branch of the FAO Fisheries and Aquaculture Department as of March 2016. Consumption data for 2013 should be considered preliminary. Food Balance Sheet data refer to "average food available for consumption", which, for a number of reasons (e.g. waste at the household level), is not equal to average food intake or average food consumption. Production from subsistence fisheries, as well as cross-border trade between some developing countries, may be incompletely recorded and might therefore lead to an underestimation of consumption.

30 These figures are likely to be a major underestimate of the total consumption of food from forests because information about production (and consumption) of these products is far from complete. collected wild food from forest and non-forest environments (Hickey et al., 2016). It is estimated that insects are regularly eaten by at least 2 billion people worldwide (van Huis et al., 2013). According to Coad et al. (2017), estimates of per capita wildmeat consumption from studies conducted in tropical areas where wild meat is eaten range from 0.05 to $0.28 \mathrm{~kg} /$ person/day.

\section{Country-report analysis}

Countries were invited to report the proportion of their respective populations that consumes wild food on a regular basis, as well as to supply other information such as the proportion of the diet that is collected from the wild in normal times and in times of scarcity and the degree to which wild foods are used for various purposes. ${ }^{31}$ The numbers of countries reporting various types of wild-food use are shown in Figure 2.3.

\footnotetext{
31 Countries were also invited to report on gender differences in the patterns of use, management and consumption of wild foods. The information provided is discussed in Section 2.5 and Section 3.8
} 


\section{PART A}

Each category is further discussed in the following subsections.

\section{Regular use of wild foods}

Sixteen percent of all respondents (15 countries, all non-members of the Organisation for Economic Co-operation and Development [OECD]) report that regular use of wild foods is widespread nationally. Nine countries provide quantitative data indicating that at least a third of their respective populations use wild foods. ${ }^{32}$ In some cases, the figures are substantially higher: Eswatini and Gabon both report that approximately twothirds of their population consume wild foods regularly. Ethiopia reports that the proportion of the population consuming wild plants varies from 30 or 40 percent in some regions to as much as 56 percent or 67 percent in others. It also mentions that over 50 percent of the population in its Gambella region consumes wild meats. Burkina Faso reports that non-wood forest products are eaten by 43 percent of its households.

Several Pacific countries report high levels of dependence on seafood. For instance, Palau reports that an estimated 80 percent of its population eats wild foods, mainly aquatic species. Niue reports that 60 percent of households hunt coconut crabs and 62 percent engage in fishing, with an average fresh-fish consumption estimated at $31.1 \mathrm{~kg}$ per person per year. ${ }^{33}$ Kiribati reports that in its Line and Phoenix Islands the proportion of wild food in the diet can at times reach 100 percent.

\section{Regular use by specific population groups}

Twenty-nine percent of respondents (25 percent of OECD and 30 percent of non-OECD respondents) indicate regular use of wild foods by specific segments of the population, such as indigenous peoples, nomadic groups, remote rural populations or forest or highland communities.

32 Burkina Faso, Cameroon, Eswatini, Ethiopia, Gabon, Kiribati, Niue, Palau and Zambia.

33 The country report indicates that the figures are from Niue's Agricultural Census of 2009 and its Food Security Assessment of 2011
For example, the Gambia, Nepal, Rwanda and Sri Lanka report widespread use of wild foods among communities living near forests. Nepal mentions that wild foods are especially important for some tribal groups (namely the Chepang, Raji, Bankariya and Raute), with wild foods constituting approximately 25 percent of their diets. ${ }^{34}$ Angola mentions the importance of wild foods to Khoisan nomads, who collect approximately 30 percent of their food from the wild under normal conditions.

Some OECD countries note that although wild-food consumption is generally low it makes a substantial contribution to the diets of some population groups. For instance, Finland reports that the indigenous Sámi population continues to depend on wild fish and meat for a significant portion of its diet. The United States of America mentions that wild-food use is highest in Alaska, where 86 percent of rural households consume wild meat. ${ }^{35}$

\section{Use in times of scarcity}

Fifteen percent of respondents (14 countries, ${ }^{36}$ all non-OECD) report that wild-food consumption increases during times of scarcity, such as "the hungry gap" shortly before harvest when food stores are depleted or periods following natural disasters, crop failures or conflicts. For instance, Kiribati mentions that in times of emergency or when there are shortages of imported food (usually rice) consumption of wild staple foods, such as giant swamp taro and breadfruit, increases.

\section{Use of wild foods as supplementary food sources}

This category of use refers to the addition of wild foods to a predominately non-wild food diet to add diversity and/or increase the quantity of minerals, vitamins or other nutrients consumed. Twelve percent of respondents (15 percent of

\footnotetext{
34 The country report cites Thapa (2013).

35 The country report cites Titus, Haynes and Paragi (2009).

36 Burkina Faso, Chad, China, El Salvador, Eswatini, Ethiopia, Kiribati, Nauru, Nepal, Panama, Sudan, United Republic of Tanzania, Zambia and Zimbabwe
} 
OECD and 11 percent of non-OECD respondents) report this kind of use, with reported frequency ranging from occasional to daily. A few countries provide specific nutritional information for key wild foods used to supplement the diet. For example, China notes that wild fish are important sources of unsaturated fatty acids, protein, calcium, phosphorus and vitamins A, D, B1 and B2 in highly bioavailable form. It also mentions that wild insects are high in protein, unsaturated fatty acids and a range of other nutrients including calcium, iron, magnesium, phosphorus, zinc and selenium, and that amphibians and reptiles serve as supplementary sources of protein. The Gambia mentions that some wild food species that serve as sources of food supplements (e.g. the African locust bean or néré tree [Parkia biglobosa]) have become increasingly rare and that their contributions to livelihoods have declined.

\section{Use of selected species}

Eighteen percent of respondents (60 percent of OECD and 6 percent of non-OECD respondents) indicate selective use of wild food species (i.e. use only of a small number of particularly soughtafter wild food species). In many European countries and in the United States of America, consumption of various mushrooms, berries and game species falls into this category. Elsewhere in the world, Fiji reports that the edible fern ota (Diplazium esculentum and D. proliferum) is a popular delicacy among the local population and is also exported to meet demand from Fijians living overseas. Jamaica reports that among Maroon indigenous groups, root drinks and tonics made from selected wild plants are consumed for their medicinal properties.

\section{Commercial use}

Twenty-nine percent of respondents (40 percent of OECD and 25 percent of non-OECD respondents) mention commercial use of wild foods. Specific types of products mentioned include fish, wild meat, berries and other fruits, vegetables, mushrooms and invertebrates. For example, Burkina Faso notes the importance of non-wood forest products as a source of income and employment for rural households. Gabon mentions a rapidly growing market for wild meat, with consumption estimated to be between 20000 and 30000 tonnes annually, up from an estimated 12000 tonnes in 2008. A number of OECD countries mention substantial commercial harvesting of wild foods (i.e. in addition to the very frequently mentioned commercial capture fishing industry). For example, Finland notes that commercial harvesting of its most popular wild mushroom species (Lactarius spp., Boletus spp. and Chanterelle spp.) totalled approximately $299200 \mathrm{~kg}$ in 2013. Belarus mentions that exports of snails brought in more than USD 3.8 million over the five years preceding the preparation of the country report (submitted in 2016).

\section{Recreational use}

Eighteen percent of respondents (65 percent of OECD and 4 percent of non-OECD respondents) mention recreational harvesting of wild foods. Hunting, angling, mushroom gathering and berry picking are among the commonly reported activities. For example, the United States of America reports that 6 percent of its population over the age of 16 participated in hunting as of 2011. ${ }^{37}$ Angling is widely mentioned as a popular pastime in Europe and North America. Germany, for example, reports that it has 1.6 million anglers.

\section{Cultural use}

Even where wild foods are not vital for food security, they may still be valued for cultural reasons and play central roles in festivities and celebrations. Use of this kind is reported by 9 percent of all respondents ( 15 percent of OECD respondents and 7 percent of non-OECD respondents). Grenada, for example, mentions that wild meat is regarded as a delicacy and is consumed at fetes and festivals. The United States of America mentions the evergreen huckleberry (Vaccinium ovatum) and the American matsutake mushroom (Tricholoma magnivelare) as wild food species

\footnotetext{
37 The country report cites USFWS (2011).
} 
used by Native Americans for a variety of culinary and cultural purposes. It also notes the key significance of the salmon in the diets and culture of some Native American peoples.

\subsubsection{Needs and priorities}

Priorities reported by countries in terms of supporting the contribution of BFA to food security and nutrition included the following:

- supporting ex situ and in situ conservation and sustainable use of relevant components of BFA, including by promoting biodiverse production systems and sustainable management practices and by promoting consumption of biodiverse products so as to increase market demand for them;

- supporting breeding activities targeting the development of improved varieties and breeds, including ones providing products that have improved nutrient content, with focus on adaptation to environmental shocks and stressors and in particular those associated with climate change; and

- raising awareness of the importance of BFA, with a specific focus on the significance of local and traditional foods in food security and the provision of nutritionally balanced, healthy diets.

A number of country reports highlight the need for greater recognition of the contribution that wild foods make to global food security and nutrition. However, it is clear that there are considerable knowledge gaps with regard to the extent of this contribution in quantitative terms - several countries note the need to improve data collection on wild-food use, for example by including wild foods in national censuses and surveys or in ethnobiological or other scientific studies. Several countries note that a lack of monitoring systems for wild food species constrains the development of conservation and management programmes and makes it difficult to determine the effectiveness of such programmes. Limitations in terms of capacity development and stakeholder involvement are also highlighted. Some countries identify a need to quantify and clarify the effects of wild food use on human health and well-being, including in some cases not only nutritional impacts but also effects on cultural life and the possible stress-reduction effects of collecting wild foods. 


\section{Part B}

\section{DRIVERS, STATUS AND TRENDS}





\section{Chapter 3 \\ Drivers of change of biodiversity for food and agriculture}

Key messages

- Analysis of country reports and recent literature provides a rich and complex picture of the drivers that directly or indirectly influence biodiversity for food and agriculture (BFA) and the ecosystem services it provides.

- BFA is affected by a range of drivers of change: major global trends such as changes in climate, international markets and demography give rise to more immediate drivers such as land-use change, pollution and overuse of external inputs, overharvesting, and proliferation of invasive species. Interactions between drivers often exacerbate their effects on BFA.

- Demographic changes, urbanization, markets, trade and consumer preferences are reported to have strong influence on food systems, often with negative consequences for BFA and the ecosystem services it provides. However, such drivers are also reported to provide opportunities to make food systems more sustainable.

- Many of the drivers that have negative impacts on BFA, including overexploitation, overharvesting, pollution, overuse of external inputs, and changes in land and water management, are at least partially caused by inappropriate agricultural practices.
- The driver mentioned by the highest number of countries as having negative effects on regulating and supporting ecosystem services is changes in land and water use and management. Loss and degradation of forest and aquatic ecosystems and, in many production systems, transition to intensive production of a reduced number of species, breeds and varieties, remain major drivers of loss of BFA and ecosystem services.

- Countries report that the maintenance of traditional knowledge related to BFA is negatively affected by the loss of traditional lifestyles as a result of population growth, urbanization and the industrialization of agriculture and food processing, and by overexploitation and overharvesting.

- Policies and advances in science and technology are largely seen by countries as positive drivers that offer ways of reducing the negative effects of other drivers on BFA. They provide critical entry points for interventions supporting the sustainable use and conservation of BFA. However, policies intended to promote the sustainable management of BFA are often weakly implemented.

\subsection{Introduction}

This chapter discusses major drivers of change in the state of biodiversity for food and agriculture (BFA), with a particular focus on associated biodiversity and the ecosystem services it provides and on wild foods. It draws principally on the information provided in the country reports. ${ }^{1}$

\footnotetext{
Throughout this chapter, unless noted otherwise, the term "country reports" refers to the country reports submitted as contributions to The State of the World's Biodiversity for Food and Agriculture. See "About this publication" for additional information.
} 
Other global assessments have reviewed drivers of change affecting biodiversity and ecosystem services in general (e.g. IPBES, forthcoming, a,b, 2016a; MEA, 2005b), specific drivers such as climate change (e.g. FAO, 2015b; IPCC, 2014), drivers affecting various production systems and ecosystems of importance to food and agriculture (e.g. FAO's regular publication series The State of Food and Agriculture, The State of the World's Forests and The State of World Fisheries and Aquaculture, and other reports such as Status of the World's Soil Resources published by FAO and the Intergovernmental Technical Panel on Soils [FAO and ITPS, 2015] and The First Global Integrated Marine Assessment [United Nations, 2017b]) and drivers affecting genetic resources in the various sectors of food and agriculture (e.g. FAO, forthcoming, 1997, 2007a, 2010a, 2014a, 2015a).

To briefly summarize the conclusions of the sectoral assessments of genetic resources: in the case of plant genetic resources for food and agriculture, land clearing, population pressure, overgrazing, environmental degradation and changing agricultural practices are identified as major causes of genetic erosion (FAO, 2010a). For forest genetic resources, land-use change, particularly forest conversion to cropland and pasture, overexploitation, selective harvesting, and high tree mortality caused by extreme climatic events are considered major threats (FAO, 2014a). Growth in demand for animal-source foods, transformation of production systems and inadequate policies and breeding strategies are regarded as major challenges to the sustainable management of animal (livestock) genetic diversity (FAO, 2015a). Habitat loss and degradation, pollution of waters, the direct and indirect effects of climate change, and the establishment of invasive species have been identified as major drivers affecting aquatic ecosystems and hence aquatic genetic resources, both wild relatives and farmed types (FAO, forthcoming).

For the current assessment, countries were invited to report on a set of drivers of change (Table 3.1) and to indicate whether their effects on the supply of specific ecosystem services ${ }^{2}$ within particular production systems (Table 1.1) during the preceding ten years had been positive, negative or neutral. Countries were also specifically invited to report on the effects of the same set of drivers on the availability and diversity of wild foods and on the state of knowledge of these resources.

Although countries were invited to report on each driver individually, in reality the drivers interact with each other and may operate at different levels (i.e. some may drive others). For example, major global trends such as changes in international markets and demography may give rise to changes in demand for agricultural products that lead to changes in land use, changes in production methods or changes in the level of exploitation of particular resources. These in turn may lead to further effects such as soil erosion, the spread of invasive alien species or the pollution of land, air or water. As well as giving rise to gradual changes, some drivers can increase the risk of shocks such as climatic disasters or disease outbreaks that can have a major impact on biodiversity in a short period of time. Opportunities created by technological innovations may increase or decrease the impacts of other drivers. Public policies can deliberately or inadvertently affect drivers at all levels, and may be specifically introduced in order to reduce harmful impacts on BFA. The status of a given component of BFA will therefore normally depend on a range of interacting drivers operating at a range of scales. Similarly, a given driver may give rise to both direct and indirect effects on BFA via a number of different pathways. For example, urbanization may lead (inter alia) to the destruction of habitat as a result of infrastructure development, to quantitative and qualitative changes in demand for food and agricultural products, to changes in levels of pollution at various scales and to population migrations that lead to changes in the availability of labour to work in agriculture.

\footnotetext{
The ecosystem services are described in Section 2.2 .
} 
TABLE 3.1

\section{Drivers of change explored in the country-reporting guidelines}

\begin{tabular}{|c|c|}
\hline Drivers & Explanatory notes provided in the guidelines \\
\hline $\begin{array}{l}\text { Population growth and } \\
\text { urbanization }\end{array}$ & $\begin{array}{l}\text { Population - changes in population metrics (e.g. growth, fertility, composition, mortality, migration, health } \\
\text { and disease, including different effects on men and women) } \\
\text { Urbanization - for example, shifts in proportion of urban and rural populations; change in urbanization } \\
\text { trends, including different effects on men and women }\end{array}$ \\
\hline $\begin{array}{l}\text { Markets, trade and the private } \\
\text { sector }\end{array}$ & $\begin{array}{l}\text { Trade - changing terms of trade, globalization of markets, commercialization of products, retailing, the } \\
\text { separate capacities of men and women to commercialize products, etc. } \\
\text { Markets and consumption - demand-driven changes in production or practices, including the tastes, values } \\
\text { or ethics of consumers that may directly or indirectly impact biodiversity for food and agriculture, product } \\
\text { quantity or quality } \\
\text { Private sector - the changing role and influence of the private sector and corporate interests }\end{array}$ \\
\hline $\begin{array}{l}\text { Changing economic, sociopolitical } \\
\text { and cultural factors }\end{array}$ & $\begin{array}{l}\text { Economic development - changes in economic circumstances of countries, industries, households } \\
\text { (e.g. change in GDP and economic growth, structural change of economy, income diversification, and the } \\
\text { different economic circumstances of men and women) } \\
\text { Changing sociopolitical, cultural or religious factors - variation in the forces influencing the decision-making } \\
\text { of men and women (e.g. public participation, shifts in the influence of the state vs the private sector, changes } \\
\text { in levels of education and knowledge, shifts in the beliefs, values and norms held by groups of people) } \\
\text { Participatory actions - the role of collective action towards conservation and use of biodiversity by } \\
\text { stakeholders }\end{array}$ \\
\hline Climate change & $\begin{array}{l}\text { The impacts and effects of progressive climate change (alterations in precipitation regimes, temperature } \\
\text { changes, loss of water supply, increased variability, sea-level rise, shifts in flowering time or seasonality, etc.) }\end{array}$ \\
\hline Natural disasters & $\begin{array}{l}\text { Climate shocks, extreme weather events and other natural disasters that threaten agricultural production } \\
\text { and the resilience of production systems (e.g. hurricanes, earthquakes, floods and fires) }\end{array}$ \\
\hline $\begin{array}{l}\text { Pests, diseases and invasive } \\
\text { alien species }\end{array}$ & $\begin{array}{l}\text { New and emerging threats from pests, diseases and invasive species affecting biodiversity for food and } \\
\text { agriculture (shifting ranges, introductions, increased suitability, loss of predators, etc.) }\end{array}$ \\
\hline $\begin{array}{l}\text { Advancements and innovations in } \\
\text { science and technology }\end{array}$ & $\begin{array}{l}\text { Development and diffusion of scientific knowledge and technologies (e.g. advances in breeding, } \\
\text { improvements in mobile extension, tools for monitoring, biotechnology applications and access of men and } \\
\text { women to information) }\end{array}$ \\
\hline $\begin{array}{l}\text { Changes in land and water use } \\
\text { and management }\end{array}$ & $\begin{array}{l}\text { Changes in use, management and practices around land and water (deforestation, fragmentation, } \\
\text { modification of water regimes, forest degradation, land conversion for agriculture, ecosystem restoration, } \\
\text { the role of women and men in land and water use and management, etc.) }\end{array}$ \\
\hline Pollution and external inputs & $\begin{array}{l}\text { Mismanaged, excessive or inappropriate use of external inputs (overapplication of fertilizer and pesticides, } \\
\text { excessive use of antibiotics or hormones, nutrient loading, including from use of imported feed, ocean } \\
\text { acidification, } \mathrm{CO}_{2} \text { fertilization, chemical and particulate pollutants, etc.) }\end{array}$ \\
\hline $\begin{array}{l}\text { Overexploitation and } \\
\text { overharvesting }\end{array}$ & $\begin{array}{l}\text { Unsustainable extraction practices (overfishing, overhunting, overgrazing, logging and extractive activities } \\
\text { exceeding replacement rates or affecting species of uncertain and at-risk conservation status, etc.) }\end{array}$ \\
\hline Policies & $\begin{array}{l}\text { Policies - global, regional, national and subnational legislation and regulations (e.g. conservation } \\
\text { regulations, and participation and compliance with international treaties and conventions) } \\
\text { Economic and policy interventions - interventions that impact biodiversity for food and agriculture directly } \\
\text { or indirectly (e.g. taxes, subsidies, charges for resource use and payments for ecosystem services) } \\
\text { Intellectual property rights (IPR), access and benefit-sharing (ABS) - direct or indirect impacts of IPR and } \\
\text { ABS policy and regulations on biodiversity for food and agriculture }\end{array}$ \\
\hline
\end{tabular}

Note: The list of drivers was developed based on the findings of global assessments of genetic resources for food and agriculture (FAO, 1997, 2007a, 2010a, 2014a, 2015a), the Millennium Ecosystem Assessment (MEA, 2005b) and Hazell and Wood (2008). Source: FAO, 2013b.

The driver-by-driver approach taken in the country reporting is reflected in the structure of the chapter. After a short overview of the findings, each driver is given its own dedicated section, each of which provides an introduction to the respective driver, where possible presents a literature-based summary of global trends, and then summarizes the information provided in the country reports on the driver and its impacts on BFA, ecosystem services and wild foods. Drivers 


\section{PART B}

TABLE 3.2

Reported effects of drivers of change on regulating and supporting ecosystem services, all production systems aggregated

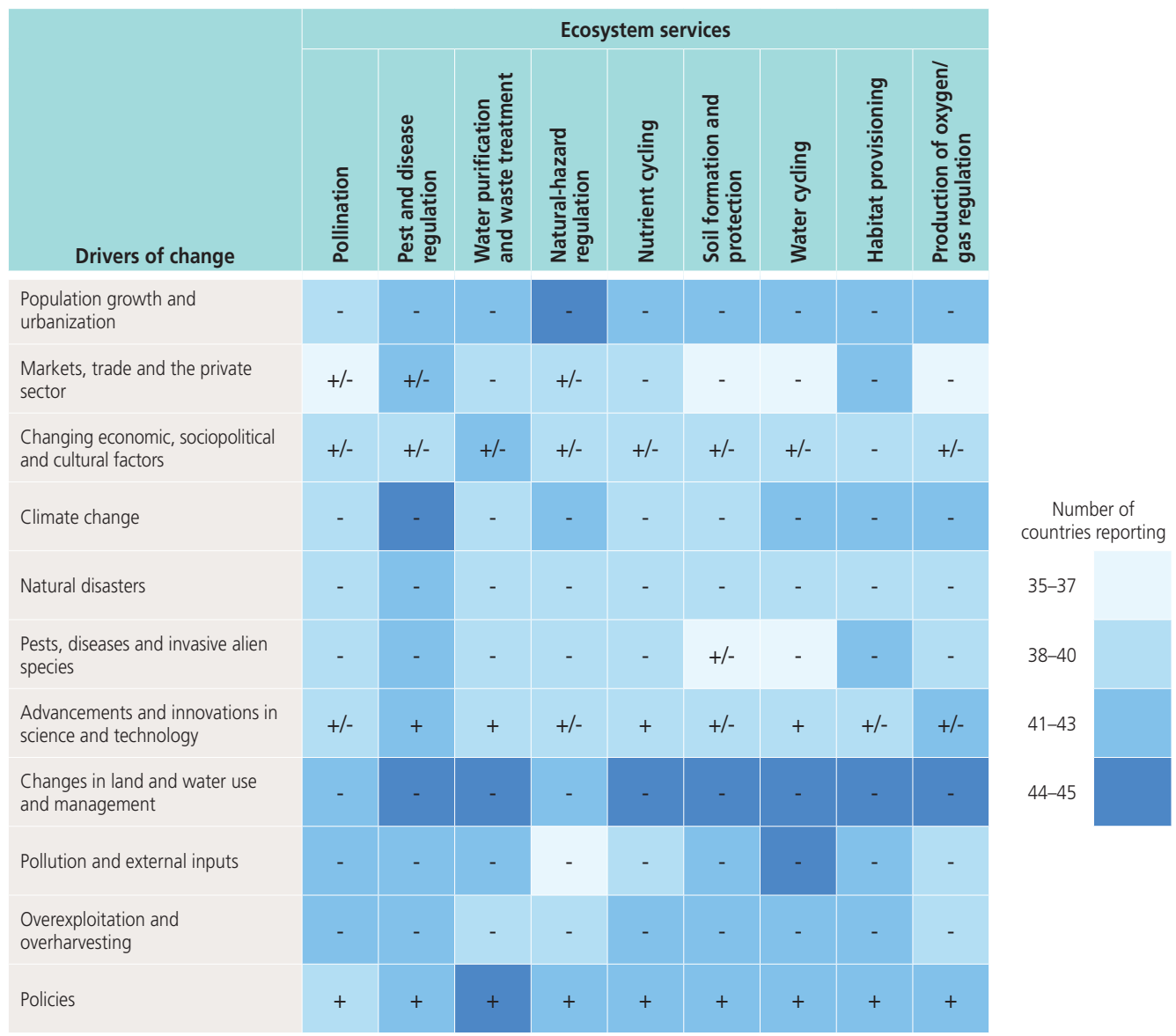

Notes: Countries were invited to report the effects (positive, negative or "no effect") of drivers on the provision of each ecosystem service in each production system. In this table the answers reported for different production systems are aggregated. If $50 \%$ or more of the responses for a given combination of driver and ecosystem service indicate the same trend (positive [+], negative [-] or "no effect" [0]) then this trend is indicated in the respective cell of the table. In other cases, mixed effects (+/-) are indicated. The colour scale indicates the number of countries reporting any effect of the respective driver (positive, negative or "no effect") on the provision of the respective ecosystem service. See Section 1.5 for descriptions of the production systems and a discussion of ecosystem services. Analysis based on a total of 91 country reports.

Source: Country reports prepared for The State of the World's Biodiversity for Food and Agriculture.

are discussed under a series of broad headings, beginning with higher-level economic and social, environmental and technological drivers, followed by drivers at production-system level and finally policies.
In addition to the general discussion of the impacts of the various drivers on BFA and its role in the supply of ecosystem services (Sections 3.2 to 3.7), the chapter also includes separate discussions of the effects of drivers of change on the involvement 
of women in the management of BFA and on the maintenance and use of traditional knowledge related to BFA (Sections 3.8 and 3.9, respectively).

\subsection{Overview}

This section provides an overview of the countryreport responses before the individual drivers are discussed in greater detail below. A total of 68 countries - including countries from all regions and both OECD and non-OECD member countries - provided evaluations of the effects of at least one of the individual drivers identified.

As noted above, countries were invited to indicate whether the effects of each driver on ecosystem services in each production system category had been positive, neutral or negative during the preceding ten years, and to provide additional information on the effects of individual drivers. Table 3.2 presents the reported effects of the drivers of change for all production systems aggregated. Negative impacts on ecosystem services in production systems are more frequently reported than positive, mixed (i.e. both positive and negative) or neutral effects for the following drivers: changes in land and water use and management; pollution and external inputs; overexploitation and overharvesting; climate change; natural disasters; pest, diseases and invasive species; markets, trade and the private sector; and population growth and urbanization. In the case of policies and advancements in science and technologies, positive effects are more frequently reported than negative, mixed or neutral effects for most ecosystem services. Responses related to changing economic, sociopolitical and cultural factors are more evenly divided between negative, positive, and mixed effects, possibly reflecting the broad range of factors potentially falling within this category. In addition to the drivers listed in Table 3.2, countries provide information on the effects of four other drivers, in each case either in one or in two country reports. Three of these drivers (migration, ethnic conflicts and acidification) are reported to have negative impacts on the supply of ecosystem services and one (afforestation) to have both positive and negative impacts.

Countries were invited to report on drivers affecting the availability and diversity of wild foods and knowledge of these resources (Table 3.3). In the case of the following drivers, negative effects on the availability and diversity of wild foods are far more frequently reported than the combined total of positive or neutral effects: overexploitation and overharvesting; changes in land and water use and management; pests, diseases and invasive alien species; population growth and urbanization; climate change; pollution and external inputs; and natural disasters. In the case of policies and advancements and innovations in science and technology, reports of positive effects on availability substantially outnumber other responses. For the remaining drivers (markets, trade and the private sector, and changing economic, sociopolitical and cultural factors) responses are more mixed, but with negative responses the more frequent. With regard to knowledge of wild foods, reports of positive impacts are more frequent than other responses in the case of the following drivers: advancements and innovations in science and technology; policies; markets, trade and the private sector; and changing economic, sociopolitical and cultural factors. For diversity, the only two drivers for which positive responses outnumber negative are policies, and advancements in science and technologies.

\subsection{Economic and social drivers}

- Information from countries indicates that population growth and urbanization, and associated habitat destruction and land conversion, are having a negative effect on biodiversity for food and agriculture (BFA) and ecosystem services, with forests and coastal habitats appearing to be particularly threatened.

- Outmigration from rural areas is tending to lead to changes in management practices and land use, in some cases leading to the decline of traditional, biodiverse production systems. 


\section{PART B}

TABLE 3.3

Number of countries reporting negative, neutral and positive effects of drivers of change on the diversity, availability and knowledge of wild foods

\begin{tabular}{|c|c|c|c|c|c|c|c|c|c|}
\hline \multirow[b]{2}{*}{ Driver } & \multicolumn{3}{|c|}{ Negative } & \multicolumn{3}{|c|}{ Neutral } & \multicolumn{3}{|c|}{ Positive } \\
\hline & $\frac{\frac{\pi}{n}}{\frac{\pi}{0}}$ & $\frac{\text { 吾 }}{\frac{0}{\frac{0}{0}}}$ & $\begin{array}{l}\frac{0}{0} \\
\frac{0}{0} \\
\frac{0}{3} \\
\frac{0}{5}\end{array}$ & 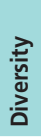 & 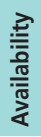 & $\frac{\text { o }}{\frac{0}{0}}$ & $\begin{array}{l}\frac{2}{\text { जे }} \\
\frac{ \pm}{0} \\
0\end{array}$ & $\frac{\frac{7}{0}}{\frac{\sqrt{0}}{\frac{\pi}{\pi}}}$ & $\begin{array}{l}\frac{0}{0} \\
\frac{0}{3} \\
\frac{0}{3} \\
\frac{0}{5}\end{array}$ \\
\hline Population growth and urbanization & 29 & 37 & 22 & 9 & 6 & 8 & 1 & 2 & 4 \\
\hline Markets, trade and the private sector & 18 & 20 & 10 & 9 & 6 & 6 & 11 & 16 & 21 \\
\hline Changing economic, sociopolitical and cultural factors & 19 & 18 & 9 & 8 & 8 & 8 & 12 & 14 & 18 \\
\hline Climate change & 31 & 35 & 13 & 7 & 5 & 13 & 3 & 2 & 2 \\
\hline Natural disasters & 22 & 29 & 11 & 8 & 6 & 11 & 2 & 2 & 3 \\
\hline Pests, diseases and invasive alien species & 34 & 40 & 15 & 6 & 2 & 9 & 2 & 2 & 2 \\
\hline Advancements and innovations in science and technology & 5 & 8 & 3 & 9 & 9 & 6 & 20 & 24 & 28 \\
\hline Changes in land and water use and management & 32 & 41 & 21 & 8 & 5 & 10 & 5 & 6 & 7 \\
\hline Pollution and external inputs & 29 & 35 & 13 & 8 & 5 & 9 & 1 & 1 & 6 \\
\hline Overexploitation and overharvesting & 36 & 45 & 18 & 6 & 4 & 10 & 1 & 2 & 5 \\
\hline Policies & 9 & 9 & 4 & 11 & 7 & 8 & 23 & 34 & 26 \\
\hline
\end{tabular}

Notes: The numbers in the table represent counts of country reports. Sixty-one out of 91 country reports provided information. Source: Country reports prepared for The State of the World's Biodiversity for Food and Agriculture.

- Markets and trade have a generally homogenizing effect globally, and international trade, urbanization and increasing regulation of markets are considered by countries to have a largely negative effect on BFA and ecosystem services. Locally, effects may be more mixed, with consumer demand and market regulation (of labelling, etc.) sometimes helping to promote biodiversity-friendly production or harvesting practices.

- The effects of economic, social and cultural changes are complex, but changes in dietary preferences have had a largely negative effect on BFA, with an increasing emphasis on meat-based diets and the use of a narrow range of major cereals (maize, wheat and rice).

\subsubsection{Population growth and urbanization}

It is generally agreed that population growth, together with an increase in average per capita incomes, will result in higher pressure on natural resources and biodiversity (e.g. Foley et al., 2011).
Feeding, housing and meeting the other needs of more than 9 billion people in the coming two to three decades will exert pressures on ecosystems worldwide.

People living in cities now outnumber those living in rural areas (United Nations, 2014a). Projections indicate that population growth in cities and small rural towns, along with the number of people migrating from rural to urban areas, will continue to increase. Urban population growth rates actually decreased from around 3 percent in the 1960 s to around 2 percent in the five years to $2016 .{ }^{3}$ However, the percentage of the world population living in urban areas grew from 33 percent to 54 percent over the same period, or from 1.01 billion to 4.2 billion

\footnotetext{
World Bank staff estimates based on the United Nations Population Division's World Urbanization Prospects: 2014 Revision.
} 
in absolute terms (United Nations, 2014a, 2018). It has been predicted that the figure will rise to 68 percent by 2050 (United Nations, 2018). The global rural population is now close to 3.4 billion and is expected to rise slightly and then decline to around 3.1 billion in 2050 (ibid.). Urban population growth will, therefore, not mean an "emptying" of the countryside in the near future, at least at global level. At regional or local levels, however, there are already cases of rural depopulation, fuelled largely by outmigration to neighbouring, or more distant, town or cities, or to other countries (e.g. Gray and Bilsborrow, 2014; Chen et al., 2014). This often leads to increasing involvement of women in the management of agricultural holdings (e.g. Agarwal, 2015; FAO, 2011e) (see also Section 3.8). Out-migration from rural areas can be permanent or temporary, involve people of various social strata and education levels, and often results in an inflow of remittances to family members who remain. The inflow of remittances may represent up to 30 percent of gross domestic product in some countries (World Bank, 2018). ${ }^{4}$

As noted in the introduction to this chapter, urbanization can affect biodiversity in many ways. Globally, urban development is a significant direct driver of land-use change, deforestation and habitat fragmentation (Elmqvist et al., eds., 2013). However, it also has numerous effects on (inter alia) lifestyles and consumption patterns, social and political attitudes, and the organization of production and supply chains, all of which can have knock-on effects on biodiversity, on a range of scales (ibid.). For example, as people move to cities they tend to depend increasingly on purchased foods, often from a few supermarket chains (Macfadyen et al., 2015). They often also tend to lose ties with rural areas and rural foods, and increasingly opt for processed foods rather than fresh foods (Popkin, 2017). While supermarkets and other modern retailers can make a more diverse diet available and accessible to more people, they can also encourage

4 World Bank staff estimates for 2016 based on International Monetary Fund balance of payments data, and World Bank and OECD GDP estimates. the consumption of energy-dense, nutrient-poor, highly processed foods and reduce the ability of marginalized populations to purchase the food needed for a high-quality diet (Hawkes, 2008). This often has negative consequences for nutrition (see Section 2.6). Urban consumption patterns are also associated with a greater proportion of food going to waste (Parfitt, Barthel and Macnaughton, 2010).

Demand for standardized foods can lead in turn to a decrease in the diversity of the crops and animals raised in food and agricultural systems (see also Section 3.3.2). However, demand from urban consumers can also help promote "BFAfriendly" approaches such as organic agriculture (Seto and Ramankutty, 2016) or the maintenance of non-mainstream species, varieties and breeds of crops and livestock (FAO, 2013g; Lamers et al., 2016). Moreover, trends in consumption and retailing are more advanced in some countries than others. Urban food systems in developing counties often remain complex and diverse, with traditional outlets such as wet markets, street and mobile vendors still playing a major role (Crush, 2014) and substantial amounts of food being produced within the boundaries of cities (Orsini et al., 2013). The impacts of dietary changes on BFA are further discussed in Section 3.3.3.

Human population growth and the resulting industrialization, agricultural intensification and urbanization are considered to be among the main global drivers of degradation of aquatic ecosystems (Verdonschot et al., 2013). Infrastructure development associated with urbanization affects water quantity and quality, changes river channels, destroys habitats and habitat connectivity and favours the spread of invasive species (Speed et al., 2016). Pressures on aquatic ecosystems, especially rivers, are expected to increase (ibid.). Population growth is also driving other threats to aquatic BFA, including overharvesting, pollution (including sediment loading caused by coastal development) and detrimental land and water use associated with touristic developments (United Nations, 2014a).

The impacts of population growth and urbanization on ecosystem-service provision as reported 


\section{PART B}

TABLE 3.4

Reported effects of population growth and urbanization on the provision of regulating and supporting ecosystem services, by production system

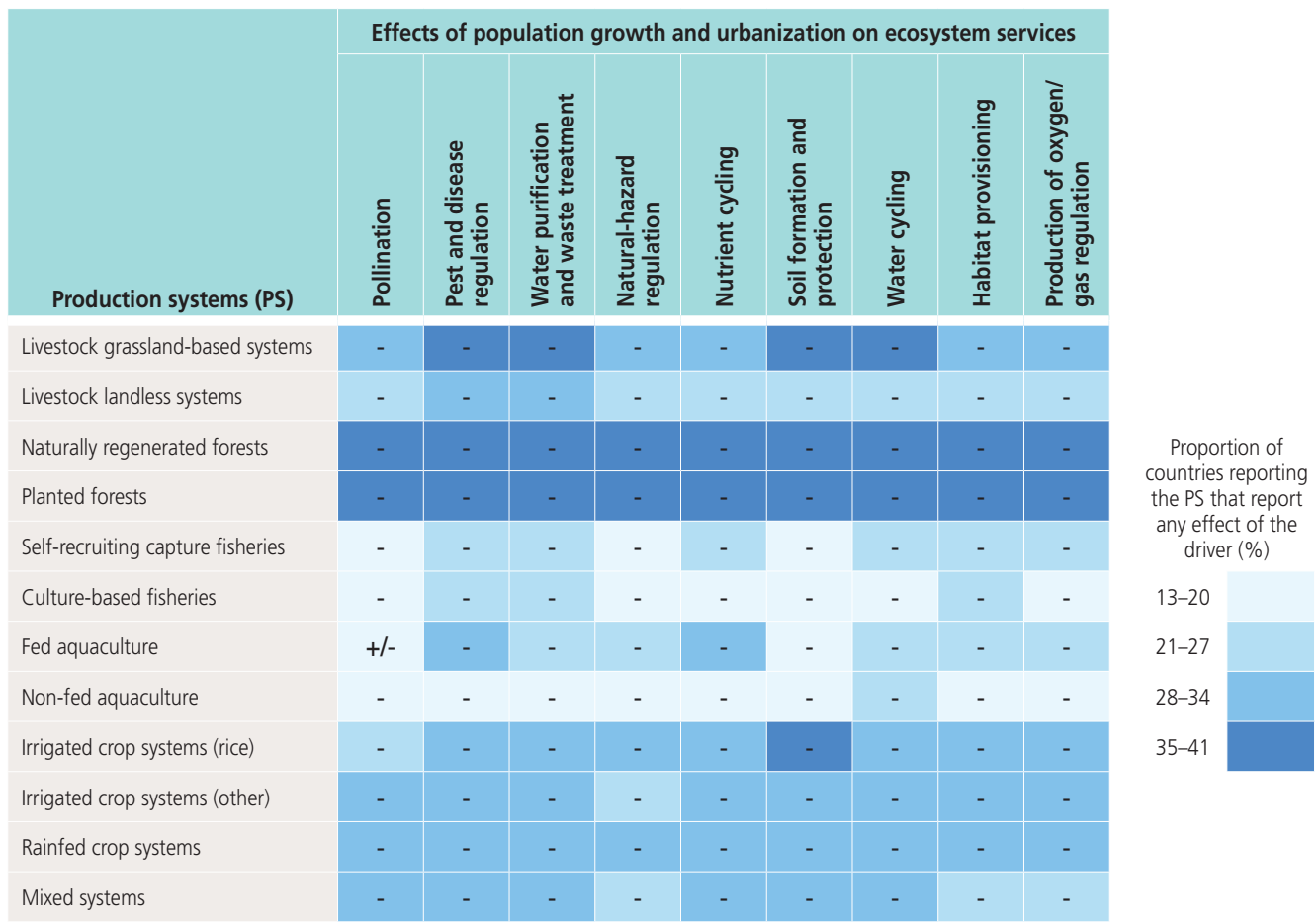

Notes: Countries were invited to report the effects (positive, negative or "no effect") of this driver on the provision of each ecosystem service in each production system. If $50 \%$ or more of the responses for a given combination of production system and ecosystem service indicate the same trend (positive [+], negative [-] or "no effect" [0]) then this trend is indicated in the respective cell of the table. In other cases, mixed effects (+/-) are indicated. The colour scale indicates the proportion of countries reporting the presence of the respective system that report any effect of the driver (positive, negative or "no effect") on the provision of the respective ecosystem service. See Section 1.5 for descriptions of the production systems and a discussion of ecosystem services. Analysis based on a total of 91 country reports.

Source: Country reports prepared for The State of the World's Biodiversity for Food and Agriculture.

by countries are summarized in Table 3.4. In nearly all production systems and for nearly all ecosystem services, negative impacts are by far the most frequently reported. Countries report a diverse range of different impacts associated with this driver. Some emphasize the effects of habitat destruction linked to the expansion of towns and cities. For example, Morocco reports that urbanization is one of the most serious threats to its biodiversity. It notes that the rapid expansion of human settlements into areas that are rich in BFA and the removal of sand and rocks from sites such as coastal dunes and wadi beds ${ }^{5}$ for use in construction are resulting in the loss of habitats and the species they shelter. China notes that since the late 1950s urbanization and the rapid development of industry, along with population growth, have led to ever-increasing discharge of industrial wastes, municipal sewage and garbage, including the disposal of garbage and solid wastes in farmland.

\footnotetext{
A wadi is a valley or streambed that contains water only during the rainy season.
} 
A number of countries emphasize the various ways in which population growth is driving expansion of the agricultural frontier and greater exploitation of natural resources. For example, Ecuador, one of the most densely populated countries in Latin America, reports that the high density of the rural population is increasing local demand for resources and leading to the occupation of land that is not suitable for use for food and agriculture and that this is threatening the survival of wild species. Ethiopia notes that growth of the population has led to expansion and intensification of land use, overutilization of biological resources, increasing use of marginal lands and the breakdown of traditional resource-management systems. These changes are reported to be putting pressure on all ecosystem services and all the country's biodiversity, including impacts on the availability and diversity of wild foods and on the maintenance of associated traditional knowledge. ${ }^{6}$ Zimbabwe mentions that human populations have been encroaching on previously unused habitats such as wetlands in an effort to escape the effects of drought, poverty and climate change and that this has led to the degradation of the affected ecosystems. Countries also note impacts on aquatic ecosystems, both via the effects of the increasing demand of growing populations for fish and other aquatic products and via the effects of pollution and infrastructure development.

Several countries mention the effects of migration out of rural areas. For example, Ecuador notes that rural migration to urban centres is more common among men than among women, and is permanent, i.e. the migrants do not return. It further notes that this has led to an increasing proportion of women and elderly people in the rural population and in turn to the abandonment of cropping systems to make way for pastures and livestock, as these require less labour. This is reported to have led to a decline of crop genetic diversity. Several country reports from Europe note that the

6 The report cites Kelbessa et al. (1992), Addis (2009) and Asfaw (2009). abandonment of farming areas can have negative consequences for some components of biodiversity. Norway, for example, reports that the decline of grazing and haymaking on more marginal land is leading to forest expansion and that this is threatening a number of rare grassland species. ${ }^{7}$

Several countries report that urbanization and population growth, and associated infrastructure development and economic activities, are threats to marine biodiversity and aquatic resources. For example, Spain reports that increased coastal development due to tourism has affected populations of Neptune grass (Posidonia oceanica), a key Mediterranean seagrass species. In Europe in general, offshore wind parks, sand and gravel extraction and gas and petroleum pipelines are considered to be particularly damaging to marine flora and fauna, depriving fisheries of key fishing grounds and many species of their habitats. Among Latin American countries, Argentina reports that urban infrastructure development is affecting wetlands in its Delta region - damaging the region's traditional productive agroecosystems, diminishing their capacity to supply ecosystem services such as flood control and reducing their resilience. Mexico notes that, with a population of 123 million growing at an average rate of 1.8 percent per annum, demand for food will be a key source of pressure on its fisheries and aquaculture sector, and mentions that it will be necessary to find new species to culture and new strategies for the sustainable use of already-established fisheries.

Where wild foods are concerned, population growth and urbanization are reported to be exerting increasing pressure on wild plant, fish and game populations in a number of countries, whether via the effects of increased demand or via habitat destruction. For example, Cameroon reports that population growth is creating more demand for forest products, including wild meat. It notes that settlements are occupying land even in protected areas and that roads through parks are destroying habitats and disturbing wild species. Kiribati mentions that the most notable

\footnotetext{
The report cites Kålås et al. (2010).
} 
driver affecting its wild food resources is population pressure, resulting either from increased urbanization or general high population growth. It notes that a large proportion of the population is concentrated in urban centres and that this leads to overexploitation of some of the marine wild food species commonly used in these areas. These species are reported to be easily accessible to the public, making them easy targets for unsustainable exploitation. Solomon Islands notes that in heavily populated urban and peri-urban areas marine species are being affected by effluent discharge, overexploitation and habitat destruction caused by land clearing and reclamation.

\subsubsection{Markets, trade and value chains}

The way in which food systems (and their associated markets and value chains) evolve can influence BFA and associated ecosystem services in various ways. Many regions in the world are undergoing waves of economic development based on the exploitation of natural resources through the expansion of activities such as mining and fossil-energy extraction, extensive cattle ranching, tree monoculture and production of agricultural commodities such as soybean, palm oil and sugar cane (e.g. UNCTAD, 2012). These trends, mostly driven by the private sector, but often with governmental support or facilitated by a lack of adequate regulation, have major implications for the world's ecosystems and biodiversity (e.g. IPBES, 2018c, 2018d, 2018e).

Commercial harvesting of wild foods (including fish), medicinal plants, charcoal and timber and non-wood forest products creates the risk of overexploitation (see also Section 3.6.3). The involvement of international markets may exacerbate such risks. As noted in Section 3.3.1, quantitative and qualitative changes in consumer demand are major drivers of change affecting BFA. However, consumption patterns and food habits can be influenced not only by changes in consumers' incomes and lifestyles, but also by changes in the value chain. For example, increases in fish consumption are influenced by urbanization and rising incomes on the demand side and by improved distribution and international trade on the supply side (FAO, 2018a).
Markets may also impose requirements in terms of product uniformity and the timing and continuity of supply. Demands of this kind can exert pressure on producers to continuously grow/ keep only a limited range of species, breeds and varieties of crops, livestock, trees, fish, etc., with both individual holdings and wider productive landscapes thus becoming more homogeneous in space and time in terms of their genetics and their physical structure. Such changes will often have negative implications for the resilience of production systems (see Section 2.3 for further discussion) and for their roles as habitats for biodiversity (Macfadyen et al., 2015). A case in point is the development of private food standards by supermarkets and other buyers (sometimes partly on the grounds of aesthetics), which have helped to steer farmers towards particular varieties and management procedures (Dolan and Humphrey, 2000; Lang, Barling and Caraher, 2009; Stuart, 2009). International markets may be particularly restrictive and impose specific requirements for market entry, including for food-safety reasons (Kahane et al., 2013). This can effectively debar the entry into the market of minor crops from developing countries (Davis, 2006).

Conversely, markets may also be a means of promoting production practices that help to protect biodiversity or the supply of ecosystem services, for instance when regulations and certification schemes are put in place to satisfy consumer demands for sustainably supplied products (e.g. organic farming, fair trade, welfare-friendly animal products, shorter supply chains, sustainable forestry or sustainable fishing practices) or products with distinctive characteristics associated with their origin (e.g. geographical indications). The development of voluntary sustainability standards - for example, those of the Rainforest Alliance ${ }^{8}$ and the Marine Stewardship Council $^{9}$ - is contributing to the inclusion of biodiversity-related variables in food standards (Potts et al., 2017). The establishment of a value

\footnotetext{
https://www.rainforest-alliance.org

9 https://www.msc.org
} 


\section{TABLE 3.5}

Reported effects of markets, trade and the private sector on the provision of regulating and supporting ecosystem services, by production system

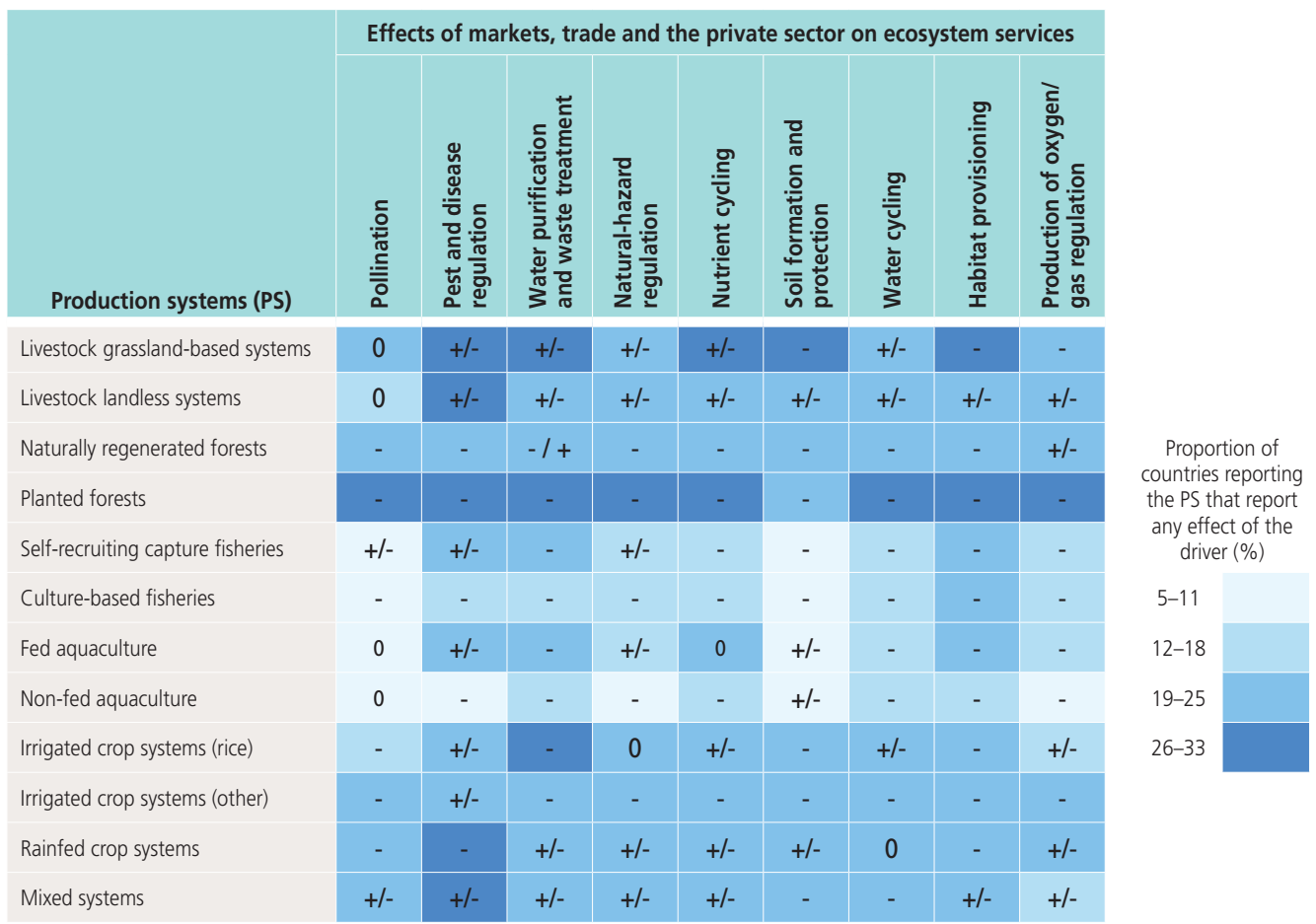

Notes: Countries were invited to report the effects (positive, negative or "no effect") of this driver on the provision of each ecosystem service in each production system. If $50 \%$ or more of the responses for a given combination of production system and ecosystem service indicate the same trend (positive [+], negative [-] or "no effect" [0]) then this trend is indicated in the respective cell of the table. In other cases, mixed effects (+/-) are indicated. The colour scale indicates the proportion of countries reporting the presence of the respective system that report any effect of the driver (positive, negative or "no effect") on the provision of the respective ecosystem service. See Section 1.5 for descriptions of the production systems and a discussion of ecosystem services. Analysis based on a total of 91 country reports. Source: Country reports prepared for The State of the World's Biodiversity for Food and Agriculture.

chain for specific varieties or breeds can help to promote continued use of these resources and reduce their risk of extinction (e.g. FAO, 2013g; FAO and SINER-GI, 2010; Keleman and Hellin, 2009; Vandecandelaere et al., 2018). International trade can also facilitate the introduction of invasive alien species, pests and diseases that may affect BFA (see Section 3.4.3). For example, trade in honey bees can contribute to the spread of diseases around the world and lead to the infection of native wild pollinators (Fürst et al., 2014). International trade can also function as a means of "exporting" environmental problems. For example, the intensive animal production based on concentrate feeds that takes place in Europe and China affects not only the surrounding environment, but also the environments where the raw materials for these feeds are produced, for instance through the expansion of soybean production into native forests in South America (e.g. Grau and Aide, 2008; Ran et al., 2013).

Information provided by countries on the effects of this driver on ecosystem services is summarized in Table 3.5. Although effects on 
ecosystem services are often reported to be negative, in particular in the case of habitatprovisioning services, positive effects on pest and disease regulation are reported across production systems, and on water purification, natural-hazard regulation and nutrient cycling in livestock and mixed production systems. Countries that describe specific impacts include Peru, which notes that growing demand for fishmeal and fish oils has led to an increase in the number of large boats fishing for anchovy (Engraulis ringens) and other coastal species. This is reported to be negatively affecting the coastal ecosystem and hence on fish species that are important for human consumption and underpin the livelihoods and food security of artisanal fishers and their households. Loss of the species captured in small-scale fisheries is leading in turn to more consumption of imported frozen fish nationally.

New markets for wild-food products are reported to be emerging in various parts of the world. Examples include llex guayusa (a tree whose leaves are used to make a drink) in Ecuador, ota (Diplazium esculentum and D. proliferum) (an edible fern delicacy) in Fiji, sumac (Rhus coriaria) (a shrub whose dried fruits are used as a spice) in Jordan, wild mushrooms in Scotland, various wild fish species in the Netherlands, forest foods such as cane rat (Thryonomys swinderianus), Gnetum spp. (a leafy vegetable), Ricinodendron spp. (a tree that produces oily seeds) and Irvingia spp. (bush mango) in Cameroon (in some cases for export), and cabbage palm (Euterpe precatoria), aguaje (Mauritia flexuosa) (a palm), brazilnut (Bertholletia excelsa) and sacha inchi (Plukenetia volubilis) (a source of oily seeds) in Peru.

In some cases, new markets are created when rural populations move to cities and carry their traditional food preferences with them. Gabon, for example, mentions that this is the case with urban wild-meat markets. Several countries, however, report a revival of interest in wild foods among long-standing urban residents. In some cases, commercialization leads to overexploitation (see Section 3.6.3), but in others can lead to more positive outcomes. For example,
China notes that development and utilization of wild-food resources has attracted the attention of local governments and enterprises, creating job opportunities and incentivizing environmental protection.

Argentina mentions the potential of national and international trade in fibres from wild species such as the guanaco (Lama guanicoe) and the vicuña (Vicugna vicugna) to promote the conservation of these species, their habitats and the biodiversity and ecosystem services associated with them. It notes that income-generating initiatives related to this trade encourage local indigenous communities to organize themselves into cooperatives and develop plans for the sustainable use of natural resources. Argentina also mentions the work of the Southern Cone Grasslands Alliance, ${ }^{10}$ an initiative involving a number of non-governmental organizations under the umbrella of BirdLife International, ${ }^{11}$ which certifies bird-friendly beef from the pampas and campos grasslands of South America, including for export to Europe, as a means of contributing to the conservation of these ecosystems.

\subsubsection{Changing economic, sociopolitical and cultural factors}

Economic and political aspects of this driver are discussed in Sections 3.3.1, 3.3.2 and 3.7. The focus in this section is therefore largely on cultural factors.

One aspect of culture that has a significant influence on the use of BFA is diet. As discussed above, urbanization, globalization and a slow but steady rise in the average purchasing capacity of households are leading - in broad terms to a homogenization of global diets, often with negative consequences for human nutrition ( $\mathrm{Ng}$ et al., 2014) (see also Section 2.6). Worldwide, the use of three cereals (maize, wheat and rice) has increased at the expense of local and often better adapted and more nutritious crops such as smallgrain cereals and pulses (Khoury et al., 2014).

\footnotetext{
http://www.alianzadelpastizal.org/en

1 www.birdlife.org
} 
TABLE 3.6

Reported effects of changing economic, sociopolitical and cultural factors on the provision of regulating and supporting ecosystem services, by production system

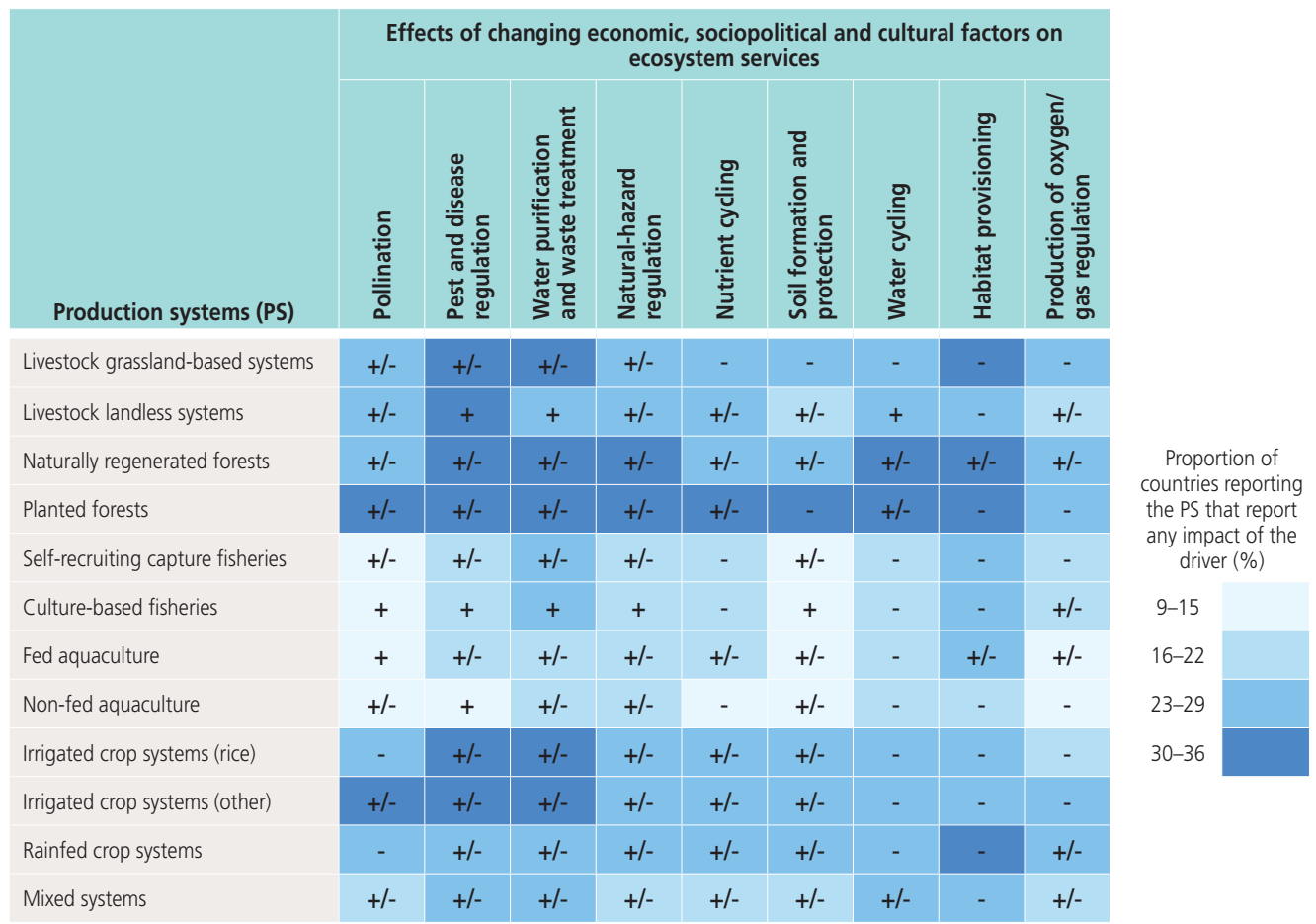

Notes: Countries were invited to report the effects (positive, negative or "no effect") of this driver on the provision of each ecosystem service in each production system. If $50 \%$ or more of the responses for a given combination of production system and ecosystem service indicate the same trend (positive [+], negative [-] or "no effect" [0]) then this trend is indicated in the respective cell of the table. In other cases, mixed effects (+/-) are indicated. The colour scale indicates the proportion of countries reporting the presence of the respective system that report any effect of the driver (positive, negative or "no effect") on the provision of the respective ecosystem service. See Section 1.5 for descriptions of the production systems and a discussion of ecosystem services. Analysis based on a total of 91 country reports.

Source: Country reports prepared for The State of the World's Biodiversity for Food and Agriculture.

In many developing countries people tend to perceive traditional food crops as poor people's food. For example, in much of sub-Saharan Africa maize is perceived to be a "modern" crop and is promoted over traditional small grains by governmental extension services or private input suppliers (Shiferaw et al., 2011). Preference for traditional foods may decline for other reasons, such as their longer processing and cooking times (Global Panel, 2017). At the same time, however, products from some traditional varieties and breeds are also perceived as more tasty and hence may remain popular or provide opportunities for the development of new speciality products for high-value niche markets (e.g. LPP et al., 2010). Where wild foods are concerned, similar diverging trends - abandonment on the one hand and revival for cultural, recreational, nutritional or environmental reasons on the other can be observed in some developed regions such as Europe and North America, as well as in some urban centres in developing regions (Alexander and Mclain, 2001; Łuczaj et al., 2012; Reyes-Garcia et al., 2015; Stryamets et al., 2015). 
As discussed in Section 3.3.1, many rural areas are experiencing large-scale outmigration of young people and increases in the inflow of remittances. Cultural changes associated with these developments and with the greater accessibility of rural areas are contributing to the decline of some traditional biodiverse production systems as a consequence of, inter alia, lack of interest or involvement on the part of the younger generation and loss of traditional knowledge associated with these systems (see Section 3.9).

Information from the country reports on the effects of changing economic, sociopolitical and cultural factors on the supply of ecosystem services is summarized in Table 3.6. The table indicates that for many production-system/ecosystemservice combinations the overall reported effect of this driver is mixed (i.e. not dominated either by responses indicating negative effects or by those indicating positive effects). Most countries reporting positive effects of changing economic, sociopolitical and cultural factors refer to changes in food habits associated with health concerns or greater awareness of the environmental and societal impacts of agriculture and food production. Reported developments in this category include growth in the consumption of organic foods and the establishment of certification schemes for sustainably produced foods and other agricultural products. For example, Argentina reports a certification scheme for goat meat from a traditional transhumant system in northern Patagonia that aims to promote the conservation of the production system, the local goat breed and the goat herders' traditional knowledge ${ }^{12}$ (see Sections 3.9 and 8.7 for further information on certification schemes). Another factor noted by a number of countries is increasing interest in local landscapes and biodiversity - including those associated with food and agricultural systems as components of national heritage. An example from Switzerland is presented in Box 3.1.

Several countries report impacts of cultural and/or socio-economic changes on the use of wild

\footnotetext{
12 The report cites López Raggi et al. (2008).
}

foods. Eswatini, for example, notes that women are increasingly active in wage labour and lack time for collecting wild foods, and that this is leading to the erosion of traditional knowledge. ${ }^{13}$ Nepal mentions that year-round availability of cultivated vegetables means that indigenous populations no longer rely on wild foods, again resulting in the loss of traditional knowledge. Togo reports that use of the seeds of néré (African locust bean) (Parkia biglobosa) and kapok (Ceiba pentandra) trees to make mustard has been replaced by the use of peanuts and soybeans as a consequence of a growing dislike for the smell created by traditional mustard-production methods.

\subsection{Environmental drivers}

- Climate change is considered by countries to be having a negative effect on biodiversity for food and agriculture (BFA) and ecosystem services in all production systems. Coastal areas are likely to be particularly affected.

- The distribution and phenology of important associated-biodiversity species are expected to change as a result of climate change, with possible negative effects on many production systems, especially on ecosystem services such as pollination and pest and disease control.

- Meteorological disasters can have severe long-term effects on BFA, with forest production systems and coastal areas appearing to be particularly vulnerable. Countries note negative effects on ecosystem services.

- Across production systems, countries note the negative effects of pests, diseases and invasive species on the supply of ecosystem services. Several of the invasive species, however, are also reported under certain circumstances to provide ecosystem services themselves.

\subsubsection{Climate change}

Climate change affects BFA and ecosystem services both directly and indirectly. Direct impacts include those caused by changes in rainfall,

\footnotetext{
13 The report cites Howard (2003).
} 
Box 3.1

Human-made grasslands as a cultural and ecological asset

Switzerland's species-rich mountain grasslands are a result of hundreds of years of extensive agricultural activity that maintains open and semi-open habitats below the timberline. Without human interference, most of these habitats would quickly revert to their natural forest state, resulting in the loss of the existing biodiversity.

The primary function of these grasslands is to provide fodder for domestic grazing animals. However, landscapes and species diversity play an increasingly important role in attracting tourists, which creates additional income for mountain regions. With the ongoing intensification of agriculture in the surrounding lowlands, mountain grasslands increasingly function as refuges for species that were once common throughout Europe.

Mountain grasslands occupy 940000 ha, or almost a quarter of the country's total land area, and are still actively used. However, there is a trend towards intensification of grassland management near mountain farms and extensive use of marginal grasslands further away, and this is likely to increase. In particular, increases in the level of nitrogen input and altered grazing and/or mowing regimes have had significant negative effects on the extent and diversity of mountain grasslands.
To combat the decline of dry grasslands in general, and mountain dry grassland pastures in particular, the Federal Office for the Environment has established an inventory of dry grasslands of national importance. In 2010, the Federal Council approved a Federal Ordinance on the implementation of the Federal Inventory of Dry Grasslands. The inventory includes 3000 items representing 0.5 percent of the national territory (Federal Office for the Environment of Switzerland, 2018).

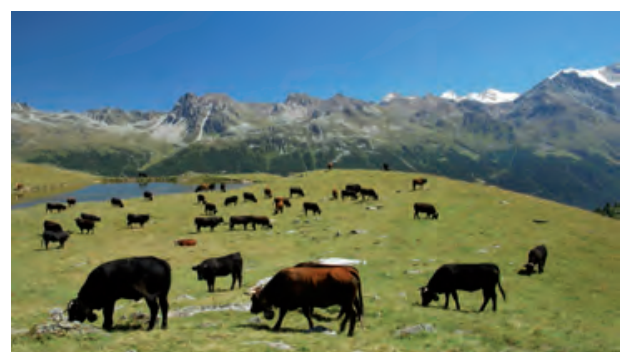

Mountain grassland in the Val d'Hérens, Canton of Valais. @ Federal Office for Agriculture of Switzerland.

Source: Adapted from the country report of Switzerland. temperature and the frequencies of events such as droughts, cyclones/hurricanes, floods, fires and early or late frosts and by changes in plant flowering seasons and growing periods, animal breeding seasons, the oxidation rate of soil organic matter and the ranges and population dynamics of invasive species, pests, pathogens and disease vectors. Indirect impacts include those associated with climate change adaptation and mitigation strategies. For example, rising temperatures in the tropics are pushing coffee growing towards higher elevations in mountainous areas, leading to replacement of natural vegetation (Läderach et al., 2017). This exposes more soil to erosion and degradation and affects water regulation, habitat provisioning and other ecosystem services. The ranges of some important pests, such as the coffee berry borer (Hypothenemus hampei), have also extended to higher elevations - for example in East Africa (e.g. Jaramillo et al., 2011) - prompting coffee farmers to spray pesticides in newly opened highland environments. Irrigation to counter the effects of a drier climate or more erratic rainfall may disrupt river flows and lead to negative effects on fisheries (Cochrane et al., eds., 2009).

Temperature changes associated with climate change can lead to shifts in flowering periods and mismatches between them and the active periods of pollinating insects, with negative consequences both for pollinator populations and for pollination services (Kjøhl, Nielsen and Stenseth, 2011), although effects on pollination may be mitigated by the presence of a diverse range of pollinators 
(Bartomeus et al., 2013). Other seasonal abnormalities such as more frequent cold or windy days in spring can also disrupt pollination services, with pollinator diversity again potentially playing a buffering role (Christmann and Aw-Hassan, 2012). Shifting climatic zones are likely to require pollinator species to alter their geographical ranges. Some species may struggle to do this with sufficient speed (Bedford, Whittaker and Kerr, 2012).

The effects of climate change on soil ecosystems are complex and involve a large number of interacting processes and interactions with other drivers. Together with the diverse characteristics of soil ecosystems themselves, this means that it is difficult to predict outcomes for soil biodiversity (Cock et al., 2011). Temperature, moisture and carbondioxide levels affect the composition of soil invertebrate and micro-organism communities and many of the functions they perform, both directly and via their effects on other components of the ecosystem (e.g. plants). As climatic conditions change, the distribution of production systems can be expected to shift. Some existing relationships between plant species and soil micro-organism and invertebrate communities are likely to break down, as many soil invertebrates are relatively immobile and those that can move may not necessarily adapt well to new locations even if the climate is suitable, for example because of direct or indirect effects of photoperiod differences (ibid.).

The impacts of climate change on aquatic ecosystems include those associated with changes in the temperatures of lakes, rivers and oceans, which may affect species' reproductive patterns and growth, and their physiology, morphology and behaviour more generally (e.g. Spalding, Ravilious and Green, 2001; Speed et al., 2016). Impacts on aquatic biogeochemical processes are expected to affect the roles of aquatic ecosystems as carbon sinks or sources (Boyd and Hutchins, 2012; Erickson et al., 2015; Wrona et al., 2006). Ocean acidification as a result of increased absorption of carbon dioxide threatens marine organisms that use carbonate minerals to form shells and skeletons (CBD Secretariat, 2009). Climate change can also be expected to lead to reductions in wetland areas, changes in flooding periods, water levels, mixing regimes, water clarity and food webs and greater risk of alien-species invasions (Speed et al., 2016). Climate change is a major threat to the world's coral reefs, for example via the effects of higher water temperatures, ocean acidification and increasing frequency of extreme weather events (Heron, Eakin and Douver, 2017; Wilkinson, 2008) (see also Section 4.5.4).

Countries were invited to provide information on cases in which associated biodiversity is believed to be affected by climate change, indicating the severity and frequency of the effects and the production systems in which they occur. Fiftyfive countries provided information. The following specific threats are mentioned in the country reports: changes in temperature (37 reports); changes in precipitation patterns (34); droughts (31); pests and diseases (22); floods (20); changes in sea level (18); changes in phenology (8); soil erosion (8); wildfires (8); changes in nutrient cycles (7); and unspecified extreme events (6). Less frequently reported threats include desertification, strong winds and changes in snow cover. The most frequently reported climate change-related threats to associated biodiversity vary by region. Figure 3.1 shows a breakdown of responses by production system and region.

Information provided by countries on the impact of climate change on the supply of ecosystem services is summarized in Table 3.7. In almost all cases impacts are reported to be negative. Pest and disease regulation, natural-hazard regulation, water cycling, habitat provisioning and pollination are the ecosystem services most frequently reported to be affected by climate change. Several countries provide information on threats affecting particular regions and ecosystems within their national territories. For example, Peru mentions the threat that climate change is posing to high Andean ecosystems (vital to water- and climate-regulation services) as a result of rising temperatures and obstacles to altitudinal migrations. In the case of the Amazonian forests, it notes that climatic changes are predicted to lead to "savannization", which would affect the supply of wild foods, including fish, medicinal plants and 
FIGURE 3.1

Reported climate change-related threats to associated biodiversity, (A) by region and (B) by production system

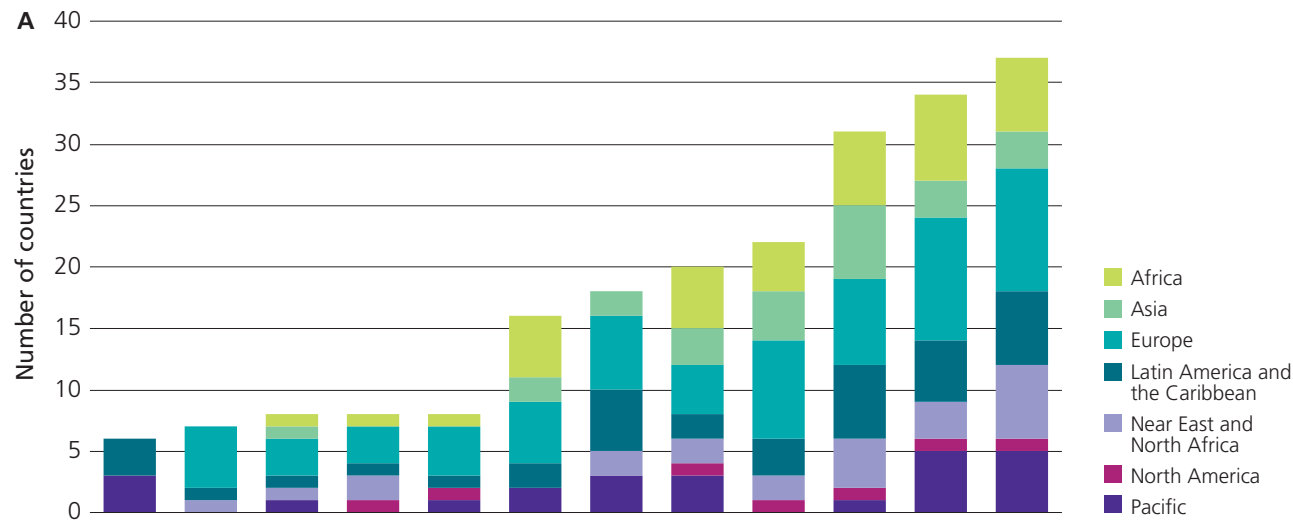

B 60

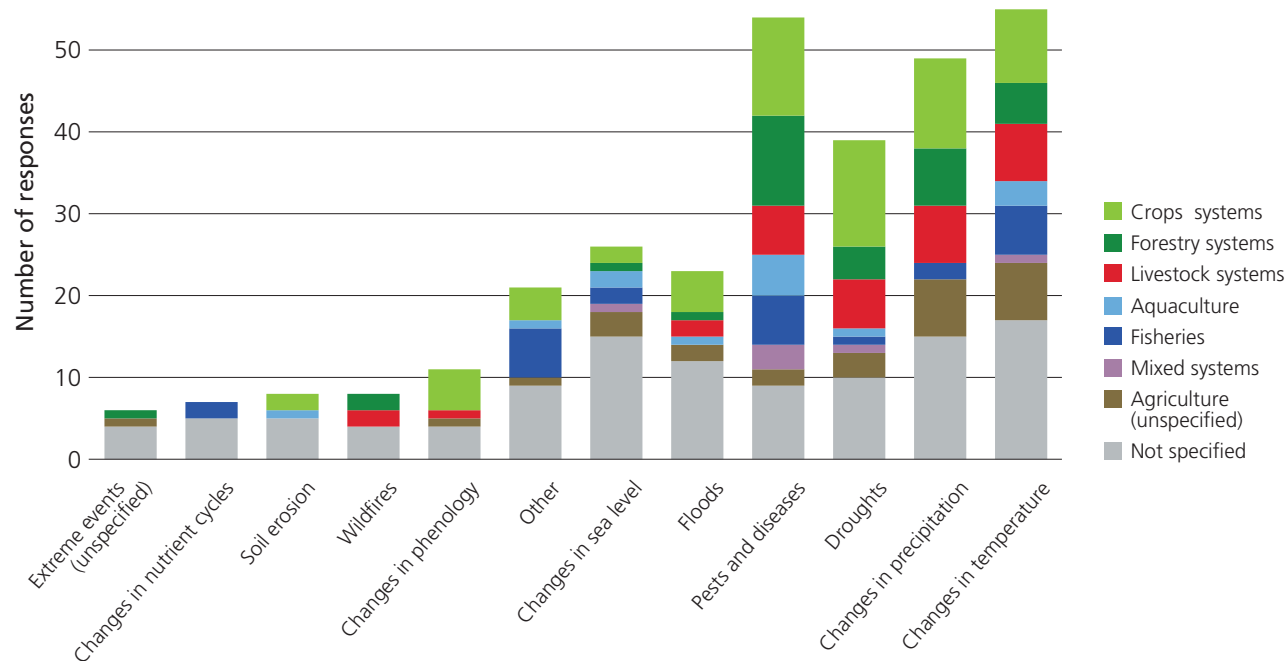

Notes: Part A of the figure shows the total number of countries that reported the respective threat for at least one production system, broken down by region. A given country may have reported a given threat for more than one production system category. Part B of the figure shows the total number of responses referring to the respective threat, broken down by production system. Fifty-five out of a total of 91 reporting countries reported at least one threat.

Source: Country reports prepared for The State of the World's Biodiversity for Food and Agriculture. 


\section{PART B}

\section{TABLE 3.7}

\section{Reported effects of climate change on the provision of regulating and supporting ecosystem} services, by production system

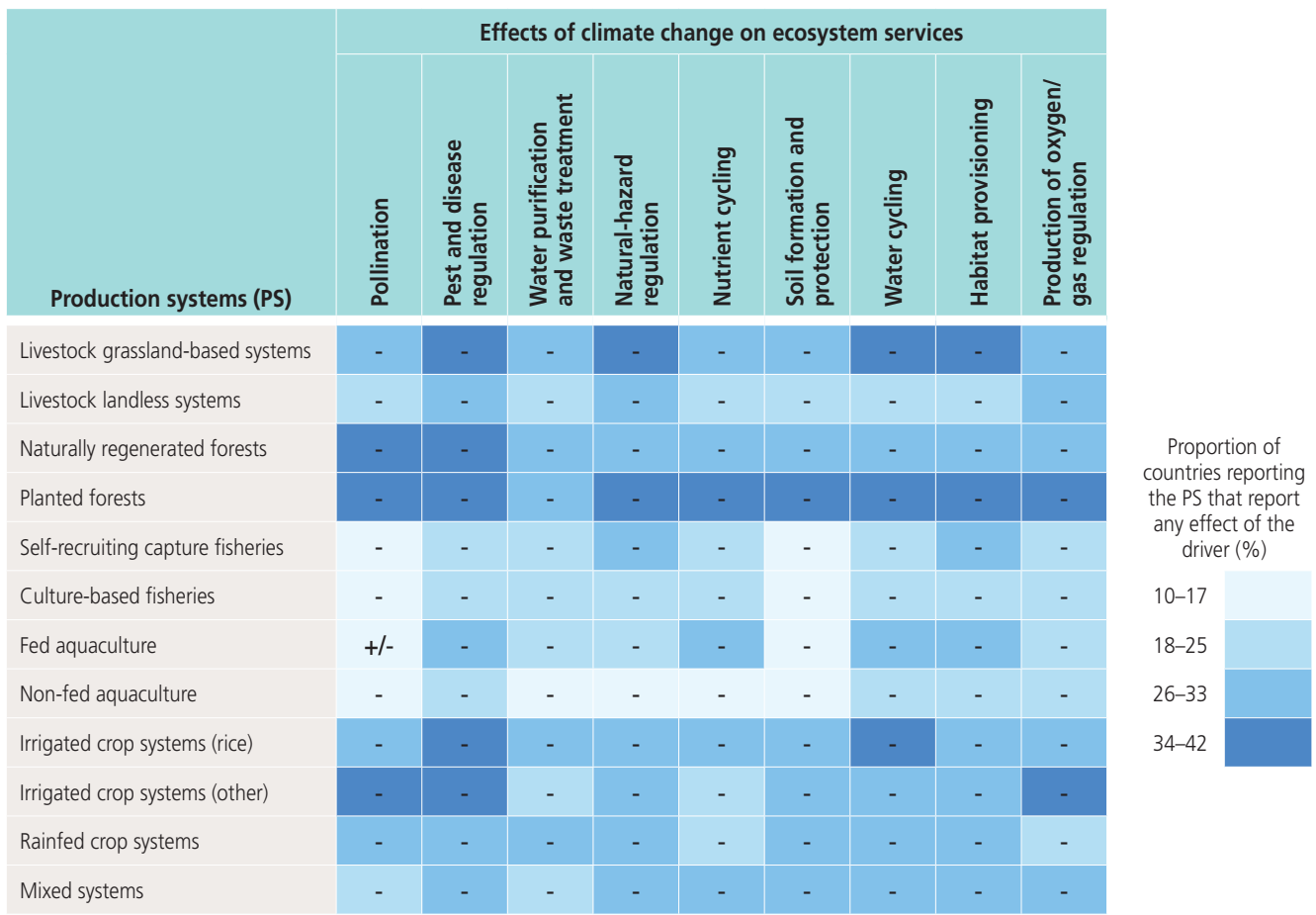

Notes: Countries were invited to report the effects (positive, negative or "no effect") of this driver on the provision of each ecosystem service in each production system. If $50 \%$ or more of the responses for a given combination of production system and ecosystem service indicate the same trend (positive [+], negative [-] or "no effect" [0]) then this trend is indicated in the respective cell of the table. In other cases, mixed effects (+/-) are indicated. The colour scale indicates the proportion of countries reporting the presence of the respective system that report any effect of the driver (positive, negative or "no effect") on the provision of the respective ecosystem service. See Section 1.5 for descriptions of the production systems and a discussion of ecosystem services. Analysis based on a total of 91 country reports. Source: Country reports prepared for The State of the World's Biodiversity for Food and Agriculture.

other goods, as well as regulating services such as air purification, temperature regulation, water cycling and flood regulation, with serious consequences for the local population. In the case of marine ecosystems, expected impacts of climate change are reported to be potentially catastrophic owing to rising temperatures and intense rains in the north of the country: ecosystem services predicted to be affected include climate regulation and the supply of fish and other products, with impacts on human nutrition, particularly among resource-poor coastal populations. China reports that in recent decades there has been a marked warming and drying of the climate in the vicinity of Hulun Lake (a large lake in Inner Mongolia), with a decline in the size of the lake, deterioration of the grasslands around it, desertification and a reduction in vegetation cover. These changes are reported to be a severe threat to several terrestrial species.

Numerous other countries highlight climate change as a major threat to biodiversity in inlandwater and coastal ecosystems. Predicted effects relate mainly to drier summers or to more intense rainfall that may result in floods and landslides 
that affect habitats such as lakes. With regard to marine ecosystems, the Netherlands reports that rising sea temperatures in the southern North Sea have resulted in changes in the fish community, with species that prefer warmer temperatures (e.g. sea bass) becoming more common and those that prefer cooler waters (e.g. plaice and cod) becoming less common or moving to deeper water. ${ }^{14}$ Similarly, Egypt reports that rising temperatures will lead to northwards shifts in the ranges of fish species, with impacts on fishery production. Mexico notes that its fisheries sector is considered highly vulnerable to climate change via the effects of current and predicted changes in water temperature, salinity, nutrient availability and other factors that influence the number and distribution of marine and freshwater biota. Several countries from the Pacific region mention the effects of coral bleaching, particularly during El Niño years.

A number of island nations mention the severe threats they face from climate change. For example, the Bahamas reports that out of all the identified threats to biodiversity, climate change is considered to be the most serious: 80 percent of the country's landmass is within 1.5 metres of sea level and 90 percent of its freshwater lenses ${ }^{15}$ are within 1.5 metres of the land surface, making groundwater resources highly vulnerable to contamination. It further notes that it is very vulnerable to climate-related threats such as coral bleaching, increasingly powerful hurricanes and rising sea levels. Saint Lucia mentions that rising temperatures and changing ocean currents have led to an increase in the quantity of Sargassum seaweed along the eastern coasts of Caribbean islands. It notes that marine plants and animals become trapped and die in thick sheets of seaweed and that under anaerobic conditions the seaweed degrades and emits a stench that creates problems for coastal communities. It also mentions, however, that the

\footnotetext{
14 The report cites Dulvy et al. (2008) and Ter Hofstede and Rijnsdorp (2011)

15 A freshwater lens is a body of freshwater that has percolated through the soil and floats on top of denser seawater below (Bailey, Jenson and Olsen, 2009).
}

seaweed has increased fish populations and thus led to larger catches for some fishers.

Aside from species targeted by capture fisheries, a number of other wild foods are reported to be threatened by climate change-related effects. For example, Eswatini reports that altered precipitation patterns and erratic rainfall are predicted to hinder the germination of wild fruits and other wild food plants. Peru notes that changes to fruiting seasons are expected to reduce the availability of wild fruits such as camu-camu (Myrciaria dubia), humarí (Poraqueiba sericea) and pijuayo (peach palm - Bactris gasipaes). Finland notes that climate change-related threats associated with the country's northern position include declines in the availability of wild mushrooms and berries as a result of poleward movement of the coniferous zone. It also mentions that earlier flowering when there is still a risk of frost exposure may also negatively affect the availability of wild berries.

\subsubsection{Natural disasters}

Ecosystems and food and agricultural production are often seriously affected by natural disasters. ${ }^{16}$ For example, a study of post-disaster needs assessments covering 74 medium- to large-scale disasters in 53 developing countries between 2006 and 2016 showed that agriculture accounted for 23 percent of all losses and damage incurred (FAO, 2018e). Where droughts are concerned, agriculture absorbed 83 percent of the economic impact. Overall, the crop sector was the most affected (49 percent of all damage and losses), followed by the livestock sector (36 percent) (see Figure 2.1 in Section 2.3). The most damaging types of disaster in the crop sector were floods, in the livestock sector droughts, in the forest sector storms, and in fisheries floods and storms (ibid.). Data from the International Disaster Database EM-DAT ${ }^{17}$ indicate that the number of disasters reported worldwide

\footnotetext{
16 The country-reporting guidelines invited countries to report on "natural" disasters. The use of this term is not intended to suggest that human actions do not contribute to many disasters in this category.

17 http://www.emdat.be/
} 


\section{PART B}

FIGURE 3.2

Global trends in the occurrence of natural disasters - 1980 to 2017

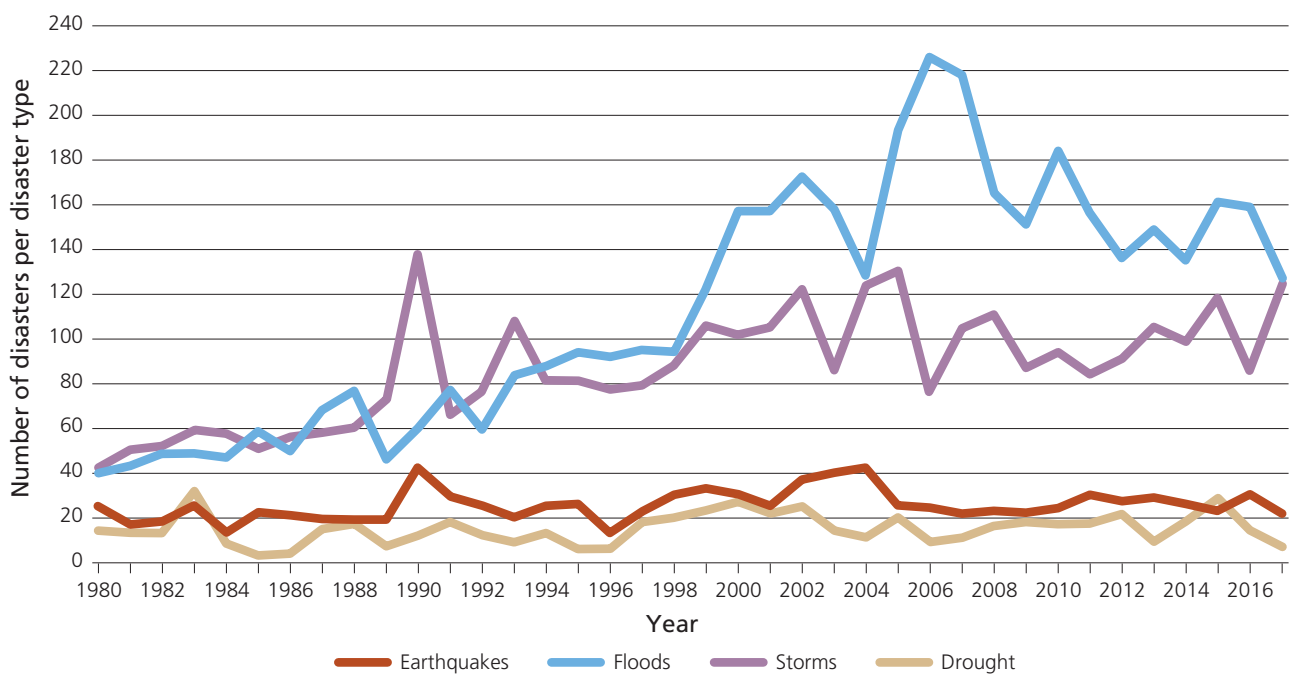

Source: EM-DAT, the OFDA/CRED International Disaster Database, www.emdat.be

increased rapidly between the 1960s and the early 2000s before reaching a plateau (Renaud and Murti, 2013). Figure 3.2 shows global trends in natural disasters for the period 1980 to 2017.

Disaster risk is influenced by complex and interacting drivers that affect both exposure ${ }^{18}$ and vulnerability. ${ }^{19}$ The latter is generally associated with poor land-use planning, poverty, rapid urbanization and ecosystem degradation (FAO and UNISDR, 2017; Sudmeier-Rieux et al., 2017). Several of the drivers discussed elsewhere in this chapter (e.g. climate change, population growth, land-use change, overexploitation of natural resources, policies and technological innovations) are involved.

Despite the impact that disasters have on the food and agriculture sector, their link to BFA

\footnotetext{
18 "People, property, systems, or other elements present in hazard zones that are thereby subject to potential losses" (UNISDR, 2009).

19 "The characteristics and circumstances of a community, system or asset that make it susceptible to the damaging effects of a hazard" (UNISDR, 2009).
}

remains poorly understood. Disasters of various kinds are widely recognized as threats to plant (crop), animal (livestock), forest and aquatic genetic resources, although the levels of threat posed to particular genetic resources (species, varieties, breeds, etc.) are generally not well established (FAO, forthcoming, 2010a, 2014a, 2015a, 2018e). Where associated biodiversity and the supply of ecosystem services are concerned, information on impacts is generally available at the ecosystem rather than the species level. For example, coastal and estuarine wetlands in some areas can be threatened by hurricanes (Morton and Barras, 2011). Sediment loss means that affected wetlands may be unable to recover properly (ibid.). Many wetlands are subject to multiple hazards, with flooding the most pervasive (Kusler, 2009). The roles played by BFA in reducing disaster risk are discussed in Section 2.3.

Countries were invited to report any disasters that had had a significant effect on their BFA during the preceding ten years. As shown in Table 3.8, 
TABLE 3.8

Natural disasters reported to have had a significant effect on biodiversity for food and agriculture and/or on ecosystem services in the past ten years

\begin{tabular}{|c|c|}
\hline $\begin{array}{l}\text { Type of disaster } \\
\text { (number of countries) }\end{array}$ & Reporting countries \\
\hline Droughts and heat waves (32) & $\begin{array}{l}\text { Afghanistan, Angola, Argentina, Belgium, Burkina Faso, China, Croatia, El Salvador, Eswatini, } \\
\text { Ethiopia, Gambia, Germany, Guyana, Hungary, India, Ireland, Jordan, Kenya, Mali, Nicaragua, Niger, } \\
\text { Panama, Peru, Saudi Arabia, Slovenia, Spain, Sri Lanka, Syrian Arab Republic, Togo, Viet Nam, Yemen, } \\
\text { Zambia, Zimbabwe }\end{array}$ \\
\hline Floods (31) & $\begin{array}{l}\text { Angola, Argentina, Bangladesh, Burkina Faso, Cameroon, China, Costa Rica, Croatia, Ecuador, } \\
\text { Ethiopia, Germany, Guyana, Hungary, India, Ireland, Mali, Nepal, Panama, Peru, Saudi Arabia, } \\
\text { Slovakia, Slovenia, Spain, Sri Lanka, Sudan, Togo, United Kingdom, Viet Nam, Yemen, Zambia, } \\
\text { Zimbabwe }\end{array}$ \\
\hline Fires and wildfires (21) & $\begin{array}{l}\text { Angola, Argentina, Cameroon, China, Costa Rica, Eswatini, Ethiopia, France, Jordan, Kenya, Mexico, } \\
\text { Niger, Panama, Saudi Arabia, Slovenia, Spain, Sri Lanka, Sudan, Syrian Arab Republic, United States of } \\
\text { America, Viet Nam, Zimbabwe }\end{array}$ \\
\hline $\begin{array}{l}\text { Oil spills, mining pollution, chemical } \\
\text { industrial accidents* (17) }\end{array}$ & $\begin{array}{l}\text { Angola, Belgium, China, Finland, Hungary, Jordan Lebanon, Mexico, Nepal, Niger, Norway, Peru, } \\
\text { Sudan, Sri Lanka, Viet Nam }\end{array}$ \\
\hline $\begin{array}{l}\text { Epidemics (in animals and plants) and } \\
\text { pest and disease outbreaks (15) }\end{array}$ & $\begin{array}{l}\text { Belgium, Burkina Faso, China, Estonia, Germany, Niger, Peru, Poland, Saudi Arabia, Slovenia, Sudan, } \\
\text { Sweden, United States of America, Zambia, Zimbabwe }\end{array}$ \\
\hline Cyclones/typhoons/hurricanes (13) & $\begin{array}{l}\text { Bangladesh, China, Cook Islands, Costa Rica, El Salvador, Fiji, France, Grenada, India, Samoa, } \\
\text { Solomon Islands, Viet Nam, Yemen }\end{array}$ \\
\hline Storms (11) & $\begin{array}{l}\text { Argentina, Croatia, France, Germany, Hungary, Ireland, Panama, Slovakia, Slovenia, Spain, United } \\
\text { Kingdom }\end{array}$ \\
\hline Landslides (9) & Argentina, Bangladesh, Cameroon, Nepal, Panama, Peru, Spain, Sri Lanka, Viet Nam \\
\hline Cold, frost and heavy snow episodes (7) & Belgium, Croatia, Ireland, Jordan, Peru, Slovenia, United Kingdom \\
\hline Volcanic eruptions (6) & Argentina, Cameroon, Ecuador, El Salvador, Ireland, Solomon Islands \\
\hline Earthquakes (5) & Costa Rica, Nepal, India, Solomon Islands, Spain \\
\hline Tsunamis (4) & Bangladesh, India, Solomon Islands, Yemen \\
\hline Heavy rainfall and hail storms (4) & Ethiopia, Hungary, Slovenia, Zambia \\
\hline Avalanches (2) & Nepal, Spain \\
\hline Armed conflicts* $(2)$ & Lebanon, Yemen \\
\hline
\end{tabular}

Notes: *Although the guidelines referred to "natural disasters", some countries reported on human-made disasters such as armed conflicts, oil spills, mining pollution and chemical industrial accidents. Analysis based on 91 country reports.

Source: Country reports prepared for The State of the World's Biodiversity for Food and Agriculture.

meteorological disasters are the most commonly reported category. Many country reports note the exacerbating effects of climate change. Information provided on how disasters are affecting the supply of particular ecosystem services is summarized in Table 3.9. Here again, in nearly all production systems and for nearly all ecosystem services, negative impacts are by far the most frequently reported. Given the devastating impacts that some disasters have on the affected areas, it is perhaps not surprising that many countries describe multiple effects on the supply of ecosystem services. Grenada, for example, reports that the major losses of forest species and forest cover caused by hurricanes in 2004 and 2005 substantially reduced the supply of services such as pollination, pest and disease regulation, and nutrient and water cycling. It notes that effects have been long lasting and that the impacts of the hurricanes are still (as of 2016) being felt, with many parts of the country continuing to suffer from water shortages caused by these disasters. 


\section{PART B}

\section{TABLE 3.9}

Reported effects of natural disasters on the provision of regulating and supporting ecosystem services, by production system

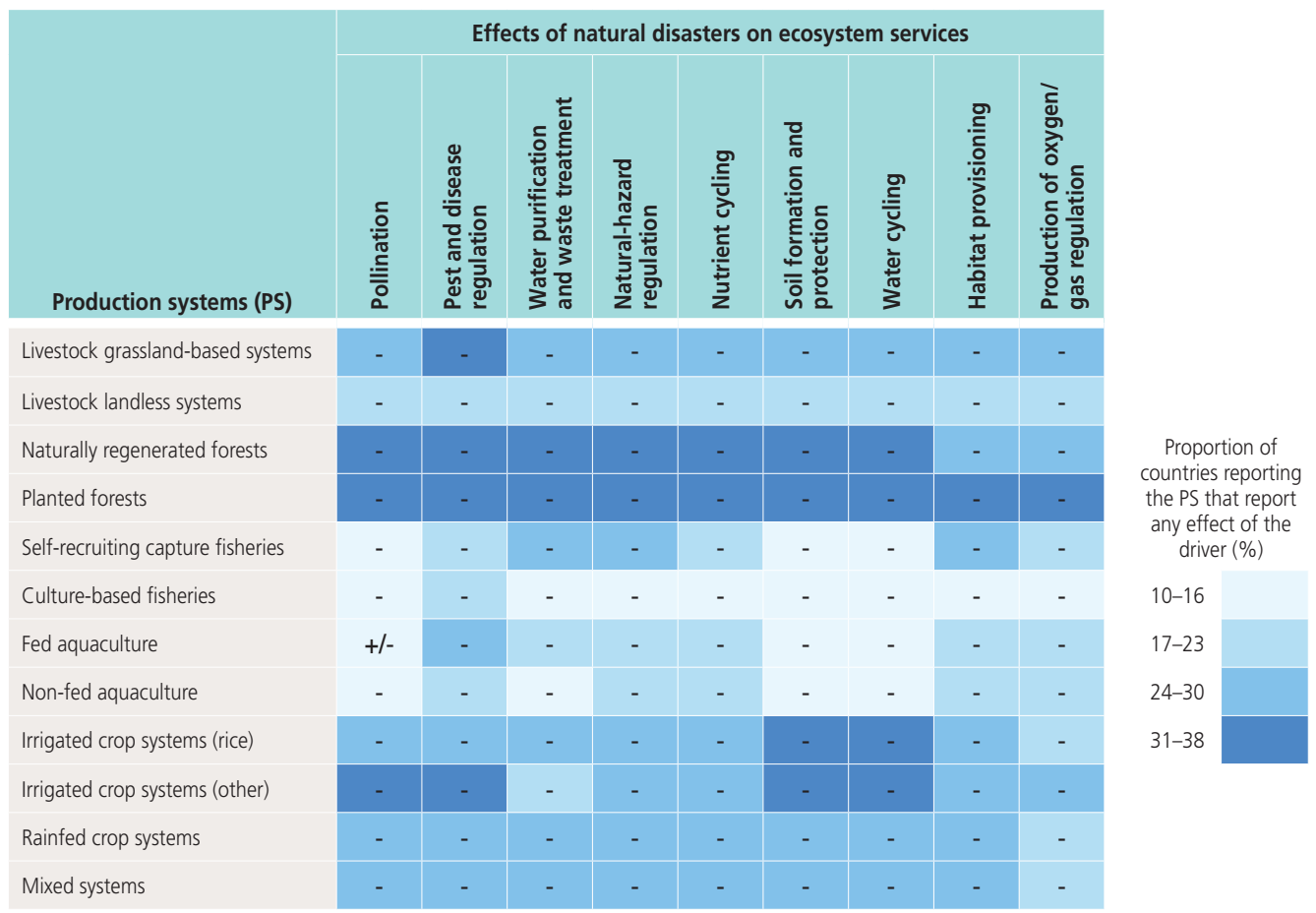

Notes: Countries were invited to report the effects (positive, negative or "no effect") of this driver on the provision of each ecosystem service in each production system. If $50 \%$ or more of the responses for a given combination of production system and ecosystem service indicate the same trend (positive [+], negative [-] or "no effect" [0]) then this trend is indicated in the respective cell of the table. In other cases, mixed effects (+/-) are indicated. The colour scale indicates the proportion of countries reporting the presence of the respective system that report any effect of the driver (positive, negative or "no effect") on the provision of the respective ecosystem service. See Section 1.5 for descriptions of the production systems and a discussion of ecosystem services. Analysis based on a total of 91 country reports. Source: Country reports prepared for The State of the World's Biodiversity for Food and Agriculture.

Fires are another category of disaster widely reported to be affecting BFA. ${ }^{20}$ For example, Mali reports that human-made bushfires are one of the most important causes of degradation of its vegetation and soils. It notes that fires slow the growth of trees, reduce soil organic matter levels and have restricted the distribution of some species. Impacts of geological disasters are also quite widely

\footnotetext{
20. The frequency and intensity of fires are likely to increase under climate change in several parts of the world (Barbero et al., 2015).
}

reported. Solomon Islands, for example, mentions that (in addition to cyclones) earthquakes, volcanic eruptions and tidal waves have serious impacts on its coastal environments. It notes that in the area affected in 2007 by an earthquake and tsunami there has been considerable loss of reefs and seagrass beds as a result of landform lifting and underwater landslides.

Many wild food species are reported to be vulnerable to drought, for example mangos in Nauru and aguaje (Mauritia flexuosa) in Peru. Togo mentions losses of wild foods caused by a drought in 
Box 3.2

Links between biodiversity, biodiversity loss and disease risk

An increasing number of emerging infectious diseases in humans, animals and plants have been reported over recent decades (Anderson et al., 2004; Fisher et al., 2012; Jones et al., 2008). This has been linked to rapid habitat changes caused by urbanization and agriculture intensification (Hassell et al., 2017). Empirical studies show that high levels of biodiversity are associated with high levels of pathogen diversity (Morand and Lajaunie, 2017). However, increases in epidemics and the risk of disease emergence are associated with decreased biodiversity (ibid.), as deforestation and agricultural intensification increase contacts between wildlife, domestic animals and humans, favouring the spread of zoonotic diseases (Keesing et al., 2010).

Empirical studies have also shown that species-rich host communities contribute to reducing the transmission of infectious diseases, a phenomenon known as the "dilution effect". The effect has been observed in studies on several vector-borne and zoonotic diseases. A meta-analysis of 90 studies on various diseases that affect humans, wildlife, livestock or plants concluded that they provide broad support for a negative effect of diversity on disease transmission (Johnson, Ostfeld and Keesing, 2015). The magnitude of the effect, however, appears to be related to the structure of species communities and not only to species diversity per se (Civitello et al., 2015).

Similar effects operate at the infraspecies (genetic) level. Species that have high genetic diversity may sustain a high diversity of pathogens, but with each pathogen showing low transmission and rarely causing an epidemic. In contrast, while species that have low genetic diversity may sustain fewer pathogens, these pathogens may have high transmissibility and the potential to cause dramatic epidemics (Heesterbeek et al., 2015; Karvonen et al., 2016; King and Lively, 2012).

Source: Provided by Serge Morand.
2013 and by a flood in 2008. Peru notes ${ }^{21}$ that climatic events will cause long-term changes in forest structure, composition and plant diversity and exert additional pressure on already-reduced terrestrial mammal populations.

\subsubsection{Pests, diseases and invasive alien species $^{22}$}

Pests and diseases affect food and agriculture worldwide and can pose a threat to the supply of ecosystem services and to the survival of some components of BFA, particularly species or withinspecies populations confined to small geographical areas. Aside from their direct effects, diseases can also threaten BFA indirectly, for example when their presence triggers practices such as

21 Citing Bodmer et al. (2014).

22 The term alien species has been defined as "a species, subspecies or lower taxon, introduced outside its natural past or present distribution" and an invasive alien species as "an alien species whose introduction and/or spread threaten biological diversity" (CBD, 2002) the excessive use of pesticides, fire, antibiotics or tillage. Disease epidemiology is, in turn, affected by a range of drivers, including climate change, trade and changes in land use. Loss of biodiversity can itself be a risk factor (see Box 3.2).

Invasive alien species are regarded as a major threat to biodiversity (e.g. CBD Secretariat, 2006). Alien species may be introduced into a new ecosystem accidentally, for example as a result of trade or travel (Wittenberg and Cock, 2001). However, they may also be introduced deliberately as part of various management measures, including for biological control purposes, and later turn out to be invasive (Myers and Cory, 2017). Ecological changes and imbalances caused by human actions can also contribute to invasions. For example, shrub encroachment by invasive thorny species is often a result of overgrazing (e.g. Kgosikoma and Mogotsi, 2013; see also Section 3.6.3).

Invasive species have had substantial impacts on various important components of BFA. For example, the New Zealand flatworm (Arthurdendyus 


\section{PART B}

TABLE 3.10

Reported effects of pests, diseases and invasive alien species on the provision of regulating and supporting ecosystem services, by production system

\begin{tabular}{|c|c|c|c|c|c|c|c|c|c|c|}
\hline \multirow[b]{2}{*}{ Production systems (PS) } & \multicolumn{9}{|c|}{$\begin{array}{l}\text { Effects of pests, diseases and invasive alien species on } \\
\text { ecosystem services }\end{array}$} & \\
\hline & 드을 & 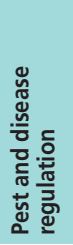 & 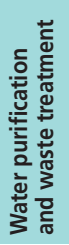 & 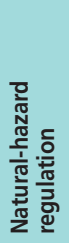 & 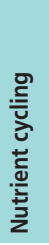 & 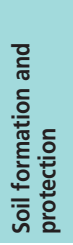 & $\begin{array}{l}\text { 을 } \\
\frac{.0}{2} \\
\frac{1}{d} \\
\frac{1}{\pi} \\
3\end{array}$ & 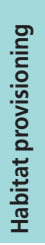 & 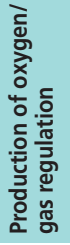 & \\
\hline Livestock grassland-based systems & - & - & - & - & - & $+/-$ & $+1-$ & - & $+/-$ & \\
\hline Livestock landless systems & $+/-$ & - & - & - & - & $+/-$ & - & - & - & \multirow{4}{*}{$\begin{array}{l}\text { Proportion of } \\
\text { countries reporting } \\
\text { the PS that report } \\
\text { any effect of the } \\
\text { driver }(\%)\end{array}$} \\
\hline Naturally regenerated forests & - & - & - & - & - & - & - & - & - & \\
\hline Planted forests & - & - & - & - & - & - & - & - & - & \\
\hline Self-recruiting capture fisheries & - & - & - & - & - & 0 & - & - & - & \\
\hline Culture-based fisheries & - & - & - & - & - & - & $+/-$ & - & - & $9-17$ \\
\hline Fed aquaculture & - & - & - & - & - & $+/-$ & - & - & - & $18-25$ \\
\hline Non-fed aquaculture & - & - & - & - & - & - & - & - & - & $26-33$ \\
\hline Irrigated crop systems (rice) & - & - & - & - & - & - & - & - & - & $34-41$ \\
\hline Irrigated crop systems (other) & - & - & - & - & - & 0 & $+1-$ & - & - & \\
\hline Rainfed crop systems & - & - & - & - & - & - & - & - & - & \\
\hline Mixed systems & - & - & - & - & 0 & 0 & 0 & - & 0 & \\
\hline
\end{tabular}

Notes: Countries were invited to report the effects (positive, negative or "no effect") of this driver on the provision of each ecosystem service in each production system. If $50 \%$ or more of the responses for a given combination of production system and ecosystem service indicate the same trend (positive [+], negative [-] or "no effect" [0]) then this trend is indicated in the respective cell of the table. In other cases, mixed effects (+/-) are indicated. The colour scale indicates the proportion of countries reporting the presence of the respective system that report any effect of the driver(positive, negative or "no effect") on the provision of the respective ecosystem service. See Section 1.5 for descriptions of the production systems and a discussion of ecosystem services. Analysis based on a total of 91 country reports. Source: Country reports prepared for The State of the World's Biodiversity for Food and Agriculture.

triangulates) is a significant threat to earthworms in the United Kingdom and some other European countries (Murchie and Gordon, 2013). Invasive plants may affect the abundance and community structure of mycorrhizal fungi or affect the leaf litter, and hence the habitats of litter-dwelling arthropods and other invertebrates (Cole et al., 2006; Jordan et al., 2012; Turbé et al., 2010). Invasive herbivores can influence soil ecosystems via their effects on the structure of plant communities (although not in all cases with a negative impact on soil biodiversity) (e.g. Bellingham et al., 2016; Stritar et al., 2010).
Numerous invasive species have had severe impacts on forests. For example, Hymenoscyphus fraxineus, a fungus that causes ash dieback disease, has been rapidly spreading across much of Europe (Forestry Commission, 2018). Ash dieback and the emerald ash borer (Agrilus planipennis), a beetle that is spreading westwards across Europe, are posing a major threat to ash tree (Fraxinus excelsior) populations (Thomas, 2016). Loss of the ash would have a significant impact on biodiversity. For example, 44 species in the United Kingdom (4 lichens, 11 fungi and 29 invertebrates) are 
considered "obligate" ash-associated species and a further 62 (19 fungi, 13 lichens, 6 bryophytes and 24 invertebrates) to be highly associated with the ash (Mitchell et al., 2014).

Many aquatic ecosystems are also affected by invasive alien species, which can cause problems, inter alia, by preying on native species, impeding watercourses and affecting ecological processes such as nutrient cycling (MEA, 2005b). Major examples include water hyacinth (Eichhornia crassipes), a highly invasive species that covers and chokes major waterways and lake surfaces in many countries, negatively affecting biodiversity, fisheries, hydroelectric production, transportation and local economies across large parts of Africa and Asia (CABI, 2018).

Information provided by countries on the effects of pests, diseases and invasive alien species on the supply of ecosystem services is summarized in Table 3.10. The ecosystem services most often reported to be negatively affected are pollination, pest and disease regulation and habitat provisioning. Several countries report that invasive species and/or pests and diseases are becoming more prevalent, with a number noting that climate change, habitat destruction or changes in agricultural practices are exacerbating factors (see below for further information). Some provide specific examples of the effects of pests, diseases and invasive alien species on associated biodiversity and the supply of ecosystem services. For instance, Zambia reports that invasive alien species have negatively affected the habitats of some pollinators. The Bahamas mentions that the lionfish (Pterois volitans), an invasive species that entered the country's waters in recent years, is a threat both to biodiversity and to fisheries. More specifically, it notes that as well as feeding on the juveniles and adults of commercially important fish species such as grunts and snapper, the lionfish is feared to be affecting coral reefs by predating on herbivores that keep the reefs free of algae. In order to counteract the impact of the lionfish, the country's Fisheries Department is introducing initiatives to encourage the consumption of the species (see Section 4.4 for additional information).
Sri Lanka reports that the clown knife fish (Chitala ornatus), first introduced as an ornamental aquarium fish, is affecting some of the county's most threatened endemic freshwater fish populations. The Netherlands mentions that the Pacific oyster (Crassostrea gigas), an invasive alien species that has been spreading through the country's waters since the 1960 s, is considered a serious threat to the functions of coastal waters, including shellfish culture and the provision of feeding areas for birds. It notes, however, that reefs created by this species can provide an important habitat for certain species. ${ }^{23} \mathrm{~A}$ few countries mention the threat posed by hybridization between invasive alien species and native species. For example, Zambia reports that the Nile tilapia (Oreochromis niloticus), an escapee from fish farms, is not only competing with indigenous fish but also likely to be altering the genetic composition of native cichlid species.

Countries were invited to report examples of invasive alien species that had had a significant effect on BFA and/or ecosystem services in the preceding ten years. The 59 countries $^{24}$ that responded reported a total of 1077 such cases, involving 633 distinct species and 509 distinct genera. The most commonly reported species are shown in Table 3.11. Half of the reported invasive alien species are plants, 46 percent animals, and the remaining 4 percent fungi, chromists, viruses or bacteria (Figure 3.3). Almost 60 percent are reported by Asian or European countries.

With regard to the causes of species invasions, some country reports, as noted above, mention a link to climate change, for example in the case of the threat posed by Kikuyo grass (Pennisetum clandestinum) to the páramo

\footnotetext{
23 The report cites Smaal, Kater and Wijsman (2009).

24 Angola, Argentina, Bangladesh, Belarus, Belgium, Bulgaria, Burkina Faso, Cameroon, China, Cook Islands, Croatia, Ecuador, Egypt, El Salvador, Estonia, Eswatini, Ethiopia, Fiji, Finland, France, Gambia, Grenada, Guyana, Hungary, India, Iraq, Ireland, Jordan, Kenya, Lebanon, Mali, Mexico, Nepal, Netherlands, Niger, Norway, Palau, Panama, Papua New Guinea, Peru, Poland, Qatar, Samoa, Saudi Arabia, Slovakia, Slovenia, Spain, Sri Lanka, Sudan, Sweden, Switzerland, Togo, Tonga, United Kingdom, United States of America, Viet Nam, Yemen, Zambia, Zimbabwe.
} 
TABLE 3.11

Invasive alien species reported by five or more countries as present in one or more production systems

\begin{tabular}{|c|c|c|c|c|c|c|c|c|c|}
\hline \multirow[b]{2}{*}{$\begin{array}{l}\text { Species } \\
\text { (Latin name) }\end{array}$} & \multirow[b]{2}{*}{$\begin{array}{c}\text { Common } \\
\text { English } \\
\text { name }\end{array}$} & \multirow[b]{2}{*}{$\begin{array}{l}\text { Number } \\
\text { of } \\
\text { countries }\end{array}$} & \multirow[t]{2}{*}{$\begin{array}{l}\text { Production systems where reported } \\
\text { (in decreasing order of frequency) }\end{array}$} & \multicolumn{3}{|c|}{$\begin{array}{c}\text { Impact } \\
\text { on BFA } \\
\text { (number of } \\
\text { responses) }\end{array}$} & \multicolumn{3}{|c|}{$\begin{array}{l}\text { Impact on } \\
\text { ecosystem } \\
\text { services } \\
\text { (number of } \\
\text { responses) }\end{array}$} \\
\hline & & & & 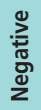 & 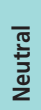 & 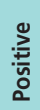 & 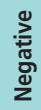 & $\begin{array}{l}\overline{0} \\
\text { एँ } \\
\frac{0}{2}\end{array}$ & 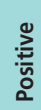 \\
\hline
\end{tabular}

\begin{tabular}{|c|c|c|c|}
\hline $\begin{array}{l}\text { Eichhornia } \\
\text { crassipes }\end{array}$ & $\begin{array}{l}\text { Water } \\
\text { hyacinth }\end{array}$ & 21 & $\begin{array}{l}\text { irrigated crop systems (rice), mixed systems (livestock, crop, } \\
\text { forest and/or aquatic and fisheries), fed aquaculture, irrigatec } \\
\text { crop systems (non-rice), non-fed aquaculture, livestock } \\
\text { grassland-based systems, naturally regenerated forests, } \\
\text { planted forests, rainfed crop systems }\end{array}$ \\
\hline Lantana camara & $\begin{array}{l}\text { Largeleaf } \\
\text { lantana }\end{array}$ & 14 & $\begin{array}{l}\text { Livestock grassland-based systems, naturally regenerated } \\
\text { forests, irrigated crop systems (rice), planted forests, irrigated } \\
\text { crop systems (non-rice), mixed systems (livestock, crop, forest } \\
\text { and/or aquatic and fisheries), rainfed crop systems, livestock } \\
\text { landless systems }\end{array}$ \\
\hline Cyprinus carpio & $\begin{array}{l}\text { Common } \\
\text { carp }\end{array}$ & 10 & Self-recruiting capture fisheries, fed aquaculture \\
\hline Prosopis juliflora & Ironwood & 10 & $\begin{array}{l}\text { Naturally regenerated forests, livestock grassland-based } \\
\text { systems, irrigated crop systems (non-rice), irrigated crop } \\
\text { systems (rice), mixed systems (livestock, crop, forest and/or } \\
\text { aquatic and fisheries), planted forests, rainfed crop systems }\end{array}$ \\
\hline $\begin{array}{l}\text { Mikania } \\
\text { micrantha }\end{array}$ & Bitter vine & 9 & $\begin{array}{l}\text { Naturally regenerated forests, livestock grassland-based } \\
\text { systems, irrigated crop systems (rice), livestock landless } \\
\text { systems, mixed systems, planted forests, rainfed crop systems }\end{array}$ \\
\hline $\begin{array}{l}\text { Chromolaena } \\
\text { odorata }\end{array}$ & Siam weed & 9 & $\begin{array}{l}\text { Naturally regenerated forests, planted forests, livestock } \\
\text { grassland-based systems, irrigated crop systems (rice), } \\
\text { livestock landless systems, rainfed crop systems }\end{array}$ \\
\hline $\begin{array}{l}\text { Oreochromis } \\
\text { mossambicus }\end{array}$ & $\begin{array}{l}\text { Mozambique } \\
\text { tilapia }\end{array}$ & 8 & $\begin{array}{l}\text { Self-recruiting capture fisheries, culture-based fisheries, fed } \\
\text { aquaculture }\end{array}$ \\
\hline $\begin{array}{l}\text { Parthenium } \\
\text { hysterophorus }\end{array}$ & Santa-Maria & 8 & $\begin{array}{l}\text { Livestock grassland-based systems, naturally regenerated } \\
\text { forests, mixed systems (livestock, crop, forest and/or aquatic } \\
\text { and fisheries), planted forests, rainfed crop systems, irrigated } \\
\text { crop systems (non-rice), irrigated crop systems (rice), livestock } \\
\text { landless systems }\end{array}$ \\
\hline Harmonia axyridis & $\begin{array}{l}\text { Harlequin } \\
\text { ladybird }\end{array}$ & 7 & $\begin{array}{l}\text { Rainfed crop systems, irrigated crop systems (non-rice), } \\
\text { livestock grassland-based systems, mixed systems (livestock, } \\
\text { crop, forest and/or aquatic and fisheries), planted forests }\end{array}$ \\
\hline Salvinia molesta & Giant salvinia & 7 & $\begin{array}{l}\text { Irrigated crop systems (rice), self-recruiting capture fisheries, } \\
\text { culture-based fisheries, fed aquaculture, mixed systems } \\
\text { (livestock, crop, forest and/or aquatic and fisheries), rainfed } \\
\text { crop systems }\end{array}$ \\
\hline Bemisia tabaci & $\begin{array}{l}\text { Sweet potato } \\
\text { whitefly }\end{array}$ & 6 & $\begin{array}{l}\text { Rainfed crop systems, irrigated crop systems (non-rice), } \\
\text { irrigated crop systems (rice) }\end{array}$ \\
\hline $\begin{array}{l}\text { Micropterus } \\
\text { salmoides }\end{array}$ & $\begin{array}{l}\text { Largemouth } \\
\text { bass }\end{array}$ & 6 & Self-recruiting capture fisheries \\
\hline $\begin{array}{l}\text { Oncorhynchus } \\
\text { mykiss }\end{array}$ & $\begin{array}{l}\text { Rainbow } \\
\text { trout }\end{array}$ & 6 & Fed aquaculture, self-recruiting capture fisheries \\
\hline $\begin{array}{l}\text { Oreochromis } \\
\text { niloticus }\end{array}$ & Nile tilapia & 6 & Self-recruiting capture fisherie \\
\hline
\end{tabular}

Self-recruiting capture fisheries, culture-based fisheries,

irrigated crop systems (rice), mixed systems (livestock, crop, grassland-based systems, naturally regenerated forests, planted forests, rainfed crop systems

fivestock grassland-based systems, naturally regenerated crop systems (non-rice), mixed systems (livestock, crop, forest and/or aquatic and fisheries), rainfed crop systems, livestock andless systems

Naturally regenerated forests, livestock grassland-based . aquatic and fisheries), planted forests, rainfed crop systems

Naturally regenerated forests, livestock grassland-based systems, mixed systems, planted forests, rainfed crop systems

Naturally regenerated forests, planted forests, livestock grassland-based systems, irrigated crop systems (rice), livestock landless systems, rainfed crop systems

Self-recruiting capture fisheries, culture-based fisheries, fed quaculture

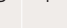

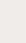

\section{西}


TABLE 3.11 (Cont.)

Invasive alien species reported by five or more countries as present in one or more production systems

\begin{tabular}{|c|c|c|c|c|c|c|c|c|c|}
\hline \multirow[b]{2}{*}{$\begin{array}{c}\text { Species } \\
\text { (Latin name) }\end{array}$} & \multirow[b]{2}{*}{$\begin{array}{l}\text { Common } \\
\text { English } \\
\text { name }\end{array}$} & \multirow[b]{2}{*}{$\begin{array}{l}\text { Number } \\
\text { of } \\
\text { countries }\end{array}$} & \multirow[t]{2}{*}{$\begin{array}{l}\text { Production systems where reported } \\
\text { (in decreasing order of frequency) }\end{array}$} & \multicolumn{3}{|c|}{$\begin{array}{l}\text { Impact } \\
\text { on BFA } \\
\text { (number of } \\
\text { responses) }\end{array}$} & \multicolumn{3}{|c|}{$\begin{array}{c}\text { Impact on } \\
\text { ecosystem } \\
\text { services } \\
\text { (number of } \\
\text { responses) }\end{array}$} \\
\hline & & & & 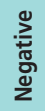 & $\begin{array}{l}\frac{\pi}{2} \\
\frac{1}{2} \\
\frac{0}{2}\end{array}$ & 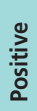 & 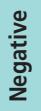 & 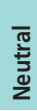 & $\sum_{\substack{\infty \\
:}}^{0}$ \\
\hline Pistia stratiotes & Water lettuce & 6 & $\begin{array}{l}\text { Self-recruiting capture fisheries, culture-based fisheries, } \\
\text { irrigated crop systems (rice), mixed systems (livestock, crop, } \\
\text { forest and/or aquatic and fisheries), naturally regenerated } \\
\text { forests }\end{array}$ & 3 & 0 & 1 & 3 & 0 & 1 \\
\hline Tuta absoluta & $\begin{array}{l}\text { Tomato } \\
\text { leafminer }\end{array}$ & 6 & $\begin{array}{l}\text { Irrigated crop systems (non-rice), rainfed crop systems, } \\
\text { irrigated crop systems (rice), naturally regenerated forests }\end{array}$ & 1 & 0 & 1 & 0 & 0 & 1 \\
\hline $\begin{array}{l}\text { Leucaena } \\
\text { leucocephala }\end{array}$ & $\begin{array}{l}\text { White } \\
\text { leadtree }\end{array}$ & 6 & $\begin{array}{l}\text { Mixed systems (livestock, crop, forest and/or aquatic and } \\
\text { fisheries), naturally regenerated forests, livestock grassland- } \\
\text { based systems }\end{array}$ & 3 & 0 & 0 & 3 & 0 & 0 \\
\hline Merremia peltata & Merremia & 5 & $\begin{array}{l}\text { Naturally regenerated forests, mixed systems (livestock, crop, } \\
\text { forest and/or aquatic and fisheries) }\end{array}$ & 3 & 0 & 0 & 1 & 0 & 0 \\
\hline $\begin{array}{l}\text { Ambrosia } \\
\text { artemisiifolia }\end{array}$ & $\begin{array}{l}\text { Common } \\
\text { ragweed }\end{array}$ & 5 & $\begin{array}{l}\text { Rainfed crop systems, irrigated crop systems (non-rice), mixed } \\
\text { systems (livestock, crop, forest and/or aquatic and fisheries) }\end{array}$ & 3 & 0 & 1 & 2 & 0 & 0 \\
\hline Ceratitis capitata & Medfly & 5 & $\begin{array}{l}\text { Rainfed crop systems, irrigated crop systems (non-rice), mixed } \\
\text { systems (livestock, crop, forest and/or aquatic and fisheries) }\end{array}$ & 1 & 0 & 0 & 1 & 0 & 0 \\
\hline $\begin{array}{l}\text { Cherax } \\
\text { quadricarinatus }\end{array}$ & $\begin{array}{l}\text { Australian } \\
\text { redclaw }\end{array}$ & 5 & Self-recruiting capture fisheries & 5 & 0 & 0 & 2 & 0 & 0 \\
\hline Clarias gariepinus & $\begin{array}{l}\text { North African } \\
\text { catfish }\end{array}$ & 5 & Self-recruiting capture fisheries, fed aquaculture & 4 & 1 & 0 & 2 & 2 & 0 \\
\hline $\begin{array}{l}\text { Heracleum } \\
\text { mantegazzianum }\end{array}$ & $\begin{array}{l}\text { Giant } \\
\text { hogweed }\end{array}$ & 5 & $\begin{array}{l}\text { Rainfed crop systems, mixed systems (livestock, crop, forest } \\
\text { and/or aquatic and fisheries), livestock grassland-based } \\
\text { systems, irrigated crop systems (non-rice), naturally irrigated } \\
\text { crop systems, planted forests }\end{array}$ & 4 & 0 & 0 & 2 & 0 & 0 \\
\hline $\begin{array}{l}\text { Pacifastacus } \\
\text { leniusculus }\end{array}$ & Signal crayfish & 5 & $\begin{array}{l}\text { Self-recruiting capture fisheries, fed aquaculture, culture- } \\
\text { based fisheries, non-fed aquaculture }\end{array}$ & 3 & 0 & 0 & 2 & 0 & 0 \\
\hline Fallopia japonica & $\begin{array}{l}\text { Japanese } \\
\text { knotweed }\end{array}$ & 5 & $\begin{array}{l}\text { Naturally regenerated forests, planted forests, mixed systems } \\
\text { (livestock, crop, forest and/or aquatic and fisheries), irrigated } \\
\text { crop systems (non-rice), livestock grassland-based systems, } \\
\text { rainfed crop systems }\end{array}$ & 4 & 0 & 0 & 2 & 0 & 0 \\
\hline $\begin{array}{l}\text { Robinia } \\
\text { pseudoacacia }\end{array}$ & Black locust & 5 & $\begin{array}{l}\text { Naturally regenerated forests, irrigated crop systems (non- } \\
\text { rice), planted forests, mixed systems (livestock, crop, forest } \\
\text { and/or aquatic and fisheries) }\end{array}$ & 1 & 2 & 1 & 3 & 0 & 1 \\
\hline $\begin{array}{l}\text { Solidago } \\
\text { canadensis }\end{array}$ & $\begin{array}{l}\text { Common } \\
\text { goldenrod }\end{array}$ & 5 & $\begin{array}{l}\text { Mixed systems (livestock, crop, forest and/or aquatic and } \\
\text { fisheries), rainfed crop systems, livestock grassland-based } \\
\text { systems, irrigated crop systems (non-rice), naturally irrigated } \\
\text { crop systems, planted forests }\end{array}$ & 2 & 2 & 0 & 3 & 0 & 1 \\
\hline Solidago gigantea & Tall goldenrod & 5 & $\begin{array}{l}\text { Mixed systems (livestock, crop, forest and/or aquatic and } \\
\text { fisheries), rainfed crop systems, irrigated crop systems (non- } \\
\text { rice), livestock grassland-based systems, naturally irrigated } \\
\text { crop systems }\end{array}$ & 3 & 1 & 0 & 3 & 0 & 1 \\
\hline Varroa destructor & Varroa mite & 5 & $\begin{array}{l}\text { Rainfed crop systems, livestock grassland-based systems, } \\
\text { irrigated crops (other), mixed systems (livestock, crop, forest } \\
\text { and/or aquatic and fisheries), planted forests }\end{array}$ & 4 & 0 & 0 & 2 & 0 & 0 \\
\hline
\end{tabular}

Note: Analysis based on a total of 91 country reports.

Source: Country reports prepared for The State of the World's Biodiversity for Food and Agriculture. 


\section{PART B}

FIGURE 3.3

Invasive alien species reported by countries to be impacting biodiversity for food and agriculture, (A) by type of organism and (B) by region

A

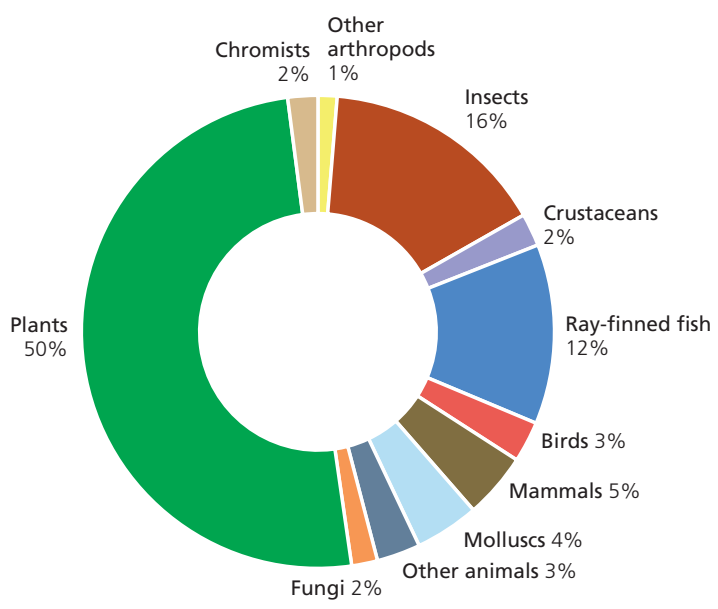

B

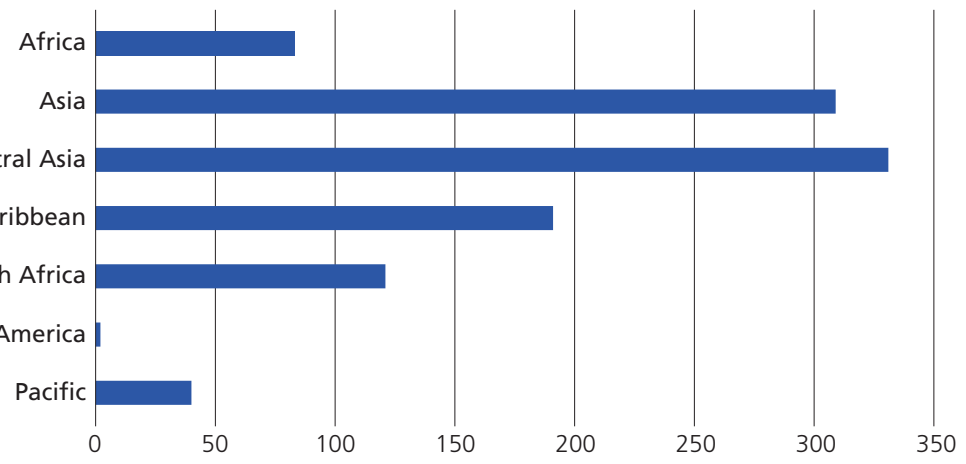

Number of responses

Notes: A "response" is a mention by a specific country of a specific component of biodiversity (species or genus). Out of 91 reporting countries, 59 provided a combined total of 1077 responses. A single species or genus may be reported by more than one country. Source: Country reports prepared for The State of the World's Biodiversity for Food and Agriculture.

ecosystem in Ecuador. Zimbabwe mentions that heightened climatic variability, including floods and droughts, are increasing susceptibility to invasive species, with negative impacts on, inter alia, wild foods. Mexico refers to a number of human actions (e.g. modernization of transport systems, mining, biological control practices and artificially joining water bodies) and natural phenomena (e.g. natural disasters) as contributing to the introduction of invasive species. ${ }^{25}$ Palau reports that, in the last 20 years, land clearing, road construction and other human activities have enabled the invasive vine Merremia peltata to thrive. 25 The report cites Comité Asesor Nacional sobre Especies
Invasoras (2010). 


\subsection{Advances and innovations in science and technology}

- Advances in science and technology are largely seen as positive by countries and as ways of reducing negative effects of other drivers on biodiversity for food and agriculture (BFA).

- Science and technology are crucial to the generation of knowledge related to genes, species and ecosystems and hence to the sustainable use and conservation of BFA.

- Some technologies have negative effects on BFA and its role in the supply of ecosystem services. The precautionary approach provides a framework that can guide the adoption of science and technology advances in agriculture and food production.

Advances and innovations in science and technology can have both positive and negative effects on BFA and associated ecosystem services, often by increasing or reducing the impact of other drivers discussed in this chapter. Although it can be argued that it is how the technologies are used rather than the fact that they exist that "drives" impacts on BFA and the supply of ecosystem services, there are some technologies that open major new opportunities for more sustainable management and others whose use on any significant scale inevitably involves serious negative impacts on components of biodiversity and/or substantial homogenization of the production system.

Any technology used to control pests, weeds or diseases that is toxic to non-target organisms is a potential threat to associated biodiversity. For example, unintended negative impacts of pesticide use on soil biodiversity have been documented (FAO and ITPS, 2015) (see also Section 3.6.2). However, impacts on BFA can also arise because of the ways in which a new technology influences the broader management of the production system. For example, in areas where genetically modified glyphosate-resistant crop cultivars have been adopted, for instance in parts of Argentina and the United States of America, this has tended to lead to a simplification of landscapes as crop rotations decline (Schutte et al., 2017).
The adoption of a precautionary approach ${ }^{26}$ to advances in science and technology has been widely advocated. In the case of capture fisheries (including species introductions), detailed guidelines on the application of the precautionary approach have been elaborated (FAO, 1996b).

Technologies that have had, or could have, positive effects on BFA include nanotechnology, which offers multiple opportunities to improve detection and monitoring and thus support rational decision-making, resource-use efficiency and precision targeting, all of which have the potential to reduce environmental impacts. For example, the use of nanosensors allows detection of plant diseases before symptoms become evident, meaning that infected plants can be removed to prevent the spread of disease and reduce or eliminate the need to use pesticides (Chen and Yada, 2011). Another example from the field of crop production is the use of robotics and nanosensors to improve mechanical weeding and hence reduce or eliminate the need for chemical herbicides (Duhan et al., 2017; Westwood et al., 2018). In addition to developments of this kind, advances in "nature-based" solutions involving the deployment of components of BFA can provide environmentally friendly means of addressing the various challenges facing food and agriculture. Many of these approaches are discussed in Section 2.4 and in Chapter 5.

The impacts of developments in genetics on the management of plant (crop), animal (livestock), forest and aquatic genetic resources are discussed in the respective sectoral global assessments published by FAO (FAO, forthcoming, 2010a, 2014a, 2015a). In addition to opening new opportunities in the fields of characterization and genetic improvement (see Chapters 5 and 6 for brief

\footnotetext{
26 The 1992 Rio Declaration on Environment and Development states that "in order to protect the environment, the precautionary approach shall be widely applied by States according to their capabilities. Where there are threats of serious or irreversible damage, lack of full scientific certainty shall not be used as a reason for postponing cost-effective measures to prevent environmental degradation" (Principle 15) (UNCED, 1992)
} 


\section{PART B}

TABLE 3.12

Reported effects of advances and innovations in science and technology on the provision of regulating and supporting ecosystem services, by production system

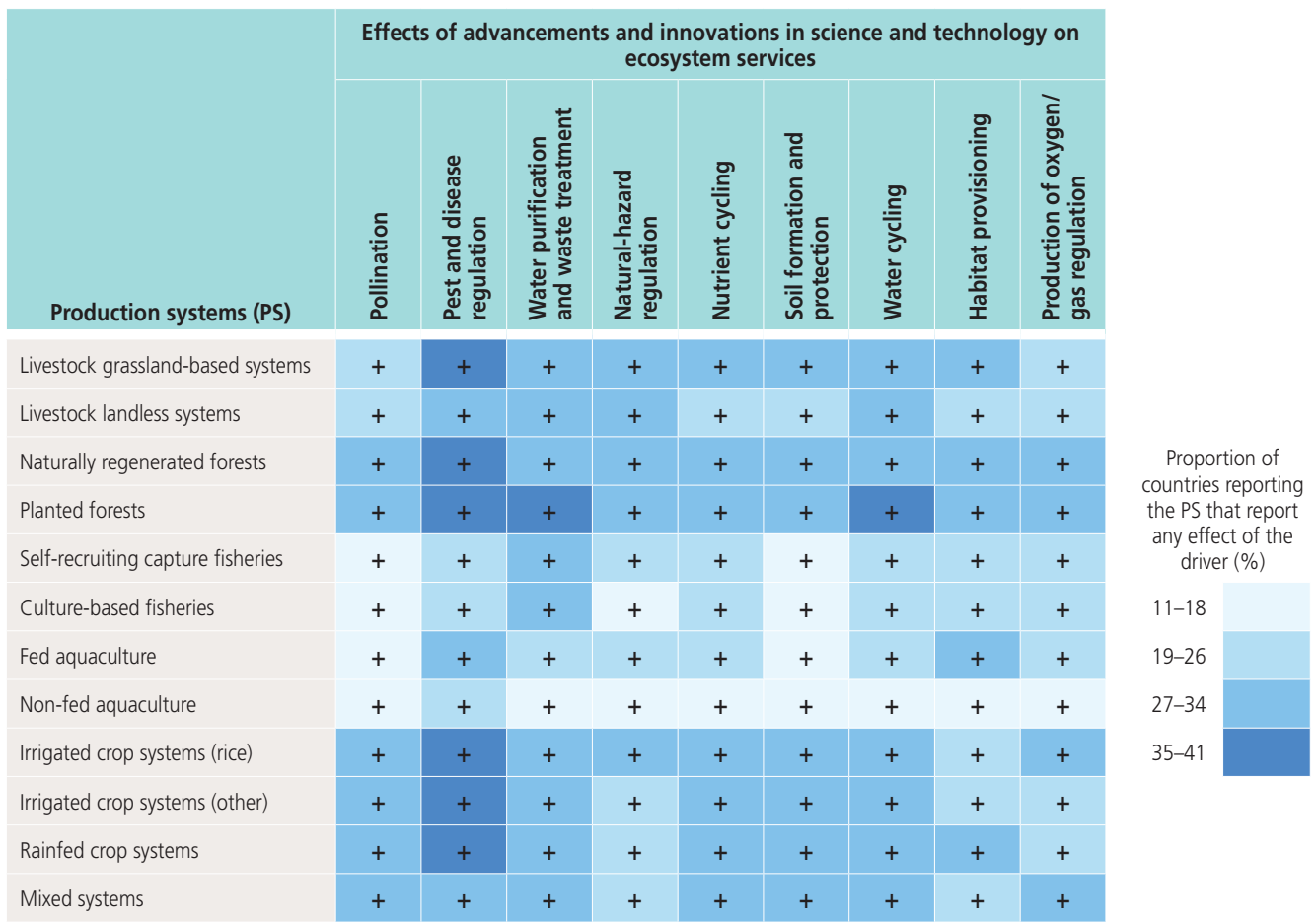

Notes: Countries were invited to report the effects (positive, negative or "no effect") of this driver on the provision of each ecosystem service in each production system. If $50 \%$ or more of the responses for a given combination of production system and ecosystem service indicate the same trend (positive [+], negative [-] or "no effect" [0]) then this trend is indicated in the respective cell of the table. In other cases, mixed effects (+/-) are indicated. The colour scale indicates the proportion of countries reporting the presence of the respective system that report any effect of the driver (positive, negative or "no effect") on the provision of the respective ecosystem service. See Section 1.5 for descriptions of the production systems and a discussion of ecosystem services. Analysis based on a total of 91 country reports. Source: Country reports prepared for The State of the World's Biodiversity for Food and Agriculture.

discussions of developments in these fields) genetic technologies contribute to other aspects of BFA management such as the enforcement of laws related to forestry and to trade in endangered species (FAO, 2014a).

Information provided by countries on the effects of advances and innovations in science and technology on the supply of ecosystems services is summarized in Table 3.12. In all production systems and for all ecosystem services, positive impacts are by far the most frequently reported. The country reports generally indicate that technologies are seen as a means of countering the negative effects that other drivers are having on BFA and the supply of ecosystem services. A wide variety of technologies are highlighted, ranging from those used for characterization and monitoring of components of BFA to those used in conservation, various sustainable management practices, education or awareness raising. Among the latter, for example, Estonia mentions that mobile phone applications have been developed to inform people about various components of biodiversity including mushrooms, amphibians, 
epiphyte lichens and birds. Where promoting sustainable management is concerned, Mexico reports advances in the development of moreselective capture systems for fisheries that reduce bycatch. Spain mentions that technological advances and recent innovations in aquaculture have fostered positive interactions between aquaculture and the surrounding environment and associated biodiversity. The United States of America reports that the use of genetically modified crops such as Bt maize has led to a decrease in the application of insecticides, and that the use of herbicide-tolerant varieties has increased levels of adoption of conservation tillage relative to levels with conventional crops. It also notes, however, that while the toxicity and persistence of glyphosate, the most commonly used herbicide for tolerant varieties, are lower than those of herbicides formerly used, ${ }^{27}$ the emergence of glyphosate-resistant weeds may to some extent offset the advantages of the adoption of herbicide-tolerant crops as it has led farmers to raise application rates in recent years.

Negative effects mentioned include those associated with technologies that allow more effective harvesting of wild foods and have led to overexploitation. Some countries note that new technologies are contributing to the displacement of traditional lifestyles and the loss of traditional ecological knowledge (see also Section 3.9).

\subsection{Drivers at production-system level}

- Loss and degradation of forest and aquatic ecosystems and, in many production systems, transition to intensive production of a reduced number of species, breeds and varieties, often coupled with inappropriate management practices, remain major drivers of loss of biodiversity for food and agriculture (BFA) and ecosystem services.

27 The report cites WHO (1994) and NRC (2010). It notes, however, that recent publications have raised questions regarding the toxicity of glyphosate.
- Various management practices have been identified that can limit the harmful effects of other drivers and may even have positive effects on BFA and ecosystem services.

- Pollution, from within production systems and beyond, remains a major cause of decline in the populations of many important species of associated biodiversity. Excess nutrients, pesticide residues, urban effluent, plastics and heavy metals are among the pollutants of most concern.

- Overharvesting, particularly in forest and aquatic ecosystems, as well as excessive or badly managed grazing and browsing by livestock, are substantial threats to many components of BFA.

\subsubsection{Changes in land and water use and management}

Changes in land and water use and management encompass a wide range of effects, many of which will influence or be influenced by other drivers discussed in this chapter. In the context of terrestrial ecosystems, such changes have classically been studied and categorized using the concept of "land-use transitions" (e.g. Foley et al., 2005; Mazoyer and Roudart, 2006; Ruthenberg, 1980). According to this concept, changes in land use follow a unidirectional pathway of succession from the natural ecosystems of the pre-settlement period, through smallholder subsistence agriculture, to landscapes dominated by intensive agriculture interspaced with urban, recreational and conservation areas. This classical view broadly reflects the history of land-use changes in many temperate and tropical regions of the world, especially those where forests once dominated, with the process being most complete in parts of Europe, temperate Asia and North America. However, changes taking place today in locations where the land-transition trajectory is less complete do not necessarily follow the sequential pattern of past events elsewhere. For example, many of the hundreds of thousands of hectares of forest cleared in various parts of the world each year are incorporated directly into large-scale, commercially oriented, intensive crop or livestock production systems without passing 
through a phase of being used by smallholders. The following paragraphs briefly describe major recent land-use trends in various ecosystems used for food and agriculture.

The world's total forest area has continued to decline in recent years (FAO, 2018b) (see Section 4.5.5 for further discussion of trends in forest ecosystems). In the tropics and subtropics, the expansion of commercial large-scale agriculture accounted for 40 percent of forest loss during the period 2010 to 2015 (FAO, 2016e). Smallholder farming accounted for 33 percent of the loss, urbanization and infrastructure for 10 percent each and mining for 7 percent (ibid.). These patterns, however, vary considerably from region to region. For example, Hosonuma et al. (2012) estimated that during the period 2000 to 2010 transformation to commercial agriculture accounted for almost 70 percent of forest-area loss in Latin America, compared to about 35 percent in Africa and Asia. In Africa, 40 percent was lost to subsistence farming and up to 10 percent to mining (ibid.).

In recent years, forest loss (mostly native forest) has been partially offset by natural expansion of forest (2.2 million ha/year during the period 2010 to 2015), often onto abandoned agricultural land, notably in Europe and Central America, and by forest plantations (3.1 million ha/year during the period 2010 to 2015), particularly in parts of Asia (FAO, 2016e).

In addition to reductions in the absolute extent of forest area, forest fragmentation is a major threat to biodiversity and ecosystem-service provision (Haddad et al., 2015), as is conversion from natural forests to monoculture forest plantations in some parts of the world (e.g. Ahrends et al., 2015; Edwards et al., 2010; Hosonuma et al., 2012; Warren-Thomas, Dolman and Edwards, 2015). It has been estimated that 70 percent of the world's remaining forest area is within $1 \mathrm{~km}$ of a forest edge (Haddad et al., 2015). Fragmentation has implications for habitat structure and quality, microclimate, hydrology, and wildlife recolonization and dispersal. It also increases accessibility and thus increases pressure on wild foods and other forms of associated biodiversity.
Land use for livestock production has traditionally involved either integrated crop-livestock systems (see Section 5.5.1) or extensive grassland-based systems. In places, initially in developed regions such as Europe and North America, but in recent decades increasingly in other regions, mixed production has tended to give way to specialized intensive crop production systems on the one hand and "landless" livestock systems on the other. In the case of grassland production, traditional management systems and practices, notably mobile pastoralism, have declined in many parts of the world (FAO, 2009a, 2015a). Large areas of species-rich grassland have been replaced by croplands or high-yielding single-species grasslands (see Section 4.5.6). In other cases, changes in management have contributed to grasslands becoming overgrown with shrubs. Extensive commercial grassland livestock production has also declined in some places over recent years. For example, expansion of soybean production in South America is taking place on land previously cleared of forest for livestock production (De Sy et al., 2015) - with the soy produced going to feed animals in an increasing number of large-scale intensive landless livestock operations, both in the region and elsewhere (Modernel et al., 2016). These various changes have been accompanied by an increase in the global population sizes of all major livestock species, although with considerable regional variations (FAO, 2015a).

Land-use changes associated with livestock production threaten biodiversity in various ways. Direct effects include those caused by effluents from landless production units or other intensive systems escaping into waterbodies and those caused by excessive or badly managed grazing. Indirect effects include those associated with demand for raw materials to produce concentrate feeds (Godde et al., 2018). Livestock production is also one of the main sources of greenhouse-gas emissions, accounting for 14.5 percent of all global emissions by some estimates (Gerber et al., 2013). The loss and degradation of grassland areas around the world has negative implications for many species, including, for example, many birds (see Box 3.3). 
Box 3.3

Unsustainably managed production systems are a key threat to bird species

Birdlife International classifies the extinction risk of all the world's birds for the International Union for Conservation of Nature Red List. Their 2017 assessment concluded that 1469 species of birds (13 percent of extant species) are globally threatened with extinction (BirdLife International, 2018). While birds provide many ecosystem services to production systems, unsustainable management of these systems has a negative impact on bird populations. As shown in the figure below (on the left) the three most important threats globally (those with the largest number of species facing the highest level of threat) are agriculture, which affects 911 threatened bird species (73 percent), logging and wood harvesting, which affect 669 species (54 percent), and invasive alien species, which affect 422 species (34 percent) (Butchart et al., 2010).

In recent decades, both increases in the extent of cropland (particularly marked in the tropics) and intensification of agriculture have driven the loss of natural habitats and increased threats to birds (BirdLife International, 2013). For example, the European Farmland Bird Index showed a 55 percent decline in common farmland birds between 1980 and 2016, and the downward trend appears to be continuing (see figure below on the right).

Expansion and intensification of agriculture are the most important of many threats affecting threatened bird species

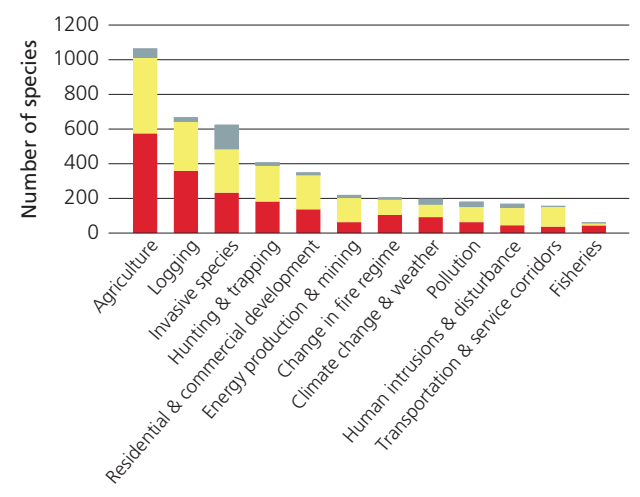

High/medium impact Low impact Unknown impact

Source: Butchart et al., 2010.
Long-term trend data for Europe (1980 to 2016) are based on national breeding-bird surveys in 28 countries collated and synthesized by the Pan-European Common Bird Monitoring Scheme (EBCC, 2017; Gregory et al., 2005, 2008; Gregory and van Strien, 2010). A large body of research in Europe has attributed the steep decline of farmland birds to a general process of agricultural intensification, which has adversely affected many other taxa in addition to birds (Donald, Green and Heath, 2001; Donald et al., 2006; Gregory et al., 2005).

Similar trends are seen in the marine environment. Increased fishing pressure is affecting seabird numbers, especially long-lived species such as albatrosses (Anderson et al., 2011a). At Bird Island (South Georgia), long-term monitoring and demographic studies have revealed steady declines of 2 to 4 percent per year over the last few decades for the wandering albatross (Diomedea exulans), grey-headed albatross (Thalassarche chrysostoma) and black-browed albatross ( $T$. melanophrys) as a result of bycatch from longline fisheries (Croxall et al., 1998; Pardo et al., 2017).

Source: Provided by the Royal Society for the Protection of Birds (RSPB) and Birdlife International.

\section{European Union Wild Bird Index 1980 to 2016}

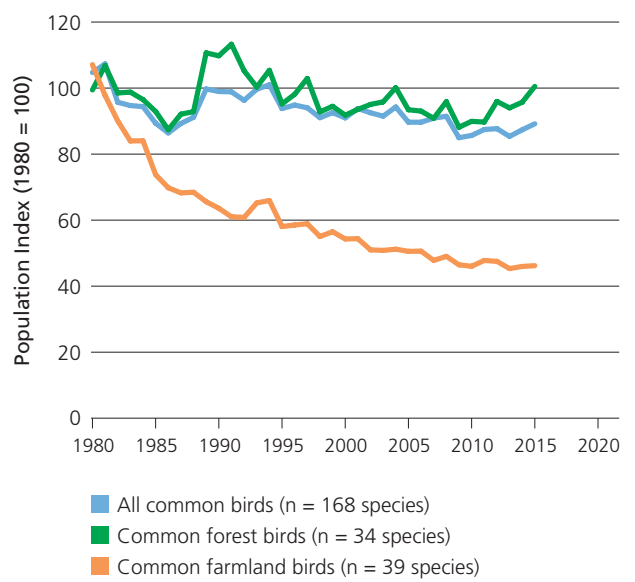

Source: EBCC/RSPB/BirdLife International/Statistics Netherlands. 
Agriculture accounts for the largest share of water withdrawals worldwide (approximately 70 percent of the total), although the proportions taken by industry (approximately 20 percent) and by domestic use (approximately 10 percent) are increasing, as is the share taken by urban areas relative to rural areas (FAO, 2011a). This trend is more pronounced in high- and middle-income countries than in low-income countries, where agricultural withdrawals still account for 90 percent of the total. The area equipped for irrigation has more than doubled worldwide over the last five decades, from 139 million ha to 301 million ha (an increase from 10 percent to 20 percent of the total cultivated land area), while water withdrawal for irrigation grew from $1540 \mathrm{~km}^{3}$ to $2710 \mathrm{~km}^{3}$ per year over the same period. About 80 percent of this capacity is located in low- to middle-income countries (ibid.). The consequences of irrigation expansion for BFA are variable and context specific. However, major irrigation infrastructure developments are often associated with the expansion of market-oriented monocultures such as sugar cane or cotton, while the infrastructure associated with irrigation schemes (dams, channels, etc.) can also affect aquatic biodiversity (e.g. Tendall et al., 2014; Verones et al., 2012). Poorly managed irrigation can result in salinization, the accumulation of water-soluble salts in the soil, which eventually inhibits crop growth. At least a fifth of irrigated land is believed to be salt-affected to some degree (Pitman and Läuchli, 2002), with researchers suggesting that half of all arable land might be affected by 2050 (Butcher et al., 2016).

Wetlands and inland aquatic ecosystems around the world are facing a range of expanding demands, including those associated with agriculture, urban development, flood protection, transport and hydropower generation. These are giving rise to a number of serious threats to freshwater biodiversity, including channelization of watercourses, habitat fragmentation and loss of riparian forests (Angelopoulos, Cowx and Buijse, 2017; Boulton, Ekebom and Gislason, 2016; Carrizo et al., 2017; Speed et al., 2016). The degradation of freshwater ecosystems and loss of their physical and functional complexity eliminate vital components of natural flood-control mechanisms, inhibit the recharging of wetlands and destroy and fragment habitats that support fisheries (Friberg et al., 2016; Gleick, Singh and Shi, 2001). Weirs, dams and other barriers have interfered with the migratory routes of several fish and river-dolphin species, and reduced connectivity along the length of most large rivers (Addy et al., 2016; Pivari, Pacca and Sebrian, 2017). The loss of riparian forests increases the risk of seasonal flooding and results in the loss of habitat and nursery grounds for fish and other aquatic species (Larsen et al., 2012; NRC, 2002). In places, however, successful efforts have been made to improve water quality, construct fish passages and restore waterway banks to create spawning habitats and increase fish population sizes (see Section 5.4 for further discussion).

Across production systems, much of the world's soil is in a degraded and often deteriorating state (FAO and ITPS, 2015). Key threats to soil biodiversity and the capacity of soils to deliver ecosystem services include land-use changes that involve vegetation clearance or the sealing of soils under permanent cover such as concrete, the increasing frequency of forest fires, the spread of inappropriate crop-production practices and overgrazing (Turbé et al., 2010; Orgiazzi et al., eds., 2016). Globally, 33 percent of land is moderately to highly degraded due to erosion, salinization, compaction, acidification and chemical pollution of the soil (FAO and ITPS, 2015). Around a fifth of the Earth's vegetated surface shows persistent declining trends in productivity, leaving 1.3 billion people living on degrading agricultural land (UNCCD, 2017).

The management of a crop production system involves decisions with regard to (inter alia) what tillage practices will be used, which crop species or varieties will be grown, whether trees or livestock will be integrated into the system, how crop residues will be managed, what and how external inputs such as fertilizers, herbicides and pesticides will be applied and whether hedges and uncultivated strips will be left around fields or plots. All these decisions will influence the 
characteristics and the diversity of the local soil fauna and flora.

Soil biodiversity is greatly influenced by the quantity and quality of organic matter present in the soil. The biodiversity in overexploited soils is less abundant, dominated by fewer species and characterized by simpler trophic networks (Creamer et al., 2016). Loss of soil organic matter may lead to weaker soil structure, soil sealing, surface crusting and/or compaction, reducing the soil's capacity to capture and store water, buffer its $\mathrm{pH}$ and regulate its salinity.

Declines in the soil's organic-matter and nutrient content are caused by misbalances between inputs and outputs. Inputs are provided by plant litter and by the addition of organic matter and nutrients (e.g. in the form of manure - FAO, 2018f). Losses occur through the decomposition of organic matter and soil erosion. Nutrients can also be lost via leaching, volatilization and removal in harvested products. Soil-nutrient depletion through negative nutrient balances is widespread throughout much of sub-Saharan Africa (Tittonell and Giller, 2013).

Soil biodiversity will generally benefit from management methods that increase the input of organic matter and reduce its loss, for example mulching, manuring and composting. Increasing crop diversity in the form of rotations or intercropping tends to increase soil biodiversity (Tiemann et al., 2015; Zander, Jacobs and Hawkins, 2016). Tillage generally has a negative effect on soil biodiversity (e.g. Creamer et al., 2016; Nielsen et al., 2011; Tsiafouli et al., 2015). For further discussion of soil-management practices, and the status and trends of their use, see Section 5.6.3.

Appropriate management of non-cultivated areas within agricultural landscapes is also vital to the supply of many ecosystem services. For example, the health of pollinator populations often depends on the floristic diversity of areas such as field margins (Carvalheiro et al., 2010; Holland et al., 2015; Ricketts et al., 2008). Further information can again be found in Chapter 5 .

The information provided by countries on the effects of changes in land and water use and man- agement on the supply ecosystem services in different production systems is summarized in Table 3.13. In a large majority of cases (i.e. production system by ecosystem service combinations) reports of negative impacts outnumber reports of positive impacts. In some production system categories (livestock grassland-based, livestock landless, naturally regenerated forests, rainfed crop and irrigated crop [non-rice]), this is the case for all ecosystem services. Moreover, for several vital ecosystem services such as pollination, pest and disease control and water purification, the number of countries reporting negative effects exceeds (or at best equals) the number reporting positive effects across all production systems. However, for all ecosystem services there are at least some reports of positive impacts. The most frequently reported positive effects are on the production of oxygen in planted forests and nutrient cycling and soil formation and protection services in mixed systems.

The country reports do not always include details of the mechanisms through which landor water-use changes are giving rise to the reported changes in the supply of ecosystem services. However, some examples are provided. With regard to aquatic systems for instance, a number of countries stress the negative impact that water-management practices such as the fragmentation of watercourses through the creation of dams, levees, irrigation systems or flood-protection barriers have had on aquatic biodiversity. Several mention that dams and hydroelectric-power schemes have led to declines in river fish stocks. Developments of this kind are reported to have blocked the migration routes of commercially valuable fish species, disturbed the spawning grounds and habitats of a range of aquatic species, contributed to the loss of forest trees near watercourses and negatively affected downstream habitats including those in estuaries and coastal areas. For example, Iraq reports that various large-scale water-diversion projects have degraded the Tigris-Euphrates alluvial saltmarsh and greatly affected land use in this area. It notes also that these effects have been exacerbated by a decrease in rainfall in recent years. 


\section{PART B}

TABLE 3.13

Reported effects of changes in land and water use and management on the provision of regulating and supporting ecosystem services, by production system

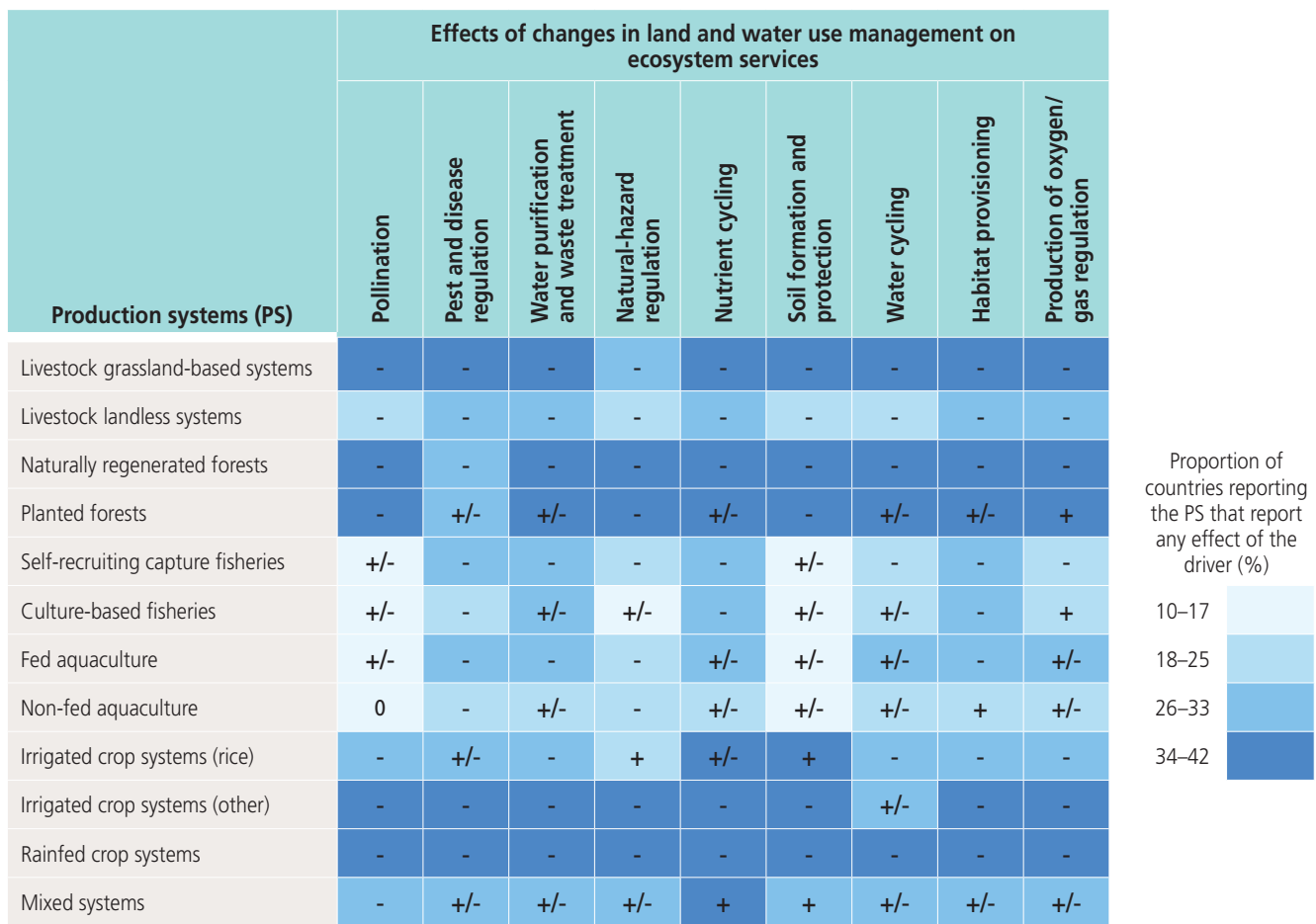

Notes: Countries were invited to report the effects (positive, negative or "no effect") of this driver on the provision of each ecosystem service in each production system. If $50 \%$ or more of the responses for a given combination of production system and ecosystem service indicate the same trend (positive [+], negative [-] or "no effect" [0]) then this trend is indicated in the respective cell of the table. In other cases, mixed effects (+/-) are indicated. The colour scale indicates the proportion of countries reporting the presence of the respective system that report any effect of the driver (positive, negative or "no effect") on the provision of the respective ecosystem service. See Section 1.5 for descriptions of the production systems and a discussion of ecosystem services. Analysis based on a total of 91 country reports. Source: Country reports prepared for The State of the World's Biodiversity for Food and Agriculture.

Several countries mention that freshwater or marine biodiversity and related ecosystem services have been negatively affected by wetland conversion for use in crop, livestock or aquaculture production or by the destruction or poor management of forests. For example, Argentina reports that inappropriate management of forests in the upper stretches of river basins has led to changes in water quality and quantity in low-lying areas and that the conversion of forests into grasslands is affecting the feeding and breeding grounds of fish species targeted by artisanal and sport fisheries.
With regard to the management of marine and coastal ecosystems, the Bahamas reports that fisheries are being compromised by the creation of navigation channels and the physical destruction of habitats such as coral reefs and mangroves for infrastructure development (docks and piers). Where wild foods from forests are concerned, the type of land-use change most commonly reported to be having an impact is deforestation, in many cases linked to agricultural expansion and in some to other factors such as urban expansion, mining and infrastructure development. 


\subsubsection{Pollution and external inputs}

There is abundant evidence that intensification of crop, livestock and aquaculture systems through excessive use of synthetic inputs adversely affects BFA and particularly associated biodiversity (e.g. Angelini et al., 2013; Brodeur and Vera Candioti, 2017; Van Dijk et al., 2013; Geiger et al., 2010; Hussain et al., 2009; Pelosi et al., 2013; White, 2017). The use of nutrient inputs in excess of efficient levels results in pollution of soil, air and water (e.g. Carpenter et al., 1998; van Dijk, Lesschen and Oenema, 2016). Although nutrient inputs in all forms may have negative effects when used in excess, nutrients carried in mineral fertilizers are particularly susceptible to ending up as pollutants, owing to their high concentration and solubility (although not necessarily in the case of phosphorus fertilizers), their volatility (in some cases) and the changes they induce in the soil ecosystem when used for an extended period (changing the $\mathrm{pH}$, promoting oxidation of organic matter, modifying soil biota, etc.) (e.g. Barak et al., 1997; Fonte et al., 2012; Guo, 2010; Mäder et al., 2008; Marschner, Kandeler and Marschner, 2003). Contamination of soils with pesticide residues is also a major concern in intensive crop-production systems (FAO and ITPS, 2015; Rodríguez-Eugenio, McLaughlin and Pennock, 2018).

Intensive landless and intensive grassland-based livestock production creates large amounts of nutrient-rich effluent and solid residue, often containing high concentrations of antimicrobials, pathogens, heavy metals and other pollutants (FAO, 2006b; Maron, Smith and Nachman, 2013; Modernel, Astigarraga and Picasso, 2013). Industrial and urban sources are also contributing to the contamination of soils with pollutants such as heavy metals and microplastics (Alloway, 2013; Chae and An, 2018; Ng et al., 2018; Tóth et al., 2016; Wuana and Okieimen, 2011). Other significant soil pollutants include persistent organic pollutants, polycyclic aromatic hydrocarbons, radionuclides and antimicrobial-resistant bacteria (RodríguezEugenio, McLaughlin and Pennock, 2018). Humaninduced salinity (see Section 3.6.1) and acidification are widespread problems, the former mostly associated with inappropriate irrigation practices and the latter with high rates of ammonium-based fertilizer application (FAO and ITPS, 2015).

The diversity and functions of soil invertebrates and micro-organisms are known to be affected by the presence of excessive nutrients and by the use of herbicides and pesticides (Ceulemans et al., 2014; Ewald et al., 2015; Hussain et al., 2009; Wolmarans and Swart, 2014). However, the processes involved are complex and a lot of uncertainty remains as to how particular substances, and combinations of substances, affect particular organisms and how these effects are influenced by environmental factors and by other management practices (Lo, 2010; Goulson, 2013; SanchezMoreno et al., 2015; Sebiomo, Ogundero and Bankole, 2011; Turbé et al., 2010; Wu et al., 2014). Although research on the impact of microplastics in the soil is limited, there is evidence that they affect the biophysical environment and biodiversity of the soil (Rochman, 2018; De Souza Machado et al., 2018). For example earthworms have been shown to have reduced growth rates and increased mortality if they ingest microbeads (Huerta Lwanga et al., 2016).

There is increasing evidence that some classes of pesticides threaten arthropod pollinators worldwide (IPBES, 2016a). High herbicide doses can be deleterious to the flora within and around agricultural fields (Egan and Mortensen, 2012; Gaba et al., 2016), with knock-on effects on biodiversity at higher trophic levels, for example insects and birds. One problem associated with pesticide use is the synergistic toxic effect that some molecules have when applied in mixtures. Most active ingredients are tested before they are released onto the market. However, the tests are done on the pure product in its commercial formulation (Brodeur et al., 2014). Most farmers, however, use such products in mixtures (e.g. a herbicide plus an insecticide in the same water suspension), and evidence obtained using biological indicators shows that some of the most common mixtures increase the toxicity of all active ingredients (ibid.). It is also important to note that the toxicity of active ingredients has increased over time, reducing the 
dosage needed to have an impact (Letourneau, Fitzsimmons and Nieto, 2017).

A number of factors are driving increased use of pesticides and herbicides in some areas. For example, introduction of glyphosate-resistant genetically modified crop cultivars in North and South America and the Pacific led to greater use of glyphosate, leading in turn to the emergence of glyphosate-resistant weeds that resulted in the application of ever higher doses of this herbicide (Benbrook, 2012; Mortensen et al., 2012), with possible consequences for certain soil organisms (Van Bruggen et al., 2018; Gaupp-Berghausen et al., 2015). Pest pressures that trigger high doses of pesticide use appear to be increasing as a result of climate change (Cannon, 1998; Cilas et al., 2016; Taylor et al., 2018).

The increasing contamination of freshwater systems with pathogens and chemical pollutants, including nutrients, is a major global threat to aquatic biodiversity (Dudgeon, 2012; Okano et al., 2018). The most significant problem affecting water quality globally is eutrophication caused by nitrogen and phosphorus runoff from agricultural land, flows of domestic sewage and industrial effluents, and atmospheric inputs from fossil-fuel combustion and forest fires (FAO and IWMI, 2018; Russi et al., 2013; UN Environment, 2016a). Lakes throughout the world are affected by eutrophication, and those in some regions (Scandinavia, northeastern United States of America/eastern Canada and (hina) are affected by acidification (Gleick, Singh and Shi., 2001). Lakes and reservoirs are particularly susceptible to the effects of pollution, as the water that flows into them carrying sediments, dissolved nutrients and other pollutants normally remains standing for some time, leading to problems such as algal blooms, other species invasions and hypoxia (Speed et al., 2016). An issue that has recently been receiving increasing attention is nitrate accumulation in the vadose zone (i.e. the part of the Earth's crust situated above the aquifers) in areas where highly intensive agriculture is practised. Ascott et al. (2017) describe this as a latent "nitrate bomb" that could cause major damage to aquatic biodiversity if released.
It has been estimated that more than 80 percent of wastewater globally is released into the environment without adequate treatment (WWAP, 2017). Aquatic pollution is exacerbated when ecosystems such as forests, grasslands and wetlands that provide water purification services are destroyed or degraded and when rivers lose their ability to self-purify due to changes in the biota that perform this function (Ostroumov, 2005; WWAP and UN-Water, 2018). Problems are also caused by the operation of dams, which results in the discharge of water with low oxygen levels into downstream areas (WWF, 2004). Another concern is the passage of personal-care products and pharmaceuticals into the aquatic environment via domestic sewage. Some of these pollutants contain microplastics (UN Environment, 2016b) and some are believed to mimic natural hormones in humans and other species (UN Environment, 2008; Vilela, Bassin and Peixoto, 2018).

Seawater quality and marine and coastal biodiversity all around the world are also seriously affected by pollution (FAO, 2011a). The problem is becoming increasingly widespread near heavily populated regions of Latin America and Southeast Asia, threatening marine food sources and the economic activities of coastal communities (UN Environment, 2008, 2016c). So-called "dead zones" caused by excess nitrogen undermine fish production and other ecosystem services (Halpern et al., 2009). ${ }^{28}$ Coastal pollution is one of the many threats facing coral reefs (see also Section 4.5.4). For example, the Great Barrier Reef off the coast of Australia is seriously affected by nutrient and pesticide runoff from sugar-cane farming and other types of agriculture (Queensland Government, 2017; Schaffelke et al., 2017).

An emerging threat to marine wildlife is increasing pollution by microplastics. Microplastics (plastic particles of less than $5 \mathrm{~mm}$ in diameter) are classified into two groups. Primary microplastics are plastics

\footnotetext{
28 Such effects (and those noted above for freshwater and terrestrial systems) are among those that led Rockström et al. (2009) to conclude that the Earth may have crossed the so-called planetary boundary (i.e. the upper tolerable limit) for the disruption of its nitrogen and phosphorus cycles.
} 
TABLE 3.14

Reported effects of pollution and external input use on the provision of regulating and supporting ecosystem services, by production system

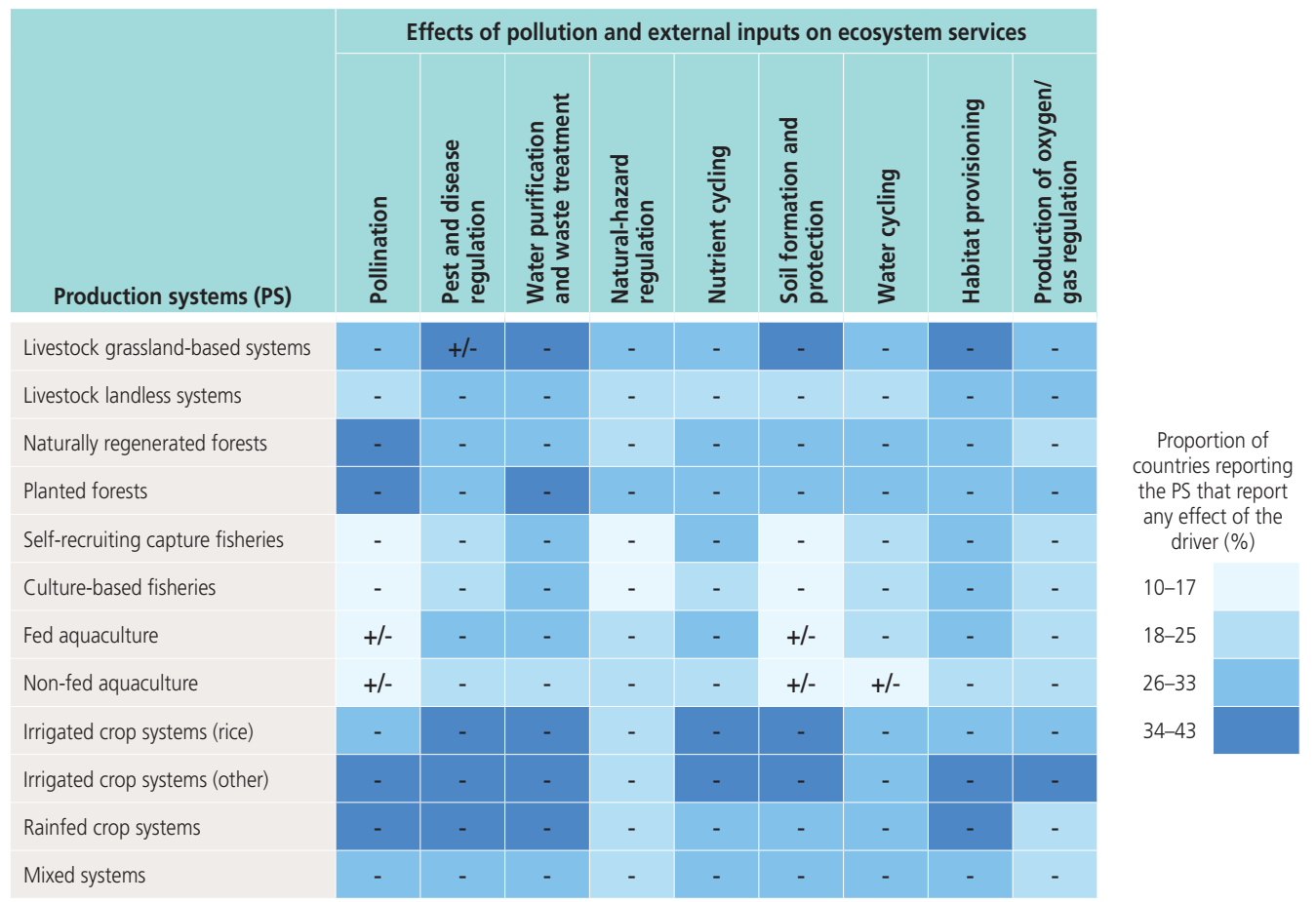

Notes: Countries were invited to report the effects (positive, negative or "no effect") of this driver on the provision of each ecosystem service in each production system. If $50 \%$ or more of the responses for a given combination of production system and ecosystem service indicate the same trend (positive [+], negative [-] or "no effect" [0]) then this trend is indicated in the respective cell of the table. In other cases, mixed effects (+/-) are indicated. The colour scale indicates the proportion of countries reporting the presence of the respective system that report any effect of the driver (positive, negative or "no effect") on the provision of the respective ecosystem service. See Section 1.5 for descriptions of the production systems and a discussion of ecosystem services. Analysis based on a total of 91 country reports. Source: Country reports prepared for The State of the World's Biodiversity for Food and Agriculture.

directly released into the environment in the form of particulates smaller than $5 \mathrm{~mm}$, while secondary microplastics originate from the degradation of larger plastic items once exposed to the marine environment (Boucher and Friot, 2017). The global release of primary microplastics into the ocean is estimated at around $\mathbf{1 . 5}$ million tonnes per year (ibid.). Given the large amount of plastic entering the ocean, it is assumed that secondary microplastics are far more prevalent, but because fragmentation rates of plastics are largely unknown, there are no estimates available for the amount of sec- ondary microplastic present (Duis and Coors, 2016; Koelmans et al., 2014; Sundt, Schulze and Syversen, 2014). Ingestion of microplastics by aquatic fauna (fish, turtles, birds) has been shown to inhibit hatching, decrease growth rates and alter feeding patterns (Lönnstedt and Eklöv, 2016).

Information from the country reports on how pollution and external input use are driving changes in the supply of ecosystem services in specific production systems is summarized in Table 3.14. Perhaps not surprisingly given the connotations of the word "pollution", negative impacts 
are far more frequently reported than positive ones. Where positive impacts are reported and explanations provided, they normally relate to the benefits of using additional external inputs in systems where use is currently very low. Countries highlight a range of different effects. In the case of grassland systems for example, some European countries note that the overuse of nitrogen and phosphorus fertilizers is directly affecting species diversity. The report from the Netherlands, for instance, cites a study (Melman and Van der Heide, 2011) that found that the number of grass and herb species in unfertilized grasslands with relatively poor soils is between 20 and 30, while in fertilized grassland the number of species is between 5 and 15. The report further notes (citing LEI, 2015) that although average grassland fertilization rates in the Netherlands have declined, they still remain high. Among examples from the crop sector, China mentions the problem of so-called "white pollution", i.e. pollution of the soil with plastic films used for mulching, and the negative effects of excess herbicide use on the native flora surrounding agricultural fields. Egypt notes that the excessive use of fertilizers and pesticides has led to the decline of important components of agricultural biodiversity such as owls, kites and various pollinators.

Where aquatic ecosystems are concerned, many countries report that pollutants originating from crop and livestock production are negatively affecting biodiversity. For example, Spain reports that pollution from agricultural runoff has affected the composition and abundance of aquatic microorganism communities and other components of aquatic biodiversity. It also notes that this pollution may alter the physical and chemical composition of the marine bed, influencing, in turn, the biological composition and structure of benthic communities. Argentina mentions that agricultural runoff seems to be the most significant source of pollution in aquatic ecosystems, noting in particular that soybean production is affecting wetland biodiversity in surrounding areas and is leading, inter alia, to changes in the population sizes of various aquatic organisms, changes in the physiology and behaviour of fish and amphibians, eutrophication of water bodies and changes in the structure of riparian communities. The country reports provide little specific information on pollution problems associated with aquaculture. However, Viet Nam reports that intensive aquaculture, in particular catfish farming in the Mekong Delta, has significantly contributed to eutrophication in surrounding waters.

Several countries note the impacts of pollutants from mining and other industries on aquatic ecosystems. For example, Zambia mentions that effluents from the mines of its Copperbelt and Northwestern provinces negatively affect the diversity of dragonflies and other benthic invertebrates in major river systems as a result of elevated levels of redox, electrical conductivity and turbidity. ${ }^{29}$ Zimbabwe mentions that more than a million people are illegally panning for gold along its rivers and that this is resulting in the clearance of trees and digging in river beds, which in turn cause soil erosion and landslides that lead to the siltation of water bodies and destruction of aquatic biodiversity. It further notes that there has been an increase in the use of mercury, iron and cyanide to process ore and that this has polluted watercourses and affected the livelihood sources of local people. Mexico mentions that oil spills in the Gulf of Mexico have caused tremendous damage to marine and coastal ecosystems, biodiversity and economic activities such as fishing and aquaculture.

\subsubsection{Overexploitation and overharvesting}

Overexploitation and overharvesting are serious threats to the world's biodiversity in general (Maxwell et al., 2016) and to BFA specifically. As well as affecting target populations directly through removal, overharvesting can affect them indirectly by modifying their habitats. It can also adversely affect non-targeted components of BFA in the surrounding ecosystem. For example, overharvesting of woody species for fuel or timber can lead to major changes in the local environment, including in its microclimate and hydrology,

\footnotetext{
29 The report cites Chama and Siachoono (2015).
} 
nutrient-cycling processes and capacity to provide habitat services. Overharvesting of wild species of plants or animals can lead to misbalances in trophic networks that affect the survival of non-target species (e.g. Baum and Worm, 2009).

A range of factors can lead to the overharvesting of wild foods. For example, 16 of the world's 36 biodiversity hotspots are in areas where the human population suffers from malnutrition and hunger (Treweek, Brown and Bubb, 2006), which clearly has the potential to place pressure on wild biodiversity used as a source of food. Overharvesting can also be triggered by the commercialization of species that have previously been used exclusively for local subsistence (Kala, 2009). Overharvesting for medicinal purposes can be another threat (Schippmann, Leaman and Cunningham, 2002).

Where aquatic ecosystems are concerned, overharvesting of fish and other species is a threat both to biodiversity and to the long-term sustainability of fisheries (Speed et al., 2016). According to FAO (2018a), 33.1 percent of marine fish stocks are classified as overfished. The bluefin tuna of the Northern Pacific Ocean provides an emblematic example. By 2016, overfishing had led to a fall of about 97 percent in its population relative to estimated unfished levels; a large majority of the catch were young fish that had not yet reached reproductive age (ISC, 2018). According to WWF (2015), more than 85 percent of fish stocks in the world's oceans are at significant risk of "illegal, unreported and unregulated" fishing. Changes in fishing activities by international fleets are exerting particular pressure in the waters of some developing countries through, inter alia, the use of "flags of convenience" (Ferrel, 2005; Miller and Sumaila, 2014).

Overgrazing is a particular form of overharvesting in which the harvest is extracted via (mostly) domesticated herbivores. Impacts include loss of soil cover and consequent increases in the soil's susceptibility to erosion and declines in its capacity to capture and retain water, cycle nutrients, etc. As noted above, grazing can also contribute to the spread of woody vegetation, leading to the loss of grassland biodiversity (including forage species used by livestock) and potentially to a complete transformation of the vegetation structure and ecology of the affected area (Archer et al., 2017). Mechanisms involved include reduced competition from grasses as a result of selective grazing, reduced frequency of fires as a result of removal of fine fuel, and seed dispersal by livestock (ibid.). Overgrazed wetland soils that have lost their permanent surface cover often become salinized and accumulate surface salt, especially in dry regions (e.g. Di Bella et al., 2014; Zhang et al., 2015).

The effects of livestock grazing on grassland biodiversity and associated ecosystem services depend greatly on the type of grassland involved (vegetation structure, climatic and hydrological regimes, soil type and geomorphology) and are also affected by the types of animals stocked and how grazing is managed (Briske, ed., 2017). In some grassland production systems, vegetation is more influenced by environmental variables such as rainfall patterns than by livestock (ibid.), and in various circumstances well-managed grazing can be a means of promoting biodiversity and the supply of ecosystem services (FAO, 2016f). However, it is also clear that in many locations excessive or badly managed grazing is an important driver of soil erosion and biodiversity loss (e.g. FAO, 2016f; Kairis et al., 2015; Palmer and Bennett, 2013).

Information from the country reports on the effects of overharvesting and overexploitation on the supply of ecosystem services is summarized in Table 3.15. Given that this driver by definition gives rise to adverse effects at least on the targeted species, it is not surprising that that negative effects on ecosystem services are far more frequently reported than positive effects.

Overgrazing is mentioned as a problem by countries from most regions. For example, Spain mentions that stocking rates on its rangelands are higher or lower than those appropriate for local conditions, especially in the Mediterranean region, and that this is leading to land degradation in several locations. This effect (in combination with a reduction in the spatial frequency of hedgerows often as a result of land consolidation) is reported to be disrupting habitats and leading to the loss of ecosystem services such as biological pest control 


\section{PART B}

TABLE 3.15

Reported effects of overexploitation and overharvesting on the provision of regulating and supporting ecosystem services, by production system

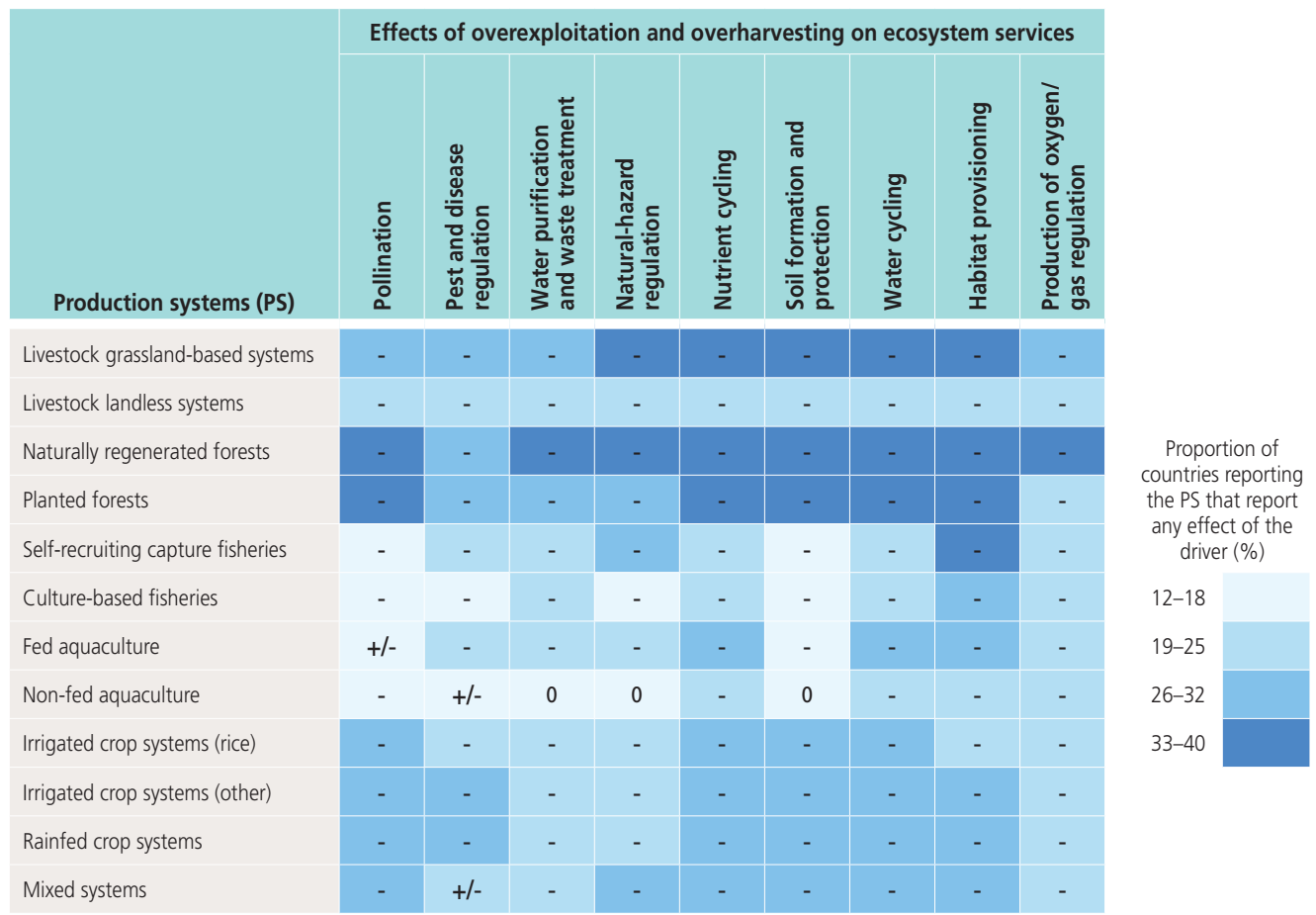

Notes: Countries were invited to report the effects (positive, negative or "no effect") of this driver on the provision of each ecosystem service in each production system. If $50 \%$ or more of the responses for a given combination of production system and ecosystem service indicate the same trend (positive [+], negative [-] or "no effect" [0]) then this trend is indicated in the respective cell of the table. In other cases, mixed effects (+/-) are indicated. The colour scale indicates the proportion of countries reporting the presence of the respective system that report any effect of the driver (positive, negative or "no effect") on the provision of the respective ecosystem service. See Section 1.5 for descriptions of the production systems and a discussion of ecosystem services. Analysis based on a total of 91 country reports. Source: Country reports prepared for The State of the World's Biodiversity for Food and Agriculture.

and control of water runoff. Finland mentions that overgrazing by reindeer is negatively affecting the quality and abundance of lichen pastures. Stocking pressure is reported to have increased as a result of the introduction of fences and supplementary winter feeding, which allows larger herds of reindeer to be kept than could be sustained by the pastures alone. Sri Lanka mentions that overgrazing by buffalo and cattle in protected areas has had negative consequences for biodiversity and the supply of ecosystem services. The United Arab Emirates reports that overgrazing is one of the most serious threats to its desert environment. It notes that in the past nomadic pastoralists kept small herds and moved them from one place to another according to the availability of water and natural vegetation, which provided the main source of feed for the animals. Today, in contrast, herds are reportedly large, managed under sedentary systems within relatively small areas, supplied with water and fed on imported feed. The resulting overgrazing, which has been exacerbated in recent years by scarcity of rainfall, has led to erosion and the removal of natural vegetation, including a 
significant decline in some palatable plant species such as arfaj (Rhanterium epapposum) and sometimes their replacement by poisonous plants such as Calotropis procera and Rhazya stricta.

Impacts of the overharvesting of wild foods and forest products of various kinds are also widely reported. For example, Nepal reports overharvesting and overexploitation of some wild foods (e.g. mushrooms, ferns and bamboo shoots), medicinal plants and various other forest products, but notes that a lack of relevant studies has prevented assessment of the specific effects these practices have had on ecosystem services. In most cases, the impacts reported by countries are on the supply of the harvested resources themselves rather than on the wider supply of ecosystem services. Mali reports that the removal of wood for charcoal production empties forests and savannahs of resources. Some species - kantakara (Combretum glutinosum), African rosewood (Pterocarpus erinaceus), small-leaved bloodwood ( $P$. lucens) and the gum arabic tree (Acacia nilotica) - are reported to be particularly endangered because of the calorific value of their wood. Others such as guelé (Prosopis africana) and siri (Burkea africana) are intensively sought after as their charcoal is popular in local crafts.

Most European countries do not indicate that wild foods are being affected by overharvesting. Many reports from this region note that legislation has been put in place to protect potentially threatened resources. In some cases, however, commercial collection of wild food resources results in overexploitation and/or otherwise damaging the local environment. This is reported to be the case, for example, with wild herbs in Slovenia and locally with wild berries in Finland.

Some countries note that socio-economic factors can influence exploitation rates. For instance, Croatia mentions that unemployment increases threats to wild mushroom species, as people gather them to supplement their incomes. Jordan reports that poverty drives the overexploitation of wild fauna and wild edible plants and mushrooms.

Overfishing is highlighted by countries from all regions as a threat to freshwater and marine ecosystems and their biodiversity. Again, countries mainly note impacts on the supply of food rather than on any other ecosystem services. For example, Solomon Islands mentions that overexploitation for both subsistence and commercial purposes has resulted in the depletion of several important species, including greensnails, blacklip and goldlip shells, coconut crabs, giant clams and sandfish (sea cucumber). Some countries specifically note the impact of damaging fishing practices. For example, Sudan reports that some fish populations are decreasing as a consequence of the use of destructive fishing gear, the violation of closed fishing periods and illegal trawling. Viet Nam mentions that destructive fishing methods such as fishing with poison and creating electric shocks to stun and kill fish are widely used in both coastal and inland waters. Use of poison is reported to be severely threatening over 80 percent of the country's coral reefs.

Lack of regulation is noted as an exacerbating factor in some reports. For example, in addition to the above-noted problems, Solomon Islands mentions that companies engaged in coral exports are not monitored or supervised by any authority and that this is leading to the decline of reef ecosystems.

\subsection{Policies}

- Policies directly addressing the management of biodiversity for food and agriculture (BFA), and particularly those that restrict unsustainable practices, are considered by many countries to have positive effects on diversity and the supply of ecosystem services. However, negative impacts are also reported, for example in the case of policies favouring inappropriate mining, dam or reservoir construction or road building.

- The impacts of policies considered favourable to BFA or to the supply of ecosystem services have often not been adequately assessed.

- Policies intended to promote the sustainable management of BFA are often weakly implemented as a consequence of shortages of resources, inadequate stakeholder involvement and conflicts of interest. 
BFA can be affected both by policies that are specifically intended to promote its sustainable use and conservation and by the impacts of other policies. The former include policies that restrict unsustainable practices such as inappropriate use of fertilizers and pesticides, establish protected areas or limit the harvesting of wild species so as to prevent their overexploitation. Many policies of this kind have been put in place at both national and international levels (see Chapter 1 for an overview of global policy agendas and Chapter 8 for further discussion of BFA-related policies in general). However, it is often difficult to determine the extent to which such measures are being implemented and what influence they are having on the status of BFA. Policies that have indirect effects on BFA and ecosystem services are very diverse in nature and can include those influencing any of the drivers discussed in this chapter. Many of these policies have had a significant negative effect on BFA. Examples include those that support agricultural intensification, favour industrial development, mining or development of infrastructure such as roads, reservoirs or largescale dams in areas where there are high levels of BFA (e.g. IAASTD, 2009; Laurance, Sayer and Cassman, 2014; World Bank, 2008).

Information provided by countries on the effects of policies on the supply of ecosystem services is summarized in Table 3.16. Positive effects on ecosystem services are more frequently reported than negative effects for most production systems and types of ecosystem service. Countries that provide details of positive outcomes include, for example, Estonia, which reports that policy measures aimed at protecting soils and the environment have benefited soil formation and protection services, and Argentina, which mentions that its export-tax policies on soybean and export quotas for wheat and beef have indirectly contributed to the diversification of agricultural systems as a result of economic decisions taken by individual farmers. Several countries mention fisheries policies that have had positive impacts on biodiversity. For example, the Netherlands reports that restrictions (catch limits, limits on the number of days when species can be caught, regulation of fishing practices and establishment of marine protected areas) imposed by policies at European Union and national levels have meant that fishing practices in the North Sea have become more sustainable. It notes that mortality rates imposed by fishing have decreased by about 35 percent since 2000 and that spawningstock biomass is starting to recover. ${ }^{30}$

Some countries note that despite major policy initiatives their BFA remains under threat. For example, Finland reports that European Union policies that aim to promote the utilization of ecosystem processes such as nutrient cycling and biological control to replace external inputs in food and agricultural production have so far only been implemented to a limited extent and notes that the overall impact of policy may have remained negative as a result of a focus on the economic performance of individual farms rather than on overall sustainability. Several European Union member countries note that such measures are increasingly difficult for farmers to comply with. This is often ascribed to the high costs associated with land and labour resources, and in some cases to the low prices farmers receive for their produce, which forces them to intensify production per unit area using the cheapest available means, even if they are not sustainable. Another issue raised in some country reports is a lack of adequate assessment of the impact of policies on BFA and the supply of ecosystem services. For example, Finland reports that over recent decades legislative and voluntary measures have alleviated pressures on natural resources caused by threats such as overgrazing and the overexploitation of forests, for example by promoting the establishment of riparian buffer zones and the protection of key habitats. It notes, however, that the effectiveness of such measures in terms of improving the supply of ecosystem services remains unconfirmed. Several countries provide examples of policies and legal instruments that support the maintenance of traditional knowledge (see Section 8.8.4).

\footnotetext{
30 The report cites ICES (2013)
} 
TABLE 3.16

Reported effects of policies on the provision of regulating and supporting ecosystem services, by production system

\begin{tabular}{|c|c|c|c|c|c|c|c|c|c|}
\hline \multirow[b]{2}{*}{ Production systems (PS) } & \multicolumn{9}{|c|}{ Effects of policies on ecosystem services } \\
\hline & 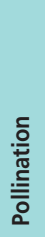 & 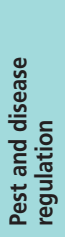 & 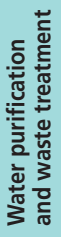 & 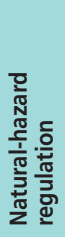 & 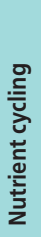 & 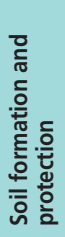 & 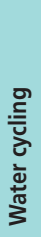 & 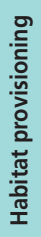 & 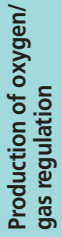 \\
\hline Livestock grassland-based systems & $+1-$ & + & + & $+/-$ & + & + & + & + & $+/-$ \\
\hline Livestock landless systems & + & + & + & + & + & + & + & + & + \\
\hline Naturally regenerated forests & + & + & + & + & + & + & + & + & + \\
\hline Planted forests & + & + & + & + & + & + & + & + & + \\
\hline Self-recruiting capture fisheries & + & + & + & + & + & + & + & + & + \\
\hline Culture-based fisheries & + & + & + & + & + & + & + & + & + \\
\hline Fed aquaculture & + & + & + & + & + & + & + & + & + \\
\hline Non-fed aquaculture & + & + & + & + & + & + & + & + & + \\
\hline Irrigated crop systems (rice) & + & + & + & + & + & + & + & + & + \\
\hline Irrigated crop systems (other) & + & + & + & + & + & + & + & + & + \\
\hline Rainfed crop systems & + & + & + & + & + & + & + & + & + \\
\hline Mixed systems & + & + & + & + & + & + & + & + & + \\
\hline
\end{tabular}

Proportion of countries reporting the PS that report any effect of the driver (\%)

$10-17$

$18-25$

26-33

$34-43$

Notes: Countries were invited to report the effects (positive, negative or "no effect") of this driver on the provision of each ecosystem service in each production system. If $50 \%$ or more of the responses for a given combination of production system and ecosystem service indicate the same trend (positive [+], negative [-] or "no effect" [0]) then this trend is indicated in the respective cell of the table. In other cases, mixed effects (+/-) are indicated. The colour scale indicates the proportion of countries reporting the presence of the respective system that report any effect of the driver (positive, negative or "no effect") on the provision of the respective ecosystem service. See Section 1.5 for descriptions of the production systems and a discussion of ecosystem services. Analysis based on a total of 91 country reports. Source: Country reports prepared for The State of the World's Biodiversity for Food and Agriculture.

Countries reporting less positive outcomes include Viet Nam, which notes that policies promoting the construction of dams, reservoirs, roads and other infrastructure have caused the degradation and fragmentation of ecosystems, destroying habitats and creating barriers to species migrations. These effects are reported to be leading to long-term negative impacts on wildlife populations. Ecuador mentions, inter alia, its decision to allow open-pit mining. Although the methods to be deployed are termed low impact and environmentally friendly, it notes most of the sites identified for mining operations are in highly bio- diverse ecosystems and that the projects represent a threat to biodiversity.

\subsection{Drivers of women's involvement in the management of biodiversity for food and agriculture}

As discussed in greater detail in Section 8.2, women play vital roles in the management of BFA. The country-reporting guidelines specifically invited countries to report on drivers affecting the 
involvement of women in the maintenance and use of BFA. Responses indicate that a number of socio-economic and environmental changes are transforming women's roles in the management of BFA and are to some extent altering traditional divisions of labour between men and women. The factors highlighted range from improved access to education to increasing demand for products typically produced by women. Responses do not always include explicit indications of how such changes are affecting BFA, i.e. whether they have impact in terms of promoting or constraining the sustainable use of these resources. The focus is also mainly on changes at production-system level, such as increases or decreases in women's participation in particular aspects of management (as opposed to, for example, changes in levels of involvement in policy-making, research, etc.).

Several countries mention that alternative livelihood opportunities for women are reducing their roles as managers of BFA. Bangladesh, for example, reports that such changes have led to a decline in women's participation in poultry breeding. On the other hand, several countries report that changing economic conditions have provided women with new opportunities to market the products they have traditionally been involved in supplying, including both wild foods (e.g. reported by Cameroon and Sri Lanka) and crop and livestock products (e.g. reported by Eswatini).

In some cases, women's participation in specific activities has been promoted by the weakening of sociocultural barriers defining gender roles. For example, Grenada notes that women's greater self-reliance and independence has led to more direct involvement in farming, with some activities now dominated by women. For example, over 90 percent of the country's flower growers are reported to be women. Similarly, Eswatini reports that better access to markets from which they were traditionally excluded has led to increased participation of women in cattle production, a traditionally male-dominated sector. Several countries highlight women's increasing access to education, either as a factor facilitating their participation in the management of BFA or as a factor facilitating transition out of food and agriculture-related livelihood activities.

Several countries also acknowledge that women's participation in BFA management is constrained by a lack of access to external inputs and productive resources. Some note the significance of increasing levels of poverty. For example, Jordan and Zambia note that this factor has led to higher numbers of women participating in wild-food collection. Some mention the effects of the so-called feminization of agriculture resulting from the outmigration of men from rural areas because of poverty and lack of job opportunities. China, for example, notes that women have increasingly been taking responsibility for decision-making in agriculture. It mentions that increasing workloads may have pushed women towards more rapid adoption of unsustainable and biodiversity-eroding practices, including the adoption of crop varieties that require the use of large amounts of chemical fertilizers and pesticides. Women's lack of education in sustainable agricultural practices is reported to be an exacerbating factor. Nepal notes that labour shortages, combined with flows of remittances and the increasing availability of cheap alternative products on local markets, have contributed to the abandonment of local crops. High levels of widowhood are another factor noted by some countries. Eswatini, for example, reports that the HIVIAIDS pandemic has on the one hand meant that many women have lost their husbands and are taking the lead in farm-management decisions and on the other that women's roles as primary care givers limits the amount of time they have available for agriculture.

Agricultural "modernization" is reported to be affecting women's roles in some countries. For example, Guyana notes that mechanization has led to displacement of women from the rice industry, where they used to be responsible for land preparation, planting, weeding, harvesting and processing. Bangladesh notes that the spread of commercial orchard plantations growing crops such as bananas in hilly areas has swept away local plants that women relied on to diversify their diets. 
A number of countries note that environmental drivers such as climate change and land degradation are compromising women's involvement in the use and management of BFA. Several highlight the particular vulnerability of women to the impacts of climate change on agriculture and local ecosystems. Jordan, for instance, reports that climate change is likely to reduce the availability of wild foods and add to the burden on women from traditional communities, who are responsible for collecting wild foods and in future will probably have to walk longer distances to find them. Some countries note women's vulnerability to natural disasters such as droughts and hurricanes. Various unsustainable management practices and changes in land and water use are reported to be threatening women's livelihoods via their impacts on common-property resources such as fuelwood, fodder and wild foods, resources upon which women are often disproportionately dependent. Examples include land conversion (Zambia), overfishing (Jamaica, Nepal), deforestation and soil erosion (Jamaica), overgrazing (Yemen) and disturbance of food webs as a consequence of infrastructure development (Nepal).

\subsection{Drivers of traditional knowledge of biodiversity for food and agriculture}

Countries were invited to provide information on the most significant drivers affecting the maintenance and use of traditional knowledge relating to BFA. The majority of drivers reported to be having a negative effect on the maintenance of traditional knowledge are connected to declining use of such knowledge and therefore declining transmission to the next generation. Many countries report that traditional knowledge is vanishing along with the older generation, with younger people not interested in acquiring it. Drivers widely reported to be affecting the use of traditional knowledge include population growth, urbanization and the loss of traditional rural lifestyles. Many countries report that market-driven industrialization of agriculture and food processing is contributing to the disappearance of traditional knowledge by driving the decline of traditional farming practices and indigenous varieties and breeds. Loss of components of BFA as a result of overexploitation and overharvesting is also widely reported to be having a negative effect on the maintenance of traditional knowledge related to these resources. A few countries note that traditional knowledge is perceived to be primitive, inferior and related to poverty. Grenada, for example, states that colonialism instilled a belief that foreign products are superior to local ones and that this has led to the replacement of traditional varieties and local foods with imported ones. Advances and innovations in science and technology are reported to have mainly negative effects on the maintenance of traditional knowledge.

Dietary trends and changes in consumer demands are reported to have both negative and positive effects on the maintenance of traditional knowledge. Some countries report that the availability of processed foods has reduced the use of traditional foods. However, a number of European countries note that an increased interest in traditional local foods in academia and among the wider public is contributing to the maintenance and use of traditional knowledge associated with them. France, for example, notes that designatedorigin labels promote the continued use of traditional foods and the conservation of knowledge associated with their production.

Several countries report that policies have a positive effect on the maintenance and use of traditional knowledge (see Chapter 8 for further information on relevant policies and legal frameworks). Some countries mention that efforts to record traditional knowledge in writing have contributed to its continued use. Several report initiatives and organizations that contribute to the active maintenance of traditional practices through a variety of cultural activities (see Chapter 8 for examples). A number of countries also report that educational measures, such as awareness raising in schools, universities, on television and online, have had a significant impact on the use of traditional knowledge. 



\section{Chapter 4 \\ The status and trends of biodiversity for food and agriculture}

\begin{tabular}{|c|c|}
\hline \multicolumn{2}{|l|}{ Key messages } \\
\hline $\begin{array}{l}\text { - Many key components of biodiversity for food and } \\
\text { agriculture (BFA) at genetic, species and ecosystem } \\
\text { levels are in decline. } \\
\text { - Evidence suggests that the proportion of animal } \\
\text { breeds at risk of extinction is increasing, and that - } \\
\text { for some species and in some areas - crop diversity } \\
\text { in farmers' fields is decreasing and threats to } \\
\text { diversity are increasing. Nearly a third of fish stocks } \\
\text { are overfished and a third of freshwater fish species } \\
\text { assessed are classed as threatened. } \\
\text { - Countries report that many species that contribute } \\
\text { to vital ecosystem services, including pollinators, } \\
\text { natural enemies of pests, soil organisms, and wild } \\
\text { food species, are in decline as a consequence } \\
\text { of the destruction and degradation of habitats, } \\
\text { overexploitation, pollution and other threats. } \\
\text { - Forests, rangelands, mangroves, seagrasses, coral } \\
\text { reefs and wetlands in general - key ecosystems } \\
\text { that deliver many essential services to food } \\
\text { and agriculture, including supply of freshwater, } \\
\text { protection against storms, floods and other hazards, } \\
\text { carbon sequestration and provision of habitat for } \\
\text { countless species - are declining rapidly. }\end{array}$ & $\begin{array}{l}\text { - Assessment and monitoring of the status and trends } \\
\text { of BFA at national, regional and global levels are } \\
\text { uneven and often limited. While declining trends are } \\
\text { clear, lack of data often constrains the planning and } \\
\text { prioritization of effective remedial measures. } \\
\text { - Priorities for improving the monitoring of the status } \\
\text { and trends of BFA include: } \\
\text { - addressing the knowledge and data gaps that } \\
\text { exist across all categories of BFA; } \\
\text { - establishing or strengthening monitoring } \\
\text { programmes for BFA and providing these } \\
\text { programmes with the resources needed to } \\
\text { operate over the long term; } \\
\text { - improving methods for recording, storing and } \\
\text { analysing data on changes in the status of } \\
\text { species and habitats in and around production } \\
\text { systems, and making them accessible to those } \\
\text { that need them; and } \\
\text { - addressing skill gaps, such as shortages of trained } \\
\text { taxonomists, and exploring innovative options for } \\
\text { improving knowledge of status and trends, such } \\
\text { as involving non-specialist "citizen-scientists" in } \\
\text { monitoring some components of BFA. }\end{array}$ \\
\hline
\end{tabular}

\subsection{Introduction}

Approaches to monitoring the status and trends of biodiversity to food and agriculture (BFA) vary across sectors and across categories of biodiversity, depending, inter alia, on what data are considered useful for management purposes, how difficult such data are to collect, and the extent to which the relevant resources and capacity are available. A range of different aspects of diversity can potentially be monitored. For example, ecosystems can be monitored based on their geographical extent, but also on various measures of their quality. Species and within-species groups, such as varieties and breeds, can simply be counted (i.e. "richness" can be monitored), but it is also possible to establish 
extinction-risk categories to which species (or within-species populations) can be assigned and to monitor movements between categories. Risk categorization, in turn, can be based on more or less complicated methods, depending on the availability of data on population sizes, structures and trends, geographical distributions, threats and other factors. If population data are available, it is also possible to calculate statistics based on the distribution of the individual organisms within a population across species (or breeds, varieties or other categories) and to monitor how these change over time. Aside from measures based on units such as species, breeds or varieties, it is also possible simply to count the number of individual organisms or measure the amount of biomass within a particular category of biodiversity (see for example Box 4.3).

This chapter presents an overview of the status and trends of BFA category by category, beginning with short discussions of plant (crop), animal (livestock), forest and aquatic genetic resources (further details for each can be found in the respective FAO global assessments - [FAO, forthcoming, 2010a, 2014a, 2015a]). The next section provides an overview of the status and trends of associated biodiversity ${ }^{1}$ involved in the supply of particular categories of regulating and supporting ecosystem services. It also presents an overview of trends in the supply of the services themselves. This is followed by sections on the status and trends of wild foods and a number of ecosystems reported by countries to be of particular importance to food and agriculture. Finally, key needs and priorities for improving the state of knowledge on the status and trends of BFA are presented.

\subsection{Plant, animal, forest and aquatic genetic resources for food and agriculture}

- While more than 6000 plant species have been cultivated for food, fewer than 200 make substantial

See Section 1.5 for further information on the various categories of BFA. contributions to global food output, with only nine accounting for 66 percent of total crop production in 2014. Although it is not possible to make definitive statements about global trends in the erosion of on-farm crop diversity, evidence suggests that, overall, the diversity present in farmers' fields has declined and that threats to diversity are getting stronger.

- The world's livestock production is based on about 40 animal species, with only a handful providing the vast majority of global output of meat, milk and eggs. As of 2018, 7745 out of 8803 reported livestock breeds are classed as local (i.e. reported to occur in one country only); 594 of these breeds are extinct. Among extant local breeds, 26 percent are classed as being at risk of extinction, 7 percent as not at risk and 67 percent as being of unknown risk status.

- The number of trees species in the world is estimated to be about 60000 . Globally, more than 700 species are now included in tree-breeding programmes. There is no systematic global monitoring system in place for intraspecific diversity in tree species.

- Countries report the farming of 694 aquatic species and other taxonomic groups. In 2016, global capture fisheries harvested over 1800 species of aquatic animal and plants. Within these thousands of species there are numerous genetically distinct stocks and phenotypes. As of 2015, 33 percent of fish stocks were estimated to be overfished, 60 percent to be maximally sustainably fished and 7 percent to be underfished.

\subsubsection{Plant genetic resources for food and agriculture}

Globally, there are approximately 382000 species of vascular plants (RBG Kew, 2017), out of which a little over 6000 have been cultivated for food (IPK, 2017). Of these, as of 2014, fewer than 200 species had significant production levels globally, ${ }^{2}$ with only nine (sugar cane, maize, rice, wheat, potatoes, soybeans, oil-palm fruit, sugar beet and cassava) accounting for over 66 percent of all crop production by weight (FAO, 2017j).

The genetic diversity within crop species can be broad. However, the precise extent of such diversity

\footnotetext{
This refers to the number of species for which production statistics are recorded in FAOSTAT.
} 
is difficult to quantify. A widely applicable indicator for monitoring within-species diversity has yet to be developed. Important dimensions of concern are genetic erosion and genetic vulnerability at within-species level. Genetic erosion within species has been defined as "the loss of individual genes and the loss of particular combinations of genes (i.e. of gene complexes) such as those manifested in locally adapted landraces" (FAO, 1997). The term is sometimes used in a narrow sense, i.e. referring to the loss of genes or alleles, and sometimes in a broader sense, i.e. referring to the loss of varieties. Genetic vulnerability has been defined as "the condition that results when a widely planted crop is uniformly susceptible to a pest, pathogen or environmental hazard as a result of its genetic constitution, thereby creating a potential for widespread crop losses" (FAO, 1997).

Indicators of genetic erosion would ideally focus on changes in the frequency of alleles of importance to crop production (and give them more weight than less important ones), provide a measure of the extent of potential loss (e.g. by estimating the fraction of genetic diversity at risk relative to the total diversity) and allow assessment of the likelihood of loss over a specific time period in the absence of intervention (FAO, 2010a). Indicators for genetic vulnerability could be based on a number of different populationlevel attributes, for example differences in levels of resistance to, or tolerance of, actual and potential major pests and diseases or abiotic stresses (ibid.). In the absence of data that can serve as more accurate indicators of genetic vulnerability, a simple proxy is the extent to which single varieties dominate over large areas of land. This is based on the assumption that genetic vulnerability is higher when large areas are cropped with one (or only a few) varieties. ${ }^{3}$

See, for example, Indicator 42 of the monitoring framework for the Second Global Plan of Action for Plant Genetic Resources for Food and Agriculture: "The least number of varieties that together account for $80 \%$ of the total area for each of the five most widely cultivated crops" (FAO, 2016m).
The evidence presented in the country reports ${ }^{4}$ prepared for The Second Report on the State of the World's Plant Genetic Resources for Food and Agriculture (Second SoW-PGRFA) (FAO, 2010a) ${ }^{5}$ indicates that, overall, the diversity present in farmers' fields has declined and that threats to diversity are increasing (although the situation varies greatly depending on the country, location, type of production system, etc.). There is considerable consensus that, overall, the shift from traditional production systems utilizing farmers' varieties/landraces to "modern" production systems depending on officially released varieties $^{6}$ is leading to genetic erosion. Many farmers' varieties/landraces are reported to have disappeared or to have become rarer. However, the situation is complex. For example, it appears that many farmers who plant modern varieties also continue to maintain traditional varieties. Studies of trends in genetic diversity within released varieties also indicate a complex situation, with some reporting no reduction, or even increases in diversity over time. Newly adopted varieties can add genetic diversity to an agricultural system. However, in some cases they may completely substitute the original ones. The balance of diversity is therefore difficult to assess. It is also difficult to make definitive statements about trends in genetic vulnerability. However, more than half the country reports prepared for the Second SoW-PGRFA indicate the presence of significant genetic vulnerability.

The diversity of crop wild relatives has decreased in some areas and appears to be particularly threatened in places where the climatic conditions are changing but species migration is prevented by ecogeographical barriers.

\footnotetext{
4 Note that elsewhere in this chapter, unless indicated otherwise, the term "country reports" refers to the country reports submitted as contributions to The State of the World's Biodiversity for Food and Agriculture. See "About this publication" for additional information.

5 Unless otherwise indicated, the material presented in this subsection is based on this report.

6 In other words, varieties developed and made available by breeding programmes
} 


\subsubsection{Animal genetic resources for food and agriculture}

The number of animal species domesticated for use in food and agriculture is relatively small. The Global Databank for Animal Genetic Resources, hosted by FAO, records data on 38 species. ${ }^{7}$ At global level, the status and trends of animal genetic resources for food and agriculture are assessed largely on the basis of summary statistics on breed risk status, i.e. the proportions of the world's breeds that are categorized as being at risk, not at risk, extinct or of unknown risk status according to the classification system used by FAO $^{8}$ Since 1993, FAO has published global data of this kind in a number of reports, the most recent being Status and trends of animal genetic resources - 2018 (FAO, 2018g). ${ }^{9}$ The approach has some limitations in that it treats all breeds equally regardless of their significance to the overall diversity of the species (or significance in terms of other possible conservation criteria). It also only registers changes when breeds move from one risk-status category to another. Lack of regularly updated data on the size and structure of breed populations is a major practical constraint to the monitoring of risk status in many countries, particularly in the developing regions of the world. ${ }^{10}$

Sustainable Development Goal Indicator 2.5.2 is "Proportion of local breeds classified as being at risk, not-at-risk or at unknown level of risk of

\footnotetext{
Some of these are in fact groups of species (e.g. deer) or fertile interspecies crosses (e.g. dromedary $\times$ Bactrian camel crosses).

8 Breeds are assigned to risk categories on the basis of the size, structure and trends of their populations. Data are drawn from the Global Databank for Animal Genetic Resources, the backbone of FAO's Domestic Animal Diversity Information System (DAD-IS). Countries are responsible for entering data on their breed populations into the system.

9 Unless otherwise indicated the data presented in this subsection are taken from this report.

10 In 2013, the Commission on Genetic Resources for Food and Agriculture adopted the following indicators for the diversity of animal genetic resources: the number of locally adapted breeds; the proportion of the total population accounted for by locally adapted and exotic breeds; and the number of breeds classified as at risk, not at risk and unknown. The indicators have not (as of 2018) been fully put into operation because the necessary classification of breeds as locally adapted or exotic has not been completed.
}

extinction." As of March 2018, 7745 breeds out of the 8803 breeds recorded by FAO were classed as local breeds (i.e. reported present in only one country). A total of 594 local breeds were extinct. Among extant local breeds, 26 percent were classified as being at risk of extinction, 7 percent as not at risk and 67 percent as being of unknown ${ }^{11}$ risk status. A comparison of data from 2006 and 2014 shows a slight decrease (29 to 26 percent) in the proportion of local breeds classified as being at risk of extinction. ${ }^{12}$ However, the apparent trend needs to be interpreted with caution given the above-mentioned limitations in the state of reporting. Over the same period, the proportion of local breeds with unknown status increased from 62 percent to 67 percent. If all breeds are considered, regardless of whether or not they are classed as local, 59 percent are classed as being of unknown risk status, 10 percent as not at risk, 24 percent as at risk and 7 percent as extinct.

Among the extant species regarded as having been the wild ancestors of major livestock species, the most seriously at risk according to The International Union for Conservation of Nature Red List of Threatened Species ${ }^{\mathrm{TM}}$ (The IUCN Red List) ${ }^{13}$ are the African wild ass (Equus africanus) and the wild Bactrian camel (Camelus ferus), both of which are classified as Critically Endangered. The wild water buffalo (Bubalus arnee) and the banteng (Bos javanicus) are classified as Endangered. The Indian bison (Bos gaurus), wild yak (Bos mutus), mouflon (Ovis orientalis), wild goat (Capra aegagrus) and swan goose (Anser cygnoides) are classified as Vulnerable. The European rabbit (Oryctolagus cuniculus) is classified as Near Threatened. ${ }^{14}$ Overall, it appears that a higher proportion of livestock wild relative species are threatened with extinction than mammalian and

\footnotetext{
Breeds are considered to be of unknown risk status if no population data have been reported to FAO during the preceding ten years.

12 Both sets of figures were calculated on the basis of the data recorded in DAD-IS as of March 2018.

13 The IUCN Red List of Threatened Species. Version 2018-1.

14 This refers to the status of the wild rabbit in its natural range. Outside its natural range, the species is widespread and often considered a pest.
} 
bird species in general. As of 2010, 25 percent of species in order Galliformes (chicken relatives), 83 percent of species in tribe Bovini (cattle relatives), 44 percent of species in subfamily Caprinae (sheep and goat relatives) and 50 percent of species in family Suidae (pig relatives) were classified as threatened (McGowan, 2010).

\subsubsection{Forest genetic resources}

The total number of extant tree species in the world remains uncertain. However, it is estimated to be about 60000 (Beech et al., 2017). The country reports submitted for The State of the World's Forest Genetic Resources (SoW-FGR) list nearly 8000 species of trees, scrubs, palms and bamboo, of which about 2400 are actively managed for the products and/or services they supply (FAO, 2014a). Globally, more than 700 species are now included in tree-breeding programmes.

The status and trends of forest genetic resources are monitored at ecosystem, species and intraspecific levels. However, these efforts are hampered by many methodological and other constraints. Most countries face difficulties in assessing their primary forest area. Forest degradation, forest restoration and species composition are also difficult to monitor precisely. Monitoring of the risk status of tree species is currently not comprehensive globally, although a number of countries are able to monitor the status of all their tree species. The Global Tree Assessment, ${ }^{15}$ an initiative led by Botanic Gardens Conservation International and the IUCN/Species Survival Commission Global Tree Specialist Group, aims to provide conservation assessments for all the world's tree species by 2020 (Newton et al., 2015a).

Globally, forest genetic resources are being threatened and eroded by conversion of forests to agriculture, unsustainable harvesting of trees for wood and non-wood products, grazing and browsing, climate change, forest fires and invasive species (FAO, 2014a). In many parts of the world, vast areas of land once covered by forests have been converted to other land uses, with

\footnotetext{
15 https://www.bgci.org/plant-conservation/globaltreeassessment/
}

much of this change having occurred during the twentieth century. Forests still cover 30.6 percent of the world's land area and, while global forest area, and - while global forest area continues to shrink - the rate of annual net loss of forests has decreased significantly over recent decades (FAO, 2016g) (see Section 4.5.5 for further information).

There is no systematic global monitoring system in place for intraspecific diversity in tree species. The SoW-FGR provides an overview of the state of knowledge in this regard. Schemes for genetic monitoring of forest trees have been proposed at global (Namkoong et al., 1996, 2002) and regional levels (e.g. Aravanopoulos et al., 2015). However, they have not yet been implemented, and only a very few countries have tested such schemes in practice (e.g. Konnert et al., 2011). Loss of intraspecific diversity in economically important tree species has been a major concern in forest management for decades. Forest management practices can have genetic impacts on tree populations. However, they need to be assessed on a case-by-case basis. The extent of the impact depends on the management system and the stand structure, as well as on the demography, biological characteristics and ecology of the species (Wickneswari et al., 2014). In temperate forests, for example, silvicultural interventions, such as the thinning of stands, usually have limited genetic consequences (Lefèvre, 2004), and many silvicultural systems maintain genetic diversity in tree populations rather well (Geburek and Müller, 2005). However, if forest management practices change evolutionary processes within tree populations, this can have a more profound impact on the genetic diversity of subsequent generations of trees (Lefèvre et al., 2014).

\subsubsection{Aquatic genetic resources for food and agriculture}

Globally, there are more than 31000 species of finfish, 52000 species of aquatic molluscs, 64000 species of aquatic crustaceans and 14000 species of aquatic plants (Balian et al., 2007; Chambers et al., 2008; Lévêque et al., 2008; WoRMS, 2018). In 2016, global capture fisheries harvested 
over 1800 species, including finfish, crustaceans, molluscs, echinoderms, coelenterates and aquatic plants (FAO, forthcoming). Within these thousands of species there are numerous genetically distinct stocks and phenotypes.

Fisheries and aquaculture data submitted to FAO by its member countries provide valuable information on various aspects of aquatic BFA. However, information is not always reported at the species level. This is especially problematic for inland fisheries, where over half of all production is not designated by species (Bartley et al., 2015). In the case of aquaculture, available data suggest that more species are now being farmed than ever before, especially as more marine fishes are being bred in captivity (Duarte, Marbà and Holmer, 2007; FAO, 2016h). Country reports prepared for The State of the World's Aquatic Genetic Resources for Food and Agriculture (FAO, forthcoming) report the farming of 694 species and other taxonomic groups. As of 2016, FAO had recorded data on about 598 species used in aquaculture: 369 finfish species (including hybrids); 104 mollusc species; 64 crustacean species; 7 amphibian and reptile species (excluding alligators, caimans or crocodiles); 9 other aquatic invertebrate species; and 40 species of aquatic algae (FAO, 2018a).

The level of monitoring of species and populations harvested in marine and inland fisheries and raised in aquaculture varies substantially across these subsectors and across the world. Monitoring of diversity at intraspecies level is relatively undeveloped in the aquatic sector as compared to the terrestrial livestock and crop sectors (FAO, forthcoming).

The state of the world's marine fisheries is assessed by FAO through the analysis of over 400 stocks of fish. Species targeted by marine fisheries are classified according to whether they are overfished (fished at biologically unsustainable levels), maximally sustainably fished (fished at biologically sustainable levels) or underfished. As of 2015, 33.1 percent of fish stocks were estimated to be overfished, 59.9 percent to be maximally sustainably fished and 7.0 percent to be underfished (FAO, 2018a). The share of fish stocks within biologically sustainable levels (maximally sustainably fished or underfished) declined from 90 percent in 1974 to 66.9 percent in 2015 (ibid.). FAO does not provide an equivalent analysis for inland fisheries. The state of inland capture-fishery resources is more difficult to monitor for a number of reasons, including the diffuse character of the sector, the large number of people involved, the seasonal and subsistence nature of many small-scale inland fisheries, the fact that much of the catch is consumed locally or traded informally, and the fact that populations can be greatly affected by activities other than fishing, including stocking from aquaculture and diversion of water for other uses such as agriculture and hydroelectric development (FAO, 2012b). While there is no dedicated FAO programme addressing the state of inland fisheries, the Thirty-second Session of the FAO Committee on Fisheries recommended "the development of an effective methodology to monitor and assess the status of inland fisheries, to underpin their value, to give them appropriate recognition and to support their management ... [and] requested that FAO develop this assessment methodology, including broader ecosystem considerations that impact inland fisheries" (FAO, 2016h).

Top-level carnivores are reported to have declined in many marine and inland fisheries (Pauly et al., 1998). This is referred to as "fishing down the food web" and can indicate overfishing (ibid.). In such cases, the productivity of a fishery remains high, especially in inland waters, as lower trophic-level species increase in abundance in the absence of larger predators; however, the value of the fish drops as the large, more-valuable species disappear (Welcomme, 1999).

The status of many aquatic species is assessed by conservation and trade organizations. The IUCN Red List ${ }^{16}$ classifies over 1300 marine species (including plants, fish, molluscs, crustaceans and other invertebrates) and over 5200 wetland species as Endangered, Threatened or Vulnerable. ${ }^{17}$ Among freshwater fish (not the wider range of biodiversity mentioned above), out of 5785 species that had

\footnotetext{
6 http://www.iucnredlist.org/

17 The IUCN Red List of Threatened Species. Version 2017-3.
} 
been assessed for The IUCN Red List at the end of 2011, 60 were considered extinct, 8 Extinct, 8 Extinct in the Wild and 1679 (29.3 percent) threatened (Carrizo, Smith and Darwall, 2013). If it is assumed that the 1062 species classified as data deficient are threatened in the same proportion as species for which data are available, the proportion of threatened species would amount to 36.1 percent of the total (ibid.). However, not all the fish species assessed by IUCN are used for food and agriculture. The Convention on International Trade in Endangered Species of Wild Fauna and Flora (CITES) ${ }^{18}$ maintains information on the status of aquatic species that are traded internationally. Several species used in fisheries and aquaculture (e.g. sturgeons, tunas and sharks) are on the CITES Appendices. ${ }^{19}$

\subsection{Associated biodiversity}

- Across all production systems, over 450 species are reported by countries to be managed to promote the supply of ecosystem services supporting food production and agriculture, with a vastly higher number of unmanaged species also essential to these services.

- Components of BFA often provide or contribute to multiple ecosystem services, and this needs to be built on in their management and in the management of the production systems where they are found.

- Many species of associated biodiversity are reported by countries to be under threat from habitat alteration and loss, overexploitation, pollution, pests, diseases and invasive species, and agriculture intensification.

- Reports of bee-colony losses are on the rise; 16.5 percent of vertebrate pollinator species are threatened with global extinction (rising to 30 percent for island species). Declines in wild-pollinator populations are reported by several countries, with the major threats reported to include habitat loss and fragmentation, use of pesticides, decline in the diversity of landscapes and plant communities, and climate change.

$18 \mathrm{https}: / / \mathrm{www}$.cites.org/eng

19 The CITES Appendices are lists of species afforded particular types or levels of protection from overexploitation. For further information, visit the relevant page of the CITES website (https://www.cites.org/eng/app/index.php)
- Many countries report declines in the populations of birds, bats and insects that contribute to pest and disease regulation. Habitat loss and unsustainable management practices in the food and agriculture sector are noted as particular threats.

- Soil biodiversity is under threat in all regions of the world. Many indicators point to declines in soil health, and ecosystem services provided by soils are at severe risk

- The provision of water-related ecosystem services, hazard regulation, habitat provisioning, and air-quality and climate-regulation services is closely tied to the health and integrity of seagrass beds, mangroves, coral reefs, wetlands, forests and rangelands, all of which are in decline globally.

This section discusses the status and trends of components of associated biodiversity, i.e. the biodiversity present in and around production systems that contributes to the supply of supporting and regulating ecosystem services. ${ }^{20}$ While ecosystem services generally rely on the healthy functioning of whole ecosystems, some species play particularly significant roles in the supply of particular services. ${ }^{21}$ Some of these species are specifically managed for ecosystem services that support food production and agriculture.

The first section below introduces the components of associated biodiversity reported by countries to be specifically managed to promote the supply of ecosystem services. The second provides an overview of the state of information systems and monitoring programmes for associated biodiversity. The third provides an overview of countries' responses on the status and trends of associated biodiversity. The next seven discuss the status and trends of associated biodiversity involved in the supply of particular categories of ecosystem services, based on information from the country reports and other sources. They also discuss what countries reported on trends in the supply of the services themselves.

\footnotetext{
20 See Section 1.5 for further discussion

21 See Section 2.2 further discussion of the roles of BFA in the supply of ecosystem services and Section 4.5 for discussion of the status and trends of a number of important ecosystem categories.
} 


\subsubsection{Associated-biodiversity species managed for ecosystem services}

The country-reporting guidelines specifically invited countries to list species (or subspecies) of associated biodiversity that are in one way or another managed in production systems to help provide regulating or supporting ecosystem services. Sixty-eight countries provided responses, referring to a total of 462 distinct terrestrial and aquatic species, including micro-organisms, invertebrates, birds, mammals, and trees and other plants. The ecosystem service for which the largest number of species are reported to be managed is pest and disease regulation, followed by habitat provisioning, soil formation and protection, nutrient cycling and pollination. The western honey bee (Apis mellifera), which is managed for pollination purposes, is the species most frequently mentioned (Table 4.1). Several countries also mention managing ecosystems and landscape features to improve the delivery of ecosystem services, including the management of forests, wetlands, lakes, riparian buffer zones and hedgerows (see for example Sections 4.3.7, 4.3.8, 4.3.9, 4.3.10 and 4.5).

Among the species and genera managed in production systems for the delivery of regulating or supporting ecosystem services, 16 are reported to be managed for more than one service (Table 4.2). These include nine tree and seven non-tree plant species and genera. Acacia spp. are reported to be managed for the largest number of distinct ecosystem services supporting food and agriculture (eight).

The number of species of associated biodiversity that are reported to be managed for ecosystem services is particularly large in rainfed crop systems (413 species), followed by mixed systems (307), naturally regenerated forests (298), livestock grassland-based systems (256), planted forests (249) and irrigated crop (other than rice) systems (191). Several of these species are reported to be managed in production systems in more than one sector of production (Figure 4.1).

In forest, livestock and mixed production systems, the ecosystem services for which the largest numbers of species are reported to be managed are soil formation and protection and habitat provisioning (Figure 4.1). In crop production systems, pest and disease regulation is the most frequently targeted ecosystem service, with many countries referring to the use of biological control agents and to the management of invasive species. The use of cover crops to promote nutrient cycling and soil formation, or for habitat provisioning through the creation of riparian buffer zones, is also mentioned. In rainfed systems in particular, a considerable number of associatedbiodiversity species are reported to be specifically managed for pollination. In aquatic production systems, habitat provisioning is the most commonly reported ecosystem service for which associatedbiodiversity species are being managed. For example, mangrove species are noted to provide spawning grounds for fish and other aquatic species. Several countries mention planting trees, shrubs and grasses as windbreaks and to protect coastal and other areas against various hazards. Some, for example, mention planting trees such as the Mediterranean cypress (Cupressus sempervirens) around forests for fire-control purposes.

Overall, the large number of associated biodiversity species managed in various production systems and the multiplicity of ecosystem services they supply reflect their enormous value and their great potential to support food and agricultural production.

\subsubsection{Information and monitoring systems on associated biodiversity}

Countries were invited to report on national information systems on associated biodiversity. Fifty-seven country reports indicate the presence of at least one such information system (247 are reported in total). An additional four reports ${ }^{22}$ specifically indicate the absence of any such systems. Over 40 percent of the systems reported are in European countries. Several examples of information and monitoring systems are described in the "state of knowledge" subsections of Sections 4.3.4 to 4.3.10 and in Boxes 4.6 and 8.8.

Those from the Gambia, Slovakia, Sri Lanka and Suriname. 
TABLE 4.1

Examples of species and genera reported by countries to be managed for regulating or supporting ecosystem services in production systems

\begin{tabular}{|c|c|c|c|}
\hline $\begin{array}{l}\text { Ecosystem service (number } \\
\text { of distinct species reported) }\end{array}$ & Species or genus & Common name & Countries \\
\hline \multirow{11}{*}{ Pest and disease regulation (144) } & Acorus calamus & Flagroot & Nepal \\
\hline & Aphelinus mali & Woolly aphid parasite & Nepal, Peru, Syrian Arab Republic, Yemen \\
\hline & Azadirachta indica & Neem tree & Jordan, Nepal, Niger \\
\hline & Bacillus thuringiensis & Bt & Ecuador, India, Peru \\
\hline & Cecidochares connexa & Gall fly & Palau, Papua New Guinea \\
\hline & Ctenopharyngodon idella & Grass carp & Fiji, Syrian Arab Republic \\
\hline & Cryptolaemus montrouzieri & Mealybug destroyer & India, Jamaica, Syrian Arab Republic \\
\hline & Habrobracon hebetor & & Niger, Syrian Arab Republic \\
\hline & $\begin{array}{l}\text { Neochetina bruchi, } \\
\text { N. eichhorniae }\end{array}$ & $\begin{array}{l}\text { Chevroned water hyacinth } \\
\text { weevil, mottled water hyacinth } \\
\text { weevil }\end{array}$ & Papua New Guinea, Sri Lanka, Sudan \\
\hline & Trichoderma harzianum & & Bangladesh, India, Nepal \\
\hline & Typhlodromus pyri & & Croatia, France, Syrian Arab Republic \\
\hline \multirow{5}{*}{ Habitat provisioning (125) } & Brassica oleracea & Wild cabbage & Ireland, United Kingdom \\
\hline & Khaya senegalensis & African mahogany & Chad, Togo \\
\hline & Mangifera sylvatica & Nepal mango & Bangladesh \\
\hline & Platycladus orientalis & Chinese arborvitae & China \\
\hline & Tamarindus indica & Tamarind & Chad, Ecuador, Yemen \\
\hline \multirow{8}{*}{ Soil formation and protection (111) } & Chrysopogon zizanioides & Khuskhus vetiver & Jamaica, Zimbabwe \\
\hline & Leucaena leucocephala & White leadtree & Brazil, Mexico \\
\hline & Panicum turgidum & Merkba & Yemen \\
\hline & Pinus sylvestris & Scots pine & Ireland, Slovenia \\
\hline & Prosopis juliflora & Ironwood & Brazil, Yemen \\
\hline & Rhizobium leguminosarum & & Bangladesh \\
\hline & Secale cereale & Rye & Ireland, United Kingdom \\
\hline & $\begin{array}{l}\text { Swietenia humilis, } \\
\text { S. macrophylla }\end{array}$ & Mexican mahogany & Mexico \\
\hline \multirow{10}{*}{ Nutrient cycling (76) } & $\begin{array}{l}\text { Bradyrhizobium elkanii, } \\
\text { B. japonicum }\end{array}$ & & Brazil \\
\hline & Eisenia fetida & Tiger worm & Bulgaria, Jamaica \\
\hline & Faidherbia albida & Winter thorn & Burkina Faso \\
\hline & Hordeum vulgare & Barley & Sweden, United Kingdom \\
\hline & Lens culinaris & Common lentil & Jordan, Yemen \\
\hline & Leucaena leucocephala & White leadtree & Brazil, Zimbabwe \\
\hline & Lumbricus rubellus & Red earthworm & Bulgaria \\
\hline & Rhizobium leguminosarum & & Brazil, Nepal \\
\hline & Secale cereale & Rye & Sweden, United Kingdom \\
\hline & Vicia sativa & Common vetch & Jordan, Yemen \\
\hline
\end{tabular}




\section{PART B}

TABLE 4.1 (Cont.)

Examples of species and genera reported by countries to be managed for regulating or supporting ecosystem services in production systems

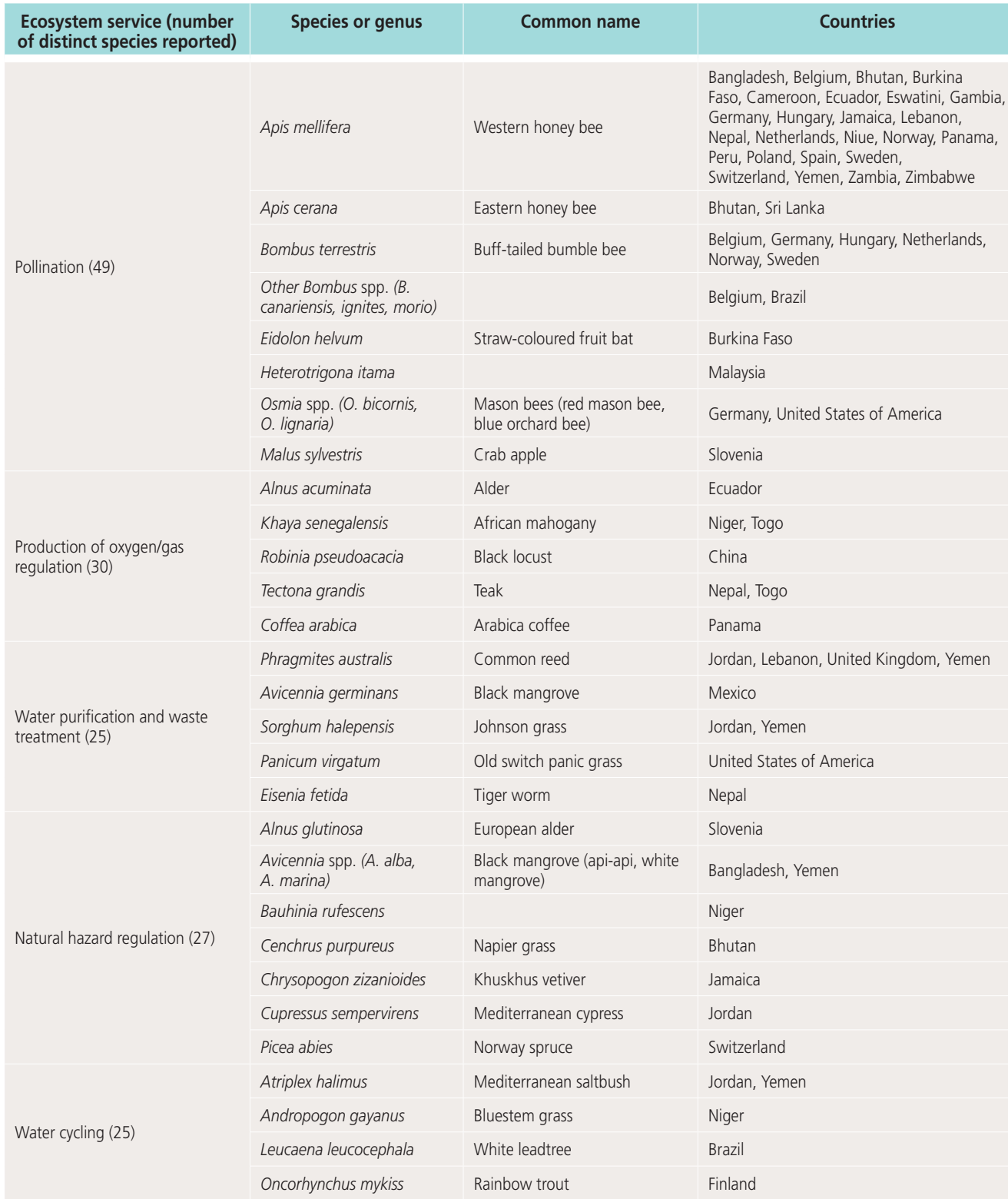

Note: Analysis based on 91 country reports.

Source: Country reports prepared for The State of the World's Biodiversity for Food and Agriculture. 
TABLE 4.2

Species and genera most frequently reported to be managed for multiple supporting and regulating ecosystem services

\begin{tabular}{|c|c|c|c|c|c|c|c|c|c|c|c|c|}
\hline & & 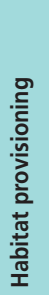 & 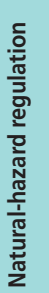 & 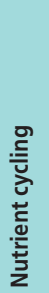 & 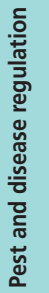 & 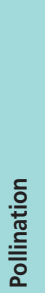 & 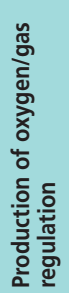 & 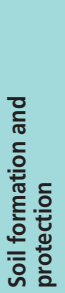 & 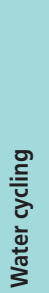 & 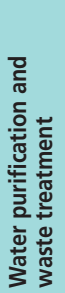 & 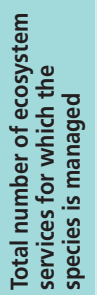 & \\
\hline $\begin{array}{l}\text { Species or } \\
\text { genus }\end{array}$ & $\begin{array}{l}\text { Common } \\
\text { name }\end{array}$ & \multicolumn{10}{|c|}{ Number of countries } & Countries \\
\hline Acacia spp. & Acacias & 3 & 1 & 2 & 2 & & 2 & 3 & 2 & 1 & 16 & $\begin{array}{l}\text { Angola, Burkina Faso, } \\
\text { Chad, China, Jordan, } \\
\text { Mexico, Nepal, Niger, } \\
\text { Saudi Arabia, Sudan, } \\
\text { Yemen, Zimbabwe }\end{array}$ \\
\hline Pinus spp. & Pines & 3 & 2 & 1 & 1 & & 1 & 4 & & & 12 & $\begin{array}{l}\text { China, Ireland, Mexico, } \\
\text { Peru, Slovakia, Slovenia }\end{array}$ \\
\hline Brassica spp. & Brassicas & 1 & & 1 & 1 & 1 & & 3 & & 1 & 8 & $\begin{array}{l}\text { Bulgaria, Ireland, Jordan, } \\
\text { United Kingdom, Slovakia }\end{array}$ \\
\hline Trifolium spp. & Clover & 1 & & 4 & & 1 & 1 & 1 & & & 8 & $\begin{array}{l}\text { Bulgaria, Ireland, Jordan, } \\
\text { Norway, Slovakia, Sweden }\end{array}$ \\
\hline $\begin{array}{l}\text { Eucalyptus } \\
\text { spp. }\end{array}$ & Eucalyptus & 1 & 1 & & 1 & & 1 & 2 & 1 & & 7 & $\begin{array}{l}\text { Cameroon, Ecuador, Peru, } \\
\text { Senegal, Sudan }\end{array}$ \\
\hline $\begin{array}{l}\text { Crotalaria } \\
\text { spectabilis }\end{array}$ & $\begin{array}{l}\text { Showy } \\
\text { rattlebox }\end{array}$ & 1 & & 1 & & 1 & 1 & 1 & 1 & & 6 & Brazil \\
\hline $\begin{array}{l}\text { Medicago } \\
\text { spp. }\end{array}$ & Medick & 1 & & 3 & & & 1 & 1 & & & 6 & Bulgaria, Jordan, Yemen \\
\hline Populus spp. & Aspen & 2 & & & & & & 1 & & 3 & 6 & $\begin{array}{l}\text { Finland, Ireland, Jordan, } \\
\text { Slovenia, Yemen }\end{array}$ \\
\hline $\begin{array}{l}\text { Bauhinia } \\
\text { rufescens }\end{array}$ & & 1 & 1 & 1 & & & & 1 & 1 & & 5 & Niger \\
\hline $\begin{array}{l}\text { Canavalia } \\
\text { ensiforms }\end{array}$ & Jack bean & 1 & & 1 & & & 1 & 1 & 1 & & 5 & Brazil \\
\hline Cajanus cajan & Pigeon pea & 1 & & 1 & & & 1 & 1 & 1 & & 5 & Brazil \\
\hline $\begin{array}{l}\text { Leucaena } \\
\text { leucocephala }\end{array}$ & $\begin{array}{l}\text { White } \\
\text { leadtree }\end{array}$ & 1 & & 2 & & & 1 & 2 & 1 & & 5 & Brazil, Mexico, Zimbabwe \\
\hline $\begin{array}{l}\text { Tithonia } \\
\text { diversifolia }\end{array}$ & $\begin{array}{l}\text { Tree } \\
\text { marigold }\end{array}$ & 1 & & 1 & & & 1 & 1 & 1 & & 5 & Brazil \\
\hline $\begin{array}{l}\text { Hordeum } \\
\text { vulgare }\end{array}$ & Barley & & 1 & 2 & 1 & & & 1 & & & 4 & $\begin{array}{l}\text { Jordan, Sweden, United } \\
\text { Kingdom }\end{array}$ \\
\hline $\begin{array}{l}\text { Tamarindus } \\
\text { indica }\end{array}$ & Tamarind & 3 & & & & & 1 & & 1 & & 3 & Chad, Ecuador, Yemen \\
\hline $\begin{array}{l}\text { Khaya } \\
\text { senegalensis }\end{array}$ & $\begin{array}{l}\text { African } \\
\text { mahogany }\end{array}$ & 2 & 1 & & & & 2 & & & & 3 & Chad, Niger, Togo \\
\hline
\end{tabular}

Note: Analysis based on 91 country reports.

Source: Country reports prepared for The State of the World's Biodiversity for Food and Agriculture. 


\section{PART B}

FIGURE 4.1

Regulating and supporting ecosystem services for which associated biodiversity is reported to be managed, by sector of production

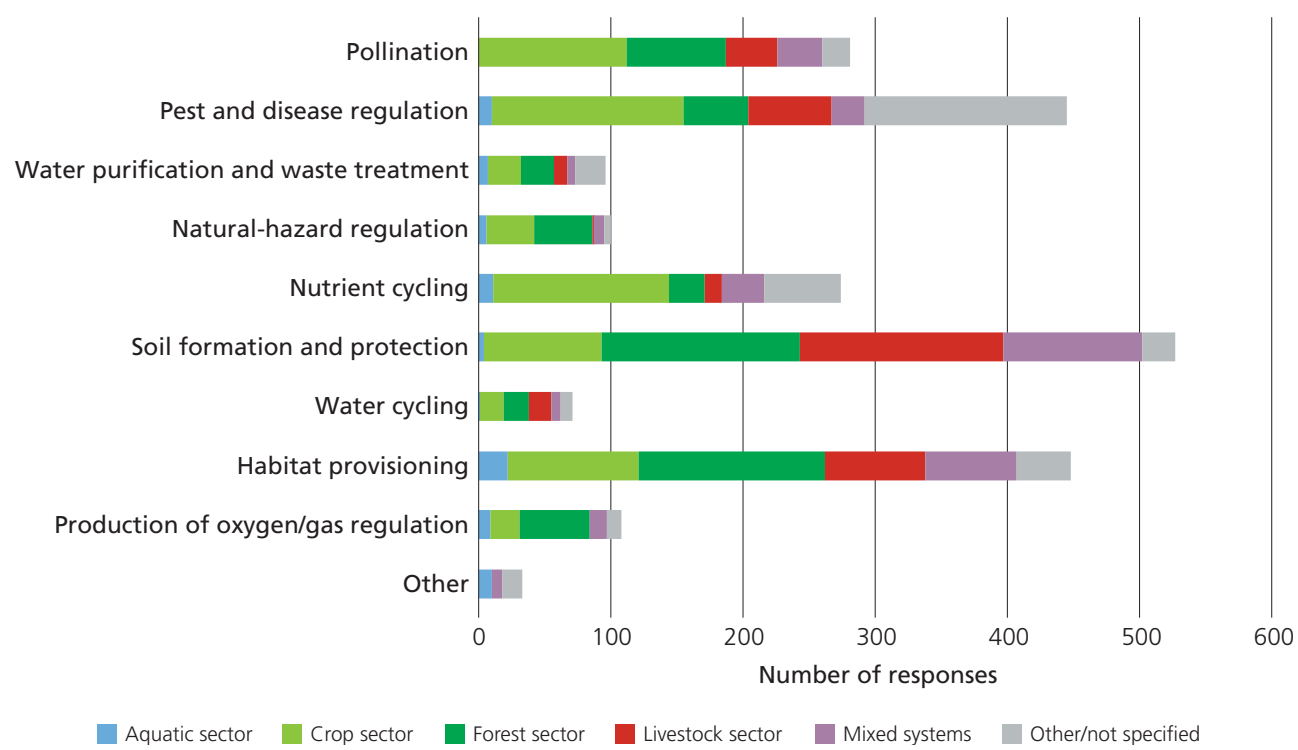

Notes: A "response" is an indication by a country that a particular species or other taxonomic group is managed within a particular production system to promote the supply of a particular ecosystem service. Several of the 462 distinct species that featured in the responses were mentioned by more than one country and/or for more than one production system. The total number of responses is 1228 . For presentation purposes, production systems are grouped by sector of production. Analysis based on 91 country reports. Source: Country reports prepared for The State of the World's Biodiversity for Food and Agriculture.

In most countries, the reported information systems were developed in the context of environmental monitoring programmes and not because the monitored species are considered of importance to food and agriculture. For example, most countries have established "red lists" that summarize the status and trends of native flora and fauna species and the threats affecting them. These lists are usually based on a methodology similar to that used for The IUCN Red List (Box 4.1) and are reviewed at regular intervals. ${ }^{23}$ In addition

\footnotetext{
23 The IUCN Red List allows species to be grouped according to the types of ecosystems in which they occur, including agricultural, forest and marine ecosystems. However, it does not allow this to be done for particular roles, or assumed roles, in the supply of regulating or supporting ecosystem services (pollination, pest control, etc.) within these ecosystems.
}

to databases of species risk status, the systems reported include a variety of sources of information on associated biodiversity, including newsletters, national reports on the state of biodiversity produced by relevant ministries (e.g. forestry or environment), radio and television programmes, Internet resources, institutes, universities, laboratories, museums and encyclopaedias. More information can be found in the regional synthesis reports prepared as part of the reporting process for The State of the World's Biodiversity for Food and Agriculture. ${ }^{24}$

The reported information systems are used to monitor a range of different components of

\footnotetext{
24 The regional synthesis reports will be made available at http://www.fao.org/cgrfa/en/
} 
Box 4.1

The International Union for Conservation of Nature Red List of Threatened Species ${ }^{\mathrm{TM}}$

The International Union for Conservation of Nature Red List of Threatened Species ${ }^{\mathrm{TM}}$ (The IUCN Red List) is the world's most comprehensive source of information on species extinction risks, and contains a wealth of information on factors affecting species survival, including on distribution ranges, population trends, ecology, conservation actions, threats and trade and use. As of November 2018, more than 96500 species were included, over 26500 of which were threatened with extinction, including 40 percent of amphibians, 34 percent of conifers, 33 percent of reef-building corals, 25 percent of mammals and 14 percent of birds.

Source: The IUCN Red List version 2018-2.

Note: For further information, see https://www.iucnredlist.org

\section{Increase in the number of species assessed for} The IUCN Red List (2000-2018)

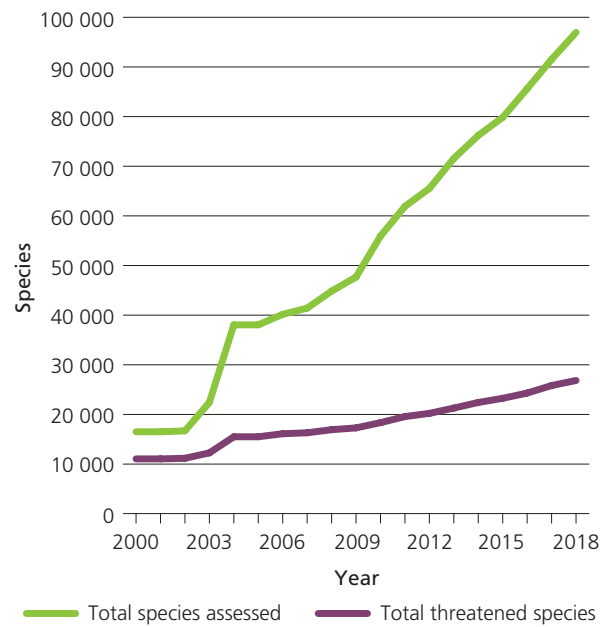

Box 4.2

Birds as indicator species

Avian species can act as valuable indicators of environmental change and complex shifts in ecosystem dynamics that may be detrimental to food and agriculture. For example, seabirds are excellent indicators of climate change thanks to their behavioural, social and life-history traits and the vast amount of long-term data available on them (Grémillet and Boulinier, 2009). Seabirds generally have highly specialized diets and rely on just a few prey species, whose abundance and distribution can shift dramatically in response to abrupt environmental changes (BirdLife International, 2009). Rising sea-surface temperatures in Antarctica have led to a reduction in the abundance of Antarctic krill (Euphausia superba), a key prey species for many seabirds, and an increase in the abundance of less favourable food. This has affected several seabird populations, including emperor penguins (Aptenodytes forsteri) in Terre Adélie, whose population declined by 50 percent during a period of abnormally warm temperatures and poor krill production (Barbraud and
Weimerskirch, 2001). When pieced together, such trends and warning signs demonstrate where, and how much, climate change is affecting the ecosystems that industries such as fishing depend upon.

Seabird numbers can also be a direct indication of fishstock depletion. A study on sardine fisheries in the Gulf of California demonstrated (taking El Niño influences into account) that a declining proportion of sardines in the diets of three seabird species (the California brown pelican [Pelecanus occidentalis], Heermann's gull [Larus heermanni] and the elegant tern [Thalasseus elegans]) gave a reliable forecast of diminishing catch per unit effort in fisheries landings in subsequent years. This allowed successful mitigation or reduced-catch measures to be implemented, helping to stabilize fisheries income (Velarde, Ezcurra and Anderson, 2013).

Source: Provided by the Royal Society for the Protection of Birds (RSPB) and BirdLife International. 
associated biodiversity, including particular ecosystem categories (e.g. forests, grasslands or aquatic ecosystems), protected areas, individual species, species in general (e.g. via the above-mentioned red lists), rare or endangered species, specific taxonomic groups (e.g. amphibians and reptiles, bats, bees, birds, butterflies, freshwater and marine fish, fungi, lichens or mosses) or other categories such as crop pests and their natural enemies. Several European countries mention monitoring efforts for micro-organisms (including bacteria, viruses and protists) and fungi, including groups that are of importance to food and agriculture, such as mycorrhizal fungi, soil microbes, planktonic microbes and rumen microbes. Despite these various initiatives, however, countries generally make it very clear that there are many gaps and weaknesses in monitoring programmes and information systems for associated biodiversity. Even where demographic data on components of associated biodiversity are collected, it often remains unclear how these relate to the geographical distribution of production systems, which makes it more difficult to draw conclusions regarding possible effects on food and agriculture.

Lack of capacity is widely reported by countries to be a significant constraint to the monitoring of associated biodiversity. Some countries indicate that much of the monitoring work that does take place is done by (expert or non-expert) volunteers. For example, Finland reports that initiatives of this kind account for approximately 70 percent of all its biodiversity-related monitoring work. Monitoring of butterflies and birds is largely volunteer-based in most countries in Europe. Efforts are also being made to develop methodologies based on indicator species that can be used even where capacity is limited. For example, the Belau National Museum, in cooperation with the Palau Conservation Society and the Palau International Coral Reef Centre, is reported to have completed preliminary studies aimed at identifying bird species that could be used as indicators for near-shore environmental quality and ecosystem health. See Box 4.2 for further information on birds as indicator species.
TABLE 4.3

Risk status of associated biodiversity for which a significant threat of extinction or loss is reported

\begin{tabular}{|l|c|c|}
\hline \multicolumn{1}{|c|}{ Risk status } & Responses & Distinct species \\
\hline Extinct (EX) & 17 & 17 \\
\hline Extinct in the Wild (EW) & 1 & 1 \\
\hline $\begin{array}{l}\text { Critically Endangered } \\
\text { (CR) }\end{array}$ & 154 & 151 \\
\hline Endangered (EN) & 811 & 766 \\
\hline Vulnerable (VU) & 304 & 300 \\
\hline Data Deficient (DD) & 13 & 13 \\
\hline Near Threatened (NT) & 65 & 63 \\
\hline Least Concern (LC) & 36 & 38 \\
\hline Threatened & 362 & 336 \\
\hline Not known & 34 & 34 \\
\hline Not specified & 277 & 261 \\
\hline Total & 2074 & 1900 \\
\hline
\end{tabular}

Notes: A "response" is a mention by a specific country of a specific component of biodiversity (species or higher taxonomic group). The "threatened" category encompasses all responses indicating that a species is threatened but without further specification of the degree of threat according to the IUCN Red List Categories and Criteria. The figures refer to the risk statuses assigned to species in the country reports. Analysis based on 91 country reports.

Source: Country reports prepared for The State of the World's Biodiversity for Food and Agriculture.

\subsubsection{Overview of status and trends}

Countries were invited to list any components of associated biodiversity for which there is evidence of a significant threat of extinction or loss of important populations, to specify the degree of the threat according to the classification system in use in the country or following the Categories and Criteria of The IUCN Red List, and to provide a description of the threat. The responses are summarized in Table 4.3. Seventy-nine percent of the responses indicate Critically Endangered, Endangered, Vulnerable or Threatened status, and 82 percent of distinct species mentioned fall into these categories.

A total of 2074 responses, from 48 countries and covering 1900 distinct species, were provided. More than half of these responses come from three countries, Bangladesh, Mexico and Panama. The groups 


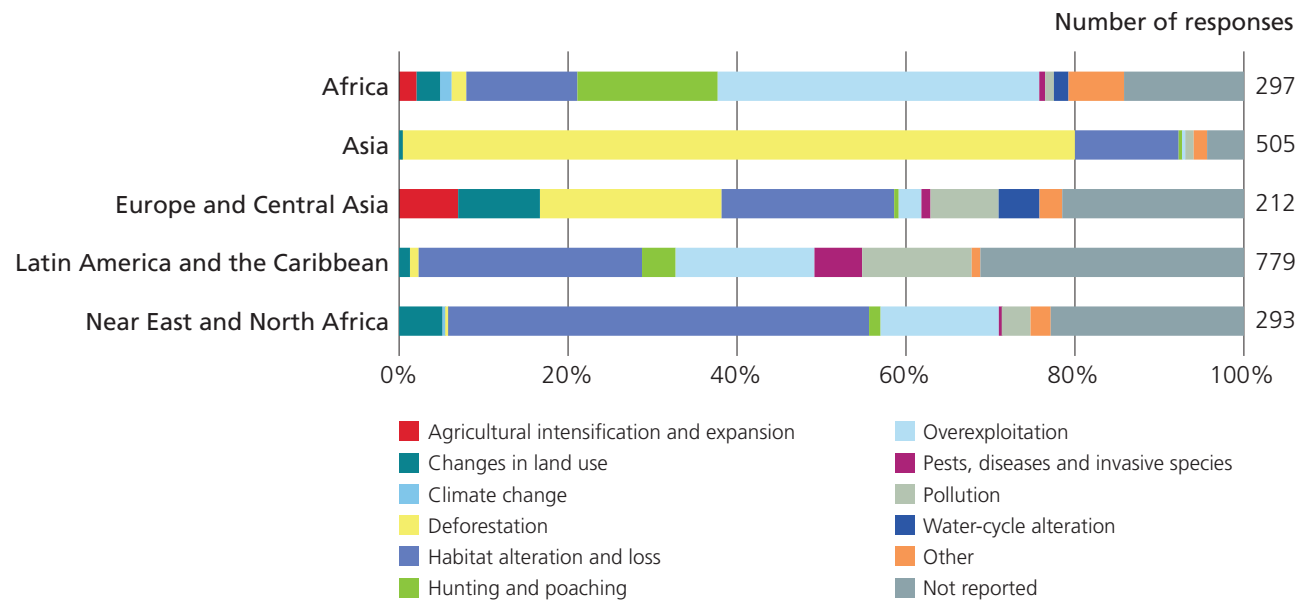

Notes: A "response" is a mention by a specific country of a specific component of biodiversity (species or higher taxonomic group) No data are available for North America or the Pacific. Analysis based on 91 country reports.

Source: Country reports prepared for The State of the World's Biodiversity for Food and Agriculture.

of species that feature most frequently in countries' responses are plants, followed by birds, fish and mammals. Plants account for 1032 (63 percent) of the responses referring to species that are classed as Critically Endangered, Endangered, Vulnerable or Threatened, birds for 180 (11 percent), fish for 125 (8 percent), mammals for 83 (5 percent), fungi for 74 ( 5 percent), reptiles for 61 (4 percent), arthropods ${ }^{25}$ for 37 ( 2 percent), molluscs for 22 (1 percent), amphibians for 13 (1 percent) and sea cucumbers for 4 (less than 1 percent).

The species most frequently mentioned, for any risk category, include the western honey bee (Apis mellifera), the green turtle (Chelonia mydas), the hawksbill sea turtle (Eretmochelys imbricate), the loggerhead sea turtle (Caretta caretta), the West African ebony (Diospyros mespiliformis), the Himalayan yew (Taxus wallichiana), the baobab (Adansonia digitata), the Eurasian skylark (Alauda arvensis), the European

\footnotetext{
25 Arthropod species mentioned include insects, spiders and crustaceans.
}

eel (Anguilla anguilla), the Palmyra palm (Borassus aethiopum), the European roller (Coracias garrulus), the leatherback sea turtle (Dermochelys coriacea), Duvalia sulcate (a succulent plant), Globularia arabica (a low shrub), the house finch (Haemorhous mexicanus), the hippopotamus (Hippopotamus amphibius), the African mahogany (Khaya senegalensis), the ocelot (Leopardus pardalis), the olive ridley sea turtle (Lepidochelys olivacea), the pomegranate (Punica granatum), the clapper rail (Rallus longirostris), the whiteheaded vulture (Trigonoceps occipitalis), biznaugita (Turbinicarpus schmiedickeanus) (a cactus) and the thirsty thorn (Vachellia seyal).

For the majority of species listed by countries, no specific indication is provided that they are being deliberately managed for their contributions to the supply of ecosystem services to food and agriculture. Countries made extensive use of national red lists as sources of information. In some cases, ecosystems included in red lists were matched with the production-system categories used in the country-reporting process 


\section{PART B}

FIGURE 4.3

Reported trends in associated biodiversity, by production system

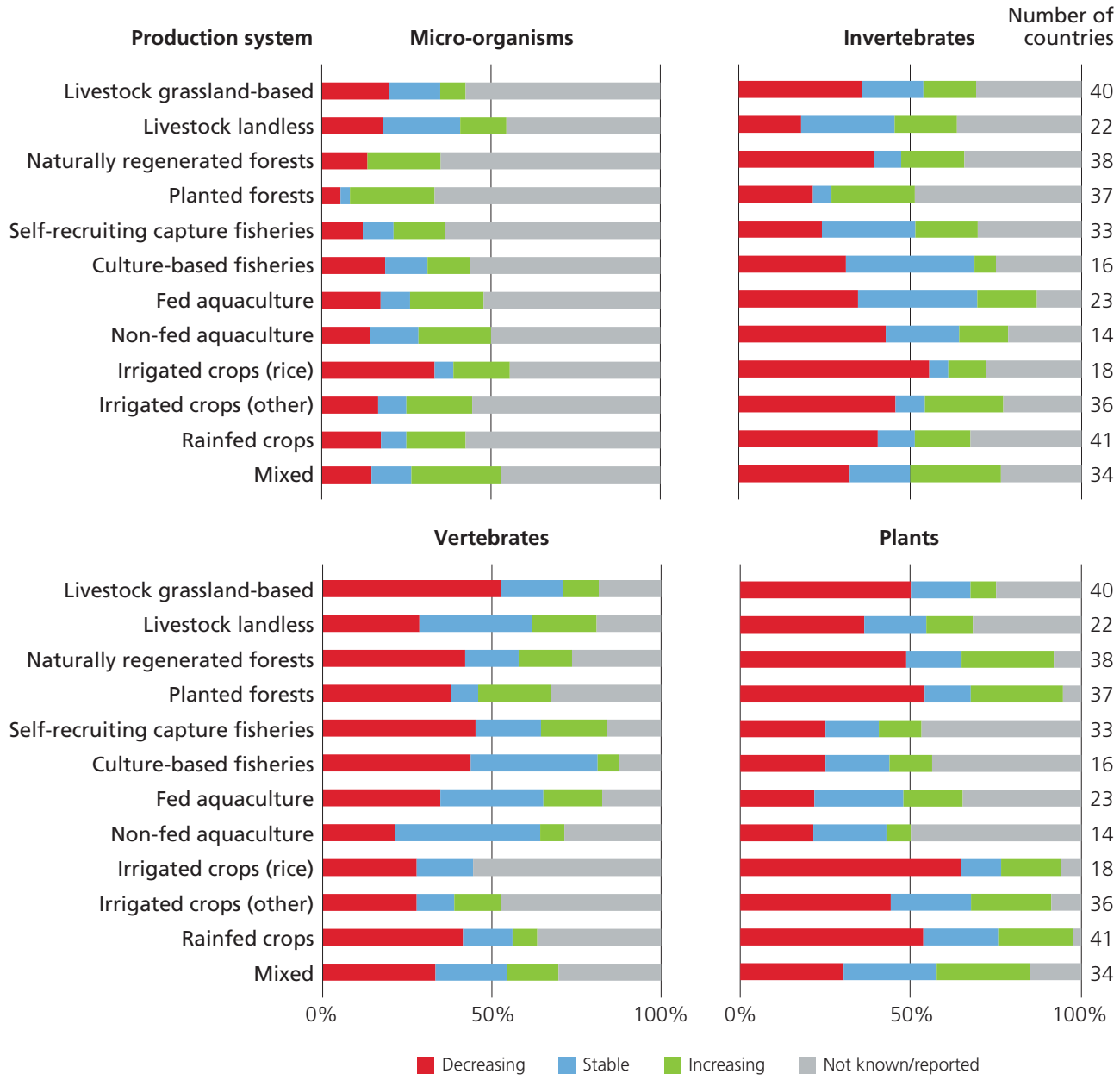

Notes: The figures refer to the ten-year period prior to the preparation of the country reports. "Number of countries" refers to the number of countries - out of 91 providing reports - that reported trends for the four categories of associated biodiversity in the respective production system. "Not known/reported" refers to cases where no response is provided or where the information is indicated to be not known or not applicable. Analysis based on 91 country reports.

Source: Country reports prepared for The State of the World's Biodiversity for Food and Agriculture.

(see Section 1.5) and all species included in the respective red lists considered to be associatedbiodiversity species, i.e. there was an assumption that each of these species plays a role in the functioning of the respective ecosystem.
The main threats reported are habitat alteration and loss (490 responses), deforestation (547), overexploitation (286), pollution (134), hunting and poaching (86), change in land use (52), pests, diseases and invasive species (49), agricultural 
intensification and expansion (19), water-cycle alteration (14) and climate change (5). Figure 4.2 provides a regional breakdown.

Figure 4.3 summarizes the information reported by countries on trends over the last ten years in the status of various categories of associated biodiversity (micro-organisms, invertebrates, vertebrates and plants). ${ }^{26}$ It presents an overview of number of countries reporting information on trends and a proportional breakdown of this information by production-system category and type of organism.

Overall, for all production systems and all types of associated biodiversity combined, 33 percent of responses indicate decreasing trends, 15 percent stable trends and 19 percent increasing trends; 33 percent indicate that information is unknown or not applicable. The breakdown presented in Figure 4.3 highlights the generally limited amount of information available on micro-organisms in production systems, in particular in forest production systems. Trends in invertebrate, vertebrate and plant species providing supporting and regulating ecosystem services in various production systems are better assessed.

Countries were invited to report on changes in regulating or supporting services detected in specific production-system categories over the preceding ten years, ${ }^{27}$ to describe the trends reported and, if possible, to provide information on baseline levels, measurements and indicators used, extent of change, likely cause(s) and references to sources of information (Table 4.4). A total of 46 countries ( 51 percent of those that provided country reports), including countries from all regions, provided information on trends in at least one ecosystem service. For individual categories of ecosystem services, the numbers

\footnotetext{
26 Specifically, countries were invited to provide qualitative assessments of trends (strongly increasing, increasing, stable, decreasing and strongly decreasing) or to indicate that information was not known or not applicable.

27 Specifically, countries were invited to provide qualitative assessments of trends (strongly increasing, increasing, stable, decreasing and strongly decreasing) or to indicate that information was not known or not applicable.
}

of countries reporting ranged from 36 (naturalhazard regulation) to 43 (habitat provisioning).

The next seven sections discuss the status and trends of associated biodiversity involved in the supply of particular categories of ecosystem services, based on information from the country reports and other sources. They also discuss what countries reported on trends in the supply of the services themselves. With regard to the trends in the latter, it should be noted that relationships between BFA and the supply of ecosystem services are complex and that trends in the diversity or distribution of components of BFA will often not be reflected straightforwardly in trends in the supply ecosystem services.

\subsubsection{Associated biodiversity for pollination}

\section{Introduction}

Nearly 90 percent ${ }^{28}$ of all flowering-plant species, including the vast majority of those in tropical forests, savannah woodlands, mangroves and temperate deciduous forests, depend, to some degree, on animal pollination (other means of pollen transfer include self-pollination and pollination by wind and water) (Bradbear, 2009; Ollerton, Winfree and Tarrant, 2011). ${ }^{29}$ Thirtyfive percent of the world's total crop production by volume comes from species that are, at least in part, pollinated by animals (Klein et al., 2007). Levels of pollinator dependence vary significantly among crops, with the highest levels found mainly in fruits, vegetables and nuts (ibid.). Potts et al. (2016) report a figure of USD 235-577 billion for the annual value of the enhancements that animal pollinators make to global crop output. ${ }^{30}$

\footnotetext{
28 This ranges from 78 percent in temperate-zone communities to 94 percent in tropical communities (IPBES, 2016a; Ollerton, Winfree and Tarrant, 2011).

${ }^{29}$ Pollination also occurs in aquatic environments. While unti recently it was thought that animal pollination does not contribute to pollination under water, it has been found that marine invertebrates contribute to the pollination of the seagrass Thalassia testudinum (Van Tussenbroek et al., 2016).

30 The figure (inflated to 2015 USD value) is based on the work of Lautenback et al. (2012), who used production and price figures for 2009
} 


\section{PART B}

TABLE 4.4

Reported trends in the state of provision of regulating and supporting ecosystem services in production systems

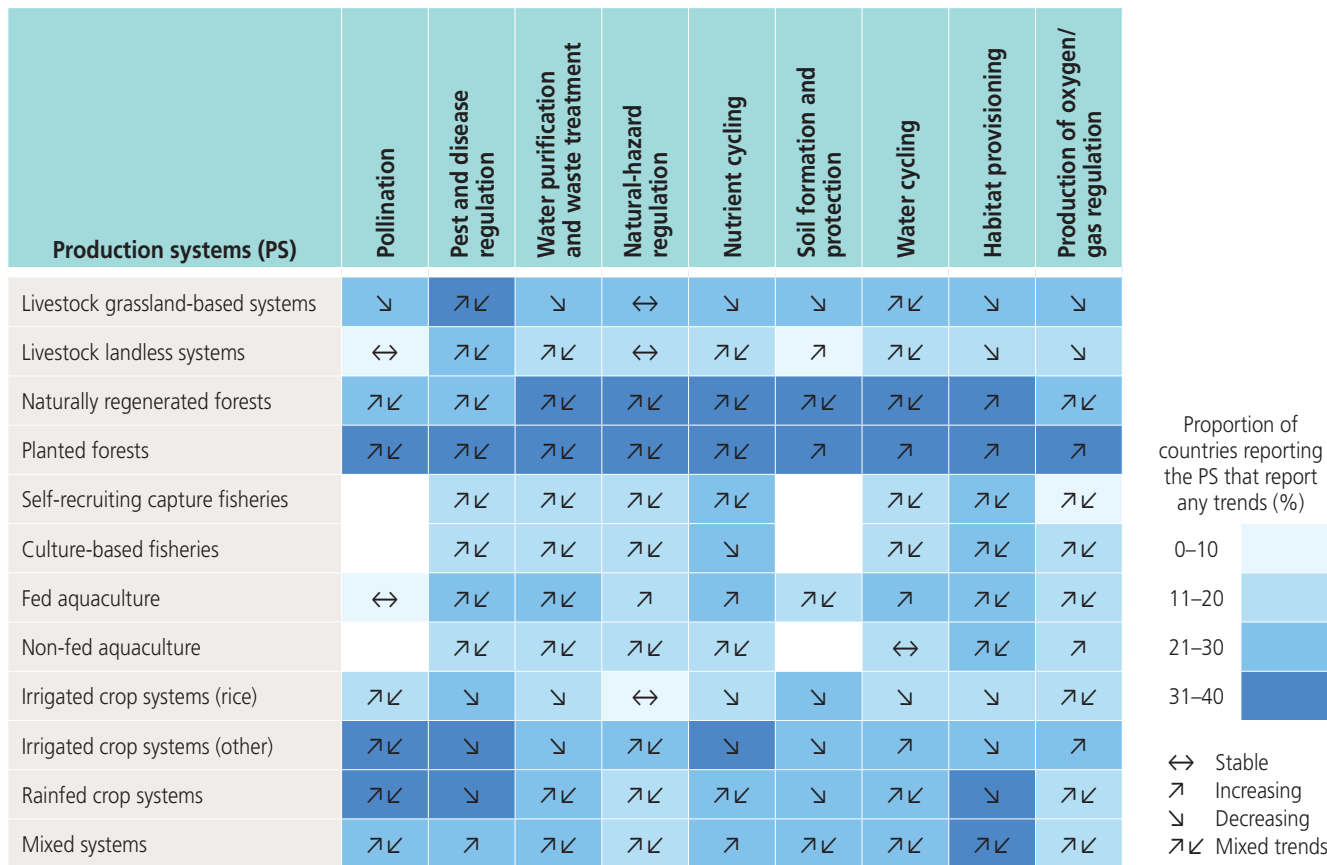

Notes: Countries were invited to report trends (increasing, stable or decreasing) in the state of provision of each ecosystem service in each production system. If $50 \%$ or more of the responses for a given combination of production system and ecosystem service indicate the same trend (increasing, decreasing or stable) then this trend is indicated in the respective cell of the table. In other cases, mixed trends are indicated. The empty cells correspond to cases in which fewer than five countries provided a response. The colour scale indicates the proportion of countries reporting the presence of the respective system that report any trends in the state of the respective ecosystem service (increasing, stable or decreasing). See Section 1.5 for descriptions of the production systems and a discussion of ecosystem services. Analysis based on 91 country reports.

Source: Country reports prepared for The State of the World's Biodiversity for Food and Agriculture.

Animal pollination in crop production systems is largely supplied by managed and wild bee species. However, there are important pollinators among other groups of insects, including flies, butterflies, moths, wasps and beetles, as well as among bats, birds and rodents (FAO, 2018i, IPBES, 2016a). ${ }^{31}$ For example, it has been estimated that bats play some part in the pollination of at least 500 Neotropical species from 96 genera (Vogel, 1969). The role of

${ }^{31}$ More than 90 percent of the leading global crop types are visited by bees and around 30 percent by flies. Each of the other animal pollinator taxa visits less than 6 percent of the crop types. birds as pollinators is discussed further in Box 4.5. Some species of pollinators are specialists (i.e. visit only one or a few plant species), while others are generalists (i.e. visit a wide range of species). Similarly, there are specialist plants, pollinated by a small number of species, and generalist plants, pollinated by a broad range of species (IPBES, 2016a).

\section{State of knowledge}

Scientific studies, citizen-science projects and indigenous and local knowledge all help to build up understanding of the economic, environmental and sociocultural values of pollination, threats to 
pollinator populations, and the status and trends of wild and managed pollinators, pollinatordependent crops and wild plants at various scales. At global level, the thematic assessment of pollinators, pollination and food production published in 2016 by the International Panel on Biodiversity and Ecosystem Services (IPBES, 2016a) remains, as of 2018 , the latest major assessment conducted on the topic.

The availability of data on the status and trends of pollinators varies significantly by region, country and type of pollinator. Data are more complete in Europe and North America than elsewhere in the world. Within these regions, managed pollinator species are better documented than wild pollinators, because they are (i) recognized as economically important, (ii) easier to monitor (they are kept in boxes) and (iii) their taxonomy is relatively well understood (IPBES, 2016a; NRC, 2007). A report on the status of pollinators in North America (NRC, 2007) notes that despite constraints associated with a lack of capacity in taxonomy and identification, quite a large amount of information is available on pollinator population trends. However, the quality of this information, and hence the state of knowledge on status and trends, varies from taxon to taxon (ibid.). The IUCN Red List of Threatened Species assessment covers 58 out of the 130 common crop-pollinating bee species in Europe and North America (IPBES, 2016a).

The country reports indicate that, across all regions, bees are the most widely monitored group of pollinator species. Honey bees are the most frequently mentioned, but some countries also refer to monitoring of bumblebees, stingless bees and other (wild) bee species. Relevant initiatives mentioned in the country reports include the bee monitoring framework developed in the United Kingdom as part of England's National Pollinator Strategy (DEFRA, 2014). Numbers of beehives are widely monitored. ${ }^{32}$ Ethiopia, for example, notes that despite a general lack of information on

\footnotetext{
32 See, for example, the country data provided in FAO's statistical database FAOSTAT (http://www.fao.org/faostat/en/\#home)
}

managed associated biodiversity, its annual inventory of beehives provides a form of "indirect" monitoring. A number of countries mention that - as an alternative to gathering data on pollinating animals themselves - monitoring plant reproductive success or pollen-deposition deficits may be an effective means of measuring pollinator trends. However, this approach will only work if the effects of other influences, such as climate and floral herbivory, can be accounted for (FAO, 2008a).

Butterfly monitoring, where it occurs, is reported to be largely conducted on a voluntary basis by experts and enthusiasts. For example, Germany notes that volunteers conduct weekly walks along set routes (transects), recording all species of diurnal butterflies, year after year. ${ }^{33}$ The population data obtained are used to track trends in butterfly populations at local, subnational and national levels. Butterflies are also among the groups of species reported to be monitored by the Dutch Network Ecological Monitoring ${ }^{34}$ programme in the Netherlands. ${ }^{35}$ Again, these data are mostly collected by volunteers. The results are published by, among others, the Netherlands Environmental Assessment Agency and Statistics Netherlands. Around 16000 volunteers are reported to be active in the programme's various monitoring networks. ${ }^{36}$ Ireland also mentions the establishment of butterfly and bumblebee monitoring programmes. ${ }^{37}$

Information on the status and trends of other pollinators is generally limited. The IUCN Red List provides information on the global status of many vertebrate pollinators (e.g. humming birds and bat species). The migratory habits of species belonging to these groups sometimes require that monitoring work is done on a multicountry scale (FAO, 2008a). Mexico and the United States of America are collaborating in several initiatives of this kind (ibid.).

\footnotetext{
33 See, for example, http://www.tagfaltermonitoring.de (in German).

34 http://www.netwerkecologischemonitoring.nl/home

35 There are also networks for mammals, birds, reptiles, amphibians, fish, dragonflies, flora and mushrooms.

36 The country report cites De Groot (2014).

37 http://www.biodiversityireland.ie
} 
Data on fly populations (Diptera) are limited (FAO, 2008a). However, some evidence can be gleaned from case studies (see below). Overall, the risk status of most of the world's insect pollinator species has not been assessed (IPBES, 2016a).

\section{Status and trends}

\section{Status and trends of pollinators}

Data from FAO's statistical database, FAOSTAT, show that the number of managed western honey-bee hives is increasing globally. In 1961, countries reported fewer than 50 million hives. In 2016, they reported more than 90.5 million hives, producing nearly 1.8 million tonnes of honey annually. IPBES (2016a), however, notes that, despite the overall upward trends globally, important seasonal colony losses are known to occur in some European countries and in North America (data for other regions of the world are largely lacking).

Concerns about colony losses are reflected in some of the country reports. For example, the report from the United States of America notes that honey bees have been in serious decline for decades: there were approximately 5.7 million managed honey-bee colonies in the country in the 1940s and approximately 2.74 million colonies in 2015. It further notes that sharp colony declines occurred following the introduction of the mite Varroa destructor ${ }^{38}$ in 1987, and again around 2006 with the first reports of colony collapse disorder. ${ }^{39}$ The number of managed honey-bee colonies in the country seems to have stabilized in recent years, but this is reported to have required increased efforts by the beekeeping industry. ${ }^{40}$ Since 2006 ,

\footnotetext{
38 An external parasite that attacks honey bees and spreads viruses among them.

39 The term colony collapse disorder describes a complex set of interacting stressors, including exposure to pesticides and other environmental toxins, poor nutrition (resulting in part from decreased availability of high-quality and diverse forage), exposure to pests (e.g. Varroa mites) and disease (viral, bacterial and fungal) that cause high colony losses (USDA, 2012).

40 When overwintering colony losses are high, beekeepers compensate for these losses by "splitting" one colony into two and supplying the second colony with a new queen bee and supplementary food in order to quickly build up colony strength.
}

the average seasonal loss of honey bees in the United States of America has reportedly averaged around 31 percent, far exceeding the 15 percent to 17 percent loss rate that commercial beekeepers consider to be an economically sustainable average. ${ }^{41}$ A few country reports from northwestern Europe mention that the state of insect colonies in general, and of bee colonies in particular, is currently below the optimal threshold for pollination of flowering plants in arable land and grassland.

With regard to wild pollinators, IPBES (2016a) concludes that they "have declined in occurrence and diversity (and abundance for certain species) at local and regional scales in North West Europe and North America" and notes that while a lack of data precludes general statements about other regions, local declines have been recorded. In Europe, 9 percent of bee and butterfly species are threatened, and populations are declining in 37 percent of bee and 31 percent of butterfly species (excluding data deficient species, which include 57 percent of bee species [ibid.] ). ${ }^{42}$ Trends of this kind are reflected in the country reports from Europe. The report from the United Kingdom, for example, refers to work showing that among 216 bee species monitored nationally, 70 percent showed a decline in distribution between 1980 and 2010. With regard to the country's butterfly populations, the report indicates that recent years (2008 to 2013) have seen no overall change, but that long-term figures (1976 to 2013) show that the populations of 50 percent of butterfly species have decreased. Several country reports from the region, including those from Ireland, Norway, Poland and Switzerland, refer specifically to a decline in bumblebees. Serious declines in two bumblebee species, the great yellow bumblebee (Bombus distinguendus) in Europe and Franklin's bumblebee ( $B$. franklini) in the western United States of America, are highlighted by IPBES (2016a). In both cases, effects on production systems have yet to be examined (ibid.).

\footnotetext{
${ }^{41}$ The country report cites Steinhauer et al. (2015).

42 Data for other regions are currently insufficient to draw general conclusions.
} 
Box 4.3

Monitoring total flying insect biomass over $\mathbf{2 7}$ years in protected areas in Germany

Insects play a central role in the supply of several ecosystem services, including pollination, biological control and nutrient cycling, and provide a food source for a wide range of species, including many birds, mammals and amphibians (Noriega et al., 2018). A decline in insect numbers therefore has serious implications for ecosystem functioning, dynamics and integrity.

Based on long-term insect-trapping results from

63 nature-protection areas in Germany, Hallmann et al. (2017) concluded that over the period 1989 to 2016 flyinginsect biomass underwent a seasonal decline of 76 percent ("seasonal" refers to the period 1 April to 300 ctober) and a mid-summer decline of 82 percent.

The fact that all sampling sites were within natureprotection areas makes the decline even more alarming. The authors note that the presence of the effect throughout the season and across all habitat types studied suggests that large-scale factors must be involved, but that analysis of data on climate, land use and local habitat characteristics indicates that changes in these factors cannot explain the decline. They mention that agricultural intensification "(e.g. pesticide usage, year-round tillage, increased use of fertilizers and frequency of agronomic measures)", although not incorporated into their analysis, may be a plausible cause (almost all the study sites were close to agricultural fields). They also note that the effect "must have cascading effects across trophic levels and numerous other ecosystem services."

Following this and other similar studies, Germany initiated an Action Programme for Insect Protection (see https://www.bmu.de/insektenschutz/).
Among countries from other regions, Brazil reports that its 1173 species of fauna classified as being threatened with extinction include 85 bird species, 63 lepidopteran species, 29 beetle species, 7 bat species and 4 bee species that can be considered pollinators. Some other countries report anecdotal indications of trends. For example, Grenada mentions that farmers frequently comment on falling numbers of butterflies and other insects in their fields, but notes that no specific studies have been conducted to confirm this perceived change or to identify possible causes.

As noted above, data on population trends in insect pollinators other than bees and Lepidoptera are generally limited. However, some studies provide insights into local trends or drivers of change among relevant taxonomic groups. For example, Lagucki, Burdine and McCluney (2017) report negative effects of urbanization on flies (Diptera), among other groups of flying arthropods. Hallmann et al. (2017) report severe declines in total flying-insect biomass over recent decades at sites in Germany (see Box 4.3).

Where vertebrate pollinators are concerned, IPBES (2016a) estimates, based on data from
The IUCN Red List, that 16.5 percent of species are threatened with global extinction (increasing to 30 percent for island species), with a trend towards more extinctions. Regan et al. (2015) report that among 1089 bird species and 343 mammalian species identified as pollinators, 18 of the former and 15 of the latter moved into a higher IUCN Red List risk-status category during the period 1988 to 2012 (with two mammalian species moving in the opposite direction). The most serious threats to vertebrate pollinators in terms of the number of species affected are reported to be habitat loss caused by unsustainable agriculture (seriously affecting both bird and mammalian pollinators), hunting and trapping (a threat to mammals in particular) and invasive alien species (a threat to birds in particular) (ibid.). Key drivers of change affecting pollinators are further discussed in Chapter 3.

Status and trends of pollinator-dependent crops A study undertaken by Aizen et al. (2009) using FAO data concluded that the global economic importance of pollinator-dependent crops relative to pollinator-independent crops increased significantly 
between 1961 and 2006. Yield growth and stability in pollinator-dependent crops have, however, been lower than in pollinator-independent crops (Aizen et al., 2009; IPBES, 2016a). The reasons for this have not been clearly established. However, many studies at local scales show that crop production is higher in fields with diverse and abundant pollinator communities than in fields with less-diverse pollinator communities (Garibaldi et al., 2016). Pollinator density and diversity depend, in turn, on the characteristics of the local environment (e.g. the quality and quantity of food and nesting resources) and on management practices in agriculture. For example, Klein et al. (2007) report case studies for nine crops on four continents that indicated that agricultural intensification jeopardizes wild-bee communities and their stabilizing effect on pollination services at the landscape scale (see Section 5.6.7 for further information on links between management practices and pollinator diversity and pollination services).

\section{Status and trends of pollination}

Countries' responses on trends in the supply of pollination services in particular production systems are summarized in Table 4.4. In livestock grassland-based systems, reports of decreasing trends predominate. In crop, forest and mixed systems, trends are mixed (i.e. neither positive nor negative nor stable trends predominate). Some countries report perceived declines (quantitative data are generally lacking) in the state of pollination services in agriculture without specifying which production systems are affected.

Where explanations for reported trends are provided, they often apply to more than one production system. Many countries identify the use of pesticides, human-induced habitat loss and fragmentation and climate change as major causes of declines in pollinator abundance across production systems. Several countries report that the availability of food sources for pollinators in agricultural production systems is being jeopardized by a decline in the diversity of landscapes and plant communities. Nepal, however, notes that crop diversification in its rainfed crop systems has increased pollination levels. Several European countries mention that the establishment of flower strips in and around fields (incentivized through agri-environmental schemes) may have led to an increase in the number of pollinators in surrounding areas. In the case of rainfed and irrigated crop (non-rice) systems, some countries (e.g. Zambia and Switzerland) report that invasive plant species are replacing plant species that pollinators depend on for food.

With regard to grassland-based livestock systems, Zambia reports that wild pollinators are among the components of BFA that have been negatively affected by a recent decline in the number of livestock herds (caused by disease outbreaks). Norway notes that the gradual abandonment of extensive grazing is leading to the disappearance of habitats that benefit pollinators. Conversely, Argentina reports that overgrazing in grassland systems is reducing pollinator habitat. Loss of habitat in naturally regenerated forests is reported to be affecting pollinators in a number of countries. Some countries, however, mention that forest area, particularly planted forest area, is increasing and that this is creating habitat for pollinators. Logging and the overharvesting of non-wood forest products (specifically plants) are reported to be among the causes of loss of pollinator habitat in forests. Grenada mentions that natural disasters such as hurricanes have disturbed forest ecosystems, with deleterious effects on pollinators.

Several countries report that efforts to raise awareness of the importance of pollinators have had positive effects. Poland, for example, reports that growing awareness of the importance of honey bees in increasing crop yields, along with growing demand for pollination services in large plantations of insect-pollinated crops, is expected to lead to increasing interest in beekeeping and an increase in the honey bee population.

\subsubsection{Associated biodiversity for pest and disease regulation}

\section{Introduction}

Pest, disease and weed regulation is a crucial ecosystem service for food and agriculture. The direct 
providers of this service are a vast category of associated biodiversity known as biological control agents (BCA). Non-BCA biodiversity contributes indirectly to the creation of a pest-suppressive environment by, inter alia, providing alternative food sources and shelter for BCAs (e.g. Settle et al., 1996). BCAs can be deliberately introduced (augmentative and classical biological pest control) or managed indirectly by manipulating the local environment and wider landscape to promote their presence (conservation biological control). See Section 5.6.6 for further information on the roles of BCAs in integrated pest management.

BCAs are taxonomically diverse and include many species of bacteria, fungi, invertebrates and vertebrates. The most significant functional groups of BCAs are parasitoid insects, predators, herbivores, entomopathogenic organisms (bacteria, fungi, nematodes and viruses) and antifungal fungi (Box 4.4). The roles of birds in the supply of ecosystem services, including pest and disease regulation, are discussed in Box 4.5.

Relationships between the status of BCA populations and the supply of pest-control services are complex. The presence of more than one BCA species that preys on a given pest may not always add to the effectiveness of regulation services (Martin et al., 2013; Rafikov, Balthazar and von Bremen, 2008; Straub, Finke and Snyder, 2008). Generally speaking, however, so-called functional redundancy is considered likely to increase the resilience of pest-control services by reducing the risk that all BCAs for a particular pest will be lost (e.g. because of climate change) (Beed et al., 2011; Cock et al., 2011). An increase in the abundance and species richness of BCAs can sometimes lead to antagonistic relationships such as superpredation (predation of predators) and hyperparasitoidism (parasitoidism of parasitoids) (Griffin, Byrnes and Cardinale, 2013; Holland et al., 2012; Landis, Wratten and Gurr, 2000; Martin et al., 2013). These kinds of trophic relationships among BCAs, and hence potentially the supply of pest-control services, are affected in turn by the characteristics of the local landscape. For example, Martin et al. (2013) found that negative interactions among natural enemies constrained pest control as landscapes became more complex. However, other studies have found increasing landscape complexity to be correlated with increased diversity and effectiveness (timing) of BCA activity (e.g. Dominik et al., 2017; Settle et al., 1996).

The country reports list many associated biodiversity species as being actively managed to provide pest- and disease-regulating services, whether directly or indirectly (e.g. via habitat provisioning for BCAs) (see Section 4.3.1). The majority are predatory and parasitoid invertebrates associated with crop production.

\section{State of knowledge}

The country reports indicate varying levels of knowledge on the status and trends of species that provide pest and disease control services. A number of countries report extensive monitoring of relevant components of associated biodiversity. Examples include Switzerland (agro-environment monitoring programmes implemented by the Federal Office for Agriculture), the United Kingdom (Bees, Wasps and Ants Recording Society; Farmland Bird Indicator), the United States of America (National Invertebrate Genetic Resources Program) and Germany. Some countries report that monitoring activities are implemented on a less systematic basis. For example, Croatia mentions that some monitoring of natural enemies (spiders and mites) is done under its Reporting and Early Warning System in Agriculture. Guyana notes that although it does not have monitoring programmes for associated biodiversity in its rice production systems, natural-enemy populations are recorded as part of pestmonitoring activities. Some countries note that some information on the status and trends of BCAs is obtained via individual research projects. Moreover, even among countries that make no specific reference to the monitoring of BCAs or other components of biodiversity that contribute to pest and disease control services, some of these species are probably covered by monitoring programmes reported to be undertaken 
Box 4.4

The main functional groups of biological control agents

Parasitoids. Species belonging to this group spend part of their life cycles (usually the larval stage) inside or on the surface of a host, killing it in the process. Approximately 10 percent of known insect species are parasitoids (Godfray, 1994). Parasitoid biological control agents are used in agricultural systems on a large scale in augmentative, classical and conservation biological control (Heimpel and Cock, 2018; Jonsson et al., 2008; Van Lenteren et al., 2018). Examples include wasps of the suborder Apocryta and several families of flies, for example the Tachinidae family.

Predators. This group includes many arthropod species - including members of the Acari (mites), Araneae (spiders), Opiliones (harvestmen), Odonata (dragonflies), Hemiptera (e.g. assassin bugs), Thysanoptera (thrips), Neuroptera (lacewings), Coleoptera (beetles), Diptera (flies) and Hymenoptera (ants, bees and wasps) (Cock et al., 2011) as well as a number of vertebrates (amphibians, birds, fish, mammals and reptiles). Predators help to control a wide range of pest species, although some may feed on useful species as well. Subcategories of this functional group include aerial, aquatic (subsurface- and surface-dwelling), vegetation-dwelling and ground-dwelling predators (Holland et al., 2012). The first group have good dispersion ability and can predate on pests in the air. Examples include many species of flying insects (e.g. families within the orders Odonata, Hymenoptera and Diptera) and insectivorous birds and bats. Aquatic predators include many species of insects, in both larval and adult forms. Aquatic predators used specifically as control agents include fish species in rice-field systems (e.g. common carp [Cyprinus carpio] and Nile tilapia [Oreochromis niloticus]), Labridae (wrasses) employed as removers of sea lice in salmon cages, and a number of carnivorous species (e.g. bronze featherback [Notopterus notopterus]) used to control tilapia breeding by predating on their young. Ground predators are associated with the soil surface and the upper layer of the soil. Predatory mites of the family Phytoseiidae, for instance, play an important role in augmentative, classical and conservation biocontrol of pest mites and insects in openfield and greenhouse crops (Calvo et al., 2015; Maoz et al., 2014; Yaninek and Hanna, 2003). Other examples include ground and rove beetles. Predatory amphibians include toads and frogs, although the importance of their role (as well as that of reptiles) in biological control remains poorly understood (Hocking and Babbit, 2014).

Entomopathogenic fungi. This group comprises members of the Fungi Kingdom that invade arthropod tissues and reproduce in them, killing the host. Several species (e.g. Beauveria bassiana and Metarhizium anisopliae) are important in the control of grasshoppers and locusts (Jaronski and Goettel, 1997).

Antifungal fungi. This group comprises members of the Fungi Kingdom that limit the development of fungal disease in plants by killing or competing with the disease-causing fungi or by promoting plant resistance. Examples include Trichoderma spp. (John et al., 2010; Zeilinger et al., 2016).

Entomopathogenic nematodes. These nematodes invade the tissues of many types of insects (including Lepidoptera, Coleoptera and Diptera). Important examples include Steinernema spp. and Heterorhabditis spp. (Cock et al., 2011).

Entomopathogenic bacteria. An important species in this category is the bacterium Bacillus thuringiensis, which synthesizes a compound (Bt) that is toxic to insects.

Entomopathogenic viruses. Although a number of virus families are known to infect arthropods, baculoviruses stand out within this group because of their ability to kill insects with high specificity. These viruses are commonly used as biopesticides against lepidopteran pests (e.g. the Anticarsia gemmatalis nuclear polyhedrosis virus used to control the velvetbean caterpillar on soybean and the Helicoverpa armigera nuclear polyhedrosis virus used to control the cotton boll worm [Reid, Chan and van Oers, 2014]).

Weed- and algae-damaging herbivores. Herbivores such as Curculionidae (weevils) and Chrysomelidae (leaf beetles) help control weeds in croplands (Cock et al., 2011). Fish such as the grass carp (Ctenopharyngodon idella) are used in irrigation systems to control aquatic weeds (Halwart and Gupta, 2004). Rabbitfish (Siganus spp.) and scats (Scatophagus spp.) help control fouling epiphytic algae in marine fish cages. 
Box 4.5

The roles of birds in the supply of supporting and regulating ecosystem services

Pest control: Pest predation by birds enhances crop yields in many regions. More than 50 percent of bird species are primarily insectivores (Wenny et al., 2011).

The European pied flycatcher (Ficedula hypoleuca) has been shown to be a major suppressor of insects harmful to forest vegetation, especially destructive moths and caterpillars. Because of these benefits, plantation owners actively encourage the presence of pied flycatchers by providing them with nest-boxes (BirdLife International, 2015). The success of such schemes means the use of nest-boxes for flycatchers and tits has become a standard management tool throughout European forests (ibid.).

A study in a cacao agroforesty system in Central Sulawesi, Indonesia, found that exclusion of insectivorous birds and bats increased insect-herbivore abundance, despite the presence of other insectivorous predators, an effect that decreased the final crop yield by 31 percent, equating to a loss of USD 730 per ha per year (Maas, Clough and Tscharntke, 2013). A study in Costa Rica on the effect of bird predation on the coffee berry borer (Hypothenemus hampei), a pest that often devastates coffee crops, demonstrated that infestations nearly doubled when birds were excluded from foraging on coffee shrubs (Karp et al., 2013). Similarly, the findings of a study on a coffee farm in Jamaica led researchers to conclude that the value of coffee berry borer removal by birds equated to 12 percent of the total crop value (Johnson, Kellermann and Stercho, 2010).

Pollination: Birds are thought to be particularly important as pollinators in circumstances where the density and activity of pollinating insects is limited, for example in cold, high-rainfall or dry conditions or on isolated islands with poor insect colonization (Cronk and Ojeda, 2008).

Anderson et al. (2011b) demonstrated that seed output of the bird-pollinated shrub New Zealand gloxinia (Rhabdothamnus solandri) was 84 percent lower and shrub regeneration 55 percent lower at sites in New Zealand that had lost two out of three major avian pollinator species than at sites where all three species were present. Studies have demonstrated strong relationships between birds and the plants they pollinate: often the role of the bird species cannot be substituted by other pollinators such as insects (Nabhan and Buchmann, 1997).
Seed dispersal: Vertebrates, including birds, are the main seed dispersers for flowering and woody plants (Sekercioglu, 2006). Nearly 33 percent of bird species disperse seeds, primarily through fruit consumption, but also through scatter-hoarding of nuts and conifer seeds. Seed dispersal benefits plants by increasing the likelihood that seeds will colonize areas with favourable germination conditions.

Removing carrion: Vultures fulfil an extremely important ecological role as scavengers, helping to keep the environment free of carcasses and waste that spread disease among people and livestock. Vultures in South Asia have declined drastically over recent decades. For example, the abundance of the Indian vulture (Gyps indicus) and the slender-billed vulture (Gyps tenuirostris) declined by 96.8 percent between 1992 and 2007 (Prakash et al., 2007). This is largely because of widespread use of the anti-inflammatory drug "diclofenac" in livestock (Ogada, Kessing and Virani, 2012). The drug is highly toxic to vultures, which ingest it when feeding on livestock carcasses. Declines in vulture populations meant that carcasses became more prevalent, which in turn led to increases in feral dog populations, and hence increased the risk to humans of contracting rabies via dog bites (Markandya et al., 2008). Based on the costs of commercial carcass-disposal plants, the value of a single vulture has been estimated at about 600000 Indian rupees (approximately USD 9 200) (IUCN, 2016a). India, Nepal and Pakistan banned the use of diclofenac as a veterinary drug in 2006, and surveys suggest that vulture populations have stabilized, although numbers still remain too low across the region (e.g. Prakash et al., 2012).

Source: Provided by the Royal Society for the Protection of Birds (RSPB) and Birdlife International. 


\section{PART B}

\section{TABLE 4.5}

Examples of associated-biodiversity species or species groups that contribute to pest and disease regulation reported to be under threat

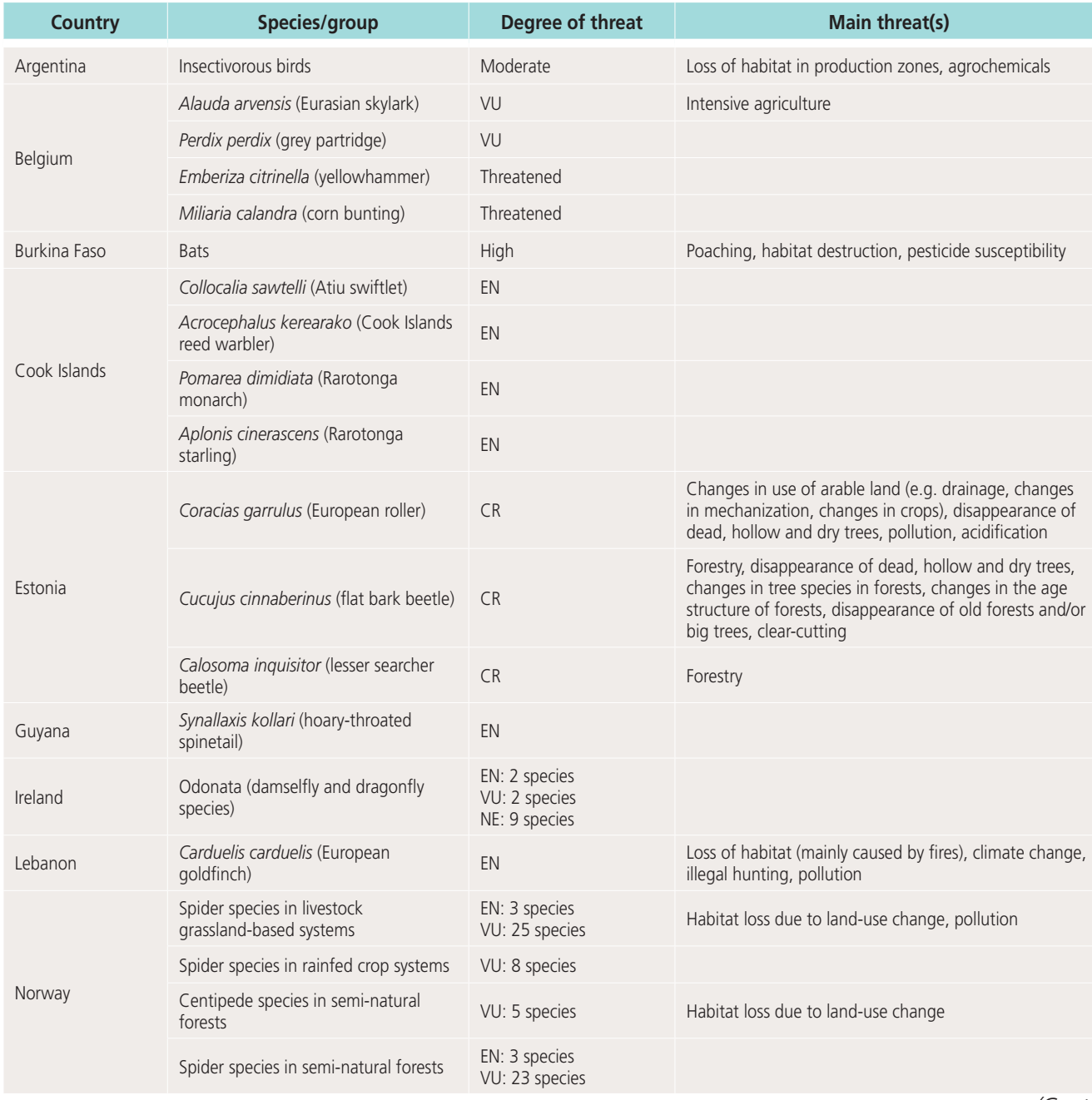

for other purposes or for which the purpose is not specified. It is also likely that the status of managed BCAs is at least to some degree monitored, although this is often not stated explicitly in the country reports. Monitoring programmes for pests and diseases themselves exist throughout the world. Notwithstanding these various strands of reporting, however, many country reports note major weaknesses in monitoring programmes for BCAs.

\section{Status and trends}

While, as described above, the state of knowledge remains very far from complete, the country reports 
TABLE 4.5 (Cont.)

Examples of associated-biodiversity species or species groups that contribute to pest and disease regulation reported to be under threat

\begin{tabular}{|c|c|c|c|}
\hline Country & Species/group & Degree of threat & Main threat(s) \\
\hline \multirow{7}{*}{ Panama } & Tinamus major (great tinamou) & EN & \\
\hline & Crypturellus soui (little tinamou) & EN & \\
\hline & Crax rubra (great curassow) & EN & \\
\hline & $\begin{array}{l}\text { Nothocercus bonapartei (highland } \\
\text { tinamou) }\end{array}$ & EN & \\
\hline & $\begin{array}{l}\text { Pharomachrus mocinno (resplendent } \\
\text { quetzal) }\end{array}$ & EN & \\
\hline & $\begin{array}{l}\text { Odontophorus gujanensis (marbled } \\
\text { wood-quail) }\end{array}$ & EN & \\
\hline & $\begin{array}{l}\text { Geotrygon chiriquensis (Chiriquí } \\
\text { quail-dove) }\end{array}$ & EN & \\
\hline \multirow{7}{*}{ Slovenia } & Alauda arvensis (Eurasian skylark) & VU & Habitat loss \\
\hline & Crex crex (corncrake) & EN & \\
\hline & Otus scops (Eurasian scops owl) & EN & \\
\hline & Jynx torquilla (Eurasian wryneck) & VU & \\
\hline & Lanius minor (lesser grey shrike) & VU & \\
\hline & Lanius collurio (red-backed shrike) & VU & \\
\hline & Lullula arborea (woodlark) & EN & \\
\hline Sri Lanka & Spider species & $\begin{array}{l}\text { Threatened: } 100 \text { species } \\
\text { EN: } 40 \text { species } \\
\text { CR: } 21 \text { species }\end{array}$ & Habitat loss, excessive use of pesticides \\
\hline \multirow{4}{*}{ Switzerland } & Bat species & $\begin{array}{l}\text { NT: } 7 \text { species ( } 23 \%) \\
\text { On Swiss Red List: } 15 \\
\text { species }(50 \%)\end{array}$ & $\begin{array}{l}\text { Renovation and reassignment of historic buildings, } \\
\text { intensive agriculture and forestry practices, land-use } \\
\text { changes, use of pesticides. Habitat fragmentation due } \\
\text { to the presence of infrastructure (e.g. communication } \\
\text { routes, lights) }\end{array}$ \\
\hline & $\begin{array}{l}\text { Odonata (damselfly and dragonfly } \\
\text { species) }\end{array}$ & $\begin{array}{l}\text { EX: } 2 \text { species }(3 \%) \\
\text { CR: } 12 \text { species }(16 \%) \\
\text { EN: } 7 \text { species }(10 \%) \\
\text { VU: } 5 \text { species }(7 \%)\end{array}$ & Habitat loss (e.g. fragmentation, drainage) \\
\hline & $\begin{array}{l}\text { Carabidae (ground beetle and tiger } \\
\text { beetle species) }\end{array}$ & $\begin{array}{l}\text { On Swiss Red List: } 148 \\
\text { species }(29 \%)\end{array}$ & $\begin{array}{l}\text { Habitat loss (e.g. draining of moors), intensive } \\
\text { agriculture }\end{array}$ \\
\hline & Chrysopidae (lacewing species) & $\begin{array}{l}\text { On Swiss Red List: } 21 \\
\text { species }(18 \%)\end{array}$ & Loss of habitat for larvae \\
\hline
\end{tabular}

Notes: Countries followed the IUCN Red List Categories and Criteria (IUCN, 2012) (CR [Critically Endangered]; EN [Endangered]; EX [Extinct]; NT [Near Threatened); VU [Vulnerable]) except where stated otherwise. The numbers in the "Degree of threat" column indicate the numbers of species in the respective risk category and the percentages indicate the proportion of the evaluated species in the respective taxonomic group falling within the respective risk category. See Cordillot and Klaus (2011) for more information on the Swiss Red List classification system. Analysis based on 91 country reports.

Source: Country reports prepared for The State of the World's Biodiversity for Food and Agriculture.

provide a number of indications of the status of individual BCA species, groups of BCAs or species categories that include substantial numbers of BCAs. For example, Bangladesh reports a decline in spiders and predatory insects in crop fields. Nepal mentions a general decline in the diversity of the natural enemies of pests. The United Kingdom reports that its indicator for farmland 
birds (many of which are insectivorous) ${ }^{43}$ declined by 55 percent between 1970 and 2013. Similarly, the United States of America reports a decline of almost 40 percent in its grassland bird index between 1968 and 2014. India notes the decline of parasitoid wasps (Ichneumonidae, Braconidae families) and parasitoid flies (Tachinidae). Table 4.5 presents examples from the country reports of the reported risk status of components of associated biodiversity that contribute to pest and disease control, along with (where available) the main reported threats to these species.

Countries' responses on trends in the supply of pest- and disease-regulation services in particular production-system categories are summarized in Table 4.4. Reports of decreasing trends predominate in all three crop production-system categories, while increasing trends predominate in mixed systems. In all other production-system categories, trends are mixed (i.e. neither positive nor negative nor stable trends predominate). Many countries report factors that are threatening BCAs in and around production systems, including the use of agrochemicals (particularly pesticides), habitat loss and fragmentation, overexploitation and climate change. For further discussion of drivers of change, see Chapter 3.

\subsubsection{Associated biodiversity for soil-related ecosystem services}

\section{Introduction}

This section addresses the status and trends of components of BFA involved in soil formation and protection and in nutrient cycling. The biota of the soil itself is highly diverse (Orgiazzi et al., eds., 2016). Components include micro-organisms (e.g. fungi, bacteria, algae, nematodes and protozoa), mesofauna (invertebrates ranging from $0.1 \mathrm{~mm}$ to $2 \mathrm{~mm}$ in length, and including mites, springtails and molluscs) and macrofauna (larger animals such

${ }^{43}$ Eleven out of 19 species are predominantly insectivorous during the spring and summer and therefore have a potential role in controlling insect pests (DEFRA, 2017). However, little is known about the effectiveness of these species as pest control agents (ibid.). as earthworms, ants, beetles, termites, spiders and moles) (see Figure 4.4 and Table 4.7). These organisms are vital to a range of processes that build and maintain the capacity of the soil to support plant growth, regulate water flows and store carbon (Balvanera et al., 2016; FAO and ITPS, 2015; Beed et al., 2011; Okoth, Okoth and Jefwa, 2013) (see Table 4.6 for a summary). All these functions depend on complex webs of interactions between different functional and taxonomic groups of soil organisms. Plants and above-ground animals also contribute, for example by supplying nutrient inputs or protecting the soil against erosion (Angers and Caron, 1998b; Graham, Grandy and Thelen, 2009; Vanni, 2002).

Aquatic organisms are vital to the formation of pond sediments, the accumulation of deposits in flood plains and river beds, and nutrient cycling within these sediments and deposits and in the wider aquatic environment (Hauer et al., 2016; Palmer et al., 2000). More information on biodiversity that contributes to nutrient cycling in aquatic ecosystems is provided in Section 4.3.7.

\section{State of knowledge}

The role of soil biota in the supply of ecosystem services has become a key focus for soil science over the last few decades (FAO and ITPS, 2015), and soils and soil biodiversity in general have been receiving increasing attention. Recent milestones have included the launch of the Global Soil Biodiversity Initiative in 2011, the establishment of the Global Soil Partnership in 2012, and the inauguration of World Soil Day in $2013 .{ }^{44}$ The first major global assessment of soils and how they are changing, The Status of the World's Soil Resources (FAO and ITPS, 2015), was published in 2015. The following year saw the publication of the Global Soil Biodiversity Atlas (Orgiazzi et al., eds., 2016), which provided the first comprehensive overview of the geographical and temporal distribution of soil biodiversity in both natural and managed ecosystems. A number of regional soil-biodiversity surveying initiatives

\footnotetext{
44 In December 2013, the 68th UN General Assembly declared 5 December as the World Soil Day.
} 


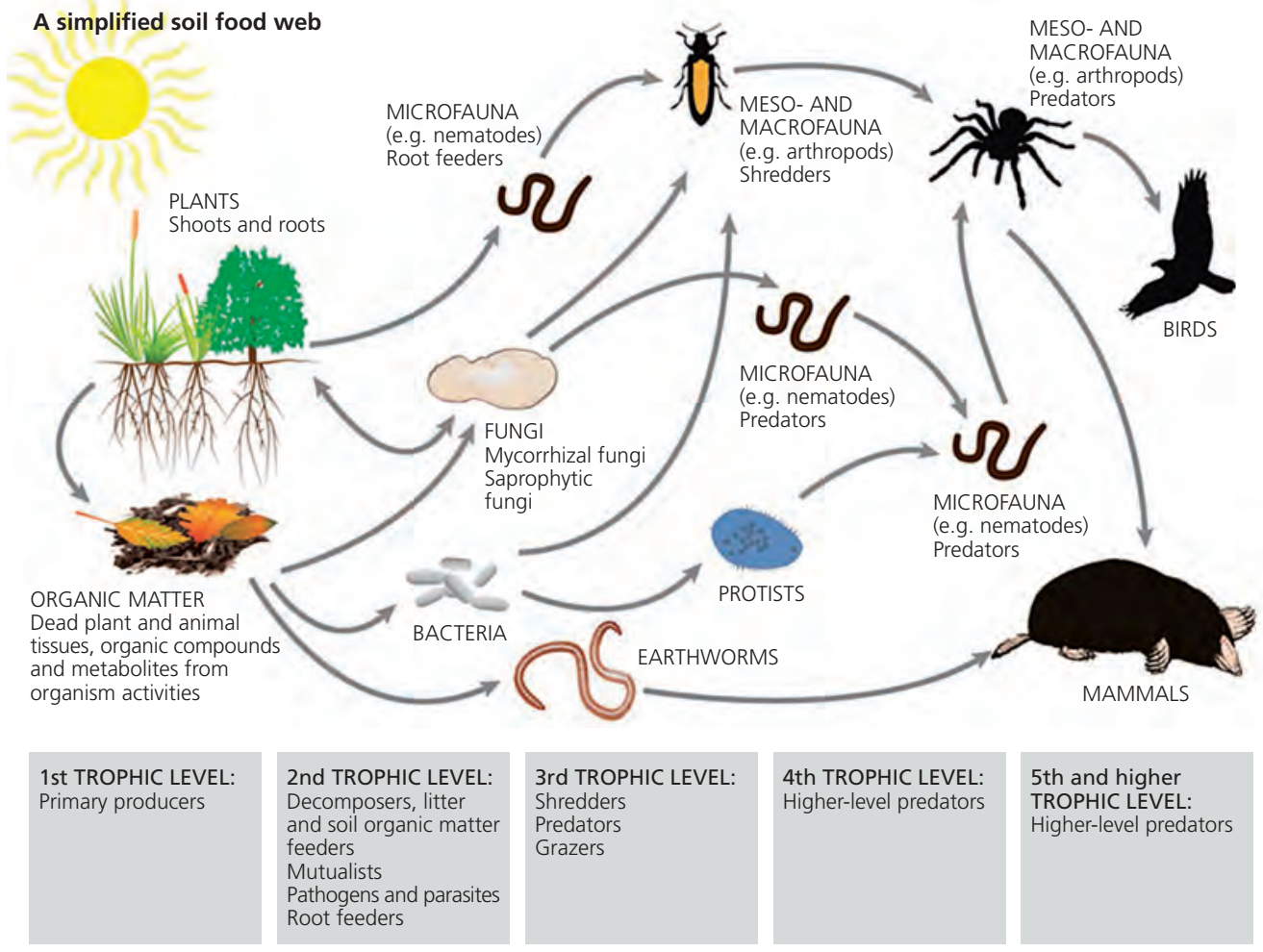

Source: Orgiazzi et al., eds., 2016. ㅇ European Union, 2016.

have also been established, including the African Soil Microbiology Project and activities under the Environmental Assessment of Soil for Monitoring Project, ${ }^{45}$ as have various national initiatives, for example in several European countries (Gardi et al., 2009) (see also Box 4.6).

The country reports generally indicate that knowledge of the biodiversity that contributes to soil formation and protection and to nutrient cycling in production systems is limited and that trends in the status of these resources are not monitored. Among the 91 reporting countries, eight

\footnotetext{
45 https://esdac.jrc.ec.europa.eu/projects/envasso
}

indicate that they have a monitoring system in place explicitly for organisms that play a role in soil function. The level (sampling frequency and type of analysis) and coverage (number of species monitored) of these systems vary greatly from country to country. Some countries describe monitoring efforts focused on a particular component of soil biodiversity. For example, Estonia notes that its Agricultural Research Centre monitors the diversity and distribution of earthworms. Sri Lanka mentions monitoring activities for soil biodiversity in specific production systems: arthropod diversity in paddy fields and microbial diversity in various farming systems. Other countries mention more-general 


\section{PART B}

TABLE 4.6

The functions of soil organisms

\begin{tabular}{|c|c|c|}
\hline \multicolumn{2}{|c|}{ Type of soil organism } & \multirow[b]{2}{*}{$\begin{array}{l}\text { Capture energy } \\
\text { Use solar energy to fix carbon dioxide } \\
\text { Add organic matter to soil }\end{array}$} \\
\hline Primary producers & Plants, algae, bacteria & \\
\hline Decomposers & Bacteria, fungi & $\begin{array}{l}\text { Break down organic residues } \\
\text { Immobilize (retain) nutrients in their biomass } \\
\text { Create new organic compounds (cell constituents, waste products) that are } \\
\text { sources of energy and nutrients for other organisms } \\
\text { Produce organic compounds that help bind soil into aggregates } \\
\text { Enmesh and bind soil aggregates with fungal hyphae } \\
\text { Convert nitrogen into plant-available, leachable or gaseous forms (nitrifying } \\
\text { and denitrifying bacteria) } \\
\text { Compete with or inhibit disease-causing organisms }\end{array}$ \\
\hline Mutualists & Bacteria, fungi & $\begin{array}{l}\text { Enhance plant growth } \\
\text { Protect plant roots from disease-causing organisms } \\
\text { Fix nitrogen (some bacteria) } \\
\text { Form mycorrhizal associations with roots and improve access and delivery of } \\
\text { key nutrients (e.g. phosphorus) and water to the plant (some fungi) }\end{array}$ \\
\hline Pathogens and parasites & $\begin{array}{l}\text { Bacteria, fungi, nematodes, } \\
\text { micro-arthropods }\end{array}$ & $\begin{array}{l}\text { Potentially cause disease } \\
\text { Consume roots and other plant parts, causing disease } \\
\text { Parasitize nematodes or insects, including disease-causing organisms }\end{array}$ \\
\hline Root feeders & $\begin{array}{l}\text { Nematodes, macro-arthropods } \\
\text { (e.g. cutworm, weevil larvae, } \\
\text { symphylans and white grubs) }\end{array}$ & $\begin{array}{l}\text { Consume plant roots } \\
\text { Potentially cause significant crop yield losses }\end{array}$ \\
\hline Bacterial feeders & Protozoa, nematodes & $\begin{array}{l}\text { Graze on bacteria } \\
\text { Release plant-available nitrogen and other nutrients when feeding on bacteria }\end{array}$ \\
\hline Fungal feeders & Nematodes, micro-arthropods & $\begin{array}{l}\text { Graze on fungi } \\
\text { Control many root-feeding or disease-causing pests } \\
\text { Stimulate and control the activity of fungal populations }\end{array}$ \\
\hline Ecosystem engineers & Earthworms, termites, ants & $\begin{array}{l}\text { Maintain soil structure } \\
\text { Enhance soil aggregation by passing soil through their guts }\end{array}$ \\
\hline Shredders & Macro-arthropods & $\begin{array}{l}\text { Break down residue and enhance soil structure } \\
\text { Process organic residue into smaller fragments } \\
\text { Shred plant litter as they feed on bacteria and fungi }\end{array}$ \\
\hline Higher-level predators & $\begin{array}{l}\text { Nematode-feeding nematodes, } \\
\text { larger arthropods, mammals, } \\
\text { birds, other vertebrates }\end{array}$ & $\begin{array}{l}\text { Control populations } \\
\text { Control populations of lower trophic-level predators } \\
\text { Larger organisms improve soil structure by burrowing } \\
\text { Larger organisms carry smaller organisms over long distances }\end{array}$ \\
\hline
\end{tabular}

Source: Based on Tugel, Lewandowski and Happe-vonArb, eds. (2000).

monitoring systems. The Netherlands, for example, reports a nationwide monitoring programme for soil biodiversity (see Box 4.6). China indicates that it has developed a national biodiversity monitoring network and drafted monitoring guides for, inter alia, soil-dwelling animals. Information on monitoring activities conducted by France's Observatory of Agricultural Biodiversity is provided in Box 8.8.

Some countries indicate that while they have no systematic national monitoring programmes in place for soil biodiversity, relevant activities are sometimes conducted within the framework of individual projects. For example, Norway mentions the Living Topsoil project, under which soil biodiversity and health are assessed and farmers are then encouraged to modify their management practices to improve soil health. The United Kingdom reports a pilot project that is identifying and characterizing soil-organism communities using genetic barcoding and metabarcoding 
TABLE 4.7

Typical numbers of soil organisms in healthy ecosystems

\begin{tabular}{|c|c|c|c|c|}
\hline & & Agricultural soils & Prairie soils & Forest soils \\
\hline Bacteria & \multirow{4}{*}{ 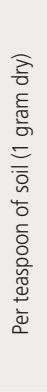 } & 100 million to 1 billion & 100 million to 1 billion & 100 million to 1 billion \\
\hline Fungi & & $\begin{array}{l}\text { Several yards } \\
\text { (dominated by vesicular- } \\
\text { arbuscular mycorrhizal fungi) }\end{array}$ & $\begin{array}{l}\text { Tens to hundreds of yards } \\
\text { (dominated by vesicular- } \\
\text { arbuscular mycorrhizal fungi) }\end{array}$ & $\begin{array}{l}\text { Several hundreds of yards in } \\
\text { deciduous forests } \\
\text { One to forty miles in coniferous } \\
\text { forests (dominated by } \\
\text { ectomycorrhizal fungi) }\end{array}$ \\
\hline Protozoa & & $\begin{array}{l}\text { Several thousand flagellates and } \\
\text { amoebae, one hundred to several } \\
\text { hundred ciliates }\end{array}$ & $\begin{array}{l}\text { Several thousand and amoebae, } \\
\text { one hundred to several hundred } \\
\text { ciliates }\end{array}$ & $\begin{array}{l}\text { Several hundred thousand } \\
\text { amoebae, fewer flagellates }\end{array}$ \\
\hline Nematodes & & $\begin{array}{l}\text { Ten to twenty bacterial-feeders } \\
\text { A few fungal-feeders } \\
\text { Few predatory nematodes }\end{array}$ & Tens to several hundred & $\begin{array}{l}\text { Several hundred bacterial- and } \\
\text { fungal-feeders } \\
\text { Many predatory nematodes }\end{array}$ \\
\hline Arthropods & \multirow{2}{*}{ 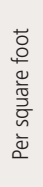 } & Up to one hundred & Five hundred to two thousand & $\begin{array}{l}\text { Ten to twenty-five thousand } \\
\text { Many more species than in } \\
\text { agricultural soils }\end{array}$ \\
\hline Earthworms & & $\begin{array}{l}\text { Five to thirty } \\
\text { More in soils with high organic } \\
\text { matter }\end{array}$ & $\begin{array}{l}\text { Ten to fifty } \\
\text { Arid or semi-arid areas may have } \\
\text { none }\end{array}$ & $\begin{array}{l}\text { Ten to fifty in deciduous } \\
\text { woodlands } \\
\text { Very few in coniferous forests }\end{array}$ \\
\hline
\end{tabular}

Note: 1 foot $=0.3048 \mathrm{~m} ; 1$ yard $=0.9144 \mathrm{~m} ; 1$ mile $=1.609344 \mathrm{~km}$.

Source: The table is included in the country report of the United States of America (also published in Tugel, Lewandowski and HappevonArb, eds. [2000] and online in the Soil biology primer of the National Resources Conservation Service available at https://www.nrcs. usda.gov/wps/portal/nrcs/detailfull/soils/health/biology/?cid=nrcs142p2_053860).

approaches. Denmark mentions a study of the effects of the herbicide glyphosate and nitrogen fertilizer on small terrestrial biotopes such as hedgerows and field margins, which measured, inter alia, impacts on biodiversity and functional traits in soil fauna. ${ }^{46}$ The United States of America reports an example of indirect monitoring, noting that using data from the National Resource Inventory (a survey conducted once every five years) and other studies, trends in soilmanagement practices can be monitored as a proxy for soil health - with a focus on soil carbon, soil erosion, adoption of reduced-tillage practices, adoption of crop rotations and adoption of cover crops. Countries also report a number of other initiatives that, while not strictly focused on monitoring of soil biodiversity, nonetheless contribute to the accumulation of knowledge on their soil resources. For example, Norway reports a "soil mapping" initiative that involves surveys of soil

46 The country report cites Damgaard et al. (2016). properties in predetermined areas of the country (about $40 \mathrm{~km}^{2}$ are surveyed each year). The data collected provide a basis for identifying trends in soil texture and health.

\section{Status and trends}

A summary of the regional trends in soil biodiversity loss as identified by FAO and ITPS (2015) is presented in Table 4.8. Among the ten factors identified as major threats to the continued provision of soil ecosystem services, the loss of soil biodiversity is listed as the fourth most important, after soil erosion, organic-carbon decline and nutrient imbalance. As the table shows, although information is limited, there are grounds for serious concern about the status of soil biodiversity in all regions of the world. Many indicators of soil health are in decline and ecosystem services provided by soils are under severe threat (ibid.).

Figure 4.5 shows the outcome of the first attempt to map soil biodiversity at global scale (Orgiazzi et al., eds., 2016). It combines two datasets: 


\section{PART B}

FIGURE 4.5

Map of the Soil Biodiversity Index

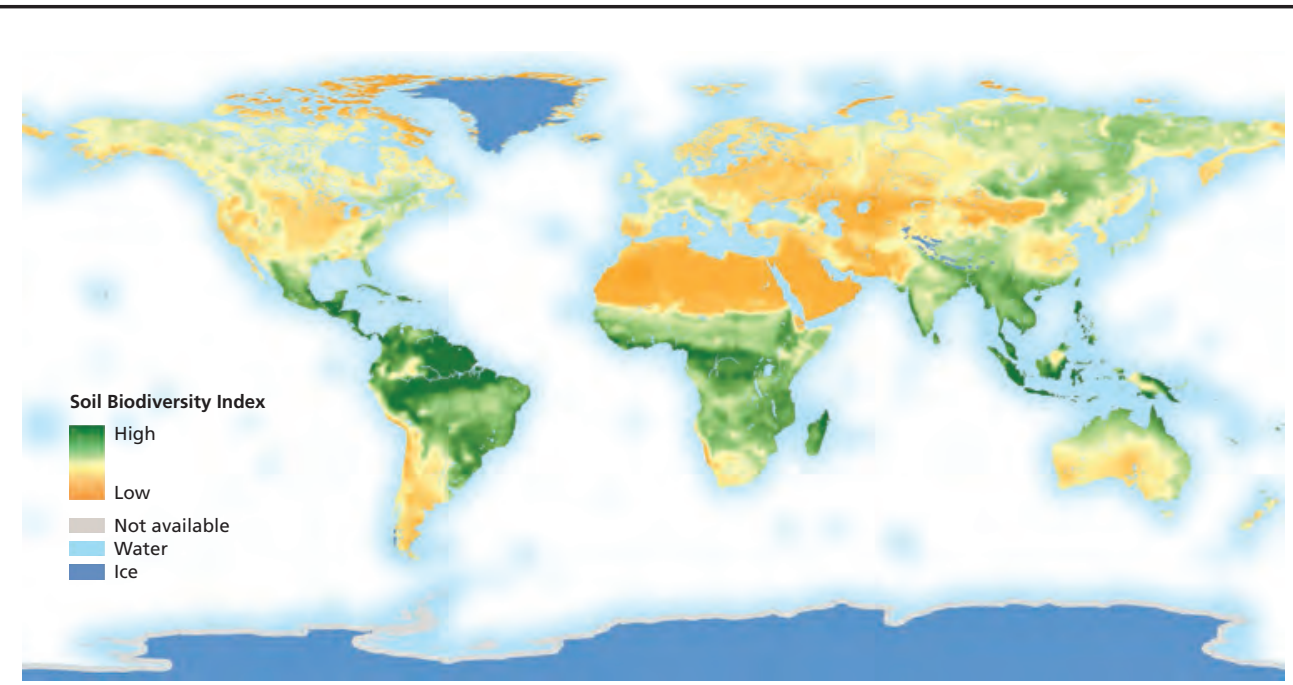

Source: Orgiazzi et al., eds., 2016. @) European Union, 2016.

FIGURE 4.6

\section{Map of potential threats to soil biodiversity}

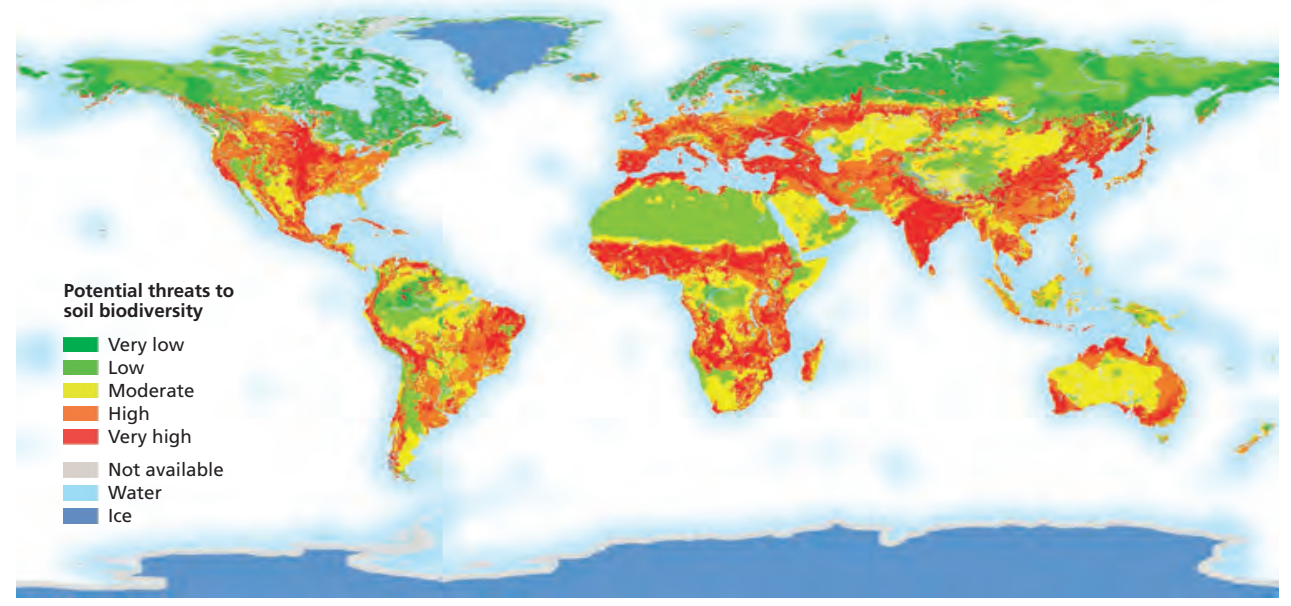

Source: Orgiazzi et al., eds., 2016. () European Union, 2016. 
distribution of microbial biomass, as a proxy for soil micro-organism diversity (Serna-Chavez, Fierer and Van Bodegom, 2013); and distribution of 14 groups of soil macrofauna, as a proxy for soil-fauna diversity (Orgiazzi et al., eds., 2016). The two datasets were harmonized on a 0 to 1 scale and summed to generate an index. Due to the current lack of data, important groups of soil organisms such as nematodes, collembolans and mites are not included the index. There is thus a need for significantly more research and data collection.

Figure 4.6 shows a first global map of the distribution of potential threats to soil organisms. A risk index was generated by combining eight potential stressors of soil biodiversity: loss of above-ground diversity; pollution and nutrient overloading; overgrazing; intensive agriculture; fire; soil erosion; desertification; and climate change. Specific proxies were chosen to represent the spatial distribution of each threat (Orgiazzi et al., eds., 2016). All datasets were harmonized on a 0 to 1 scale and summed, with total scores categorized into five risk classes (very low to very high). Some potential threats, such as soil sealing and salinization, were not included due to a lack of data. The exercise indicated the need for better data collection that will allow the development of conservation actions specifically for soil-dwelling organisms.

As noted above, the majority of country reports do not include detailed information on the status and trends of components of associated biodiversity involved in soil formation and protection and nutrient cycling. Some countries, however, provide partial or tentative statements in this regard. For

Box 4.6

The Netherlands' soil biological monitoring programme

In the Netherlands, the nationwide soil biological monitoring programme BISQ (Biological Indicator of Soil Quality) was developed with the aim of collecting data that would enable policy-makers to assess the quality and resilience of soil ecosystem services. BISQ is considered to rank among the most advanced soil-monitoring systems in the world.

BISQ links soil functioning to soil biodiversity. First, the most important life-support functions of the soil were identified: decomposition of organic matter; nutrient cycling; soil-structure formation; plant-soil interactions; and ecosystem stability. Next, ecological processes linked to these functions were described. Finally, the dominant soil-organism groups and ecological-process parameters were determined and combined into an indicator system (see table below).

About 300 locations, with different combinations of land use and soil type, were selected, and from 1999 onwards samples were collected from about 60 locations (farms, natural areas and urban sites) and analysed for soilbiological characteristics. Because of budget constraints, soi sampling was discontinued in 2014, but the data obtained so far continue to be used for policy formulation. Sampling may restart when budget becomes available again.
In general, the abundance of soil organisms was found to be higher in the soil of dairy farms than in that of arable land. Earthworms, especially, appeared to be scarce in arable land, and were virtually absent in mixed forests and heathlands. Nematode abundance was highest in dairy farms on peat and lowest in the mineral layer of mixed forest on sand.

Data from BISQ have been used to develop benchmarks for ten combinations of soil type and land use. For each of these combinations, a limited number of monitoring sites were selected that were considered to be well managed and to represent relatively good-quality soil ecosystems. The average of the BISQ parameters for these sites was taken as a benchmark for a good-quality soil ecosystem. In agriculture, these benchmarks can serve to help farmers improve soil quality and establish more-sustainable farming practices. In nature conservation, the benchmarks can guide managers of protected areas in their efforts to restore former agricultural lands.

The main lesson learned from the programme is that biological soil monitoring, with measurements carried out for more than 15 years on a semi-routine scale, is feasible.

(Cont.) 


\section{PART B}

Box 4.6 (Cont.)

The Netherlands' soil biological monitoring programme

\section{The BISQ indicator framework}

\begin{tabular}{|c|c|c|c|}
\hline $\begin{array}{l}\text { Life support } \\
\text { functions }\end{array}$ & Ecological processes & $\begin{array}{c}\text { Dominant soil-organism } \\
\text { groups and ecological process } \\
\text { parameters }\end{array}$ & Indicators \\
\hline \multirow{2}{*}{$\begin{array}{l}\text { Decomposition of } \\
\text { organic matter }\end{array}$} & Fragmentation & $\begin{array}{l}\text { Earthworms, enchytraeids, mites, } \\
\text { wood-related fungi }\end{array}$ & Taxonomic diversity per trophic level \\
\hline & Transformation of organic substrate & $\begin{array}{l}\text { Bacterial degradation routes } \\
\text { Litter-and dung-related fungi } \\
\text { Genetically diverse microflora }\end{array}$ & $\begin{array}{l}\text { Taxonomic diversity per trophic level } \\
\text { Bacterial DNA polymorphism }\end{array}$ \\
\hline \multirow{3}{*}{ Nutrient cycling } & Carbon and nitrogen mineralization & Trophic interactions & Model-derived nitrogen production \\
\hline & Microbial activity & Micro-organisms & $\begin{array}{l}\text { Concentration, biomass, thymidine } \\
\text { incorporation }\end{array}$ \\
\hline & Predation microfauna & $\begin{array}{l}\text { Protists } \\
\text { Nematodes } \\
\text { Springtails } \\
\text { Mites }\end{array}$ & $\begin{array}{l}\text { Active/inactive cysts } \\
\text { Maturity index } \\
\text { Functional diversity } \\
\text { Maturity index }\end{array}$ \\
\hline $\begin{array}{l}\text { Soil-structure } \\
\text { formation }\end{array}$ & $\begin{array}{l}\text { Bioturbation and formation of soil } \\
\text { aggregates }\end{array}$ & $\begin{array}{l}\text { Earthworms } \\
\text { Enchytraeids } \\
\text { Mycelium hyphae }\end{array}$ & $\begin{array}{l}\text { Functional diversity } \\
\text { Number of organisms } \\
\text { Biomass }\end{array}$ \\
\hline \multirow{3}{*}{$\begin{array}{l}\text { Plant-soil } \\
\text { interactions }\end{array}$} & Uptake of $\mathrm{N}_{1} \mathrm{P}_{1} \mathrm{H}_{2} \mathrm{O}$ and heavy metals & Mycorrhizal macrofungi & Functional diversity \\
\hline & Nitrification & Nitrifying bacteria & Nitrate production from $\mathrm{NH}_{4}^{+}$ \\
\hline & Feeding on plant roots & Nematodes and fungal pathogens & Plant parasitic index \\
\hline Ecosystem stability & $\begin{array}{l}\text { Trophic links; loops and cascade } \\
\text { effects }\end{array}$ & Structure of community & $\begin{array}{l}\text { Food-web structure; food-web } \\
\text { pyramid }\end{array}$ \\
\hline
\end{tabular}

After Rutgers et al., 2009

Source: Provided by Martin Brink, drawing on British Ecological Society (2016), CBS, PBL and WUR (2016), Rutgers et al. (2014, 2009) and personal communication with Michel Rutgers (National Institute for Public Health and the Environment, the Netherlands), 24 November 2016.

example, the United States of America notes that the above-mentioned soil-related monitoring activities indicate positive trends in the implementation of the management practices considered potential proxies for the status of soil biodiversity. Other countries that indicate at least some positive trends include Ethiopia, which reports that the planting of trees that symbiotically fix nitrogen has had a positive effect on soil micro-organism diversity in planted forest systems. Countries reporting unfavourable developments include El Salvador, which notes large-scale soil erosion associated with loss of forest cover and mentions that this has been accompanied by loss of soil invertebrates and micro-organisms. Zambia mentions negative trends among grassland invertebrates and micro-organisms. These effects are attributed to a decline in livestock numbers (caused by disease outbreaks) that has disrupted soil-formationprocesses, although the report also mentions that overstocking and overgrazing in communal areas have negatively affected soils and their capacity to supply water-related ecosystem services. Grenada notes that farmers have reported a decline in earthworm numbers.

Countries' responses on trends in the supply of soil-related ecosystem services (i.e. nutrient cycling and soil formation and protection) in particular production systems are summarized in Table 4.4. Where nutrient cycling is concerned, reports 
TABLE 4.8

Summary of regional extent, trends and uncertainties of soil-biodiversity loss presented in the Status of the World's Soil Resources

\begin{tabular}{|c|c|c|c|c|c|c|c|c|}
\hline \multirow[b]{2}{*}{ Region } & \multirow[b]{2}{*}{ Summary } & \multicolumn{5}{|c|}{ Condition and trend } & \multicolumn{2}{|c|}{ Confidence } \\
\hline & & $\frac{i}{\frac{0}{2}}$ & 흥 & 言 & 응 & $\begin{array}{l}\text { 응 } \\
\frac{8}{8} \\
\frac{1}{d}\end{array}$ & $\begin{array}{l}\text { 들 } \\
\frac{\underline{\underline{t}}}{0} \\
\text { 등 } \\
\text { 드 }\end{array}$ & $\begin{array}{l}\text { 을 } \\
\text { 는 } \\
\text { 드 }\end{array}$ \\
\hline $\begin{array}{l}\text { Sub-Saharan } \\
\text { Africa }\end{array}$ & $\begin{array}{l}\text { Sub-Saharan Africa suffers a high } \\
\text { rate of deforestation. The areas most } \\
\text { affected are those in the moist areas of } \\
\text { West Africa and the highland forests } \\
\text { of the Horn of Africa. Cultivation, } \\
\text { introduction of new species, oil } \\
\text { exploration and pollution reduce the } \\
\text { population of soil organisms, thus } \\
\text { reducing faunal and microbial activities. }\end{array}$ & & & $\searrow$ & & & & \\
\hline Asia & $\begin{array}{l}\text { Limited information is available for soil } \\
\text { biodiversity in Asia. Some reports show } \\
\text { high microbial biodiversity in the soils } \\
\text { of organic farming lands. }\end{array}$ & & & $\pi \swarrow$ & & & & \\
\hline $\begin{array}{l}\text { Europe and } \\
\text { Eurasia }\end{array}$ & $\begin{array}{l}\text { Loss of biodiversity is expected in the } \\
\text { most urbanized and contaminated } \\
\text { areas of the region. However, there are } \\
\text { almost no qualitative estimations of } \\
\text { the biodiversity loss in soils. }\end{array}$ & & & $\searrow$ & & & & \\
\hline $\begin{array}{l}\text { Latin America } \\
\text { and the } \\
\text { Caribbean }\end{array}$ & $\begin{array}{l}\text { Loss of soil biodiversity is suspected to } \\
\text { occur in deforested and overexploited } \\
\text { agricultural areas. }\end{array}$ & & & オレ & & & & \\
\hline $\begin{array}{l}\text { Near East and } \\
\text { North Africa }\end{array}$ & $\begin{array}{l}\text { The extent of loss of soil biodiversity } \\
\text { due to human impact is largely } \\
\text { unknown in the Near East and North } \\
\text { Africa region. More studies need to be } \\
\text { undertaken to understand the scope of } \\
\text { the problem. }\end{array}$ & & $y$ & & & & & \\
\hline North America & $\begin{array}{l}\text { The extent of loss of soil biodiversity } \\
\text { due to human impact is largely } \\
\text { unknown in North America. The effects } \\
\text { of increasing agricultural chemical use, } \\
\text { especially pesticide use, on biodiversity } \\
\text { are a major public concern. Known } \\
\text { level of carbon loss suggests similar } \\
\text { loss in biodiversity. }\end{array}$ & & & $\lambda レ$ & & & & \\
\hline $\begin{array}{l}\text { Southwest } \\
\text { Pacific }\end{array}$ & $\begin{array}{l}\text { Rates of loss were most likely highest } \\
\text { during the expansion of agriculture, } \\
\text { particularly over the last } 100 \text { years, } \\
\text { and this may have slowed. However, } \\
\text { information on baselines and trends } \\
\text { is lacking in nearly all districts and } \\
\text { countries. }\end{array}$ & & & $\pi レ$ & & & & \\
\hline
\end{tabular}

Source: FAO and ITPS, 2015. 
of downward trends predominate in livestock grassland-based systems, irrigated crop systems and culture-based fisheries. In most other systems, trends are mixed (i.e. neither positive nor negative nor stable trends predominate). In the case of soil formation and protection services, reports of negative trends predominate in livestock grassland-based systems and in all categories of crop system. Reports of positive trends predominate for planted forest systems (possibly reflecting increasing areas of planted forests in some countries) and landless livestock systems. Trends are mixed (i.e. neither positive nor negative nor stable trends predominate) for naturally regenerated forests. While, as in the case of other ecosystem service categories, levels of reporting are low, the substantial proportion of countries that report negative trends in major food-producing systems reinforces the concerns that have emerged from the global assessments described above.

A few country reports provide information linking trends in soil-related ecosystem services to management practices in specific production systems. For example, the report from Panama mentions that in grassland systems the use of herbicides and antiparasitic livestock drugs is leading to contamination of the soil, affecting soil invertebrates and inhibiting soil-formation and nutrientcycling services. Similarly, Bangladesh reports that soil formation and protection are being hampered in areas where soil micro-organism diversity is affected by the use of pesticides and fertilizers. Further information on trends in management practices that are considered beneficial to soil biodiversity can be found in Section 5.6.3.

\subsubsection{Associated biodiversity for water-related ecosystem services}

\section{Introduction}

Water is vital to all species and to all ecosystem functions and services. While much of the Earth's estimated 1.4 billion $\mathrm{km}^{3}$ of water is in long-term storage in oceans, ice caps and aquifers, about $41000 \mathrm{~km}^{3}$ circulates between the atmosphere, the surface of the land, subsurface zones, freshwater bodies and the ocean (Acreman, 2004). Ecosystems and the living organisms within them influence the hydrological cycle and hence the amount of water available at particular locations at particular points in time: for example, whether or not there is sufficient water to meet the needs of plants during the growing season in a cropping area or whether or not a vulnerable area is hit by flooding.

Vegetation and soils are vital to the control of water flows in terrestrial ecosystems. Vegetation promotes the infiltration of water into the soil, thus helping to recharge underground aquifers and lowering flood risk (Acreman, 2004). Soil biota - plants, micro-organisms and invertebrate and vertebrate animals - modifies the structure of the soil and affects the pathways and rates of water infiltration, influencing the capacity of the soil to hold water (BIO Intelligence Service, 2014; Sans and Meixner, 2016) (see Section 4.3.4 for further information on the status and trends of associated biodiversity contributing to soil-related ecosystem services). Plants also return water to the atmosphere through transpiration (Acreman et al., 2014; Stewart, 1977) and in some cases influence the amount of precipitation that falls in the local area (Spracklen, Arnold and Taylor, 2012; Wright et al., 2017) (see Box 4.7).

As well as influencing the quantity of water available, biodiversity also influences water quality, including by cycling nutrients within waterbodies and between them and other ecosystems. Nutrient-cycling services are essential to the health of aquatic ecosystems. On the one hand, aquatic organisms clearly need to be able to access sufficient quantities of nutrients to allow them to grow and reproduce. On the other, however, waterbodies can become overloaded with nutrients, for example in agricultural areas where there is a heavy use of fertilizers, and this can have negative impacts on biodiversity and the supply of ecosystem services (see Chapter 3).

A myriad of interconnected physical, physiochemical, chemical and biological processes contribute to water-purification and nutrientcycling services in aquatic ecosystems (Cardinale, 2011; Ostroumov, 2002, 2005). Some species 
Box 4.7

Páramos - a vital provider of water-regulating services under threat

\section{What are páramos?}

Páramos are high-altitude ecosystems found mainly in a discontinuous belt stretching along the Andean mountain range from the Cordillera de Merida in the Bolivarian Republic of Venezuela to the Huancabamba depression in northern Peru, passing through Colombia and Ecuador (Buytaert et al., 2006; IUCN, undated). There are separate páramo complexes in Costa Rica and in the Sierra Nevada de Santa Marta, Colombia (Hofstede, Segarra and Mena, 2003).

Páramo ecosystems extend from the upper tree line to the perennial snow border (3 200 to 5000 metres above sea level) (IUCN, undated). It is estimated that they host around 5000 different plant species, a high proportion of which are endemic (i.e. found nowhere else) (Buytaert et al., 2006). Species that occupy the páramos have developed remarkable adaptations to harsh physiochemical and climatic conditions such as low atmospheric pressure, intense ultraviolet radiation and the drying effects of the wind (ibid.).

\section{How do páramos contribute to water regulation?}

Páramos play a key role in regulating water flows (Buytaert et al., 2006): rainfall is high and may be supplemented by fog condensation; water consumption is low as the leaves of the tussock grasses are protected against radiation and dry air by accumulated dead leaves and because the herbaceous vegetation consists of xerophytic species (plants adapted to a lack of water); the tussock grasses and dwarf shrubs protect the soil and reduce evaporation. The soils themselves

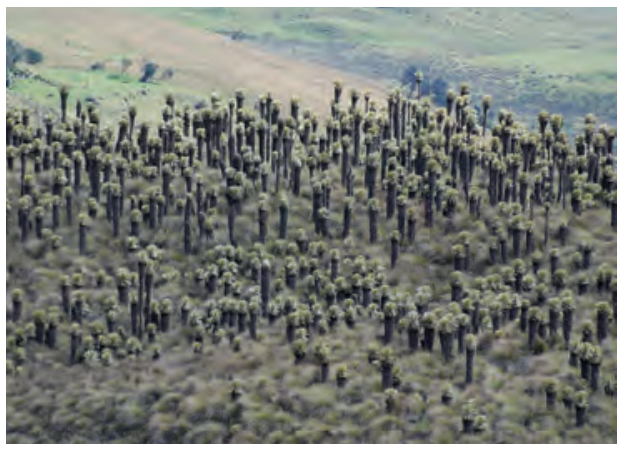

Páramos ecosystem on the foothills of Puracé National Park in the Andes, Colombia. (c) Nigel Dudley. have extraordinary water-retention capacity (ibid.). Many of the largest tributaries of the Amazon basin have their headwaters in páramo ecosystems, which thus help sustain the lives and livelihoods of millions of people, providing water for domestic, agricultural and industrial consumption and for use in generating hydropower (Buytaert et al., 2006).

\section{Why are páramos under threat?}

The country reports mention several threats to the páramos and the ecosystem services they provide. For example, the report from Peru states that the country's páramos are undergoing a process of transformation, desertification and erosion, mainly as a result of overgrazing, extractive activities, intensive agriculture and pollution. It notes that this is directly affecting the ecosystem's capacity to moderate extreme events, prevent erosion, maintain soil fertility and maintain genetic diversity. Ecuador mentions that the invasive alien species Kikuyu grass (Pennisetum clandestinum) represents a threat to páramos, as it could outcompete native species and, given its value as a fodder, promote more livestock grazing in mountain areas. Costa Rica reports that, according to a scenario study, climate change will lead to altitudinal shifts in life zones that will potentially result in the disappearance of the country's páramos in the coming decades.

Sources: Country reports of Costa Rica, Ecuador and Peru (plus the references cited in the text).

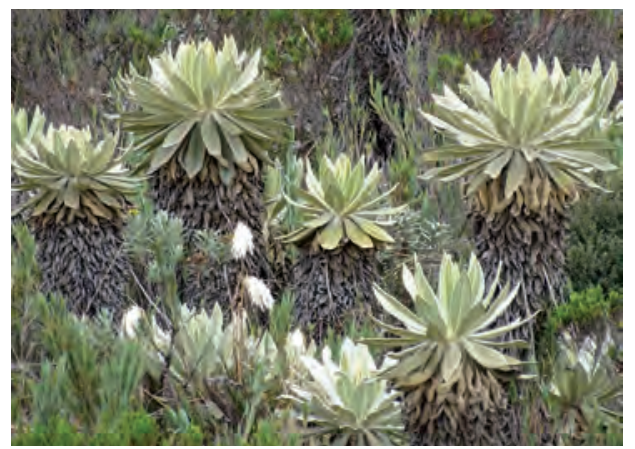

Espeletia spp., commonly known as frailejones, are typical plants of páramos ecosystems. (c) Nigel Dudley. 
play particularly prominent roles. For example, some plant species, such as the water hyacinth (Eichhornia crassipes), duck weed (e.g. Lemna spp.), aquatic ferns (e.g. Azolla spp.), cattails (Typha spp.) and reeds (Phragmites spp.), are recognized for their ability to remove toxic substances such as heavy metals from waterbodies (Ramsar Convention, 2011a). ${ }^{47}$ Filter-feeding animals, such as ascidians (sea squirts), cirripeds (barnacles), bryozoans (colony-forming invertebrates sometimes referred to as moss animals), bivalves (e.g. clams, oysters, mussels and scallops), polychaetes (bristle worms) and sponges, play a conspicuous "cleaning" role in the ecosystem as they remove suspended particles from the water (Ostroumov, 2005). However, virtually all the species in an aquatic ecosystem are involved in water-purification and nutrient-cycling processes, either directly (e.g. by trapping, transforming, accumulating and/or translocating pollutants via their behavioural activities and physiological processes) or indirectly (e.g. by releasing oxygen into the water, mixing the water column, influencing the physical and chemical properties of the water by contributing organic matter, or influencing the behaviour of other organisms such a prey species) (Ostroumov, 2002, 2005; Vanni, 2002).

In addition to processes occurring within waterbodies themselves, water-purification services are provided by other ecosystems through which water flows (forests, grasslands, etc.) (FAO, 2007d; Oregon State University, 2008; Ostroumov, 2005). As with water-cycling services, the capacity of these ecosystems to purify water is greatly affected by the state of the vegetation and the soils within them - and in turn on a wide range of components of biodiversity that contribute to soil health or help maintain plant communities. ${ }^{48}$

In response to a question about species managed specifically to promote water-related ecosystem services, countries mention approximately 80 species. Examples include willows

\footnotetext{
${ }^{47}$ It should be noted that some of those species are invasive in some regions of the world.

${ }^{48}$ See Section 4.5 for further discussion of the status and trends of rangelands, forests and wetlands.
}

(Salix spp.), cattails (Typha spp.), the oyster mushroom (Pleurotus ostreatus) and bamboos (Bambusa spp.) (see Section 4.3.1). Trees are particularly widely mentioned, as is the importance of soils, wetland ecosystems, forests and riparian areas. For example, the United States of America highlights the importance of the soil as a filter that improves water quality, and also notes the role played by riparian buffers in reducing the amount of fertilizer and other agricultural chemicals passing from farmland into waterways. Countries also note a number of marine and coastal ecosystems as important suppliers of water-purification services. For example, Norway mentions kelp forests and Solomon Islands mentions coral reefs, mangroves, seagrass beds and intertidal mud ecosystems. Several groups of aquatic species are noted as contributors to marine water-purification services, including shellfish and micro-organisms (Mexico) and microalgae (Peru).

\section{State of knowledge}

As described above, a wide range of taxonomic and functional groups of organisms, across a range of different ecosystems, contribute to water-purification and water-cycling services. However, although the processes involved may be broadly understood, in many cases little is known about the underlying ecological mechanisms that keep them in operation or about the relationships between the diversity and distribution of BFA and provision of these services (Cardinale, 2011; Harrison et al., 2014; Ostroumov, 2005).

Water quality itself has not yet been assessed comprehensively at global scale. In 1978, the Global Environment Monitoring System for freshwater (GEMS/Water) was established under the auspices of the United Nations Environment Programme, the United Nations Educational, Scientific and Cultural Organization, the World Health Organization and the World Meteorological Organization (UN Environment, 2016c). The GEMS/Water Data Centre maintains the Global Water Quality database and information system (GEMStat), which stores data received from a global network of national 
focal points (ibid.). A global assessment of water quality (Meybeck et al., 1989; UNESCO, WHO and UN Environment, 1996) was published in 1988. However, inconsistencies in spatial and temporal coverage and differences in the ranges of variables reported meant that the assessment relied on sources other than the GEMS/Water database (UN Environment, 2016c). In 2016, UN Environment published $A$ snapshot of the world's water quality: towards a global assessment (ibid.), a prestudy aiming to provide some of the building blocks of a global assessment and to provide a preliminary estimate of the state of water quality in freshwater ecosystems, with a focus on lakes and rivers in Africa, Asia and Latin America.

The status of relevant ecosystems and groups of species are assessed and monitored under a number of global initiatives. For example, IUCN monitors the conservation status of marine and freshwater invertebrates and how they are being affected by environmental changes (Collen et al., 2012). The IUCN Species Programme Marine Biodiversity Unit assesses extinction risks for marine vertebrates, plants and selected invertebrates, including those in important ecosystems such as coral reefs, mangroves and seagrass beds (GMSA, 2017). The Global Census of Marine Life, ${ }^{49}$ conducted between 2000 and 2010 to assess and explain the diversity, distribution and abundance of marine life, resulted in the creation of a global marine-life database (see Chapter 6 for more information). More information on relevant ecosystem assessments can be found in Section 4.5.

Regional and national initiatives within the framework of The IUCN Red List have provided detailed reviews of the status of particular groups of aquatic species. For instance, the European Red List of Non-Marine Molluscs (Cuttelod, Seddon and Neubert, 2011) provides information on the state of freshwater bivalves and gastropods. A study of African freshwater biodiversity (Darwall et al., 2011) addresses the state, diversity, distribution and conservation of, inter alia, freshwater molluscs and plants in

\footnotetext{
49 http://www.coml.org/
}

a range of ecosystems, including river and artesian basins, ancient, montane and crater lakes, saline lagoons, salt-marshes and mangroves. Other examples include studies of the status of freshwater biodiversity in the Eastern Himalaya (Allen, Molur and Daniel, 2010), Western Ghats (Molur et al., 2011) and Indo-Burma biodiversity hotspots (Allen, Smith and Darwall, 2012).

In as far as the country reports mention research or monitoring programmes addressing the role of biodiversity in the delivery of water-cycling and water-purification services, it is generally to note a lack of knowledge or a lack of studies on relevant components of biodiversity (e.g. microorganisms), on the capacity of particular ecosystems to deliver these services or on trends in the supply of these services. Finland does, however, mention water purification among the ecosystem services for which there has been a rapid growth of research in recent decades.

\section{Status and trends}

As discussed above, while water-related supporting and regulating ecosystem services depend to a large degree on the extent, distribution and general health of relevant ecosystems and on a very wide range of different organisms, some species play particularly prominent roles. In the case of water purification services, these include aquatic plants and various groups of aquatic invertebrates. The risk status of species in these categories is, in general, relatively poorly monitored, as compared to that of vertebrates, for example. Data from The IUCN Red List for some relevant taxa - Maxillopoda (crustaceans such as barnacles and copepods), Holothuroidea (sea cucumbers), Bivalvia (e.g. clams, oysters, mussels and scallops) and Polychaeta (bristle worms) - are summarized in Figure 4.7, disaggregated by class.

Countries' responses on trends in the supply of water-purification, waste-treatment, watercycling and nutrient-cycling services in particular production systems are summarized in Table 4.4. Where water-purification and waste-treatment services are concerned, trends are mixed (i.e. neither positive nor negative nor stable trends 


\section{PART B}

FIGURE 4.7

Global risk status of invertebrates in the classes Bivalvia, Holothuroidea, Maxillopoda and Polychaeta

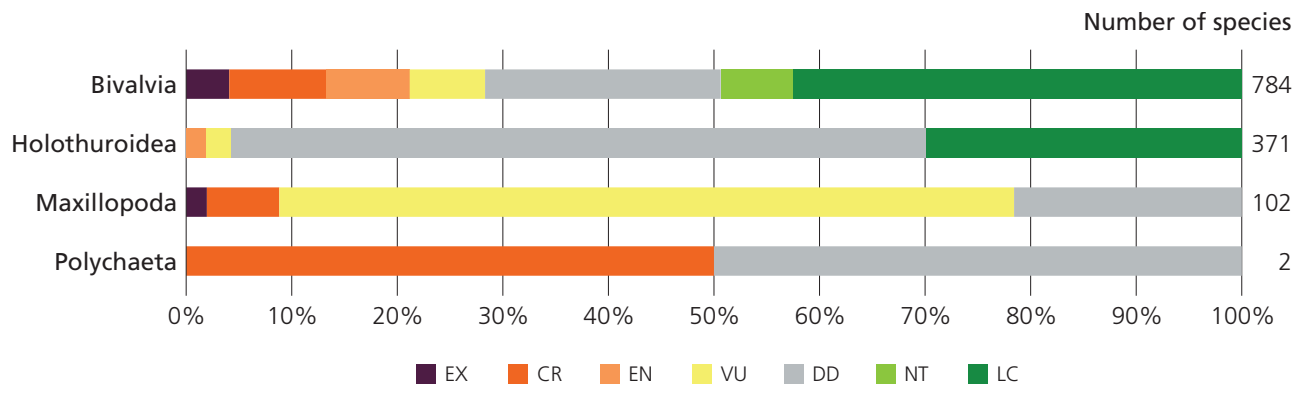

Note: EX (Extinct); CR (Critically Endangered); EN (Endangered); VU (Vulnerable); DD (Data Deficient); NT (Near Threatened) and LC (Least Concern).

Source: The IUCN Red List version 2017-2.

predominate) in all production systems except livestock grassland-based and irrigated crop systems, where reports of negative trends predominate. In the case of water-cycling services, reports of positive trends predominate in planted forest, fed aquaculture and irrigated (non-rice) crop systems. Although few responses are provided for these production systems, reports of stable trends predominate for non-fed aquaculture and decreasing trends for irrigated rice systems. In all the remaining production systems trends are mixed. Few countries provide information on trends in nutrient-cycling services in aquatic production systems. In the case of fed aquaculture systems, increasing trends predominate. Decreasing trends predominate for culture-based fisheries. For other aquatic systems, trends are mixed. The various reports of positive trends in aquaculture systems may relate to the proactive introduction of management techniques and strategies aimed at addressing concerns about the environmental impacts of these systems.

Reasons for negative trends are indicated in a number of country reports. The most frequently mentioned drivers include deforestation, expansion of the agricultural frontier and increased livestock grazing in riparian or coastal areas.
China reports that water-purification services in the Miyun Reservoir watershed in Beijing have declined substantially as a result of the expansion of construction and other land-use changes. Finland mentions that recent milder winters may have disrupted the water-purification function of vegetation on land surrounding waterbodies, an effect reported to have arisen because soils are increasingly unfrozen during the non-vegetative period when plants are less able to intercept eroded matter. Panama lists water-purification services among those predicted to decrease as a result of a net loss of forest area. The Gambia notes that changes in land use are diminishing the capacity of forests to provide water-purification and waste-treatment services. The Cook Islands mentions that the removal of trees from littoral forests may be increasing algal growth and sedimentation in some lagoon areas. Switzerland, in contrast, provides a more positive assessment of trends in water-related ecosystem services, noting that the capacity of lakes and rivers to purify water has probably increased as a result of restoration efforts. The capacity of the country's forests to provide water-purification services is reported to have been secured for decades through appropriate forest management. 


\subsubsection{Associated biodiversity for natural-hazard regulation}

\section{Introduction}

Natural-hazard regulation is defined in the guidelines for the preparation of country reports as the "capacity of ecosystems to ameliorate and reduce the damage caused by natural disasters." Numerous mechanisms can contribute (see Section 2.3) and it is difficult to distinguish a clearly defined subset of associated biodiversity that contributes to hazard regulation. Services of this kind are often provided by whole ecosystems or landscapes. However, within these systems some species (wild or domesticated), or functional groups of species, may play a particularly direct or significant role in hazard regulation, and some of these may be managed specifically in order to promote these roles. The country reports mention a number of species or groups in this regard (see Section 4.3.1). A large majority of these are trees managed for storm protection and as wind breaks, including mangroves for protection of coastal areas. Tree, grass and fodder species that help to protect riverbanks and limit landslides are also mentioned. Jordan reports planting cypresses (Cupressus sempervirens) and carob trees (Ceratonia siliqua) around forests for fire-control purposes. Further discussion and examples of the roles of BFA in natural-hazard regulation can be found in Section 2.3. The impacts of disasters on BFA are discussed in Section 3.4.2.

Several types of ecosystem that are used in food and agricultural production and/or provide habitats for associated biodiversity and wild food species are noted for their major contributions to hazard regulation. For example, evidence from many countries indicates the important role of forests in flood prevention, and there is also growing interest in their roles in mitigating other hazards such as avalanches and rock falls (UN Environment, 2010). The roles of wetland and coastal ecosystems such as mangroves, coral reefs and salt-marshes in flood control, shoreline stabilization and storm protection are also widely recognized, as is the importance of peatlands, grasslands and floodplains in flood protection (Bravo de Guenni et al., 2005; Ferrario et al., 2014; GEAS, 2013; Narayan et al., 2016; Ramsar Convention, 2011b, 2011c, 2015a). Soil biodiversity plays a particularly significant role in resilience to droughts and floods, via its influence on the soil's capacity to absorb and hold water (FAO, 2011a). More information on the status and trends of relevant ecosystems, and of soil biodiversity, is provided in Sections 4.5 and 4.3.4, respectively.

The frequency and intensity of many types of natural disasters are expected to increase as a result of climate change (IPCC, 2012). The roles played by BFA in carbon sequestration (see Section 2.2), and hence in climate change mitigation, thus also make an important contribution to hazard regulation.

\section{State of knowledge}

A number of monitoring systems for natural disasters are in operation at global level, including the Global Disaster Alert and Coordination System, ${ }^{50}$ the International Disaster Database (EM-DAT) ${ }^{51}$ and climate- and weather-related information systems operated by the World Meteorological Organization. ${ }^{52}$ Many countries have national monitoring and assessment programmes for various kinds of natural hazards. Generally, however, these global and national initiatives do not involve any particular focus on components of BFA (or biodiversity in general) that provide hazard-regulating services.

There are also a number of global and national information systems devoted to ecosystems associated with food and agriculture that are recognized as playing an important role in hazard regulation. In the case of forests, for example, FAO's CountryStat system ${ }^{53}$ makes available data from the Global Forest Resource Assessment, a five-yearly assessment of about 90 variables

\footnotetext{
50 http://gdacs.org

51 https://www.emdat.be

52 https://public.wmo.int/en

53 http://countrystat.org/default.aspx
} 
covering the extent, condition, uses and values of forests and other wooded land (FAO, 2016i). Where wetland ecosystems are concerned, the GEO-Wetlands Initiative 2017-2019, a global partnership coordinated by the University of Bonn (Germany), Wetlands International and the Ramsar Convention Secretariat, is working to establish a Global Wetlands Observing System (GEO BON Secretariat, 2016). Further discussion of relevant information systems can be found in Section 4.5.

\section{Status and trends}

As discussed above, the role of BFA in naturalhazard regulation depends largely on the status of whole ecosystems rather than on that of individual species. Global trends in the status of relevant ecosystem categories are often negative (see Section 4.5 for further discussion).

Countries' responses on trends in the supply of hazard-regulation services are summarized in Table 4.4. Reports of upward trends predominate in the case of fed aquaculture systems, while reports of stable trends predominate in livestock and irrigated rice systems. For most production systems, however, trends are mixed (i.e. neither positive nor negative nor stable trends predominate). Few countries provide further details on the reported trends. It is possible that in some cases reported upward trends indicate an increase in the need for natural-hazard regulation rather than an improvement in the capacity of ecosystems to deliver this service.

The limited extent to which countries were able to provide information on the status and trends of hazard regulation services in food and agricultural systems reflects a general lack of information on trends in this ecosystem service. For example, as of 2010, trends in natural-hazard regulation in most of the ecosystems in Europe were reported to be unknown (EEA, 2015). Delivery of this service in Europe was reported to be in a mixed state in wetlands and in a degraded state in lakes and rivers, with trends reported to be stable in both cases (ibid.).

\subsubsection{Associated biodiversity for habitat provisioning}

\section{Introduction}

As discussed in Chapter 2, the survival of any species in the wild depends on its access to sufficient suitable habitat, i.e. to environments that allow members of the species to meet their physiological needs, protect themselves from hazards and reproduce. A habitat is typically created and maintained via a wide range of interactions among and between abiotic structures and processes (climate, geology, etc.) and components of biodiversity. Habitat services are thus to a large extent products of whole ecosystems rather than of specific components within them. Some species may, however, play a particularly significant role in the supply of particular habitat services, either because they play a key role in shaping and maintaining the overall characteristics of the ecosystem or because they are a key component of the habitat of a specific species, for example providing an animal species with a major source of food or a nesting site. In turn, some habitats are particularly significant, for example because of the exceptional richness of the biodiversity they support or because of their role in supporting species at key points in their life cycles, for example during migration (TEEB, 2010).

The country reports note the importance of various components of BFA, mainly at ecosystem level, in habitat provisioning. Most frequently mentioned are forests, followed by marine and coastal ecosystems, such as mangroves and coral reefs, non-marine wetlands (including waterbodies such as lakes and rivers), mountains, grasslands and deserts. A few countries also mention crop systems and specific components within them (e.g. field margins) as important habitats. Countries also report a number of species of associated biodiversity as being actively managed for the provision of habitat services. These are mostly tree species, for example tamarind (Tamarindus indica), acacias (Acacia spp.), eucalyptuses (Eucalyptus spp.), African mahogany (Khaya senegalensis) and whitebeams (Sorbus spp.) (see also Section 4.3.1). 
The status and trends of several key ecosystem services, including wetlands, forests, coral reefs, mangroves, seagrass beds and rangelands, are discussed in Section 4.5 .

\section{State of knowledge}

Trends in the extent of various key ecosystems of importance to food and agriculture that serve as vital habitats for large numbers of species are monitored at global, regional or national levels. These monitoring efforts increasingly include the use of satellite technologies/remote sensing (Bunce et al., 2008; Committee on the Peaceful Uses of Outer Space, 2015; Lucas et al., 2015). For example, the EU-funded project BIOdiversity multi-Source monitoring System: from Space to Species (BIO_SOS) has developed the Earth Observation Data for HAbitat Monitoring (EODHaM) system, a standardized framework for habitat mapping and monitoring (Lucas et al., 2015). The system has been applied successfully to Natura $2000^{54}$ sites and their surroundings in a few European countries, but also at other locations in Europe and beyond, and is expected to be more widely adopted by the managers of protected sites (ibid.).

Weaknesses in habitat-monitoring programmes are widely recognized in the country reports. However, a range of monitoring activities targeting relevant ecosystems are reported (again further discussion can be found in Section 4.5). Several countries mention national habitat-monitoring schemes or refer to institutions that keep track of the status of important habitats at national or subnational levels. For example, Norway mentions that the Norwegian Biodiversity Information Centre ${ }^{55}$ undertakes habitat risk assessments, disseminates information on the state of habitats and manages the country's Red List for habitat types. The United States of America reports that the databases of the State Natural Heritage Programs operated by The Nature Conservancy, ${ }^{56}$ a non-profit conservation organization, contain

\footnotetext{
${ }^{54}$ http://ec.europa.eu/environment/nature/natura2000/index_en.htm

55 http://www.biodiversity.no

56 http://www.nature.org
}

information on the occurrences of rare species and their habitats. It notes that the databases list species, natural communities and ecosystems in need of protection and contain information on the vegetation structure and composition, succession patterns, natural disturbances, distribution and rarity of specific community types throughout their geographic ranges. China mentions using a habitat-quality index to evaluate the biodiversity maintenance function of habitats. A number of countries also mention habitat-monitoring activities implemented in the context of specific projects, particularly in the field of conservation.

\section{Status and trends}

Countries' responses on trends in the supply of habitat services in particular production systems are summarized in Table 4.4. Reports of positive trends predominate in forest production systems. In all fisheries and aquaculture systems, trends are mixed (i.e. neither positive nor negative nor stable trends predominate). Reports of negative trends predominate in crop and livestock systems, reflecting both the analysis of trends in major ecosystem categories presented below in Section 4.5 and the analysis of drivers of change presented in Chapter 3. Many countries highlight ongoing habitat degradation or destruction, or note the continued precariousness of many habitats despite the introduction of conservation programmes. For example, China reports that its above-mentioned habitat-quality indexes show that for the period 2000 to 2010 a large proportion of studied ecosystems were estimated to be of low habitat quality and that the extent of ecosystems with higher habitat quality was declining. Switzerland mentions that almost half of its habitats are listed as threatened on its red lists and notes that "negative developments outweigh the positive developments in terms of the area and quality of habitats that merit special conservation efforts." The findings of the European Union's monitoring activities for a number of habitats relevant to food and agriculture are discussed in Box 4.8.

Figure 4.8 presents the risk status of species included on The IUCN Red List, broken down by 


\section{PART B}

Box 4.8

\section{Trends in the state of habitats in the European Union}

The European Union's Habitats Directive, adopted in 1992, ${ }^{1}$ aims to protect biodiversity by promoting the conservation of habitats and wild flora and fauna. Member states are required to report every six years on their implementation of the directive. The most recently completed round of reporting covered the 2007 to 2012 period. Findings were published in 2015. The conservation status and trends of major habitat groups are summarized in the following figure.

Only 16 percent of all habitat assessments undertaken in this round of reporting indicated a "favourable" status. Most found the status of ecosystems to be either "unfavourable inadequate" (47 percent) or "unfavourable - bad" (30 percent). Unfavourable assessments were particularly common in the case of dunes, grasslands, coastal habitats and wetlands.

Where trends are concerned, 30 percent of all assessed habitats fell into the "unfavourable - deteriorating" category and 33 percent into the "unfavourable - stable" category. Only 4 percent were classified as "unfavourable improving". Wetland habitats, followed by grasslands, were the categories for which the highest proportion of assessments indicated negative trends.

Council Directive 92/43/EEC of 21 May 1992 on the conservation of natural habitats and of wild fauna and flora (available at http://ec.europa.eu/ environment/nature/legislation/habitatsdirective/index_en.htm).

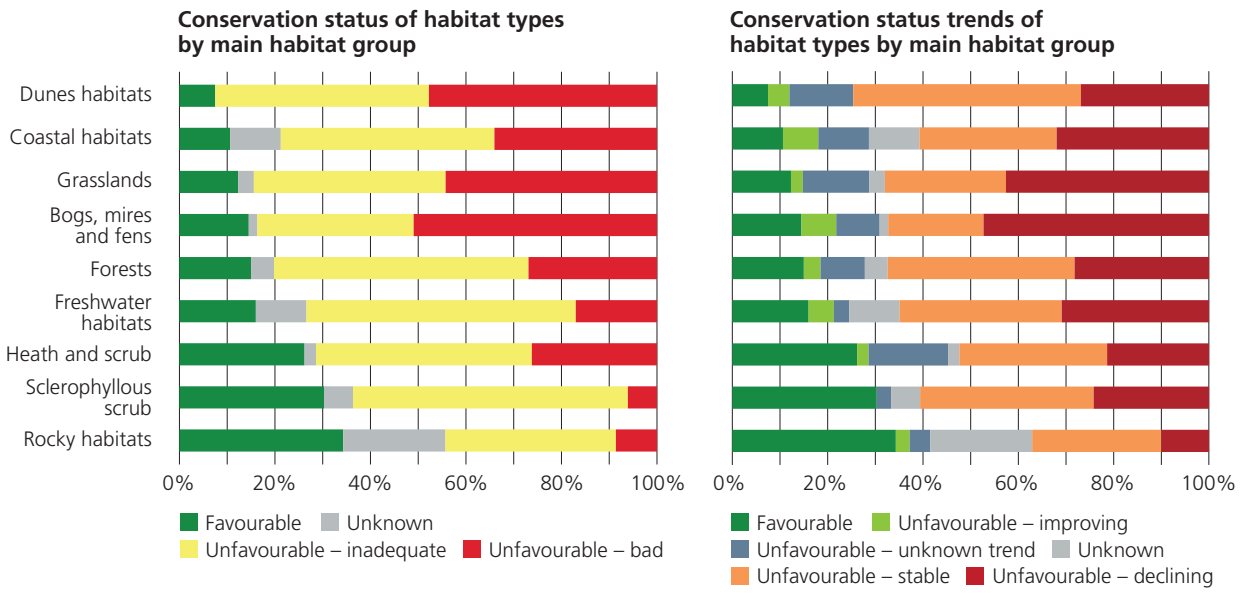

Source: European Commission, 2015

habitat type. ${ }^{57}$ Habitats of particular interest to food and agriculture include artificial aquatic (which includes aquaculture ponds, irrigated land, seasonally flooded agricultural land, mariculture cages and mari/brackishculture ponds), artificial

\footnotetext{
57 More information on the Habitats Classification Scheme (version 3.1) is available at http://www.iucnredlist. org/technical-documents/classification-schemes/ habitats-classification-scheme-ver3
}

terrestrial (which includes arable land, pastureland, plantations and rural gardens), forests, grasslands, marine coastal, marine intertidal (which includes mangroves), marine neritic (which includes macroalgal/kelp habitats, coral reefs and seagrass habitats), savannahs, shrublands and wetlands. Of these, the habitats with the highest proportion of species classed as Extinct, Extinct in the Wild, Critically Endangered, Endangered or Vulnerable 
FIGURE 4.8

Global risk status of species included in The IUCN Red List of Threatened Species, by habitat

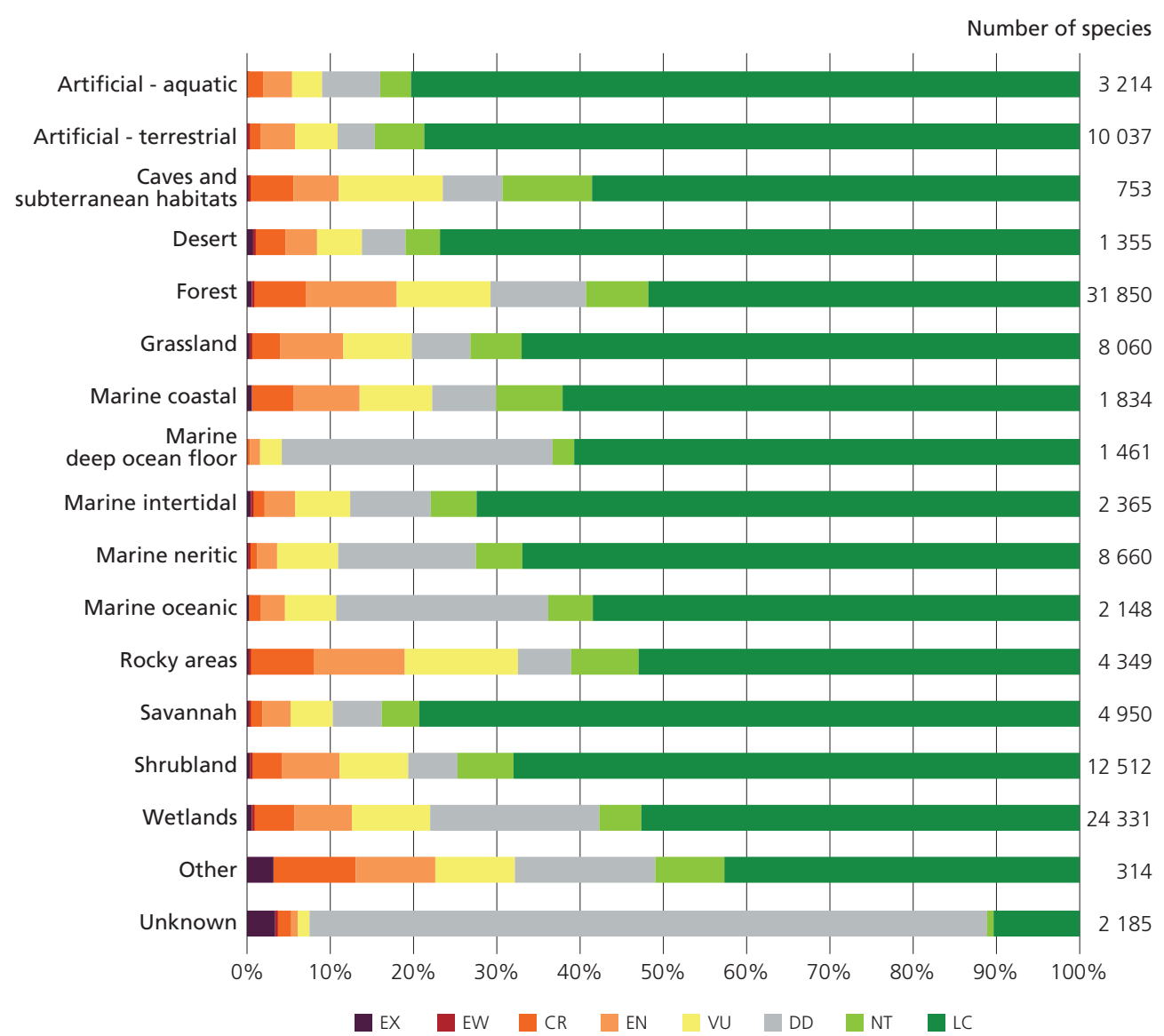

Notes: EX (Extinct); EW (Extinct in the Wild); CR (Critically Endangered); EN (Endangered); VU (Vulnerable); DD (Data Deficient); NT (Near Threatened) and LC (Least Concern). Species can be assigned to more than one habitat.

Source: The IUCN Red List version 2017-3.

are forests (29 percent of species), marine coastal habitats and wetlands (both 22 percent).

\subsubsection{Associated biodiversity for air-quality and climate regulation}

\section{Introduction}

As discussed in Chapter 2, BFA plays a significant role in air-quality regulation. Plants, and in particular trees and shrubs, are the direct providers of this service, as they are able to trap particulate and gaseous pollutants from the surrounding air. Capacity to do this varies from species to species depending on characteristics such as leaf structure, size and growth rate, evergreen versus deciduous character, and pollution tolerance (Baró et al., 2014; Smith, 2012; Yang et al., 2005). A wider range of species contribute indirectly, for example the 
pollinators and soil organisms that plants depend upon in order to reproduce and grow. The supply of this service is particularly significant in urban areas, where pollution levels tend to be high and where large numbers of people are potentially exposed to harmful effects (e.g. Gupta, Chaudhari and Wate, 2008; Nowak et al., 2014; Yang et al., 2005b).

Climate-regulating services operate at both global and local levels. Ecosystems such as forests, grasslands, wetlands and aquatic ecosystems both marine and freshwater - play a key role in the Earth's carbon cycle and hence in controlling the levels of greenhouse gases in the atmosphere. Complex mechanisms and interactions, involving a wide range of different components of biodiversity, govern the uptake and release of carbon in these ecosystems (Beed et al., 2011; Cock et al., 2011; Laffoley and Grimsditch, 2009; Nellemann et al., 2009; Pullin and White, 2011). For further discussion, see Section 2.2 .

The country reports mention a number of species that are actively managed for the provision of air-quality and climate-regulation services (see Section 4.3.1). The species in question are almost exclusively trees. The vast majority of reporting countries also mention forest ecosystems as major carbon sinks, in some cases (e.g. Cameroon and the United Arab Emirates) referring specifically to the role of mangroves. A number of countries highlight the contributions of grasslands, and/or marine or freshwater ecosystems. A few examples of the roles of individual species other than trees are mentioned. For example, Finland and Panama mention the potential significance of the role of dung beetles in reducing the release of greenhouse gases from bovine excreta (for further information on this effect, see for example Piccini et al., 2017 and Slade et al., 2016). Spain mentions the role of alfalfa (Medicago sativa) in crop systems, noting that crop rotations that include forage legumes reduce the use of fertilizers and therefore limit greenhouse-gas emissions. The United States of America notes that the pollination activities of native wild bees maintain plant communities that provide valuable ecosystem services, including carbon sequestration.

\section{State of knowledge}

As noted above, climate-regulation services are normally regarded as the outcome of complex processes within ecosystems such as forests, grasslands, wetlands and oceans (or within subcomponents such as soils) that involve the combined effects of many different species and taxonomic and functional groups of organisms. The state of knowledge on the status and trends of relevant ecosystems is discussed in Section 4.5 and on the status and trends of biodiversity contributing to the formation and maintenance of soils in Section 4.3.6.

The availability of high-resolution satellite imagery means that it is becoming easier to monitor changes in the extent of tree cover, including in urban areas, where air-quality regulation services are particularly significant (e.g. McGee et al., 2012). Air quality and atmospheric greenhousegas concentrations are monitored under various national and international initiatives. For example, the 2016 version ${ }^{58}$ of the World Health Organization's Global Ambient Air Pollution Database ${ }^{59}$ records annual mean concentrations of particulate matter from over 3000 human settlements, mostly cities, in 103 countries (WHO, 2016). Real-time air-quality data collected by environmental-protection agencies at more than 10000 stations $^{60}$ in 1000 major cities in 80 countries can be accessed via the World Air Quality website ${ }^{61}$ (World Air Quality, 2018). The United States of America's National Oceanic and Atmospheric Administration's Global Greenhouse Gas Reference Network ${ }^{62}$ measures the atmospheric distribution and trends of carbon dioxide, methane and nitrous oxide, as well as carbon monoxide, an important indicator of air pollution (Global Greenhouse Gas Reference Network, 2017). Clearly, however, changes in air-quality indicators do not necessarily correspond to changes in

\footnotetext{
${ }^{58}$ The latest version available as of October 2018.

59 http://www.who.int/phe/health_topics/outdoorair/databases/ cities/en/

${ }^{60}$ As of September 2018.

61 http://aqicn.org/here/

62 https://www.esrl.noaa.gov/gmd/ccgg/
} 
Box 4.9

Soil carbon assessment initiatives - examples from the United States of America

Soils act as either a sink or as a source of atmospheric carbon dioxide, depending on their use and management. Soil properties such as texture, mineralogy, drainage class and depth affect how much carbon is retained and released. The Rapid Carbon Assessment project was developed to obtain statistically reliable estimates of current carbon stocks in soils in the United States of America, taking into consideration ecosystem properties, soil type with respect to carbon retention, land cover and agricultural management. Approximately 32500 soil profiles have been sampled at 6500 locations to develop the largest soil-carbon dataset in the world. Reports are available for total carbon stocks for cropland, Conservation Reserve Program land, forestland, pasture, rangeland and wetland. The data will be valuable for calibrating models such as COMET (see below) and quantifying land-management impacts on soil carbon for environmental markets.

The CarbOn Management Evaluation Tool (COMET)

is an online tool developed through a partnership between the National Resources Conservation Service and Colorado State University. It helps farmers and ranchers understand and assess the impacts of changes in land management. The latest version, COMET-FARM ${ }^{\mathrm{TM}}$, is a whole-farm/ranch carbon and greenhouse-gas accounting and reporting system that can estimate the "carbon footprint" for all or part of a farm/ranch operation and allows users to evaluate different options for reducing greenhouse-gas emissions and sequestering more carbon. As it uses detailed spatially explicit data on climate and soil conditions for specific locations, and allows farmers and ranchers to enter detailed information on their field and livestock operations, it is able to produce accurate estimates tailored to specific situations.

Source: Adapted from the country report of the United States of America, with additional information from the COMET-Farm website (http:// cometfarm.nrel.colostate.edu/Home).

Note: For further information on the Rapid Carbon Assessment, see the project website (https://www.nrcs.usda.gov/wps/portal/nrcs/detail/soils/ survey/?cid=nrcs142p2_054164). the capacity of ecosystems to provide regulating services. They are also affected by emissions levels and by climatic effects.

The country reports provide little indication that efforts are being made to evaluate the impact of population trends in specific components of BFA on the supply of air-quality or climate-regulation services. With regard to the above-mentioned dung-beetle example, Finland notes that although 50 percent of its dung-beetle species are redlisted, it has not been determined whether their decline has affected climate regulation or nutrient cycling in pastures. More generally, it notes that data on population changes in many functionally important species in agricultural and forest systems are unavailable. Several countries, however, mention initiatives related to the monitoring of carbon stocks in forest and agricultural systems. For example, Zambia reports the establishment of a national forest-monitoring system that, inter alia, keeps track of changes in forest carbon stocks. Some examples from the United States of America are presented in Box 4.9.

\section{Status and trends}

The status and trends of various ecosystems that play a major role in the supply of services in this category (particularly climate regulation) are discussed in Section 4.5.

Countries' responses on trends in the supply of air-quality and climate-regulation services in particular production systems are summarized in Table 4.4. Reports of downward trends predominate in livestock systems and upward trends in planted forest systems, irrigated crops (non-rice) and non-fed aquaculture. Trends are mixed for other production systems (i.e. neither positive nor negative nor stable trends predominate). Several countries note the significance of trends in forest area to the supply of air-quality and climateregulation services. For example, Burkina Faso mentions that its net carbon emissions from the 
"land use, land-use change and forestry" sector ${ }^{63}$ are negative thanks to forest protection and reforestation efforts. Malaysia mentions that its policy of retaining at least 50 percent of its land under permanent forest cover in perpetuity has contributed to reducing greenhouse-gas emissions and maintaining and enhancing carbon sequestration.

\subsection{Wild foods}

- The country reports refer to over 2800 distinct wild species as being used for human food. The IUCN Red List of Threatened Species contains over 9600 wild species reported to be used for this purpose.

- Close to 20 percent of the species recorded in The IUCN Red List of Threatened Species as sources of human food are classed as threatened.

- The main threats to wild foods reported by countries are overexploitation, habitat alteration or loss, pollution and change in land use.

According to the definition provided in Section 1.5, wild foods are food products obtained from non-domesticated species. However, the distinction between wild and domesticated foods is not clear cut: wild foods lie "along a continuum ranging from the entirely wild to the semidomesticated, or from no noticeable human intervention to selective harvesting, transplanting, and propagation by seed and graft" (Harris, 1989). Wild food products are obtained from a variety of sources including plants, bacteria, animals and fungi. They may be harvested (gathered or hunted) from within cultivated production systems or from natural or semi-natural ecosystems. As noted in Section 2.6.6, capture fisheries in marine and freshwater ecosystems are probably the largest example of the human use of wild foods, providing a total of 90.9 million tonnes of aquatic animals and plants in 2016 (FAO, 2018a).

\footnotetext{
63 "A greenhouse gas inventory sector that covers emissions and removals of greenhouse gases resulting from direct humaninduced land use, land-use change and forestry activities" (UNFCCC, 2017a).
}

In discussions of wild foods, a distinction is sometimes drawn between subsistence and commercial fishing. In the case of forests, wild foods are often referred to as a category of non-wood forest products, and include plants, mushrooms, wild meat, and insects and other invertebrates.

Contrary to what is often assumed, evidence demonstrates that a significant proportion of wild food comes from areas used for crop and/ or livestock production, or from around the home (Powell et al., 2014). In crop and mixed production systems, a large variety of wild herbs, insects, fish (e.g. in rice fields), weeds and unmanaged plants are often harvested for food: see Bharucha and Pretty (2010) and Halwart (2006) for example. Because of the relative abundance of food sources, several game species thrive in habitat mosaics of swiddens and forest, and can serve as valuable sources of protein (Parry, Barlow and Peres, 2009). The contribution of wild foods to food security and nutrition is discussed in greater detail in Section 2.6.6.

\subsubsection{State of knowledge}

Information on the use, state and conservation of wild foods remains limited, as few assessments of wild foods are conducted at national, regional or global levels, even though these foods represent an important part of the global food basket (Bharucha and Pretty, 2010). Information on non-wood forest products is available to varying degrees in national databases, depending on the importance of such products to the respective country (Sorrenti, 2017). However, as wild foods are often collected informally, they are usually overlooked in inventories and economic assessments (Schulp, Thuiller and Verburg, 2014). Commercial fisheries are an exception. However, fisheries may not be monitored closely when they are conducted as artisanal, subsistence or recreational activities.

Information on wild foods often comes from ethnobiological/ethnobotanical inventories, usually carried out by universities or research institutes. Many such assessments are conducted. However, they tend to be localized and one-off studies. Other sources of information include 
scientific literature from other fields of research (e.g. nutrition), game-bag statistics from national organizations, and local cookbooks (which can be used to identify wild food species and their uses).

Although wild-food use may not be particularly high in the Europe and Central Asia and North America regions, the status and trends of wild food resources are better monitored in these regions than elsewhere. Fish and game species seem to be systematically monitored in most of the reporting countries in these regions. Monitoring levels for fungi, wild berries, medicinal plants and herbs vary from country to country.

Several country reports refer to sources of information on the use of wild foods. The United States of America, for example, mentions data on participation in hunting and fishing, the value of capture fisheries and the value of various other commercially harvested wild foods such as mushrooms, maple syrup, blueberries, ginseng, herbs, and kelp and other seaweed. Data on some wild foods are included in national statistics in some countries, for example on the hunting of small game and deer and on catches of wild fish in Norway and on marketed wild mushrooms, berries, other fruit and medicinal plants in Belarus. Data may also be kept by organizations such as angling associations (as reported by Poland). Data on wild-food use do not, however, necessarily provide a good indication of the status of the targeted species. For example, Slovenia notes that trends in data on the harvesting of wild mushrooms do not significantly reflect changes in the environment but rather indicate changes in market prices and interest in trading fungi; year-to-year changes may reflect specific conditions for fructification.

The IUCN Red List flags species that are consumed (or have any parts or products that are consumed) by humans in any part of the species' geographic ranges. However, not all described species have been assessed for The IUCN Red List, and, among those that have, not all those that are utilized for food will necessarily be flagged as such in the dataset. Global inventories and assessments have been undertaken for wild edible fungi (Boa, 2004) and edible insects (van Huis et al., 2013). Regular assessments are conducted for key commercial marine fish stocks (FAO's biennial assessment The State of World Fisheries and Aquaculture). However, no equivalents exist from the many smaller-scale fisheries and minor stocks present in marine and freshwaters. Global overviews of the status, trends and use of wild foods are provided in the Millennium Ecosystem Assessment (MEA, 2005b) and in a number of other recent reports (Bioversity International, 2017; WHO and CBD, 2015; HLPE, 2017a; Vinceti et al., 2013). ${ }^{64}$

\subsubsection{Status and trends}

\section{Wild-food diversity}

Providing definitive figures on the number of wild species used for food worldwide is challenging for several reasons, including difficulties in the identification of the species in question. In many cultures, and even from one village to the next, more than one common or vernacular name is used for the same species (Powell et al., 2014). Nonetheless, thousands of wild species used for food have been documented and recorded. For example, studies in Asia, the Near East and Africa, conducted at various locations and at levels ranging from communities to entire countries, have recorded the use of between 6 and 800 wild food species, with an average of 90 to 100 species recorded in the community-level and other below country-level studies (Bharucha and Pretty, 2010). A total of 1154 species and genera of wild mushrooms used for food have been recorded from 85 countries (Boa, 2004). An inventory of the literature conducted in 2017 enumerated 2111 edible insect species worldwide (Jongema, 2017). As noted in Section 4.2.4, over 1800 species items feature in FAO capture-fisheries data, including fish, crustaceans, molluscs, echinoderms, coelenterates and aquatic plants, most of them used as food or feed (FAO, forthcoming, 2018i). As of December 2017, 9627 species on The IUCN Red

\footnotetext{
64 In addition, the draft of a first evaluation of the scale and drivers of subsistence and commercial harvesting of wild terrestrial vertebrates for food in tropical and subtropical regions was submitted to CBD SBSTTA 21 (Coad et al., 2017).
} 


\section{PART B}

FIGURE 4.9

Number of wild food species reported, by type and region

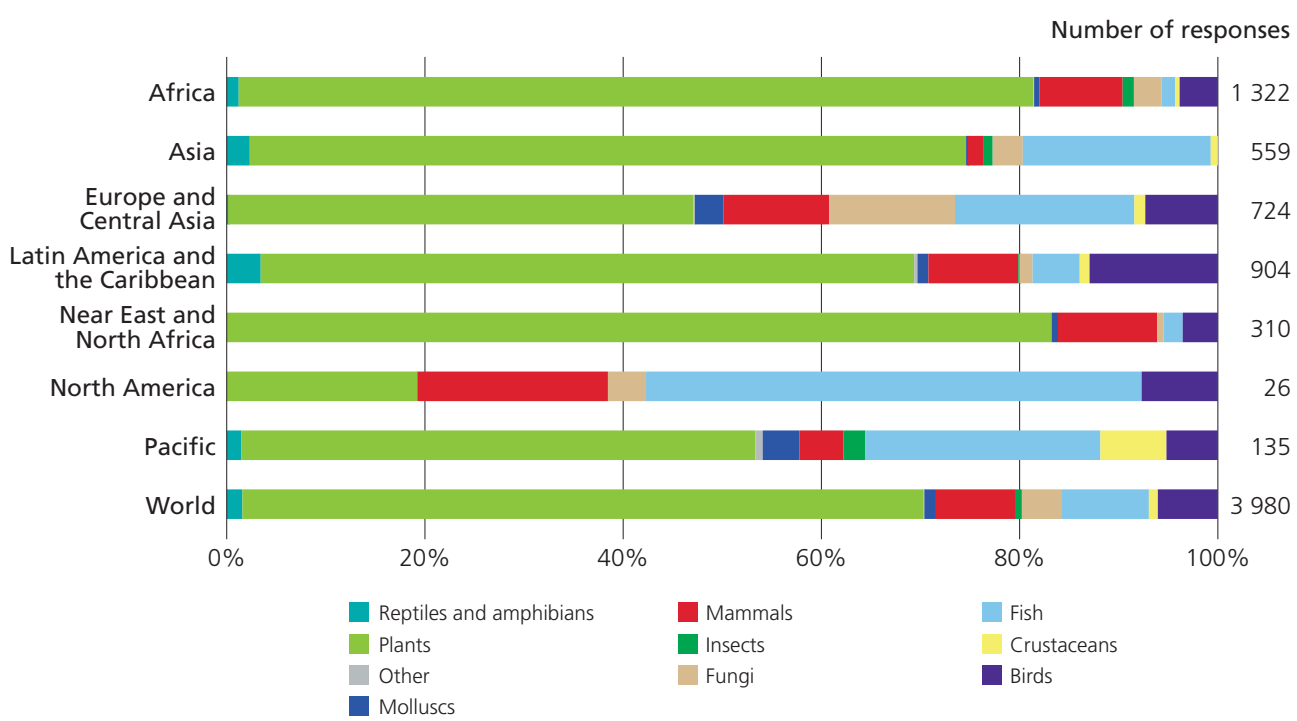

Notes: A "response" is the report of a given wild food species by a given country. Analysis based on 91 country reports. Source: Country reports prepared for The State of the World's Biodiversity for Food and Agriculture.

List (11 percent of the total) were recorded as being used for human food. Almost half of these species (4 617) were bony fishes. Large numbers of bird (1 646) and mammal (1 237) species were also recorded as being used for food.

In their reports prepared for The Second State of the World's Plant Genetic Resources for Food and Agriculture (FAO, 2010a), several countries included lists of wild species used for food and other purposes. At least 800 unique species (from 55 countries) were explicitly mentioned as being used for food.

The country-reporting guidelines ${ }^{65}$ invited countries to provide information on wild foods known to be harvested, hunted, captured or gathered. The 4323 responses (from 69 countries) feature over 2822 distinct species. ${ }^{66}$ The number of wild

${ }^{65}$ This refers to the country-reporting guidelines for The State of the World's Biodiversity for Food and Agriculture.

${ }^{66}$ Additionally, 205 distinct genera were reported without the species being indicated. foods reported in each region is presented, by type, in Figure 4.9. In addition to these responses, several countries provided information on the use of wild foods without indicating individual species by their scientific names. For example, the report from the United States of America mentions that a study in the state of Maine found that the target population, which included Native Americans, utilized 55 different types of wild foods from forests, including blueberries, cranberries, chives, fiddlehead ferns, young dandelion leaves and beaked hazelnuts. Spain mentions that 138 crop wild relatives have been identified as being used for food.

The number of wild foods reported by countries does not reflect the full global picture. For example, more than 2000 species of insects are known to be used as human food worldwide (van Huis et al., 2013), while only 21 species are reported by countries. Reasons for this include the fact that a number of country reports (22 out of the 91 submitted) provide no information on wild foods 
TABLE 4.9

\section{Selected examples of wild food species and genera reported by countries}

\begin{tabular}{|c|c|}
\hline $\begin{array}{l}\text { Type (number of species } \\
\text { reported) }\end{array}$ & Examples \\
\hline Plants (1955) & $\begin{array}{l}\text { Adansonia digitate, Allium spp., Amaranthus spp., Annona spp., Artocarpus altilis, Capparis spp., Colocasia } \\
\text { esculenta, Cordia spp., Crataegus spp., Dioscorea spp., Diospyros spp., Ficus spp., Garcinia spp., Grewia spp., } \\
\text { Moringa oleifera, Morus spp., Opuntia spp., Passiflora spp., Portulaca oleracea, Prosopis spp., Prunus spp., Rosa } \\
\text { spp., Rumex spp., Rubus idaeus, Sclerocarya birrea, Solanum spp., Sorbus spp., Syzygium spp., Tamarindus } \\
\text { indica, Vaccinium spp., Vachellia spp., Vitellaria paradoxa, Ximenia americana, Ziziphus mauritiana }\end{array}$ \\
\hline Fungi (117) & $\begin{array}{l}\text { Armillaria spp., Boletus spp., Cantharellus spp., Craterellus spp., Hydnum repandum, Lactarius spp., Leccinum } \\
\text { spp., Lentinus spp., Morchella spp., Russula spp., Termitomyces spp., Tricholoma spp., Tuber spp. }\end{array}$ \\
\hline Mammals (187) & $\begin{array}{l}\text { Alces spp., Axis axis, Capra spp., Capreolus spp., Cervus spp., Cuniculus spp., Dama spp., Dasypus } \\
\text { novemcinctus, Hystrix cristata, Lepus spp., Mazama spp., Odocoileus spp., Oryctolagus spp., Ovis spp., Pecari } \\
\text { spp., Pteropus spp., Sus spp., Sylvilagus spp., Syncerus caffer, Tragelaphus spp. }\end{array}$ \\
\hline Birds (156) & $\begin{array}{l}\text { Alectoris spp., Anas spp., Anser spp., Aythya spp., Callipepla spp., Coturnix spp., Ducula spp., Francolinus spp., } \\
\text { Lagopus spp., Mareca spp., Meleagris spp., Numida meleagris, Ortalis spp., Patagioenas spp., Phasianus spp., } \\
\text { Scolopax spp., Streptopelia spp., Struthio camelus }\end{array}$ \\
\hline Insects (21) & $\begin{array}{l}\text { Apis spp., Atta laevigata, Brachytrupes membranaceus, Gonimbrasia belina, Gryllus bimaculatus, Olethrius } \\
\text { tyrannus, Parides alopius, Raphia spp., Rhynchophorus phoenicis, Samia cynthia, Vespa cincta }\end{array}$ \\
\hline Crustacea (30) & $\begin{array}{l}\text { Birgus spp., Cardisoma spp., Farfantepenaeus duorarum, Homarus gammarus, Litopenaeus vannamei, } \\
\text { Macrobrachium spp., Nephrops spp., Pacifastacus leniusculus, Pandalus spp. , Palinurus spp., Procambarus } \\
\text { clarki, Scylla spp. }\end{array}$ \\
\hline Molluscs (38) & $\begin{array}{l}\text { Achatina achatina, Anadara spp., Anadara tuberculosa, Archachatina spp., Helix spp., Mytilus spp., Octopus } \\
\text { spp., Ostrea edulis, Perna viridis, Potadoma spp., Scutellastra flexuosa, Sepia spp., Tivela stultorum }\end{array}$ \\
\hline Fish (262) & $\begin{array}{l}\text { Acanthocybium solandri, Anguilla spp., Aphareus rutilans, Barbus spp., Carasobarbus luteus, Channa spp., } \\
\text { Clarias spp., Coptodon spp., Coryphaena hippurus, Epinephelus spp., Gadus morhua, Heteropneustes fossilis, } \\
\text { Labeo spp., Prochilodus lineatus, Salmo spp., Siganus spp., Sorubim lima, Tenualosa ilisha, Thunnus spp., } \\
\text { Tilapia spp. }\end{array}$ \\
\hline Reptiles and amphibians (45) & Crocodylus spp., Iguana iguana, Melanochelys trijuga, Varanus spp. \\
\hline Others (5) & Holothuria atra, Isostichopus fuscus, Loxechinus albus, Spirulina platensis \\
\hline
\end{tabular}

Note: Analysis based on 91 country reports.

Source: Country reports prepared for The State of the World's Biodiversity for Food and Agriculture.

and others do not provide an extensive inventory, in some cases because wild foods are not seen as contributing significantly to food security and nutrition in the respective countries. There is also a bias in the distribution of reporting countries across the regions of the world. For example, many more countries from the Europe and Central Asia region contributed country reports than countries from the Asia or the Near East and North Africa regions. The reported figures therefore clearly need to be interpreted with caution.

Several countries report very high numbers of wild food species. For example, Peru alone reports 523 species of edible fruits, of which only 66 are domesticated. Nicaragua reports a series of studies that provide information on some 150 wild and domesticated plant species, found mostly in well-conserved forests and used mainly by indigenous communities and by communities of African origin living on the country's Caribbean coast.

The 12 genera most frequently reported by countries are all plants - Ficus (64 mentions), Rubus (47), Dioscorea (45), Amaranthus (39), Prunus (39), Grewia (36), Solanum (35), Ziziphus (30), Annona (29), Vaccinium (27), Garcinia (26) and Sorbus (26). Anas (a genus of ducks) is also frequently reported (25 mentions). Examples of species reported are listed in Table 4.9. Photos of some examples of wild foods are presented in Figure 4.10.

The production systems and environments from which the reported wild food species are harvested are not known or not specified for 


\section{PART B}

FIGURE 4.10

Examples of wild plants reported to be used for food
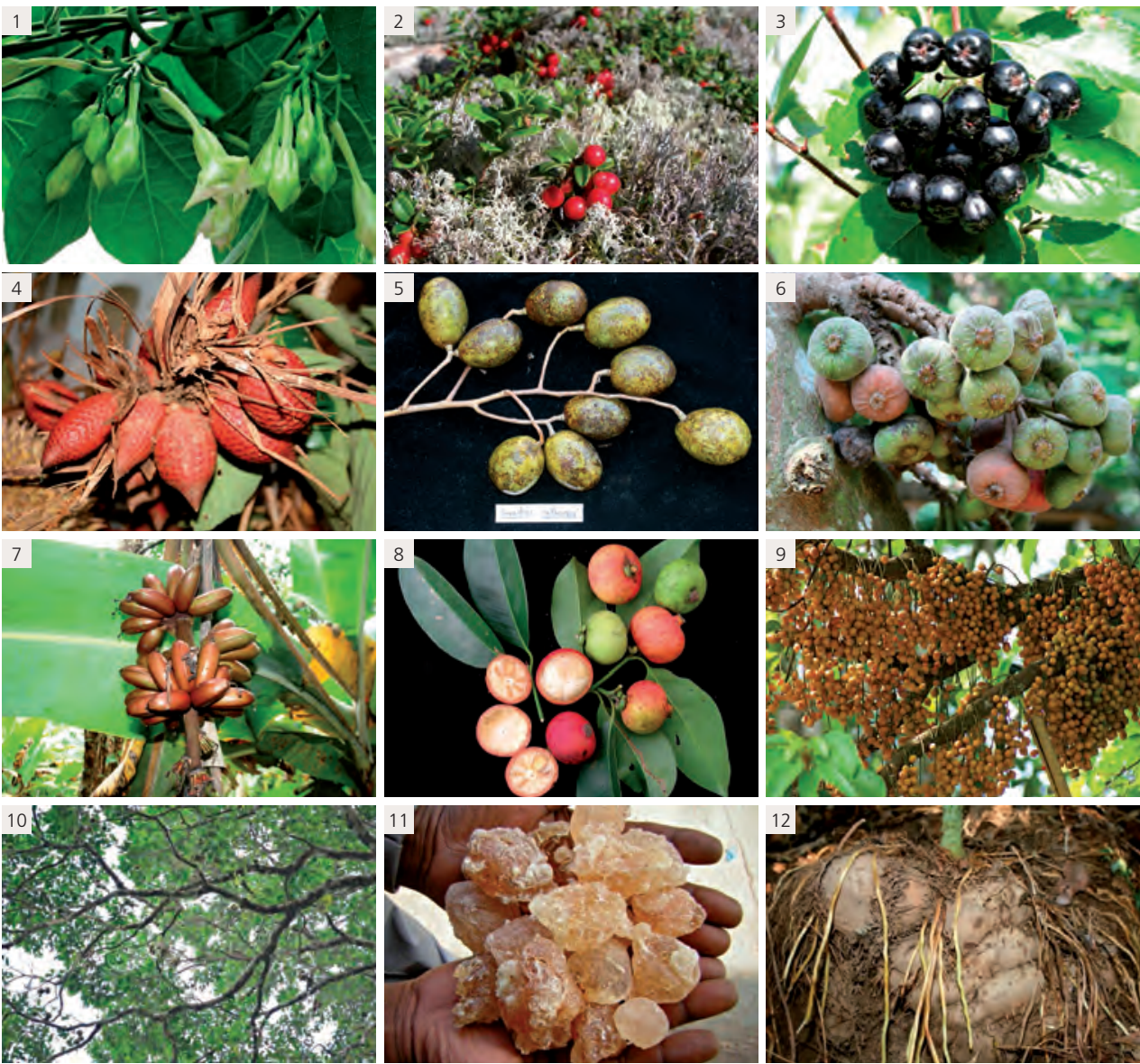

Notes: 1. Fernaldia pandurata (ioroco) (Source: Country report of El Salvador, ๑ Eduardo Funes); 2. Vaccinium vitis-idaea (cowberry) (Source: NIBIO, ๑ Michael Angeloff); 3. Aronia melanocarpa (black chockeberry) (Source: Country report of Belarus, ๑ Institute of Food Growing of the National Academy of Sciences of Belarus); 4. Salacca affinis (Source: Country report of Malaysia, @ Mohd Norfaizal Ghazalli); 5. Spondias pinnata (wild mango) (Source: Country report of Malaysia, ๑ Mohd Norfaizal Ghazalli); 6. Ficus roxburghii (Source: Country report of Malaysia, @ Mohd Norfaizal Ghazalli); 7. Musa sp. (Source: Country report of Malaysia, ๑ Mohd Norfaizal Ghazalli); 8. Garcinia hombroniana (Source: Country report of Malaysia, @ Salma Idris); 9. Baccaurea polyneura (Source: Country report of Malaysia, ๑ Khadijah Awang); 10. Irvingia gabonensis (African mango) (Source: Country report of Cameroon, ๑ Oben); 11. Gum product from Senegalia senegalensis (gum acacia) (Source: Country report of Niger, @ Idrisa Noma); 12. Dioscorea hispida (intoxicating yam) (Source: Country report of Malaysia, @ Mohd Norfaizal Ghazalli).

40 percent of the responses. ${ }^{67}$ Among the remaining 2530 responses, the largest numbers of species

\footnotetext{
${ }_{67} \mathrm{~A}$ "response" is the report of a given wild food by a given country.
}

are reported to be obtained from forest production systems (including planted and naturally regenerated forests) (26 percent), capture fisheries, aquaculture and other aquatic environments 
FIGURE 4.11

Production systems and environments in which wild food species are present and harvested, by type

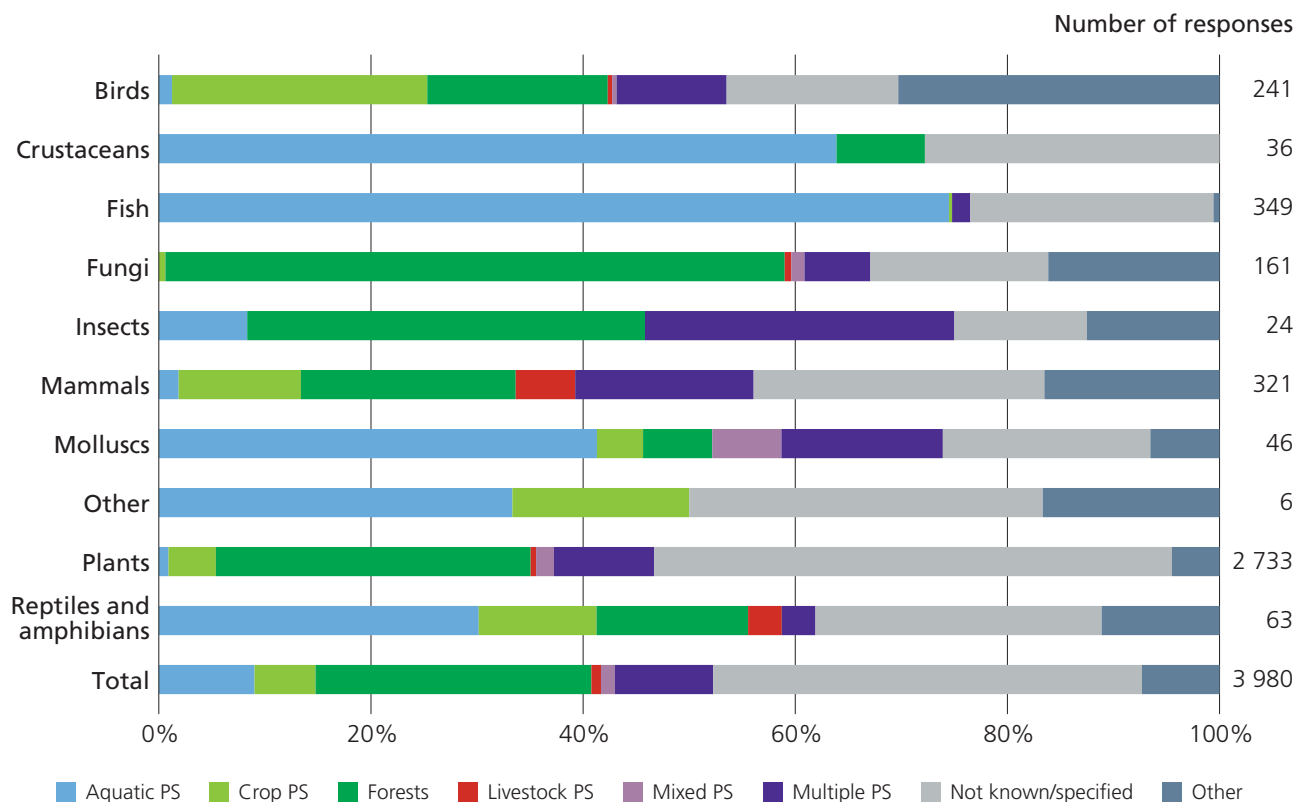

Notes: PS = production systems. A "response" is the report of a given wild food species, by a given country, in a given production system. Analysis based on 91 country reports.

Source: Country reports prepared for The State of the World's Biodiversity for Food and Agriculture.

(rivers, canals, ponds, etc.) (9 percent), multiple production systems (9 percent), other environments (roadsides, home gardens, etc.) (7 percent), crop production systems (6 percent), mixed production systems (1 percent) and livestock production systems (1 percent) (Figure 4.11).

\section{Trends in the status of wild foods}

Countries were invited to provide information on trends in the status of the wild foods they reported. In 60 percent of the 4323 reported cases, trends are either not reported or not known (Figure 4.12). In 24 percent of cases, the respective wild food is reported to be decreasing in abundance. Abundance is reported to be stable in 8 percent of cases and increasing in 7 percent of cases. Asia is the region with the highest proportion of cases (46 percent) in which abun- dance is reported to be decreasing, followed by the Pacific (44 percent) and Africa (33 percent). The taxonomic groups with the highest number of cases in which abundance is reported to be decreasing are plants (714), followed by fish (126). The highest proportions of cases of declining abundance are reported among crustaceans (44 percent), fish (37 percent), molluscs and insects (both 28 percent) (Figure 4.13). Among production systems and environments, forests have the highest proportion of cases in which abundance is reported to be decreasing (49 percent), followed by aquatic production systems and environments (36 percent).

Countries were also invited to report on wild food species for which there is a significant threat of extinction or loss of important populations, using the categories and criteria of The IUCN Red 


\section{PART B}

FIGURE 4.12

Reported trends in the status of wild food species, by region

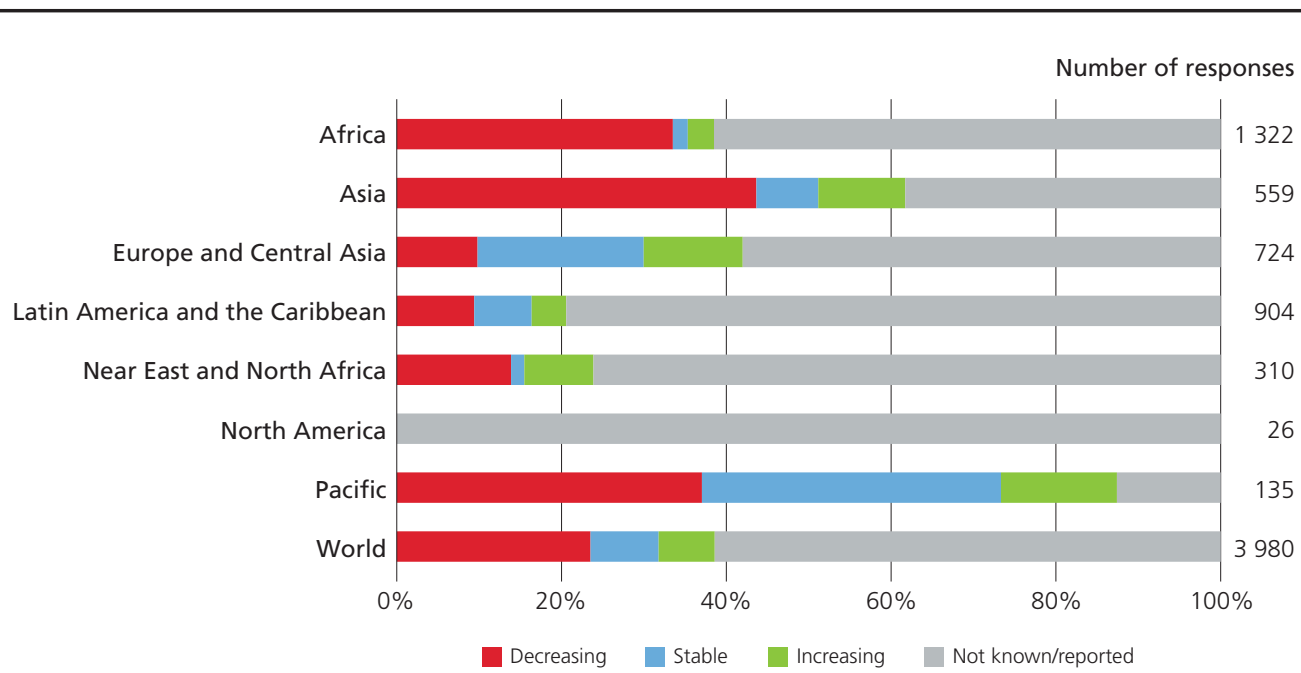

Notes: A "response" is the report of a given wild food species, by a given country. Analysis based on 91 country reports. Source: Country reports prepared for The State of the World's Biodiversity for Food and Agriculture.

FIGURE 4.13

Reported trends in the status of wild food species, by type

Number of responses

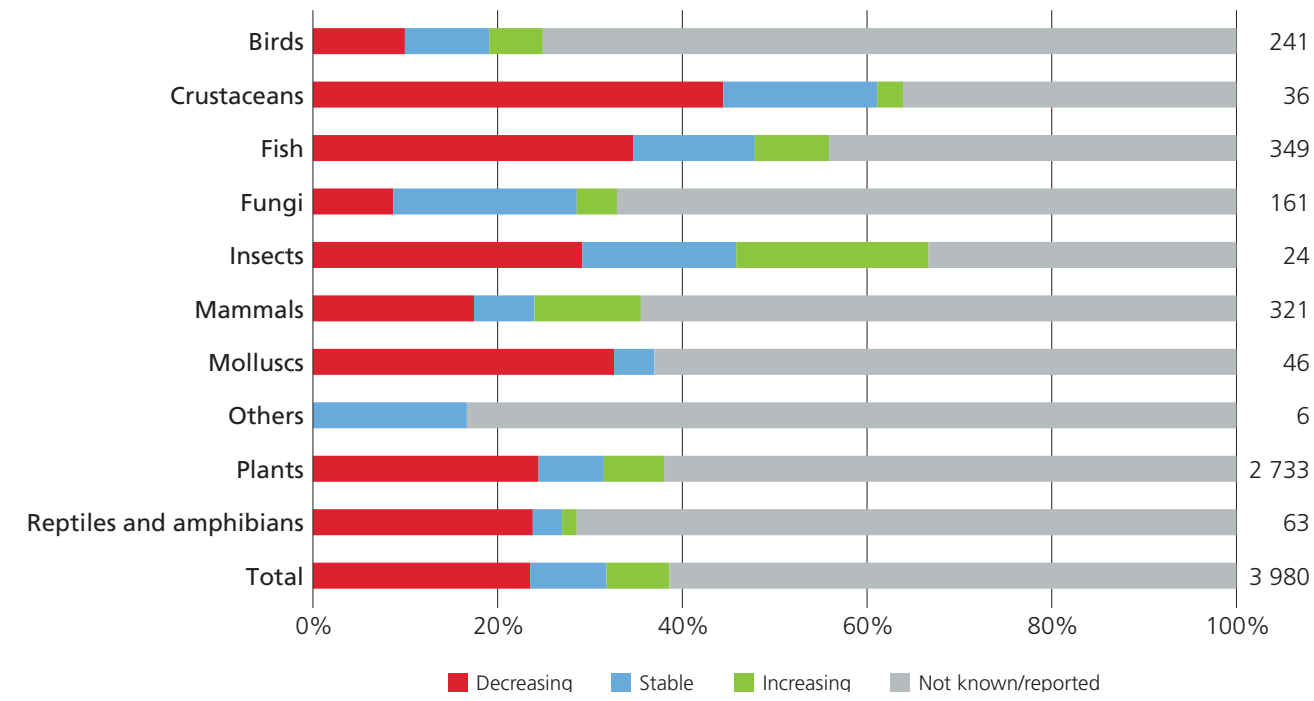

Notes: A "response" is the report of a given wild food species, by a given country. Analysis based on 91 country reports.

Source: Country reports prepared for The State of the World's Biodiversity for Food and Agriculture. 


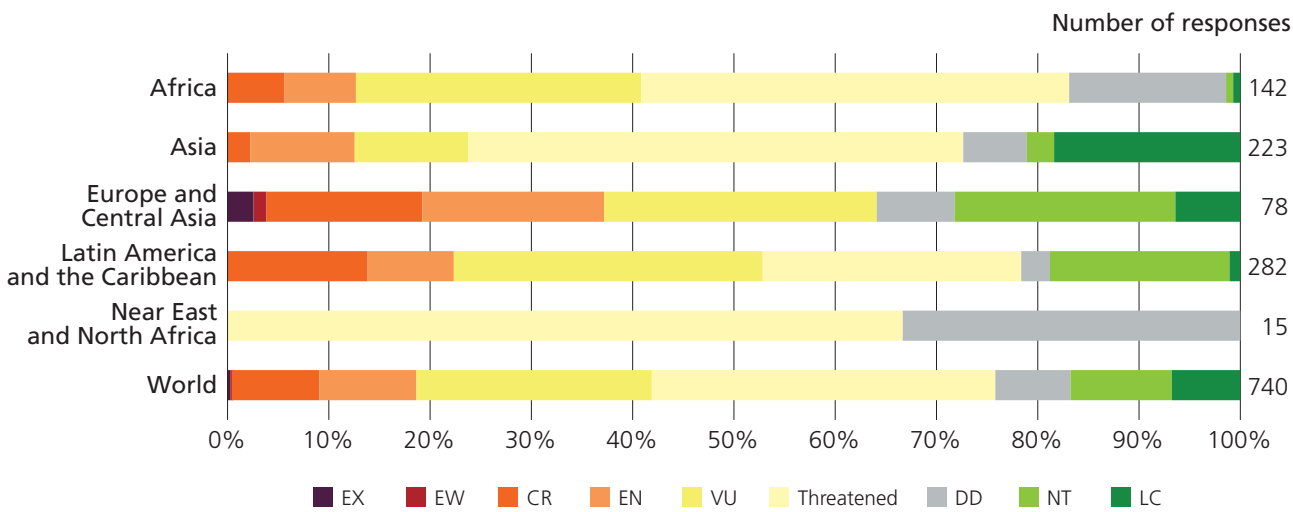

Notes: Countries reported according to the IUCN Red List Categories and Criteria: EX (Extinct); EW (Extinct in the Wild); CR (Critically Endangered); EN (Endangered); and VU (Vulnerable); NT (Near Threatened) and LC (Least Concern). The DD (Data Deficient) category includes cases where risk status is not reported or not known. In addition, several species were reported to be to be "threatened", without further specification of the IUCN Category. Not represented in the figure are data from the country reports of the United States of America, which noted five populations of salmon that have been listed as endangered under the Endangered Species Act and 23 populations listed as threatened, and the countries of the Pacific region, which reported a total of 12 species, all of unknown risk status. Analysis based on 91 country reports.

Source: Country reports prepared for The State of the World's Biodiversity for Food and Agriculture.

List (IUCN, 2012) as reference. Overall, 34 country reports provide a total 725 assessments of the risk status of wild food species, representing 648 distinct species (some of which are reported by more than one country). Four responses indicate Extinct status, 64 Critically Endangered status, 70 Endangered status, 168 Vulnerable status, 244 Threatened status without further specification of the IUCN category, 74 Near-Threatened status, 45 Least-Concern status and 56 Data-Deficient or unknown status. The responses are summarized, by region, in Figure 4.14. The largest numbers of threatened wild food species are reported by countries from Latin America and the Caribbean, followed by those from Asia and Africa. These figures can be expected to differ from global figures based on IUCN data, such as those presented in Figure 4.16, as the latter apply to species across their entire ranges rather than to national populations, are not restricted to the 91 reporting countries, and do not focus specifically on species considered to be under threat.
Several countries that list wild foods do not explicitly report any of them as being threatened. At the other end of the spectrum, Cameroon reports that most of its wild foods are threatened with extinction. It indicates that this applies mostly to species that are found in locations that do not have protected-area status and are affected by agriculture, hunting, grazing and other human activities. Bangladesh notes that a number of wild animals, such as the swamp deer (Cervus duvaucelii), the Indian rhinoceros (Rhinoceros unicornis) and the wild water buffalo (Bubalus arnee), that were once abundant and used as food have become extinct in the country.

The main threats to wild foods reported by countries are summarized in Figure 4.15. Together, overexploitation (27 percent), habitat alteration or loss (17 percent), pollution (9 percent) and change in land use (9 percent) account for 62 percent of the threats reported.

Figure 4.16 shows the risk status of species recorded on The IUCN Red List as being used for 


\section{PART B}

FIGURE 4.15

\section{Reported threats to wild foods species}

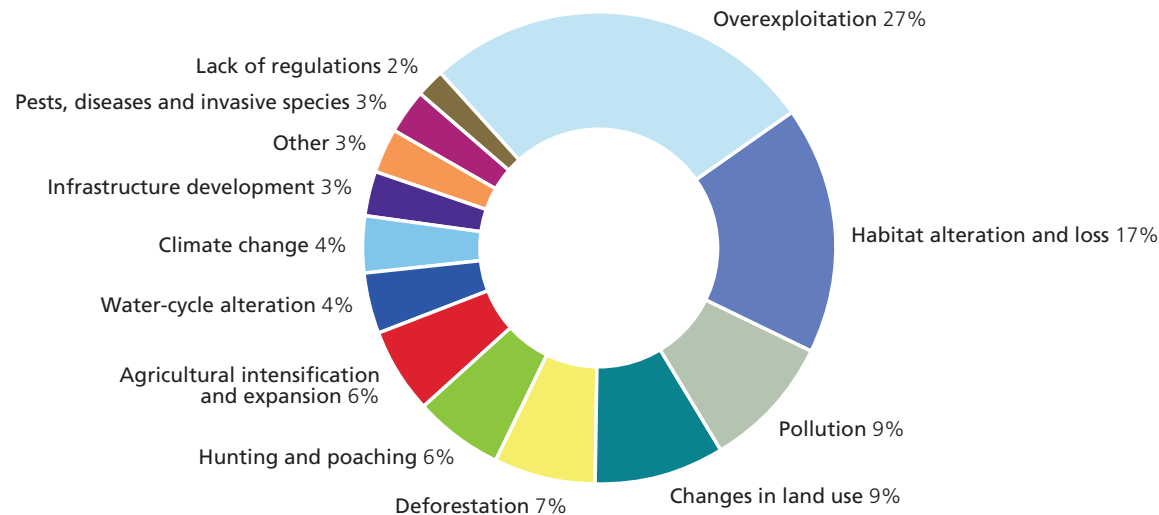

Notes: Percentages are calculated on a total of 1214 mentions of threats for 648 distinct species. More than one threat from more than one country may be reported for the same species. Analysis based on 91 country reports.

Source: Country reports prepared for The State of the World's Biodiversity for Food and Agriculture.

human food. Although the number of species assessed is low in the first two categories, reptiles and mammals have the highest proportion of species classified as Critically Endangered, Endangered or Vulnerable. Overall, 62 percent of species are classified as being of Least Concern, 13 percent as Data Deficient, 9 percent as Vulnerable, 6 percent as Endangered, 6 percent as Near Threatened, 4 percent as Critically Endangered and 1 percent as Extinct. It should be noted that insects and other terrestrial invertebrates, whether used for food or not, are poorly represented in The IUCN Red List.

As discussed above, capture fisheries are a major commercial industry, and as such are subject to relatively comprehensive monitoring. As noted in Section 4.2.4, as of 2015, 33 percent of fish stocks were estimated to be overfished, 60 percent to be maximally sustainably fished and 7 percent to be underfished (FAO, 2018a). Compared to the situation in the 1970s, this is a clear deterioration, although there have been some improvements at regional scales (ibid.). For other types of wild foods, evidence for trends in rates of exploitation and for their impacts on biodiversity is generally limited. As noted in Section 4.4.1, some data are available on other commercially used wild foods. In other cases, there are anecdotal indications or sometimes surveys of relevant stakeholders. A range of other drivers of change, including land-use change, climate change, natural disasters and invasive alien species, are recognized as threats to wild food species (see Chapter 3 for further discussion). However, knowledge of the extent of such impacts is generally limited. Relevant examples from the country reports are provided below.

The country reports indicate that recent decades have seen a decline in the availability and diversity of a range of wild foods. For example, Nepal reports that the status of its wild edible plant species is believed to have deteriorated as a result of the (often cumulative) effects of landuse changes (e.g. expansion of agriculture and infrastructure development), habitat destruction (resulting from timber harvesting, fuelwood collection and forest fires), overharvesting, 
FIGURE 4.16

Number of species classified as used for human food on The IUCN Red List of Threatened Species, by type and risk category

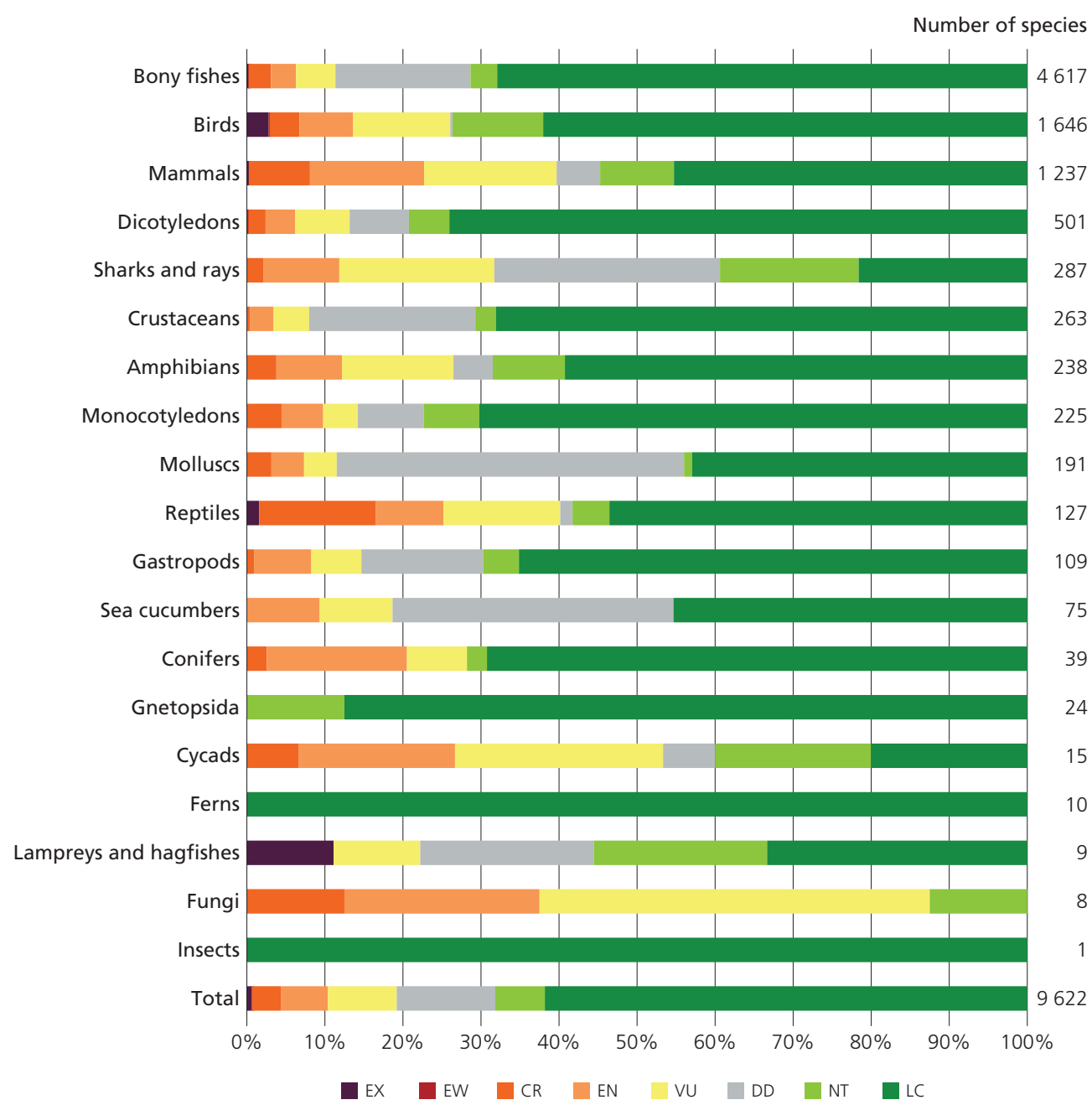

Note: EX (Extinct); EW (Extinct in the Wild); CR (Critically Endangered); EN (Endangered); VU (Vulnerable); DD (Data Deficient); NT (Near Threatened) and LC (Least Concern).

Source: IUCN, 2017a.

overgrazing and invasive species. At the same time, land-use changes, such as infrastructure development, are reported to have contributed to increasing the availability of wild foods by improving access to remote areas. Yemen mentions that, although it difficult to assess losses accurately, its wild food species are believed to be declining as a result of overharvesting, 
overgrazing, deforestation and woodland degradation. Oman reports that the supply of wild foods, such as figs and berries, from forest trees has declined over time. It indicates that this has probably occurred because of the loss of pollinator populations (driven in turn by extreme heat associated with climate change) and the effects of pests and diseases.

Invasive species are reported to be affecting wild food stocks in a number of countries. For example, the United States of America notes that data from the 1990s and 2000s show 44 native species of fish to be threatened or endangered by invasive alien species. It also refers to a further 27 native fish species negatively affected by introductions. ${ }^{68}$ Invasive mussels, such as zebra mussels, are reported to compete with native mussels, clams and snails, and to reduce oxygen availability for fish and other aquatic species.

Saint Lucia reports that it does not depend greatly on wild foods or hunting, but mentions that anecdotal information indicates that the supply of wild meat from animals such as agoutis, opossums and wild pigs declined as a result of the effects of hurricane Tomas. It further notes, however, that populations of wild pigs and redrumped agoutis (Dasyprocta antillensis) have recovered to such extent that they are disrupting production on farms. Efforts are being made to domesticate the agouti and control the pigs. Another example from Saint Lucia of how overabundance of a wild food species can be problematic is the case of the lionfish (Pterois volitans), an invasive alien species that grows and reproduces quickly and feeds predominantly on reef species such as snappers, parrotfish and grunts. Its only known natural predator is the grouper fish. The lionfish has become common in local waters and the country's Fisheries Department is now promoting its consumption.

Some countries, Switzerland for example, indicate that no declines in the availability of wild foods that have affected the livelihoods of those that depend on them have been recorded

\footnotetext{
68 The country report cites Pimentel, Zuniga and Morrison (2005).
}

in recent decades. Other countries, however, report that declines in the availability of wild foods have had significant impacts. The Gambia, for example, mentions that massive losses of wild foods have obliged communities to turn to alternatives (often industrially produced foods) to supplement their diets. Finland notes that the collapse of freshwater populations of native salmonids has meant that food from these sources has been replaced by imported farmed salmon. Similarly, wild berries harvested from farmlands and forests have been replaced by commercially produced cultivars and imports. In Cameroon, the impacts of the loss of wild foods are reported to be numerous: (i) local communities lose income from the sale of wild food products, as well as valuable nutritional benefits; (ii) migration increases among these populations as they can no longer make a livelihood from the wild food products; (iii) population movements may lead to problems with land acquisition and co-existence with local communities, and may cause intertribal conflicts; (iv) loss of income sources may lead to poverty, misery and crime; (v) people may have difficulty adapting their diets and lifestyles to the loss of traditional products.

Many countries express the need for an inventory of their wild food species and for the development of plans and strategies that ensure these species are conserved and used sustainably. This will require technical skills and equipment, as well as financial resources, all of which are currently in short supply in this field. Bangladesh mentions that, while wild food species have been used by rural communities across the region for centuries, there are still no organized programmes or projects that highlight, for example, the value of crop wild relatives and edible wild plants to food security and nutrition, both in normal times and in times of food crisis. It reports that, with a large number of wild edible plant species disappearing as a result of the expansion of agricultural land, development projects and other factors, there is a need to develop breeding programmes and activities that will help to maintain and sustainably use these species. 


\subsection{Ecosystems of importance to food and agriculture}

- Ecosystems provide countless services that are essential to food and agriculture, for example providing habitats for a wide range of species that contribute to production, maintaining flows of freshwater, removing pollutants from water supplies and providing protection against hazards.

- Most key ecosystems of importance to food and agriculture are in decline globally.

- Inland and coastal wetlands are declining rapidly. Recent years have seen massive losses of corals. The global area covered by seagrass beds is contracting. The world's mangrove area decreased by an estimated 20 percent between 1980 and 2005; although the rate of loss has slowed, these vital ecosystems remain widely threatened.

- Global forest area continues to decline, although the rate of loss decreased by 50 percent between the periods 1990-2000 and 2010-2015.

- Rangelands cover at least 34 percent of global land area. They are often among the ecosystems most affected by land-use changes and land degradation.

As discussed in the sections above, the supply of ecosystem services is often more affected by trends in the extent and quality of whole ecosystems than by trends in the status of individual species or groups of species. This section is intended to complement those above by providing overviews of the status and trends of the ecosystem categories most frequently reported in the country reports to be important to the supply of ecosystem services. The overviews are based on the wider literature. Information from the country reports on the significance of ecosystems and their status and trends to the supply of particular ecosystem services is presented in the sections above.

\subsubsection{Wetlands}

\section{Introduction}

As defined by the Convention on Wetlands (Ramsar Convention), wetlands are "areas of marsh, fen, peatland or water, whether natural or artificial, permanent or temporary, with water that is static or flowing, fresh, brackish or salt, including areas of marine water the depth of which at low tide does not exceed six metres" (Ramsar Convention, 2016). It is estimated that inland and coastal wetlands cover more than 12.1 million $\mathrm{km}^{2}$ globally, 54 percent of which is permanently inundated and 46 percent seasonally inundated (Ramsar Convention, 2018).

Wetlands are vital to food production. For example, wetland habitats such as mangroves, seagrass beds and coral reefs (these three ecosystem categories are discussed in more detail in Sections 4.5.2, 4.5.3 and 4.5.4, respectively) provide critical habitats for species targeted by small-scale fisheries that provide food and jobs for millions of people worldwide. Wetlands underpin the supply of rice, one of the world's major staple food crops and a particularly significant source of food in many low-income and lower-middleincome countries (GRISP, 2013). Wetlands also maintain flows of freshwater, remove pollutants from water supplies, store carbon and provide protection against flooding (Kumar et al., 2017; Russi et al., 2013; Ramsar Convention, 2015b; Mitsch and Gosselink, eds., 2015; WWF and IES, 2004). Coastal wetlands act as frontline defences against natural disasters, resist erosion by wind and waves, and provide physical barriers that slow storm surges and tidal waves (UNEP-WCMC, 2014).

Wetlands provide habitat for a wide range of species. For example, freshwater wetlands are home to more than 125000 species, almost 10 percent of all the world's described species (Strayer and Dudgeon, 2010). Wetlands underpin the annual migrations of vast numbers of birds, providing them with critical stopover habitats that offer food and protection (Ramsar Convention, 2015a).

\section{Status and trends}

Wetlands are in serious decline globally. Davidson (2014) estimates that between 64 percent and 71 percent of wetlands have been lost since the beginning of the twentieth century. Both inland and coastal natural wetlands are declining. Between 69 percent and 75 percent of the 
former and between 62 percent and 63 percent of the latter are estimated to have been lost over this period (ibid.). The rate of loss of natural wetlands is estimated to have increased from between 0.68 percent and 0.69 percent a year between 1970 and 1980 to between 0.85 percent and 1.60 percent a year since 2000 (Ramsar Convention, 2018).

Land-use change for commercial development, drainage schemes, extraction of minerals and peat, overfishing, tourism, siltation, pesticide discharges from intensive agriculture, toxic pollutants from industry, and the construction of dams and dykes (often in an attempt to improve flood protection) are major global threats to wetlands (Adams, 2012; Ramsar Convention, 2015a; UNCCD, 2017). Climate change threatens wetlands via changes in water levels, increases in temperature and the effects of abnormal weather patterns (Adams, 2012; IPCC, 2014). In many places, the amount of water being taken from aquifers far exceeds replenishment rates (Ramsar Convention, 2015a). Water demand is now greater than supply in many parts of the world and this is expected to be the case in many more areas in the near future (Burek et al., 2016; Mekonnen and Hoekstra, 2016). Hundreds of thousands of hectares of wetlands have been drained for agriculture. Globally, agriculture accounts for 70 percent of the total water withdrawal on Earth (FAO, 2016j). Along with other industries such as paper making, agriculture is often very wasteful and inefficient in its use of water (WWF International and Institute for Environmental Studies, 2004).

Although almost 2.5 million $\mathrm{km}^{2}$ of wetlands (as of 2018) are protected as Ramsar Sites (Davidson and Finlayson, 2018), additional wetland areas are protected under other mechanisms, and various wetland restoration activities are under way in Asia, Europe and North America (Ramsar Convention, 2015c; Mitsch and Gosselink, 2015), coverage is still inadequate and many wetlands remain threatened (Leadley et al., 2014; Ramsar Convention, 2018). Loss and degradation of wetlands are often caused or exacerbated by a lack of strong land-protection frameworks, inadequate land-planning policies and insufficient enforcement of existing policies (Mediterranean Wetlands Observatory, 2012).

\subsubsection{Mangroves}

Mangroves are a group of woody plants found mainly in intertidal environments in tropical and subtropical areas (Spalding, Kainuma and Collins, 2010). They have developed a number of physiological and morphological characteristics that enable them to survive in these environments, including aerial roots, propagules adapted for tidal dispersal, rapid rates of canopy production, highly efficient nutrient-retention mechanisms, and the ability to cope with salinity and maintain an appropriate water and carbon balance (Hogarth, 2015; UNEP-WCMC, 2014). The term mangrove is also applied to the ecosystems in which these plants grow. Mangrove habitats are highly productive and biodiverse areas that provide shelter and feeding grounds for a large number of invertebrate, fish and bird species, many of which are in danger of extinction (FAO, 2003b; UNEP-WCMC, 2014). Mangroves are found in 123 of the world's countries (Spalding, Kainuma and Collins, 2010). Their global distribution is shown in Figure 4.17.

Mangroves make enormous contributions to food security and livelihoods. The litter that falls from the mangrove plants, estimated to amount to 10 tonnes/ha/year, decomposes in the water into small particles of organic matter (Ezcurra, Aburto and Rosenzweig, 2009). Along with the sediments trapped by the root system and the fauna and epiphytic flora that flourish in this part of the ecosystem, these particles are consumed by marine invertebrates such as lobsters, crabs, clams and oysters and by fish such as tarpon, snook, catfish and snapper and many other species valued in industrial and artisanal fisheries (Badola and Hussain, 2005; Daru et al., 2013; Ezcurra, Aburto and Rosenzweig, 2009; Nagelkerken et al., 2008). Many of these species find shelter in mangrove systems as juveniles before migrating to seagrass beds in deeper water and finally to rocky and coral reefs (Figure 4.18). Mangrove-supported aquatic food production (fishes, shrimps, crabs and 
FIGURE 4.17

Global distribution of mangroves

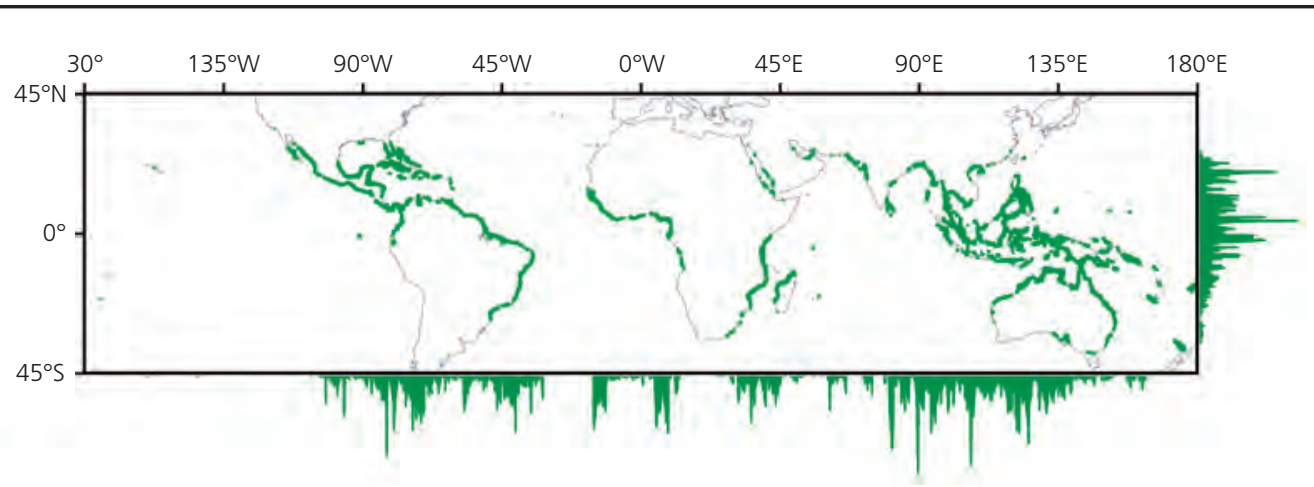

Note: Global Mangrove Watch mangrove baseline for 2010 and distribution of mangroves by longitude and latitude. Source: Bunting et al., 2018.

FIGURE 4.18

Interconnectivity between coastal ecosystems

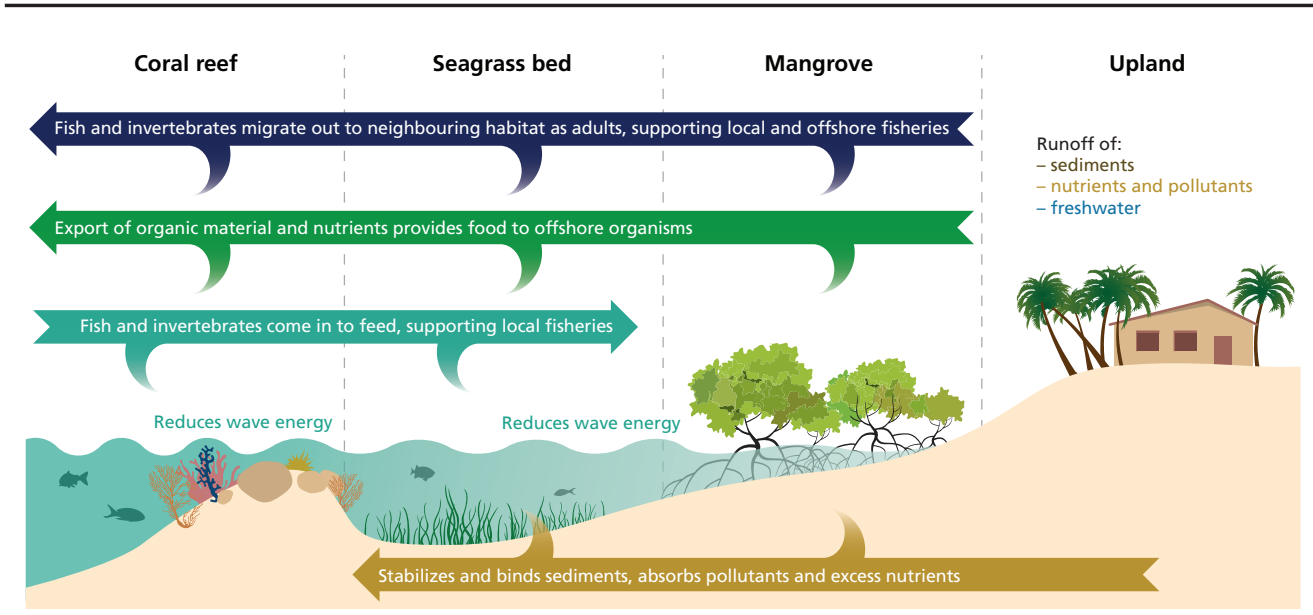

Source: UNEP-WCMC, 2014

molluscs) sustains the nutrition and livelihoods of millions of poor people, contributing immense amounts of protein to diets (UNEP-WCMC, 2014). For many people, hand collecting of aquatic products, hunting and wood harvesting in mangroves are the only available sources of livelihood support. UNEP-WCMC (2006) estimated that the annual value of commercial fish harvests from mangroves ranged from USD 62/ha in the United States of America to USD 600/ha in Indonesia.

Mangrove forests, together with seagrass meadows (see below) and salt-marshes, are among the most effective ecosystems on Earth at carbon capture and storage, and for this reason are 
sometimes referred to as "blue carbon ecosystems" (Alongi et al., 2016; McLeod et al., 2011; Pendleton et al., 2012). They not only store large amounts of carbon in their living biomass, but also sequester it long term in the soil (Spalding, Brumbaugh and Landis, 2016). It has been estimated that mangroves store up to four times more carbon than other major types of forest (Donato et al., 2011). Preventing mangrove loss and degradation is thus an important component of efforts to mitigate climate change (Murdiyarso et al., 2015; UNEPWCMC, 2014). Mangroves also provide waterpurification and erosion-prevention services, protect coastal areas against storms, and offer opportunities for educational and recreational activities, including ecotourism (Barbier et al., 2011; UNEP-WCMC, 2014). They provide a potential refuge for corals threatened by rising temperatures and ocean acidification. A study carried out in the United States Virgin Islands (Yates et al., 2014) found more than 30 species of coral thriving among mangroves in an area where nearby reefs had been seriously affected by bleaching. Costanza et al. (2014) estimated that the economic value of ecosystem services provided by mangroves and tidal marshes amounted to USD 194 000/ha/year.

\section{State of knowledge}

Over recent years there have been a number of efforts to assess the global status and trends of mangrove ecosystems. The World Mangrove Atlas, the first global assessment of the state of the world's mangroves, was published in 1997 and updated version published in 2010 (Spalding, Blasco and Field, eds., 1997; Spalding, Kainuma and Collins, 2010). The increasing availability of openly accessible high spatio-temporal resolution data has allowed the emergence of a systematic approach to mangrove mapping that reduces uncertainties and promotes consistency in the reporting of status and trends (see examples and references below).

\section{Status and trends}

Global mangrove area declined markedly during the late twentieth and early twenty-first centuries, with an estimated 20 percent loss during the period between 1980 and 2005 (FAO, 2007e). Losses continue in many regions, although at a slower rate globally (Hamilton and Casey, 2016; Strong and Minnemeyer, 2015). Numerous attempts have been made over recent decades to estimate the total global area covered by mangroves. Results have varied due to the multiplicity of different datasets used and methodologies applied. Using the highest spatio-temporal resolution data available, Hamilton and Casey (2016) found a global mangrove area of $81849 \mathrm{~km}^{2}$ in 2012 and projected a figure of $81485 \mathrm{~km}^{2}$ for 2014. The same authors report a loss of $1646 \mathrm{~km}^{2}$ globally over the period 2000 to 2012, which amounts to 1.97 percent of the estimated global total at the start of this period. The region with the greatest rate of loss is Southeast Asia, where an estimated 3.58 percent of mangrove area was lost over the same period (ibid.).

Mangrove losses are driven by high levels of human pressure, including from coastal development, agriculture, fishing, aquaculture, timber extraction, water diversion and overexploitation (FAO, 2007e; Van Lavieren et al., 2012; UNEPWCMC, 2014). Valiela, Bowen and York (2001) estimated that aquaculture accounted for 52 percent of mangrove loss globally during the 1980s and 1990s, with shrimp farming alone accounting for 38 percent. However, faced with the social and environmental problems associated with intensive shrimp farming, and with growing interest in the carbon-sequestration and protective roles of mangroves and the other ecosystem services they supply, many countries are now receptive to adopting integrated mangrove-aquaculture systems (Ahmed, Thompson and Glaser, 2018). This provides real opportunities to reforest abandoned shrimp farms and other degraded mangrove areas so that they can again support productive coastal fisheries and aquaculture. For example, under the so-called Tambak Tumpangsari system in Indonesia, mangroves supply nutrients to plankton in aquaculture ponds and also reduce the vulnerability of the ponds to strong winds and tidal floods during at least part of the life cycle of the aquaculture venture (Van Lavieren et al., 
2012). Climate change is also a threat, as rising sea levels, erosion and increased frequency of storms all have serious impacts on mangrove ecosystems (Blankespoor, Dasgupta and Lange, 2017; Mumby et al., 2004).

The most recent available review (Polidoro et al., 2010) indicates that 11 out of the 70 mangrove species assessed for The IUCN Red List are classed as Threatened - two of these are classed as Critically Endangered (Sonneratia griffithii, found in parts of India and Southeast Asia, and Bruguiera hainesii, found in fragmented locations in Indonesia, Malaysia, Myanmar, Papua New Guinea, Singapore and Thailand), three as Endangered and six as Vulnerable. A further seven species are considered Near Threatened or Data Deficient (ibid.).

\subsubsection{Seagrasses}

Seagrasses are submerged flowering plants found in shallow nearshore marine and estuarine waters in almost every part of the world except Antarctica (Green and Short, 2003). Seagrass beds support high rates of production in valuable commercial and artisanal fisheries, including those targeting finfish such as snappers, emperors, rabbitfish, surgeonfish and flounder, molluscs such as conch, oysters, mussels, scallops and clams, crustacea such as shrimp, lobster and crab, and echinoderms such as starfish, sea urchins and sea cucumbers (Barbier et al., 2011; Green and Short, 2003; Nordlund et al., 2018; Saenger, Gartside and Funge-Smith, forthcoming). A global-scale review of the contribution of seagrass ecosystems to commercial, artisanal and recreational fisheries (Nordlund et al., 2018) concludes that most fishing in these ecosystems is small scale and thus that they are of major importance to livelihoods in many coastal communities in developing countries. According to Jackson et al. (2015), seagrass-associated species contribute 30 to 40 percent to the value of commercial fishery landings in the Mediterranean.

Declines in fish production following the loss of seagrass beds have been recorded, for example in Australia (Coles et al., 2007). However, there have been cases in which loss of seagrass did not lead to a loss of fishery yield (Saenger, Gartside and Funge-Smith, forthcoming). For example, largescale losses of common eelgrass (Zostera marina) meadows in Europe and North America in the 1930s, attributed to a slime mould parasite, did not cause a decline in fish catches as the loss of the eelgrass led to the exposure of rocky substrate that was colonized by macro-algae that served as an alternative habitat (Heck, Hays and Orth, 2003).

Seagrass beds contribute to nutrient cycling and water purification, help to protect coastal areas by stabilizing sediments, sequestrate carbon and serve as key habitats for marine biodiversity (Barbier et al., 2011; Coles et al., 2007; Green and Short, 2003; Saenger, Gartside and FungeSmith, forthcoming). According to Fourqurean et al. (2012), the global loss of seagrasses since the beginning of the nineteenth century has resulted in a decrease in carbon sequestration of between 6 million and 24 million tonnes of carbon per year, with current rates of seagrass loss annually exposing soils containing an estimated 63 million to 297 million tonnes of carbon. Costanza et al. (2014) estimated that as of 2011 a hectare of seagrass or algae bed delivered ecosystem services worth USD 28916 per year on average, which amounted to an estimated global total of USD 6.8 trillion per year.

\section{State of knowledge}

A number of initiatives are helping to build knowledge of the status and trends of the world's seagrass ecosystems. For example, UN Environment World Conservation Monitoring Centre's (UNEPWCMC's) Global Distribution of Seagrasses dataset was used to compile the World atlas of seagrasses (Green and Short, 2003), the first official global assessment of the distribution, status and trends of seagrasses and the threats affecting them. The latest dataset ${ }^{69}$ can be viewed in mapped form via UNEP-WCMC's Ocean Data Viewer. ${ }^{70}$ National and subnational assessments are also published (e.g. Coles et al., 2007 and McKenzie et al., 2017).

\footnotetext{
${ }^{69}$ At the time of writing, version 6, dated November 2018

70 http://data.unep-wcmc.org
} 


\section{PART B}

FIGURE 4.19

\section{Global distribution of seagrasses}

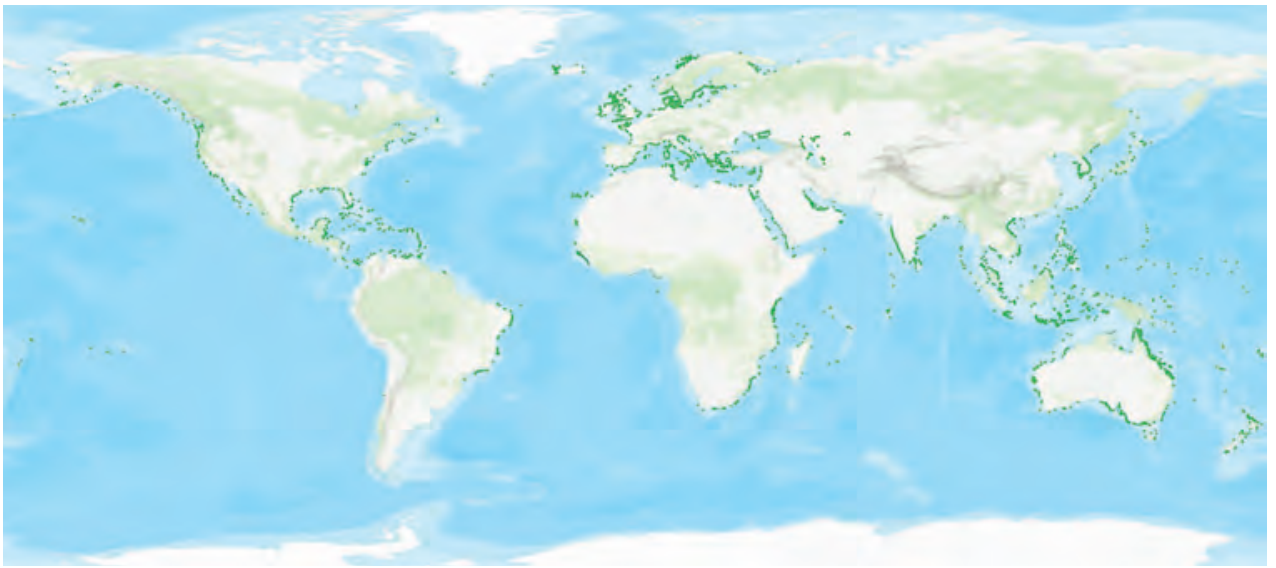

Source: UNEP-WCMC and Short, 2017

The international monitoring programmes Seagrass Watch ${ }^{71}$ and Seagrass Net ${ }^{72}$ keep track of the status of seagrass resources at sites around the world (335 sites in 19 countries and 122 sites in 33 countries, respectively). ${ }^{73}$ Both programmes involve contributions from coastal communities, academia, NGOs, research institutions and national and local government. Improving knowledge of the status and trends of seagrass ecosystems will require better standardization of sampling and monitoring methods (Duarte et al., 2008; Orth et al., 2006; Short et al., 2011). There is also a great need for more detailed research on specific seagrass habitats, their links to other ecosystems such as mangroves and their influence on fisheries (Saenger, Gartside and Funge-Smith, forthcoming).

\section{Status and trends}

Seagrass beds cover an estimated 344958 km² $^{2}$ across 128 countries and territories globally (Figure 4.19) (UNEP-WCMC and Short, 2017;

\footnotetext{
1 www.seagrasswatch.org

72 www.seagrassnet.org

73 Figures from the respective programme websites as of November 2018
}

Weatherdon et al., 2017). There is a general consensus that the global extent of seagrass beds is contracting and that a range of human activities and natural factors are driving this process (Coles et al., 2007; Green and Short, 2003; Orth et al., 2006; Waycott et al., 2009). However, changes in the extent of seagrass habitat are well documented only in areas such as Europe, the United States of America and Australia and a few specific locations in Africa, Asia and South America (Duarte et al., 2008; Duarte, 2017). It has been estimated that the area covered by seagrass has declined by 29 percent in the last 100 years (Waycott et al., 2009), with the lost seagrass beds being replaced by naked mud and sandy soils or in some cases by algae beds (Fourqurean et al., 2012; Heck, Hays and Orth, 2003). Waycott et al. (2009) report that there have been some increases in seagrass area at local scales in recent decades, but that these seem to be small relative to global losses.

Where individual seagrass species are concerned, out of 70 assessed by IUCN, 7 are classed as Vulnerable and 3 as Endangered. Of the remainder, 48 are classed as being of Least Concern, 5 as Near Threatened and 7 as Data Deficient (IUCN, 
2017a). Twenty-two of the assessed populations show a decreasing trend, 3 an increasing trend and 31 a stable trend. Trends for the remaining 14 are unknown.

Climate change is considered to be the main threat to seagrass ecosystems globally: changes in temperature and rainfall are reducing seagrasses' access to light and hence affecting their growth and their role as primary producers (Coles et al., 2007). Extreme climate events such as hurricanes can destroy seagrass beds. Threats such as eutrophication, turbidity and sediment discharge are often being exacerbated by poor land-use and water-use practices, including watershed deforestation, clearing of coastal forests, inappropriate management of fertilizers, dredging and destructive fishing practices (Ocean Health Index, 2018; Waycott et al., 2009). Aquaculture can give rise to threats such as invasive-species escapes, eutrophication, shading and excessive influxes of organic matter (Duarte et al., 2008; Green and Short, 2003; Waycott et al., 2009). Loss of predators as a result of overfishing can cause a cascade through the food web that leads to the loss of herbivores that cleanse seagrasses of fouling algae (Waycott et al., 2009). Disease outbreaks such as the "wasting disease" and stand diebacks that affected seagrasses in North America and Europe in the last century are another threat (Duarte et al., 2008; Green and Short, 2003; Waycott et al., 2009).

\subsubsection{Coral reefs}

Coral reefs are highly diverse aquatic ecosystems that host vast numbers of species of algae, invertebrates, fish and reptiles (Karr et al., 2015). Corals themselves are colonial animals consisting of merged fleshy polyps that live in symbiotic association with algae known as zooxanthellae: the polyp protects the algae and provides them with some essential nutrients and the algae provide food and oxygen to the polyp (Buddemeier, Kleypas and Aranson, 2004; Kemp et al., 2012). The structure of a coral reef consists of calcium carbonate secreted by certain coral species (referred to as reef-building or hermatypic corals) to provide themselves with a protective exoskeleton (Dubinsky and Stambler, eds., 2011). Reefs come in three main types: atoll reefs (ring-shaped reefs surrounding lagoons); barrier reefs (separated from the mainland by a channel of deep water); and fringing reefs (separated from the shoreline only by shallow waters) (Spalding, Ravilious and Green, 2001).

Corals are found in all the oceans of the world, from the tropics to polar regions, but form reefs only in waters with temperatures above $18^{\circ} \mathrm{C}$, which generally limits the distribution of reefs to latitudes below $30^{\circ}$. It has been estimated that coral reefs cover approximately $250000 \mathrm{~km}^{2}$ globally (Burke et al., 2011), less than 0.1 percent of the Earth's surface or 0.2 percent of the ocean surface, and that reefs protect around $150000 \mathrm{~km}$ of shoreline in 100 countries and territories (ibid.).

The value of the ecosystem services provided by coral reefs is enormous. They provide vital habitat for 25 percent of the world's known marine species (Cesar, Burke and Pet-Soede, 2003; Karr et al., 2015). Many marine fish and invertebrates targeted by commercial and artisanal fisheries (including groupers, snappers, sharks, sea cucumbers and lobsters) use reefs for feeding, reproduction and breeding (Burke et al., 2011; Jackson et al., 2014; Del Monaco et al., 2010). Coral reefs also protect shorelines, coastal communities and coastal ecosystems such as mangroves and seagrass beds that serve as nurseries for a wide range of species (Buddemeier, Kleypas and Aranson, 2004; Ferrario et al., 2014; Saenger, Gartside and Funge-Smith, forthcoming). Reef fisheries are fundamental to the nutrition of millions of people in coastal areas in developing countries (Cesar, Burke and Pet-Soede, 2003). It has been estimated that one-eighth of the world's population live within $100 \mathrm{~km}$ of a coral reef (Burke et al., 2011). Costanza et al. (2014) estimated that, if all categories of ecosystem services are taken into account, the total value of coral reefs' contributions to humanity amounts to approximately USD 350 000/ha/year.

\section{State of knowledge}

A number of global initiatives contribute to monitoring and reporting on the state of the world's 
coral reefs. For example, the International Coral Reef Initiative, ${ }^{74}$ an informal partnership of governments, non-governmental organizations and international organizations, published five Status of the Coral Reefs of the World reports between 1998 and 2008, drawing on data and information provided by a large number of experts around the world (e.g. Wilkinson, 2008). It has also published several reports on the status of coral reefs at regional or subregional levels (e.g. Chin et al., 2011; Jackson et al., 2014) and on the impacts of various threats and drivers of change (e.g. Salvat and Allemand, 2009).

The Reefbase information system ${ }^{75}$ features a global database of country-level information on coral-reef resources, their status, threats affecting them, and the status of management activities such as monitoring programmes and the establishment of protected areas. Its Online Geographic Information System (ReefGIS) allows coral reef-related information (e.g. locations of protected areas, areas covered by monitoring programmes, bleaching events, disease outbreaks and threats such as coastal developments and marine pollution) to be displayed on interactive maps. The Millennium Coral Reef Mapping Project Seascape, a global coral-reef database compiled from a number of sources by UNEP-WCMC and the WorldFish Centre, in collaboration with the World Resources Institute and The Nature Conservancy, records the global distribution of tropical and subtropical coral reefs (UNEP-WCMC, 2010). Global Reef Record ${ }^{76}$ makes available highdefinition imagery shot along transects at numerous coral-reef sites around the world by the $\mathrm{XL}$ Catlin Seaview Survey. ${ }^{77}$ The Ocean Health Index ${ }^{78}$ has been assessing oceans globally every year since 2012 by synthesizing data on a range of components, including coral reef area and condition ,to provide index scores for 220 coastal nations and territories (Halpern et al., 2012, 2017). The

\footnotetext{
4 https://www.icriforum.org

www.reefbase.org

6 www.globalreefrecord.org

77531 transects from 305 reefs available as of December 2018

78 http://www.oceanhealthindex.org
}

Global Ocean Acidification Observing Network ${ }^{79}$ monitors, and makes data available on, variables related to ocean acidification and the responses of ecosystems to this process (GOA-ON, 2016; Newton et al., 2015b). Data on various categories of biodiversity are targeted, including data specifically on the state of coral-reef biodiversity, for example on changes in the biomass of corals, coralline algae and other photosynthesizers in coral reefs, changes in the population structure of corals and other components of reef biodiversity, and changes in reef ecosystem processes and habitat quality (ibid.).

Significant national initiatives include the Coral Reef Information System (CoRIS), ${ }^{80}$ the information portal of the United States of America's National Oceanic and Atmospheric Administration's (NOAA's) Coral Reef Conservation Program, which provides access to the organization's coral reef information and data products. NOAA's coral reef-related activities include mapping, monitoring and assessment, along with natural and socio-economic research and modelling (NOAA, 2018). The Australian Research Council's Centre of Excellence for Integrated Coral Reef Studies ${ }^{81}$ has, since 2005, been undertaking integrated research supporting the sustainable use and management of coral reefs in Australia (ARC, 2018).

\section{Status and trends}

Recent decades have seen massive losses of corals globally. Declines are attributed to anthropogenic pressures, particularly the effects of climate change, coastal developments and misuse of fishing gear (trawlers) (Buddemeier, Kleypas and Aranson, 2004; Jackson et al., 2014). Rising temperatures affect the symbiosis between corals and zooxanthellae (see above): a prolonged increase of at least $1{ }^{\circ} \mathrm{C}$ affects the algae's ability to photosynthesize, which causes bleaching and subsequent death of the corals (Heron, Eakin and

\footnotetext{
79 http://goa-on.org/home.php

80 https://www.coris.noaa.gov/

81 www.coralcoe.org.au
} 
Douver, 2017). Temperature variations are also associated with higher frequency of hurricanes (Bender et al., 2010; Holland, 2012), which can negatively affect corals by increasing the amount of sediment in the water (Cesar, Burke and PetSoede, 2003). Overfishing, illegal fishing and destructive fishing practices such as the use of explosives and cyanide pose a threat in some parts of the world (Cesar, Burke and Pet-Soede, 2003). Declines or shifts in fish populations can affect the ecological balance of reef communities, compromising their dynamics and processes (Burke et al., 2011). For example, a decrease in the number of herbivores can allow an increase in the growth of macro-algae, which have a negative effect on corals (ibid.). A dramatic example of this effect occurred in the 1980s, when a collapse (due to overfishing) in the numbers of parrotfish, one of the most important grazers of Caribbean reefs, coincided with the disappearance of another grazing species, the long-spined sea urchin Diadema antillarum (Buddemeier, Kleypas and Aranson, 2004; Jackson et al., 2014; Mumby et al., 2006). Other threats include coastal pollution, invasive species, coral harvesting and mining (Buddemeier, Kleypas and Aranson, 2004; Jackson et al., 2014)

The precise extent of historical losses is difficult to estimate as records are incomplete. Wilkinson (2008) concluded that the world had lost 19 percent of its original coral-reef area and that a further 35 percent was under threat of loss in the coming decades. In some regions, even greater losses appear to have occurred. For example, based on data from 88 locations in the Caribbean, covering the periods 1970 to 1983, 1984 to 1998, and 1999 to 2011, Jackson et al. (2014) concluded that coral cover declined from 34.8 percent in the first of these periods to 19.1 percent in the second and 16.3 percent in the third, i.e. a decline of more than 50 percent overall. Burke et al. (2011) rated 60 percent of the world's coral reefs as being under immediate and direct threat from local effects (overfishing, pollution, etc.) and rated 75 percent as threatened if thermal stress is also taken into account. These
FIGURE 4.20

Global status of reef-building corals

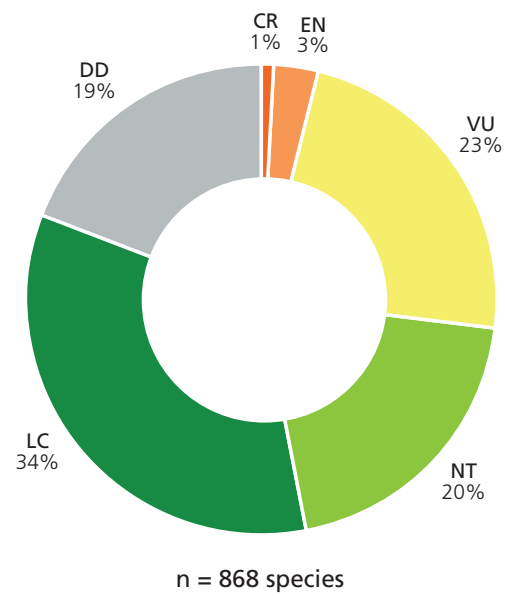

Note: CR (Critically Endangered); EN (Endangered); VU (Vulnerable); DD (Data Deficient); NT (Near Threatened) and LC (Least Concern).

Source: The IUCN Red List version 2018-2.

authors also estimated that by 2050, 95 percent of reefs globally would be experiencing thermal stress sufficient to cause severe bleaching in most years (ibid.). Since these studies were published, the world's oceans haves experienced the longest and most severe coral-bleaching event on record (2014 to 2017) (Hughes et al., 2017, 2018). A 2017 assessment of coral-reef World Heritage Sites concluded that all 29 such sites would cease to exist as functioning coral reef ecosystems by the end of the twenty-first century under a "business as usual" carbon-emissions scenario (Heron, Eakin and Douver, 2017).

Where the risk status of reef-building coral species themselves is concerned, data from IUCN (IUCN, 2018) indicate that out of 868 species of corals assessed, 1 percent (6) are classed as Critically Endangered, 3 percent (26) as Endangered and 23 percent (202) as Vulnerable (a further 19 percent are classified as Data Deficient) (Figure 4.20). Human assisted-evolution efforts to restore coral reefs are discussed in Section 5.9.6. 


\subsubsection{Forests}

\section{Introduction}

The contributions of forests to the well-being of humankind are extraordinarily vast and far reaching (FAO, 2016g). Forests are the world's largest repository of terrestrial biodiversity. They also play a vital role in climate change mitigation and contribute to soil and water conservation in many fragile ecosystems. They make many significant contributions to food security, livelihoods and poverty alleviation. Millions of people depend on food from forests and from trees located outside forests to increase the nutritional quality and diversity of their diets. This is particularly important during seasonal food shortages, extreme climatic events and conflicts. Employment in the production of forest goods and services provides a source of income for many (FAO, 2014a). Around one-third of the world's population, or about 2.4 billion people, use wood as a source of energy for basic needs such as cooking, boiling water and heating (FAO, 2018b).

FAO has a long tradition of monitoring the world's forests. It periodically collects and analyses data on forest resources through several wellestablished processes, including the Global Forest Resources Assessment (FRA) (FAO, 2012c, 2017k). Many countries conduct national assessments of their forest areas and other forest variables, increasingly using remote sensing to complement ground-level forest inventories. The data generated by such assessments are reported periodically to the FRA. The FRA has contributed greatly to improving

Box 4.10

\section{FAO global definition of forest}

\section{FOREST}

Land spanning more than 0.5 ha with trees higher than $5 \mathrm{~m}$ and a canopy cover of more than 10 percent, or trees able to reach these thresholds in situ. It does not include land that is predominantly under agricultural or urban land use.

\section{Explanatory notes}

1. Forest is determined both by the presence of trees and the absence of other predominant land uses. The trees should be able to reach a minimum height of $5 \mathrm{~m}$ in situ.

2. Includes areas with young trees that have not yet reached but which are expected to reach a canopy cover of 10 percent and tree height of $5 \mathrm{~m}$. It also includes areas that are temporarily unstocked due to clear-cutting as part of a forest management practice or natural disasters, and which are expected to be regenerated within five years. Local conditions may, in exceptional cases, justify that a longer time frame is used.

3. Includes forest roads, firebreaks and other small open areas; forest in national parks, nature reserves and other protected areas such as those of specific environmental, scientific, historical, cultural or spiritual interest.
4. Includes windbreaks, shelterbelts and corridors of trees with an area of more than 0.5 ha and width of more than $20 \mathrm{~m}$.

5. Includes abandoned shifting cultivation land with a regeneration of trees that have, or are expected to reach, a canopy cover of 10 percent and tree height of $5 \mathrm{~m}$.

6. Includes areas with mangroves in tidal zones, regardless whether this area is classified as land area or not.

7. Includes rubber-wood, cork oak and Christmas tree plantations.

8. Includes areas with bamboo and palms provided that land use, height and canopy cover criteria are met.

9. Includes areas outside the legally designated forest land which meet the definition of "forest".

10. Excludes tree stands in agricultural production systems, such as fruit-tree plantations, oil-palm plantations, olive orchards and agroforestry systems when crops are grown under tree cover. Note: Some agroforestry systems such as the "Taungya" system where crops are grown only during the first years of the forest rotation should be classified as forest.

Source: FAO, 2018j. 
TABLE 4.10

Global forest area change (1990-2015)

\begin{tabular}{|c|c|c|c|c|}
\hline & & \multicolumn{3}{|c|}{ Annual net change } \\
\hline Year & Forest (thousand ha) & Period & Area (thousand ha) & Rate $^{\mathrm{a}} \mathbf{( \% )}$ \\
\hline 1990 & 4128269 & & & -0.18 \\
\hline 2000 & 4055602 & $1990-2000$ & -7267 & -0.11 \\
\hline 2005 & 4032743 & $2000-2005$ & -4572 & -0.08 \\
\hline
\end{tabular}

Note: ${ }^{\text {a }}$ Calculated as the compound annual growth rate.

Source: FAO, $2016 \mathrm{~g}$

concepts, definitions and methods related to the assessment of forest resources (FAO, 2012c).

Results from the FRA show a steady decrease in the rate of forest loss globally. Other sources have, however, reported that the rate of forest loss is increasing. The discrepancy in the findings is explained mainly by the fact that FAO defines forest as a combination of tree cover and land use (see Box 4.10), while some define forest only in terms of tree cover. Datasets based solely on remote-sensing sources such as Landsat imagery cannot differentiate between tree cover in agricultural production systems (oil-palm plantations, coffee plantations, etc.) and tree cover on land that is not predominantly under agricultural or urban land use. In addition, areas with tree cover that has been temporarily removed as part of a forest-management scheme or temporarily lost through natural disturbances are still considered forest according to the FAO definition, while a remote-sensing analysis of tree cover will interpret these areas as forest loss. Moreover, newly established forest cannot easily be detected by remote sensing (FAO, 2016g).

\section{Status and trends}

Forests and forest management have changed substantially over the past 25 years. Overall, this period has seen a number of positive developments. For example, although the extent of the world's forests continues to decline as human populations continue to grow and demand for food and land increases, the rate of net forest loss fell by over 50 percent between the periods 1990 to 2000 and 2010 to 2015 (Table 4.10) (FAO, 2016g). ${ }^{82}$ Globally, natural forest area is decreasing and planted forest area is increasing. However, the bulk of the world's forest is natural forest, with reported natural forest area accounting for 93 percent of the total global forest area, or 3.7 billion ha, in 2015. The annual net loss of natural forest area declined from 10.6 million ha per year during the period 1990 to 2000 to 6.5 million ha per year during the period 2010 to 2015.

Forest designated primarily for biodiversity conservation accounts for 13 percent of the world's forest area, or 524 million ha, with the largest areas reported in the United States of America and Brazil. This area has increased by 150 million ha since 1990, although the rate of increase slowed during the 2010 to 2015 period. Over this latter period, Africa, Asia and South America each reported an increase of about 1 million ha per year of area designated for the conservation of biodiversity, while Europe, North and Central America and Oceania together reported an increase of about 600000 ha.

Seventeen percent of the world's forest area is located within legally established protected areas, accounting for a total of 651 million ha. South

\footnotetext{
82 The description of status and trends presented here draws on FAO (2016g). Except where otherwise indicated, all the statistics presented are taken from this source and refer to the state of forest resources as of 2015 .
} 


\section{PART B}

FIGURE 4.21

Annual change in forest area (1990-2015)

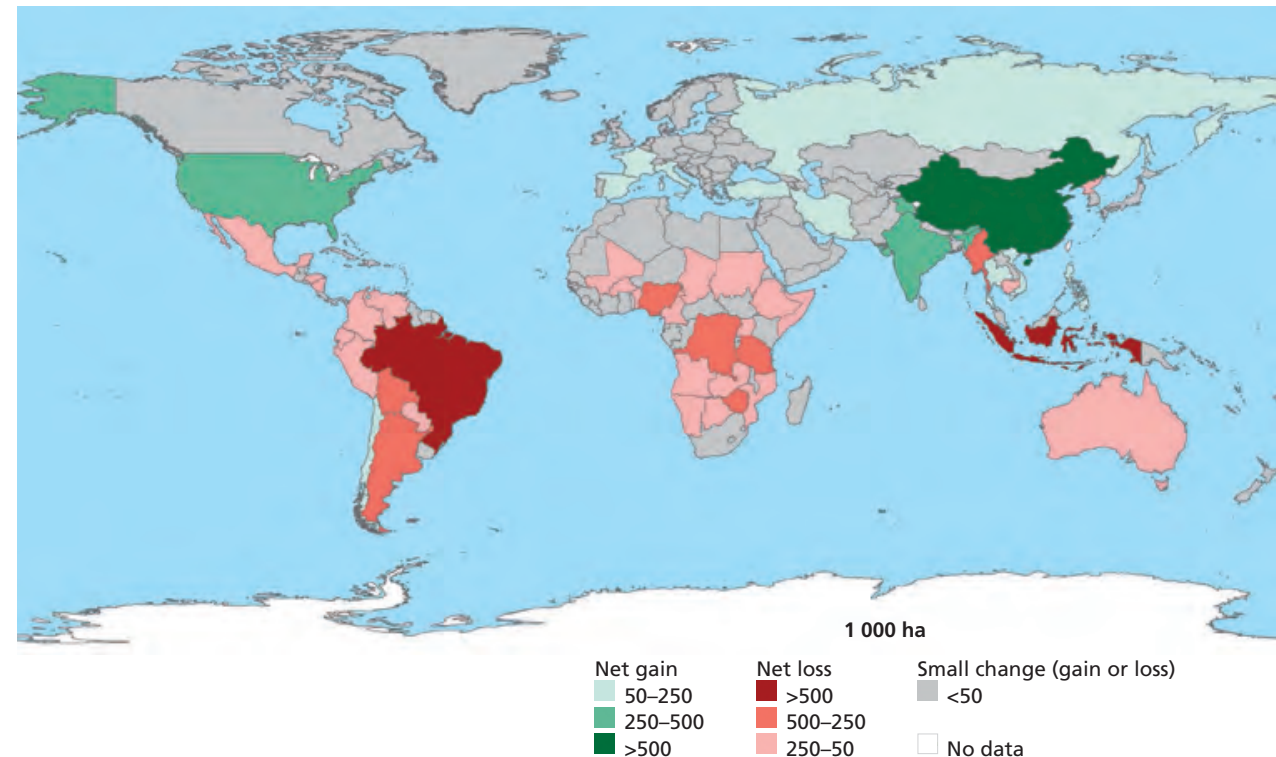

Source: FAO, 2015d

America has the highest proportion (34 percent) of protected forest, largely because of the contribution of Brazil, where 42 percent of forest area is located within the protected areas network. The area of forest within protected areas increased by 200 million ha between 1990 and 2015, but the rate of increase slowed during the 2010 to 2015 period. The increase in the area of forest within protected areas was particularly evident in the tropics, where an additional 143 million ha of forest were put under protection between 1990 and 2015.

The forest-area changes summarized in Table 4.9 amounted to a decline in forest area from 31.6 percent of global land area in 1990 to 30.6 percent in 2015. Such figures, however, do not fully reflect the complicated nature of deforestation or forest conversion to other land use. Forest gains and losses occur continuously, and while deforestation can be easily detected with remote sensing, forest gains are difficult to monitor even with high-resolution satellite imagery and require a long time period to assess reliably. Changes in forest area, by country, for the period 1990 to 2015 are summarized in Figure 4.21.

There are also differences between the impacts of large-scale commercial agriculture and those of subsistence agriculture as deforestation drivers. An analysis of national data for 46 tropical and subtropical countries representing about 78 percent of the forest areas in these domains (Hosonuma et al., 2012) revealed that large-scale commercial agriculture is the most prevalent driver of deforestation, accounting for 40 percent. Local subsistence agriculture was found to account for 33 percent of deforestation, urban expansion for 10 percent, infrastructure for 10 percent and mining for 7 percent. Moreover, although it may bring other economic benefits and enhance global food security, the largescale, export-focused commercial production 
of agricultural commodities may contribute little to food security at the local or national level. Hosonuma et al. (2012) note that, in some cases, land-use change was preceded by forest degradation, for example caused by unsustainable or illegal wood removal. ${ }^{83}$

Natural forest expansion may occur when agricultural land is abandoned, for example when a rural population declines, when land becomes so degraded that it becomes unproductive as agricultural land or when more productive agricultural land becomes available elsewhere. Forest policies may be put in place to encourage tree planting with the aim of meeting anticipated future needs for forest goods and environmental services. The impact on forest area of "reverse drivers" such as afforestation policies is particularly evident in high-income countries such as the United States of America and those in western Europe, where net deforestation bottomed out many decades ago. However, there is now evidence of a similar trend in some developing countries.

In the period 1990 to 2015, 93 countries recorded net losses in forest area (totalling 242 million ha), while 88 countries recorded net gains (totalling almost 113 million ha) (FAO, 2016e). In Asia, 24 countries experienced a net increase in forest area over this period, amounting to 73.1 million ha, mainly a result of large-scale afforestation programmes in China. In Europe, 35 countries recorded a net increase in forest area, totalling $\mathbf{2 1 . 5}$ million ha. Thirteen countries in Africa, eight in Oceania, six in North and Central America, and two in South America also recorded net increases in forest area over this period.

Although there have been significant advances in recent years in the capacity of countries to monitor their forests, and an unprecedented increase in the availability of satellite imagery and monitoring tools, there are still important gaps and needs in forest monitoring. For example, there is still no agreed operational global definition of forest degradation, and consequently no

83 This and the following two paragraphs are adapted from FAO (2016e). established methods for measuring and monitoring this indicator. Status and trends in forest biodiversity are still difficult and costly to monitor, as this requires substantial fieldwork, and countries lack the necessary financial resources. Similarly, data on the socio-economic aspects of forests, for example on their contribution to livelihoods and food security, are scarce.

\subsubsection{Rangelands}

Rangeland has been defined in many ways, ${ }^{84}$ usually based on land cover or land use (Lund, 2007). According to the Society for Range Management, rangelands are "lands on which the indigenous vegetation (climax or natural potential) is predominantly grasses, grass-like plants, forbs, or shrubs and is managed as a natural ecosystem. If plants are introduced, they are managed similarly. Rangelands include natural grasslands, savannas, shrublands, many deserts, tundras, alpine communities, marshes and meadows" (Society for Range Management, 1998). Rangelands are found from the Asian steppes to the Andean regions of South America and from the mountains of western Europe to the African savannahs. Land-cover types or biomes that can be classified as rangelands make up between 6.4 billion ha (if deserts and other barren lands are included) and 4.5 billion ha (without barren lands) globally, ${ }^{85}$ amounting to 49 percent and 34 percent of global land area, respectively. Many of the world's grazing systems, including those in African savannahs, North American prairies and Asian steppes, were established in natural grasslands or open woodlands long grazed by large herds of wild ungulates (hoofed animals). Most European grasslands were developed from forests many centuries ago.

Livestock production is the major land use in the world's grasslands. Grasses and leaves constitute the most important livestock feed resources

\footnotetext{
84 For a compilation of definitions of rangelands see Lund (2014)

85 Calculated from FAOSTAT land cover data for 2015, including the following categories: grassland; shrub-covered areas; shrubs and/or herbaceous vegetation, aquatic or regularly flooded; and sparsely natural vegetated areas
} 


\section{PART B}

FIGURE 4.22

\section{Global distribution of ruminant livestock production systems}

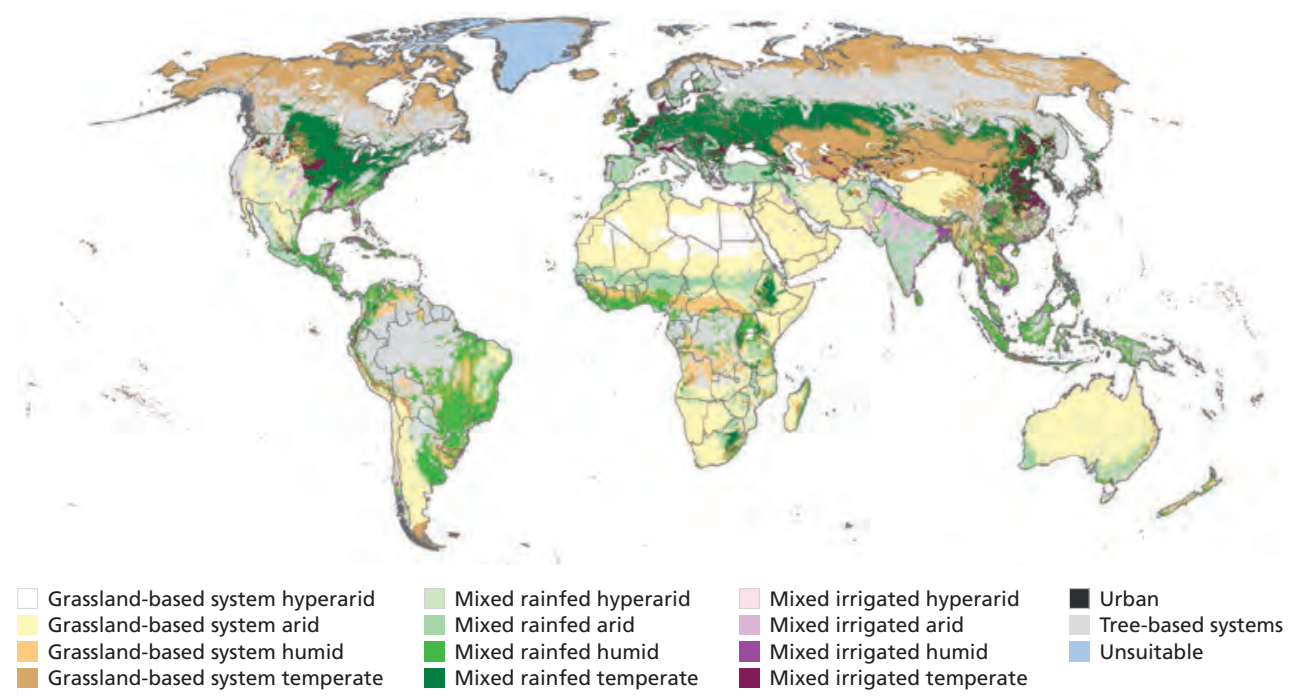

Note: Global Livestock Production Systems based on a modified version of the GLC-Share (FAO, July 2014). Source: Robinson et al., 2018.

globally, making up between 46 percent and 50 percent of the livestock diet (Herrero et al., 2013; Mottet et al.; 2017). Figure 4.22 shows the global distribution of livestock production systems. However, not all rangelands are used for grazing. Alkemade et al. (2013) estimate that the proportion lies between 10 percent and 60 percent, depending on the biome. Even the FAO landuse classification "permanent grasslands", which accounts for about 3.5 billion ha globally (2016 figures), includes about 1.5 billion ha of very marginal rangelands and shrubby ecosystems that host no livestock (Mottet et al., 2017).

Today's rangeland production systems include both traditional pastoralist systems and fenced-in ranching systems. Rangelands provide a livelihood for more than 600 million people (FAO, 2011a). Pastoralism is the only feasible agricultural strategy in many dry areas (Davies et al., 2010). Pastoralists in some of these areas operate mobile systems in which herds are moved, sometimes over long distances, to track changes in the availability of vegetation and other resources (ibid.). Precise figures for the number of nomadic and transhumant pastoralists are hard to come by, partly because of the difficulties involved in defining these categories and tracking them in national censuses. A figure of 100 to 200 million people globally is often cited (e.g. IUCN, 2011). Grassland-based systems (including grazed tree-covered areas), which harbour 37 percent of all the world's cattle, contributed 22 percent of global beef production and 16 percent of global milk production in 2005, respectively (MacLeod et al., 2013). In Africa and the Near and Middle East, arid and semi-arid grassland-based systems accounted for around 20 percent of the ruminant-meat production in 2000 (Herrero et al., 2014). Output from grazing systems in developing countries, especially in arid regions is low, due to limitations in feed availability and quality and, consequently, low 
livestock growth rates. However, food and income from livestock play a crucial role in supporting livelihoods in pastoral and other extensive livestock systems (Herrero et al., 2013).

In addition to food, rangelands provide fibre, fuel and other ecosystem services, including carbon sequestration, control of water cycles and provision of habitats for wildlife (FAO, 2011a, 2014c; Sala et al., 2017). Marshall et al. (2018) found that the nutrient diversity and increased spatial heterogeneity created by Neolithic pastoralists enriched and diversified African savannah landscapes over three millennia. Many of today's rangeland areas offer potential for increasing the supply of supporting and regulating ecosystem services. However, when they are not managed appropriately, rangelands are prone to loss of biodiversity, stored carbon and water-retention capacity and declines in productivity (FAO, 2011a).

Globally, there are about 780 genera and 12000 species of grass (Christenhusz and Byng, 2016). Rangelands are not only rich reservoirs of grasses, shrubs and trees, but also important for many kinds of fauna. For example, grasslands contain 11 percent of the world's Endemic Bird Areas ${ }^{86}$ (White, Murray and Rohweder, 2000) and contribute to the maintenance of pollinators and other insects that have important regulating functions (FAO, 2005a). The importance of grasslands for biological diversity is evident from the biological distinctiveness index developed by WWF, which considers species richness, species endemism, rarity of habitat type and ecological phenomena, among other criteria. For North America and Latin America, respectively, 10 out of 32 and 9 of 34 regions rated as "globally outstanding" for biological distinctiveness are in grassland ecosystems (WRI et al., 2000). Grasslands provide ecosystem services estimated to be worth USD 18.4 trillion per year globally (Costanza et al., 2014). Grasslands are also the

${ }^{86}$ An Endemic Bird Area (EBA) is "an area which encompasses the overlapping breeding ranges of restricted-range species, such that the complete ranges of two or more restricted-range species are entirely included within the boundary of the EBA" (Stattersfield et al., 1998). locations of origin of many domesticated livestock breeds and many of the world's cultivated plants, including wheat, maize, rice, rye, millet and sorghum, as well as of forage species, for which they remain important genetic reservoirs.

Although a figure of 10 percent to 20 percent rangeland degradation is often cited, there is no scientific consensus about the definition or the extent of rangeland degradation (Sayre et al., 2017). A review by Gibbs and Salmon (2015) found that global estimates of total degraded area vary from less than 1 billion ha to over 6 billion ha. IPBES (2018a) notes that rangelands are among the ecosystems most affected by land degradation and that, in many rangelands, livestock stocking density is at or above the land's long-term carrying capacity, leading to long-term declines in plant and animal production. It concludes that "the capacity of rangelands to support livestock will continue to diminish in the future, due to both land degradation and loss of rangeland area." The effects of climate change, including greater climatic variability, are exacerbating these problems and can be expected to add to future pressures on rangelands (ibid.).

Herrero et al. (2013) note that grasslands are often at the epicentre of land-use change processes, and conclude that detailed studies on the role and fate of grasslands as a multifunctional resource require urgent attention. One key area in this regard is Latin America, where forest conversion into human-made grasslands has been widespread in recent years. Globally, the extent of rangeland area changes over time due to conversion of forests into grassland, the conversion of rangeland into cropland and improved grasslands, and the replacement of abandoned rangeland with forests. Between 2000 and 2016, the global land area under permanent meadows and pastures declined by 4 percent (FAOSTAT). The rates of land conversion and the intensity of rangeland use are likely to continue changing over the coming decades. Mottet et al. (2017) estimated that of the 2 billion ha of grassland currently used for grazing, 1 billion ha can be considered non-convertible into cropland because they 


\section{PART B}

FIGURE 4.23

Global grasslands suitable and unsuitable for crop production and share of land use

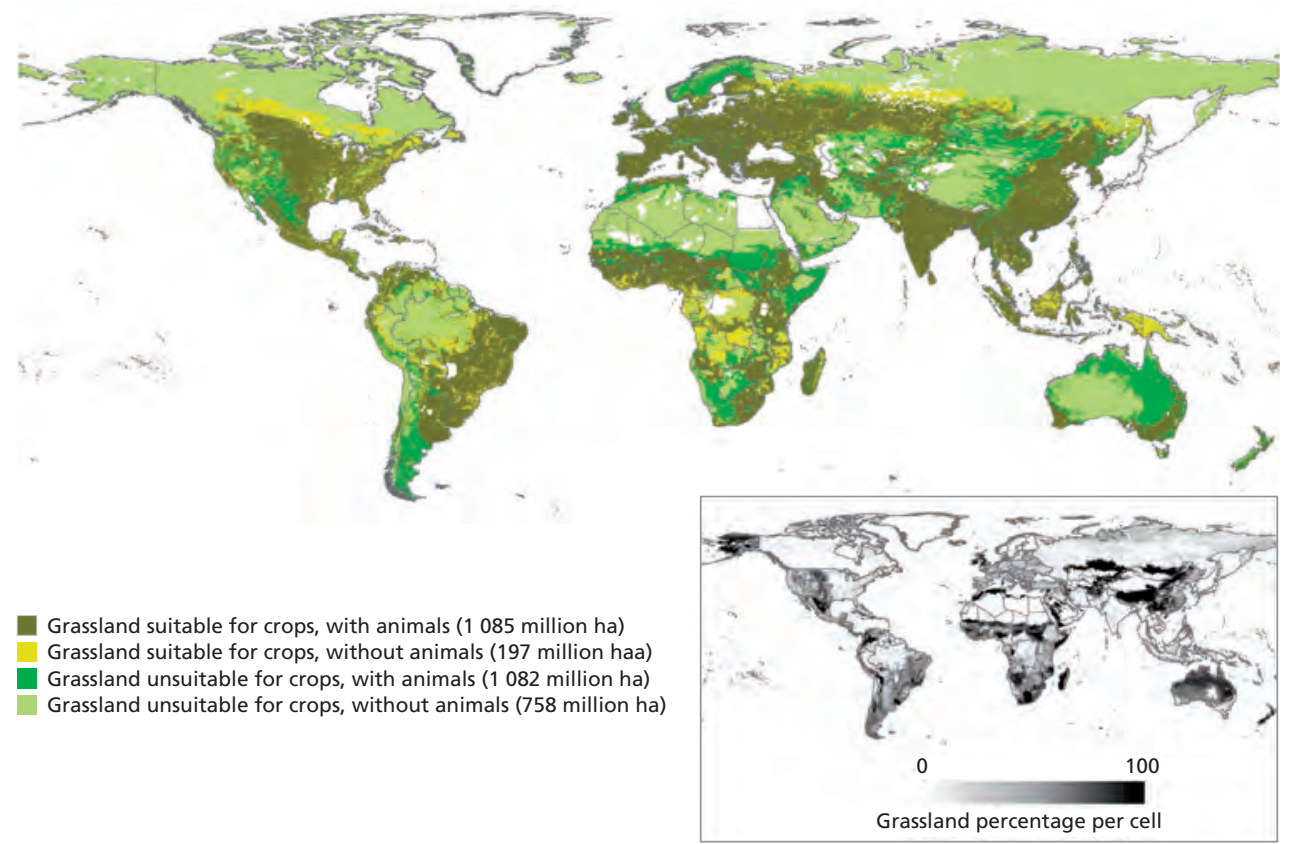

Notes: Threshold of $25 \%$ ratio of actual/potential yield used for suitability, as defined by IIASA and FAO (2012). Livestock distribution based on Gridded Livestock of the World (Robinson et al., 2014).

Source: Mottet et al., 2017.

are too arid or otherwise marginal (Figure 4.23). For some of the remaining 1 billion ha, the ecological costs of conversion would be prohibitive (Searchinger et al., 2015). These areas thus offer potential for biodiversity conservation.

Although approximately 9 percent of drylands are under formal protection, these areas are not representative of all dryland subtypes. For example, deserts are disproportionately represented, while temperate grasslands have among the lowest levels of protection of all biomes (4 to 5 percent). To some extent, this is because, traditionally, areas with the lowest economic value were the ones designated as protected areas. Large areas of drylands are protected informally by local communities either consciously (e.g. as sacred sites) or as a by-product of traditional sustainable management practices (e.g. as seasonal grazing reserves). This indigenous protection is rarely recognized by government and is often undermined by government policies (Davies et al., 2012).

\subsection{Needs and priorities}

Across all categories of BFA, the country reports and/or the previous global assessments of genetic resources make it clear that there are substantial knowledge gaps with respect to status and trends. The extent and character of these gaps vary from category to category of BFA. In the case of domesticated species and those that are 
widely harvested from the wild, species inventories are largely complete and the range of within-species populations (breeds, varieties, etc.) is also often well documented, although to varying degrees across the regions of the world. In contrast, many associated biodiversity species, particularly micro-organisms and invertebrates, have never been documented. An inventory of the world's tree species also remains to be completed. Population trends are relatively well documented for some taxonomic groups (particularly vertebrates), but in others knowledge is almost non-existent at species level and very limited even in general terms. Where associated-biodiversity species are monitored, data are often not linked to spatial data on the distribution of production systems, and hence their potential significance to particular categories of production can be difficult to evaluate. In many cases, the contributions of specific components of BFA to the supply of ecosystem services are poorly understood, as are the effects of particular drivers (including climate change) on population sizes and distributions and on the ecological relationships that underpin the supply of ecosystem services.

The main need and priority identified in the country reports is improving the availability of data in all the above fields. Also significant is the need to strategically plan data-collection efforts so that they provide the data needed to support management decisions that support the sustainable use and conservation of components of BFA and promote their roles in the supply of ecosystem services in food and agricultural systems. More specific priorities noted include improving methodologies for recording, storing and analysing data on changes in the abundance and distribution of species and the distribution of ecosystems (including geographic information system facilities) and increasing the supply of skilled taxonomists. Establishing or strengthening relevant research, education, capacity-building and cooperation programmes (including cooperation between the public sector and other stakeholders) is widely emphasized (see Chapter 8 for further discussion of needs and priorities in all these fields). As noted in some of the sections above, certain types of associated biodiversity are monitored through citizen-science projects and a number of countries note the potential benefits of expanding activities of this kind. Many countries emphasize the point that effective monitoring requires systematic and long-term commitment, noting in some cases the need to clarify responsibilities including, where relevant, establishing national bodies to organize or oversee monitoring activities. 



\section{Part C \\ STATE OF \\ MANAGEMENT}





\section{Chapter 5 \\ The state of use of biodiversity for food and agriculture}

\begin{tabular}{|c|c|}
\hline \multicolumn{2}{|l|}{ Key messages } \\
\hline $\begin{array}{l}\text { - The sustainable use and conservation of biodiversity } \\
\text { for food and agriculture (BFA) calls for approaches } \\
\text { that involve the integrated management of genetic } \\
\text { resources, species and ecosystems in the context of } \\
\text { production systems and their surroundings. } \\
\text { - A wide range of management practices and } \\
\text { approaches make use of various components of BFA } \\
\text { and thus potentially contribute to its sustainable } \\
\text { use. However, in most cases it is difficult to evaluate } \\
\text { the extent to which these practices and approaches } \\
\text { are being used owing to the variety of scales and } \\
\text { contexts involved and the absence of data and } \\
\text { appropriate assessment methods. } \\
\text { - Eighty percent of reporting countries indicate } \\
\text { that one or more of the BFA-focused practices } \\
\text { on which they were invited to report are being } \\
\text { used in one or more types of production system. } \\
\text { A much higher proportion of OECD countries } \\
\text { than non-OECD countries report the use of these } \\
\text { practices. Seventy-five percent of countries report } \\
\text { the adoption of one or more types of ecosystem, } \\
\text { landscape or seascape approach. } \\
\text { - Countries indicate that there is an upward trend } \\
\text { in the adoption or use of all the BFA-focused }\end{array}$ & $\begin{array}{l}\text { practices and approaches on which they were } \\
\text { invited to report. } \\
\text { - Although countries generally indicate that the } \\
\text { impacts of the BFA-focused practices on biodiversity } \\
\text { are perceived to be positive, they emphasize the } \\
\text { need for more research in this regard, even for } \\
\text { practices where research on management issues is } \\
\text { well established. } \\
\text { - Many BFA-focused practices are relatively } \\
\text { complex and require good understanding of } \\
\text { the local ecosystem. They can be knowledge } \\
\text { intensive, context specific and provide benefits } \\
\text { only in the relatively long term. Many countries } \\
\text { note major challenges in up-scaling such } \\
\text { practices and the need to promote them through } \\
\text { capacity development and strengthening } \\
\text { policy frameworks. } \\
\text { - A number of management practices targeting } \\
\text { micro-organisms used in food processing and } \\
\text { agro-industrial processes, or found in the rumens } \\
\text { of livestock species, contribute to improving } \\
\text { food security and nutrition while reducing the } \\
\text { environmental footprint of food production. }\end{array}$ \\
\hline
\end{tabular}

\subsection{Introduction}

This chapter considers the state of use of biodiversity for food and agriculture (BFA). Use is here taken to comprise the various actions that can be undertaken to maintain or enhance the capacity of BFA to supply ecosystem services of one kind or another. It encompasses activities at many levels, including the ecosystem, landscape and seascape, the farm (or forest, livestock or aquaculture holding), the plot (or pond, greenhouse, etc.), the biological community and the population (at species or within-species level). Conservation (i.e. actions specifically focused 
on preventing the loss of BFA) and characterization (activities specifically focused on improving knowledge of BFA) are discussed separately (Chapters 6 and 7), although they are clearly often closely linked to use. The policy, legal and institutional frameworks (including fields such as education and training, research, cooperation and the implementation of incentive measures) for use (and other aspects of BFA management) are discussed in Chapter 8 . The use of BFA in building resilient production systems and livelihoods, promoting food security and nutrition, and sustainably intensifying production is discussed in Chapter 2. Inevitably, there is some overlap in the scope of these various chapters. For example, many of the methods and approaches described in this chapter are relevant to in situ conservation. Policy and legal frameworks related to specific management practices are also mentioned at several points. Similarly, there are many linkages and overlaps between the various approaches and practices discussed in the sections of this chapter.

The chapter is structured as follows. Section 5.2 presents a short overview of the information provided by countries on the implementation of the various practices and approaches on which they were invited to report. Section 5.3 discusses approaches at ecosystem, landscape and seascape scales. Section 5.4 discusses restoration practices in terrestrial and aquatic ecosystems. Section 5.5 considers diversification (in terms of the range of species, breeds, varieties, etc. raised) at farm level (or at the level of equivalent holdings or operations in other sectors). Section 5.6 considers a number of specific management practices and approaches at farm or within-farm level (or equivalent levels in other sectors) that favour or involve the use of BFA. Section 5.7 discusses the use of micro-organisms in food processing and agro-industrial processes. Section 5.8 discusses rumen microbial diversity. Section 5.9 discusses the management of populations at genetic level (domestication, breeding programmes, etc.). In line with the rest of the report, particular attention is paid to associated biodiversity and to presenting the information provided in the country reports.

\subsection{Overview of management practices and approaches}

This section provides an overview of the information provided by countries on their implementation of the various management practices and approaches that are further discussed in the other sections of the chapter. Countries were invited to report on the extent of use of a range of management practices and approaches considered to favour or involve the use of BFA and on trends in their use over the preceding ten years. Out of the 91 country reports, 73 (80 percent) refer to the implementation of one or more of the management practices and approaches in one or more production systems. The remaining 18 (20 percent) do not make any explicit reference to any of the practices or approaches. Some countries report as many as 21 different practices and approaches. Findings are summarized by region in Table 5.1. The table should, however, be interpreted with caution as variations in the levels of detail provided in the country reports mean that the figures probably underestimate the actual frequencies of adoption. It should also be noted that the figures do not take into account the levels of adoption (importance in terms of land area or production output) within countries, i.e. a country with a low but non-zero level of adoption in only one production-system category is counted in the same way as a country with a high level of adoption across many production-system categories.

Bearing the above caveats in mind, general highlights from Table 5.1 are that a large proportion of countries globally (75 percent) report one or more types of ecosystem, landscape or seascape approach. More than half report some

\footnotetext{
Throughout this chapter, unless noted otherwise, the term "country reports" refers to the country reports submitted as contributions to The State of the World's Biodiversity for Food and Agriculture. See "About this publication" for additional information.
} 


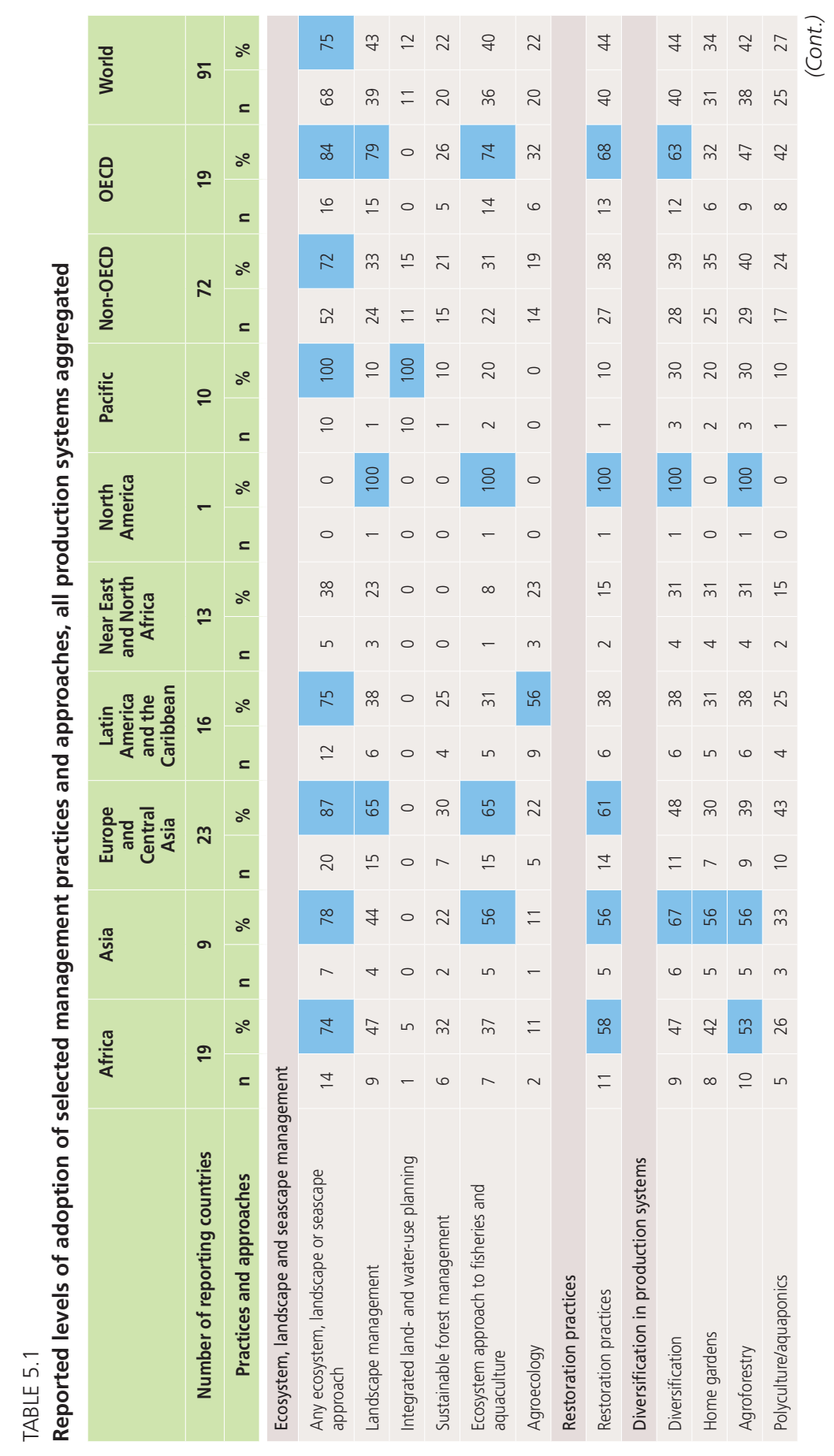




\section{PART C}

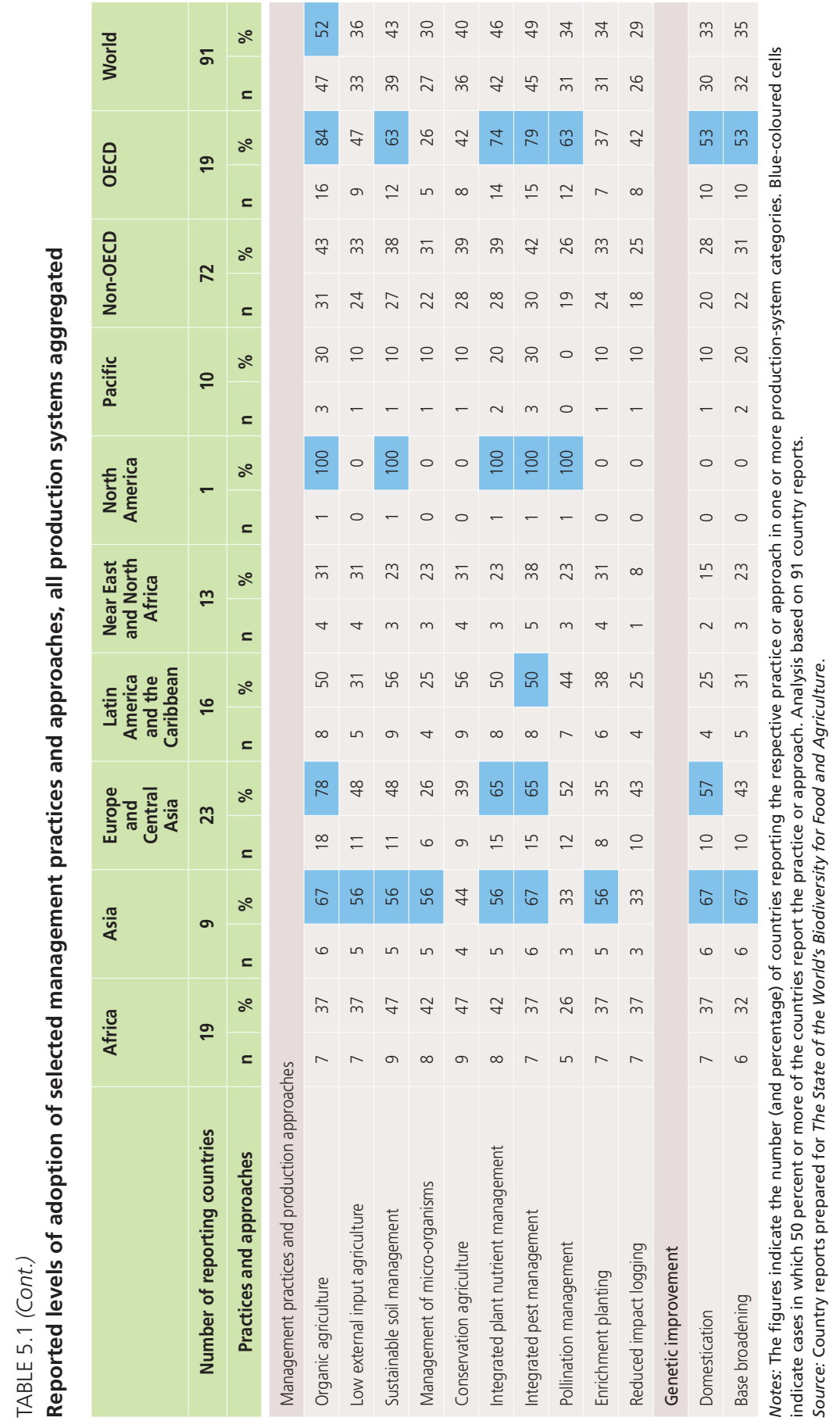


implementation of organic agriculture in one of more production-system categories. Overall, there is a marked difference in reporting between countries that are members of the Organization for Economic Co-operation and Development (OECD) and those that are not. With the exception of integrated land- and water-use planning, home gardens and management of micro-organisms, for which more non-OECD countries report implementation, every practice or approach is reported by a higher proportion of OECD countries. A few practices are reported by more than half the reporting countries in a particular region. For example, all countries from the Pacific region report implementation of integrated land- and water-use planning, 67 percent of Asian countries report adoption of diversification practices, 56 percent of countries from Latin America and the Caribbean report agroecological approaches, and 65 percent of European countries report implementation of landscape management.

Qualitative assessments provided by countries ${ }^{2}$ on trends in the use of management practices and approaches over the preceding ten years are summarized in Table 5.2. Here again, the table should be interpreted with caution, as variations in the levels of detail provided in the country reports mean that the figures probably underestimate the actual frequencies of adoption. Reports of increasing trends outnumber reports of negative or stable trends in almost every combination of management practice/approach and production system. The status and trends of the adoption of the management practices and approaches featured in Table 5.1 and Table 5.2 (among others) are further discussed in the remaining sections of this chapter, drawing on information from the country reports and other sources.

Countries were also invited to report on the effects the various management practices and approaches are having on BFA. Responses are summarized in Figure 5.1. Impacts are largely perceived

More specifically, countries were invited to provide qualitative assessments of trends (strongly increasing, increasing, stable, decreasing and strongly decreasing) or to indicate that information was not known or not applicable. to be positive. However, countries very clearly express the need to improve understanding of the impacts of different management practices and approaches, at various scales from local to global, on BFA and the supply of ecosystem services, as a basis for better decision-making among relevant stakeholders. Integrated pest management, integrated plant nutrient management, management of micro-organisms, sustainable soil management and landscape management are the practices with the highest proportions of responses specifically indicating that impacts on BFA are not known.

Although for presentation purposes this chapter devotes a separate section to each of the main management practices and approaches that countries were invited to report on, in reality these practices and approaches do not exist in isolation from each other. In order to implement them effectively, attention needs to be given to any potential synergies, complementarities and trade-offs that may exist between them. Given the current gaps in knowledge on the nature of these linkages, the multiple scales on which they operate and the many different stakeholders that may benefit or lose out, this is a substantial challenge. Adoption or further development of all the various approaches and practices discussed below requires producers, and often also other stakeholders, to change how they operate. Such changes normally require overcoming a number of obstacles and involve a degree of risk. In many cases, there may be conflicts of interest.

The need to develop and share knowledge on specific techniques and to build capacity to implement them, where appropriate, is recognized as a priority across all the practices and approaches discussed below. Successfully implementing them will generally require addressing knowledge gaps at all levels, from identifying relevant research questions, through identifying appropriate support and advice to be delivered by national programmes and extension workers, to addressing specific constraints to adoption faced by producers in different contexts. Little information is generally available on strategies for transitioning to more sustainable management at farm (or other holding), community 


\section{PART C}

TABLE 5.2

Reported trends in the adoption of selected management practices and approaches, by production system

\begin{tabular}{|c|c|c|c|c|c|c|c|c|c|c|c|c|c|}
\hline \multirow[b]{2}{*}{$\begin{array}{l}\text { Management } \\
\text { practices and } \\
\text { approaches }\end{array}$} & \multicolumn{12}{|c|}{ Production systems (PS) } & \\
\hline & 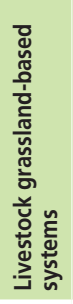 & 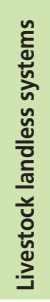 & 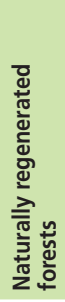 & 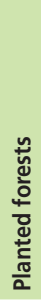 & 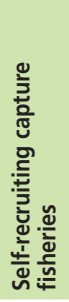 & 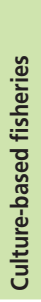 & 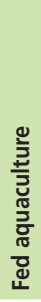 & 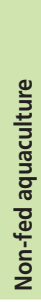 & 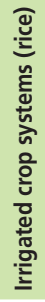 & 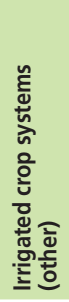 & 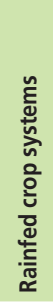 & $\begin{array}{l}\frac{n}{E} \\
\frac{\tilde{y}}{n} \\
\frac{\pi}{0} \\
\frac{d}{x} \\
\frac{x}{\Sigma}\end{array}$ & \\
\hline Landscape management & $\lambda$ & $\pi$ & $\pi$ & $\pi$ & & & & & $\pi$ & $\pi$ & $\pi$ & 入 & \\
\hline $\begin{array}{l}\text { Ecosystem approach to } \\
\text { fisheries }\end{array}$ & & & & & $\pi$ & $\pi$ & $\pi$ & & & & & & \multirow{4}{*}{$\begin{array}{l}\text { Proportion } \\
\text { of countries } \\
\text { reporting the PS } \\
\text { that report any } \\
\text { trends }(\%)\end{array}$} \\
\hline Restoration & $\pi$ & & $\lambda$ & $\pi$ & $\pi$ & & & & $\pi$ & $\pi$ & $\pi$ & $\pi$ & \\
\hline Diversification & $\pi$ & $\pi$ & ス & $\pi$ & $\pi$ & $\pi$ & $\pi$ & & $\pi$ & $\pi$ & $\pi$ & $\pi$ & \\
\hline Home gardens & $\pi$ & $\leftrightarrow$ & $\lambda$ & $\pi$ & & & & & $\pi$ & $\pi$ & $\lambda$ & オ & \\
\hline Agroforestry & $\pi$ & $\pi$ & $\pi$ & $\pi$ & & & & & $\pi$ & $\pi$ & $\lambda$ & $\lambda$ & $0-9$ \\
\hline Polyculture/aquaponics & & & & & & & $\pi$ & & & & & ス & $10-19$ \\
\hline Organic agriculture & $\pi$ & $\pi$ & $\pi$ & $\pi$ & & & & & $\leftrightarrow$ & $\pi$ & $\pi$ & $\pi$ & $20-29$ \\
\hline $\begin{array}{l}\text { Low external input } \\
\text { agriculture }\end{array}$ & $\pi \swarrow$ & $\pi$ & $\lambda$ & $\lambda$ & & & & & $\pi$ & $\pi$ & $\pi レ$ & $\pi$ & $30-39$ \\
\hline $\begin{array}{l}\text { Sustainable soil } \\
\text { management }\end{array}$ & $\pi$ & $\pi$ & $\lambda$ & $\pi$ & & & & & $\pi$ & $\pi$ & $\lambda$ & $\pi$ & \multirow{10}{*}{$\begin{array}{ll}\leftrightarrow & \text { Stable } \\
\nearrow & \text { Increasing } \\
\searrow & \text { Decreasing } \\
\nearrow \swarrow & \text { Mixed } \\
& \text { trends }\end{array}$} \\
\hline $\begin{array}{l}\text { Management of micro- } \\
\text { organisms }\end{array}$ & $\pi$ & & $\pi$ & $\pi$ & $\lambda$ & & & & $\pi$ & $\pi$ & $\lambda$ & 入 & \\
\hline Conservation agriculture & $\pi$ & ス & ス & 入 & & & & & $\pi$ & $\pi$ & $\lambda$ & $\pi$ & \\
\hline $\begin{array}{l}\text { Integrated plant nutrient } \\
\text { management }\end{array}$ & $\pi$ & $\pi$ & $\pi$ & $\pi$ & & & & & $\pi$ & $\pi$ & $\pi$ & $\pi$ & \\
\hline $\begin{array}{l}\text { Integrated pest } \\
\text { management }\end{array}$ & $\pi$ & $\pi$ & $\lambda$ & $\lambda$ & $\lambda$ & & & & $\pi$ & $\pi$ & $\pi$ & $\lambda$ & \\
\hline Pollination management & $\lambda$ & $\pi$ & $\lambda$ & $\pi$ & & & & & & $\pi$ & $\lambda$ & 入 & \\
\hline Enrichment planting & & & オ & $\pi$ & & & & & & & & オ & \\
\hline Reduced impact logging & & & $\pi$ & $\pi$ & & & & & & & & & \\
\hline Domestication & $\lambda$ & $\leftrightarrow$ & オレ & $\pi$ & & & $\pi$ & & $\pi$ & $\pi$ & 入 & ス & \\
\hline Base broadening & 入 & $\pi$ & $\pi \swarrow$ & $\pi$ & & & & & $\pi$ & $\pi$ & $\lambda$ & $\pi$ & \\
\hline
\end{tabular}

Notes: Countries were invited to report trends (increasing, stable or decreasing) in the adoption of selected management practices and approaches in each production system in the past ten years. If $50 \%$ or more of the responses for a given combination of production system and practice or approach indicate the same trend (increasing, decreasing or stable) then this trend is indicated in the respective cell of the table. In other cases, mixed trends are indicated. The empty cells correspond to cases in which fewer than five countries provided a response. The colour scale indicates the proportion of countries reporting the presence of the respective system that report any trends in the state of the respective practices and approaches (increasing, stable or decreasing). See Section 1.5 for descriptions of the production systems and Sections 5.2 to 5.9 for a discussion of the management practices and approaches. Analysis based on 91 country reports. Source: Country reports prepared for The State of the World's Biodiversity for Food and Agriculture. 
FIGURE 5.1

Perceived impacts on biodiversity for food and agriculture of various management practices and approaches

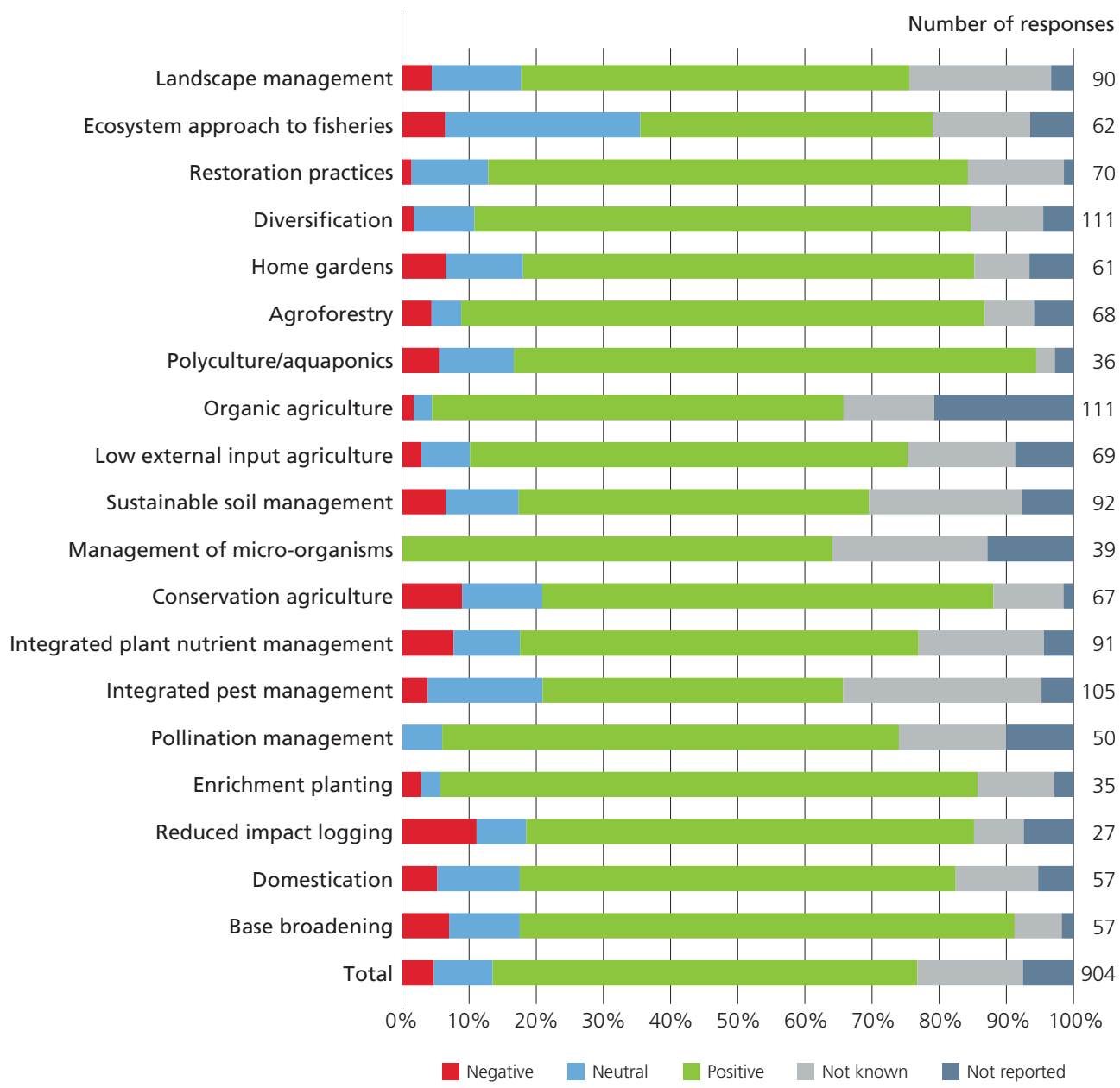

Notes: A "response" is the report of an impact by a country for a given combination of practice and production system. Countries were invited to indicate the extent of use of each practice and approach, by production system. For production systems where a given practice or approach is implemented, countries were invited to indicate its perceived effects on BFA. This figure shows the distribution of impacts reported for all combinations of practices and production systems. Analysis based on 91 country reports.

Source: Country reports prepared for The State of the World's Biodiversity for Food and Agriculture.

or country level. Approaches such as farmer field schools are being used to promote shared learning on some of the practices and approaches discussed below (see also Section 8.4). Creating greater opportunities for cross-sectoral learning by promoting closer links and greater collaboration among the actors involved in implementing the various practices and strategies discussed is another 
widespread priority. The importance of comprehensive stakeholder involvement in planning implementation activities is, likewise, common across nearly all the approaches and practices (and is among the defining features of ecosystem, landscape and seascape approaches). The significance of adopting a more cross-sectoral approach at policy level as a means of promoting linkages at the more practical level is also widely recognized. Another theme common to several of the practices and approaches discussed is the need to address constraints related to land-tenure issues.

\subsection{Ecosystem, landscape and seascape approaches}

- Ecosystem, landscape and seascape approaches have been adopted in many countries around the world, at various scales, to improve livelihoods, sustain or enhance ecosystem services, ensure the supply of food and other products, and promote efficient and sustainable use of resources.

- Seventy-five percent of reporting countries indicate the adoption of one or more types of ecosystem, landscape or seascape approach. Positive trends in the adoption and implementation of landscape and ecosystem approaches are reported. However, the extent of use of these approaches and their effects on biodiversity for food and agriculture remain unclear.

- Indicators show that adoption and application of sustainable forest management is increasing. The global area under forest management plans has increased steadily in recent decades, reaching 2.1 billion ha in 2010 . The forest area covered by international certification schemes has also increased.

- Among the 127 countries that reported on their progress in the implementation of the Code of Conduct for Responsible Fisheries in 2018, 77 percent indicated that they had started to implement the ecosystem approach to fisheries.

- Although estimates of the state and trends of implementation of agroecological practices at global level are lacking, an increasing number of countries (28 as of July 2018) have introduced laws, regulations and policies in support of agroecology.
- Information and knowledge gaps, lack of crosssectoral institutional frameworks, lack of financial and political commitment, and a lack of skilled personnel in public institutions are among reported constraints to the adoption and implementation of landscape, seascape and ecosystem approaches.

Interactions between people and the natural environment shape the characteristics of terrestrial and aquatic production systems and their surroundings. Within these areas, a wide range of ecosystem components, both biological and physical, interact with each other across a range of scales. This means that planning the use and management of one component - or one relatively small area of land such as a single farm - in isolation may lead to negative impacts on other components or to missed opportunities to benefit from positive interactions. Effects of this kind mean that management decisions will normally affect the interests of a range of stakeholders, including in potentially conflicting ways.

Awareness of the importance of taking a more holistic approach to the management of ecosystems and landscapes has been increasing, and has led to the development and adoption of a range of integrated, multiscale approaches that aim to allow the interests of multiple stakeholders to be taken into consideration, synergies identified and trade-offs negotiated (CGIAR, 2016).

This section begins by presenting an overview of ecosystem, landscape and seascape approaches and then provides a more detailed description of the specific approaches most frequently referred to in the country reports as having been adopted in food and agricultural production systems. For each approach, the reported status and trends of adoption are presented and gaps and priorities in terms of adoption and implementation discussed.

\subsubsection{Overview}

The ecosystem approach has been defined in various ways, both in the literature and in international agreements. In 2000, the Parties to the Convention on Biological Diversity (CBD) officially defined the ecosystem approach as "a strategy for 
Box 5.1

The Convention on Biological Diversity's principles and operational guidelines for the ecosystem approach

The ecosystem approach is the primary framework for action under the Convention on Biological Diversity (CBD). At its fifth meeting, held in Nairobi, Kenya, in 2000, the Conference of the Parties to the CBD endorsed the following twelve interlinked principles, first identified during a workshop held in Lilongwe, Malawi, in 1998:

1. The objectives of management of land, water and living resources are a matter of societal choices.

2. Management should be decentralized to the lowest appropriate level.

3. Ecosystem managers should consider the effects (actual or potential) of their activities on adjacent and other ecosystems.

4. Recognizing potential gains from management, there is usually a need to understand the ecosystem in an economic context. Any such ecosystemmanagement programme should: (a) reduce those market distortions that adversely affect biological diversity; (b) align incentives to promote biodiversity conservation and sustainable use; and (c) internalize costs and benefits in the given ecosystem to the extent feasible.

5. Conservation of ecosystem structure and functioning, in order to maintain ecosystem services, should be a priority target of the ecosystem approach.

6. Ecosystems must be managed within the limits to their functioning.

7. The ecosystem approach should be undertaken at the appropriate spatial and temporal scales.
8. Recognizing the varying temporal scales and lageffects that characterize ecosystem processes, objectives for ecosystem management should be set for the long term.

9. Management must recognize that change is inevitable.

10. The ecosystem approach should seek the appropriate balance between, and integration of, conservation and use of biological diversity.

11. The ecosystem approach should consider all forms of relevant information, including scientific and indigenous and local knowledge, innovations and practices.

12. The ecosystem approach should involve all relevant sectors of society and scientific disciplines.

The fifth meeting of the Conference of the Parties to the CBD also endorsed following five operational guidelines for the ecosystem approach:

1. Focus on the functional relationships and processes within ecosystems.

2. Enhance benefit-sharing.

3. Use adaptive management practices.

4. Carry out management actions at the scale appropriate for the issue being addressed, with decentralization to lowest level, as appropriate.

5. Ensure intersectoral cooperation.

Source: CBD, 2000a. the integrated management of land, water and living resources that promotes conservation and sustainable use in an equitable way." As the term ecosystem can refer to any functioning unit - it could, for example, be a grain of soil, a pond, a forest, a biome or the entire biosphere - the ecosystem approach can be applied at various scales (CBD, 2000a). In 2000, the Parties to the CBD also formally adopted the approach, together with twelve governing principles (also referred to as the Malawi Principles) and five operational guidelines, as the primary framework for action under the Convention (see Box 5.1). Both before and after 2000, a number of more specific ecosystem approaches targeting (or relevant to) particular sectors of food and agriculture were also developed, for example sustainable forest management, integrated coastal management and integrated water resources management. The application of such approaches has been particularly effective in 
FIGURE 5.2

The ten principles that characterize the landscape approach

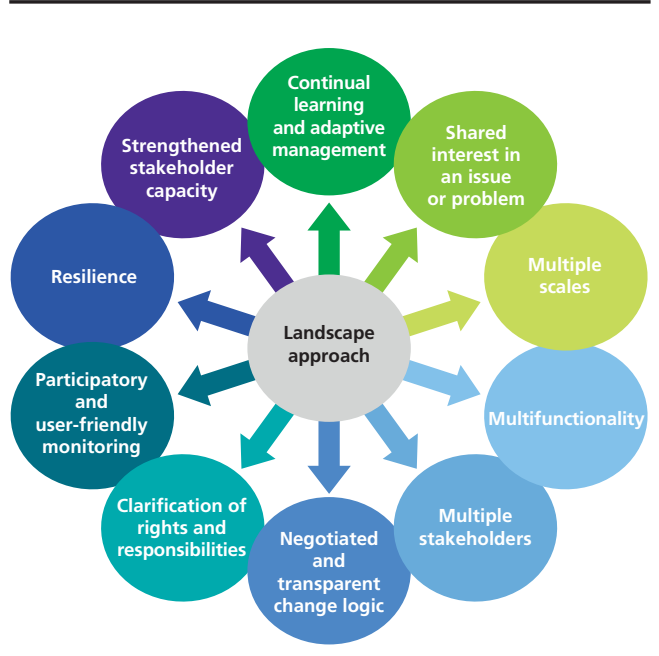

Source: van Oosten (2015) based on Sayer et al. (2013).

forestry and fisheries (see Sections 5.3.2 and 5.3.3) and in specific fields such as integrated pest management (see Section 5.6.6) (FAO, 2007f). At the ninth meeting of the Conference of the Parties to the CBD, in 2008, it was noted that "global assessments suggest that the ecosystem approach is not being applied systematically to reduce the rate of biodiversity loss, but there are many examples of successful application at the regional, national and local scales which should be widely promoted and communicated. Most of these examples can be considered as positive outcomes for both biodiversity and human well-being" (CBD, 2008a). ${ }^{3}$

Although the term "landscape approach" has come to be widely used, it remains difficult to define it precisely or to distinguish it clearly from the range of other landscape-scale management methodologies and frameworks that have emerged under various names in recent years (Reed, Deakin and Sunderland, 2015; Scherr, Shames and Friedman, 2013). The term "landscape" itself has

The global assessments referred to in the quote are $C B D$ (2007a) and CBD (2007b). numerous connotations, but in the field of landuse management typically refers to an area of land that can be regarded as a "whole" composed of a number of interlinked components. For example, Forman (1995) defines a landscape as a "heterogeneous land area composed of a cluster of interacting ecosystems that is repeated in similar form."

In the context of (terrestrial) food and agricultural production systems, the landscape is taken to include not only the fields, pastures and agroforests themselves, but also managed or unmanaged fallow and wild land in and around them (Brookfield, 2002; Kremen and Merenlender, 2018; Landis, 2017). Generally speaking, landscape approaches intended to support the maintenance and use of BFA aim both to balance diverse, and often competing, land uses within the landscape and to manage the biodiversity associated with each of these individual land uses (ibid.).

It is possible to distinguish three basic characteristics of landscape approaches:

- Multiple objectives: landscape approaches provide a framework for allocating and managing land in areas where land uses such as agriculture, forestry and mining compete with environmental and biodiversity goals (Sayer et al., 2013).

- Multiple stakeholder engagement and dialogue within and beyond the landscape: management goals need to be negotiated among those with a stake in the landscape (e.g. farmers and their communities, businesses, civil society and government agencies) and build on their experiences, knowledge and aspirations (Scherr, Shames and Friedman, 2013). At national and institutional levels, cross-sectoral collaboration in policy development is essential.

- Adaptive management: landscapes themselves are dynamic, and hence landscape approaches also need to be flexible and dynamic (Reed, 2014).

Figure 5.2 shows a more detailed guiding framework for the landscape approach, consisting of ten complementary and interlinked principles, developed by the Center for International Forestry 
Research (CIFOR) and partner institutions (Sayer et al., 2013).

To date, there is very little information available on where, or how effectively, landscape approaches have been implemented in practice. CIFOR has been trying to address this knowledge gap through a systematic mapping exercise using aggregated data from published scientific literature (Reed, Deakin and Sunderland, 2015). As well as geographically mapping where and how such approaches are being implemented in the field, the review is aiming to document evidence of positive and/or negative effects of landscape approaches in practice on social, agronomic, environmental or economic outcomes (ibid.).

As the word "landscape" implies a terrestrial focus, the term "seascape" or "oceanscape" approach is sometimes used to describe a similar approach in marine environments. Seascape approaches are often referred to in the context of efforts to manage marine and terrestrial areas in an integrated way, for example the Pacific Ridge to Reef initiative ${ }^{4}$ or the Source to Sea approach. ${ }^{5}$

Based on the descriptions of ecosystem ${ }^{6}$ and landscape ${ }^{7}$ approaches provided in the country-reporting guidelines, 75 percent of the

\footnotetext{
https://www.pacific-r2r.org

http://www.fao.org/land-water/water/watergovernance/ source-to-sea/en

6 "An ecosystem approach is generally understood to encompass the management of human activities, based on the best understanding of the ecological interactions and processes, so as to ensure that ecosystems structure and functions are sustained for the benefit of present and future generations. Ecosystem approaches include the Convention on Biological Diversity's Ecosystem Approach, Integrated Land Use Planning, Integrated Water Resource Management, Sustainable Forest Management, Code of Conduct for Responsible Fisheries, [and the] Ecosystem approach to fisheries management."

"A landscape approach means taking both a geographical and socio-economic approach to managing the land, water and forest resources that form the foundation - the natural capital - for meeting our goals of food security and inclusive green growth. By taking into account the interactions between these core elements of natural capital and the ecosystem services they produce, rather than considering them in isolation from one another, we are better able to maximize productivity, improve livelihoods, and reduce negative environmental impacts." (wording taken from World Bank [2012]).
}

91 reporting countries indicate that ecosystem, landscape and/or seascape approaches have been adopted, at least to some extent. A large majority of these countries indicate that they consider these approaches to be of major importance to the development of management strategies for BFA. ${ }^{8}$ A few European countries specifically mention that ecosystem and landscape approaches are at the basis of their agricultural policies. Table 5.3 lists the ecosystem, landscape and seascape approaches most commonly mentioned $^{9}$ in the country reports. A number of these approaches were among the management practices that countries were specifically invited to report upon elsewhere in their reports. ${ }^{10}$ The table, therefore, also shows the number of countries reporting the use of the respective approaches/practices in these contexts. Sustainable forest management, the ecosystem approach to fisheries and aquaculture, agroecology, landscape and seascape approaches as a general category and integrated land-use planning, are briefly introduced below (Sections 5.3.2, 5.3.3, 5.3.4, 5.3.5, 5.3.6), along with information on their status and trends. More detailed information on the remaining approaches/practices and on their reported levels of implementation can be found in the respective subsections of Sections 5.5 and 5.6, and in Chapter 7.

\subsubsection{Sustainable forest management}

\section{Introduction}

Sustainability was identified as an important principle in forest management theory as early as 1713, when Hans Carl von Carlowitz published his book Economics of silviculture in Germany (Schmithüsen, 2013). Today sustainable forest

\footnotetext{
Countries were invited to indicate whether "major importance", "some importance" or "no importance" is assigned to the reported ecosystem approaches.

9 The table shows approaches mentioned by five or more countries in response to a question specifically seeking information on the adoption of ecosystem and/or landscape approaches

10 Specifically, integrated pest management, agroforestry, sustainable soil management and organic agriculture.
} 


\section{PART C}

TABLE 5.3

Reported ecosystem, landscape and seascape approaches

\begin{tabular}{|l|c|c|c|}
\hline Approach & $\begin{array}{c}\text { Number of countries } \\
\text { reporting } \\
\text { the approach }\end{array}$ & $\begin{array}{c}\text { Number of countries } \\
\text { reporting the approach } \\
\text { as a management } \\
\text { practice }\end{array}$ & $\begin{array}{c}\text { Production systems } \\
\text { where reported }^{3}\end{array}$ \\
\hline
\end{tabular}

Protected areas management ${ }^{4}$

Sustainable forest management

Ecosystem approach to fisheries and aquaculture

Integrated pest management

Agroforestry

Landscape approaches and management

Integrated land- and water-use planning ${ }^{5}$

Sustainable soil management

Ecosystem approach to aquaculture

Organic agriculture

Other ecosystem approaches to agriculture

(integrated crop management and agroecology)
Self-recruiting capture fisheries

Naturally regenerated forests

Livestock grassland-based systems

Livestock landless systems

Irrigated crop systems (non-rice)

Rainfed crop systems

Mixed systems

Culture-based fisheries

Naturally regenerated forests

Planted forests

Self-recruiting capture fisheries

Culture-based fisheries

Fed aquaculture

Non-fed aquaculture

Irrigated crop systems (non-rice)

Rainfed crop systems

Livestock grassland-based systems

Naturally regenerated forests

Irrigated crop systems (rice)

Mixed systems

Family farms

Mixed systems

Rainfed crop systems

Planted forests

Livestock grassland-based systems Mixed systems

Naturally regenerated forests

Planted forests

Rainfed crop systems

Irrigated crop systems (non-rice)

Livestock landless systems

Irrigated crop systems (non-rice)

Rainfed crop systems

Irrigated crop systems (rice)

Naturally regenerated forests

Planted forests

Fed aquaculture

Non-fed aquaculture

Rainfed crop systems

Irrigated crops (non-rice)

Mixed systems

Livestock grassland-based systems

Irrigated crop systems (rice)

Notes: 1. This column shows the number of countries reporting the respective approach in response to a question about whether, and to what extent, ecosystem and/or landscape approaches are being implemented in their production systems. The question was open ended, i.e. countries could mention any ecosystem approach they wished. 2 . This column shows the number of countries reporting the implementation of the respective approaches in response to questions on the level of implementation of specific management practices. 3. This column shows the production systems for which the approaches were reported. 4 . The kinds of protected areas that were reported on by countries include national parks, nature reserves and conservation areas, including marine and forest protected areas and high nature value farmlands. For further information see Section 7.5. In most cases this refers to the Pacific Ridge to Reef approach (https://www.pacific-r2r.org). Analysis based on a total of 91 country reports.

Source: Country reports prepared for The State of the World's Biodiversity for Food and Agriculture. 
management is a globally accepted concept that guides the development and implementation of policies and practices that aim to maintain and enhance the economic, social and environmental values of forests.

International policy dialogue on forests was initiated by the United Nations Conference on Environment and Development (UNCED) in 1992. In addition to adopting the United Nations conventions on biodiversity, climate change and desertification, UNCED also released a non-legally binding statement called "Forest Principles" (UNCED, 1992) in which countries affirmed their commitment to the conservation, management and sustainable development of all types of forests. After UNCED, the Intergovernmental Panel on Forests (IPF) (1995-1997) and the Intergovernmental Forum on Forests (IFF) (19972000) facilitated follow-up discussions to the Forest Principles. Since 2000, the United Nations Forum on Forests (UNFF) has continued the IPF/IFF work and sought ways to strengthen long-term political support for sustainable forest management. As a result of the work of UNFF, the United Nations General Assembly adopted, in 2007, the Non-Legally Binding Instrument on All Types of Forests (United Nations, 2007), which provides a global definition for sustainable forest management (Box 5.2). ${ }^{11}$

Following the adoption of the 2030 Agenda for Sustainable Development and its Sustainable Development Goals in 2015, the United Nations Economic and Social Council agreed on International Arrangements on Forests beyond 2015 (United Nations, 2015b). It also decided to change the name of the Non-Legally Binding Instrument on All Types of Forests to the United Nations Forest Instrument, and requested UNFF to develop a strategic plan for the period 2017 to 2030 (ibid.). In 2017, a special session of UNFF agreed on the United Nations Strategic Plan for Forests 2017-2030 (United Nations, 2017c), which provides a global framework for actions at all

1 Further information on these processes can be found via the UNFF website https://www.un.org/esa/forests/index.html
Box 5.2

The concept of sustainable forest management

In Resolution 62/98 (2007) (United Nations, 2007), the United Nations General Assembly recognized that forests and trees outside forests provide multiple economic, social and environmental benefits, and emphasized that sustainable forest management contributes significantly to sustainable development and poverty eradication. It further recognized sustainable forest management as a dynamic and evolving concept that is intended to maintain and enhance the economic, social and environmental value of all types of forests, for the benefit of present and future generations. The resolution lists the following seven elements of sustainable forest management: (1) extent of forest resources; (2) forest biological diversity; (3) forest health and vitality; (4) productive functions of forest resources; (5) protective functions of forest resources; (6) socioeconomic functions of forests; and (7) legal, policy and institutional framework.

levels to sustainably manage all types of forests and trees outside forests and halt deforestation and forest degradation. The strategic plan includes six global forest goals and 26 associated targets to be achieved by 2030 . These voluntary goals and targets contribute to the implementation of the 2030 Agenda for Sustainable Development, the Paris Agreement of the United Nations Framework Convention on Climate Change, the CBD and the United Nations Convention to Combat Desertification.

In parallel with the international policy dialogue on forests, a total of nine regional and eco-regional initiatives or processes were launched by countries in the period after 1992 with the aim of translating the concept of sustainable forest management into practice (Wilkie, Holmgren and Castañeda, eds., 2003). These regional and ecoregional processes developed criteria and indicators for sustainable forest management. Although the various processes carried out their work 
independently, they had similar objectives. They also shared information and experiences, and some countries participated in more than one process. This paved the way for consensus on sustainable forest management and its seven elements in the context of the United Nations Forum on Forests. Additionally, the regional processes on criteria and indicators for sustainable forest management were instrumental to the evolution of certification schemes for wood-based products traded in international markets. The major global certification schemes for wood sourced from sustainably managed forests are the Programme for the Endorsement of Forest Certification (PEFC) ${ }^{12}$ and the Forest Stewardship Council (FSC). ${ }^{13}$

Sustainable forest management requires action at all levels from the field (i.e. forest management unit), where it involves the implementation of practices based on science and knowledge of local conditions and traditions, to the levels of policy, legislation and governance. In the forest sector, it has long been recognized that sectoral policies should contribute to achieving the development goals of the whole society and should take other sectors into consideration (e.g. FAO, 2003c). Consequently, the development and implementation of forest policy in many countries have been based on a holistic and cross-sectoral approach (e.g. Husch, 1987).

A forest policy is typically a government document that sets out objectives for the forest sector's contributions to sustainable development. A national or subnational forest strategy describes how these goals and objectives will be achieved. In many countries, a legal framework has been established to support the implementation of the forest strategy. Action plans are developed to translate the forest policy into concrete activities. A national forest programme (NFP) or similar arrangement is commonly used as the mechanism for developing forest policy and related strategies and action plans and for facilitating and monitoring their implementation (FAO, 2010b). An NFP involves a continuous process of communication

\footnotetext{
12 https://www.pefc.org

13 https://ic.fsc.org/en
}

and dialogue (FAO and NFPF, 2006). In many cases, a forest forum or similar multistakeholder platform is established to provide an opportunity for all relevant stakeholders within and outside of the forest sector to express their views on forest policy. It is widely acknowledged that NFPs play an important role in the implementation of sustainable forest management (NFPF and FAO, 2012).

\section{Status and trends}

Over the past two decades, many countries have made considerable progress in implementing sustainable forest management by strengthening policy and legal frameworks and by improving the application of management practices in the field. Several indicators based on the global forest statistics assembled by FAO show positive trends for this period (FAO, 2016g). Although global forest area continued to decline between 1990 and 2015, the rate of annual loss of forest area decreased significantly (see Section 4.5.5. for further discussion). Several countries had significant annual net gains in forest area between 2010 and 2015, including China (1.5 million ha), Chile (301 000 ha), the Philippines (240 $000 \mathrm{ha}$ ) and Gabon (200 $000 \mathrm{ha}$ ) (ibid.). As of 2008, 135 countries and areas $^{14}$ had developed a forest policy and 131 had established an NFP (FAO, 2010c).

The widespread existence of policy, legal and regulatory frameworks facilitating the implementation of sustainable forest management is also reflected in the country reports. A range of specific issues addressed by these frameworks are highlighted, including the maintenance and restoration of natural forests, timber-harvesting practices and the conservation of forest biodiversity (e.g. deliberately leaving dead wood in place), aesthetic values, water quality and soil conditions. Some countries also refer to the implementation of sustainable forest management within the context of specific projects. For example, the Gambia mentions the Expansion of Community Participation in the Management of Forests and Protected Areas project, which aimed to manage

14 Out of a total of 233 countries and areas assessed. 
forest resources in the interests of sustainable livelihoods, including by enhancing the conservation of biodiversity in forest and woodland ecosystems.

Where field-level operations are concerned, forest management plans are the main instruments for ensuring that forests are managed sustainably. Increasingly, such plans integrate a wide range of management practices associated with multiple objectives, including the supply of wood and non-wood products and various cultural, supporting and regulating ecosystem services. The global area under forest management plans has increased steadily since 1990 , reaching 2.1 billion ha in 2010 (FAO, 2016g). Similarly, the forest area covered by the two above-mentioned international certification schemes increased from 14 million ha in 2000 to 438 million ha in 2014 (ibid.). As of September 2018, PEFC indicated that it had certified 307 million ha (PEFC, 2018) and FSC that it had certified 200 million ha (FSC, 2018)..$^{15}$ Several country reports emphasize the importance of forest management plans. Belgium, for example, reports mandatory implementation of forest management plans, noting that particular attention is paid, inter alia, to the diversity of planted forest tree species and the maintenance of trees of biological interest. Ethiopia reports that its area under sustainable forest management is expanding and that the main objectives of its forest management plans include increasing forest coverage through massive tree planting.

\subsubsection{Ecosystem approach to fisheries and aquaculture}

\section{Introduction}

In the mid-1970s, growing concerns over the health of the oceans, the regulation of human activities affecting them, and the allocation of resources, rights and responsibilities in their use began to shift global approaches to fisheries management and led to the introduction of exclusive economic zones and the adoption, in 1982, of the United

15 These figures include some double accounting, as some forest owners have opted to certify their forests under both schemes.
Nations Convention on the Law of the Sea (FAO, 2003d, 2005b). While these steps were important, they were not sufficient to ensure the effective management and sustainable development of fisheries, and by the late 1980s it had become clear that a new approach was needed (FAO, 2005b). In October 1995, the Code of Conduct for Responsible Fisheries (FAO, 1995a) was adopted by the Conference of FAO to provide a framework for national and international efforts to ensure the sustainable exploitation of aquatic biodiversity.

The early years of the twenty-first century saw the emergence of the term "ecosystem approach to fisheries" (FAO, 2003d). A FAO technical consultation held in 2002 agreed that the purpose of an ecosystem approach to fisheries is

to plan, develop and manage fisheries in a manner that addresses the multiple needs and desires of societies, without jeopardizing the options for future generations to benefit from the full range of goods and services provided by marine ecosystems and that such an approach

strives to balance diverse societal objectives, by taking account of the knowledge and uncertainties about biotic, abiotic and human components of ecosystems and their interactions and applying an integrated approach to fisheries within ecologically meaningful boundaries (FAO, 2003e).

The ecosystem approach to fisheries involves a range of inter-related guiding principles and concepts that have been summarized as follows:

- fisheries should be managed to limit their impact on the ecosystem to the extent possible;

- ecological relationships between harvested, dependent and associated species should be maintained;

- management measures should be compatible across the entire distribution of the resource (across jurisdictions and management plans);

- the precautionary approach should be applied because the knowledge on ecosystems is incomplete; and 
- governance should ensure both human and ecosystem well-being and equity (ibid.).

The ecosystem approach concept has also been applied to aquaculture. According to FAO (2010d), an ecosystem approach to aquaculture

is a strategy for the integration of the activity within the wider ecosystem such that it promotes sustainable development, equity, and resilience of interlinked social-ecological systems.

Current efforts to promote an ecosystem approach to aquaculture focus on developing tools to improve decision-making processes, with the aim of minimizing impacts on natural ecosystems, improving knowledge of interactions between aquaculture and the supply of ecosystem services and strengthening communication between scientists and decision-makers (Bricker et al., 2016; Kluger et al., 2016; Lithgow, de la Lanza and Silva, 2017).

\section{Status and trends}

FAO's 2018 report on progress in the implementation of the Code of Conduct for Responsible Fisheries (FAO, 2018k) indicates that among 127 reporting countries, 77 percent stated that they had begun to implement the ecosystem approach to fisheries. Among these, 97 percent had established ecological, socio-economic and governance objectives, 95 percent had identified key issues to be addressed by management actions and 67 percent had established monitoring mechanisms (ibid.).

Although the ecosystem approach to fisheries has spread to all regions of the world, practical adoption can be challenging (Fletcher and Bianchi, 2014; Hilborn, 2011). Pitcher et al. (2009) evaluated progress in the implementation of ecosystem-based management ${ }^{16}$ of fisheries in

\footnotetext{
16 The authors note the existence of a range of terms and definitions in this field and state that they use the term ecosystem-based management "to denote a holistic approach to the management of fisheries, but not the management nor control of pollution, shipping lanes, recreation and other nonfisheries issues."
}

33 countries using a scoring framework based on key principles, elements and steps associated with the implementation of the approach. Only two countries were judged to have a "good" performance and four countries to have an "acceptable" performance. Sixteen were assigned "fail grades" (ibid.). Van Hoof (2015) notes that, in the case of the European Union, although a number of regional marine policies recognize the need for an ecosystem approach, practical implementation has run up against various constraints associated with the complexities of the institutional and policy framework and the difficulty of ensuring adequate stakeholder involvement. Where impacts are concerned, there is evidence that implementation of the ecosystem approach to fisheries over any extended area tends to increase fish catches (Bundy et al., 2017).

Thirty-six out of the 91 country reports mention the adoption of an ecosystem approach in at least one category of aquatic production system. Adoption is reported by a higher proportion of non-OECD countries (74 percent) than of OECD countries (31 percent). While many country reports provide few details of their reported implementation efforts, some report a diverse range of measures. For example, Burkina Faso mentions the establishment of co-management regimes for water bodies of economic interest, with multistakeholder management committees operating specifically formulated development plans. It describes procedures for the granting of fishing concessions, and notes the benefits of having favourable legal and institutional frameworks in place (including consultative bodies and grassroots community organizations). Practical measures mentioned include establishment of spawning grounds (habitat improvement) and temporary closures of fisheries. An example from Panama of the implementation of the ecosystem approach to fisheries at project level is presented in Box 5.3. Actions taken to ensure the adoption of an ecosystem approach to fisheries management and a code of conduct on sustainable fisheries in Saint Lucia are presented in Box 5.4. With reference to aquaculture, Malta reports that an 
Box 5.3

Application of the ecosystem approach in capture fisheries - an example from Panama

The project Development of Sustainable Economic Alternatives and Conservation Strategies in Marine Protection areas of the Gulfs of Chiriquí and Montijo, implemented by Fundación MarViva, has contributed to improving the livelihoods of eight coastal fishing communities in Panama by training local people (300 families, comprising more than 1634 individuals) on better fishing practices and promoting alternative businesses (whale watching and rural tourism) that sustainably use marine and coastal resources. Twentyfive microbusinesses have implemented environmentalmanagement plans, which in 2013 won the county's Clean Production Award. Other achievements have included the generation of microcredit opportunities for very poor communities and the formulation of fishing agreements with three artisanal fishers' groups. Mollusc and lobster harvesters have been trained in marketing and product management. Value chains in fisheries and tourism have been created through strategic alliances between the private sector and beneficiary groups, which have worked together to establish more responsible approaches to fishing and tourism.

Source: Adapted from the country report of Panama.

\section{Box 5.4}

\section{Ecosystem approach to fisheries management in Saint Lucia}

An ecosystem approach to fisheries management and a code of conduct on sustainable fisheries adopted in Saint Lucia led to widespread compliance among fishers with measures aimed at improving the management and development of the industry. This led to increased biomass of fishery species, greater marine biodiversity and enhancements to marine ecosystems. However, achieving these results required a long series of actions and political investments. Specific actions taken to ensure adoption included:

- signing the Caribbean Regional Fisheries Mechanism 2010 Castries (St. Lucia) Declaration on Illegal, Unreported or Unregulated Fishing;

- accession to the 2009 FAO Port State Measures Agreement to Prevent, Deter and Eliminate Illegal, Unreported or Unregulated Fishing (Saint Lucia officially acceded on 17 June 2016);

- signing the 2015 St. George's Declaration on the Conservation, Management and Sustainable Use of the Caribbean Spiny Lobster (Panulirus argus);

- endorsement of the Draft Management Plan for Blackfin Tuna;

- endorsement of the Draft Management Plan for Fish Aggregating Device Fishery;
- endorsement of the Management Plan for Queen Conch;

- promotion of consultative processes among fishers and other stakeholders in every aspect of fisheries planning, development, management, conservation and sustainable utilization;

- expansion of the marine protected areas programme as a tool to enhance fisheries management;

- adoption of the Caribbean Regional Fisheries Mechanism Regional Management Plan for Flying Fish Fishery; and

- promotion of fisherfolk organizations at local and national levels.

\section{Lesson learned}

Engaging in meaningful consultation and building partnerships with fishers and other stakeholders, including development agencies and partners at regional and international levels, proved key to strengthening fisheries management and development.

Source: Adapted from the country report of Saint Lucia 
ecosystem approach is implemented in bluefin tuna mariculture. Actions undertaken include the establishment of a quota on the amount of wild fish that can be captured for breeding and a size threshold below which individuals cannot be recruited.

Several countries mention the significance of national or regional policy and legal frameworks supporting the implementation of the ecosystem approach. For example, Mexico notes that its Sectoral Programme for Agricultural, Fishing and Food Development (2013-2018) and General Law for Sustainable Fishing and Aquaculture, ${ }^{17}$ which guide its fishing policies, were developed based on ecosystem approaches. A number of European Union member countries mention the Common Fisheries Policy and/or the European Marine Strategy Framework Directive in this regard. Several countries from the Pacific Region mention the Noumea Strategy (A New Song for Coastal Fisheries: Pathways to Change) (SPC, 2015), which highlights the central role of community-based ecosystem approaches to fisheries management in ensuring the future sustainability of coastal fisheries across the region and sets out a pathway for change involving (inter alia) empowering coastal communities, generating the information needed to guide management and policy, strengthening policy and legal frameworks, enhancing collaboration among stakeholders, promoting equitable access to benefits and decision-making, and diversifying livelihood activities.

\subsubsection{Agroecology}

\section{Introduction}

Agroecology has been variously defined as a scientific discipline, a set of farming practices, a social movement or as all three (Altieri, 2002; Dalgaard, Hutchings and Porter, 2003; Francis et al., 2003; Gliessman, 1997, 2015; Timmermann, Félix and Tittonell, 2018; Tomich et al., 2011; Vandermeer,

\footnotetext{
17 Ley General de Pesca y Acuacultura Sustentables. Nueva Ley publicada en el Diario Oficial de la Federación el 24 de julio de 2007 (available, in Spanish, at http://www.fao.org/faolex/ results/details/en/?details=LEX-FAOC072880)
}

2011; Wezel, et al., 2009, 2015). Definitions have ranged from the more ecological concept initially proposed by Gliessman (1997), in which principles such as diversity, integration, synergies and natural regulation were used to characterize agroecological management, to more recent variants that stress the social and cultural aspects of agroecological farming and agroecological movements (e.g. Dumont et al., 2016; Timmermann, Félix and Tittonell, 2018). According to the High Level Panel of Experts on Food Security and Nutrition,

from a scientific and technical perspective, agroecology applies ecological concepts and principles to food and farming systems, focusing on the interactions between microorganisms, plants, animals, humans and the environment, to foster sustainable agriculture development in order to ensure food security and nutrition for all, now and in the future. Today's more transformative visions of agroecology integrate transdisciplinary knowledge, farmers' practices and social movements while recognizing their mutual interdependence (HLPE, 2016).

Ten elements of agroecology elaborated on the basis of regional seminars on agroecology organized by $\mathrm{FAO}^{18}$ and consultations with various stakeholders are listed in Box 5.5.

The focus on the food system means that agroecology extends beyond the individual farm or rural community and encompasses not only production or ecological dimensions but also social, economic, geographical and cultural dimensions (Dumont et al., 2016; Duru, Fares and Therond, 2014; Sevilla Guzmán, 2002; Tittonell et al., 2016; Warner, 2005). Structural and functional diversification of

\footnotetext{
18 In September 2014, FAO hosted the First International Symposium on Agroecology for Food Security and Nutrition. Building on the outcomes, FAO convened a series of regional meetings to better understand the different contexts and specific local needs of agroecology. From 2015 to 2017, multiactor regional seminars were held in five regions (sub-Saharan Africa, Latin America and the Caribbean, Asia and the Pacific, Europe and Central Asia, and the Near East and North Africa), involving 1400 participants from 170 FAO member countries In April 2018, FAO hosted the Second International Symposium on Agroecology for Food Security and Nutrition.
} 
Box 5.5

The ten elements of agroecology

Between 2015 and 2017, FAO held several multi-actor regional meetings on agroecology, which led to the elaboration of ten elements of agroecology. Based on scientific literature, in particular Altieri's five principles of agroecology (Altieri, 1995) and Gliessman's five levels of agroecological transitions (Gliessman, 2015), and aligned with civil-society values on agroecology, the ten elements identify important properties of agroecological systems and approaches, as well as key considerations in the development of an enabling environment for agroecology. They serve as a guide for policy-makers, practitioners and other stakeholders in planning, managing and evaluating agroecological transitions.
The ten elements of agroecology are interlinked and interdependent (see figure below). They can be grouped by their characteristics as follows:

- Diversity, synergies, efficiency, resilience, recycling and co-creation and sharing of knowledge are common characteristics of agroecological systems, foundational practices and innovation approaches.

- Human and social values and culture and food traditions are context-specific elements.

- Responsible governance and circular and solidarity economy constitute an enabling environment.

Source: FAO, 20181.

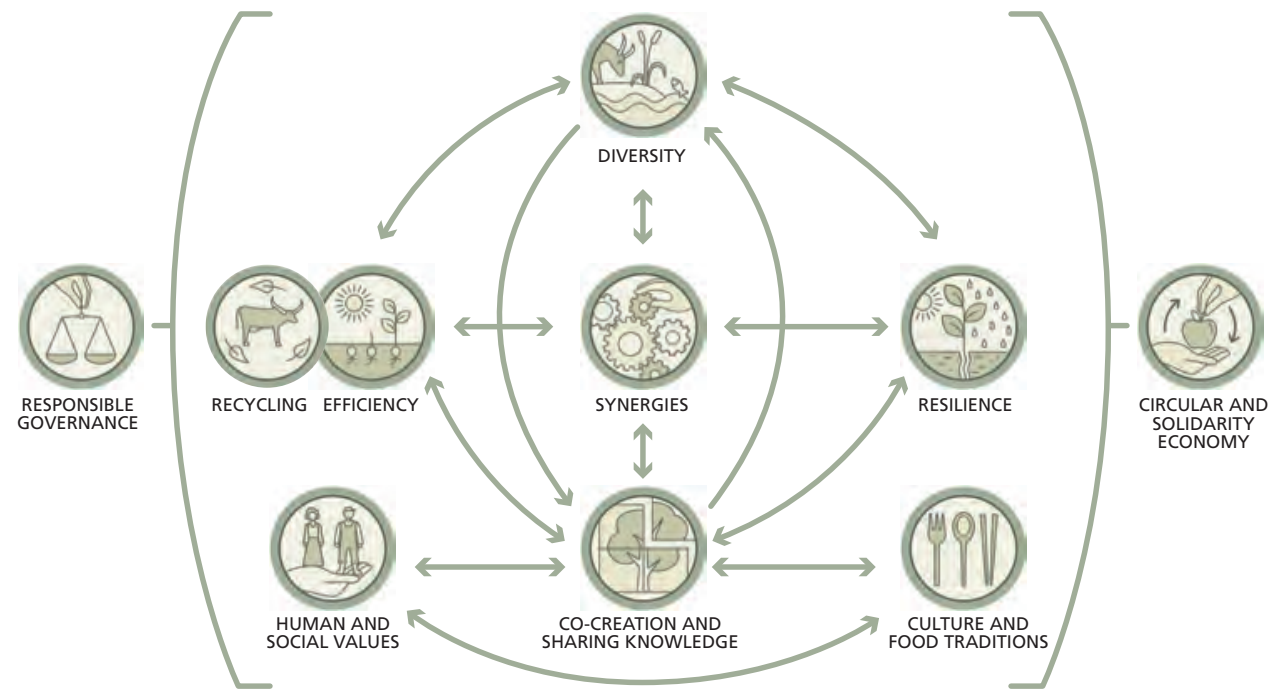

the biological components of production systems in space and time (e.g. intercropping, polycultures, crop-livestock integration, agroforestry, multispecies livestock keeping) is at the core of agroecological design and management. This means that, although no types of production systems are specifically excluded from the scope of agroecology, practical application is largely confined to systems that are cultivated or otherwise actively managed (i.e. as opposed to unmanaged ecosystems from which products are harvested, for example ocean ecosystems used for capture fishing).

Agroecology combines producers' knowledge, including local and traditional knowledge, with formal scientific knowledge. Distinctive features of the science of agroecology include a focus on 
ecological communities (rather than individual species populations), complex feedback mechanisms, randomness and hysteresis (non-linearity, irreversibility and discontinuity), and emerging properties and interactions rather than simple aggregations (Tittonell, 2014). Diversity is regarded as an asset - a source of synergies and risk-spreading and the basis for ecological interactions that sustain essential ecosystem services.

\section{Status and trends}

In describing the state of methods and broader approaches in the management of BFA, many of the sections in this chapter attempt to provide an indication of how widely these methods and approaches have been adopted and what the trends are in this regard. Agroecology, however, is not a technology or a single practice, but rather the context-specific application of ecological and social principles. Arguably, therefore, the concept of "adoption", as used in agricultural economics to assess the diffusion of practices or technologies (agricultural inputs, tillage systems, credit, etc.), may not be useful in discussions of agroecology. Moreover, there are very few registries of agroecological farms (or other types of agroecological holding), i.e. registries of the kind that exist, for example, in many countries for organic farms, and thus no handy sets of statistics that can be quoted to give an indication of trends. While there is a growing body of evidence demonstrating the holistic benefits of agroecology across the environmental, social and economic dimensions of sustainability, one of the challenges is that agroecology is heterogeneous and location specific. FAO is working with partners to coordinate efforts and build a more consolidated evidence base through the development of a global knowledge product and community of practice. One indicator that may be more amenable to monitoring is the extent to which legal and policy frameworks that specifically seek to create an enabling environment that promotes agroecology have been put in place (see for example Figure 5.3), although usage of the term in this context will inevitably vary from country to country.
A substantial share of smallholder farmers and pastoralists around the world practise some form of agroecology, or follow some agroecological principles. However, it is difficult to determine both how many producers there are in these categories (e.g. Lowder, Skoet and Singh, 2014) and what proportion of their farms or holdings might reasonably be described as agroecological. According to Lowder, Skoet and Singh (2014), family farms account for 90 percent of the 570 million farms worldwide and produce more than 80 percent of the world's food in value terms. Moreover, 84 percent of all farms are smaller than 2 ha, although these account for only 12 percent of total agricultural land (ibid.). Some estimates (e.g. Tittonell et al., 2016) have suggested that at least a third of family farms follow agroecological principles in full or in part, which would mean that a substantial proportion of global food output comes from agroecological production.

Although the country-reporting guidelines did not include any specific question on agroecology per se, a substantial number of country reports (approximately 20 out of the 91) include explicit references to agroecological approaches in the context of one or more of the various BFArelated activities and provisions reported. Many more refer to activities that while not specifically described in these terms are relevant to agroecology. France, for example, mentions a range of initiatives specifically promoting agroecology. It notes, for instance, that as of 2016 about 300000 ha (which amounts to approximately 1 percent of the country's agricultural land) ${ }^{19}$ were being managed in accordance with agroecological principles, by about 4000 farmers belonging to 246 Economic and Environmental Interest Groups (Groupements d'Intérêt Économique et Environnemental).

Policies and legal frameworks that specifically aim to promote agroecological approaches are mentioned in several reports. For example, Brazil refers to its National Policy of Agroecology and Organic Production, which, among other objectives, aims to promote food and nutritional

\footnotetext{
19 Based on 2014 data recorded in FAOSTAT.
} 


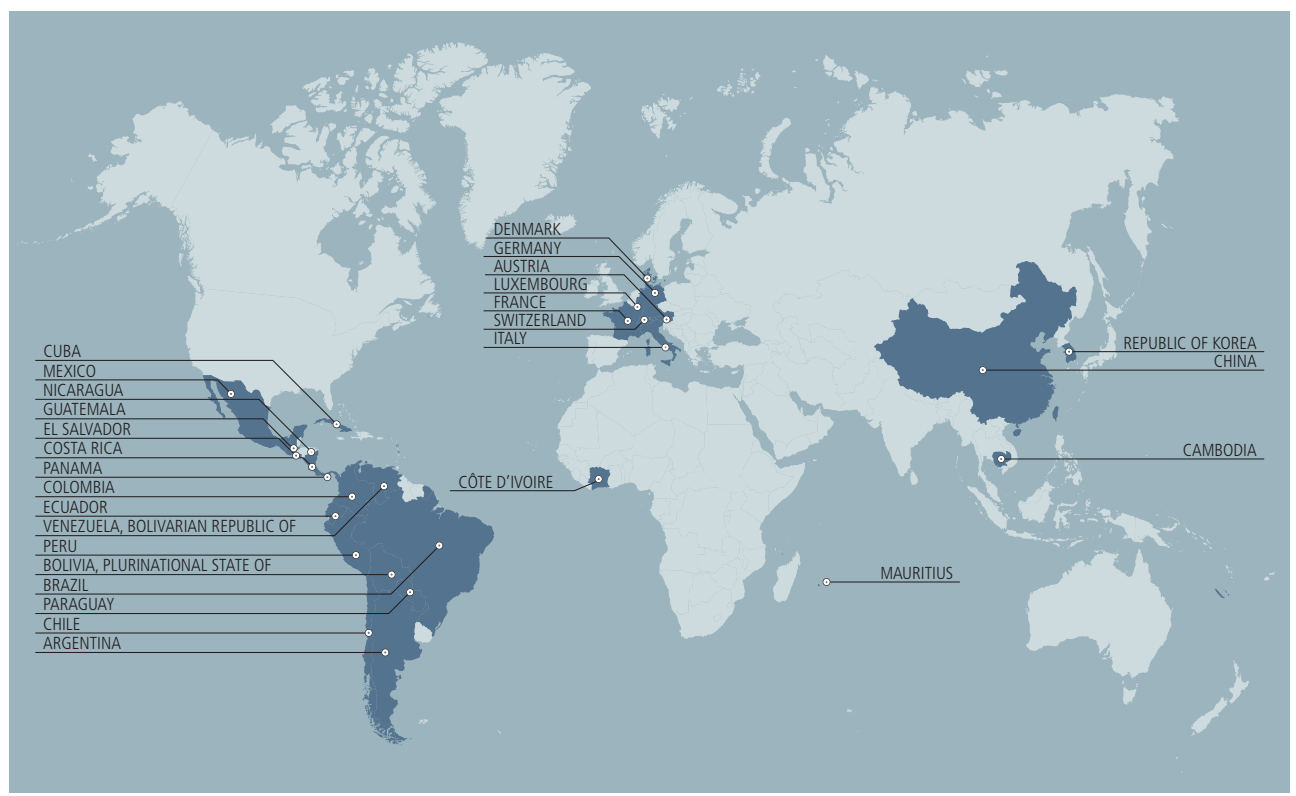

Notes: Countries that have implemented laws, regulations and policies in support of agroecology (based on data available in FAOLEX [http://www.fao.org/faolex/en] in April 2018) are highlighted in dark blue. Detailed information and links to the documents can be found in the Agroecology Lex database, part of FAO's Agroecology Knowledge Hub (http://www.fao.org/agroecology/policies-legislations/en).

sovereignty and security and the human right to adequate and healthy food, by means of the provision of organic and agroecological products (see Box 7.19 for further information on the National Plan for Agroecology and Organic Production [PLANAPO] and related instruments). The report from Nicaragua indicates that the country's National Biodiversity Strategy includes two targets specifically related to the promotion of agroecological production.

Some reports mention the work of NGOs that are promoting agroecology. Zimbabwe, for example, mentions the Participatory Ecological Land Use Management (PELUM) Zimbabwe ${ }^{20}$ whose members

20 Part of the PELUM Association, a regional network that was founded in 1995 to promote participatory ecological land-use management practices for improved livelihoods. are "advocating, promoting and provoking debate, sharing information, and lobbying around issues relating to the way forward for sustainable agriculture and land use practices in Zimbabwe."

The other main areas of agroecology-related activity noted in the country reports are research and education, the latter mostly carried out by universities, although the report from Niger mentions training for farmers provided by the Peasant Platform of Niger (Plateforme Paysanne du Niger). See also Box 8.15 for an example of participatory workshops on agroecological management and biodiversity conservation in Chile. Where research is concerned, Argentina mentions that its National Agricultural Technology Institute (Instituto Nacional de Tecnología Agropecuaria) ${ }^{21}$ has

\footnotetext{
21 https://inta.gob.ar
} 
conducted several research projects related to agroecology and in 2013 established an Agroecology Network, ${ }^{22}$ with the objective of compiling existing knowledge, supporting agroecological research in a comprehensive manner, and linking research and extension at national, regional and local levels. The country report notes that within this framework a system has been developed to monitor soil quality and soil management on agroecological farms and conduct long-term trials. Research themes are prioritized by a coordination team in consultation with the crop, livestock, aquaculture and forest sectors.

China mentions that the Twelfth Five-year Plan for Agricultural Technology Development, compiled by the Ministry of Agriculture, includes monitoring of biodiversity in agroecological systems. It further notes that a demonstration project focused on changing production patterns in ecologically fragile zones in northwestern China promotes agroecology, along with ecotourism and rotational grazing, to improve the living standards of local farmers and livestock keepers while conserving biodiversity.

\subsubsection{Landscape and seascape approaches and management}

Ten reporting countries, located across various regions, indicate the implementation of landscape approaches. ${ }^{23}$ Such approaches are reported to have been adopted, at least to some extent, in each of the terrestrial production system categories listed in the country-reporting guidelines. However, the approaches described in the country reports are quite diverse, both in terms of the scale at which they are applied and their objectives. Bhutan, Germany and Switzerland, for example, report that the landscape approach is the very basis of national policies for the conservation and sustainable use of BFA. Other countries mention applying landscape approaches for more specific purposes. For example, the United States of America mentions its use in pest management.

\footnotetext{
22 https://inta.gob.ar/proyectos/red-de-agroecologia-0

23 Countries were not specifically invited to report on seascape approaches, but nonetheless reported relevant initiatives.
}

Among examples of the implementation of landscape or seascape approaches at a multicountry scale, Kiribati refers to the Framework for a Pacific Oceanscape, ${ }^{24}$ a collaborative agreement between 15 Pacific Island nations for the integrated management of 38.5 million $\mathrm{km}^{2}$ of ocean (four times the size of continental Europe) surrounding their territories. It notes that the agreement covers ocean health and security, governance, sustainable resource management, research and knowledge, and facilitation of the partnerships and cooperation needed to support the conservation of such vast ecosystems.

The information provided in the country reports does not allow conclusions to be drawn as to the extent of the area covered by landscape approaches or the effect that such approaches are having on BFA. However, most of the reporting countries indicate that adoption and implementation are becoming increasingly widespread.

As well as including a question on landscape approaches per se, the country-reporting guidelines also invited countries to report on "landscape management", i.e. practices that support the maintenance of biodiversity-friendly farming systems and diversity of landscape mosaics within and around production systems, for example the management of riparian corridors, hedges, field margins, windbreaks, woodland patches, clearings in forests, waterways, ponds or other biodiversity-friendly features of the production environment. The practices most commonly reported in this context include agroforestry and (mainly by European countries) the use of herbivorous animals to manage and maintain open and diverse semi-natural landscapes. Several countries mention the relevance of protected areas (see Chapter 7). Some note that they have adopted environmentally friendly farming practices (sometimes encouraged by incentive programmes) for the maintenance of landscape diversity, including the maintenance of hedgerows, grass strips and vegetated field margins.

\footnotetext{
24 http://www.forumsec.org/pages.cfm/strategic-partnershipscoordination/pacific-oceanscape/pacific-oceanscapeframework.html
} 
More than 40 percent of the country reports indicate the implementation of practices considered to fall into the landscape-management category (Table 5.1 and Table 5.3). ${ }^{25}$ Approximately 50 percent of these countries indicate that the practices in question are applied in livestock grassland-based production systems. A similar proportion mention their use in mixed production systems. Their use in forest and rainfed crop systems is reported somewhat less frequently. For all these categories of production system, most countries report a positive trend in the use of the landscape-management practices. Use is reportedly increasing most markedly in mixed systems and in naturally regenerated and planted forests (Table 5.2).

\subsubsection{Integrated land- and water-use planning}

Like many other integrated approaches, integrated land- and water-use planning is an evolving concept for which there is no generally agreed definition. FAO $(2018 \mathrm{~m})$ describes integrated landuse planning as the "allocation of land to different uses across a landscape in a way that balances economic, social and environmental values." It notes that the objective of the approach is "to identify, in a given landscape, the combination of land uses that is best able to meet the needs of stakeholders while safeguarding resources for the future" and that "effective land-use planning provides direction on the manner in which land-use activities should take place and encourages synergies between different uses." Management of this kind can be carried out at various scales, including the landscape, subnational, national or regional. At the landscape level, it is often an integral part of a landscape approach, which (as discussed above) will involve comprehensive stakeholder participation aimed at harmonizing different uses and minimizing the risk of conflict. Land-use planning generally takes place within a framework of

\footnotetext{
${ }^{25}$ Several countries note that these practices are difficult to distinguish from each other and from other types of intervention they were invited to report on, for example restoration practices (see Section 5.4).
}

Box 5.6

The Pacific Ridge to Reef approach an example of integrated land- and water-use planning

The Pacific Ridge to Reef approach is a Global Environment Facility programmatic initiative involving multiple United Nations agencies, the Pacific Community and 14 Pacific Small Island Developing States (PacSIDS) (GEF, 2016). The overall objective of the projects undertaken in PacSIDS under this initiative is to maintain and enhance ecosystem goods and services contributing to poverty reduction, sustainable livelihoods and climate resilience, through integrated approaches to land, water, forest, biodiversity and coastal-resource management that span the whole landscape from the ridges of the hills to the fringing reefs of the coasts. The importance of actively engaging multiple stakeholders in the planning, implementation, monitoring and evaluation of the projects is broadly acknowledged throughout the Pacific Island region, where the Ridge to Reef approach is referred to as the "community to cabinet" approach.

Note: For further information, see the Pacific R2R - Ridge to Reef website at https://www.pacific-r2r.org

laws, policies and customary norms that guide the uses to which land may be allocated (ibid.).

As far as the country reports are concerned, the specific integrated land-use planning approach most frequently mentioned is the Pacific Ridge to Reef approach (see Box 5.6). A number of Pacific Island countries indicate that this approach is a key means of promoting the conservation and sustainable use of natural resources at all levels from community to regional. Some explicitly highlight the importance of Ridge to Reef projects as a means of promoting community involvement and empowerment. The projects implemented under the Pacific Ridge to Reef approach mainly aim to strengthen national and local capacities to effectively manage national systems of protected areas in order to promote the conservation of biodiversity, sustainable use of natural resources and 
safeguarding of ecosystem services. Countries note that the approach needs to be better integrated into policy planning, and mention a number of potential means of promoting its adoption and strengthening its implementation, including capacity-building based on lessons learned from implementation to date and awareness raising among decision-makers. Other integrated planning approaches mentioned include integrated coastal zone management.

\subsubsection{Needs and priorities}

Many country reports include information on the challenges countries face in the implementation of ecosystem and landscape approaches. The country-reporting guidelines specifically invited countries to report on gaps and constraints in the fields of information and knowledge, resources and capacity, and policy and institutional frameworks, and to indicate priority actions needed to address these issues.

\section{Information and knowledge}

Several countries report that both a lack of data on the characteristics of their ecosystems (their extent, temporal and spatial variations, etc.) and limited understanding of ecosystem function and services, including specifically the roles of BFA in this context, are major constraints to the development and adoption of ecosystem approaches. Some note that a lack of clarity regarding the nature of ecosystem and landscape approaches is also an issue, in some cases suggesting that the multiplicity of confusing terminology in this field needs to be harmonized. Several developing countries indicate that information on the application of ecosystem approaches and other innovative practices that may be beneficial to BFA often does not reach producers or only does so after significant delays. Most countries that have adopted ecosystem and landscape approaches mention that there is little concrete evidence as to how successful these approaches are in practice.

Proposed actions in this context include the development of guidelines providing definitions of terms and elucidating the potential benefits of developing and adopting ecosystem, landscape and seascape approaches. Countries emphasize the importance of enhancing research on (i) the functional roles of the various components of BFA in key ecosystem processes and in the supply of ecosystem services at production system, ecosystem and landscape levels and (ii) the effects of adopting ecosystem or landscape approaches (as opposed to more conventional approaches) on components of BFA. Measuring success in landscape or ecosystem approaches also remains challenging. Some countries note the need for baseline surveys, indicators and monitoring systems that allow impacts to be evaluated. Some mention the need to establish national databases for mapping and monitoring components of BFA and the production systems in which they occur, including for the purposes of valuating them and assessing linkages and trade-offs between different ecosystem services. Several European countries state that exercises of this kind are crucial for the development of payment for ecosystem services schemes.

\section{Resources and capacity}

Across all regions, most reporting countries indicate that the financial resources needed to develop and implement ecosystem approaches are insufficient or insecure. The absence of adequate funding is reported to constrain a range of key activities, including research (see above), education and training, and the implementation of existing legislation, strategies and programmes. A lack of trained and qualified technical and scientific personnel (both specialists, such as taxonomists and entomologists, and experts with cross-disciplinary knowledge) is widely regarded as a constraint. Several countries indicate that inadequacies in transport and communications infrastructures also hamper implementation.

Aside from stepping up efforts to mobilize funds to build the institutional and technical capacity needed (including long-term funding essential in this context, as average project length is too short), reported priorities in this field include capturing and disseminating lessons learned, 
including success stories, in the development and implementation of ecosystem, landscape and seascape approaches. Many countries also note the importance of integrating (or strengthening the integration of) such approaches into education and training programmes at all levels.

\section{Policy and institutional environment}

Landscape and ecosystem approaches are integrated approaches that require cross-sectoral thinking and governance. However, relevant institutional frameworks (policies, laws and regulations) are reported still to be very compartmentalized. Many countries indicate that the lack of a holistic, multidisciplinary approach at policy level is one of the major constraints to the adoption of ecosystem approaches. Many countries indicate that they have a range of relevant sectoral policies in place but note that these are operated by different agencies and are not integrated into a broader institutional framework. Some report that they have made significant efforts to address this constraint, for example by strengthening collaboration and consultation between environmental and agricultural authorities.

Several countries note the potential for conflicts in the planning and implementation of ecosystem approaches and emphasize the importance of involving diverse stakeholders with diverse values and perceptions in planning processes. Some, however, note that such processes can be difficult and time consuming and may give rise to "fudged" compromises rather than effective plans. Some also mention a lack of consultation between policy-makers at national or regional levels and stakeholders at local level, noting that this leads to a degree of disconnection between political and operational levels. Policy development and implementation related to ecosystem, landscape and seascape approaches are frequently reported to be hampered by knowledge gaps and/ or by shortages of financial resources and trained personnel (see the subsections above).

Reported priorities in this field include:

- reviewing, and if necessary updating, relevant policies and legal instruments, across sectors, and, where needed, developing integrated policies, plans or strategies that facilitate more holistic and multidisciplinary approaches;

- promoting interdisciplinary consultation and cooperation, including between agricultural and environmental authorities; and

- better integrating the outcomes of valuation exercises for biodiversity and ecosystem services into policy-making.

\subsection{Restoration practices}

- Restoration has acquired a prominent place on the global environmental agenda since 1990.

- If well planned, restoration practices can provide simultaneous benefits for agricultural productivity, biodiversity conservation and the supply of ecosystem services.

- In recent years, the concept of forest landscape restoration, with its emphasis on the restoration of a balanced set of ecosystem functions, has inspired ambitious pledges from governments and subnational jurisdictions.

- Many countries report successful examples of restoration practices and their benefits in both terrestrial and marine environments. However, more research is needed into the long-term impacts of restoration, and national policy frameworks that allow restoration practices to be scaled up need to be developed.

\subsubsection{Overview}

The term "restoration practices" can be applied to a variety of techniques employed for a range of different objectives. It is defined as follows in the country-reporting guidelines: "restoring functionality and productive capacity to ecosystems, forests, landscapes, waterways, grasslands and rangelands in order to provide food, fuel, and fibre, improve livelihoods, store carbon, improve adaptive capacity, conserve biodiversity, prevent erosion and improve water provisioning and quality." This focus on functionality and productive capacity can, however, be contrasted with notions of ecological and ecosystem restoration 
that aim to "assist the recovery of a degraded ecosystem towards a reference native ecosystem" with "specific composition, structure and functions" (McDonald et al., 2016).

Recent global policy discourse around restoration of terrestrial ecosystems has focused on the concept of forest and landscape restoration, defined as "the long-term process of regaining ecological functionality and enhancing human well-being across deforested or degraded forest landscapes" (IUCN and WRI, 2014). Like other landscape approaches (see Section 5.3), forest and landscape restoration seeks simultaneously to improve both ecological integrity and human well-being (Holl, 2017), balancing different goals by creating a mosaic of interdependent land uses, including crop and livestock production, agroforestry, improved fallow systems, ecological corridors, discrete areas of forest and woodland, and riparian plantings that protect watercourses (IUCN, 2016b). It aims to use comprehensive spatial planning, undertaken in consultation with landowners and other stakeholders, to allocate land uses more efficiently and improve their individual and overall sustainability. For example, ecological intensification techniques can increase agricultural productivity in those parts of the landscape identified as being the most suitable for production while allowing natural regeneration to occur elsewhere (Latawiec et al., 2015). Restoration of mixed-use agricultural land between areas of primary forest can create habitat corridors for wildlife (IUCN, 2016b).

Numerous restoration projects have shown that it is possible to recover elements of the original composition, function and structure of natural ecosystems at specific sites (Wortley, Hero and Howes, 2013). Some argue, however, that the high costs and long time frames often associated with ecological restoration efforts mean that such approaches cannot achieve recovery at the large spatial scales that would be required in order to have a substantial impact in global terms (Murcia et al., 2015). Landscape-scale restoration efforts focus on recreating conditions that allow natural regeneration to take place, aided where necessary by judicious planting or other interventions.
In conditions where resources are limited, restoration can be implemented in a number of steps, for example restoring forest cover first and later focusing on the wider aspects of ecosystem complexity required for resilience against climate change and other pressures (Dudley and Maginnis, 2018). The effects of large-scale restoration measures typically extend beyond the immediate area targeted: for example, at the scale of a watershed, restoration practices in upstream areas may provide positive effects downstream, such as reduced sedimentation and siltation of river courses and lower risk of flooding.

Restoration can play a vital role in wetland and other aquatic ecosystems (Speed et al., 2016), although (as in the example above) improving the state of aquatic ecosystems generally requires action in connected terrestrial ecosystems. In the case of lakes, restoration typically focuses on reducing eutrophication (generally this requires action on land to reduce runoff from agriculture) and, in the case of rivers, on habitat improvement, creation of riparian buffers and removal of weirs and other barriers to connectivity (Verdonschot et al., 2013). Efforts in marine ecosystems typically focus on the removal of sediment barriers, restoration of water flow and salinity balance, direct creation of habitat features and reduction of nutrient concentrations (ibid.). Key restoration measures and their objectives are listed in Table 5.4.

It is relatively easy to "restore" fish populations by restocking waterbodies where capacity to expand stocks naturally has been lost because of destruction of spawning grounds or loss of ecosystem connectivity - and this tends to be a popular option given that it can be done with short-term funding and provides results that are immediately visible. It is far harder and more time consuming to restore the functioning of the ecosystem, as this requires re-establishing connectivity or at least removing source(s) of ongoing damage to the ecosystem. The latter is very challenging when the problems are being caused by runoff or other forms of pollution (see Chapter 3 for further discussion of the impacts of pollution, land-use change and other drivers on aquatic ecosystems and biodiversity). 
TABLE 5.4

\section{Restoration measures for wetlands and other aquatic ecosystems}

\begin{tabular}{|c|c|c|}
\hline $\begin{array}{l}\text { Component of the } \\
\text { ecosystem }\end{array}$ & Restoration measure & Objectives \\
\hline Catchment & Catchment management & $\begin{array}{l}\text { Altering the entry of water, sediment and other matter into } \\
\text { the river channel. }\end{array}$ \\
\hline \multirow{5}{*}{ Flow regime } & Restoration of ecological flows & Changing the volume, timing, frequency and duration of flows. \\
\hline & Storm-water management & $\begin{array}{l}\text { Altering the flow pattern of water runoff from urban areas } \\
\text { (e.g. altering flood peak). }\end{array}$ \\
\hline & $\begin{array}{l}\text { Removal/retrofitting and management of dams and } \\
\text { other barriers to water connectivity and flow (weirs, } \\
\text { gates, culverts, etc.) }\end{array}$ & $\begin{array}{l}\text { Improving flows and ecological outcomes, including improving } \\
\text { the movement of sediment and fish. }\end{array}$ \\
\hline & Flood management & $\begin{array}{l}\text { Managing flooding to improve ecosystem services, but prevent } \\
\text { flooding of key infrastructure or cropland. } \\
\text { Improving flood management through increasing the capacity } \\
\text { of the river system and associated floodplain to store and } \\
\text { release floodwaters. }\end{array}$ \\
\hline & Reconnection of floodplains and wetlands & $\begin{array}{l}\text { Allowing the movement of biota, sediment and other matter } \\
\text { between the channel and the floodplain. }\end{array}$ \\
\hline \multirow[t]{2}{*}{ Regulatory function } & Water-quality improvement & $\begin{array}{l}\text { Protecting or improving water quality, including chemical } \\
\text { composition and particulate load. } \\
\text { Increasing capacity for biological degradation and/or assimilation } \\
\text { of pollutants. }\end{array}$ \\
\hline & Groundwater & Groundwater recharge. \\
\hline \multirow[t]{2}{*}{ Habitat (riparian) } & Riparian management & $\begin{array}{l}\text { Altering the entry of water, sediment and other matter into } \\
\text { the river channel. } \\
\text { Creating or fostering habitat features. } \\
\text { Altering water temperature through shading. } \\
\text { Facilitating migration along the river corridor. }\end{array}$ \\
\hline & Land acquisition & $\begin{array}{l}\text { Acquiring riparian lands to control land use and/or allow } \\
\text { restoration work. }\end{array}$ \\
\hline \multirow{3}{*}{ Habitat (aquatic) } & Habitat improvement & Fostering or creating habitat features. \\
\hline & Bank stabilization & $\begin{array}{l}\text { Reducing erosion/slumping of bank material into the } \\
\text { river/coastal water. }\end{array}$ \\
\hline & Channel reconfiguration & $\begin{array}{l}\text { Altering the channel planform or the longitudinal profile, } \\
\text { increasing hydraulic diversity and habitat heterogeneity and } \\
\text { decreasing channel slope. }\end{array}$ \\
\hline Biodiversity & Species management & Maintaining or increasing the number/diversity of key species. \\
\hline Other & Aesthetic/recreation/education & $\begin{array}{l}\text { Increasing community value, e.g. by improving appearance, } \\
\text { access or knowledge. }\end{array}$ \\
\hline
\end{tabular}

Source: Adapted from Speed et al. (2016).

Although all types of ecosystem can potentially be restored, restoration interventions may in practice favour some at the expense of others (Veldman et al., 2015). Focus on a single function for example climate change mitigation - may lead to the conversion of ecosystems that are valuable for other reasons. For instance, old-growth grassy biomes may be at risk of afforestation as they store less carbon than forested land (Miles and Kapos, 2008; Veldman et al., 2017). This risk can be addressed by analysis at finer scales in the planning of restoration strategies (Chazdon et al., 2016).

Taking account of genetic diversity in the design and implementation of restoration initiatives can significantly increase the chance of success over the long term (Huenneke, 1991). The effects of genetic 
homogeneity in a reintroduced population may not be immediately evident, but over a period of years the population may have lower rates of growth, survival and reproduction, and may be less able to cope with periods of environmental variability. For example, if all individuals in a population are of a genotype that has limited drought tolerance, a single drought may destroy the entire population (Falk, Knapp and Guerrant, 2001). Introducing hatchery-bred fish can lead to genetic introgression into wild populations (Bekkevold, Hansen and Nielsen, 2006; Naish et al., 2007; White et al., 2018).

\subsubsection{Status and trends}

Many of the world's managed and natural ecosystems are degrading. Over the last two decades, approximately 20 percent of the Earth's vegetated surface has persistently declined in productivity (UNCCD, 2017). According to a global assessment of restoration potential carried out for the Global Partnership on Forest Landscape Restoration, there may be more than 2 billion ha of deforested and degraded forest land around the world where there may be opportunities for some type of restoration (WRI, 2014). Further information on the status and trends of forests and other ecosystems of importance to food and agriculture can be found in Section 4.5.

Increasing the functionality and productivity of degraded lands has become a global priority (Aronson and Alexander, 2013), and is reflected in a number of global policy commitments. The Bonn Challenge, launched in 2011, aims to bring 150 million ha of degraded and deforested land under restoration by 2020 . The initiative was endorsed - and its target extended to 350 million ha by 2030 - by the 2014 New York Declaration on Forests (United Nations, 2014b). As of May 2018, 47 national and subnational jurisdictions, private entities and nongovernmental initiatives had made pledges under the Bonn Challenge, amounting to a total of over 160 million ha (see Figure 5.4). ${ }^{26}$

${ }^{26}$ Up-to-date information on these commitments can be found at http://www.bonnchallenge.org/commitments
The restoration and sustainable management of ecosystems have proven to be a cost-effective, safe and immediately available means of sequestering carbon and preventing the emission of greenhouse gases (Epple et al., 2016). Many countries have therefore included ecosystem-based solutions, including ecosystem restoration, in their "nationally determined contributions" to the objectives of climate change mitigation and adaptation under the Paris Agreement ${ }^{27}$ (Laurans, Ruat and Barthélemy, 2016). Sustainable Development Goal 15.3 calls on governments to "strive to achieve a degradation neutral world." In response to the adoption of this goal, the United Nations Convention to Combat Desertification's Land Degradation Neutrality Target Setting Programme has received commitments from 114 countries to date, and is rolling out technical support to refine these commitments and plan their implementation (Orr et al., 2017). Restoration is also a key component of the CBD's Strategic Plan for Biodiversity and the Aichi Targets. Target 5, for example, calls for the restoration of 15 percent of degraded ecosystems (CBD, 2010a). A review covering 62 countries in Asia, Africa and Latin America found that more than 50 percent of countries in each region had a restoration target in their National Biodiversity Strategy and Action Plan or a preliminary target in their Fifth National Report to the CBD (CBD, 2016b). However, in many cases, targets lacked specificity or quantitative elements (ibid.). Some examples of national policy and legislative initiatives related to the contributions of agroforestry to restoration efforts are described in Box 5.11.

While restoration has gained momentum in terms of policy commitments, implementing these commitments is still a challenge. Because of the complexity involved in developing restoration activities, and the amount of data and technical capacity required, many countries are still in the process of planning interventions and land-use transitions (see Figure 5.4). There have,

\footnotetext{
${ }^{27}$ UNFCCC (2015). For further information on nationally determined contributions, see https://unfccc.int/process/ the-paris-agreement/nationally-determined-contributions/ ndc-registry
} 


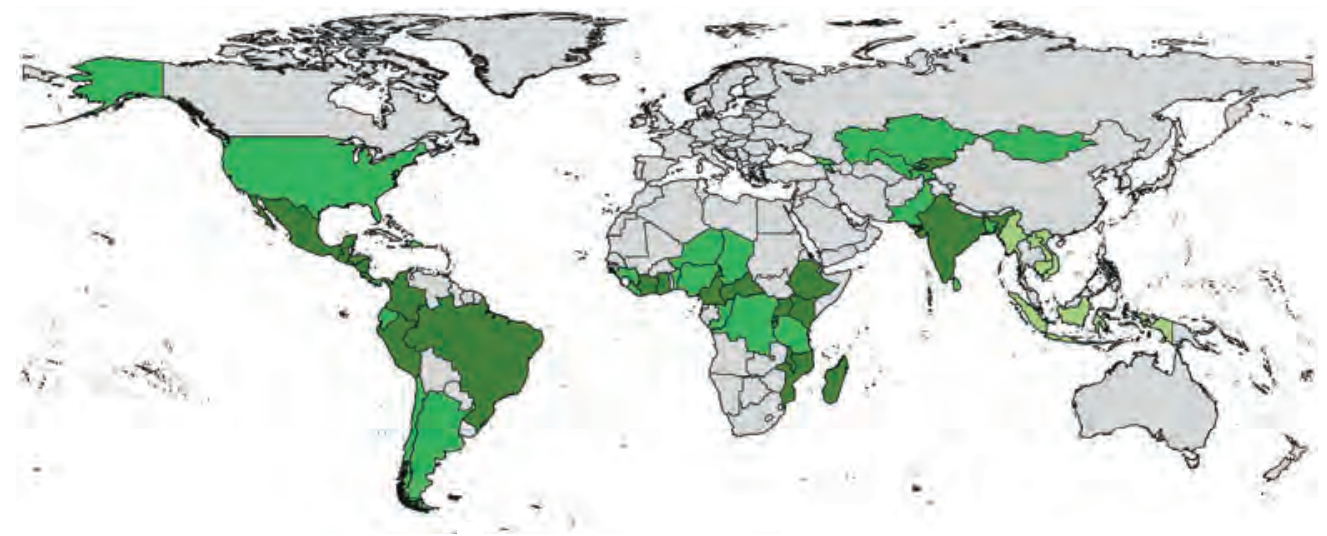

Notes: Dark green indicates countries that have made a commitment to the Bonn Challenge and have completed or are in the process of implementing a Restoration Opportunities Assessment. Mid green indicates countries that have made a commitment to the Bonn Challenge. Light green indicates countries that have completed a Restoration Opportunities Assessment at national scale. The map does not reflect subnational pledges to the Bonn Challenge.

Source: Global Partnership on Forest Landscape Restoration, 2018.

nonetheless, been several examples of successful large-scale restoration efforts (particularly restoration of forest cover) that have been shown to deliver social, environmental and economic benefits. For example, forest cover in the Republic of Korea was significantly increased as the result of an ambitious government-led forest policy (Soo Bae, Won Joo and Kim, 2012). Similarly, forest cover in Costa Rica increased by over 500000 ha between 1992 and 2013, thanks to a governmental payment for ecosystem service scheme (SINAC-MINAE, 2014). In the West African Sahel, 200000 ha of degraded land were reclaimed over three decades through the improvement and diffusion of indigenous soil and water conservation practices and, in another example, land productivity increased over an estimated 5 million ha through farmer-managed natural regeneration using local agroforestry practices (Reij, Tappan and Smale, 2009b).

Most countries that have committed to ambitious forest and landscape restoration strategies are still in the early stages of implementing their commitments, and data are often lacking on the impacts of actions undertaken to date. However, there are some cases in which the effects of forest and landscape restoration on biodiversity and ecosystem services have been quantified. For example, in Colombia, partnerships between land owners and the government are seeking to increase cattle productivity per hectare so that grazing can be stopped on steep slopes and along streams to allow the restoration of riparian forest and improvements to water quality and habitat connectivity (Calle et al., 2013). Results across several farms show that it has been possible to reconcile the goals of improving agricultural productivity, conserving biodiversity and promoting the supply of other ecosystem services: cattle productivity improved by 44 percent, the number of bird species present increased by 32 percent and soil erosion declined by 45 percent (LazosChavero, 2016).

Wetland restoration has been on the global environmental agenda for more than three decades (Ramsar Convention, 1990). A large 
Box 5.7

Needs and challenges in coral-reef restoration

Restoration programmes globally are at various stages of maturity, with the largest concentration of efforts in the Caribbean, where many partners (various governmental and non-governmental research and conservation organizations) are producing the equivalent of 100000 moderate-sized coral outplants per year. Globally, work is showing that restoration of reefs is possible, and the spatial scale of success is steadily increasing. However, to matter at an ecosystem level, major upscaling is needed in terms of resources dedicated to the task and in terms of efficiency in production. While some biological challenges remain to be overcome, most of the challenges to upscaling are engineering ones, and are very similar to hurdles that over been overcome in other fields. Working to close the gap between success at the local level and impact at the ecosystem level will not be easy or quick, but it is the current goal and trajectory of the coral-reef restoration community.

Source: Provided by Tom Moore.

number of restoration projects have been undertaken, primarily in Europe and the United States of America (Speed et al., 2016), and many organizations have been involved. The Ramsar Convention adopted principles and guidelines for wetland restoration in 2002 (Ramsar Convention, 2002), and has long been supporting restoration initiatives through alliances with other organizations. ${ }^{28}$ Examples of significant projects and initiatives in Europe and North America in the past decade include: REFORM (REstoring rivers FOR effective catchment Management) ${ }^{29}$ (Friberg et al., 2016); the MARS project (Managing Aquatic ecosystems and water Resources under multiple

\footnotetext{
28 For further information on partnership agreements entered into by the Secretariat of the Ramsar Convention, see https://www. ramsar.org/about/formal-partnership-agreements

29 http://www.reformrivers.eu/about
}

Stress); ${ }^{30}$ AMBER (Adaptive Management of Barriers in European Rivers); ${ }^{31}$ the WISER project (Water bodies in Europe: Integrative Systems to assess Ecological status and Recovery); ${ }^{32}$ the MERCES project (Marine Ecosystems Restoration in Changing European Seas); ${ }^{33}$ the Reef Resilience Network; ${ }^{34}$ the Coral Restoration Foundation; ${ }^{35}$ and the United States Environmental Protection Agency's work on wetlands protection and restoration. ${ }^{36}$ Needs and challenges involved in coralreef restoration are discussed in Box 5.7.

Information provided in the country reports on the status and trends of restoration practices is summarized in Table 5.1 and Table 5.2. Restoration practices are more frequently reported for terrestrial than aquatic systems, most commonly for forest (both naturally regenerated and planted), grassland-based, crop and mixed systems. Among aquatic systems, restoration practices are relatively frequently reported for self-recruiting capture fisheries. In all cases, reports of increasing trends outnumber reports of stable or negative trends.

Countries providing examples of restoration practices in forest ecosystems include the Netherlands, which mentions that a shift in forest management objectives towards multiple goals - including recreation and nature conservation has led to a greater focus on restorative practices such as increasing the amount of dead wood in the forest, the number of large and thick trees, structural and age-class diversity and the number of native trees. These changes are reported to have led to increases in the numbers of certain forest birds, bats, invertebrates and mushrooms. Finland reports that a forest-biodiversity programme run collaboratively by the Ministry of Agriculture and Forestry and the Ministry of Environment that uses conservation agreements with private landowners to incentivize voluntary forest conservation and

\footnotetext{
30 http://mars-project.eu/index.php/aims.html

31 https://amber.international

32 http://www.wiser.eu

$33 \mathrm{http}: / /$ www.merces-project.eu

34 http://www.reefresilience.org

35 https://www.coralrestoration.org

36 https://www.epa.gov/wetlands
} 
restoration actions covers an estimated 50000 ha. Some countries (e.g. El Salvador, Fiji and Viet Nam) mention the significance of (ongoing or planned) restoration activities in coastal forest ecosystems, in particular mangroves, in terms of reducing coastal erosion and providing protection against disasters caused by extreme weather events or tsunamis.

With regard to restoration practices aimed at agricultural systems, some country reports from Africa note the importance of assisted-fallow systems involving the planting of shade and fruit trees (United Republic of Tanzania) or nitrogenfixing leguminous species for restoring soil fertility (Chad). The report from the United States of America provides an example of a production system being managed to provide a substitute for natural habitat. It notes that in California many farmers now allow their rice fields to flood in the winter instead of burning them after the growing season, which provides 275000 acres (approximately $111000 \mathrm{ha}$ ) of surrogate wetlands and open space for 230 bird species along the Pacific Flyway, many of which are at risk of extinction. ${ }^{37}$ It further notes that this is especially important as 95 percent of California's traditional wetlands have been lost. ${ }^{38}$ Many species are reported to have begun to increase in numbers and the number of ducks to have doubled.

Countries from all regions report restoration practices of one kind or another in aquatic ecosystems. A range of different objectives are mentioned. Supporting wildlife, and in particular migratory species, is emphasized by a number of countries. Finland, for example, reports measures taken to improve migration passages through dams and to regulate water levels in rivers and lakes to accommodate the needs of wild species. It mentions that under its Fishing Act, ${ }^{39}$ extensive river restoration has been carried out across the country, but notes that the impacts of these measures have only been partially evaluated. It

37 The report cites Cline (2005).

38 The report cites California Rice Commission (2015).

39 Fishing Act (379/2015) (available, in English and Swedish, at http://www.fao.org/faolex/results/details/ en/?details=LEX-FAOC 169562) further mentions various policies and programmes that promote practices such as the restoration of potential spawning and nursery areas, construction of fishways, maintenance of natural bypass channels, removal of obstacles to fish migration, and use of natural hydrological-engineering methods. Similarly, the Netherlands notes that measures such as the construction of fish passages and the restoration of waterway banks to create spawning habitats have had positive effects on species population sizes. Poland reports that hydrographic network restoration activities are being implemented in the Biebrza National Park with the aim of improving water conditions, nesting habitats and feeding and resting grounds used by birds during migration and wintering. It notes, however, that in general it has paid too much attention (in relative terms) to restocking measures and too little to improving aquatic habitats by restoring the ecological continuity of rivers. A number of European Union member countries mention the Water Framework Directive, ${ }^{40}$ which requires member countries to "protect, enhance and restore all bodies of surface water... [and] all bodies of groundwater."

Several countries provide examples of restoration activities that have had positive impacts on livelihoods or on the supply of supporting or regulating ecosystem services. For example, Bangladesh mentions its Wetland Biodiversity Rehabilitation Project, which between 2009 and 2015 helped to increase biodiversity and fish production and improve the livelihoods of local people by restoring wetland habitats and the functions of floodplain ecosystems. Nepal refers to the Rupa Lake Restoration Cooperative, the largest agriculture-sector cooperative in the country, which successfully restored the degraded Lake Rupa in the late 1990s by "biomanipulating" it through fish stocking. It notes that the lake has now been restored and cleaned and serves

\footnotetext{
40 Directive 2000/60/EC of the European Parliament and of the Council of 23 October 2000 establishing a framework for Community action in the field of water policy (available at http://eur-lex.europa.eu/legal-content/EN/ TXT/?uri=CELEX:32000L0060)
} 
as a source of livelihood for about 740 families. Rwanda describes the Gishwati Water and Land Management Project and the Landscape Approach to Forest Restoration and Conservation Project, which have tackled flooding disasters by establishing buffer zones for lakes and rivers and restoring lakeshores and riverbanks. These measures are reported to have also benefited local biodiversity, especially fish stocks.

While most of the reported examples of aquatic restoration practices relate to freshwater ecosystems, a few examples from marine ecosystems are also mentioned. For example, Tonga notes that its national Ridge to Reef projects (see Section 5.3.6) include one that seeks to conserve the ecosystem services supplied by the Fanga'uta Lagoon catchment on Tongatapu (the country's main island) by (inter alia) improving the state of critical habitats. Grenada notes that its integrated climate-smart adaptation strategy is targeting the restoration of marine ecosystems, and specifically mentions a project that is restoring coral reefs.

Finally, a number of country reports describe policy frameworks used to support restoration practices. For example, Senegal mentions that restoration of degraded ecosystems takes place within the framework of community-based plans for land use and land designation. Mexico reports that its government supports forest restoration actions through the provision of subsidies, with eligibility being determined based on levels of degradation, the extent of perturbation caused by natural disasters and the environmental importance of catchment areas. The programme is estimated to have brought about the restoration of over 400000 ha of forest between 2013 and 2014. France mentions the difficulty of attributing restoration practices to a particular production system, ${ }^{41}$ noting that many restoration projects and programmes in terrestrial production systems adopt a landscape approach that involves a mosaic of land uses. It also highlights the fact that 30 percent of agricultural subsidies from the European Union

${ }^{41}$ Countries were invited to report restoration activities production system by production system. are now conditional upon a percentage of arable land being set aside to allow the recovery of natural grasslands and other habitats of ecological interest, and notes that these are monitored though a GIS-based online register.

\subsubsection{Needs and priorities}

Countries note a number of needs and priorities in the field of restoration. Some of these relate to the types of ecosystems or specific objectives that need to be targeted. Restoration of forest ecosystems is widely highlighted as a priority, including in some cases restoring connectivity between forest fragments. Spain, for example, mentions the importance of restoring forest cover in areas that are important to the supply of hydrological and erosion-control ecosystem services. Mexico mentions the need for genetic improvement of priority forest species, taking into account the predicted effects of climate change, and promotion of their use in the restoration of degraded forest areas. Countries also highlight a range of freshwater, marine and coastal ecosystems as priorities, including dunes, mangroves, seagrass beds, coral reefs, coastal sand dunes, lakeshores and riverbanks. The need to improve connectivity between ecosystems and to account for threats posed by climate change is again noted. Some countries emphasize the importance of improving habitat ecosystem services, including the restoration of fish-spawning sites.

A number of countries note the need to improve policy and legal frameworks in this field, including with respect to identifying responsibilities for restoration activities, streamlining procedures for the use of protected species in restoration programmes and introducing or strengthening incentive measures for restoration. Reflecting the wider literature on forest-landscape restoration (e.g. Holl, 2017), several countries note the need to strengthen the involvement of stakeholders, including local communities, in planning and implementing restoration activities. Research on the effectiveness of restoration activities, including over the long term, is also highlighted as a priority. This is again consistent with the wider 
literature, for example Wortley, Hero and Howes (2013), whose review of ecological restoration projects underlined the need for further investment in monitoring the impacts of restoration, especially with regard to quantifying ecosystem services and other socio-economic outcomes.

\subsection{Diversification in production systems}

- Countries generally report upward trends in the implementation of various diversification practices in food and agriculture (approaches combining different varieties, species and groups of organisms within the production system).

- Integrated crop-livestock systems are major contributors to global food production and can provide opportunities to reduce waste and the use of external inputs. Despite the spread of "landless" livestock systems, low-income countries have seen a general trend towards greater integration of crop and livestock production activities as population density has increased.

- Home gardens are often vital reservoirs of biodiversity for food agriculture (BFA), particularly in the case of plants, but there are no comprehensive global statistics on their distribution. Countries that report the presence of home gardens generally note increases in their use.

- Agroforestry is reported to be increasing in every region: it is estimated that more than 5 million $\mathrm{km}^{2}$ of agricultural land ( 23 percent of the total) have at least 20 percent tree cover. Global recognition of the contributions of agroforestry has increased over the past decade, as has the mainstreaming of agroforestry into development and environmental agendas and appreciation of its potential impact on rural livelihoods, climate-smart agriculture, biodiversity conservation and land restoration.

- While there is no systematic global monitoring of diversification practices in aquaculture (integration of different aquatic species and/or integration with other components of BFA, such as crops, livestock or trees), it is clear that the relative contributions of different kinds of integrated systems are changing in response to economic transformations, technical developments, space constraints, production-system intensification, climate change, diseases and other drivers.

The discussion of ecosystem services, resilience, sustainable intensification, livelihoods and food security and nutrition presented in Chapter 2 provides numerous illustrations of the potential benefits of increasing or maintaining the diversity of the species, varieties or breeds raised in a production system, including by combining different groups of species such as crops, livestock, trees and aquatic organisms. Aside from being invited to report on the significance of BFA in each of the above-mentioned thematic areas, countries were also specifically invited to report on the status and trends of diversification practices and on any impact they have had on BFA. In addition, countries were invited to report on a number of other management practices that by definition involve diversification, namely agroforestry, home gardens and diversification practices in aquaculture. ${ }^{42}$ This section provides an overview of these practices and the information reported by countries on each of them. Although countries were not specifically invited to report on integrated crop-livestock systems as a distinct category, a short discussion of this type of production system is also included.

According to the country-reporting guidelines, diversification is "the introduction of new varieties, species and groups of organisms (e.g. livestock, crops, trees, fish) into a production system or managed environment without replacement or abandonment of other groups, or the maintenance of already-existing diversity in the case of traditionally diverse production systems." Based on this definition, 40 country reports indicate "diversification" in at least one category of production system (Table 5.1).

Across all types of production system, diversification is more frequently reported to be increasing than to be decreasing. Unsurprisingly,

\footnotetext{
42 Specifically polyculture and aquaponics.
} 
diversification is most frequently reported for mixed systems (32 percent of countries that report the presence of such systems) (Table 5.2). If all production systems are aggregated, the practice is reported by 63 percent of OECD countries and 39 percent of non-OECD countries (Table 5.1).

Specific diversification practices mentioned include intercropping, crop rotations, use of multiple crop varieties within a given species, multispecies aquaculture, and multispecies livestock herds and flocks. Countries generally provide few additional details about trends in diversification. Some mention drivers of change that are influencing trends. Finland, for example, notes that diversification is increasing as a result of increasing awareness among farmers of the benefits of including additional crops in their rotations. The Netherlands notes that consumer demand for organic products is driving diversification in Dutch agricultural systems. Poland mentions that in fed aquaculture disease threats have led to the introduction of resistant fish species (e.g. Salvelinus spp.). The floating gardens of Bangladesh, a traditional intercropping production system, are described in Box 5.8 .

\subsubsection{Integrated crop-livestock systems}

\section{Introduction}

Integrated crop-livestock systems are very widespread globally, can be found in many types of environment, operate on a range of scales and

Box 5.8

The floating gardens of Bangladesh

The specific agroecological conditions of the wetlands of the south central coastal districts of Bangladesh have led to the development of a very particular production system known as floating gardens, or locally as dhap.

The system involves growing a wide range of crops vegetables and spices - on beds made of water hyacinths and other aquatic weeds such as tapapana, dulalilata and khudipana, which are widely available locally. Crop seeds are prepared separately in containers using a structure called a tema, which is made of locally available peat soil and wrapped in coconut coir. Grown seedlings are subsequently transplanted into the floating garden beds. The major vegetable crops grown in summer include okra, ribbed gourd, Indian spinach, brinjal, cucumber, red amaranths, stem amaranths and wax gourd. In winter the main crops are turnip, cabbage, cauliflower, tomato and red amaranths. Spices grown include turmeric and chili.

Mixed intercropping is the predominant form of production in floating gardens. Pest and disease infestations are minimal. As decomposed water hyacinths are used as fertilizer, external-input requirements and production costs are low. Under flooded conditions, the open water is used for fishing.

This production system is the only food production and livelihood option for 60 to 90 percent of the country's

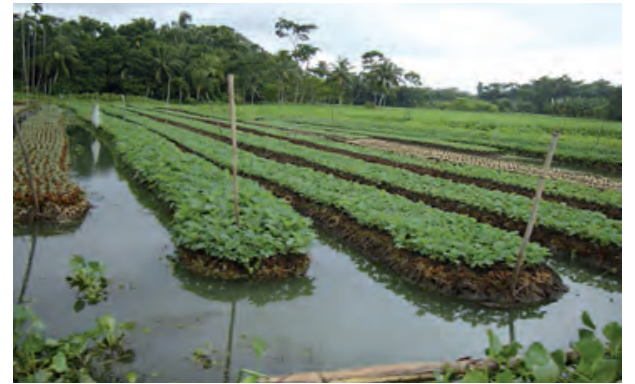

local communities, providing them with a diversified and nutritious diet thanks to the wide range of vegetables and spices it produces. Given the very specific and difficult growing conditions, production yields are satisfactory.

Options for further improving the production system include strengthening the social organization and distribution of activities at local level, improving product marketing, development of scientifically recommended adapted crop-production packages and development of ad hoc agroprocessing activities.

Source: Adapted from the country report of Bangladesh. Picture provided by Aziz Zilani Chowdhury. 
involve many different combinations of crop and livestock species. There are multiple links between crop and livestock production. Livestock are often fed on crop residues, such as straw or leaves, and by-products of crop-processing, such as bran, molasses and pulps, that might otherwise be discarded. These residues and by-products represent about one-third of the total feed intake of livestock globally (considering cattle, buffaloes, sheep, goats, chickens and pigs across all production systems) (Mottet et al., 2017). Livestock, as well as producing milk, meat and offspring, provide draught power for farm operations, transportation and pumping water. Their dung and urine can be applied to fields as fertilizers. Animal manure can be used as a source of energy in the

\section{Livestock and crop integration: from a linear to a circular bioeconomy}

\section{LINEAR}

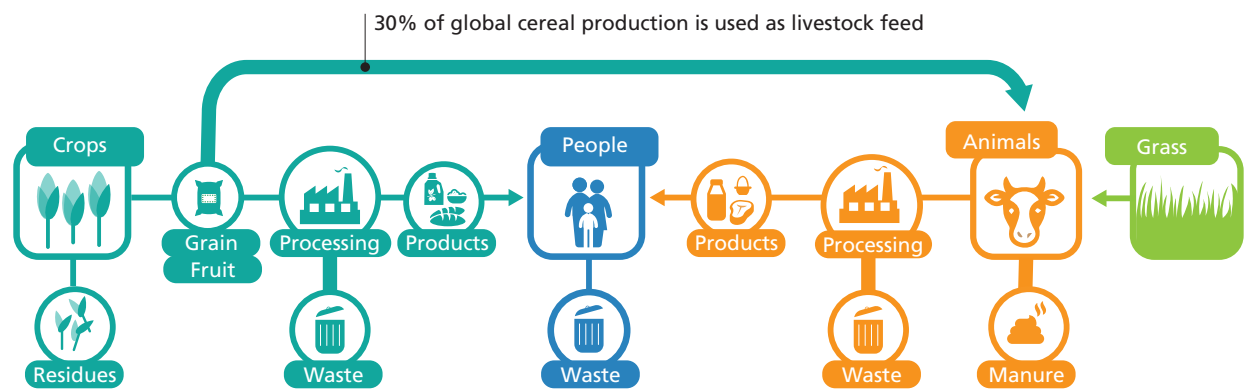

CIRCULAR

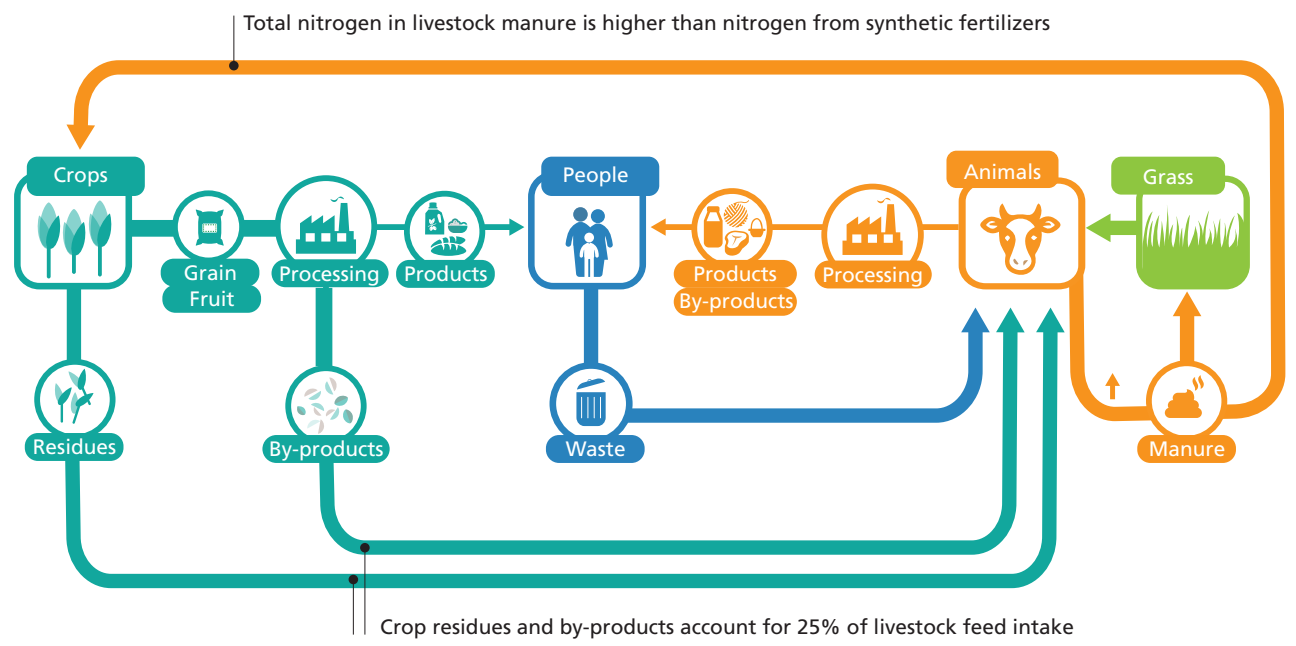

Source: FAO, 20180 
form of biogas or dung cakes that can replace charcoal and wood. Figure 5.5 illustrates how the relationship between crop and livestock production can either be "linear", with the by-products of each activity being wasted, or "circular" with the by-products of each component of the system serving as inputs to the other. Integration of this kind can occur within an individual farm or between separate farms. As well as providing biophysical benefits, crop-livestock integration can also provide a buffer against economic risks associated with the failure in one component of the system caused, for example, by climatic shocks or pest or disease outbreaks (see also Section 2.3).

Historically, crop-livestock integration has been strongly driven by population growth and the need to generate more food from the same amount of land and hence to intensification through ploughing with draught animals and the use of animal manure as fertilizer (Boserup, 1965; Mazoyer and Roudart, 2006; McIntire, Bourzat and Pingali, 1992).

Although the environmental impacts of mixed systems vary greatly, integration creates opportunities to reduce environmental problems (including impacts on biodiversity) associated with waste disposal or the supply and use of external inputs. Appropriately used livestock manure can benefit soil biodiversity (FAO, 2018f). If a farm contains a combination of crop fields and pastures, this will add some diversity to local habitats and may help support a more diverse range of pollinators, biological control agents and other components of associated biodiversity. Where domesticated biodiversity is concerned, while the crop or livestock components of mixed farms are not necessarily diverse in terms of their species and within-species composition, overall such systems can be assumed to create a variety of "niches" that do not exist in specialized crop or livestock systems and hence to promote the maintenance of a relatively diverse range of genetic resources. For example, a mixed farm may require animals that can provide draught power and thrive on diets that are heavy in crop residues.

Agropastoral systems are a specific form of croplivestock integration. They are found mainly in drylands and are characterized by the integration of crop production with rangeland grazing, in some cases involving transhumance, i.e. the movement of herds/flocks away from the farm for part of the year. This kind of integration can involve the herds and croplands belonging to a single household, but can also involve arrangements between households. For example, transhumant Fulani pastoralists in West Africa arrange to graze their animals on the stubble left in fields after farmers have harvested their crops, the animals benefiting from the feed and the fertility of the cropland benefiting from the droppings left by the animals.

Integration of trees with livestock production (a form of agroforestry, see also Section 5.5.3) is widespread globally. Systems in which perennial trees or shrubs are grown together with herbaceous crops and integrated with livestock production are referred to as agrosilvopastoral systems. These systems are particularly common in parts of Africa, where uncertain weather conditions mean that crop production is risky. Multipurpose trees (e.g. Leucaena and Gliricidia) grown in hedges between crop plots enhance soil fertility, improve crop yields, provide feed for animals and serve as a source of fuelwood (Devendra and Ibrahim, 2004). Integration of trees and shrubs into pastures grazed by animals (silvopastoralism) is very common in the tropics, particularly in small-scale systems. Intensive silvopastoral systems in which fodder shrubs planted at high densities are combined with improved pastures are also common, especially in Latin America (Chará et al., 2018). Grazing livestock can also be integrated with various kinds of tree crops, for example coconut trees in the tropics or fruit trees in Europe (see, for example, Box 5.11).

\section{Status and trends}

Sources of information on the status of croplivestock integration are scattered and usually not consolidated at regional or global level (Herrero et al., 2007). National agricultural statistics services collect data on crop and livestock in agricultural holdings, but these data are often incomplete, especially in developing 
countries. In addition, they include little specific data about the integration between crops and livestock (for example, on the use of crop residues or manure). These data gaps are a major constraint to the understanding and assessment of integrated production systems. Some initiatives are, however, attempting to address these weaknesses. For example, the FAO/World Bank project Improving Data for Better Policies undertook surveys and organized workshops in subSaharan Africa to collect, validate and disseminate data on livestock and integrated mixed systems, with the goal of facilitating public and private investments in such systems (PicaCiamarra et al., 2010). The Pastoralist-Driven Data Management System project implemented by FAO's Pastoralist Knowledge $\mathrm{Hub}^{43}$ is collecting information on the complementarities of crop and livestock production in household economies in Argentina, Chad and Mongolia. The Livestock Data for Decisions (LD4D) ${ }^{44}$ initiative brings together "data suppliers" and "data users" to ensure data supply meets data demand.

In developed countries, official statistics on the status of integrated crop-livestock farming are more common, for example in the European Union, where data on integrated systems are available through the agri-environmental indicators on specialization. About 30 percent of farms in the European Union can be classified as mixed, a figure ranging from 3 percent in Ireland (where most farms are specialized in livestock) to 62 percent in Lithuania (Eurostat, 2016). Mixed farms in Europe occupy about 20 percent of the agricultural area (ibid.), implying that they are, on average, smaller than other farms.

When national statistics are not available, limited household surveys can provide some insight into the status of integrated crop-livestock systems and, when repeated over time, on their trends. However, livestock is inadequately represented in most surveys, and available data are rarely sufficient to provide a systematic picture

${ }^{43}$ http://www.fao.org/pastoralist-knowledge-hub/en

44 https://ld4d.org of integrated crop-livestock systems in the areas assessed. What is clear, however, is that livestock keeping is widespread among the rural population in many developing countries, many of whom will also be crop producers. For example, an analysis of data from household surveys in 14 (mainly developing) countries showed that around 60 percent of rural households kept at least one species of livestock (FAO, 2009a). Similarly, Arslan et al. (2018) showed that in Zambia at least 60 percent of rural households own livestock.

Modelling can also provide insights. For example, the FAO Global Livestock Environmental Assessment Model (GLEAM) ${ }^{45}$ provides information on livestock production systems, including mixed crop-livestock systems, and (inter alia) the numbers of animals raised within them, the production levels and feed intakes of these animals, and the contributions of the systems to the supply of livestock products and to greenhousegas emissions. Results from GLEAM (FAO, 2018n) show that about 60 percent of ruminants in the world are held in integrated crop-livestock systems. This share varies from around 25 percent in regions such as Central Asia and Central Africa, where livestock are mostly kept in extensive, specialized grazing systems, to over 66 percent in regions such as West Africa, Southern Europe and the Caribbean, where integrated crop-livestock systems are predominant. Crop-ruminant integrated systems produce about two-thirds of all meat and milk from ruminants at global level (expressed in protein equivalent). Where monogastrics are concerned, results from GLEAM show that backyard pigs, which are usually in integrated systems, account for about 45 percent of pigs and 27 percent of pig-meat production globally. Backyard chickens account for 18 percent of all the world's chickens, about 14 percent of global egg production and about 4 percent of global chickenmeat production.

Overall, integrated crop-livestock systems make a larger contribution to livestock production than any other system (Gerber et al.,

\footnotetext{
45 http://www.fao.org/gleam/en
} 
2013). In 2000, integrated production systems generated close to 50 percent of the world's cereals: 41 percent of maize; 86 percent of rice; 64 percent of sorghum; and 67 percent of millet (Herrero et al., 2012). These systems also produced the bulk of livestock products in the developing world (75 percent of the milk and 60 percent of the meat) and employed millions of people on farms, in formal and informal markets, at processing plants and at other stages of the value chain (FAO, 2010e). Most of the world's 430 million poor livestock keepers are found in mixed systems (Robinson et al., 2011). The most economically important livestock systems in Asia, Latin America and North Africa are mixed systems (Thornton and Herrero, 2001).

With regard to trends, the past four decades have seen the expansion of specialized livestock production systems in high-income countries and those with emerging economies, mainly for monogastrics but also to some extent for cattle (FAO, 2009a). This has been accompanied by a homogenization of crop production systems, with greater use of synthetic fertilizers at the expense of livestock manure. The consequences of this have included decreases in soil organic matter and high discharge of nutrients into the environment in areas where large numbers of animals are raised in intensive units, with negative impacts in turn on aquatic, soil and other biodiversity (see also Chapter 3). Time-series data for such changes are rare. However, data from the above-mentioned Eurostat database on agrienvironmental indicators indicate that the number of mixed crop-livestock farms in the European Union declined by 45 percent between 2005 and 2013 , and that the area under mixed crop-livestock systems decreased by 26 percent over the same period (Eurostat, 2016).

Low-income countries have, in contrast, seen a general trend towards greater integration of crop and livestock production activities as population density has increased and the availability of land has declined (Robinson et al., 2011; Thornton and Herrero, 2001). The land area occupied by mixed systems in developing countries is projected to increase slightly by 2030, with most of the increase occurring in sub-Saharan Africa (Herrero et al., 2012). However, this will be far outweighed by the increase in the human population associated with these systems (ibid.). These high population densities will place significant pressure on natural resources and ecosystem services, including on water supplies and biodiversity.

\section{Needs and priorities}

Livestock (and particularly ruminants) will continue to play key roles in providing draught power and manure in the mixed production systems of developing countries for the foreseeable future. If productivity is to increase despite the limited availability of land and other resources, there is a real need for research into how complementarities between crop and livestock production can be enhanced (Thornton and Herrero, 2001, 2015). This will require greater emphasis on multidisciplinary approaches, both in research and in project implementation. There will be a need to improve assessment of the performance of crop-livestock systems relative to that of specialized systems, not only in terms of the supply of food and non-food products, but also in terms of the supply of a range of other ecosystem services. Attention also needs to be paid to socio-economic dimensions such as employment, income generation and gender equity. As noted above, detailed information on trends in the extent to which crop-livestock integration is practised is often lacking. There is therefore a need to improve data collection and to provide concrete guidance to governments and researchers on how to monitor and assess the evolution of mixed systems.

\subsubsection{Home gardens}

\section{Introduction}

The country-reporting guidelines defined a home garden as follows: "an integrated system which comprises different components in a small area around the homestead, including staple crops, vegetables, fruits, medicinal plants, livestock and fish both for home consumption or use and for 
income. [It] may include the family house, a living/ playing area, a kitchen garden, a mixed garden, a fish pond, stores, an animal house [or other elements]." ${ }^{46}$ In many parts of the world, home gardens typically include trees and are considered a type of agroforestry practice (see Section 5.5.3). While such gardens are generally not among households' main sources of income or staple food, ${ }^{47}$ they often serve as essential supplementary sources of food and income and contribute to the overall diversity and security of livelihoods (Galhena, Freed and Maredia, 2013; Landon-Lane, 2011). These roles can be especially significant among disadvantaged sections of the population, whose diets often consist largely of a limited selection of staple foods. Products from home gardens can dramatically improve the quality of such diets by increasing the availability and accessibility of micronutrient-rich or protein-rich foods such as leafy green vegetables, fish and eggs (Buchmann, 2009; Galhena, Freed and Maredia, 2013; LandonLane, 2011).

Species diversity in home gardens is often very high (Nair, 2006). They are often also rich in intraspecific diversity. For example, Thaman, Elevitch and Kennedy (2006) documented the presence of 21 different coconut cultivars, 28 breadfruit cultivars and 37 banana cultivars in home gardens in Yap, Federated States of Micronesia. Home gardens can therefore be major reservoirs of domesticated biodiversity, particularly in countries where commercial agricultural systems make little use of landraces (Galluzzi, Eyzaguirre and Negri, 2009). As discussed in Section 2.2, home gardens in some areas serve as important habitats for potentially threatened wild species. They can also contribute a number of other environmental benefits (e.g. carbon sequestration), particularly when they replace more wasteful land uses such as lawns in urban areas and are managed using sustainable practices, for example using greywater for irrigation (Cleveland et al., 2017).

$\overline{46}$ Definition based on FAO (1995b).

47 There are some exceptions. For example, many households in the Pacific Islands grow their main staple root crops in home gardens (Galhena, Freed and Maredia, 2013)
While it is well recognized in the literature (e.g. Landon-Lane, 2011) that home gardens are part of the daily life of most communities - rural and to some extent urban - worldwide, there are no comprehensive global statistics on the distribution and status of such systems. Kumar and Nair (2006) report some attempts to compile statistics on home gardens at national or subnational levels in some South and Southeast Asian countries, citing, for example, figures reported by Kumar (2006) of 5.13 million ha of land under home gardens in Indonesia, 1.05 million ha in Sri Lanka and 1.44 million ha in Kerala, India. Some studies have looked at the ways in which drivers of change are affecting the extent and characteristics of home gardens. For example, Mohri et al. (2013), again referring to parts of South and Southeast Asia, note that a range of factors including socioeconomic drivers are promoting a shift from subsistence to commercial production in home gardens, with more land area being dedicated to such systems, but also an increasing focus on the cultivation of cash crops.

\section{Status and trends}

Analysis of the country reports shows that 31 countries indicate the presence of home gardening (Table 5.1). The practice is reported mainly in the context of irrigated and rainfed crop systems, but also for mixed, forest and livestock-based systems. Only a few countries provide information on whether the use of the practice is increasing, decreasing or stable. However, to the extent that information is available, it indicates that the use of home gardens is increasing across most systems (Table 5.2). Trends appear to be either stable or increasing across most regions, with no instances of downward trends reported from Africa, Asia or the Pacific and only a few from Europe, the Near East and Latin America and Caribbean.

\section{Significance in terms of biodiversity and livelihoods}

The country reports indicate that home gardens are important reservoirs of biodiversity, particularly plant biodiversity. Some reports from Asia 


\section{PART C}

Box 5.9

Promotion of home gardens for healthy diets in Solomon Islands

The people of Solomon Islands have a long tradition of maintaining home gardens as sources of food and nutrition security and income diversification. While, like the people of other Pacific Island nations, Solomon Islanders have increasingly come to rely on imported foods, subsistence home gardens are still the main source of many staple and vegetable foods for most of the population. The importance of home gardens is not confined to rural areas - there is a well-established tradition of tending urban home gardens (sup sup gardens, as they are known locally), where food crops are grown in association with fruit trees.

Recognizing the value of home gardens to the health of the local population, the Ministry of Agriculture and

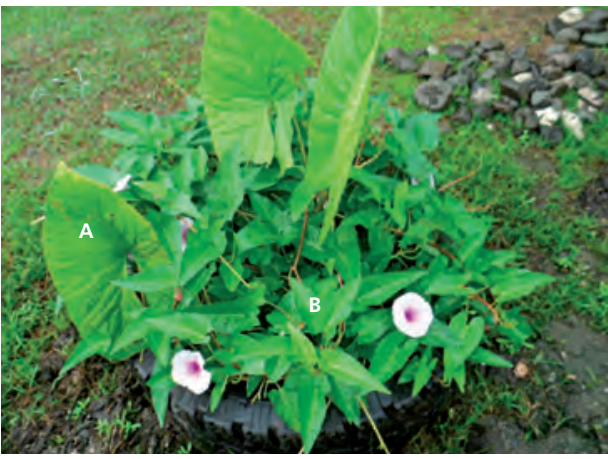

Wetland crops grown in old tyres. A: Cyrtosperma merkusii (giant swamp taro) and B: Ipomoea aquatica (a leafy vegetable). CHelen Tsatsia.
Livestock and the Ministry of Health of Solomon Islands have, over the years, promoted the role of these systems as a means of increasing people's access to fresh produce and countering the rising occurrence of chronic diseases. Measures have included the provision of training on the cultivation of crop and tree species that are easily adaptable to urban conditions and require little maintenance, including Chinese cabbage (Brassica rapa), pak choi (Brassica rapa subsp. chinensis), peppers (Capsicum spp.), papaya (Carica papaya), guava (Psidium guajava) and star fruit (Averrhoa carambola).

Sources: Country report of Solomon Islands and FAO et al., 2016.

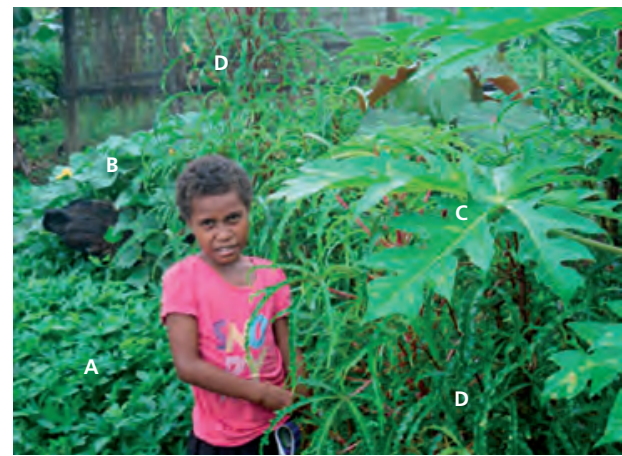

Mixed crops in backyard garden. A: Ipomoea batatas (sweet potato), B: Cucurbita species (pumpkin), C: Carica papaya (papaya) and D: Abelmoschus manihot (aibika, bele, slippery cabbage). CHelen Tsatsia. (the Lao People's Democratic Republic, Nepal and Viet Nam) describe how home gardens in the region traditionally include fishponds, as well as fruit and fuelwood tree species. Some countries report quantitative data illustrating the high levels of diversity that can be found in home gardens. For example, Ecuador mentions the existence of home gardens in which 127 forest, crop, livestock and aquatic species have been recorded in 0.45 ha. Peru mentions gardens containing up to 90 species used for food or medicinal purposes. However, the precise contributions of home gardens to the maintenance of BFA are generally difficult to assess on account of their diverse characteristics and/or a lack of comprehensive information on their size and distribution.

Countries report a range of specific ways in which home gardens contribute to the sustainable use and conservation of BFA. For example, Papua New Guinea mentions that farmers bring crop wild relatives into home gardens for cultivation, noting in particular that "tulip" (Gnetum gnemon), a leafy delicacy used in many traditional dishes, is widely grown in home gardens. Among European countries, 
Estonia reports that its Crop Research Institute relies in part on home gardens as a source of seeds for its gene bank. The Netherlands notes that while most traditional plant varieties are not grown in commercial systems, many survive in home gardens.

Some countries mention circumstances in which home-gardening practices can threaten biodiversity. For example, Oman notes that cultivation of exotic species, such as leucaena (Leucaena leucocephala), in home gardens is increasingly threatening local biodiversity. France mentions the need to consider the impacts that agrochemicals used in home gardens have on biodiversity, and refers to a national law, intended to enter into force in $2017,{ }^{48}$ that limits the use of such products to professional producers and is expected to have a positive impact on biodiversity associated with home gardens. Similarly, Switzerland notes that in recognition of the potentially harmful effects of pesticides on the environment and human health, including when used in allotment gardens, its Federal Office for the Environment has issued guidance and recommendations on the handling of plant-protection products by non-professional users. Poland reports threats to biodiversity associated with the expansion of single-family housing areas and the related uncontrolled use of groundwater for irrigation of home gardens, which has led to decreases in local groundwater levels and water flows into rivers. Conversely, the same report notes that kitchen gardens near pasture areas have a positive impact on local biodiversity, including insect pollinators and other invertebrates.

Countries that provide information on home gardens generally seem to regard them as important contributors to livelihoods and to food

\footnotetext{
48 Under Law 2012-100 (LOI n 2014-110 du 6 février 2014 visant à mieux encadrer l'utilisation des produits phytosanitaires sur le territoire national - available, in French, at https://www.legifrance.gouv.fr/affichTexte. do? cidTexte=JORFTEXT000028571536\&dateTexte $=20160927$ ) use of pesticides in places open or accessible to the public has been banned since 1 January 2017. A ban in private areas came into force on 1 January 2019. The ban does not apply to authorized biocontrol products, products that can be utilized in organic agriculture and products classified as "low-risk" under the relevant European Union legislation.
}

security and nutrition. A range of different initiatives aimed at supporting and extending these roles are reported (see Box 5.9 and Box 5.10 for examples). A number of countries note the significant role of women in the management of home gardens, and hence as custodians of the BFA associated with them. Countries across several regions (e.g. China, the Gambia, Panama and Slovenia) note that it is usually women who are aware of the edible and medicinal properties of plants and who tend home gardens, including saving seeds for the following season. This role is also well documented in the literature (e.g. Nair, 2006).

\section{Threats and drivers of change}

Many countries provide information on threats to home gardens and hence potentially to the biodiversity found in these systems. Countries from several regions mention threats associated with the spread of invasive alien species. For example, the Cook Islands reports that changing dietary preferences, particularly among the younger generation, have led to increases in wild pig and fowl populations and that this has led to more frequent occurrences of serious damage to home gardens. Both Nepal and Argentina report that increasing populations of giant African snails (Lissachatina fulica) present a serious threat to home gardens in both urban and rural areas. Estonia mentions that the Colorado potato beetle (Leptinotarsa decemlineata) has caused severe damage in small-scale production systems, including home gardens. Climate change is also noted as a threat, particularly by some Pacific Island countries, where home gardens are often located in low-lying coastal areas.

Changes in farming systems, including shifts towards intensive practices and a more marketfocused orientation - along with some broader socio-economic drivers - are also mentioned. Countries report a range of different challenges in this regard. For example, Peru mentions that, while family home gardens have traditionally played a key role in the preservation of indigenous varieties and species (e.g. the tree tomato [Solanum betaceum]), such plants are increasingly 


\section{PART C}

Box 5.10

Projects and initiatives targeting home gardens - examples from around the world

\section{Argentina}

The nationwide PROHUERTA programme has led the development of home gardens in Argentina. The programme was launched in 1990 and now extends to over 90 percent of the country's municipalities. The programme's goals are to increase access to fresh and nutritious foods, as well as to increase incomes, particularly among the most disadvantaged sections of the population. The programme has created some 560000 home gardens and 12000 school and community gardens, and has benefited 2.8 million people. The programme has also included South-South cooperation efforts involving exchange of information and experiences with other countries, including Angola, Ghana, Haiti and Mozambique. In addition, an interdisciplinary group of experts from the University of Buenos Aires has been set up to work, inter alia, on promoting agroecological home gardens to improve community livelihoods and establishing community nurseries to grow native plants (including those used as foods) and improve soil health.

\section{Finland}

Finland has established a catalogue of horticultural species used in home gardens and launched an online portal for recording traditional and heritage cultivars, via which users can report and provide information (including cultural/historical information) on potentially valuable plants and possible landraces.

\section{Lao People's Democratic Republic}

In the Lao People's Democratic Republic, small gardens have been successfully established in schools for use in education and awareness raising. The resulting increase in interest in agrobiodiversity management led the Department of Education of Xieng Khouang Province to develop a curriculum for agrobiodiversity education, which was later approved by the national ministry for use throughout the country.

\section{Mexico}

The NGO Visión Mujer focuses on promoting training for women, including on the preservation and cultivation of plants that have edible or medicinal uses. The first experimental community garden was established at the Fisheries Research Centre on Isla Mujeres to serve as a reference centre for organic production practices and build capacity on home and school gardening.

\section{Nauru}

In Nauru, the Horticulture and Livestock Breeding Project promoted by the Taiwan Technical Mission and the Department of Commerce, Industries and Environment focuses on supporting horticultural and livestock production in home gardens as a means of improving food and nutrition security. The project has promoted sustainable management practices, for example the use of composting to improve soil fertility. Local farmers are encouraged to cultivate native tree species for use in reafforestation programmes. The project has successfully set up vegetable gardens with 50 farmers and three schools and supplied vegetables for 800 schoolchildren through the Nauru School Feeding Program. It has also raised awareness and built capacity on vegetable growing and cooking and on composting practices.

\section{Nepal}

A Swiss-funded project implemented by Local Initiatives for Biodiversity, Research and Development (LI-BIRD), in collaboration with national authorities, is promoting the conservation and sustainable use of agrobiodiversity through home gardens. The project aims to increase families' food security, dietary diversity and incomes by promoting diversification in home gardens, including by combining the cultivation of vegetables, fruits and mushrooms with the rearing of livestock, fish and honey bees. As a result of the project, over two-thirds of the 7700 target households have both diversified their diets by increasing consumption of fresh garden produce and reduced their expenditure on vegetables by 75 percent.

\section{Sri Lanka}

In Sri Lanka, the Department of Agriculture encourages the cultivation of organic vegetables in home gardens using traditional varieties that do not require chemical fertilizers or pesticides. Activities have included the distribution of the True Sri Lanka Taste seed pack consisting of traditional vegetable varieties. 
Box 5.10 (Cont.)

Projects and initiatives targeting home gardens - examples from around the world

\section{Tonga}

The Tonga Health Promotion Foundation (TongaHealth) promotes home gardens as a means of increasing the consumption of a range of local fruit and vegetables. For example, villages wishing to access resources such as seedlings and fencing are provided with grants via the Community Gardening Programme. The aim of this initiative is to increase the consumption of healthy foods among Tongan families. To ensure sustainability, each household is encouraged to plant eight local vegetables and fruits in their residential garden for easy access throughout the year. Over 1800 households have participated in the Community Gardening Programme since 2009. Tonga's 2015 Census recorded a total of 2888 home gardens in the country.

\section{Zimbabwe}

In 2001, the Municipality of Bulawayo, together with World Vision, established urban allotment gardens to support vulnerable groups such as people living with HIVIAIDS, the elderly, widows and orphans. The main aims were to address acute food shortages and nutritional imbalances, raise awareness on HIV/AIDs, improve well-being and build people's capacities. As of 2008 , more than 1500 people had already benefited from the gardens.

Sources: Country reports of Argentina, Finland, Mexico, Nauru, Nepal, Sri Lanka, Tonga (with additional information from the website of the Tonga Health Promotion Foundation - https://www.tongahealth.org/about_us) and Zimbabwe, and the Lao People's Democratic Republic Agrobiodiversity Programme and Action Plan II (2015-2025). More information on PROHUERTA can be found (in Spanish) at http://prohuerta.inta.gov.ar. being replaced by more profitable crops. As well as leading to genetic erosion, this trend is reported also to be contributing to the loss of traditional knowledge. Nauru, in contrast, reports renewed interest in home gardens but a lack of relevant local knowledge and technical skills. Panama mentions that, among other factors, the increasing availability of ready-to-eat products is reducing the use of food from home gardens. China reports that rural families are increasingly being drawn towards economically more attractive off-farm work, which leaves them little time to tend to their home gardens, and notes that this is negatively affecting BFA.

\section{Needs and priorities}

The main gap identified in the country reports in relation to home gardening is a lack of information on the status and trends of home gardens and on the contributions they make to the conservation of BFA and to the resilience of production in the face of challenges associated with (inter alia) climate change and socio-economic trends. Reported priorities in this regard include the provision of funding for thorough assessments of home-gardening practices and their impacts and for adequate dissemination of the data collected. Some countries mention priorities related to capacity development. For example, Panama identifies the need to strengthen the capacity of extension services to support home gardening. A few priorities related to the use of specific components of BFA within home gardens are also noted. The Lao People's Democratic Republic mentions the potential of diversifying livestock and fish production in home gardens, but notes that indigenous poultry are poorly understood and need to be studied systematically. Belarus mentions the importance of developing recommendations on the cultivation of wild plant species used for food, including in home gardens.

\subsubsection{Agroforestry}

\section{Introduction}

The country-reporting guidelines define agroforestry as "a collective name for land-use systems where woody perennials ... are integrated in the farming system." In practice, however, use of the term varies from country to country, reflecting local, national and regional contexts. Moreover, since the word rose to prominence in the late 
1970s (Bene, Beall and Côte, 1977), its usage has evolved considerably. Van Noordwijk, Coe and Sinclair (2016) describe three successive paradigms: the first focused on plot-level interactions of trees with crops or livestock; the second based on a landscape-level understanding of agroforestry as a land use with explicit (positive) impacts (Leakey, 1996); and the third encompassing the combination and interface of all agriculture and forestry issues without reference to the institutional barriers that have traditionally separated them. Van Noordwijk, Coe and Sinclair (2016) propose a new definition of agroforestry that recognizes all three paradigms and can be paraphrased as "land use that combines aspects of agriculture and forestry, including the agricultural use of trees." Moreover, usage of the term by farmers and development practitioners is often more specific than usage in scientific circles. Generalizations about the state of agroforestry are thus difficult to make, even at country level. The following paragraphs provide illustrative examples of the types of agroforestry practised in various regions of the world.

In East and Southern Africa, agroforestry systems include cereal-based systems that feature indigenous and introduced tree species valued for timber (Grevillea robusta, eucalypts [Eucalyptus and Corymbia spp.]), fruits (e.g. mango [Mangifera indica] and avocado [Persea americana]), charcoal (acacias [Acacia spp.]), fodder (Calliandra spp.) and soil-fertility enhancement (e.g. winter thorn [Faidherbia albida]). Systems include many indigenous and exotic tree species that are planted or protected in a variety of niches to supply various ecosystem services (Bein et al., 1996; Kindt et al., 2017). Although many indigenous tree species also feature in priority lists, farmers are increasingly replacing them with exotics (Kehlenbeck et al., 2011).

Traditional "parkland" systems, i.e. mixed croptree-shrub-livestock assemblages derived from savannah ecosystems (Maranz, 2009), are the main sources of food, income and environmental services across the Sahelian zone of West Africa (Bayala et al., 2011a). Their species richness ranges from monospecificity to more than 100 species of trees and shrubs, although species-rich systems may be dominated by a few species (Bayala et al., 2011b; Kessler, 1992; Kindt et al., 2008). Shrubs in parklands may be coppiced throughout the rainy (cropping) season. Farmers actively manage and protect trees, including by protecting naturally regenerating trees from livestock and during tillage operations (Brandt et al., 2018; Hanan, 2018; Reij and Garrity, 2016). Tree density is kept low so that canopy cover is not continuous. These practices contribute to agricultural productivity and help to conserve plant and animal biodiversity by offering diverse above-ground and below-ground habitat niches.

In the humid tropics of West and Central Africa, prevalent agroforestry practices include the following: home gardens; perennial tree crop-based systems (cocoa, coffee, oil palm, rubber); slash-andburn agriculture where high-value species providing timber and non-timber forest products are retained; improved fallows (e.g. with red calliandra [Calliandra calothyrsus], leucaena [Leucaena leucocephala], gliricidia [Gliricidia sepium], ice-cream bean [Inga edulis], mangium (Acacia mangium) and Acacia auriculiformis, pigeon pea [Cajanus cajan], Vogel's tephrosia [Tephrosia vogelii], sesbania [Sesbania sesban]); boundary planting (mostly in hilly areas); and small woodlots with Eucalyptus spp., red stinkwood (Prunus africana) and grevillea (Grevillea robusta) (Atangana et al., 2014).

Mosquera-Losada et al. (2012) identified six main categories of European agroforestry: silvoarable practices; silvopasture; forest farming ("forested areas used for production ... of natural standing speciality crops for medicinal, ornamental or culinary purposes"); riparian buffers; improved fallow; and multipurpose trees. They noted that many practices that had declined during the period of agricultural intensification that followed the industrial revolution are now reviving as a consequence of policy changes. However, as documented by den Herder et al. (2015), the dominant practices in terms of land area continue to be those traditional practices that were relatively unaffected by agricultural intensification, for example the oak-based systems known as dehesa (Spain) and montados (Portugal) and (particularly) 
reindeer-husbandry systems in Scandinavia. The reindeer-husbandry systems are practised more widely (41.4 million ha) than all other European systems combined.

Agroforestry practice in Latin America is thousands of years old (Miller and Nair, 2006). Dominant current types of agroforestry include the following: cacao and coffee systems (Somarriba et al., 2014); silvopasture (Montagnini, Ibrahim and Murgueitio, 2013); tree fallows (improved or otherwise) in swidden agriculture (Cotta, 2017; Smith et al., 1999); home gardens (Padoch and de Jong, 1991); and native trees and shrubs in field boundaries and along contour lines in mountain areas (Mathez-Stiefel, 2016). Use of both natural regeneration - particularly timber and shade species - and planted trees is common. The acronym SAF (an abbreviation of the Portuguese and Spanish words for "agroforestry system") has wide currency, and usually refers to multistorey systems of varying complexity. In Brazil, marketoriented systems may consist of intercropping three or more, mostly perennial, planted crops, for example cacao (Theobroma cacao), açai (Euterpe oleracea), black pepper (Piper nigrum), cupuaçu (Theobroma grandiflorum) or some timber species or oilseeds (Bolfe and Batistella, 2011), or much more complex high-biodiversity systems in which natural regeneration is managed, for example cabruca ${ }^{49}$ systems (Sambuichi et al., 2012) and successional agroforests (Cezar et al., 2015).

Agroforestry practice and concepts in Oceania vary widely. Agroforestry has traditionally been an important farming system for Pacific Islanders (Thaman, Elevitch and Kennedy, 2006). On the smaller, land-scarce Pacific islands, tree fruits and nuts are important components in intensive farming systems (Evans, 1999). In rural communities in Papua New Guinea, native and exotic tree species such as casuarina (Casuarina oligodon), betelnut palm (Areca catechu) and gliricidia (Gliricidia sepium) provide important agroecological services and products for sale or home consumption (Page et al., 2016; Bourke and Harwood, eds., 2009). In

${ }_{49}$ Cocoa trees grown under a thinned natural-forest canopy.
Australia, the term "agroforestry" is used broadly, but with some emphasis on timber production and agroforestry as "farm forestry" (e.g. Reid, 2017).

Prominent agroforestry systems in South Asia include: poplar-based commercial agroforestry (especially in India); fruit orchards; home gardens; cardamom and alder mixtures (Bhutan, India and Nepal); tree and shrub fodder production; silvopastoral systems; coastal shelterbelts (India and Sri Lanka); shifting cultivation ("chena" in Sri Lanka); trees interspersed on farmland; taungya (India, Sri Lanka); and tea and coffee agroforestry. In India, trees outside forests, of which trees grown on farms are a subset, account for 65 percent of timber production and almost half of fuelwood production (Government of India, 2017).

Southeast Asian farmers use a rich variety of agroforestry practices. These include: high-diversity home gardens; improved fallow (e.g. with naturalized leucaena [Leucaena spp.] in the Philippines); commodity-based agroforestry systems (in Indonesia these smallholder mixed systems produce 96 percent of the national coffee yield, 92 percent of the cacao, 80 percent of the rubber, 39 percent of the oil palm and 26 percent of the tea - DGEC, 2012); agroforests such as the damar agroforests and "jungle rubber" of Sumatra and Kalimantan, taungya and tumpangsari in teak or pine plantations in Indonesia and Thailand; trees planted at wide spacing in open-field agriculture (e.g. forest-rice terrace systems in the southern and northern Philippines); SALT (sloping agricultural land technologies), for example hedgerow planting, alley cropping and NVS (natural vegetative strips) on sloping land in Indonesia, the Philippines and Viet Nam; and boundary planting around farms and fields (e.g. of fodder trees in Indonesia and the Philippines). In Indonesia, agroforestry has become one of the land-based strategies for the national climate change adaptation and mitigation, and social-forestry, programmes.

\section{Status and trends}

Estimates of the global extent of agroforestry have differed by orders of magnitude. Reasons for this include the many different ways of using trees 
in agriculture, the "invisibility" of agroforestry in official statistics and differing understandings of what constitutes agroforestry (see above). What is clear is that where tree growth is not limited by environmental factors - usually temperature or precipitation (Runyan and D'Odorico, 2016) trees are ubiquitous in agricultural landscapes, the most obvious exceptions being some agroindustrial landscapes.

Under a landscape-level definition of agroforestry, global datasets assembled for other purposes can be used to estimate the extent of agroforestry. For example, Zomer et al. (2014), using $1 \mathrm{~km}^{2}$ resolution gridded data layers of tree cover and land use, defined agroforestry as occurring in pixels that are classified as "agricultural land" and have a certain level of tree cover. They estimated the global land area under agroforestry (based on three-year averages for 2008 to 2010 ) to be 3.1 million $\mathrm{km}^{2}$ if taken to include agricultural land with $\geq 30$ percent tree cover, and 9.6 million $\mathrm{km}^{2}$ if taken to include agricultural land with $\geq 10$ percent tree cover. ${ }^{50}$ These are vast areas, roughly equivalent, respectively, to the areas of India and China. Table 5.5 shows regional estimates of the area under agroforestry, using an intermediate ( $\geq 20$ percent tree cover) criterion. In absolute area, South America and Southeast Asia are easily the most significant "agroforestry regions", together constituting about 45 percent of the global total. In proportional terms, agroforestry is far more preponderant in Central America and Southeast Asia than in any other region. It should be noted that in

\footnotetext{
50 Two aspects of the methodology used in this analysis should be noted. First, pixels corresponding to $1 \mathrm{~km}^{2}$ area were used as the basis for tree cover classification. A given percentage tree cover in a given pixel may indicate various things. For example, 30 percent tree cover might mean 70 percent treeless and 30 percent forested or an intimate mixture of trees and crops in which tree crowns overlay 30 percent of the area (or anything in between). Although all pixels are located on land classified as "agricultural", it is possible that some pixels that consist of contrasting treeless areas and closed canopy forest areas may not constitute agroforestry as commonly understood. Second, the estimates will have excluded some areas under agroforestry, because these occur on land classified as non-agricultural (Zomer et al., 2014).
}

some cases the regional values mask important intraregional variation.

Global recognition of the contributions of agroforestry has increased over the past decade, as have the mainstreaming of agroforestry into development and environmental agendas and appreciation of its potential impact on rural livelihoods, climate-smart agriculture, biodiversity conservation and land restoration. This higher profile also reflects wider acceptance and adoption of agroecological practices in agriculture. In individual countries and regions, the move towards mainstreaming is related - as both cause and effect - to policy and legal changes. Examples from several regions are provided in Box 5.11. A number of the country reports mention policies and programmes supporting agroforestry, including through education and extension, research and the provision of payments for ecosystem services. France's Agroforestry Development Plan is described in Box 5.12.

Increasing levels of awareness and support can be expected to lead to increases in the land area under agroforestry. Globally, there seems already to have been a slight increase (Table 5.5), although unravelling the causes of particular regional trends would require more detailed analysis. Increases in tree cover are not necessarily the result of policy measures or other high-level support, i.e. they may reflect wider macroeconomic and societal factors (e.g. Redo et al., 2012).

Countries' responses on the state of and trends in the adoption of agroforestry practices are summarized in Table 5.1 and Table 5.2. Across all systems, reports of increasing trends outnumber reports of decreasing trends, in most cases by a substantial margin. Many country reports mention that agroforestry is a traditional element of local production systems, in many cases noting its importance to food security, to the supply of ecosystem services such as soil protection and carbon sequestration and to the resilience of farms to both biophysical (e.g. climatic) and economic shocks and trends. Countries generally do not provide detailed information about the causes of the trends reported. A number, however, mention 
TABLE 5.5

Land area under agroforestry (2008-2010) and trends (2000-2010), by region

\begin{tabular}{|c|c|c|c|}
\hline Region & $\begin{array}{c}\text { Area } \\
\left(\text { million } \mathbf{k m}^{2}\right)\end{array}$ & $\begin{array}{l}\text { Proportion of total } \\
\text { agricultural land (\%) }\end{array}$ & $\begin{array}{c}\text { Increase } \\
(2000-2010)(\%)\end{array}$ \\
\hline Central America & 0.2 & 79.0 & 8.2 \\
\hline East Asia & 0.4 & 22.1 & 3.4 \\
\hline Europe & 0.5 & 20.4 & 1.6 \\
\hline North Africa and Western Asia & 0.1 & 5.5 & 0.3 \\
\hline North America & 0.6 & 26.3 & 2.2 \\
\hline Northern and Central Asia & 0.2 & 9.7 & 1.2 \\
\hline Oceania & 0.2 & 23.8 & 3.4 \\
\hline South America & 1.2 & 31.8 & 3.5 \\
\hline South Asia & 0.1 & 7.8 & 0.9 \\
\hline Southeast Asia & 1.0 & 62.9 & 2.0 \\
\hline Sub-Saharan Africa & 0.6 & 15.0 & 0.0 \\
\hline World & 5.1 & 23.1 & 1.8 \\
\hline
\end{tabular}

Notes: Figures refer to agricultural land with $\geq 20$ percent tree cover. Land area estimates are based on three-year averages for 2008 to 2010.

Source: Zomer et al., 2014.

policies that provide support to the development of agroforestry via measures such as knowledge transfer and the provision of subsidies.

\section{Needs and priorities}

At the turn of the millennium, regional studies in Southeast Asia identified the following priority areas for support to agroforestry: germplasm quality and availability; marketing and market access; supportive policies; tree and system (particularly timber and fruit) management; and training and information dissemination (Gunasena and Roshetko, 2000; Roshetko and Evans, 1999). A global review by Leakey et al. (2012) found that, while significant progress had been made, many of those topics remained in need of attention. The following subsections present gaps and needs under five broad, partially overlapping, headings: concepts; policy; development approaches; germplasm; and research.

\section{Concepts of agroforestry}

Although diversity of concepts and practices across regions and countries is practically inevitable and not necessarily undesirable, it becomes a problem when limited concepts of agroforestry - for example, agroforestry as only multistorey systems - lead to limited understanding of its relevance to issues such as poverty, climate change adaptation and mitigation and land degradation. This underscores the importance of not only clarifying agroforestry definitions, but also of sharing experiences of different types of agroforestry and how they can successfully contribute to addressing problems and opportunities.

\section{Policy}

Agroforestry often continues to occupy a "no man's land" between forestry and agriculture, and benefits neither from specific supportive policies nor from an institutional home. In many cases, farmers are still not allowed to harvest trees, or even tree products, on their land. Even where such activities are allowed under current law, the complexity or cost of fulfilling requirements may be beyond the capacities of resourcepoor farmers (Foundjem-Tita et al., 2013; Sears et al., 2018). 


\section{PART C}

Box 5.11

Policy and legislative frameworks promoting agroforestry - examples from around the world

\section{East and Southern Africa}

Policy changes have been key to wider inclusion of trees on farms in East and Southern Africa. For example, Kenya's Agriculture (Farm Forestry) Rules of $2009^{1}$ - a response to deforestation, increased demand for agricultural land and farmers' desire to plant trees - require at least 10 percent tree cover on all farms. The country's government has allocated funds to assist farmers to meet this requirement (Jamnadass et al., 2013). Kenya and other East African countries have pledged millions of hectares to the Bonn Challenge ${ }^{2}$ and AFR $100^{3}$ restoration initiatives (e.g. 15 million ha in Ethiopia, 5.1 million ha in Kenya and 2 million ha in Rwanda). Agroforestry plays a prominent role in these pledges (e.g. Ministry of Natural Resources - Rwanda, 2014).

\section{West and Central Africa}

Analysis suggests that both rainfall patterns and land-management practices are responsible for the "re-greening" of the Sahel (Ouedraogo et al., 2014). In the case of Niger, widespread adoption of farmer-managed natural regeneration (FMNR) (Reij, Tappan and Smale, 2009a) led the government to relax provisions in the Forest Law, allowing farmers the right to harvest trees nurtured or planted on their own land. This policy change is thought to have contributed to the spread of FMNR to over 5 million ha (Garrity et al., 2010). The trend towards increasing tree cover is likely to continue, as a result of multiple international initiatives to upscale on-farm natural regeneration and tree planting, particularly those related to forest landscape restoration (Minasny et al., 2017; Reij and Garrity, 2016).

\section{Latin America}

In Peru, the Forest and Wildlife Law of $2011^{4}$ recognizes and provides an official definition of agroforestry, and created the Agroforestry Concessions mechanism (Robiglio and Reyes, 2016), for which guidelines were issued in

\footnotetext{
Agriculture (Farm Forestry) Rules (available at http://www.fao.org/faolex results/details/en/?details=LEX-FAOC101360).

2 http://www.bonnchallenge.org/content/challenge

3 http://www.afr100.org

4 Ley N ${ }^{\circ} 29763$ - Ley Forestal y de Fauna Silvestre. El Peruano, 22 de julio de 2011 (available, in Spanish, at http://www.fao.org/faolex/results/details/en/cl LEX-FAOC104648/).
}

2017. ${ }^{5}$ This measure aims to formalize hitherto illegal occupation of state forestland, based on the scaling-up of sustainable management (including agroforestry) on about 1.2 million ha of land in the country's Amazon region. In Brazil, the Forest Law of $2012^{6}$ established the principle that agroforestry serves both social and environmental functions in protected areas, allowing farmers to restore Permanent Preservation Areas (riparian zones, springs, hillsides and ridge tops) and conservation set-asides (known as Legal Reserves), which are required on all rural lands, through agroforestry (for which a legal definition is provided). In these cases, farmers may include short-cycle crops, legumes and some exotic species provided they are intercropped with native trees and maintain basic ecological functions (Miccolis et al., 2016).

\section{Southeast Asia}

Many countries in Southeast Asia have mainstreamed agroforestry into agriculture, watershed management and social-forestry programmes. For example, the Government of the Philippines has been implementing an upland-agroforestry programme since 2000. Viet Nam is revising its Forestry Law, introducing provisions that allow agroforestry to be practised in allocated forestlands, which will pave the way for agroforestry to become an official forest land-use type. At the regional level, the 2016-2025 Vision and Strategic Plan of the Food, Agriculture and Forestry Sector of ASEAN (Association of Southeast Asian Nations) has a specific action programme aimed at agroforestry expansion (Strategic Thrust 4, Action Programme 5). In 2017, the ASEAN Working Group on Social Forestry agreed to the preparation of ASEAN-level guidelines on agroforestry development for Member States (Finlayson, 2017).

(Cont.)

\footnotetext{
Resolución № 081-2017-SERFOR - Lineamientos para el otorgamiento de contratos de cesión en uso para sistemas agroforestales. El Peruano, 31 de marzo de 2017 (available, in Spanish, at http://www.fao.org/faolex/results/ details/en/c/LEX-FAOC171777/).

6 Lei de Proteção da Vegetação Nativa n. 12.727, de 17 de Outubro de 2012 (available, in Portuguese, at http://www.planalto.gov.br/ccivil_03/_ato20112014/2012/lei//12727.htm)
} 
Box 5.11 (Cont.)

Policy and legislative frameworks promoting agroforestry - examples from around the world

\section{South Asia}

In 2014, India promulgated its National Agroforestry Policy, backed with a capital outlay of USD 450 million for four years (2016/17 to 2019/20) (Chavan et al., 2015). The policy has been an effective instrument for promoting agroforestry, has created an institutional "home" for agroforestry (the Ministry of Agriculture) and constitutes a negotiation platform for agroforestry in the country (Singh et al., 2016). Its effect on sustainable utilization of India's vast stock of trees on farms (1.5 million $\left.\mathrm{m}^{3}\right)$ has been notable, particularly the relaxation of tree-felling and transit regulations, deregulation of sawmill opening and inclusion of agroforestry in many central government agricultural schemes. Twenty of 29 states have excluded at least 20 tree species from felling and transit regulations. Prior to approval and implementation of the agroforestry policy, felling and transport of the majority of tree species were prohibited through regulatory laws that discouraged farmers from growing trees on farms.

\section{Box 5.12}

\section{France's Agroforestry Development Plan 2015-2020}

In 2015, the French Ministry of Agriculture launched the Agroecological Project, a policy aimed at rendering production systems more effective with respect to their economic, environmental and social dimensions. ${ }^{1}$ Sustainable use and conservation of biodiversity are key elements of agroecology. One element of this policy initiative is the Agroforestry Development Plan, ${ }^{2}$ which consists of five axes:

- gaining better understanding of the diversity of agroforestry systems and their functioning;

- improving the legal framework and strengthening financial support;

- developing extension, training and promotion of agroforestry;

1 http://agriculture.gouv.fr/le-projet-agro-ecologique-pour-la-france

$2 \mathrm{http}: / /$ agriculture.gouv.fr/un-plan-national-de-developpement-pourlagroforesterie
- increasing the economic valuation of agroforestry production in a sustainable way; and

- promoting and disseminating agroforestry internationally.

The axes comprise 23 actions that are coordinated by the Ministry of Agriculture and implemented with a dozen partners, including the National Institute for Agricultural Research (INRA), the Ministry of the Environment, the associations involved in the territories, and the network of Chambers of Agriculture.

The objective of the Agroforestry Development Plan is to develop existing agroforestry systems such as hedgerows (about 1 million ha in France, but decreasing), tree intercropping (about 5000 ha), fruit-tree silvopasture and silvopastoralism.

Source: Provided by Patricia Larbouret, Christophe Pinard and Pierre Velge.

\section{Approaches to agroforestry development} Agroforestry innovations often encounter problems in scaling up (Coe, Sinclair and Barrios, 2014; Shiferaw, Okello and Reddy, 2009). A diverse range of factors may be responsible. For example, Porro (2009) lists 46 causes of failure in adoption of agroforestry systems in the Amazon. Three specific areas stand out.
First, rural advisory services, where they exist, often struggle to address some forms of agroforestry, which can be knowledge intensive, context specific and provide benefits in the long term rather than the short term. Rural resource centres (Degrande et al., 2015) - training and demonstration hubs that are managed by grassroots organizations and may operate outside the formal 
extension model - are one promising approach. The exchange of knowledge and experiences between farmers should also be facilitated and supported (Martini, Roshetko and Paramita, 2017).

Second, special attention needs to be paid to gender differences in access to agroforestry resources and potential to benefit from them. Men and women often play different roles in production and along value chains, which means that they have different knowledge about species and management practices, and different perceptions of the value of the potential benefits of agroforestry practices (Colfer et al., 2016; Kiptot, Franzel and Degrande, 2014; Mulyoutami et al., 2015).

Third, support to agroforestry often tends to neglect marketing, business practices and financial incentives such as credit (Blare and Donovan, 2016). This can apply to agroforestry commodities (e.g. the principal beverage crops) (Donovan, Blare and Poole, 2017), to companion crops grown in agroforestry systems (e.g. Sears et al., 2018) and to farmer-produced timber (Holding-Anyonge and Roshetko, 2003; Perdana, Roshetko and Kurniawan, 2012). When markets are considered, the focus has often been on export markets rather than on establishing more stable local and regional demand (Blare and Donovan, 2016). A more integrated vision is needed, in which promotion of agroforestry includes efforts to identify markets for the mix of crop and tree species cultivated.

These and many other factors are part of a general failure to adequately consider local contexts (Coe, Sinclair and Barrios, 2014). The latter authors propose an "options-by-context", co-learning approach in which different agroforestry interventions (potentially including innovation in policy, advisory services, institutions and value chains, as well as in production systems) are considered in relation to local social, economic, biophysical and political contexts.

\section{Germplasm}

The availability of germplasm has long been considered a constraint to the scaling-up of treeplanting by smallholders (Caveness and Kurtz, 1993; Franzel et al., 2001; Kakuru, Doreen and
Wilson, 2014; Koffa and Roshetko, 1999; Roshetko, Mulawarman and Dianarto, 2008; Walters et al., 2005). Expansion of restoration initiatives implies significantly higher demand for germplasm (Broadhurst et al., 2016). For example, if half of the area currently pledged to the Bonn Challenge (140 million ha) (see Section 5.4) were to be subject to relatively low-density planting averaging 100 trees per ha over a period of ten years, the demand for seed would be around 1.4 billon seeds per year. ${ }^{51}$ The quantities of seeds and the institutional frameworks required would be beyond the current capacities of most, if not all, developing countries (e.g. Atkinson et al., 2017).

In some cases, the market may respond adequately to increased demand. However, profit-seeking nursery producers will tend to concentrate on the most profitable species, meaning that germplasmsupply systems based purely on the market are unlikely to offer the diversity that tree planters seek (Cornelius and Miccolis, 2018). Lillesø et al. (2018) have argued for legislation that favours public-private partnerships, with small-scale entrepreneurs becoming the major producers and distributors of quality tree-planting materials. Low income may prevent resource-poor farmers from purchasing planting stock (Harrison, Gregorio and Herbohn, 2008; Murray and Bannister, 2004; Osemeobo, 1987), and distribution of free or subsidized seedlings is an option in such cases. Although there is a risk of undermining private nurseries (Graudal and Lillesø, 2007), development agencies that distribute free or low-cost planting material can avoid this problem if they themselves purchase from private nurseries (Cornelius and Miccolis, 2018). In this way, they can strengthen emerging germplasm-supply systems by acting as intermediaries between nurseries and farmers that are too poor or too distant to purchase from them.

\section{Research}

Enumerating the full range of research needs in agroforestry research is beyond the scope of this

\footnotetext{
7 million ha per year, 100 seedlings per ha, 2 seeds per seedling produced.
} 
overview. It is important, however, to stress that the agroforestry research agenda must reflect the full scope of agroforestry, i.e. from landscape-level effects (e.g. relationships between trees and water supply, or optimum configurations for biodiversity objectives) to plot-level, and including socialscience research as well as the hitherto more dominant biophysical research.

Integration of research into development is essential to the scaling up of agroforestry. As noted above, potential agroforestry interventions need to be adapted to specific local contexts. This may require formal planned comparisons nested within development activities (Coe et al., 2017).

\subsubsection{Diversification practices in aquaculture}

\section{Introduction}

Recent decades have seen a general upward trend in the share of aquaculture production in total fish production across all continents (FAO, 2018a). Aquaculture accounted for 47 percent of total world fish production in 2016, up from 42 percent in 2012 and 31 percent in 2004 (FAO, 2016k, 2018a). Given that production from capture fisheries is fairly stable (FAO, 2018a), it is likely that aquaculture will be the main source of future growth in the fisheries sector.

Aquaculture is very diverse in terms of the range of species, environments and production systems utilized..$^{52}$ It also includes a range of diversification practices. The country-reporting guidelines invited countries to provide information both on "diversity-based practices" in aquaculture, including specifically on polyculture and aquaponics, and on "mixed systems", including integrated aquaculture, i.e. systems in which aquaculture is integrated with crop or livestock production. The first three subsections below present an overview of such practices. The first two cover systems that

52 FAO estimates that about 598 aquatic species are currently farmed around the world, including seaweeds, molluscs, crustaceans, fish and other groups (FAO, 2018a). This number is increasing very fast, as there were only 472 aquatic species reportedly farmed in 2006 (ibid.) involve combining aquaculture with other components (integrated aquaculture and the specialized case of aquaponics) and the third covers the use of multiple aquatic species (polyculture) in the context of aquaculture itself. The final subsection discusses trends in the use of diversification practices in aquaculture and presents findings from the country reports on the levels of (and trends in) the use of polyculture and aquaponics practices.

\section{Integrated aquaculture}

Much of modern aquaculture operates in relative isolation from other types of food and agricultural production and with little attention to its impacts on, or interactions with, surrounding ecosystems and biodiversity (see Chapter 3 for further discussion of the impacts on BFA). Traditional aquaculture, in contrast, is not an isolated operation but rather an integral component of local farming systems, and is managed in accordance with farmers' overall strategies for the use of their labour capacity, land and other resources (Dabbadie and Mikolasek, 2015). Such systems are often referred to as "integrated aquaculture" (Edwards, Little and Demaine, 2002; FAO, IIRR and WorldFish Center, 2001; Nhan et al., 2007; van der Zijpp et al., eds., 2007).

A 2001 review of integrated agricultureaquaculture (FAO, IIRR and WorldFish Center, 2001) identified a wide range of systems within this category:

- grass-fish and embankment-fish systems - fish ponds integrated with vegetable crops and grass. Grass, plant wastes and vegetable cuttings are fed to grass carp (Ctenopharyngodon idella) or other herbivorous fish species;

- seasonal ponds and ditches - components of other farming systems that become inundated for a period of the year, allowing fish stocking and culture;

- livestock-fish integration systems featuring chickens, ducks or pigs - typically involving the placement of a livestock pen or cage over or next to a fish pond so that waste feed and manure drop into the pond, directly feeding the fish or fertilizing the water to increase primary productivity; 
- rice-fish systems - integration of fish and other aquatic species into rice paddies. This typically requires specific water-management practices to provide sufficient water for the aquatic species, which may be wild species that enter the system of their own accord or species (fish or shrimps) that are deliberately introduced; and

- a few examples involving shrimp (in coastal areas) and prawn (in freshwater areas) integration may involve rotational cropping, i.e. alternation with rice production. In more brackish water, shrimp may be integrated with fish, seaweeds or molluscs. The more traditional systems are tidal trap ponds that capture wild aquatic species, which may or may not be fed.

Integrated systems have been advocated as a means of increasing land- and water-use efficiency and nutrient recycling (Nhan et al., 2006). However, studies have shown that integrated systems are complex to manage, as maximizing benefits to farmers while minimizing negative environmental impacts not only requires good management of the pond subsystem itself, but also effective integration of the subsystem with other farming activities (Dabbadie and Mikolasek, 2015).

Rice-fish farming is probably one of the oldest integrated fish-crop systems, and developed through a kind of co-evolution between agriculture and aquaculture. Once found mostly in Asia, it has now spread to other regions of the world (Halwart and Gupta, 2004). In some countries, such as Madagascar, it is the dominant fishproduction system and plays a major role in diversifying diets and improving nutrition, particularly in remote rural areas. The system has sometimes been introduced in response to external drivers. For example, in Senegal, after two decades of drought had led to expansion of mangrove areas and a resulting salinization of surface and ground water, lowland rice farmers built fishponds along the foreshore to protect their fields against the inflow of salt water and began to produce fish (Diallo, 1998; cited by Halwart and Gupta, 2004). Among the country reports, Burkina Faso mentions that it is testing the application of rice-fish farming at three pilot sites to explore the system's potential for use on a larger scale.

Around the world, integrated aquaculture remains the main gateway into sustainable fish production (or sustainable intensification of fish production) for small- or medium-scale farmers who lack access to inputs such as good-quality feeds. It is seen as an efficient way of recycling nutrients and organic matter (Ahmed, Ward and Saint, 2014; Billard, 1986; Edwards, 1980; Moriarty and Pullin, eds., 1987) and can provide economic benefits at a level similar to (and frequently much higher than) those obtainable from alternative agricultural or other rural activities (Berg, 2002; Nhan et al., 2007; Simon and Benhamou, 2009). Despite these benefits, the development of integrated aquaculture faces a number of challenges. The most significant are probably commercial, cultural and legal, as many consumers around the world regard the use of manures and similar organic matter as problematic. The use of such wastes in animal production is forbidden by law in some countries. Regulatory issues of this kind, along with the complexity involved in the management of integrated systems and the increasing availability and affordability of fish-farming feeds in Asia in recent decades, may be responsible for the sharp decline in integrated aquaculture observed in this region and elsewhere (Edwards, 2015).

Another challenge to the development of integrated aquaculture is the fact that such systems have upper yield limits associated with internal effects such as decreasing oxygen levels, caused by the addition of organic matter to the water, and the possible accumulation of toxic compounds (ammonia, nitrite, etc.). While integrated aquaculture is an economically viable activity in many regions of the world, it is not expected to be able to meet predicted future levels of demand for fish. However, the current global imbalance in the production and use of organic waste and manures may create opportunities for integrated aquaculture to reinvent itself through the development of technologies such as insect or plankton production (Edwards, 2015). 


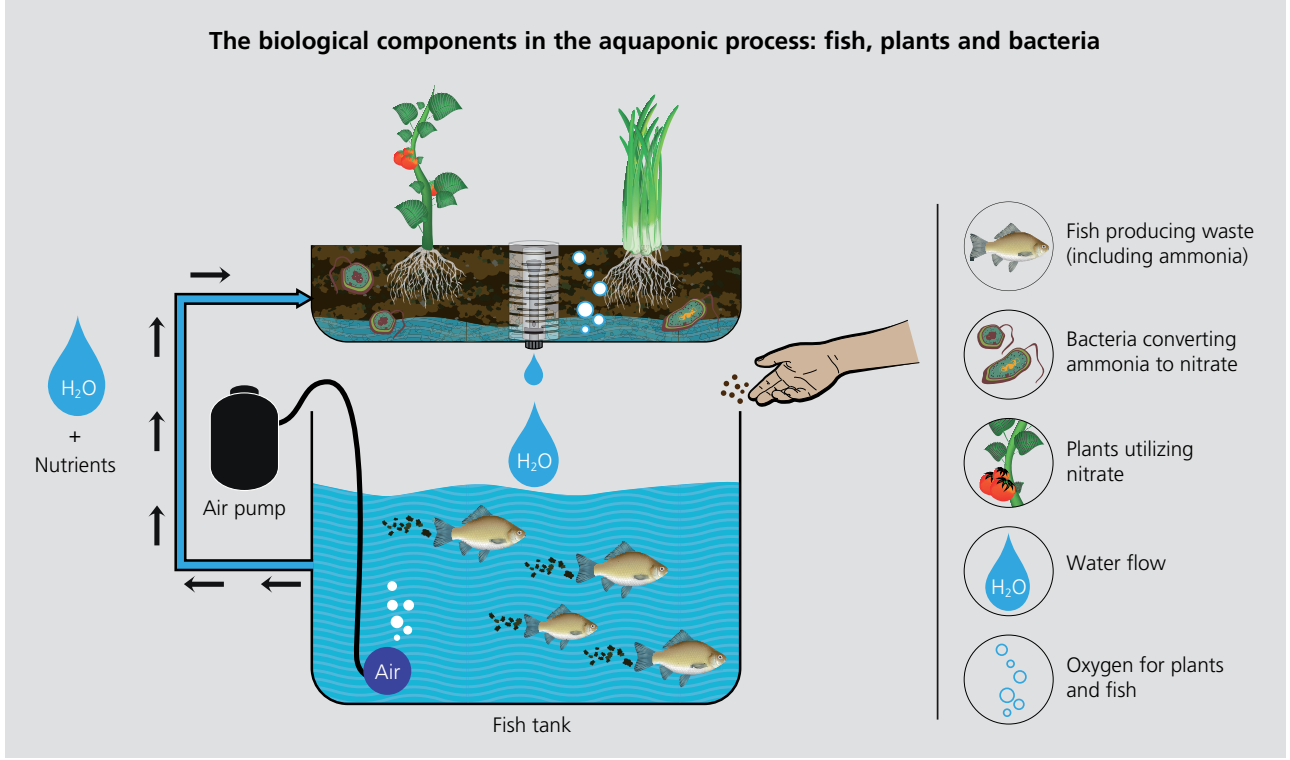

Source: Somerville et al., 2014.

\section{Aquaponics}

Aquaponics is the symbiotic integration of aquaculture (fish farming) and hydroponics (the cultivation of plants in water without soil) within a closed recirculating system (FAO, 2016k) (Figure 5.6). Given that it combines crop and aquatic production, aquaponics can be regarded as a specialized kind of mixed production system. From the aquatic perspective, it can be considered a specialized kind of integrated multitrophic aquaculture (IMTA) (see below).

Aquaponics is regarded as a potential way of obtaining higher yields with less labour, less land, less fertilizer, less pesticide and much less water usage, and of overcoming some of the challenges confronting traditional agriculture in the face of freshwater shortages, climate change, soil degradation and the need to reduce the nutrient pollution of waterbodies (FAO, 2016k). It works well in places where the soil is poor and water is scarce, for example in urban areas (aquaponics systems can be set up in locations such as backyards, rooftops and balconies), in arid zones and on low-lying islands (ibid.).

Recirculating aquaculture systems and hydroponics have both become widespread because of (among other benefits) the high yields and high-quality products they supply, their efficient use of land and water and their easy management (including in terms of pollution control) (Somerville et al., 2014). However, combining these two systems (i.e. aquaponics) can be complicated and expensive, and requires reliable access to electricity, fish seed and plant seed (ibid.). Another factor that needs to be considered before investing in large commercial aquaponics systems is access to markets where consumers are willing to pay premium prices for locally produced, pesticide-free vegetables (FAO, 2016k). The main benefits and challenges of aquaponics are summarized in Table 5.6. 


\section{PART C}

TABLE 5.6

Major benefits and challenges of aquaponic food production

\begin{tabular}{|c|c|}
\hline Benefits & Challenges \\
\hline $\begin{array}{l}\text { - Sustainable and intensive food production } \\
\text { - Two products (fish and vegetables) produced from one nitrogen source } \\
\text { - Extremely water efficient } \\
\text { - Does not require soil } \\
\text { - Does not use fertilizers or chemical pesticides } \\
\text { - High yields and high-quality products } \\
\text { - Organic-like management and production } \\
\text { - High levels of biosecurity and low risks from external contaminants } \\
\text { - High control of production leading to lower losses } \\
\text { - Can be used on non-arable land such as deserts, degraded soil or } \\
\text { salty, sandy islands } \\
\text { - Creates little waste } \\
\text { - Daily tasks, harvesting and planting are labour-saving } \\
\text { - Provides economical production of either family food or cash crops } \\
\text { - Construction materials and information base are widely available }\end{array}$ & $\begin{array}{l}\text { - High initial start-up costs compared with soil vegetable production } \\
\text { or hydroponics } \\
\text { - Knowledge of fish, bacteria and plant production needed } \\
\text { - Fish and plant requirements do not always match perfectly } \\
\text { - Not recommended in places where cultured fish and plants cannot } \\
\text { meet their optimal temperature ranges } \\
\text { - Reduced management choices compared with stand-alone } \\
\text { aquaculture or hydroponic systems (no pesticides for the plants, } \\
\text { no antibiotics for the fish) } \\
\text { - Mistakes or accidents can cause collapse of the system } \\
\text { - Daily management mandatory } \\
\text { - Energy demanding } \\
\text { - Requires reliable access to electricity, fish seed and plant seed } \\
\text { - Aquaponics alone will not provide a complete diet }\end{array}$ \\
\hline
\end{tabular}

Source: Adapted from Somerville et al. (2014).

\section{Polyculture in the context of aquaculture}

In the context of aquaculture, the term polyculture refers to the production of more than one aquatic species in the same pond or system. The motivating principle behind this approach is that raising a combination of species with complementary feeding habits and niches in the same system means that food and water resources can be utilized more efficiently and production per unit area maximized. However, although the feeding niches of some of the species used in polyculture are reasonably well known, predicting synergies and antagonisms between species remains difficult. The balance between complementarity and competition among the cultured species is therefore a key issue in polyculture (Azim and Little, 2006).

Polyculture originally referred to the practice of raising multiple fish species in a pond-culture system. However, the concept has expanded to include the raising of multiple aquatic species belonging to a range of taxa in a range of different contexts. A polyculture unit in this sense may involve several diverse components, for example a fish cage, a seaweed bed and shellfish lines. Goals have shifted from a simple focus on maximizing production efficiency to encompass other objectives such as improving water quality. Systems that specifically target production at different trophic levels are becoming more widespread. The first subsection below discusses polyculture in its traditional sense in the context of fishponds. The next subsection provides a brief overview of marine polyculture systems and the next expands on the concept of IMTA.

\section{Fish-pond polyculture}

Fish-pond polyculture involves a range of different practices. For example, Rahman, Varga and Chowdhury eds. (1992) distinguish three main types (extensive, semi-intensive and intensive systems), based on levels of management (i.e. fish stocking density and combination, nutritional inputs, etc.).

- Extensive polyculture involves no addition of nutritional inputs (i.e. manure or feed) to the system. The polycultured animals depend solely on the food that is naturally available in the environment. Such systems provide lower fish production yields than intensive systems, but they also require much less effort and are less costly. 
- Semi-intensive practices involve the addition of manure to promote growth of phytoplankton, but do not involve adding feed supplements, or only in very limited amounts. Such systems, therefore, require additional expenditure, but also provide higher output than extensive systems.

- Intensive systems provide the highest levels of output, but are also the most expensive to operate. They involve the use of highquality pellet feed that covers all the nutritional requirements of the cultivated animals. They also involve the use of water aeration and recirculation techniques to ensure water quality remains high. Because of these feeding and management methods, intensive systems are able to maintain higher stocking densities than the other types of system.

Another way of classifying polyculture systems is on the basis of spatial organization. In this respect, the three main types are direct, cage-cumpond and sequential.

- Direct polyculture involves housing two or more species in the same pond or aquaculture unit, without partitioning. This means that there may be direct contact between the species, so extra aeration is often required (depending on stocking densities) to ensure there is sufficient oxygen in the system.

- Cage-cum-pond polyculture also involves housing more than one species in the same pond. However, at least one species is kept within a cage or net-like enclosure to separate it from the other(s).

- Sequential polyculture is an integrated aquaculture system in which water flows through a series of units, each housing a separate species. This system requires more space and greater energy input, and therefore has higher costs. However, it can be very useful in situations where there are antagonistic relationships or competition between the cultured species.

Where the country reports are concerned, detailed descriptions of polyculture practices come largely from Europe. Poland states that its aqua- culture sector focuses mainly on freshwater fish, in particular the common carp (Cyprinus carpio) and the rainbow trout (Oncorhynchus mykiss). The former is often bred in semi-intensive polyculture systems and fed on non-processed grain. In these systems, the most important species raised with the European carp is the Chinese carp (Procypris mera), followed by the crucian carp (Carassius carassius), tench and sturgeons. Sturgeons are the most important group of species raised with trout. Hungary mentions the use of seven major fish species in polyculture, with carp being the most frequently used.

Fish-pond polyculture practices provide numerous benefits. The presence of multiple species with different feeding habits promotes effective use of food resources. For example, partially digested excreta from the macrovegetationfeeding grass carp can be eaten by the bottomdwelling coprofagous European carp (Rahman, Varga and Chowdhury, eds., 1992). Multiple predator species can reduce the prevalence of trophic deadlocks ${ }^{53}$ (Lazard and Dabbadie, 2002). Polyculture can also enhance the availability of natural foods within the system. For example, the feeding actions of fish such as the common carp and the bottom-dwelling mrigal (Cirrhinus mrigala) resuspend nutrients in the water and aerate sediments, thus promoting nutrient cycling (Rahman, Varga and Chowdhury, eds., 1992).

Polyculture can also contribute to improving water quality and the control of undesirable organisms. For example, stocking phytoplanktophagous silver and variegated carp helps to keep harmful algal blooms (a very common phenomenon in most tropical manure-fed ponds) under control. Various predators of tilapia fry are used to control pond overpopulation in semi-intensive polyculture systems (Bogne Sadeu et al., 2013; Dabbadie, 1996; Kaewpaitoon, 1992; El Nagar, 2007). Another benefit of polyculture can be an increase in the nutritional quality of the fish harvest (Box 5.13).

\footnotetext{
${ }^{53}$ A trophic deadlock is a component of the food web that is not consumed by any other.
} 


\section{PART C}

Box 5.13

Fish polyculture for improved nutrition - an example from Bangladesh

Studies in rural Bangladesh have shown that small fish make up 50 percent to 80 percent of the total fish intake of the local population in the peak fish-production season. Although they are consumed in small quantities, the frequency of small-fish intake is high. As many species are eaten whole - complete with head, viscera and bones - they are particularly rich in bioavailable calcium, and some are also rich in vitamin $\mathrm{A}$, iron and zinc. In areas where suitable fish resources are available and fish is consumed on a regular basis, there is scope for agricultural policies and programmes to promote the production of micronutrient-rich small fish and thereby increase people's fish consumption and improve their nutrition and health.

The results of many studies and field trials conducted in Bangladesh with carps and small fish species in pond polyculture have shown that the presence of the small, native, vitamin A-rich mola carplet (Amblypharyngodon mola) greatly improves the nutritional quality of the total fish harvest, without affecting the growth of the carps. Mola breed in the pond, and the frequent harvesting of small quantities favours home consumption. Production of only $10 \mathrm{~kg}$ of mola/pond/year in the estimated 4 million small seasonal ponds in Bangladesh could meet the annual recommended fish intake of 6 million children.

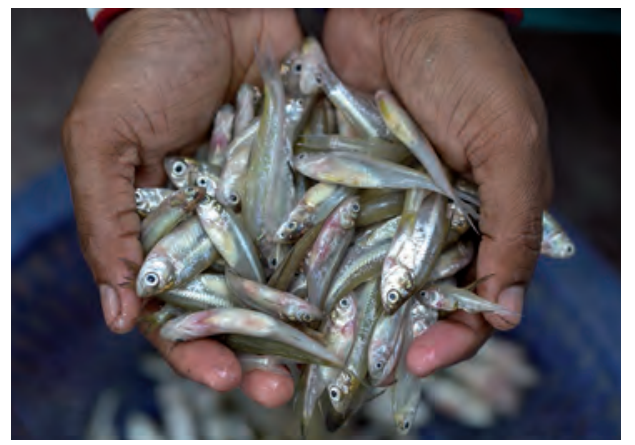

Bangladeshi woman showing mola (Amblypharyngodon mola) cultured in her backyard pond. CWorldFish.

Successful trials with the polyculture of small and large fish species have also been conducted in rice fields and wetlands. The approach, therefore, has the potential to be widely implemented. However, to fully realize its potential to improve nutrition, further data are needed on nutrient bioavailability, on intrahousehold seasonal consumption and on cleaning, processing and cooking methods for small fish species.

Sources: FAO, 2016k and Thilsted, 2012.
Challenges involved in fish-pond polyculture include the need to strike the right balance between complementarity and competition among the fish species used (Lazard and Dabbadie, 2002). Stocking density has to be carefully controlled. If it is too high, fish yields decrease, as there is less naturally available food per individual animal. Another complicating factor is the need to sort the different fish species at harvest time, which involves extra work and negatively affects the benefit-cost ratio of the system (ibid.).

\section{Marine systems}

Several types of marine aquaculture involve the integrated use of multiple species (Troell, 2009). Such systems include those in which several species are raised in a pond/tank/cage, those involving sequential integration (in which a flow of wastes is directed between culture units containing different species), and those involving temporal integration (in which species are housed sequentially within the same holding site, with the species housed later in the sequence benefiting from the wastes generated by those housed earlier). Sequential practices include systems that involve the use of mangroves as biofilters. These latter systems can be viewed as a kind of integrated aquaculture in the sense discussed above (i.e. to involve "cross-sectoral" integration of aquaculture and forestry). Although integrated approaches (whether cross-sectoral or within aquaculture) generally appear to be less widely applied in 
marine than in freshwater environments, the need to mitigate the problem of excess nutrient/organic matter generation in intensive aquaculture has helped to drive interest in the concept of IMTA.

\section{Integrated multitrophic aquaculture}

As the name implies, the distinguishing feature of IMTA is the explicit incorporation of species from different trophic levels (Chopin and Robinson, 2004). Barrington, Chopin and Robinson (2009) describe IMTA as an approach that combines the cultivation of fed aquaculture species (e.g. finfish/ shrimp) with that of species (e.g. shellfish/herbivorous fish) that filter organic matter (e.g. uneaten feed and faeces) from the water and species (e.g. seaweed) that extract dissolved inorganic nutrients (e.g. nitrogen and phosphorus).

IMTA is based on the premise that combining aquatic production at different trophic levels can allow aquaculture to have a minimal impact on the environment while improving the profitability of raising multiple species. Although it has been demonstrated that, in many cases, IMTA provides economic benefits, it may not always provide significant benefit to fish farmers in terms of directly increasing their profits (Troell, 2009). This may not matter, however, if IMTA provides the farmers with other benefits, such as improving their ability to meet environmental standards. This latter benefit may prove decisive from the commercial point of view, as it may increase market access. Possible challenges to the expansion of IMTA systems include issues related to the social acceptance of the technology in some parts of the world and those related to managing integration at the level of the production area rather than at the level of the individual operator. The ecological functioning of IMTA also needs to be better understood. Much progress has been made in recent years in terms of improving understanding of nutrient recycling, mitigation of benthic impact and various other benefits provided by IMTA (e.g. control of diseases or sea lice). However, there is a need for further research to support the development of efficient site-specific guidelines for sustainable operations.

\section{Status and trends}

There appears to be no systematic global monitoring of the status and trends in the application of diversification practices in aquaculture. However, it is clear that the relative contributions of the various types of systems described in this section are changing in response to economic transformations, technical developments, constraints on space, system intensification, climate change, diseases and other drivers (Chopin et al., 2001; Edwards, 2015; Powell et al., 2018; Somerville et al., 2014; Wang et al., 2015):

- Extensive integrated aquaculture is declining, mainly due to pressures on land and water resources. There is a tendency towards monoculture systems with higher-intensity production.

- Some polyculture systems may be losing ground, as the high value of certain species and the specialization of operations tend to favour the raising of single rather than multiple species.

- Water-quality, environment and health issues are driving efforts to explore innovative approaches to integration that help to limit water exchange and reduce effluent impacts in some freshwater and brackishwater systems.

- Health and disease issues are forcing some intensive systems to mix species.

- Increasing interest in the use of marine space for aquaculture and the environmental constraints to this are providing incentives for integrated mariculture.

- Urbanization and interest in smallholder vegetable and fish culture are helping to drive the emergence of aquaponics.

Countries' responses on the status and trends of the adoption of polyculture and aquaponics in different production systems are summarized in Table 5.1 and Table 5.2. Nearly half of the 25 countries that report the adoption of polyculture and/ or aquaponics indicate that these practices are used in fed aquaculture systems. One-third of these indicate the use of these practices in mixed production systems. While the number of countries reporting these practices is low, increasing trends 
are more commonly reported than decreasing trends across all the production systems where they are reported to be present.

\subsubsection{Needs and priorities}

Despite the diversity of the various practices described in the subsections above, some common needs and priorities can be identified. Obtaining more-complete knowledge of where diversification is likely to bring the greatest benefits with respect to production, sustainability and the delivery of ecosystem services is a key concern. Given that diversification practices often cut across the boundaries of traditional disciplines, crosssectoral collaboration is essential in this regard. The further development and wider application of the "options-by-context" approach (see Section 5.5.3) or of similar approaches that relate general diversification concepts to specific benefits in particular situations may be helpful in identifying desirable diversification pathways. This needs to take account of the ways in which diversification fits into the wider production landscape and to reflect not only the characteristics of the production system and relevant markets, but also stakeholder concerns and interests. The full involvement of all stakeholders and the development of governance systems that can take account of differences in objectives and interests is an important aspect of effective diversification.

A major constraint identified for many types of diversification initiative is a lack of availability of the materials needed, whether crop varieties, animal breeds or populations of aquatic or forest species. The supply of planting materials is identified as particularly important for agroforestry species, but is mentioned by countries in a range of different contexts. There is a need for new and imaginative supply systems - supported by relevant national institutions - that satisfy producers' requirements for appropriate, high-quality material at the right time. This will require not only improved delivery of diverse and well-adapted materials to where they are needed - a major challenge in itself - but also conserving and developing them. Many widely used varieties and breeds have been developed for use in high-input, standardized production systems, and may not provide the best returns under the approaches described in this section and elsewhere in this chapter.

There are significant market issues involved in diversification, and demand aspects are as important as supply ones. Appropriate policies can play an important role. The country reports provide a number of examples of where and how these can help. Improved partnerships between the private and public sectors are also desirable. Other important elements in the implementation of effective diversification strategies include support from national agricultural extension systems, clear identification of benefits for producers and a willingness to build producer capacity and knowledge. Also important is the need to monitor the effectiveness of diversification projects and programmes from various perspectives, including overall effectiveness in terms of productivity, livelihoods, sustainability and effects on the status of BFA.

\subsection{Management practices and production approaches}

- Countries report that management practices and production approaches promoting the conservation and sustainable use of biodiversity for food and agriculture (BFA) are increasingly being used.

- Organic agriculture continues to expand with support from governments and NGOs. Certified organic agriculture now (2018) covers 58 million ha worldwide, more than 1 percent of global agricultural land. Monitoring non-certified organic agriculture is difficult and this reduces the accuracy of trend data.

- A wide variety of management practices are increasingly being used to preserve and enhance soil biodiversity, although global data on implementation are uneven and limited. Countries generally identify the need to expand monitoring of beneficial soil species and improve the development and application of sustainable soil management practices.

- Conservation agriculture (an approach based on minimizing soil disturbance, maintaining soil cover 
and crop diversification) is already practised on 180 million ha, over 12 percent of global arable land, and has been increasing at a rate of 10 million ha/year for the last decade.

- Although countries appear to indicate an increase in the uptake of integrated plant nutrient management, data are too limited to allow firm statements about trends. Better indicators are needed to support global monitoring efforts.

- Awareness of the benefits of integrated pest management among consumers, farmers, governments and international agencies is increasing and its use is increasing in most production systems.

- Pollination management is widespread and countries report that it is increasingly being implemented. Promoting pollinators can be done through a variety of management choices at farm and ecosystem levels, mainly by increasing habitat diversity, reducing the use of potentially harmful products and avoiding soil disturbance.

- Many BFA-focused practices are relatively complex and require a good understanding of the local ecosystem. They can be knowledge intensive, context specific and provide benefits only in the relatively long term. Capacity development and technical and policy support are needed in order to overcome these challenges and promote wider implementation.

This section discusses various management practices and production approaches that may favour the conservation and sustainable use of BFA. The practices and approaches in question were presented in the country-reporting guidelines as "practices that are considered to favour the maintenance and use of BFA." 54 Countries were invited to report on the extent of implementation of each practice or approach, on trends in the level of implementation over the preceding ten years and on the impacts the practice or approach has on BFA (see Table 5.1, Table 5.2 and Figure 5.1 for summaries of responses).

\footnotetext{
54 Some of the practices and approaches included in the guidelines in this context are discussed above in the sections on ecosystem, landscape and seascape approaches (Section 5.3) and on diversification in production systems (Section 5.5).
}

The list of practices and approaches discussed should not be considered exhaustive. Moreover, as noted in the introduction to this chapter, although each practice or approach is presented separately, there are many linkages and overlaps between them. Many are based on similar underlying principles. It should also be noted that the main objective in this section is to review the status and trends of implementation of each practice or approach rather than to draw definitive conclusions regarding their impacts on BFA. Each subsection introduces the respective practice or approach, reviews literature (where available) on its status and trends and discusses the respective country-report responses.

\subsubsection{Organic agriculture}

Organic agriculture is described in the countryreporting guidelines as "a production management system which promotes and enhances agroecosystem health, including biodiversity, biological cycles, and soil biological activity. It emphasizes the use of management practices in preference to the use of off-farm inputs, taking into account that regional conditions require locally adapted systems. This is accomplished by using, where possible, agronomic, biological and mechanical methods, as opposed to using synthetic materials, to fulfil any specific function within the system." 55 While some production systems managed in this way are certified as organic by official bodies, others - especially in non-OECD countries - are not. Many farms that practise de facto organic agriculture are not certified. Organic standards can be applied to any type of production system, including crop, livestock, aquaculture, beekeeping, forest and mixed systems. Major commodities produced under organic standards include bananas, cocoa, coffee, cotton, forest products, palm oil, soybeans, cane sugar and tea (Willer and Lernoud, 2018), although most commodities are now available in certified organic form. ${ }^{56}$

Characteristics of organic agriculture include maximized use of natural alternatives to synthetic

\footnotetext{
55 This definition is adapted from FAO and WHO (1999).

56 Statistics on organic production can be found on the FiBL Statistics website: http://statistics.fibl.org/world.htm
} 
inputs (pesticides, fertilizers, veterinary products, etc.), a focus on soil health (use of compost, minimal tillage, cover crops, green manure, etc.), diversification of species, breeds or varieties (polyculture, rotations, companion crops, animal-plant integration, etc.), maintenance or establishment of semi-natural habitats (grass strips, flower strips, hedges, etc.), livestock management that privileges animal welfare (cage-free management, access to open fields, etc.), sustainable pasture management and use of local feed sources (IFOAM, 2017). The production of irradiated products and genetically modified organisms, and their use in animal feed, is not allowed (ibid.). Because of the environmental benefits it provides, organic agriculture is considered to be an (agri) environmental indicator by institutions such as the OECD, FAO, the European Environmental Agency and Eurostat (EEA, 2016; Eurostat, 2011, 2018; FAO, 2018p; OECD, 2013). Certification standards for organic aquaculture remain controversial, with debate continuing on issues such as recirculation or containment systems, feed sources, use of hormones, breeding techniques and conversion periods (Willer and Lernoud, 2018).

Production systems managed under organic standards are tightly linked to the surrounding ecosystems (except for those in high-containment greenhouses). In organic crop production, for example, management involves harnessing ecosystem services such as biological pest control, pollination, nutrient cycling and water retention as direct or indirect substitutes for off-farm inputs such as synthetic pesticides and fertilizers (MEA, 2005b). Ecosystem services are delivered by associated biodiversity communities and several studies have shown increases in the abundance and diversity of such communities in organic production systems (Bengtsson, Ahnström and Weibull, 2005; Costanzo and Bàrberi, 2013; Gaston and Spicer, 2004). The categories of associated biodiversity that benefit most from organic management in terms of abundance and diversity are birds, predatory and parasitoid insects, spiders, pollinators, soil-dwelling organisms and field flora (FiBL, 2016; Reganold and Wachter, 2016). For example, establishing permanent strips of flowering plants at the margins of crop fields attracts pollinators (see Section 5.6.7) and arthropod biological pest control agents (see Section 5.6.6) by providing them with shelter and alternative food sources (Landis, Wratten and Gurr, 2000).

According to the Research Institute of Organic Agriculture, 57.8 million ha of agricultural land (1.2 percent of the global total), including at least 15 million ha of cropland and almost 38 million ha of grassland, ${ }^{57}$ and involving 2.7 million producers, ${ }^{58}$ were under organic production or under conversion to organic production in 2016. Worldwide, the area of organic agricultural land has increased five-fold since 1999 (Willer and Lernoud, 2018). Certified organic products remain a small percentage of the total volume of aquaculture production. As of 2016, the reported global total was about 415000 tonnes (an increase of 8 percent on the preceding year), although the figures exclude a number of countries with major aquaculture industries (ibid.). Organic beekeeping is reported in 63 countries and accounts for 2.1 million beehives ${ }^{59}$ ( 2.3 percent of the world's beehives based on FAOSTAT data for 2016) (ibid.). Table 5.7 presents a number of indicators of the status of organic agriculture globally.

The difficulty involved in monitoring non-official organic production systems is an important factor contributing to gaps in information on the status and trends of organic agriculture. Many smallholder farms (e.g. low-input or traditional systems) may produce according to organic standards but not be recognized as such by official bodies, for example because of a lack of regulatory frameworks, difficulties regulatory bodies may have in reaching and assessing sites, or farmers' inability to pay certification fees or to access the international

\footnotetext{
57 The remaining area is accounted for by "other agricultural land" (e.g. hedges) and agricultural land for which no details of use are available.

58 The figures are considered to be underestimates, as some countries report numbers of companies, projects or grower groups that may involve a number of individual producers.

5946 percent of these are reported in Latin America and 42 percent in Europe.
} 
TABLE 5.7

Indicators of the status of organic agriculture worldwide

\begin{tabular}{|c|c|c|}
\hline Indicator & World & Top regions \\
\hline Countries with organic production systems & 178 & \\
\hline Organic agricultural land & 57.8 million ha & $\begin{array}{l}\text { Oceania: } 27.3 \text { million ha } \\
\text { Europe: } 13.5 \text { million ha } \\
\text { Latin America: } 7.1 \text { million ha }\end{array}$ \\
\hline Organic share of total agricultural land & $1.2 \%$ & $\begin{array}{l}\text { Oceania: } 6.5 \% \\
\text { Europe: } 2.7 \%\end{array}$ \\
\hline Number of producers* & 2.7 million & $\begin{array}{l}\text { Asia: } 1080000 \\
\text { Africa: } 729000 \\
\text { Latin America: } 459000\end{array}$ \\
\hline Number of countries with organic regulations (2015) & 87 & $\begin{array}{l}\text { Europe: } 39 \\
\text { The Americas and the Caribbean: } 21\end{array}$ \\
\hline Size of organic market & USD 89.7 billion & $\begin{array}{l}\text { North America: USD } 46.3 \text { billion } \\
\text { Europe: USD } 35 \text { billion }\end{array}$ \\
\hline
\end{tabular}

Notes: Data as of 2016. *The number of producers may be an underestimate as some countries that contributed data reported numbers of companies, projects or grower groups that may involve a number of individual producers.

Source: Willer and Lernoud, 2018.

organic market. Participatory guarantee schemes and internal control systems are alternative certification frameworks recognized by some governments (e.g. India and Brazil) for internal markets (Gould, 2007). Such frameworks allow groups of smallholders to assert that their production follows organic standards (or other rules such as fair trade) in a self-organized way, enabling them to access premium markets and to be recognized by official bodies at relatively low costs (ibid.).

The country-reporting guidelines invited countries to provide information on the extent of use of organic agriculture in different productions systems. ${ }^{60}$ Reponses are summarized in Table 5.1 and Table 5.2. Forty-seven out of 91 countries (84 percent of reporting OECD members and 43 percent of reporting non-OECD members) indicate that organic management is practised in at least one production-system category. The systems where organic agriculture is most frequently reported are rainfed crop systems, irrigated (nonrice) crop systems and mixed systems. Organic production is less frequently reported in livestock and forest systems, and fewer than five countries

60 The questionnaire did not draw a distinction between certified and uncertified organic production. report organic aquaculture. For all productionsystem categories but one, upward trends in the extent of organic production are more commonly reported than downward trends.

The generally positive trends in the levels of adoption of organic agriculture are reflected in the fact that many country reports refer to policies aimed at promoting the expansion of organic agriculture. For example, Bhutan notes its objective of becoming 100 percent organic by 2020. Costa Rica mentions that its National Development Plan 2014-2018 projects a 20 percent increase in the area of organic farmland. Jordan reports that expansion of organic agriculture is targeted in its National Programme for Organic Farming (2009) and that it has established a section in the Ministry of Agriculture dedicated to organic production. A number of countries mention long-standing schemes supporting and monitoring organic agriculture, for example the Federal Programme for Organic Farming and Other Forms of Sustainable Agriculture in Germany and the National Organic Program in the United States of America.

\subsubsection{Low external input agriculture} The term "low external input agriculture" (LEIA) was coined to refer to a set of agronomic practices 
that involve reduced use of inputs (seeds, agrochemicals, irrigation water, fuel, etc.) from outside the production system. ${ }^{61}$ The country-reporting guidelines defined LEIA as "production activities that use synthetic fertilizers or pesticides below rates commonly recommended for industrial tillage agriculture. It does not mean elimination of these materials. Yields are maintained through greater emphasis on agronomic practices, integrated pest management, and utilization of on-farm resources (especially labour) and management." LEIA in this sense refers to strategies that aim to reduce the need for external inputs rather than to the mere absence of their use, for example because producers are unable to afford or access them. The presence of "default" LEIA of the latter kind is noted in a number of country reports from Africa. There is a major difference between systems that just mine natural resources because inputs are unavailable, resulting in low productivity and declining production, and those that involve strategies that reduce losses from the system and allow low use of external inputs without sacrificing production or sustainability (see for example Box 5.17). The various LEIA movements active in developing countries aim to develop strategies that can help achieve food security while maintaining a low ecological footprint (Graves, Matthews and Waldie, 2004) and are well suited for implementation by resourcepoor farmers (Tripp, 2006; Vaessen and De Groot, 2003). In developed countries the term LEIA can be applied to various strategies that depart from "conventional" high external input practices.

Key LEIA methods include the use of green and animal manures and crop diversification in time and space (Graves, Matthews and Waldie, 2004; Liebman and Davis, 2000; Parr et al., 1990;

\footnotetext{
61 Low external input agriculture has been given a number of different names, for example "low external input technology (LEIT)" (Tripp, 2005, 2006), "low input farming systems" (Parr et al., 1990), "low-external-input (LEI) farming systems" (Liebman and Davis, 2000), "low external input agriculture technologies" (Moser and Barret, 2003), "low external input strategies" (Yengoh and Svensson, 2008) and "low external input sustainable agriculture (LEISA)" (Mendoza, 2002).
}

Yengoh and Svensson, 2008). Herbicide, insecticide and fungicide use is limited or avoided so as to increase the potential for biological control by natural enemies (Geiger et al., 2010). Practices such as crop rotation, intercropping and the use of cover crops disrupt the life cycles and dispersal of pests, diseases and weeds (Liebman and Davis, 2000). Crops and crop residues with allelopathic effects can also be used to combat weeds (ibid.). Crop diversification also promotes improvements to soil structure, efficient nutrient cycling and nitrogen fixation (if legumes are included) (Davis et al., 2012; Duru et al., 2015; Power, 2010). The use of these various techniques means that farms managed under LEIA are likely to harbour higher levels of associated biodiversity than conventional farms (Geiger et al., 2010). LEIA approaches may be more labour intensive and provide less output than high external input alternatives (Graves, Matthews and Waldie, 2004). However, in terms of profitability lower output may be compensated for by lower expenditure on inputs and higher prices for products (Poux, 2008).

The uptake of LEIA systems (i.e. the deliberate adoption of strategies such as those mentioned above rather than the default absence of external inputs because of lack of availability) often requires a redesign of the agroecosystem and investment in items such as extra soil amendments, additional crops for diversification, extra labour (human or animal) and training (Moser and Barret, 2003; Tripp, 2005, 2006; Yengoh and Svensson, 2008). The need for these extra investments explains, at least partly, why the adoption of proposed LEIA strategies has not always been successful in developing countries (Graves, Matthews and Waldie, 2004; Moser and Barret, 2003). For example, a LEIA scheme that was shown to be capable of increasing rice yields in smallholders' fields in Madagascar from 2 tonnes/ ha to 4-6 tonnes/ha proved to be unattractive to farmers, as it required additional labour (at a time of year when demand was already high) and training (Moser and Barret, 2003).

Country responses on trends in the use of LEIA are summarized in Table 5.1 and Table 5.2. 
Of the 91 reporting countries, 33 indicate that LEIA is practised in one or more of their production system categories. LEIA is most frequently reported (as a proportion of the total number of countries reporting the respective system) for crop and mixed systems. Where information is provided on the extent to which LEIA is practised, figures vary greatly across countries and production systems. However, the trends in adoption are generally increasing or mixed.

\subsubsection{Management practices to preserve and enhance soil biodiversity}

The Revised World Soil Charter defines sustainable soil management as follows:

Soil management is sustainable if the supporting, provisioning, regulating, and cultural services provided by soil are maintained or enhanced without significantly impairing the soil functions that enable those services. The balance between the supporting and provisioning services for plant production and the regulating services the soil provides for water quality and availability and for atmospheric greenhouse gas composition is a particular concern (FAO, 2015e).

The definition can encompass a wide variety of specific management practices and broader production strategies or approaches. Working on the basis of this definition, the Voluntary Guidelines for Sustainable Soil Management (Box 5.14) include a number of recommendations on how to "preserve and enhance soil biodiversity." This section presents a short overview of the status of adoption of practices and approaches that preserve and enhance soil biodiversity in the context of food and agriculture. Many of the practices and approaches mentioned are discussed in greater detail in other sections in this chapter.

The presence of a range of species and organisms capable of supporting critical soil processes is essential to soil health and productivity, particularly in the face of changing environmental conditions. Maintaining soil biodiversity is thus a vital aspect of sustainable soil manage- ment. Interventions can involve both the direct manipulation of the biological community (e.g. introduction of beneficial organisms) and indirect interventions that alter or maintain the environment in ways that favour the presence of beneficial species or biodiversity in general. The impacts of various management practices on soil biodiversity are reviewed by Beed et al. (2017), Briones and Schmidt (2017), Cock et al. (2012), D'Hose et al. (2018), FAO and ITPS (2015), Lehmann et al. (2011), Orgiazzi et al., eds. (2016) and Tsiafouli et al. (2015). Key means of benefiting soil biodiversity include reducing the use of synthetic fertilizers, pesticides and herbicides, maintaining or increasing soil organic matter, and minimizing soil erosion and disturbance. No-tillage agriculture, agroforestry and diversified cropping practices, for example, help to provide stable habitats for soil organisms (Clapperton, Chan and Larney, 2007; Prabhu et al., 2015).

Implementation of several of the management practices and approaches mentioned in other sections of this chapter that can contribute to the sustainable management of soil biodiversity is reported to be increasing globally, including agroecological approaches (Section 5.3.4), agroforestry (Section 5.5.3), conservation agriculture (Section 5.6.4), integrated pest management (Section 5.6.6), integrated plant nutrient management (Section 5.6.5), LEIA (Section 5.6.2), pushpull strategies (Box 5.18) and organic agriculture (Section 5.6.1). However, while the extent of implementation of organic agriculture and agroforestry is relatively well documented, data on the implementation of many sustainable soil management practices at global or regional scales are limited. Project data can provide snapshots of the extent of adoption of particular practices in particular locations. For example, the Alliance for a Green Revolution in Africa Soil Health Programme led to the adoption of integrated soil fertility management practices by 1.8 million smallholder farmers (FAO and ITPS, 2015).

Countries were invited to report on the proportion of land on which sustainable soil management is implemented and on trends in the use 


\section{PART C}

Box 5.14

The Voluntary Guidelines for Sustainable Soil Management

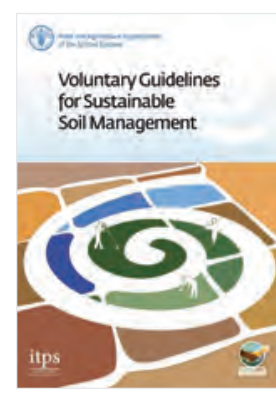

The Voluntary Guidelines for Sustainable Soil Management (FAO, 2017l) aim to provide generally accepted, practically proven and scientifically based principles that promote sustainable soil management, whether for farming, pastoralism, forestry or more general natural-resources management. The guidelines were developed to serve as a reference for a wide variety of stakeholders, ranging from government officials and policy-makers to farmers. They were adopted by the Fourth Meeting of the Global Soil Partnership Plenary Assembly (May 2016), approved by the Twenty-fifth Session of the FAO Committee on Agriculture (September 2016) and endorsed by the 155th Session of the FAO Council (December 2016).

Because soils provide one of the largest reservoirs of biodiversity on Earth, and soil organisms play key roles in the delivery of many ecosystem services, Section 3.7 of the Voluntary Guidelines is dedicated to addressing the issue of preserving and enhancing soil biodiversity. Although little is currently known about the precise relationships between the diversity of soil biological communities and the maintenance of core soil functions, new biochemical techniques and tools for DNA analysis suggest significant progress in this area is possible.

The recommendations provided in the Voluntary Guidelines on how to preserve and enhance soil biodiversity are presented below:

\section{"3.7 Preserve and enhance soil biodiversity}

- Soils provide one of the largest reservoirs of biodiversity on earth, and soil organisms play key roles in the delivery of many ecosystem services. Little is known about the degree of biodiversity required to maintain core soil functions, but new tools for biochemical techniques and DNA analysis suggest significant progress in this area is possible;

- Monitoring programs for soil biodiversity, including biological indicators (e.g. community ecotoxicology) and in-situ early warning signals, should be undertaken;
- Soil organic matter levels supporting soil biodiversity should be maintained or enhanced through the provision of sufficient vegetative cover (e.g. cover crops, multiple crops), optimal nutrient additions, addition of diverse organic amendments, minimizing soil disturbance, avoiding salinization, and maintaining or restoring vegetation such as hedgerows and shelterbelts;

- The authorization and use of pesticides in agricultural systems should be based on the recommendations included in the International Code of Conduct on Pesticide Management and relevant national regulations. Integrated or organic pest management should be encouraged;

- The use of nitrogen fixing leguminous species, microbial inoculants, mycorrhizas (spores, hyphae, and root fragments), earthworms and other beneficial micro-, meso- and macro- soil organisms (e.g. beetle banks) should be encouraged where appropriate, with attention to limiting the risk of invasive processes by promoting the use of local biodiversity and avoiding the risk of disturbance in soil services;

- Restoring plant biodiversity in ecosystems, thereby favouring soil biodiversity;

- In-field crop rotation, inter-cropping, and preservation of field margins, hedges and biodiversity refuges should be encouraged; and

- Any land use change in areas with high biodiversity should be subject to land use planning and in line with the UNCBD, UNCCD and other relevant international instruments and with national law."

Notes: UNCBD = United Nations Convention on Biological Diversity; UNCCD $=$ United Nations Convention to Combat Desertification 
of such practices. ${ }^{62}$ Of the 91 reporting countries, 39 reported the adoption of sustainable soil management practices. Responses are summarized in Table 5.1 and Table 5.2. Sustainable soil management practices are reported for all land-based production-system categories. In each case, increases in implementation are indicated more frequently than decreases. Depending on the country and production system, the reported percentage area currently under sustainable soil management practices ranges from less than 0.002 percent to 100 percent.

A wide range of specific soil-management practices are reported. For example, countries report beneficial effects on BFA from the implementation of organic agriculture, agroforestry, reduced tillage, integrated soil fertility management, cover cropping, crop diversification, crop rotation, crop associations and fallows. A few report that shifting cultivation has a negative effect on forest biodiversity. Chad, however, mentions that if fallow periods are sufficiently long, the practice offers opportunities to counteract deforestation and forest degradation. Many countries report management practices aimed at minimizing soil erosion. For example, Peru and Cameroon both mention the benefits of terracing and farming along the contours of slopes. The United States of America reports the use of windbreaks, shelterbelts and hedgerows to minimize the effects of erosion by the wind. Several countries report the use of various organic-matter inputs to improve soil conditions, including compost, vermicompost, biochar and mulch. For example, Niue mentions

\footnotetext{
62 Countries were provided with the following description and examples of sustainable soil management practices based on Swift (1999): "Management of soil biodiversity to enhance agricultural production by both direct and indirect means, including alteration of the abundance or activity of specific groups of organisms through inoculation and/or direct manipulation of soil biota. Indirect interventions may include manipulation of the factors that control biotic activity (habitat structure, microclimate, nutrients and energy resources) rather than the organisms themselves such as the maintenance of soil cover with organic mulch including crop residues, green manure/cover crops including legumes, and compost to increase soil organic matter, irrigation and liming, as well as cropping system design and management."
}

an initiative that included the establishment of an organic-waste collection system to produce compost for use as organic fertilizer. Burkina Faso's Operation Manure Pits is described in Box 5.15.

Countries were also invited to report on the "management of micro-organisms". ${ }^{63}$ Twelve countries report the use of such methods in crop production systems (irrigated and rainfed) and mixed production systems, and ten countries report their use in planted and naturally regenerated forests. All these countries report that the use of the practice is increasing in these production systems.

A number of countries mention monitoring programmes that assess soil conditions and thus help to prevent the overuse of fertilizer. For example, Switzerland describes the Swiss Soil Monitoring Network, a long-term monitoring programme for soils under various management conditions that detects changes in soil properties and thus helps promote long-term soil fertility and allows the effectiveness of soil-protection measures to be evaluated. Malaysia notes that it monitors soil erosion and has elaborated an erosion-risk map of Peninsular Malaysia. The Netherlands' soil biological monitoring programme is described in Box 4.6.

Several countries report policies and programmes aimed at supporting sustainable soil-management practices. For example, both Guinea and Senegal report that land-use and land-allocation plans developed in collaboration with various stakeholders provide frameworks for the implementation of actions aimed at restoring degraded soils. A number of countries report that sustainable soil management is addressed in their strategic plans for agriculture. A few report payment schemes promoting the sustainable use of soil resources. For example, the United Kingdom mentions that farmers benefiting from the European Union's basic payment scheme have to fulfil certain soil-protection standards, such as

\footnotetext{
63 Defined in the country-reporting guidelines as the "intentional incorporation, management or maintenance of ... microorganisms into a production system e.g., inoculation of plants and seeds with arbuscular mycorrhizal fungi, the addition of probiotics in aquaculture and livestock, etc."
} 
Box 5.15

Burkina Faso's Operation Manure Pits

In 2001, the Government of Burkina Faso launched a national programme known as Operation Manure Pits (Opération Fosse Fumière) to increase the production of compost using farmyard manure and crop residues. The aim of the programme is to enhance or restore soil fertility by increasing the application of compost to fields and hence to improve yields. In the first phase of the programme, the government helped smallholders acquire tools to construct manure pits (with a recommended area of $3 \mathrm{~m}^{2}$ and a depth of $1.20 \mathrm{~m}$ ), as well as tools for the production and transport of compost.

During the growing season of 2006/2007, it was observed that the production of organic matter did not meet expectations in terms of quality and quantity. One of the reasons was that livestock density per farm was too low to produce sufficient manure to supply the fields with enough fertilizer. In order to counteract the difficulties encountered, the focus of the programme shifted from building pits to enhancing the quality and quantity of compost. Training was provided on aerobic composting in heaps, which was found to be well suited to farms located in areas of high evaporation and low water availability. Guided field visits were held at agricultural extension centres. Farmers were encouraged to compost crop residues from cereal, banana and cotton production close to the fields, thus limiting transport and dependence on livestock. Additionally, farmers were supplied with a compost starter (a substance designed to speed up the composting process, usually in the form of dry organic matter containing a mixture of dormant soil micro-organisms that become active upon watering) to increase the pace of decomposition, and phosphate (a nutrient that is scarce in many of the country's arable soils) to increase the quality of the compost. A study in 2011 found that the application of compost following the implementation of the programme led to significant yield increases in grain crops (Zongo, 2011).

Source: Adapted from information and reports provided by Widegnoma Jean de Dieu Nitiema. minimizing soilerosion and maintaining appropriate levels of organic matter. Poland mentions its rural development programme, which includes agrienvironmental payments to farmers for appropriate soil management (see Section 8.7).

Awareness-raising projects intended to increase the adoption of sustainable soil management practices are reported by a number of countries. For example, Fiji mentions a soil-health programme that taught farmers about alternative nutrient sources, the use of the legume mucuna, crop rotation and alley cropping, and trained them in soil sampling, interpreting soil-test results and producing compost.

\subsubsection{Conservation agriculture}

Conservation agriculture is described in the guidelines for the preparation of country reports as a system that "aims to achieve sustainable and profitable agriculture and improve livelihoods of farmers through the application of three ... principles: no or minimal soil disturbance through direct seeding into untilled soils, maintenance of permanent soil mulch cover through crop residues and cover crops, and crop diversification through rotations, associations and sequences." Implementing each of these principles contributes to the supply of a range of ecosystem services (Table 5.8), particularly if implemented together so as to create synergistic effects.

Implementation of conservation agriculture is based on locally developed sets of practices involving integrated management of crops, soil, nutrients, water, pests, labour and energy - that aim to enhance and sustain an optimum environment for efficient and resilient production (FAO, 2011c; Kassam et al., 2009, 2013). Soil, landscape and cropping-system health are primary concerns. Success requires a thorough understanding of local soil and landscape ecology, and active cooperation among stakeholders, including researchers, advisers, service providers and farmers, to 
formulate the most appropriate set of production activities for the given location. ${ }^{64}$

It is widely reported that conservation agriculture increases the diversity and abundance of soil and above-ground biota (e.g. Kassam et al., 2009; Langellotto and Denno, 2004; Six et al., 2002, 2004). For example, reduced tillage can increase the abundance of fungi (Thiele-Bruhn et al., 2012), which can increase nitrogen retention in the agroecosystem (de Vries and Bardgett, 2012). It is also generally considered that adopting conservation agriculture provides financial benefits to farmers: profit margins can be equal or higher than in conventional agriculture, as yields can be maintained at similar or higher levels while the use of agrochemicals and labour and tractor hours is reduced (Dumanski et al., 2006; FAO, 2013h, 2016l; Kassam et al., 2009, 2013, 2015). However, benefits of this kind will only be achieved if the three principles of conservation agriculture are applied simultaneously (Jat, Sahrawat and Kassam, 2014; Kassam, Saidi and Friedrich, eds., 2017). There are also concerns that the adoption of conservation agriculture by smallholders can be constrained by high labour requirements for hand weeding in the absence of herbicides or by competition for the use of crop residues as livestock feed rather than as mulch (Giller et al., 2015). Complementary practices may need to be introduced to make conservation agriculture systems more functional for smallholders (Thierfelder et al., 2018).

In recent years, international research and development organizations, including FAO, the World Bank the International Fund for Agricultural Development and CGIAR, as well as a number of bilateral and multilateral donor agencies, have been supporting the adoption of conservation agriculture as a core component of climate-smart agriculture (Box 5.16). It is also an important element of the Save and Grow approach (Box 5.17). Since

\footnotetext{
${ }^{64}$ Some activities associated with conservation agriculture (e.g. mulching and cultivation of cover crops) can be considered "sustainable soil management practices" and are discussed in Section 5.6.3. They may also contribute to other approaches such as agroecology (see Section 5.3.4) and organic agriculture (see Section 5.6.1)
}

2001, FAO has supported seven World Congresses on Conservation Agriculture.

Severe soil erosion and land degradation linked to soil-disturbing practices, such as tillage and lack of maintenance of soil cover - along with the increasing costs and poor climate-change adaptability of conventional tillage agriculture - have led to the widespread introduction of conservation agriculture worldwide over the last three decades. Figures presented by Kassam, Friedrich and Derpsch (2018) for 2015/2016 indicate the use of conservation agriculture on an estimated 180 million ha of cropland globally (12.5 percent of global arable land), up from 2.8 million ha in 1973/74 and 106 million ha in 2008/2009, although not all this land is necessarily being managed fully in line with all three of the principles of conservation agriculture. ${ }^{65}$ South America is the region where conservation agriculture is most widely practised (70 million ha or 63 percent of the region's cropland), followed by Australia and New Zealand ( 23 million ha or 45 percent of the region's cropland) and North America (63 million ha or 28 percent of the region's cropland) (ibid.). Expansion in these regions over the last several decades has been facilitated, inter alia, by the availability of no-till planters, effective herbicides and, in some cases, herbicide-resistant

\footnotetext{
${ }^{65}$ The following criteria are used to define conservation agriculture (CA) for the purpose of data collection: “(1) Continuous no or minimum mechanical soil disturbance: Refers to permanent low soil disturbance no-tillage, and includes no-till direct seeding and no-till weeding. The disturbed area for crop establishment must be less than 15 $\mathrm{cm}$ wide or less than $25 \%$ of the cropped area (whichever is lower). There should be no periodic tillage that disturbs a greater area than the aforementioned limits. In special cases, low soil disturbance strip or band seeding is allowed if the disturbed surface area is less than the set limits. (2) Permanent soil mulch cover with biomass: Soil mulch cover is achieved with biomass from crop residues, stubbles and cover crops. Three categories are distinguished: $30-60 \%,>60-90 \%$ and $>90 \%$ ground cover, measured immediately after the direct seeding operation. Area with less than $30 \%$ cover is not considered as CA. (3) Crop diversification through rotations/ sequences/association: Should ideally concern at least three different crops. Repetitive wheat, maize or rice cropping is not an exclusion factor for the purpose of this data collection, but rotations/sequences/associations are noted where practised" (Kassam, Friedrich and Derpsch, 2018)
} 
Box 5.16

Conservation agriculture for climate-smart agriculture

The implementation of conservation agriculture leads to significant improvements in soil biological, physical and chemical properties, resulting in improved soil structure and aggregate stability. Soil mulch cover with crop residues increases soil organic matter and carbon sequestration, which contributes to climate change mitigation. Conservation agriculture also augments water-infiltration and water- retention capacity, and reduces runoff and direct evaporation from the soil, thus improving the efficiency of water use and the quality of water resources. Conservation agriculture is therefore increasingly being recognized as climate smart.

Source: Provided by Amir Kassam

Notes: For further information, see FAO, 2017c; González-Sánchez et al., 2017; Kassam et al., 2013; Kassam, Friedrich and Derpsch, 2017. genetically modified crops (Giller et al., 2015). Several regions with lower levels of adoption saw major expansions in percentage terms over the period between 2008/2009 and 2015/216, including Asia (430 percent increase), West Asia and North Africa (259 percent), Africa (211 percent) and Europe (not including the Russian Federation and Ukraine) (127 percent), although totals still remain low - about 1 percent of cropland in Africa, for example (Kassam, Friedrich and Derpsch, 2018). In addition to arable cropland, conservation agriculture is being implemented on significant areas of land under perennial crops (e.g. orchards, plantations and agroforestry systems) (ibid.).

The information provided in the country reports on the extent of implementation of conservation agriculture generally reflects the global patterns of use described above. Of the 91 reporting countries, 36 report the implementation of conservation agriculture. It is reported to be applied in all terrestrial production systems, most frequently in rainfed crop systems, irrigated non-rice crop systems and mixed systems (Table 5.1 and Table 5.2). As indicated in Table 5.2, in all systems where data on trends are provided, more countries report that the use of conservation agriculture is increasing than report that it is remaining stable or decreasing.

Most of the countries that provide information on conservation agriculture indicate that the practice has a positive effect on BFA in terms of both taxonomic diversity and population abundance. This is perceived to be the case in all production systems where the practice is applied. Argentina, for example, reports an increase in the diversity and abundance of both vertebrates and invertebrates (especially detritivores such as millipedes, woodlice and earthworms), although it notes that effects vary depending on local conditions and land-use history.

A number of countries provide information on national policies that have fostered - or will foster - the application of conservation agriculture. For example, Nepal reports that the adoption of conservation agriculture is being promoted via farmer field schools (see Box 8.13 for further information on farmer field schools in Nepal). Spain mentions that relevant soil-conservation measures have been receiving support since the first set of agri-environmental regulatory measures was introduced between 1994 and 1999 under European Union legislation. It further notes that national legislative measures and various programmes implemented by its Ministry of Agriculture, Fisheries, Food and the Environment have increased support for crop rotation, soil cover and direct seeding. Finland mentions support for reduced soil disturbance under the European Agricultural Fund for Rural Development. The United States of America reports that its Environmental Quality Incentives Programme provides financial and technical assistance to farmers who wish to implement farm-tailored conservation agriculture systems and practices. With regard to future priorities in this field, Panama notes the need to improve the extension services of the Ministry of Agricultural 
TABLE 5.8

Environmental and other benefits of implementing the three principles of conservation agriculture

\begin{tabular}{|c|c|c|c|}
\hline \multirow[b]{2}{*}{ Benefits } & \multicolumn{3}{|c|}{ Conservation agriculture principle } \\
\hline & $\begin{array}{l}\text { No or minimal soil } \\
\text { disturbance }\end{array}$ & $\begin{array}{l}\text { Soil mulch } \\
\text { cover }\end{array}$ & $\begin{array}{l}\text { Crop } \\
\text { diversification }\end{array}$ \\
\hline Increase and maintenance of nitrogen levels in root zone & $\bullet$ & $\bullet$ & $\bullet$ \\
\hline Increase of cation-exchange capacity of root zone & $\bullet$ & $\bullet$ & $\bullet$ \\
\hline Increase of rate of biomass production & $\bullet$ & $\bullet$ & $\bullet$ \\
\hline Maintenance of natural layering of soil horizons by actions of soil biota & - & - & \\
\hline Maintenance of supply of soil organic matter as substrate for soil biota & & $\bullet$ & \\
\hline Maximization of rain infiltration; minimization of runoff & $\bullet$ & $\bullet$ & \\
\hline Minimization of temperature fluctuations at the soil surface & & $\bullet$ & \\
\hline $\begin{array}{l}\text { Minimization of compaction by intense rainfall, passage of feet and } \\
\text { machinery }\end{array}$ & & $\bullet$ & \\
\hline Minimization of oxidation of soil organic matter and $\mathrm{CO}_{2}$ loss & $\bullet$ & & \\
\hline Minimization of soil loss in runoff or wind & $\bullet$ & $\bullet$ & \\
\hline Minimization of weeds & $\bullet$ & $\bullet$ & \\
\hline Improvement of pollination services & $\bullet$ & & $\bullet$ \\
\hline Rebuilding of damaged soil conditions and dynamics & $\bullet$ & $\bullet$ & $\bullet$ \\
\hline Recycling of nutrients & $\bullet$ & $\bullet$ & $\bullet$ \\
\hline Reduction of evaporative loss of moisture from soil surface & & $\bullet$ & \\
\hline Reduction of evaporative loss of moisture from upper soil layers & $\bullet$ & $\bullet$ & \\
\hline Reduction of fuel-energy input & $\bullet$ & & \\
\hline Reduction of labour input & $\bullet$ & & \\
\hline Reduction of pests and diseases & & & $\bullet$ \\
\hline Simulation of "forest floor" conditions & $\bullet$ & $\bullet$ & \\
\hline Increase in speed of soil porosity recuperation by soil biota & $\bullet$ & $\bullet$ & $\bullet$ \\
\hline
\end{tabular}

Source: Adapted from Kassam et al. (2013).

Development and farmer field schools to promote the adoption of conservation agriculture, along with other sustainable agricultural practices.

\subsubsection{Integrated plant nutrient management}

The term integrated plant nutrient management (IPNM) refers to soil, nutrient, water, crop and vegetation management practices undertaken with the aim of improving and sustaining soil fertility and land productivity and reducing environmental degradation, often tailored to a particular cropping and farming system (FAO, 2018q). It is typically a combination of practices and may include the use of farmyard manures, organic and mineral fertilizers, soil amendments, crop residues and farm wastes, agroforestry, conservation tillage, green manures, cover crops, legumes, intercropping, crop rotations, fallows, irrigation and drainage, plus a variety of other agronomic, vegetation-management and structural measures designed to conserve both water and soil. IPNM is a key component of sustainable and systems approaches to agriculture, such as agroecology (Section 5.3.4) and climate-smart agriculture. 
Box 5.17

The Save and Grow approach

FAO's model of ecosystem-based agriculture, Save and Grow, addresses the need to intensify production and achieve higher yields sustainably by drawing on nature's contributions to crop growth, such as soil organic matter formation, nitrogen fixation, water-flow regulation, pollination and biological control of pests and diseases. It offers a toolkit of adoptable and adaptable practices that can help smallholder farmers achieve higher productivity, profitability and resource-use efficiency.

The model encourages the use of conservation agriculture, which boosts yields while restoring soil health. Save and Grow systems use diverse, complementary groups of crops to achieve higher productivity and strengthen food and nutrition security. Pests are controlled by protecting their natural enemies rather than by spraying crops indiscriminately with pesticides. Judicious use of mineral fertilizer is promoted in order to preserve water quality, and precision irrigation is used to deliver the appropriate amount of water.

The Save and Grow approach often combines traditional knowledge with modern technologies that are adapted to the needs of small-scale producers. Practices promoted include legume rotations, rice-fish systems and "push-pull"' systems (see Box 5.18). The Save and Grow model is consistent with the principles of climate-smart agriculture, as it builds resilience to climate change and reduces greenhouse-gas emissions (see Box 5.16).

Sources: FAO, 2011c and FAO, 2016l.

As outlined in Section 2.2 and Section 4.3.6, soil biodiversity has a strong influence on the soil's physical and chemical properties. The micro-organisms (e.g. bacteria, fungi, protozoa and nematodes), mesofauna (e.g. mites and springtails) and macrofauna (e.g. earthworms and termites) that constitute the living part of soil are essential to the biogeochemical processes that maintain nutrient cycles and flows in soils and provide nutrients to plants (FAO, 2017m). At the same time, the physical and chemical components of the soil also strongly affect soil biodiversity through the provision of suitable habitats (Schlüter, Weller and Vogel, 2011).

Some IPNM practices, such as returning crop residues, animal wastes and other organic materials to the land, provide soil fauna with sources of food. Others, such as promoting greater reliance on biologically fixed and recycled nutrients, judicious use of mineral fertilizers, intercropping, conservation tillage and careful management of fodder and pasture plants, contribute to soil biodiversity via effects on soil architecture, soil chemistry and nutrient cycles (Barrios, 2007; FAO, 2011c; Mbuthia et al., 2015). In addition to promoting biodiversity within the soil, IPNM can also help to ensure water quality by reducing nutrient leaching into rivers, lakes and coastal waters (Quemada et al., 2013; Sharpley et al., 2013) and thus to protect aquatic biodiversity and fisheries (Meals, Dressing and Davenport, 2010; Woodward et al., 2012). Finally, IPNM can also help to reduce nutrient losses to the atmosphere, in particular nitrous oxide and ammonia emissions from fertilizer application and methane from stored organic fertilizers, such as manure (Galloway et al., 2008; Snyder et al., 2009), thereby contributing to climate change mitigation (Bellard et al., 2012). Further information on the use of microbial biofertilizers, including research priorities in this field, can be found in Section 5.7.2

Forty-two out of 91 reporting countries indicate that IPNM is practised (Table 5.1). Across all production system categories, increasing trends in the use of IPNM practices are more frequently reported than decreasing trends (Table 5.2). A number of countries note that it is difficult to report on the status and trends of IPNM practices, inter alia because of a lack of available data and the fact that different practices are implemented in different production systems. The country reports provide little detailed qualitative information on the effects of IPNM on biodiversity.

\subsubsection{Integrated pest management}

FAO uses the following broad definition of Integrated Pest Management (IPM):

IPM is the careful consideration of all available pest control techniques and subsequent 


\section{integration of appropriate measures} that discourage the development of pest populations and keep pesticides and other interventions to levels that are economically justified and reduce or minimize risks to human health and the environment. IPM emphasizes the growth of a healthy crop with the least possible disruption to agroecosystems and encourages natural pest control mechanisms (FAO and WHO, 2014c).

The guidelines for the preparation of country reports note that relevant pest-management methods include: "crop rotation; inter-cropping; seedbed sanitation, [appropriate] sowing dates and densities, under-sowing, conservation tillage, pruning and direct sowing; ... use of pest resistant/ tolerant cultivars, push-pull strategies and standard/certified seed and planting material; balanced soil fertility and water management, making optimum use of organic matter; ... [prevention of the spread] of harmful organisms by field sanitation and hygiene measures; [and] protection and enhancement of important beneficial organ- isms." Practices of this kind are more knowledge intensive than the calendar-based application of pesticides and therefore farmers need to understand the ecology of their production systems and to regularly monitor the environment. They need to know how to maintain healthy soils and healthy populations of biological control agents (BCAs) (organisms that are harmful to pests - see Section 4.3.5 for further details).

Almost all production systems benefit from "natural biological control", i.e. from the actions of BCAs naturally present in the local environment (Cock et al., 2009, 2011). These contributions can be enhanced through the practice of "conservation biological control" (modification of the agroecosystem and/or its immediate surroundings so as to increase the impact of local BCAs - Orr, 2009). Other forms of biological control include augmentative (mass culture and periodic release of specific BCA species) and classical biological control (permanent introduction of a BCA into an area where it does not naturally occur) (see Table 5.9) (Orr, 2009; Waage, 2007).

\section{TABLE 5.9}

\section{Examples of integrated pest management measures}

\begin{tabular}{|c|c|c|c|}
\hline $\begin{array}{l}\text { Integrated pest } \\
\text { management } \\
\text { practices }\end{array}$ & Measure & Examples and notes & Source \\
\hline \multirow{3}{*}{ Biological control } & Augmentation & $\begin{array}{l}\text { Release of Trichogramma parasitoid wasps to control } \\
\text { lepidopteran pests }\end{array}$ & Knutson, 1998 \\
\hline & Classical & $\begin{array}{l}\text { Introduction of Cactoblastis cactorum (cactus moth) to } \\
\text { control Opuntia cacti }\end{array}$ & $\begin{array}{l}\text { Zimmermann, Moran and Hoffmann, } \\
2000\end{array}$ \\
\hline & Conservation & \multirow{2}{*}{$\begin{array}{l}\text { Maintenance or establishment of vegetation near } \\
\text { fields to attract natural enemies to the field }\end{array}$} & Sengonca, Kranz and Blaeser, 2002 \\
\hline \multirow{4}{*}{ Cultural control } & $\begin{array}{l}\text { Permanent vegetation in } \\
\text { field margins }\end{array}$ & & Kremen and Miles, 2012 \\
\hline & Crop rotation & $\begin{array}{l}\text { Growing multiple crops in rotation to disrupt the life } \\
\text { cycles of pests }\end{array}$ & Zehnder et al., 2007 \\
\hline & Resistant crop varieties & Use of locally adapted varieties & Teetes, 1994 \\
\hline & "Push-pull" systems & $\begin{array}{l}\text { Integrating Cenchrus purpureus (Napier grass) and } \\
\text { Desmodium into the field to control maize and } \\
\text { sorghum stemborers }\end{array}$ & ICIPE, 2015 \\
\hline \multirow[b]{2}{*}{ Physical control } & Soil sterilization & Solarization & Stapleton and DeVay, 1986 \\
\hline & Barriers & Use of nets against birds & $\begin{array}{l}\text { Briassoulis, Mistriotis and } \\
\text { Eleftherakis, } 2007\end{array}$ \\
\hline Chemical control & Pesticides & If the pest surpasses the economic threshold & Alston, 2011 \\
\hline
\end{tabular}


Cultural control (modifying the environment to reduce its suitability for pests) and physical control (use of physical barriers to keep pests away) are also important components of IPM strategies. An IPM approach can include chemical control measures, for example highly localized "spot" applications and the use of insecticides that are relatively environmentally benign. Both pest and BCA populations have to be constantly monitored so that levels of yield damage can be predicted and decisions taken as to whether pesticides need to be applied.

IPM prioritizes prevention over intervention. This requires a good understanding of the local biodiversity and the trophic relationships within the local ecosystem (see also Sections 2.2 and 4.3.5). IPM often leads to large-scale reductions in chemical pesticide use, which over time can lead to greater species diversity in the agroecosystem, including among herbivore species. However, any impact the additional herbivore species may have is generally outweighed by the decline of the dominant pest species (Cock et al., 2011; Heong et al., 2007; Islam et al., 2012).

Cultural control methods include so-called push-pull systems (originally developed in East Africa to control sorghum and maize stemborers), which involve the use of a repellent plant (e.g. Desmodium spp.) in the field and an attractant plant (e.g. Napier grass [Cenchrus purpureus]) at the field edges (ICIPE, 2015) (Box 5.18). Other options include intercropping, use of cover crops and the establishment of permanent wild-flower strips. Complex vegetation cover and the presence of alternative food sources (e.g. nectar and pollen) attract natural enemies and may make it easier for them to survive the winter (Langellotto and Denno, 2004). Examples of the roles of different components of associated biodiversity in IPM in various production systems are shown in Table 5.10. Additional information on pest and disease regulation is provided in Section 4.3.5.

Livestock and aquatic animals can also be protected using IPM tactics, mainly by using biological control to replace the use of pesti- cides. For example, the stable fly Stomoxys calcitrans, which causes skin lesions and stress in mammalian livestock and may transmit pathogens, can be controlled using the parasitoid wasp Spalangia endius (FAO and IAEA, 2016). Some fungal species show promise as means of controlling parasitic nematodes in small ruminants (FAO, 2018r). The salmon louse (Lepeophtheirus salmonis) can be controlled by fallowing growing sites to disrupt its life cycle, farming resistant varieties, such as the coho salmon (Oncorhynchus kisutch), instead of the Atlantic salmon (Salmo salar) or using wrasses (small fish that predate on the lice) (Ottesen et al., 2011; Salmon Health Consortium and PMRA, 2003). In turn, the use of fish to control crop pests is widespread in Asian rice-fish systems. Grass carp (Ctenopharyngodon idella), common carp (Cyprinus carpio) and Nile tilapia (Oreochromis niloticus) are actively introduced into rice fields, where they feed on planthoppers and leafhoppers (Halwart and Gupta, 2004). In traditional rice cultivation, water-management regimes promote aquatic species such as fish and amphibians that predate on rice pests.

IPM strategies to control weeds and plant diseases (bacterial, viral, fungal and nematode-related) involve crop, soil and, in some cases, water management. For example, mulching and use of allelopathic cover crops hamper weed growth in soil-based systems. Application of certain organic amendments has been shown to help reduce soil-borne diseases by increasing the concentrations of ammonia and/or nitrous acid and possibly by increasing the overall abundance of soil micro-organisms (Bailey and Lazarovits, 2003; Lazarovits, 2001). The mechanisms involved are diverse, complex and not fully understood (Noble and Coventry, 2005). In rice-fish systems, aquatic weeds and algae can be regulated by the fish and by appropriate water-management practices (Halwart and Gupta, 2004). Rabbitfish (Siganus spp.) and scats (Scatophagus spp.) can be introduced into marine fish cages to reduce fouling by epiphytic algae.

Policy measures supporting IPM have been introduced in various parts of the world. Measures 
Box 5.18

The push-pull approach

Push-pull is a cultivation and pest-control practice in which pest-repelling ("push") and pest-attracting ("pull") companion crops are grown to reduce pest damage in crops. The strategy, also known as stimulo-deterrent diversion, was documented in the late 1980s. However, the research that resulted in the current system started in 1994 through collaboration between the Kenya-based International Centre of Insect Physiology and Ecology (ICIPE) and Rothamsted Research in the United Kingdom. The practice was developed to reduce maize yield losses caused by lepidopteran stemborers (Busseola fusca and Chilo partellus) in Africa, which usually reach 20 to 40 percent.

The "push" component is desmodium (Desmodium uncinatum), a short legume grown between maize rows, which repels the adult stemborer by releasing volatile chemicals (semiochemicals). Although molasses grass (Melinis minutiflora) can also be used, desmodium is preferred because it also supresses the parasitic weed Striga hermonthica and increases soil fertility through nitrogen fixation. The "pull" component of the system consists of Napier grass (Cenchrus purpureus) or Sudan grass (Sorghum sudanense) grown at the field margins. These plants attract the stemborers and their natural enemies through the release of semiochemicals. Napier grass secretes a sticky sap that traps stemborers when they perforate the plant.

\section{Mode of action of the push-pull system}

By 2014, the push-pull technique had been adopted by nearly 97000 farmers in Ethiopia, Kenya, Uganda and the United Republic of Tanzania. The desmodium-Napier grass combination has doubled maize yields by reducing stemborer and striga damage while increasing soil fertility. In addition, farmers obtain economic benefits by selling Napier grass as fodder, if it is not used for their own livestock, and by reducing expenditure on pesticides, herbicides and fertilizers. The push-pull system can be used with a variety of other crops including sorghum, millet and upland rice. The large initial investments required to start the system and in some cases a lack of infrastructure (e.g. storage units for yield surplus) are the major constraints to its wider adoption.

Source: Adapted from ICIPE (2015).

'Push'

$$
\begin{array}{cc}
\text { Volatile chemicals from } & \text { Volatile chemicals from } \\
\text { border plants attract } & \text { Desmodium intercrop } \\
\text { stemborers to lay eggs } & \text { repel stemborers }
\end{array}
$$

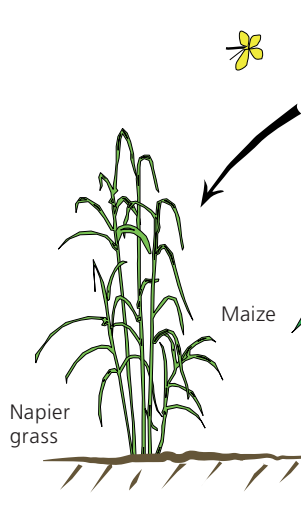

Chemicals secreted by desmodium roots control striga and

deplete striga seed bank in the soi

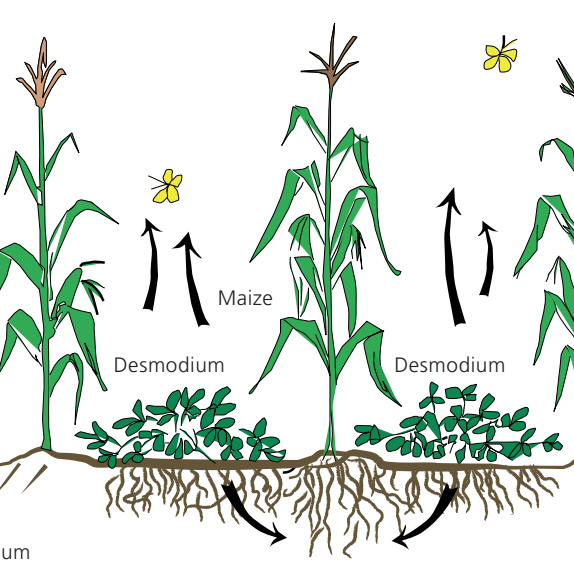

Source: ICIPE, 2015. 


\section{PART C}

TABLE 5.10

Examples of the roles of associated biodiversity in integrated pest management

\begin{tabular}{|c|c|c|c|c|c|}
\hline $\begin{array}{c}\text { Integrated pest } \\
\text { management } \\
\text { practice }\end{array}$ & $\begin{array}{l}\text { Component } \\
\text { of associated } \\
\text { biodiversity }\end{array}$ & Control agents & Pests controlled & Species protected & Source \\
\hline \multirow{9}{*}{ Biological control } & Aquatic species & Fish, amphibians & Rice-field pests & $\begin{array}{l}\text { Oryza sativa } \\
\text { (Asian rice) }\end{array}$ & $\begin{array}{l}\text { Halwart and Gupta, } \\
\text { 2004; Hocking and } \\
\text { Babbitt, } 2014\end{array}$ \\
\hline & \multirow[b]{2}{*}{ Arthropods } & $\begin{array}{l}\text { Ladybird beetles } \\
\text { (Coccinellidae, } \\
\text { Coleoptera) }\end{array}$ & $\begin{array}{l}\text { Aphids (Aphidoidea } \\
\text { superfamily) }\end{array}$ & $\begin{array}{l}\text { Citrus spp., apples and } \\
\text { several annual crops }\end{array}$ & Roy and Migeon, 2010 \\
\hline & & $\begin{array}{l}\text { Parasitoid wasps } \\
\text { (several } \\
\text { Hymenoptera } \\
\text { families) }\end{array}$ & $\begin{array}{l}\text { Cnaphalocrocis } \\
\text { medinalis } \\
\text { (rice leaffolder) }\end{array}$ & $\begin{array}{l}\text { Oryza sativa } \\
\text { (Asian rice) }\end{array}$ & Gurr et al., 2011 \\
\hline & Bacteria* & $\begin{array}{l}\text { Bacillus thuringiensis } \\
\text { (Bt formulations) }\end{array}$ & Helicoperva spp. & $\begin{array}{l}\text { Solanum lycopersicum } \\
\text { (tomato) }\end{array}$ & Zhang et al., 2013 \\
\hline & Birds & $\begin{array}{l}\text { Ficedula hypoleuca } \\
\text { (European pied } \\
\text { flycatcher) }\end{array}$ & Lepidopteran larvae & Forest vegetation & Unwin, 2011 \\
\hline & Fish & Labridae (wrasses) & $\begin{array}{l}\text { Lepeophtheirus } \\
\text { salmonis } \\
\text { (salmon louse) }\end{array}$ & $\begin{array}{l}\text { Salmo salar } \\
\text { (Atlantic salmon) }\end{array}$ & Ottesen et al., 2011 \\
\hline & \multirow[t]{2}{*}{ Fungi* } & $\begin{array}{l}\text { Beauveria bassiana } \\
\text { (white muscardine } \\
\text { fungus) }\end{array}$ & $\begin{array}{l}\text { Leptinotarsa } \\
\text { decemlineata } \\
\text { (Colorado potato } \\
\text { beetle) }\end{array}$ & $\begin{array}{l}\text { Solanum tuberosum } \\
\text { (potato) }\end{array}$ & $\begin{array}{l}\text { Wraight and Ramos, } \\
2002\end{array}$ \\
\hline & & $\begin{array}{l}\text { Metarhizium } \\
\text { anisopliae }\end{array}$ & $\begin{array}{l}\text { Agriotes sputator } \\
\text { (common click beetle) }\end{array}$ & Zea mays (maize) & Eckard et al., 2014 \\
\hline & Nematodes* & $\begin{array}{l}\text { Steinernema } \\
\text { carpocapsae }\end{array}$ & $\begin{array}{l}\text { Prionoxystus robiniae } \\
\text { (carpenter moth) }\end{array}$ & $\begin{array}{l}\text { Castanea spp. } \\
\text { (chestnut) }\end{array}$ & $\begin{array}{l}\text { Hannon and Beers, } \\
2007\end{array}$ \\
\hline $\begin{array}{l}\text { Cultural control: } \\
\text { "push-pull" system }\end{array}$ & Plants & $\begin{array}{l}\text { Cenchrus purpureus } \\
\text { (Napier grass) and } \\
\text { Desmodium spp. }\end{array}$ & $\begin{array}{l}\text { Chilo partellus } \\
\text { (spotted stalk borer) }\end{array}$ & Sorghum spp. & ICIPE, 2015 \\
\hline
\end{tabular}

Note: *Usually applied as biopesticides.

of this kind can lead to economic benefits and help to reduce countries' dependence on pesticide imports. For example, during the 1980s Indonesia adopted an IPM policy and introduced strong regulation of pesticide use, leading to a decline of two-thirds in the country's pesticide imports (Bottrell and Schoenly, 2012; Islam et al., 2012). Under legislation introduced in 2009 (Directive 2009/128/EC), ${ }^{66}$ the European Union

66 Directive 2009/128/EC of the European Parliament and of the Council of 21 October 2009 establishing a framework for Community action to achieve the sustainable use of pesticides (available at http://eur-lex.europa.eu/legal-content/EN/ ALL/?uri=CELEX:02009L0128-20091125). requires its Member States to reduce pesticide application and implement the principles of IPM (see example in Box 5.19).

One striking weakness is the virtual absence of adequate human health and environmental risk assessment studies for pesticide use in developing countries. Without such studies, national and regional legislation efforts are working essentially in the dark. Perhaps the only field study to have touched on this at a multiscale level with advanced technical methods (Jepson et al., 2014) showed a high level of pesticide-related ecological and health risks along two major rivers in West Africa. There is no reason 
Box 5.19

Integrated pest management in horticultural production in Almería, Spain

The Province of Almería in southeastern Spain has one the world's largest horticultural areas (approximately 36000 ha). Globally, it is also the location where integrated pest management (IPM) is most widely applied. In 2013, pests were regulated using biological control on 27000 ha (75 percent of the total area). In 2016, 10000 ha of peppers (nearly 100 percent of the total), 9500 ha of tomatoes (more than 80 percent), 3500 ha of cucumbers and substantial areas of zucchini, eggplant, melon and green beans, among other crops, were managed under biological control practices. IPM is also important in the citrus and grape sectors. Examples of the biological control agents (BCAs) used are presented in the table below.

Spanish authorities have been actively promoting IPM programmes to reduce the use of phytosanitary products through national and international legal frameworks.
Exotic invasive species and pests are strictly monitored (Law 42/2007; Royal Decree 630/2013), while the release of exotic BCAs requires authorization and an assessment of their environmental and biodiversity impacts (Law 43/2002; Royal Decree 951/2014). The use of non-exotic BCAs is also regulated under the latter law. The use of BCAs must comply with good agricultural practices as set out in the European Union's Directive 2009/128/EC, which promotes IPM. Additionally, the European Union enforces ecotoxicological assays before registration of new phytosanitary products (Regulation [EC] No. 1107/2009), and prevention and management measures for invasive alien species (Regulation [EU] No. 1143/2014).

\section{Examples of biological control agents used in Almeria, Spain, for horticultural production}

\begin{tabular}{|c|c|c|}
\hline Crop & Pest & Biological control agent \\
\hline Chestnut trees & Dryocosmus kuriphilus (gall wasp, exotic from China) & Torymus sinensis (a parasitoid wasp, exotic from China) \\
\hline Citrus trees & Aonidiella aurantii (red scale) & Aphytis melinus (a parasitoid wasp) \\
\hline \multirow{2}{*}{ Cucumber, pepper } & Aphids & Aphidius colemani (a parasitoid wasp) \\
\hline & Bemisia tabaci (whitefly) & Amblyseius swirskii (a predatory mite) \\
\hline Cucurbits & Tetranychus urticae (red spider mite) & Phytoseiulus persimilis (a predatory mite) \\
\hline \multirow{3}{*}{ Eucalyptus } & \multirow{3}{*}{$\begin{array}{l}\text { Gonipterus scutellatus (eucalyptus weevil, exotic from } \\
\text { Australia) }\end{array}$} & Anaphes inexpectatus (a parasitoid wasp, under research) \\
\hline & & Anaphes nitens (a parasitoid wasp, exotic from Australia) \\
\hline & & Anaphes tasmaniae (a parasitoid wasp, under research) \\
\hline Pepper & Frankliniella occidentalis (western flower thrips) & Orius laevigatus (a predatory bug) \\
\hline \multirow{7}{*}{ Table grape } & \multirow{2}{*}{ Frankliniella occidentalis (western flower thrips) } & Amblyseius cucumeris (a predatory mite) \\
\hline & & Amblyseius swirskii (a predatory mite) \\
\hline & \multirow{2}{*}{ Planococcus citri (citrus mealybug) } & Anagyrus pseudococci (a parasitoid wasp) \\
\hline & & Cryptolaemus montrouzieri (a predatory beetle) \\
\hline & \multirow{3}{*}{ Tetranychus urticae (red spider mite) } & Amblyseius andersoni (a predatory mite) \\
\hline & & Neoseiulus californicus (a predatory mite) \\
\hline & & Amblyseius swirskii (a predatory mite) \\
\hline Tomato & $\begin{array}{l}\text { Bemisia tabaci (whitefly), Tuta absoluta (tomato } \\
\text { leafminer) }\end{array}$ & Nesidiocoris tenuis (a predatory bug) \\
\hline
\end{tabular}

Source: Information provided by Gonzalo Eiriz. 
to suppose that similarly high levels of risk do not exist in most, if not all, developing countries.

Out of 91 reporting countries, 45 indicate that IPM is practised in at least one production-system category (Table 5.1 and Table 5.2). Another six countries mention that it is practised in their territories without specifying the production system. IPM is reported in 79 percent of reporting OECD member countries and in 42 percent of reporting non-OECD member countries. The production systems for which IPM is most frequently reported are crop systems (rainfed and non-rice irrigated) and mixed systems (Table 5.2). A few countries, predominantly in Europe, report IPM in aquaculture systems.

In almost every production-system category for which trends are reported, increases in the use of IPM are indicated more frequently than decreases (Table 5.2). These findings reflect longterm (albeit slow) upward trends in the use of the technology globally (FAO et al., 2016). Countries generally do not provide details of the levels of adoption within particular production-system categories. The Netherlands, however, notes that, as of 2010, 60 percent of growers of arable crops, fruit crops and vegetables and between 65 percent and 70 percent of tree nurseries and flower-bulb farms used IPM. Where countries elaborate on the causes of the trends reported, it is mainly to note policy or legal measures put in place to promote IPM or policy-level or institutional constraints to adoption. Among European countries for example, Denmark notes that it has implemented a national action plan for the 2013 to 2020 period to make the adoption of IPM compulsory in cropbased systems. Malta reports a rural development programme (Agri-Environment-Climate Measures) for 2014 to 2020 that promotes IPM in vineyards and orchards. Among Asian countries, Bhutan mentions that the Pesticides Act of Bhutan, 2000, ${ }^{67}$ which enables tight centralized regulation of the import, sale and use of pesticides, also promotes the use of IPM.

67 Available (in English) at http://faolex.fao.org/cgi-bin/ faolex.exe?rec_id=028426\&database=faolex\&search type=link\&table=result\&lang=eng\&format_name=@ERALL
Among Latin American countries, Argentina and Brazil report the application of IPM in a variety of production systems, particularly in crop and mixed systems. However, Argentina indicates that progress in the implementation of IPM, which started in the 1980s, has been mixed owing to a lack of adequate agricultural extension programmes in some regions. Several country reports from the region mention policies that, directly or indirectly, facilitate the adoption of IPM. For example, Panama notes that it aims to stimulate IPM practices through its Executive Decree No. 121 of $2015,{ }^{68}$ which promotes organic production and the use of biological pestcontrol measures. Mexico reports that its National Forestry Commission monitors about 50000 ha of pest-affected systems every year and recommends the adoption of IPM. Argentina mentions that it has established IPM partnerships (Consorcios de Manejo Integrado de Plagas) at regional level through the National Agricultural Technology Institute's National Programme on Crop Protection (Programa Nacional de Protección Vegetal). These partnerships bring stakeholders together to find common ground on IPM approaches. In Africa, Burkina Faso identifies a lack of appropriate agricultural advice and a lack of awareness of the adverse effects of the misuse of pesticides on ecosystem services as major factors limiting the wider adoption of IPM.

Globally, although awareness of the benefits of IPM among consumers, farmers, governments and international agencies is increasing and the use of IPM practices is becoming more widespread, insecticide use is still at a high level. Reasons for this include aggressive marketing, the absence of public-sector advisory or extension services, insufficient legal regulation and the

\footnotetext{
68 Decreto Ejecutivo №121 (De martes 08 de septiembre de 2015) Aprueba el Nuevo Reglamento Para la Producción, Transformación y Comercialización de Productos Agropecuarios Orgánicos de Panamá y Deroga el Decreto Ejecutivo No. 146 de 11 de agosto de 2004, Que Reglamenta la Ley 8 del 24 de enero de 2002 (available in Spanish at https://www.gacetaoficial.gob.pa/pdfTemp/27876_A/ GacetaNo_27876a_20150925.pdf)
} 
knowledge-intensive nature of IPM (Islam et al., 2012; Waage, 2007). Pesticides may seem attractive to growers because of their low costs and simplicity of use (Islam et al., 2012). IPM systems require training and monitoring (by trained farmers or extension workers) and this can be costly (Waage, 2007). Frequent release of natural enemies in places with high pest pressures can also be prohibitively expensive (Cock et al., 2009). The effectiveness of IPM strategies can also be limited by the fact that they are often based on single control measures rather than an ecosystem approach (FAO and CBD, 2016). Needs and priorities related to facilitating the use of biopesticides (and to research priorities in this field) are discussed in Section 5.7.2.

\subsubsection{Pollination management}

Growing demand for fruit, nut and vegetable crops means that the dependence of agriculture on pollination is increasing (Aizen et al., 2008, 2009). Efforts are being made to improve understanding of the relative benefits of different pollination-management strategies involving both wild and managed pollinators (Potts et al., 2010) and to identify best practices and tools that can be used by farmers and others (Isaacs et al., 2016). This section presents a short overview of the main groups of managed pollinators (various types of bees), the practices and approaches that can be used to maintain and support them, and the status of adoption of these practices and approaches. Many of the practices and approaches mentioned are discussed in greater detail in other sections in this chapter.

\section{Bees managed for pollination}

Various types of bees (mainly honey bees, and some species of bumble bees, solitary and stingless bees) are managed to provide pollination services in crop production (and in some cases for other purposes such as supplying honey).

\section{Honey-bee management}

The two major honey-bee species managed around the world are the western honey bee (Apis mellifera) and the eastern honey bee (Apis cerana) (IPBES, 2016b). Managed honey bees are kept in human-made, portable containers, known as hives, that can be easily managed and transported (Crane, 1983). Migratory beekeeping allows beekeepers to target demand for pollination services and/or to maximize honey production (IPBES, 2016b). However, it can affect local bee populations as it facilitates the spread of bee diseases and pests and can cause pathogen spillover into native bee populations (Fürst et al., 2014; Goulson, 2003; Moritz, Hartel and Neumann, 2005; Smith et al., 2014).

Renting managed honey-bee colonies to increase pollination services for intensive production of fruit, vegetable, oilseed and nut crops is a common practice in many countries (Delaplane and Mayer, 2000; Isaacs et al., 2016). In the United States of America, for example, 1.5 million or more colonies are moved across the country to California each year to pollinate almond trees in February and March (Sumner and Boriss, 2006). However, in some parts of the world, crop producers and farmers do not always have the skills needed, or access to the resources needed, to ensure adequate pollination services through the addition of managed honey-bee colonies (Isaacs et al., 2016).

The advantages of managed honey-bee colonies include the ability to control and increase the abundance of foraging bees in a specific area at the time of crop bloom, even if honey bees may not be the most efficient pollinators of many crops (ibid.). Recent years have, however, seen growing interest in wild pollinators as potential complements to managed bees in the supply of pollination services in crop production (Garibaldi et al., 2013, 2016; Winfree et al., 2018). Both wild pollinators and other managed bee species, such as bumble bees (Bombus spp.) and solitary bees (e.g. Osmia spp.), have been found to be equally or more efficient pollinators for some crops and could complement, or in some cases even replace, honey-bee pollination (Banda and Paxton, 1991; Freitas and Paxton, 1998; James and Pitts-Singer, 2008; Vicens and Bosch, 2000). 


\section{Bumble-bee management}

In the past few decades, bumble bees (the genus Bombus) have increasingly been traded commercially for use as pollinators (Velthuis and van Doorn, 2006). Five Bombus species are currently used for crop pollination (B. terrestris [buff-tailed bumble bee], $B$. lucorum [white-tailed bumble bee], $B$. ignitus, $B$. occidentalis [western bumble bee] and $B$. impatiens [common eastern bumble bee]), the major ones being the European species $B$. terrestris and the North American B. impatiens (ibid.).

The massive introduction of colonies, both within and outside the natural range of the respective species, is one of the main threats to native bees, particularly bumble bees (Cameron et al., 2011). These introductions can lead to (i) competition for resources (including forage and nesting sites), (ii) reproductive interference due to interspecific mating between introduced and native species (Kanbe et al., 2008), (iii) greater threat from parasites (Meeus et al., 2011) and (iv) transmission of diseases and pathogens (Colla et al., 2006). It has been relatively well documented that the spread of pathogens and diseases associated with bumble-bee management can occur at large scales as well as locally (Goka, Okabe and Yoneda, 2006). For example, "chronic pathogen spillover" from commercial bumble-bee colonies has caused declines in some wild bumble-bee populations in North America (e.g. Szabó et al., 2012).

\section{Stingless-bee management}

In most areas where they occur, stingless bees (tribe Meliponini) were traditionally a source of honey, propolis ${ }^{69}$ and wax (Cortopassi-Laurino et al., 2006; Heard and Dollin, 2000; Kwapong et al., 2010; Nates-Parra, 2001, 2004). Recently, however, there has been increasing interest in their potential role as managed pollinators in crop production (Giannini et al., 2015; Slaa et al., 2006), as they could compensate for local declines in

69 Propolis is a mixture of beeswax, plant resins collected by bees from plants (particularly from flowers and leaf buds) and bee saliva (Krell, 1996). Bees use it as a sealant within the hive. It is harvested for use in (inter alia) the production of cosmetics and alternative medicines (ibid.). honey-bee populations (Brown and Paxton, 2009; Van Engelsdorp and Meixner, 2010; Jaffé et al., 2010) and thus ensure adequate levels of pollination in target crops (Aizen and Harder, 2009). For some plants and crops, stingless bees have been found to be more effective pollinators than honey bees (Slaa et al., 2006).

Stingless beekeeping (meliponiculture) remains underdeveloped compared to apiculture. However, while managing stingless bees for crop pollination remains relatively uncommon, efforts are being made in several countries to promote the practice. In Brazil, for example, Melipona fasciculata has been found to be an efficient pollinator of eggplant (Nunes-Silva et al., 2013) and M. quadrifasciata anthidioides to increase seed and fruit production in apples in the presence of honey-bee hives (Viana et al., 2014). In Mexico, it has been found that the stingless bee Nannotrigona perilampoides could act as an alternative to honey bees and bumble bees in the pollination of greenhouse tomatoes (Cauich et al., 2004; González-Acereto, QuezadaEuán and Medina-Medina, 2006). In Australia, meliponiculture has acquired a foothold in crop (mainly macadamia) production, mainly using Trigona carbonaria, T. hockingsi and Austroplebeia australis (Cortopassi-Laurino et al., 2006; Heard and Dollin, 2000; Heard, 1999). Developments in Malaysia are described in Box 5.20.

\section{Solitary-bee management}

Their ease of handling and their ability to adapt to new environments (in the field or in greenhouses) mean that solitary bees have considerable potential as providers of additional or complementary pollination services (Bosch and Kemp, 2000; Wilkaniec and Radajewska, 1997). Several solitary-bee species are being used to provide pollination services, the most widely reported being the alfalfa leafcutter bee (Megachile rotundata). Greenhouse experiments have shown that this species is far superior to honey bees as a pollinator of alfalfa (Medicago sativa) (per single floral visit) (Cane, 2008). It is estimated that alfalfa leafcutter bees have tripled seed yields in North America and contribute to over 50 percent of alfalfa-seed 
Box 5.20

Management of stingless bees in Malaysia

Stingless bees are important pollinators of forest species in Malaysia (Momose et al., 1998). The value of pollination services provided by the country's stingless bees has been estimated to amount to USD 19 million per year (Mohd et al., 2010). According to the latest inventories, there are 35 stingless-bee species in Peninsular Malaysia (Mohd Fahimee et al., 2016) and 45 in East Malaysia (unpublished data). Heterotrigona itama, Geniotrigona thoracica, Tetragonilla atripes and Tetrigona peninsularis have been identified as pollinator species for many important crops in Malaysia (Mohd et al., 2010).

Bees raised in captivity to provide pollination services need to be well adapted to secondary forest and agricultural ecosystems, i.e. to using the food sources and nesting material found in these ecosystems. The ecosystems, in turn, need to be managed so as to ensure that they support and sustain stingless-bee colonies and allow them to flourish, expand and multiply.

In 2012, the Malaysian Agricultural Research and Development Institute launched an initiative to promote the keeping of Heterotrigona itama and Geniotrigona thoracica, as these two species are commonly found in agricultural areas and pollinate many crops, including mango, starfruit and cantaloupe (Mohd Fahimee, 2012; Mohd Fahimee et al., 2016). Stingless beekeeping (meliponiculture) is an attractive option for many farmers, not only because of the pollination services the bees provide, but also because of the high demand for stingless-bee honey, known for its high antioxidant content. To control the quality of stingless-bee honey, a Malaysian standard for the specification of the product was published in 2017 (Department of Standards Malaysia, 2017).

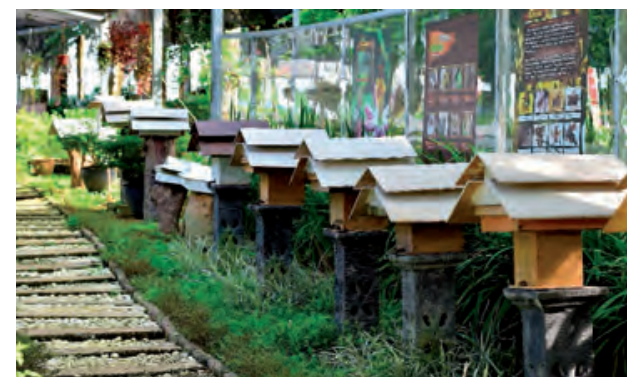

Stingless-bee mini farm/garden.
With proper maintenance, a stingless-bee colony can last many years. In a conducive environment, a parent colony can be split into two colonies once a year. Another method is to use pheromone bait (using dissolved stingless-bee propolis) during the swarming season to attract bees to make their nests in designated places. However, this method is not very effective at present. On average, farmers can harvest $0.5 \mathrm{~kg}$ of honey per month from a mature stingless-bee colony. The price of stingless-bee honey on the retail market is three times higher than honey-bee honey. Apart from honey, many cosmeceutical and nutraceutical products made using propolis and bee bread from stingless bees can generate extra income for farmers.

Future priorities include developing the mass rearing of stingless-bee queens through in vitro techniques. Further research is required on a number of factors influencing the success of this technique, including the formulation of the queens' diet and the behaviour of drones in mating virgin queens.

Source: Provided by Rosliza Jajuli and Mohd Fahimee Bin Jaapar. Pictures provided by Rosliza Jajuli.

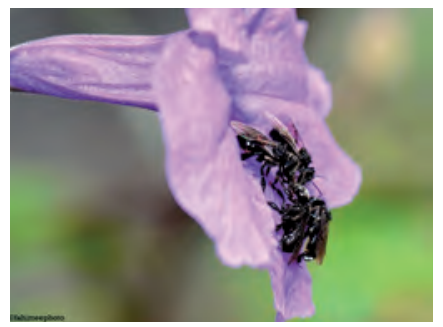

Heterotrigona itama.

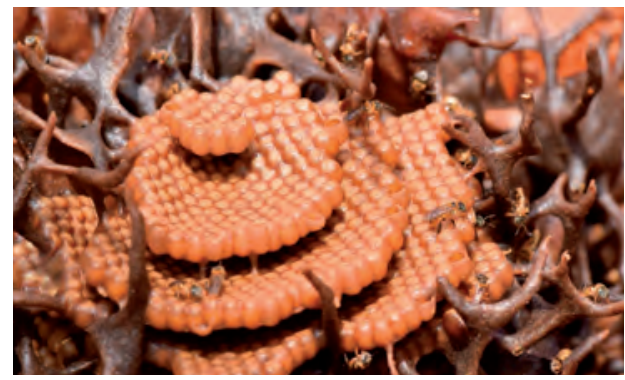

The colony. 
production in parts of the region (Pitts-Singer and Cane, 2011). They nest in large numbers in above-ground holes that they line and plug with parts of leaves (ibid.). These nesting holes can be human-made, which along with the fact that the bees' emergence coincides with alfalfa blooms, makes this species highly suitable for management as pollinators in alfalfa production (ibid.).

Many mason bees (Osmia spp.) have also been managed for commercial-crop (orchard/fruittree) pollination. Osmia cornifrons (the hornfaced bee) has been used widely in Japan to pollinate apple (Bosch and Vicens, 2000) and sweet pepper (Kristjansson and Rasmussen, 1991), among other crops. O. lignaria (the blue orchard bee) has been used in the United States of America and Canada to pollinate apple (Torchio, 1984), commercial sweet cherry (Bosch, Kemp and Trostle, 2006) and almond (Bosch, Kemp and Peterson, 2000). O. cornuta has been used in Europe (Bosch and Kemp, 2002) for pear (Pyrus communis) pollination (Maccagnini et al., 2003). These cavitynesting bees readily set up home in artificial nests, which can easily be placed in strategic positions within fields.

The only ground-nesting bee intensively managed for pollination services, mainly for alfalfa, is the alkali bee (Nomia melanderi) (Cane, 2002, 2008). This species nests in large aggregations in certain soil types (Johansen, Mayer and Eves, 1978) that can be created artificially (Stephen, 1960).

\section{Management practices promoting the abundance of wild bees in and around production systems}

Wild bees, which make up the overwhelming majority of the over 20000 described bee species (Michener, 2007), contribute significantly to pollination services worldwide. Their importance to pollination varies from crop to crop and according to the production system, with contributions ranging from very little to providing most of the pollination services (Isaacs and Kirk, 2010; Rogers, Tarpy and Burrack, 2014; Winfree et al., 2008). A wide-ranging meta-analysis of the data on more than 40 crops grown in 600 fields across every populated continent (Garibaldi et al., 2013) found that wild pollinators were twice as effective as honey bees in producing seeds and fruit in crops including oilseed rape, coffee, onions, almonds, tomatoes and strawberries.

\section{Diversity}

Ensuring high diversity and abundance of wild pollinator species will increase the probability of complementarity or synergy in pollination services within a given area (whether used for agriculture or natural/semi-natural) (Blüthgen and Klein, 2011; Garibaldi et al., 2013), even in the presence of abundant managed bees (Garibaldi et al., 2011). Relatively high diversity and abundance of insect visitors to a plant ensures (i) that visits occur with greater frequency and at a greater range of times (during the day) and (ii) greater diversity of body sizes (i.e. for stigma contact and pollen delivery).

There are various ways of promoting high diversity and abundance in pollinator assemblages within and around production systems (see examples below). In regions such as Europe where farms themselves do not support high levels of pollinator diversity, maintaining or creating grasslands or other semi-natural habitats near farms (within $3 \mathrm{~km}$ ) is generally essential (Carré et al., 2009; Carvalheiro et al., 2011; Klein et al., 2012; Öckinger and Smith, 2007; Ricketts et al., 2008b; Rollin et al., 2013).

\section{Nesting resources}

Research indicates that the abundance and composition of bee communities on farms may be sensitive to the availability of nesting resources (Forrest et al., 2015; Potts et al., 2005). Most wild bees nest in the ground, in plant stems or in pre-existing cavities of various kinds (Winfree, 2010; Hudewenz and Klein, 2013). Ensuring that a range of nesting sites, either natural or artificial, are available will encourage wild bees to move into an area and remain there. For example, in the case of ground-nesting bees, bare patches of soil and minimal tilling activity will encourage nesting. Hedgerows can supply nesting resources 
for many pollinators, for example in the form of dry branches, stems, logs, or exposed soil banks or other patches of bare ground (IPBES, 2016b; Willmer, 2011). Generally, increasing the heterogeneity of any landscape increases the potential for pollinator richness (Blüthgen and Klein, 2011; Kennedy et al., 2013; Kremen and Miles, 2012; Shackelford et al., 2013).

\section{Foraging resources}

Highly diverse plant communities can provide ideal foraging resources for pollinators. Enhancing plant diversity by intercropping and/or leaving weedy herbaceous ground cover can increase the availability of nectar and pollen resources for wild bees within agricultural landscapes (Altieri et al., 2015b). Normally, for both strategies, the non-crop forage plants should flower outside the flowering period of the focal crop, so as not to create competition for pollinators (Free, 1993) and to sustain pollinator populations when the focal-crop flowers are not available (Blüthgen and Klein, 2011; Mandelik et al., 2012). As well as providing nesting sites and nesting material (see above), hedgerows and flower strips also provide food resources for pollinator communities (Garibaldi et al., 2014; Isaacs et al., 2009; Pywell et al., 2005).

\section{Farm-management practices}

There are several ways in which farm management can be adjusted to reduce adverse effects on pollinators, for example by reducing pesticide, including herbicide, use to reduce direct impacts on pollinators and impacts on the flora on which pollinators depend (e.g. via integrated pest management - see Section 5.6.6), introducing no-till or organic agriculture or diversifying the system in

Box 5.21

Enhancing pollinator presence in cassava fields in Ghana

For many years, Ghanaian farmers have been applying management practices that enhance crop production by promoting the presence of pollinators in their fields. To mark field boundaries between neighbouring farms, some vegetable growers line their field margins with one or two rows of cassava plants. The practice has both socio-economic and ecological value. Socio-economically, the farmers gain from being able to harvest some cassava from the boundary areas in addition to the vegetables in the fields. This multiple cropping contributes to food security and mitigates the potential risk of crop failure. However, there is a further benefit of having a cassava border crop around a vegetable field. Cassava flowers produce profuse amounts of nectar, which attracts bees and other species (Nassar, 2003). In Ghana, the most commonly attracted bee species include Apis mellifera and a host of stingless bees that forage for both nectar and pollen. Because of the attractiveness of cassava plants to pollinators, vegetable crops growing within a field bounded by cassava stand a greater chance of being visited by pollinators. Although the phenomenon is still under investigation, it is likely that vegetable crops such as eggplant, tomato and pepper - none of which are highly attractive to pollinators - benefit from visits by pollinators initially attracted to the cassava flowers at the field borders. Aside from the benefits provide by cassava flowers, cassava stems are pithy and serve as nests for many carpenter bees and other wood-boring bees and wasps. Moreover, cassava plants provide the delicate stems of vegetable crops with some protection against wind storms.

Other on-farm practices in Ghana that are "pollinator friendly" include leaving bushes within the farming area that serve as refugia for pollinators and as forage resources when crop fields are not in bloom. The high diversity of plants in many smallholder farms - whether bushes, crop borders or weedy areas - may provide benefits both by producing flowers early, and thus attracting pollinators into the fields before the crop flowers bloom, and by producing flowers after the crop has been harvested, and thus helping to retain and support pollinators until the next cropping season.

Source: Adapted from Isaacs et al. (2016). 
ways that favour pollinator habitat (see examples above) (IPBES, 2016b; Tuell and Isaacs, 2010). Ground-nesting bee species normally place their brood cells in the top $30 \mathrm{~cm}$ of the soil (Roulston and Goodell, 2011; Williams et al., 2010), which means that they may benefit from no-till systems or conscious tilling (appropriate timing and depth). Organic farming practices can provide multiple benefits for pollinators at local and landscape scales (IPBES, 2016b). Although these relationships have not been researched extensively, some studies have found greater bee, hoverfly and butterfly diversity in areas where organic production is practised than in areas where it is not (Gabriel et al., 2013; Holzschuh, SteffanDewenter and Tscharntke, 2008; Kennedy et al., 2013; Kremen and Miles, 2012; Nicholls and Altieri, 2013; Rundlöf, Bengtsson and Smith, 2008). For example, Holzschuh, Steffan-Dewenter and Tscharntke (2008) examined bee species richness and abundance in fallow strips adjacent to organic and conventional wheat fields and found that an increase in organic cropping in the surrounding landscape from 5 percent to 20 percent enhanced bee species richness by 50 percent. Such effects are probably caused by the absence or limited use of chemical inputs and the presence of additional non-crop floral resources (Holzschuh, SteffanDewenter and Tscharntke, 2010; Kennedy et al., 2013; Rundlöf, Bengtsson and Smith, 2008).

\section{Status and trends}

As discussed in other sections of this chapter, many management practices that can be considered favourable to pollinators, including integrated pest management, organic agriculture, conservation agriculture and agroforestry, as well as landscape-management and restoration initiatives, are reported to be becoming more widespread. Increasing awareness of the importance of pollinators and the need to address their decline has led to a range of developments at national and regional levels, under the umbrella of the International Initiative on the Conservation and Sustainable Use of Pollinators, aimed at addressing the decline of pollinators and contributing to global conservation efforts. In 2018, the Plan of Action 2018-2030 of the International Pollinator Initiative was adopted at the fourteenth meeting of the Conference of the Parties to the CBD. Regional initiatives have been established in Africa, ${ }^{70}$ Oceania, ${ }^{71}$ Europe $^{72}$ and North America. ${ }^{73}$ National initiatives in other regions include the Brazilian Pollinators Initiative ${ }^{74}$ and the Colombian Pollinators Initiative. ${ }^{75}$ Promote Pollinators, the Coalition of the Willing on Pollinators, ${ }^{76}$ was established in 2016 and today (late 2018) has 23 member countries.

Thirty-one out of the 91 country reports indicate that pollination-management practices are being implemented. The proportion is higher among OECD countries (63 percent) than among non-OECD countries (26 percent) (Table 5.1). The reports indicate that such practices are most commonly used in crop production systems, including rainfed and irrigated systems, and in mixed systems. For example, Norway notes that honeybee rental is important to the production of rapeseed, cherries, apples, pears, plums, raspberries, strawberries and blackcurrants, particularly in areas where the density of feral honey-bee colonies is low. Somewhat lower figures are reported for livestock grassland-based systems and for naturally regenerated and planted forests. Most countries do not indicate the extent to which pollination-enhancing practices are being applied. However, upward trends in adoption are reported across production-system categories (Table 5.2).

\subsubsection{Forest-management practices}

More than 60000 tree species are currently known to science, over 90 percent of which are found in the tropical and subtropical biomes (Beech et al., 2017). Tropical forests maintain

\footnotetext{
o http://www.fao.org/docrep/010/a1490e/a1490e00.htm

71 http://www.oceanicpollinators.org

$72 \mathrm{http} / / /$ ec.europa.eu/environment/nature/conservation/species/ pollinators/index_en.htm

73 http://pollinator.org/nappc

74 http://www.webbee.org.br/bpi/ibp_english.htm

75 http://www.uneditorial.com/pageflip/acceso-abierto/pdf/abejaspolinizadoras-ebook-40217.pdf

76 https://promotepollinators.org/
} 
high levels of biomass, but because of their high species diversity, they typically provide much lower volumes of merchantable wood per hectare than temperate or boreal forests, which are dominated by fewer tree species. This means that selective logging is a common harvesting method in tropical forests, typically targeting fewer than ten individuals of timber species per hectare and providing rather low volumes of wood (<30 $\mathrm{m}^{3}$ per ha) (FAO, 1993).

By the early 1990s, it was widely recognized that the mechanization of timber harvesting represented a major challenge to the implementation of sustainable forest management (see Section 5.3.2), especially in the tropics (e.g. Dykstra, 2002). After the 1950s, mechanized logging technologies using heavy machinery had been introduced rapidly from temperate and boreal regions into the tropics, and the scale and intensity of logging operations had increased considerably relative to those of operations that relied largely on human and animal power (ibid.). As a consequence, logging operations in the tropics spread across large areas, and the high density of skid trails and roads needed to extract scattered timber species heavily affected non-commercial species and degraded forest ecosystems in general. In parallel with post-1992 efforts to advance sustainable forest management, various concepts and practices were proposed for making logging operations more environmentally friendly. "Reducedimpact logging" (RIL) emerged as the most widely used term referring to such practices.

RIL has been described as a set of logging practices implemented to reduce the residual damage, biodiversity loss and carbon-dioxide emissions associated with conventional logging practices (Edwards et al., 2012). There are several other definitions of RIL, but they all emphasize the importance of well-planned, carefully implemented and closely supervised logging operations, carried out by trained personnel, that minimize impacts on forest stands and soils (Dykstra, 2002) (see Box 5.22 for a list of practices typically involved in RIL). Many of these measures were common practices in temperate and boreal forests long before the invention of RIL in the 1990s. Moreover, although RIL and tropical forests were a major focus of attention in the 1990s, there were also broader efforts to make timber-harvesting practices more sustainable in all forest biomes (e.g. Dykstra and Heinrich, 1996).

RIL needs to be part of a silvicultural system within which specific measures aimed at achieving specific objectives are prescribed and scheduled in a management plan. The management plan should also set out the method to be used to regenerate the forest, artificially or naturally, after wood harvesting. In tropical forests in particular,

Box 5.22

Measures or steps typically included in reduced-impact logging

- Preharvest planning of roads, skid trails and landings to provide access to trees that will be harvested and to minimize damage to remaining trees and environmental impacts.

- Preharvest vine/climber-cutting in areas where vines bridge tree crowns.

- The use of appropriate felling and bucking techniques, including directional felling, cutting stumps low to the ground to avoid waste, and optimal crosscutting of tree stems into logs in a way that maximizes the recovery of useful wood.

- Construction of roads, landings and skid trails following engineering and environmental-design guidelines.

- Winching of logs to planned skid trails and ensuring that skidding machines remain on the trails at all times.

- Where feasible, utilizing yarding systems that protect soils and residual vegetation by suspending logs above the ground.

- Conducting a post-harvest assessment to provide feedback to the forest manager and logging crews and to evaluate the degree to which reduced impact logging guidelines were successfully applied.

Source: Dykstra, 2002 (based on Sist et al., 1998). 
silvicultural measures implemented after selective logging often include (FAO, 1998):

- enrichment planting using nursery-raised seedlings or so-called wildings (wild seedlings) transplanted from another forest;

- weeding and clearing of forest undergrowth to reduce competition with planted or naturally established seedlings; and

- liberation cutting in dense stands of trees of both commercial and non-commercial species.

"Enrichment planting" is a term used to describe "the planting of desired tree species in a modified natural forest or secondary forest or woodland with the objective of creating a high forest dominated by desirable (i.e. local and/or high-value) species" (ITTO, 2002). This practice is implemented in forests managed to supply both wood and non-wood products, as well as in traditional agroforestry systems and in degraded forests under restoration efforts. Areas where selective logging and enrichment planting have been practised to increase the abundance of useful species for food, medicine and timber can be referred to as "enriched forests" (Peters, Nepstad and Schwartzman, 1992).

\section{Reported adoption of reduced-impact logging and enrichment planting}

Countries were invited to report on the proportion of production area under RIL $^{77}$ and changes in this proportion over the preceding ten years. Twenty-six country reports indicate that the practice is implemented (Table 5.1). Eleven of these also provide the percentage of the total production area on which the practice is applied. Several European countries indicate that 100 percent of their forest area is under reduced-impact logging, some specifying that the practice is part of their

\footnotetext{
Reduced-impact logging is described in the country-reporting guidelines as "a series of practices to improve logging practices such as vine removal, directional felling, limiting skid trails, logging roads and stumping grounds, restrictions on the size and number of trees felled, and post felling removal of waterway blockages, to reduce the residual damage, biodiversity loss and excess $\mathrm{CO}_{2}$ emissions associated with conventional logging practices" (based on Edwards et al. 2012).
}

forestry policy. Most countries indicate that the area under the practice is increasing or stable (Table 5.2). Reduced-impact logging is most commonly reported to be practised in naturally regenerated forests ( 22 countries), followed by planted forests (14 countries). A few countries provide more-detailed information on how the practice is implemented. For example, Cameroon reports that skidding trails are constructed so as to reduce the destruction of vegetation. Norway reports that measures include leaving strips of forest close to ponds, lakes, mires and rivers, leaving single selected trees, snags and logs on clear cuts, and leaving small set-aside areas. It also notes that there are restrictions on the use of specific tree species and that there are areas where there is only selective cutting of trees.

Countries were also invited to report on the proportion of production area under enrichment planting, ${ }^{78}$ and changes in this proportion over the preceding ten years. Thirty-one countries report this practice, 11 of which also specify the proportion of forest area on which it is practised (Table 5.1). Responses range from 0.01 percent to 100 percent. The majority of countries report that the area where enrichment planting is practised is increasing (Table 5.2). The production systems where enrichment planting is most commonly reported to be practised are naturally regenerated forests and planted forests (reported by 16 countries in both cases). A few countries provide more-detailed information on how enrichment planting is practised. Finland notes that forests under continuous-cover forestry, which is currently practised only on 50000 hectares, can be considered enriched forests. Norway reports that forests are enriched by maintaining a proportion of at least 10 percent of broadleaved species in coniferous stands. Costa Rica notes that since 1979 it has had a reforestation policy that includes traditional medicinal and edible

\footnotetext{
78 Enriched forests are described in the country-reporting guidelines as "selective logging and enrichment planting to increase the abundance of useful species for food, medicine and timber, often a feature of traditional management practices," (based on Peters, Nepstad and Schwartzman, 1992).
} 
species such as ice-cream bean (Inga edulis), earpod (Enterolobium cyclocarpum) and copperwood (Bursera simaruba).

\subsubsection{Needs and priorities}

While the various management practices described above are extremely diverse, and each has its own specific set of issues to be addressed, some general needs and priorities can be identified. Most, if not all, of the management practices discussed are knowledge intensive and often context specific. Implementing them effectively often requires a combination of traditional and new knowledge. The farmer field school approach has been widely applied, and creates a framework in which farmer knowledge and experience can be shared and developed. It also allows traditional and alternative practices to be tested and combined in beneficial ways.

Adopting biodiversity-friendly practices often involves some cost to the producer in terms of, for example, labour, equipment or time spent acquiring knowledge. More needs to be done to support the process of transition, including by developing the capacity of agricultural extension services. Strong social institutions are also important. The implementation of many relevant practices has a significant social or community dimension, for example in the case of terrace building, establishing windbreaks or reducing the likelihood of disease epidemics. Supporting cooperation and strengthening social institutions within producer communities are often as important as the dissemination of specific management practices.

A number of countries identify policies and regulations as playing a key role in promoting the adoption of desirable management practices. These include both those that support specific positive actions and those that place constraints on unsustainable practices, for example those that restrict inappropriate use of pesticides and other inputs. Thus, governments can play an important part in improving management practices and in providing adequate rewards for the adoption of practices that support the maintenance of BFA. Certification schemes are one approach currently playing a role. However, in many contexts such schemes are not yet sufficiently robust, flexible or diverse.

\subsection{The use of micro-organisms in food processing and agro-industrial processes}

- Micro-organisms provide a wide variety of ecosystem services and are put to a wide range of uses in the food and agriculture sector. Important uses include the production of biofertilizers and biopesticides, composting of agricultural by-products, conversion of lignocellulosic biomass into industrial products (including biofuels), environmental bioremediation and the production and preservation of many kinds of foods and drinks.

- While countries note the potential of biofertilizers and biopesticides to reduce the need for conventional agrochemicals and report ongoing research activities in this field, they also indicate that the use of such products is not yet very widespread.

- Some countries mention the significance of microorganisms in efforts to adapt food and agricultural production to the effects of climate change and other environmental stressors, noting that strengthening these roles will require better identification, inventory and characterization of relevant microbial resources.

- Many countries emphasize the importance of foodprocessing micro-organisms. Priorities noted include strengthening research into traditional fermentation processes and establishing or improving the supply of starter cultures to small-scale producers.

- Policy and institutional priorities related to the use of micro-organisms in food and agriculture include:

- improving frameworks for quality control of microbial products and for evaluating potential risks to human health or the environment;

- improving registration policies for microbial products;

- improving education and awareness raising, including via extension programmes and demonstrations in farmers' fields; and

- improving relevant partnerships between the public and private sectors. 
Micro-organisms are vital to many of the management practices discussed elsewhere in this chapter, and to the provision of a wide variety of ecosystem services (see Sections 2.2 and 4.3). They are also used in a range of agro-industrial processes and environmental-management techniques. The most prominent of these uses are in the formulation of biofertilizers and biopesticides, composting of agro-industrial by-products, conversion of lignocellulosic ${ }^{79}$ biomass into industrial products (including biofuels), environmental bioremediation and animal nutrition. In addition, micro-organisms are vital to the preparation of many types of food and drink, at industrial, artisanal or domestic scales. This section presents an overview of these various uses, considering first uses in food processing and then uses in agroindustrial processes. Further information on the roles of micro-organisms in management at production-system level (e.g. their significance in integrated pest management and sustainable soil management) can be found in the respective subsections above.

\subsubsection{Micro-organisms in food processing}

\section{Overview of the roles of micro-organisms in food processing}

Microbial fermentation has played an important role in food processing for millennia. It contributes not only to food preservation and safety, but also to the nutritional value and sensory qualities of foods and to the diversity of people's diets. ${ }^{80}$ There may be more than 5000 different types of fermented foods and drinks consumed in the world (Campbell-Platt, 1987; Tamang, 2010). Classic examples include cheese, quorn, beer, wine, vinegar, soy sauce, yoghurt and breads. The main groups of micro-organisms involved are bacteria, yeasts and filamentous fungi, also known as moulds (Tamang, Watanabe and Holzapfel,

\footnotetext{
79 Structural material found in the cell walls of plants.

80 This overview draws on the CGRFA Background Study Paper prepared by Alexandraki et al. (2013).
}

2016). In addition to their roles in fermentation, micro-organisms are used to produce many compounds used in food processing, including enzymes, flavourings, fragrances and bacteriocins (substances produced by bacteria that kill or inhibit the growth of other bacteria). Microbial food cultures whose metabolic activity helps to inhibit or control the growth of undesirable micro-organisms (e.g. pathogenic or toxogenic bacteria) are referred to as "protective cultures". These cultures play a role in fermentation, but can also be used to improve the safety of nonfermented foods, including meats, fruits, vegetables and seafood.

In some countries, fermented foods are major components of local diets, often fortifying and adding variety to otherwise bland starchy diets. For example, gundruk, a fermented and dried vegetable product, is very important to food security in many Nepali communities, especially in remote areas and particularly during the off-season when the diet consists primarily of starchy tubers and maize, which tend to be low in minerals. In Africa, fermented cassava products, such as gari and fufu, are major foods for many people. The emergence of alternatives such as refrigeration has reduced the significance of fermentation as a preservation technique in parts of the world. Where this is the case, the main role of fermentation often lies in the production of a variety of products with specific flavours, aromas and textures. It also remains a relatively efficient, low-energy and cheap means of preservation and its lack of reliance on the use of chemical additives appeals to some consumers (Battcock and Azam-Ali, 1998; Guizani and Mothershaw, 2007).

Recent decades have seen increasing interest in foods containing so-called probiotics, which have been defined as "live microorganisms which when administered in adequate amounts confer a health benefit on the host" (FAO and WHO, 2002). Probiotic micro-organisms are mainly used in dairy products such as cheese, yoghurt, ice cream and other dairy desserts. They have to be able to survive passage through the upper parts of the digestive tract (i.e. to resist gastric juices and exposure to 
bile) and to proliferate in and colonize the intestine. The most commonly used strains are lactic acid bacteria (Lactobacillus spp., Enterococcus spp. and Bifidobacterium spp.) (Ouwehand, Salminen and Isolauri, 2002; Saad et al., 2013). However, other bacteria, and even yeasts, have been developed as potential probiotics (Ouwehand, Salminen and Isolauri, 2002). Micro-organisms and their metabolites have also been used in the production of nutraceuticals, or functional foods, i.e. foods, or parts of foods, that provide medical or health benefits, including the prevention and treatment of disease (e.g. Wang et al., 2016).

Food-processing micro-organisms are used under a wide variety of different circumstances, ranging from small-scale production using long-established traditional techniques to large-scale industrial applications. Large-scale enterprises in industrialized countries are able to access established culture collections (either internally within the company or from public collections) in which precisely characterized and defined microbial strains are maintained. They generally have sufficient resources at their disposal to support research and development and to acquire the technologies they need. In contrast, food processing in the "informal" sector is driven by the availability of raw materials and cultural traditions, with gradual development of technologies over time. Modern, large-scale production depends almost entirely on the use of defined starter strains, which have replaced the undefined strain mixtures traditionally used in food processing. This has dramatically improved culture performance and product quality and consistency. It also means that a relatively small number of strains are intensively used and relied upon by the food and beverage industries.

The majority of small-scale fermentations in developing countries are still spontaneous processes: a range of micro-organisms present at the start of the process compete - and those that are best adapted to the food substrate and the conditions in which they are maintained eventually come to dominate. In many cases, material from a previous successful batch is used to facilitate the initiation of a new process. This practice, known as "backslopping", shortens the initial phase of the fermentation process and reduces the risk of fermentation failure. However, as demand for traditional fermented products grows and manufacturing has to be scaled up, it tends to be necessary to introduce the use of starter cultures (isolated cultures that can be produced on a large scale). This often reduces the uniqueness of the original product and leads to the loss of the characteristics that originally made it popular.

Although the country-reporting guidelines did not include any questions specifically related to the use of micro-organisms in food processing, a number of country reports mention the significance of this role. The report from Ethiopia, for example, notes that micro-organisms play pivotal roles in the preparation of traditional foods, such as injera, kocho, bulla and cheese, and local drinks such as tella, tej, borde, cheka and areke, that are sources of livelihood and income for millions of rural and urban Ethiopians. ${ }^{81}$ It further notes that with the growth of dairy and other food and drink agro-industries the contribution of microbial genetic resources to the national economy is set to increase enormously. Viet Nam notes that (like the country's other microbial genetic resources) microorganisms used in the production of traditional fermented foods, such as sour fermented meat rolls, soy sauce, pickles and Hue sour fermented shrimp, are well adapted to tropical climates and that strains isolated from such products can produce aromatic substances, proteins and enzymes that impart unique flavour. Mali mentions traditional fermented products such as soumbala ${ }^{82}$ and local beers and cheeses, and notes the potential use of genetically modified micro-organisms to add value

\footnotetext{
81 Injera is a sour fermented bread made from tef, sorghum or other grains; kocho and bulla are produced from the Abyssinian banana (Ensete ventricosum); tella and borde are drinks brewed from grains; cheka is brewed from grains and vegetables; tej is a honey wine; areke is a distilled beverage (Bacha, Mehari and Ashenafi, 1998; Battcock and Azam-Ali, 1998; Berza and Wolde, 2014; Haard et al., 1999; Worku, Woldegiorgis and Gemeda, 2016).

82 Soumbala is a condiment traditionally produced from the seeds of the African locust bean tree (Parkia biglobosa) (Lamien, Sidibe and Bayala, 1996).
} 
to such products. Spain refers to a growing interest in the use of micro-organisms in the design of new "functional foods" for sections of the population that have special nutritional requirements, for example for the elderly and those suffering from coeliac disease, noting the potential benefits both of probiotics and of using micro-organisms to synthesize vitamins or to increase the bio-availability of minerals in food products.

\section{Priorities in the management of food- processing micro-organisms}

As discussed elsewhere in this chapter, countries' priorities in terms of enhancing the use and development of BFA tend to include improving the state of knowledge of relevant components of biodiversity and how they can be used, disseminating this knowledge, improving stakeholder cooperation at both national and international levels and, where relevant, strengthening policy and legal frameworks. The country reports include few priorities specifically related to the use of food-processing micro-organisms. ${ }^{83}$ The priorities listed below are therefore largely based on expert opinion, in particular on a background study paper prepared for the Commission on Genetic Resources for Food and Agriculture in 2013 (Alexandraki et al., 2013).

The latter paper identifies a number of challenges to the sustainable management of foodprocessing micro-organisms. With regard to drivers of change, it notes that:

- traditional food-processing practices and indigenous knowledge are in decline worldwide;

- agricultural practices are changing and urbanization is affecting dietary preferences; and

- product availability is being influenced by the effects of climate change on production and post-harvest storage.

With regard to the current state of use and development, the paper notes that:

- there are food safety concerns about some traditional foods; and

${ }^{83}$ The country-reporting guidelines did not invite countries to list priorities in this field.
- the development of single-strain inoculations has tended to result in a lack of attention to the potential of mixed cultures and their contributions to the attributes of traditional products.

With regard to institutional, policy and legal matters, it notes that:

- local producers of fermented products are often ignored or marginalized by government agencies and financial institutions; and

- legal frameworks related to intellectual property rights, food safety and claims about the health-promoting properties of particular products need to be strengthened.

The following paragraphs summarize the main priorities identified.

\section{Research and development}

There is a need to facilitate and encourage in-depth study of traditional food-fermentation processes - improving the characterization of microbial populations, identifying strains and species that play key roles in conferring quality attributes to products and selecting appropriate strains for use in the development of starter cultures. So-called "omics" approaches can provide important insights. Another priority is to use knowledge of the preservation mechanisms associated with food fermentation to further the development and application of "natural" processing methods that can serve as alternatives to chemical and thermal preservation. Studies are also needed on the functional properties of traditional fermented foods to identify possible health-promoting (probiotic) effects. "Functional genomics" can be a valuable tool in this regard. Further research on the efficacy of nutraceuticals based on microbes is also required. Methods for preserving these products also need further study. In view of climate change, there is a need to develop mathematical models that can predict the behaviour of microbial communities under changing conditions.

\section{Starter cultures for small-scale producers} Introducing starter cultures for small-scale food fermentations is another priority area. The potential 
benefits of this approach in terms of improving product quality and safety have long been recognized. Use of starter cultures accelerates metabolic activities and means that fermentation can be better controlled. Progress has, however, been limited. Infrastructure and technical facilities need to be improved. For example, in many regions, basic laboratory equipment and biobank facilities for preserving and storing microbial cultures are often lacking. Industrial bioreactor design needs to be improved, as does diagnostic equipment for monitoring starter-culture performance.

Promoting small-scale starter-culture processing in rural areas is likely to require the use of "lowtech" procedures and the provision of support for local networking between the providers of starter cultures and small-scale processors. Key tasks include the development and implementation of simple but effective methods for preserving and maintaining traditional starter cultures without refrigeration and the further development and standardization of traditional methods so as to increase their ability to withstand climatic fluctuations.

\section{Coordination and information exchange}

Although a degree of progress has been made in establishing mechanisms for coordination and information-exchange among stakeholders, further work is needed at both national and international (regional and global) levels. For example, efforts to improve the quality and safety of food produced via traditional "low-tech" processes would benefit from the creation of multistakeholder fora at local and national levels. Such bodies would need to address a wide range of tasks, including the following:

- promoting the exchange of general, scientific and technical information;

- facilitating access to specialized technical information on food-processing biotechnology, including by promoting knowledge transfer between the public and private sectors;

- organizing training and educational activities;

- giving guidance to small-scale processors and addressing their concerns;
- facilitating unbureaucratic, low-cost access to microbial strains suitable for use in smallscale operations from culture collections;

- enabling communication and exchange between local and central governments and small-scale producers;

- providing guidance and support to governments on the application of food-processing biotechnologies and on their role and importance in food safety and food security;

- providing technical advice and facilitating access to science parks and other infrastructure; and

- supporting the dissemination of scientific and technical information generated by collaborative research projects.

Many of these tasks have international dimensions and hence the work of country-level stakeholder bodies needs to be coordinated at regional and global levels. There is a need, for example, to develop a comprehensive global database in which information on the nutritional and health-related properties of fermented foods can be collected and organized.

Much still needs to be done to improve cooperation within the research community. For example, strains cited in the scientific literature should, whenever possible, be secured for future use. Project consortia such as the European Consortium of Microbial Resource Centres (EMbaRC) ${ }^{84}$ and organizations such as Microbial Resource Research Infrastructure (MIRRI) ${ }^{85}$ and the Global Biological Resource Centre Network (GBRCN) ${ }^{86}$ have tried to address these issues, and several journals have revisited their policies to try and ensure the biological material on which published information is based is available for the future. Policies are also in place to ensure that voucher specimens underpinning microbial taxonomy are preserved and made available for the long term. However, the accessibility of key strains still needs to be improved (Stackebrandt et al., 2014). Collections

\footnotetext{
84 http://www.embarc.eu/

85 http://www.mirri.org/home.html

${ }^{86}$ http://www.gbren.org/
} 
also need to work together to make the best use of new technologies. Common policies are needed to address regulatory issues such as the control of access to dangerous organisms and access and benefit-sharing under the Nagoya Protocol.

\section{Training and education}

Training and education for small-scale producers, both on practical techniques and on product marketing, are another priority. Trainers need to be trained to address the specific needs and concerns of this group. In addition to providing training per se, trainers can potentially also serve as a vital link between the formal and informal sectors, contribute to the work of national and international stakeholder bodies and support efforts to promote traditional fermented foods.

\subsubsection{Micro-organisms in agro-industrial processes}

\section{Overview of agro-industrial uses ${ }^{87}$}

\section{Biofertilizers}

A biofertilizer is a substance that contains living unicellular micro-organisms that, when applied to seeds, plant surfaces or soil, colonize the rhizosphere ${ }^{88}$ or the interior of the plant and promote growth by increasing the supply or availability of primary nutrients to the host. Micro-organisms used in biofertilizers come from a range of different taxa, ranging from bacteria to yeasts and filamentous fungi. They perform a variety of different functions, including nitrogen fixation, production of phytohormones and plant growth regulators, solubilization of phosphorus and other elements, production of siderophores (substances that facilitate the uptake of iron from the soil) and the formation of mycorrhizae (symbiotic associations between fungi and plants that, inter alia, facilitate the uptake of nutrients by the plants).

87 This overview draws on the CGRFA Background Study Paper prepared by Chatzipavlidis et al. (2013).

${ }^{88}$ The region of the soil surrounding plant roots that is influenced by secretions from the roots and inhabited by distinctive communities of micro-organisms.
Production of a biofertilizer involves the identification of micro-organisms that can perform the desired functions in the targeted agroecological conditions. These then have to be multiplied and packed in carrier materials that allow them to be stored and distributed effectively.

Advantages of biofertilizers over their synthetic counterparts include their capacity to provide a wide range of nutrients, particularly micronutrients, their contribution to increasing soil organic matter content, their relatively low cost and the fact that they do not contain harmful materials such as heavy metals (or only in negligible amounts). Disadvantages include (i) much lower nutrient density, (ii) the need for different machinery from that used to apply mineral fertilizers, (iii) difficulties with supply in certain areas, (iv) the need for special care in their long-term storage (as they need to be kept alive), (v) finite expiry dates, (vi) ineffectiveness if the soil is too hot or dry, (vii) potential loss of effectiveness if the carrier medium is contaminated by other micro-organisms or if the wrong strain is used, (viii) the need for the soil to contain sufficient nutrients for the biofertilizer organisms to thrive and work, (ix) limited effectiveness in excessively acidic or alkaline soils or if the soil contains an excess of their natural microbiological competitors and (x) constraints to availability caused by shortages of particular strains of micro-organisms or shortages of growth medium.

\section{Biopesticides}

Microbial biopesticides are used to control a variety of pests and diseases in food and agricultural systems. Their use can help reduce some of the problems caused by conventional pesticides, such as the loss of beneficial organisms (pollinators, etc.), damage to wildlife habitats and adverse effects on human health (see Section 5.6.6). However, there are some drawbacks, including their susceptibility to environmental stress, the fact that they need to be kept alive and their slow kill rates (Chandler et al., 2011).

Biopesticides based on bacteria are used to control plant diseases, nematodes, insects and 
weeds. The bacterium most widely used is the insect pathogenic species Bacillus thuringiensis (Bt). During spore formation Bt produces $\mathrm{Bt}$ $\delta$-endotoxin, a highly specific endotoxin that binds to and destroys the cellular lining of the insect's digestive tract, causing the insect to stop feeding and die. The $\delta$-endotoxin crystals are mass produced in fermentation tanks and supplied in the form of a sprayable product. Bt sprays kill caterpillars, fly and mosquito larvae, and beetles. They are used on fruit and vegetable crops and on broadacre crops such as maize, soybean and cotton. Some other biopesticides are based on the capacity of certain strains of bacteria to prevent plant diseases by outcompeting plant pathogens in the rhizosphere, producing anti-fungal compounds or promoting plant growth. Preparations based on bacteria with these capacities are used against a range of plant pathogens, including damping-off and soft rots.

Fungal biopesticides can be used to control plant diseases caused by fungi, bacteria or nematodes, as well as against some insect pests and weeds. They operate via competitive exclusion, mycoparasitism ${ }^{89}$ and the production of metabolites that adversely affect the target organisms. The most common commercial fungal biopesticides used in the nursery, ornamental, vegetable, field-crop and forestry industries are Trichoderma spp., Beauveria bassiana and Metarhizium anisopliae. Trichoderma is able to colonize plant roots and out-compete pathogenic fungi for food and space. Under certain environmental conditions it can attack and parasitize plant pathogens. It can also stimulate the plant host's defences and affect root growth. Beauveria bassiana has proved effective in controlling crop pests such as aphids, thrips and pesticide-resistant strains of whitefly. The entomopathogenic fungus Metarhizium anisopliae is used against the desert locust (Schistocerca gregaria).

Baculoviruses are a family of naturally occurring viruses that infect only insects and some related arthropods. A virus of this kind is widely used in Europe and the United States of America

\footnotetext{
${ }^{89}$ Parasitism of fungi by other fungi.
}

to control the codling moth (Cydia pomonella), a pest of apple and other fruit trees. Most applications occur in conventional orchards, where its use can help minimize the risk of resistance to chemical insecticides. In Brazil, the nucleopolyhedrovirus is used to control the soybean caterpillar Anticarsia gemmatalis.

Non-pathogenic yeasts have also been developed into biopesticides. For example, a pesticide based on Candida oleophila strain $\mathrm{O}$ is used to control post-harvest fruit rots. The yeast acts as an antagonist to fungal pathogens such as grey mould (Botrytis cinerea) and blue mould (Penicillium expansum) that cause post-harvest decay.

\section{Composting of agro-industrial by-products}

Large quantities of agro-industrial by-products are generated worldwide, including straw, stalks, leaves, husks, shells, peel, lint, seeds/stones, fruit pulp, sugar-cane bagasse, sweet-sorghum milling, spent coffee grounds and brewers' spent grains. Much of this material is made up of cellulose, hemicellulose and lignin. Most is either used as animal feed or burned. However, several groups of fungi are able to decompose these substances and convert them into compost that can be used as a soil amendment. Various agro-industrial byproducts can also be used as substrates for medicinal or edible mushroom production.

\section{Production of microbial metabolites}

As well as producing compost, micro-organisms cultured on agro-industrial by-products can supply a number of other useful products including organic acids, chemical additives, pigments, enzymes, food additives, antibiotics, biofuels, solvents and bioplastics.

Organic acids. Micro-organisms are widely used to produce organic acids used in the food and beverage industries and in the production of cosmetics, pharmaceuticals, leather and textiles, biodegradable plastics and coatings, cleaning products, herbicides and pesticides. Citric acid, for example, the most important bio-industrial organic acid, is produced commercially mainly via submerged fermentation using the fungus Aspergillus niger. 
Fermentation using this fungus cultivated on a range of agro-industrial by-products including corncob, sugar-cane bagasse, coffee husks, kiwifruit peels, wheat bran, rice bran, pineapple waste, mixed fruit waste, sugar-beet molasses, sawdust with rice hulls, cassava waste, apple pomace and potato-starch residue has been intensively studied. Microbial-strain selection is very important in the production of organic acids. The micro-organisms used must have stable characteristics, be able to grow rapidly and vigorously, be non-pathogenic and produce high yields of the desired product.

Aroma and flavour compounds. Microbial biosynthesis or bioconversion systems are emerging as promising substitutes for synthetic methods of producing aroma compounds for use in the production of food, drinks, perfumes and essential oils. Both fungi and bacteria can be used to produce aroma compounds via fermentation (Dastager, 2009).

Enzymes. Fungi and bacteria grown on agroindustrial by-products in large-scale fermenters are an important source of enzymes used in a variety of industries, including the food-biotechnology, animal-feed, pharmaceutical, textile and paper industries. Rising demand for economical production methods, new functionalities, improved safety and reduced environmental impact is driving a trend towards the replacement of traditional chemical processes with enzyme-based processes. Microbial diversity is important in enabling the production of a range of enzymes suitable for various different uses.

Fructooligosaccharides. Various strains of species belonging to the fungal genera Aspergillus, Aureobasidium and Penicillium can be grown on agro-industrial by-products such as corncobs, coffee silverskin and cork oak to produce fructooligosaccharides (substances used as sweeteners and as "prebiotic" substrates for beneficial microbiota in the gut).

Bioactive compounds. Micro-organisms grown on a variety of agricultural by-products, including wheat straw, rice hulls, spent cereal grains, various brans (e.g. wheat and rice) and corncobs, can be used in the commercial production of bioactive compounds (non-nutrient substances used as ingredients in the food and cosmetics industries).
Surfactants. These substances are used to decrease surface and interfacial tension in a variety of industrial processes. Surfactants used in industry are almost all derived chemically from petroleum. However, they can also be produced by micro-organisms. Microbially derived surfactants have several advantages, including low toxicity and good biodegradability. However, although interest in their use is increasing, they are not economically competitive with synthetically produced alternatives. Agro-industrial by-products with a high carbohydrate or lipid content can be used as substrates for biosurfactant production. Potential options include peat hydrolysate, effluent from olive-oil mills, lactic whey, soybean-curd residue, potato-process effluent and molasses.

Microbial pigments. There is growing interest in microbially derived substitutes for synthetic food colouring agents, some of which have been banned on account of their potential carcinogenicity and teratogenicity. ${ }^{90}$ Currently, the cost of natural pigments is higher than that of synthetic colours, but this hurdle could be overcome by mass production. The fast growth rates of microorganisms should help to give microbial pigments a competitive advantage over pigments extracted from plant or animal sources. Riboflavin (vitamin B2) (a yellow pigment permitted in most countries and produced by Eremothecium ashbyii and Ashbya gossypi) and pigments from Monascus purpureus and $M$. ruber are already in commercial use. Carotenoids (yellow pigments) are produced by several types of micro-organisms, but only microalgae have so far been used for commercial production. Spirulina spp. produce phycobiliproteins, such as phycocyanin (blue pigment), used in food and cosmetics.

Protein-enriched feed. A wide range of microorganisms can be used to produce protein-enriched livestock feed from agro-industrial by-products (Ugwuanyi, McNeil and Harvey, 2009). Potential substrates include cassava waste, coffee pulp, wheat bran and straw, maize stover (straw), millet,

\footnotetext{
90 The ability to disturb the development of the embryo or foetus.
} 
sugar-beet pulp, citrus waste, mustard straw, agave bagasse, perennial grass, apple pomace and pulp, grape waste, pineapple waste, cactus-pear waste, rice polishings, rice bran and straw, viticulture waste, maize straw, sugar-cane bagasse, sawdust, mango waste, palm-kernel cake, and cabbage and Chinese-cabbage wastes.

Single-cell protein. Since ancient times, people in Africa and Mexico have been harvesting the cyanobacterium spirulina from water bodies, drying it and using it as food. Several other species of cyanobacteria can also be used in this way. Single-cell protein can also be produced by a range of different fungal species grown on various agro-industrial by-products.

Biologically active polysaccharides. Many strains of bacteria, yeasts and filamentous fungi are used commercially to produce extracellular polysaccharides. For example, pullulan (a substance used in the manufacture of foods and other products) is produced from agro-industrial by-products by the yeast-like fungus Aureobasidium pullulans (Israilides et al., 1999). Medicinal mushrooms, such as Ganoderma spp., are grown by solid-state fermentation using agricultural by-products as a source of polysaccharides.

Bioplastics. Micro-organisms can be used in the production of several types of bioplastic. For example, acetic acid produced through the microbial fermentation of sugar feedstocks (e.g. beets) and by converting starch in maize and potatoes, can be polymerized to produce polylactic acid, a polymer that is used to produce plastic. Bioplastics can also be made from compounds called polyhydroxyalkanoates, which are accumulated by bacteria in the presence of excess carbon sources.

Biofuels. Micro-organisms are used to produce both liquid and gaseous biofuels. Bioethanol, for example, can be produced by simple fermentation processes using feedstocks such as sugar-cane stalks, sugar-beet tubers and sweet sorghum, with yeasts as biocatalysts.

\section{Bioremediation}

Bioremediation is the use of micro-organism metabolism to remove pollutants from, for example, soils or water. The main advantage of bioremediation is its low cost compared to thermal and physico-chemical remediation. It also often offers a permanent solution, i.e. provides complete transformation (i.e. mineralization) of the pollutant rather than transferring it from one phase to another.

Bioremediation can be conducted in several ways: in situ via methods such as bio-augmentation (the addition of externally sourced micro-organisms capable of degrading the targeted contaminant), biosparging and bioventing (methods involving the injection of air and, if necessary, nutrients to increase the biological activity of indigenous micro-organisms that can degrade the targeted contaminant); ex situ via methods such as (i) landfarming (a process in which contaminated soil or other material is transported to a designated site, incorporated into uncontaminated soil and periodically tilled to aerate the mixture and promote the degradation of contaminants), (ii) biopiles (structures in which contaminated soils are mixed with soil amendments and enclosed) and (iii) bioreactors (containers in which contaminated material and bioremediating micro-organisms can be maintained under controlled conditions).

\section{Ensiling}

The use of lactic-acid bacteria to improve the quality of silage is common in Europe and North America. The practice can, inter alia, promote faster fermentation and reduce the presence of yeasts and undesirable filamentous fungi, and thus increase the time that the silage remains stable upon exposure to air (Muck, Filya and Contreras-Govea, 2007; Tabacco et al., 2011).

\section{Agro-industrial uses of micro-organisms as described in the country reports}

Among the agro-industrial uses discussed above, the most frequently mentioned in the country reports are those deployed directly in and around production systems. Generally, the reports do not include much information on manufacturing processes involving micro-organisms. This probably reflects the content of the country-reporting 
guidelines, which focused largely on the roles of BFA at production-system level.

Many country reports note the contributions that naturally occurring micro-organisms make to the maintenance of soil fertility, to the control of pests and pathogens or to traditional management activities such as composting. Many also mention growing interest in the use of micro-organisms in biofertilizers and biopesticides or otherwise to promote plant growth. The report from India, for example, states that "this largely unexplored reservoir of resources has begun to be harnessed for innovative applications." More specifically, it mentions the use of biofertilizers containing nitrogen-fixing bacteria, phosphorus-, potassiumand zinc-solubilizing bacteria, sulphur-oxidizing bacteria and arbuscular mycorrhizal fungi. ${ }^{91}$ It also notes that many formulations based on fungi or bacteria have been developed for use in the control of fungal pathogens and insect pests. Similarly, Argentina mentions that the inoculation of maize, tomato, sunflower and wheat plants with native mycorrhizas produces positive effects in terms of growth and nutrient uptake and that fungi from the genus Trichoderma are used to control pathogens and solubilize phosphorus. Actions reported by Costa Rica include the establishment of beneficial micro-organisms (mycorrhizal fungi) at sites that have been subject to monoculture. Examples of reported research activities related to the use of micro-organisms in agriculture and agro-industries can be found in Section 6.3.2.

Several countries refer to the potential of biofertilizers and biopesticides to reduce the need to use conventional agrochemicals that may be environmentally unfriendly, harmful to human health, expensive or demanding in terms of energy. Some mention the significance of microbial genetic resources in efforts to adapt agriculture to the effects of climate change or other environmental stressors, often emphasizing the point that developing effective adaptation strategies

91 Arbuscular mycorrhizal fungi form symbiotic relationships with plants by penetrating roots and forming structures referred to as arbuscules and vesicles. will require better inventory and characterization of micro-organisms.

Some countries note that the use of biopesticides and biofertilizers is not yet very widespread, but report ongoing research activities in this field. Some, however, mention the need to address constraints to research, such as insufficient funding and shortages of trained specialists. Another concern mentioned is the potential for harmful effects if microbial inputs are utilized inappropriately. For example, Ecuador mentions that in many cases the active ingredients of microbial preparations are imported without the necessary mechanisms having been put place to evaluate them prior to distribution and commercialization. It notes that this has probably led to the introduction of strains that have had damaging impacts on native soil biodiversity. The same country report notes the need to strengthen regulatory frameworks in order to better guarantee the quality of commercial products (i.e. to ensure that the product contains the types and concentrations of micro-organisms claimed on the label and that the organisms are in a viable state).

In addition to the use of biofertilizers and biopesticides, a number of countries mention the use of micro-organisms in waste treatment and bioremediation of soil and water. However, few details are provided. Some countries also mention the use of micro-organisms as bio-indicators in environmental monitoring. As noted above, the country reports do not focus heavily on the use of micro-organisms in manufacturing industries. A few mention roles in the production of biofuels. For example, Sudan notes that several yeast strains are used to produce ethanol from molasses and Panama mentions the production of biogas using biodigestors. A few other countries mention uses in other sectors, such as pharmaceuticals.

\section{Needs and priorities}

The country reports provide little information on priorities for action in terms of further developing the technologies discussed in this subsection. Where priorities are indicated, they relate mainly to improving knowledge of micro-organisms 
and their potential for use in agro-industries or to strengthening regulatory frameworks (see examples above). ${ }^{92}$ More-detailed priorities are presented in the background study paper prepared for the Commission on Genetic Resources for Food and Agriculture in 2013 (Chatzipavlidis et al., 2013). The material presented here is based on the priorities highlighted in this paper. General policy and institutional priorities identified include improving frameworks for quality control of microbial products and for evaluating potential risks to human health or to the environment, improving registration policies for microbial products, improving education and awareness raising, including via extension programmes and demonstrations in farmers' fields, and improving relevant partnerships between the public and private sectors. The following paragraphs discuss priorities related to specific products and processes.

\section{Biofertilizers}

Expanding the use of biofertilizers requires more research into the interactions between plants and rhizosphere micro-organisms. The rhizosphere is a highly dynamic system in which a vast number of micro-organisms interact simultaneously. A better understanding of the ecological factors that control the performance of nitrogen-fixation systems in crop fields is essential. Priorities for research and development include strain selection - strains need to be able to establish themselves effectively in the targeted soils, perform well and be persistent in the field, tolerate environmental stressors (ultraviolet radiation, heat, desiccation, etc.), survive well in storage and have little harmful impact on the environment. Field trials need to be organized to test multiple strain inoculations. Potential objectives for geneticimprovement activities include higher yield, faster growth, improved fermentation properties, better tolerance of process conditions, less formation of undesirable by-products, better resistance to

92 Micro-organism-related priorities in fields such as integrated pest management and sustainable soil management are discussed in the respective sections. bacteriophages (viruses that infect bacteria), new or modified activities and regulation of enzyme synthesis. New and improved carrier materials for bacterial inocula are also required. The potential use of bacterial biofilms as carriers is a significant emerging area of research. Promoting the use of biofertilizers will require evaluation of the economics of using them in specific circumstances, taking into account costs in terms of labour, equipment and other inputs and benefits in terms of impacts on production. Ensuring quality control in biofertilizer production is another priority. Critical benchmarks need to be identified at all stages of the production process.

Institutional frameworks also need to be improved. Collaboration between research institutes and the biotechnology industry needs to be strengthened, inter alia in order to allow for industrial-scale testing of inocula. National and international guidelines for inoculum production and trade need to be established to protect end users and ensure product safety. Effective use of biofertilizers requires a high level of knowledge on the part of farmers. Improving education and training is therefore also important. Advice offered to farmers needs to be appropriate to local circumstances and kept up to date with ongoing technological developments. Links between researchers and farmers need to be improved. Local and traditional knowledge can potentially play a role in enabling the effective use of biofertilizers in local conditions.

\section{Biopesticides}

Increasing recognition of the need for safer and more-environmentally friendly pest-control methods should create opportunities to expand the use of biopesticides. However, research and development are costly, and biopesticides are often not able to compete on the market with synthetic alternatives. Continued investment in research needs to be ensured. Priorities include the establishment and strengthening of partnerships among and between public- and private-sector organizations, the establishment of appropriate legal frameworks in fields such 
as intellectual property rights and safety regulations for the release of new products, and efforts to educate and raise awareness among potential users and suppliers of biopesticides. Achieving better uptake of biopesticides may be easier in segments of the market where conventional pesticides have relatively poor efficacy (e.g. in the control of slugs). The challenges involved in introducing the use of biopesticides vary from production system to production system. The environmental constraints in horticulture systems are typically fewer than in arable-crop systems and the likelihood of success is therefore greater. Biocontrol-based integrated pest management has been adopted widely in the labour-intensive and technically complex greenhouse-crop industry and by growers that have a high level of knowledge and are used to technological innovation.

Priorities for research include ensuring that the effectiveness achieved in the laboratory can be reproduced in field conditions. Ultraviolet light, for example, is a major cause of rapid loss of activity in biopesticides after application to leaf surfaces in the field. Inability to withstand rainfall or dry conditions can also be a problem. Another challenge is posed by the fact that the activity spectra of biopesticides tend to be very narrow in comparison to those of synthetic agrochemicals. Host range can be addressed by using conjugal mating to produce strains that combine the host ranges of their parent strains. In addition to improving effectiveness in the field, there is also a need to improve the shelf-life of biopesticides so that they can easily be distributed via the conventional distribution chains used for other products.

Improving knowledge of the genomes of pests and their microbial natural enemies will provide new insights into their ecological interactions and open new possibilities for strain improvement. Other potential targets for research include inoculation of plants with endophytic strains ${ }^{93}$ of entomopathogenic fungi ${ }^{94}$ to prevent infestation by insect herbivores, exploiting the volatile alarm

\footnotetext{
93 Strains that live inside plants.

94 Fungi that cause disease in insects.
}

signals emitted by plants as a means of recruiting microbial natural enemies as "bodyguards" against pest attack and using novel chemicals to impair the immune systems of crop pests to make them more susceptible to microbial biopesticides. Many microbial biological control agents produce secondary metabolites that have properties relevant to the control of plant diseases. These metabolites should be studied in order to assess their potential for use in product development and to identify any potential harmful effects on the environment or on human health. Another potential option is the development of a "total-system" approach to pest management, in which the farm environment becomes resistant to the buildup of pests, and therapeutic treatments are used as a second line of defence (Kaewchai, Soytong and Hyde, 2009; Malusa, Sas-Paszt and Ciesielska, 2012; Nakkeeran, Fernando and Siddiqui, 2005).

The use of fungi as biocontrol agents is relatively underdeveloped. There is still a wide gap between laboratory research and use in the field. Future research efforts need to focus on developing fungal products that have significant effects in the field and are stable in storage. Specific areas requiring research include the choice of fungal strains, cheap and reliable methods for large-scale production, potential detrimental effects on the environment and human health, and the potential for combining the use of different types of beneficial fungi. Better communication between researchers and industry is needed in the early stages of product development (Kaewchai, Soytong and Hyde, 2009; Malusa, Sas-Paszt and Ciesielska, 2012; Nakkeeran, Fernando and Siddiqui, 2005).

\section{Biofuels}

Rising demand for biofuels will mean that there is a need to take greater advantage of low-cost biomass (lignocellulosic material) from agriculture and forestry as feedstock. This will require significant improvements in technology. With regard to bioethanol production from lignocellulosics, specific challenges include the need to develop cost-effective pre-treatment strategies for various lignocellulosic materials (e.g. increasing the 
digestibility of these by-products), reduce the costs of producing cellulase enzymes, ensure the availability of robust recombinant microbes (filamentous fungi, yeasts and bacteria) that provide high ethanol yields from the sugars produced from lignocellulosic substances, and develop products and markets for non-reactive lignin by-products (e.g. potential use in paints and adhesives). In the case of biodiesel, which is generally produced from vegetable oils, residual oil present in oil cake (a by-product of oil extraction) has great potential. Where biogas is concerned, one barrier to more widespread production is the fact that people in rural areas are often unable to afford the initial investment needed to set up a biogas plant. Thus, the development of biogas technology depends on political will. Governments and administrative authorities can promote expansion by providing access to technology and financial resources and by establishing a supportive legal framework. Governments can also play a supportive role in biogas research and in the dissemination of information. A further general priority is acquiring more information on total carbon balance of biofuel production, i.e. on when it will result in a net gain and when a net loss of carbon.

\section{Composting}

The main priority in this field is promotion and dissemination of information to farmers on the benefits of vermicomposting (i.e. composting using worms).

\section{Microbial metabolites}

Research into micro-organisms, their genomics and their communities has great potential to allow the development of novel products and processes for use in agro-industries. Genetic sequencing and "meta" approaches (i.e. analysis of genomes, transcriptomes, ${ }^{95}$ proteins, etc. from whole communities of micro-organisms) are opening yet more opportunities. There may be a need for increased investment in "bioprospecting", in which ecosystems

95 The set of messenger RNA molecules in a cell or a population of cells. are surveyed for micro-organisms that can be tested for metabolite production of interest to agro-industry (Paterson and Lima, eds., 2017).

\subsection{Rumen microbial diversity}

- Low-quality plant material is converted in the rumen to energy and nutrients for the ruminant animal. Rumen microbes have a major influence on feed digestion and the release of greenhouse gases into the environment.

- The diversity of rumen microbes is vast, but progress is being made in understanding their functions. Better knowledge of these microbes is the key to using science to influence rumen-microbial function in order to enhance animal productivity while reducing environmental impacts.

- There are opportunities to develop practical and effective microbial on-farm technologies or practices that harness the potential of rumen microbes to support sustainable livestock development that contributes to food security while reducing its environmental footprint.

\subsubsection{Roles and drivers}

The micro-organisms (bacteria, archaea, fungi, protozoa and viruses) that live in the fore-stomach (reticulorumen or rumen) of ruminant animals have a major influence on feed digestion and the release of end-products into the environment (Figure 5.7). Ruminants are unable to produce the enzymes required to use the lignocellulose component of plant material as an energy source. This metabolic role is instead fulfilled by the rich and dense set of anaerobic microbes that inhabit the rumen. Ruminants and their microbial communities have evolved to thrive on a range of plant species and this has enabled them to occupy many different habitats, spanning a wide range of climates.

Bacteria, fungi and protozoa all contribute to the microbial degradation of lignocellulose and other plant polymers. Fermentation of the released soluble sugars produces short-chain fatty acids (acetate, propionate and butyrate) that are absorbed across the rumen epithelium and used 


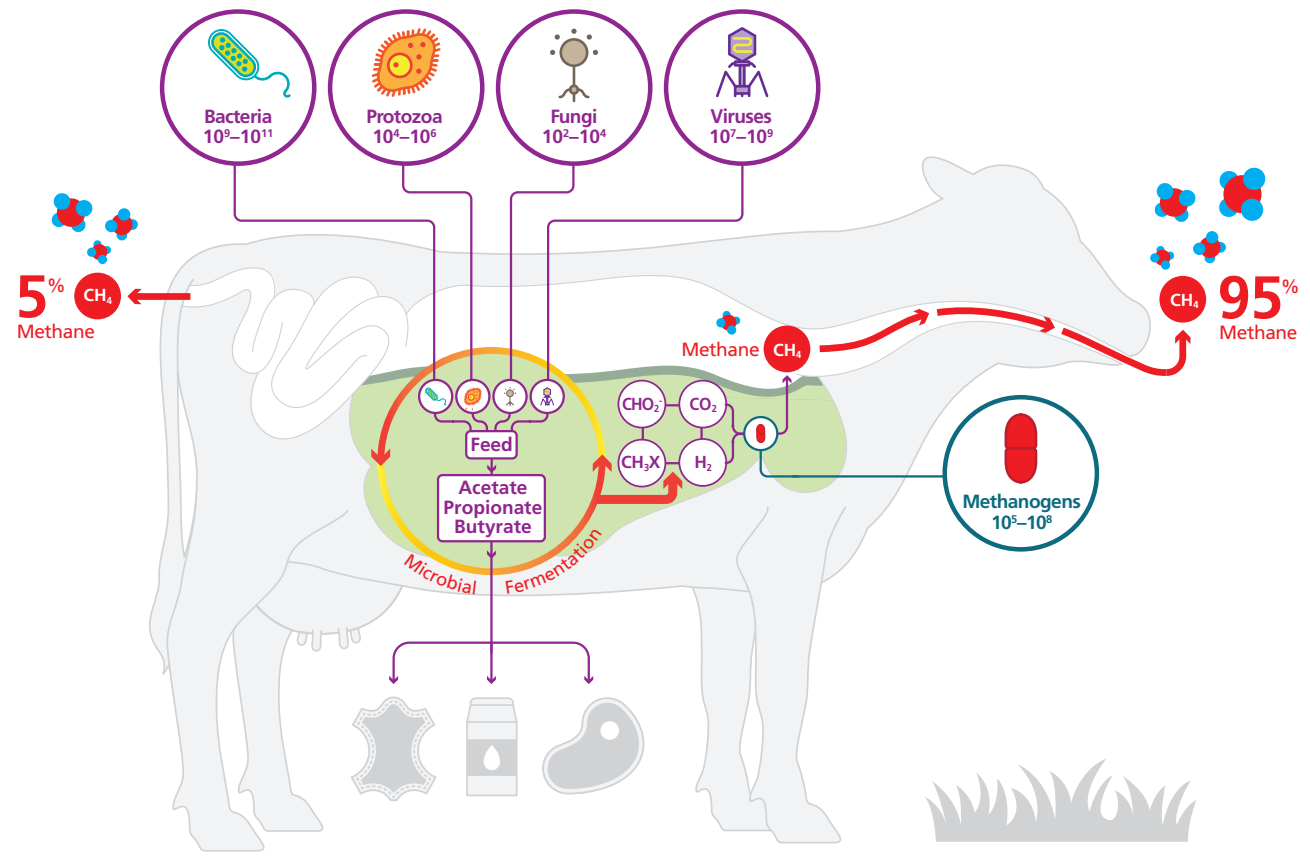

Notes: Microbial numbers are listed per $\mathrm{ml}$ or gram of ruminal contents. Abbreviations: $\mathrm{CO}_{2}=$ carbon dioxide; $\mathrm{H}_{2}=$ hydrogen $\mathrm{CHO}_{2}^{-}=$formate; $\mathrm{CH}_{3} \mathrm{X}=$ methoxy compounds or methylamines; $\mathrm{CH}_{4}=$ methane.

Source: Image courtesy of the New Zealand Agricultural Greenhouse Gas Research Centre (www.nzagrc.org.nz).

by the ruminant as a source of energy. Microbial cells pass from the rumen into the lower digestive tract where they become the main source of protein and amino acids for the animal. Other fermentation end-products, including hydrogen, carbon dioxide, formate and methyl-containing compounds, are important substrates for the rumen's methane-forming archaea (methanogens). Viruses infect the other microbial groups in the rumen, probably influencing their population balances and hence the structure of the rumen community. The characteristics of these various groups of rumen microbes are discussed in greater detail below.

A wide range of different microbes inhabit the rumen. This diversity is the net result of a myriad of counteracting selective forces. Host species have evolved rumen conditions that favour the growth and retention of a community of microbes (microbiome) with the best combination of metabolic pathways to mediate the breakdown of ingested plant material, provide the greatest yield of microbial cells, carry out the maximum biochemical work and deliver a mix of fermentation end products for the nutrition of the host (Hungate, 1966). This has led to the co-evolution of a set of microbes (the "core microbiome") common to all ruminant species across different geographical locations and climatic conditions (Henderson et al., 2015; Ley et al., 2008). Running counter to this is the heterogeneous composition of the feeds ingested by ruminants in different production systems 
across the world, which selects for microbial types adapted to using plant components characteristic of local ruminant diets. This results in diet-driven changes in the relative abundance of the species in the core microbiome, plus the proliferation of less-abundant species that can use specific feed components (Henderson et al., 2015).

Some microbes are specialists in attacking certain plant components (e.g. cellulose degradation by the bacterial Ruminococcus spp.), while others are generalists that use a wide range of substrates (e.g. the bacterial Butyrivibrio spp.). Moreover, the micro-environments provided by the physical structure of the rumen and the ingested plant material, trophic interactions between microbial groups and changes over time caused by feeding events or the aging of the animal present a wide range of situations and niches for colonization by different microbes. Recent evidence also indicates that genetic variation between animals feeding on the same diet gives rise to different microbiome types (called ruminotypes) and that these in turn lead to significant differences in rumen metabolism (e.g. Shi et al., 2014).

\subsubsection{Methane emissions}

Ruminant livestock contribute significantly to current global anthropogenic greenhouse-gas emissions through the production of methane by their rumen methanogen communities. One of the consequences of microbial diversity in the rumen is that methane is not formed only by one type of methanogen, but rather by a variety of methanogens using different metabolic pathways and producing methane from different precursors (Figure 5.7).

Interventions aimed at reducing methane emissions can directly target rumen methanogens or target microbes that produce the substrates necessary for methanogenesis. Technologies such as vaccines and inhibitors can be used to directly affect specific methanogen species. However, there is a need to understand whether non-targeted methanogens will expand to occupy the vacant niche if only some species are eliminated, and also how rumen function is changed by eliminating particular types of methanogen.

Targeted inhibition of methanogen activity in the rumen requires the identification of features that are unique to methanogens and are amenable to inhibition or interference. Such features can be discovered experimentally, but this can be a hit-or-miss process. Generating genome sequences of representative rumen methanogens is a more direct way of identifying useful targets for vaccine and inhibitor approaches (Leahy et al., 2010). Knowledge of the function and structure of the target gene product (i.e. the protein encoded by the gene) can also help narrow the search for inhibitory compounds that might interfere with its function in the methanogen. This approach is being used in several methane-mitigation programmes around the world. Specific targeting of microbes that produce the substrates necessary for methanogenesis requires a much better understanding of rumen-microbial function than is currently available. Projects such as the Hungate 1000 (see Box 5.23) are providing new knowledge in this field. Any attempts to reduce methane emissions via a microbiological route need to consider ways of avoiding adverse effects on the role of the rumen microbiome in animal nutrition.

\subsubsection{State of knowledge}

\section{Bacteria}

The Global Rumen Census (GRC) project (see Box 5.23) allowed an assessment of rumen bacterial diversity to be made across animal species, continents and diets, although any survey of this kind is inevitably incomplete (Henderson et al., 2015). This study, in conjunction with many local surveys of rumen bacteria (synthesized by Creevey et al., 2014), revealed that core bacterial groups are found in all rumens. The largest part of the bacteria in the rumen, some 90 percent, belong to 30 groups, with a further 94 bacterial groups making up another 9.5 percent. These groups are nominally classified at the bacterial genus level, but in many cases their taxonomy is incomplete. At least 10 of the 30 dominant groups correspond 
Box 5.23

Global research efforts in rumen microbiology

Major global research efforts in rumen microbiology have included the Global Rumen Census (GRC) and the Hungate1000. The GRC (Henderson et al., 2015) is the most extensive exploration of rumen microbial communities to date, representing 742 samples from 32 animal species from 35 countries, and supported by 140 scientists from 73 research institutions worldwide. A key finding of the GRC was that similar bacteria and archaea dominated in nearly all samples, and that diet is a key driver of microbial-community structure. Building on the results of the GRC, the Hungate1000 project (Seshadri et al., 2018) used the culture resources of multiple rumen microbiology laboratories around the world (57 researchers, from 14 research organizations in nine countries) to develop a reference set of 501 rumen-microbial genome sequences and cultures. The Hungate1000 has captured almost all cultured rumen bacterial and archaeal species that have been taxonomically characterized and several as yet uncharacterized strains belonging to novel species and genera. It represents the single largest effort to provide a catalogued and curated culture and genome resource for rumen microbes. Both projects have been collaborations among members of the Rumen Microbial Genomics Network (www.rmgnetwork.org).

to families or orders that may contain multiple as yet undifferentiated and unnamed genera. This lack of comprehensive classification needs to be addressed, starting with the major groups.

The ten most abundant groups comprise half of all rumen bacteria. Three of these ten have a valid genus name (Prevotella, Fibrobacter and Butyrivibrio), and some understanding of their metabolism has been gained from decades of laboratory study. Some isolates are available for another four of the ten most abundant groups, which has allowed genome sequences to be generated through the Hungate1000 Project (see Box 5.23). Analysis of the genomes in conjunction with confirmatory laboratory investigations of the physiology of the isolates will allow more-rapid assessment of the roles and potential functions of these bacteria. The remaining three of the ten most abundant groups are currently not represented by any known cultured isolates, and so their physiologies and roles are not understood.

More effort needs to be made to culture a more representative set of isolates, especially for the major taxa of rumen bacteria. Another approach is to assemble genomes from total DNA extracted from rumen samples. For example, reconstructed genomes of the BS11 group have provided insights into their possible roles as previously unrecognized cellulose-degrading bacteria (Solden et al., 2017). The genomic approach allows progress to be made in the absence of cultures that can be studied in the laboratory.

\section{Archaea}

The archaea indigenous to the rumen all appear to be methanogens, forming methane from simple substances produced by other microbes (Figure 5.7). The GRC showed that rumen methanogens are the same across the globe (Henderson et al., 2015). The most abundant genus is Methanobrevibacter, from which multiple strains have been isolated and some genomes sequenced (Seedorf, Kittelmann and Janssen, 2015). The main species of Methanobrevibacter in the rumen fall into two clades, $M$. ruminantium and its relatives (also called the SO clade) and M. gottschalkii and its relatives (the SGMT clade). Some host diets can, however, result in members of a third clade, $M$. wolnii and its relatives, becoming the dominant group (Henderson et al., 2015). Exactly how many species there are in each clade is not known. It is also not known how multiple species with apparently the same physiology co-exist - but they may occupy temporally or spatially separated niches. Both of these questions require further investigation (St-Pierre et al., 2015). There are also other taxa of methanogens in the rumen, some of which have physiologies that are different from Methanobrevibacter (e.g. Lang et al., 2015; Li et al., 2016). Not all of these other methanogen groups are well defined taxonomically. Some are 
not represented by isolates and genomes, and so their functions in the rumen are not known (Seedorf, Kittelmann and Janssen, 2015).

\section{Fungi}

Anaerobic fungi (phylum Neocallimastigomycota) account for up to 20 percent of the microbial biomass in the rumen. To date, nine genera of anaerobic fungi have been described, most of which have been detected in ruminants (Edwards et al., 2017). Further novel clades are known to exist based on culture-independent molecular surveys, but so far lack cultivated representatives. Anaerobic fungal communities are more variable than bacterial, archaeal and ciliate-protozoal communities, suggesting that different genera occupy similar ecological niches and replace each other even in the same host species. So far, however, little is known about the full metabolic repertoires of individual species and genera. Because of the high level of variation, studies analysing a large number of animals are needed in order to detect correlations of anaerobic fungal taxa with host physiology. Evidence is accumulating that anaerobic fungi that co-exist in the rumen perform niche partitioning, for example in response to carbon source and type of host (Edwards et al., 2017). However, the specific niches of each species remain to be understood. Currently, research efforts are focused on improving cryopreservation methods, establishing a centralized culture collection, scoping possibilities to use anaerobic fungi as direct-fed microbials to increase digestibility and feed efficiency and using genomics (for example the 1000 Fungal Genomes project) ${ }_{1}^{96}$ proteomics and transcriptomics to reveal the physiologies of individual species.

\section{Protozoa}

Ciliate protozoa of the subclass Trichostomatia can account for up to 50 percent of the total microbial biomass in the rumen. Currently, at least 15 genuslevel clades of rumen-inhabiting ciliates have been described using molecular methods (Kittelmann et al., 2015). However, as isolation, cultivation and

\footnotetext{
96 http://1000.fungalgenomes.org/home
}

cryopreservation of ciliate protozoa are challenging, there is considerable discrepancy between the number of species that have been observed microscopically and the number for which an accompanying DNA reference sequence is known. Thus, most knowledge of rumen ciliate diversity and community structure is derived from microscopic observations (Williams and Coleman, 1992).

Like those of anaerobic fungi, rumen ciliate communities are highly variable. Despite some limitations, next-generation sequencing is becoming a useful tool for studying them across large numbers of animals (Ishaq and Wright, 2014; Kittelmann et al., 2015). This approach allows dominant members of the ciliate community to be identified and communities to be classified into the distinct types first described by Eadie (1962). Further studies are needed to provide more-detailed insights into the ecology and function of individual genera and species (isolation, cultivation, [meta]genomics) and into the dynamics within the distinct community types ([meta] transcriptomics).

\section{Viruses}

The viruses of the rumen are a highly heterogeneous group, and high-throughput methods based on universal markers to assess viral community structures do not exist. Moreover, as environmental viruses cannot be propagated in the laboratory, sequencing the genetic material from the viral particle fraction (the virome) is the most effective way to explore viral diversity and function. Few rumen-virome studies have been undertaken to date (e.g. Berg Miller et al., 2012), but information from those that have is consistent with physical observations that the tailed bacteriophages (order Caudovirales) are the most prevalent types. Sequence data from rumen viromes suggest that their genetic diversity is much greater than the observed morphological diversity seen via electron microscopy of rumen contents (Ross et al., 2013). Viral genetic material is frequently observed in rumen bacterial and archaeal genome sequences, which provides information on viral function and host specificity. Better understanding of the 
contributions of viruses to rumen microbial ecosystem function will require more detailed characterization of rumen viromes and viral genes.

\subsubsection{Needs and priorities}

Although the diversity of rumen microbes is vast, considerable progress has been made in terms of understanding the functions of microbial groups for which cultured representatives exist, primarily through genome-sequence information and in vitro characterization. However, there are highly abundant groups for which cultures are still not available. Targeted efforts to cultivate such groups and characterize them genomically and physiologically are needed to fill the largest knowledge gaps. The scope of this endeavour would require concerted global efforts, similar to those described in Box 5.23.

An understanding of a microbe's functions within its natural ecological context (i.e. the rumen microbial community) is needed in order to understand its contribution to rumen functional dynamics and hence to host nutrition and methane production. Many rumen-microbiome studies have highlighted an apparent overlap in functional potential, particularly between closely related microbes. Better understanding of ecologicalniche partitioning among microbial groups is needed in order to help elucidate how species with similar physiologies are able to co-exist, and further resolve differences observed between the activities of pure and/or co-cultures of microbial groups in vitro and those exhibited in situ.

Significant new light has been shed on microbial activities in situ through deep metagenomic and metatranscriptomic sequencing with metabolite analyses (Shi et al., 2014). Global efforts to further collect such data from a wider range of production animals and diets have been initiated (e.g. Joint Genome Institute, 2017), ${ }^{97}$ but there is enormous scope to extend these to a more extensive range of ruminants and production systems worldwide. Considerable opportunities also exist to further explore existing high-throughput

\footnotetext{
97 https://jgi.doe.gov/gene-function-rumen-microbes
}

sequencing-based datasets and integrate this information with that on matter and energy flow in the rumen. This will allow better understanding of specific metabolic pathways and genes that may represent targets for rumen modification.

Fundamental gaps in knowledge of rumen microbial diversity still remain to be addressed. A more complete understanding of this diversity and its function, both in vitro and in situ, will greatly facilitate the development of effective technologies or practices that support sustainable livestock development that contributes to food security while reducing its environmental footprint.

\subsection{Genetic improvement}

- Public and/or private breeding programmes exist in most countries, in particular for major commercial crop and livestock species and breeds, aquacultured species and farmed trees. While quantity of product output remains a primary target for genetic-improvement efforts, there is often an increasing focus on a wider range of traits, including those related to resistance to pests, diseases and abiotic stresses, nutrient density and other aspects of product quality.

- More than a third of country reports note the value of domestication and base broadening in addressing threats to production caused by reduced diversity in domesticated plant and animal populations. Reported trends suggest a slight overall increase in such activities, but countries note constraints associated with a lack of resources and capacity.

- With the exception of honey bees and silk worms, genetic-improvement activities for insects are generally uncommon. The most important traits bred for in the western honey bee (Apis mellifera) are high honey production, docility, reduced swarming and, increasingly, disease tolerance.

- Assisted evolution of climate resilience in corals has emerged as a research topic in recent years and efforts in this field are likely to intensify as pressures on corals increase.

This section discusses the state of breeding (genetic-improvement) activities for BFA. The first 
subsection provides an overview of domestication and base broadening - two management practices that countries were specifically invited to report on in their country reports. The remaining subsections address genetic improvement activities for particular components of BFA, beginning with crop, livestock, forest and aquatic genetic resources and then considering various categories of associated biodiversity for which genetic-improvement activities are being implemented.

\subsubsection{Domestication and base broadening}

Domestication is described in the countryreporting guidelines as "the development of new crop, aquatic, forest and animal species through deliberate breeding programmes or the continued selection and improvement of existing species from their wild progenitors." Base broadening is described as "increasing the amount of genetic diversity used to produce new varieties or breeds used in agricultural production" (see IPGRI and FAO [2001] for a fuller discussion). Thus, while domestication increases diversity through the introduction of new species, base broadening increases diversity within the varieties, breeds and populations that are already being used in production systems.

Domestication of crop and animal species began over 12000 years ago (FAO, 2015a; Fuller, 2007; Vigne, 2011). The extent to which species used in crop and livestock production possess the various attributes of "domestication" varies (see e.g. Miller and Gross, 2011; Zeder, 2012). In the case of crops, domestication is probably best considered as a more or less continuous process that in many cases is still ongoing, both through formal crossing programmes (as in the generation of new bread-wheat materials from their wild progenitors - Dreisigacker et al., 2008) or through more informal processes such as the "domestication" of wild and feral types of yam in West Africa (Scarcelli et al., 2006). Many animal species can also be considered to be partially domesticated (FAO, 2000, 2015a). In the case of fish, domestication was limited to a few species until about
100 years ago, but since then has expanded very rapidly: Duarte, Marbà and Holmer (2007) reported that 430 aquatic species (97 percent of those in culture at the time) had been domesticated since the start of the twentieth century and 106 within the preceding decade. Many aquatic species remain in a state of partial domestication, with production still dependent on the availability of wild resources (Teletchea and Fontaine, 2014).

New crop and animal species are being domesticated by public-sector programmes (see below), by the private sector and by rural communities and farmers (e.g. in home gardens) (Abizaid, Coomes and Perrault-Archambault, 2016; Galluzzi, Eyzaguirre and Negri, 2010; Jamnadass et al., 2010). There is continuing progress in the domestication of new oil crops, bioenergy species, fruits, vegetables, deer and a wide range of fish species around the world (e.g. Montes and Melchinger, 2016; Sedbrook, Phippen and Marks, 2014; Teletchea and Fontaine, 2014). Work on the domestication of bee species is also ongoing (see Section 5.9.4).

Base broadening seeks to address the increasingly low level of genetic diversity of many modern varieties, breeds and populations of crop, livestock and plantation-forest species. This narrow genetic base can lead to vulnerability ${ }^{98}$ and has been responsible for significant production losses in recent times, for example in the case of maize in the United States of America in the 1970s (NRC, 1972) and taro in the South Pacific in the 1990s (Hunter, Pouono and Semisi, 1998b). Base broadening may be required when there has been a marked founder effect ${ }^{99}$ in the domestication of a crop, or subsequent genetic bottlenecks, for example as a result of breeding programmes with a narrow genetic base. Base broadening may be needed if rates of progress in breeding programmes are low, if there are production failures as a result of vulnerability or if farmers identify

\footnotetext{
98 Populations of a crop species are said to be genetically vulnerable if they lack the diversity necessary to adapt to a biotic challenge or to an abiotic stress.

99 The term "founder effect" refers to the reduced genetic diversity that results when a population is descended from a small number of colonizing ancestors.
} 
the need for a wider range of options than those provided by currently available varieties (see IPGRI and FAO [2001] for a more comprehensive discussion). The importance of base broadening in crops is reflected in its inclusion in the Global Plan of Action for Plant Genetic Resources for Food and Agriculture (FAO, 2011b; see also Mba, Guimaraes and Ghosh, 2012).

Over 50 percent of the country reports refer to base broadening or domestication activities, and about 40 percent mention both. While a small number of countries report only base broadening, a larger number (13) report only domestication. The information provided usually includes descriptions of specific activities (see examples below) and in some cases estimates of the areas involved, which range from a few hectares to many hundreds. Activities are most commonly mentioned in crop and mixed systems, although all categories of production system are referred to at least once.

The targets of domestication most commonly mentioned in the country reports are wild food species, medicinal plants, tree and shrub species used in agroforestry and aquatic species. Agroforestry species mentioned included Gnetum (a plant grown for its edible leaves and for medicinal purposes), Senegal saba (Saba senegalensis) (a plant used for food and to combat soil degradation) and Sterculia setigera (a food source with medicinal and other properties). Support from CGIAR centres is noted in the case of both forestry and agroforestry species. Medicinal plant species mentioned include flagroot (Acorus calamus), spiny asparagus (Asparagus racemosus), emblic myrobalan (Phyllanthus emblica), belleric myrobalan (Terminalia bellirica) and chebulic myrobalan ( $T$. chebula). Other plant species mentioned include stevia (Stevia rebaudiana) (a natural sweetener with anti-inflammatory properties). A few countries also report domestication activities for animal species, including deer, wild pigs, cane rats, quails and frogs. A small number note the importance of maintaining traditional knowledge on crops or animals as part of any domestication-related activities. In the case of fish species, mullet, carp and rainbow trout are mentioned. The risks associated with narrowing the genetic base as a result of domestication are noted in a number of the reports, particularly, but not exclusively, in relation to fish species. Some countries that do not themselves report specific domestication activities nonetheless recognize its importance in increasing diversity within production systems and identify it as an activity that is constrained by lack of resources and capacity and is in need of greater support.

Over 30 country reports mention base broadening, referring variously to activities involving animal, forest and crop species (Table 5.1). The most commonly reported trend is a low level of increase in base-broadening activities (Table 5.2). ${ }^{100}$ However, very few countries provide details of the crop, animal, fish or forest species involved or the type of activities undertaken. Where details are provided, countries most commonly note the value of maintaining traditional breeds or crop varieties or of introducing new varieties, breeds or forest provenances, i.e. a broader view of base broadening than that used in the country-reporting guidelines. A few countries specifically mention the use of crop wild relatives as part of their basebroadening programmes. Some mention the institutions involved in base-broadening activities, which include both universities and national research centres. Norway reports that in 2011 a public/private partnership for prebreeding was established at the regional level by the Nordic Council of Ministers to increase genetic diversity and thus enhance the development of new crop varieties. It notes that the partnership aims to address the long-term needs of the agriculture and horticulture industries, specifically with regard to adaptation to climate change, environmental targets and changing consumer and market demands. A number of country reports clearly recognize base broadening as desirable and necessary, but also that it is a process that requires resources on a long-term basis and time

\footnotetext{
${ }^{100}$ Countries were invited to indicate whether the "production area or quantity" had been strongly increasing, increasing, stable, decreasing or strongly decreasing over the preceding ten years. The most frequent response was "increasing".
} 
to achieve the desired results. In this respect, the above-mentioned regional public/private partnership may be a useful model.

\subsubsection{Plant, animal, forest and aquatic genetic resources for food and agriculture}

\section{Plant genetic resources for food and agriculture}

Public and/or private plant-breeding programmes of some kind exist in most countries. The Second Report on the State of the World's Plant Genetic Resources for Food and Agriculture (FAO, 2010a) ${ }^{101}$ indicated that the number of programmes, particularly private-sector programmes, had increased over the preceding ten years. Biotechnological techniques had evolved considerably and there was an increase in their use in plant breeding worldwide, although many breeding programmes, especially in developing countries, lacked the capacity to apply them. In general, investment in breeding programmes mirrored the economic importance of the crop species. Thus, major crops were receiving the bulk of breeding investments, although several country reports ${ }^{102}$ highlighted the importance of giving attention to underutilized crops. There appeared to have been an increase in the use of wild species in crop improvement, due in part to the increased availability of methods for transferring useful traits from them to domesticated crops. The principal traits targeted by plant breeders continued to be those related to yield of primary product per unit area. However, increasing attention was being paid to tolerance and resistance to pests, diseases and abiotic stresses. There was also reported to be an increase in farmer participation in plantbreeding activities in all regions of the world.

Breeding programmes in most regions remained constrained by shortages in funding, trained

101 Unless otherwise indicated, the material presented in this subsection is based on this source.

102 The references to country reports in this subsection refer to those submitted for The Second Report on the State of the World's Plant Genetic Resources for Food and Agriculture (FAO, 2010a). personnel and technical facilities. Several country reports also expressed concern about the lack of fully effective linkages between basic researchers, breeders, curators, seed producers and farmers.

\section{Animal genetic resources for food and agriculture}

Breeding programmes for animal genetic resources for food and agriculture (AnGR) are implemented in a range of different circumstances around the world. The stakeholders involved, the organizational set-up and the sophistication of the techniques applied vary greatly (FAO, 2015a). ${ }^{103}$

Breeding programmes for high-input production systems generally involve well-developed systems for performance and pedigree recording and the use of advanced methods of genetic evaluation to estimate the breeding value of individual animals or families. Breeding programmes in the dairy sector have been revolutionized in recent years by developments in genomics. With some variation from region to region and from species to species, the main operators of programmes in high-input systems tend to be breeders' associations, cooperatives or private companies. The most advanced breeding programmes, particularly in the poultry, pig and, to a lesser degree, dairy sectors, tend to target only a limited number of breeds, generally originating from the temperate regions of the world. Selection criteria often encompass an increasingly wide range of traits, including those related to product quantity and quality, reproduction and health. Cross-breeding strategies of various kinds are widely used.

Breeding programmes for the low-input systems of the developing world tend either to be centralized public-sector programmes or community-level initiatives of some kind, often supported by outside agencies. Establishing and sustaining breeding programmes for such systems has generally proved to be challenging. For many breeds in developing

\footnotetext{
${ }^{103}$ The material presented in this subsection is based on The Second Report on the State of the Worlds Animal Genetic Resources for Food and Agriculture (FAO, 2015a).
} 
countries, breeding programmes are either nonexistent or in a rudimentary state. Nonetheless there appear to be upward trends in the number of breeds in developing countries covered by some of the elements or "building blocks" of breeding programmes, for example animal identification and performance recording.

Use of exotic breeds to replace or cross with locally adapted breeds is a popular strategy. However, cross-breeding programmes need to be well-planned so as to ensure that cross-bred animals are suited to the production environments in which they are to be raised and that locally adapted AnGR are not lost. There is growing recognition of the value of the locally adapted breeds of developing countries, for example in addressing challenges associated with climate change. However, there are many constraints to the development of effective breeding programmes for these breeds. In addition to the limited availability of financial resources and shortfalls in human and technical capacity, organizational frameworks that enable effective participation of livestock keepers in the planning and operation of breeding programmes are often lacking. Systems and infrastructure for distribution of superior genetic material are also generally lacking, providing little incentive for entrepreneurs to enter the business of developing and marketing breeding stock.

\section{Forest genetic resources}

Trees have been the subject of informal selection and germplasm transfer for centuries if not millennia (FAO, 2014a). ${ }^{104}$ More systematic research and development efforts have been conducted for a little over a century, and the first tree-breeding programmes were initiated in the 1930s. Most tree-breeding programmes aim to achieve gradual improvement of breeding populations rather than development of new varieties (exceptions include breeding of eucalyptus and poplars).

Until recently, tree breeding focused on (comparatively few) species used for wood production

${ }^{104}$ The material presented in this subsection is based on The State of the World's Forest Genetic Resources (FAO, 2014a). and on improving a relatively small number of traits that maximize economic gains (including growth rate, volume, stem form, processing and product quality). However, in recent decades government agencies and the private sector have subjected a wider range of tree species to domestication and formal breeding programmes targeting the production of a variety of goods including timber, pulp, fuelwood, fruits, nuts, oils, traditional medicines, dyes, resins and thatch, as well as various service functions. In addition, tree-breeding efforts have increasingly focused on adaptabilityrelated traits, such as those conveying resistance to drought, fire, pests and diseases. These breeding programmes are primarily initiated by public agencies. The main drivers of change have included the increasing scale and unpredictability of environmental change, and new demands for trees for food and nutritional security, environmental restoration and carbon sequestration.

Increasingly sophisticated approaches and technologies are being applied to tree breeding to generate faster rates of gain. Hybrid breeding, involving interspecific hybrids and wide provenance crosses, is used in many countries to produce trees with superior productive capabilities (and also to introduce genes for disease resistance). New molecular tools offer opportunities for markerassisted selection to shorten the long cycles of breeding, testing and selection, and even for estimating quantitative genetic parameters directly from natural tree populations (e.g. El-Kassaby et al., 2011). In many developing countries, however, a lack of skilled tree breeders constrains the use of advanced breeding methods.

Overall, much remains to be done to realize the full potential benefits of tree-breeding programmes and the genetic diversity of natural tree populations, particularly in the tropics. In most countries, priority requirements include the establishment of national information systems and better coordination among stakeholders within and between government agencies and departments (especially departments of forestry, agriculture and environment), research institutes and universities and the private sector. Developing 
a national FGR strategy is a key means of improving coordination between such actors.

\section{Aquatic genetic resources for food and agriculture}

The majority of farmed aquatic species are very similar to the wild type, i.e. to their wild relatives. As noted elsewhere in this report, breeding and domestication of aquatic species is generally a relatively recent development, although a small number of species were domesticated a few thousand years ago, for example the common carp (Cyprinus carpio) (Balon, 1995). The breeding of ornamental fish has been an important aspect of Asian culture for millennia. Increasing numbers of aquatic species are being bred under farmed conditions and this has helped the aquaculture sector become the fastest-growing foodproducing sector (Duarte, Marbà and Holmer, 2007). Increasing numbers of ornamental species are also being bred in captivity. Some wild types can be bred in captivity through manipulation of photoperiod, temperature, hormone treatment or through natural processes.

Once controlled breeding has been established, a number of different genetic improvement methods can be applied to aquatic species. Among these, selective breeding has the longest history of use in aquaculture and is the form of genetic technology most commonly reported in the country reports ${ }^{105}$ submitted for The State of the World's Aquatic Genetic Resources for Food and Agriculture (FAO, forthcoming). Other approaches include monosex production, hybrid production and triploid/ polyploid production through chromosome-set manipulation. Gene transfer and other geneticengineering technologies have been successful under research conditions, but have not been used commercially due to consumer resistance and environmental concerns. Genomic selection and gene editing show promise and may become increasingly important in the genetic improvement of farmed aquatic species (Dunham, 2011).

\footnotetext{
${ }^{105}$ All references to country reports in this subsection refer those on aquatic genetic resources for food and agriculture.
}

The country reports indicate that the use of genetic technologies and genetic-resources management of some kind is occurring in about 50 percent of farmed species. Approximately half indicate that genetically improved aquatic organisms contribute at least to some extent to national aquaculture production. All the reports indicate at least some use of selective breeding in aquaculture: 35 percent to a great extent; 53 percent to some extent; and 13 percent to a minor extent. Genetic improvement of aquatic genetic resources is often the result of advanced breeding programmes conducted by large private companies in areas outside the natural distribution range of the species.

The objective of most genetic-improvement programmes in aquatic species is to increase growth rate. However, colour, body shape, spawning time and fecundity can also be improved. Disease resistance is an important trait, especially in marine shrimp aquaculture, and is being targeted by genetic improvement programmes in various species (Lightner, 2011).

Genetic improvement creates tremendous opportunities to increase food production from aquaculture (Gjedrem, Robinson and Rye, 2012). However, there are challenges. Genetic data are technically demanding and costly to collect. The availability of funding for breeding programmes is often inadequate. Expanding the role of public-private partnerships is a potential means of addressing some funding constraints.

\subsubsection{Associated biodiversity - overview}

\section{Introduction}

Although most associated-biodiversity species are not domesticated or even maintained outside their natural habitats, some are reared in captivity in order to maintain or increase their numbers for conservation purposes, so that they can be readily deployed to promote the supply of ecosystem services or for purposes such as use as fishing bait. Comprehensive information on mass production of beneficial invertebrates and entomopathogens for biological control, protein for 
human and animals (including fish) and pollination is compiled in Morales-Ramos, GuadalupeRojas and Shapiro-llan (2014). Only a few such species are subject to genetic-improvement programmes. However, even if no deliberate genetic improvement activities are implemented, inbreeding depression, founder effects, genetic drift and adaptation to the captive environment often mean that animal populations in captivity differ genetically from their wild counterparts (van Huis et al., 2013). A number of country reports mention captive breeding of associated biodiversity species among ex situ conservation activities (see Section 7.3).

Even though most insects used in food and agriculture are collected from the wild, a few species have been domesticated, for example the silkworm (Bombyx mori) and some pollinators (particularly Apis spp. and Bombus spp.). Literature on genetic improvement efforts aimed at improving the efficacy of arthropod BCAs is very limited (Henry et al., 2010). However, there have been a few cases in which such species have been bred for pesticide resistance so that they can be used in conjunction with pesticides (Orr, 2009). In 2015, the European Union started the Breeding Invertebrates for Next Generation BioControl (BINGO) ${ }^{106}$ project (within the EU Horizon 2020 programme), an international initiative targeting research and training on breeding and trait improvement in arthropod natural enemies such as the mite Phytoseiulus persimilis, the mirid bug Nesidiocoris tenuis and the parasitoid jewel wasp Nasonia vitripennis.

In the case of soil biodiversity, considerable work is being undertaken on the selection of naturally occurring beneficial micro-organisms that play roles in plant nutrition (e.g. Rhizobium, Trichoderma, Beauveria and Bacillus spp.), biological control of weeds, pests and pathogens, biological control of aflatoxin-producing fungi (e.g. using Aflasafe) ${ }^{107}$ and post-harvest management (e.g. Card et al., 2016; Trognitz et al.,

\footnotetext{
${ }^{106} \mathrm{https}: / /$ www.bingo-itn.eu/en/bingo.htm

${ }^{107} \mathrm{https}: / /$ aflasafe.com
}

2016; Yin et al., 2008). Some soil-dwelling invertebrates can be cultivated to supply horticultural products (vermicompost) or for protein production for use in animal feed or human food (Lowe, Butt and Sherman, 2014). However, there are no reports of genetic-improvement activities for soil invertebrates.

Unlike other components of associated biodiversity, micro-organisms for food processing are generally maintained by companies and kept under controlled conditions to ensure the purity of strains. Breeding is undertaken to develop strains with desirable properties such as increased productivity or tolerance of particular chemical compounds.

\subsubsection{Pollinators}

\section{Introduction}

Among honey-bee species, only one, the western honey bee (Apis mellifera), has been widely managed and transported across the world. A few other pollinator species are managed on a more limited scale, including solitary bees, such as the alfalfa leafcutter bee Megachile rotundata in the United States of America and Canada and the red mason bee Osmia bicornis in Europe (IPBES, 2016b) (see also Section 5.6.6). The commercially most significant managed pollinators other than honey bees are bumble bees (Bombus spp.) (Velthuis and van Doorn, 2006). Apis mellifera has been the main target of genetic selection and breeding efforts and is the main focus of this section.

Honey bees (Apis spp.) are eusocial insects, meaning that they live in colonies comprising one queen, tens of thousands of workers and thousands of males (referred to as drones) (Seeley, 1985). The workers collect nectar from flowers and convert it into honey using self-excreted enzymes. They also excrete wax scales from abdominal wax glands and form it into combs used to store honey and pollen and for rearing offspring (Winston, 1987).

Prior to the development of moveable frame hive beekeeping for the western honey bee in the middle of the nineteenth century (Crane, 1999), which allowed the rearing of queens from 
chosen colonies, there were no conscious efforts to breed honey bees. However, once this method had become established, numerous commercial enterprises were set up in North America, Europe, Asia and Australasia to produce Apis mellifera queens for sale to beekeepers. The most important traits bred for by such companies have been high honey production, docility, reduced swarming and - especially in the last two decades - disease tolerance. Companies, however, reveal few details of their breeding efforts or the degree of success achieved.

A peculiarity of honey bees is that the queen only mates within the first few days of emergence as an adult and does so only with 10 to 20 drones from surrounding colonies at a "drone congregation area" situated at 10 to 50 metres above ground and up to several kilometres from her natal colony - a mechanism that is likely to reduce inbreeding (Koeniger et al., 2014). Honey-bee mating is therefore difficult to control, and this hampers selection. Instrumental (artificial) insemination overcomes these drawbacks (Laidlaw, 1977). However, it is complicated, requires expensive specialist equipment, and is rarely practised outside academic laboratories.

\section{Objectives of bee-breeding programmes}

Research in the mid-twentieth century (Rothenbuhler, 1964) led to the discovery of two behavioural traits, "uncapping" and "removal" of diseased larvae, that give honey-bee colonies a level of tolerance to the virulent brood disease American foulbrood (causative agent: Paenibacillus plutonius). Another trait that has been successfully selected for is "pollen hoarding" (Page, 2013). Other traits such as honey production, defence behaviour, swarming and disease resistance are heritable, i.e. can be selected for and improved (Bienefeld, 2016), although little is known about their genomic underpinning.

Arguably the most serious problem facing honey bees is the highly prevalent and virulent varroa-virus nexus, i.e. the ectoparasitic mite Varroa destructor and the viruses it transmits (Le Conte, Ellis and Ritter, 2010; McMahon et al., 2016; Natsopoulou et al., 2017; Rosenkranz,
Aumeier and Ziegelmann, 2010). Recent attention in honey-bee selection has focused on local populations that seem to exhibit tolerance to the varroa-virus nexus (Locke, 2016) and on the search for the genetic basis of varroa resistance (Spötter et al., 2016). Evidence for the heritability of traits conferring tolerance provides the scientific rationale for efforts to breed for tolerant honey bees.

\section{Status and trends of bee-breeding programmes}

Estimating the number of bee-breeding programmes is difficult because most or all are in the hands of commercial enterprises, whose numbers vary as new companies become established and others shut down. There are probably around 100 such commercial enterprises worldwide, including a few long-term programmes that over the past 20 years have selected for honey bees tolerant to the varroa-virus nexus, for example in the United States of America (Ibrahim, Reuter and Spivak, 2007; Rinderer et al., 2010) and in Europe (Kefuss et al., 2015). There is growing interest among institutions and beekeeper groups in selecting local (particularly endemic) honey bees that are tolerant to the varroa-virus nexus (e.g. the SmartBees project funded by the European Union - see Box 5.24). Such efforts are generally devolved to regional or local beekeeper groups and institutes, but may number well over 100 worldwide.

The performance of the queens (and colonies they head) generated by commercial breeding companies is rarely quantified, and therefore rigorous data on the success of breeding programmes are unavailable, although an improvement in honey production and pollination potential is likely. Current breeding and selection efforts for honey bees tolerant to the varroa-virus nexus are in too early a stage to have had their success quantified. If successful they could reduce reliance on commercial acaricides, which would provide an immediate environmental-health benefit by reducing the risk of these pesticides entering honey and the human food chain (Mullin et al., 2010).

The small number of companies in Australasia, East Asia, North America and Europe that rear 
Box 5.24

SmartBees: a European project for the conservation of endangered honey-bee subspecies

Adaptation of honey-bee populations to the climate and diseases of their particular local environments has given rise to approximately ten different subspecies across Europe. This diversity is, however, under pressure. One reason for this is the effects of the varroa mite (Varroa destructor), which has led to catastrophic losses of honey-bee colonies. Another is the systematic replacement of many native European honeybee populations with two races that have been bred for productivity, gentle behaviour and disease resistance. Both these factors are drastically reducing the genetic diversity of honey bees in Europe and endangering sustainable, regionally acclimated beekeeping.

Under the European Union-sponsored SmartBees project, which ran from 2014 to 2018, 16 institutes from 11 countries cooperated to address this problem. One achievement of SmartBees was an assessment of remaining honey-bee diversity in Europe in unprecedented detail and quality. Another major outcome was the characterization of the genetic basis of factors conferring resistance to varroa mites. Results from these studies were combined to produce a lowcost molecular tool that enables beekeepers and scientists to easily check the subspecies affiliation and potential resistance of a given bee or hive. The project also monitored the attitudes and information needs of beekeepers with respect to honey-bee biodiversity, and compiled a toolkit of extension methods to address these needs.

SmartBees shed light on the intricate interactions between varroa mites, viruses and bees, which will hopefully allow the identification of new angles of attack for preventing colony losses caused by diseases such as varroosis. Moreover, breeding groups have also been initiated for most of the endangered subspecies of Apis mellifera. These have already completed three seasons of performance testing, with the aim of adapting local bees to the requirements of "preservation through utilization". Towards the end of the project period, the groups were transformed into an international breeding association for the conservation and improvement of local bee populations, which will hopefully allow the success of the project to be built on and its positive spirit to be carried into the future.

Source: Provided by Kaspar Bienefeld.

Note: For further information, visit the SmartBees website: http://www.smartbees-fp7.eu bumble bees do not report on whether selection is practised or if so what successes have been achieved.

\section{Constraints to bee breeding and key needs and priorities}

The selection of traits in honey bees requires performance testing of the entire colony. This can take one or more years for traits such as honey yield or overwinter survival and hence represents a time constraint. The haplodiploid character of honey bees (the male is haploid and the female is diploid) and the fact that traits of interest to breeders, such as the amount of honey stored, are colony-level characteristics (i.e. relate to the products of the workers, while it is only the queen that produces offspring) also create challenges. However, these have been largely overcome by population-genetic and selection theory (e.g. Rinderer, ed., 1986). An approach to estimation of the breeding value of honey bees that takes the eusocial colony into proper consideration (best linear unbiased prediction [BLUP]-animal model) has been developed (Bienefeld et al., 2007).

Across its native distribution, Apis mellifera is genetically differentiated into diverse subspecies (Wallberg et al., 2014), a pattern that is probably also true for the eight recognized Asiatic Apis species. A key priority is to maintain the genetic diversity of endemic populations that may harbour locally adapted traits (Büchler et al., 2014) in the face of the commercial transport of colonies from one region to another. Though beekeeping per se does not seem to negatively affect the genetic diversity of honey bees (Harpur et al., 2012), research is needed into the impact of 
hybridization between subspecies of $A$. mellifera, which could lead to the loss of genes underpinning local adaptations.

Because beekeeper (as opposed to commercial) breeding and selection proceed via the rearing of queens from selected colonies and allowing them to mate naturally with drones from surrounding colonies, a key need is to encourage the local community of beekeepers to use selected stock in their colonies. This has the benefit of maintaining the genetic diversity of local endemic populations and their adaptive potential. Engagement and participation of beekeepers are therefore essential to the success of any long-term bee-breeding endeavour. Another priority is to objectively quantify the traits sought by beekeepers. This requires research into efficient performance testing and estimation of the heritability of these traits (and markers correlated with them). Research also needs to address the following three outstanding questions: are local (particularly endemic) subspecies of honey bee better adapted than other bees to local conditions? Does heritable variance exist for tolerance not only to varroa mites but also to co-transmitted viruses? Can such tolerance be selected for within local (particularly endemic) subspecies?

\subsubsection{Assisted evolution for reef-building corals}

\section{Introduction}

(Human)-assisted evolution is defined as the acceleration of naturally occurring evolutionary processes to enhance certain traits (Jones and Monaco, 2009; van Oppen et al., 2015). For reef-building corals, the primary focus of this intervention is to increase resilience to climate change (van Oppen et al., 2017), which is a major threat to coral reefs worldwide (Hughes et al., 2018) (see also Section 4.5.4). Assisted evolution is based on several biological-engineering principles that are successfully being applied to improve human health and food production, but which are only just beginning to be explored in the field of biodiversity conservation (Piaggio et al., 2017). While genetic engineering or synthetic biology could also potentially be used to increase the climate resilience of corals, little work has been done on this and such approaches are not discussed further here. Assisted evolution can target the coral host animal or any of the associated microbial symbionts (Figure 5.8). Research on assisted evolution is in its early stages and the few results that have been published are summarized below.

\section{Host manipulations}

Host manipulations currently being explored are based on genetic (points 1 to 3 below) or epigenetic (point 4) manipulations:

1. Assisted gene flow is the intentional translocation of individuals within a species range to facilitate adaptation to anticipated local conditions (Aitken and Whitlock, 2013). Coral populations in relatively cooler regions can theoretically be prepared for further ocean warming by translocating coral colonies from warmer reef locations to the cooler ones. Translocated colonies may propagate asexually and sexually, in the latter case breeding among themselves or interbreeding with the native population. It is anticipated that interbreeding will lead to the introgression of thermal tolerance alleles into the genetic background of the local corals. This will give rise to offspring that have increased thermal tolerance relative to the native population while still being sufficiently adapted to other environmental parameters to maintain overall higher fitness. As a variation on assisted gene flow, interbreeding between colonies from cool and warm locations can be conducted ex situ, with the hybrid offspring subsequently deployed on the cooler reefs (van Oppen et al., 2014).

Progress: Recent work found that F1 hybrid larvae bred ex situ from conspecific parents collected in different thermal environments had higher thermal tolerance (tested only under laboratory conditions) if the mother or both parents were sourced from the warmer location (Dixon et al., 2015). Further, regional F1 hybrid recruits reared in the laboratory but grown at the cooler field location showed survival intermediate between that of the pure-bred recruits reared 


\section{PART C}

FIGURE 5.8

Motivation for and steps involved in the assisted-evolution approaches in corals

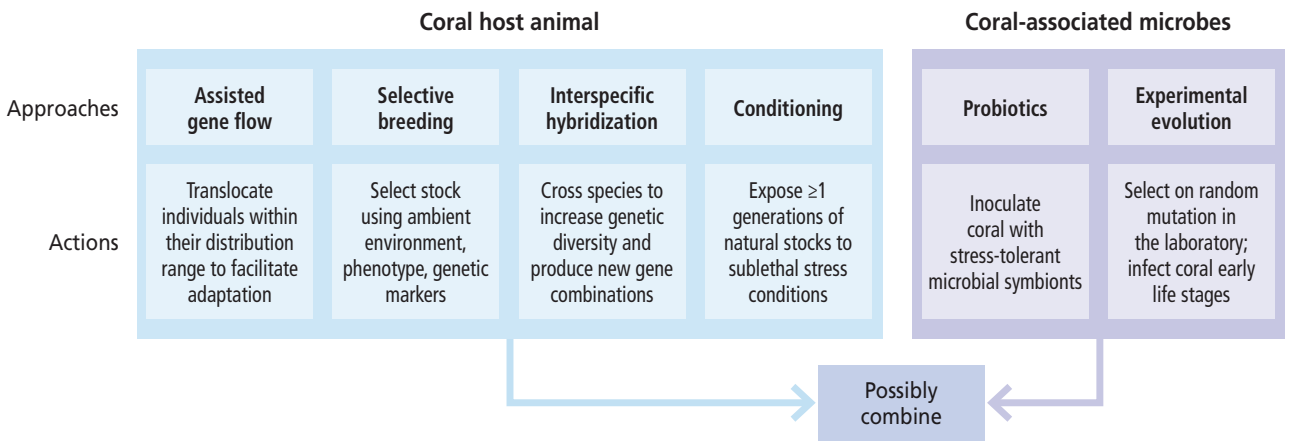

from parents collected from the cooler location and those reared from parents collected from the warmer location (van Oppen et al., 2014). These early findings point to the promise of assisted gene flow as a means of preparing coral populations in relatively cool regions for further climate warming. Further research is required into possible negative impacts of assisted gene flow in later generations, for example outbreeding depression.

2. Selective breeding is the intentional breeding of organisms with desirable traits in an attempt to produce offspring with similar desirable or improved traits. A common way of selecting brood stock is the use of quantitative trait loci (QTLs) for relevant phenotypic traits. A small number of QTLs have been identified for coral-bleaching tolerance and antioxidant capacity (Bay and Palumbi, 2014; Jin et al., 2016; Lundgren et al., 2013). Another approach is to breed survivors from recent bleaching events. The rationale here is that natural selection will have removed the more thermally sensitive individuals and that the survivors will have genetic characteristics underpinning high thermal tolerance.

Progress: No QTL-guided selective breeding of coral has been conducted, but bleaching survivors are currently being used in breeding experiments.

3. Interspecific hybridization is a process whereby egg and sperm from two different species produce viable young. In coral, this process occurs only occasionally in nature, i.e. it is only relevant over evolutionary time scales (with the exception of the Caribbean Acropora discussed below). However, hybrids can also be created in the laboratory (Isomura, Iwao and Fukami, 2013; Isomura et al., 2016; Willis et al., 1997). This process increases genetic diversity and makes novel genetic combinations that may be beneficial for adaptation. Artifical (i.e. in the laboratory) or natural (i.e. in the field) selection can be used to identify hybrid genotypes that have augmented climate resilience relative to pure-bred corals.

Progress: The natural hybrid between the Caribbean species Acropora palmata (elkhorn coral) and $A$. cervicornis (staghorn coral), A. prolifera (fused staghorn), has equivalent or higher fitness relative to its parent species, and has increased its distribution and abundance in recent times of massive coral-reef degradation (Fogarty, 2012). Similarly, experimentally produced F1 hybrids between $A$. pulchra and $A$. millepora (fluro scale cushion coral) from the Great Barrier Reef grew faster than their parents in some reef environments (Willis et al., 2006). Some F1 hybrid genotypes of several other Acropora species pairs from the Great Barrier Reef produced in the laboratory had equal or higher fitness (growth, survival and climate resilience) relative to at least one of the pure-bred parent species (Chan et al., 2018). While it remains 
to be demonstrated that these fitness advantages are also expressed in later generations, these findings suggest that interspecific hybridization is a useful means of maintaining or restoring genetic diversity and hence adaptive capacity. Genetic diversity will undoubtedly decrease if high mortality events, such as those seen on the Great Barrier Reef in 2016 and 2017, become more frequent, and ex situ hybridization followed by deployment of hybrids in the field may help combat this decline.

4. Conditioning is the exposure of an organism to sublethal levels of stress with the goal of inducing a change in its phenotype (here, an increase in climate resilience or stress tolerance). This is sometimes also referred to as epigenetic programming or stress memory, and refers to nongenetic changes. If adaptive epigenetic changes are passed on to later generations, then conditioning (i.e. transgenerational acclimatization) may be a potential means of increasing climate resilience in corals. A possible approach would be to condition adult coral broodstock with the aim of producing larval material that has an increased chance of surviving its early life stages, during which levels of mortality are typically high, and hence enhancing the success of coral reef restoration efforts.

Progress: The extent to which adaptive epigenetic changes are heritable in corals is currently poorly understood (Putnam and Gates, 2015; Torda et al., 2017). Experiments to test this are under way.

\section{Manipulation of coral-associated microbes}

Manipulations of coral-associated microbes aim to increase coral's climate resilience, either by changing the composition of microbial communities (point 1) or by manipulating the genomes of a small number of microbial symbionts (point 2).

1. Probiotics are live micro-organisms that when administered in adequate amounts confer a health benefit to the host. Where increasing coral resilience is concerned, relevant organisms are likely to include bacteria, algal endosymbionts (Symbiodinium spp.) and fungi.

Progress: Coral larvae or early recruits can establish symbiosis with a range of Symbiodinium strains, often with far-reaching consequences for the thermal tolerance of the coral (reviewed in Quigley et al. [2018]). However, the temporal stability of manipulated Symbiodinium symbioses is variable and therefore the efficacy of probiotic treatments with Symbiodinium is questionable. Little research has been done on the potential of manipulating coral-associated prokaryotic or fungal community composition as a means of increasing coral stress tolerance. However, preliminary findings are promising. For example, Damjanovic et al. (2017) found that prokaryotic communities differed significantly in four-month old juveniles of the coral Acropora tenuis (purple tipped acropora) that were inoculated at the larval stage with microbiomes isolated from the mucus of four different coral species and kept under ambient conditions in experimental aquariums, suggesting manipulation of coral prokaryotic communities is feasible. Inoculation of the coral model the anemone Aiptasia pallida with a cocktail of bacteria able to inhibit biofilm formation and swarming in a bacterial coral pathogen prevented the progression of the disease caused by the pathogen (Alagely et al., 2011). Exposure of experimental corals to oil and a cocktail of bacteria with the ability to degrade hydrocarbons resulted in a change in the coral-associated prokaryotic communities and reduced the negative effects of oil compared to those in corals that were exposed to oil but not inoculated with the bacteria (dos Santos et al., 2015). These findings are particularly encouraging given that evidence that prokaryotes have a role in coral thermal tolerance is growing (Liang et al., 2017; Ziegler et al., 2017).

2. Experimental evolution is the directed evolution of a population across multiple generations under defined and reproducible conditions. This is mostly done in the laboratory.

Progress: Exposure of cultures of algal endosymbionts of corals to increasing temperatures over 55 to 80 generations has been shown to cause a stable and adaptive increase in temperature tolerance (Chakravarti, Beltran and van Oppen, 2017; Huertas et al., 2011). Corals have been found to be able to establish symbiosis with the evolved algal strains, but the increase in bleaching 
tolerance in corals associating with the evolved strain was limited and smaller than that observed for the algae in vitro (Chakravarti, Beltran and van Oppen, 2017). There is a need to develop methods that transfer thermal tolerance more efficiently from the cultured to the in hospite situation. Naturally thermally tolerant Symbiodinium strains tend to be less effective as suppliers of nutrients to the coral host than thermally sensitive strains, and it is currently unknown whether this trade-off can be overcome via experimental evolution.

\section{Concluding remarks}

As of 2018, assisted evolution for coral-reef restoration remains in the early stages of research and development. Following the publication of the concept in 2015 (van Oppen et al., 2015), various research groups around the world have been developing research programmes and projects in this field, ${ }^{108}$ and considerable progress can be expected over the next five years. This will need to be accompanied by research on the public and political acceptance of these approaches. Practical application will require legislative approval for the deployment of manipulated coral stock or its symbionts onto reefs. Research on the upscaling of coral-rearing facilities, assessment of ecological risks and benefits, economic (cost) analyses and the development of decision-making frameworks for the timing and spatial scale/location of deployment are also needed (van Oppen et al., 2017).

\subsubsection{Needs and priorities}

Genetic improvement requires sustained selection over several generations and thus involves rela- tively long periods of time. Ensuring the long-term availability of the necessary financial, technical and human resources is a major need identified by countries across all sectors. Skilled capacity and access to the technical resources needed to deploy the tremendous advances that have been made in characterization and genetic-improvement methods are widely recognized as priorities. An underlying concern is that a few favoured crop species and livestock species and breeds receive a very large proportion of the resources put into genetic improvement, thus amplifying the relative neglect of other species and breeds. A number of countries identify public-private partnerships as a way of securing long-term support and spreading genetic-improvement efforts to a wider range of species.

Limited use of available genetic diversity is another issue highlighted across sectors. Again, the need for long-term support and improved capacity to explore the range of diversity available and begin to introduce it into improvement programmes is noted. The need for improved links between research, genetic-improvement programmes and producers is another frequently mentioned concern. Assisted-evolutionary approaches of the kind being explored for corals might prove useful for other types of associated biodiversity, for example through assisted gene flow or population selection. While consideration would need to be given to possible unintended consequences, such approaches provide options that do not require the full apparatus associated with long-term breeding programmes of the kind implemented in crop and livestock species.

\footnotetext{
${ }^{108}$ For more information, visit the following websites:

https://www.aims.gov.au/reef-recovery/assisted-evolution https://www.researchgate.net/project/CORALASSIST-AssistingCoral-Reef-Survival-in-the-Face-of-Climate-Change http://coralassistedevolution.com https://www.aims.gov.au/reef-recovery/rrap; https://www.microbial-symbiosis.com/research
} 


\section{Chapter 6 \\ The state of characterization of biodiversity for food and agriculture}

\begin{tabular}{|c|c|}
\hline Key messages & \\
\hline $\begin{array}{l}\text { - Characterization of the components of biodiversity } \\
\text { for food and agriculture, for example the } \\
\text { acquisition of data on the morphological and } \\
\text { physiological characteristics of species (or varieties } \\
\text { or breeds) or on their geographical distributions, } \\
\text { production levels in particular environments, } \\
\text { demographics or ecological functions and } \\
\text { relationships, is vital to the sustainable use and } \\
\text { conservation of these resources. } \\
\text { - While a large amount information has been } \\
\text { accumulated on the characteristics of the } \\
\text { domesticated species used in food and agriculture, } \\
\text { many information gaps remain, particularly for } \\
\text { species, varieties and breeds that are not widely } \\
\text { used commercially. Information on wild food } \\
\text { species is also often limited. }\end{array}$ & $\begin{array}{l}\text { - Many associated-biodiversity species (the } \\
\text { biodiversity present in and around production } \\
\text { systems that contributes to the supply of regulating } \\
\text { and supporting ecosystem services) have never } \\
\text { been identified and described, particularly in } \\
\text { the case of invertebrates and micro-organisms. } \\
\text { Information on the characteristics and functions of } \\
\text { many other components of associated biodiversity } \\
\text { is extremely limited. } \\
\text { - For several types of associated biodiversity, } \\
\text { including soil micro-organisms and those used for } \\
\text { food processing, advances in molecular techniques } \\
\text { and sequencing technologies are facilitating } \\
\text { characterization. In many countries, however, gaps } \\
\text { in terms of skills, facilities and equipment constrain } \\
\text { opportunities to benefit from these developments. }\end{array}$ \\
\hline
\end{tabular}

\subsection{Introduction}

Effective management of components of biodiversity for food and agriculture (BFA) (e.g. particular species, or breeds or varieties within species) requires information on their characteristics. However, the use of the term "characterization" varies from one sector of food and agriculture to another. Broader definitions encompass not only the tangible characteristics of the organisms themselves, but also their geographical distributions, the size and structure of their populations, their uses in food and agriculture, their other roles within the ecosystem, and potential threats to their survival. Molecular genetic data can be used, inter alia, to assess genetic variability within and between populations and to investigate the genetics underlying particular traits (e.g. physical appearance, productivity, disease resistance and other adaptive characteristics). Clearly, factors such as geographical distribution and population size and structure can change significantly over relatively short periods of time. Repeated measurement to keep track of changes of this kind is often referred to as monitoring. Monitoring programmes for various components of BFA are discussed in the "state of knowledge" subsections of Chapter 4.

This chapter presents an overview of the state of characterization efforts for each of the main categories of BFA discussed in this report. It begins 
with an overview of the state of characterization of plant (crop), animal (livestock), forest and aquatic genetic resources, drawing on the respective global assessments prepared by FAO (FAO, forthcoming, 2010a, 2014a, 2015a). The next sections discuss associated biodiversity and wild foods, drawing mainly on the information provided in the country reports. ${ }^{1}$ The chapter ends with a short discussion of needs and priorities, focusing on the latter two categories of BFA.

\subsection{Plant, animal, forest and aquatic genetic resources for food and agriculture}

- Characterization of genetic resources is essential to their sustainable use and conservation, providing information on, inter alia, genetic diversity and the presence of useful traits in species, breeds or varieties, on the size, structure and geographical distribution of populations, and on threats affecting them.

- A significant proportion of crop accessions conserved ex situ, particularly underutilized crops and crop wild relatives, remains incompletely characterized and evaluated for morphological and agronomic traits. The limited availability of characterization and evaluation data in publicly available databases is a major constraint to the use of plant genetic resources in breeding programmes.

- In the case of animal genetic resources, while recent years have seen some improvement in the state of inventory, characterization and monitoring activities, major gaps remain, particularly in the developing regions of the world. Breed inventories are often incomplete and population trends inadequately monitored. Data on breeds' phenotypic characteristics are often lacking, constraining their use in breeding programmes.

- In the case of forest and aquatic genetic resources, characterization at within-species level is often

Throughout this chapter, unless noted otherwise, the term "country reports" refers to the country reports submitted as contributions to The State of the World's Biodiversity for Food and Agriculture. See "About this publication" for additional information. absent or limited to information on distribution and origins. Characterization data that exist often remain scattered and difficult to obtain. There is an urgent need to develop effective information systems and to encourage the use of agreed protocols and practices in characterization activities.

\subsubsection{Plant genetic resources for food and agriculture}

Where plant genetic resources for food and agriculture (PGRFA) are concerned, the term "characterization" is used to describe the process by which genebank accessions are described with respect to a particular set of universally agreed morphological traits, known as descriptors (FAO, 2010a, 2014f). ${ }^{2}$ These traits are usually highly heritable, easily measured or assessed, and expressed the same way in all environments. "Evaluation", on the other hand, provides data about traits that are generally considered to have actual or potential agronomic utility. Often, the expression of these traits varies with the environment, so valid conclusions require evaluation in different environments.

The state of characterization and evaluation is typically assessed on the basis of the proportion of accessions that have been characterized and evaluated. Table 6.1 provides an indication of the level of implementation of various components of characterization and evaluation as of 2008 (at the time of writing, the most recent available dataset providing information at this level for a large sample of countries globally).

In reporting on activities undertaken to implement the Second Global Plan of Action for Plant Genetic Resources for Food and Agriculture between January 2012 and June 2014, 27 countries provided information on the level of morphological characterization of their ex situ collections. Table 6.2 shows the percentage of accessions characterized for at least one morphological trait and the average number of morphological traits per conserved accession for the five crops with

\footnotetext{
The material presented in this subsection is largely based on The Second Report on the State of the World's Plant Genetic Resources for Food and Agriculture (FAO, 2010a).
} 
TABLE 6.1

Traits and methods used for characterizing germplasm: percentage of accessions characterized and/or evaluated, by region

\begin{tabular}{|l|c|c|c|c|c|c|}
\hline \multicolumn{1}{|c|}{ Region } & $\begin{array}{c}\text { Number of } \\
\text { collections }\end{array}$ & $\begin{array}{c}\text { Morphology } \\
\text { (\%) }\end{array}$ & $\begin{array}{c}\text { Molecular } \\
\text { markers (\%) }\end{array}$ & $\begin{array}{c}\text { Agronomic } \\
\text { traits (\%) }\end{array}$ & $\begin{array}{c}\text { Biochemical } \\
\text { traits (\%) }\end{array}$ \\
\hline stresses (\%) \\
stresses (\%)
\end{tabular}

Notes: The figures are based on responses from 323 stakeholders from 42 developing countries to a question on the percentage of accessions characterized and/or evaluated for the various traits. Percentages are averaged across countries in each region.

"Number or collections" = total number of ex situ collections surveyed for which characterization data exist.

Source: FAO, 2010a.

TABLE 6.2

Degree of characterization for the five largest crop collections conserved by 27 reporting countries

\begin{tabular}{|l|c|c|c|}
\hline Crop & $\begin{array}{c}\text { Number of accessions } \\
\text { conserved }\end{array}$ & $\begin{array}{c}\text { Accessions characterized } \\
\text { (\%) }\end{array}$ & $\begin{array}{c}\text { Average number of traits } \\
\text { per conserved accession }\end{array}$ \\
\hline Wheat & 138873 & 53 & 9.9 \\
\hline Barley & 67591 & 81 & 16.6 \\
\hline Rice & 31871 & 73 & 18.1 \\
\hline Sorghum & 16293 & 80 & 16.1 \\
\hline Beans & 21105 & 55 & 12.2 \\
\hline
\end{tabular}

Source: FAO, 2016m.

the largest collections in these countries (FAO, $2016 \mathrm{~m}$ ). Highest levels of characterization are reported for barley, sorghum and rice collections, both in terms of the proportion of accessions covered and in terms of the average number of traits characterized.

Despite ongoing work on the part of genebanks and associated programmes, often involving regional and international collaboration, a significant portion of germplasm accessions remains uncharacterized or not properly documented. Lack of standardization in data collection, storage and dissemination, and suboptimal access to data, are also constraints. Many countries regard a lack of readily available characterization and evaluation data as a major constraint to the greater use of PGRFA in breeding programmes. Problems are particularly acute for underutilized crops and crop wild relatives, some of which are likely to become increasingly important in the context of climate change. Molecular characterization of germplasm has become more widespread across regions and crops. However, much remains to be done both to generate more data and to make them more readily available. Systematic surveying and inventory of PGRFA in situ remain underdeveloped. This area of work tends to be constrained by a lack of funding, human resources, knowledge and coordination.

\subsubsection{Animal genetic resources for food and agriculture}

Characterization of animal genetic resources for food and agriculture (AnGR) encompasses a 
range of data-gathering activities (FAO, 2015a). ${ }^{3}$ The unit of management for AnGR is generally the breed. A primary task of characterization activities is therefore to identify (if this has not already been done) the distinct breed populations present in the targeted area. Countries interested in promoting sustainable management of their AnGR generally seek to establish complete national inventories of their breeds. Both phenotypic and molecular genetic studies can contribute to the process of breed inventory and to the further accumulation of knowledge on breeds (including breeds not included in official inventories) and the relationships among them.

Phenotypic characterization encompasses description of breeds' morphological and physiological traits, production performance and adaptive characteristics (FAO, 2012d). If data on production levels are to be interpreted properly, data are also needed on the production environments in which the animals are raised. Data of this kind may also allow inferences to be drawn regarding the breeds' adaptive characteristics and help in the development of plans for their sustainable management. Data on breeds' geographical distributions can be useful in increasing the precision of estimates of their risk status ${ }^{4}$ and in identifying the characteristics (climate, terrain, etc.) of the production environments in which breeds are raised. The term "landscape genomics" has been coined to describe studies that relate detectable genetic variation to geographical locations and their characteristics (Joost et al., 2007).

A survey that collects data on the size and structure of a breed's population and its geographical distribution and hence allows its extinction risk status to be determined is often referred to as a baseline survey (FAO, 2011f). Baseline surveys need to be followed up by regular monitoring of

The material presented in this subsection is largely based on The Second Report on The State of the World's Animal Genetic Resources for Food and Agriculture (FAO, 2015a).

4 For example, breeds whose populations are concentrated in a limited geographical area tend to be at greater risk of losing a large proportion of their populations to events such as disease outbreaks and climatic disasters. population demographics so that trends in risk status can be tracked over time. Potential threats, such as changes in production practices, markets or disease epidemiology, also need to be monitored.

Various types of genetic markers have been used in characterization studies over the years, starting with blood groups or other proteins, followed by microsatellite markers. Genomic approaches, such as the use of single nucleotide polymorphism markers and whole-genome sequencing, are now increasingly used. One shortcoming of many genetic characterization studies, however, has been that they have been undertaken as academic activities, with the results destined to appear in the scientific press, rather than undertaken to provide information targeted for use by stakeholders directly involved in the management of AnGR. Exceptions include cases in which studies have revealed high levels of inbreeding within a given breed or high levels of similarity between breeds previously believed to be more distinct. Specifically designed molecular-characterization studies have also been used to identify the genetic basis (or at least to develop genetic tests) for various defects or other simply inherited traits.

While recent years have seen some improvements in the state of inventory, characterization and monitoring activities for AnGR, major gaps remain, particularly in the developing regions of the world (Figure 6.1). Many countries consider that their breed inventories are not yet complete. Many breed populations are not subject to monitoring activities that are sufficiently comprehensive and regular to allow risk status to be tracked over time. The phenotypic data needed to adequately compare the performance of different breeds in specific production environments or to take advantage of developments in molecular genetics are often unavailable.

\subsubsection{Forest genetic resources}

Efforts to promote conservation and sustainable use of forest genetic resources (FGR) require information on, inter alia, the following: levels of diversity, in particular tree populations and the extent of the risks facing them; the location of populations 
FIGURE 6.1

Reported progress in the implementation of (A) phenotypic and (B) molecular characterization in livestock species of economic importance

A

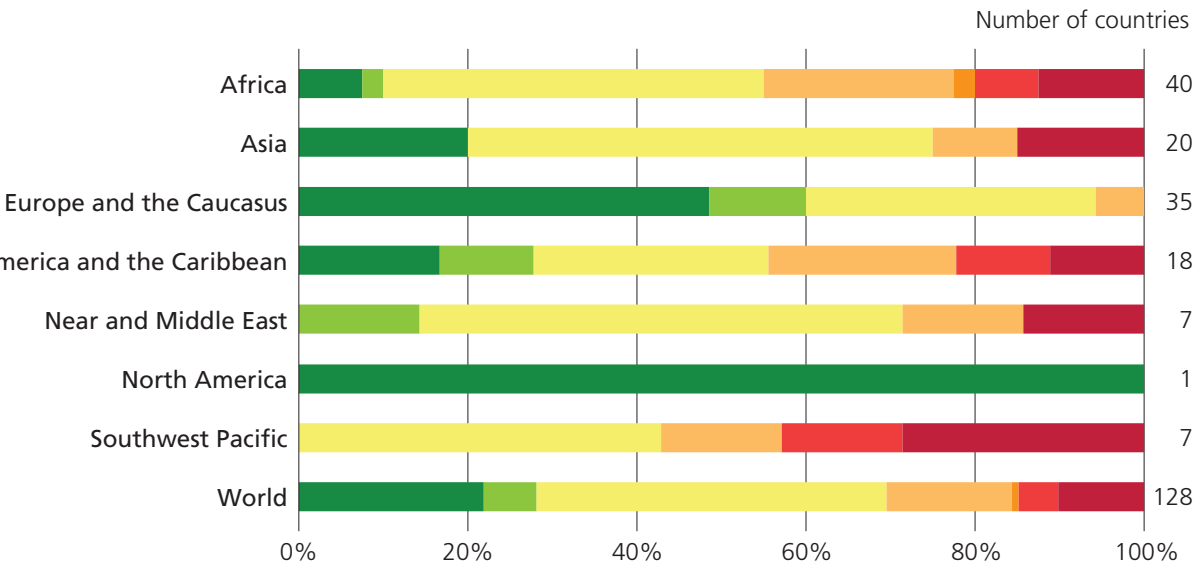

Number of countries

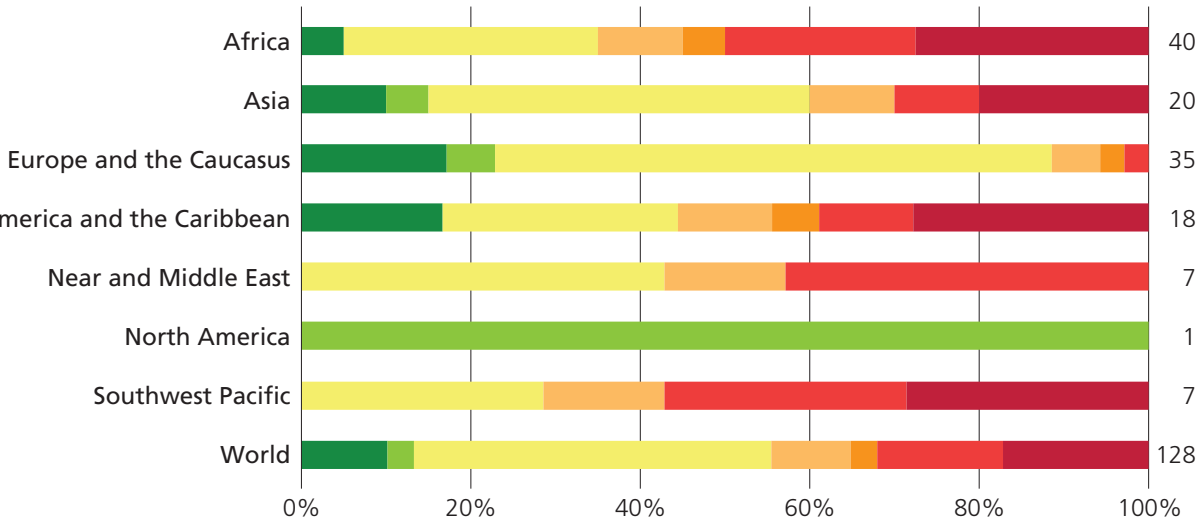

Comprehensive studies were undertaken before the adoption of the GPA

Sufficient information has been generated because of progress made since the adoption of the GPA

Some information has been generated (further progress since the adoption of the GPA)

Some information has been generated (no further progress since the adoption of the GPA)

None, but action is planned and funding identified

None, but action is planned and funding is sought

None

Notes: Analysis based on 128 reports prepared by countries in 2014 on their implementation of activities relevant to the implementation of the Global Plan of Action for Animal Genetic Resources (GPA). Part A of the figure summarizes answers to a question on "progress in implementing phenotypic characterization studies covering morphology, performance, location, production environments and specific features in all livestock species of economic importance." Part B of the figure summarizes answers to a question on "progress in molecular characterization of [the respective country's] animal genetic resources covering all livestock species of economic importance."

Source: FAO, 2014g. 


\section{PART C}

TABLE 6.3

Characters most frequently assessed in 692 evaluations of forest-tree genetic variability reported by countries

\begin{tabular}{|l|c|c|}
\hline \multicolumn{1}{|c|}{ Character } & Type of character & $\begin{array}{c}\text { Proportion of total evaluations } \\
\text { assessing this character (\%) }\end{array}$ \\
\hline $\begin{array}{l}\text { Characters least subject to phenotypic } \\
\text { variation, i.e. seed, fruits, cones and pods }\end{array}$ & Morphological & 17.5 \\
\hline Disease and pest resistance & Adaptive/productive & 13 \\
\hline Leaf anatomy & Morphological & 7 \\
\hline Bole/stem diameter & Productive & 7 \\
\hline Growth rate & Productive & 5.5 \\
\hline Biomass/fodder productivity & Productive & 5 \\
\hline Height & Productive & 5.5 \\
\hline Drought resistance & Adaptive/productive \\
\hline Phenology & Adaptive & 5 \\
\hline Bark & Morphological & 5 \\
\hline Chemistry/exudates & Biochemical & 5 \\
\hline
\end{tabular}

Source: FAO, 2014a

or individuals with rare alleles; relationships between genetic variability and environmental parameters; and trends in genetic variability, for example in response to silvicultural regimes and environmental changes (FAO, 2014a). ${ }^{5}$ Treebreeding programmes require information on the identity of species and populations with the greatest potential for commercial development, on desirable productive or adaptive traits in priority species (including those relevant to climate change), on genetic markers linked to adaptive or other desirable characteristics and on sources of propagation materials. Data can be gathered through studies of morphological characteristics, field-based studies, provenance and progeny trials, the use of various biochemical and DNA markers, and other laboratory-based investigations. At interspecific level, characterization data are often captured through forest inventories undertaken in the course of resource-management activities. However, such surveys often fail to capture and

The material presented in this subsection is largely based on The State of the World's Forest Genetic Resources (FAO, 2014a). document the genetic resources present in circa situm environments. ${ }^{6}$ Characterization of intraspecific diversity is recognized as a central component of the conservation and use of individual tree species. However, the sheer number of species present in many countries makes characterizing more than a small fraction of species at this level extremely challenging. The impracticality of measuring changes in genetic variation in all or most tree species means that monitoring of FGR is mainly done either by monitoring only priority or model species or by monitoring surrogate measures such as forest area or tree cover (see Section 4.5.5).

Provenance testing - growing trees selected from different locations (provenances) under the same environmental conditions so as to determine the extent to which observed variation among populations or individuals can be attributed to genetic differences - has a long history and continues to be used widely in tree-breeding and improvement programmes. Provenance testing is time consuming,

\footnotetext{
Heavily modified or fragmented landscapes, such as those of traditional agroforestry and farming systems.
} 
expensive and vulnerable to risks associated with natural disasters and other disruptions. However, as it does not require advanced technical infrastructure, it is widely used in tropical countries, where trees often have fast growth rates and relatively short rotation periods. Great reductions in the costs of gene sequencing and increases in computer processing speed and power have led to a proliferation of DNA studies in tree species, including wholegenome sequencing, and rapid progress in identifying the location and function of genes.

The country reports prepared for The State of the World's Forest Genetic Resources refer to 27 characters assessed in the course of evaluating genetic variability (in a total of 692 evaluations). The most frequently mentioned are shown in Table 6.3. These data indicate that purely morphological characters remain widely used in the evaluation of variability, despite the increasing focus on molecular markers. They also highlight the importance that countries place on identifying trees and genotypes for breeding for pest and disease resistance.

The level of monitoring efforts varies greatly between countries. Developed countries with well-established national forest inventories and monitoring systems have comprehensively documented their forest resources and described changes in their FGR. Several developing countries have also made good progress in this regard during the past decade. However, genetic monitoring of forests is at a very early stage of development, with only a small number of pilot studies having been implemented to date. A substantial amount of genetic information is available only on the most widely planted genera globally: Acacia, Eucalyptus, Populus and Pinus. Efforts to characterize species that are less widely planted but important locally or in naturally regenerated forests urgently need to be strengthened. Even when FGR-related data are collected, they often remain scattered and difficult for potential users to obtain. Thus, information systems for FGR urgently need to be established or strengthened. The use of common protocols for FGR inventories, characterization and monitoring would help to ensure that data collected from different countries are comparable.

\subsubsection{Aquatic genetic resources for food and agriculture}

Characterization and monitoring of aquatic genetic resources for food and agriculture (AqGR) occurs mainly at species level. Where monitoring is concerned, the international standards for reporting production from cultured and captured species are the Aquatic Sciences and Fisheries Information System (ASFIS) list and the classification system of the International Standard Statistical Classification of Aquatic Animals and Plants (ISCAAP). Member countries provide an annual report to $\mathrm{FAO}$ on their fisheries and aquaculture production and this information can be publicly accessed through FAO FishStatJ. ${ }^{7}$ The information is also summarized in FAO's biennial publication series The State of World Fisheries and Aquaculture, which also provides information (at species level) on the status of aquaculture and marine capture fisheries resources (see Section 4.2.4).

There is at present no global information system on aquatic genetic diversity below species level (FAO, 2016n). The international standard classification for use in fishery statistics, (the ASFIS list - see above), does not include any subspecies, stocks, or farmed types ${ }^{8}$ or their wild relatives. Powerful genetic-sequencing and geneticmapping technologies are now making it easier and less expensive to characterize aquatic organisms at finer scales of resolution, such as at stock, strain and even individual-pedigree levels (FAO, 2017n). Efforts are being made to find ways of applying these tools in the assessment and management of capture-fishery stocks (Bravington, Grewe and Davies, 2016). These various developments will enable more-refined reporting for farmed types of cultured species, as well as for some highly migratory capture-fishery stocks.

Although information on genetic diversity at within-species level can be extremely useful in AqGR management, little is collected or made

\footnotetext{
http://www.fao.org/fishery/statistics/software/fishstatj/en

A farmed type may be a strain, hybrid, triploid, monosex group, other genetically altered form, variety or wild type.
} 
available to potential users, except in the case of some high-value species in developed countries. About 70 percent of the country reports submitted for The State of the World's Aquatic Genetic Resources for Food and Agriculture (SoW-AqGR) (FAO, forthcoming) indicate that genetic information is used only to a minor extent or not at all in managing farmed aquatic resources.

In the aquaculture sector, monitoring at the level of the strain, as is done for breeds in the terrestrial livestock sector, is constrained by a lack of standardized strain nomenclature and characterization, and the relatively recent history of strain development in aquatic species (FAO, 2016n). In capture fisheries, genetic diversity is sometimes used in the management of high-value species. For example, within-species data are available on salmonids, and are used in managing populations in the wild (NMFS, 2016). However, the financial and technical capacity needed in order to establish baseline data and conduct regular sampling, monitoring and analyses is lacking in many areas. Stock identification in capture fisheries has traditionally been based on geographic location, and production has been reported and monitored accordingly (e.g. North Atlantic cod stocks, Lake Victoria Nile perch, in-shore herring stocks and Columbia River chinook salmon). If waters are to be stocked using fish reared in captivity, characterization is critical to efforts to avoid undesirable impacts on the genetic diversity of wild populations.

For given countries or habitats, aquatic species can be categorized as native or non-native (sometimes called exotic or alien species). Nonnative species are important in aquaculture, with approximately 200 species or species items ${ }^{9}$ being farmed in areas where they are non-native (FAO, forthcoming). Nine of the ten most widely cultured species are farmed in more countries where they are non-native than countries where they are native. Introductions of aquatic species across national boundaries are recorded in FAO's

\footnotetext{
A species item refers to a single species, a group of species (where identification to the species level is not possible) or an interspecific hybrid.
}

Database on Introductions of Aquatic Species (DIAS). ${ }^{10}$ DIAS contains over 5000 records from inland and marine ecosystems, including fishes, molluscs, crustaceans, echinoderms and plants. This database is not updated annually, and currently serves more as a historical record of introductions than as a monitoring system.

In addition to establishing or strengthening surveying and monitoring systems and national, regional and global information systems for farmed AqGR and their wild relatives, priorities in this field of AqGR management include improving information on fish genetic diversity and adopting standard nomenclature for its description. Neither the SoW-AqGR process nor the FAO fisheries and aquaculture databases have required countries to list aquaculture farming systems or report on the state of aquatic ecosystems. Monitoring and characterization of these are therefore generally missing from global fishery reports. Given that many wild relatives of farmed aquatic species are in decline due to habitat loss or degradation (FAO, forthcoming), particular attention needs to be paid to characterizing species found in ecosystems that are threatened by disturbances such as wetland drainage and the construction of dams or hydropower plants.

\subsection{Associated biodiversity}

- Characterization of associated biodiversity is limited and mostly undertaken at species level. While many larger species have been identified and described, over 99 percent of bacteria and protist species remain unknown.

- Molecular technologies, including metagenomics and barcoding, are allowing rapid progress to be made in identifying associated-biodiversity species, especially those present in soils. Such techniques also allow investigation of the functional attributes of populations. Several countries have active programmes for characterizing soil micro-organisms using molecular methods.

\footnotetext{
10 http://www.fao.org/fishery/dias/en
} 
- A number of ex situ collections of associated biodiversity are being characterized. Many of these are species associated with food-production processes (e.g. fermentation), with collections being maintained in both the private and the public sectors.

\subsubsection{Overview}

While characterization of associated biodiversity ${ }^{11}$ is not such a well-established or clearly defined area of activity as characterization of PGRFA, AnGR, FGR or AqGR, understanding the characteristics of the species and ecosystems associated with food and agricultural production is a vital part of efforts to promote their sustainable use and conservation. A distinguishing feature of associated biodiversity relative to crops, livestock, species raised in aquaculture or targeted by capture fisheries and (to a lesser extent) forest trees, is that many species remain unknown to science. Mora et al. (2011) estimate that 86 percent of the extant species on Earth and 91 percent of those in the ocean are still undescribed. ${ }^{12}$ While there are about 1 million described insect species, an estimated 4 million species are undescribed (Chapman, 2009). In the case of micro-organisms, it is estimated that 99.999 percent of taxa remain to be discovered (Locey and Lennon, 2016).

After a species has been formally described and named, additional knowledge about its characteristics can be accumulated over time. In the case of associated biodiversity, functional traits - characteristics that affect a species' responses to the environment and its role in ecosystem functioning - are of particular interest. For example, knowledge of whether a species can perform particular functions (pollination, control of pest species, roles in soil formation, etc.) under particular ecological

11 A description of associated biodiversity can be found in Section 1.5 and state and trends of associated biodiversity are presented in Section 4.3.

12 Newly discovered species are considered scientifically described when they have been given a two-part Latin name and have had a description published in a peer-reviewed scientific journal. The description typically includes a thorough listing of morphological characteristics, in particular of those that distinguish the species from other species. For more information, visit http://eol.org/info/467 conditions, for example during stressful events such as droughts, may be useful. Data on biogeographical distribution and population size, structure and trends are valuable in determining species' risk statuses and assessing the need for conservation measures. The state of knowledge of the status and trends of associated biodiversity involved in the supply of various ecosystem services is discussed in Section 4.3.

As illustrated in Table 6.4, the vast majority world's soil microfauna and micro-organism species are thought to be undescribed. In general, the percentage of species described decreases with the size of the organisms. However, significant progress is currently being made in characterizing soil biodiversity through the application of molecular technologies, which can be used (inter alia) to characterize unculturable microorganisms (FAO and ITPS, 2015). The availability of these technologies has led to an increased number of studies characterizing soil biodiversity at large spatial scales (Orgiazzi et al., 2015). Molecular technologies are also revolutionizing taxonomic research on larger organisms. For example, DNA barcoding allows the identification of bee species that are difficult to recognize using traditional methods (Packer et al., 2016).

With regard to aquatic biodiversity, the Census of Marine Life, a ten-year international effort to assess the diversity, distribution and abundance of marine species, completed in 2010, concluded that nearly 250000 valid marine species had been described (Ausubel, Crist and Waggoner, 2010). The census itself found more than 6000 potentially new species and completed formal descriptions of more than 1200 of them (ibid.). The Census of Coral Reef Ecosystems, conducted as a part of the project, developed methods of molecular analysis and standardized sampling for organisms living in coral reefs and led to the discovery of approximately 100 new species (Mclntyre, ed., 2010).

Only a fraction of the estimated 5000 types of micro-organisms used in the production of artisanal (including indigenous) fermented foods and beverages worldwide have been studied scientifically. Moreover, studies have often merely 


\section{PART C}

TABLE 6.4

Known and estimated number of species of soil organisms and vascular plants

\begin{tabular}{|c|c|c|c|}
\hline Type of organism & $\begin{array}{c}\text { Number of } \\
\text { described species }\end{array}$ & $\begin{array}{l}\text { Estimated total number of } \\
\text { species }\end{array}$ & Proportion described (\%) \\
\hline Vascular plants & 350700 & 400000 & 88 \\
\hline \multicolumn{4}{|l|}{ Macrofauna } \\
\hline Earthworms & 7000 & 30000 & 23 \\
\hline Ants & 14000 & $25000-30000$ & $60-50$ \\
\hline Termites & 2700 & 3100 & 87 \\
\hline \multicolumn{4}{|l|}{ Mesofauna } \\
\hline Mites & 40000 & 100000 & 55 \\
\hline Collembolans (springtails) & 8500 & 50000 & 17 \\
\hline \multicolumn{4}{|c|}{ Microfauna and micro-organisms } \\
\hline Nematodes & $20000-25000$ & $1000000-10000000$ & $0.2-2.5$ \\
\hline Protists & 21000 & $7000000-70000000$ & $0.03-0.3$ \\
\hline Fungi & 97000 & $1500000-5100000$ & $1.9-6.5$ \\
\hline Bacteria & 15000 & $>1000000$ & $<1.5$ \\
\hline
\end{tabular}

Source: Orgiazzi et al., eds. (2016), updated from Barrios (2007).

identified the primary microbiota in the finished product or undertaken some preliminary characterization of them. However, in-depth information is now rapidly accumulating on microbial communities involved in food processing, including on their structure, interactions, succession during the fermentation process and influence on product quality and safety. ${ }^{13}$

In the case of fermentation processes that are already relatively well understood, the goals are to further improve reliability and product quality by optimizing starter-culture performance and eliminating factors that impede the fermentation process. Some micro-organisms used in food production have already been sequenced genetically, and this has created new opportunities to improve culture performance. The use of up-to-date analytical methods is providing detailed information on the roles of individual strains and species in fermentation processes. This is allowing

3 These paragraphs on food-processing organisms draw on the CGRFA Background Study Paper prepared by Alexandraki et al. (2013) the choice of starter cultures and the management of the fermentation process to be finetuned to increase product quality and safety. One challenge is to ensure that the manufacture of traditional food products on a large scale under conditions that favour product safety and provide consistency in terms of quality do not lead to the loss of the unique flavours and other characteristics associated with the original products. This will require a more thorough understanding of the types of micro-organisms involved and their specific activities. The significance of advances in the use of molecular techniques in the characterization of food-processing micro-organisms is discussed in Box 6.1.

\subsubsection{Country-report analysis}

The country-reporting guidelines invited countries to indicate whether the associated biodiversity species they conserve ex situ have been characterized or evaluated. Fifty-one countries report ex situ collections of species of associated biodiversity (see Section 7.3.2). Forty-five distinct species within these collections are reported to have been 
Box 6.1

The role of molecular techniques in the characterization of food-processing micro-organisms

High-throughput sequencing technologies are providing new means of improving the functionality and safety of microbial food processing (Alkema et al., 2016). Sequencing technologies have evolved rapidly in recent years, and it is now possible to sequence a bacterial genome in a few hours and at a relatively low cost. Recent developments in singlecell sequencing allow the genomes of uncultured microorganisms to be sequenced (at present, the vast majority of micro-organisms cannot be cultured in vitro) (Nawy, 2013). Complete, annotated genome sequences are available for thousands of bacterial and dozens of fungal species (NCBI, 2018). Comparative genomics uses these data to identify biological similarities and differences and evolutionary relationships between organisms. Partial genome sequencing (random or targeted) and single nucleotide polymorphism (SNP) microarrays allow genetic markers linked to traits of interest to be identified more rapidly.

Technologies that target gene expression (RNA-seq, gene expression microarrays), protein levels (mass spectrometry, protein chips) and metabolites (chromatography, mass spectrometry, nuclear magnetic resonance) are being used to identify and quantify gene products and other molecules at a high resolution. Data obtained using these methods can be used to study the effects of the environment (temperature, humidity, nutrients, etc.) on microbial physiological properties and metabolic processes, and the impact of industrial production parameters on gene expression and metabolite accumulation. Food-safety applications include risk analysis, and detection and quantification of transcripts or proteins that predict the presence of undesirable molecules (Giraffa and Carminati, 2008; Postollec et al., 2011).

Metagenomics is the study of genetic material recovered directly from complex samples to characterize the diversity of microbial communities (Bokulich et al., 2016; Handelsman, 2004; Nikolaki and Tsiamis, 2013). The ability to clone large fragments of metagenomic DNA allows entire functional operons (units of genomic DNA containing clusters of genes) to be targeted and entire metabolic pathways to be traced. Comparative metagenomics, in which libraries (collections of DNA sequences) prepared from different sites or at different times are compared, also provides insights (Randazzo, Caggia and Neviani, 2009; Riesenfeld, Schloss and Handelsman, 2004). Metagenomics and metatranscriptomics can be very powerful means of studying the microbiology of fermented foods, for example critical fermentation parameters affecting quality, and interactions between bacteria in fermentation ecosystems. Work in these fields will be propelled forward by the ongoing rapid advances in sequencing technologies and bioinformatics (van Hijum, Vaughan and Vogel, 2013).

Source: Provided by François Fauteux, drawing on Alexandraki et al. (2013). characterized or evaluated completely or partially (15 species of fish, 10 of insects, 9 of plants, 9 of bacteria and 1 each of crustaceans and mammals). The status of characterization or evaluation of a further 262 distinct associated-biodiversity species maintained in ex situ collections is reported as not known or not characterized (Figure 6.2). ${ }^{14}$ Only two species (Rhizobium leguminosarum and the western honey bee [Apis mellifera]) are reported by more than one country to have been characterized or evaluated.

\footnotetext{
14 In addition, a single country reported 885 distinct plant species as characterized or characterized partially.
}

The country-reporting guidelines did not invite countries to provide detailed descriptions of their characterization studies or to report on studies conducted outside the context of ex situ conservation programmes. However, the country reports describe a number of initiatives targeting the characterization of components of associated biodiversity in a range of different contexts. ${ }^{15}$

Many countries highlight the need to address gaps in knowledge on the characteristics of the micro-organisms found in and around production

\footnotetext{
15 Examples of initiatives that assess trends in the status of various components of associated biodiversity are presented in Section 4.3
} 


\section{PART C}

FIGURE 6.2

Status of characterization or evaluation of associated biodiversity species reported to be conserved ex situ, by region

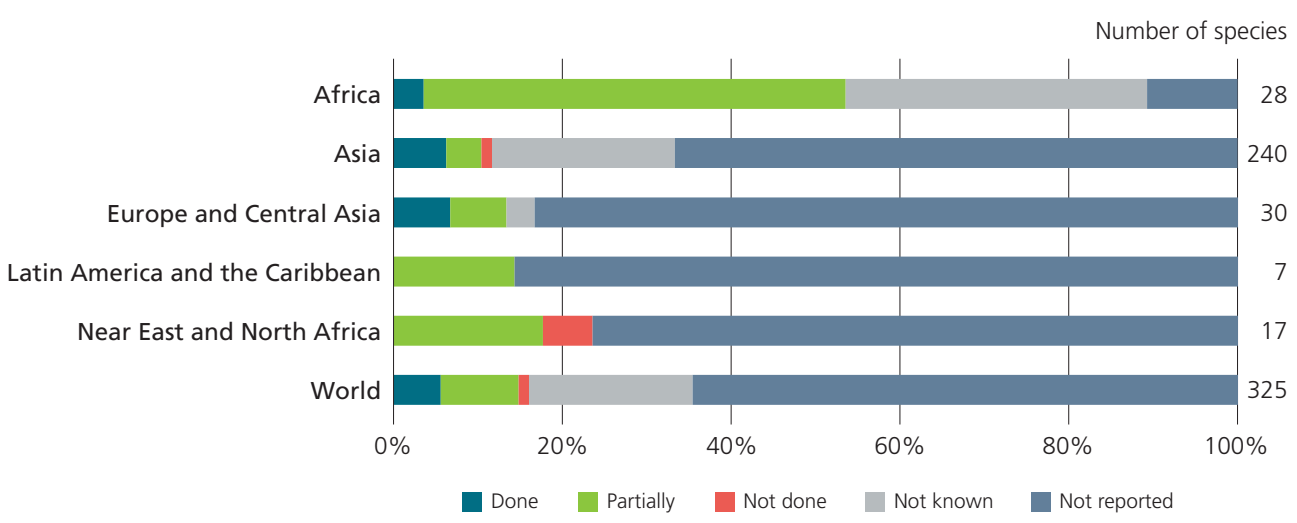

Notes: Fifty-one countries out of 91 report conservation of associated biodiversity species in ex situ collections. Some species were reported by more than one country.

Source: Country reports prepared for The State of the World's Biodiversity for Food and Agriculture.

systems, and several projects and programmes in this field are reported. For example, the United Kingdom mentions a pilot project involving government and research institutions that is developing and applying genetic barcoding and metabarcoding approaches to the identification and characterization of soil micro-organism communities. It notes that the outcome of this work may in the future enable trends in soil micro-organisms to be monitored. Sri Lanka mentions that the state of its micro-organism diversity is poorly known and not monitored, but that there are plans to collect baseline data on micro-organisms (and invertebrates) across production systems in order to enable changes to be detected.

A number of countries highlight work related to the roles of micro-organisms in the supply of particular ecosystem services (e.g. pest control, soil formation or improving/maintaining soil fertility, carbon sequestration and bioremediation) or to the development of products such as biofertilizers, biopesticides and biofuels. For example, Switzerland reports that the tasks of the Swiss Collection of Arbuscular Mycorrhizal Fungi include identification of arbuscular mycorrhizal species and determination of spore densities, the extent of root colonization and the infection potential of crops with mycorrhizal fungi. Spain mentions a study entitled Exploration of Microbial Diversity and its Biotechnological Potential, which targets the characterization of marine micro-organisms and of lactic acid bacteria associated with traditional Andean fermented-food products, with the most relevant strains being deposited at the Spanish Type Culture Collection.

Ecuador highlights the Higher Polytechnic School of Chimborazo's BIOCENOSIS project, a multidisciplinary initiative that focuses mainly on the identification, characterization and evaluation of micro-organisms for potential use in improving soil fertility, pest control and bioremediation. Outcomes have included the identification of phosphorus-solubilizing bacteria. Techniques for controlling diseases such as sigatoka (a disease of bananas) and pests such as the chocho borer (a pest of the Andean lupin species tarwi [Lupinus mutabilis]) using microorganisms are reported to be in the final stages 
Box 6.2

\section{Characterization studies on micro-organisms - examples from Peru}

Peru's microbial biodiversity remains largely unknown. However, a number of research programmes are targeting the characterization of these resources.

The Marino Tabuso Biology and Biotechnology Laboratory of National Agrarian University - La Molina (UNALM) is studying, inter alia, the molecular characterization of symbiotic and free-living nitrogen-fixing bacteria, the optimization of biofertilizer production, the beneficial effects of rhizobia and plant growth-promoting rhizobacteria in crops such as beans, cotton, maize, maca (Lepidium meyenii), tara (Caesalpinia spinose) and aguaymanto (Physalis peruviana) and the microbial interactions occurring in the rhizosphere of various crops. UNALM's Mycology and Biotechnology Laboratory has been studying fungi and bacteria associated with the nitrogen cycle since the 1970 s, and is currently conducting microbial and molecular bioprospecting of undisturbed soils in the Amazon rainforest and in hot springs. Several bacterial and fungal strains have been isolated and evaluated for the production of alkalophilic and thermophilic lignocellulase.

Researchers at the Laboratory of Microbial Ecology, National University of San Marcos, are studying marine organisms, especially actinomycetes with antibacterial activities. The Biological Oceanography Unit of the Marine Institute of Peru (IMARPE) is implementing research on phytoplankton dynamics and on the micro-organisms of marine sediments. IMARPE's Aquatic Organism Germplasm Bank aims to identify strains of aquatic organisms, characterize them molecularly and biochemically, conserve them and make them available to the scientific community, private institutions and universities for research (in the fields of aquaculture, bioremediation, toxicity testing and food production) and teaching. Research projects have investigated the potential use of micro-algae in fuel production, in cosmetics and for other biotechnological purposes. The Environmental Biotechnology Laboratory of Cayetano Heredia University is studying micro-organisms with the aim of developing biotechnologies for the recovery of metals and for bioremediation.

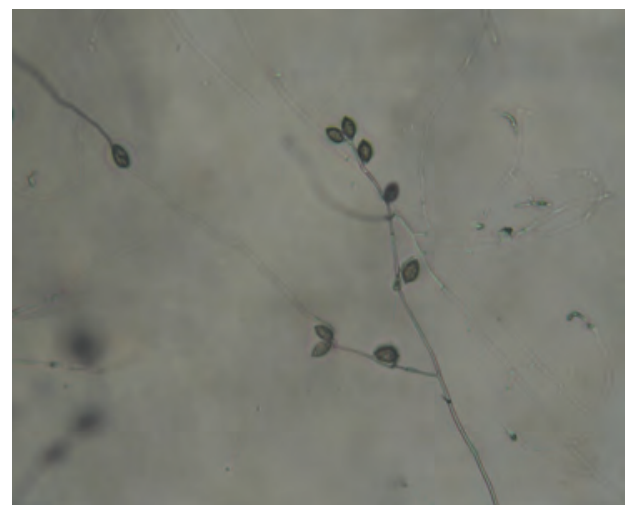

Phytophthora infestans, the micro-organism that causes potato blight seen through a microscope. (C) International Potato Center (CIP) and National Institute of Agricultural Innovation (Peru).

Notes: This organism is conserved ex situ in the Division for Integrated Crop Management of the International Potato Center for the Project Characterization of Populations of Phytophthora infestans and in three Agroecological Regions of Peru and Strengthening of INIA Capacities for Continuous Monitoring of the Principal Pathogens of the Potato.

The country's legislation related to the establishment of a moratorium on the entry of living modified organisms ${ }^{1}$ requires the development of a baseline of data on biodiversity (explicitly including soil fungi and bacteria present in crop fields) potentially affected by the introduction of living modified organisms. The Ministry of the Environment is implementing baseline studies within this framework. In the case of maize production systems, for example, specific objectives include surveying and sampling air and soil organisms associated with these systems in order to identify them and determine their distribution, establishing methodologies for characterization and monitoring, and developing georeferenced databases that can be used to generate thematic maps.

\footnotetext{
Source: Adapted from the country report of Peru.

1 Decreto Supremo № 008/12/MINAM - Reglamento de la Ley № 29.811, Ley que establece la moratoria al ingreso y producción de organismos vivos modificados (available, in Spanish, at http://www.fao.org/faolex/results/ details/en/c/LEX-FAOC117809/)
} 
of testing and to be showing good potential. Panama mentions a project on the characterization of soil micro-organisms in biointensive ${ }^{16}$ production systems. A number of examples from Peru are presented in Box 6.2.

Some countries mention work on the identification of micro-organisms that are well adapted to particular harsh conditions or that have the potential to play a role in adapting production systems to environmental change. For example, Costa Rica notes that there is a lack of information on how soil micro-organisms will be affected by climate change and mentions initiatives targeting the identification of micro-organisms that can help plants cope under conditions of water stress. India mentions projects focusing on bacterial genera that predominate in extreme environments and their use in agriculture and allied sectors and on the role of archaea in alleviating salinity stress and moisture stress in plants.

The country reports provide relatively little information on efforts to identify the characteristics of associated biodiversity species belonging to other taxonomic groups. In the case of invertebrates, reported examples include a study on the functions of carabid beetles in quinoa and potato agroecosystems in Peru's Altiplano. Ecuador reports that it has characterized coral ecosystems and other vulnerable marine ecosystem and is implementing concrete actions aimed at preventing, controlling and mitigating the impacts that human activities and climate change are having on them. Bulgaria mentions that it has established a National Centre of Excellence in Biodiversity and Ecosystem Research, which, among other activities, has developed a laboratory for work on the taxonomy and phylogeny of invertebrates. Numerous countries mention that botanic gardens and herbaria play an important role in taxonomic activities.

As noted above, reported examples of monitoring programmes for various components of associated biodiversity are discussed in Section 4.3.

${ }^{16}$ An organic production system focused on maximum yields using a minimal area of land, while increasing biodiversity and soil fertility.
Several countries refer to the significant role that citizen-science approaches can play in monitoring programmes and a number of initiatives of this kind are reported. For example, the United Kingdom mentions the involvement of nonspecialist members of the public in collecting data on butterflies, bees and plants. Bhutan refers to the web-based Bhutan Biodiversity Portal, ${ }^{17}$ which features citizen-contributed observation data on components of biodiversity. Ireland reports that the Irish National Biodiversity Data Centre runs an extensive annual programme of training and identification workshops for people involved in monitoring species from a range of taxonomic groups, including bumblebees and butterflies.

\subsection{Wild foods}

- There is a growing body of literature on the nutrient composition of wild foods and on their medicinal properties. Other data (molecular-genetic data, ecogeographical data, vernacular names, parts used, modes of preparation, specific uses, seasonal patterns in harvesting and use, and traditional knowledge related to various aspects of management) can all be important in planning the sustainable use and conservation of wild food species.

- Within-species differences are reported to have been identified and characterized in 27 percent of the wild food species reported by countries.

- Half the countries reporting ex situ wild food collections report the complete or partial characterization or evaluation of accessions from a combined total of 150 wild food species.

- Needs and priorities for the characterization of wild foods include strengthening capacity, increasing the availability of resources and improving mechanisms for sharing and documenting knowledge.

\subsubsection{Overview}

The characterization of wild foods involves the collection of various types of data. For example, molecular genetic data (Box 6.3) and data on

\footnotetext{
17 https://biodiversity.bt
} 
Box 6.3

Why undertake genetic data analysis of crop wild relatives and wild food plants?

The Voluntary Guidelines for the Conservation and Sustainable Use of Crop Wild Relatives and Wild Food Plants (FAO, 20170) (see Box 7.16) list the following benefits of molecular genetic diversity studies:

Identification and classification of populations. Molecular markers can help distinguish between closely related taxa and identify gene flow between taxa.

Provision of genetic baseline information. An understanding of the pattern of allelic richness and evenness across the geographic breadth of a species establishes a relative baseline against which change can be measured during later monitoring. By assessing genetic diversity regularly over time, genetic erosion can be detected early, and necessary population management measures can be implemented before significant genetic loss occurs.

Identification of populations for conservation. The amount and patterns of genetic diversity both within and between the populations of a species can help identify which crop wild relative and wild food plant populations should be targeted for in situ and ex situ conservation. Duplicate accessions, as well as novel genetic variability and gaps in collections, can also be identified.

\section{Assistance in the identification of traits of interest} for crop improvement. Genetic diversity analysis can also help detect particular populations for characterization and evaluation. Genetic diversity analysis is a common approach to establishing genebank core collections (van Hintum et al., 2000).

Understanding of evolutionary forces. Genetic diversity analysis can help to assess and understand how natural selection and neutral evolutionary forces are affecting populations targeted for conservation.

The Voluntary Guidelines were developed by FAO and endorsed by the Commission on Genetic Resources for Food and Agriculture. They are intended as reference material for use by national governments when preparing National Plans for the Conservation and Sustainable Use of Crop Wild Relatives and Wild Food Plants. The focus is on in situ conservation and fostering linkages between in situ and ex situ conservation, and ultimately the use of crop wild relatives and wild food plants.

Source: FAO, 2017 . ecogeography (i.e. the effect of environment and ecology on the distribution of species), vernacular names, parts used, modes of preparation, specific uses, seasonal patterns in harvesting and use, and traditional knowledge related to these and other aspects of management can all be important in planning the sustainable use and conservation of wild food species. Further information on the characterization of species targeted by capture fisheries is presented in Section 6.2.4.

There is a growing body of literature on the nutrient composition of wild foods and on their medicinal properties. The FAO/INFOODS Food Composition Database for Biodiversity ${ }^{18}$ compiles composition values for foods at within-species level (i.e. variety/cultivar/breed level) and for wild

\footnotetext{
18 http://www.fao.org/infoods/infoods/en
}

and underutilized foods. ${ }^{19}$ The latest version (4.0) contains data on 10156 foods, of which 3118 (31 percent) are identified as wild plant and animal foods (belonging to a total of 1289 species) (Figure 6.3). Wild foods from 63 countries are included in the database, with the highest number of species entries based on studies in the United States of America (27 studies, total of 66 species) followed by Canada (12 studies, total of 33 species), Turkey (23 studies, total of 27 species), Nigeria (20 studies, total of 22 species), Mexico (7 studies, total of 17 species), Brazil (12 studies, total of 16 species), India (9 studies,

\footnotetext{
19 It should be noted that most data are the results of targeted searches on particular foods (potatoes, cassava, quinoa, pulses, fish, beef, pork, insects and milk of underutilized species) while other foods were included randomly. This explains the uneven distribution of foods included.
} 


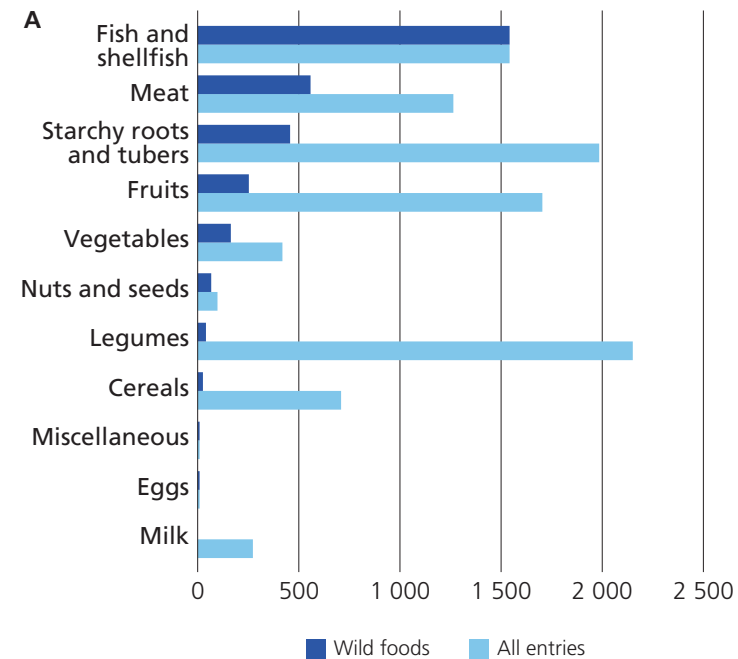

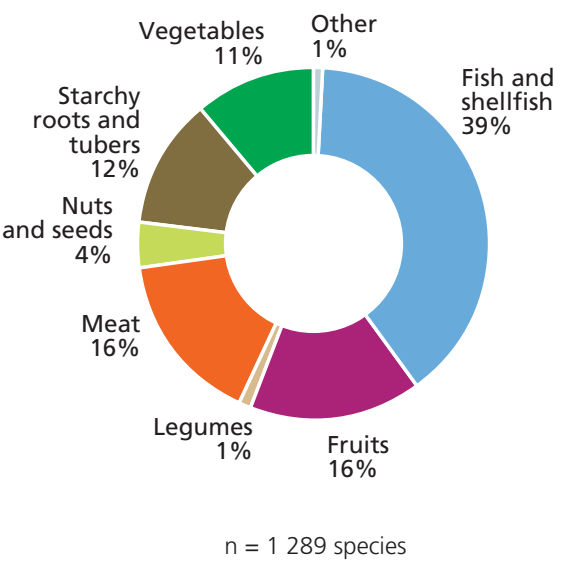

Notes: In part A of the figure, "All entries" (light blue bars) include wild foods, underutilized foods, and foods for which data are available at the variety, cultivar or breed levels. In part B, "Other" includes milk, eggs and miscellaneous wild foods. Source: Authors' calculation based on BioFoodComp 4.0, FAO/INFOODS.

total of 16 species), Italy (9 studies, total of 15 species), Australia (5 studies, total of 11 species), China (6 studies, total of 10 species) and Greece (10 studies, total of 10 species).

The wild food species with the largest number of records in the database ${ }^{20}$ are the following: (within the fish and shellfish group) Nile tilapia (Oreochromis niloticus), Atlantic horse mackerel (Trachurus trachurus), Arctic grayling (Thymallus arcticus), European perch (Perca fluviatilis), lake whitefish (Coregonus clupeaformis), burbot (Lota lota), northern pike (Esox lucius), mola carplet (Amblypharyngodon mola), Atlantic bonito (Sarda sarda); (within the meat group) reindeer (Rangifer tarandus), ringed seal (Phoca hispida), Eurasian elk (Alces alces), walrus (Odobenus rosmarus),

20 Each record includes data from a specific nutritional analysis targeting the respective species, for example from a study in a specific country, of food from a specific breed or variety, of food from a specific body part or of food subject to a specific cooking process (e.g. raw vs cooked). narwhal (Monodon monoceros), American beaver (Castor canadensis); (within the starchy roots and tubers group) various species of potatoes, including Solanum infundibuliforme, Commerson's nightshade (S. commersonii), S. jamesii, heartleaf nightshade (S. cardiophyllum), S. microdontum, S. spegazzinii, S. megistacrolobum, S. brachistotrichum and Chaco potato (S. chacoense).

In total, food-composition data for wild foods are taken from 245 studies, ${ }^{21} 70$ of which characterize foods from two or more countries. In most cases, data are available for macronutrients and minerals. For fish, fatty acids and amino acids are also included. Vitamin and phytochemical compositions, which are particularly relevant to the promotion of wild and biodiverse foods, are rarely investigated. While the FAO/ INFOODS database contains only a very small

\footnotetext{
21 The list of studies can be found in the downloadable BioFoodComp 4.0, available on the dedicated webpage.
} 
FIGURE 6.4

Status of identification and characterization of differences within wild food species reported by countries, by type

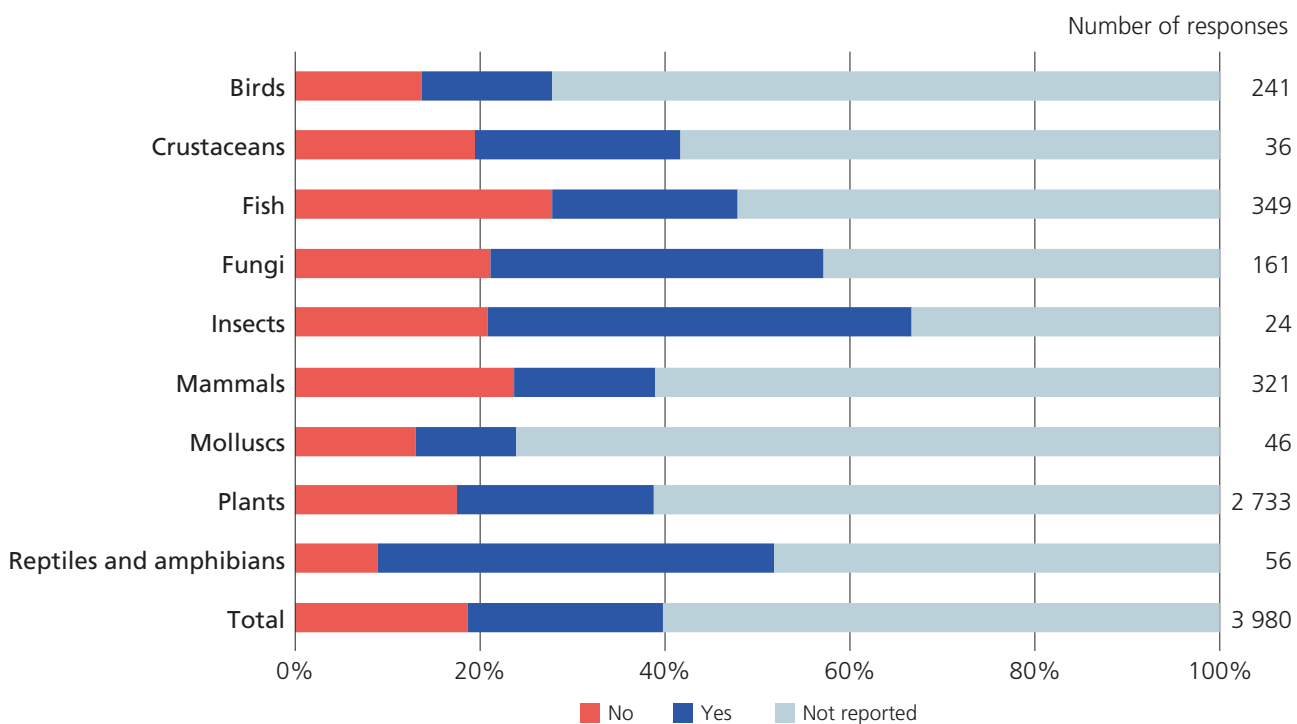

Notes: A "response" is the report of a given wild food species by a given country. Yes = Identification and characterization of withinspecies differences have been conducted; No = not conducted; Not reported = characterization status is not indicated in the country report. A single species may be reported by more than one country. Analysis based on 91 country reports.

Source: Country reports prepared for The State of the World's Biodiversity for Food and Agriculture.

fraction of all studies on the characterization of wild food species, it is nonetheless the most comprehensive of its kind.

\subsubsection{Country-report analysis}

\section{Characterization of differences within wild food species}

Among the 2822 wild food species reported by countries (see Section 4.4), within-species differences are reported to have been identified and characterized for a total of 772 species from 23 countries (Figure 6.4). Fifty-one species are reported by more than one country as having been characterized at this level, with the most frequently mentioned being brown trout (Salmo trutta) (seven countries) and jujube (Ziziphus mauritiana) (four countries). The following species were each mentioned by three countries: African oil palm (Elaeis guineensis); governor's plum (Flacourtia indica); Mysore gamboges (Garcinia xanthochymus); horseradish tree (Moringa oleifera); white mulberry (Morus alba); common purslane (Portulaca oleracea); Atlantic salmon (Salmo salar); pike-perch (Sander lucioperca); Java plum (Syzygium cumini); tamarind (Tamarindus indica); and grayling (Thymallus thymallus).

The state of characterization of wild foods varies by type of food and by country, with insects, reptiles and amphibians having a higher proportion of species characterized than other categories. Overall, the highest number of species reported to be characterized are plants.

Reported objectives for the characterization of wild foods are diverse. For example, Argentina 


\section{PART C}

Box 6.4

Study and development of foods and natural products with potential health benefits in Paraguay

The Faculty of Chemical Sciences of the National University of Asuncíon has been working since 1981 on the chemical, nutritional and pharmacological properties of plant resources and their extracts, with the objective of developing foods and other products with potential health benefits. Topics of research projects aimed at increasing nutritional knowledge of indigenous, native and wild food resources as a basis for enhancing their conservation and sustainable use have included:

- characterization of native fruits (genus Campomanesia) in Paraguay;

- nutritional value of pods of the South American mesquite (Prosopis alba) and the Chilean mesquite ( $P$. chilensis) harvested in indigenous communities of the Boquerón, Chaco Department;

- chemical composition and nutritional value of pigeon pea (Cajanus cajan);

- nutritional value and aflatoxin content of Aloysia polystachya (a kind of beebrush) extracts;

- nutritional composition of fresh common purslane (Portulaca oleracea) growing in the city of Villa Hayes;
- macronutrient composition of the spotted sorubim (Pseudoplatystoma coruscans), barred sorubim ( $P$. fasciatum) and streaked prochilod (Prochilodus scrofa) of the Paraguay River;

- physicochemical characterization, vitamin C content and antioxidant capacity of native wild raspberry, Rubus hassleri var. paraguariensis;

- nutritional value of fruits of tarumá (Vitex megapotamica);

- physical characteristics, centesimal composition and minerals in fruits of the macadamia (Macadamia integrifolia) harvested in the Department of Cordillera; and

- total antioxidant potential of two native fruits: guavijú (Myrcianthes pungens) and pakurí (Rheedia brasiliensis).

Source: Adapted from the country report of Paraguay. reports ongoing work on the taxonomic, phytochemical and morphological characterization of native plants used for medicinal, aromatic and nutritional purposes, including valeriana (Valeriana sp.), peperina (Minthostachys mollis), incayuyo (Lippia integrifolia), marcela (Achyrocline satureioides) and cedrón (Aloysia triphylla), with the objective of improving food production and social conditions in the regions where these species grow. Paraguay reports that research programmes on the chemical, nutritional and pharmacological properties of plant resources and their extracts are aiming to develop products with potential health benefits (Box 6.4). El Salvador mentions plans to work on the identification, georeferencing, characterization and inventory of plant genetic resources and their underutilized wild relatives, with the objective of exploring genetic and production potential on a commercial scale.

\section{Characterization of ex situ collections of wild foods}

With regard to the characterization of ex situ collections of wild foods (see Section 7.4.2), 16 countries (out of 32 countries reporting ex situ wild food collections) report characterization or evaluation to have been completed or partially completed for at least one species or genus - amounting to a total of 150 species, of which 9 percent are fungi, 27 percent animals (most frequently fish and molluscs) and 64 percent plants. Together, Asia and Europe represent over 65 percent of the reports of partial and complete characterization or evaluation of wild food species conserved ex situ. Countries refer to a range of different types of characterization activities for wild food species conserved ex situ, including phenotypic, phylogenetic, genetic and chemical characterization. Few provide information on the specific 
traits characterized. Those that are mentioned include traits related to food and nutrition (starch content for example), responses to different water regimes and resistance to pests and diseases. A number of countries note that $e x$ situ collections of some species have been developed with the aim of establishing national reference collections for comparison with unknown samples and for documenting species distribution and within-species variation. For example, Norway reports that some species of wild fruits and medicinal and aromatic herbs conserved ex situ have been investigated quite thoroughly in the institutions that keep them. It notes, however, that there is no common database that assembles information on the characterization and evaluation status of these collections.

\subsection{Needs and priorities}

Countries generally recognize the need to strengthen the characterization of associated biodiversity and wild foods, noting in some cases that a lack of characterization data constrains the implementation of activities in the fields of conservation and sustainable use. Several specifically mention the need to collect data that can serve as a baseline for the assessment of the status and trends of associated-biodiversity species. Some identify the need to establish biodiversity information systems. A few specific priorities in terms of taxonomic or functional groups are mentioned. For example, India refers to the need for studies on the taxonomy of pollinators and detritivores.

The factor most commonly reported in the country reports as a constraint to the characterization of associated biodiversity is a lack of resources. Numerous countries mention a shortage of taxonomists, with many specifying the need to allocate funds for training in this field, in particular on molecular techniques. Some countries mention that there is a diminishing interest in taxonomy on the part of young scientists. Switzerland notes that knowledge on systematics is being lost as a result of the dissolution of relevant professorial chairs. Kenya reports that knowledge is being lost because of the transfer of experienced taxonomists from collection facilities such as museums to universities without replacement. Countries mention the need to invest in characterization facilities and equipment, again particularly for molecular characterization. A few mention that a lack of policies or national programmes addressing characterization is a constraint. Where wild foods are concerned, lack of capacity and resources, and the absence of mechanisms for sharing and documenting knowledge, are highlighted. 



\section{Chapter 7}

\section{The state of conservation of biodiversity for food and agriculture}

\begin{tabular}{|c|c|}
\hline \multicolumn{2}{|l|}{ Key messages } \\
\hline $\begin{array}{l}\text { - Crop, livestock, forest and aquatic genetic resources } \\
\text { for food and agriculture are conserved in situ through } \\
\text { a variety of approaches, including the promotion of } \\
\text { management strategies that involve the sustainable } \\
\text { use of these resources and the establishment of } \\
\text { protected areas. Although efforts are reported to be } \\
\text { increasing, coverage is often incomplete. } \\
\text { - Ex situ conservation efforts for genetic resources for } \\
\text { food and agriculture are increasing, in particular for } \\
\text { plant genetic resources, although many gaps remain. } \\
\text { Technical challenges persist with respect to the } \\
\text { ex situ conservation of some species. Conservation } \\
\text { programmes need to become more comprehensive } \\
\text { and research into conservation strategies and } \\
\text { techniques needs to be strengthened. } \\
\text { - Relatively few associated biodiversity species } \\
\text { (species such as pollinators, soil organisms }\end{array}$ & $\begin{array}{l}\text { and pest natural enemies found in and around } \\
\text { production systems) are specifically targeted by } \\
\text { in situ conservation programmes. Most conservation } \\
\text { occurs via the promotion of biodiversity-friendly } \\
\text { production practices, the establishment of } \\
\text { protected areas, and policy and legal measures } \\
\text { aimed at restricting activities that damage } \\
\text { biodiversity. Although limited, public-sector and } \\
\text { private-sector ex situ conservation initiatives } \\
\text { exist for some species of associated biodiversity, } \\
\text { with many countries having culture collections } \\
\text { of micro-organisms used in agriculture or in } \\
\text { agrifood industries. } \\
\text { - Where wild foods are concerned, } 8 \text { and } 13 \text { percent } \\
\text { of the number of wild species reported by countries } \\
\text { to be used for food are reported to be conserved } \\
\text { in situ and ex situ, respectively. }\end{array}$ \\
\hline
\end{tabular}

\subsection{Introduction}

Conservation of biodiversity for food and agriculture (BFA) comprises a diverse range of actions taken with the aim of preventing the loss of diversity at genetic, species and/or ecosystem level. These actions can operate on a variety of scales, including the individual plot, field, forest stand, aquaculture pond or gene bank, the farm or holding, the ecosystem, landscape or larger geographical area, the species migration route, the country, the region or the whole world. They can involve, inter alia, hands-on management activities in and around production systems, education and awareness-raising efforts, research, monitoring of species or ecosystems or threats affecting them, provision of incentives for biodiversity-friendly management activities, or the development and implementation of policy and legal measures that address threats to biodiversity or promote its sustainable use. Actions can be specifically targeted (e.g. aiming to protect a particular species) or more diffuse (e.g. aiming to protect all the biodiversity in and around a given production system or in a given geographical area). They may or may not involve use of the targeted components of biodiversity (e.g. farming or harvesting them, or deploying them to promote the supply of supporting or regulating ecosystem services). 
Practical conservation measures are typically categorized as in situ or ex situ (see Section 1.5), although there are some differences in how these terms are used in the different sectors of food and agriculture (see below for further details). The two approaches are generally regarded as complementary to each other.

This chapter discusses the state of conservation measures for the various categories of BFA considered in this report. It begins with a short overview of efforts to conserve plant (crop), animal (livestock), forest and aquatic genetic resources, drawing on the respective sectoral global assessments prepared by FAO (FAO, forthcoming, 2010a, 2014a, 2015a). This is followed by sections on the conservation of associated biodiversity ${ }^{1}$ and wild foods, drawing mainly on the information provided in the country reports. ${ }^{2}$ Two cross-cutting issues are then discussed in greater detail: first the role of protected areas in the conservation of BFA and then the state of efforts to maintain traditional knowledge related to BFA. The chapter ends with a short discussion of needs and priorities in the field of conservation, focusing on associated biodiversity and wild foods.

Various aspects of BFA management that may contribute to conservation efforts are discussed in other chapters. Monitoring and characterization of BFA are discussed in Chapters 4 and 6. Potentially "biodiversity-friendly" management practices and approaches in food and agriculture are discussed in Chapter 5. BFA-related education and training, research, cooperation, incentive measures, and policy and legal frameworks are discussed in Chapter 8.

\footnotetext{
The biodiversity present in and around production systems that supports food and agriculture through pollination, pest and disease regulation, improving soil fertility and the supply of many other ecosystem services - see Section 1.5 for a discussion of this term.

2 Given the above-noted wide range of activities potentially contributing to conservation - and the various ways in which the boundaries between conservation and other aspects of management can be drawn - there has inevitably been some variation in how the concept of conservation has been interpreted in the country reports prepared for The State of the World's Biodiversity for Food and Agriculture and across the various sectoral global assessments of genetic resources.
}

\subsection{Plant, animal, forest and aquatic genetic resources for food and agriculture}

- Plant, animal, forest and aquatic genetic resources are conserved through various in situ, ex situ and circa situm approaches that seek to provide complementary and effective coverage of the target genepools and combine conservation of existing genetic diversity with continuing evolution and adaptation.

- Ex situ collections are relatively well developed for plant (crop) genetic resources. However, in only a very few species (major staple crops) is it likely that a substantial percentage of the total genetic diversity present in the species is conserved ex situ. Much of the diversity present in minor crops, and in livestock, forest and aquatic species, is also not yet secured ex situ.

- Ex situ programmes are constrained by various technical issues, including those related to the cryoconservation of some animal reproductive materials (particularly in the case of aquatic animals) and those related to regeneration of stored seeds. Biotechnological methods that do not involve the storage of reproductive material may in future improve coverage of ex situ conservation across sectors.

- In situ conservation measures for plant, animal, forest and aquatic genetic resources are generally insufficient to provide these components of biodiversity with adequate protection. Various steps can be taken, depending on the circumstances, to make conservation efforts more comprehensive and effective, including improving support for the production and marketing of potentially threatened domesticated breeds and varieties, and improving the targeting and management of protected areas to better account for crop and livestock wild relatives and for genetic diversity within tree and aquatic species.

\subsubsection{Plant genetic resources for food and agriculture}

Ex situ conservation is the most significant and widespread means of conserving plant genetic resources for food and agriculture (PGRFA). Most conserved plant accessions are kept in specialized facilities known as genebanks, maintained by public or private institutions acting alone or 
Box 7.1

The World Information and Early Warning System on Plant Genetic Resources for Food and Agriculture

The World Information and Early Warning System on Plant Genetic Resources for Food and Agriculture (WIEWS) is the global information system on plant genetic resources for food and agriculture (PGRFA) used by FAO for the preparation of periodic, country-driven global assessments of the status of conservation and use of PGRFA. WIEWS is used to monitor the implementation of:

- the plant component of Indicator 2.5.1 of Sustainable Development Goal 2, Zero Hunger; and

- the Second Global Plan of Action for PGRFA.

WIEWS data are conveyed via a global network of national focal points appointed by governments.

WIEWS contains information on:

- the implementation by countries of the 18 priority activities of the Second Global Plan of Action, based on 63 indicators adopted by the Commission on Genetic Resources for Food and Agriculture, addressing in situ conservation of crop wild relatives and wild food plants, on-farm management of farmers' varieties/landraces, ex situ conservation, management and sustainable use of PGRFA, and human and institutional capacity building;

- more than 4.9 million accessions from over 6900 genera conserved under medium- or long-term conditions in over 575 genebanks in 90 countries and 16 international/regional centres; and

- more than 17000 national, regional and international institutes and organizations dealing with the conservation and sustainable use of PGRFA, each assigned a unique identifier as an ex situ germplasmholding organization.

Note: For more information see: http://www.fao.org/wiews/en networked with other institutions. Orthodox seeds are kept in specially designed cold stores. Vegetatively propagated crops and those with recalcitrant seeds are maintained as living plants in field genebanks. In some cases, tissue samples are stored through in vitro culture or cryogenically. Pollen or embryos are also sometimes conserved, and there is increasing interest in the conservation implications of storing DNA samples or digital DNA sequence information.

Germplasm of crops and crop wild relatives is conserved in more than 575 genebanks worldwide, with a total of about 4.9 million accessions maintained under medium- and long-term conditions globally (see Box 7.1). The 11 genebanks of the CGIAR and the World Vegetable Centre maintain over 800000 accessions from over 600 different genera. It is estimated that almost 2 million accessions have been added to ex situ genebanks with medium- and long-term collections since 1995, although gaps still remain (FAO, 2018s). There are also substantial ex situ collections in botanic gardens, of which there are over 3400 around the world (BGCl, 2018). The Svalbard Global Seed Vault, ${ }^{3}$ which opened in 2008 , provides a secure global backup of crop diversity held in genebanks around the world. Concerted efforts have been made to deposit duplicate samples of accessions from the CGIAR global collections and many national and regional collections.

For several staple crops, for example wheat and rice, a large proportion of the genetic diversity within the species is represented in ex situ collections. ${ }^{4}$ However, for many other crops, considerable gaps remain. Many countries still lack adequate human capacity, facilities, funds or management systems to meet their ex situ conservation needs, putting a number of collections at risk. The documentation and characterization

\footnotetext{
https://www.croptrust.org/our-work/svalbard-global-seed-vault

4 Except where indicated otherwise, the material presented in this subsection is based on The Second Report on the State of the World's Plant Genetic Resources for Food and Agriculture (FAO, 2010a)
} 
of many collections is still inadequate, and where information does exist it is often difficult to access. The overall poor documentation of ex situ collections also constrains efforts to reduce duplication of conservation measures and hence reduces efficiency at global and regional levels. Greater efforts are needed to build a truly rational global system of ex situ collections. This requires, in particular, stronger regional and international trust and cooperation.

Interest in collecting crop wild relatives, wild food plants and neglected and underutilized species is growing, and coverage in genebanks has increased in recent years. However, there are concerns about possible losses in ex situ collections as a result of a lack of funds for regeneration (FAO, $2016 \mathrm{~m}$ ). Given that the reproductive behaviours and seed physiology of crop wild relatives and wild food species are generally not well known and that their regeneration is therefore more difficult and demanding, it can be expected that these species will increasingly be affected by such budgetary constraints.

In situ conservation of PGRFA is often taken to include both on-farm conservation of domesticated crop species and conservation of crop wild relatives in natural or semi-natural ecosystems. However, the term is sometimes used in a narrower sense to refer only to the latter (i.e. a distinction is sometimes drawn between in situ and on-farm conservation). In situ conservation of crop wild relatives generally occurs as a side-effect of efforts to protect habitats or charismatic species, rather than as a result of deliberate targeting. The main mechanism involved is the designation of protected areas of various types (see Section 7.5 for further discussion of the roles of protected areas). The lack of specific measures targeting crop wild relatives increases the risk that important resources will fall through gaps in conservation coverage.

Areas rich in crop wild relative diversity (e.g. areas of origin) are less well covered by protected areas than overall global figures would suggest. Wild relatives are also often less comprehensively surveyed than other components of biodiversity, although surveys targeting these resources are becoming more common. A substantial amount of crop wild relative diversity is located outside protected areas, including on farms. Protecting them may require, for example, specific management agreements between conservation agencies and those who own, or have rights over, the respective sites. Such agreements are becoming more common, especially in North America and Europe. See Box 7.16 for information on the Voluntary Guidelines for the Conservation and Sustainable Use of Crop Wild Relatives and Wild Food Plants endorsed by the Commission on Genetic Resources for Food and Agriculture in 2017.

In reporting on activities undertaken to implement the Second Global Plan of Action for Plant Genetic Resources for Food and Agriculture between 2012 and 2014, countries indicated that increased attention was being given to the in situ conservation and use of crop wild relatives. Overall, 9 percent of the over 30000 in situ conservation sites that were reported in 39 countries had management plans addressing crop wild relatives and wild food plants (FAO, 2018t). A total of 104 activities on in situ conservation and management of crop wild relatives and wild food plants implemented, with institutional support, in 32 countries were reported (ibid.).

On-farm conservation efforts, particularly efforts to maintain traditional crop varieties, have gained considerable ground in recent years. Many programmes have been established and new tools have been developed that allow better assessment of this diversity and the mechanisms through which it is maintained. Increasing attention has been paid, for example, to the significance of particular types of management system (e.g. home gardens), "informal" seed systems, the interface between wild and agricultural plants and ecosystems, traditional knowledge and the roles of particular groups of farmers as custodians of diversity.

A number of different measures can be taken, depending on the circumstances, to support the maintenance of PGRFA on-farm. These include adding value to local genetic resources via improved characterization, improving them 
through breeding and seed processing, increasing consumer demand through market incentives and awareness-raising efforts, improving access to PGRFA and information about them, and establishing supportive policies, legislation and incentives. Recent years have, to varying degrees, seen positive developments in all these fields.

Despite the broadly upward trend in the level of implementation of in situ conservation and on-farm management activities for PGRFA, much remains to be done. There continues to be a need for more-effective policies, legislation and regulations governing the in situ conservation and on-farm management of PGRFA, both inside and outside protected areas. Closer collaboration and coordination are needed between the agriculture and environment sectors. Many aspects of in situ conservation and on-farm management require further research. There is also a need for more detailed surveys of crop wild relatives and wild food plants, and for research on their morphological and molecular characterization and evaluation, to allow better targeting of conservation actions.

\subsubsection{Animal genetic resources for food and agriculture}

As noted above for BFA in general, in situ and ex situ approaches to the conservation of animal genetic resources for food and agriculture (AnGR) are generally regarded as complementary to each other. In situ conservation of AnGR has been defined as follows: "support for continued use by livestock keepers in the production system in which the livestock evolved or are now normally found and bred" (FAO, 2015a). However, a broader definition would include actions targeting feral populations or the wild relatives of domesticated animals. In situ conservation strategies can involve a wide range of actions, including those that aim to increase demand for products and services from at-risk breeds (e.g. market development or promotion of breeds' roles in tourism or in habitat or landscape management), those that focus on supporting or incentivizing livestock keepers (e.g. incentive or subsidy payments, recognition or award programmes, extension programmes or awareness raising), activities focused on breeding programmes, and activities focused on participation and empowerment at community level (FAO, 2010a, 2013g). The benefits of in situ conservation are considered to include the opportunities it provides for: livestock populations to continue to evolve in response to changes in the production environment; the maintenance of knowledge and skills related to the management of these populations; and the ongoing supply of any ecosystem services the populations may provide (FAO, 2015a).

Where ex situ conservation is concerned, a distinction is drawn between ex situ in vivo and ex situ in vitro conservation (FAO, 2015a). Ex situ in vivo conservation is achieved "through the maintenance of live animal populations not kept under normal management conditions (e.g. in a zoological park or a governmental farm) and/or outside the area where they evolved or are now normally found and bred." Ex situ in vitro conservation (also referred to as cryoconservation) is achieved "through the maintenance, under cryogenic conditions, of cells or tissues that have the potential to be used to reconstitute live animals and populations at a later date." The material most commonly cryoconserved is semen, followed by embryos. Oocytes, somatic cells and isolated DNA are also sometimes stored. Ex situ in vitro conservation provides a source of genetic material that can be drawn upon as a backup if a disaster (e.g. a disease epidemic) strikes the live population or used in other ways to support the genetic management of the live population (FAO, 2012e). Where live animals are maintained, distinctions between in situ and ex situ conservation are not always clear cut. In vivo conservation can be regarded as a spectrum ranging from the maintenance of animals in very "artificial" environments such as zoos, through maintenance in experimental farms and farm parks, to actions taken to support the maintenance of at-risk breeds by livestock keepers in normal production systems (FAO, 2007a).

Most countries that participated in the reporting process for The Second Report on the State of the World's Animal Genetic Resources for Food 
Box 7.2

The Domestic Animal Diversity Information System

The Domestic Animal Diversity Information System (DAD-IS), ${ }^{1}$ maintained and developed by FAO, contains data from 182 countries on a total of more than 8000 livestock breeds belonging to 38 species. Data are entered into the system by national coordinators for the management of animal genetic resources, who are nominated by their respective governments.

Data from DAD-IS have long been used in the publication of periodic reports on the status and trends of animal genetic resources. They are now also used to monitor the animal-related components of Sustainable Development Goal Indicators 2.5.1 (Number of plant and animal genetic resources for food and agriculture secured in medium- or long-term conservation facilities) and 2.5.2 (Proportion of local breeds, classified as being at risk, notat-risk or at unknown level of risk of extinction).

DAD-IS can also be used to access detailed data on the status and characteristics of individual breeds, including on population size and structure, uses, origin and development, notable adaptive features, morphology, performance, management conditions and conservation programmes. It contains a large number of photographs of individual breeds. Users can access standard selfgenerated reports or export data for further analysis.

http://www.fao.org/dad-is/en

and Agriculture (FAO, 2015a) indicated that they had at least some AnGR conservation activities in place. In vitro genebanks had been established by 64 out of 128 reporting countries, and a further 41 countries were planning to do so. Many of these genebanks were in the early stages of development and the collections often had many gaps in their coverage of relevant breeds and populations. Based on data from the Domestic Animal Diversity Information System (DAD-IS) (see Box 7.2), Sustainable Development Goal Indicator 2.5.1 (Number of plant and animal genetic resources for food and agriculture secured in medium- or long-term conservation facilities) shows that fewer than 1 percent of breeds are reported to have sufficient genetic material stored in genebanks ( 3 percent are reported to have insufficient material and the status of the others is unknown). The coverage of in situ conservation activities was also incomplete (i.e. many countries considered that their conservation measures were insufficient to adequately protect their breeds from the risk of extinction). However, a diverse range of different activities were reported. For example, countries were increasingly developing niche markets for speciality products as a means of increasing the profitability of potentially threatened breeds.

Inadequate funding, infrastructure and technical skills often remain significant obstacles to the establishment or further development of genebanks for AnGR. More generally, in order to strengthen both in situ and ex situ conservation efforts, there is a need to strengthen the human capacities and institutional structures that underpin conservation measures (and other aspects of AnGR management), for example in the fields of research, education and training, stakeholder participation (particularly livestock-keeper participation), policies and legal frameworks.

\subsubsection{Forest genetic resources}

In situ conservation is the preferred means of conserving forest genetic resources (FGR), as it is a dynamic approach that allows temporal and spatial changes in genetic diversity. The main goal is to maintain evolutionary processes (natural selection, genetic drift, gene flow and mutation) within tree populations, rather than to preserve their current genetic diversity (e.g. Eriksson, Namkoong and Roberds, 1993; FAO, FLD and IPGRI, 2004a; Lande and Barrowclough, 1987). Ex situ conservation, in contrast, is mostly static (i.e. maintains one-off samples of genetic diversity). In most cases, it is easier and cheaper to conserve tree populations in their natural habitats than under ex situ conditions. However, ex situ conservation of FGR (e.g. in seed banks, seed orchards, field collections, provenance trials, planted conservation stands or botanic gardens) is a necessary 
complement to in situ conservation, especially when population size is critically low in the wild.

In the forest sector, where conservation largely focuses on wild species, a third category - circa situm conservation - is distinguished from in situ and ex situ conservation. The term is used to describe a type of conservation that emphasizes the role of regenerating saplings in linking vegetation remnants in heavily modified or fragmented landscapes, such as those of traditional agroforestry and farming systems (FAO, 2014a). Conservation of FGR on farms often falls into this category. In other cases, it constitutes a type of ex situ conservation.

In situ conservation of FGR is typically carried out in protected areas or managed natural forests by designating conservation stands (FAO, DFSC and IPGRI, 2001). Both protected areas and managed natural forests may have some limitations from the genetic conservation point of view. Most protected areas are established to conserve endangered animal and plant species or ecosystems, and rarely to conserve the genetic diversity of forest trees. Consequently, conservation of FGR is often given a low priority or not recognized at all in the management of protected areas. Furthermore, silvicultural treatments that may be necessary to maintain or enhance genetic processes within tree populations are often not permitted in protected areas. In the case of managed forests, past or current utilization and management practices may have altered the genetic composition of tree populations, and some forest stands may have been established with tree germplasm brought in from other locations. Thus, the conservation value and suitability of a given tree population located in a protected area or a managed forest should be carefully evaluated based on historical records, if available, or other relevant information, before stands are designated for FGR conservation. Ideally, a network of such conservation stands should cover the whole distribution range of a tree species.

In forest trees that have orthodox seeds, ex situ conservation can be implemented by drying and storing seeds at low temperatures. The seeds can be maintained for years without losing their viability.
However, many tree species produce seeds that cannot be stored using this method. This is a major constraint to ex situ conservation, especially in the humid tropics, where more than 70 percent of tree species have recalcitrant or intermediate seed behaviour (Sacandé et al., 2004). Ex situ conservation of such species is based on field collections, conservation stands and breeding populations and on more sophisticated approaches, such as cryopreservation, seedling conservation, in vitro conservation, pollen storage and DNA storage (FAO, FLD and IPGRI, 2004b).

Countries that contributed to The State of the World's Forest Genetic Resources (SoW-FGR) (FAO, 2014a) reported a wide variety of in situ conservation activities, covering a total of nearly 1000 species of trees, scrubs, palms and bamboo (including subspecies). However, interpretation of the concept of in situ conservation varies from country to country (e.g. whether or not the mere presence of a given tree species in a protected area can be regarded as sufficient grounds for stating that it is subject to FGR conservation). For the SoW-FGR process, countries were not asked to report on the completeness of in situ conservation (i.e. whether conservation efforts cover the whole distribution range of a given species). These factors, along with the general incompleteness of reporting, make the global situation difficult to assess. However, out of nearly 8000 species reportedly used by countries for various purposes, only about 12 percent were reported to be subject to any form of in situ conservation. Although many countries reported that protected areas represent their main in situ conservation activity for FGR, most of these areas had not been designated with the aim of conserving FGR and did not have management plans specifically addressing this objective.

Most in situ conservation of FGR takes place outside protected areas on a range of public, private and traditionally owned lands, especially in multiple-use forests and forests primarily designated for wood production (FAO, 2014a). Unfortunately, in situ conservation of FGR within the world's many protected areas and managed forests remains poorly documented, and countries 
have developed their national strategies for FGR conservation based on a variety of different approaches to, and interpretations of, in situ conservation. Work in Europe offers a rare example of the development of a regional strategy for FGR conservation based on a systematic assessment of existing conservation efforts (Lefèvre et al., 2013; de Vries et al., 2015) and a harmonized concept of conservation units (Koskela et al., 2013).

Countries that contributed to the SoW-FGR reported a total of 1800 species to be conserved ex situ, many conserved only in botanic gardens. Of the 2260 priority species listed in the country reports, ${ }^{5} 626$ were reported to be subject to some form of ex situ conservation. Only 135 were being conserved in more than one country. Globally, the total number of FGR accessions reported was 159579 , including an unknown number of multiple accessions. Most accessions are in field collections, including clone banks and provenance trials; far fewer are in seed or in vitro collections.

In conclusion, there is a need to enhance all types of FGR conservation. Priorities for action are set out in the Global Plan of Action for the Conservation, Sustainable Use and Development of Forest Genetic Resources, adopted in 2013 (FAO, 2014b).

\subsubsection{Aquatic genetic resources for food and agriculture}

In situ conservation measures in the aquatic sector comprise actions taken to protect aquatic genetic resources (AqGR) both in the wild and in aquaculture. The main in situ measures for wild aquatic biodiversity are the establishment of protected areas and the use of fisherymanagement methods that promote sustainable fishing and conservation. As noted in Section 4.2.4, in contrast to the crop and livestock sectors, where producers have been maintaining a range of breeds and for millennia, domestication of most farmed aquatic species only started in the last century. On-farm (i.e. in-aquaculture) conservation

This refers to the country reports submitted for The State of the World's Forest Genetic Resources (FAO, 2014a). measures for such species are therefore less common than the equivalent measures for terrestrial domesticated animals and plants. On-farm conservation in aquaculture is not easily distinguishable from ex situ conservation in an in vivo genebank. There are a few examples of managed genebanks that maintain live genetically improved farmed types under farming conditions that allow continued evolution. Such facilities exist, for example, for common carp in Hungary (Bakos and Gorda, 2001).

At global level, the Aichi Biodiversity Targets under the Convention on Biological Diversity's Strategic Plan for Biodiversity 2011-2020 call on governments and other stakeholders to establish protected areas in 17 percent of their terrestrial and inland waters and 10 percent of their marine areas by 2020 (see Section 7.5 for further discussion). Moreover, since 1996, criteria for identifying wetlands for inclusion in the Ramsar Convention's List of Wetlands of International Importance have included criteria related to fish biodiversity. The list's 2200 sites represent one of the world's largest networks of protected areas and make a major contribution to in situ conservation of AqGR. Many studies have indicated that increasing fish populations within a marine protected area leads to spillover and increased fisheries catches outside the protected area (Halpern, 2003). However, this is not invariably the case and depends on numerous site-specific conditions (Charles et al., 2016; Fletcher et al., 2015). Levels of protection in protected areas range from strict "no-take" areas to multiple use areas that are managed for a variety of purposes, including conservation and harvesting (see Section 7.5). The country reports submitted for The State of the World's Aquatic Genetic Resources for Food and Agriculture (SoW-AqGR) (FAO, forthcoming) generally bear out the view that protected areas can be an effective means of protecting aquatic biodiversity, with over 2100 out of 2300 protected areas mentioned in the reports considered to be very or somewhat effective, although these results are heavily influenced by a few countries reporting large numbers of effective aquatic protected areas. 
The country reports ${ }^{6}$ listed several objectives for in situ conservation of AqGR, including maintenance of genetic diversity, maintenance of good strains for aquaculture production, meeting consumer and market demands, facilitating adaptation to the impacts of climate change and providing material for future genetic improvement in aquaculture. Maintenance of genetic diversity was reported to be the most important objective in both developed and developing countries. Meeting market demands was reported to be the least important objective. The ecosystem approach to fisheries and aquaculture, an approach that aims to "plan, develop and manage fisheries in a manner that addresses the multiple needs and desires of societies, without jeopardizing the options for future generations to benefit from the full range of goods and services provided by marine ecosystem" (FAO, 2003d), is being adopted by fisheries managers around the world (FAO, 2016h) (for more information see Section 5.3.3). However, only a minority of reporting countries were able to indicate the existence of policies that clearly address the objective of conserving AqGR in fisheries and aquaculture. The country reports also provided little evidence of organized efforts specifically to promote the conservation of AqGR in modified ecosystems such as rice fields. To ensure the conservation of AqGR there is a need for better harmonization of fishery and environmental data and for the development and implementation of appropriate regulatory measures for the management of wild relatives of farmed species.

Ex situ measures for AqGR include the maintenance and captive breeding of live organisms in zoos, aquaria and live genebanks, the storage of cell lines and tissue cultures in vitro and the cryopreservation of male gametes, tissue cultures and cells. However, embryos and eggs of aquatic species are extremely difficult to freeze and keep viable. Therefore, it is only the male gamete that can be effectively cryopreserved. Research is

6 This refers to the country reports prepared for The State of the World's Aquatic Genetic Resources for Food and Agriculture (SoW-AqGR) (FAO, forthcoming). addressing this problem (Lee et al., 2013), but no practical solutions have yet been found.

Sixty-nine (75 percent) of the 92 countries that submitted reports for the SoW-AqGR indicated that ex situ conservation activities were being implemented at national level for aquatic organisms of national relevance falling within the scope of the report. Approximately 290 different species were being maintained in 690 ex situ collections in these countries. Almost 200 of these species were considered to be threatened or endangered at national and/or international levels. Thirty-four countries (49 percent) had such species among their collections. Finfish account for 90 percent of the species conserved, with the other 10 percent accounted for by macro-invertebrates and aquatic micro-organisms such as rotifers and micro-algae. The finfishes maintained include both those used for direct human consumption and those used as live feed for aquaculture. The micro-organisms are in most cases used as live feed for aquaculture. About 38 percent of reporting countries indicated that they had in vitro collections of AqGR (farmed species and wild relatives), covering a total of 133 different species.

Priorities for improving the conservation of AqGR include, on the in situ side, maintaining and improving aquatic habitats, improving fishery management, designating freshwater and marine protected areas (taking into account genetic, ecological and demographic parameters to promote the conservation of distinct target populations), improving water management, reducing pollution, reducing the negative impacts of capture fisheries, and using an ecosystem approach in the management of riparian and open-water habitats. Ex situ conservation efforts could be stepped up through the establishment of new conservation facilities and captive-breeding programmes, as well as through research into conservation strategies and techniques, including maintenance of live populations, cryopreservation of gametes and embryos, and tissue banking.

Effective integration of in situ and ex situ conservation is important, particularly given the strong links between farmed stocks and their 
wild relatives. Hatcheries have been developed to raise aquatic species ex situ for eventual release back into the wild or into modified habitats such as rice fields and reservoirs. These are sometimes called "conservation hatcheries" and they attempt to reduce the artificial selection pressures of the hatchery environment by maintaining relatively "natural" conditions (e.g. providing natural substrates and feed). This approach is common in restoration efforts in North America and Europe (Schramm, 1995). Conservation hatcheries are usually devoted to rare, threatened or endangered species or stocks.

\subsection{Associated biodiversity}

- In situ conservation of associated biodiversity (species such as pollinators, soil organisms and pest natural enemies found in and around production systems) is achieved through a number of approaches, including the establishment of protected areas, use of biodiversityfriendly management practices, provision of protection against invasive species and pollution, ecosystem restoration, establishment of wildlife corridors and strengthening relevant policies and institutions.

- Community participation and the development and implementation of biodiversity-friendly management practices provide important mechanisms for in situ conservation of associated biodiversity.

- Culture collections maintaining a wide range of fungi, bacteria and other micro-organisms of relevance to food and agriculture are becoming increasingly widespread. Information exchange combined with the use of new biotechnological methods is strengthening the effectiveness of these collections as contributors to ex situ conservation.

- Botanic gardens provide a very substantial global repository of plant species with potential to be used for restoration and other purposes.

\subsubsection{In situ conservation}

Associated biodiversity (i.e. the biodiversity present in and around production systems that supports food and agriculture through pollination, pest and disease regulation, improving soil fertility and the supply of many other ecosystem services - see Section 1.5 for a discussion of this term) can benefit both from in situ conservation measures that target individual species and those that target the protection of whole ecosystems. In both cases, the conservation measures may or may not be motivated specifically by the objective of maintaining or promoting the supply of ecosystem services to food and agriculture. In situ conservation programmes relevant to associated biodiversity can involve a range of different approaches, including the establishment of protected areas, provision of legal protection for threatened species, and various policy and legal measures aimed at restricting activities that damage biodiversity or promoting those that are biodiversity friendly. On a more local scale, efforts can be made to maintain and enhance habitats for particular species or groups of species that are under threat, to directly manage threatened populations (via translocation, release of captive-bred individuals, etc.) or to provide protection against specific threats such as hunting, overharvesting, disease outbreaks or fires.

This section describes the state of in situ conservation activities for associated biodiversity as presented in the country reports. Except where noted otherwise, it focuses on the activities specifically reported to constitute "in situ conservation and management activities or programmes that support the maintenance of associated biodiversity." The state of implementation of various individual management methods at production-system level that may contribute to in situ conservation strategies for associated biodiversity is discussed in detail in Chapter 5. The role of protected areas is further discussed in Section 7.5. Broader institutional, policy and legal frameworks for the management of associated biodiversity, including those that directly or indirectly contribute to in situ conservation efforts, are discussed in Chapter 8.

\section{Overview}

Countries were invited to indicate the components of associated biodiversity being conserved 
TABLE 7.1

Associated biodiversity species and genera reported to be conserved in situ, by taxonomic group

\begin{tabular}{|c|c|c|c|}
\hline Taxonomic group & Count of species & Count of genera & Examples of species and genera reported \\
\hline Birds & 48 & 50 & $\begin{array}{l}\text { Amazona spp. (a genus of parrots), Dendrocopos spp. (a genus of } \\
\text { woodpeckers), Gallinago gallinago (common snipe), Lanius spp. (typical } \\
\text { shrikes), Oxyura leucocephala (white-headed duck), Saxicola rubetra } \\
\text { (winchat), Milvus milvus (black kite) }\end{array}$ \\
\hline Crustaceans & 40 & 41 & $\begin{array}{l}\text { Acasta spp. (a genus of barnacles), Astacus spp. (a genus of crayfish), } \\
\text { Austropotamobius spp. (a genus of crayfish), Birgus latro (coconut } \\
\text { crab), Lepas spp. (a genus of barnacles), Megabalanus spp. (a genus of } \\
\text { barnacles), Nobia spp., Savignium spp. (a genus of barnacles), Tetraclita } \\
\text { spp. (a genus of barnacles) }\end{array}$ \\
\hline Fish & 70 & 75 & $\begin{array}{l}\text { Alosa spp. (a genus of ray-finned fish), Labeo spp. (a genus of ray-finned } \\
\text { fish), Lampetra spp. (a genus of lampreys), Salmo spp. (salmons and } \\
\text { trouts), Tor spp. (mahseers), Zingel spp. (a genus of ray-finned fish) }\end{array}$ \\
\hline Insects and arachnids & 108 & 115 & $\begin{array}{l}\text { Apis mellifera (western honey bee), Coccinella spp. (a genus of ladybird } \\
\text { beetles), Cirrospilus spp. (a genus of hymenoptera), Scymnus spp. } \\
\text { (a genus of ladybird beetles), Typhlodromus spp. (a genus of mites) }\end{array}$ \\
\hline Mammals & 64 & 72 & $\begin{array}{l}\text { Barbastella barbastellus (barbastelle - a bat), Castor fiber (Eurasian } \\
\text { beaver), Dugong dugon (dugong), Myotis spp. (a genus of bats), Ovis spp. } \\
\text { (sheep), Rhinolophus spp. (a genus of bats), Sus scrofa (wild boar), Ursus } \\
\text { spp. (a genus of bears) }\end{array}$ \\
\hline Molluscs & 11 & 25 & $\begin{array}{l}\text { Margaritifera spp. (a genus of freshwater mussels), Pinctada spp. (pearl } \\
\text { oysters), Sepia spp. (a genus of cuttlefish), Trochus spp. (a genus of sea } \\
\text { snails), Unio crassus (thick-shelled river mussel), Vertigo spp. (a genus of } \\
\text { land snails) }\end{array}$ \\
\hline Plants & 532 & 629 & $\begin{array}{l}\text { Abelmoschus spp., Abies alba (European silver fir), Acer pseudoplatanus } \\
\text { (sycamore), Acorus calamus (flagroot), Adansonia digitata (baobab), } \\
\text { Allium spp., Citrus medica (citron), Dioscorea spp., Fagus sylvatica } \\
\text { (European beech), Fraxinus excelsior (European ash), Jatropha spp., Piper } \\
\text { spp. (pepper plants), Quercus spp. (oaks), Solanum spp., Vigna spp., } \\
\text { Ziziphus spp. }\end{array}$ \\
\hline $\begin{array}{l}\text { Reptiles and } \\
\text { amphibians }\end{array}$ & 22 & 22 & $\begin{array}{l}\text { Bombina spp. (fire-bellied toads), Dermochelys coriacea (leatherback sea } \\
\text { turtle), Triturus spp. (a genus of newts), Natrix spp. (colubrid snakes), } \\
\text { Vipera berus (common viper) }\end{array}$ \\
\hline Others & 2 & 4 & $\begin{array}{l}\text { Arthrospira fusiformis, Holothuria spp. (a genus of sea cucumbers), } \\
\text { Tachypleus spp. (a genus of horseshoe crabs) }\end{array}$ \\
\hline Total & 897 & 1033 & \\
\hline
\end{tabular}

Note: The count of genera covers those mentioned in responses at genus level and those mentioned in responses at species level. Sixty out of a total of 91 countries reported at least one species or other taxon.

Source: Country reports prepared for The State of the World's Biodiversity for Food and Agriculture.

in situ, ${ }^{7}$ the types of conservation activity being undertaken to protect them, the site or location of the activities, the production system(s) involved and the objectives of the conservation efforts. Sixty countries provided information, amounting to a total of 1237 responses at various tax-

\footnotetext{
The country-reporting guidelines invited countries to report separately on micro-organisms, invertebrates, vertebrates and plants.
}

onomic levels. In total, 897 distinct species and 1033 genera were identified. Some individual countries reported large numbers of species/taxonomic groups. India, for example, reported 258 different entities. As indicated in Table 7.1, the species and genera reported belong to a fairly wide range of taxonomic groups, although they include very few micro-organisms and no fungi. However, at least four countries from Africa and Europe indicate that fungi in general are 


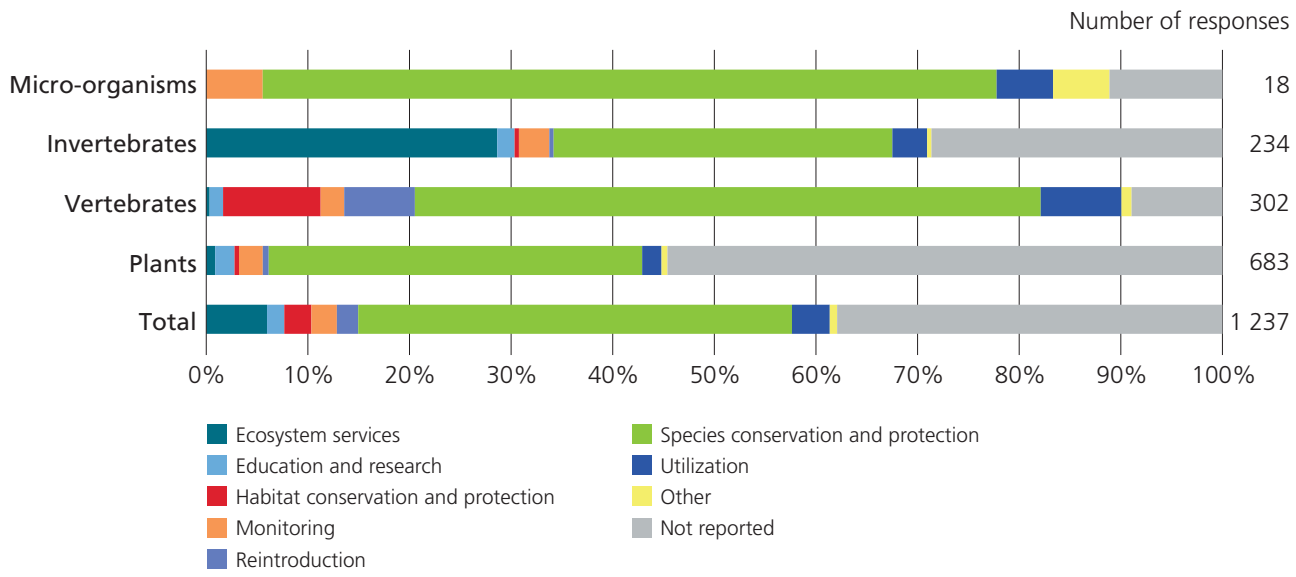

Notes: A "response" is a mention by a specific country of a specific component of associated biodiversity (species or higher taxonomic group) reported in the respective category (micro-organisms, invertebrates, vertebrates and plants). Sixty out of a total of 91 countries reported at least one response.

Source: Country reports prepared for The State of the World's Biodiversity for Food and Agriculture.

the object of in situ conservation. Other broad groups mentioned include nitrogen-fixing bacteria, soil micro-organisms, zooplankton and phytoplankton. Among animals, arthropods (particularly insects) and vertebrates are strongly represented. Several of the animal species listed in Table 7.1 contribute to the supply of ecosystem services in crop, livestock, forest or aquatic production systems, including pest and disease regulation (e.g. many birds, insects, bats, reptiles and amphibians), pollination (e.g. many insects, birds and bats), ecosystem engineering and provision of habitat (e.g. large mammals and fish) and water purification (e.g. crustaceans and molluscs). Plants are the group with the most species reported to be conserved in situ. Many herbaceous and woody species contribute to ecosystem services such as nutrient cycling, natural-hazard regulation, provision of habitat and erosion control. More information on BFA and ecosystem services, and on associated biodiversity species reported to be managed for the provision of ecosystem services, is provided in Section 2.2 and Section 4.3.1, respectively.
Countries' responses regarding objectives for the in situ conservation of specific species/other taxa of associated biodiversity are summarized in Figure 7.1. The most frequently reported objective is simply the conservation and protection of the respective components of associated biodiversity (43 percent of responses). Only 6 percent of responses indicate provision of ecosystem services as an objective, although this objective is more commonly mentioned for invertebrates (29 percent of responses), and only 4 percent mention utilization.

For each reported component of associated biodiversity (i.e. species or other taxon), countries were invited to indicate specific actions undertaken to promote its conservation. As indicated in Figure 7.2, the implementation of biodiversityfriendly management practices is the most commonly mentioned action (26 percent of aggregated responses), followed by monitoring and collection missions (11 percent) and strengthening institutions and policies (9 percent). The establishment and maintenance of protected areas is 
FIGURE 7.2

Reported actions for the in situ conservation of associated biodiversity

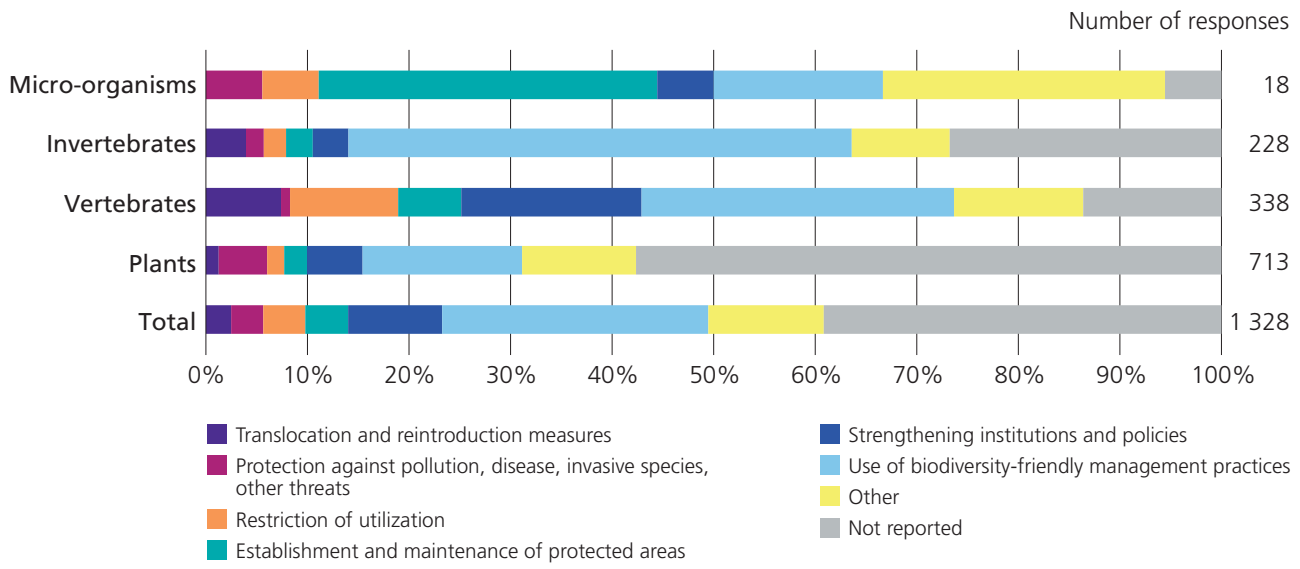

Notes: A "response" is a mention by a specific country of an action for a specific component of associated biodiversity (species or higher taxonomic group). In some cases more than one action was reported for the same component of associated biodiversity. Sixty out of a total of 91 countries reported at least one response.

Source: Country reports prepared for The State of the World's Biodiversity for Food and Agriculture.

mentioned in 4 percent of responses related to the conservation of specific components of biodiversity, although a majority of the countries reporting in situ conservation activities for associated biodiversity mention at least some role for protected areas (see below).

\section{Establishment and maintenance of protected areas}

As noted above, protected areas are widely mentioned in the country reports as components of in situ conservation efforts for associated biodiversity (more information on the global status and trends of protected areas can be found in Section 7.5). ${ }^{8}$ The protected areas referred to in this context are mostly located in forest, marine (e.g. Box 7.3), freshwater or grassland areas. Where specific production systems are mentioned,

8 Some countries explicitly state that protected area status contributes to the protection of associated biodiversity, while others list protected areas as sites at which conservation activities for associated biodiversity are undertaken (in some cases also indicating the specific actions involved). they are most commonly forest, fishery or grazing systems. Some countries, however, also mention crop and mixed systems. Where individual species are reported to be conserved via protected areas, little information is generally provided on why these particular species are targeted or regarded as significant (e.g. on their risk status or their significance in the provision of ecosystem services). Many of the species mentioned are trees, fish, plants that are sources of wild foods, medicinal plants and/or wild relatives of domesticated crops or livestock. A number of large, spectacular or "charismatic" species, as well as some that are characteristic of particular targeted habitats, are also mentioned. Some countries indicate that conservation efforts are directed at whole ecosystems (e.g. mangroves, hill forests or coral reefs) or note that all taxonomic groups present in the local area benefit.

The country reports provide some examples of cases in which conservation in protected areas is explicitly regarded as a means of promoting the supply of regulating or supporting 


\section{PART C}

Box 7.3

Marine sanctuaries and monitoring systems - examples from Jamaica

The Boscobel Sanctuary is a protected area off the north coast of Jamaica. It is part of the Sandals Foundation's Marine Plan, which includes a commitment to the management of marine sanctuaries, placement of marker buoys in designated areas, monitoring of reefs and fish populations, and working alongside the Jamaican Government, fisherfolk and community members to ensure the country's citizens are aware of the benefits of marine protected areas. Since the launch of the Boscobel Sanctuary in 2010, and subsequently its declaration as a Special Fishery Conservation Area in 2012, several surveys have shown signs of new coral growth and an increase in the fish population. ${ }^{1}$

In Fish Sanctuaries, no fishing is allowed under any circumstances. In Special Fisheries Conservation Areas, fishing may be permitted under special circumstances, for instance to control invasive alien species or for research.
The Conch Abundance Survey Programme, implemented every three to five years on the $8000 \mathrm{~km}^{2}$ Pedro Bank, the fishing ground of the queen conch, establishes research transects on the seafloor, at depths ranging from $10 \mathrm{~m}$ to $30 \mathrm{~m}$, at 80 sites. Counts are made within these transects and other critical ecosystem parameters are recorded in order to determine the biomass and stock size. The data are used to establish a national quota for the subsequent fishing season. Between surveys, catch and effort data based on landings are used to determine annual quotas.

\section{Jamaican fish sanctuaries}

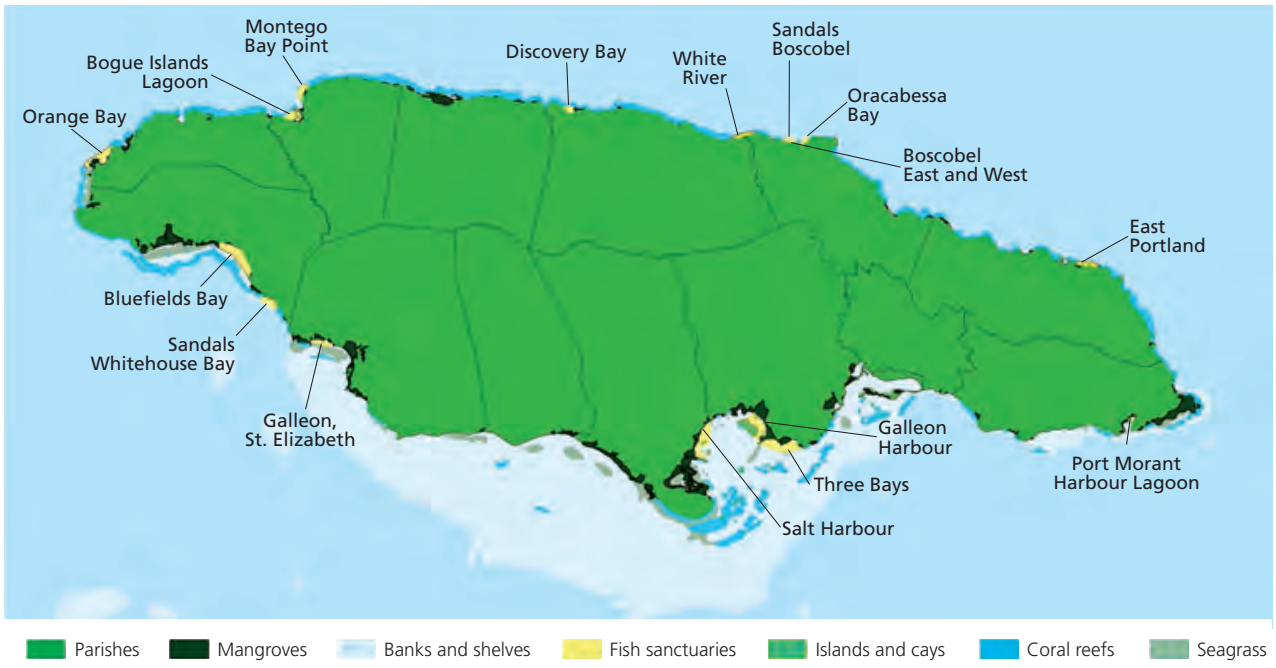

Map credits: S. Lee, The CARIBSAVE Partnership (in collaboration with C-Fish, The Nature Conservancy, Fisheries Division and Caribbean Coastal Area Management Foundation).

ecosystem services to food and agriculture. For example, Senegal mentions that the country's forest protected areas include some that are designated as "soil conservation reserves". Nepal
Source: Adapted from the country report of Jamaica. 
Box 7.4

Marine protected areas in Palau

For centuries, traditional leaders in Palau have worked to protect local waters and habitats that are critical to the community's food security through the custom of bul-a moratorium on catching key species or fishing on certain reefs.

Palau has now created a modern-day bul in the form of the Palau National Marine Sanctuary Act (2015), which establishes one of the world's largest protected areas of ocean. The sanctuary will fully protect about 80 percent of the nation's maritime territory, a higher percentage than in any other country. Full protection means that no extractive activities, such as fishing or mining, can take place. The reserve covers $500000 \mathrm{~km}^{2}$.

Most existing marine protected areas (MPAs) in Palau have been found to harbour a larger biomass of "resource fish" (commercially important species) than nearby unprotected areas. Studies have found that total resource-fish biomass is, on average, twice as large in MPAs as in nearby control areas and have found top-predator biomass to be a striking five times greater in MPAs. The Palau Protected Area Network is an innovative mechanism designed to protect the nation's critical biodiversity and ensure these resources are effectively conserved.

In 2009, Palau established the world's first shark sanctuary. All types of shark fishing are forbidden within the country's exclusive economic zone. The sanctuary covers roughly $600000 \mathrm{~km}^{2}$ and protects over 135 shark and ray species - animals that are vital to the balance of the ocean's ecosystems.

Source: Adapted from the country report of Palau. to more general benefits. Kenya, for example, reports that protected areas help to maintain the various ecosystem services provided by forests and their associated biodiversity. Samoa mentions that its objective of designating 15 percent of its terrestrial area as protected is motivated by the objective of maintaining the supply of ecosystem services. Aside from responses explicitly related to the in situ conservation of associated biodiversity, a number of countries mention protected areas (particularly forest and marine protected areas) in their responses to a question on "actions and countermeasures taken to limit unsustainable use and/or support sustainable use of associated biodiversity and/or wild foods."

Several countries note the significance of traditional protected sites and traditional resource-management strategies that complement or reinforce official protected areas or inspire their establishment. For example, Niue reports that small areas have traditionally been defined as strict protection zones (referred to as tapu) or subject to seasonal closures. It notes, however, that these practices are in danger of dying out because of a lack of formal recognition by government.
On the positive side, it mentions that the 5400 ha Huvalu Forest Conservation Area, the country's largest area specifically managed for conservation and sustainable resource use, includes 100 ha of tapu land where hunting, logging and research are prohibited. Examples from Palau and Jordan of how traditional conservation practices have influenced the establishment of protected areas are presented in Box 7.4 and Box 7.5. Senegal mentions that in some communities, traditional conservation sites that are maintained essentially for religious reasons (places of worship, sacred woods and forests, sites with funerary monuments, cemeteries, etc.) have allowed the recovery of populations of some species that had disappeared from exploited sites. Kenya notes that many sacred groves (kayas) in coastal forests are being managed and protected using local knowledge and practices.

\section{Use of biodiversity-friendly management practices}

A number of countries report in situ conservation measures based on the use of management practices that protect or promote biodiversity in 


\section{PART C}

Box 7.5

The traditional Hima rangeland management system in Jordan

Hima ("protected area" in Arabic) is a traditional system of land-resource tenure that has been practised for more than 1400 years on the Arabian Peninsula. Pastoralist communities establish rules for the grazing of herds and designate set-aside areas where grazing is only permitted under certain conditions, for instance during drought periods (Davies et al., 2012). Hima contributes to the conservation of biodiversity and the sustainable use of rangelands.

The practice has generally declined in recent years due to industrialization, climate change and population pressure. However, some villages in Jordan whose pasturelands have been affected by overgrazing are adopting the Hima system in order to maintain local biodiversity and improve local living standards.

In 2011, the Bani Hashem village project was established through a partnership between the Ministry of Agriculture and the International Union for Conservation of Nature with the aim of reviving Hima. In the initial phase, an awarenessraising programme was launched to inform stakeholders of the benefits of regulating grazing. One-hundred hectares of rangeland were allocated to the community for their use and management, and a tribal charter was drafted and signed by community members. As a result, overgrazing and

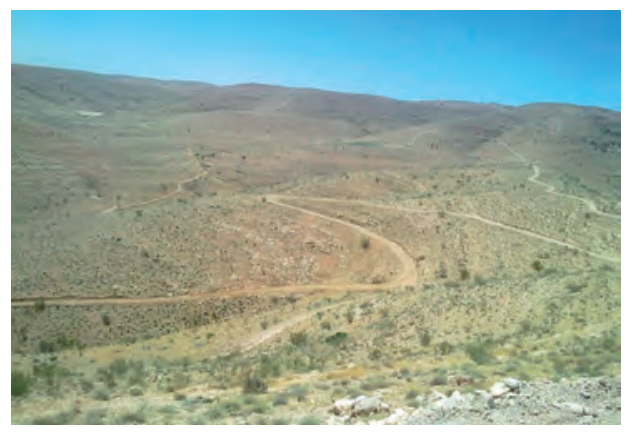

Rangeland of the Hima Bani Hashem with species such as Salsola sp., Paronychia argentea, Atriplex halimus, Artemisia herba-alba and Teucrium polium. (C) Amer Maadat.

conflicts over natural resources have declined, while biomass and indigenous plant species have increased. Shared responsibility for the environment and effective participation of the local community have greatly contributed to the project's success. After the success in Bani Hashem, Hima has been implemented in other regions.

Source: Adapted from the country report of Jordan.

Note: For more information, see https://www.unenvironment.org/news-andstories/story/back-future-rangeland-management-jordan crop, livestock, forest or aquatic production systems. ${ }^{9}$ For example, Senegal mentions the introduction of agroforestry practices - implemented at community level and based on local conven-

\footnotetext{
As discussed in Chapter 5, many countries report management practices that are likely to promote the presence of particular components of associated biodiversity. However, these are not always reported in the context of in situ conservation. This may be because the species in question are not targets for conservation (e.g. are not rare) and/or because actions are motivated by the production benefits obtained rather than by conservation objectives. A large number of countries also mention the promotion of sustainable management practices, mostly in crop production but also in some cases in livestock keeping, forestry and fisheries, in their responses to a question on "actions and countermeasures taken to limit unsustainable use and/or support sustainable use of associated biodiversity and/or wild foods" in the section of the country-reporting guidelines on sustainable use.
}

tions for the management of shared resources in response to observed declines in biodiversity. Argentina mentions the work of the Alianza del Pastizal (Grassland Alliance), ${ }^{10}$ which brings together NGOs from Argentina, Brazil, Paraguay and Uruguay, under the auspices of BirdLife International, along with research organizations, national parks and private entities, in an effort to reconcile grassland meat production with the conservation of biodiversity through the use of livestock-management practices that help to maintain grassland habitats and the survival of grassland species (see also Section 3.3.2). Norway reports that conservation programmes for native and endangered cattle breeds tend

\footnotetext{
10 http://www.alianzadelpastizal.org/en
} 
Box 7.6

Agri-environmental schemes supporting cropland and grassland biodiversity examples from Belgium

Wild-flower biodiversity in crop systems is promoted by providing farmers with contracts for extensive management practices (grain-based crop rotations), with requirements modified to accommodate the needs of the particular wild-flower species present. Insect biodiversity is promoted by adjusting sowing and cutting practices so as to leave $3 \mathrm{~m}$ to $30 \mathrm{~m}$ wide strips of flowerrich pasture. A range of vertebrate species associated with grasslands are supported via contracts for extensive use of meadows, with specific requirements modified to accommodate particular conservation objectives based on expert advice. Options for supporting meadow birds, for example, include delaying mowing and grazing dates on meadows and pastures, conversion of arable land to grassland, provision of protective structures around the birds' nests and adapting mowing practices. Options for birds associated with croplands include sowing strips containing a mix of grass and herb species, adapting

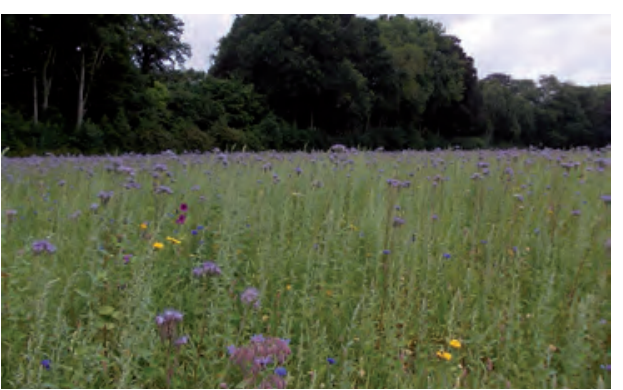

Wild-flower strip designed to attract bees. (C) Vlaamse Landmaatschappij (Flemish Land Agency).

within-field practices (no pesticides, adaptive mowing) and maintaining unharvested land to provide cereals as winter food.

Source: Adapted from the country report of Belgium to promote grazing in outlying fields, which helps to maintain and enhance the diversity of grasses, other plants, invertebrates and microorganisms associated with open landscapes. Where forest management is concerned, it notes that increasing the volume of standing and lying dead wood provides a habitat for many associatedbiodiversity species.

Many countries from developed regions mention that biodiversity-friendly practices are promoted via agri-environmental schemes (see Section 8.7 for further information). Examples are presented in Box 7.6 and Box 7.7.

Some country reports highlight in situ conservation activities that involve the deployment of management techniques specifically designed to favour particular functional groups of associated diversity. Pollinators are the group most commonly targeted. Programmes promoting pollinator-friendly practices and pollinatorhabitat creation in the United States of America are described in Box 7.7. Several countries also note the importance of providing support to the development of the beekeeping sector, including support for beekeepers' organizations. Other groups of species targeted include soil organisms and the natural enemies of pest species. For example, Cameroon mentions that farmers are being taught about soil management and water conservation and encouraged to abandon slash-and-burn practices that destroy humus and soil invertebrates and micro-organisms. The United Kingdom reports schemes promoting the creation of flower-rich margins that provide habitat for beneficial predators. It also mentions the conversion of cropland to grassland to benefit soil biodiversity, and the maintenance of hedgerows, enhanced stubbles and species-rich grassland to benefit the natural enemies of pests. Lebanon mentions that a number of invertebrate species are conserved on-farm because of their role in biological control. 


\section{PART C}

Box 7.7

Initiatives supporting the in situ conservation of pollinators in the United States of America

The Conservation Stewardship Program (CSP) provides longterm stewardship payments to landowners who implement advanced conservation systems. As of 2015, nearly 3000 CSP contract holders had established pollinator habitats in non-cropped areas on their lands. Participants had seeded over 11000 acres (4 452 ha) of nectar- and pollen-producing plants in field borders, vegetative barriers, buffer strips and along waterways. In addition to habitat-enhancement measures, the CSP supports producers in reducing pesticide application and in providing critical food supplies for pollinators and other beneficial insects.

The Conservation Reserve Program (CRP) provides payments to farmers who agree to remove environmentally sensitive land from production and to plant species that will improve environmental health. In June 2014, the United States Department of Agriculture (USDA) announced the availability of USD 8 million in management incentives for farmers and ranchers in Michigan, Minnesota, North Dakota, South Dakota and Wisconsin who establish new habitats for declining honey-bee populations on their existing CRP land (these five states are home to more than half of the country's commercially managed honey bees during the summer and offer a large area of potential habitat). In 2012, USDA reserved 100000 acres (40 469 ha) of CRP land for pollinator habitat. As of 2015 , about 35 percent of this land had been enrolled in the programme. In addition to the land covered by the special CRP pollinator-habitat initiative, USDA estimates that a further 98000 acres (39 659 ha) of CRP land are pollinator habitat. The National Strategy to Promote the Health of Honey Bees and Other Pollinators (adopted in 2015) is seeking ways to increase the area covered by the initiative.

Source: Adapted from the country report of the United States of America.

\section{Protection against pollution, disease, invasive species and other threats}

Aside from the establishment of protected areas and measures targeting management practices at production-system level, countries report a number of other measures that help to protect associated biodiversity against various threats. Measures of this type include national legal and policy instruments targeting activities such as infrastructure development, release of pollutants, hunting, trapping and poisoning, as well as strategies and programmes implemented by government agencies and other stakeholders involved in natural-resources management to limit threats such as habitat destruction and the spread of diseases or invasive species. The country reports generally do not provide much detail on activities in this category or on the specific species, species groups or ecosystems that benefit. Jamaica mentions efforts to control invasive species such as lionfish. Cameroon reports efforts to protect aquatic ecosystems against pollution from agriculture and mining. Burkina Faso refers to the project African
Reference Laboratory (with Satellite Stations) for the Management of Pollinator Bee Diseases and Pests for Food Security. Several examples from Ireland are presented in Box 7.8. Legal measures restricting or regulating hunting, fishing and wildfood gathering and/or trade in products sourced from the wild are widely reported in countries' responses on measures implemented to reduce the unsustainable use of associated biodiversity and wild foods.

\section{Establishment and maintenance of connective habitat}

A number of country reports note the significance of maintaining wildlife corridors or other habitat features that help to connect potentially isolated populations or allow migratory species to complete their life cycles. The report from the United States of America, for example, mentions collaborative work with Canada and Mexico to protect the migratory monarch butterfly (Danaus plexippus). Ecuador reports a plan to create 16 corridors encompassing four globally relevant 
Box 7.8

Selected species-conservation measures in Ireland

\section{Plants}

Slender green feather-moss (Hamatocaulis vernicosus): prevention of peatland damage.

Slender naiad (Najas flexilis): prevention of eutrophication, acidification and peatland damage.

Killarney fern (Trichomanes speciosum): prevention of deliberate collection; habitat protection - prevention of encroachment of invasive or vigorous species, water pollution, removal of woodland or alteration of watercourses.

\section{Invertebrates}

Freshwater pearl mussel (Margaritifera margaritifera): prevention of sedimentation and enrichment of habitat; restoring/improving water quality; management of urban and industrial waste.

White-clawed crayfish (Austropotamobius pallipes): maintenance of Ireland's status as free of both nonnative crayfish species and the crayfish plague disease; restoring/improving water quality.

Narrow-mouthed whorl snail (Vertigo angustior): monitoring of grazing and wetland drainage.

Desmoulin's whorl snail ( $V$. moulinsiana): management to prevent further declines caused by succession and drying out of wetlands.

\section{Vertebrates}

Lesser horseshoe bat (Rhinolophus hipposideros): forestmanagement measures; specific management of traffic and energy-transport systems.

Otter (Lutra lutra): forestry-related measures; restoring/ improving water quality; regulation/management of hunting and taking; management of urban and industrial waste; management of traffic and energy-transport systems.

Grey seal (Halichoerus grypus): measures to prevent disturbance by human activities, accidental entanglement in fishing gear, illegal killing and pollution; establishment of protected areas/sites; regulation/management of hunting and taking; regulation/management of fisheries and other exploitation of natural resources in marine and brackish systems.

Sea lamprey (Petromyzon marinus): wetland-related measures - the Office of Public Works has cooperated with Inland Fisheries Ireland to develop strategies to minimize the adverse impacts of drainage maintenance work.

Killarney shad (Alosa fallax killarnensis): action to preclude the use, or bringing onto lakes, of any craft without a permit - the system includes a provision requiring all applicants to produce documentation that their craft has been powerhosed locally as recently as possible, in order to reduce the risk of introducing invasive aquatic organisms.

Source: Adapted from the country report of Ireland. ecosystems, namely páramos (for more information on páramos, see Box 4.7), mangrove swamp, dry forest and tropical rainforest. These corridors are being established through participatory approaches within the framework of the project Biocorredores para el buen vivir (Biocorridors for Good Living). The aim is to increase human well-being and the maintenance of biodiversity by connecting habitat patches, supporting sustainable production practices and facilitating the involvement of local community organizations in conservation and restoration interventions, with support from the Global Environment
Facility programme Pequeñas Donaciones (Small Donations). As of 2016, 324 organizations had undertaken work that had contributed to ecological connectivity.

\section{Translocation and reintroduction measures}

Another type of conservation activity mentioned in the country reports is direct manipulation of targeted populations via translocation, introduction or reintroduction of populations into new or former habitats or release of captive-bred individuals to supplement wild populations an approach that clearly needs to be implemented 
with caution. The report from the United Kingdom, for example, mentions the reintroduction of the short-haired bumble bee (Bombus subterraneus), a species that was declared extinct at national level in 2000. Following genetic analysis of specimens in natural-history collections and potential source populations, Sweden was chosen as a source of queen bees for the reintroduction programme. Bees were collected, screened for disease and released at Dungeness National Nature Reserve in southeastern England in 2012 and 2013. Flower-rich habitat corridors were created on neighbouring land. Other countries reporting reintroduction or translocation measures include Hungary (beaver [Castor fiber]) and Belgium (crayfish, sea trout [Salmo trutta trutta] and Atlantic salmon [S. salar]). India mentions the breeding and ranching of several fish species to support self-recruitment. Peru mentions the release of young taricaya turtles (Podocnemis unifilis). Jamaica mentions the replanting of corals.

\section{Product processing and marketing}

Some countries refer to in situ conservation activities that are creating opportunities for income generation from associated-biodiversity species or from the ecosystems that support them. For example, Chad mentions a project supporting the utilization of non-timber forest products. Slovenia reports that the marketing of high-value products (e.g. cheeses and other dairy products) contributes to the conservation of extensive semi-natural grasslands and their associated biodiversity, as the higher prices obtained allow for investment in the labour and skills needed to manage these systems. It notes the importance, in this context, of local marketing systems, product promotion and awareness raising among producers and customers.

\section{Strengthening institutions and policies}

Institutional development efforts that support the in situ conservation of associated biodiversity are highlighted in a number of country reports. Tonga, for example, mentions the project Marine and Coastal Biodiversity Management in the Pacific Island Countries, which focuses on developing and strengthening institutional and individual capacities for biodiversity conservation in five target countries. ${ }^{11}$

A number of countries note the importance of community participation, including, where relevant, the involvement of indigenous communities and the utilization of traditional knowledge in the planning and operation of protected areas and other in situ conservation initiatives targeting associated biodiversity. Solomon Islands, for example, mentions the Dugong and Seagrass Conservation Project, which aims to enhance the conservation of dugongs (Dugong dugon) and associated seagrass ecosystems in eight countries in the Indo-Pacific region. It notes that a key objective of the project is to mobilize community participation and ownership of conservation efforts, with a focus on introducing sustainable fisheries practices, innovative financial incentives and the establishment of locally managed marine protected areas. Several countries note the significance of multistakeholder cooperation, both at local and national levels and internationally (see examples above and in Chapter 8). Several also mention the importance of a supportive policy framework (see for example Box 7.9), noting, for instance, that in situ conservation measures for associated biodiversity are included in their national biodiversity strategy and action plans or mainstreamed into national development plans and policies.

\subsubsection{Ex situ conservation}

Associated-biodiversity species can be conserved ex situ in various ways, including in genebanks, culture collections, zoos, botanic gardens or privately held collections. Ex situ collections can serve as a backup against losses in situ and provide an accessible source of material for ongoing research or other uses. For some important types of associated biodiversity, however, practical issues constrain the effectiveness of ex situ conservation and mean that its potential role is relatively limited. For example, invertebrates

1 Fiji, Kiribati, Solomon Islands, Tonga and Vanuatu. 
Box 7.9

Plan of Action for the Conservation of the Nordic Brown Bee

The brown bee, Apis mellifera mellifera, is the honey-bee subspecies native to the Nordic region and is well adapted to the climate in the Nordic countries. During the twentieth century, other honey-bee subspecies were introduced into the region by beekeepers, and the native brown bee is now threatened by displacement and introgression (hybridization). However, the value of the subspecies is increasingly being recognized and conservation efforts are under way.

The Nordic Genetic Resource Center (NordGen) initiated a project aiming to document the status of the Nordic brown bee, and conservation activities targeting it, in the Nordic and Baltic region. Following the publication of the project report (Status and conservation of the Nordic brown bee: final report) in 2014, a Nordic brown bee network consisting of beekeepers, researchers and members of national beekeeping organizations was established, with NordGen acting as a secretariat. In 2015, the working group compiled a Plan of Action for the Conservation of the Nordic Brown Bee (NordGen, 2015). The working group concluded that cooperation among stakeholders and coordination at national and international levels are of utmost importance to the conservation of the brown bee.
The brown bee network carries out the following activities recommended in the action plan:

- NordGen has created a "brown bee wiki"1 for the collection of traditional knowledge on brown beespecific management. Beekeepers are encouraged to contribute to the wiki by adding information and changing content, as necessary. The wiki is intended as a resource for anyone who keeps brown bees.

- Genotyping is under way, with several projects having provided ancestry-informative markers for a number of brown-bee populations.

- Database solutions for breeding purposes are being assessed and experiences in different countries discussed.

- Branding of brown-bee honey by creating a small information leaflet in the various national languages of the region to accompany honey jars is being considered.

Source: Provided by Birgitte Lund, Malene Karup Palne, Kim Holm Boesen, Peer Berg, Linn Fenna Groeneveld and Anja Laupstad Vatland. https://wiki.nordgen.org/brownbee have no long-lived dormant stages in their life cycles (Cock et al., 2011) and if bred in captivity can undergo genetic changes that impair their ability to provide ecosystem services (Bouletreau, 1986; Hopper, Roush and Powell, 1993; Waage, 2007). Although there have been studies on the cryopreservation of bee semen (Hopkins, Herr and Sheppard, 2012; Hopkins and Herr, 2010), the method has not yet been established and mainstreamed. Where potential reintroductions are concerned, it needs to be recalled that the roles of individual species in the supply of ecosystem services generally depend on complex interactions with many other species, and that therefore conserving an associated-biodiversity species ex situ does not mean that its in situ roles can necessarily be restored. Identifying priority species for conservation ex situ is also difficult because of the large numbers of potential candidates and the complexity of their ecological roles.

\section{Species reported to be conserved ex situ}

In response to a question in the country-reporting guidelines on species of associated biodiversity conserved ex situ, 51 countries mentioned a total of 1549 species and other taxonomic groups, including 1184 distinct species (Table 7.2). ${ }^{12}$ The taxonomic balance of the responses presumably reflects both the above-mentioned practical constraints to the ex situ conservation of some types of organisms and the ways in which countries interpreted the concept of associated biodiversity. More information on associated biodiversity

\footnotetext{
12 These include 917 distinct plant species reported by a single country (Lebanon).
} 
TABLE 7.2

Associated biodiversity species reported to be conserved ex situ, by taxonomic group

\begin{tabular}{|l|c|}
\hline \multicolumn{1}{|c|}{ Taxonomic group } & $\begin{array}{c}\text { Count of distinct } \\
\text { species }\end{array}$ \\
\hline Bacteria & 56 \\
\hline Birds & 6 \\
\hline Crustaceans & 3 \\
\hline Fish & 36 \\
\hline Fungi & 38 \\
\hline Insects and arachnids & 21 \\
\hline Mammals & 18 \\
\hline Molluscs & 1 \\
\hline Plants & 996 \\
\hline Reptiles and amphibians & 5 \\
\hline Annelids and nematodes & 4 \\
\hline Total & 1184 \\
\hline
\end{tabular}

Note: Fifty-one out of a total of 91 countries reported at least one species.

Source: Country reports prepared for The State of the World's Biodiversity for Food and Agriculture.

and the ecosystem services it provides to food and agriculture, and on associated biodiversity species reported to be managed for the provision of ecosystem services, is provided in Sections 2.2 and 4.3.1, respectively.

Reported objectives for ex situ conservation are summarized in Figure 7.3. For all categories aggregated, where objectives are mentioned, research and education represent the most common response (38 percent of answers), followed by agricultural use (17 percent of answers). There are marked differences between objectives for the conservation of the different types of associated biodiversity. For example, a stronger focus on research and education is reported for micro-organisms, on commercial activities for invertebrates and on leisure purposes for vertebrates.

The main methods used for the ex situ conservation of associated biodiversity, i.e. culture collections, genebanks, living collections in botanic gardens and captive breeding and rearing, are described in more detail in the following sections, with supporting examples taken from the country reports.

\section{Culture collections ${ }^{13}$}

A range of different methods can be used to preserve micro-organisms under laboratory conditions. Box 7.10 presents an overview of the main methods available. Molecular tools are increasingly being used to differentiate between strains and to aid in their identification. Non-optimized conservation techniques can lead to genetic changes in conserved samples, and molecular techniques can be used to determine whether strains are being maintained without change (Smith, 2012).

Collections range from small operations targeting a limited number of species, collected and maintained by individual researchers, through larger operations based in laboratories within large multifunctional organizations, to institutions established as public-service collections and covering a broad range of organisms from many sources. They may focus on a particular kingdom (e.g. fungi or bacteria) or on specific genera. Alternatively, they may focus on a specific use, for example on industrial enzymes or antimicrobials, or on particular host crops. They may be linked to a particular sector, for example the environment, health care or agriculture.

Over recent decades, the concept of the microbial culture collection as a mere repository of micro-organisms has given way to that of the microbiological resource centre serving as "an essential part of the infrastructure underpinning life sciences and biotechnology" - supporting and conducting research and development activities, conserving biodiversity, addressing intellectual property issues and providing information to the public and to policy-makers (OECD, 2001). Collections can include culturable organisms (e.g. most algae, bacteria, filamentous fungi, yeasts, protozoa and viruses), their replicable parts (e.g. genomes, plasmids and complementary DNA), viable but not yet culturable organisms, cells and tissues, and related databases of molecular, phys-

\footnotetext{
13 This subsection draws on the CGRFA Background Study Paper prepared by Alexandraki et al. (2013).
} 
FIGURE 7.3

Reported objectives for the ex situ conservation of associated biodiversity

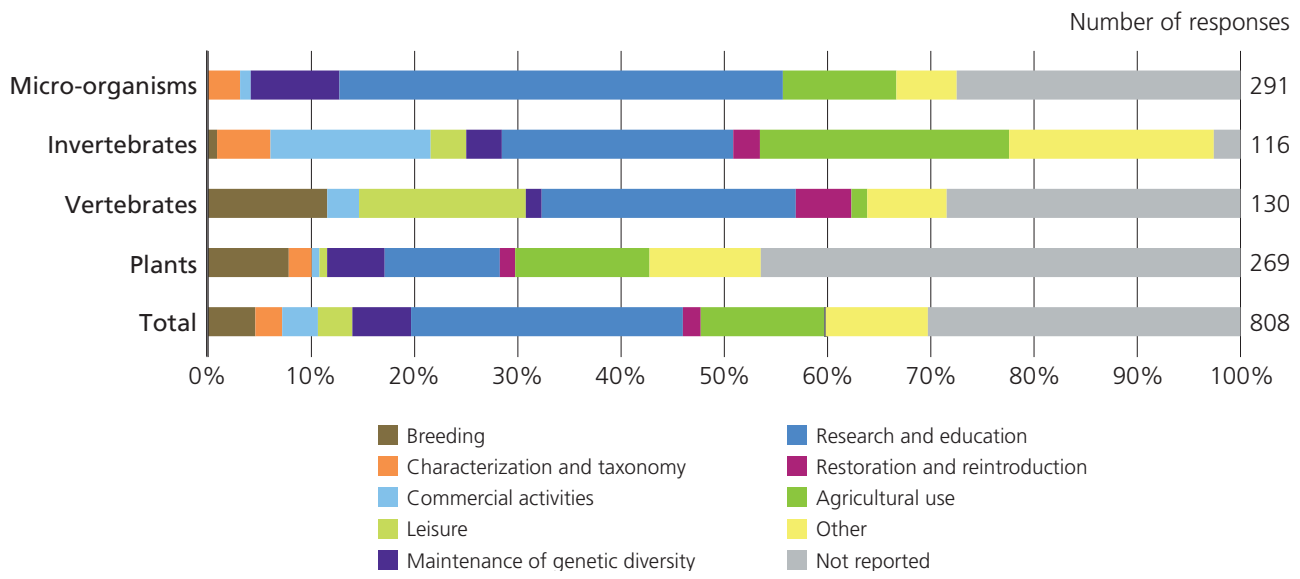

Notes: A "response" is a mention by a specific country of an objective for a specific component of associated biodiversity (species or higher taxonomic group). These figures do not include 1005 reports of "conservation" as the objective for the conservation of plant associated biodiversity. Fifty-one out of a total of 91 reporting countries reported at least one species.

Source: Country reports prepared for The State of the World's Biodiversity for Food and Agriculture.

iological and structural information (Arora et al., 2005). Many initiatives promoting collaborative activities among culture collections at both international and national levels have been established. Several examples are presented in Box 7.11.

The coverage of microbial diversity in culture collections remains far from complete. In the food-processing sector, for example, although many microbial strains involved in traditional and small-scale operations have been isolated and studied, relatively few of these have been deposited in national or other well-maintained institutional culture collections.

Culture collections are the type of conservation activity for micro-organisms most commonly referred to in the country reports. As noted in Section 7.3.1, very few in situ conservation programmes that specifically target micro-organisms are mentioned. Culture collections are reported from all regions except the Pacific, although only a minority of country reports explicitly mention such collections. The facilities referred to range from national genebanks for micro-organisms in general or for particular types of micro-organisms, to collections held by individual research institutes or universities and collections held by private organizations. In many cases, the reported activities cover a diverse range of micro-organisms, both in taxonomic terms and in terms of their sources and current or potential uses.

Several countries report the establishment of national programmes targeting the ex situ conservation of micro-organisms, or networks that aim to coordinate the work of culture collections at national level. For example, Spain mentions the Spanish Micro-organisms Network (REDESMI). ${ }^{14}$ Objectives include mapping the microbial genetic resources conserved in Spain and increasing their visibility via the REDESMI website, sharing good practices in the management, characterization and conservation of microbial strains, and generating a database of strains with "added value" (e.g. those with high biotechnological potential). Initiatives in Mexico, Ethiopia and India are described in Box 7.12, Box 7.13 and Box 7.14.

\footnotetext{
14 www.redesmi.es
} 


\section{PART C}

Box 7.10

\section{Conservation methods for micro-organisms stored ex situ}

The primary objective of ex situ storage is to maintain micro-organisms in a viable state, without morphological, physiological or genetic change, until they are required for use. Ideally, complete viability and stability should be maintained. However, factors such as ease of use, availability and cost may also have to be considered when choosing a storage method.

Conservation through subcultivation. This method involves repeated cultivation of the micro-organism on an agar nutrient medium. It is a widely used technique and is perhaps the oldest, simplest and most cost-effective means of maintaining micro-organisms under laboratory conditions, especially if cultures are required frequently and quickly. Conserved material is often refrigerated, as this extends the intervals between each round of cultivation. Intervals vary depending on the type of micro-organism involved, ranging from 30 days to several years at $3^{\circ} \mathrm{C}$ to $5^{\circ} \mathrm{C}$. The average longevity for yeasts is one to three months. Some bacteria can be maintained for 5 to 12 months, and filamentous fungi for over five years. A problem with subcultivation is that culturing conditions select for a distinct subpopulation of the bacteria present.

Conservation under mineral oil. This method is normally used for conserving yeasts and filamentous fungi. However, it can also be used for bacteria. The technique involves covering a microbial culture grown on a liquid or agar nutrient medium with sterile non-toxic mineral oil. This limits the culture's access to oxygen and reduces its metabolism and growth. It also reduces cell drying. The length of time for which micro-organisms can be maintained using this method ranges from several months to several years. Many cultures deteriorate under mineral oil and have to be transferred regularly. However, organisms that react badly to other techniques can be stored using this method. Disadvantages include the risk that samples may be contaminated by airborne spores, slow growth on retrieval and the possibility that continuous growth under adverse conditions may have a selective influence. The technique is nonetheless recommended as a storage method for laboratories with limited resources and facilities.

Water storage. Immersion in sterile water can be used to extend the life of a culture grown on agar. This method is generally used for preserving fungi, including yeasts. The advantages of storage in water are low cost and easy application. Some phytopathogenic fungi have reportedly been stored successfully for ten years using this method. However, the maximum potential length of storage is often limited, and some fungi will not survive submerged even for short periods. As with all methods that allow growth or metabolism during storage, it is considered only to be useful for short-term preservation and should be backed up by longer-term storage methods.

Silica-gel storage. This method involves inoculating a suspension of fungal propagules onto cold silica gel. The culture is then dehydrated to enable storage without growth or metabolism. Silica-gel storage has a number of advantages: it is cheap, simple and does not require complex apparatus. However, it can only be used for sporulating fungi. Organisms of this kind have been stored for 7 to 18 years using this technique and appear to remain morphologically stable after resuscitation.

Soil storage. This technique can be applied to a range of micro-organisms that can withstand a degree of desiccation, for example to the spores and resting stages of filamentous fungi and bacteria such as Bacillus spp. The method involves inoculating double autoclaved soil with $1 \mathrm{ml}$ of spore suspension in sterile distilled water and then incubation at $20^{\circ} \mathrm{C}$ to $25^{\circ} \mathrm{C}$ for five to ten days, depending on the growth rate of the organism. This initial growth period allows the organism to utilize the available moisture before dormancy is induced. The bottles are then stored in a refrigerator at $4^{\circ} \mathrm{C}$ to $7^{\circ} \mathrm{C}$. Soil storage can be one of the most practical and cost-efficient ways to preserve filamentous sporulating micro-organisms. Other advantages include good viability of cultures for up to ten years, reduced risk of mite infestation and the possibility of repeatedly obtaining inocula from the same source.

Drying. This method takes advantage of the natural ability of micro-organisms to fall into anabiosis, i.e. a state of suspended animation. A range of materials can be used as carriers for the cultures, and they can be dried at room temperature or by heating to $36^{\circ} \mathrm{C}$ to $40^{\circ} \mathrm{C}$. Drying is widely used to preserve brewery and bakery yeasts.

(Cont.) 
Box 7.10 (Cont.)

\section{Conservation methods for micro-organisms stored ex situ}

Freeze-drying. This method is a very effective means of conserving bacteria, yeasts and the spores of filamentous fungi. The process involves water being removed from the sample by sublimation under a vacuum. If carried out correctly, freeze-drying prevents shrinkage and structural change and helps retain viability. The many advantages of freeze-drying include the fact that the specimen is totally sealed and protected from infection and infestation. Cultures generally have good viability/stability and can be stored for many years. Ampoules take up little space and can be stored easily. Samples do not have to be revived before postal distribution. However, freeze-drying does have some disadvantages: some isolates fail to survive the process, others have reduced viability and genetic change may occur. The freeze-drying process is also relatively complex and can be time-consuming and expensive. Ampoules of freeze-dried organisms must be stored out of direct sunlight. Chilled storage will reduce the rate of deterioration and extend shelf-life.

Liquid-drying. This method is a useful alternative that can be used for preserving bacteria that are particularly sensitive to the initial freezing stage of the normal freezedrying process. The distinctive feature of liquid-drying is that cultures are not allowed to freeze. Drying occurs directly from the liquid phase. The method can be used for long-term preservation of nearly all yeast genera.

Cryoconservation. This method involves the storage of samples at very low temperatures. Although little metabolic activity takes place below $-70^{\circ} \mathrm{C}$, recrystallization of ice can occur at temperatures above $-139^{\circ} \mathrm{C}$, and this can cause structural damage during storage. The favoured method is therefore storage at ultralow temperatures, normally $-150{ }^{\circ} \mathrm{C}$ to $-196{ }^{\circ} \mathrm{C}$, in vapour- or liquid-phase nitrogen. Provided adequate care is taken during freezing and thawing, the culture will not change either phenotypically or genotypically. To reduce the risks of cryo-injury, traditional cryopreservation methods have involved controlled cooling at a rate of $-1{ }^{\circ} \mathrm{C}$ per minute, typically in the presence of a cryoprotectant. Advantages of this method include the length of storage (considered to be effectively limitless if the storage temperature is kept below $-150^{\circ} \mathrm{C}$ ), the wide range of organisms that can be conserved, and the fact that organisms remain free of contamination when stored in sealed ampoules. Disadvantages include the high cost of the apparatus and the need for a continuous supply of liquid nitrogen. If the supply fails (or the double-jacketed, vacuumsealed storage vessels corrode and rupture), a whole collection can be lost. The technique should therefore not be used in places where a regular supply of liquid nitrogen cannot be guaranteed.

Source: Adapted from Alexandraki et al. (2013).

Note: For further information on these methods see Malik and Hoffmann (1993) Simões et al. (2013), Smith and Ryan (2012), Smith, Ryan and Day, eds. (2001), Uzunova-Doneva and Donev (2005).
Many countries emphasize the links between culture collections and research activities (as noted above, collections are often maintained by universities or research institutes). A potential concern in this regard is that "conservation" associated with individual research projects may end when the projects end. For example, the country report from Viet Nam mentions the loss of a number of strains of pathogenic micro-organisms used in veterinary research as a result of inadequate management over the longer term. Another concern mentioned in some country reports is that potential users of conserved micro-organisms may not have adequate access to information on them. For example, the report from Spain notes that in many cases collections lack up-to-date catalogues containing basic information (taxonomic information, origin and culture conditions) on the conserved strains. Efforts to address this issue are being made through the REDESMI network (see above).

\section{Genebanks}

Both plants and animals can be conserved ex situ in genebanks (Section 7.2). In the case of animals, the term is normally used to refer to cryoconserved collections of semen, embryos or other 
Box 7.11

Cooperation in the ex situ conservation of micro-organisms

A number of organizations help to promote coordination, collaboration and discussion among the holders of culture collections. The World Federation for Culture Collections (WFCC), Microbial Strain Data Network (MSDN) and Microbial Resource Centres (MIRCENs) operate globally. WFCC oversees the World Data Center for Microorganisms, which holds information on 764 culture collections in 76 countries and regions, together containing almost 3 million cultures $^{1}$ (the figures do not cover all the collections in the world, as there are many private industrial collections and some in independent laboratories). The European Culture Collection Organization (ECCO) fosters initiatives that help collections obtain support and organize the delivery of products and services. For example, European Community Framework Programme projects include the electronic catalogue project Common Access to Biological Resources and Information (CABRI), ${ }^{2}$ which sets operational standards for European biological resource centres. Cooperation is also fostered through national and international affiliations such as the Belgian Coordinated Collection of Micro-organisms $(\mathrm{BCCM})^{3}$ and the United Kingdom National Culture Collection (UKNCC). ${ }^{4}$ Information on other important networks, federations and societies (e.g. the Asian Consortium for the

\footnotetext{
http://www.wfcc.info/ccinfo/statistics/

2 http://www.cabri.org/

3 http://bccm.belspo.be/

4 http://www.ukncc.co.uk/
}

Conservation and Sustainable Use of Microbial Resources ${ }^{5}$ and the United States Culture Collection Network ${ }^{6}$ can be found via the WFCC website. ${ }^{7}$

Microbial Resource Research Infrastructure (MRRI) brings together European microbial resource collections and stakeholders (collection users, policy-makers, research programmes and potential funders) to improve access to high-quality microbial resources in an appropriate legal framework. It aims to promote coherence in the application of quality standards, homogeneity in data storage and management, and workload sharing. The intention is to link European collections to partners elsewhere in the world.

Several initiatives have sought to design qualitymanagement systems for microbial culture collections. The first community-designed system was the WFCC guidelines for the establishment and operation of collections of micro-organisms. ${ }^{8}$ Quality-management systems have also been established by national culture-collection organizations, such as the UKNCC, and by various project consortia, including CABRI.

\section{Source: Adapted from Alexandraki et al. (2013).}

Note: The figures from the World Data Center for Microorganisms have been updated to correspond to those available on the organization's website as of November 2018.

5 www.acm-mrc.asia

6 www.uscen.org

http://www.wfcc.info/collections/networks

8 www.wfcc.info/guidelines biological materials stored in liquid nitrogen. The feasibility of this approach varies across species and taxonomic groups and - as noted above in the introduction to this subsection - is not a practical option in the case of many important associatedbiodiversity species. Plant genetic resources can be conserved in the form of seeds kept in cold storage, as living plants grown in field genebanks, or via in vitro culture or cryopreservation.

Nineteen country reports (25 percent) indicate the conservation of plant or animal components of associated biodiversity in genebanks. Many countries state that collections are used for research purposes as well as for conservation. The majority of species reported to be conserved in genebanks are plants. The range of species reported to be maintained is diverse, both in taxonomic terms and in terms of their roles or potential roles in the supply of ecosystem services. For example, Jordan mentions the genus Ziziphus (a spiny shrub), which plays a role in habitat provisioning. Lebanon mentions the genus Acacia, which plays a role in pest control, soil formation and protection, and habitat provisioning. Bangladesh reports a field genebank for mangrove species. The reports from Chad and Kenya mention the conservation of plant species 
Box 7.12

The culture collection of Mexico's National Genetic Resources Centre

The establishment of Mexico's National Genetic Resources Centre, which opened in 2012, has permitted the development of a national strategy for in vitro conservation of micro-organisms of importance to national food security. The Centre's micro-organism culture collection, established in accordance with the requirements of the World Federation of Culture Collections, the World Intellectual Property Organization (WIPO) and the Mexican Institute of Industrial Property, is recognized as an international depository authority under WIPO's Budapest Treaty on the International Recognition of the Deposit of Microorganisms for the Purposes of Patent Procedure. Its mission is to serve as a public collection that provides high-quality services in the fields of conservation, identification and characterization of micro-organisms associated with various activities in the food, agriculture and livestock industries - with the main aim being to conserve the diversity of micro-organisms of importance to food security. As of 2015, the collection had about 3000 accessions, including filamentous fungi and bacteria useful for biological control, bacteria and yeasts used in food production, industrial processes and agriculture, bacteria that affect plant and animal health, mycorrhizal fungi, probiotics, growth-promoting bacteria, bacteria used in bioremediation and cyanobacteria associated with ecological impacts and climate change. The challenge for the future is to increase the efficiency, accessibility and sustainability of the collection through the introduction of technologies that favour the use of the conserved resources in a wide range of ecological niches to support national development.

Source: Adapted from the country report of Mexico.

Box 7.13

The Microbial Biodiversity Directorate of the Ethiopian Biodiversity Institute

The Ethiopian Biodiversity Institute (EBI) ${ }^{1}$ is mandated with promoting the conservation and sustainable use of the country's biodiversity and regulating access and benefit-sharing. The Institute consists of five Directorates: the Crop and Horticulture Biodiversity Directorate; the Animal Biodiversity Directorate; the Microbial Biodiversity Directorate; the Forest and Rangeland Plants Biodiversity Directorate; and the Genetic Resources Access and Benefit Sharing Directorate. This structure ensures efficiency in research on, and conservation of, Ethiopia's biodiversity and associated indigenous knowledge.

Through their roles as biodegraders, biofertilizers, nitrogen fixers and fermenters, naturally occurring microorganisms provide a wide range of benefits to food and agriculture. The Microbial Biodiversity Directorate of EBI plays an important role in surveying and exploring the diversity and distribution of microbial genetic resources, building capacity among stakeholders in the conservation and sustainable use of microbial biodiversity and establishing national microbial-collection centres. Its in situ conservation research on Lakes Chitu, Arenguade and Kille explores the potential of blue-green algae (Arthrospira) as a functional and nutritious food source with health-promoting properties (Gutiérrez-Salmeán, Fabila-Castillo and ChamorroCevallos, 2015). Other fields of research include the growing of oyster mushrooms using agricultural residues such as cotton waste, coffee waste and wood chips.

A wide variety of traditional Ethiopian foods are produced through fermentation, using a wide range of raw materials and traditional techniques. Kocho and bulla, for example, are foods produced from the fermentation of ensete (Ensete ventricosum), commonly known as the Abyssinian banana. The Microbial Biodiversity Directorate has undertaken research on the isolation, identification and characterization of yeast species involved in kocho and bulla fermentation, with the aim of increasing the nutritional quality of these foods (Tsegay, Gizaw and Tefera, 2016). 


\section{PART C}

Box 7.14

Micro-organism conservation for improved agricultural production in India

Soil biodiversity, including micro-organism biodiversity, plays multiple roles in food and agriculture, including in the formation of soil organic matter, maintenance of soil fertility, nitrogen fixation, nutrient uptake by plants, reduction of erosion, degradation of dead plant and animal material, and elimination of hazardous waste.

In 2001, conscious of the degradation of the country's soil quality and micro-organism resources as a result of drivers such as excessive use of agrochemicals, inappropriate agricultural practices, climate change and repeated floods and other natural disasters, the Government of India established the National Bureau of Agriculturally Important Microorganisms. ${ }^{1}$ Emphasis was given to ex situ conservation, and numerous micro-organisms - bacteria, fungi and actinomycetes - are now conserved in 18 microbial resource centres. The microbial biodiversity conserved includes about 850 bacterial and viral species, 7175 species of algae, including 1453 species of cyanobacteria, 14500 species of fungi and 2223 species of lichens.

http://nbaim.org.in/default.aspx
The collections constitute a valuable reservoir of resources for use in improving agricultural production and processing. They have been used to develop innovative applications in areas such as the use of biofertilizers, biopesticides and bio-inoculants to reduce the use of synthetic agrochemical inputs, the biofortification of micronutrients in crops, the use of microbes to mitigate abiotic stresses caused by nutrient deficiency, drought, salinity, temperature, etc., and the use of microbes in processes such as fermentation and in the production of antibiotics and vitamins.

Needs and priorities in this field include improving baseline data on the diversity of micro-organisms in different ecosystems and agroecological zones. A lack of such data means that impacts of management practices, natural disasters and climate change are difficult to estimate. The use of microbial diversity and microbe-based technologies needs to be scaled up and disseminated among farmers through an effective extension network. There is also a need to address the lack of national policies supporting the use of microbe-based technologies.

Source: Adapted from the country report of India. with medicinal uses. Where animals are concerned, a few countries report the cryopreservation of fish milt. Denmark mentions the Plan of Action for the Conservation of the Nordic Brown Bee (Apis mellifera mellifera) (NordGen, 2015) (see Box 7.9). Among other measures, the plan foresees the establishment of a collection of cryoconserved brown-bee semen from the Nordic and Baltic region. Norway mentions a project that attempted to cryoconserve endangered honey-bee subspecies but was not successful. The role of Japan's national genebank in restoring genetic resources for food and agriculture after the earthquake and tsunami of 2011 is briefly described in Box 7.15.

\section{Living collections in botanic gardens}

Botanic gardens are widespread in every region of the world. Collections are maintained for a variety of purposes, including conservation, research, and ornamental and educational displays aimed at the public. The relative weight given to these objectives varies: not all botanic gardens operate conservation programmes in the sense of schemes that specifically target defined conservation objectives and maintain the quantities of specimens and genetic diversity required to meet these objective (Hernándes Bermejo, 1998). While associated biodiversity may not be a category that is widely recognized or targeted for conservation in botanic gardens, many gardens maintain plants that grow in and around crop, livestock, forest and aquatic production systems. Botanic gardens can play an important role in species reintroductions. They are increasingly becoming involved in ecological restoration programmes in habitats such as grasslands 
Box 7.15

The role of Japan's National Agriculture and Food Research Organization Genebank in recovering genetic resources after the earthquake of 2011

The natural environment of the Pacific coast in Tohoku Region was heavily impacted by the Great East Japan Earthquake of March 2011, which caused major changes to the topography of the area. The earthquake caused land subsidence, and the tsunami that followed the earthquake moved vast amounts of soil. The affected zone contains many priority areas for biodiversity conservation, including some of the 500 Important Wetlands in Japan and some Important Bird Areas.

Although much of the area inundated by the tsunami was farmed or urban land, there were also major impacts on vegetation in coastal areas, including in afforested land planted with the Japanese black pine (Pinus thunbegii) and the Japanese red pine ( $P$. densiflora), rivers, ponds, marshes and other wetlands, secondary grasslands and sand-dunes. About 497 ha of sand-dune vegetation and about 829 ha of coastal forests were lost. The composition of species living on some tidal flats has changed significantly due to the changes in their topography and substrates.
The National Agriculture and Food Research Organization (NARO) has been implementing the NARO Genebank project since 1985. NARO's Genetic Resources Center manages the project as the core institution of the national network for genetic resources for food and agriculture. The project plays a key role in the ex situ conservation of genetic resources for food and agriculture in Japan, and holds 226000 plant accessions, 33000 micro-organism accessions and 2000 animal accessions (livestock and insects). The Forest Research and Management Organization and Japan Fisheries Research and Education Agency have, respectively, managed genebank projects for forest genetic resources and aquatic genetic resources since 1985. The NARO Genebank's activities will contribute to the recovery of genetic resources for food and agriculture affected by the earthquake and to the revival of the region.

Source: Adapted from the country report of Japan and forests (BGCl, 2013). As well as maintaining field and greenhouse collections, some botanic gardens also maintain seed banks or in vitro collections (see above). More than 500 botanic gardens in more than 100 countries are members of Botanic Gardens Conservation International, ${ }^{15}$ an organization that aims "to collect, conserve, characterize and cultivate samples from all of the world's plants as an insurance policy against their extinction in the wild and as a source of plant material for human innovation, adaptation and resilience" (BGCl, 2018).

\section{Captive breeding and rearing of animals}

Many vertebrate and invertebrate associatedbiodiversity species are bred and reared in captivity, for instance in zoos, aquariums or research institutes or by commercial companies. In many cases, conservation is not the primary objective.

\footnotetext{
15 http://www.bgci.org
}

For example, companies that raise biological control agents for sale are motivated by profitmaking rather than by concerns about the loss of biodiversity. They may nonetheless maintain large populations of important associatedbiodiversity species in ex situ conditions. Zoos and aquariums have the potential to play an "insurance" role in conservation and may be the only option available for the short-term conservation of wild species threatened by severe habitat loss (Conde et al., 2011). They do not normally have any particular focus on associated biodiversity, but often keep species that are found in and around production systems. As with some botanic gardens, some zoos may be more oriented towards educational and/or recreational objectives than towards implementing conservation programmes in a strict sense. However, an increasing number do have explicit conservation objectives, with links to field programmes (e.g. ZSL, 2017). 
Invertebrate biocontrol organisms

Eight countries (11 percent) report captive breeding and rearing activities as a form of ex situ conservation of invertebrate biocontrol organisms. The organisms mentioned are entomophagous, ${ }^{16}$ parasitic ${ }^{17}$ or parasitoid ${ }^{18}$ invertebrates, with the most frequently reported being parasitoid wasps, mostly belonging to the genus Trichogramma, followed by ladybird beetles (Coccinellidae). Other types of organisms mentioned include earwigs (Dermaptera), rove beetles (Staphylinidae) and spiders. Biocontrol organisms are reported to be bred both by private companies and by public research institutes and universities.

\section{Invertebrate pollinators}

Seven countries (9 percent) report captive breeding and rearing activities as a form of ex situ conservation of invertebrate pollinators. The genera most commonly reported to be conserved ex situ are Bombus and Apis. This low number of countries reflects the findings of IPBES (2016b), which indicate that while there are a number of in situ pollinator-conservation initiatives based on habitat management, very few initiatives target the ex situ conservation of wild pollinators. Several countries mention that invertebrate pollinators are conserved in national agricultural research centres. For example, Georgia maintains a breeding farm for its native honey bee, the Caucasian honey bee (Apis mellifera caucasia). Jordan conserves 2000 queen cells of Syrian honey bees (Apis mellifera syriaca) per year at a research facility.

\section{Other invertebrates}

Very few countries mention captive breeding and rearing of invertebrates other than pollinators and biocontrol organisms. Exceptions include Bangladesh, which mentions that the tiger worm (Eisenia fetida) and the red earthworm (Lumbricus rubellus) are raised for the production of vermicompost. Panama mentions that corals

\footnotetext{
16 An organism that eats insects.

17 An organism that lives in or on an organism of a different species, the host. The parasite benefits at the expense of the host.

18 A parasite that eventually kills its host.
}

are conserved ex situ at the laboratories of the Agricultural and Livestock Research Institute of Panama ${ }^{19}$ and the Aquatic Resources Authority of Panama ${ }^{20}$ for research purposes.

\section{Vertebrates}

A few country reports mention zoos as institutions contributing to the ex situ conservation of vertebrate associated biodiversity. However, none provide information at species level. Some countries note that zoos contribute to research and to raising public awareness. Captive breeding of fish species is a common way of increasing depleted natural stocks (see Section 7.2.4). A few countries report activities of this kind conducted by governmental agencies or private companies, with salmon species the most frequently mentioned. ${ }^{21}$

\subsection{Wild foods}

- Countries report that they are implementing in situ conservation measures that target the protection of whole ecosystems that supply wild foods, and to a lesser extent, measures targeting individual wild food species.

- Over 350 wild food species are reported to be conserved ex situ, representing 13 percent of all wild food species reported.

\subsubsection{In situ conservation}

Species that are sources of wild foods can benefit from a range of in situ conservation measures that target individual species or that target the protection of whole ecosystems. In both cases, the conservation measures may or may not be motivated specifically by the objective of protecting supplies of wild foods.

\footnotetext{
19 http://www.idiap.gob.pa

20 http://arap.gob.pa

21 Salmon are normally recognized mainly for their role in supplying provisioning services (i.e. serving as a source of food). However, they also contribute to regulating and supporting services. For example, the country report from Belgium mentions that they play a role in nutrient cycling and the report from Sweden mentions their role in habitat provisioning.
} 
TABLE 7.3

Wild food species and genera reported to be conserved in situ, by taxonomic group

\begin{tabular}{|c|c|c|c|}
\hline Taxonomic group & Count of species & Count of genera & Examples of species reported \\
\hline Birds & 3 & 3 & Perdix perdix (grey partridge), Phasianus colchicus (Common pheasant) \\
\hline Crustaceans & 5 & 4 & $\begin{array}{l}\text { Astacus astacus (European crayfish), Macrobrachium rosenbergii (giant } \\
\text { river prawn), Pacifastacus leniusculus (signal crayfish) }\end{array}$ \\
\hline Fish & 55 & 44 & $\begin{array}{l}\text { Barbus barbus (barbel), Labeo bata (bata), Salmo salar (Atlantic salmon), } \\
\text { Salmo trutta (brown trout), Merluccius hubbsi (hake), Tor tor (mahseer) }\end{array}$ \\
\hline Mammals & 14 & 13 & $\begin{array}{l}\text { Capreolus capreolus (European roe deer), Cervus elaphus (red deer), } \\
\text { Cervus nippon (sika deer), Giraffa camelopardalis (giraffe), Hippopotamus } \\
\text { amphibius (hippopotamus), Lepus europaeus (European hare), Pecari } \\
\text { tajacu (collared peccary), Rupicapra rupicapra (chamois), Sus scrofa (wild } \\
\text { boar) }\end{array}$ \\
\hline Reptiles & 4 & 3 & $\begin{array}{l}\text { Melanosuchus niger (black caiman), Podocnemis expansa (tartaruga), } \\
\text { Python sebae (African rock python) }\end{array}$ \\
\hline Fungi & 2 & 2 & $\begin{array}{l}\text { Ophiocordyceps sinensis (yartsa gunbu), Tricholoma matsutake } \\
\text { (matsutake) }\end{array}$ \\
\hline Plants & 150 & 126 & $\begin{array}{l}\text { Aegle marmelos (Indian bael), Capparis spinosa (caper), Centella asiatica } \\
\text { (centella), Dillenia indica (chulta), Dioscorea bulbifera (air potato), } \\
\text { Diplazium esculentum (vegetable fern), Malus sylvestris (crab apple), } \\
\text { Mauritia flexuosa (aguaje) Parkia biglobosa (African locust bean tree), } \\
\text { Prunus avium (wild cherry), Pyrus pyraster (wild pear), Sclerocarya birrea } \\
\text { (marula), Vitellaria paradoxa (shea tree), Ximenia caffra (sourplum) }\end{array}$ \\
\hline Total & 233 & 195 & \\
\hline
\end{tabular}

Notes: The count of genera refers to all genera reported, whether at genus level or at species level. Thirty-four out of a total of 91 countries reported at least one species or other taxon.

Source: Country reports prepared for The State of the World's Biodiversity for Food and Agriculture.

The range of different approaches that can be used in the in situ conservation of domesticated and wild components of BFA is discussed in Sections 7.2 and 7.3.1. Protected areas are discussed in detail in Section 7.5, including an assessment of the level of coverage of wild food species within the comprehensively assessed taxonomic groups of The International Union for Conservation of Nature Red List of Threatened Species $^{\mathrm{TM}}$ (The IUCN Red List). Broader institutional, policy and legal frameworks for the management of BFA, including those that directly or indirectly contribute to in situ conservation efforts, including for wild foods, are discussed in Chapter 8. The present section focuses on the state of in situ conservation activities for wild foods as presented in the country reports. Except where noted otherwise, it refers to activities specifically reported to constitute "in situ conservation and management activities or programmes that support the maintenance of wild foods." The Voluntary Guidelines for the Conservation and Sustainable Use of Crop Wild Relatives and Wild Food Plants, endorsed by the Commission on Genetic Resources for Food and Agriculture, are described in Box 7.16.

Countries were invited to list wild food species conserved in situ, to report the types of in situ conservation activities undertaken, and to indicate the site or location of the activity and the objectives of the conservation efforts. A total of 407 responses at various taxonomic levels were reported by a total of 34 countries. These responses mentioned 233 distinct species and 195 genera. Examples of wild food species reported to be conserved in situ are provided in Table 7.3.

While the country reports mention over 2800 wild food species (see Section 4.4), the number of such species reported to be conserved in situ is much lower (8 percent of those reported). 


\section{PART C}

Box 7.16

Voluntary Guidelines for the Conservation and Sustainable Use of Crop Wild Relatives and Wild Food Plants

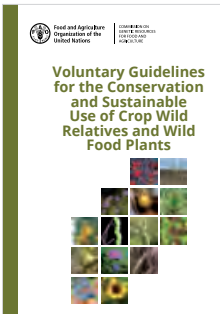

The continuously evolving adaptive characteristics of crop wild relatives have enabled them to cope with changing environmental conditions and made them a rich reservoir of novel traits and genes that can be used to develop crop varieties that are tolerant of biotic and abiotic stresses and adapted

to climate change. Wild food plants constitute important components of the diets of many people across the globe and are rich sources of very important micronutrients. In response to increasing levels of threat to both categories of species, the Commission on Genetic Resources for Food and Agriculture oversaw the preparation of Voluntary Guidelines for the Conservation and Sustainable Use of Crop Wild Relatives and Wild Food Plants.

The Voluntary Guidelines are intended primarily for use by governments in the development of national plans for the conservation and sustainable use of crop wild relatives and wild food plants. They present the general context and requisites for developing a national plan, then focus on assessment of the particular national context to generate the evidence base needed to underpin the national plan and determine the appropriate scope in terms of geographical and taxa coverage. They also stress the critical importance of adequate and sustainable financial and human resources. Technical activities recommended for inclusion in a national plan are described and guidance is given on how to write the strategic national plan itself, along with advice on how to implement the activities identified. Monitoring and datamanagement methodologies and an inventory of relevant learning tools for capacity building are also presented. The Voluntary Guidelines were endorsed by the Commission in 2017.

Note: The voluntary guidelines can be viewed at http://www.fao.org/3/ a-i7788e.pdf
This may in part be explained by the fact that many wild food species are conserved under broader habitat or ecosystem conservation programmes that do not target individual species. Countries' responses frequently refer to groups of wild foods rather than particular species. For example, Ecuador mentions that several hundred species of fish are found in aquatic conservation areas.

Countries' responses on objectives for the in situ conservation of wild foods are summarized in Figure 7.4. The most frequently reported objectives are simply the conservation and protection of species (41 percent of responses) and of habitats (16 percent). Objectives related to food and nutrition account for 10 percent of responses, those related to education and research for 9 percent and those related to reintroduction and utilization for 7 percent each.

Among specific actions taken to promote the in situ conservation of wild foods, the establishment of protected areas is the most commonly reported (16 percent of aggregated answers), followed by monitoring, inventory and characterization (14 percent), conservation of habitats (12 percent) and the establishment of management plans (9 percent). Actions mentioned by a few countries include fish and fry stocking, restrictions on the collection of wild foods, establishing and reinforcing surveillance to ensure regulations are complied with, awareness raising, provision of subsidies, and introduction and translocation of species. Several countries report ways in which habitats are managed with a view to conserving wild foods in situ, for example via the establishment of wildlife corridors (Switzerland) and the maintenance of freshwater ecosystems for migrating fish (Belgium).

Conservation actions for wild foods are reported to operate on a range of different scales and to involve a range of different stakeholders. Guinea, 


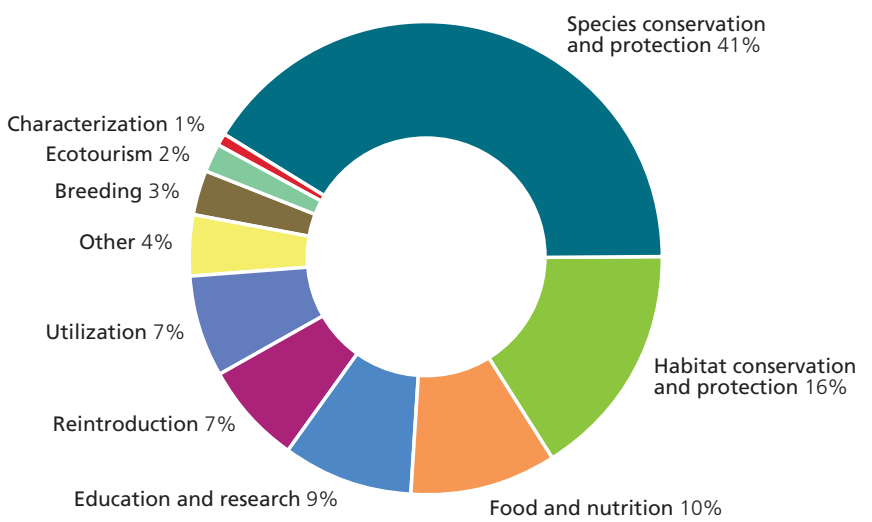

Notes: Based on 373 responses. A "response" is a mention by a specific country of a conservation objective for a specific wild food species or higher taxonomic group. In some cases more than one conservation objective was reported for the same wild food. Thirty-four out of a total of 91 reporting countries provided information for at least one species or other taxon. Source: Country reports prepared for The State of the World's Biodiversity for Food and Agriculture.

for example, reports the following activities in this context:

- raising awareness (of communities) and setting up village committees to combat bush fires;

- involving local communities in the management of natural resources;

- establishing an eco-ranger service to protect forest reserves and protected areas;

- regulating hunting;

- conducting inventory and characterization activities for wild species used for food purposes;

- strengthening the regulation of the exploitation of wild food resources; and

- strengthening networking among neighbouring countries.

Although not explicitly reported as a form of in situ conservation of wild foods, a few countries in their responses to a question on "actions and countermeasures taken to limit unsustainable use and/or support sustainable use of associated biodiversity and/or wild foods" refer to the cultivation or domestication of wild food species with the aim of reducing pressure on overexploited wild stocks or mention the development of other alternative livelihood activities. For example, Kenya mentions domestication and commercialization of aloe. Bhutan reports the initiation of community-based projects to grow two species of orchid (Cymbidium erythraeum and C. hookerianum) commonly harvested from the wild for use as food.

\subsubsection{Ex situ conservation}

This section describes the state of ex situ conservation activities for wild foods as presented in the country reports. It focuses on activities and programmes specifically reported to be established for the conservation of wild foods.

Countries were invited to list wild food species that are conserved ex situ, to provide information on the size of collections and on conservation conditions, to indicate the objectives of the conservation efforts, and to provide information on characterization and evaluation status of the collections (see Section 6.4 for information on the state of characterization of ex situ collections of wild foods). Thirty-four country reports refer to a total of 527 responses at various taxonomic levels, 


\section{PART C}

TABLE 7.4

Wild food species and genera reported to be conserved ex situ, by taxonomic group

\begin{tabular}{|c|c|c|c|}
\hline Taxonomic group & Count of species & Count of genera & Examples of species and genera reported \\
\hline Insects & 1 & 2 & Gonimbrasia belina (mopane worm), Choreutis spp. (a genus of moths) \\
\hline Birds & 5 & 6 & $\begin{array}{l}\text { Perdix perdix (grey partridge), Phasianus colchicus (common pheasant), } \\
\text { Chlamydotis undulata (houbara bustard), Struthio camelus (common } \\
\text { ostrich) }\end{array}$ \\
\hline Crustaceans & 1 & 1 & Litopenaeus vannamei (Pacific white shrimp) \\
\hline Molluscs & 9 & 9 & $\begin{array}{l}\text { Mytilus galloprovincialis (Mediterranean mussel), Crassostrea gigas (Pacific } \\
\text { oyster), Crassostrea sikamea (Kumamoto oyster), Lamellidens marginalis, } \\
\text { Bellamya bengalensis, Brotia costula, Haliotis rufescens (red abalone), Pila } \\
\text { globosa }\end{array}$ \\
\hline Fish & 50 & 36 & $\begin{array}{l}\text { Oncorhynchus mykiss (rainbow trout), Salmo salar (Atlantic salmon), } \\
\text { Anoplopoma fimbria (sablefish), Heteropneustes fossilis (airsac catfish), } \\
\text { Paralichthys californicus (California halibut) }\end{array}$ \\
\hline Mammals & 12 & 13 & $\begin{array}{l}\text { Hystrix indica (Indian porcupine), Axis axis (chital), Cephalophus rufilatus } \\
\text { (red-flanked duiker), Damaliscus lunatus (topi), Moschiola meminna } \\
\text { (Indian spotted mouse deer), Muntiacus muntjak (barking deer), Sus } \\
\text { scrofa (wild boar) }\end{array}$ \\
\hline Fungi & 14 & 24 & $\begin{array}{l}\text { Auricularia olivaceus (jelly fungus), Calocybe indica, Cantharellus } \\
\text { applanatus, Cantharellus elongatipes, Helvella villosa, Lentinus } \\
\text { squarrosulus, Phlebopus sudanicus, Tricholoma matsutake (matsutake), } \\
\text { Volvariella volvacea (paddy straw mushroom) }\end{array}$ \\
\hline Plants & 275 & 189 & $\begin{array}{l}\text { Carissa spinarum (bush plum), Capparis spinosa (caper), Foeniculum } \\
\text { vulgare (fennel), Origanum vulgare (oregano), Portulaca oleracea } \\
\text { (common purslane), Sambucus nigra (elderberry), Ziziphus mauritiana } \\
\text { (jujube) }\end{array}$ \\
\hline Other & 1 & 1 & Chaetoceros calcitrans \\
\hline Total & 368 & 281 & \\
\hline
\end{tabular}

Note: The count of genera refers to all genera reported, whether at genus level or at species level. Thirty-four out of a total of 91 countries reported at least one species or other taxon.

Source: Country reports prepared for The State of the World's Biodiversity for Food and Agriculture.

including references to 368 distinct species and 281 genera (Table 7.4). As in the case of in situ conservation (Section 7.4.1), the number of wild food species reported to be conserved ex situ is much lower than the total number mentioned in the country reports (13 percent).

The main ex situ conservation methods reported for wild food species include genebanks, living collections in botanic gardens, and captive breeding and rearing. Many of the species reported as sources of wild foods fall within other categories of BFA discussed in this report, for example species harvested in the fisheries and forest sectors, wild relatives of crops, livestock and species raised in aquaculture, and species classed as associated biodiversity. Thus the main methods used in the ex situ conservation of these categories of BFA are also relevant in the context of the conservation of wild food species. These methods are discussed in Sections 7.2 and 7.3.

For 71 percent of responses referring to species or other taxonomic groups of wild foods conserved ex situ, countries also provided information on conservation objectives. The most frequently reported objective is simply species conservation (25 percent of responses). Other responses include research (10 percent), breeding (9 percent) and objectives related to food and nutrition (7 percent). 


\subsection{Roles of protected areas}

- Approximately 15 percent of land and inland waters, 10 percent of coastal and marine areas within national jurisdiction and just over 4 percent of the world's oceans lie within protected areas. However, protected area networks remain ecologically unrepresentative and poorly connected, and many critical sites for biodiversity are poorly conserved.

- A first overview of how the biodiversity used for human food included in The IUCN Red List is covered by the protected areas network concludes that over 98 percent of species used for human food (95 percent in the case of threatened species) partially or fully meet conservation targets for coverage.

- In addition to protected areas, countries report a wide range of designated areas of particular significance for biodiversity for food and agriculture, including Globally Important Agricultural Heritage Systems, World Heritage Sites and Wetlands of International Importance (Ramsar Sites).

Protected areas, as defined by the International Union for Conservation of Nature (IUCN), are clearly delineated geographical spaces, recognized, dedicated and managed, through legal or other effective means, to achieve the long-term conservation of nature, along with associated ecosystem services and cultural values (IUCN, 2008). Within this broad framework, protected areas can be managed in a wide variety of ways and under a range of governance types, ranging from strictly protected sites entirely set aside from human intervention to protected landscapes that include long-term managed areas and settled human communities, reserves owned and run by governments and self-declared protected areas run by indigenous communities within their traditional territories (Davies et al., 2012). IUCN classifies protected areas into six management categories (one with a subdivision) according to their management objectives (see Table 7.5). The categories are recognized by international bodies such as the United Nations and by many national governments as the global standard for defining and recording protected areas, and as such are increasingly being incorporated into government legislation.

Designation of protected areas is recognized as an important component of global efforts to improve the in situ conservation of biodiversity. Aichi Biodiversity Target 11, under the Convention on Biological Diversity's (CBD's) Strategic Plan for Biodiversity 2011-2020 reads as follows:

By 2020, at least 17 percent of terrestrial and inland water, and 10 percent of coastal and marine areas, especially areas of particular importance for biodiversity and ecosystem services, are conserved through effectively and equitably managed, ecologically representative and well connected systems of protected areas and other effective area-based conservation measures, and integrated into the wider landscapes and seascapes (CBD, 2010a).

Protected areas contribute in many ways to the achievement of the Sustainable Development Goals (Dudley et al., 2017). One target under Sustainable Development Goal 14 (Conserve and sustainably use the oceans, seas and marine resources for sustainable development) and two under Sustainable Development Goal 15 (Protect, restore and promote sustainable use of terrestrial ecosystems, sustainably manage forests, combat desertification, and halt and reverse land degradation and halt biodiversity loss) are directly related to protected areas. ${ }^{22}$

Protected areas contribute to the delivery of a range of ecosystem services that are essential to food and agriculture, including by protecting and enhancing water flows and water quality, conserving habitats that maintain nursery, feeding and breeding areas for fish and other species harvested by people, forming soils and maintaining soil fertility, reducing land degradation, providing havens for pollinators, reducing pollution,

\footnotetext{
22 Indicator 14.5.1 is "Coverage of protected areas in relation to marine areas." Indicator 15.1.2 is "Proportion of important sites for terrestrial and freshwater biodiversity that are covered by protected areas, by ecosystem type." Indicator 15.4.1 is "Coverage by protected areas of important sites for mountain biodiversity."
} 
TABLE 7.5

\section{IUCN Protected Area Management Categories}

\begin{tabular}{|c|c|c|}
\hline Category & Definition & Primary objective \\
\hline $\begin{array}{l}\text { Category la: } \\
\text { Strict Nature Reserve }\end{array}$ & $\begin{array}{l}\text { Strictly protected for biodiversity and also possibly } \\
\text { geological/geomorphological features, where human } \\
\text { visitation, use and impacts are controlled and limited to } \\
\text { ensure protection of the conservation values. }\end{array}$ & $\begin{array}{l}\text { To conserve regionally, nationally or globally outstanding } \\
\text { ecosystems, species and/or geodiversity features: these } \\
\text { attributes will have been formed mostly or entirely by } \\
\text { non-human forces and will be degraded or destroyed when } \\
\text { subjected to all but very light human impact. }\end{array}$ \\
\hline $\begin{array}{l}\text { Category lb: } \\
\text { Wilderness Area }\end{array}$ & $\begin{array}{l}\text { Usually large unmodified or slightly modified areas, } \\
\text { retaining their natural character and influence, without } \\
\text { permanent or significant human habitation, protected and } \\
\text { managed to preserve their natural condition. }\end{array}$ & $\begin{array}{l}\text { To protect the long-term ecological integrity of natural } \\
\text { areas that are undisturbed by significant human activity, } \\
\text { free of modern infrastructure and where natural forces } \\
\text { and processes predominate, so that current and future } \\
\text { generations have the opportunity to experience such areas. }\end{array}$ \\
\hline $\begin{array}{l}\text { Category II: } \\
\text { National Park }\end{array}$ & $\begin{array}{l}\text { Large natural or near-natural areas protecting large- } \\
\text { scale ecological processes with characteristic species and } \\
\text { ecosystems, which also have environmentally and culturally } \\
\text { compatible spiritual, scientific, educational, recreational and } \\
\text { visitor opportunities. }\end{array}$ & $\begin{array}{l}\text { To protect natural biodiversity along with its underlying } \\
\text { ecological structure and supporting environmental } \\
\text { processes, and to promote education and recreation. }\end{array}$ \\
\hline $\begin{array}{l}\text { Category III: } \\
\text { Natural Monument } \\
\text { or Feature }\end{array}$ & $\begin{array}{l}\text { Areas set aside to protect a specific natural monument, } \\
\text { which can be a landform, sea mount, marine cavern, } \\
\text { geological feature such as a cave, or a living feature such as } \\
\text { an ancient grove. }\end{array}$ & $\begin{array}{l}\text { To protect specific outstanding natural features and their } \\
\text { associated biodiversity and habitats. }\end{array}$ \\
\hline $\begin{array}{l}\text { Category IV: } \\
\text { Habitat/Species } \\
\text { Management Area }\end{array}$ & $\begin{array}{l}\text { Areas to protect particular species or habitats, where } \\
\text { management reflects this priority. Many will need regular, } \\
\text { active interventions to meet the needs of particular species } \\
\text { or habitats, but this is not a requirement of the category. }\end{array}$ & To maintain, conserve and restore species and habitats. \\
\hline $\begin{array}{l}\text { Category V: } \\
\text { Protected Landscape/ } \\
\text { Seascape }\end{array}$ & $\begin{array}{l}\text { Where the interaction of people and nature over time } \\
\text { has produced a distinct character with significant } \\
\text { ecological, biological, cultural and scenic value: and where } \\
\text { safeguarding the integrity of this interaction is vital to } \\
\text { protecting and sustaining the area and its associated nature } \\
\text { conservation and other values. }\end{array}$ & $\begin{array}{l}\text { To protect and sustain important landscapes/seascapes } \\
\text { and the associated nature conservation and other values } \\
\text { created by interactions with humans through traditional } \\
\text { management practices. }\end{array}$ \\
\hline $\begin{array}{l}\text { Category Vl: } \\
\text { Protected area with } \\
\text { sustainable use of } \\
\text { natural resources }\end{array}$ & $\begin{array}{l}\text { Areas which conserve ecosystems, together with } \\
\text { associated cultural values and traditional natural resource } \\
\text { management systems. Generally large, mainly in a natural } \\
\text { condition, with a proportion under sustainable natural } \\
\text { resource management and where low-level non-industrial } \\
\text { natural resource use compatible with nature conservation is } \\
\text { seen as one of the main aims. }\end{array}$ & $\begin{array}{l}\text { To protect natural ecosystems and use natural resources } \\
\text { sustainably, when conservation and sustainable use can be } \\
\text { mutually beneficial. }\end{array}$ \\
\hline
\end{tabular}

Source: Based on Dudley, ed., 2008.

maintaining coastal protection and natural flood-control mechanisms, and protecting reservoirs of crop wild relatives that can be used to enhance crop productivity and resilience (FAO, 2014h; World Bank, 2010). Their role in climate change adaptation and mitigation is increasingly recognized. It has been estimated that the global network of protected areas stores at least 15 percent of terrestrial carbon (World Bank, 2010). However, the effectiveness of protected areas in the delivery of ecosystem services depends on how effectively sites are managed, how they are integrated with surrounding landscapes and land-use strategies, and whether or not they are supported by local communities. As protected areas exist under a range of management and governance regimes (see above), the effectiveness of delivery varies across sites.

As indicated in the Aichi Target quoted above, in addition to protected areas per se, the significance of "other effective area-based conservation measures" (OECMs) to in situ conservation is 


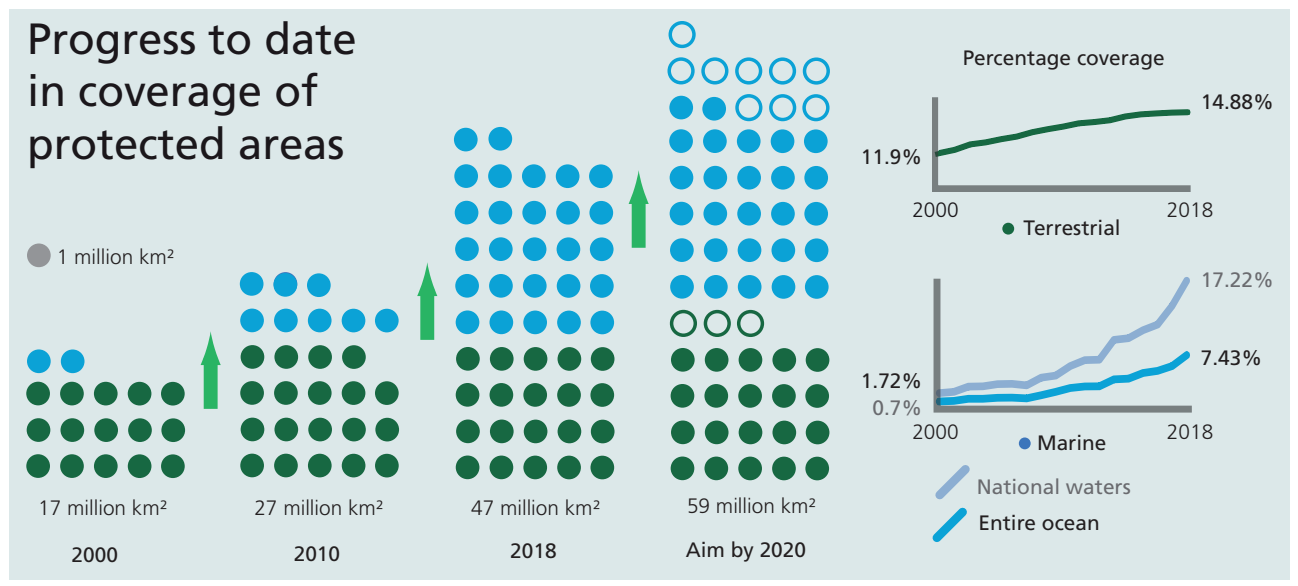

Note: The figure is based on the situation in November 2018. Source: UNEP-WCMC.

also recognized. The Conference of the Parties to the $C B D$, at its fourteenth meeting, held in 2018, adopted the following definition of OECMs:

a geographically defined area other than a Protected Area, which is governed and managed in ways that achieve positive and sustained long-term outcomes for the in situ conservation of biodiversity, with associated ecosystem functions and services and, where applicable, cultural, spiritual, socioeconomic, and other locally relevant values.

\subsubsection{Status and trends}

Approximately 15 percent of land and inland waters, 10 percent of coastal and marine areas within national jurisdiction and just over 4 percent of the world's oceans lie within protected areas (UNEP-WCMC and IUCN, 2018). The Protected Planet Report 2018 (UNEP-WCMC, IUCN and NGS, 2018) (which is based on the data contained in the World Database on Protected Areas, the most comprehensive source of information about protected areas) anticipates that the coverage element of Aichi Target 11 (see above) on conserving
17 percent of terrestrial areas by 2020 is likely to be met globally (see Figure 7.5). However, protected area networks remain ecologically unrepresentative and poorly connected, and many critical sites for biodiversity are poorly conserved. The element of Aichi Target 11 on protecting 10 percent of coastal and marine areas is on course to be met in coastal waters, although open-ocean and deep-sea areas, including the high seas, are not well covered (see Figure 7.6). The CBD reports that inadequate management, monitoring and enforcement of protected areas remains widespread (CBD Secretariat, 2014a), and this can limit the effectiveness of protected areas networks (Watson et al., 2014). The precise extent of such problems, however, remains unclear as information on the effectiveness of protected areas management in many countries, and on trends in this regard, is limited (Geldmann et al., 2015), although reporting is improving. To address this knowledge gap on the effectiveness of protected areas, in 2010 Parties to the CBD were invited to implement management-effectiveness evaluations in at least 60 percent of their total protected areas by 


\section{PART C}

Geographic distribution of the terrestrial, marine and coastal protected areas of the world

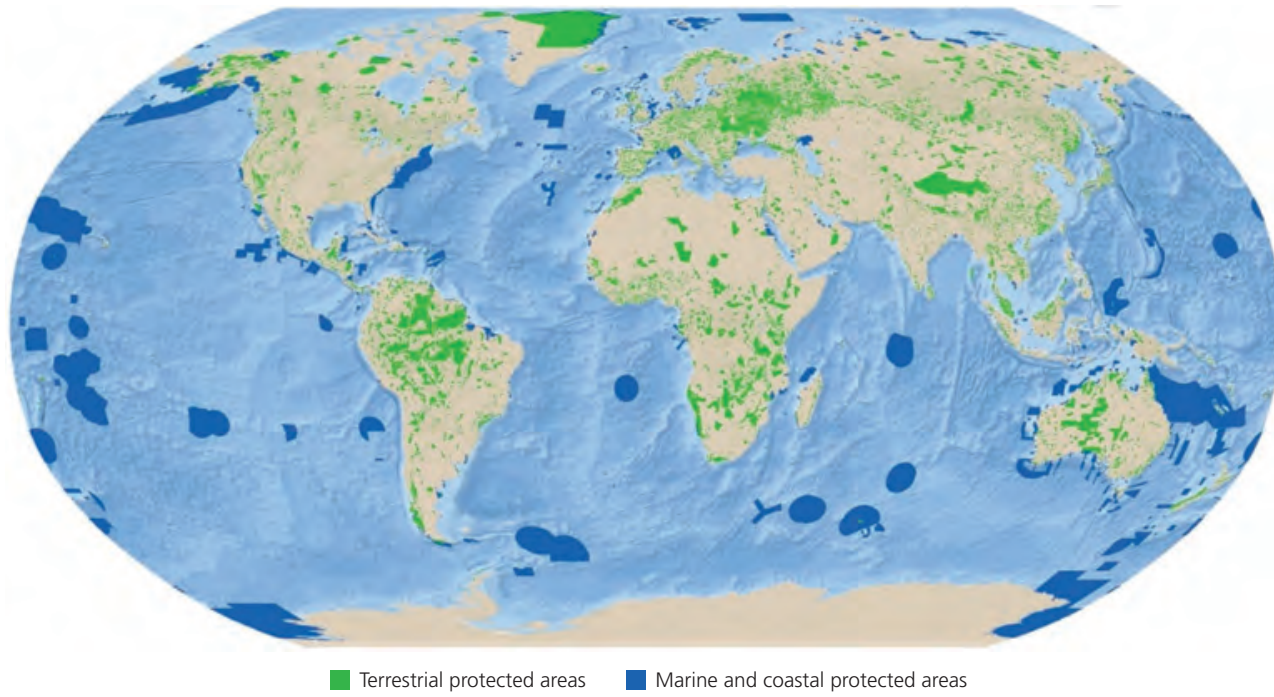

Source: UNEP-WCMC and IUCN, 2018

2015 (CBD Secretariat, 2010b). In 2016, all national focal points to the CBD were invited to review and update their management-effectiveness data in the Global Database on Protected Areas Management Effectiveness (GD-PAME), ${ }^{23}$ which is the most comprehensive global dataset on assessments, providing information on 238563 protected areas, from 244 countries and territories, covering more than 46 million $\mathrm{km}^{2}$ (UNEP-WCMC, 2018). The latest report from the GD-PAME indicates that only 20 percent of national governments provided updated information on management effectiveness. However, it is widely recognized that many more assessments have been made than those that are formally reported. For example, analyses of national commitments for improving the management effectiveness of protected areas were informally submitted to the CBD Secretariat by 95 countries in 2018. Reported commitments included

23 https://pame.protectedplanet.net
240 priority actions in the area of addressing protected-area management. This indicates significant improvements in the reporting, and effectiveness, of the management of protected areas.

In order to address gaps in reporting and implementation of effective management in protected areas and sites that are defined as OECMs, IUCN has adopted a new standard for the IUCN Green List of Protected and Conserved Areas (IUCN and WCPA, 2017) (see Box 7.17). In addition, the IUCN World Commission on Protected Areas (IUCN WCPA) has developed guidance for conservation in marine protected areas (IUCN WCPA, 2018).

\subsubsection{Contribution to conservation of wild species used for food}

As spatial data for species distribution ranges have become more widely accessible and available, various studies have analysed the extent to which the protected area network effectively conserves biodiversity (Butchart et al., 2015; 
Rodrigues et al., 2004). Global gap analyses have been conducted for several complete taxonomic groups, for example cacti, amphibians, turtles, birds and mammals (Butchart et al., 2015; Goettsch, Durán and Gaston, 2018; Rodrigues et al., 2004). This subsection presents an analysis of the extent to which selected components of BFA are covered by protected areas.

With regard to scope, it should be noted that OECMs (see above) are not included in the analysis. While these areas are recognized as being vitally important to the in situ conservation of biodiversity, there is currently no globally managed dataset on areas defined as OECMs from which data could easily be extracted to conduct a spatial analysis. There is a global dataset on Indigenous and Community Conserved Areas (ICCAs) ${ }^{24}$ maintained alongside the World Database on Protected Areas, by the United Nations Environment Programme's World Conservation Monitoring Centre (UNEP-WCMC). ICCAs are recognized as contributing to Aichi Target 11. However, the term OECM also applies to other conservation areas, such as privately conserved areas. After the adoption of a globally agreed definition for OECMs, Parties to the CBD invited IUCN and UNEP-WCMC to expand the World Database on Protected Areas by providing a section on OECMs. Subject to availability of resources, reporting of OECMs by governments and non-state actors and confidentiality restrictions (for example, information on some private sites and ICCA locations is confidential), this work is due to start in 2019. Finally, the analysis also does not include mapping of key biodiversity areas (KBAs), as data on their location were not accessible for analysis within the timeframe of the study. ${ }^{25}$

The analysis was based on two global datasets, The IUCN Red List (see Box 4.1) (Version 2017-2)

\footnotetext{
24 http://www.iccaregistry.org/

${ }^{25}$ KBAs are geographical areas on land and/or in water with defined ecological, physical, administrative or management boundaries that are actually or potentially manageable as a single unit (e.g. a protected area or other managed conservation unit) (IUCN, 2016c). Efforts are underway to map the distribution of protected areas in relation to KBAs.
}

and the World Database on Protected Areas (UNEP-WCMC and IUCN, 2018). The former is the world's most comprehensive information source for the extinction risk of species (IUCN, 2017a). The version used for the analysis includes 87967 species, of which 11 percent (9 627 species) are classified as used for food by humans. Of these, a total of 1783 species (18 percent) are listed under a threatened category (Critically Endangered, Endangered or Vulnerable), 611 (6 percent) as Near Threatened and 1218 (13 percent) as Data Deficient (Figure 4.25). Almost half (48 percent) of the assessed species that are utilized for food are fishes (4 611 species). Birds account for 1 646, mammals for 1237 and plants for 804 . The latter include 14 crop wild relative species (out of a total 760 such species assessed globally for The IUCN Red List). However, to avoid biases the analysis only covered taxonomic groups that had been comprehensively assessed ${ }^{26}$ for The IUCN Red List and for which complete data on their distribution ranges were available (see Table 7.6). Among these groups, the selected groups of bony fishes had the highest percentage (29 percent) of species utilized for food, followed by sharks and rays (26 percent), the selected groups of crustaceans (26 percent) and mammals (21 percent).

The methodology described by Rodrigues et al. (2004) was used to systematically identify gaps in the current global protected areas network. For each species, the percentage of its geographical range covered by protected areas was determined by overlaying a species-distribution map with a map of protected areas. A species was classed as a "gap species" if it was not found within protected areas, and classed as "covered" if a predetermined percentage of its geographic range (referred to as the "conservation target") was included in protected areas. For species with geographic ranges of $1000 \mathrm{~km}^{2}$ or less, the conservation target was taken to equate to the entire range. For species with ranges of $250000 \mathrm{~km}^{2}$

\footnotetext{
${ }^{26}$ Comprehensively assessed groups are the taxonomic groups for which the extinction risk of all extant species have been evaluated following the IUCN Red List Categories and Criteria.
} 


\section{PART C}

TABLE 7.6

Number of species in the comprehensively assessed groups of The IUCN Red List with mapped ranges and classified as used for human food

\begin{tabular}{|c|c|c|c|c|c|c|c|}
\hline $\begin{array}{l}\text { Taxonomic group/IUCN } \\
\text { Red List Category }\end{array}$ & CR & EN & VU & NT & LC & DD & Total \\
\hline Amphibians & 9 & 20 & 34 & 22 & 141 & 12 & 238 \\
\hline Birds & 55 & 113 & 205 & 191 & 1019 & 5 & 1588 \\
\hline Selected bony fishes & 12 & 10 & 31 & 38 & 503 & 92 & 686 \\
\hline Conifers & 0 & 0 & 0 & 0 & 1 & 0 & 1 \\
\hline Selected crustaceans & 0 & 4 & 9 & 6 & 158 & 54 & 231 \\
\hline Selected dicots & 0 & 0 & 1 & 2 & 10 & 1 & 14 \\
\hline Selected gastropods & 0 & 0 & 0 & 0 & 3 & 0 & 3 \\
\hline Hagfishes & 0 & 0 & 1 & 1 & 0 & 2 & 4 \\
\hline Mammals & 81 & 168 & 198 & 112 & 543 & 67 & 1169 \\
\hline Seagrasses & 0 & 0 & 0 & 0 & 4 & 0 & 4 \\
\hline Selected reptiles & 3 & 0 & 5 & 1 & 11 & 0 & 20 \\
\hline Sharks and rays & 6 & 27 & 57 & 51 & 62 & 82 & 285 \\
\hline Total & 166 & 342 & 541 & 424 & 2455 & 315 & 4243 \\
\hline
\end{tabular}

Note: Figures indicate the number of species classified as used for human food in comprehensively assessed groups in The IUCN Red List grouped by IUCN Red List Category (CR = Critically, EN = Endangered, VU = Vulnerable, NT = Near Threatened, LC = Least Concern, and DD = Data Deficient). Selected bony fishes = sturgeons, tunas, billfishes, blennies, pufferfishes, angelfishes, butterflyfishes, surgeonfishes, groupers, wrasses, seabreams, picarels and porgies; selected crustaceans = lobsters, freshwater crabs, freshwater crayfishes and freshwater shrimps; selected dicots = magnolias, mangroves; selected gastropods = cone snails; selected reptiles = marine turtles, seasnakes and crocodiles.

Source: The IUCN Red List version 2017-2.

or more, the conservation target was taken to equate to 10 percent of the range. Conservation targets for species with intermediate ranges were determined by interpolating between these two extremes (see Rodrigues et al., 2004).

Species whose conservation target was only partly met were classed as "partial gap" species. ${ }^{27}$ The analysis excluded species that were extinct or whose ranges were uncertain. Only species considered to be native or reintroduced were included. The analysis considered a total of 214879 protected areas and a total of 4243 species.

\footnotetext{
27 Further information about the scope, assessment methodology and caveats to this analysis is presented in the thematic study Study on the linkages between protected areas and the conservation of biodiversity for food and agriculture commissioned to support the preparation of The State of the World's Biodiversity for Food and Agriculture.
}

Among the species considered, 4 percent (166) are classed as Critically Endangered, 8 percent as Endangered, 13 percent as Vulnerable, 10 percent as Near Threatened, 58 percent as Least Concern and 7 percent as Data Deficient. Following the "best estimate" calculation method (Schipper et al., 2008; Hoffman et al., 2010), i.e. assuming that Data Deficient species are threatened in the same proportion as data sufficient species, a total of 27 percent of the species considered are threatened with extinction.

Of the species included in the analysis, 83 species ( 2 percent) were found not to be present in protected areas, (i.e. to be gap species - see above), 1472 (35 percent) to partially meet their conservation target (i.e. to be partial gap species) and 2688 species (63 percent) to meet their conservation target (i.e. to be "covered"). Among 
FIGURE 7.7

Protected area coverage of species in the comprehensively assessed taxonomic groups of The IUCN Red List with mapped ranges and classified as used for human food

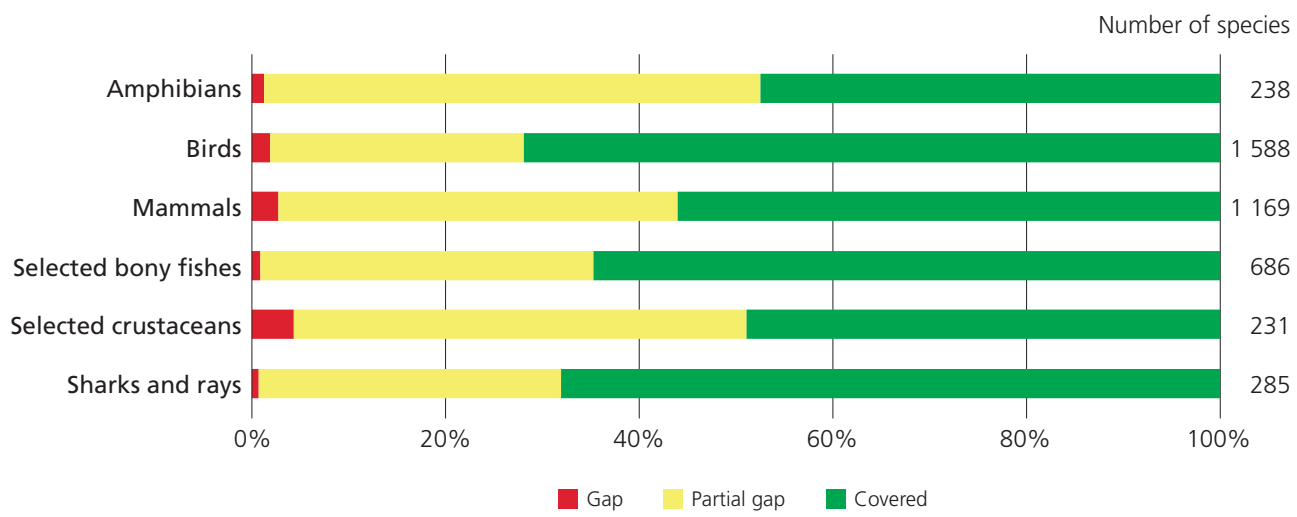

Notes: "Gap" = species range not covered by protected areas. "Partial gap" = species range partially covered by protected areas but not to target level. "Covered" = species range covered to target level. Selected crustaceans = lobsters, freshwater crabs, freshwater crayfishes and freshwater shrimps; selected bony fishes = sturgeons, tunas, billfishes, blennies, pufferfishes, angelfishes, butterflyfishes, surgeonfishes, groupers, wrasses, seabreams, picarels and porgies. Comprehensively assessed taxa with fewer than 25 mapped species utilized for food are not shown. These correspond to conifers (1 species), hagfishes (4 species), seagrasses (4 species), selected dicots (magnolias and mangroves, 14 species), selected gastropods (cone snails, 3 species) and selected reptiles (marine turtles, seasnakes and crocodiles, 20 species).

Source: Authors' calculations using data from The IUCN Red List version 2017-2 and the World Database on Protected Areas (UNEP-WCMC and IUCN, 2018).

the groups of species considered, crustaceans were found to have the highest proportion of gap species (4 percent), followed by mammals (3 percent) and birds (2 percent) (see Figure 7.7). A total of 52 threatened species ( 5 percent of the total) were found to be gap species, 611 (58 percent) to be partial gap species and 388 (37 percent) to be covered (Figure 7.8). Birds and mammals were found to have the highest proportion of threatened species located outside protected areas (6 percent in both cases), followed by amphibians (3 percent) (Figure 7.8).

The proportion of gap species found in the present analysis is over six-fold lower than the 12 percent found to fall into this category in an analysis of all species within comprehensively assessed taxonomic groups (Butchart et al., 2015). The proportion of species found to be covered to target level is substantially higher than the 43 percent found in the wider study. The finding that the proportion of gap species is higher among threatened species is comparable to the outcomes of global gap analyses, which have found that threatened species, which frequently have smaller ranges, are more likely than others to fall outside the protected area network (Akasaka et al., 2017; Goettsch, Durán and Gaston, 2018; Gruber et al., 2012; Rodrigues et al., 2004).

The analysis provides a first overview of how the biodiversity used for human food included in The IUCN Red List is covered by the protected areas network. However, it is important to note that, even though The IUCN Red List is the most comprehensive source of information on species extinction risk at the global level, not all species utilized for food are included and not all species included have information recorded on their uses. Although use and trade information is currently not part of the minimum required standards for Red List assessments, provision of this information 
FIGURE 7.8

Protected area coverage of species in the comprehensively assessed taxonomic groups of The IUCN Red List with mapped ranges and classified as threatened and as used for human food

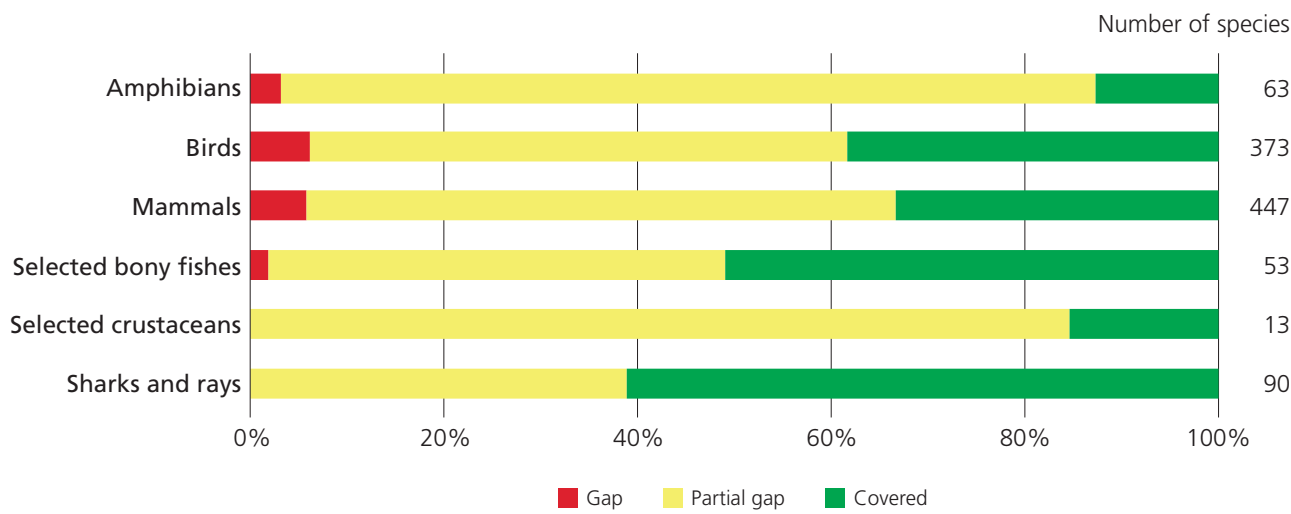

Notes: "Gap" = species range not covered by protected areas. "Partial gap" = species range partially covered by protected areas but not to target level. "Covered" = species range covered to target level. "Selected bony fishes" = sturgeons, tunas, billfishes, blennies, pufferfishes, angelfishes, butterflyfishes, surgeonfishes, groupers, wrasses, seabreams, picarels and porgies. "Selected crustaceans" = lobsters, freshwater crabs, freshwater crayfishes and freshwater shrimps. Comprehensively assessed taxa with fewer than 25 mapped species utilized for food are not shown. These correspond to hagfishes (1 partial gap species), selected dicots ([magnolias and mangroves] 1 covered species), selected reptiles ([marine turtles, seasnakes, and crocodiles] 5 partial gap and 3 covered species). There were no mapped threatened species utilized for food for the following taxonomic groups: conifers, seagrasses and selected gastropods (cone snails) Source: Authors' calculations using data from The IUCN Red List version 2017-2 and the World Database on Protected Areas (UNEP-WCMC and IUCN, 2018).

needs to be encouraged as it would allow analyses of this kind to be more comprehensive and accurate. As The IUCN Red List broadens its taxonomic and geographic coverage in its efforts to achieve a "barometer of life" (Stuart et al., 2010) and highly relevant taxonomic groups such as fungi, plants, insects and fish come to be better represented, it will be important to update the analysis. An obvious next step is to improve understanding of the threats affecting biodiversity used for food so as to allow better planning of conservation actions, including the identification of priority sites for the conservation of unprotected species.

\subsubsection{Management of biodiversity for food and agriculture in protected areas}

The IUCN Green List of Protected and Conserved Areas (Box 7.17) helps protected-area managers and other stakeholders to progress towards their conservation objectives. A survey ${ }^{28}$ shared by IUCN with the managers of 50 participating sites (both candidate sites and Green-List certified sites, see Box 7.17) received 29 responses from 22 countries across six continents, representing all major biomes, including forests, coastal areas and islands, and wetlands, and a range of designations, including five UNESCO World Heritage Areas. They also represented every IUCN Protected Area Category (Table 7.7) and each IUCN governance type (Borrini-Feyerabend et al., 2013).

The survey results highlighted the close relationship that many protected areas have with agricul-

\footnotetext{
28 The survey was in a "prism" format: for each question, respondents were offered a trio of answering statements positioned at the corners of a triangle and asked to place a marker at the point within the triangle that best matched their context and situation. An "other" box was provided, as well as a text box in which respondents could add narrative comments if desired.
} 
Box 7.17

The IUCN Green List of Protected and Conserved Areas

The IUCN Green List of Protected and Conserved Areas (IUCN Green List) aims to increase the number of protected and conserved areas that deliver successful conservation outcomes through effective and equitable governance and management.

The IUCN Green List of Protected and Conserved Areas Standard (IUCN Green List Standard) provides an international benchmark for quality that motivates improved performance. By committing to meet this global standard, site managers (in both formally protected areas and locations where other effective area-based conservation measures are in operation) seek to demonstrate and maintain performance and deliver real results.

The IUCN Green List Standard is organized into four components: Good Governance; Sound Design and Planning; Effective Management; and Successful Conservation Outcomes. The first three support the fourth. Each component has a set of criteria and indicators to measure its achievement.
Sites wishing to achieve IUCN Green List status must demonstrate, and then maintain, successful implementation of the IUCN Green List Standard. This is evaluated in two phases:

- Candidate phase: A voluntary commitment to the IUCN Green List Programme is followed by the start of the application process. This indicates whether sites meet the basic requirements for consideration. Sites then undergo an initial assessment against the IUCN Green List Standard. During the candidate phase, site managers learn what may need to be strengthened before the site can be further considered for inclusion on the Green List.

- IUCN Green List status: The management and representatives of the site are provided with a certificate, and the site is recognized and promoted by IUCN as a global exemplar in conservation.

Source: IUCN and WCPA, 2017 tural practice and production, and indicated a clear need for better support to protected-area managers in defining BFA and accounting for it in their conservation work. The main findings were as follows:

- 81 percent of respondents indicated that agricultural activity occurs within the boundaries and overall management area of their respective sites, and 83 percent concluded that agriculture is a significant activity in the surrounding area;

- nearly 40 percent of protected areas from which responses were received are situated within an agriculture-dominated landscape - including 73 percent of "National Park" (IUCN Category II) designations;

- 90 percent of respondents indicated that they consider their protected area to deliver significant benefits to agricultural production, for example through ecosystem services such as insect pollination or water provision;

- only 35 percent of respondents indicated that they consider that it is necessary to include agriculture in management planning, and only 25 percent indicated that they deliberately include agriculture as part of their management operations.

\subsubsection{Country-report analysis}

The country-reporting guidelines invited countries to provide information on "landscape-based initiatives to protect or recognize areas of land and water ... of particular significance for biodiversity for food and agriculture." 29 Responses refer to a range of designations established within the framework of international agreements or

\footnotetext{
${ }^{29}$ Countries were provided with the following list of examples: "International Partnership for the Satoyama Initiative (IPSI) designated areas; Globally Important Agricultural Systems (GIAHS) designated areas; Identified buffer zones around UNESCO Man and Biosphere reserves; Indigenous and Community Conserved Areas; IUCN Category V (Protected Landscape/Seascape); High Nature Value grasslands, Ramsar Wetlands of International Importance, UNESCO World Heritage Sites (Natural, Mixed Natural Cultural), UNESCO World Heritage Forests, Conservation forests, etc."
} 


\section{PART C}

\section{TABLE 7.7}

\section{Types of designated area reported to be of particular significance for biodiversity for food and agriculture}

\begin{tabular}{|c|c|c|}
\hline Type of designated area & Description & $\begin{array}{l}\text { Number of } \\
\text { countries } \\
\text { reporting }\end{array}$ \\
\hline $\begin{array}{l}\text { Areas designated for the } \\
\text { conservation of nature }\end{array}$ & Any area designated for conservation of nature based on any national or international criteria. & 89 \\
\hline $\begin{array}{l}\text { Wetlands of International } \\
\text { Importance (Ramsar sites) }\end{array}$ & $\begin{array}{l}\text { Ramsar sites are designated on the basis of a set of nine criteria related to wetland types, } \\
\text { ecological communities and support for waterbirds, fish or other taxa. }\end{array}$ & 25 \\
\hline $\begin{array}{l}\text { Biosphere reserves (UNESCO Man } \\
\text { and Biosphere Programme) }\end{array}$ & $\begin{array}{l}\text { Biosphere reserves may contain terrestrial, marine and/or coastal ecosystems. They should be } \\
\text { representative of their biogeographic region and of significance for biodiversity conservation. } \\
\text { Each site promotes solutions that reconcile the conservation of biodiversity with its sustainable } \\
\text { use in the interests of sustainable development at regional scale. The approach is based on a } \\
\text { three-tiered zoning structure consisting of one or more legally constituted core areas, buffer } \\
\text { zones, and an outer transition area. }\end{array}$ & 16 \\
\hline UNESCO World Heritage Sites & $\begin{array}{l}\text { World Heritage Sites are designated based on six cultural and four natural criteria. The } \\
\text { latter include containing "the most important and significant natural habitats for in-situ } \\
\text { conservation of biological diversity, including those containing threatened species of } \\
\text { outstanding universal value from the point of view of science or conservation." }\end{array}$ & 9 \\
\hline $\begin{array}{l}\text { Indigenous and community } \\
\text { conserved areas (ICCAs) }\end{array}$ & $\begin{array}{l}\text { ICCAs are natural and/or modified ecosystems containing significant biodiversity values, } \\
\text { ecological services and cultural values, voluntarily conserved by indigenous peoples and local } \\
\text { communities, both sedentary and mobile, through the use of traditional practices, knowledge } \\
\text { and customary law. }\end{array}$ & 14 \\
\hline $\begin{array}{l}\text { Globally Important Agricultural } \\
\text { Heritage Systems (GIAHS) }\end{array}$ & $\begin{array}{l}\text { GIAHS are defined as "remarkable land use systems and landscapes which are rich in globally } \\
\text { significant biological diversity evolving from the co-adaptation of a community with its } \\
\text { environment and its needs and aspirations of sustainable development." }\end{array}$ & 2 \\
\hline $\begin{array}{l}\text { Areas recognized as sources of } \\
\text { products assigned geographical } \\
\text { indications }\end{array}$ & $\begin{array}{l}\text { A geographical indication is "a sign used on products that have a specific geographical origin } \\
\text { and possess qualities or a reputation that are due to that origin." }\end{array}$ & 4 \\
\hline Others & $\begin{array}{l}\text { Areas designated to support the maintenance of traditional management practices; } \\
\text { landscapes protected by virtue of their ecological and cultural values; areas managed under } \\
\text { agro-environment schemes; multiple-use management areas. }\end{array}$ & 15 \\
\hline
\end{tabular}

Notes: "Number of countries reporting" = number of countries mentioning the respective type of site in response to a question about "landscape-based initiatives to protect or recognize areas of land and water ... of particular significance for biodiversity for food and agriculture." Analysis based on 91 country reports.

Sources: FAO, 2018u; ICCA Consortium, 2018; Ramsar Convention, 2010; UNESCO, 2016; UNESCO World Heritage Centre, 2015; WIPO, 2017; country reports prepared for The State of the World's Biodiversity for Food and Agriculture.

regulations, under the auspices of international networks or based on national or regional regulations. Table 7.7 provides a summary.

Nearly all reporting countries (89) refer to areas designated for the conservation of nature, including sites officially recognized as protected areas. Wetlands of International Importance (Ramsar Sites), ${ }^{30}$ and Globally Important Agricultural Heritage

30 As of November 2018, there were 2334 Ramsar sites covering almost 250 million hectares. Details can be found via the Ramsar Convention website at https://rsis.ramsar.org
Systems (GIAHS) (see Box 7.18) are among the designations mentioned. For example, Germany reports that in the Rhön Biosphere Reserve, the motto of which is "protection through use", several management practices, including the reintroduction of endangered livestock breeds such as the Rhön sheep, contribute to the conservation of the agricultural landscape. China, which hosts $15 \mathrm{GIAHS}$, mentions several of these systems, including the rice-fish symbiotic system of Qingtian County and the rice-fish-duck system of Dong County. Algeria refers to its ghout system, a 
Box 7.18

\section{FAO's Globally Important Agricultural Heritage Systems}

In 2002, FAO launched a global initiative for the identification, conservation and adaptive management of Globally Important Agricultural Heritage Systems (GIAHS), defined as "remarkable land use systems and landscapes which are rich in globally significant biodiversity evolving from the co-adaptation of a community with its environment and its needs and aspirations for sustainable development." The designation of agricultural systems as GIAHS aims, inter alia, to promote wider recognition of their contributions to food security and biodiversity conservation on a national and world scale and to enhance the benefits local people derive from the maintenance of existing sustainable practices and local biodiversity through, for instance, the establishment of payment for ecosystem services or ecolabelling schemes.

The official designation of candidate sites follows a vetting process that considers their contributions to local food and livelihood security, the uniqueness and richness of their in situ agrobiodiversity, their associated traditional knowledge and farming practices, their cultural richness and social organization and their ability to conserve centuries-old human-shaped unique landscapes or seascapes. Between 2005 and 2018, about 50 systems were officially recognized as GIAHS. Sites range from rice-fish-duck systems in China to North African oases, and from the underground water-collection tunnels of Kashan, in the Islamic Republic of Iran, to a water-resilient Maasai agropastoralist system in Kenya.

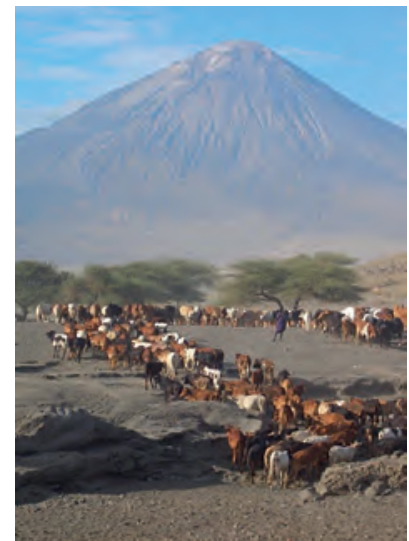

Pastoral landscape and Mount Kilimanjaro, Kenya-United Republic of Tanzania. CFAO/David Boerma.

The designation of GIAHS contributes to the achievement of several Sustainable Development Goals including those related to reducing poverty and increasing food security. For instance, producers in the Chinese ricefish culture system benefited from a rise in prices for their products, as well as from increasing numbers of tourists visiting the local area, following the designation of the system in 2005. Finally, GIAHS play a key role in climate change mitigation and adaptation, and in the fight against the genetic erosion of locally adapted crops and livestock.

Sources: FAO, 2018c, 2018u; Koohafkan and Altieri, 2010.

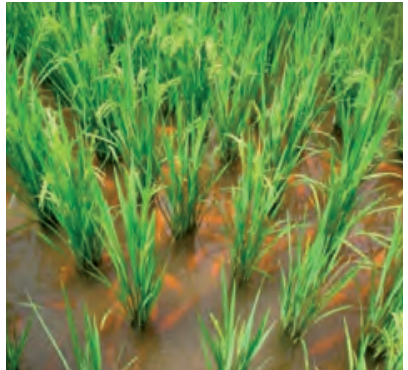

Rice-fish culture, China. @FAO/Luohui Liang.

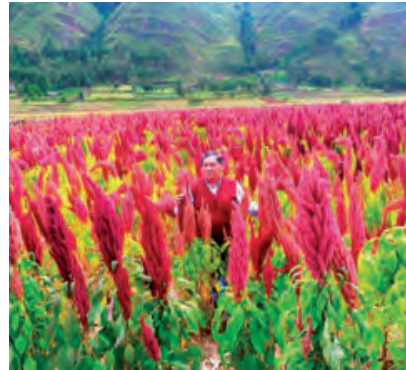

Andean agriculture, Kiwicha, Peru. CFAOIAlipio Canahua.

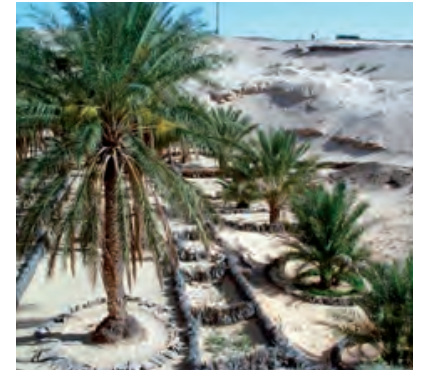

Ghout system, Oued Souf, Algeria CInstitut National de la Recherche Agronomique d'Algérie. 


\section{PART C}

Box 7.19

The role of geographical indications in the maintenance of biodiversity for food and agriculture

Geographical indications are used to differentiate products that have specific characteristics, qualities or reputation that result essentially from their geographical origin. This differentiation can relate to the product's history or to distinctive characteristics linked to local natural or human factors such as soil, climate, knowledge or traditions. The Agreement on Trade-Related Aspects of Intellectual Property Rights (TRIPS Agreement) requires members of the World Trade Organization to protect geographical indications as a form of intellectual property. Different legal tools are used depending on the country, including sui generis systems (e.g. the European Union's Protected Designation of Origin and Protected Geographical Indication schemes) and trademark systems.

Geographical indications can contribute to the development of sustainable food systems, particularly when they are developed and managed by local producers. They add value to traditional food products, benefiting producers, especially family farmers and smallholders, and can also benefit consumers by promoting better access to local nutritious food. Origin-linked products often use specific traditional, endemic or locally adapted species, varieties or breeds of plants, animals or micro-organisms. The promotion of such products through geographical indications can thus help to maintain biodiversity, by preventing the disappearance

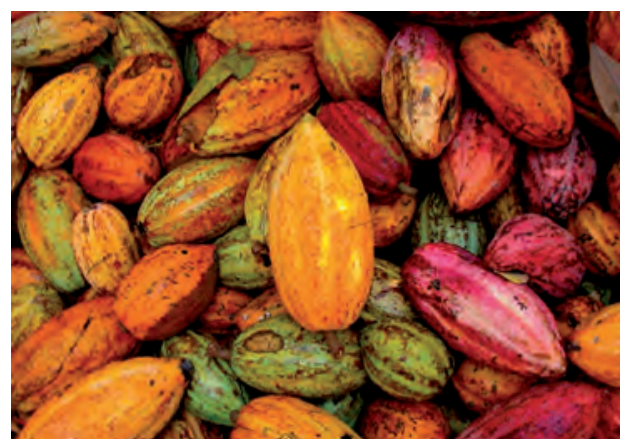

Cocoa Arriba beans from a local Ecuadorian variety. c) Emilie Vandecandelaere.

of these genetic resources or habitats or landscapes associated with them. One example is the geographical indication of Cocoa Arriba in Ecuador, which aims to preserve ancient cacao varieties that were increasingly being replaced by new, widely used varieties (hybrids) that are more productive but do not taste as good and lack the specific characteristics of the ancient local varieties.

Source: Provided by Florence Tartanac and Emilie Vandecandelaere, based on FAO (2017i) and FAO and SINER-GI (2010). traditional and complex hydroagricultural system for food production in dry areas, which was designated as a GIAHS in 2011. ICCAs (see above) are widely reported, mainly by non-OECD countries. Bangladesh, Burkina Faso and Cameroon, for instance, report the presence of communitymanaged forests, where indigenous and local communities can harvest fuelwood and non-timber forest products and concurrently work towards their long-term conservation. A few countries refer to areas recognized as sources of products assigned geographical indications (see Box 7.19).

Several countries note the contributions that various categories of areas designated for nature protection make to the supply of ecosystem services. For example, Malta reports that designation of marine protected areas containing meadows of the endemic Mediterranean seagrass Posidonia oceanica provides a fish spawning and nursing habitat that is expected to increase the resilience of the surrounding ecosystem to fishing pressure. Bangladesh notes that the establishment of fish sanctuaries has resulted in a substantial increase in fish production and in the abundance of endangered species. Gabon stresses the importance of forests in protected areas to food security and nutrition and as sources of valuable medicinal plant species. Fiji mentions the Ucunivanua locally managed marine protected area, a stretch of inshore water that was declared a no-take zone for three years in 1997, building upon local traditions and taboos. This strategy led to the 
Box 7.20

Maintenance and use of indigenous knowledge - examples from Kenya

The National Museums of Kenya document indigenous knowledge through various research activities, usually coordinated through the Kenya Resource Center for Indigenous Knowledge (KENRIK) under the Center for Biological Diversity Department. The main aim of KENRIK is to document and preserve the endangered/threatened indigenous knowledge held by various communities in Kenya. Such knowledge has traditionally played an important role in environmental conservation, natural-resources management, food security and traditional healthcare systems.

The communities around the Kakamega Forest have formed a community-based organization known as the
Kakamega Environmental and Education Programme (KEEP), whose main objectives are to participate in conservation efforts within the forest and create awareness in local communities and schools. KEEP community activities include butterfly farming/silkworm rearing, beekeeping, snake rearing, growing medicinal plants and maintaining tree nurseries. Activities are based on the traditional knowledge held by members of this community that have been passed from generation to generation.

Source: Adapted from the country report of Kenya. recovery of rapidly declining clam populations and to more-abundant harvests and higher incomes for local inhabitants. Further examples are presented in Section 7.3.1.

\subsection{Maintenance of traditional knowledge associated with food and agriculture}

Countries were invited to report on activities undertaken to maintain traditional knowledge of associated biodiversity (for further information on drivers of change affecting the status of traditional knowledge see Section 3.9). Various initiatives related both to associated biodiversity and to other components of BFA were reported. Several countries note that public institutions such as museums, national archives and research centres play an important role in maintaining traditional knowledge and practices associated with BFA. For example, Jordan's National Center for Agricultural Research and Extension has documented more than 100 wild edible plants that are traditionally utilized by local communities. Activities undertaken by the Kenya Resource Center for Indigenous Knowledge are described in Box 7.20. Sri Lanka notes that its Department of Agriculture is collecting and trying to preserve traditional knowledge on the preparation of traditional foods through a project called "Hela bojun" that has established a number of food outlets throughout the country.

A number of countries note that some traditional knowledge related to skills cannot be recorded in writing and can only be maintained if it is used in practice. Several mention civil-society organizations that contribute to the active maintenance of traditional practices through a variety of cultural activities. Some examples from the Pacific are presented in Box 7.21. Examples of the role of women in the maintenance of traditional knowledge for improved food and seed security under climate change can be found in Box 7.22.

Countries were invited to indicate whether traditional knowledge is used to inform conservation decisions and to share best practices and lessons learned. A few country reports state that traditional knowledge has been considered in the planning of protected areas. Some note that traditional knowledge has influenced efforts to promote the sustainable management of arable land, forests, fisheries and aquaculture holdings, often through participatory approaches involving local communities in the elaboration of management plans. Examples include traditional forest-management 


\section{PART C}

Box 7.21

Maintenance and use of traditional practices in the Pacific

In the Cook Islands, many farmers see training on sustainable crop production provided by the Ministry of Agriculture as a revival of the traditional knowledge passed down through the generations. School students learn about traditional knowledge when visiting conservation sites.

Fiji has used mass media such as television programmes to promote the use of traditional knowledge in food systems. Examples include the Talk Business programme on Fiji TV ${ }^{1}$ and a series of Fiji Farmers Leaflets ${ }^{2}$ published by the Ministry of Agriculture. Traditional knowledge is also passed on at community level through the use of traditional varieties of yams and other crops, and practices such as hunting for wild pigs.

In Kiribati the traditional technique of rearing milkfish in natural or human-made brackish-water ponds is still practised today. The milkfish fry are caught from the wild, during new- and full-moon phases, using coconut leaves and plant branches. They are then guided into brackish-water ponds using pandanus leaves, and are harvested as food during festivals.

In Niue, the traditional processing of arrowroot (Tacca spp.) starch for food is still widely practised. Arrowroot is an annual plant that grows in the wild. Each year, during April and May, families usually harvest arrowroot tubers to be processed as food. The processed arrowroot starch is a delicacy used in local desserts such as nane (pudding) and pitako (bread).

In Palau traditional knowledge is passed to the next generation not only by oral transmission but also via wood carvings of ancient customs and traditional practices. One such practice is bul, a traditional way of conserving certain marine species during times of low availability that involves a total ban on harvesting the species to allow them to reproduce and multiply (see also Box 7.4).

\footnotetext{
See http://fijione.tv/talk-business-2/ for more information.

2 See http://www.agriculture.gov.fj/index.php/publications/farmers-leaflets for more information.
}

In Papua New Guinea farmers traditionally use natural insect-repelling plants such as ginger, lemon grass, chili and marigold. The National Agricultural Research Institute has developed formulas for using these species as plant-derived pesticides and trains many rural farmers in their use. Certain cultural practices foster the genetic diversity of food crops, for instance when a bride leaves her parents' home village to join the family of her bridegroom, she usually brings seeds or seedlings given to her by her parents and other relatives during the wedding. This allows varieties, and the traditional knowledge related to their cultivation, to be spread from one community to another. The practice also promotes the "safe keeping" of genetic materials through duplication: if the bride's parents lose a particular variety, they can go to her to obtain a replacement.

In Solomon Islands, traditional knowledge associated with forest foods in Central Choiseu is documented in a book titled The forest foods of Lauru (Jansen and Sirikolo, 2010). This publication not only documents the plants used for food and how they are processed and cooked, but also the area's traditional land-classification system, which is based on ecological zones ranging from the coastal mangrove swamps to the mountain tops. In addition, the country's National Cultural Policy Framework (Nasinol Policy Framework blong KALSA) fosters the protection and revival of indigenous culture and promotes the transmission of traditional knowledge to younger generations.

Tonga holds annual agriculture, forestry and fisheries shows throughout the main islands of Tongatapu, Vava'u, Ha'apai, Eua, Niuafo'ou and Niuatoputapu. The shows promote biodiversity through the promotion and display of the best local products from each island. Prizes are awarded for traditional products such as various nut oils, thereby encouraging the production of traditional varieties.
Sources: Country reports of the Cook Islands, Fiji, Kiribati, Niue, Palau, Papua New Guinea, Solomon Islands and Tonga. 
Box 7.22

Women's traditional knowledge for improved food and seed security under climate change

In deciding what to grow, when and where, women often rely on gender-specific biocultural indicators that can help reduce the vulnerability of their households to the stresses and shocks affecting agricultural production. Oxfam Novib's programme Putting Lessons into Practice: Scaling up People's Biodiversity Management for Food Security capitalized on women's traditional knowledge about seed and plant management to facilitate female-led innovation and capacity building as a response to local environmental challenges.

As part of the programme, women in Peru's Lares region sorted native potato landraces to be reintroduced into the area based on the quality of sprouts, the absence of blights and pests, resistance to local climatic conditions and nutritional properties. In this region, the selection of sowing sites for potato cultivars is based on knowledge about the previous occurrence of late blights and on plant properties, often used as proxy indicators for soil fertility. The sowing time is decided, inter alia, by observing the behaviour of wild animals and reading the stars.

practices that are used across the country in the United Republic of Tanzania, whereby land used for grazing and firewood collection is fallowed for a period of time to allow for regeneration, and the project Technological Innovation of Family Farming Production Systems (Innovación Tecnológica de los Sistemas de Producción de la Agricultura Familiar) in Panama, which designed and implemented agroecological food systems through a participatory process with the population of the Ngäbe Buglé district. Guyana reports that its National Agricultural Research and Extension Institute has benefited from traditional knowledge when setting conservation priorities for the management of its ex situ field genebanks and in vitro stored collections. An example of successful forest management based on traditional knowledge in Viet Nam is presented in Box 7.23.
For the (re)introduction of additional crops into Zimbabwe's Chiredzi and Goromonzi districts, the programme also relied on women's weather forecasting based on a set of environmental indicators. These included tree phenology, wild-animal behaviour and recent weather patterns. For instance, the presence of migrant storks in the area is interpreted as indicating forthcoming rain, and sowing and crop-diversification strategies are planned accordingly. Women's forecasts are considered more accurate than the national weather forecasts, as the latter tend to cover wider areas and are therefore less specific.

Taking women's particular knowledge about local environmental conditions, seed systems and cropdiversification strategies into account facilitated the farmer-to-farmer transfer of innovation and strengthened the capacity of (women) farmers to autonomously identify "new" coping mechanisms in traditional practices, knowledge and biodiversity for food and agriculture.

Source: Oxfam Novib et al., 2016 (Report submitted to FAO in contribution to The State of the World's Biodiversity for Food and Agriculture).

\subsection{Needs and priorities}

Needs and priorities in the conservation of plant (crop), animal (livestock), forest and aquatic genetic resources are discussed in detail in the respective sectoral global assessments (FAO, forthcoming, 2010a, 2014a, 2015a). As discussed above, many gaps remain in conservation programmes for genetic resources in these categories. The following paragraphs focus on associated biodiversity and wild foods.

By far the most commonly reported constraint to conservation activities for associated biodiversity and wild foods is a lack of knowledge. Many countries indicate that species inventories for various categories of associated biodiversity are incomplete. Even for species that have been recorded, geographical distributions are often not well mapped and monitoring of population trends 
Box 7.23

Community forest management and development in Ban Banh, Viet Nam

Forest management in a village named Ban Banh in the North West Mountain Region of Viet Nam is directly related to the spiritual life of the Thai ethnic minority community. The belief that the spirits of local people's ancestors reside in the forest provided the basis for the development of customary laws to manage and protect it. The forest is the common property of the community, and profits made from selling forest products go into a community fund. The Thai villagers' traditional knowledge tells them what, when and how they should collect from the forest. Transgressing is believed to threaten the safety and tranquillity of all villagers, as the spirits are believed to take revenge on the community if the forest is harmed. A number of factors contribute to the success of community forest management and development in Ban Banh:

- The system is appropriate to Thai custom, in which the forest is considered the common property of the whole community. Community members join together to uphold their local law. The village chief and the village elders' council are highly respected and play the most important roles in ensuring that the interests of the whole community are protected.

- The community rules were developed by the villagers themselves. They initiated the process and committed themselves to participating in all steps involved in creating their own effective set of regulations. The villagers' motivation to protect the forest stems from their desire to maintain their traditional culture and lifestyle, which are closely linked to this natural resource.

- The rules were developed based on Thai indigenous knowledge of local forest flora and other biodiversity so as to avoid human disturbance in the critical growth period of the year and prevent overexploitation.

Source: Adapted from the country report of Viet Nam. is often inadequate or non-existent. Many countries also report that knowledge about the significance of particular species or species groups in the supply of ecosystem services is limited. Some note a lack of information on how drivers of change are affecting associated biodiversity and wild foods or on the effectiveness of potential conservation interventions. All these knowledge gaps make it difficult to prioritize species (or species groups, production systems or geographical locations) and to plan conservation activities.

Several country reports mention problems associated with inadequate diffusion of relevant information to those who need it in order to plan conservation activities. Some note that a lack of information systems or databases is a constraint. Several mention that stakeholders lack adequate information on methods and strategies for both in situ and ex situ conservation. As noted above, technical barriers to the long-term ex situ conservation of some species still need to be addressed.
Activities aimed at maintaining and building on traditional knowledge relevant to conservation efforts also often need to be strengthened. Many countries note that a large amount of traditional knowledge has already been lost without ever having been documented, and that loss is ongoing as the use of traditional practices dwindles.

Resource constraints are also widely reported. Inadequate funding and a lack of trained personnel are the most commonly reported problems, but a number of countries also mention a lack of technical resources. Where human resources are concerned, several countries specifically refer to weaknesses in taxonomy and systematics. Some also mention that a lack of an interdisciplinary approach in research hampers efforts to improve conservation methods and strategies. Many countries note that a lack of resources makes it more difficult to bridge knowledge gaps of the kind described above. Others note that a lack of resources constrains programme implementation 
or prevents effective enforcement of regulations aimed at protecting biodiversity. A number of countries report that conservation-related education, training and awareness-raising activities for stakeholders, at all levels from producers and consumers to policy-makers, need to be strengthened.

The other main category of constraint highlighted in the country reports is weaknesses in legal, policy and institutional frameworks. Many countries mention a lack of mainstreaming of associated-biodiversity conservation into policies targeting the various sectors of food and agriculture and other sectors of the economy. Some note a lack of focus on associated biodiversity and wild foods in general biodiversity-related policy frameworks. Many countries that have developed relevant policies and laws report that they are not properly implemented.

Lack of collaboration and coordination between stakeholders is another widely reported constraint. Many countries highlight, in particular, a lack of cross-sectoral coordination, including at policy level. Some note constraints associated with a lack of adequate links between ministries, between researchers and policy-makers, or between policymakers and producers or local communities.

Priorities for action mentioned in the country reports mostly relate to addressing the underlying knowledge, resource and policy-related constraints to the establishment of effective conservation programmes. With respect to the specifics of conservation strategies themselves, some countries mention the need to expand the use of biodiversity-friendly management practices in agriculture, forestry and fisheries, including, where relevant, traditional management practices associated with local or indigenous communities. Some note the potential role of organic certification or other schemes that promote the marketing of products produced using sustainable management practices.

Several countries note the importance of maintaining viable areas of natural or semi-natural habitat within and around production systems, including those that are intensively managed, some noting that this will need to involve restoring or reconnecting damaged or fragmented habitats. Some also highlight the need to address specific threats, such as invasive alien species, overexploitation and overharvesting, or particular unsustainable practices in agriculture, fisheries or forestry. Also emphasized in a number of country reports is the importance of ecosystem or landscape/seascape approaches or similar joined-up strategies that integrate the conservation of particular components of associated biodiversity into wider efforts to sustainably manage the production systems in which they are found, improve the livelihoods of local people and promote the supply of ecosystem services. 

Part D

\section{ENABLING FRAMEWORKS}





\section{Chapter 8 \\ The state of policies, institutions and capacities}

\footnotetext{
Key messages

- Ensuring the sustainable use of biodiversity for food and agriculture (BFA) requires effective actions by competent authorities and improved collaboration among a range of stakeholder groups (producers and their organizations, consumers, suppliers and marketers, policy-makers, and national and international governmental and nongovernmental organizations) across the sectors of food and agriculture and between the food and agriculture sector and the environment/natureconservation sector.

- Education and training on the management of BFA at all levels needs to be strengthened, as does awareness raising on the importance of BFA among a range of stakeholders, including policymakers and the general public.

- There are many gaps in BFA-related research, especially with respect to associated biodiversity (species such as pollinators, soil organisms and pest natural enemies found in and around production systems), particularly invertebrates and micro-organisms, wild foods, and the ecosystem functions of BFA.
}

- Economic valuation tools can make the benefits and costs of BFA more visible and thus drive more effective conservation policies. However, such valuations are difficult and costly to implement.

- Many different types of incentive measures are being used by a range of actors to promote the conservation and sustainable use of BFA. Effectiveness can be increased by combining them into integrated packages. Perverse incentives need to be identified and removed.

- Appropriate legal and policy frameworks are essential for the effective management of BFA, but generally remain relatively weak and/or poorly implemented. Improving them is challenging because of the multiple stakeholders and interests involved.

- In most countries, access and benefit-sharing measures are under development or in the early stages of implementation. Measures increasingly reflect the importance and distinctive features of genetic resources for food and agriculture.

\subsection{Introduction}

This chapter discusses the institutional framework for the management of biodiversity for food and agriculture (BFA). The first section provides an overview of the roles played by various categories of stakeholders in the management of BFA. The subsequent sections address the state of cooperation in the management of BFA (including cooperation between different stakeholder groups, cross-sectoral cooperation and international cooperation), the state of ancillary or supportive components of the institutional framework such as education, training and research, the state of 
implementation of valuation studies for BFA and the state of incentive measures promoting the sustainable use and conservation of BFA. The final section presents an overview of the state of policies and legislation across a range of fields relevant to the management of BFA. Other chapters of the report include information on programmes in specific fields of activity such as conservation, characterization, monitoring, genetic improvement and various potentially biodiversity-friendly management practices and approaches. In many cases, needs and priorities identified in these chapters include actions related to strengthening policy, legal and institutional frameworks.

\subsection{Stakeholders}

- Large- and small-scale farmers, livestock keepers, fishers, fish farmers and forest dwellers, among others, all rely directly on biodiversity for food and agriculture (BFA). Small-scale producers, in particular, often play a key role in the sustainable use and conservation of BFA and are often heavily dependent on the supporting and regulating ecosystem services it provides in and around their production systems.

- Despite their significance to BFA management, small-scale and indigenous producers - including in particular women - are often marginalized and excluded from decision-making processes that affect their production systems.

- Many producers' and community-based organizations play significant roles both in providing practical support for the sustainable management of BFA and in advocating policies that support the roles of smallscale producers as custodians of BFA.

- A range of subregional, regional and international organizations and partnerships contribute to the management of associated biodiversity, including through projects targeting the sustainable use of pollinators, soil biodiversity or biological control agents, the management of ex situ conservation programmes and broader efforts promoting sustainable production.

\subsubsection{Producers and their organizations ${ }^{1}$}

\section{Small- and large-scale producers}

Producers in the crop, livestock, forest and aquatic sectors range from small-scale farmers, livestock keepers, fishers, aquaculturists and forest dwellers to very large commercial companies. All rely on BFA and their actions can have major impacts on the state of biodiversity. Much of the world's BFA is managed in, or associated with, smallholder cropping or mixed systems, pastoralist systems or small-scale forest, aquaculture or fishing systems. ${ }^{2}$ It is estimated, for example, that out of 570 million farms worldwide, 475 million are less than 2 ha in area (Lowder, Skoet and Raney, 2016). These farms support at least 2 billion people but occupy only 12 percent of total agricultural land (ibid.).

Where domesticated biodiversity is concerned, small-scale producers tend, broadly speaking, to be relatively reliant on the adaptive characteristics of the species, breeds and varieties that they use, i.e. on traits that allow plants and animals to survive and produce in harsh and changing local conditions without the need for large quantities of external inputs (FAO, 2010a, 2015a). They often make use of multiple products and services supplied by the plants they grow and/or the animals they keep. Diverse production environments and a diverse range of uses typically mean that a relatively diverse range of genetic resources is maintained. Small-scale producers are often also key players in the management of associated biodiversity. ${ }^{3}$ Limited use of external inputs means that they are often heavily dependent on ecosystem services provided by the associated

\footnotetext{
This section draws on the thematic study Biodiversity for Food and Agriculture: the perspectives of small-scale food providers (IPC, forthcoming).

2 These are clearly quite loosely defined categories. What counts as "small-scale" varies from place to place, as do the circumstances (access to inputs, subsistence vs market orientation, etc.) in which small-scale producers operate.

The biodiversity present in and around production systems that supports food and agriculture through pollination, pest and disease regulation, improving soil fertility and the supply of many other ecosystem services. See Section 1.5 for further discussion of this term
} 
biodiversity in and around their production systems. The maintenance, revival or adaptation of traditional management practices developed by small-scale producers often contributes significantly to the sustainable use and conservation of $B F A$, as do ongoing processes of innovation on the part of small-scale producers.

While small- and medium-scale systems remain significant, large-scale commercial production is expanding globally, and increasingly dominant in many subsectors. Large-scale producers can often draw on technologies and inputs that enable them to base their enterprises on crops, livestock or aquatic organisms from a narrowing range of high-output species, varieties and breeds or to extract vast quantities of products from aquatic and forest ecosystems. Although ultimately dependent on the range of ecosystem services provided by BFA, their access to inputs means that they can often operate relatively independently of the local ecological processes that have traditionally underpinned and constrained production. Their management practices and strategies can, however, have major detrimental effects on biodiversity both locally and at a greater distance, for example as a result of the environmental impacts of the discharge of wastes or the production and transport of inputs (see Chapter 3 for further discussion). Large-scale, specialist companies are also playing an ever-greater role in breeding (geneticimprovement) programmes for domesticated plants and animals (terrestrial and aquatic), often focusing their efforts on a relatively narrow range of species, breeds and varieties. In some subsectors, such as poultry, the breeding industry has become very concentrated in the hands of a small number of companies (FAO, 2015a).

\section{Producers' organizations}

Despite being major stakeholders in the sustainable management of BFA, producers in all sectors particularly small-scale and indigenous producers - are often excluded from decision-making processes that affect their production and livelihood systems. In many countries, small-scale producers' civil society organizations (CSOs) play a significant role both in campaigning and advocacy and in promoting practical activities relevant to the sustainable use and conservation of BFA. On the campaigning side, some small-scale producers' CSOs have sought to challenge the so-called industrial model of production and consumption, counterposing an approach based on agroecology that, in the words of the Declaration of the International Forum for Agroecology (IFA, 2015),

displaces ... the control of global markets and generates self-governance by communities ... minimize[s] the use of purchased inputs ... requires the re-shaping of markets so that they are based on the principles of solidarity economy and the ethics of responsible production and consumption ... promotes direct and fair short distribution chains ... implies a transparent relationship between producers and consumers ... is based on the solidarity of shared risks and benefits ... challenge[s] and transform[s] structures of power in society [and] put[s] the control of seeds, biodiversity, land and territories, waters, knowledge, culture and the commons in the hands of the peoples who feed the world.

At a relatively local level, CSO's campaigning activities target a range of BFA-related issues, including the maintenance or re-establishment of collective local control over resources such as forests, grazing lands and fisheries (IPC, forthcoming). Box 8.1 presents governance outcomes sought by small-scale producers' organizations as summarized in the thematic study on the perspectives of small-scale food providers (ibid.) prepared as a contribution to the development of The State of the World's Biodiversity for Food and Agriculture (SoW-BFA).

Producers' and community-based organizations of various kinds contribute in many practical ways to the sustainable management of local production systems, whether by providing practical support and advice on management techniques, facilitating the collective management of local resources or providing support for the marketing of local products (see Box 8.2, Box 8.3 


\section{PART D}

Box 8.1

\section{Governance outcomes promoted by small-scale food providers' organizations}

In the framework of food sovereignty, and respecting the rights of the women and men who use, maintain and enhance peasant biodiversity for food and agriculture, the organizations of small-scale food providers seek to:

- strengthen and promote dynamic management of biodiversity based on ecological principles and collective rights over knowledge and resources;

- improve access to and control over biodiversity and secure collective rights over the commons;

- realize seed policies that guarantee the collective rights of peasants and indigenous peoples to use, exchange, breed, select and sell their seeds;
- reinforce their interconnecting rural-urban food webs and local markets so that they sustain biodiversity in their territories;

- transform research undertaken by scientists in public institutions so that it is reframed by peasants for the co-creation of diverse knowledges, which shall not be patented; and

- change the rules that perversely protect policies and practices that destroy the biodiversity that supports food sovereignty.

Source: IPC, forthcoming.

\section{Box 8.2}

\section{Community control of a coastal ecosystem - an example from Senegal}

In 2008, worried about a decline in fish stocks, local communities in Mangagoulack, Casamance, Senegal, created the Association of Fishermen of the Rural Community Mangagoulack (APCRM). The association established a community conservation area named Kawawana. The name derives from the Djola expression "Kapooye Wafolal Wata Nanang", which means "our patrimony, for us all to preserve." The conservation area was demarcated and rules put in place to control access to the coastal waters and combat the use of destructive methods that threaten local fish resources.

In 2010, APCRM obtained statutory rights of management for Kawawana, including a preferential right to fish on the local coastal strip. Mangagoulack is the first local community in Senegal to have been devolved management rights for coastal fisheries.

The waters of the conserved area are divided into three zones, denoted by the colours red, orange and yellow. No fishing or collection of shells or wood is permitted in the red zone. The orange zone is reserved for fishing that supplies local consumption and markets. The yellow area is open to fishing, but there are limitations on the fishing methods and gear that can be used.

The red zone is marked with fetishes and revives the local tradition of "sacred bolongs." It serves as a refuge for aquatic life. Mangroves and inlets provide habitat for humpback dolphins, manatees, fish and shellfish.

The new management arrangements rapidly increased fish stocks and improved the local diet. Three years after the creation of the conservation area, local fishermen's catches had doubled.

Source: Adapted from IPC (forthcoming), with additional information from ICCA Registry (2012). and Box 8.4 for examples). In some cases, the use, development and/or conservation of a particular component of biodiversity are the main objective of the organization. For example, in many countries, particularly in the developed regions of the world, breeders' associations are major players in livestock genetic-improvement programmes, particularly in ruminant species (see Section 5.9).

Where associated biodiversity is concerned, beekeepers' organizations play an important role in bee management and maintaining the supply of pollination services in many countries. The 
Box 8.3

Agroforestry under local control - an example from Costa Rica

The Coproalde (Coordination of Non-Governmental Organizations with Alternative Development Projects) ${ }^{1}$ Network was formed in 1988 and brought together a number of NGOs and peasants' and indigenous peoples' organizations working on alternative development projects. In around 2009, Coproalde members started to implement successional agroforestry systems. The initiative was motivated by exchanges with peasants from the Plurinational State of Bolivia via the "campesino a campesino" (farmer-to-farmer) methodology. The successional agroforestry systems mimic forest ecological conditions and supply a very diverse range of foods from small plots of land. Up to 85 food or medicinal species can be planted in a $2000 \mathrm{~m}^{2}$ area. The agroforestry plots enable families to ensure their food and nutritional security and obtain extra income by selling surplus in local markets.

Source: Adapted from IPC (forthcoming) (based on testimony from Juan Arguedas Chaverri, Red Coproalde, Costa Rica, 2014).

1 Coproalde is an abbreviated form of the Spanish name Coordinadora de Organismos no Gubernamentales con Proyectos Alternativos de Desarrollo.

\section{Box 8.4}

The role of a women's group in promoting sustainable fishing - an example from Ecuador

The Pescado Azul (Blue Fish) Women's Association of Isabela in the Galapagos promotes responsible fishing by empowering the women of the local community. The association emphasizes traditional knowledge and the conservation and sustainable use of marine resources.

Illegal and unsustainable fishing in local coastal waters has led to the overexploitation of sea cucumbers, spiny lobsters and a variety of fish species. To reduce pressures on these resources, Pescado Azul promotes alternative livelihood opportunities. The main focus has been on developing value- added smoked products from sustainably sourced yellowfin tuna. Wood from guava shrubs, an invasive species, is used to smoke the fish. Products are marketed under the Pescado Azul brand, and the association has developed links with ecotourism operators to help identify markets. Other activities have included reforestation of local mangroves and efforts to promote ecological awareness.

Sources: Country report of Ecuador and UNDP, 2013. country report ${ }^{4}$ from Jordan, for example, mentions a project initiated by the Jordan Beekeepers' Union that succeeded in involving beekeepers in conserving and planting trees to provide forage for honey bees. It notes that over 20000 trees were planted by union members in 2013-2014. A number of country reports also highlight the roles of local community-based organizations in the sustainable use of products harvested from

\footnotetext{
4 Throughout this chapter, unless noted otherwise, the term "country reports" refers to the country reports submitted as contributions to The State of the World's Biodiversity for Food and Agriculture. See "About this publication" for additional information.
}

the wild. For example, the Gambia mentions the important role of women oyster farmers' associations in various management activities. One such organization, the Niumi Women Oyster Farmers' Association, is reported to be collaborating with the country's Department of Parks and Wildlife Management in monitoring shellfish exploitation in the Niumi National Park. Examples from Senegal and Ecuador of the roles played by communitybased organizations in promoting sustainable fishing are presented in Box 8.2 and Box 8.4.

More generally, the country reports highlight the significance of a range of community-based organizations and other collective bodies (involving 


\section{PART D}

producers of various scales) in promoting participation in sustainable management activities. For example, Viet Nam mentions the roles of People's Committees, especially at commune and district levels, the Women's Union, Farmers' Association and the Youth Union. Zambia notes the significance of the traditional leadership in local communities as potential catalysts for the participation of local people. Among developed countries, the Netherlands notes a shift in mechanisms for implementing agri-environmental schemes away from a focus on individual enterprises and towards the establishment of collective bodies intended to improve information sharing and allow schemes to be implemented over larger areas and hence to have a greater impact. A number of countries mention the need to improve collaborative links among producers' and community-based groups, and between them and other stakeholders.

\section{The roles of women producers}

Women farmers, livestock keepers, fishers and forest dwellers often play vital - although sometimes overlooked - roles in the use and conservation of BFA. Across the globe, women gather wild plants for food, medicinal use, fuelwood and other purposes, act as herbalists, tend home gardens, select, manage and store seeds, manage crops, trees and small livestock, domesticate plants, participate in small-scale fisheries and aquaculture, and store, preserve and process foods after harvesting (FAO, 1999b, 2012a, 2014a, 2018a; HLPE, 2017a; Kennedy et al., 2017; World Bank, FAO and IFAD, 2009).

In several parts of East and Southeast Asia and sub-Saharan Africa women represent the majority of the agricultural workforce (FAO, 2011e). In 2016, women were estimated to account for 14 percent of people directly engaged in fisheries and aquaculture, but it is estimated that if secondary activities (processing, trading, etc.) are included, women make up about half the workforce (FAO, 2018a; World Bank, 2012b). Women's work in agriculture, fisheries, forestry, etc. is often accompanied by time-consuming, demanding and often unpaid household and community-related tasks (FAO, 20160). Moreover, women generally have less access than men to assets such as land and livestock, various production inputs and services such as education, extension and credit, and tend not to be well represented in decisionmaking processes related to food and agriculture (FAO, 2011e). See Section 3.8 for a discussion of drivers of change affecting the roles of women in the management of BFA.

Women's close involvement in tasks such as food and fuel gathering, gardening, livestock management and food processing often gives them unique knowledge about local BFA, which is often passed from generation to generation (Kennedy et al., 2017). This knowledge, along with their particular roles in the economy, influences their management strategies and priorities, which may differ from those of men (IUCN, 2017b). Women, for instance, may prioritize particular crop characteristics, such as cooking time or preservability, that may be overlooked by men, who may be more concerned about marketability and yield (FAO, 1999b). In the case of livestock, it has been argued that locally adapted breeds can be especially important for women, and hence that women are often key players in the use - and hence potentially in the survival - of such breeds (FAO, 2012a). Reasons for this include the fact that locally adapted animals tend to be relatively easy to care for, which means that raising them can be combined more easily with child-rearing and other household tasks. Moreover, such animals are often able to make good use of common-property resources, such as communal pastures and feed that can be scavenged from waste ground, a characteristic that can make them important resources for people who, like many women, are disadvantaged in terms of land ownership.

Many of the country reports note the significance of women's roles in food and agricultural production and processing or specifically mention their roles in the sustainable management of BFA. In the latter case, countries generally refer to women's roles in using - and hence maintaining traditional species, varieties or breeds of crops 
or livestock or note women's roles in gathering wild plants and hence their knowledge of these resource and interest in conserving them. Cameroon, for example, mentions that in some rural communities women monitor the presence, growth and ripening of important wild foods and medicinal plants in forest and farm lands, and that when preparing land for cropping they make sure that key plants are maintained. It further notes that women are the main conservers of such plant species and have good knowledge of their phenology (the timing of life-cycle events such as flowering), how to harvest them sustainably and how to process them for household use or for sale. Several countries, however, acknowledge that women's roles in food and agriculture are undervalued and that this can lead to missed opportunities to strengthen their roles as stewards of BFA. Several also note that women's decision-making power in the management and conservation of BFA still tends to be constrained by stereotypes and socio-economic barriers and that women are under-represented in decision-making processes related to BFA.

The country reports describe a variety of initiatives aimed at enhancing the roles of women in the conservation and sustainable use of BFA. Bangladesh, for instance, reports that efforts are being made to engage women in communitybased conservation of fish and other aquatic biodiversity, involve them in social-forestry programmes run under the Department of Forestry, and train them on integrated management of vegetables and fruit crops. Jordan notes that the Conservation of Medicinal and Herbal Plants project (among other activities) targeted women's organizations to improve awareness and knowledge on the conservation and sustainable management of medicinal plants, supported women's "conservation through cultivation" of plant species and facilitated women's access to microcredit and participation in growers' and producers' organizations. Cameroon mentions that women are being trained as forest or agricultural engineers, eco-guards or wildlife technicians and are being sensitized in forest-resource management.
It further notes that participatory workshops on ecological appraisal methodologies and conservation are enabling women in local communities to participate in decision-making on how to invest in and sustain their local resources (further examples of education and training activities targeting women are described in Section 8.4). A number of countries mention the contributions of women's producer groups to the sustainable use and conservation of BFA (see examples above).

Only a few reporting countries mention the inclusion of gender dimensions in their national biodiversity strategies and action plans (NBSAPs). However, an analysis of NBSAPs available as of 2016 (IUCN, 2017b) found that the latest plans from 24 percent of the 174 countries covered included at least one activity addressing the inclusion of women or gender considerations (although not necessarily specifically related to the food and agriculture sector). Most of the activities in question relate to education on biodiversityrelated issues. The NBSAPs from 9 percent of the 174 countries were found to include activities that explicitly promote women's empowerment (e.g. gender analysis, education and outreach activities targeting women, or capacity development for women, including in fields such as agricultural skills and access to seeds) (ibid.).

Needs and priorities noted in the country reports with regard to strengthening women's roles in the management BFA include:

- providing education on conservation and sustainable use tailored to women's specific needs;

- improving women's access to markets to increase economic returns from the sustainable use and conservation of BFA;

- providing scholarships for women and girls to pursue careers in food and agriculture;

- improving the integration of women into relevant decision-making processes at all levels; and

- improving women's access to assets, especially land and external inputs, including by improving their access to credit.

Some country reports also refer to genderdifferentiated vulnerability to the impacts of climate change on food and agricultural systems. 


\section{PART D}

Women tend to be relatively more dependent on the products of their local production systems for their food security, fuel and other products and services, and hence may be more vulnerable to the local-scale effects of climate change (FAO, 2017p). No specific priorities are mentioned in this regard in the country reports. However, FAO (2017p) emphasizes the need to tap into women's potential as key actors in disaster risk reduction and climate change adaptation strategies and to address the specific constraints they face in building resilience to disasters and adapting to climate change.

\subsubsection{Suppliers, processors, traders and retailers}

Many operators, large and small, are involved in processing and transporting food and agricultural products and retailing them to consumers, or use such products as inputs for a range of different industrial processes. The requirements of users at all points in the value chain influence demand for raw materials and hence the characteristics of crop, livestock, forest and aquatic production systems. Similarly, a range of industries serve as suppliers of inputs to food and agricultural production and can influence the types of production practised. The impacts of changing market demands and technological developments on BFA and its management are discussed in Chapter 3. As well as acting as markets or suppliers, industries outside the immediate food and agriculture sector can directly affect BFA via their impacts on land use or the effects of pollutants they release (again see Chapter 3 for further discussion). They may also benefit from the various regulating ecosystem services provided by BFA (and biodiversity more generally) - maintenance of water supplies or disaster risk reduction, for example. The cultural and habitat services provided by biodiversity (see Section 2.2 for further discussion) can be valuable to the tourism and recreational industries. Suppliers, processors, traders and retailers are also involved in a range of initiatives that contribute to the sustainable use and conservation of BFA (see examples in Section 8.2.4 and Section 8.7).

\subsubsection{The public sector}

Public policies and the activities of public-sector organizations can have a major influence on BFA and its management. Protecting biodiversity is typically a stated objective of national environmental policies. Parties to the Convention on Biological Diversity (CBD) are obliged to put in place national strategies, plans or programmes to address the conservation and sustainable use of biodiversity and to integrate the management of biodiversity into relevant cross-cutting policies. The public sector may directly operate projects and programmes in fields such as conservation, monitoring or genetic improvement (see Section 5.9 and Chapters 6 and 7 for examples), help to facilitate BFA management via education and research programmes (see Sections 8.4 and 8.5 ) or take measures that influence the actions of other stakeholders, for example via legal measures, provision of incentives or provision of information (see Sections 8.6, 8.7 and 8.8).

Public bodies mentioned in the country reports as contributing to BFA management generally either have a broad biodiversity focus (largely working on the conservation of wild biodiversity), address the general development of a particular sector (e.g. the forest sector) or target the management of particular farmed or harvested resources (e.g. crops, livestock or fish). Few countries mention public organizations with a mandate specifically related to the contributions that components of associated biodiversity make to food and agriculture. Exceptions include the United States of America's National Genetic Resources Program, which includes the Microbial Germplasm Program and the National Invertebrate Genetic Resource Program. The former aims to ensure that the genetic diversity of agriculturally important micro-organisms is maintained. Its activities include the authentication and characterization of potentially useful microbial germplasm, conservation of microbial genetic diversity and measures that facilitate the distribution and utilization of microbial germplasm for use in research and industry. The latter aims to inventory and characterize the various insect species, races, stocks, strains, biotypes and other genetic entities associated with agricultural systems and to document 
their interactions with agriculture and the environment. Activities implemented under this programme include the preservation of reference specimens, maintenance of genetically important germplasm, documentation of specific insect stocks, management of databases and distribution of material to researchers and breeders.

\subsubsection{The non-governmental sector}

In addition to the producers' organizations discussed above, non-governmental and civilsociety organizations, including social movements, contribute in various ways to the sustainable use and conservation of BFA, including by promoting dynamic and sustainable management practices, including agroecology, at production-system level, promoting the marketing and consumption of biodiverse or biodiversity-friendly products, or advocating policies that favour sustainable approaches to production. For example, local food movements - both in developed and in developing countries - create spaces for farmers to sell biodiverse products. Farmers' markets, box-delivery schemes, consumer-purchase groups and participatoryguarantee schemes, for example, all help to make biodiverse products more available and affordable to consumers, especially in urban settings (FAO and INRA, 2016; Goodman, DuPuis and Goodman, 2012; Kneafsey et al., 2008). A recent study carried out in 11 developing countries, shows how such "innovative" markets have allowed people to regain - or maintain - access to products that were being lost (FAO and INRA, 2018). Not only do these initiatives help farmers find marketing channels for biodiverse foods, they also have an educational role, again especially in urban settings (Brunori, Rossi and Guidi, 2012; FAO and INRA, 2018).

Several country reports mention NGOs specifically dedicated to promoting the conservation and sustainable use of traditional plant varieties or animal breeds, some of which also address the management of pollinators (see for example Box 8.5 and Box 8.6). These NGOs often collaborate with producers, private companies and the general public on conservation and awareness-raising projects. Examples include Frøsamlerne ("seed savers") in Denmark, which offers courses on seed propagation for interested non-experts, and Pro Specie Rara in Switzerland and Germany, which has been collaborating with a major supermarket chain since 1999 on the distribution of products from endangered traditional fruit and vegetable species.

A number of countries mention NGOs with a broad focus on environmental and conservation issues or on livelihoods and rural development that operate some projects specifically addressing the management of BFA. For example, Bangladesh mentions Policy Research for Development Alternative (UBINIG), a community-led and community-based policy and research organization that has connections to farmers, weavers, fishers, artisans, craftspeople, community health providers

\section{Box 8.5}

Contributions of non-governmental organizations to the sustainable management of biodiversity for food and agriculture examples from the Near East

In Iraq, the NGO Nature Iraq successfully surveyed the north of the country to find and conserve the indigenous wild goat (Capra aegagrus). The organization is also effectively raising public awareness on the importance of conserving biological diversity.

In Jordan, the Beekeepers' Union, in collaboration with the country's National Center for Agricultural Research and Extension, its Royal Botanic Garden and the Honey Bee Online Studies Project ${ }^{1}$ (Germany), set up an educational programme to teach school and university students about the value of honey bees as bio-indicators and as providers of ecosystem services and healthy products.

In Lebanon, several NGOs are actively working to conserve and maintain the country's nature reserves and its natural and cultural heritage more generally. Among other activities, these organizations document and publish data on traditional knowledge concerning wild food species and promote the use of wild and healthy foods.

Sources: Adapted from the country reports of Iraq, Jordan and Lebanon. https://www.hobos.de 


\section{PART D}

Box 8.6

\section{Zambia's Biodiversity Community Network}

In Zambia, the Biodiversity Community Network - an NGO working within the International Federation of Organic Agriculture Movements (IFOAM) framework and involved in building the capacity of communities in the conservation and use of biodiversity - implemented a project to strengthen community-based on-farm conservation and sustainable use of crop diversity in the semi-arid Zambezi Gwembe Valley. The project was supported by the Benefit-Sharing Fund of the International Treaty on Plant Genetic Resources for Food and Agriculture. It focused on the conservation of crop diversity and strengthening local seed systems for sorghum, pearl millet, cowpea and bambara nuts.

Source: Adapted from the country report of Zambia.

and rural entrepreneurs and works to conserve forests and the livelihoods of indigenous communities. UBINIG aims, inter alia, to foster climate change adaptation by disseminating knowledge and practices that help to minimize river erosion, promote the selection of appropriate seed for specific agroecological zones and strengthen the conservation of mangroves. Zimbabwe mentions several NGOs that have established community seed banks or hosted seed-diversity fairs in support of the conservation and participatory breeding of local varieties. Nepal notes the role of NGOs such as Local Initiatives for Biodiversity, Research and Development (LI-BIRD) in the establishment of community seed banks that enhance access to - and exchange, use and management of - crop genetic resources.

\subsubsection{The general public}

While many members of the general public have no direct involvement in the management of BFA, their choices as consumers and their political decisions and activities as citizens have the potential to increase or reduce pressures on BFA or influence its management. For example, consumers may decide to support social or environmental objectives by buying fair-trade or organic products or to use farmers' markets to support local agriculture. They may boycott foods seen as unsustainable to pressurize producers and retailers to change their practices.

In some countries, citizen scientists make an important contribution to monitoring the status of particular categories of biodiversity such as birds and butterflies. A global review of such initiatives (Chandler et al., 2017) concluded that they provide a large amount of data on distribution and population abundance and on traits such as phenology, in birds, Lepidoptera and plants, as well as on ecosystem-function variables, mainly in Europe, North America, South Africa, India and Australia (ibid.). A considerable amount of work on conservation projects is also undertaken by volunteers from among the general public.

The roles of citizen scientists are widely noted in the country reports, mainly in those from developed regions (see Chapters 4 and 6 for further discussion). Many countries also mention awareness-raising activities aimed at informing the general public about issues related to BFA (see Section 8.4).

\subsubsection{Regional and international organizations}

Many regional and international organizations contribute to the conservation and sustainable use of BFA. The roles of such organizations in the management of livestock, crop, forest and aquatic genetic resources are discussed in detail in the respective FAO global assessments (FAO, forthcoming, 2010a, 2014a, 2015a), and therefore the focus here is mainly on contributions to the management of associated biodiversity and wild foods. Given that these are broad and diverse categories of biodiversity that can be affected by many different types of activity, there are many international organizations whose work is potentially relevant.

A number of regional and international organizations provided reports as inputs to the SoW-BFA process. ${ }^{5}$ Most are based on a standard questionnaire

For further details of the reporting process, see the "About this publication" section in the preliminary pages of the report. 
that invited organizations to provide information on their activities related to assessment, monitoring, conservation and sustainable use of BFA (including in particular associated biodiversity and wild foods) and to policies, institutions, capacity-building and regional and international cooperation in the management of these components of biodiversity. In addition, the country-reporting guidelines invited countries to provide information on their involvement in regional and/or international initiatives targeting the conservation and sustainable use of associated biodiversity and on the contributions of regional organizations and international programmes to country-level efforts to promote the contributions of associated biodiversity to food security and nutrition, productionsystem resilience and the supply of ecosystem services. The overview presented below is based largely on the information provided in the international organization reports and the country reports. Given the above-noted broad range of potentially relevant organizations and spheres of activity, it is inevitably non-exhaustive. Further information on collaborative activities promoted by international organizations is presented in Section 8.3.

\section{Regional and subregional organizations}

Many of the reports submitted by regional organizations describe a wide variety of activities related to the management of associated biodiversity. Several mention work on the sustainable use and conservation of specific groups of beneficial organisms, such as biological control agents, soil organisms and pollinators. A number mention the maintenance of ex situ collections of organisms belonging to these groups for identification and research purposes. Others provide more general descriptions of their efforts to improve the management of biodiversity in and around production systems. In many cases, activities span all aspects of management from assessment and monitoring to capacitydevelopment, education and awareness raising. Some of the reporting organizations are specialized crop or livestock research and development institutions and report a range of activities related to the management of domesticated genetic resources.
Most of these mention at least some activities targeting associated biodiversity (Table 8.1). Some, however, refer only to the management of domesticated resources and wild relatives and their role in the supply of provisioning services. The report from Africa Rice Center, for example, focuses on rice, highlighting in particular the organization's work on breeding, ex situ conservation and research.

The regional organizations most frequently mentioned in the country reports as contributors to initiatives related to the management of associated biodiversity are intergovernmental bodies or multilateral partnerships working in fields such as fisheries, forestry, wildlife management and the management of shared water bodies. ${ }^{6}$ Some countries simply note their membership of the respective organizations, while others refer to individual projects or programmes. Table 8.1 presents examples of actions related to associated biodiversity undertaken by organizations mentioned by countries in this context.

In their responses on policies, programmes and enabling frameworks, a number of countries mention the role of regional and subregional economic and political unions and communities. For example, several members of the European Union note the significance of regional legislation related to biodiversity-friendly production practices (e.g. controlling the use of pesticides and fertilizers) or to the protection of habitats associated with agricultural, forest or aquatic production systems. Many also refer to agri-environmental schemes funded by the European Agricultural Fund for Rural Development or to projects funded under other European Union programmes (see Section 8.7 for further discussion and examples of activities undertaken within the framework of European Union legislation and policies). Several African countries mention policy frameworks for the agriculture sector developed by subregional political and economic communities. However, few details are provided about provisions specifically related to associated biodiversity.

\footnotetext{
Most of the regional organizations that submitted reports are also mentioned in the country reports.
} 
TABLE 8.1

\section{Selected regional intergovernmental bodies and multilateral partnerships reported by countries to contribute to initiatives in the management of associated biodiversity}

\begin{tabular}{|l|l|l} 
Name of organization & Objectives/mission/mandate & $\begin{array}{c}\text { Selected activities addressing associated } \\
\text { biodiversity and ecosystem services }\end{array}$
\end{tabular}

Africa
African Union Commission
(https://www.au.int/web/en/
commission)

African Union Interafrican Bureau of Animal Resources (http://www.au-ibar.org)

Commission of Central African Forests (http://comifac.org/en/)

East African Community (http://www.eac.int/)

International Centre of Insect Physiology and Ecology (http://www.icipe.org)

International Institute of Tropical Agriculture (http://www.iita.org)

Lake Chad Basin Commission (http://www.cblt.org/en)
Mission: To become "an efficient and value-adding institution driving the African integration and development process in close collaboration with African Union Member States, the Regional Economic Communities and African citizens."

Mission: "To provide leadership in the development of animal resources for Africa through supporting and empowering AU Member States and Regional Economic Communities."

"COMIFAC is an organization responsible for directing, harmonizing and monitoring forest and environmental policies in Central Africa."

"The objectives of the Community shall be to develop policies and programmes aimed at widening and deepening co-operation among the Partner States in political, economic, social and cultural fields, research and technology, defence, security and legal and judicial affairs, for their mutual benefit."

"ICIPE's mission is to help alleviate poverty, ensure food security and improve the overall health status of peoples of the tropics, by developing and extending management tools and strategies for harmful and useful arthropods, while preserving the natural resource base through research and capacity building."

Mission: "To offer leading research partnership that facilitates agricultural solutions to hunger, poverty, and natural resource degradation throughout sub-Saharan Africa."

Mandate: "Sustainable and equitable management of the Lake Chad waters and other transboundary water resources of the Lake Chad Basin; Preservation and protection of ecosystems of the catchment area; Promotion of integration, and preservation of peace and security peace in the Conventional Basin."
Activities across all areas of management (assessment and monitoring; conservation and sustainable use policies, institutions and capacity; regional and international cooperation), particularly in capacitydevelopment and the implementation of regional strategies and projects.

Biodiversity conservation, genetic resources and ecosystems are a priority area under Goal 7: Environmentally sustainable and climate resilient economies and communities of Agenda 2063 (African Union Commission, 2015).

Bee conservation activities: the "Bee Project" (http:// www.au-ibar.org/bee-project) "aims to improve bee products and pollination services through reduced incidence of bee diseases and pests, enhanced markets access, and bee health institutional environment."

Various activities related to the conservation and sustainable use of biodiversity (e.g. establishment of protected areas, joint management of transboundary protected areas, monitoring of biodiversity, valorization of genetic resources, monitoring of resource use and management, development of ecotourism, combating illicit exploitation of forest resources and protection/ valorization of traditional knowledge).

Efforts to harmonize policy frameworks for the management of transboundary ecosystems. Operation of the Lake Victoria Basin Aquatic Biodiversity Meta-Database by the Lake Victoria Basin Commission. The East African Community Treaty refers to the establishment of api-agroforestry systems.

Work on the role of bees (including stingless bees, honey bees and carpenter bees) in the provision of pollination services, the potential of insects as human food and livestock feed, and integrated pest management strategies involving a range of natural enemies (predators and parasitoids) and fungal-based biopesticides. Maintenance of collections of insects and their natural enemies and a repository of micro-organisms with the potential for use in the control of arthropods. Hosting the African Bee Health Programme and the African Reference Laboratory for Bee Health.

Maintenance of a reference collection of arthropods and micro-organisms.

Research on the use of biological control agents in crop production and in the control of aflatoxins (toxic substances produced by certain kinds of mould growing on stored foods)

The programme Reversal of Land and Water Degradation Trends in the Lake Chad Basin Ecosystem features actions targeting the restoration, conservation and sustainable use of biodiversity, including by promoting sustainable practices in agropastoral, aquatic and forest production systems and combatting threats such as invasive alien species, desertification and deforestation. 
TABLE 8.1 (Cont.)

\section{Selected regional intergovernmental bodies and multilateral partnerships reported by countries to contribute to initiatives in the management of associated biodiversity}

\begin{tabular}{|c|c|c|}
\hline Name of organization & Objectives/mission/mandate & $\begin{array}{l}\text { Selected activities addressing associated } \\
\text { biodiversity and ecosystem services }\end{array}$ \\
\hline $\begin{array}{l}\text { Niger Basin Authority } \\
\text { (http://www.abn.ne/) }\end{array}$ & $\begin{array}{l}\text { Mission: "The NBA is ... responsible for promoting } \\
\text { cooperation amongst Member states and contributing } \\
\text { to improve the living conditions of the basin populations } \\
\text { through sustainable management of water resources } \\
\text { and associated ecosystems" }\end{array}$ & $\begin{array}{l}\text { Implementation of various projects and studies } \\
\text { addressing ecosystem management and the protection } \\
\text { of biodiversity. }\end{array}$ \\
\hline $\begin{array}{l}\text { Senegal River Basin } \\
\text { Development Authority } \\
\text { (http://www.portail-omvs. } \\
\text { org/en) }\end{array}$ & $\begin{array}{l}\text { "The objective [of the authority] ... is to implement } \\
\text { an integrated and concerted management program } \\
\text { of water resources and ecosystems for a sustainable } \\
\text { development of the basin." }\end{array}$ & $\begin{array}{l}\text { Establishment of the Regional Water and Environment } \\
\text { Observatory to monitor biodiversity and other natural } \\
\text { resources in the Fouta-Djallon massif. }\end{array}$ \\
\hline \multicolumn{3}{|l|}{ Asia } \\
\hline $\begin{array}{l}\text { South Asia Wildlife } \\
\text { Enforcement Network } \\
\text { (http://www.sawen.org/) }\end{array}$ & $\begin{array}{l}\text { Mission: "To strengthen, promote and co-ordinate } \\
\text { regional co-operation for curbing illegal wildlife trade } \\
\text { that threatens the wild flora and fauna of South Asia." }\end{array}$ & $\begin{array}{l}\text { Activities targeting wildlife in general with a focus } \\
\text { "on policy harmonization; institutional capacity } \\
\text { strengthening through knowledge and intelligence } \\
\text { sharing; and collaboration with regional and } \\
\text { international partners to enhance wildlife law } \\
\text { enforcement in the member countries." }\end{array}$ \\
\hline \multicolumn{3}{|l|}{ Europe } \\
\hline $\begin{array}{l}\text { European Environment } \\
\text { Agency } \\
\text { (https://www.eea.europa.eu/) }\end{array}$ & $\begin{array}{l}\text { Mandate: "To help the Community and member } \\
\text { countries make informed decisions about improving the } \\
\text { environment, integrating environmental considerations } \\
\text { into economic policies and moving towards } \\
\text { sustainability" and "To coordinate the European } \\
\text { environment information and observation network." }\end{array}$ & $\begin{array}{l}\text { Work on biodiversity data, indicators and assessments, } \\
\text { including on habitats and species associated with crop, } \\
\text { livestock, forest and aquatic production systems. }\end{array}$ \\
\hline $\begin{array}{l}\text { Forest Europe (The Ministerial } \\
\text { Conference on the Protection } \\
\text { of Forests in Europe) } \\
\text { (http://foresteurope.org/) }\end{array}$ & $\begin{array}{l}\text { Mission: "FOREST EUROPE enhances the cooperation } \\
\text { on forest policies in Europe under the leadership of } \\
\text { ministers, and secures and promotes Sustainable Forest } \\
\text { Management (SFM) with the aim of maintaining the } \\
\text { multiple functions of forests crucial to society." }\end{array}$ & $\begin{array}{l}\text { Development of guidelines, criteria and indicators for } \\
\text { sustainable forest management. } \\
\text { Monitoring and reporting on the state of forests and } \\
\text { forest management. } \\
\text { Work on forest ecosystem services and their valuation. } \\
\text { Work on forest protection and adaptation to climate } \\
\text { change. }\end{array}$ \\
\hline $\begin{array}{l}\text { Nordic Council of Ministers } \\
\text { (http://www.norden.org/en/ } \\
\text { nordic-council-of-ministers) }\end{array}$ & $\begin{array}{l}\text { "The Nordic Council of Ministers is the official body for } \\
\text { Nordic intergovernmental co-operation. Representatives } \\
\text { of the Nordic governments meet at the Council of } \\
\text { Ministers to draft Nordic conventions, etc." }\end{array}$ & $\begin{array}{l}\text { Promotion of sustainable use of nature and genetic } \\
\text { resources in fisheries and aquaculture, agriculture, food } \\
\text { and forestry. }\end{array}$ \\
\hline \multicolumn{3}{|c|}{ Latin America and the Caribbean } \\
\hline $\begin{array}{l}\text { Caribbean Agricultural } \\
\text { Research and Development } \\
\text { Institute } \\
\text { (http://www.cardi.org) }\end{array}$ & $\begin{array}{l}\text { "To contribute to the sustainable development of } \\
\text { Caribbean people by the generation, transfer and } \\
\text { application of appropriate technologies through } \\
\text { agricultural research for development." }\end{array}$ & $\begin{array}{l}\text { Work on the identification and use of exotic } \\
\text { coccinellidae (ladybird beetles) as biological control } \\
\text { agents for the pink hibiscus mealybug (Maconellicoccus } \\
\text { hirsutus). }\end{array}$ \\
\hline $\begin{array}{l}\text { Caribbean Regional } \\
\text { Fisheries Mechanism } \\
\text { (http://www.crfm.int) }\end{array}$ & $\begin{array}{l}\text { Objectives "(a) the efficient management and } \\
\text { sustainable development of marine and other aquatic } \\
\text { resources within the jurisdictions of Member States; } \\
\text { (b) the promotion and establishment of co-operative } \\
\text { arrangements among interested States for the efficient } \\
\text { management of shared, straddling or highly migratory } \\
\text { marine and other aquatic resources; (c) the provision } \\
\text { of technical advisory and consultative services to } \\
\text { fisheries divisions of Member States in the development, } \\
\text { management and conservation of their marine and } \\
\text { other aquatic resources." }\end{array}$ & $\begin{array}{l}\text { Regional Coral Reef Plan of Action Plan approved in } \\
2014 .\end{array}$ \\
\hline
\end{tabular}


TABLE 8.1 (Cont.)

\section{Selected regional intergovernmental bodies and multilateral partnerships reported by countries to contribute to initiatives in the management of associated biodiversity}

\begin{tabular}{|l|l|l}
\hline Name of organization & Objectives/mission/mandate & $\begin{array}{c}\text { Selected activities addressing associated } \\
\text { biodiversity and ecosystem services }\end{array}$
\end{tabular}

\section{Inter-American Institute for Cooperation on Agriculture (http://www.iica.int/en)}

Tropical Agricultural Research and Higher Education Center (https://www.catie.ac.cr/en)
Mission: "To encourage, promote and support our Member States in their efforts to achieve agricultural development and rural well-being through international technical cooperation of excellence."

Mission: "Increase sustainable and inclusive human well-being in Latin America and the Caribbean, promoting education, research and outreach for the sustainable management of agriculture and conservation of natural resources.
Priorities for future workshops and capacity-building activities to promote the use of agrobiodiversity include the adoption of territorial or landscape approaches for the integral management and sustainable use of agrobiodiversity and associated species.

Research, capacity-development and educational activities supporting sustainable use and conservation of biodiversity in forest, agricultural and coastal-marine production systems.

\section{Near East and North Africa}

Regional Organization for the Conservation of the Environment of the Red Sea and Gulf of Aden (http://www.persga.org/ index.php)
"PERSAGA is ... dedicated to the conservation of the coastal and marine environments found in the Red Sea, Gulf of Aqaba, Gulf of Suez, Suez Canal, and Gulf of Aden surrounding the Socotra Archipelago and nearby waters."

Monitoring activities, including for mangroves and coral reefs.

Establishment of marine protected areas.

Actions to protect the marine environment from land-based activities (coral reefs, mangroves and seagrass beds among the priorities).

Valuation studies of marine and coastal ecosystems. Climate change-related actions including vulnerability assessments for coastal and marine environments and development of ecosystem-based adaptation measures.

Pacific

Pacific Community (http://www.spc.int)

Coral Triangle Initiative (http://www. coraltriangleinitiative.org/)

Pacific Organic and Ethical Trade Community (http://www.organicpasifika. com/poetcom)
Mission: "We work for the well-being of Pacific people through the effective and innovative application of science and knowledge, guided by a deep understanding of Pacific Island contexts and cultures."

"The Coral Triangle Initiative on Coral Reefs, Fisheries, and Food Security (CTI-CFF) is a multilateral partnership of six countries working together to sustain extraordinary marine and coastal resources by addressing crucial issues such as food security, climate change and marine biodiversity."

"Through coordination, information sharing, networking, capacity building and establishing a regional certification scheme grow the organic and ethical trade movement and contribute to a productive, resilient, sustainable and healthy Pacific Island region."
Strategies and programmes that address the sustainable management of the region's marine and terrestrial ecosystems.

Biological Control Laboratory "facilitates and coordinates biological control programmes for managing pest problems of the Pacific Island Countries and Territories."

Goals include: the establishment of marine protected areas, targeting coral reefs, mangroves, seagrass beds and a range of other marine and coastal habitats; improving the status of threatened marine species; implementation of an ecosystem approach to management of fisheries; and implementation of climate change adaptation measures in marine and coastal environments.

A range of activities promoting organic management and hence addressing the sustainable use of biodiversity.

Sources: The organizations listed are mentioned in the country reports as examples of international cooperation and/or submitted reports on their BFA-related activities as contributions to the preparation of The State of the World's Biodiversity for Food and Agriculture. Information on mandates and activities is taken from the country reports or international organization reports and/or from organization websites (accessed May-June 2017). 
Few country reports mention regional NGOs that specifically target associated biodiversity or wild foods. One exception is the International Association for the Protection of the European Dark Bee, ${ }^{7}$ mentioned in the report from Poland. Likewise, only a few reports mention regional multistakeholder networks that promote collaboration in research or other activities explicitly related to the management of associated biodiversity and wild foods. Examples include Planta Europa, ${ }^{8}$ a network of non-governmental, governmental and scientific organizations undertaking joint actions to protect species of plants and fungi in Europe, the Association of Forestry Research of East Africa and the Asia Pacific Association of Forestry Research Institutions. ${ }^{9}$

Collaborative initiatives focusing on associated biodiversity and wild foods are further discussed in Section 8.3. Further information on the roles of regional organizations is provided in the regional synthesis reports prepared as part of the SoW-BFA process. ${ }^{10}$

\section{International organizations}

Information on the associated biodiversity-focused activities of the organizations that submitted reports as contributions to the SoW-BFA process is summarized in Table 8.2. Like their regional counterparts, global organizations report a variety of contributions to the management of associated biodiversity, ranging from projects targeting the sustainable use of pollinators or biological control agents to the management of ex situ collections and broader efforts promoting the maintenance of healthy agroecosystems. Again, organizations whose mandates focus on crops or livestock report a range of activities related to the management of domesticated genetic resources and in some cases wild relatives. Most of these organizations also mention actions targeting associated biodiversity, although some reports focus entirely on

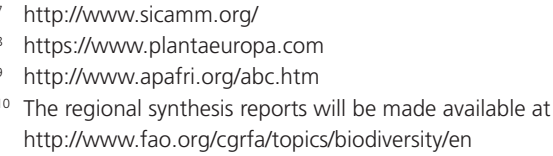

plant genetic resources for food and agriculture (PGRFA) and their role in the supply of provisioning services. For example, the report from the International Maize and Wheat Improvement Center ${ }^{11}$ describes the organization's work on ex situ conservation and characterization of its target species and their wild relatives. The report from the Global Crop Diversity Trust ${ }^{12}$ notes that, in collaboration with the Millennium Seed Bank, Kew (United Kingdom), it is implementing a project supporting national genebanks in collecting and conserving crop wild relatives.

The country reports provide limited information on the roles of international (i.e. global) organizations in the management of associated biodiversity or BFA more generally. Responses referring to collaborative initiatives at this level mainly relate to international legal instruments to which reporting countries are parties (see Section 8.8.1 for information on international policy frameworks). Several countries refer to the ongoing activities of intergovernmental bodies such as the Commission on Genetic Resources for Food and Agriculture, the Intergovernmental Sciencepolicy Platform on Biodiversity and Ecosystem Services, ${ }^{13}$ UN Environment, ${ }^{14}$ the International Whaling Commission ${ }^{15}$ and the Organisation for Economic Co-operation and Development. ${ }^{16}$ For example, Norway mentions the establishment of the GRID-Arendal Centre ${ }^{17}$ to support the work of the United Nations in the environmental field (mainly through UN Environment). Some countries mention the roles of international conservation NGOs or NGO networks (e.g. BirdLife International, ${ }^{18}$ World Conservation Society ${ }^{19}$ and $\mathrm{WWF}^{20}$ ) that operate or support projects and programmes at country or regional level.

\footnotetext{
http://www.cimmyt.org

12 https://www.croptrust.org

13 http://www.ipbes.net

14 http://www.unep.org

15 https://iwc.int/home

16 http://www.oecd.org

7 https://www.grida.no

8 http://www.birdlife.org

9 https://www.wcs.org

20 https://www.worldwildlife.org
} 
TABLE 8.2

Examples of associated-biodiversity management activities reported by international organizations

\begin{tabular}{|l|l|l|l|}
\hline Organization & $\begin{array}{c}\text { Component(s) of } \\
\text { associated biodiversity } \\
\text { targeted }\end{array}$ & \begin{tabular}{c} 
Examples of activities targeting associated biodiversity \\
\hline M
\end{tabular} I $\quad$ V & P \\
\hline
\end{tabular}

Centre for Agriculture and Biosciences International (CABI) (http://www.cabi.org)

International Center for Tropica Agriculture (CIAT)

(http://ciat.cgiar.org)

International Center for Agricultural Research in the Dry Areas (http://www.icarda.org)

Secretariat of the Convention on Biological Diversity (https://www.cbd.int/secretariat)

International Atomic Energy Agency

(https://www.iaea.org)

International Fund for Agricultural Development (https://www.ifad.org)

IFOAM - Organics International (https://www.ifoam.bio)

International Food Policy Research Institute (http://www.ifpri.org)

International Rice Research Institute (http://irri.org)

International Union for Conservation of Nature (https://www.iucn.org)

Slow Food (https://www.slowfood.com)

UN Environment World Conservation Monitoring Centre (https://www.unep-wcmc.org)
Ex situ conservation: housing a living collection of micro-organisms holding some 30000 strains representing over 6000 species from 142 countries: providing training and capacity-building to help member countries, in particular, conserve and utilize biodiversity, especially in establishing microbia culture collections.

Work on the use of micro-organism and invertebrate biocontrol agents.

Work on integrated pest management including the use of biological control agents.

Ex situ conservation: holds 1400 strains of rhizobium of food and forage legumes.

Programme of work on agricultural biodiversity addresses assessments, adaptive management, capacity building and mainstreaming of al components of agricultural biodiversity.

Cross-cutting initiatives address, inter alia, the conservation and sustainable use of soil biodiversity and the conservation and sustainable use of pollinators.

Characterization and monitoring projects on rhizobial bacteria.

Research on the use of microbial biotechnology to improve productivity and the adaptation of legumes to climate change.

Provision of technical advice and training on the use of legumes and rhizobium strains to maintain the population of essential bacteria in soils.

Work on the conservation of biodiversity in forest and grassland production systems.

Use of biodiversity is a component in all IFOAM projects and programmes.

Research on farmers' and consumers' preferences and willingness to pay for biodiversity and ecosystems.

Studies on associated biodiversity, including both beneficial organisms (e.g. for integrated pest management, Azolla as biofertilizer) and othe organisms (vertebrate and invertebrate pests, diseases and weeds). Ex situ Azolla collection

Management of The IUCN Red List of Threatened Species

Programmes addressing the conservation and sustainable use of biodiversity and the supply of ecosystem services in forest, aquatic, grassland and other production systems

Campaigns and projects supporting biodiverse food production systems. Several Slow Food Presidia (local projects that protect traditional products, traditional processing methods or rural landscape or ecosystem at risk of loss) worldwide that protect traditional beekeeping.

Monitoring and support for the management of components of biodiversity that contribute to the supply of ecosystem services, including pollinators.

Promotion of ecosystem and landscape approaches in agricultural-development planning at national scale.

Provision of advice on policies that affect biodiversity and ecosystem services, including those that support food and agriculture. 
TABLE 8.2 (Cont.)

Examples of associated-biodiversity management activities reported by international organizations

\begin{tabular}{|l|l|l|l|}
\hline Organization & $\begin{array}{c}\text { Component(s) of } \\
\text { associated biodiversity } \\
\text { targeted }\end{array}$ & Examples of activities targeting associated biodiversity \\
\hline M & I & V & P \\
\hline
\end{tabular}

Bioversity International*

World Agroforestry Centre*

World Bank*
Work on the contributions of biodiversity in forest and other terrestrial production systems to the supply of ecosystem services.

Research on the diverse roles that trees play in agricultural landscapes, and using this to advance policies and practices that benefit the poor and the environment.

Mainstreaming of climate-smart agriculture, increasingly involving the use of a landscape approach

Notes: $\mathrm{M}=$ micro-organisms; I = invertebrates; $\mathrm{V}=$ vertebrates: $\mathrm{P}=\mathrm{Plants}$. The questionnaire invited organizations to tick the categories of BFA on which they work. The organizations marked with an asterisk (*) did not specify any categories of associated biodiversity, but nonetheless mentioned relevant activities.

Sources: International organization reports prepared for The State of the World's Biodiversity for Food and Agriculture, supplemented in some cases by information from organization websites.

\subsection{Cooperation}

- A wide range of national-level multistakeholder initiatives contribute to the sustainable management of biodiversity for food and agriculture (BFA). Strengthening cooperation in this field, however, remains a priority.

- While numerous regional and international collaborative initiatives target the sustainable use and conservation of crop, livestock, forest and aquatic genetic resources, far fewer such initiatives specifically target the management of associated biodiversity (species such as pollinators, soil organisms and pest natural enemies found in and around production systems) or its role in providing ecosystem services to food and agriculture.

- Cooperation across the sectors of food and agriculture in the management of BFA often needs to be improved, as does cooperation between the food and agriculture sector and the environment/nature conservation sector.

- Priorities for enhancing cooperation in the management of BFA include:

- improving mechanisms for information-sharing between stakeholders; and

- strengthening participatory decision-making processes, including to ensure the involvement of small-scale producers and women.
As well as involving a diverse range of stakeholders, the management of BFA spans the conventional boundaries between the sectors of food and agriculture and those between food and agriculture and nature conservation. Moreover, strengthening the sustainable use and conservation of BFA often requires actions on a large geographical scale (e.g. across watersheds or along migration routes) and involving a wide range of different stakeholders. The distributional ranges of associated biodiversity species often cross national boundaries. Some categories such as invertebrate biological control agents (Cock et al., 2009) are exchanged internationally. Global challenges such as climate change and emerging disease threats require global responses. Countries are interdependent in their use of genetic resources in the crop, livestock, fishing, aquaculture and forest sectors (Bartley et al., 2009; FAO, forthcoming, 2009c, 2010a, 2014a, 2015a; Koskela et al., 2009). For all these reasons, multistakeholder and international cooperation in BFA management is vital. This section presents an overview of cooperative activities, drawing largely on the country reports, reports submitted by international organizations and the published or forthcoming global assessments of genetic resources in the crop, livestock, forest and aquatic sectors (FAO, forthcoming, 2010a, 2014a, 2015a). 


\subsubsection{Cooperation at national level}

The country reports suggest that BFA is rarely singled out as a distinct and well-defined target for collaborative activities. However, they describe a range of multistakeholder initiatives that focus on particular aspects of BFA management or that include BFA management under broader umbrellas. Examples include committees and councils addressing ecosystem services, climate change, genetically modified organisms, invasive alien species, organic agriculture, access and benefitsharing and the financing of biodiversity-related programmes. Several countries report that national policies, plans and strategies in fields such as these have been developed through multistakeholder consultative processes. In some

\section{Box 8.7}

The Norwegian Genetic Resource Centre and its genetic resources committees

The Norwegian Genetic Resource Centre was established by the Ministry of Agriculture and Food to monitor plant, forest and animal genetic resources for food and agriculture, promote their conservation and use, facilitate access to them and increase knowledge and awareness on their management. Having a single centre working on a large share of the country's genetic resources for food and agriculture puts Norway in a strong position to identify and take advantage of the synergies between sectors and to weigh trade-offs, of which there are few. The centre organizes regular and ad hoc meetings during which its sectoral committees on animal, plant and forest genetic resources, both jointly and separately, discuss and provide advice on, inter alia, the centre's strategic and action plans and national policies of relevance to genetic resources for food and agriculture (e.g. environmentrelated policies). Joint meetings of the three genetic resource committees have led to interesting exchanges of knowledge and expertise across sectors on issues such as the characterization of genetic resources, in situ and ex situ conservation, and the development of indicators.

Source: Country report of Norway. cases, efforts are being made to mainstream biodiversity into broader efforts to develop rural areas or the national economy more broadly. Ethiopia, for example, notes that the country's Climate Resilient Green Economy Strategy provides an important mechanism for mainstreaming biodiversity into the agriculture, forest, power and transport sectors. Some countries report multistakeholder initiatives aimed at improving the integration of BFA-related issues into their NBSAPs or strengthening coordination in the implementation of these instruments more generally. Even where no permanent collaborative bodies or frameworks have been set up, multistakeholder collaboration is often reported to occur at project level or between individual institutions such as universities and research centres. Many countries, however, note that there are still considerable gaps and weaknesses in terms of cooperation between research institutes and between them and other stakeholders (see Section 8.5).

Some countries report that they are making efforts to promote a more cross-sectoral approach to research. For example, Finland notes that three major sectoral institutions in applied research, the Game and Fisheries Research Institute, the Finnish Forest Research Institute and Agrifood Research Finland, are being merged into one body, with the aim of strengthening collaboration in research on (inter alia) BFA, including associated biodiversity and wild foods, and improving the cost-efficiency of research.

National multistakeholder bodies addressing the management of genetic resources are increasingly being established in the crop, livestock and forest sectors. However, they are still absent in many countries. For example, out of 129 countries that submitted country reports for The Second Report on the State of the World's Animal Genetic Resources for Food and Agriculture (FAO, 2015a), 78 indicated that in 2014 they had a national advisory committee for animal genetic resources in place. Cross-sectoral cooperation in the management of genetic resources (i.e. between the crop, livestock, forest and aquatic 
Box 8.8

\section{France's Agricultural Biodiversity Observatory}

The Agricultural Biodiversity Observatory (ABO) was established in 2009 as a participatory science programme for farmers in all types of production system. The ABO's two main objectives are (i) to populate a scientific database that can be used, inter alia, to develop biodiversity indicators for agricultural environments and to identify links between biodiversity and farming practices and (ii) to raise awareness of links between biodiversity and farming practices among stakeholders, particularly among farmers, and help them evaluate their practices.

The ABO was established by the Ministry of Agriculture, Agrifood and Forestry within the framework of France's National Biodiversity Strategy. It builds on the National Museum of Natural History's participatory science programme "Vigie-Nature". It is coordinated nationally by the Ministry of Agriculture, the Museum of Natural History and the Permanent Assembly of Chambers of Agriculture, in collaboration with the University of Rennes. At local level, various facilitators, including members of agricultural associations or chambers of agriculture, provide support to farmer volunteers in the implementation of the following four observation protocols (all of which are environmentally friendly):

(a) counting and characterization of butterflies;

(b) observation of pollinator nesting sites;

(c) use of identification tools for the observation of terrestrial invertebrates; and

(d) observation of earthworms.
Farmers are also encouraged to monitor their farming practices and to reflect on linkages between these practices and associated biodiversity.

The $A B O$ publishes its results annually. It has not yet (as of 2017) been possible to draw any firm conclusions about trends in the status of agricultural biodiversity. However, it has been possible to develop indicators based on the data gathered, which will be added to the indicators of the National Observatory for Biodiversity. ${ }^{1}$

The impact of the ABO extends far beyond the farmers directly involved and plays a key role in raising awareness of associated biodiversity and related issues. For example, in 2016, several national-level professional agricultural organizations committed themselves to long-term involvement in the National Strategy for Biodiversity. They also indicated that they wanted to see the further development of the $A B O$ and encouraged farmers to get involved.

In conclusion, the experience of establishing the $\mathrm{ABO}$ has shown that ensuring regular and coherent stakeholder participation requires time. However, it has also shown that such a programme can really raise awareness in the agricultural community and stimulate the active commitment of actors in this sector.

Source: Provided by Patricia Larbouret, Christophe Pinard and Pierre Velge. http://indicateurs-biodiversite.naturefrance.fr sectors) is often limited. Some country reports, ${ }^{21}$ however, mention national strategies, plans or policies that address genetic resources management in multiple sectors, national bodies (e.g. committees, research centres or networks) that coordinate work across sectors (see Box 8.7 for example) or (less frequently) specific cross-sectoral initiatives such as joint marketing campaigns for

\footnotetext{
${ }^{21}$ Reports submitted for The State of the World's Biodiversity for Food and Agriculture and those submitted for previous global assessments of genetic resources.
}

products from locally adapted livestock and crops. Within each sector, there are numerous examples of projects and programmes that involve a range of stakeholders (FAO, forthcoming, 2010a, 2014a, 2015a). Many countries, however, consider that mechanisms for involving stakeholders, in particular small-scale producers and women, in the planning and implementation of management activities remain inadequate (ibid.).

Where associated biodiversity is concerned, any projects or programmes that aim to promote biodiversity-friendly management practices in 


\section{PART D}

food and agricultural production systems are likely to involve a degree of collaboration between producers and/or between them and other stakeholders such as public-sector bodies or NGOs. In many cases, this will involve collaboration between stakeholders with "production" interests and those with "nature conservation" interests. The country reports provide numerous examples (see Section 8.7 and Chapters 5 and 7). The importance of participatory, multistakeholder approaches is again widely noted. Finland, for instance, reports that many projects in which environmental authorities, NGOs, advisers and land-users have cooperated from the beginning have produced impressive results. Ireland notes in this context that various management measures favourable to associated biodiversity are being promoted via the participation of farmers in agri-environmental schemes, i.e. incentive schemes operated by the public sector within the framework

\section{Box 8.9}

The Regional Project for Sustainable Management of Globally Significant Endemic Ruminant Livestock (PROGEBE)

Trypanotolerant Ndama cattle and Djallonké sheep and goats are under threat because of habitat degradation caused by deforestation and abusive logging, and because of agricultural policies that promote the intensification of production and the introduction of exotic breeds.

The Regional Project for Sustainable Management of Globally Significant Endemic Ruminant Livestock (commonly referred to using the French acronym PROGEBE) took action to improve the management of natural resources and endemic livestock breeds and their products in several West African countries. Land-use plans were discussed and validated by rural communities, and rules for the use of natural resources in target areas were established. Action was also taken in the fields of animal health and nutrition, access to water and access to markets.

Sources: Adapted from the country reports of Guinea, Mali and Senegal. of European Union legislation (see Section 8.7). Generally, however, the country reports provide little indication that producers or other local stakeholders are heavily involved in planning or prioritizing conservation and management activities for associated biodiversity or that there is much collaboration in this field among producers' or community-based organizations.

Some country reports describe initiatives that involve producers or the general public in monitoring particular categories of associated diversity. For example, France mentions the Agricultural Observatory of Biodiversity, a Ministry of Agriculture initiative that involves stakeholders, particularly farmers, in monitoring agricultural biodiversity and investigating the links between biodiversity and agricultural practices (Box 8.8). Grenada notes that its Ministry of Agriculture, Lands, Forestry, Fisheries and the Environment has established voluntary linkages with research institutions, NGOs and stakeholder groups, which work in collaboration to share primary data that inform the conservation and sustainable use of biodiversity in marine and coastal environments that support important fisheries.

Collaborative awareness-raising, education or training initiatives related to associated biodiversity are not widely mentioned in the country reports. One exception is the initiative mentioned in Box 8.5 led by the Jordan Beekeepers' Union in collaboration with national and international partners.

\subsubsection{Cooperation at international level}

As discussed in Section 8.2.6, BFA management is addressed in a number of global policy and legal instruments and by a number of international organizations. As well as supporting and regulating activities at national level, this international institutional framework serves to promote wider and more effective global, regional and bilateral cooperation.

Many country reports provide information on international collaborative activities in BFA management (e.g. Box 8.9). As at national level, many of these activities target broader areas of natural resources, biodiversity or environmental management rather than BFA as a distinct category. 


\section{Box 8.10}

\section{Appointment of national focal points and participation in the preparation of The State of the World's Biodiversity for Food and Agriculture}

Over recent years and decades, FAO has invited countries to establish national focal points to be responsible for coordinating reporting activities for the various global assessments of genetic resources and biodiversity prepared under the auspices of the Commission on Genetic Resources for Food and Agriculture. To varying degrees, these national focal points have taken on a broader role in their respective sectors in terms of coordinating genetic resources management activities at national level, promoting regional and international collaboration in this field and serving as permanent points of contact with FAO.
In the case of the The State of the World's Biodiversity for Food and Agriculture, 135 countries have nominated a national focal point ${ }^{1}$ and 92 officially submitted a country report $^{2}$ (see map below). A full list of reporting countries can be found in the "About this publication" section among the preliminary pages of the report.

\footnotetext{
As of October 2018.

2 Selected information from the country report of Japan, submitted in 2018, is presented.
}

National focal points and country reporting for The State of the World's Biodiversity for Food and Agriculture

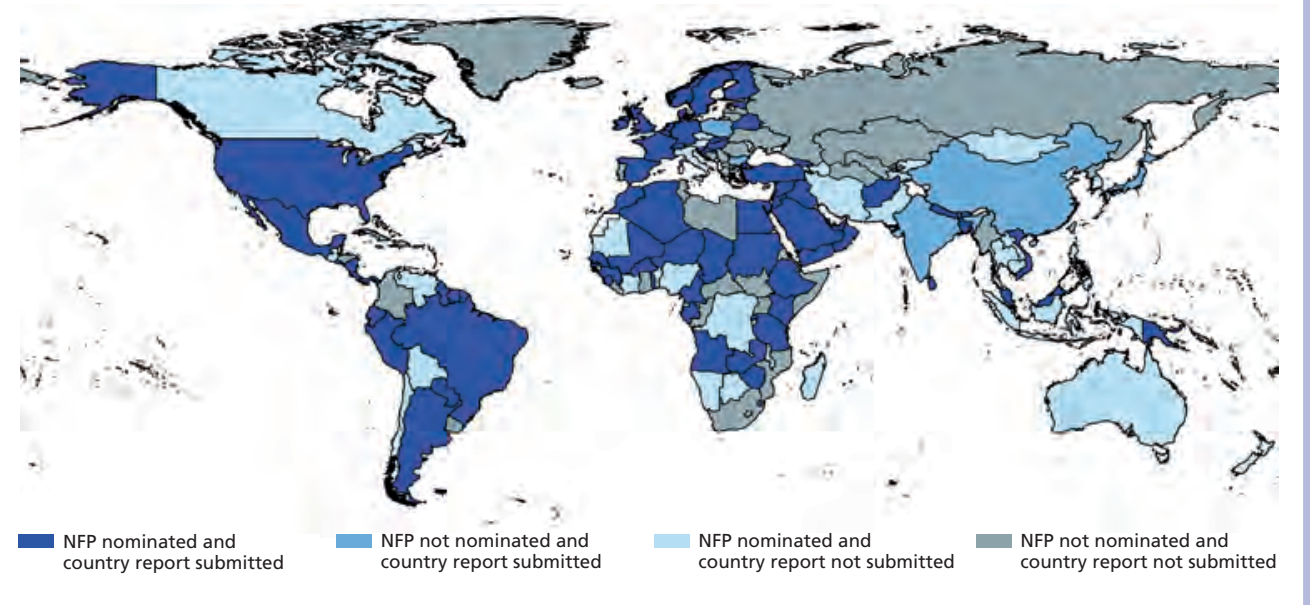

Examples include the joint management of transboundary habitats and wildlife corridors, ex situ conservation networks for particular species, cooperation in combating wildlife crime, illegal logging and illegal, unreported and unregulated fishing, certification schemes for sustainable practices and joint research projects, programmes and networks.

In the crop, livestock, forest and aquatic sectors a number of regional and international networks contribute to the sustainable use, development and conservation of genetic resources (FAO, forthcoming, 2010a, 2014a, 2015a). Some are dedicated to genetic resources management, broadly defined, across the whole of the respective sector, ${ }^{22}$ while others address specific species or specific aspects of management. Numerous international

\footnotetext{
22 Bodies of this type are probably most active in Europe, home to the European Cooperative Programme for Plant Genetic Resources (http://www.ecpgr.cgiar.org), the European Forest Genetic Resources Programme (http://www.euforgen.org) and the European Regional Focal Point for Animal Genetic Resources (https://www.rfp-europe.org).
} 


\section{PART D}

Box 8.11

Transfrontier conservation areas in Southern Africa

Several transfrontier conservation areas (TFCAs)

have been established by the Southern African

Development Community (SADC) supported by the non-profit Peace Parks Foundation. ${ }^{1}$ The objective is to develop a functional and integrated network of transfrontier areas where shared natural resources are sustainably co-managed and conserved to foster socio-economic development for the benefit of local people. The programme includes actions aimed at enhancing local livelihoods, for instance by promoting tourism, and reducing the vulnerability of ecosystems and people to the effects of climate change.

The Lubombo Transfrontier Conservation Area, for instance, is a TFCA established in 2014 and co-managed by Eswatini, Mozambique and South Africa. It links the Lubombo Mountains to the coastal wetlands and incorporates various nature and game reserves, forest parks and other conservation sanctuaries, thus forming a continuous corridor of protected natural resources. The area covers $10029 \mathrm{~km}^{2}$ and includes four distinct TFCAs and five wetlands listed in the Ramsar Convention's List of Wetlands of International Importance.

The Lubombo TFCA's core objectives are to ensure that natural resources are utilized in a sustainable manner and to promote the development of transboundary ecotourism. Communities that have allocated their land for conservation and natural-resource management benefit from outreach programmes that contribute to income generation, for example by initiating beekeeping and chilli-pepper production or supporting the maintenance of community ecolodges, campsites and trail networks. Other projects include the implementation of permaculture, climate-smart agriculture and conservation agriculture. The spread of beekeeping through the community outreach programmes has reportedly led to a decline in poaching and illegal honey harvesting in the nature reserves.

Sources: Adapted from the country reports of Angola, Eswatini and Zimbabwe. Additional information provided by Thembinkosi Gumedze. 1 http://www.peaceparks.org/ governmental and non-governmental organizations and fora contribute to collaborative activities in genetic resources management at global and regional levels. FAO coordinates global networks of government-nominated national focal points for genetic resources in the various sectors of food and agriculture (Box 8.10).

Relatively few country reports provide details of international or regional collaborative activities involving partners that specifically target components of associated biodiversity or their roles in the provision of ecosystem services to food and agriculture. Burkina Faso notes the country's involvement with the African Reference Laboratory for Bee Health ${ }^{23}$ and the African Bee Health Project. ${ }^{24}$ The reference laboratory, an initiative of the International Centre of Insect Physiology and

${ }^{23}$ http://bees.icipe.org/index.php

24 http://bees.icipe.org/index.php/project/programme-objectives
Ecology and the African Union Interafrican Bureau for Animal Resources, supported by the European Union, is in Nairobi, Kenya, and has satellite stations in Cameroon, Ethiopia and Liberia, as well as in Burkina Faso. Jamaica mentions C-Fish (the Caribbean Fish Sanctuary Partnership Initiative), a project established by the not-for-profit CARIBSAVE Partnership, which aims to strengthen communitybased fish sanctuaries and marine protected areas in five countries across the Caribbean. A number of African countries provide information on transfrontier conservation areas (Box 8.11). Further examples of cooperation in specific fields of BFA management can be found in Chapters 5 and 7.

Many of the reports submitted by international organizations as contributions to the SoW-BFA process ${ }^{25}$ mention a range of global and regional

\footnotetext{
25 See Section 8.2 and the "About this publication" section among the preliminary pages.
} 
cooperation initiatives in fields such as research and education on BFA, largely with a focus on crop and to a lesser extent livestock genetic resources. ${ }^{26}$ For example, the World Agroforestry Centre notes its role as a primary partner in the African Orphan Crop Consortium Initiative, which aims to enhance research on neglected species. The International Atomic Energy Agency mentions a regional project operated in conjunction with FAO that is aiming to improve the resistance of indigenous sheep breeds in Latin America to gastro-intestinal parasites. Some international organizations mention that they are involved in coordinating regional or global genetic resources networks that aim to share knowledge and ensure the long-term conservation of PGRFA.

Several international organizations mention that they contribute to programmes that assist countries in the development of information systems related to BFA. The $\mathrm{CGIAR}^{27}$ research centres play an important role in coordinating activities related to BFA, in particular through the Genebank Platform, ${ }^{28}$ a partnership between the eleven CGIAR genebanks and the Crop Trust. The Platform provides support to national, regional and international genebanks in the area of data management, for instance through the GRIN-Global ${ }^{29}$ genebank database management system, and Genesys, ${ }^{30}$ a global portal for access to information on PGRFA accessions. The Centre for Agriculture and Biosciences International reports that it hosts the secretariat of the Global Open Data for Agriculture and Nutrition ${ }^{31}$ initiative, which seeks to support global efforts to make agricultural and nutritionally relevant data accessible for use in improving global food security and human health.

\footnotetext{
${ }^{26}$ Few examples related to associated biodiversity are reported. Some exceptions (e.g. the African Reference Laboratory for Bee Health and African Bee Health Programme) are listed in Table 8.1

27 Originally an abbreviation of Consultative Group on International Agricultural Research: https://www.cgiar.org

28 https://www.genebanks.org/

29 https://www.grin-global.org/

${ }^{30} \mathrm{https}: / / w w w . g e n e s y s-p g r . o r g / c o n t e n t / a b o u t / a b o u t$

31 http://www.godan.info/
}

A number of organizations indicate that they are collaborating on BFA-related policy development. For example, the Inter-American Institute for Cooperation on Agriculture, the Tropical Agricultural Research and Higher Education Center and Bioversity International cooperated with technical representatives from Mexico and all the countries of Central America to develop the Strategic Action Plan to Strengthen Conservation and Use of Mesoamerican Plant Genetic Resources in Adapting to Climate Change 2014-2024, a roadmap for regional collaboration and cooperation on conservation and use of, and access to, PGRFA. The Secretariat of the CBD reports its participation in BFA-related cooperative initiatives such as the Liaison Group of the Biodiversity-related Conventions, ${ }^{32}$ the Collaborative Partnership on Forests, ${ }^{33}$ the Inter-Agency Liaison Group on Invasive Alien Species ${ }^{34}$ and the Sustainable Ocean Initiative. ${ }^{35}$

In its work on crop and livestock production, forestry, fisheries and aquaculture, FAO collaborates with countries, regions and other partners in promoting the use and conservation of BFA in the context of sustainable development. For example, FAO in collaboration with the Secretariat of the CBD has prepared technical guides for mainstreaming ecosystem services into agricultural production and management in East Africa and in the Pacific Islands (FAO and CBD, 2016; FAO et al., 2016). In collaboration with the International Network of Food Data Systems (INFOODS), it developed the FAO/INFOODS food composition database ${ }^{36}$ (see Section 6.4). It is a major partner in the implementation of the CBD and, in collaboration with other partners such as the United Nations Environment Programme, the United Nations Development Programme and the United Nations Educational, Scientific and Cultural Organization, contributes to the implementation of the CBD's Strategic Plan

\footnotetext{
32 https://www.cbd.int/blg/

${ }^{3} \mathrm{http} / / / \mathrm{www} . \mathrm{cpfw}$ eb.org/en/

${ }^{34} \mathrm{https}: / / w w w . c b d . i n t / i n v a s i v e / l g$

35 https://www.cbd.int/soi/

36 http://www.fao.org/infoods/infoods/tables-and-databases/ faoinfoods-databases/en
} 


\section{PART D}

Box 8.12

Resolution 4/2017. The Commission on Genetic Resources for Food and Agriculture and its contribution to the achievement of the Sustainable Development Goals

In 2017, the Fortieth FAO Conference adopted the following resolution on the contribution of the Commission to the achievement of the Sustainable Development Goals.

\section{THE CONFERENCE,}

Having considered the report of the Sixteenth Regular Session of the Commission on Genetic Resources for Food and Agriculture (Commission);

Stressing the important linkages between biodiversity for food and agriculture and relevant global instruments and frameworks, especially the 2030 Agenda for Sustainable Development, the Paris Agreement and the Addis Ababa Action Agenda of the Third International Conference on Financing for Development;

Recognizing the important work of the Commission in the preparation of reports on the state of the world's plant, animal, forest and aquatic genetic resources for food and agriculture and their respective follow-up processes;

Further recognizing the importance of the Commission's Global Plans of Action as frameworks for national action to enhance the management of plant, animal, and forest genetic resources for food and agriculture at national, regional and global levels;

Welcoming the preparation of the report on The State of the World's Biodiversity for Food and Agriculture and its follow-up;

Acknowledging the important work of the Commission in the development of targets and indicators on genetic resources for food and agriculture in the context of the implementation of the Commission's Global Plans of Action;

Further acknowledging the competence of the Commission and FAO technical capacity in the field of genetic resources for food and agriculture, and therefore recognizing the Commission as an important partner in efforts to achieve the Sustainable Development Goals (SDGs), particularly Target 2.5, related to genetic diversity;

Finally recalling the role genetic resources for food and agriculture can play for climate change adaptation and mitigation;

Invites Members to:

- Include the implementation of the Commission's
Global Plans of Action, as appropriate, among their priorities in their national efforts to achieve SDG 2, particularly Target 2.5, as well as other relevant SDGs;

- Consider developing funding proposals on genetic resources for food and agriculture, consistent with their national priorities, as appropriate, when seeking funding from various sources, including the Green Climate Fund, Global Environment Facility (GEF), Horizon 2020 and other funding mechanisms and modalities; and

- Mainstream biodiversity for food and agriculture into policies, programmes and national and regional plans of action on agriculture, climate change, food security and nutrition and other relevant sectors.

Requests the Organization to:

- Continue to pursue extra-budgetary funds, including from the private sector, as appropriate, to support the implementation of the Commission's Global Plans of Action, and to encourage donors to provide support to their implementation as part of the global effort to achieve the SDGs, particularly Target 2.5 on genetic diversity;

- Further integrate genetic resources for food and agriculture and biodiversity for food and agriculture into its Strategic Framework in order to reflect their contributions to ending hunger, achieving food security, improving nutrition and promoting sustainable agriculture;

- Support capacity-development efforts with regard to the conservation and the sustainable use of genetic resources for food and agriculture in developing countries, including through South-South and triangular cooperation;

- Support its Members in the development and implementation of country-led, regional or international projects on genetic resources for food and agriculture, including with resources from the Green Climate Fund, GEF and other sources and funding mechanisms, including from the private sector, as appropriate;

(Cont.) 
Box 8.12 (Cont.)

Resolution 4/2017. The Commission on Genetic Resources for Food and Agriculture and its contribution to the achievement of the Sustainable Development Goals

- Mainstream biodiversity through the promotion of ecosystem services provided by agriculture, agro-ecological practices and sustainable use of biodiversity for food and agriculture in its programmes and projects; and
- Encourage synergies between relevant stakeholders whose work contributes to achieving the SDGs related to food security and nutrition, sustainable agriculture and biodiversity.

(Adopted on 7 July 2017)

for Biodiversity ${ }^{37}$ and its Aichi Targets. FAO hosts the secretariats of the Collaborative Partnership on Sustainable Wildlife Management ${ }^{38}$ and the Global Soil Partnership ${ }^{39}$ and coordinates the action plan of the International Pollinator Initiative. ${ }^{40}$ The Biodiversity Mainstreaming Platform ${ }^{41}$ was established in 2017 with the aim of building bridges between sectors, identifying synergies, aligning goals and developing integrated cross-sectoral approaches to mainstreaming biodiversity in the agriculture, forest and fisheries sectors. The Globally Important Agricultural Heritage Programme ${ }^{42}$ aims, in collaboration with a range of stakeholders, to identify and safeguard outstanding landscapes of aesthetic beauty that combine agricultural biodiversity, resilient ecosystems and valuable cultural heritage (FAO, 2018c) (see Box 7.19). FAO also hosts the Secretariats of the Commission on Genetic Resources for Food and Agriculture, ${ }^{43}$ the International Plant Protection Convention ${ }^{44}$ and the International Treaty on Plant Genetic Resources for Food and Agriculture $^{45}$ (see Section 8.8.1). Examples at regional level include the project "Strengthening

\footnotetext{
$37 \mathrm{https://www.cbd.int/sp}$

$38 \mathrm{http}: / / w w w$. fao.org/forestry/wildlife-partnership/en

39 http://www.fao.org/global-soil-partnership/en

$40 \mathrm{http}: / / \mathrm{www}$. fao.org/pollination/en/

${ }^{41} \mathrm{http}: / /$ www.fao.org/about/meetings/multi-stakeholderdialogue-on-biodiversity/about-the-platform/en

42 http://www.fao.org/giahs/en

${ }^{43} \mathrm{http}: / / w w w . f a o . o r g / c g r f a / e n$

44 https://www.ippc.int/en

45 http://www.fao.org/plant-treaty/en
}

agro-environmental policies in countries of Latin America and the Caribbean through dialogue and exchange of national experiences" 46 conducted under the Brazil-FAO Program for International Cooperation. ${ }^{47}$ As discussed in Chapter 1, FAO is "custodian" agency for several Sustainable Development Goal indicators that are directly relevant to the sustainable use and conservation of BFA. In 2017, the FAO Conference adopted a resolution recognizing the important role of the Commission on Genetic Resources for Food and Agriculture in efforts to achieve the Sustainable Development Goals, particularly Target 2.5, related to genetic diversity (see Box 8.12).

\subsubsection{Needs and priorities}

Improving cooperation among stakeholders is widely recognized in the country reports as an important priority. Some countries particularly emphasize the need to enhance synergies between the food and agriculture and environment sectors. Where constraints are noted, they often relate to a lack of mechanisms for exchanging information (e.g. among research institutions or between research institutions and policy-makers, development practitioners or producers) or a lack of participatory decision-making processes. Specific options mentioned include establishing incentives that recognize and reward the engagement

\footnotetext{
${ }^{46}$ http://www.fao.org/in-action/program-brazil-fao/projects/ agro-environmental-policies/en

47 http://www.fao.org/in-action/program-brazil-fao/en
} 
of university researchers in decision-making processes. As discussed in Section 8.2, the need to strengthen mechanisms for involving small-scale producers, and women in particular, in decision-making, including their participation in multistakeholder bodies in the field of BFA management, is widely noted.

Some countries mention the need to pay greater attention to the specific capacities (strengths and weaknesses) of individual institutions when planning BFA-related collaborative initiatives. Some also note the need to overcome financial constraints to collaboration, although greater cooperation between sectors (e.g. agriculture and environment) is also seen as a way of increasing efficiency or as a means of securing resources for BFA-related work from biodiversity budgets that are channelled through the environment sector. Finally, the need for training and awareness raising on the organization of collaborative initiatives is mentioned in some reports.

\subsection{Education, training and awareness raising}

- Although education and training, at all levels, are widely recognized as key means of promoting the sustainable management of biodiversity for food and agriculture (BFA), gaps in provision remain widespread, particularly with regard to associated biodiversity (species such pollinators, soil organisms and pest natural enemies found in and around production systems).

- Priorities for improving the state of education and training on BFA include:

- better integrating biodiversity issues into educational courses on food and agriculture and other aspects of land and water use so as to promote interdisciplinary skills among practitioners;

- expanding the provision of training for producers on the sustainable use of BFA, including via farmer field schools, farmer group extension programmes or community-based organizations; and

- strengthening awareness-raising efforts among policy-makers and the general public on the importance of BFA.
Lack of knowledge and shortages of well-trained personnel can seriously constrain the sustainable management of BFA. Improving the skills and knowledge of scientists and technicians, development workers, NGOs, producers and policy-makers is thus essential. It is also vital that educational and training programmes are accessible to - and address the needs of - all relevant stakeholders, for example that they do not exclude women (Agarwal, 2015; FAO, 2011e). This section presents an overview of the state of BFA-related education and training programmes, beginning with short subsections on measures addressing plant, animal, forest and aquatic genetic resources for food and agriculture (drawing on the respective global assessments) and then looking in more detail at education and training related to associated biodiversity.

\subsubsection{Plant, animal, forest and aquatic genetic resources for food and agriculture}

\section{Plant genetic resources for food and agriculture}

The Second Report on the State of the World's Plant Genetic Resources for Food and Agriculture (FAO, 2010a) ${ }^{48}$ states that the years preceding its publication saw a number of improvements in the state of education and training on PGRFA-related topics, including an expansion of opportunities for collaboration at regional and international levels. Donor-funded research projects with humanresources components played a significant role. More short-term informal courses and MSc and PhD programmes were being offered by universities, and training materials and laboratory facilities for training had been improved in a number of countries, incorporating recent advances in biotechnology and in information and communication technologies. However, there was still a need to strengthen capacity in education and training to meet expanding demand for well-trained professionals and to upgrade the skills and expertise of

\footnotetext{
${ }^{48}$ Unless otherwise indicated the information in this subsection is based on this source.
} 
current personnel, including on the in situ and ex situ management of crop wild relatives and wildfood plants and their use in base broadening and genetic improvement. Most national programmes concerned with on-farm management of PGRFA were aiming to build both their own professional capacity and that of the farmers they were working with. Despite these generally positive developments, training and education capacity remained limited in some parts of the world, particularly in Africa. Many NGOs and development agencies lacked sufficient qualified personnel to impart the training needed by farming communities.

With regard to the period after 2010, the report assessing the implementation of the Second Global Plan of Action for Plant Genetic Resources for Food and Agriculture for the period 2012 to 2014 (FAO, 2016m) refers to a number of further positive developments, noting for example that

capacity-building over the past ten years or so has improved, resulting in stronger collaboration in training among national, regional and international organizations. Training courses are more frequent and new training materials and facilities have been developed. Higher education opportunities have also expanded and there are now more universities offering a wider range of courses in areas related to PGRFA, especially in the application of biotechnology to conservation and crop improvement.

Figures reported by countries on the upgrading of the skills of scientific staff through formal education and ad hoc in-service training are also considered encouraging. The report notes, however, that "human-resource capacity is still far from being adequate at virtually all levels and in all disciplines related to PGRFA conservation and use."

\section{Animal genetic resources for food and agriculture}

According to The Second Report on the State of the World's Animal Genetic Resources for Food and Agriculture (FAO, 2015a) ${ }^{49}$ weaknesses in

\footnotetext{
${ }^{49}$ The information in this subsection is based on this source.
}

education on animal breeding and other aspects of the management of animal genetic resources for food and agriculture (AnGR) remain widespread, particularly in the developing regions of the world. Country reports ${ }^{50}$ indicated that educational programmes devoted to AnGR management as a distinct topic were not common and were restricted largely to Europe. Major gaps were also reported in training and technical support programmes for the breeding (geneticimprovement) activities of livestock-keeping communities, although many countries reported that progress had been made in this field. Training and awareness-raising activities were relatively widely reported elements of conservation programmes, although countries indicated that there was still much scope for improvement in this regard.

\section{Forest genetic resources}

The State of the World's Forest Genetic Resources (FAO, 2014a) ${ }^{51}$ indicates that although forestry is widely taught in universities around the world, forest genetic resources (FGR) management is rarely recognized as a distinct discipline. In many cases, issues such as FGR conservation, tree breeding and management of non-wood forest products are inadequately covered. Worldwide, there has been a decline in enrolment in forestry education programmes and many universities have had to revise and repackage their courses in order to attract students. Most countries do not have specific programmes dedicated to raising public awareness of FGR and the significance of their conservation and sustainable use. However, awareness-raising activities are undertaken by a range of different stakeholder groups, including governments, botanical gardens, small woodlot partnership programmes, environmental NGOs and forest or tree-specific conservation groups. In some countries, provincial or central forestry authorities organize FGR-related training

\footnotetext{
50 This refers to the country reports prepared for The Second Report on the State of the World's Animal Genetic Resources for Food and Agriculture (FAO, 2015a).

51 The information in this subsection is based on this source.
} 


\section{PART D}

workshops. Training on relevant laws, regulations and policies has increased understanding of the importance of FGR and helped to promote their protection and sustainable use.

\section{Aquatic genetic resources for food and agriculture}

The forthcoming report on The State of Aquatic Genetic Resources for Food and Agriculture for Food and Aquaculture (FAO, forthcoming) states that all reporting countries indicate the presence of at least one institution involved in education and training in the field of aquatic genetic resources for food and agriculture (AqGR). General AqGR management is the most frequently reported topic for training courses, followed by characterization and monitoring, conservation, genetic improvement and economic valuation. Countries, on average, rank increasing the technical capacities (human resources and equipment/ facilities) of institutions as their top priority for improving education and training in this sector, noting that this requires (inter alia) infrastructural improvements such as the installation of modern equipment and facilities for genetic research. Other priorities include raising awareness of the importance of AqGR and improving information sharing between institutions.

\subsubsection{Associated biodiversity}

Associated biodiversity and its management fall within the scope of a wide range of academic disciplines. Many country reports mention the relevance of higher-education courses in sciences such as biology, ecology, zoology, entomology, botany, evolutionary biology, microbiology, genetics, biochemistry, soil science and oceanography and those on more applied topics such as agriculture, agronomy, horticulture, plant breeding, forestry, agroforestry, animal science, veterinary medicine, rangeland management, seed science, food science, fisheries and aquaculture. Some countries mention courses focusing on land use and the management of natural resources such as water and watersheds, on biodiversity and wildlife management, on rural development and on topics such as climate change and disaster risk reduction. Some countries, mostly in Europe, mention course titles that emphasize sustainability or that combine agricultural with environmental elements. A few mention courses on agroecology. Few countries mention courses that specifically focus on the use and conservation of biodiversity or genetic resources in the context of food and agriculture or that explicitly address particular components of associated biodiversity. Exceptions include Costa Rica, which mentions courses on agrobiodiversity and food security and on the conservation and use of agrobiodiversity, as well as a course on tropical apiculture.

Many country reports provide information on extension and training activities for farmers and other producers. Some mention the roles of farmer field schools, farmer group extension programmes or community-based organizations. Some refer specifically to training on the importance of associated biodiversity. The report from Bangladesh, for example, mentions farmer field schools that provide training on integrated pest management and on the need to maintain soil biodiversity. Experiences with farmer field schools on integrated pest management in Nepal are described in Box 8.13. As illustrated in Box 8.14 this approach, which emerged in Southeast Asia in the late 1980s with an initial focus on integrated pest management methods in rice production, has spread to many parts of the world and been applied to an expanding range of management practices and production systems. Some countries mention participatory workshops with farmers (see Box 8.15 for example). A number refer to training activities that while not explicitly focused on associated biodiversity address related topics such as the sustainable management of soils. Several mention training on wildlife-friendly or environmentally friendly farming or on organic production.

The country reports also provide information on training activities for a range of other stakeholders working in agriculture, fisheries, forestry and other fields related to food and agriculture, as well as for those working in wildlife conservation. Explicit references to training on the 
use and conservation of associated biodiversity are not frequent. The Netherlands mentions that under the European Union's Local Skills for Biodiversity Project, training materials on the use of an ecosystem approach in local planning have been developed for the staff of local and regional administrations, in particular planners, and that within the framework of this project training workshops have been conducted in the Netherlands and in several other countries. It further notes that "Biodiversity in Action" training events are organized for local organizations and government officials and that the country's Louis Bolk Institute ${ }^{52}$ offers training for farmers, policy-makers and commercial businesses on topics such as sustainable soil management. Where surveying and monitoring is concerned, Ireland notes that its National Biodiversity Data Centre $^{53}$ runs an extensive annual programme of training and identification workshops, many of which are run in conjunction with national organizations, to help build capacity in biological recording. Over 20 workshops covering a range of taxonomic groups are held each year. Specific workshops on monitoring and the identification of bumblebees and butterflies are provided as part of the centre's national monitoring schemes for these groups of insects.

A number of countries report initiatives that raise awareness among the wider public on issues related to BFA. For example the Lao People's Democratic Republic's National Agro-Biodiversity Programme and Action Plan $\mathrm{II}^{54}$ mentions that under the Agro-Biodiversity Initiative, a longterm project that aims to conserve, enhance and manage biodiversity found in agricultural systems, village school agrobiodiversity programmes have been successfully promoted in the country's Xieng Khouang and Luang Prabang provinces and have led to the development of small gardens, arboreta and herbaria in some schools. It further notes that an agrobiodiversity

\footnotetext{
52 http://www.louisbolk.org

53 http://www.biodiversityireland.ie

54 This document was submitted as a country report.
}

curriculum has been developed by Xieng Khouang Education Department and approved for use throughout the province and for future implementation in other provinces.

Box 8.13

Farmer field schools on integrated pest management - experiences from Nepal

Nepal introduced farmer field schools on integrated pest management (IPM-FFS) in 1998 in response to an outbreak of the rice pest Nilaparvata lugens (brown planthopper) that had occurred the previous year in the Chitwan district. The approach has since been modified and applied in other production systems (vegetables, cotton, potato, maize, tea and coffee) and to address other aspects of management. Farmer field schools now operate in all the 75 districts of Nepal.

Studies have found that most IPM-FFS-trained farmers change their cultivation practices, for example adopting improved seeds, using a mixture of organic and inorganic fertilizers, reducing the use of chemical pesticides, introducing crop rotations, improving the timing of irrigation or fertilizer application, or introducing the use of biopesticides. Farmers become more knowledgeable about the negative effects of pesticides on beneficial organisms within the agroecosystem.

Many farmers who have participated in IPM-FFS have improved their incomes. Many also state that they feel more empowered and that they have developed leadership capacity. The IPM-FFS involve farmers in regular discussions, discovery-based learning and making presentations. These activities help to develop self-confidence and improve decision-making abilities. Many participants have joined local farmer groups and cooperatives. Women farmers report that their selfconfidence has greatly increased. Women have become active in the planning, implementation and management of local development programmes. These changes have transformed the role of rural women within the household and helped to reduce a number of social problems.

Source: Adapted from the country report of Nepal. Note: For further information, see Jha (2008), Bhandari (2012) and Esser et al. (2012). 


\section{PART D}

\section{Box 8.14}

\section{The farmer field school approach}

The farmer field school approach aims to empower smallholder farmers through practical learning. It was developed by FAO and partners in Southeast Asia in the late 1980 s as a participatory alternative to the prevailing top-down extension method of the Green Revolution. The initial focus was on integrated pest management methods introduced in response to the need to tackle pest outbreaks related to the misuse of pesticides in rice fields. Over the years, farmer field schools have spread to over 90 countries and been used to address a growing range of management practices and production systems (see figure below).

In a typical farmer field school, a group of 20 to 25 farmers, pastoralists or fisherfolk meet once a week under the guidance of a trained facilitator. Over the course of an entire production cycle (usually for at least two years), they compare and discuss the effects of two or more alternative practices, one following a prevalent practice and another following a proposed best practice. Participants observe key elements of the agroecosystem by measuring plant or animal growth or production, taking samples of pests or comparing the characteristics of different soils. At the end of the weekly meeting, they present and discuss their findings, and take decisions for the coming weeks.

A range of different topics can be investigated in this kind of setting, including soil fertility and water resources, local varietal selection, seed quality, pesticides use, nutrition, marketing and diversification of farming systems. Local knowledge and scientific insights are tested, validated and integrated in the local ecological and socio-economic context, and participants are empowered to develop the skills required for informed decision-making.

Farmer field schools are usually spearheaded by ministries or institutions working in collaboration with them. In some cases, they have been initiated by FAO country offices and delivered through implementing partners. FAO actively supports the continued development and spread of the farmer field school approach by facilitating the sharing of knowledge on best practices and providing technical and policy advice to ministries, national extension services, farmer organizations, NGOs, research institutions and the private sector.

Sources: FAO web pages on the farmer field school approach (http://www.fao. org/agriculture/ippm/programme/ffs-approach/en/) and FAO, 2016p.

\section{Evolution of the farmer field school approach}

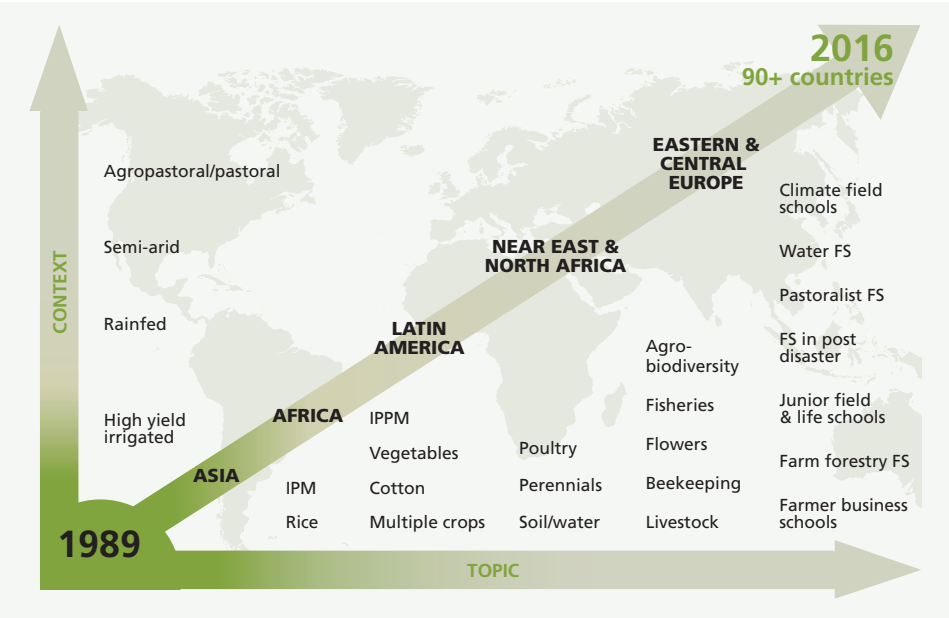

Notes: IPM = integrated pest management; IPPM = integrated production and pest management; FS = farmer school. Source: FAO, 2016p 
Box 8.15

Participatory workshops with local communities in the development of a Globally Important Agricultural Heritage System in Chile

Indigenous communities in the archipelago of Chiloé in southern Chile have been cultivating an array of local potato varieties for hundreds of years. Traditionally, the genetic diversity of potatoes was conserved by rural women through cultivation in their home gardens, and knowledge was transferred orally to the next generation rather than being recorded in writing. Changes to production systems and livelihoods and the increased use of commercial potato varieties have led to genetic erosion and to the loss of traditional knowledge. However, about 200 local potato varieties that are highly adapted to the environmental conditions of Chiloé are still cultivated.

In 2011, Chiloé agriculture was designated as a Globally Important Agricultural Heritage System (GIAHS) site (see Section 7.5 for more information on GIAHS). Agroecological principles and practices are a key aspect of the development of GIAHS sites. During the first years of implementation, multiple participatory workshops on agroecological management and biodiversity conservation were organized with the aim, inter alia, of informing farming communities about the implementation of the project, ensuring the participation of all farmers, and identifying traditional production systems, local knowledge associated with them and external and internal drivers affecting their evolution. The workshops also aimed to strengthen the organizational capacity of the communities and promote entrepreneurship, for instance collaboration with tourism agencies. During the process, farmers played an active role as teachers and instructors and developed a successful educational methodology. Among the diverse activities organized were seed exchanges, field visits, establishment of community seedbeds and seed banks, and participatory breeding programmes based on traditional practices. Training on agroecology and sustainable tourism was also provided to stakeholders outside the agricultural sector such as entrepreneurs, employees in the tourism industry and public officials. The Center for Education and Technology, a local non-profit organization, has worked with the Austral University of Chile to hold talks and workshops on agroecology and the development model promoted by GIAHS for students of agronomic sciences, rural development and related academic disciplines.

The cultivation of local varieties in the participating communities has been strengthened and revitalized, thereby ensuring their maintenance in situ. GIAHS Chiloé has actively contributed to stopping, and even reversing, the processes of genetic erosion and loss of traditional knowledge. In 2013, SIPAM ${ }^{1}$ Chiloé was registered as a certification label for products originating from Chiloé agriculture. The label helps to raise awareness among the wider public of the importance of knowledge associated with family farming and biodiversity for food and agriculture.

Source: Submitted by Chile, with additional information from the GIAHS website (http://www.fao.org/giahs/giahsaroundtheworld/designated-sites/ latin-america-and-the-caribbean/chiloe-agriculture/en)

Note: See the website http://www.fao.org/giahs/en for further information on the GIAHS initiative.

1 SIPAM (Sistemas Importantes del Patrimonio Agrícola Mundial) is the Spanish name of GIAHS.

\subsubsection{Needs and priorities ${ }^{55}$}

Many country reports note that there is a need to strengthen education, training and awareness raising related to associated biodiversity and its role in the supply of ecosystem services. Specific

55 These needs and priorities refer to associated biodiversity. Needs and priorities for PGRFA, AnGR, FGR and AqGR are briefly covered in the respective subsections above and addressed in greater detail in the respective global assessments (FAO, forthcoming, 2010a, 2014a, 2015a). requirements vary from country to country, but the reports indicate a widespread need for a greater focus on associated biodiversity (and BFA in general) in education at all levels. Several countries note that biodiversity-related issues are not well integrated into higher-education courses on food and agriculture or other aspects of land use. In some cases, countries report that courses related to biodiversity conservation are disconnected from those related to the use of biodiversity (i.e. on crop and 


\section{PART D}

livestock production, forestry, fisheries, etc.) and that this can lead to a lack of interdisciplinary skills among professionals. Some countries note the need to improve the supply of graduates trained in specific skills relevant to the management of BFA such as taxonomy, surveying, documentation, economic valuation and the use of technologies such as cryoconservation. As noted above in Section 8.2, some countries highlight the need to increase the participation of women in BFA-related education and the need for extension and training programmes that are tailored to women's needs.

Continued capacity development among professionals and technicians is also widely noted as a priority. Some countries also mention the need for better training and extension among farmers and other users of BFA. There is also widespread recognition of the need for awareness raising among the general public (including in schools) - and in some cases also among policy-makers - on the importance of associated biodiversity and BFA in general. Many country reports recognize that as well as organizing training activities there is a need to improve access to information (e.g. via publications and information systems) and create opportunities for stakeholders to interact and exchange knowledge and ideas.

Reported constraints to improving the state of education and training include shortfalls in funding and a lack of cooperation and exchange of information among educational institutions and other stakeholders.

\subsection{Research}

- Much of the associated biodiversity present in and around production systems - in particular microorganisms and invertebrates - is under-researched despite its vital contributions to food and agriculture.

- Priorities for strengthening research on associated biodiversity and other components of biodiversity for food and agriculture include:

- increasing the availability of human, physical and financial resources;
- enhancing cooperation and synergies in research and development and related training activities;

- strengthening relevant policy frameworks, including to ensure support for long-term research activities;

- investing in information management; and

- improving the transfer of research outputs to producers, consumers and policy-makers.

The respective sectoral global assessments provide information on the state of research relevant to AnGR (FAO, 2007a, 2015a), FGR (FAO, 2014a), AqGR (FAO, forthcoming) and PGRFA (FAO, 2010a). The focus here is therefore on the state of research on associated biodiversity and the ecosystem services they supply. Gaps in knowledge related to specific aspects of the sustainable use and conservation of BFA are discussed elsewhere in the report, particularly in Chapters 5 and 7 and in Section 2.4. The state of knowledge of the status and trends of BFA and needs and priorities for improving monitoring programmes are discussed in Chapter 4. This section therefore aims to present an overview of the overall state of BFA-related research and research capacity and options for improving them.

Reviews of research programmes relevant to BFA have identified various imbalances in terms of their geographical and subject focus. For example, Velasco et al. (2015) assessed 966 scientific publications on biodiversity conservation (not specifically BFA conservation) and concluded that research targeting North America and Europe still predominated, that among taxonomic groups there was a bias towards mammals, birds and other vertebrates, and that there was a lack of research on diversity at the genetic level. Where ecosystem focus is concerned, the findings indicated that a previously identified bias towards forest biodiversity had declined (ibid.). The study also identified a lack of research on the social aspects of conservation, and where research on drivers of biodiversity loss was concerned, noted that landuse change and overexploitation of resources received more attention than other drivers, such as climate change (ibid.). Even within the regions that are more favoured in terms of research attention, there tend to be some geographical areas 
or production systems that are less well addressed than others. Sutcliffe et al. (2015), for example, in a review of studies on farmland biodiversity in the European Union, identified a bias towards northern and western Europe. Some authors have identified gaps in terms of applied research. For example, Duru et al. (2015) conclude that a lack of knowledge of how agroecological principles can be applied in practice is a constraint to the implementation of "biodiversity-based agriculture".

\subsubsection{Institutions involved in research on associated biodiversity}

The country-reporting guidelines invited countries to provide information on major institutions directly involved in research on the conservation and sustainable use of associated biodiversity and on their research programmes. The majority of the country reports provide information of this kind. Most of the answers focus on research institutions related to biodiversity or agriculture in general and do not highlight research related to associated biodiversity in particular. In several cases, a very detailed list of all national research institutions related to biodiversity or agriculture is provided. Some countries provide detailed information on relevant research projects, research programmes or working groups for each of the listed research institutions. Apart from public and private universities, countries mention a range of governmental research institutes, agencies and associations.

With respect to research focus, countries report institutional capacity and specific activities targeting a range of components of associated biodiversity and ecosystem services directly relevant to food and agriculture, most frequently insect pollinators, biological control agents (mainly micro-organisms and invertebrates) and food-and agriculture-related micro-organisms in general. Some countries refer to research programmes for broad categories such as forest or grassland biodiversity or specific taxonomic groups within such ecosystems. A number of countries mention research into traditional knowledge. For example, the United Republic of Tanzania refers to ethnomedicinal studies on endemic plant species.
Kenya reports that the Kenya Resource Center for Indigenous Knowledge (KENRIK) is researching traditional knowledge and technologies in collaboration with native communities and the private sector. Some countries mention research on the status and trends of particular components of biodiversity (see the "State of knowledge" subsections of Chapter 4 for more information on the state of monitoring programmes).

A number of countries refer to research projects that aim to support specific aspects of policy development. For example, China mentions a project on the implementation of ecological compensation measures and the development of incentives to promote stakeholder participation in biodiversity conservation. Others note that research forms an integral part of their biodiversity conservation programmes, for example featuring in national biodiversity strategies and action plans.

\subsubsection{Needs and priorities}

As discussed in Section 3.5, countries generally view advances in science and technology as key elements of efforts to improve the sustainable use and conservation of BFA. However, they also recognize that much needs to be done to strengthen research on BFA and its management. The most frequently highlighted gap in this respect is a general lack of research on associated biodiversity. Addressing this gap is widely reported to be constrained by a shortage of specialists in fields such as taxonomy - and strengthening relevant educational curricula and programmes is frequently mentioned as a priority. Improvements to education and training are, in turn, often reported to be constrained by funding shortages, as are efforts to improve research facilities and the dissemination of research results.

Many countries report that research is constrained by a lack of coordination between research institutions or between researchers working in different disciplines or in different sectors (both within and beyond food and agriculture). Improving coordination and linkages between institutes nationally and at regional and international levels is regarded as a means both of strengthening 
interdisciplinary work and of making more efficient use of resources and information. Strengthening research-related information systems is widely regarded as a priority, both as a means of disseminating research outputs and as a means of making relevant information available to researchers. Countries mention, for example, the need to establish systems for monitoring the status and trends of various components of biodiversity or for managing relevant geographical data.

In many countries, policy frameworks for research are reported to be weak, absent or poorly implemented. For example, ensuring support for long-term activities such as monitoring can be a challenge. Some countries indicate that weaknesses stem from a lack of interest or awareness at political level and suggest that advocacy efforts in this regard need to be strengthened. Many also note the need to improve the mechanisms through which research on associated biodiversity informs policy-making.

Links between research and practical activities at production system level are also reported to need strengthening. Concrete proposals in this regard include involving relevant stakeholders throughout the whole research-project cycle from planning to monitoring, improving links to extension services and to producers themselves, and integrating measures of practical impact into evaluation mechanisms for research projects.

\subsection{Valuation}

- Economic valuation tools can help to make the hidden benefits and costs of biodiversity and biodiversity loss more visible, increasing awareness of the need for conservation and driving more effective conservation policies, including incentive schemes.

- A number of countries highlight the importance of valuation studies, but note that major knowledge gaps remain.

- Quantifying the values of ecosystem services and biodiversity is often challenging because of the difficulty and cost of data collection, the complexity of the ecological processes involved, and geographical and cultural differences in how biodiversity and the benefits it provides are perceived.

- Priorities for enhancing work on the valuation of biodiversity for food and agriculture include:

- strengthening policy and institutional frameworks for integrating valuation studies into conservation strategies;

- standardizing valuation methodologies and tools; and

- ensuring sufficient resources are made available to support valuation studies.

In economic terms, many of the ecosystem services supplied by biodiversity (particularly many supporting, regulating and cultural services) are public goods or common pool resources. ${ }^{56}$ In other words, people cannot be excluded from accessing them and are therefore not obliged to pay for doing so. This means that there tends to be little profit to be made from increasing or maintaining their supply. Moreover, as services of this kind are, in normal circumstances, not traded, they have no market prices, which means that they are less easy to integrate into assessments of the costs and benefits of policy interventions. This in turn may contribute to their being neglected not only by the private sector but also in the formulation of public policies and legislation (CBD Secretariat, 2007).

Various economic valuation tools can help to make the hidden benefits and costs of biodiversity and biodiversity loss more visible and may thus help both in increasing awareness of the need for conservation and in the formulation of more effective conservation policies (FAO, 2007a; TEEB, 2018). Interest in applying techniques of this kind has been increasing in recent years. For example, Sustainable Development Goal 15 includes the target: "By 2020, integrate ecosystem and biodiversity values into national and local planning, development processes, poverty reduction strategies and accounts."

\footnotetext{
56 Public goods are goods that non-excludable (i.e. everybody can access them) and non-rivalrous (i.e. people can use them without reducing their availability to others). Common pool resources are goods that are non-excludable, but are rivalrous (i.e. they cannot be used without reducing their availability to others).
} 
Evidence from global assessments in the fisheries and forest sectors shows that the benefits that conservation measures deliver in terms of ecosystem services can significantly outweigh the investment costs involved in implementing them (CBD Secretariat, 2014b). However, conservation often requires significant financial or other investments, involves some economic risk to those doing the investing and may lead to short-term declines in the flow of benefits even if they increase over the longer term. As discussed in Section 8.7, various kinds of incentive measures can help to overcome constraints of this kind and promote actions that increase the supply of ecosystem services. Valuation of the resources and services targeted plays an important role in the development of effective incentive schemes (FAO, 2007a; CBD Secretariat, 2007).

Measuring and quantifying the value derived from ecosystem services and biodiversity are often difficult (and also costly in terms of the resources needed for data collection and analysis). Benefits to humans emerge from complex interactions and interlinkages between different ecological processes and components of biodiversity (GómezBaggethun and Ruiz-Pérez, 2011). Moreover, the values people assign to ecosystem services and biodiversity vary geographically and culturally (Atkinson, Bateman and Mourato, 2012). Different valuation techniques (see below) are based on different underlying assumptions and simplifications, and each has its own sources of bias (MEA, 2005b; CBD Secretariat, 2007). Moreover, the whole concept of assigning monetary values to natural assets and ecosystem services has been criticized by some on the grounds that it facilitates the commodification of nature, which it is argued in turn may lead to a distorted or oversimplified understanding of the ecological and social processes involved and to increasing inequalities in access to the benefits of ecosystem services (e.g. GómezBaggethun and Ruiz-Pérez, 2011). Services provided by biodiversity are crucial to the survival of complex ecological systems that affect food, water and other aspects of human security. The so-called planetary boundaries for several of these services are now in danger of being breached (Rockström et al., 2009), and it has been argued that sustaining such functions and services should not be traded against other economic benefits.

Although efforts are sometimes made to estimate the full value of a given ecosystem (see further discussion below), it has been argued that for practical decision-making purposes it may be more useful to estimate the marginal changes that particular interventions will bring about in the value of ecosystem services (MEA, 2005b; CBD Secretariat, 2007).

\subsubsection{Overview of valuation approaches}

Attempts to value natural resources are often based on the so-called total economic value (TEV) framework (e.g. FAO, 2007a; MEA, 2005b; Pearce, 1993; CBD Secretariat, 2007). The TEV of a given ecosystem or component of biodiversity can be described as the sum of its direct use values, indirect use values, option values, bequest values and existence values (Pearce and Moran, 1994).

As the name suggests, direct use values are values that arise from the actual use of resources, whether in the form of tangible products, such as food, water or timber, or in the form of recreational activities, such as angling or photography. Indirect use values, in contrast, arise not from the use of the resources themselves but from their roles in underpinning flows of benefits (or in preventing losses) - for example the value of pollination, flood prevention, carbon sequestration or pest control provided by ecosystems and components of biodiversity. Option values are values derived from the maintenance of a resource for the option of using it in an uncertain future, for example a drought-tolerant crop for possible use in future climate change-affected production systems. Existence values are benefits derived from the mere knowledge that particular resources (e.g. particular species or ecosystems) exist, even if they are never used. Bequest values are derived from the knowledge that resources are being maintained for future generations.

Among the various components of TEV, direct use values are the most frequently quantified, as in many cases they can be traded on markets for cash. The difficulty involved in comprehensively 


\section{PART D}

valuing biodiversity therefore often relates to the other components of the framework, although valuing some use values (e.g. leisure activities for which there is no charge) can also be challenging. Direct and indirect use values often have more immediate influence on governments and companies than option and existence values.

Many methods can contribute to the valuation of natural resources and ecosystem services. The applicability of a particular technique depends on the circumstances, for instance on the type of value under consideration and on the availability of markets for - and data on - relevant products and services (MEA, 2005b). Three main categories of valuation techniques can be distinguished based on the availability of market information: i) direct market valuation approaches; ii) revealed-preference approaches; and iii) statedpreference approaches (e.g. Chee, 2004; TEEB, 2010). Each of these is briefly described below. Information on other methods can be found in the ValuES Methods Database. ${ }^{57}$

\section{Direct market valuation approaches}

Direct market valuation approaches use data on prices, costs and quantities derived from existing real markets. Kumar (2010) distinguishes three types of direct market valuation technique: market price-based approaches; cost-based approaches; and production function-based approaches.

Market price-based approaches are often used to obtain use values for provisioning services sold on actual markets (e.g. food and other products). Cost-based approaches estimate the cost that would be incurred if ecosystem services were absent (avoided-cost method), the cost of replacing ecosystem services with artificial substitutes (replacement-cost method) or the cost of restoring ecosystem services if they were lost (restorationcost method). Production function-based approaches can be used to estimate the contribution of a service that is not sold independently on a market (e.g. a regulating service) to another service that is (e.g. a provisioning service).

\footnotetext{
57 http://www.aboutvalues.net/method_database
}

The main limitation of direct market valuation is its dependence on the existence of real market data: for many ecosystem services, markets are distorted or do not exist at all. Interlinkages and interdependencies between different ecosystem services make it difficult to derive reliable estimates by using cost-based or production function-based approaches (TEEB, 2010a).

\section{Revealed-preference approaches}

Revealed-preference approaches estimate values on the basis of observed behaviour on real or surrogate markets. The concepts underpinning several of these methodologies are willingness to pay (WTP) for obtaining or conserving particular assets and services or willingness to accept (WTA) their degradation or loss (CBD Secretariat, 2007; MEA, 2005b; TEEB, 2010). Two popular techniques in this category are the travel-cost approach and hedonic pricing.

The travel-cost approach is a method used to derive the values people assign to components of biodiversity, landscape features, etc. by analysing monetary expenditure on travel to sites where they can be experienced. It is mainly used to assess recreational values.

The hedonic-pricing approach can be used to estimate the values of particular environmental factors (clean air, beautiful views, etc.) by comparing the prices of goods and services that are traded on real markets and whose values are affected by the factors under consideration, for example real-estate values in different environmental settings (e.g. MEA, 2005b; TEEB, 2010).

A disadvantage of revealed preference approaches is that they are relatively costly and time consuming, as they require good-quality data and involve complex analysis. They also rely on assumptions regarding the relationships between the items under valuation and the surrogates used (TEEB, 2010a). They also do not solve the problem of how to quantify non-use values (i.e. existence and bequest values) (ibid.).

\section{Stated-preference approaches}

Stated-preference methods infer WTP or WTA based on what people state about their preferences 
in hypothetical situations (e.g. CBD Secretariat, 2007; MEA, 2005b; TEEB, 2010). Such approaches have the advantage that they can be used to assess not only use values but also non-use values. Commonly used stated-preference methods include contingent valuation and choice modelling.

Contingent valuation involves directly asking respondents to state their WTP for a given ecosystem service or component of biodiversity or their WTA its loss or decline. Choice modelling is used to estimate WTP or WTA without asking respondents directly. Respondents are instead asked to choose between a given set of predefined products or services that vary in terms of the levels of a number of different attributes. If one of the attributes is measured in monetary terms (e.g. price or cost), it is possible to derive WTP or WTA for other attributes.

A major weakness of stated preference methods is the so-called hypothetical bias: statements about hypothetical behaviour on imaginary markets may not correspond to how people would behave in real life. Other limitations include the difficulty involved in designing adequate questionnaires and analytical models (e.g. Harrison and Rutström, 2008; MEA, 2005b; TEEB, 2010).

\subsubsection{State of implementation}

\section{Overview}

Recent years have seen a growing number of initiatives in the field of valuation of ecosystem services. These have included assessments of the values of specific ecosystem services, such as biological pest control (Daniels et al., 2017; Waage, 2007) and pollination (Calderone, 2012; Gallai et al., 2009), and attempts to estimate the total value of whole ecosystem categories such as forests, rangelands and coral reefs (e.g. Costanza et al., 1997, 2014).

The extent to which the outcomes of valuation studies have had a practical impact on policymaking is difficult to determine (Laurans et al., 2013), although it is clear that valuation studies of particular benefits, such as tourism revenue or flood prevention, do influence policy-making, for example in helping build confidence in investment in nature-based tourism (Balmford et al., 2009).
Understanding of valuation approaches is increasing, with a wide variety of tools and methodologies now available, ranging from software packages to bottom-up participatory approaches (Neugarten et al., 2018). A growing range of services are being targeted under payment for ecosystem service schemes (see Section 8.7). Details of a number of initiatives in the field of valuation can be found via FAO's Incentives for Ecosystem Services web page. ${ }^{58}$ The following paragraphs provide short overviews of a number of major recent and ongoing international initiatives addressing valuation of ecosystem services and biodiversity.

The Millennium Ecosystem Assessment (MEA) ${ }^{59}$ was initiated in 2000 by United Nations SecretaryGeneral Kofi Annan as a global effort to assess human impacts on the environment and the benefits humans receive from ecosystems. Outputs included a review of the merits and deficiencies of valuation paradigms and their potential contributions to decision-making and policy formulation to support the sustainable management and use of ecosystems (MEA, 2005b).

The Economics of Ecosystems and Biodiversity (TEEB), ${ }^{60}$ launched as a global initiative in 2007 under the auspices of the United Nations Environment Programme, aims to assess the economic values of biodiversity and ecosystem services and raise awareness of the costs of biodiversity loss. The TEEB approach consists of three steps: (i) recognizing the value of ecosystem services and biodiversity; (ii) demonstrating value in economic terms; and (iii) capturing value in policy decisions (TEEB, 2010a).

TEEB for Agriculture and Food (TEEBAgFood) ${ }^{61}$ was initiated in 2014 as a project focusing explicitly on the valuation of the externalities of so-called eco-agri-food systems. The term is intended to emphasize the inter-relations and dependencies between agriculture and food systems, biodiversity and ecosystems and human (social and economic)

\footnotetext{
http://www.fao.org/in-action/incentives-for-ecosystem-services/ toolkit/assessment-and-valuation/tools-and-models/en

59 http://www.millenniumassessment.org

60 http://www.teebweb.org

61 http://www.teebweb.org/agriculture-and-food
} 


\section{PART D}

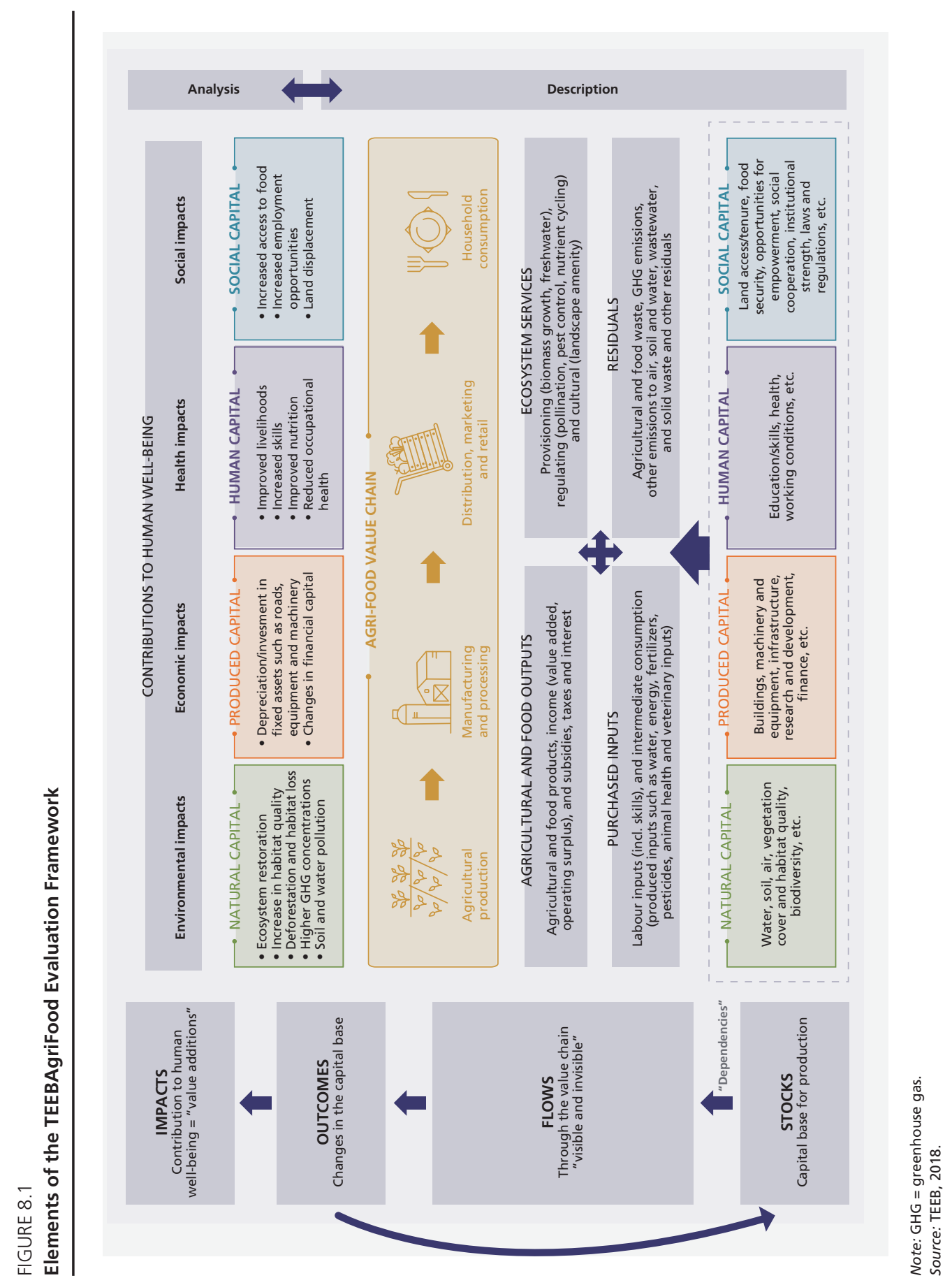


systems. TEEBAgFood aims to "make visible" the hidden impacts and externalities associated with these systems and to provide policy recommendations that will promote sustainability in agriculture and food production. It has developed a universal valuation framework specifically for the agrifood sector, covering the whole value chain from production to consumption, and assessing the flows of a broad range of benefits and disbenefits, many of which are normally invisible in economic terms (TEEB, 2018). The main components of the framework are shown in Figure 8.1.

The Intergovernmental Science-Policy Platform on Biodiversity and Ecosystem Services (IPBES), under its Deliverable 3(d): "Policy support tools and methodologies regarding the diverse conceptualization of values of biodiversity and nature's benefits to people including ecosystem services", is assessing methodologies related to the values of biodiversity to human societies and evaluating their policy relevance (IPBES, 2014).

The System of Environmental Economic Accounting (SEEA) 62 is a framework developed by the United Nations Statistics Division to integrate environmental and economic data in the interest of better-informed decision-making. The SEEA Central Framework (UN et al., 2014a) was endorsed as the international statistical standard for environmental-economic accounting by the United Nations Statistical Commission in 2012. The objective is to enable the integration of environmental information into national macroeconomic accounting systems so that national income accounts reflect environmental externalities and ultimately that these externalities can be better accounted for in decision-making. While the Central Framework takes an economic perspective, the complementary SEEA Experimental Ecosystem Accounting starts from an environmental point of view (UN et al., 2014b). A sectoral subsystem, the System of Environmental-Economic Accounting for Agriculture, Forestry and Fisheries, has also been developed. ${ }^{63}$

62 https://seea.un.org

${ }^{63} \mathrm{http}: / / \mathrm{ww}$.fao.org/economic/ess/environment/methodology/en
Wealth Accounting and the Valuation of Ecosystem Services (WAVES), ${ }^{64}$ a global partnership linked to SEEA, was launched at the tenth meeting of the Conference of the Parties to the CBD in 2010. WAVES aims to mainstream natural resources into development planning and national accounts through an approach referred to as natural capital accounting.

The Natural Capital Project, ${ }^{65}$ a partnership between the Universities of Stanford and Minnesota, the Nature Conservancy ${ }^{66}$ and $W_{W W} F^{67}$ has developed InVest (Integrated Valuation of Ecosystem Services and Tradeoffs), ${ }^{68}$ a suite of open-source software models for mapping and valuing ecosystem services.

\section{Country-report analysis}

The guidelines for the preparation of country reports did not contain specific questions on the valuation of biodiversity and ecosystem services. A substantial number of country reports, nonetheless, either provide information on the implementation of valuation studies or note needs and priorities in this field.

Several countries refer to published studies or ongoing research projects addressing the valuation of ecosystem services and biodiversity, although not all of these are explicitly related to BFA. While the information provided is fragmentary and the studies mentioned are mostly in the early stages of implementation, the general impression conveyed by the country reports is that there is an overall positive trend in the implementation of valuation studies on BFA and in the use of the outcomes of such studies in management and policy-making. The difficulties involved are, however, illustrated by the fact that some reports mention valuation studies that either were not completed or failed to get off the ground.

The reported studies generally target either specific geographical areas or specific types of

\footnotetext{
64 https://www.wavespartnership.org

65 https://www.naturalcapitalproject.org

${ }^{66}$ https://www.nature.org

67 https://www.worldwildlife.org

$68 \mathrm{http}: / /$ www.naturalcapitalproject.org/invest
} 
ecosystem at local or national scale. The former include, for example, a study reported by the Netherlands (Hein, 2011) that analysed the value of ecosystem services provided by the Hoge Veluwe forest (a protected area consisting of woodland, heath and grassland), including wood production, meat from hunting, groundwater infiltration, carbon sequestration, air-pollution removal, recreation and biodiversity. Belgium refers to the project Valuation of Terrestrial Ecosystem Services in a Multifunctional Peri-urban Space, which targeted a multi-ecosystem area in the central part of the country, deploying integrated social, biophysical and economic valuation approaches with the aim of informing decisionmaking in landscape planning ${ }^{69}$ Countries reporting an approach based on ecosystem categories include Yemen, which mentions valuation exercises for the environmental goods and services provided in rangelands, forests and mangroves. In the case of rangelands, it notes that the main service is the provision of fodder for livestock, but that other valuable benefits include the supply of pollination services to crop production, the supply of honey and medicinal plants, and the prevention of soil erosion.

A few countries refer to valuation studies targeting particular regulating or supporting ecosystem services at national level. For example, Finland mentions TEEB Nordic and TEEB Finland studies that, inter alia, estimated the value of pollination by honey bees at EUR 18 million for selected crops, EUR 39 million for produce from home gardens and EUR 3.9 million for wild berries.

A number of countries report the integration of valuation efforts into national strategies, policies or programmes targeting biodiversity and ecosystem services or describe institutional arrangements for work in this field. Viet Nam mentions that several ecosystem service-valuation studies are planned in the context of the development of a policy on payments for ecosystem services related to biodiversity protection, ecotourism, carbon sequestration and watershed

\footnotetext{
${ }^{69}$ See Fontaine et al. (2013) for further information.
}

protection (see also Section 8.7). Several countries specifically mention the inclusion of valuation-related targets in their national biodiversity strategies and action plans. For example, Switzerland notes that one of the strategic goals of the Swiss Biodiversity Strategy (Government of Switzerland, 2012) is to quantitatively assess ecosystem services by 2020 and to develop welfare indicators to complement gross domestic product. Ethiopia mentions that research aimed at addressing gaps in knowledge in the field of valuation is included in its National Biodiversity Strategy and Action Plan 2015-2020 (Government of Ethiopia, 2015) and that valuation is regarded as a key means of promoting conservation, sustainable use and access and benefit-sharing. Reports of institutions established to support valuation efforts come mainly from developed countries. For example, Ireland mentions the Irish Forum on Natural Capital, ${ }^{70}$ a body supported by public and private agencies that aims to prioritize the integration of natural capital into national accounting. The United Kingdom refers to the Natural Capital Committee, ${ }^{71}$ a body formed to provide expert advice to the government on the state of natural capital.

\subsubsection{Needs and priorities}

The importance of valuation of biodiversity and ecosystem services is emphasized in a number of country reports. ${ }^{72}$ Several mention the need to integrate the value of these resources into national accounting systems or into broader measures of social welfare, as well as to use the outputs of valuation studies to guide national policies and research programmes. Several note the importance of valuation data in efforts to develop financial incentive mechanisms for biodiversity conservation.

Countries that mention valuation efforts for natural resources and ecosystem services generally indicate that major knowledge gaps remain to be

\footnotetext{
http://www.naturalcapitalireland.com

http://www.naturalcapitalcommittee.org

72 As noted above, countries were not specifically invited to report on this topic or to list needs and priorities in this regard.
} 
filled. Some countries note specific gaps or priorities (e.g. microbial genetic resources in Ethiopia, wild pollinators in the United States of America and wild medicinal plants in Jordan).

A number of countries identify the need to strengthen institutions and policies that address the integration of the results of valuation studies into conservation strategies and other policies. Specific priorities mentioned include fostering cross-sectoral and interinstitutional cooperation in valuation efforts. Several countries mention the need for standardized valuation methodologies and tools for use in valuation exercises. The need for additional financial resources to support valuation efforts is also noted.

\subsection{Incentives}

- Incentives for the conservation and sustainable use of biodiversity for food and agriculture (BFA) can take a range of forms and originate from public programmes, private-sector investments or civil-society initiatives.

- Incentive measures are still often absent, and where they do exist a lack of coordination in their implementation often hampers success.

- Combining a range of incentive measures into an integrated package can help produce a greater impact in terms of promoting the sustainable use and conservation of BFA.

- Priorities for strengthening incentive measures include:

- better documenting, mapping and coordinating existing schemes;

- improving coordination between the public, non-governmental and private sectors; and

- strengthening links between the environmental and food and agriculture sectors.

- Steps also need to be taken to remove perverse incentives.

\subsubsection{Overview}

As described elsewhere in this chapter, and in Chapters 5 and 7, a range of different management practices, programmes, policies and legal instruments can contribute to the conservation and sustainable use of BFA. However, adoption of
BFA-friendly management practices is often constrained by various barriers, including risk aversion, technological and knowledge gaps, and the need to invest money, time or effort (even if benefits exceed costs over the long term). Incentive measures can be a means of overcoming such barriers. Incentives can take a wide range of different forms and originate from public programmes or from private-sector investment (see Figure 8.2).

Single incentive measures implemented in isolation are unlikely to be sufficient to address the multiple threats facing particular components of BFA and overcome all the barriers to their conservation and sustainable use. Mechanisms that combine multiple incentives have been encouraged by the CBD for over a decade (CBD, 2008b). In 2016, the Conference of the Parties to the CBD called again for countries to

use an appropriate mix of regulatory and incentive measures ... including the elimination, phasing out and reform of incentives harmful to biodiversity in order, ... to increase the efficiency of use of water, fertilizer and pesticides, and to avoid their inappropriate use, and to encourage public and private sources of finance to be channelled into practices that improve the sustainability of production while reducing biodiversity loss, and to promote and support the restoration of ecosystems (CBD, 2016c).

Combining incentives into an integrated package not only supports transition to practices that are biodiversity friendly on a local scale but also enables improvements in productivity and food security that reduce pressures on biodiversity (and other natural resources) more generally. FAO's Incentives for Ecosystem Services project (FAO, 2018v) is working to promote the development of efficient packages of incentives to support the sustainable use and conservation of BFA. Activities include case-study analysis, regional policy dialogues to help member countries develop enabling policy frameworks for locally adapted packages of incentives, and a web-based toolkit to guide decision-makers and practitioners in mapping and combining incentives. 


\section{PART D}

FIGURE 8.2

\section{Examples of sources of incentives to support sustainable use and conservation of biodiversity}

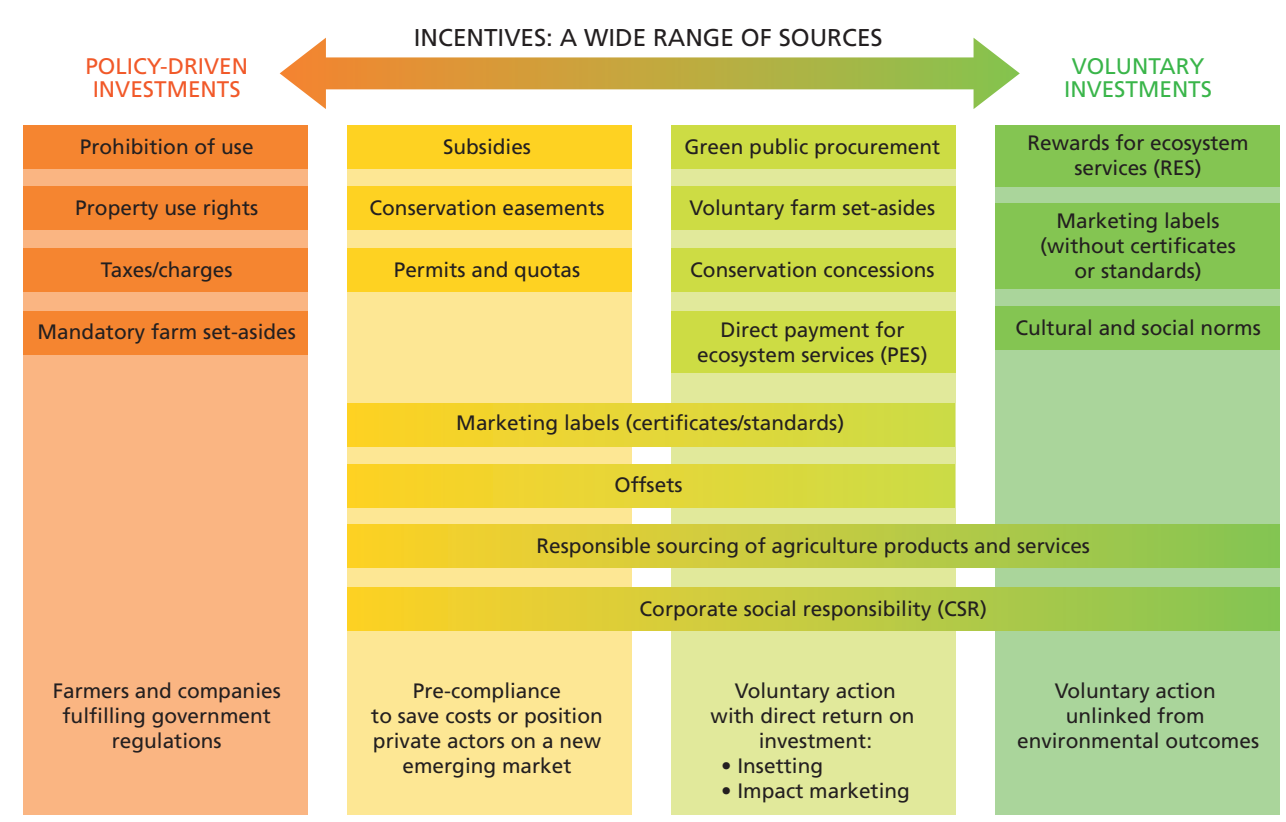

Source: FAO, 2018v.

This section focuses largely on incentive measures that promote the conservation and sustainable use of associated biodiversity. Further information on incentives related to the management of genetic resources in the crop, livestock and forest sectors is provided in the respective global assessments (FAO, 2010a, 2014a, 2014c).

\subsubsection{State of adoption}

The country reports mention a diverse range of incentive measures aimed at promoting the conservation and sustainable use of BFA. ${ }^{73}$ Table 8.3 lists examples of practices reported to be promoted through the provision of incentives.

73 Countries were invited to "Describe any incentives or benefits to support activities for the conservation and sustainable use of biodiversity for food and agriculture or associated biodiversity (such as payments, provision of inputs, subsidies or other forms of incentives/ benefits)."
A large majority of the incentive measures mentioned in the country reports are operating in Europe or in North America. ${ }^{74}$ For example, country reports from European Union (EU) members refer to a range of incentive measures linked to EU-level policies and programmes such as the EU Biodiversity Strategy. Most mention the importance of direct support schemes under the EU's Common Agricultural Policy, including payments for agricultural practices that are climate friendly and beneficial to the environment. EU payments in support of sustainable forest management practices are also mentioned. However, in discussing such schemes the country reports make few references to provisions that specifically target the conservation and

\footnotetext{
74 To some extent, this may relate to how countries interpreted the country-reporting guidelines, as there are many donordriven incentive schemes operating in other regions.
} 
TABLE 8.3

Examples of practices reported to be promoted through the provision of incentives

\begin{tabular}{|c|c|}
\hline Sectors & Practices for which incentives are provided \\
\hline \multirow{6}{*}{ Crop production } & Reduced fertilizer and pesticide use \\
\hline & Reduced tillage and prevention of nutrient runoff from crop fields \\
\hline & Retention of landscape features such as trees, field margins, ditches and terraces \\
\hline & Conservation or enhancement of field margins for pollinators \\
\hline & Improved connectivity through habitat corridors \\
\hline & Protection of plant genetic resources \\
\hline \multirow{4}{*}{ Forest } & Increased agroforestry and reforestation \\
\hline & Conversion of non-native forest to native woodlands \\
\hline & Conservation and restoration of mangrove forests \\
\hline & Establishment of forest genebanks \\
\hline \multirow{3}{*}{ Livestock } & Maintenance of grasslands \\
\hline & Grassland nutrient management \\
\hline & Protection of indigenous breeds \\
\hline \multirow{5}{*}{ Fisheries and aquaculture } & Temporary suspension of fishing activities for overexploited stock \\
\hline & Re-orientation towards more sustainable fishing practices \\
\hline & Restoration of fish habitats and migration routes \\
\hline & Conversion to organic, low-impact aquaculture \\
\hline & Wetland conservation \\
\hline \multirow{4}{*}{ Cross-sectoral } & Protection of endangered species inside or outside protected areas \\
\hline & Control and management of invasive species \\
\hline & Support for certification schemes \\
\hline & Organic farming or conversion to organic farming \\
\hline
\end{tabular}

Source: Country reports prepared for The State of the World's Biodiversity for Food and Agriculture.

sustainable use of components of associated biodiversity with well-defined roles in the provision of ecosystem services to food and agriculture (pollinators, soil-dwelling organisms, biological control agents, etc.). The report from the United Kingdom notes that the practices targeted by agrienvironmental schemes include "establishing pollen and nectar mixes on the edges of arable fields to increase the availability of essential food sources for insects, including those that contribute to the pollination of agricultural crops" and "creation of flower rich margins that provide habitat for beneficial predators." It further mentions that in the wider countryside such schemes incentivize practices that benefit pollinators, although it notes that these schemes are not intended specifically as a means of promoting the supply of pollination services in crop systems. Slovenia mentions that the benefits of agri-environmental schemes in crop production systems include the provision of food sources for bees and increasing microbiological activity in the soil.

Countries mention various other EU-level initiatives that support local food production and short supply chains. Slovenia, for example, notes that the School Fruit Scheme, ${ }^{75}$ which provides free fruit and vegetables to schoolchildren, is helping

\footnotetext{
75 http://ec.europa.eu/agriculture/sfs_en
} 
to increase the use of local food in educational institutions. Also mentioned are projects financed or co-financed by the EU's LIFE ${ }^{76}$ programme targeting the conservation of biodiversity in areas that fall within the Natura 2000 network. ${ }^{77}$

Among developed countries outside the EU, Norway mentions that part of its protected forest zone falls under the frivillig vern (voluntary protection) scheme, ${ }^{78}$ through which forest owners voluntarily propose forest areas that will not be logged. Owners receive financial compensation based on opportunity-cost value. The United States of America describes a number of incentive schemes supporting the maintenance of habitats. Examples include a project aimed at reducing the conversion of wetlands and grasslands into cropland. It also mentions several programmes under which farmers and ranchers can receive support for increasing and improving pollinator habitats. For example, under the Conservation Stewardship Program, ${ }^{79}$ which provides long-term payments for advanced conservation systems, nearly 3000 contract holders are reported to have taken action to establish pollinator habitat in non-cropped areas on their lands. Participants have seeded over 11000 acres (approximately 4450 hectares) of nectar- and pollenproducing plants in field borders, vegetative barriers and buffer strips, and along waterways.

As noted above, incentive schemes supporting the sustainable use and conservation of BFA are relatively rarely mentioned in the reports from developing regions. Many of the schemes that are described share several common characteristics:

- they tend to be implemented at local/subnational scale rather than at national scale;

- they include support for the creation of cooperatives, associations and community-based initiatives rather than targeting individual producers;

- they often involve the establishment of alternative income-generating activities;

\footnotetext{
$76 \mathrm{http}: / /$ ec.europa.eu/environment/life

$77 \mathrm{http}: / /$ ec.europa.eu/environment/nature/natura2000/ index en.htm

${ }_{78} \mathrm{http}: / /$ frivilligvern.no

79 https://www.nrcs.usda.gov/wps/portal/nrcs/main/national/ programs/financial/csp/
}

- they often target the maintenance of genetic resources and local varieties to promote food security;

- they tend to involve public-funded improvements to the environmental performance of local food production for local use rather than eco-labelling and increased market opportunities; and

- they tend not to involve the integration of individual incentives into a "package" with other incentives.

The report from Rwanda documents several programmes that use incentive measures to promote landscape approaches aimed at improving the management, conservation and use of BFA and ecosystem services. For example, the Landscape Approach to Forest Restoration and Conservation ${ }^{80}$ programme, operating with financing from the Global Environment Fund, provides financial incentives to encourage farmers to conserve protected forests and establish diverse agroforestry plots and woodlots.

A few developing countries report relatively long-standing national-level incentive schemes, in some cases also mentioning legal frameworks put in place to support and regulate them. For example, Costa Rica notes that its Forest Law No. 7575 of $1996^{81}$ provides the regulatory basis for smallholders and owners of natural forests and forest plantations to receive direct payments for the ecosystem services and biodiversity conservation benefits that their forests provide. ${ }^{82}$ Between 1995 and 2015, payments for the protection and recovery of forest habitats under this regulation are reported to have amounted to about USD 320 million. As of 2015, approximately 14500 contracts had been signed, covering more than 1 million ha and the planting of about 6 million trees in agroforestry systems.

\footnotetext{
80 https://www.thegef.org/project/ landscape-approach-forest-restoration-and-conservation-lafrec

81 Ley Forestal No. 7575 (available, in Spanish, at http://faolex. fao.org/cgi-bin/faolex.exe?rec_id=004894\&database= faolex\&search_type=link\&table=result\&lang=eng\&format name=@ERALL)

82 Further information on payments for environmental services schemes in Costa Rica can be found in Pagiola (2006).
} 
Costa Rica further notes that its Biodiversity Law No. $7788^{83}$ establishes incentives in the form of public recognition schemes such as Ecological Blue Flag ${ }^{84}$ and national and local prizes for outstanding actions promoting the conservation and sustainable use of biodiversity. The law also foresees tax exemptions on equipment and materials that are regarded as indispensable for the development, research and transfer of appropriate technology for the conservation and sustainable use of biodiversity.

Ecuador mentions Socio Bosque (Forest Partners), ${ }^{85}$ a major national programme, in place since 2008, under which conservation agreements are signed with landowners to protect native forests. Once an agreement is signed, payments (varying according to size of forest area covered) are made annually for a period of 20 years. The scheme targets areas where there is rapid landuse change, those that are critical for the maintenance of ecosystem processes and those with high levels of poverty. Ecuador further notes that, since 2013, Socio Bosque has been complemented by the Socio Manglar programme, which supports the conservation and restoration of mangroves. Socio Manglar, in turn, has a component related to livelihoods and the sustainable use of natural resources. Beneficiaries who sign a conservation agreement acquire "use rights" to sustainably extract resources such as shells, crabs and fish (respecting time and area restrictions specifically designed to promote the conservation of each species targeted).

Brazil mentions the Water Producer Program, ${ }^{86}$ which as well as providing technical and financial support for the implementation of water and soil conservation actions such as the construction of terraces and infiltration basins, provides for incentive payments to producers who have proven to contribute to the protection and recovery of springs. It further notes that

83 Ley de Biodiversidad No 7788 de 23 Abril 1998 (available at http://www.wipo.int/wipolex/en/text.jsp?file_id=20869).

$84 \mathrm{https} / / /$ banderaazulecologica.org

$85 \mathrm{http}: / /$ sociobosque.ambiente.gob.ec

86 http://produtordeagua.ana.gov.br "incentives are granted only after partial or total implementation of previously contracted conservation actions and practices and the amounts to be paid are calculated according to the results: reduction of erosion and sedimentation, reduction of diffuse pollution and increase of infiltration of water in the soil."

Viet Nam reports a national programme ${ }^{87}$ of payments for environmental services from forests, ${ }^{88}$ targeting in particular the protection of watersheds, protection of landscapes and biodiversity for touristic purposes, carbon sequestration, and provision of spawning grounds, feeds, seeds and water for aquaculture. It further notes that its National Biodiversity Strategy (MNRE, 2015) includes the objectives of improving policies and institutional capacity related to payments for forest ecosystem services at national scale and piloting a payment for ecosystem services policy for marine and wetland ecosystems. Civil-society and private-sector incentive schemes targeting the shrimp-aquaculture sector in Viet Nam are described in Box 8.16.

Countries from various regions mention examples of incentive schemes that support the certification of production practices. Bodies mentioned include the International Foundation for Organic Agriculture, ${ }^{89}$ International Organic Accreditation Service, ${ }^{90}$ International Programme for the Endorsement of Forest Certification, ${ }^{91}$ the Forest Stewardship Council, ${ }^{92}$ GLOBALG.A.P. ${ }^{93}$ and the Marine Stewardship Council. ${ }^{94}$ Also reported are farm accreditation schemes, for example those

\footnotetext{
87 The scheme initially (beginning in 2008) targeted two provinces. In 2010 a national scheme was mandated by Decree No. 99/2010/ND-CP on the Policy on Payment for Forest Environment Services (available at http://www.ecolex.org/ details/legislation/decree-no-992010nd-cp-on-the-policy-onpayment-for-forest-environment-services-lex-faoc100744).

88 The report cites Pham et al. (2013), which can be consulted for further information on payments for environmental services schemes in Viet Nam.

89 https://www.ifoam.bio

90 http://www.ioas.org

91 https://www.pefc.org

92 https://ic.fsc.org/en

93 http://www.globalgap.org

94 https://www.msc.org
} 


\section{PART D}

Box 8.16

Incentive schemes promoting sustainable shrimp aquaculture in Viet Nam

Driven by high profits in shrimp aquaculture, large areas of mangrove habitat in the Mekong Delta have been converted into shrimp farms and rice paddies. Various steps have been taken to tackle mangrove loss by incentivizing sustainable production practices, including by establishing links to higher-value markets.

A regulation introduced to protect existing coastal mangrove habitats requires the maintenance of 60 percent forest cover on private land, with non-compliance leading to the removal of aquaculture leases. Civil-society initiatives such as Mangroves and Markets ${ }^{1}$ provide finance for the reforestation of mangrove habitat on private land to support compliance. A private-sector organization, Minh Phu Seafood Cooperation, also provides financial bonuses (USD 30/ha) for the maintenance of mangrove areas within aquaculture farms to ensure the environmental sustainability of its shrimp supply for export.

Incentives are also used to support transition to integrated mangrove-shrimp farming, which is more efficient and therefore reduces farmers' need to further deforest mangroves. Training is provided on integrated organic mangrove-shrimp management (e.g. by UN-REDD) and household waste management (e.g. by Mangroves and Markets). Long-term implementation is made attractive through a private sector-supported certification scheme for organically produced shrimp (Selva Shrimp ${ }^{\circledR}{ }_{1}^{2}$ which secures a 10 percent price premium from the Minh Phu Seafood Cooperation, and marketing by Naturland ${ }^{3}$ to promote products from integrated mangrove-shrimp systems. Incentives are used along the value chain to promote sustainability. The Aquaculture Stewardship Council ${ }^{4}$ (a civil society organization) educates consumers to encourage them to purchase ecologically produced shrimp.

\footnotetext{
Source: FAO, 2018v.

https://www.iucn.org/regions/asia/our-work/regional-projects/mangroves and-markets-mam

2 https://selvashrimp.com/sustainable/sustainable-zero-input

3 https://www.naturland.de/en/naturland/what-we-do/naturland-seafood. html

${ }^{4}$ https://www.asc-aqua.org
}

promoted by LEAF (Linking Environment and Farming) ${ }^{95}$ and Conservation Grade. ${ }^{96}$

\subsubsection{Needs and priorities}

Aside from in some cases noting the need to introduce or expand the use of incentive measures, the country reports outline few specific needs and priorities in this field. ${ }^{97}$ Countries generally report individual incentive schemes rather than approaches based on multiple incentive measures as recommended in the CBD decision noted in the introduction to this section. Although the country reports do not specifically

\footnotetext{
95 http://www.leafuk.org/leaf/home.eb

96 www.conservationgrade.org

97 Countries' responses regarding incentives generally do not span the full range of options shown in Figure 8.2 - even though in many cases such measures may be in place - which also means that the needs and priorities they mentioned in this context do not cover all categories of incentives.
}

spell out the need for a more holistic approach, several note the need for greater coordination between schemes. Wider experience indicates ${ }^{98}$ that while individual public programmes, private-sector investments or civil society initiatives may provide incentives that help to address their own particular concerns, a coordinated "package of actions" can create a much larger impact in terms of improving outcomes for BFA. An enabling policy framework can help promote coordination of this kind. Long-term planning and cross-sectoral and interinstitutional collaboration will help improve the coordination of multiple incentives at farm and landscape levels. As illustrated in Box 8.17 and Box 8.18, integrated approaches are already in operation in some

\footnotetext{
98 For further information on incentive measures see FAO's incentives for ecosystem services web page: http://www.fao. org/in-action/incentives-for-ecosystem-services/en
} 
Box 8.17

\section{Integrated incentive packages for microwatershed development in Brazil}

In Brazil, the Rio Rural ${ }^{1}$ programme of the Secretariat of Agriculture of Rio de Janeiro State coordinates public programmes such as the Water Producer Programme ${ }^{2}$ and the National Plan for Low Carbon Emission in Agriculture $(\mathrm{ABC} \text { Plan })^{3}$ with private investments to provide diverse financial and technical incentives in microwatersheddevelopment projects.

Initiatives integrated under the programme include:

- public programmes investing in improved livestock breeds, pasture management and improved fodder production, technical assistance (e.g. Agricultural Research Enterprise of the State of Rio de Janeiro - PESAGRO-RIO), ${ }^{4}$ access to markets (e.g. Food Acquisition Programme - PAA $)^{5}$ and rural credit (e.g. National Programme for Strengthening Family Farming - PRONAF); ${ }^{6}$

- private companies contributing to forest conservation and rehabilitation to compensate for, and offset, their environmental impacts (e.g. electric company FURNAS);

- water user fees used to finance wastewatermanagement technologies and soil-conservation measures (e.g. Water Producer Programme);

- state and municipal governments implementing a payments for ecosystem services mechanism based on transferring funds from state tax on the circulation of goods and services directly to smallholder farmers that operate private forest reserves;

- private companies and NGOs financing capacitybuilding in sustainable practices (e.g. Integrated Eco
Technologies and Services for a Sustainable Rural Rio de Janeiro - INTECRAL Project, ${ }^{7}$ Brazilian Micro and Small Enterprises Support Service - SEBRAE) ${ }^{8}$ and

- conservation NGOs facilitating the creation of on-farm forest reserves (e.g. Critical Ecosystem Partnership Fund - CEPF). ${ }^{9}$

Together, the various initiatives provide multiple incentives that make it easier for family farmers to overcome barriers to the adoption of agricultural practices that support biodiversity and ecosystem services within microwatersheds. They facilitate farmers' compliance with forest and water protection laws, while also improving production efficiency and yields and thus helping to make sustainable practices profitable in the long term.

Source: FAO, 2018v.

1 http://www.rj.gov.br/web/informacaopublica/exibeconteudo?articleid $=1041246$

2 Programa Produtor de Água (http://produtordeagua.ana.gov.br).

3 Agricultura de Baixo Carbono (http://redd.mma.gov.br/en/legal-andpublic-policy-framework/national-plan-for-low-carbon-emission-inagriculture-abc-plan).

${ }^{4}$ Empresa de Pesquisa Agropecuária do Estado do Rio de Janeiro (http://www.pesagro.rj.gov.br)

5 Programa de Aquisição de Alimentos (http://www.mda.gov.br/sitemda/ secretaria/saf-paa/sobre-o-programa).

6 Programa Nacional de Fortalecimento da Agricultura Familiar (http://www. mda.gov.br/sitemda/secretaria/saf-creditorural/sobre-o-programa)

http://intecral-project.web.th-koeln.de/wordpress

8 Serviço Brasileiro de Apoio às Micro e Pequenas Empresas (http://www. sebrae.com.br/sites/PortalSebrae/canais_adicionais/sebrae_english).

https://www.cepf.net countries. There is also often a need to better document and map existing incentive schemes (taking all types of initiatives - public, private and civil society - into consideration). This can help improve synergies and identify whether perverse incentives need to be removed. Effective evaluation of the outcomes of implemented schemes is also essential. Further discussion of needs and priorities in this field can be found in a number of FAO publications (FAO, 2015a, 2018v).

\subsection{Policy and legal frameworks}

- Appropriate legal and policy frameworks are essential for effective management of biodiversity for food and agriculture (BFA), but often remain underdeveloped or poorly implemented.

- Weaknesses in legal and policy frameworks are particularly widespread with regard to the management of associated biodiversity (species such pollinators, soil organisms and pest natural enemies 


\section{PART D}

found in and around production systems). Contributing factors include:

- a lack of adequate coordination between the food and agriculture and nature-conservation sectors; and

- a lack of awareness among policy-makers of the significance of associated biodiversity to resilient and sustainable food systems.

- Access and benefit-sharing (ABS) measures in most countries are either still in development or in the early stages of implementation. They increasingly reflect the need to take into account the importance of and distinctive features of the different subsectors of genetic resources for food and agriculture.

- Priorities for improving legal and policy frameworks for BFA include:
- strengthening the involvement of multiple stakeholders across sectors in policy development;

- raising awareness among decision-makers on the importance of sustainably managing BFA;

- making available the resources needed for policy implementation;

- building capacity to develop and implement ABS measures; and

- improving coordination between agencies responsible for $A B S$ and those responsible for the various subsectors of food and agriculture.

This section focuses mainly on legal and policy frameworks at national level. However, it begins with a short overview of frameworks at international

\section{Box 8.18}

\section{Integrated incentive packages in Mexico}

In Mexico, the Biodiversity Commission, CONABIO, ${ }^{1}$ coordinates co-financing from public and private sources to provide farmers with incentives that help to ensure that traditional farming systems remain productive and hence to avoid further slash and burn in the Mesoamerican Biological Corridor (a multicountry effort to retain ecological connectivity through Central America on the basis of a combination of protected areas and sustainable use). Cash and seedlings financed through national payments for environmental services schemes (e.g. National Forest Programme - PRONAFOR) ${ }^{2}$ help enable farmers to rehabilitate and reforest their land to comply with forest laws.

Once their land has been rehabilitated, farmers are assisted by CONABIO to access further incentives from public programmes and private-sector investment to improve productivity - for example through training (e.g. Strategic Project for Food Security - PESA, ${ }^{3}$ Conservation and Sustainable Use of Soil and Water COUSSA), ${ }^{4}$ use of improved crop varieties and livestock breeds (e.g. Project of Support for the Productive Chain of Corn and Bean Producers - PROMAF, Sustainable Livestock Production and Management for Livestock and Beekeeping - PROGAN), ${ }^{5}$ improvements to soil fertility (e.g. Sustainable Use of Natural Resources Programme - PURSN, COUSSA) - and post-harvest processing (e.g. PROMAF, Sustainable
Modernization of Traditional Agriculture - MasAgro, ${ }^{6}$ Programme for the Acquisition of Productive Assets PAAP). ${ }^{7}$ It also promotes certification for sustainable coffee production (e.g. Certification for Agri-Food Productivity) ${ }^{8}$ to increase access to higher-value markets. The integration of investments from the agricultural and environmental sectors has enabled a landscape-level approach that pools public and private initiatives to assist farmers to raise their productivity and hence reduce deforestation and biodiversity loss and improve rural well-being.

Source: FAO, 2018v.

1 https://www.gob.mx/conabio

2 Programa Nacional Forestal (http://www.conafor.gob.mx/web/apoyos/ pronafor).

3 Proyecto Estratégico para la Seguridad Alimentaria (http://www.sagarpa.gob. $\mathrm{mx} /$ desarrolloRural/AsistenciaCapacitacion/Paginas/pesa.aspx).

${ }^{4}$ Componente de Conservación y Uso Sustentable de Suelo y Agua (http:// www.sagarpa.gob.mx/desarrolloRural/Paginas/tecnologiasatualcance.aspx).

5 Programa de Producción Pecuaria Sustentable y Ordenamiento Ganadero y Apícola (http://www.sagarpa.gob.mx/ganaderia/Programas/Paginas/ PROGRAM.aspx).

6 Modernización Sustentable de la Agricultura Tradicional (http://masagro. mx/en).

7 Programa para la Adquisición de Activos Productivos (https://www.sagarpa. gob.mx/evaluaciones-especificas-de-desempeno-eed/programa-para-laadquisicion-de-activos-productivos).

8 Certificacion para la Productividad Agroalimentaria (http://www.sagarpa. gob.mx/ProgramasSAGARPA/2015/Productividad_y_competitividad agroalimentaria/Certificacion_para_la_productividad_agroalimentaria/ Paginas/Descripci\%C3\%B3n.aspx). 
level. As in the other sections of this chapter, frameworks relevant specifically to plant (crop), animal (livestock), forest and aquatic genetic resources are addressed relatively briefly, as they are discussed in previously published global assessments for the respective sectors. Measures addressing associated biodiversity are discussed in greater detail, drawing largely on material provided in the country reports. Short overviews of the state of frameworks in relevant cross-cutting fields (climate change, access and benefit-sharing and traditional knowledge) are also presented, again highlighting information from the country reports.

\subsubsection{Frameworks at international level}

As noted in Chapter 1, BFA and biodiversity more generally are gradually acquiring a higher profile on international policy agendas, including the 2030 Sustainable Development Agenda (see Box 1.1). A wide range of international agreements, including an increasing number of legally binding instruments and a plethora of declarations, action plans and other non-binding instruments addressing biodiversity, in some cases specifically in the context of food and agriculture, have been put in place. Some other international instruments addressing aspects of the food and agriculture sector are sometimes considered to affect biodiversity (often negatively). These include, for example, instruments that set out specific requirements for the commercialization of genetic resources (e.g. crop seeds or breeding animals) or facilitate global trade in substances that may have adverse effects on biodiversity. While this second group of instruments may offer some potential for biodiversity mainstreaming, this section deals primarily with the first group, i.e. frameworks, agreements and instruments specifically established to conserve biodiversity and promote its sustainable use. Box 8.19 presents an example of the development of international binding and soft-law instruments in the capture-fisheries sector.

Several international conventions concluded over the last seven decades focus on biodiversity issues, including the International Plant Protection Convention (1952), the Ramsar Convention on
Box 8.19

Binding and soft-law instruments related to port state measures in the capture-fisheries sector

Illegal, unreported and unregulated (IUU) fishing is a global threat to sustainable fisheries and to the management and conservation of fisheries resources and marine biodiversity. The importance of enhanced port state control as a tool to combat IUU fishing has gained increasing prominence over the last decade. Port state measures (PSMs) are requirements established, or interventions undertaken, by port states with which foreign fishing vessels must comply, or to which they must be subjected, as a condition for the use of ports within the port state. Since the adoption, in 1982, of the United Nations Convention on the Law of the Sea, there has been a progressive development of international law in the field of fisheries-related PSM, including through the adoption of the Agreement to Promote Compliance with International Conservation and Management Measures by Fishing Vessels on the High Seas (1993) (FAO Compliance Agreement) and the Agreement for the Implementation of the provisions of the United Nations Convention on the Law of the Sea of 10 December 1982 Relating to the Conservation and the Management of Straddling Fish Stocks and Highly Migratory Fish Stocks (1995) (UN Fish Stocks Agreement). Voluntary instruments such as the FAO Code of Conduct for Responsible Fisheries and the International Plan of Action to Prevent, Deter and Eliminate Illegal, Unreported and Unregulated Fishing (IPOA-IUU) also encourage implementation of PSMs as tools to combat IUU fishing. The binding Agreement on Port State Measures to Prevent, Deter and Eliminate Illegal, Unreported and Unregulated Fishing was approved by the FAO Conference at its Thirty-sixth Session in 2009 and revised in 2016.

Note: For further information see FAO's Port State Measures web page: http://www.fao.org/fishery/psm/en

Wetlands (1971), the World Heritage Convention (1972), the Convention on the Conservation of Migratory Species of Wild Animals, the Convention on International Trade in Endangered Species of 


\section{PART D}

Box 8.20

Biodiversity and international law

\section{Convention on Biological Diversity ${ }^{1}$}

The objectives of the Convention on Biological Diversity (CBD) are the conservation of biological diversity, the sustainable use of its components, and the fair and equitable sharing of the benefits arising from the utilization of genetic resources. The CBD covers all ecosystems, species and genetic resources, including those used for food and agriculture. The Conference of the Parties to the CBD adopted a programme of work on agricultural biodiversity in 2000 (CBD, 2000b). The programme consists of four elements (assessment, adaptive management, capacity-building and mainstreaming) and three cross-cutting initiatives (on pollinators, soil biodiversity and biodiversity for food and nutrition), to be implemented using the ecosystem approach. Other relevant programmes of work include those on forest biodiversity, dry and subhumid land biodiversity, inland water ecosystems and marine and coastal biodiversity. At is tenth meeting, the Conference of the Parties explicitly recognized the importance of the "processes led by FAO ... which contribute directly to achieving the three objectives of the Convention on Biological Diversity, in crop and livestock sectors."

\section{Convention on International Trade in Endangered Species of Wild Fauna and Flora ${ }^{2}$}

The Convention on International Trade in Endangered Species of Wild Fauna and Flora (CITES) aims to ensure that international trade in specimens of wild animal and plant species does not threaten their survival. Through its three appendices, CITES accords varying degrees of protection to more than 30000 plant and animal species. CITES and FAO have been collaborating closely since 1997 on issues raised by the harvesting and trade of commercially exploited aquatic species listed in the CITES appendices. FAO hosts the Expert Advisory Panel for the Assessment of Proposals to Amend Appendices I and II of CITES Concerning Commercially-exploited Aquatic Species.

\section{Convention on the Conservation of Migratory Species of Wild Animals ${ }^{3}$}

The Convention on the Conservation of Migratory Species of Wild Animals (CMS), also known as the Bonn Convention, aims to conserve terrestrial, marine and avian migratory species throughout their ranges. CMS brings together the states through which given species migrate and lays the legal foundation for internationally coordinated conservation measures throughout migratory ranges.

\section{The International Treaty on Plant Genetic Resources} for Food and Agriculture ${ }^{4}$

The objectives of the Treaty are the conservation and sustainable use of plant genetic resources for food and agriculture and the fair and equitable sharing of the benefits arising out of their use, in harmony with the $C B D$, for sustainable agriculture and food security. It covers all plant genetic resources for food and agriculture, while its Multilateral System of Access and Benefit-sharing covers a specific list of 64 crops and forages. It also includes provisions on Farmers' Rights.

\section{Convention on Wetlands ${ }^{5}$}

The Convention on Wetlands, also known as the Ramsar Convention, provides the framework for national action and international cooperation on the conservation and wise use of wetlands and their resources. It covers all aspects of wetland conservation and wise use, recognizing wetlands as ecosystems that are extremely important for biodiversity conservation in general and for the well-being of human communities. Signatory states are obliged to identify at least one Wetland of International Importance (Ramsar Site). Many countries have multiple sites.

\section{World Heritage Convention ${ }^{6}$}

The primary mission of the World Heritage Convention (WHC) is to identify and conserve the world's cultural and natural heritage. This includes drawing up a list of sites whose outstanding values should be preserved for all humanity and ensuring their protection through closer cooperation among nations. The WHC recognizes some World Heritage sites specifically for their outstanding

\footnotetext{
https://www.cbd.int

2 https://www.cites.org

3 https://www.cms.int

4 http://www.fao.org/plant-treaty/en

5 https://www.ramsar.org

6 http://whc.unesco.org/en/conventiontext
}

(Cont.) 
Box 8.20 (Cont.)

Biodiversity and international law

biodiversity values. The so-called natural selection criteria, as defined in the Operational Guidelines for the Implementation of the WHC, refer, inter alia, to sites that are "outstanding examples representing significant ongoing ecological and biological processes in the evolution and development of terrestrial, fresh water, coastal and marine ecosystems and communities of plants and animals" and to sites "which contain the most important and significant natural habitats for in-situ conservation of biological diversity, including those containing threatened species of outstanding universal value from the point of view of science or conservation." Some sites, including particularly some mixed cultural and natural sites, put particular emphasis on maintaining traditional agricultural or pastoralist practices.

\section{International Plant Protection Convention ${ }^{7}$}

The International Plant Protection Convention (IPPC) aims to secure coordinated and effective action to prevent and control the introduction and spread of pests of plants and plant products under the World Trade Organization. It provides an international framework for plant protection that includes developing international standards for phytosanitary measures to safeguard plant resources. The IPPC extends beyond the protection of cultivated plants to the protection of natural flora and plant products.

International Convention for the Regulation of Whaling ${ }^{8}$ As stated in its preamble, the purpose of the International Convention for the Regulation of Whaling is to provide for the proper conservation of whale stocks and thus make possible the orderly development of the whaling industry. An integral part of the Convention is its legally binding "Schedule". The Schedule sets out specific measures that the International Whaling Commission, established under the Convention, has collectively decided are necessary in order to regulate whaling and conserve whale stocks.

\footnotetext{
https://www.ippc.int/en

8 https://iwc.int/convention
}

Wild Fauna and Flora (1975), the Convention on Biological Diversity (1993) and the International Treaty on Plant Genetic Resources for Food and Agriculture (2004) (Box 8.20). These seven conventions are currently connected through the so-called Biodiversity Liaison Group, ${ }^{99}$ a platform established jointly by the heads of the secretariats of the respective conventions. The liaison group aims to exchange information and to enhance national-level implementation of the objectives of each convention, including by promoting synergies and reducing duplication of work. Other international conventions that address the conservation and sustainable use of biodiversity, including BFA, include the International Convention for the Regulation of Whaling (1946) (Box 8.20), the United Nations Convention on the Law of the Sea (adopted in 1982, came into force

\footnotetext{
99 https://www.cbd.int/blg/
}

in 1994) and the Convention for the Protection and Development of the Marine Environment of the Wider Caribbean Region (1986). Several biodiversity conventions have developed subsidiary instruments, for example the Cartagena Protocol on Biosafety and the Nagoya Protocol on Access to Genetic Resources and the Fair and Equitable Sharing of Benefits Arising from their Utilization, both adopted under the CBD.

Among the soft-law (non-binding) instruments specifically addressing genetic resources for food and agriculture are the Commission on Genetic Resources for Food and Agriculture's global plans of action for plant, animal and forest genetic resources (FAO, 2007b, 2011b, 2014b). The Commission negotiated these action plans with the aim of creating an efficient global system for the conservation and sustainable use of genetic resources for food and agriculture. They are intended to be comprehensive frameworks 
that guide and catalyse action at community, national, regional and global levels through better cooperation, coordination and planning and by strengthening capacities. Each includes a set of recommendations and priority activities that respond to the needs identified in global assessments of genetic resources in the respective sectors (FAO, 1997, 2007a, 2010a, 2014a). While many soft-law instruments lack mechanisms to monitor their implementation, the Commission's global plans of action have fully operational monitoring and reporting mechanisms based on indicators established by the Commission. Country reports are used to prepare regular status reports and feed into the preparation of updated global assessments. The Commission oversees, monitors and evaluates the implementation of the global plans of action, and has overseen the development of a range of guidelines intended to facilitate implementation. ${ }^{100}$

\subsubsection{Frameworks at national level}

\section{Plant genetic resources for food and agriculture}

The importance of a coherent national approach to PGRFA management is widely recognized, and many countries have established national programmes of one kind or another in this field, backed up to varying degrees by national legislation and policy initiatives. As of October 2018, 144 countries (plus the European Union) were contracting parties to the International Treaty on Plant Genetic Resources for Food and Agriculture. FAO has developed guidelines to support countries in the development of national strategies for PGRFA (FAO, 2015f). The following paragraphs present short descriptions of the state of legislation and policies in various fields of PGRFA management.

In most countries, the seed system is highly regulated - from the release of new varieties and quality control of seeds to the legal status of organizations that implement seed control to certification and variety-release procedures. The

\footnotetext{
${ }^{100}$ For further information, see http://www.fao.org/cgrfa/policies/ global-instruments/codes-standards-and-guidelines/en
}

Second Report on the State of the World's Plant Genetic Resources for Food and Agriculture (SoW-PGRFA-2) (FAO, 2010a) noted three main trends in this field: emergence of voluntary arrangements regarding seed certification and variety release; growing use of accreditation principles within official national rules and standards; and regional harmonization of seed laws. These conclusions remain valid as of 2018. A number of countries have developed new national seed policies in recent years or are in the process of doing so (e.g. FAO, 2017q; SEPSA, 2017). In 2015, the Commission on Genetic Resources for Food and Agriculture endorsed a voluntary guide for national seed policy formulation (FAO, 2015f).

In the field of intellectual property rights, the SoW-PGRFA-2 noted that the number of countries providing legal protection to plant varieties through plant breeders' rights had been increasing over the preceding decade, with increasing numbers of countries in Africa, Asia, Latin America and the Caribbean, the Near East and eastern parts of Europe having enacted legislation of this kind. Debates over the issue of patenting in the PGRFA sector had also become increasingly prominent, with various countries having amended legislation in this field. At the time (2010), 67 countries and the European Union were members of the International Union for the Protection of New Varieties of Plants (UPOV). As of October 2017, 73 countries, the African Intellectual Property Organization and the European Union were UPOV members (UPOV, 2017).

The SoW-PGRFA-2 further noted that the question of Farmers' Rights ${ }^{101}$ had been attracting increasing

\footnotetext{
${ }^{101}$ Article 9 of the International Treaty on Plant Genetic Resources for Food and Agriculture states that "In accordance with their needs and priorities, each Contracting Party should, as appropriate, and subject to its national legislation, take measures to protect and promote Farmers' Rights, including: a) protection of traditional knowledge relevant to plant genetic resources for food and agriculture; b) the right to equitably participate in sharing benefits arising from the utilization of plant genetic resources for food and agriculture; and c) the right to participate in making decisions, at the national level, on matters related to the conservation and sustainable use of plant genetic resources for food and agriculture."
} 
attention. Many countries had developed, or were in the process of developing, legislative and other measures addressing this issue. Concerns over biosafety ${ }^{102}$ had also been growing and were increasingly being addressed in national legislation. Many countries had introduced or updated phytosanitary legislation, in large part in response to the adoption of the revised International Plant Protection Convention in 1997.

Potential means of strengthening legal and policy frameworks for PGRFA management include: the establishment of nationally endorsed strategies and plans for the conservation and use of PGRFA that set priorities, distribute roles and allocate resources for management actions in the sector; raising awareness and strengthening capacity among policy-makers with regard to the complexities of the legal and policy issues affecting the conservation, use and exchange of PGRFA; and promoting greater stakeholder involvement in the development of legal and policy instruments. Efforts need to be made to ensure that national legal and policy instruments complement each other coherently and are appropriate to the needs and capacities of the respective country.

\section{Animal genetic resources for food and agriculture}

According to The Second Report on the State of the World's Animal Genetic Resources for Food and Agriculture (FAO, 2015a), ${ }^{103}$ a growing number of countries have responded to the adoption of the Global Plan of Action for Animal Genetic Resources (FAO, 2007a) by developing national policy instruments, generally referred to as national strategies and action plans, as a means of putting global recommendations into practice at national level. Legal instruments that

\footnotetext{
102 "The avoidance of risk to human health and safety and to the conservation of the environment, as a result of the use for research and commerce of infectious or genetically modified organisms (GMOs)" (FAO Glossary of Biotechnology for Food and Agriculture. Available at http://www.fao.org/docrep/004/ Y2775E/y2775e07.htm)

${ }^{103}$ Unless indicated otherwise, the material presented in this subsection is based on this report.
}

address AnGR management activities such as conservation and genetic improvement in a relatively "joined-up" way are also becoming more widespread.

Many countries have also developed legal and policy instruments addressing individual components of AnGR management, including surveying and monitoring, official recognition of breeds, genetic-improvement programmes, the use of reproductive biotechnologies, conservation programmes, importation of genetic material, research programmes, use of transgenic technologies, and access and benefit-sharing (see Section 8.8.5). Although the number of countries that have put such instruments in place has been increasing in recent years, many still report gaps and weaknesses that need to be addressed. It should, however, be noted that countries do not necessarily consider the absence of legislation to be a weakness. Some report that they are well served by relatively unregulated approaches to most aspects of AnGR management. AnGR issues are also, to a degree, gaining a foothold in broader policy and legal instruments in the livestock, agriculture and environmental sectors. For example, most national biodiversity strategies and action plans include some AnGR-related provisions.

Although the livestock sector has no equivalent to the Farmers' Rights of the crop sector, civil society organizations have over recent years formulated a set of Livestock Keepers' Rights, ${ }^{104}$ which it is argued would, if implemented, enable and encourage livestock keepers to continue making a living from their breeds and thereby help both to conserve diversity and improve rural livelihood opportunities. Another initiative has been the development of biocultural community protocols in livestock-keeping communities, a concept developed in response to the Nagoya Protocol on Access and Benefit-Sharing (see Section 8.8.5), which mandates governments to support indigenous and local communities in the development of "community protocols in relation to access to traditional knowledge associated

\footnotetext{
104 For further information see Köhler-Rollefson et al., 2010.
} 
with genetic resources and the fair and equitable sharing of benefits arising out of the utilization of such knowledge." 105

Although, as noted above, countries have been quite active in recent years in developing new AnGR-related legal and policy measures, many report constraints to implementation. These include shortages of human and financial resources, logistical problems, insufficient coordination between different government departments, excessive bureaucracy, a lack of awareness on the part of stakeholders and a lack of clarity in the formulation of legal and policy texts. Identifying the most appropriate way forward in terms of updating national legal and policy frameworks for AnGR can be challenging and needs to be based on thorough analysis of gaps, needs and capacity to implement different policy and regulatory options. Stakeholder involvement in the development of policy and legal frameworks often needs to be strengthened.

\section{Forest genetic resources}

The State of the World's Forest Genetic Resources (FAO, 2014a) ${ }^{106}$ notes that many countries have no specific laws or policies on forest genetic resources (FGR) or have instruments that are outdated. A number, however, have laws and policies of relevance to FGR, most commonly instruments targeting the conservation and protection of national forests, some of which include specific FGRfocused provisions (see Section 5.3.2). Potential steps towards strengthening policy and legal frameworks for FGR include developing national policies, plans or programmes for FGR management and ensuring that FGR-related concerns are better accounted for in national forestry policies and laws. Any efforts to develop or update policy and legal frameworks for FGR will need to involve multiple stakeholders.

\footnotetext{
105 For further information, see UN Environment and Natural Justice (2009) and the Community Protocols website maintained by Natural Justice (http://www.communityprotocols.org)

${ }^{106}$ Unless indicated otherwise, the material presented in this subsection is based on this report.
}

\section{Aquatic genetic resources for food and agriculture}

As noted in Section 8.8.1, the main global nonbinding policy document addressing AqGR is the FAO Code of Conduct for Responsible Fisheries (FAO, 1995a). Many governments have incorporated elements of this instrument into national legislation and policy. The State of the World's Aquatic Genetic Resources for Food and Agriculture (FAO, forthcoming) ${ }^{107}$ indicates that AqGR are addressed by a range of national instruments, including in the fields of conservation, fisheries, aquaculture and trade. National legislation often restricts the importation of non-native aquatic species in order to protect local biodiversity or local business. Many countries have fishery management plans that regulate the timing and quantity of fishing activities and the species that can be harvested. In many cases, aquatic species are covered under general laws protecting endangered species. Aquatic species are also addressed in many conservation-related policy instruments such as national biodiversity strategy and action plans.

Particularly notable in the aquatic sector is the absence of provisions similar to those related to farmers' rights and breeders' rights in the terrestrial crop sector. This is a consequence of the relatively recent domestication of aquatic species. Unlike many terrestrial farming and livestock-keeping communities, aquaculture farmers have not spent millennia developing the species they utilize. Genetic improvement of farmed aquatic species has often been done by large companies or research institutions with modern breeding facilities and at locations outside the centres of origin of the respective species (Bartley et al., 2009). In such cases, no indigenous group was responsible for the genetic improvement of the species and there would be no basis for a claim for farmers' or breeders' rights. Policies relating to ex situ conservation (i.e. gene banks) are also not as well developed as in the crop and livestock sectors due to the difficulty of storing frozen eggs and embryos from aquatic species.

\footnotetext{
${ }^{107}$ Unless indicated otherwise, the material presented in this subsection is based on this report.
} 
Key reported constraints to the implementation of AqGR-related policies include a lack of awareness, a lack of technical capacity and a lack of resources. Many countries have adequate AqGR policies in place, especially at the species level, but lack the resources to implement and enforce them. One of the more significant policy gaps concerns the cross-sectoral development and management of freshwaters and inland aquatic ecosystems. There is strong competition among users of freshwater (e.g. industry, agriculture, hydroelectric generation, municipal drinking water, navigation, aquaculture and fisheries), each having their own set of requirements as to how water should be used and managed. However, the fishery sector is often left out of policy discussions on the use of freshwater, and as a result water-management policies often favour other sectors to the detriment of fisheries (Bartley et al., 2016).

\section{Associated biodiversity}

The country reports indicate that associated biodiversity is generally not targeted as a distinct category in policy purposes, falling instead within the scope of broader instruments targeting biodiversity, the environment, sustainable development or agricultural practices. National policies addressing biodiversity or environmental protection generally include measures that directly or indirectly affect the maintenance of habitats in and around production systems. The same is true for those addressing more specific issues such as climate change, disaster risk reduction, invasive species or desertification, and those targeting specific types of ecosystem such as forests, mountains, lakes or coastal zones. Whether directly targeted or not, associated biodiversity will often benefit from policies that reduce pollution of land and water, strengthen disaster risk reduction measures, prevent destructive landuse changes or restrict environmentally unfriendly practices in crop or livestock production, forestry, fisheries or aquaculture.

Some country reports mention efforts to integrate biodiversity into national planning and policy development across a variety of different economic sectors. The report from Sri Lanka, for example, notes that this is done via the country's Biodiversity Conservation Action Plan. It further notes that biodiversity is considered to be adequately integrated into some sectoral policies (e.g. those addressing forests, wetlands, coastal and marine habitats, fisheries and agriculture) but not in others (e.g. those addressing industrial and service sectors, including urban development, harbours, tourism, mining, energy, roads and telecommunications). Most countries have prepared national biodiversity strategies and action plans as a basis for the implementation of the CBD at national level. The extent to which these instruments specifically address BFA, associated biodiversity and the ecosystem services they deliver varies from country to country (FAO and CBD, 2016; FAO et al., 2016).

A number of reports, particularly from Europe, note the significance of agri-environmental schemes under which farmers are incentivized to manage their land in environmentally friendly ways. Some of these schemes target species or habitats that have well-recognized beneficial roles in agriculture (see Section 8.7). In general, however, schemes often focus more on protecting biodiversity from the effects of environmentally unfriendly management practices than specifically on maintaining and enhancing the benefits that biodiversity provides to food and agriculture.

The country reports generally include little information on policies devoted to specific categories of associated biodiversity. Pollinators are the most frequent exception. For example, the report from Belgium mentions a federal bee plan targeting the preservation of pollinators, particularly bees. The plan includes about 30 actions and measures dealing with six main issues: risk assessment (including pesticide risk analysis); integration of pollinator management into other policies and measures (including economic measures); orientation of markets in favour of pollinators; monitoring of honey bees and wild bees; animal-health policy; and the traceability of hives (for honey bees only). The report from the United Kingdom mentions the National Pollinator Strategy (DEFRA, 2014), which aims to safeguard insect pollinators 


\section{PART D}

Box 8.21

Brazil's experience in mainstreaming biodiversity into its Food and Nutrition Security Policy

Brazil achieved both the Millennium Development Goal target of halving the proportion of its people suffering from hunger and the more stringent World Food Summit target of reducing by half the absolute number of hungry people before the deadline of 2015. Successful reduction of hunger and extreme poverty in both rural and urban areas has been achieved through a well-coordinated array of cross-sectoral policies led by the government with strong engagement from civil society, rather than through any individual action. Joint interministerial strategies have become increasingly common, including the mainstreaming of biodiversity into food-security and nutrition policies.

The Zero Hunger Program, launched in 2003, was the first step in translating the decision to end hunger into action, and introduced a new approach that placed food security and nutrition and social inclusion at the centre of the government's agenda and linked macroeconomic, social and sustainable agricultural and development policies. The fight against hunger and poverty has remained at the centre of the political agenda ever since, and was reinforced after 2011 with the launch of the Brazil without Extreme Poverty Strategy. This new set of intersectoral policies built on the success of Zero Hunger, with the bold goal of eliminating extreme poverty in Brazil.

The underlying assumption of the Zero Hunger Program is that poverty reduction, food security and support for family farmers are intimately connected. Besides social protection programmes, the other key pillars of the strategy are the Food Acquisition Programme (PAA), the National School Meals Programme (PNAE), the National Food and Nutrition Policy (PNAN) and the National Plan for Agroecology and Organic Production (PLANAPO I/II).

In 2003, Brazil was one of the first countries to establish an institutional food procurement programme connecting institutional demand for agricultural products to a foodsecurity strategy and support for family farmers. The PAA has three main objectives: (i) to assist family farmers and family rural entrepreneurs with production and access to markets; (ii) to distribute food to people suffering from food and nutritional insecurity; and (iii) to build up strategic stocks. It buys food directly from smallholder-farmers' organizations at market prices and distributes it to hospitals, schools, other public institutions and families in need. In 2009, the government built on the PAA by linking the well-established national school feeding programme to smallholderagriculture policies. States, municipalities and federal schools are required to purchase at least 30 percent of food for school meals directly from smallholder producers.

These programmes are complemented by the PNAN and incentives for organic agriculture and agroecological production from family farms, the aim being to make nutritious, diverse and sustainably produced foods accessible to the whole population. PLANAPO I (2013-2015) benefited thousands of smallholder farmers through the provision of credit and crop insurance for agroecological food production, specific support to rural women, capacitydevelopment, rural extension and technical assistance. PLANAPO II (2016-2019) prioritizes the access of family farmers to markets, in line with the provisions of PAA and PNAE. The aim is to have 1 million family farmers producing food using agroecological techniques by 2019.

The various federal policies described above provide entry points for conservation and sustainable use of biodiversity. The PLANAPO, for instance, recognizes the importance of "sociobiodiversity" products and the valorization of local experiences of use and conservation of plant and animal genetic resources, especially those involving the management of local breeds and traditional and Creole varieties.

The implementation of PLANAPO I involved a wide range of actions on the part of various ministries and national institutions, including the Brazilian Agricultural Research Corporation (Embrapa), aimed at improving the production, management, conservation, acquisition and distribution of genetic resources of interest to agroecology and organic production. Measures included the identification of organizations and networks involved in the conservation of such genetic resources, support for the development of agroecology networks to intensify the sustainable use of agrobiodiversity, and establishment of community seed banks and other measures to increase family farmers' access to Creole and organic seeds. Research and development, rural extension and technical assistance were also promoted.

(Cont.) 
Box 8.21(Cont.)

Brazil's experience in mainstreaming biodiversity into its Food and Nutrition Security Policy

Another federal initiative that was integrated with

PLANAPO I and relates to biodiversity mainstreaming is the Plants for the Future Project, which aims to survey, document and promote the conservation and sustainable utilization of neglected/underutilized plant species with nutritional value or economic potential. This initiative is related to the GEFfunded Biodiversity for Food and Nutrition Project (BFN), ${ }^{1}$ which in Brazil is working with the ministries responsible for the implementation of food-security and nutrition policies to promote the inclusion of foods from Brazilian biodiversity in the PAA, PNAE and nutrition-education strategies (see Box 2.4). Activities led by BFN include nutritional-composition analysis of 65 native fruit species, which is being carried out in partnership with public universities and research institutes across the country and will provide evidence that can be used to promote greater mainstreaming of biodiversity into all the above-mentioned federal initiatives.

PLANAPO II builds on experience gained under PLANAPO I, as well as on the Minimum Price Guarantee Policy for Biodiversity Products, which promotes biodiversity conservation, food security and income generation in local extractive communities by establishing minimum prices for some selected biodiversity products. "Sociobiodiversity" considerations were included as one of the axes of PLANAPO II and accounted directly for at least seven of its targets and 27 of its initiatives. In this context, the Ministries of Social Development and the Environment jointly released a list of native biodiversity products to be considered in institutional procurement programmes (Ordinance MMA/MDS 163/2016). PLANAPO II recognizes the opportunity to expand the purchase of such products in the PAA and PNAE, while improving the diversification of diets, supporting family farming and strengthening biodiversity conservation.

\footnotetext{
Source: Brazilian Institute of Geography and Statistics (IBGE), National Household Sample Survey (PNAD). Elaborated by the Secretariat for Evaluation and Information Management (SAGI), Ministry of Social Development and Hunger Alleviation (MDS).

1 The Mainstreaming Biodiversity Conservation and Sustainable Use for Improved Nutrition and Well-Being Project, or Biodiversity for Food and Nutrition Project for short, is led by Brazil, Kenya, Sri Lanka and Turkey. The initiative is coordinated by Bioversity International, with implementation support from UN Environment and FAO, and contributes to the implementation of the CBD's Cross-Cutting Initiative on Biodiversity for Food and Nutrition.
}

by taking action across five key areas: supporting pollinators on farms; supporting pollinators across towns, cities and the countryside; enhancing response to pest and disease risks; raising awareness of what pollinators need to survive and thrive; and improving evidence on the status of pollinators and the services they provide. The United States of America's National Strategy to Promote the Health of Honey Bees and Other Pollinators (Pollinator Health Task Force, 2015), which aims to improve pollinator habitat and reduce stressors affecting pollinators, is another reported example.

In addition to instruments focused on biodiversity or environmental protection, many country reports list policies that aim to promote economic and social goals such as livelihood development, food security and poverty reduction (see Box 8.21 for example). Some reports explicitly note the need for policies that address links between biodiversity and productivity in food and agricultural systems. For example, the report from the Bahamas notes the need to develop a national fisheries development plan that, inter alia, addresses the "conservation and restoration of coastal habitats and wetlands important to fisheries recruitment and to the health of fringing reefs."

As with other categories of biodiversity, legal instruments can have a significant influence on sustainable use and conservation of associated biodiversity. They can, for example, serve to enforce restrictions on biodiversity-unfriendly practices in food and agricultural production and in other industries, to restrict overharvesting of wild products, to set criteria for support measures for beneficial practices and to assign responsibilities to institutions and stakeholder groups involved in 


\section{PART D}

conservation and sustainable use. Many country reports list laws dedicated to the protection of biodiversity, along with those in a range of other fields that include biodiversity-related provisions. However, little information specifically related to associated biodiversity as a category or to particular groups of organisms such as pollinators or soil flora and fauna is provided. Exceptions include the report from Zimbabwe, which mentions the country's Bees Act [Chapter 19:02] of 1973 (amended 2002), ${ }^{108}$ which provides for the conservation of honey bees (Apis mellifera) in the wild and also regulates beekeeping through registration of beekeepers and control of the movement of bees and honey within and across the country's borders. The report further notes that the act also provides for the control of bee diseases through regular surveillance and monitoring.

The country reports generally do not present detailed assessments of gaps in policies and legislation and their effects on the management of associated biodiversity (or BFA more generally). This may, in part, relate to a lack of information on the effects of existing provisions. The report from Sri Lanka, for example, notes that although policies and programmes are considered to have played a key role in promoting and safeguarding biodiversity, specific outcomes in terms of the state of biodiversity and the supply of ecosystems services have not been assessed. Some specific weaknesses are, however, noted. For example, Ecuador mentions the absence of an appropriate legal framework defining the roles and competences of institutions involved in managing biodiversity. Some countries note a more general need to strengthen policies targeting associated biodiversity. Nicaragua, for example, mentions that while it has made significant progress over recent years with regard to policies targeting domesticated biodiversity, it still lacks an effective medium- to long-term strategy for the management of associated biodiversity, as well as for wild foods and generally for ecosystem services.

\footnotetext{
${ }^{108}$ Bees Act [Chapter 19:02] (available at http://www.fao.org/ faolex/results/details/en/?details=LEX-FAOC060551).
}

A number of different constraints to the development of legislation addressing the conservation and sustainable use of associated biodiversity and wild foods are also noted. In some cases, the development of legislation is reportedly hampered by a lack of legal specialists in this field. Some country reports indicate that a lack of awareness of the significance of associated biodiversity means that legislation in this field is not prioritized. Some refer to perceived conflicts with the need to increase the output of food and agricultural systems or with other economic activities. Some mention opposition from producers and other stakeholders who fear that legal restrictions will affect their livelihoods.

Lack of knowledge of associated biodiversity, the production systems in and around which it is found and the benefits it supplies is noted in some country reports as a constraint to the development of effective legal and policy instruments. The potential impacts of different measures may not be well understood, particularly given the time scales over which they may play out and the interactions that may occur between different ecosystems and across sectors, within and beyond food and agriculture. These interactions underline the importance of intersectoral and interministerial collaboration in the formulation of laws and policies. The country reports indicate that cooperation at this level often remains insufficient. Some reports note that improving information systems and the exchange of information between different stakeholders and stakeholder groups would help to strengthen policy-making and law-making.

Where implementation of laws and policies is concerned, the country reports again refer to a range of constraints. Cameroon, for example, referring to the implementation of legislation on the use of wild foods, notes that constraints include a lack of awareness on the part of rural dwellers: people may be unaware of the rules (a problem exacerbated by a lack of translations into local languages) or not understand why they have been introduced. It also notes that poor transport infrastructure constrains the activities of law 
enforcers. Some reports mention that implementation is affected by a lack of funding or by a lack of security in rural areas because of armed conflicts, etc. Others note that problems are caused by contradictory legislation, the existence of loopholes or by a lack of cooperation between different agencies or lack of clarity as to their mandates.

\subsubsection{Climate change policy and programmes}

The importance of integrating BFA-related measures into climate change mitigation and adaptation plans and strategies is increasingly recognized internationally. For example, in 2015, the Commission on Genetic Resources for Food and Agriculture adopted Voluntary Guidelines to Support the Integration of Genetic Diversity into National Climate Change Adaptation Planning (Box 8.22). Evidence suggests, however, that concrete progress in this regard has been fairly limited. For example, a study of the 50 national adaptation programmes of action (NAPAs) developed by January 2015 (Villanueva, Halewood and Noriega, 2017) concluded that they do not effectively integrate agrobiodiversity, noting for example that although NAPAs often stress the importance of food security and nutrition, few target the improvement and use of local, indigenous or traditional crop varieties and animal breeds and none of those reviewed address underutilized species. The study also concluded that the NAPAs reviewed are overly compartmentalized at governmental level and that there is a lack of dialogue between ministries of agriculture and the environment on the protection and use of agrobiodiversity (ibid.). A study of all intended national determined contributions (INDCS) ${ }^{109}$ found that only a minority include references to the use of crop or livestock biodiversity in climate change adaptation and mitigation (Strohmaier et al., 2016).

\footnotetext{
109 Intended National Determined Contributions are outlines of how countries intend to adapt to and mitigate the effects of climate change that were prepared for the twenty-second Conference of the Parties to the UNFCCC (UNFCCC, 2018).
}

Box 8.22

Voluntary Guidelines to Support the Integration of Genetic Diversity into National Climate Change Adaptation Planning

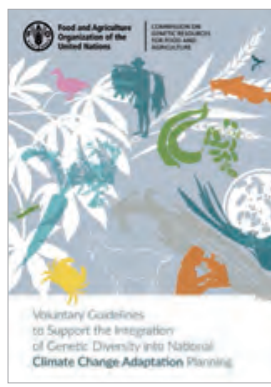

The Voluntary Guidelines to Support the Integration of Genetic Diversity into National Climate Change Adaptation Planning (FAO, 2015g) were prepared under the guidance of the Commission on Genetic Resources for Food and Agriculture and adopted at its Fifteenth Regular Session, in 2015. They were subsequently approved by the 2015 FAO Conference.

The guidelines seek to enable countries to ensure the relevance of genetic resources for food and agriculture to overall national adaptation planning processes by identifying clear goals and maximizing stakeholder involvement. They follow the structure and approach of the technical guidelines for the national adaptation plan process prepared by the Least Developed Countries Expert Group of the United Nations Framework Convention on Climate Change. The process outlined in the guidelines involves four main elements: "lay the groundwork and address gaps"; "develop the preparatory framework"; "develop the implementation strategy"; and "monitor, review, report and communicate progress". A number of steps are proposed for the implementation of each element.

Note: The voluntary guidelines can be viewed at http://www.fao.org/3/ai4940e.pdf

The country-reporting guidelines invited countries to list up to ten policies, programmes or enabling frameworks that embed the use of BFA into climate change adaptation strategies and plans. NAPAs, nationally appropriate mitigation actions, REDD+ (reducing emissions from deforestation and forest degradation) and national adaptation plans were listed as examples (see Box 8.23 


\section{PART D}

Box 8.23

The UNFCCC adaptation

and mitigation instruments

\section{National adaptation programmes of action}

The national adaptation programmes of action process provides a means for least developed countries to identify priority activities that respond to their urgent and immediate needs with respect to climate change adaptation, i.e. situations in which any further delay would increase vulnerability and/or the cost of adaptation at a later stage (UNFCCC, 2017b).

\section{Nationally appropriate mitigation actions}

Nationally appropriate mitigation actions are actions that reduce greenhouse-gas emissions in developing countries under government-led initiatives (UNFCCC, 2017c).

\section{Reducing emissions from deforestation and forest degradation}

Reducing emissions from deforestation and forest degradation (REDD+) processes supports countries' efforts to enhance the forestry sector's role in climate change mitigation. It works with stakeholders to ensure that individual projects reflect the needs of forest-dependent communities while developing the forestry sector in a sustainable manner (UN-REDD Programme, 2018).

\section{National adaptation plans}

National adaptation plans identify medium- and longterm climate change adaptation needs along with strategies and programmes for addressing them.

for explanations). In total, 59 countries provided answers to this question, with responses varying in their levels of detail and the extent to which the instruments mentioned focus explicitly on BFA rather than on food and agriculture or biodiversity more generally.

Thirty countries (approximately half of those that responded to this question) mention policies and frameworks that address the use of biodiversity in adaptation planning in food and agriculture. References are mainly to the use of landrace varieties in breeding programmes to produce climate change-adapted crops. Mitigation policies and frameworks involving BFA are mentioned by 14 countries (about 24 percent of respondents to this question). In most cases, mitigation practices are mentioned in conjunction with the adaptation practices. References are mainly to carbon sequestration through afforestation or through soilrestoration or soil-improvement measures.

A number of responses refer to policies aimed at conserving BFA in the interests of promoting resilience to climate change at production-system level. Both in situ (including on-farm) and ex situ conservation are mentioned. Finland, for example, reports that all its conservation programmes and strategies explicitly address climate change issues and actions. Many countries note that the maintenance or expansion of ecologically diverse habitats can increase the supply of relevant ecosystem services such as flood protection and carbon sequestration. Gabon, for example, emphasizes the significance of its 13 national parks in terms of carbon sequestration and the supply of a range of ecosystem services that contribute to climate change adaptation. Some countries highlight the significance of policies that promote awareness raising among stakeholders and the wider public of the links between biodiversity, climate change-related ecosystem services and resilience in the context of food and agriculture.

\subsubsection{Frameworks supporting the maintenance of traditional knowledge}

Many country reports provide information on policies and programmes that contribute to the maintenance of traditional knowledge. Some countries note that traditional knowledge is addressed in national instruments such as national biodiversity strategies and action plans or in policies and legislation related to intangible cultural heritage, agri-environmental schemes, protected geographical indications or intellectual property. Several note that traditional knowledge is addressed in international agreements they have ratified, for example the CBD and the Nagoya Protocol. 
A few countries mention national policies and programmes specifically addressing the maintenance and use of traditional knowledge. For example, Iraq reports that it is developing a law that will address the conservation, maintenance and exchange of animal and plant genetic resources and associated traditional knowledge. Others note, in more general terms, that policies promoting conservation and sustainable use of BFA also contribute to the maintenance of related traditional knowledge. Several countries mention policy frameworks addressing the role of indigenous peoples in maintaining biodiversity and the traditional knowledge associated with it. A few mention legal frameworks aimed at recording traditional knowledge and protecting the rights of indigenous knowledge holders. Peru, for instance, mentions a legal framework ${ }^{110}$ for the recording of collective traditional knowledge linked to biological resources that provides the opportunity to choose between a publicly accessible and a confidential national registry. Several countries that lack policies and legislation in this field note the need to develop relevant instruments. However, some of those that have instruments in place note that little is being done to implement them.

\subsubsection{Access and benefit-sharing}

Given that a significant proportion of the BFA used within any given country originated beyond its borders, and that efforts to diversify and adapt production systems require ongoing crossborder exchanges of genetic resources, it is clear that countries are interdependent in the use of BFA. At the same time, countries have - in accordance with the Charter of the United Nations and the principles of international environmental law "the sovereign right to exploit their own resources pursuant to their own environmental policies." 111 This sovereign right includes the right of countries to restrict access to their biodiversity and to make

${ }^{110}$ Law No. 27811 of July 24 2002, on the Introduction of the Protection Regime for the Collective Knowledge of Indigenous Peoples derived from Biological Resources (available at http://www.wipo.int/wipolex/en/details.jsp?id=3420).

111 Convention on Biological Diversity, Article 3. access conditional upon agreement regarding benefit-sharing. The CBD and the Nagoya Protocol (see Section 8.8.1) confirm and are based on this sovereign right of countries. The International Treaty on Plant Genetic Resources for Food and Agriculture, which was established in harmony with the $C B D$, recognizes this sovereign right, but includes a multilateral system of access and benefitsharing (ABS) for facilitated access to a negotiated selection of PGRFA.

$A B S$ usually refers to the ways in which genetic resources may be accessed and how benefits that result from specific uses of genetic resources are shared between providers and users. ABS measures will usually state that access to the genetic resources of the country requires prior informed consent (PIC) and an agreement on the sharing of benefits under "mutually agreed terms" (MAT). In line with the Nagoya Protocol, ABS measures often specify that PIC and MAT are required for access to genetic resources for research and development on their genetic and/or biochemical composition, including through the application of biotechnology. Other ABS laws are broader in scope in that they require PIC and MAT also for uses not covered by the Nagoya Protocol, for example the use of genetic resources as biological resources or commodities.

Following the adoption of the Nagoya Protocol, and its entry into force in 2014, many countries have been developing ABS legislation or revising their existing legislation. Even in countries that have finalized their ABS frameworks, experiences with implementation may lead to further changes and adjustments of ABS rules in the relatively near future. ABS policy frameworks are, thus, in a process of transformation, evolution and adjustment.

\section{Measures for regulating access and for ensuring compliance}

$A B S$ measures can be roughly distinguished into measures through which countries regulate access to their genetic resources and measures ensuring compliance with the ABS laws of other countries. To date, far fewer countries have adopted measures 
of the latter type, i.e. measures that require that genetic resources used within their jurisdictions have been accessed in accordance with PIC and that MAT have been established in line with the requirements of the $A B S$ measures of the other country. The European Union has adopted legislation (Regulation [EU] No 511/2014) ${ }^{112}$ that requires users of genetic resources to

exercise due diligence to ascertain that genetic resources and traditional knowledge associated with genetic resources which they utilise have been accessed in accordance with applicable access and benefit-sharing legislation or regulatory requirements, and that benefits are fairly and equitably shared upon mutually agreed terms, in accordance with any applicable legislation or regulatory requirements.

The Nagoya Protocol does not require countries to regulate access to genetic resources within their jurisdiction. The national sovereignty of countries over genetic resources within their jurisdiction includes the right to make them freely available as much as the right to regulate access to them. While a number of (mostly Northern) countries have decided not to make access to genetic resources within their jurisdiction subject to benefit-sharing, other countries have made access to their genetic resources conditional upon their PIC, which they will usually only grant if the recipient agrees to share the benefits, either up-front or once they accrue.

\footnotetext{
${ }^{12}$ Regulation (EU) No 511/2014 of the European Parliament and of the Council of 16 April 2014 on compliance measures for users from the Nagoya Protocol on Access to Genetic Resources and the Fair and Equitable Sharing of Benefits Arising from their Utilization in the Union Text with EEA relevance (available at https://eur-lex.europa.eu/ legal-content/EN/TXT/?uri=celex\%3A32014R0511). See also Guidance document on the scope of application and core obligations of Regulation (EU) No 511/2014 of the European Parliament and of the Council on the compliance measures for users from the Nagoya Protocol on Access to Genetic Resources and the Fair and Equitable Sharing of Benefits Arising from their Utilisation in the Union C/2016/5337 (available at https://eur-lex.europa.eu/legal-content/EN/ TXT/?uri=CELEX\%3A52016XC0827\%2801\%29).
}

\section{National ABS measures for biodiversity for food and agriculture and associated traditional knowledge}

ABS measures often do not distinguish between different categories of genetic resources. However, the ABS measures of countries that are Parties to the International Treaty on Plant Genetic Resources for Food and Agriculture often contain provisions on plant genetic resources aligning the measures with the provisions of the Treaty and the modalities of its Multilateral System of Access and Benefit-Sharing. Moreover, ABS measures in a number of countries distinguish different purposes for which genetic resources may be used and provide for different authorization requirements and procedures for access to genetic resources depending on their intended use.

In developing and implementing ABS legislation, Parties to the Nagoya Protocol are obliged to consider "the importance of genetic resources for food and agriculture and their special role for food security." 113 More than two-thirds of Parties reporting in 2017/2018 on their implementation of the Nagoya Protocol confirmed that they had considered the importance of genetic resources for food and agriculture in the development of their ABS frameworks (CBD, 2018).

Although ABS laws are considered "an expression of national sovereignty" over genetic resources (Morgera, Buck and Tsioumani, 2013), they often also serve, in line with the Nagoya Protocol, the additional purpose of ensuring that genetic resources held by indigenous peoples or local communities (IPLCs) are accessed with their agreement. The laws of some countries explicitly provide for the development of biocultural protocols that aim to ensure that PIC is obtained from IPLCs for access to genetic resources held by them, and that benefits from the utilization of such genetic resources are shared with them.

Even before the adoption of the Nagoya Protocol, many countries had started to regulate access to traditional knowledge associated with genetic resources (Bardi, Gutiérrez-Oppe and

\footnotetext{
${ }^{113}$ Nagoya Protocol, Article 8(c).
} 
Politano, 2011). The relevant laws usually state that such knowledge held by IPLCs should only be accessed with the PIC of the relevant IPLC and only if MAT have been established. Some country reports, however, indicate that the implementation of these provisions is still often challenging because communities often do not yet have clear decision-making structures and procedures in place and therefore PIC with one IPLC may be questioned by another IPLC.

There is consensus among Parties to the Nagoya Protocol on the need for capacity-building and other support measures critical to the development and implementation of ABS measures. ${ }^{114}$ Developing and implementing ABS measures is considered a challenge as genetic resources are used by a range of different communities of practice, many of which have developed their own exchange practices (e.g. Nijar, 2013). Legislators and competent authorities are therefore confronted with widely differing expectations and a range of existing practices and stakeholder requirements.

\section{Distinctive features of biological diversity for food and agriculture}

In line with the Nagoya Protocol requirement to consider in the development and implementation of $A B S$ legislation "the importance of genetic resources for food and agriculture and their special role for food security", countries may in the future develop tailored procedures for ABS for genetic resources for food and agriculture. The Commission on Genetic Resources for Food and Agriculture's Elements to Facilitate Domestic Implementation of Access and Benefit-sharing for Different Subsectors of Genetic Resources for Food and Agriculture (FAO, 2016q) aim to assist governments to take into account the importance of genetic resources for food and agriculture, their special role for food security and the distinctive features of the different subsectors of genetic resources for food and agriculture, while complying, as applicable, with the international $A B S$ instruments.

${ }^{114}$ See Article 22 of the Nagoya Protocol and relevant decisions of the Meeting of the Parties to the Nagoya Protocol: https:// www.cbd.int/abs/capacitybuilding-relevant.shtml 



\section{Part E \\ CONCLUSIONS}





\section{Chapter 9 \\ Needs and challenges}

\subsection{Introduction}

Chapters 1 to 8 of this report identify and assess the multiple contributions that biodiversity makes to food and agriculture, to the livelihoods of farmers, livestock keepers, fishers, fish farmers and forest dwellers, and to food security and nutrition. They document what is known about the status and trends of biodiversity for food and agriculture (BFA), the drivers of change affecting it, levels of adoption of management practices and strategies that promote its sustainable use and contribute to its conservation, and the state of policies, institutions and capacities related to its management. This final chapter draws together the various threads of the analysis to identify the main challenges to the sustainable management of BFA. ${ }^{1}$

Securing and enhancing the multiple roles of BFA will require sustainable use and conservation of the ecosystems, species and genetic diversity that compose it. For this to happen, knowledge of the roles of biodiversity in the ecological processes that underpin food and agricultural production needs to be strengthened, and used to develop management strategies that protect, restore and enhance these processes across a range of scales. Establishing effective policy and outreach measures will be needed to support the uptake of management practices that sustainably use biodiversity to promote food and livelihood security and resilience.

Needs and challenges related to the sustainable use and conservation of plant, animal, forest and aquatic genetic resources are discussed in detail in the respective global assessments (FAO, 2010a, 2014a, 2015a, forthcoming).

\subsection{Drivers of change}

BFA is affected by a variety of interacting drivers of change: global effects, such as climate change and the operations of international markets, give rise to more immediate drivers such as land-use change, pollution, overuse of external inputs, overharvesting and the proliferation of invasive species. While there are many potential means of addressing immediate threats through the adoption of various sustainable management practices and the implementation of conservation measures, these may be neglected or overwhelmed unless political will is found to address higher-level drivers. It is also essential to build on the opportunities that are emerging as a result of trends such as growing consumer demand for biodiversity-friendly products.

At minimum, there is a need to: (i) better understand the effects of drivers of change on BFA and take urgent action to address those that are undermining the sustainability of food and agricultural production; (ii) improve the monitoring of recognized threats to BFA, such as habitat destruction, pollution, inappropriate use of agricultural inputs, overharvesting, pests, diseases and invasive alien species, and strengthen efforts to reduce them or mitigate their effects; (iii) promote the use of technologies and management practices that have positive effects on BFA and the supply of ecosystem services; (iv) implement policies that help to protect biodiversity from the effects of negative drivers and support its sustainable use; (v) remove or revise policies that have harmful effects; and (vi) promote the use of BFA in climate change 
adaptation and mitigation, in disaster-risk reduction and in addressing other drivers that negatively affect production systems and the supply of ecosystem services.

\subsection{Status and trends}

Many key components of BFA at genetic, species and ecosystem levels are in decline. While the general declining trend - and hence the need for action - is clear, lack of data often constrains the planning and prioritization of effective remedial measures.

The extent and nature of knowledge gaps vary across the components of BFA. In the case of domesticated species and those that are widely harvested from the wild, species inventories are largely complete and the range of within-species populations (breeds, varieties, etc.) is often also well documented, although to varying degrees across the regions of the world. In contrast, many associated-biodiversity species (species that live in and around production systems and provide regulating and supporting ecosystem services), particularly micro-organisms and invertebrates, have never been documented.

Population trends are relatively well monitored for some taxonomic groups (e.g. vertebrates). For many others, however, knowledge is very limited, even at species level, and almost non-existent at within-species level. Moreover, where monitoring programmes for associated biodiversity are in place, population data are often not linked to spatial data on the distribution of production systems and hence potential impacts on production can be difficult to evaluate. In many cases, the contributions of specific components of BFA to the supply of ecosystem services are poorly understood.

There is an urgent need to improve the availability of data in all the above fields. Doing this will require, inter alia, improving methodologies for recording, storing and analysing data on changes in the abundance and distribution of species (including improving geographic information system facilities) and increasing the supply of taxonomists with the skills needed to work with currently neglected taxonomic groups. Strengthening research, education and capacity-building programmes will be essential. Cooperation needs to be improved, including between the public sector and other stakeholders. In a number of countries, certain types of associated biodiversity are monitored through citizen-science projects, and there may be potential to expand activities of this kind and introduce them more widely.

Effective monitoring requires systematic and long-term commitment. The roles and responsibilities of key stakeholders need to be clearly defined. Where they do not currently exist, it may be necessary to establish national bodies to organize or oversee monitoring activities.

\subsection{Management}

\subsubsection{State of use}

A range of management practices and production approaches that can potentially contribute to the conservation and sustainable use of BFA are increasingly being implemented around the world. Detailed information on trends in such practices is, however, often limited, as is detailed information on their impacts on BFA and the supply of ecosystem services. Uptake is constrained by a variety of factors.

Overall, one of the major constraints to the development, adoption and implementation of management practices and approaches that contribute to the sustainable management of BFA is a lack of data on the characteristics of relevant ecosystems and limited understanding of ecosystem functions and services, including specifically on the roles of different components of BFA. Action needs to be taken to address knowledge gaps of this kind.

Many BFA-focused practices are relatively complex and require good understanding of the local ecosystem. They can be knowledge intensive, context specific and provide benefits only in the relatively long term. Many countries note major 
challenges in up-scaling such practices and identify the need to promote them through capacity development and by strengthening incentives and policy frameworks.

Although circumstances vary greatly from country to country and across production systems, a number of broad priorities with widespread relevance can be identified. On the institutional side, policy and regulatory frameworks may need to be reviewed to assess whether they provide the necessary support to the introduction or upscaling of more sustainable and biodiversity-friendly practices and to identify any ways in which they may operate as constraints. Fuller consultation between policy-makers and a range of stakeholders, including producers, can potentially help to overcome disconnections between political and operational levels.

Where supportive frameworks are in place, any constraints to their implementation, including financial constraints, need to be identified and addressed. Education and training on sustainable management practices often need to be improved, both to increase skills and knowledge at producer level and to increase the supply of trained and qualified technical and scientific personnel (both specialists and experts with crossdisciplinary knowledge). In some places, constraints related to weaknesses in transport and communications infrastructure will need to be addressed. Everywhere, efforts will be needed to increase knowledge of how effective particular practices and approaches are in promoting the sustainable use and conservation of BFA.

The following paragraphs describe key needs and challenges related to specific management practices and approaches.

\section{Ecosystem, landscape and seascape approaches}

While available evidence suggests that there are positive trends in the adoption and implementation of ecosystem, landscape and seascape approaches in the context of food and agriculture, assessment of developments in this field is constrained by a lack of clarity regarding the nature of these approaches and the multitude of terms used to describe them. Efforts may be required to promote common understanding in this regard, as well as to increase and disseminate knowledge on the potential benefits of such approaches.

Developing effective integrated approaches requires research on: (i) the functional roles of various components of BFA in key ecosystem processes within production systems and in wider landscapes or seascapes; and (ii) the effects that adopting such approaches have on components of BFA. The latter will require better surveying and monitoring in relevant ecosystems and the development of appropriate indicators.

Information on the application of ecosystem, landscape and seascape approaches and other innovative strategies that may be beneficial to BFA often fails to reach producers and other land or water users, or only does so after substantial delays. Priorities in this field therefore include better capturing and disseminating lessons-learned from the implementation of such approaches, including success stories.

Ecosystem, landscape and seascape approaches require cross-sectoral thinking and collaboration. This creates significant challenges to their adoption, given that institutional frameworks (policies, laws, organizational structures, etc.) are still very much compartmentalized and that there is a lack of holistic and multidisciplinary approaches both at policy level and at the level of practical implementation.

\section{Restoration practices}

Restoration practices have acquired a prominent place on the global environmental agenda in recent decades. If well planned, they can provide simultaneous benefits for agricultural productivity, biodiversity conservation and the supply of ecosystem services. Among ecosystems of importance to food and agriculture, forests and grasslands, as well as of a range of freshwater, marine and coastal ecosystems, are widely recognized as priorities for restoration. Depending on the location, key forest restoration activities are likely to include restoring connectivity between forest 
fragments and restoring forest cover in areas that are important to the supply of hydrological and erosion-control ecosystem services. Where aquatic ecosystems are concerned, mangroves, seagrass beds, coral reefs, coastal sand dunes, lakeshores and riverbanks are among the key targets for restoration. Priorities will often include improving connectivity within and between aquatic ecosystems and enhancing significant habitats such as fish spawning sites. Attention will need to be paid to the threats posed by climate change.

\section{Diversification and management practices at production level}

The use of a number of diversification strategies in food and agricultural production systems seems to be increasing. Evidence indicates that agroforestry is becoming more widespread in all regions of the world. Priorities in terms of strengthening the contributions of agroforestry to sustainable development include addressing problems in germplasm supply, improving the provision of marketing advice and developing a better understanding of gender-related implications. Home gardens are major reservoirs of BFA in many parts of the world. However, knowledge of the status and trends of these systems is limited. In the case of diversification in aquaculture, while traditional extensive diversified systems are tending to decline as a consequence of resource constraints, innovative polyculture approaches are creating opportunities to increase efficiency and tackle problems related to fish health and effluent discharge. Integrated crop-livestock systems remain widespread globally. There is need for research into how complementarities between crop and livestock production can be enhanced in the context of limited availability of land and other resources, including research into the significance of within-species genetic diversity.

The use of many management practices believed to help promote the conservation of BFA, or that utilize BFA in a sustainable way, is reportedly increasing, as is awareness of the benefits of such practices among consumers, producers, governments and international agencies. This appears to be the case, for example, for organic agriculture, low external input agriculture, management practices implemented with the aim of preserving and enhancing soil biodiversity, conservation agriculture, integrated plant nutrient management, integrated pest management, pollination management and sustainable forest management practices. Nevertheless, the availability of global data on the levels of implementation of many of these practices remains limited, and knowledge of their impacts on BFA and the supply of ecosystem services needs to be improved.

Biodiversity-based and biodiversity-friendly management practices generally require detailed knowledge of local production systems and ecosystems and are often relatively labour intensive. Consequently, their implementation tends to require the active participation of producers and their organizations, as well as the presence of effective extension services. Management interventions often need to extend beyond farm boundaries into the broader landscape or seascape. Attention needs to be paid to maintaining or restoring ecosystems that deliver services to food and agriculture and conserving the species and genetic diversity that will allow adaptation to changing conditions.

\section{The use of micro-organisms in food processing and agro-industrial processes}

Micro-organisms make multiple contributions to food processing and agro-industrial processes, and there is greater potential to expand these roles still further. Potential threats include the loss of knowledge associated with traditional food-processing practices that are in decline and the effects of climate change on microbial communities. Key tasks include improving frameworks for quality control of microbial products and for evaluating potential risks to human health or to the environment, improving registration policies for microbial products, improving education and awarenessraising, and strengthening research and conservation networks. 


\section{Rumen microbial diversity}

Given their vital contributions to livestock production and their role in the production of greenhouse gases, there is an urgent need to improve knowledge of rumen micro-organisms and their functions. Considerable progress has been made in this regard in recent years, but fundamental knowledge gaps remain to be addressed.

\section{Genetic-improvement activities}

Genetic-improvement programmes for domesticated crops and livestock are well established globally, although many species and within-species populations are neglected. Programmes for trees and species used in aquaculture are becoming more widespread. Genetic-improvement activities for other components of BFA are generally uncommon, with the exception of silkworms and honey bees. There could be benefits in extending domestication and genetic-improvement activities to other invertebrate species that contribute to food and agriculture, including stingless bees, which have been found to be more effective pollinators than honey bees for certain crops, and insects that can be raised for human consumption or as animal feed. Activities of this kind are already under way in several countries. Efforts are also being made to develop methods for assisted evolution of climate resilience in corals.

\subsubsection{State of conservation}

Methods and strategies for in situ (including on-farm and in other production systems) and ex situ conservation of BFA, in particular of associated biodiversity, need to be improved and information on them made more widely available. Especially with respect to ex situ conservation, there are still technical barriers to the long-term conservation of some species. Overcoming these gaps and constraints will often require increased funding, better training of relevant personnel and better provision of technical resources. Where skills are concerned, improving capacity in the fields of taxonomy and systematics is a widespread priority. Conservation-related education, training and awareness-raising activities for stakeholders at all levels from producers to policy-makers need to be strengthened. Improving conservation methods and strategies for BFA and strengthening their implementation will also require a more interdisciplinary approach. As and where relevant, the contributions that traditional production practices and resource-management strategies associated with local or indigenous communities make to the conservation of BFA need to be given due recognition and built on, with the participation of the communities concerned. Maintenance and transfer of relevant traditional knowledge should be supported and facilitated.

While there will often be a need to target individual species or populations that are at particular risk, components of BFA should not be considered in isolation from each other or from wider ecosystems, landscapes and seascapes. Potential synergies need to be explored, whether in terms of management strategies at production-system or landscape level that create opportunities to diversify more than one category of BFA or in terms of more efficient use of resources. Productive landscapes and seascapes need to include the habitat features necessary to support the associatedbiodiversity species that underpin food and agricultural production. Ensuring that this is the case will, in places, require the restoration of degraded habitats and maintaining or recreating wildlife corridors linking patches of habitat. Given their focus on integrated action across multiple scales and on accounting for the interests and concerns of a wide range of stakeholders, ecosystem, landscape or seascape approaches (see above) may provide useful frameworks.

Conservation measures for wild foods should also not be neglected. As with other components of BFA, conservation strategies need to be based on a sound understanding of the range of species involved, their distribution, characteristics, uses and risk status. Inventory and characterization efforts for this category of BFA generally need to be strengthened. Strategies need to be put in place that allow nutritional benefits to be realized in a sustainable way and threats such as overharvesting to be identified and addressed. 


\subsection{Policies, capacities and institutions}

\section{Cooperation}

Ensuring the sustainable use of BFA requires improved collaboration among a range stakeholders at local national and regional levels. Synergies between the food and agriculture and environmental sectors, in particular, need to be strengthened. Constraints to cooperation often relate to a lack of mechanisms for exchanging information among and between stakeholder groups or a lack of participatory decision-making processes. Mechanisms for involving small-scale producers, and women and youth in particular, in decision-making processes need to be improved. Greater cooperation between sectors provides opportunities to increase efficiency and can be a means of securing resources for BFA-related work. Training and awareness-raising on the organization of collaborative initiatives is also needed.

\section{Research}

As discussed above, the sustainable management of BFA, in particular associated biodiversity, is constrained by numerous knowledge gaps. Research programmes need to be strengthened and the necessary research infrastructure put in place, including by addressing shortages of specialists in relevant fields. This in turn creates the need to strengthen educational curricula and improve training (see next subsection). All these measures will require adequate funding, as will improving the dissemination of research results. Strengthening research-related information systems, such as systems for monitoring the status and trends of components of biodiversity or for managing relevant geographical data, is a widespread priority, both as a means of disseminating research outputs and as a means of making relevant information available to researchers.

Research is also often constrained by a lack of coordination between research institutions or between researchers working in different disciplines or in different sectors (both within and beyond food and agriculture). Improving coordination and linkages between institutes nationally, and at regional and international levels, potentially provides opportunities both to strengthen interdisciplinary work and to allow more efficient use of resources and information. Links between research and practical management at production-system level also need to be improved. This could involve, inter alia, improving researchers' links to producers, extension services and other relevant stakeholders, including by promoting greater participation throughout research-project cycles from planning to monitoring, and integrating indicators of practical impact into evaluation mechanisms for research projects.

\section{Education, training and awareness-raising}

Education and training on the management of BFA at all levels need to be strengthened, as does awareness raising on the importance of BFA among a range of stakeholders, including policymakers and the general public. Biodiversityrelated issues tend not to be well integrated into higher-education courses on food and agriculture or on other aspects of land use. Courses related to biodiversity conservation are often disconnected from those related to the use of biodiversity (i.e. on agriculture, forestry, fisheries, etc.), potentially leading to a lack of interdisciplinary skills among professionals. There is often also a need to improve the supply of graduates trained in specific fields such as taxonomy, economic valuation and cryoconservation. Ongoing capacity development among professionals and technicians is also essential.

While training for producers on the sustainable use of BFA is often inadequate, countries report a variety of success stories in this regard (for example with farmer field schools) and there are likely to be opportunities to expand, adapt and build upon some of these. Constraints to the participation of women in BFA-related education need to be addressed, and relevant extension and training programmes need to be better tailored to women's needs.

As well as organizing training activities, there is a need to improve access to information 
(e.g. via publications and information systems) and create opportunities for stakeholders to interact and exchange knowledge and ideas. Improving the state of education and training will require addressing shortfalls in funding and improving cooperation and exchange of information between educational institutions and between them and other stakeholder groups.

\section{Policy and legal frameworks}

Appropriate legal and policy frameworks are essential to the effective management of BFA. However, they often remain underdeveloped or poorly implemented. Shortcomings of this kind can, for example, mean that it is difficult to ensure support for long-term activities such as monitoring. Such problems can partly be attributed to a lack of adequate coordination between the food and agriculture and nature conservation sectors and to a lack of awareness of the significance of BFA among policy-makers. Overcoming these constraints will require, in addition to awareness-raising efforts, greater involvement of multiple stakeholders in policy-development. Links between research and policy-making also often need to be improved.

For policies to have an impact, the resources needed to implement them will need to be found.

Where access and benefit-sharing (ABS) are concerned, the main priorities that can be identified are capacity-building on the development and implementation of $A B S$ measures, and improving coordination between ministries, agencies and stakeholders responsible for $A B S$ in the various sectors of food and agriculture.

\section{Valuation}

Valuation studies are widely regarded as a potential means of drawing attention to the important contributions that biodiversity and ecosystem services make to human well-being and as a means of guiding the development of policies, research programmes and incentive schemes. There are, however, many gaps in terms of the coverage of such studies, for example with respect to microbial genetic resources and wild pollinators. Potential means of strengthening work in this field include fostering cross-sectoral and interinstitutional cooperation in valuation efforts, standardizing methodologies and tools, and mobilizing financial resources.

\section{Incentives}

Although incentive programmes supporting the sustainable management of BFA are becoming more widespread, such schemes are often isolated measures targeting the particular concerns of individual public programmes, private-sector operations or civil-society initiatives, and in many cases are very localized. Evidence suggests that a coordinated package of measures can create more impact in terms of improving outcomes for BFA. Other priorities include better documenting and mapping existing schemes, taking a longer-term perspective in planning, and improving cross-sectoral cooperation and institutional collaboration so as to improve the coordination of multiple incentives.

\subsection{Towards a more diverse and sustainable future}

BFA and the ecosystem services it supports are fundamental to efforts to increase the resilience, sustainability and productivity of food and agricultural systems, sustain livelihoods and enhance food security and nutrition around the world. Yet, much of the planet's BFA - ecosystems, species and within-species genetic diversity - is being eroded, often at an alarming rate. Urgent action and long-term commitment are needed, both to enhance the multiple contributions that BFA makes to sustainable development and to tackle the multiple threats currently driving its loss. This will require the involvement of stakeholders at all levels, nationally and internationally. Governments will need to take concrete steps to ensure their responsibilities in this field are fulfilled, particularly in light of the significance of BFA to efforts to meet the 2030 Sustainable Development Goals.

Positive global developments include, on the one hand, growing awareness internationally of 
threats to the sustainability of food and agriculture, including those related to the loss of biodiversity, and on the other, upward trends in levels of adoption of various management practices that potentially contribute to the conservation and sustainable use of BFA. These developments need to be built upon by the global community. Knowledge gaps need to be filled, cooperation strengthened, including cross-sectorally and internationally, and financial, human and technical resources mobilized. Effective legal and policy frameworks need to be put in place.

The country-driven process of preparing The State of the World's Biodiversity for Food and
Agriculture has led to the identification of numerous gaps, needs and potential actions in the management of BFA. The next step is to take action. Over the years, the Commission on Genetic Resources for Food and Agriculture has overseen the development of global plans of action for genetic resources in the plant, animal and forest sectors. Implementation of these instruments needs to be stepped up. Consideration also needs to be given to how the international community can more effectively promote synergies in the management of all components of biodiversity, across these sectors and others, in the interests of a more sustainable food and agriculture. 


\section{References}

Abizaid, C., Coomes, O.T. \& Perrault-Archambault, M. 2016. Seed sharing in Amazonian indigenous rain forest communities: a social network analysis in three Achuar villages, Peru. Human Ecology, 44(5): 577-594.

Acreman, M. 2004. Water and ecology. Series on Water and Ethics, Essay 8. Paris, UNESCO.

Acreman, M.C., Arthington, A.H., Colloff, M.J., Couch, C.A., Crossman, N.D., Dyer, F., Overton, I.C., Pollino, C., Stewardson, M.H. \& Young, W.J. 2014. Environmental flows for natural, hybrid and novel riverine ecosystems in a changing world. Frontiers in Ecology and the Environment, 12: 466-473.

Adams, J. 2012. Determination and implementation of environmental water requirements for estuaries. Ramsar Technical Report No. 9/CBD Technical Series No. 69. Gland, Switzerland, Ramsar Convention Secretariat, and Montreal, Canada, Secretariat of the Convention on Biological Diversity.

Addis, G. 2009. Wild and semi-wild edible plants of Hamar and Xonso (South Ethiopia) with emphasis on their ethnobotany and nutritional composition of selected species. Addis Ababa University. (PhD dissertation)

Addy, S., Cooksley, S., Dodd, N., Waylen, K., Stockan, J., Byg, A. \& Holstead, K. 2016. River restoration and biodiversity: nature-based solutions for restoring rivers in the UK and Republic of Ireland. Aberdeen, UK, Scotland's Centre of Expertise for Waters.

Adhikari, B., Di Falco, S. \& Lovett, J.C. 2004. Household characteristics and forest dependency: evidence from common property forest management in Nepal. Ecological Economics, 48(2): 245-257.

African Union Commision. 2015. 11 Overview of Agenda 2063. Addis Ababa. (available at https:// au.int/sites/default/files/documents/33126-doc-11_ an_overview_of_agenda.pdf)

Agarwal, B. 2015. Food security, productivity and gender inequality. In R.J. Herring, ed. The Oxford handbook of food, politics and society, pp. 273-301. Oxford, UK, Oxford University Press.

Ahmed, N., Ward, J.D. \& Saint, C.P. 2014. Can integrated aquaculture-agriculture (IAA) produce "more crop per drop" ? Food Security, 6(6): 767-779.

Ahmed, N., Thompson, S. \& Glaser, M. 2018. Integrated mangrove-shrimp cultivation: potential for blue carbon sequestration. Ambio, 47(4): 441-452.
Ahrends, A., Hollingsworth, P.M., Ziegler, A.D., Fox, J.M., Chen, H., Su, Y. \& Xu, J. 2015. Current trends of rubber plantation expansion may threaten biodiversity and livelihoods. Global Environmental Change, 34: 48-58.

Aitken, S.N. \& Whitlock, M.C. 2013. Assisted gene flow to facilitate local adaptation to climate change. Annual Review of Ecology, Evolution, and Systematics, 44: 367-388.

Aizen, M.A. \& Harder, L.D. 2009. The global stock of domesticated honey bees is growing slower than agricultural demand for pollination. Current Biology, 19(11): 915-918.

Aizen, M.A., Garibaldi, L.A., Cunningham, S.A. \& Klein, A.M. 2008. Long-term global trends in crop yield and production reveal no current pollination shortage but increasing pollinator dependency. Current Biology, 18: 1572-1575.

Aizen, M.A., Garibaldi, L.A., Cunningham, S.A. \& Klein, A.M. 2009. How much does agriculture depend on pollinators? Lessons from long-term trends in crop production. Annals of Botany, 103: 1579-1588.

Akasaka, M., Kadoya, T., Ishihama, F., Fujita, T. \& Fuller, R. 2017. Smart protected area placement decelerates biodiversity loss: a representationextinction feedback leads rare species to extinction. Conservation Letters, 10: 539-546.

Alagely, A., Krediet, C.J., Ritchie, K.B. \& Teplitski, M. 2011. Signaling-mediated cross-talk modulates swarming and biofilm formation in a coral pathogen Serratia marcescens. ISME Journal, 5: 1609-1620.

Alexander, S.J. \& Mclain, R.J. 2001. An overview of non-timber forest products in the United States today. Journal of Sustainable Forestry, 13(3-4): 95-103.

Alexandraki, V., Tsakalidou, E., Papadimitriou, K., Holzapfel, W. 2013. Status and trends of the conservation and sustainable use of micro-organisms in food processes. Commission on Genetic Resources for Food and Agriculture. Background Study Paper No. 65. Rome, FAO. (available at http:// www.fao.org/docrep/meeting/028/mg309e.pdf).

Alkama, R. \& Cescatti, A. 2016. Biophysical climate impacts of recent changes in global forest cover. Science, 351(6273): 600-604. 
Alkema, W., Boekhorst, J., Wels, M. \& Van Hijum, S.A.F.T. 2016. Microbial bioinformatics for food safety and production. Briefings in Bioinformatics, 17(2): 283-292.

Alkemade, R., Reid, R.S., van den Berg, M., de Leeuw, J. \& Jeuken, M. 2013. Assessing the impacts of livestock production on biodiversity in rangeland ecosystems. PNAS, 110(52): 20900-20905.

Allen, D.J., Molur, S. \& Daniel, B.A. 2010. The status and distribution of freshwater biodiversity in the Eastern Himalaya. Cambridge, UK, and Gland, Switzerland, IUCN, and Coimbatore, India, Zoo Outreach Organisation.

Allen, D.J., Smith, K.G. \& Darwall, W.R.T. 2012. The status and distribution of freshwater biodiversity in Indo-Burma. Cambridge, UK, and Gland, Switzerland, IUCN.

Alloway, B.J. 2013. Sources of heavy metals and metalloids in soils. In B. Alloway, ed. Heavy metals in soils. Environmental pollution, Vol. 22, pp. 11-50. Dordrecht, Netherlands, Springer.

Alongi, D.M., Murdiyarso, D., Fourqurean, J.W., Kauffman, J.B., Hutahaean, A., Crooks, S., Lovelock, C.E. et al. 2016. Indonesia's blue carbon: a globally significant and vulnerable sink for seagrass and mangrove carbon. Wetlands Ecology and Management, 24(1): 3-13.

Alston, D.G. 2011. Pest management decision-making: the economic-injury level concept. Utah Pests Fact Sheet (IPM-016-11). Logan, USA. Utah State University Extension and Utah Plant Pest Diagnostic Laborato.

Altieri, M.A. 1995. Agroecology: the science of sustainable agriculture. Boulder, USA, Westview Press.

Altieri, M.A. 1999. The ecological role of biodiversity in agroecosystems. Agriculture, Ecosystems and Environment, 74(1-3): 19-31.

Altieri, M.A. 2002. Agroecology: the science of natural resource management for poor farmers in marginal environments. Agriculture, Ecosystems \& Environment, 93: 1-24.

Altieri, M.A., Nicholls, C.I., Henao, A. \& Lana, M.A. 2015a. Agroecology and the design of climate change-resilient farming systems. Agronomy for Sustainable Development, 35(3): 869-890.

Altieri, M.A., Nicholson, C.I., Gillespie, M., Waterhouse, B., Wratten, S., Gbehounou, G.
\& Gemmill-Herren, B. 2015b. Crops, weeds and pollinators. Understanding ecological interaction for better management. Rome, FAO. (available at http:// www.fao.org/3/a-i3821e.pdf).

Anderson, P.K., Cunningham, A.A., Patel, N.G., Morales, F.J., Epstein, P.R. \& Daszak, P. 2004. Emerging infectious diseases of plants: pathogen pollution, climate change and agrotechnology drivers. Trends in Ecology and Evolution, 19(10): 535-544.

Anderson, O.R.J., Small, C.J., Croxall, J.P., Dunn, E.K., Sullivan, B.J., Yates, O. \& Black, A. 2011a. Global seabird bycatch in longline fisheries. Endangered Species Research, 14(2): 91-106.

Anderson, S.H., Kelly, D., Ladley, J.J., Molloy, S. \& Terry, J. 2011b. Cascading effects of bird functional extinction reduce pollination and plant density. Science, 331(6020): 1068-1071.

Angelini, J., Silvina, G., Taurian, T., Ibáñez, F., Tonelli, M.L., Valetti, L., Anzuay, M.S., Ludueña, L., Muñoz, V. \& Fabra, A. 2013. The effects of pesticides on bacterial nitrogen fixers in peanutgrowing area. Archives of Microbiology, 195(10-11): 683-692.

Angelopoulos, N.V., Cowx, I.G. \& Buijse, A.D. 2017. Integrated planning framework for successful river restoration projects: upscaling lessons learnt from European case studies. Environmental Science and Policy, 76: 12-22.

Angers, D.A. \& Caron, J. 1998. Plant-induced changes in soil structure: processes and feedbacks. Biogeochemistry, 42: 55-72.

AOCC. 2018 The African Orphan Crops Consortium. [Cited 26 June 2018]. http://africanorphancrops.org/

Aravanopoulos, F.A., Tollefsrud, M.M., Graudal, L., Koskela, J., Kätzel, R., Soto, A., Nagy, L. et al. 2015. Development of genetic monitoring methods for genetic conservation units of forest trees in Europe. Rome, European Forest Genetic Resources Programme (EUFORGEN), Bioversity International.

ARC (Australian Research Council). 2018. ARC Centre of Excellence for Coral Reef Studies. [Cited 7 November 2018]. https://www.coralcoe.org.au/

Archer, S.R., Andersen, E.M., Predick, K.I., Schwinning, S., Steidl, R.J. \& Woods, S.R. 2017. Woody plant encroachment: causes and consequences. In D.D. Briske, ed. Rangeland 
systems. Processes, management and challenges, pp. 25-84. Cham, Switzerland, Springer.

Aronson, J. \& Alexander, S. 2013. Ecosystem restoration is now a global priority: time to roll up our sleeves. Restoration Ecology Journal, 21: 293-296.

Arora, D.K., Saikia, R., Dwievdi, R. \& Smith, D. 2005. Current status, strategy and future prospects of microbial resource collections. Current Science, 89(3): 488-495.

Arslan, A., Cavatassi, R., Alfani, F., Mccarthy, N., Lipper, L. \& Kokwe, M. 2018. Diversification under climate variability as part of a CSA strategy in rural Zambia. The Journal of Development Studies, 54(3): 457-480.

Ascott, M.J., Gooddy, D.C., Wang, L., Stuart, M.E., Lewis, M.A., Ward, R.S. \& Binley, A.M. 2017. Global patterns of nitrate storage in the vadose zone. Nature Communications, 8: 1416.

Asfaw, T.Y. 2009. Gender, justice and livelihoods in the creation and demise of forests in north western Ethiopia's Zeghie Peninsula. The Faculty of Graduate Studies (Resource Management and Environmental Studies), University of British Columbia. (PhD dissertation)

Asfaw, S. \& Lipper, L. 2012. Economics of plant genetic resource management for adaptation to climate change: a review of selected literature. ESA Working Paper No. 12-02. Rome, FAO. (available at http:// www.fao.org/3/a-an649e.pdf).

Atangana, A., Khasa, D., Chang, S. \& Degrande, A. 2014. Major agroforestry systems of the humid tropics. In A. Atangana, D. Khasa, S. Chang \& A. Degrande, eds. Tropical agroforestry, pp. 49-93. Dordrecht, Netherlands, Springer.

Atkinson, G., Bateman, I. \& Mourato, S. 2012. Recent advances in the valuation of ecosystem services and biodiversity. Oxford Review of Economic Policy, 28(1): 22-47.

Atkinson, R., Thomas, E., Cornelius, J., Zamora, R. \& Franco, M. 2017. Fit for purpose seed supply systems for the implementation of landscape restoration under Initiative 20×20: an analysis of national seed systems in Mexico, Guatemala, Costa Rica, Colombia, Peru, Chile and Argentina. Washington, DC, WRI, Rome, Bioversity International, and Nairobi, ICRAF.
Attwood, S.J., Ranieri, J., Park, S.E., Kennedy, G. \& Smith, P. 2016. The rise of sustainable intensification, limitations of its focus, and the need for evidence. Conference Proceedings of the EcoSummit Conference. (available at https://ec.europa.eu/jrc/en/event/conference/ ecosummit-2016).

Attwood, S., Carmona, N.E., Declerck, F., Wood, S. \& Beggi, F. 2017a. Using biodiversity to provide multiple services in sustainable farming systems. In Bioversity International, ed. Mainstreaming agrobiodiversity in sustainable food systems: scientific foundations for an Agrobiodiversity Index, pp. 53-80. Rome, Bioversity International.

Attwood, S.J., Park, S., Loos, J., Phillips, M., Mills, D. \& McDougall, C. 2017b. Does sustainable intensification offer a pathway to improved food security for aquatic agricultural system-dependent communities? In I. Oborn, B. Vanlauwe, M. Phillips, R. Thomas, W. Brooijmans \& K. Atta-Krah, eds. Sustainable intensification in smallholder agriculture: an integrated systems research approach, pp. 71-87. London, Routledge.

Ausubel, J.H., Crist, D. \& Waggoner, P.E. 2010. First Census of Marine Life 2010 - Highlights of a decade of discovery. Washington, DC, Census of Marine Life International Secretariat.

Ayalew, W., King, J.M., Bruns, E. \& Rischkowsky, B. 2003. Economic evaluation of smallholder subsistence livestock production: lessons from an Ethiopian goat development program. Ecological Economics, 45(3): 473-485.

Azim, M.E. \& Little, D.C. 2006. Intensifying aquaculture production through new approaches to manipulating natural food. CAB Reviews: Perspectives in Agriculture, Veterinary Science, Nutrition and Natural Resources, 1(62).

Bacha, K., Mehari, T. \& Ashenafi, M. 1998. The microbial dynamics of 'borde' fermentation, a traditional Ethiopian fermented beverage. Ethiopian Journal of Science, 21(5): 195-205.

Badola, R. \& Hussain, S.A. 2005. Valuing ecosystems functions and empirical study on the storm protection function of Bhitorkanika mangrove ecosystem, India. Enviromental Conservation, 32(1): 85-92. 
Bailey, K.L. \& Lazarovits, G. 2003. Suppressing soilborne diseases with residue management and organic amendments. Soil and Tillage Research, 72(2): 169-180.

Bailey, R.T., Jenson, J.W. \& Olsen, A.W. 2009. Numerical modeling of atoll island hydrogeology. Ground Water, 47(2): 184-196.

Bakos, J. \& Gorda, S. 2001. Genetic resources of common carp at the Fish Culture Research Institute Szarvas, Hungary. FAO Fisheries Technical Paper No. 417. Rome, FAO.

Balian, E.V., Segers, H., Martens, K. \& Lévéque, C. 2007. The Freshwater Animal Diversity Assessment: an overview of the results. Freshwater Animal Diversity Assessment, pp. 627-637. Dordrecht, Netherlands, Springer.

Balmford, A., Beresford, J., Green, J., Naidoo, R., Walpole, M. \& Manica, A. 2009. A global perspective on trends in nature-based tourism. PLOS Biology, 7(6): e1000144.

Balon, E.K. 1995. Origin and domestication of the wild carp, Cyprinus carpio: from Roman gourmets to the swimming flowers. Aquaculture, 129: 3-48.

Balvanera, P., Quijas, S., Martín-López, B., Barrios, E., Dee, L., Isbell, F., Durance, I., White, P., Blanchard R. \& de Groot, R. 2016. The links between biodiversity and ecosystem services. In M. Potschin, R. Haines-Young, R. Fish \& R.K. Turner, eds. Handbook of ecosystem services, pp. 45-49. London, Routledge.

Balzer, P., Balzer, T., Bartley, D., Choulamany, X., Funge-Smith, S., Guttman, H., Halwart, M. et al. 2006. Use and availability of aquatic biodiversity in rice-based ecosystems of Southeast Asia. Journal of Food Composition and Analysis, 19(6-7): 765-766.

Banda, H.J. \& Paxton, R.J. 1991. Pollination of greenhouse tomatoes by bees. Acta Horticulturae, 288: 194-198.

Barak, P., Jobe, B.O., Krueger, A.R., Peterson, L.A. \& Laird, D.A. 1997. Effects of long-term soil acidification due to nitrogen fertilizer inputs in Wisconsin. Plant and Soil, 197(1): 61-69.

Barbero, R., Abatzoglou, J.T., Larkin, N.K., Kolden, C.A. \& Stocks, B. 2015. Climate change presents increased potential for very large fires in the contiguous United States. International Journal of Wildland Fire, 24(7): 892-899.
Barbier, E.B., Hacker, S.D., Kennedy, C., Koch, E.W., Stier, A.C. \& Silliman, B.R. 2011. The value of estuarine and coastal ecosystem services. Ecological Monographs, 81(2): 169-193.

Barbraud, C. \& Weimerskirch, H. 2001. Emperor penguins and climate change. Nature, 411: 183-186.

Bardgett, R.D. \& Van Der Putten, W.H. 2014 Belowground biodiversity and ecosystem functioning. Nature, 515(7528): 505-511.

Bardi, M.A.G., Gutiérrez-Oppe, E. \& Politano, R. 2011. Traditional knowledge products in Latin America and their misappropriation. Journal of Intellectual Property Law \& Practice, 6(1): 34-42.

Baró, F., Chaparro, L., Gómez-Baggethun, E., Langemeyer, J., Nowak, D.J. \& Terradas, J. 2014. Contribution of ecosystem services to air quality and climate change mitigation policies: the case of urban forests in Barcelona, Spain. Ambio, 43(4): 466-479.

Barrington, K., Chopin, T. \& Robinson, S. 2009. Integrated multi-trophic aquaculture (IMTA) in marine temperate waters. In D. Soto, ed. Integrated mariculture. A global review, pp. 7-46. FAO Fisheries and Aquaculture Technical Paper No. 529. Rome, FAO. (available at http://www.fao.org/docrep/012/ i1092e/i1092e00.htm).

Barrios, E. 2007. Soil biota, ecosystem services and land productivity. Ecological Economics, 64(2): 269-285.

Barrios, E., Valencia, V., Jonsson, M., Brauman, A., Hairiah, K., Mortimer, P.E. \& Okubo, S. 2018. Contribution of trees to the conservation of biodiversity and ecosystem services in agricultural landscapes. International Journal of Biodiversity Science, Ecosystem Services \& Management, 14(1): 1-16.

Bartley, D.M., Nguyen, T.T.T., Halwart, M. \& De Silva, S.S. 2009. Use and exchange of aquatic genetic resources in aquaculture: information relevant to access and benefit sharing. Reviews in Aquaculture, 1(3-4): 157-162

Bartley, D.M., De Graaf, G.J., Valbo-Jørgensen, J. \& Marmulla, G. 2015. Inland capture fisheries: status and data issues. Fisheries Management and Ecology, 22: 71-77.

Bartley, D.M., Leonard, N.J., Youn, S., Taylor, W.W., Baigún, C., Barlow, C., Fazio, J. et al. 2016. Moving towards effective governance of fisheries and freshwater resources. In W.W. Taylor, 
D.M. Bartley, C.I. Goddard, N.L. Leonard \& R.L. Welcomme, eds. Freshwater, fish and the future, pp. 251-280. Rome, FAO, and East Lansing, USA, Michigan State University. (available at http://www.fao.org/3/a-i5711e.pdf).

Bartomeus, I., Park, M.G., Gibbs, J., Danforth, B.N., Lakso, A.N. \& Winfree, R. 2013. Biodiversity ensures plant-pollinator phenological synchrony against climate change. Ecology Letters, 16(11): 1331-1338.

Battcock, M. \& Azam-Ali, S. 1998. Fermented fruits and vegetables: a global perspective. FAO Agricultural Services Bulletin No. 134. Rome, FAO.

Baulcombe, D., Crute, I., Davies, B., Dunwell, J., Gale, M., Jones, J., Pretty, J., Sutherland, W. \& Toulmin, C. 2009. Reaping the benefits: science and the sustainable intensification of global agriculture. London, The Royal Society.

Baum, J.K. \& Worm, B. 2009. Cascading top-down effects of changing oceanic predator abundances. Journal of Animal Ecology, 78(4): 699-714.

Bay, R.A. \& Palumbi, S.R. 2014. Multilocus adaptation associated with heat resistance in reef-building corals. Current Biology, 24: 2952-2956.

Bayala, J., Kalinganire, A., Tchoundjeu, Z., Sinclair, F. \& Garrity, D. 2011a. Conservation agriculture with trees (CAWT) in the West African Sahel: a review. Occasional Paper No. 14. Nairobi, ICRAF.

Bayala, J., Kindt, R., Belem, M. \& Kalinganire, A. $2011 \mathrm{~b}$. Factors affecting the dynamics of tree diversity in agroforestry parklands for cereal and cotton farming system in Burkina Faso. New Forest, 41(3): 281-296.

Bedford, F.E., Whittaker, R.J. \& Kerr, J.T. 2012. Systemic range shift lags among a pollinator species assemblage following rapid climate change. Botany, 90(7): 587-597.

Beech, E., Rivers, M., Oldfield, S. \& Smith, P.P. 2017. GlobalTreeSearch: the first complete global database of tree species and country distributions. Journal of Sustainable Forestry, 36(5): 454-489.

Beed, F., Benedetti, A., Cardinali, G., Chakraborty, S., Dubois, T., Garrett, K. \& Halewood, M. 2011. Climate change and micro-organism genetic resources for food and agriculture: state of knowledge, risks and opportunities. Rome,
FAO. (available at http://www.fao.org/docrep/ meeting/022/mb392e.pdf).

Beed, F., Dubois, T., Coyne, D., Lesueur, D. \& Ramasamy, S. 2017. Soil biodiversity. In D. Hunter, L. Guarino, C. Spillane \& P.C. McKeown, eds. Routledge handbook of agricultural biodiversity, pp. 127-144. London, Routledge.

Bein, E., Habte, B., Jaber, A., Birnie, A. \& Tegnas, B. 1996. Useful trees and shrubs in Eritrea. Identification, propagation and management for agricultural and pastoral communities. Nairobi, Regional Soil Conservation Unit.

Bekkevold, D., Hansen, M.M. \& Nielsen, E.E. 2006. Genetic impact of gadoid culture on wild fish populations: predictions, lessons from salmonids, and possibilities for minimizing adverse effects. ICES Journal of Marine Science, 63(2): 198-208.

Bellard, C., Bertelsmeier, C., Leadley, P., Thuiller, W. \& Courchamp, F. 2012. Impacts of climate change on the future of biodiversity. Ecology Letters, 15(4): 365-377.

Bellingham, P.J., Kardol, P., Bonner, K.I., Buxton, R.P., Morse, C.W. \& Wardle, D.A. 2016. Browsing by an invasive herbivore promotes development of plant and soil communities during primary succession. Journal of Ecology, 104(6): 1505-1517.

Benbrook, C.M. 2012. Impacts of genetically engineered crops on pesticide use in the U.S. - the first sixteen years. Environmental Sciences Europe, 24(1): 24

Bender, M.A., Knutson, T.R., Tuleya, R.E., Sirutis, J.J., Vecchi, G.A., Garner, S.T. \& Held, A.M. 2010. Modeled impact of anthropogenic warming on the frequency of intense Atlantic hurricanes. Science, 327(5964): 454-458.

Bene, J.G., Beall, H.W. \& Côte, A. 1977. Trees, food and people. Ottawa, International Development Research Centre (IDRC).

Béné, C., Steel, E., Luadia, B.K. \& Gordon, A. 2009. Fish as the "bank in the water" - Evidence from chronic-poor communities in Congo. Food Policy, 34(1): 108-118.

Bengtsson, J., Ahnström, J. \& Weibull, A.-C. 2005. The effects of organic agriculture on biodiversity and abundance: a meta-analysis. Journal of Applied Ecology, 42(2): 261-269. 
Berg, H. 2002. Rice monoculture and integrated rice-fish farming in the Mekong Delta, Vietnam -economic and ecological considerations. Ecological Economics, 41(1): 95-107.

Berg Miller, M.E., Yeoman, C.J., Chia, N., Tringe, S.G., Angly, F.E., Edwards, R.A., Flint, H.J., Lamed, R., Bayer, E.A. \& White, B.A. 2012. Phage-bacteria relationships and CRISPR elements revealed by a metagenomic survey of the rumen microbiome. Environmental Microbiology, 14(1): 207-227.

Berkes, F. 2012. Sacred ecology. New York, USA, Routledge.

Berkes, F., Folke, C. \& Gadgil, M. 1995. Traditional ecological knowledge, biodiversity, resilience and sustainability. In C.A. Perrings, K.G. Mäler, C. Folke, C.S. Holling \& B.O. Jansson, eds. Biodiversity conservation, ecology, economy \& environment, Vol 4. pp. 281-299. Dordrecht, Netherlands, Springer.

Berti, P.R. \& Jones, A.D. 2013. Biodiversity's contribution to dietary diversity: magnitude, meaning and measurement. In J. Fanzo, D. Hunter, T. Borelli \& F. Mattei, eds. Diversifying food and diets: using agricultural biodiversity to improve nutrition and health, pp. 186-206. Oxford, UK, and New York, USA, Routledge.

Berza, B. \& Wolde, A. 2014. Food processing \& technology fermenter technology modification changes microbiological and physico- chemical parameters, improves sensory characteristics in the fermentation of tella, an Ethiopian traditional fermented alcoholic beverage. Journal of Food Processing \& Technology, 5: 316.

BGCI (Botanic Gardens Conservation International).

2013. Restoring damaged ecosystems: the role of botanic gardens and the Ecological Restoration Alliance. BG Journal. Journal of Botanic Gardens Conservation International, 13(2).

BGCI. 2018. GardenSearch. [Cited 15 June 2018]. https://www.bgci.org/garden_search.php

Bhandari, P.S. 2012. Farmers perception about gains from integrated pest management farmer field school. International Journal of Agricultural Science, Research and Technology in Extension and Education Systems, 2(3): 137-142.

Bharucha, Z. \& Pretty, J. 2010. The roles and values of wild foods in agricultural systems. Philosophical
Transactions of the Royal Society B: Biological Sciences, 365(1554): 2913-2926.

Bianchi, F.J.J., Booij, C.J.H. \& Tscharntke, T. 2006. Sustainable pest regulation in agricultural landscapes: a review on landscape composition, biodiversity and natural pest control. Proceedings of the Royal Society B: Biological Sciences, 273(1595): 1715-1727.

Bienefeld, K. 2016. Breeding success or genetic diversity in honey bees? Bee World, 93: 40-44.

Bienefeld, K., Ehrhardt, K., \& Reinhardt, F. 2007. Genetic evaluation in the honey bee considering queen and worker effects-A BLUP-Animal Model approach. Apidologie, 38(1): 77-85.

Billard, R. 1986. Symbiotic integration of aquaculture and agriculture. Fisheries, 11(4): 14-19.

Binam, J.N., Place, F., Kalinganire, A., Hamade, S., Boureima, M., Tougiani, A., Dakouo, J. et al. 2015. Effects of farmer managed natural regeneration on livelihoods in semi-arid West Africa. Environmental Economics and Policy Studies, 17(4): 543-575.

BIO Intelligence Service. 2014. Soil and water in a changing environment. Final report prepared for European Commission (DG ENV). Paris.

Bioversity International. 2017. Mainstreaming agrobiodiversity in sustainable food systems: scientific foundations for an Agrobiodiversity Index. Rome.

BirdLife International. 2009. Seabirds are key indicators of the impact of climate change on the world's oceans. [Cited 11 April 2018]. http://datazone. birdlife.org/sowb/casestudy/seabirds-are-keyindicators-of-the-impact-of-climate-change-on-theworld's-oceans

BirdLife International. 2013. Crop expansion is a major threat to biodiversity in tropical countries. [Cited 30 April 2018]. http://datazone.birdlife.org/ crop-expansion-is-a-major-threat-to-biodiversity-intropical-countries

BirdLife International. 2015. Birds control insect pests in farmlands and forests. [Cited 3 May 2018]. http:// datazone.birdlife.org/sowb/casestudy/birds-controlinsect-pests-in-farmlands-and-forests

BirdLife International. 2018. State of the world's birds: taking the pulse of the planet. Cambridge, UK, BirdLife International. $41 \mathrm{pp}$. 
Blankespoor, B., Dasgupta, S. \& Lange, G.M. 2017. Mangroves as a protection from storm surges in a changing climate. Ambio, 46(7): 478-491.

Blare, T. \& Donovan, J. 2016. Building value chains for indigenous fruits: lessons from camu-camu in Peru. Renewable Agriculture and Food Systems, 33(1): 6-18.

Blitzer, E.J., Dormann, C.F., Holzschuh, A., Klein, A.M., Rand, T.A. \& Tscharntke, T. 2012. Spillover of functionally important organisms between managed and natural habitats. Agriculture, Ecosystems and Environment, 146(1): 34-43.

Blüthgen, N. \& Klein, A.M. 2011. Functional complementarity and specialisation: the role of biodiversity in plant-pollinator interactions. Basic and Applied Ecology, 12(4): 282-291.

Boa, E. 2004. Wild edible fungi. A global overview of their use and importance to people. Non-wood Forest Products 17. Rome, FAO. (available at http:// www.fao.org/3/a-y5489e.pdf).

Bodmer, R., Fang, T.G., Puertas, P.E., Antúnez, M., Chota, K. \& Bodmer, W.E. 2014. Cambio climático y fauna silvestre en la Amazonía Peruana. Impacto de la sequía e inundaciones intensas en la Reserva Nacional Pacaya Samiria, FundAmazonia/Sernanp. Lima, Wust Ediciones.

Bogne Sadeu, C., Mikolasek, O., Pouomogne, V. \& Tomedi Eyango Tabi, M. 2013. The use of wild catfish (Clarias spp.) in combination with Nile tilapia (Oreochromis niloticus L.) in western Cameroon: technical performances, interests, and limitations. Journal of Applied Aquaculture, 25(4): 359-368.

Bokulich, N.A., Lewis, Z.T., Boundy-Mills, K. \& Mills, D.A. 2016. A new perspective on microbial landscapes within food production. Current Opinion in Biotechnology, 37: 182-189.

Bolfe, L.E. \& Batistella, M. 2011. Análise florística e estrutural de sistemas silviagrícolas em Tomé-Açu, Pará Pesquisa Agropecuária Brasileira, 46(10): 1139-1147.

Bommarco, R., Kleijn, D. \& Potts, S.G. 2013. Ecological intensification: harnessing ecosystem services for food security. Trends in Ecology and Evolution, 28(4): 230-238.

Borrini-Feyerabend, G., Dudley, N., Jaeger, T., Lassen, B., Pathak Broome, N., Phillips, A. \& Sandwith, T. 2013. Governance of protected areas: from understanding to action. Gland, Switzerland, IUCN
Bosch, J. \& Kemp, W.P. 2000. Developmental biology and rearing methods for Osmia bees used as crop pollinators. In M.J. Sommeijer \& A. Ruijter, eds. Insect pollination in greenhouses, pp. 119-126. The Hague, CIP-DATA Koninklijke Bibliotheek.

Bosch, J. \& Kemp, W.P. 2002. Developing and establishing bee species as crop pollinators: the example of Osmia spp. (Hymenoptera: Megachilidae) and fruit trees. Bulletin of Entomological Research, 92: 3-16.

Bosch, J. \& Vicens, N. 2000. Pollinating efficacy of Osmia cornuta and Apis mellifera (Hymenoptera: Megachilidae, Apidae) on 'Red Delicious' apple. Environmental Entomology, 29(2): 235-240.

Bosch, J., Kemp, W.P. \& Peterson, S.S. 2000. Management of Osmia lignaria (Hymenoptera: Megachilidae) populations for almond pollination: methods to advance bee emergence. Environmental Entomology, 29(5): 874-883.

Bosch, J., Kemp, W.P. \& Trostle, G.E. 2006. Bee population returns and cherry yields in an orchard pollinated with Osmia lignaria (Hymenoptera: Megachilidae). Journal of Economic Entomology, 99(2): 408-413.

Boserup, E. 1965. The conditions of agricultural growth: the economics of agrarian change under population pressure. London, Routledge.

Bottrell, D. \& Schoenly, K. 2012. Resurrecting the ghost of green revolutions past: the brown planthopper as a recurring threat to high-yielding rice production in tropical Asia. Journal of Asia-Pacific Entomolgy, 15(1): 122-140.

Boucher, J. \& Friot, D. 2017. Primary microplastics in the oceans: a global evaluation of sources. Cambridge, UK, and Gland, Switzerland, IUCN.

Bouletreau, M. 1986. The genetic and coevolutionary interactions between parasitoids and their hosts. In J. Wagge \& D. Greathead, eds. Insect parasitoids, pp. 169-200. London, Academic Press.

Boulton, A.J., Ekebom, J. \& Gislason, G.M. 2016. Integrating ecosystem services into conservation strategies for freshwater and marine habitats: a review. Aquatic Conservation: Marine and Freshwater Ecosystems, 26: 963-985.

Bourke, R.M. \& Harwood, T., eds. 2009. Food and agriculture in Papua New Guinea. Canberra, The Australian National University Press. 
Boyd, P.W. \& Hutchins, D.A. 2012. Understanding the responses of ocean biota to a complex matrix of cumulative anthropogenic change. Marine Ecology Progress Series, 470: 125-135.

Bradbear, N. 2009. Bees and their role in forest livelihoods - A guide to the services provided by bees and the sustainable harvesting, processing and marketing of their products. Rome, FAO. (available at http://www.fao.org/3/a-i0842e.pdf).

Brandt, M., Rasmussen, K., Hiernaux, P., Herrmann, S., Tucker, C.J., Tong, X., Tian, F. et al. 2018. Reduction of tree cover in West African woodlands and promotion in semi-arid farmlands. Nature Geoscience, 11: 328-333.

Bravington, M. V., Grewe, P.M. \& Davies, C.R. 2016. Absolute abundance of southern bluefin tuna estimated by close-kin mark-recapture. Nature Communications, $7: 13162$

Bravo de Guenni, L., Cardoso, M., Goldammer, J., Hurtt, G., Mata, L.J., Ebi, K. \& Valdes, J. 2005. Regulation of natural hazards : floods and fires. In R. Hassan, R. Scholes \& N. Ash, eds. Ecosystems and human well-being: current state and trends, Volume 1, pp. 441-453. Washington, DC, Covelo and London, Island Press.

Briassoulis, D., Mistriotis, A. \& Eleftherakis, D. 2007 Mechanical behaviour and properties of agricultural nets - Part I: Testing methods for agricultural nets. Polymer Testing, 26(6): 822-832.

Bricker, S.B., Getchis, T.L., Chadwick, C.B., Rose, C.M. \& Rose, J.M. 2016. Integration of ecosystembased models into an existing interactive web-based tool for improved aquaculture decision-making. Aquaculture, 453: 135-146

Briones, M.J.I. \& Schmidt, O. 2017. Conventional tillage decreases the abundance and biomass of earthworms and alters their community structure in a global meta-analysis. Global Change Biology, 23(10): 4396-4419

Briske, D.D., ed. 2017. Rangeland systems. Processes, management and challenges. Cham, Switzerland, Springer.

British Ecological Society. 2016. Soil health: a response from the British Ecological Society to the Environmental Audit Committee. London.
Broadhurst, L., Jones, T.A., Smith, F.S., North, T. \& Guja, L. 2016. Maximizing seed resources for restoration in an uncertain future. BioScience, 66: 73-79.

Brodeur, J.C. \& Vera Candioti, J. 2017. Impacts of agriculture and pesticides on amphibian terrestrial life stages: potential biomonitor/bioindicator species for the Pampa Region of Argentina. Ecotoxicology and genotoxicology: non-traditional terrestrial models, pp. 163-194. Cambridge, UK, Royal Society of Chemistry.

Brodeur, J.C., Poliserpi, M.B., D'Andrea, M.F. \& Sánchez, M. 2014. Synergy between glyphosate- and cypermethrin-based pesticides during acute exposures in tadpoles of the common South American toad Rhinella arenarum. Chemosphere, 112: 70-76.

Broegaard, R.B., Rasmussen, L.V., Dawson, N., Mertz, O., Vongvisouk, T. \& Grogan, K. 2017. Wild food collection and nutrition under commercial agriculture expansion in agriculture-forest landscapes. Forest Policy and Economics, 84: 92-101.

Brooker, R.W., Bennett, A.E., Cong, W.F., Daniell, T.J., George, T.S., Hallett, P.D., Hawes, C. et al. 2015. Improving intercropping: a synthesis of research in agronomy, plant physiology and ecology. New Phytologist, 206(1): 107-117

Brookfield, H. 2002. Agricultural biodiversity at the landscape level. Expert review for the ELCI/UNEP BPSP initiative on: Managing Agricultural Resources for Biodiversity Conservation: A Guide to Best Practices. Montreal, Canada, Secretariat of the Convention on Biological Diversity.

Brown, M.J.F. \& Paxton, R.J. 2009. The conservation of bees: a global perspective. Apidologie, 40(3): 410-416.

Bruijnzeel, L.A. 1990. Hydrology of moist tropical forests and effects of conversion: a state of knowledge review. Paris, UNESCO International Hydrological Humid Tropics Programme.

Brunori, G., Rossi, A. \& Guidi, F. 2012. On the new social relations around and beyond food. Analysing consumers' role and action in Gruppi di Acquisto Solidali (Solidarity Purchasing Groups). Sociologia Ruralis, 52(1).

Büchler, R., Costa, C., Hatjina, F., Andonov, S. Meixner, M.D., Le Conte, Y., Uzunov, A. et al. 2014. The influence of genetic origin and its interaction with environmental effects on the 
survival of Apis mellifera L. colonies in Europe. Journal of Apicultural Research, 53(2): 205-214.

Buchmann, C. 2009. Cuban home gardens and their role in social-ecological resilience. Human Ecology, 37(6): 705

Buckles, D., Triomphe, B. \& Sain, G. 1998. Cover crops in hillside agriculture: farmer innovation with Mucuna. Ottawa, International Maize and Wheat Improvement Centre.

Buddemeier, R.W., Kleypas, J.A. \& Aranson, R.B. 2004. Coral reefs and global climate change. Potential contributions of climate change to stresses on coral reef ecosystems. Arlington, USA, Pew Center on Global Climate Change.

Bunce, R.G.H., Metzger, M.J., Jongman, R.H.G., Brandt J., De Blust, G., Elena-Rossello, R., Groom, G.B. et al. 2008. A standardized procedure for surveillance and monitoring European habitats and provision of spatial data. Landscape Ecology, 23(1): 11-25.

Bunch, R. 1999. More productivity with fewer external inputs: Central American case studies of agroecological development and their broader implications. Environment, Development and Sustainability, 1(3): 219-233.

Bundy, A., Chuenpagdee, R., Boldt, J.L., de Fatima Borges, M., Camara, M.L., Coll, M., Diallo, I. et al. 2017. Strong fisheries management and governance positively impact ecosystem status. Fish and Fisheries, 18: 412-439.

Bunting, P., Rosenqvist, A., Lucas, R.M., Rebelo, L.-M., Hilarides, L., Thomas, N., Hardy, A. et al. 2018. The Global Mangrove Watch-a new 2010 global baseline of mangrove extent. Remote Sensing, 10(10): 1669.

Burek, P., Satoh, Y., Fischer, G., Kahil, M.T., Scherzer, A., Tramberend, S., Nava, L.F. et al. 2016. Water futures and solution - fast track initiative (Final Report). IIASA Working Paper WP-16-006. Laxenburg, Austria, International Institute for Applied Systems Analysis.

Burke, L., Reyta, K., Spalding, M. \& Perry, A. 2011. Reef at risk revisited. Washington, DC, World Resources Institute.

Burlingame, B., Charrondiere, R. \& Mouille, B. 2009. Food composition is fundamental to the cross-cutting initiative on biodiversity for food and nutrition. Journal of Food Composition and Analysis, 22(5): 361-365.
Bush, M. 2018. Climate change adaptation in small island developing states. Oxford, UK, Wiley Blackwell.

Butchart, S.H.M., Collar, N.J., Stattersfield, A.J. \& Bennun, L.A. 2010. Conservation of the world's birds: the view from 2010. Foreword. In J. Del Hoyo, A. Elliott \& D. Christie, eds. Handbook of the world's birds. Volume 15, pp. 13-60. Barcelona, Spain, Lynx Edicions.

Butchart, S.H.M., Clarke, M., Smith, R.J., Sykes, R.E., Scharlemann, J.P.W., Harfoot, M., Buchanan, G.M. et al. 2015. Shortfalls and solutions for meeting national and global conservation area targets. Conservation Letters, 8(5): 329-337.

Butcher, K., Wick, A.F., Desutter, T., Chatterjee, A. \& Harmon, J. 2016. Soil salinity: a threat to global food security. Agronomy Journal, 108(6): 2189-2210.

Buytaert, W., Célleri, R., De Bièvre, B., Cisneros, F., Wyseure, G., Deckers, J. \& Hofstede, R. 2006. Human impact on the hydrology of the Andean páramos. Earth-Science Reviews, 79: 53-72.

Cabel, J.F. \& Oelofse, M. 2012. An indicator framework for assessing agroecosystem resilience. Ecology and Society, 17(1): 1-18

CABI (Centre for Agriculture and Bioscience International). 2018. Eichhornia crassipes. [Cited 6 July 2018]. www.cabi.org/isc

Calderone, N.W. 2012. Insect pollinated crops, insect pollinators and US agriculture: trend analysis of aggregate data for the period 1992-2009. PLOS ONE, 7(5).

California Rice Commission. 2015. Wildlife. [Cited 22 April 2018]. http://calrice.org/wildlife/

Calle, Z., Murgueito, E., Chará, J., Molina, C.H., Zuluaga, A.F. \& Calle, A. 2013. A strategy for scaling-up intensive silvopastoral systems in Colombia. Journal of Sustainable Forestry, 32: 677-693.

Calvo, F.J., Knapp, M., van Houten, Y.M., Hoogerbrugge, H. \& Belda, J.E. 2015. Amblyseius swirskii: what made this predatory mite such a successful biocontrol agent? Experimental and Applied Acarology, 65(4): 419-433.

Cameron, S.A., Lozier, J.D., Strange, J.P., Koch, J.B., Cordes, N., Solter, L.F. \& Griswold, T.L. 2011. Recent widespread decline of some North American bumble bees: current status and causal factors. PNAS, 108: 662-667. 
Campbell-Platt, G. 1987. Fermented foods of the world - a dictionary and guide. London, Butterworths.

Cane, J.H. 2002. Pollinating bees (Hymenoptera: Apiformes) of U.S. alfalfa compared for rates of pod and seed set. Journal of Economic Entomology, 95(1): 22-27.

Cane, J.H. 2008. A native ground-nesting bee (Nomia melanderi) sustainably managed to pollinate alfalfa across an intensively agricultural landscape. Apidologie, 39: 315-323.

Cannon, R.J.C. 1998. The implications of predicting climate change for insects pests in the UK, with emphasis on non-indigenous species. Global Change Biology, 4(7): 785-796

Cardinale, B. 2011. Biodiversity improves water quality through niche partitioning. Nature, 472: 86-89.

Carney, D., ed. 1998. Sustainable rural livelihoods : what contribution can we make? London, Department for International Development.

Carney, D., Drinkwater, M., Rusinow, T., Neefjes, K., Wanmali, S. \& Singh, N. 1999. Livelihoods approaches compared. A brief comparison of the livelihoods approaches of the UK Department for International Development (DFID), CARE, Oxfam and the United Nations Development Programme (UNDP). London, Department for International Development.

Carpenter, A.S.R., Caraco, N.F., Correll, D.L., Howarth, R.W., Sharpley, A.N. \& Smith, V.H. 1998. Nonpoint pollution of surface waters with phosphorus and nitrogen. Ecological Applications, 8(3): 559-568.

Carré, G., Roche, P., Chifflet, R., Morison, N., Bommarco, R., Harrison-Cripps, J., Krewenka, K. et al. 2009. Landscape context and habitat type as drivers of bee diversity in European annual crops. Agriculture, Ecosystems and Environment, 133(1-2): 40-47.

Carrizo, F., Smith, K.G. \& Darwall, W.R.T. 2013. Progress towards a global assessment of the status of freshwater fishes (Pisces) for the IUCN Red List: application to conservation programmes in zoos and aquariums. International Zoo Yearbook, 47(1): 46-64.

Carrizo, S.F., Lengyel, S., Kapusi, F., Szabolcs, M., Kasperidus, H.D., Scholz, M., Markovic, D. et al. 2017. Critical catchments for freshwater biodiversity conservation in Europe: identification, prioritisation and gap analysis. Journal of Applied Ecology, 54:

1209-1218.

Carvalheiro, L.G., Seymour, C.L., Veldtman, R. \& Nicolson, S.W. 2010. Pollination services decline with distance from natural habitat even in biodiversity-rich areas. Journal of Applied Ecology, 47: 810-820.

Carvalheiro, L.G., Veldtman, R., Shenkute, A.G., Tesfay, G.B., Pirk, C.W.W., Donaldson, J.S. \& Nicolson, S.W. 2011. Natural and within-farmland biodiversity enhances crop productivity. Ecology Letters, 14(3): 251-259.

Cattermoul, B., Brown, D. \& Poulain, F., eds. 2014. Fisheries and aquaculture emergency response guidance. Rome, FAO. (available at http://www.fao. org/3/a-i3432e.pdf).

Cauich, O., Quezada-Euán, J.J.G., Macias-Macias, J.O., Reyes-Oregel, V., Medina-Peralta, S. \& Parra-Tabla, V. 2004. Behavior and pollination efficiency of Nannotrigona perilampoides (Hymenoptera Meliponini) on greenhouse tomatoes (Lycopersicon esculentum) in subtropical México. Journal of Economical Entomology, 97: 475-481.

Cavendish, W. 2000. Empirical regularities in the poverty-environment relationship of rural households: evidence from Zimbabwe. World Development, 28(11): 1979-2003.

Caveness, F.A. \& Kurtz, W.B. 1993. Agroforestry adoption and risk perception by farmers in Sénégal. Agroforestry Systems, 21(1): 11-25.

CBD (Convention on Biological Diversity). 1992. Article 2. Use of terms. Montreal, Canada. (available at https://www.cbd.int/convention/text/default.shtml).

CBD. 2000a. COP 5 Decision V/6. Ecosystem approach. Fifth Meeting of the Conference of the Parties to the Convention on Biological Diversity, Nairobi, 15-26 May 2000. UNEP/CBD/COP/5/23.

CBD. 2000b. COP 5 Decision VI5. Agricultural biological diversity: review of phase I of the programme of work and adoption of a multi-year work programme. Fifth Meeting of the Conference of the Parties to the Convention on Biological Diversity, Nairobi, 15-26 May 2000. UNEP/CBD/COP/5/23

CBD. 2002. Alien species that threaten ecosystems, habitats or species. COP 6 Decision VI/23. Sixth Meeting of the Conference of the Parties to the 
Convention on Biological Diversity, The Hague, Netherlands 7-19 April 2002.UNEP/CBD/COP/6/20.

CBD. 2006. COP 8 Decision VIII/23. Agricultural biodiversity. Eighth Meeting of the Conference of the Parties to the Convention on Biological Diversity, Curitiba, Brazil, 20-31 March 2006. UNEP/CBD/COP/DECNIII/23.

CBD. 2007a. In-depth review of the application of the ecosystem approach. Subsidiary Body on Scientific, Technical and Technological Advice. Twelfth Meeting, Paris, 2-6 July 2007. UNEP/CBD/SBSTTA/12/2. (available at https://www.cbd.int/doc/meetings/sbstta/ sbstta-12/official/sbstta-12-02-en.pdf).

CBD. 2007b. In-depth review of the application of the ecosystem approach. Review of information in the third national reports. Subsidiary Body on Scientific, Technical and Technological Advice. Twelfth Meeting, Paris, 2-6 July 2007. UNEP/CBD/ SBSTTA/12/INF/1.

CBD. 2008a. COP 9 Decision IX/7. Ecosystem approach. Ninth Meeting of the Conference of the Parties to the Convention on Biological Diversity, Bonn, Germany, 19-30 May 2008. UNEP/CBD/COP/DEC/IX/7.

CBD. 2008b. COP 9 Decision IX/6. Incentive measures (Article 11). Ninth Meeting of the Conference of the Parties to the Convention on Biological Diversity, Bonn, Germany, 19-30 May 2008. UNEP/CBD/COP/DEC/IX/6.

CBD. 2010a. The Strategic Plan for Biodiversity 2011-2020 and the Aichi Biodiversity Targets. Conference of the Parties to the Convention on Biological Diversity. Tenth Meeting of the Conference of the Parties to the Convention on Biological Diversity, Nagoya, Japan, 18-29 October 2010. UNEP/CBD/COP/DEC/X/2.

CBD. 2010b. COP 10 Decision X/31. Protected areas. Tenth Meeting of the Conference of the Parties to the Convention on Biological Diversity, Nagoya, Japan, 18-29 October 2010. UNEP/CBD/COP/ DEC/X/31. (available at https://www.cbd.int/doc/ decisions/cop-10/cop-10-dec-31-en.pdf).

CBD. 2016a. The Cancun Declaration on Mainstreaming the Conservation and Sustainable Use of Biodiversity for Well-Being. Thirteenth Meeting of the Conference of the Parties to the Convention on Biological Diversity, Cancun, Mexico, 4-17 December 2016. UNEP/CBD/COP/13/24.

CBD. 2016b. Updated assessment of progress towards Aichi Biodiversity Targets 5 and 15. Conference of the Parties to the Convention on Biological Diversity. Thirteenth Meeting of the Conference of the Parties to the Convention on Biological Diversity, Cancun, Mexico, 4-17 December 2016. UNEP/CBD/COP/ 13/INF/12.

CBD. 2016C. COP 13 Decision XIII/3. Strategic actions to enhance the implementation of the Strategic Plan for Biodiversity 2011-2020 and the achievement of the Aichi Biodiversity Targets, including with respect to mainstreaming and the integration of biodiversity within and across sectors. Thirteenth Meeting of the Conference of the Parties to the Convention on Biological Diversity, Cancun, Mexico, 4-17 December 2016. CBD/COP/DEC/XIII/3.

CBD. 2018. Analysis of information contained in the interim national reports and information published in the access and benefit-sharing clearing house. Subsidiary Body on Implementation, Second Meeting, Montreal, Canada, 9-13 July 2018. CBD/SBI/2//NF/3. (available at https://www.cbd.int/doc/c/767b/a3b0/ e4934613a1a3fd1116b1c89a/sbi-02-inf-03-en.pdf).

CBS, PBL \& WUR. 2016. Compendium voor de leefomgeving. The Hague, Netherlands, Centraal Bureau voor de Statistiek, The Hague, Netherlands, Plambureau voor de Leefomgeving, and Wageningen, Netherlands, Wageningen University \& Research.

CBD Secretariat. 2006. Global Biodiversity Outlook 2. Montreal, Canada.

CBD Secretariat. 2007. An exploration of tools and methodologies for valuation of biodiversity and biodiversity resources and functions. Technical Series No. 28. Montreal, Canada.

CBD Secretariat. 2009. Scientific synthesis of the impacts of ocean acidification on marine biodiversity. Technical Series No. 46. Montreal, Canada.

CBD Secretariat. 2010. Global Biodiversity Outlook 3. Montreal, Canada.

CBD Secretariat. 2014a. Global Biodiversity Outlook 4. Montreal, Canada.

CBD Secretariat. 2014b. Resourcing the Aichi Biodiversity Targets: an assessment of benefits, investments and resource needs for implementing the Strategic Plan for Biodiversity 2011-2020. Second Report of the High-Level Panel on Global Assessment of Resources for Implementing the Strategic Plan for Biodiversity 2011-2020. Montreal, Canada. 
Cesar, H.J.S., Burke, L. \& Pet-Soede, L. 2003. The economics of worldwide coral reef degradation. Arnhem, Netherlands, Cesar Environmental Consulting, and Zeist, Netherlands, WWF-Netherlands.

Ceulemans, T., Stevens, C.J., Duchateau, L., Jacquemyn, H., Gowing, D.J.G., Merckx, R., Wallace, H. et al. 2014. Soil phosphorus constrains biodiversity across European grasslands. Global Change Biology, 20(12): 3814-3822.

Cezar, R.M., Vezzani, F.M., Schwiderke, D.K., Gaiad, S., Brown, G.G., Sícoli Seoane, C.E. \& Maranhão Froufe, L.C. 2015. Soil biological properties in multistrata successional agroforestry systems and in natural regeneration. Agroforestry Systems, 89(6): 1035-1047.

CGIAR. 2016. Climate-smart agriculture guide. [Cited 14 May 2018]. https://csa.guide/

Chabi-Olaye, A., Nolte, C., Schulthess, F. \& Borgemeister, C. 2007. Short-term effects of cover crops on stem borers and maize yield in the humid forest of southern Cameroon. In A. Bationo, B. Waswa, J. Kihara \& J. Kimetu, eds. Advances in integrated soil fertility management in sub-Saharan Africa: challenges and opportunities, pp. 195-200. Dordrecht, Netherlands, Springer.

Chae, Y. \& An, Y.J. 2018. Current research trends on plastic pollution and ecological impacts on the soil ecosystem: a review. Environmental Pollution, 240: 387-395.

Chagnon, M., Kreutzweiser, D., Mitchell, E.A.D., Morrissey, C.A., Noome, D.A. \& Van Der Sluijs, J.P. 2015. Risks of large-scale use of systemic insecticides to ecosystem functioning and services. Environmental Science and Pollution Research, 22(1): 119-134.

Chakravarti, L.J., Beltran, V.H. \& van Oppen, M.J.H. 2017. Rapid thermal adaptation in photosymbionts of reef-building corals. Global Change Biology, 23: 4675-4688.

Chama, L. \& Siachoono, S. 2015. Effectiveness of birds, butterflies, dragonflies, damselflies and invertebrates as indicators of freshwater ecological integrity. Geophysical Research, 17: 2015EGUGA..1713383C.

Chambers, R. \& Conway, G. 1991. Sustainable rural livelihoods: practical concepts for the 21st century. IDS Discussion Paper, 296. Brighton, UK, Institute of Development Studies.
Chambers, P.A., Lacoul, P., Murphy, K.J. \& Thomaz, S.M. 2008. Global diversity of aquatic macrophytes in freshwater. Hydrobiologia, 595(1): 9-26.

Chan, W.Y., Peplow, L.M., Menendez, P., Hoffmann, A.A. \& van Oppen, M.J.H. 2018. Interspecific hybridization provides novel opportunities for coral reef restoration. Frontiers in Marine Science, 5(May): article 160.

Chandler, D., Bailey, A.S., Tatchell, G.M., Davidson, G., Greaves, J. \& Grant, W.P. 2011. The development, regulation and use of biopesticides for integrated pest management. Philosophical Transactions of the Royal Society B: Biological Sciences, 366(1573): 1987-1998.

Chandler, M., See, L., Copas, K., Bonde, A.M.Z., López, B.C., Danielsen, F., Legind, J.K. et al. 2017. Contribution of citizen science towards international biodiversity monitoring. Biological Conservation, 213: 280-294.

Chapman, A.D. 2009. Numbers of living species in Australia and the world. 2nd edition. Canberra, Australian Biological Resources Study.

Chará, J., Reyes, E., Peri, P., Otte, J., Arce, E. \& Schneider, F. 2018. Silvopastoral systems and their contribution to improved resource use and sustainable development goals: evidence from Latin America. Cali, Colombia, Centre for Research on Sustainable Agriculture (CIPAV), agri benchmark and FAO.

Charles, A., Westlund, L., Bartley, D.M., Fletcher, W.J., Garcia, S., Govan, H. \& Sanders, J. 2016. Fishing livelihoods as key to marine protected areas: insights from the World Parks Congress. Aquatic Conservation: Marine and Freshwater Ecosystems, 26(February): 165-184.

Chatzipavlidis, I., Kefalogianni, I., Venieraki, A. \& Holzapfel, W. 2013. Status and trends of the conservation and sustainable use of microorganisms in agroindustrial processes. Commission on Genetic Resource for Food and Agriculture. Background Study Paper No. 64. Rome, FAO. (available at http:// www.fao.org/docrep/meeting/028/mg339e.pdf).

Chavan, S.B., Keerthika, A., Dhyani, S.K., Handa, A.K., Newaj, R. \& Rajarajan, K. 2015. National Agroforestry Policy in India: a low hanging fruit. Current Science, 108(10): 1826-1834. 
Chazdon, R.L., Brancalion, P.H., Laestadius, L., Bennett-Curry, A., Buckingham, K., Kumar, C., Moll-Rocek, J., Vieira, I.C.G. \& Wilson, S.J. 2016. When is a forest a forest? Forest concepts and definitions in the era of forest and landscape restoration. Ambio, 45: 538-550.

Chee, Y. 2004. An ecological perspective on the valuation of ecosystem services. Biological Conservation, 120(4): 549-565.

Chen, H. \& Yada, R. 2011. Nanotechnologies in agriculture: new tools for sustainable development. Trends in Food Science \& Technology, 22(11): 585-594.

Chen, R., Ye, C., Cai, Y., Xing, X. \& Chen, Q. 2014. The impact of rural out-migration on land use transition in China: past, present and trend. Land Use Policy, 40: 101-110.

Chen, S., Wang, W., Xu, W., Wang, Y., Wan, H., Chen, D., Tang, Z. et al. 2018. Plant diversity enhances productivity and soil carbon storage. Proceedings of the National Academy of Sciences of the United States of America, 115(16): 4027-4032.

Chin, A., Lison De Loma, T., Reytar, K., Planes, S., Gerhardt, K., Clua, E., Burke, L. \& Wilkinson, C. 2011. Status of coral reefs of the Pacific and outlook: 2011. Global Coral Reef Monitoring Network. Publishers Global Coral Reef Monitoring Network. 260 P. (available at https://www.icriforum. org/sites/default/files/Pacific-Coral-Reefs-2011.pdf).

Chopin, T. \& Robinson, S.M.C. 2004. Defining the appropriate regulatory and policy framework for the development of integrated multi-trophic aquaculture practices: introduction to the workshop and positioning of the issues. Bulletin-Aquaculture Association of Canada, 104(3): 4-10.

Chopin, T., Buschmann, A.H., Halling, C., Troell, M., Kautsky, N., Neori, A., Kraemer, G.P. et al. 2001. Integrating seaweeds into marine aquaculture systems: a key toward sustainability. Journal of Phycology, 37(6): 975-986.

Chornesky, E.A., Bartuska, A.M., Aplet, G.H., Britton, K.O., Cummings-Carlson, J., Davis, F.W., Eskow, J. et al. 2005. Science priorities for reducing the threat of invasive species to sustainable forestry. Bioscience, 55(4): 335-348.
Christenhusz, M.J.M. \& Byng, J.W. 2016. The number of known plants species in the world and its annual increase. Phytotaxa, 261(3): 201-217.

Christmann, S. \& Aw-Hassan, A.A. 2012. Farming with alternative pollinators (FAP) - an overlooked win-winstrategy for climate change adaptation. Agriculture, Ecosystems \& Environment, 161: 161-164.

Chytrý, M., Maskell, L.C., Pino, J., Pyšek, P., Vilà, M., Font, X. \& Smart, S.M. 2008. Habitat invasions by alien plants: a quantitative comparison among Mediterranean, subcontinental and oceanic regions of Europe. Journal of Applied Ecology, 45(2): 448-458.

Cilas, C., Goebel, F.R., Babin, R. \& Avelino, J. 2016. Tropical crop pests and diseases in a climate change setting - A few examples. In E. Torquebiau, ed. Climate change and agriculture worldwide, pp. 73-82. Dordrecht, Netherlands, Springer.

Civitello, D.J., Cohen, J., Fatima, H., Halstead, N.T. Liriano, J., McMahon, T.A., Ortega, C.N. et al. 2015. Biodiversity inhibits parasites: broad evidence for the dilution effect. Proceedings of the National Academy of Sciences, 112(28): 8667-8671.

Clapperton, M.J., Chan, K.Y. \& Larney, F.J. 2007 Managing the soil habitat for enhanced biological fertility. In L.K. Abbott \& D.V Murphy, eds. Soil biological fertility. A key to sustainable land use in agriculture, pp. 203-224. Dordrecht, Netherlands, Springer Netherlands.

Cleveland, D.A., Phares, N., Nightingale, K.D., Weatherby, R.L., Radis, W., Ballard, J., Campagna, M. et al. 2017. The potential for urban household vegetable gardens to reduce greenhouse gas emissions. Landscape and Urban Planning, 157: 365-374.

Cline, H. 2005. Sacramento Vallely rice growers winter flood, ducks keep coming. [Cited 22 April 2018] http://www.westernfarmpress.com/sacramentovallely-rice-growers-winter-flood-ducks-keep-coming

Coad, L., Fa, J.E., Van Vliet, N., Abernethy, K., Santamaria, C., Wilkie, D., Cawthorn, D. \& Nasi, R. 2017. Towards a sustainable, participatory and inclusive wild meat sector. Draft Technical Report. Twenty-first meeting of the Subsidiary Body on Scientific, Technical and Technological Advice. Montreal, Canada, 11-14 December 2017. UNEP/CBD/SBSTTA/21/INF/6. 
Cochrane, K., De Young, C., Soto, D. \& Bahri, T., eds. 2009. Climate change implications for fisheries and aquaculture. Overview of current scientific knowledge. FAO Fisheries and Aquaculture Technical Paper No. 530. Rome, FAO. (available at http://www. fao.org/docrep/012/i0994e/i0994e00.htm).

Cock, M.J.W., van Lanteren, J.C., Brodeur, J., Barrat, B.I.P., Bigler, F., Blockmans, K., Cônsoli, A., Haas, F., Mason, P.G. \& Parra, J.R.P. 2009. The use and exchange of biological control agents for food and agriculture. Commission on Genetic Resources for Food and Agriculture. Background Study Paper No. 47. Rome, FAO. (available at http://www.fao.org/ tempref/docrep/fao/meeting/017/ak569e.pdf).

Cock, M.J.W., Biesmeijer, J.C., Cannon, R.J.C., Gerard, P.J., Gillespie, D., Jiménez, J.J., Lavelle, P.M. \& Raina, S.K. 2011. Climate change and invertebrate genetic resources for food and agriculture: state of knowledge, risks and opportunities. Commission on Genetic Resources for Food and Agriculure. Background Study Paper No. 54. Rome, FAO. (available at http://www.fao.org/docrep/ meeting/022/mb390e.pdf).

Cock, M.J.W., Biesmeijer, J.C., Cannon, R.J.C., Gerard, P.J., Gillespie, D., Jimeez, J.J., Lavelle, P.M. \& Raina, S.K. 2012. The positive contribution of invertebrates to sustainable agriculture and food security. CAB Reviews, 7(043): 1-27.

Coe, R., Sinclair, F. \& Barrios, E. 2014. Scaling up agroforestry requires research "in" rather than "for" development. Current Opinion in Environmental Sustainability, 6(1): 73-77.

Coe, R., Hughes, K., Sola, P. \& Sinclair, F. 2017. Planned comparisons demystified. ICRAF Working Paper No. 263. Nairobi, ICRAF.

Cole, L., Bradford, M.A., Shaw, P.J.A. \& Bardgett, R.D. 2006. The abundance, richness and functional role of soil meso- and macrofauna in temperate grassland-A case study. Applied Soil Ecology, 33(2): 186-198.

Coles, R.G., McKenzie, L.J., Rasheed, M.A., Mellors, J.E., Taylor, H., Dew, K., McKenna, S., Sankey, T.L., Carter, A.B. \& Grech, A. 2007. Status and trends of seagrass habitats in the Great Barrier Reef World Heritage Area. Cairns, Australia, Department of Primary Industries and Fisheries.
Colfer, C.J.P., Catacutan, D., Naz, F. \& Pottinger, A.J. 2016. Gender in agroforestry [Special Issue] International Forestry Review on Gender in Agroforestry, 17(4).

Colfer, C.J.P., Sheil, D. \& Kishi, M. 2006. Forests and human health: assessing the evidence. CIFOR Occasional Paper No. 45. Bogor, Indonesia, Center for International Forestry Research.

Colla, S.R., Otterstatter, M.C., Gegear, R.J. \& Thomson, J.D. 2006. Plight of the bumble bee: pathogen spillover from commercial to wild populations. Biological Conservation, 129(4): 461-467.

Collen, B., Böhm, M., Kemp, R. \& Baillie, J.E.M. 2012. Spineless: status and trends of the world's invertebrates. London, Zoological Society of London.

Comité Asesor Nacional sobre Especies Invasoras. 2010. Estrategia nacional sobre especies invasoras en México, prevención, control y erradicación. Mexico City, Comisión Nacional para el Conocimiento y Uso de la Biodiversidad, Comisión Nacional de Áreas Protegidas, Secretaría de Medio Ambiente y Recursos Naturales.

Committee on the Peaceful Uses of Outer Space. 2015. Space technologies for monitoring and protecting biodiversity and ecosystems. A proposed new thematic priority for the United Nations Programme on Space Applications. Committee on the Peaceful Uses of Outer Space. Fifty-eighth Session, Vienna, Austria, 10-19 June 2015. AVAC. 105/2015/CRP.10.

Compant, S., Clément, C. \& Sessitsch, A. 2010. Plant growth-promoting bacteria in the rhizo-and endosphere of plants: their role, colonization, mechanisms involved and prospects for utilization. Soil Biology and Biochemistry, 42: 669-678.

Concenço, G., Marques, R.F., Santos, S.A., Correia, I.V.T., Palharini, W.G., Alves, M.S., Melo, T.S., Xavier, L.B. \& Linhares, L.T. 2015. Integration croplivestock: is it efficient in suppressing troublesome weeds? A case study. African Journal of Agricultural Research, 10(16): 1882-1890.

Conde, D.A., Flesness, N., Colchero, F., Jones, O.R. \& Scheuerlein, A. 2011. An emerging role of zoos to conserve biodiversity. Science, 331(6023): 1390-1391.

Coomes, O.T., Barham, B.L. \& Takasaki, Y. 2004. Targeting conservation-development initiatives in tropical forests: insights from analyses of rain forest 
use and economic reliance among Amazonian peasants. Ecological Economics, 51(1-2): 47-64.

Cordillot, F. \& Klaus, G. 2011. Threatened species in Switzerland. Red List Synthesis Report, Status 2010. Bern, Federal Office for the Environment.

Cornelius, J.P. \& Miccolis, A. 2018. Can market-based agroforestry germplasm supply systems meet the needs of forest landscape restoration? New Forests: 49(4): 457-469.

Cortopassi-Laurino, M., Imperatriz-Fonseca, V.L., Roubik, W., Dollin, A., Heard, T., Aguilar, I., Venturieri, G.C., Eardley, C. \& Nogueira-Neto, P. 2006. Global meliponiculture: challenges and opportunities. Apidologie, 37: 275-292.

Costanza, R., D'Arge, R., De Groot, R., Farber, S., Grasso, M., Hannon, B., Limburg, K. et al. 1997. The value of the world's ecosystem services and natural capital. Nature, 387(6630): 253-260.

Costanza, R., de Groot, R., Sutton, P., van der Ploeg, S., Anderson, S.J., Kubiszewski, I., Farber, S. \& Turner, R.K. 2014. Changes in the global value of ecosystem services. Global Environmental Change, 26(1): 152-158.

Costanzo, A. \& Bàrberi, P. 2013. Functional agrobiodiversity and agroecosystem services in sustainable wheat production. A review. Agronomy for Sustainable Development, 34(2): 327-348.

Cotta, J.N. 2017. Revisiting Bora fallow agroforestry in the Peruvian Amazon: enriching ethnobotanical appraisals of non-timber products through household income quantification. Agroforestry Systems, 9(1): 17-36.

Coulibaly-Lingani, P., Tigabu, M., Savadogo, P., Oden, P.C. \& Ouadba, J.M. 2009. Determinants of access to forest products in southern Burkina Faso. Forest Policy and Economics, 11(7): 516-524.

Crane, E. 1983. The archaeology of beekeeping. Ithaca, USA, Cornell University Press.

Crane, E. 1999. The world history of beekeeping and honey hunting. London, Duckworth.

Creamer, R.E., Hannula, S.E., Leeuwen, J.P.V., Stone, D., Rutgers, M., Schmelz, R.M., de Ruiter, P.C. et al. 2016. Ecological network analysis reveals the inter-connection between soil biodiversity and ecosystem function as affected by land use across Europe. Applied Soil Ecology, 97: 112-124.
Creevey, C.J., Kelly, W.J., Henderson, G. \& Leahy, S.C. 2014. Determining the culturability of the rumen bacterial microbiome. Microbial Biotechnology, 7: 467-479.

Cronk, Q. \& Ojeda, I. 2008. Bird-pollinated flowers in an evolutionary and molecular context. Journal of Experimental Botany, 59(5): 715-727.

Croxall, J.P., Prince, P.A., Rothery, P. \& Wood, A.G. 1998. Population changes in albatrosses at South Georgia. In G. Robertson \& R. Gales, eds. Albatross biology and conservation, pp. 69-83. Chipping Norton, Australia, Surrey Beatty \& Sons.

Crush, J. 2014. Approaching food security in cities of the global south. In S. Parnell \& S. Oldfield, eds. The Routledge handbook on cities of the global south, pp. 543-555. London, Taylor and Francis.

Cunningham, S.A., Attwood, S.J., Bawa, K.S., Benton, T.G., Broadhurst, L.M., Didham, R.K., McIntyre, S. et al. 2013. To close the yield-gap while saving biodiversity will require multiple locally relevant strategies. Agriculture, Ecosystems and Environment, 173: 20-27.

Cuttelod, A., Seddon, M. \& Neubert, E. 2011. European Red List of non-marine molluscs. Luxembourg, European Commission, Publications Office of the European Union.

Dabbadie, L. 1996. Étude de la viabilité d'une pisciculture rurale à faible niveau d'intrant dans le Centre-Ouest de la Côte d'Ivoire : approche du réseau trophique. University Pierre et Marie Curie - Paris VI.

Dabbadie, L. \& Mikolasek, O. 2015. Aquaculture systems \& farming systems: inside, outside or side-byside? The 5th International Symposium for Farming Systems Design "Multi-functional farming systems in a changing world", 7-10 September 2015, Le Corum Conference Center, Montpellier, France.

Dalgaard, T., Hutchings, N.J. \& Porter, J.R. 2003. Agroecology, scaling and interdisciplinarity. Agriculture, Ecosystems \& Environment, 100: 39-51.

Damgaard, C., Strandberg, B., Dupont, Y., Holmstrup, M. \& Krogh, P.H. 2016. The effect of glyphosate and nitrogen on plant communities and the soil fauna in terrestrial biotopes at field margins. Pesticide Research No. 163. Copenhagen, The Danish Environmental Protection Agency. 
Damjanovic, K., Blackall, L.L., Webster, N.S. \& van Oppen, M.J.H. 2017. The contribution of microbial biotechnology to mitigating coral reef degradation. Microbial Biotechnology, 10: 1236-1243.

Daniels, S., Witters, N., Beliën, T., Vrancken, K., Vangronsveld, J. \& Van Passel, S. 2017. Monetary valuation of natural predators for biological pest control in pear production. Ecological Economics, 134: 160-173.

Darnhofer, I. 2014. Resilience and why it matters for farm management. European Review of Agricultural Economics, 41(3): 461-484.

Darnhofer, I., Bellon, S., Dedieu, B. \& Milestad, R. 2010. Adaptiveness to enhance the sustainability of farming systems: a review. Agronomy for Sustainable Development, 30(3): 545-555.

Daru, B.H., Yessoufou, K., Mankga, L.T. \& Davies, T.J. 2013. A global trend towards the loss of evolutionarily unique species in mangrove ecosystems. PLOS ONE, 8(6): e66686.

Darwall, W.R.T., Smith, K.G., Allen, D.J., Holland, R.A., Harrison, I.J. \& Brooks, E.G.E. 2011. The diversity of life in African freshwaters: under water, under threat. An analysis of the status and distribution of freshwater species throughout mainland Africa. Cambridge, UK, and Gland, Switzerland, IUCN.

Dastager, S.G. 2009. Aroma compounds. In P. Singh nee' Nigam \& A. Pandey, eds. Biotechnology for agroindustrial residues utilisation, pp. 105-127. Dordrecht, Netherlands, Springer \& Business Media B.V.

Davidson, N.C. 2014. How much wetland has the world lost? Long-term and recent trends in global wetland area. Marine and Freshwater Research, 65(10): 934-941.

Davidson, N.C. \& Finlayson, C.M. 2018. Extent, regional distribution and changes in area of different classes of wetland. Marine and Freshwater Research, 69(10): 1525-1533.

Davies, J., Niamir-Fuller, M., Kerven, C., Bauer, K., Steinfeld, H., Mooney, H.A., Schneider, F. \& Neville, L.E. 2010. Extensive livestock production in transition: the future of sustainable pastoralism. Livestock in a changing landscape, Volume 1: Drivers, consequences and responses, pp. 285-308. Washington, DC, Island Press.
Davies, J., Poulsen, L., Schulte-Herbrüggen, B., Mackinnon, K., Crawhall, N., Henwood, W.D., Dudley, N., Smith, J. \& Gudka, M. 2012. Conserving dryland biodiversity. Nairobi, Drylands Initiative, IUCN.

Davis, J.R. 2006. How can the poor benefit from the growing markets for high value agricultural products? Chatham, UK, Natural Resources Institute. (available at http://www.fao.org/docs/eims/ upload/210971/global_issues_paper.pdf).

Davis, A.S., Hill, J.D., Chase, C.A., Johanns, A.M. \& Liebman, M. 2012. Increasing cropping system diversity balances productivity, profitability and environmental health. PLOS ONE, 7(10): 1-8.

Dawson, I.K., Carsan, S., Franzel, S., Kindt, R., Graudal, L., Orwa, C. \& Jamnadass, R. 2014. Agroforestry, livestock, fodder production and climate change adaptation and mitigation in East Africa: issues and options. ICRAF Working Paper No. 178. Nairobi, The World Agroforestry Centre.

Dawson, I.K., Attwood, S.J., Park, S.E., Jamnadass, R., Powell, W., Sunderland, T., Kindt, R. et al. 2018a. Contributions of biodiversity to the sustainable intensification of food production. Thematic study prepared for The State of the World's Biodiversity for Food and Agriculture. Rome.

Dawson, I.K., Hendre, P., Powell, W., Sila, D., McMullin, S., Revoredo-Giha, C., Odeny, D.A. et al. 2018b. Supporting human nutrition in Africa through the integration of new and orphan crops into food systems: placing the work of the African Orphan Crops Consortium in context. ICRAF Working Paper No. 276. Nairobi, World Agroforestry Centre.

de Boer, I.J.M., Cederberg, C., Eady, S., Gollnow, S., Kristensen, T., Macleod, M., Meul, M. et al. 2011. Greenhouse gas mitigation in animal production: towards an integrated life cycle sustainability assessment. Current Opinion in Environmental Sustainability, 3(5): 423-431.

De Clercq, P., Mason, P.G. \& Babendreier, D. 2011 Benefits and risks of exotic biological control agents. BioControl, 56(4): 681-698.

DEFRA (Department for Environment, Food \& Rural Affairs). 2014. The National Pollinator Strategy: for bees and other pollinators in England. Bristol, UK.

DEFRA. 2017. Wild bird populations in the UK, 1970 to 2016. York, UK. 
Degrande, A., Tchoundjeu, Z., Kwidja, A. \& Fongang

Fouepe, G. 2015. Rural resource centres: a community approach to extension. GFRAS Good

Practice Notes for Extension and Advisory Services. Lindan, Switzerland, GFRAS

De Groot, M. 2014. The natural way forward. Government vision 2014. The Hague, Netherlands, Ministry of Economic Affairs.

Delaplane, K.S. \& Mayer, D.R. 2000. Crop pollination by bees. Wallingford, UK, CABI.

Del Monaco, C., Narciso, S., Frank, A., Gimenez, E. \& Bustillos, F. 2010. Evaluación de las comunidades de corales y peces de algunos arrecifes de la isla La Tortuga y cayos adyacentes, Venezuela. Boletin del Centro de Investigaciones Biológicas, 44(3): 353-376.

den Herder, M., Burgess, P., Mosquera-Losada, M.R., Herzog, F., Hartel, T., Upson, M., Viholainen, I. \& Rosati, A. 2015. Preliminary stratification and quantification of agroforestry in Europe. Milestone Report 1.1 for EU FP7 AGFORWARD Research Project (613520). 55 pp. (available at https://agforward.eu/index.php/en/preliminarystratification-and-quantification-of-agroforestryin-europe.html?file=files/agforward/documents/ M1_Stratification of agroforestry.pdf).

Department of Standards Malaysia. 2017. Kelulut (Stingless bee) honey - Specification. Malaysian Standard MS 2683:2017. Selangor Darul Ehsan, Malaysia, Department of Standards Malaysia.

De Souza Machado, A.A., Lau, C.W., Till, J., Kloas, W., Lehmann, A., Becker, R. \& Rillig, M.C. 2018. Impacts of microplastics on the soil biophysical environment. Environmental Science \& Technology, 52(17): 9656-9665.

De Sy, V., Herold, M., Achard, F., Beuchle, R., Clevers, J.G.P.W., Lindquist, E. \& Verchot, L. 2015. Land use patterns and related carbon losses following deforestation in South America. Environmental Research Letters, 10(12).

Devendra, C. \& Ibrahim, M. 2004. Silvopastoral systems as a strategy for diversification and productivity enhancement from livestock in the tropics. In C.L. Mannet, M. Ramirez, M. Ibrahim, C. Sandoval \& J. Ku, eds. The importace of silvopastoral systems in rural livelihoods to provide ecosystem services. Second
International Symposium of Silvopastoral Systems, Universidad Autónoma de Yucatán, Mérida. pp. 8-22.

de Vries, F.T. \& Bardgett, R.D. 2012. Plant-microbial linkages and ecosystem nitrogen retention: lessons for sustainable agriculture. Frontiers in Ecology and the Environment, 10(8): 425-432.

de Vries, S.M.G., Alan, M., Bozzano, M., Burianek, V., Collin, E., Cottrell, J., Ivankovic, M. et al. 2015. Pan-European strategy for genetic conservation of forest trees and establishment of a core network of dynamic conservation units. Bonn, Germany, European Forest Genetic Resources Programme (EUFORGEN), and Rome, Bioversity International.

DGEC (Director General of Estate Crops). 2012. Commodities data. Jakarta, Director General of Estate Crops, Department of Agriculture, Government of Indonesia.

D'Hose, T., Molendijk, L., Vooren, L. Van, van den Berg, W., Hoek, H., Runia, W., van Evert, F. et al. 2018. Responses of soil biota to non-inversion tillage and organic amendments: an analysis on European multiyear field experiments. Pedobiologia, 66: 18-28.

Diallo, A. 1998. Integrated farming: a new approach in Basse Casamanche, Senegal. In J.A. Mathias, A.T. Charles \& B.T. Hu, eds. Integrated fish farming. Proceedings of Workshop on Integrated Fish Farming, 11-15 October 1994, Wuxi, Jiangsu Province, P.R. China, pp. 257-264. Boca Raton, USA, CRC Press.

Diaz, S., Quetier, F., Caceres, D.M., Trainor, S.F., Perez-Harguindeguy, N., Bret-Harte, M.S., Finegan, B., Pena-Claros, M. \& Poorter, L. 2011. Linking functional diversity and social actor strategies in a framework for interdisciplinary analysis of nature's benefits to society. Proceedings of the National Academy of Sciences, 108(3): 895-902.

Di Bella, C.E., Jacobo, E., Golluscio, R.A. \& Rodríguez, A.M. 2014. Effect of cattle grazing on soil salinity and vegetation composition along an elevation gradient in a temperate coastal salt marsh of Samborombón Bay (Argentina). Wetlands Ecology and Management, 22(1): 1-13.

Di Falco, S. \& Chavas, J.P. 2009. On crop biodiversity, risk exposure, and food security in the highlands of Ethiopia. American Journal of Agricultural Economics, 91(3): 599-611. 
Dijkstra, J., Oenema, O. \& Bannink, A. 2011. Dietary strategies to reducing $\mathrm{N}$ excretion from cattle: implications for methane emissions. Current Opinion in Environmental Sustainability, 3(5): 414-422.

Dixon, G.B., Davies, S.W., Aglyamova, G.A., Meyer, E., Bay, L.K. \& Matz, M. V. 2015. Genomic determinants of coral heat tolerance across latitudes. Science, 348: 1460-1462.

Dolan, C. \& Humphrey, J. 2000. Governance and trade in fresh vegetables: the impact of UK supermarkets on the African horticulture industry. Journal of Development Studies, 37(2).

Dominik, C., Seppelt, R., Horgan, F.G., Marquez, L., Settele, J. \& Václavík, T. 2017. Regional-scale effects override the influence of fine-scale landscape heterogeneity on rice arthropod communities. Agriculture Ecosystems and Environment, 246: 269-278.

Donald, P.F., Green, R.E. \& Heath, M.F. 2001. Agricultural intensification and the collapse of Europe's farmland bird populations. Proceedings of the Royal Society B: Biological Sciences, 268: 25-29.

Donald, P.F., Sanderson, F.J., Burfield, I.J. \& van Bommel, F.P.J. 2006. Further evidence of continentwide impacts of agricultural intensification on European farmland birds, 1990-2000. Agriculture Ecosystems and Environment, 116: 189-196.

Donato, D.C., Kauffman, J.B., Murdiyarso, D., Kurnianto, S., Stidham, M. \& Kanninen, M. 2011b. Mangroves among the most carbon-rich forests in the tropics. Nature Geoscience, 4(5): 293-297.

Donovan, J., Blare, T. \& Poole, N. 2017. Stuck in a rut: emerging cocoa cooperatives in Peru and the factors that influence their performance. International Journal of Agricultural Sustainability, 15(2): 169-184.

Döring, T.F., Annicchiarico, P., Clarke, S., Haigh, Z., Jones, H.E., Pearce, H., Snape, J., Zhan, J. \& Wolfe, M.S. 2015. Comparative analysis of performance and stability among composite cross populations, variety mixtures and pure lines of winter wheat in organic and conventional cropping systems. Field Crops Research, 183: 235-245.

dos Santos, H.F., Duarte, G.A.S., Da Costa Rachid, C.T., Moreira Chaloub, R., Calderon, E.N., De Barros Marangoni, L.F., Bianchini, A. et al. 2015. Impact of oil spills on coral reefs can be reduced by bioremediation using probiotic microbiota. Scientific Reports, 5: 18268.

Doswald, N. \& Estrella, M. 2015. Promoting ecosystems for disaster risk reduction and climate change adaptation: opportunities for integration. Discussion Paper UN Environment. Geneva, Switzerland, UN Environment Post-conflict and Disaster Management Branch.

Dreisigacker, S., Kishii, M., Lage, J. \& Warburton, M. 2008. Use of synthetic hexaploid wheat to increase diversity for CIMMYT bread wheat improvement. Australian Journal of Agricultural Research, 59(5): 413-420.

Duarte, C.M. 2017. Reviews and syntheses: hidden forests, the role of vegetated coastal habitats in the ocean carbon budget, Biogeosciences, 14: 301-310.

Duarte, C.M., Marbà, N. \& Holmer, M. 2007. Rapid domestication of marine species. Science, 316 : 382-383.

Duarte, C.M., Borum, J., Short, F.T. \& Walker, D.I. 2008 Seagrass ecosystems: their global status and prospects In N. Polunin, ed. Aquatic ecosystems, pp. 281-306. Cambridge, UK, Cambridge University Press.

Dubinsky, Z. \& Stambler, N., eds. 2011. Coral reefs: and ecosystem in transition. Dordrecht, Netherlands, Springer.

Dudgeon, D. 2012. Threats to freshwater biodiversity globally and in the Indo-Burma biodiversity hotspot. In D.J. Allen, K.G. Smith \& W.R.T. Darwall, eds. The Status and distribution of freshwater biodiversity in Indo-Burma, pp. 1-28. Cambridge, UK, and Gland, Switzerland, IUCN.

Dudley, N., ed. 2008. Guidelines for applying Protected Area Management Categories. Gland, Switzerland, IUCN.

Dudley, N. \& Maginnis, S. 2018. Stepwise approach to increasing ecological complexity in forest landscape restoration. Ecological Restoration, 36(3): 174-176.

Dudley, N. \& Stolton, S. 2003. Running pure: the importance of forest protected areas to drinking water. Gland, Switzerland, World BankMWF Alliance for Forest Conservation and Sustainable Use.

Dudley, N., MacKinnon, K. \& Stolton, S. 2014. The role of protected areas in supplying ten critical ecosystem services in drylands: a review. Biodiversity, 15(2-3): 178-184. 
Dudley, N., Ali, N., Kettunen, M. \& MacKinnon, K. 2017. Editorial essay: protected areas and the sustainable development goals. Parks, 23(2): 9-12.

Duhan, J.S., Kumar, R., Kumar, N., Kaur, P., Nehra, K. \& Duhan, S. 2017. Nanotechnology: the new perspective in precision agriculture. Biotechnology Reports, 15(May): 11-23.

Duis, K. \& Coors, A. 2016. Microplastics in the aquatic and terrestrial environment: sources (with a specific focus on personal care products), fate and effects. Environmental Sciences Europe, 28(1): 2.

Dulloo, M.E., Rege, J.E.O., Ramirez, M., Drucker, A.G., Padulosi, S., Maxted, N., Sthapit, B. et al. 2017. Conserving agricultural biodiversity for use in sustainable food systems. In Bioversity International, ed. Mainstreaming agrobiodiversity in sustainable food systems: scientific foundations for an Agrobiodiversity Index, pp. 103-140. Rome, Bioversity International.

Dulvy, N.K., Rogers, S.I., Jennings, S., Stelzenmüller, V., Dye, S.R. \& Skjoldal, H.R. 2008. Climate change and deepening of the North Sea fish assemblage: a biotic indicator of warming seas. Journal of Applied Ecology, 45: 1029-1039.

Dumanski, J., Peiretti, R., Benetis, J., McGarry, D. \& Pieri, C. 2006. The paradigm of conservation tillage. Proceedings of World Association of Soil and Water Conservation, P1: 58-64.

Dumont, A.M., Vanloqueren, G., Stassart, P.M. \& Baret, P. V. 2016. Clarifying the socioeconomic dimensions of agroecology: between principles and practices. Agroecology and Sustainable Food Systems, 40(1): 24-47.

Dunham, R.A. 2011. Aquaculture and fisheries biotechnology: genetic approaches. Wallingford, UK, CABI.

Duru, M., Fares, M. \& Therond, O. 2014. A conceptual framework for thinking now (and organising tomorrow) the agroecological transition at the level of the territory. Cahiers Agricultures, 23(2): 84-95.

Duru, M., Therond, O., Martin, G., Martin-Clouaire, R., Magne, M.A., Justes, E., Journet, E.P. et al. 2015. How to implement biodiversity-based agriculture to enhance ecosystem services: a review. Agronomy for Sustainable Development, 35(4): 1259-1281.
Duval, A., Mijatovic, D. \& Hodgkin, T. 2018. The contribution of biodiversity for food and agriculture to resilience of production systems to environmental change and uncertainty. Thematic study prepared for The State of the World's Biodiversity for Food and Agriculture. Rome, FAO.

Dwyer, J.T. 2012. Dietary standards and guidelines: similarities and differences among countries. In J.W. Erdman, I.A. Macdonald \& S.H. Zeisel, eds. Present knowledge in nutrition. 10th Edition, pp. 1110-1134. Hoboken, USA, Wiley-Blackwell.

Dykstra, D.P. 2002. Reduced impact logging: concepts and issues. In T. Enters, P.B. Durst, G.B. Applegate, P.C.S. Kho \& G. Man, eds. Applying reduced impact logging to advance sustainable forest management Bangkok, FAO Regional Office for Asia and the Pacific. (available at http://www.fao.org/docrep/005/ ac805e/ac805e04.htm).

Dykstra, D.P. \& Heinrich, R. 1996. FAO model code of forest harvesting practice. Rome, FAO. 85 pp.

Eadie, J.M. 1962. Inter-relationships between certain rumen ciliate protozoa. Journal of General Microbiology, 29: 579-588.

EASAC (European Academies Science Advisory Council). 2015. Ecosystem services, agriculture and neonicotinoids. EASAC Policy Report 26. Halle, Germany, German National Academy of Sciences.

EBCC (European Bird Census Council). 2018 What is Pan-European Common Bird Monitoring Scheme? [Cited 30 April 2018]. http://www.ebcc.info/paneuropean-common-bird-monitoring-scheme-pecbms/

Eckard, S., Ansari, M., Bacher, S., Butt, T., Enkerli, J. \& Grabenweger, G. 2014. Virulence of in vivo and in vitro produced conidia of Metarhizium brunneum strains for control of wireworms. Crop Protection, 64: 137-142.

Edwards, P. 1980. A review of recycling organic wastes into fish, with emphasis on the Tropics. Aquaculture, 21(3): 261-279.

Edwards, P. 2015. Aquaculture environment interactions: past, present and likely future trends. Aquaculture, 447: 2-14.

Edwards, P., Little, D. \& Demaine, H. 2002. Rural aquaculture. Wallingford, UK, CABI.

Edwards, D.P., Hodgson, J.A., Hamer, K.C., Mitchell, S.L., Ahmad, A.H., Cornell, S.J. \& Wilcove, D.S. 
2010. Wildlife-friendly oil palm plantations fail to protect biodiversity effectively. Conservation Letters, 3(4): 236-242.

Edwards, D.P., Woodcock, P., Edwards, F.A., Larsen, T.H., Hsu, W.W., Benedick, S. \& Wilcove, D.S. 2012. Reduced-impact logging and biodiversity conservation: a case study from Borneo. Ecological Applications, 22(2): 561-571.

Edwards, J.E., Forster, R.J., Callaghan, T.M., Dollhofer, V., Dagar, S.S., Cheng, Y., Chang, J. et al. 2017. PCR and omics based techniques to study the diversity, ecology and biology of anaerobic fungi: insights, challenges and opportunities. Frontiers in Microbiology, 25(8): 1657

EEA (European Environment Agency). 2015a. Ecosystem services in the EU - Ecosystem services still degrading. [Cited 21 March 2018]. https://www. eea.europa.eu/themes/biodiversity/where-we-stand/ ecosystem-services-in-the-eu

EEA. 2016. Agriculture - Organic farming. [Cited 26 April 2018]. https://www.eea.europa.eu/soer-2015/ countries-comparison/agriculture

Egan, J.F. \& Mortensen, D.A. 2012. Quantifying vapor drift of dicamba herbicides applied to soybean. Environmental Toxicology and Chemistry, 31(5): 1023-1031.

Eilers, E.J., Kremen, C., Greenleaf, S.S., Garber, A.K. \& Klein, A.M. 2011. Contribution of pollinatormediated crops to nutrients in the human food supply. PLOS ONE, 6(6): e21363.

Eisler, M.C., Lee, M.R.F., Tarlton, J.F. \& Martin, G.B. 2014. Steps to sustainable livestock. Nature, 507(7490): 32-34.

Ejlertsen, M., Poole, J. \& Marshall, K. 2012. Traditional breeding objectives and practices of goat, sheep and cattle smallholders in The Gambia and implications in relation to the design of breeding interventions. Tropical Animal Health and Production, 45(1): 219-229

El-Kassaby, Y., Cappa, E.P., Liewlaksaneeyanawin, C., Klápš, J. \& Lstiburek, M. 2011. Breeding without breeding: is a complete pedigree necessary for efficient breeding? PLOS ONE, 6(10): e25737.

Elliott, J., Firbank, L.G., Drake, B., Cao, Y. \& Gooday, R. 2013. Exploring the concept of sustainable intensification. Land Use Policy Group. (available at https://www.nature.scot/sites/default/files/2017-06/ A931058.pdf).

Elmqvist, T., Folke, C., Nystrom, M., Peterson, G., Bengtsson, J., Walker, B. \& Norberg, J. 2003. Response diversity, ecosystem change, and resilience. Frontiers in Ecology and the Environment, 1(9): 488-494.

Elmqvist, T., Fragkias, M., Goodness, J., Güneralp, B., Marcotullio, P.J., McDonald, R.I., Parnell, S. et al. eds. 2013. Urbanization, biodiversity and ecosystem services: challenges and opportunities. A global assessment. Dordrecht, Netherlands, Springer.

El Nagar, G. 2007. Efficiency of African catfish Clarias gariepinus in controlling unwanted reproduction of Nile tilapia Oreochromis niloticus in low input production system. Egyptian Journal of Aquatic Biology and Fisheries, 11(3): 105-113.

Epple, C., García Rangel, S., Jenkins, M. \& Guth, M. 2016. Managing ecosystems in the context of climate change mitigation: a review of current knowledge and recommendations to support ecosystem-based mitigation actions that look beyond terrestrial forests. CBD Technical Series No.86. Montreal, Canada, Secretariat of the Convention on Biological Diversity.

Eriksson, G., Namkoong, G. \& Roberds, J.H. 1993. Dynamic gene conservation for uncertain futures. Forest Ecology and Management, 62(1-4): 15-37.

Erickson, D.J., Sulzberger, B., Zepp, R.G. \& Austin, A.T. 2015. Effects of stratospheric ozone depletion, solar UV radiation, and climate change on biogeochemical cycling: Interactions and feedbacks. Photochemical and Photobiological Sciences, 10(2): 261-279.

Esser, K.B., Sæthre, M.G., Pradhananga, N. \& Ojha, H. 2012. Midterm review of the National Integrated Pest Management Programme in Nepal, Phase II. Noragric Report No. 67. Aas, Department of International Environment and Development Studies, Noragric, Norwegian University of Life Sciences.

European Commission. 2015. The state of nature in the EU - Reporting under the EU Habitats and Birds Directives 2007-2012. Luxembourg: Office for Official Publications of the European Union. (available at http://ec.europa.eu/environment/nature/pdf/state_ of_nature_en.pdf). 
Eurostat. 2011. Data requirements, availability and gaps in agri-environment indicators (AEIS) in Europe. Luxembourg, Publication office of the European Union.

Eurostat. 2016. Agri-environmental indicatorspecialisation. [Cited 20 November 2018]. https:// ec.europa.eu/eurostat/statistics-explained/index.php/ Agri-environmental_indicator_-_specialisation

Eurostat. 2018. Agri-environmental indicators. [Cited 26 April 2018]. http://ec.europa.eu/ eurostat/statistics-explained/index.php/Agrienvironmental\%7B_\%7Dindicators

Evans, B.R. 1999. Edible nut trees in Solomon Islands: a variety collection of Canarium, Terminalia and Barringtonia. ACIAR Technical Report No. 44. Canberra, Australian Centre for International Agricultural Research.

Evenson, R.E. \& Gollin, D. 2003. Assessing the impact of the Green Revolution, 1960 to 2000. Science, 300: 758-762.

Ewald, J.A., Wheatley, C.J., Aebischer, N.J., Moreby, S.J., Duffield, S.J., Crick, H.Q.P. \& Morecroft, M.B. 2015. Influences of extreme weather, climate and pesticide use on invertebrates in cereal fields over 42 years. Global Change Biology, 21(11): 3931-3950.

Ezcurra, E., Aburto, O. \& Rosenzweig, L. 2009. Los riñones del mundo: porqué debemos proteger los manglares de México. Investigación ambiental ciencia y política pública, 1(2): 202-206.

Fabre, P., Guérin, G. \& Bouquet, P.M. 2010. The management of natural areas by pastoralism - a French Mediterranean example: the Merinos D'Arles in transhumance. Paper presented at the Eighth World Merino Conference, 3-5 May 2010, Rambouillet, France.

Falk, D.A., Knapp, E.E. \& Guerrant, E.O. 2001. An introduction to restoration genetics. Washington, DC, Society for Ecological Restoration.

FAO. 1993. Forest Resources Assessment 1990: tropical countries. FAO Forestry Paper 112. Rome. (available at http://www.fao.org/docrep/007/t0830e/ t0830e00.htm).

FAO. 1995a. Code of Conduct for Responsible Fisheries. Rome. (available at http://www.fao.org/3/ a-v9878e.pdf).

FAO. 1995b. Improving nutrition through home gardening - A training package for preparing field workers in Southeast Asia. Rome. (available at http:// www.fao.org/docrep/v5290e/v5290e00.htm).

FAO. 1996a. Rome Declaration on World Food Security. (available at http://www.fao.org/docrep/003/ w3613e/w3613e00.HTM).

FAO. 1996b. Precautionary approach to capture fisheries and species introductions. FAO Technical Guidelines for Responsible Fisheries. Rome. (available at http:// www.fao.org/3/a-w3592e.pdf).

FAO. 1997. The State of the World's Plant Genetic Resources for Food and Agriculture. Rome. (available at http://www.fao.org/3/a-w7324e.pdf).

FAO. 1998. Guidelines for the management of tropical forests. Rome. (available at http://www.fao.org/ docrep/w8212e/w8212e00.HTM).

FAO. 1999a. The global strategy for the management of farm animal genetic resources: executive brief. Rome.

FAO. 1999b. Women: users, preservers and managers of agrobiodiversity. Rome. (available at http://www.fao. org/docrep/x0171e/x0171e03.htm).

FAO. 2000. World watch list for domestic animal diversity. B.D. Scherf, ed. Rome. (available at http:// www.fao.org/docrep/009/x8750e/x8750e00.htm).

FAO. 2003a. Biological management of soil ecosystems for sustainable agriculture. Report of the International Technical Workshop organized by EMBRAPA-Soybean and FAO, Londrina, Brazil, 24-27 June 2002. Rome. (available at http://www.fao.org/ docrep/006/y4810e/y4810e00.htm).

FAO. 2003b. Status and trends in mangrove area extent worldwide. M.L. Wilkie \& S. Fortuna, eds. Forest Resources Assessment Working Paper No. 63. Forest Resources Division. Rome, FAO Internal document. (available at http://www.fao.org/docrep/007/j1533e/ J1533E00.htm).

FAO. 2003c. Cross-sectoral policy impacts between forestry and other sectors. Forestry Paper No. 142 Rome. (available at http://www.fao.org/docrep/006/ Y4653E/y4653e00.htm).

FAO. 2003d. The ecosystem approach to fisheries. Issues, terminology, principles, institutional foundations, implementation and outlook. FAO Fisheries Technical Paper No. 443. Rome. (available at http://www.fao. org/3/a-y4773e.pdf).

FAO. 2003e. Fisheries management. 2. The ecosystem approach to fisheries. FAO Technical Guidelines for 
Responsible Fisheries 4. Suppl. 2. Rome. (available at http://www.fao.org/3/a-y4470e.pdf).

FAO. 2005a. Grasslands of the world. J.M. Suttie, S.G. Reynolds \& C. Batello, eds. Rome. (available at http:// www.fao.org/docrep/008/y8344e/y8344e00.htm).

FAO. 2005b. Putting into practice the ecosystem approach to fisheries. Rome. (available at https://www.cbd. int/doc/meetings/mar/cbwsoi-seasi-01/other/cbwsoiseasi-01-putting-into-practice-eaf-en.pdf).

FAO. 2006a. Food security. Policy Brief No. 2. Rome. (available at http://www.fao.org/fileadmin/templates/ faoitaly/documents/pdf/).

FAO. 2006b. Livestock's long shadow - Environmental issues and options. Rome. (available at http://www. fao.org/docrep/010/a0701e/a0701e00.HTM).

FAO. 2007a. The State of the World's Animal Genetic Resources for Food and Agriculture. B. Richkowsky \& D. Pilling, eds. Rome. (available at http://www.fao. org/3/a-a1260e.pdf).

FAO. 2007b. The Global Plan of Action for Animal Genetic Resources and the Interlaken Declaration. Rome. (available at http://www.fao.org/3/a-a1404e.pdf).

FAO. 2007c. Report of the Eleventh Regular Session of the Commission on Genetic Resources for Food and Agriculture. Rome, 11-15 June 2007.

CGRFA-11/07/Report. (available at http://www.fao. org/tempref/docrep/fao/meeting/014/k0385e.pdf).

FAO. 2007d. Forests and water. Unasylva No. 229, Vol. 58. Rome. (available at ftp://ftp.fao.org/docrep/ fao/010/a1598e/a1598e00.pdf).

FAO. 2007e. The world's mangroves 1980-2005. FAO Forestry Paper No. 153. Rome. (available at http:// www.fao.org/docrep/010/a1427e/a1427e00.htm).

FAO. 2007f. The ecosystem approach applied to food and agriculture: status and needs. Commission on Genetic Resources for Food and Agriculture. Eleventh Regular Session, Rome, 11-15 June 2007. CGRFA-11/07/15.4 Rev.1. (available at http:// www.fao.org/tempref/docrep/fao/meeting/014/ j9731e.pdf).

FAO. 2008a. Rapid assessment of pollinators' status: a contribution to the international initiative for the conservation and sustainable use of pollinators. Rome. (available at http://www.fao.org/uploads/ media/raps\%7B_\%7D2.pdf).
FAO. 2008b. Expert Consultation on Nutrition Indicators for Biodiversity: 1. Food Composition. Rome. (available at http://www.fao.org/3/a-a1582e.pdf).

FAO. 2009a. The State of Food and Agriculture. Livestock in the balance. Rome. (available at http:// www.fao.org/docrep/012/i0680e/i0680e.pdf).

FAO. 2009b. Declaration of the World Summit on Food Security. World Summit on Food Security, Rome, 16-18 November 2009. WSFS 2009/2. (available at http://www.fao.org/tempref/docrep/fao/ Meeting/018/k6050e.pdf).

FAO. 2009c. The use and exchange of animal genetic resources for food and agriculture. Commission on Genetic Resources for Food and Agriculture. Background Study Paper No. 43. Rome. (available at http://www.fao.org/tempref/docrep/fao/ meeting/017/ak222e.pdf).

FAO. 2010a. The Second Report on the State of the World's Plant Genetic Resources for Food and Agriculture. Rome. (available at http://www.fao.org/ docrep/013/i1500e/i1500e.pdf).

FAO. 2010b. Developing effective forest policy. FAO Forestry Paper No. 161. Rome. (available at http:// www.fao.org/docrep/013/am007e/am007e00.pdf).

FAO. 2010c. Global Forest Resources Assessment 2010. Main Report. FAO Forestry Paper No. 163, Rome. (available at http://www.fao.org/docrep/013/i1757e/ i1757e.pdf).

FAO. 2010d. Aquaculture development. 4. Ecosystem approach to aquaculture. FAO Technical Guidelines for Responsible Fisheries 5. Suppl. 4. Rome. (available at http://www.fao.org/docrep/013/11750e/11750e00.htm).

FAO. 2010e. An international consultation on integrated crop-livestock systems for development. The way forward for sustainable production. Integrated Crop Management Vol. 13-2010. Rome. (available at http:// www.fao.org/fileadmin/templates/agphome/images/ iclsd/documents/crop_livestock_proceedings.pdf).

FAO. 2011a. The state of the world's land and water resources for food and agriculture. Managing systems at risk. Rome, FAO, and London, Earthscan. (available at http://www.fao.org/docrep/017/i1688e/i1688e.pdf).

FAO. 2011b. Second Global Plan of Action for Plant Genetic Resources for Food and Agriculture. Rome. (available at http://www.fao.org/docrep/015/i2624e/ i2624e00.pdf). 
FAO. 2011c. Save and grow. A policymakers guide to the sustainable intensification of smallholder agriculture. Rome. (available at http://www.fao.org/docrep/014/ i1951e/i1951e.pdf).

FAO. 2011d. Expert Consultation on Nutrition Indicators for Biodiversity: 2. Food Consumption. Rome. (available at http://www.fao.org/docrep/014/i1951e/ i1951e.pdf).

FAO. 2011e. The State of Food and Agriculture 2010-11. Women in agriculture: closing the gender gap for development. Rome. (available at http://www.fao. org/docrep/013/i2050e/i2050e.pdf).

FAO. 2011f. Surveying and monitoring of animal genetic resources. FAO Animal Production and Health Guidelines. No. 7. Rome. (available at http://www. fao.org/docrep/014/ba0055e/ba0055e00.pdf).

FAO. 2012a. Invisible guardians: women manage livestock diversity. FAO Animal Production and Health Paper No. 174. Rome. (available at http:// www.fao.org/docrep/016/i3018e/i3018e00.pdf).

FAO. 2012b. The State of World Fisheries and Aquaculture. Rome. (available at http://www.fao. org/3/a-i2727e.pdf).

FAO. 2012c. FRA 2015. Terms and definitions. Forest Resources Assessment Working Paper No. 180. Rome. (available at http://www.fao.org/docrep/017/ ap862e/ap862e00.pdf).

FAO. 2012d. Phenotypic characterization of animal genetic resources. FAO Animal Production and Health Guidelines No. 11. Rome. (available at http:// www.fao.org/docrep/015/i2686e/i2686e00.pdf).

FAO. 2012e. Cryoconservation of animal genetic resources. FAO Animal Production and Health Guidelines No. 12. Rome. (available at http://www. fao.org/docrep/016/i3017e/i3017e00.pdf).

FAO. 2013a. Report of the Fourteenth Regular Session of the Commission on Genetic Resources for Food and Agriculture. Commission on Genetic Resources for Food and Agriculture. Rome, 15-19 April 2013. CGRFA-14/13/Report. (available at http://www.fao. org/docrep/meeting/028/mg538e.pdf).

FAO. 2013b. Guidelines for the preparation of the Country Reports for The State of the World's Biodiversity for Food and Agriculture. Rome. (available at http://www.fao.org/3/a-as644e.pdf).
FAO. 2013c. Our priorities: the FAO Strategic Objectives. Rome. (available at http://www.fao.org/docrep/018/ mi317e/mi317e.pdf).

FAO. 2013d. Climate-smart agriculture sourcebook. Rome. (available at http://www.fao.org/docrep/018/ i3325e/i3325e.pdf).

FAO. 2013e. Resilient livelihoods: disaster reduction for food and nutrition security. Rome. (available at http://www.fao.org/3/a-i3270e.pdf).

FAO. 2013f. Review of key issues on biodiversity and nutrition. Commission on Genetic Resources for Food and Agriculture. Fourteenth Regular Session, Rome, 15-19 April 2013. CGRFA-14/13/8. (available at http:// www.fao.org/docrep/meeting/027/mf917e.pdf).

FAO. 2013g. In vivo conservation of animal genetic resources. FAO Animal Production and Health Guidelines. No. 14. Rome. (available at http://www. fao.org/docrep/018/i3327e/i3327e.pdf).

FAO. 2013h. Policy support guidelines for the promotion of sustainable production intensification and ecosystem services. Integrated Crop Management Vol. 19-2013. Rome. (available at http://www.fao. org/ag/ca/ca-publications/icm19.pdf).

FAO. 2014a. The State of the World's Forest Genetic Resources. Rome. (available at http://www.fao. org/3/a-i3825e.pdf).

FAO. 2014b. Global Plan of Action for the Conservation, Sustainable Use and Development of Forest Genetic Resources. Rome. (available at http://www.fao. org/3/a-i3849e.pdf).

FAO. 2014c. Ecosystem services by livestock species and breeds, with special consideration to the contribution of small-scale livestock keepers and pastoralists. I. Hoffmann, T. From \& D. Boerma, eds. Commission on Genetic Resources for Food and Agriculture. Background Study Paper No. 66 Rev. 1. Rome. (available at http://www.fao.org/3/a-at598e.pdf).

FAO. 2014d. State of the World's Forests: Enhancing the socioeconomic benefits from forests. Rome. (available at http://www.fao.org/3/a-i3710e.pdf).

FAO. 2014e. FAO Global Land Cover (GLC-SHARE) BetaRelease 1.0 Database. J. Latham, R. Cumani, I. Rosati \& M. Bloise, eds. Rome. (available at http://www.fao. org/uploads/media/glc-share-doc.pdf).

FAO. 2014f. Genebank standards for plant genetic resources for food and agriculture. Revised edition. 
Rome. (available at http://www.fao.org/3/ a-i3704e.pdf).

FAO. $2014 \mathrm{~g}$. Synthesis progress report on the implementation of the global plan of action for animal genetic resources - 2014. Commission on Genetic Resource for Food and Agriculture. Fifteenth Regular Session, Rome, 19-23 January 2015. CGRFA-15/15/Inf.19. Rome. (available at http:// www.fao.org/3/a-mm282e.pdf).

FAO. 2014h. Protected areas, people and food security. A FAO contribution to World Park Congress, Sydney, 12-19 November 2014. Rome. (available at http:// www.fao.org/3/a-i4198e.pdf).

FAO. 2015a. The Second Report on the State of World's Animal Genetic Resources for Food and Agriculture. B.D. Scherf \& D. Pilling, eds. Rome. (available at http://www.fao.org/3/a-i4787e.pdf).

FAO. 2015b. Coping with climate change - the roles of genetic resources for food and agriculture. Rome. (available at http://www.fao.org/3/a-i3866e.pdf).

FAO. 2015c. The State of Food Insecurity in the World. Meeting the 2015 international hunger targets: taking stock of uneven progress. Rome. (available at http://www.fao.org/3/a-i4646e.pdf).

FAO. 2015d. Global Forest Resources Assessments Maps and figures. [online]. Rome. http://www.fao. org/forest-resources-assessment/current-assessment/ maps-and-figures/en/

FAO. 2015e. Revised World Soil Charter. Rome. (available at http://www.fao.org/3/a-i4965e.pdf).

FAO. 2015f. Guidelines for developing a National Strategy for Plant Genetic Resources for Food and Agriculture. Rome. (available at http://www.fao.org/3/a-i4917e.pdf).

FAO. 2015g. Voluntary Guidelines to Support the Integration of Genetic Diversity into National Climate Change Adaptation Planning. Rome. (available at http://www.fao.org/3/a-i4940e.pdf).

FAO. 2016a. Fisheries in the drylands of sub-Saharan Africa - "Fish come with the rains". Building resilience for fisheries-dependent livelihoods to enhance food security and nutrition in the drylands. J. Kolding, P. van Zwieten, F. Marttin \& F. Poulain, eds. Fisheries and Aquaculture Circular No. 1118. Rome, FAO. (available at http://www.fao.org/3/a-i5616e.pdf).

FAO. 2016b. Sustainable intensification of aquaculture in the Asia-Pacific region. W. Miao \& K.K. Lal, eds.
Bangkok. (available at http://www.fao.org/3/ai5362e.pdf).

FAO. 2016c. Regional strategy and action plan for sustainable intensification of aquaculture in the AsiaPacific region. Bangkok. (available at http://www. fao.org/3/a-i5466e.pdf).

FAO. 2016d. Voluntary Guidelines for Mainstreaming Biodiversity into Policies, Programmes and National and Regional Plans of Action on Nutrition. Rome. (available at http://www.fao.org/3/a-i5248e.pdf).

FAO. 2016e. State of the World's Forests 2016.

Forests and agriculture: land-use challenges and opportunities. Rome. (available at http://www.fao. org/3/a-i5588e.pdf).

FAO. 2016f. The contributions of livestock species and breeds to ecosystem services. Rome. (available at http://www.fao.org/3/a-i6482e.pdf)

FAO. 2016g. Global Forest Resources Assessment 2015. How are the world's forests changing? Second edition. Rome. (available at http://www.fao.org/3/ai4793e.pdf).

FAO. 2016h. Report of the 32nd Session of the Committee on Fisheries (Rome, 11-15 July 2016). Committee on Fisheries. Fortieth Session, Rome, 3-8 July 2017. C 2017/23. (available at http://www. fao.org/3/a-mr484e.pdf).

FAO. 2016i. CountryStat. [Cited 24 November 2016]. Rome. http://countrystat.org/home.aspx?c=FOR

FAO. 2016j. AQUASTAT Main Database. [Cited 23 October 2018]. Rome. http://www.fao.org/nr/ water/aquastat/data/query/index.html?lang=en \%0A; http://www.fao.org/nr/aquastat

FAO. 2016k. The State of World Fisheries and Aquaculture. Contributing to food security and nutrition for all. Rome. (available at http://www.fao. org/3/a-i5555e.pdf).

FAO. 2016l. Save and Grow in practice: maize, rice, wheat - A guide to sustainable cereal production. Rome. (available at http://www.fao.org/3/a-i4009e.pdf).

FAO. $2016 \mathrm{~m}$. Assessment of the implementation of the Second Global Plan of Action for Plant Genetic Resources for Food and Agriculture 2012-2014. Commission on Genetic Resources for Food and Agriculture. Sixteenth Regular Session, Rome, 30 January-03 February 2017. CGRFA-16/17//nf.17.2. Rome. (available at http://www.fao.org/3/a-mr796e.pdf). 
FAO. 2016n. Report of the Expert Workshop on Incorporating Genetic Diversity and Indicators into Statistics and Monitoring of Farmed Aquatic Species and their Wild Relatives. Rome, 4-6 April 2016. Fisheries and Aquaculture Report No. 1173. Rome. (available at http://www.fao.org/3/a-i6373e.pdf).

FAO. 2016o. Meeting our goals: FAO's programme for gender equality in agriculture and rural development. Rome. (available at http://www.fao.org/3/a-i6618e.pdf).

FAO. 2016p. Farmer field school guidance document: planning for quality programmes. Rome. (available at http://www.fao.org/3/a-i5296e.pdf).

FAO. 2016q. ABS Elements. Elements to facilitate domestic implementation of access and benefitsharing for different subsectors of genetic resources for food and agriculture. Rome. (available at http:// www.fao.org/3/a-i5033e.pdf)

FAO. 2017a. FAO's work on climate change. United Nations Climate Change Conference 2017. Rome. (available at http://www.fao.org/3/a-i8037e.pdf).

FAO. 2017b. FAO and the SDGs. Indicators: measuring up to the 2030 Agenda for Sustainable Development. Rome. (available at http://www.fao. org/3/a-i6919e.pdf).

FAO. 2017c. Climate-smart agriculture sourcebook. [Cited 10 March 2018]. Rome. http://www.fao.org/ climate-smart-agriculture-sourcebook/en/

FAO. 2017d. Strategic work of FAO to increase the resilience of livelihoods. Rome. (available at http:// www.fao.org/3/a-i6463e.pdf)

FAO. 2017e. The future of food and agriculture - Trends and challenges. Rome. (available at http://www.fao. org/3/a-i6583e.pdf).

FAO. 2017f. Strategic work of FAO for sustainable food and agriculture. Rome. (available at http://www.fao. org/3/a-i6488e.pdf).

FAO. 2017g. Nutrition-sensitive agriculture and food systems in practice. Options for intervention. Rome. (available at http://www.fao.org/3/a-i7848e.pdf).

FAO. 2017h. FAO/INFOODS Food Composition Database for Biodiversity Version 4.0 - BioFoodComp4.0. Rome. (available at http://www.fao.org/3/a-i7364e.pdf).

FAO. 2017i. The State of Food and Agriculture 2017. Leveraging food systems for inclusive rurall transformation. Rome. (available at http://www.fao. org/3/a-17658e.pdf).
FAO. 2017j. FAOSTAT. [Cited 6 September 2017]. Rome. http://www.fao.org/faostat/en/

FAO. 2017k. Keeping an eye on SDG 15. Rome. (available at http://www.fao.org/3/a-i7334e.pdf).

FAO. 2017l. Voluntary Guidelines for Sustainable Soil Management. Rome. (available at http://www.fao. org/3/a-bl813e.pdf).

FAO. $2017 \mathrm{~m}$. Soil organic carbon: the hidden potential. Rome. (available at http://www.fao.org/3/a-i6937e.pdf).

FAO. 2017n. Genome-based biotechnologies in aquaculture. Thematic Background Study No. 3. SubCommittee on Aquaculture. Ninth Session, Rome, 24-27 October 2017. COFI:AQ/IX/2017/SBD.5. Rome. (available at http://www.fao.org/cofi/460550e1ecdb708ffdf3609b3c2aa4dc46bc8a.pdf).

FAO. 2017o. Voluntary Guidelines for the Conservation and Sustainable Use of Crop Wild Relatives and Wild Food Plants. Rome. (available at http://www.fao. org/3/a-i7788e.pdf).

FAO. 2017p. Big roles, little powers: the reality of women in agriculture in ECOWAS region. Rome. (available at http://www.fao.org/3/a-i7005e.pdf)

FAO. 2017q. National seed policy takes root. [Cited 4 March 2018]. Rome. http://www.fao.org/laos/news/ detail-events/en/c/1039592/

FAO. 2018a. The State of World Fisheries and Aquaculture 2018 - Meeting the sustainable development goals. Rome. (available at http://www.fao.org/3/i9540en/ 19540EN.pdf).

FAO. 2018b. The State of the World's Forests $2018-$ Forest pathways to sustainable development. Rome. (available at http://www.fao.org/state-of-forests/en/).

FAO. 2018c. Globally Important Agricultural Heritage Systems (GIAHS). Combining agricultural biodiversity, resilient ecosystems, traditional farming practices and cultural identity. Rome. (available at http://www. fao.org/3/i9187en/l9187EN.pdf).

FAO. 2018d. Resilience. [Cited 28 November 2016]. Rome. http://www.fao.org/emergencies/how-wework/resilience/en/

FAO. 2018e. The impact of disasters and crises on agriculture and food security. Rome. (available at http://www.fao.org/3//8656EN/i8656en.pdf).

FAO. 2018f. Nitrogen inputs to agricultural soils from livestock manure. New statistics. Integrated Crop 
Management Vol. 24. Rome. (available at http:// www.fao.org/3/i8153en/l8153EN.pdf).

FAO. 2018g. Status and trends of animal genetic resources. CGRFAWG-AnGR-10/18/Inf.3. Rome. (available at http://www.fao.org/3/CA0121EN/ ca0121en.pdf).

FAO. 2018h. Fishery and aquaculture statistics. Fishstat - Global production by production source 1950-2016. Rome.

FAO. 2018i. FAO's global action on pollination services for sustainable agriculture. [Cited 13 March 2018]. Rome. http://www.fao.org/pollination/en/

FAO. 2018j. Global Forest Resources Assessment 2020 Terms and definitions. Rome. (available at http:// www.fao.org/3//8661EN/i8661en.pdf).

FAO. 2018k. Progress in the implementation of the Code of Conduct for Responsible Fisheries and related instruments. Committee on Fisheries. Thirty-third Session, Rome, 9-13 July 2018. COFI/2018/Inf.7. Rome. (available at http://www.fao.org/3/MX233EN/ mx233en.pdf)

FAO. 2018l. The 10 elements of agroecology. Guiding the transition to sustainable food and agricultural systems. Rome. (available at http://www.fao.org/3/ 19037EN/i9037en.pdf).

FAO. 2018m. Land-use planning. [Cited 10 May 2018]. Rome. http://www.fao.org/sustainable-forestmanagement/toolbox/modules/land-use-planning/ basic-knowledge/en/

FAO. 2018n. Global Livestock Environmental Assessment Model (GLEAM). [Cited 23 September 2018]. Rome. http://www.fao.org/gleam/en.

FAO. 20180. Livestock and agroecology - How they can support the transition towards sustainable food and agriculture. Rome (available at http://www.fao.org/3/ I8926EN/i8926en.pdf).

FAO. 2018p. Agri-environmental statistics. Taking the pulse of the planet, one country at a time! [Cited 22 April 2018]. Rome. http://www.fao.org/ economic/ess/environment/en/

FAO. 2018q. What is Integrated Plant Nutrient Management? [Cited 4 December 2018]. Plant Production and Protection Division. Rome. http://www. fao.org/agriculture/crops/thematic-sitemap/theme/spi/ scpi-home/managing-ecosystems/integrated-plantnutrient-management/ipnm-what/en/
FAO. 2018r. Regulating services. [online]. Rome. http:// www.fao.org/ecosystem-services-biodiversity/ background/regulating-services/en/

FAO. 2018s. SDG Indicator 2.5.1 - Conservation of genetic resources for food and agriculture. [online]. Rome. http://www.fao.org/sustainable-developmentgoals/indicators/251/en/

FAO. 2018t. WIEWS - World Information and Early Warning System on Plant Genetic Resources for Food and Agriculture. [online]. Rome. http://www. fao.org/wiews/en/

FAO. 2018u. Globally Important Agricultural Heritage Systems (GIAHS). [Cited 22 April 2018]. Rome. http://www.fao.org/giahs/en/

FAO. 2018v. Incentives for ecosystem services. [Cited 5 April 2018]. Rome. http://www.fao.org/in-action/ incentives-for-ecosystem-services/en/

FAO. 2019. Biodiversity for food and agriculture and ecosystem services. Thematic study prepared for the SoW-BFA. Rome.

FAO. forthcoming. The State of the World's Aquatic Genetic Resources for Food and Agriculture. Rome.

FAO \& Bioversity International. 2017. Guidelines on assessing biodiverse foods in dietary intake surveys. Rome, FAO. (available at http://www.fao.org/3/ai6717e.pdf).

FAO \& FHI 360. 2016. Minimum dietary diversity for women: a guide for measurement. Rome, FAO. (available at http://www.fao.org/3/a-i5486e.pdf).

FAO \& CBD. 2016. Mainstreaming ecosystem services and biodiversity into agricultural production and management in East Africa. Practical issues for consideration in National Biodiversity Strategies and Action Plans to minimize the use of agrochemicals. Technical guidance document. Rome, FAO. (available at http://www.fao.org/3/a-i5603e.pdf).

FAO, CBD, SPREP \& SPC. 2016. Mainstreaming ecosystem servi ces and biodiversity into agricultural production and management in the Pacific Islands. Technical guidance document. Rome, FAO. (available at http://www.fao.org/3/a-i6505e.pdf).

FAO, DFSC \& IPGRI. 2001. Forest genetic resources conservation and management. Vol. 2: In managed natural forests and protected areas (in situ). Rome, International Plant Genetic Resources Institute (IPGRI). (available at http://www.bioversityinternational.org/ 
fileadmin/_migrated/uploads/tx_news/Forest_genetic resources_conservation_and_management_In managed_natural_forests_and_protected_areas_in_ situ__Vol._2_775.pdf).

FAO, FLD \& IPGRI. 2004a. Forest genetic resources conservation and management. Vol. 3: In plantations and genebanks (ex situ). Rome, IPGRI. (available at http://www.bioversityinternational.org/fileadmin/user_ upload/online_library/publications/pdfs/1053.pdf).

FAO, FLD \& IPGRI. 2004b. Forest genetic resources conservation and management. Vol. 1: Overview, concepts and some systematic approaches. Rome, International Plant Genetic Resources Institute (IPGRI). (available at http://www. bioversityinternational.org/fileadmin/_migrated/ uploads/tx_news/Forest_genetic_resources_ conservation_and_management_overview_ concepts_and_some_systematic_approaches_ Vol._1_1018.pdf).

FAO \& IAEA. 2016. Supporting biological control of stable flies (Stomoxys calcitrans, L) through the use of parasitoids reproduced on fruit flies. Insect \& Pest Control Newsletter No. 87. Vienna. (available at http:// www-naweb.iaea.org/nafa/ipc/public/IPC-NL-87.pdf).

FAO, IIRR \& WorldFish Center. 2001. Integrated agriculture-aquaculture. A primer. FAO Fisheries Technical Paper. No. 407. Rome. (available at http:// www.fao.org/docrep/005/Y1187E/y1187e00.HTM).

FAO \& INRA. 2016. Innovative markets for sustainable agriculture. A. Loconto, A.S. Poisot \& P.

Santacoloma, eds. Rome, FAO. (available at http:// www.fao.org/3/a-i5907e.pdf).

FAO \& INRA. 2018. Constructing markets for agroecology: An analysis of diverse options for marketing products from agroecology. A. Loconto, A. Jimenez \& E. Vandecandelaere, eds. Rome, FAO. (available at http:// www.fao.org/3/i8605en//8605EN.pdf).

FAO \& ITPS. 2015. Status of the World's Soil Resources (SWSR) - Main Report. Rome, FAO and ITPS. (available at http://www.fao.org/3/a-i5199e.pdf).

FAO \& IWMI. 2018. More people, more food, worse water? a global review of water pollution from agriculture. J. Mateo-Sagasta, S.M. Zadeh \& H. Turral, eds. Rome, FAO, and Colombo, International Water Management Institute on behalf of the Research Program on Water Land and Ecosystems of the CGIAR. (available at http://www.fao.org/3/ ca0146en/CA0146EN.pdf).

FAO \& PAR. 2011. Biodiversity for food and agriculture. Contributing to food security and sustainability in a changing world. Outcomes of an expert workshop held by FAO and Platform on Agrobiodiversity Research. Rome, 14-16 April 2010. Rome, FAO. (available at http://www.fao.org/3/a-i1980e.pdf).

FAO \& SINER-GI. 2010. Linking people, places and products. A guide for promoting quality linked to geographical origin and sustainable geographical indications. Second edition. E. Vandecandelaere, F. Arfini, G. Belletti \& A. Marescotti, eds. Rome, FAO. (available at http://www.fao.org/docrep/013/i1760e/ i1760e00.pdf).

FAO \& The National Forest Programme Facility. 2006. Understanding national forest programmes. Rome, FAO. (available at http://www.fao.org/ tempref/docrep/fao/012/a0826e/a0826e00.pdf).

FAO \& UNISDR. 2017. Lineamientos y recomendaciones para la implementación del Marco de Sendai para la Reducción del Riesgo de Desastres en el Sector Agrícola y Seguridad Alimentaria y Nutricional. América Latina y el Caribe. Santiago de Chile, FAO.

FAO \& WHO. 1999. Guidelines for the production, processing, labelling and marketing of organically produced foods. Rome, FAO. (available at www.fao. org/input/download/standards/360/cxg_032e.pdf).

FAO \& WHO. 2002. Guidelines for the evaluation of probiotics in food. London, Canada. (available at https://www.who.int/foodsafety/fs_management/en/ probiotic_guidelines.pdf).

FAO \& WHO. 2014a. Conference Outcome Document: Rome Declaration on Nutrition. Second International Conference on Nutrition, Rome, 19-21 November 2014. ICN2 2014/2. (available at http://www.fao. org/3/a-ml542e.pdf).

FAO \& WHO. 2014b. Framework for action. Report of the Joint FAOMHO Second International Conference on Nutrition, Rome, 19-21 November 2014. ICN2 2014/3 Corr. 1. (available at http://www.fao.org/3/amm215e.pdf).

FAO \& WHO. 2014c. The International Code of Conduct on Pesticide Management. Rome, FAO. (available at http://www.fao.org/fileadmin/templates/agphome/ 
documents/Pests\%7B_\%7DPesticides/Code/ CODE\%7B_\%7D2014Sep\%7B_\%7DENG.pdf).

FAO, IFAD, UNICEF, WFP \& WHO. 2018. The State of Food Security and Nutrition in the World 2018. Building climate resilience for food security and nutrition. Rome, FAO. (available at http://www.fao. org/3/19553EN/i9553en.pdf).

Faruque, G., Sarwer, R.H., Karim, M., Phillips, M., Collis, W.J., Belton, B. \& Kassam, L. 2017. The evolution of aquatic agricultural systems in Southwest Bangladesh in response to salinity and other drivers of change. International Journal of Agricultural Sustainability, 15(2): 185-207.

Federal Office for the Environment of Switzerland. 2018. Prairies et pâturages secs. [Cited 30 April 2018]. https://www.bafu.admin.ch/bafu/fr/home/ themes/biodiversite/info-specialistes/mesures-deconservation-de-la-biodiversite/infrastructureecologique/biotopes-d_importance-nationale/ prairies-et-paturages-secs.html

Ferrario, F., Beck, M.W., Storlazzi, C., Micheli, F., Shepard, C. \& Airoldi, L. 2014. The effectiveness of coral reefs for coastal hazard risk reduction. Nature Communications, 5(3794): 1-9.

Ferrel, J.K. 2005. Controlling flags of convenience: one measure to stop overfishing of collapsing fish stocks. Environmental Law, 35(2): 323-390.

FiBL (Forschungsinstitut für Biologischen Landbau). 2016. Organic agriculture promotes biodiversity. [Cited 26 April 2018]. http://www. fibl.org/en/ themes/biodiversity.html

Finckh, M.R., Gacek, E.S., Goyeau, H., Lannou, C., Merz, U., Mundt, C.C., Munk, L. et al. 2000. Cereal variety and species mixtures in practice, with emphasis on disease resistance. Agronomie, 20(7): 813-837.

Finke, D.L. \& Denno, R.F. 2004. Predator diversity dampens trophic cascades. Nature, 429(6990): 407-410.

Finlayson, R. 2017. ASEAN calls for agroforestry guidelines. [Cited 23 April 2018]. http://blog. worldagroforestry.org/index.php/2017/07/11/aseancalls-agroforestry-guidelines/

Fisher, M.C., Henk, D.A., Briggs, C.J., Brownstein, J.S., Madoff, L.C., McCraw, S.L. \& Gurr, S.J. 2012. Emerging fungal threats to animal, plant and ecosystem health. Nature, 484(7393): 186-194.
Fletcher, W.J. \& Bianchi, G. 2014. The FAO-EAF toolbox: making the ecosystem approach accessible to all fisheries. Ocean \& Coastal Management, 90: 20-26.

Fletcher, W.J., Kearney, R.E., Wise, B.S. \& Nash, W.J. 2015. Large-scale expansion of no-take closures within the Great Barrier Reef has not enhanced fishery production. Ecological Society of America, 25(5): 1187-1196.

Fogarty, N.D. 2012. Caribbean acroporid coral hybrids are viable across life history stages. Marine Ecology Progress Series, 446: 145-159.

Foley, J.A., DeFries, R., Asner, G.P., Barford, C., Bonan, G., Carpenter, S.R., Chapin, F.S. et al. 2005. Global consequences of land use. Science, 309(5734): 570-574.

Foley, J.A., Ramankutty, N., Brauman, K.A., Cassidy, E.S., Gerber, J.S., Johnston, M., Mueller, N.D. et al. 2011. Solutions for a cultivated planet. Nature, 478(7369): 337-342.

Folke, C., Carpenter, S., Walker, B., Scheffer, M., Elmqvist, T., Gunderson, L. \& Holling, C.S. 2004. Regime shifts, resilience, and biodiversity in ecosystem management. Annual Review of Ecology, Evolution, and Systematics, 35(1): 557-581.

Folke, C., Carpenter, S.R., Walker, B., Scheffer, M., Chapin, T. \& Rockström, J. 2010. Resilience thinking: integrating resilience, adaptability and transformability. Ecology and Society, 15(4): 20-28.

Fontaine, C.M., De Vreese, R., Jacquemin, I., Marek, A., Mortelmans, D., Dendoncker, N., François, L.M., Van Herzle, A. \& Devillet, G. 2013. Valuation of terrestrial ecosystem services in a multifunctional peri-urban space (The VOTES project). Final Report. Brussels, Belgian Science Policy.

Fonte, S.J., Vanek, S.J., Oyarzun, P., Parsa, S., Quintero, C.D., Rao, I.M. \& Lavelle, P. 2012. Chapter 4: Pathways to agroecological intensification of soil fertility management by smallholder farmers in the Andean Highlands. Advances in Agronomy, 116: 125-184.

Forestry Commission. 2018. Chalara dieback of ash (Hymenoscyphus fraxineus). [Cited 17 May 2018]. https://www.forestry.gov.uk/ashdieback

Forman, R.T.T. 1995. Land mosaics: the ecology of landscapes and regions. Cambridge, UK, Cambridge University Press. 
Fornara, D.A. \& Tilman, D. 2008. Plant functional composition influences rates of soil carbon and nitrogen accumulation. Journal of Ecology, 96(2): 314-322.

Forrest, J.R.K., Thorp, R.W., Kremen, C. \& Williams, N.M. 2015. Contrasting patterns in species and functional-trait diversity of bees in an agricultural landscape. Journal of Applied Ecology, 52(3): 706-715.

Foundjem-Tita, D., Tchoundjeu, Z., Speelman, S., D'Haese, M., Degrande, A., Asaah, E., van Huylenbroeck, G., van Damme, P. \& Ndoye, O. 2013. Policy and legal frameworks governing trees: incentives or disincentives for smallholder tree planting decisions in Cameroon? Small-scale Forestry, 12(3): 489-505.

Fourqurean, J.W., Duarte, C.M., Kennedy, H., Marbà, N., Holmer, M., Mateo, M.A., Apostolaki, E.T. et al. 2012. Seagrass ecosystem as a globally significant carbon stock. Nature Geoscience, 5: 505-509.

Francis, C., Lieblein, G., Gliessman, S., Breland, T.A., Creamer, N., Harwood, R., Salomonsson, L. et al. 2003. Agroecology: the ecology of food systems. Journal of Sustainable Agriculture, 22(3): 99-118.

Franzel, S., Coe, R., Cooper, P., Place, F. \& Scherr, S.J. 2001. Assessing the adoption potential of agroforestry practices in sub-Saharan Africa. Agricultural Systems, 69(1-2): 37-62.

Free, J.B. 1993. Insect pollination of crops. London, Academic Press.

Freitas, B.M. \& Paxton, R.J. 1998. A comparison of two pollinators: the introduced honey bee Apis mellifera and an indigenous bee Centris tarsata on cashew Anacardium occidentale in its native range of $\mathrm{NE}$ Brazil. Journal of Applied Ecology, 35(1): 109-121.

Friberg, N., Angelopoulos, N.V., Buijse, A.D., Cowx, I.G., Kail, J., Moe, T.F., Moir, H., O’Hare, M.T., Verdonschot, P.F.M. \& Wolter, C. 2016. Effective river restoration in the 21st century: from trial and error to novel evidence-based approaches. Advances in Ecological Research, 55: 535-611.

Frison, E.A., Cherfas, J. \& Hodgkin, T. 2011.

Agricultural biodiversity is essential for a sustainable improvement in food and nutrition security. Sustainability, 3(1): 238-253.

FSC. 2018. Forest Stewardship Council. [Cited 23 April 2018]. https://ic.fsc.org/en
Fuller, D.Q. 2007. Contrasting patterns in crop domestication and domestication rates: recent archaeobotanical insights from the Old World. Annals of Botany, 100: 903-924.

Fürst, M.A., McMahon, D.P., Osborne, J.L., Paxton, R.J. \& Brown, M.J.F. 2014. Disease associations between honeybees and bumblebees as a threat to wild pollinators. Nature, 506: 364-366.

Gaba, S., Gabriel, E., Chadœuf, J., Bonneu, F. \& Bretagnolle, V. 2016. Herbicides do not ensure for higher wheat yield, but eliminate rare plant species. Scientific Reports, 6: 30112.

Gabriel, D., Sait, S.M., Kunin, W.E. \& Benton, T.G. 2013. Food production vs. biodiversity: comparing organic and conventional agriculture. Journal of Applied Ecology, 50(2): 355-364.

Gadgil, M., Berkes, F. \& Folke, C. 1993. Indigenous knowledge for biodiversity conservation. Ambio, 22(2-3): 151-156.

Galhena, D.H., Freed, R. \& Maredia, K.M. 2013. Home gardens: a promising approach to enhance household food security and wellbeing. Agriculture \& Food Security, 2(8).

Gallai, N., Salles, J.M., Settele, J. \& Vaissière, B.E. 2009. Economic valuation of the vulnerability of world agriculture confronted with pollinator decline. Ecological Economics, 68(3): 810-821.

Galloway, J.N., Townsend, A.R., Erisman, J.W., Bekunda, M., Cai, Z., Freney, J.R. \& Sutton, M.A. 2008. Transformation of the nitrogen cycle: recent trends, questions, and potential solutions. Science, 320(5878): 889-892.

Galluzzi, G., Eyzaguirre, P. \& Negri, V. 2009. Uncovering European home gardens: their human and biological features and potential contribution to the conservation of agro-biodiversity. In A. Bailey, P. Eyzaguirre \& L. Maggioni, eds. Crop genetic resources in European home gardens: Proceedings of a Workshop, 3-4 October 2007, Ljubljana, Slovenia, pp. 8-17. Rome, Bioversity International.

Galluzzi, G., Eyzaguirre, P. \& Negri, V. 2010. Home gardens: neglected hotspots of agro-biodiversity and cultural diversity. Biodiversity and Conservation, 19(13): 3635-3654.

Gardi, C., Montanarella, L., Arrouays, D., Bispo, A., Lemanceau, P., Jolivet, C., Mulder, C. et al. 2009. 
Soil biodiversity monitoring in Europe: ongoing activities and challenges. European Journal of Soil Science, 60: 807-819.

Garibaldi, L.A., Carvalheiro, L.G., Leonhardt, S.D., Aizen, M.A., Blaauw, B.R., Isaacs, R., Kuhlmann, M. et al. 2014. From research to action: enhancing crop yield through wild pollinators. Frontiers in Ecology and the Environment, 12(8): 439-447.

Garibaldi, L.A., Steffan-Dewenter, I., Kremen, C., Morales, J.M., Bommarco, R., Cunningham, S.A., Carvalheiro, L.G. et al. 2011. Stability of pollination services decreases with isolation from natural areas despite honey bee visits. Ecology Letters, 14(10): 1062-1072.

Garibaldi, L.A., Steffan-Dewenter, I., Winfree, R., Aizen, M.A., Bommarco, R., Cunningham, S.A., Kremen, C. et al. 2013. Wild pollinators enhance fruit set of crops regardless of honey bee abundance. Science, 340(6127): 1608-1611.

Garibaldi, L.A., Carvalheiro, L.G., Vaissière, B.E., Gemmill-Herren, B., Hipólito, J., Freitas, B.M., Ngo, H.T. et al. 2016. Mutually beneficial pollinator diversity and crop yield outcomes in small and large farms. Science, 351(6271): 388-391.

Garnett, T., Appleby, M.C., Balmford, A., Bateman, I.J., Benton, T.G., Bloomer, P., Burlingame, B. et al. 2013. Sustainable intensification in agriculture: premises and policies. Science, 341(6141): 33-34.

Garrity, D.P., Akinnifesi, F.K., Ajayi, O.C., Weldesemayat, S.G., Mowo, J.G., Kalinganire, A., Larwanou, M. \& Bayala, J. 2010. Evergreen agriculture: a robust approach to sustainable food security in Africa. Food Security, 2: 197-214.

Gaston, K. \& Spicer, J. 2004. Does biodiversity matter? In K. Gaston \& J. Spicer, eds. Biodiversity: an introduction, pp. 91-107. Malden, USA, Blackwell Publishing

Gaupp-Berghausen, M., Hofer, M., Rewald, B. \& Zaller, J.G. 2015. Glyphosate-based herbicides reduce the activity and reproduction of earthworms and lead to increased soil nutrient concentrations. Scientific Reports, 5: 12886

GEAS (UN Environment Global Alert Service). 2013. Mangrove forest cover fading fast. Environmental Development, 8: 105-112. (available at https:// na.unep.net/geas/archive/pdfs/GEAS_Aug2013_ Mangroves.pdf).
Geburek, T. \& Müller, F. 2005. How can silvicultural management contribute to genetic conservation? In T. Geburek \& J. Turok, eds. Conservation and management of forest genetic mesources in Europe, pp. 651-669. Zvolen, Slovakia, Arbora Publishers.

GEF (Global Environment Facility). 2016. Pacific R2R Ridge to Reef - Home. [Cited 29 June 2018]. https:// www.pacific-r2r.org/

Geiger, F., Bengtsson, J., Berendse, F., Weisser, W.W., Emmerson, M., Morales, M.B., Ceryngier, P. et al. 2010. Persistent negative effects of pesticides on biodiversity and biological control potential on European farmland. Basic and Applied Ecology, 11(2): 97-105.

Geldmann, J., Coad, L., Barnes, M., Craigie, I.D., Hockings, M., Knights, K., Leverington, F. et al. 2015. Changes in protected area management effectiveness over time: a global analysis. Biological Conservation, 191: 692-699.

GEO BON Secretariat. 2016. Global Wetlands Observing System (GWOS). [Cited 21 March 2018]. http://geobon.org/global-wetlands-observingsystem-gwos/

Gerber, P.J., Steinfeld, H., Henderson, B., Mottet, A., Opio, C., Dijkman, J., Falcucci, A. \& Tempio, G. 2013. Tackling climate change through livestock - A global assessment of emissions and mitigation opportunities. Rome, FAO. (available at http://www. fao.org/3/a-i3437e.pdf).

Giannini, T., Boff, S., Cordeiro, G., Cartolano Jr., E., Veiga, A., Imperatriz-Fonseca, V. \& Saraiva, A.M. 2015. Crop pollinators in Brazil: a review of reported interactions. Apidologie, 46: 209-223.

Gibbs, H.K. \& Salmon, J.M. 2015. Mapping the world's degraded lands. Applied Geography, 57: 12-21.

Giller, K.E. Andersson, J.A., Corbeels, M., Kirkegaard, J., Mortensen, D., Erenstein, O. \& Vanlauwe, B. 2015. Beyond conservation agriculture. Frontiers in Plant Science, 6: 870.

Gilman, R.T., Fabina, N.S., Abbott, K.C. \& Rafferty, N.E. 2012. Evolution of plant-pollinator mutualisms in response to climate change. Evolutionary Applications, 5(1): 2-16.

Giraffa, G. \& Carminati, D. 2008. Molecular techniques in food fermentation: principles and applications. In L. Cocolin \& D. Ercolini, eds. Molecular techiques in 
the microbial ecology of fermented foods, pp. 1-30. New York, Springer Science \& Business Media.

Gjedrem, T., Robinson, N. \& Rye, M. 2012. The importance of selective breeding in aquaculture to meet future demands for animal protein: a review. Aquaculture, 350: 117-129.

Gleick, P.H., Singh, A. \& Shi, H. 2001. Emerging threats to the world's freshwater resources. Oakland, USA, Pacific Institute for Studies in Development, Environment, and Security.

Gliessman, S. 1997. Agroecology: ecological processes in sustainable agriculture. Boca Raton, USA, CRC Press.

Gliessman, S. 2015. Agroecology - the ecology of sustainable food systems. Boca Raton, USA, CRC Press.

Global Greenhouse Gas Reference Network. 2017. What is the Global Greenhouse Gas Reference Network? [Cited 22 March 2018]. https://www.esrl. noaa.gov/gmd/about/contacts.html

Global Panel. 2017. Urban diets and nutrition: trends, challenges and opportunities for policy action. Policy Brief No. 9. London, UK, Global Panel on Agriculture and Food Systems for Nutrition.

Global Partnership on Forest Landscape Restoration. 2018. The Bonn challenge - Commitments. [Cited 29 May 2018]. http://www.bonnchallenge.org/ commitments

GMSA. 2017. About the Global Marine Species Assessment (GMSA). [Cited 21 March 2018]. https:// sites.wp.odu.edu/GMSA/about/

GOA-ON. 2016. Global Ocean Acidification Observing Network. [Cited 21 March 2018]. http://www.goaon.org/home.php

Godde, C.M., Garnett, T., Thornton, P.K., Ash, A.J. \& Herrero, M. 2018. Grazing systems expansion and intensification: drivers, dynamics, and trade-offs. Global Food Security, 16: 93-105.

Godfray, H.C.J. 1994. Parasitoids: behavioral and evolutionary ecology. Princeton, USA, Princeton University Press.

Godfray, H.C.J. 2015. The debate over sustainable intensification. Food Security, 7(2): 199-208.

Goettsch, B., Durán, A.P. \& Gaston, K.J. 2018. Global gap analysis of cactus species and priority sites for their conservation. Conservation Biology, doi: 10.1111/cobi.13196.
Goka, K., Okabe, K. \& Yoneda, M. 2006. Worldwide migration of parasitic mites as a result of bumblebee commercialization. Population Ecology, 48(4): 285-291.

Golden, C.D., Fernald, L.C.H., Brashares, J.S., Rasolofoniaina, B.J.R. \& Kremen, C. 2011. Benefits of wildlife consumption to child nutrition in a biodiversity hotspot. Proceedings of the National Academy of Sciences, 108(49): 19653-19656.

Gómez, M.I. \& Ricketts, K.D. 2013. Food value chain transformations in developing countries: selected hypotheses on nutritional implications. Food Policy, 42: 139-150.

Gómez-Baggethun, E. \& Ruiz-Pérez, M. 2011. Economic valuation and the commodification of ecosystem services. Progress in Physical Geography, 35(5): 613-628.

Gonzalez Fischer, C. \& Garnett, T. 2016. Plates, pyramids, planet. Developments in national healthy and sustainable dietary guidelines: a state of play assessment. Rome, FAO, and Oxford, UK, Food Climate Research Network. (available at http://www. fao.org/3/a-i5640e.pdf).

González-Acereto, J.A., Quezada-Euán, J.J.G. \& Medina-Medina, L.A. 2006. New perspectives for stingless beekeeping in the Yucatán: results of an integral program to rescue and promote the activity. Journal of Apicultural Research, 45(4): 234-239.

González-Sánchez, E.J., Moreno-García, M., Kassam, A., Holgado-Cabrera, A., Triviño-Tarradas, P., Carbonell-Bojollo, R., Pisante, M., VerozGonzález., O. \& Basch, G. 2017. Conservation agriculture: making climate change mitigation and adaptation real in Europe. Brussels, European Conservation Agriculture Federation (ECAF).

Goodman, D., DuPuis, M. \& Goodman, M. 2012. Alternative food networks. New York, USA, Routledge.

Gould, D. 2007. Training Guide 4.0 for small farmers' organizations "Developing and Implementing Internal Control Systems with Focus on Fair Trade Environmental Standards". Bonn, Germany, Fairtrade Labelling Organizations International.

Goulson, D. 2003. Effects of introduced bees on native ecosystems. Annual Review of Ecology Evolution and Systematics, 34: 1-26. 
Goulson, D. 2013. An overview of the environmental risks posed by neonicotinoid insecticides. Journal of Applied Ecology, 50: 977-987.

Government of Ethiopia. 2015. Ethiopia's National Biodiversity Strategy and Action Plan 2015-2020. Addis Ababa, Ethiopian Biodiversity Institute.

Government of India. 2017. Indian State of Forest Report (ISFR)-2017, Volume 17, 2016-17. Forest Survey of India. New Delhi.

Government of Switzerland. 2012. Swiss Biodiversity Strategy. Bern, Federal Office for the Environment FOEN.

Graham, E., Grandy, S. \& Thelen, M. 2009. Manure effects on soil organisms and soil quality. Emerging Issues in Animal Agriculture. East Lansing, USA, Michigan State University.

Grau, H.R. \& Aide, M. 2008. Globalization and land-use transitions in Latin America. Ecology and Society, 13(2): 16-27.

Graudal, L. \& Lillesø, J.P.B. 2007. Experiences and future prospects for tree seed supply in agricultural development support: based on lessons learnt in Danida supported programmes 1965-2005. Copenaghen, Ministry of Foreign Affairs of Denmark.

Graves, A., Matthews, R. \& Waldie, K. 2004. Low external input technologies for livelihood improvement in subsistence agriculture. Advances in Agronomy, 82: 473-555.

Gray, C.L. \& Bilsborrow, R.E. 2014. Consequences of out-migration for land use in rural Ecuador. Land Use Policy, 36: 182-191.

Green, E.P. \& Short, F.T. 2003. World atlas of seagrasses. Los Angeles, USA, University of California Press.

Gregory, N.G. 1995. The role of shelterbelts in protecting livestock: a review. New Zealand Journal of Agricultural Research, 38(4): 423-450.

Gregory, R.D. \& van Strien, A. 2010. Wild bird indicators: using composite population trends of birds as measures of environmental health. Ornithological Science, 9(1): 3-22.

Gregory, R.D., van Strien, A., Vorisek, P., Gmelig Meyling, A.W., Noble, D.G., Foppen, R.P.B. \& Gibbons, D.W. 2005. Developing indicators for European birds. Philosophical Transactions of the Royal Society B: Biological Sciences, 360(1454): 269-288.
Gregory, R.D., Vořišek, P., Noble, D.G., Van Strien, A., Klvaňová, A., Eaton, M., Meyling, A.W.G., Joys, A., Foppen, R.P.B. \& Burfield, I.J. 2008. The generation and use of bird population indicators in Europe. Bird Conservation International, 18: S223-S244.

Grémillet, D. \& Boulinier, T. 2009. Spatial ecology and conservation of seabirds facing global climate change: a review. Marine Ecology Progress Series, 391: 121-137.

Griffin, J., Byrnes, J. \& Cardinale, B. 2013. Effects of predator richness on prey suppression: a metaanalysis. Ecology, 94(10): 2180-2187.

Griffiths, B.S., Ritz, K., Bardgett, R.D., Cook, R., Christensen, S., Ekelund, F., Sorensen, S.J. et al. 2000. Ecosystem response of pasture soil communities to fumigation-induced microbial diversity reductions: an examination of the biodiversity-ecosystem function relationship. Oikos, 90(2): 279-294.

GRISP (Global Rice Science Partnership). 2013. Rice almanac, 4th edition. Los Baños, Philippines, International Rice Research Institute. (available at http://books.irri.org/9789712203008_content.pdf).

Grivetti, L.E. \& Ogle, B.M. 2000. Value of traditional foods in meeting macro- and micronutrient needs: the wild plant connection. Nutrition Research Reviews, 13(01): 31.

Grubben, G.J.H. \& Denton, O.A. 2004. Plant resources of Tropical Africa 2. Vegetables. Wageningen, Netherlands, PROTA Foundation.

Gruber, B., Evans, D., Henle, K., Bauch, B., Schmeller, D., Dziock, F., Henry, P.-Y., Lengyel, S., Margules, C. \& Dormann, C. 2012. "Mind the gap!" - How well does Natura 2000 cover species of European interest? Nature Conservation, 3: 45-62.

Gugić, G., Župan, D. \& Zupan, I. 2012. Croatia: the floodplain ecosystem of the Centraal Sava River Basin. In N. Dudley \& S. Stolton, eds. Protected landscapes and wild biodiversity, pp. 19-26. Values of protected landscapes and seascapes, Volume 3. Gland, Switzerland, The Protected Landscapes Specialist Group of IUCN's World Commission on Protected Areas.

Guizani, N. \& Mothershaw, A. 2007. Fermentation as a method for food preservation. Handbook of food preservation. Second edition, pp. 215-236. New York, USA, CRC Press. 
Gunasena, H.P.M. \& Roshetko, J.M. 2000. Tree domestication in Southeast Asia: results of a regional study on institutional capacity. Bogor, Indonesia, ICRAF Southeast Asia Regional Program.

Guo, J.H. 2010. Significant acidification in major Chinese croplands. Science, 327(5968): 1008-1010.

Gupta, R.B., Chaudhari, P.R. \& Wate, S.R. 2008. Overview on attenuation of industrial air pollution by greenbelt. Journal of Industrial Pollution Control, 24(1): 1-8.

Gurr, G., Read, D., Catindig, J., Cheng, J., Liu, J., Lan, L. \& Heong, K. 2011. Parasitoids of the rice leaffolder Cnaphalocrocis medinalis and prospects for enhancing biological control with nectar plants. Agricultural and Forest Entomology, 14(1): 1-12.

Gurr, G.M., Wratten, S.D., Landis, D.A. \& You, M. 2017. Habitat management to suppress pest populations: progress and prospects. Annual Review of Entomology, 62(1): 91-109.

Gutiérrez-Salmeán, G., Fabila-Castillo, L. \& Chamorro-Cevallos, G. 2015. Nutritional and toxicological aspects of Spirulina (Arthrospira). Nutricion hospitalaria, 32(1): 34-40.

Haard, N.F., Odunfa, S.A., Cherl-Ho, L. \& QuinteroRamírez, R. 1999. Fermented cereals. A global perspective. FAO Agricultural Services Bulletin No. 138. Rome, FAO.

Haddad, N.M., Brudvig, L.A., Clobert, J., Davies, K.F., Gonzalez, A., Holt, R.D., Lovejoy, T.E. et al. 2015 Habitat fragmentation and its lasting impact on Earth's ecosystems. Science Advances, 1(2): 1-9.

Haider, J.L., Quinlan, A. \& Peterson, G.D. 2012. Interacting traps: resilience assessment of a pasture management system in Northern Afghanistan. Planning Theory and Practice, 13: 299-333.

Hall, S.J., Delaporte, A., Phillips, M.J., Beveridge, M. \& O'Keefe, M. 2011. Blue frontiers: managing the environmental costs of aquaculture. Penang, Malaysia, The WorldFish Centre.

Hallmann, C.A., Sorg, M., Jongejans, E., Siepel, H., Hofland, N., Schwan, H., Stenmans, W. et al. 2017. More than 75 percent decline over 27 years in total flying insect biomass in protected areas. PLOS ONE, 12(10): e0185809.
Halpern, B.S. 2003. The impact of marine reserves : do reserves work and does reserve size matter? Ecological Applications, 13(1): 117-137.

Halpern, B.S., Ebert, C.M., Kappel, C. V, Madin, E.M.P., Micheli, F., Perry, M., Selkoe, K.A. \& Walbridge, S. 2009. Global priority areas for incorporating land-sea connections in marine conservation. Conservation Letters, 2(4): 189-196.

Halpern, B.S., Longo, C., Hardy, D., McLeod, K.L., Samhouri, J.F., Katona, S.K., Kleisner, K. et al. 2012. An index to assess the health and benefits of the global ocean. Nature, 488: 615-620.

Halpern, B.S., Frazier, M., Afflerbach, J., O’Hara, C., Katona, S., Stewart Lowndes, J.S., Jiang, N., Pacheco, E., Scarborough, C. \& Polsenberg, J. 2017. Drivers and implications of change in global ocean health over the past five years. PLOS ONE, 12(7): e0178267.

Halwart, M. 2006. Biodiversity and nutrition in rice-based aquatic ecosystems. Journal of Food Composition and Analysis, 19(6-7): 747-751.

Halwart, M. 2008. Biodiversity, nutrition and livelihoods in aquatic rice-based ecosystems. Biodiversity, 9(1-2): 36-40.

Halwart, M. \& Gupta, M. V. 2004. Culture of fish in rice fields. Rome, FAO, and Penang, Malaysia, WorldFish Center. (available at http://www.fao.org/3/a-a0823e. pdf).

Halwart, M., Bartley, D., Buoeno, P.B. \& InnesTaylor, N., eds. 2016. Aquaculture and fisheries in rice-based ecosystems: studies and reports from Indonesia, Lao PDR and the Philippines. Rome, FAO. (available at http://www.fao.org/3/a-i3841e.pdf).

Hamilton, S.E. \& Casey, D. 2016. Creation of a high spatio-temporal resolution global database of continuous mangrove forest cover for the 21st century (CGMFC-21). Global Ecology and Biogeography, 25: 729-738.

Hanan, N.P. 2018. Agroforestry in the Sahel. Nature Geoscience: 11: 296-297.

Handelsman, J. 2004. Metagenomics: application of genomics to uncultured microorganisms. Microbiology and Molecular Biology Reviews, 68(4): 669-685.

Hannon, E.R. \& Beers, E.H. 2007. Carpenterworm. [Cited 27 April 2018]. http://jenny.tfrec.wsu.edu/ opm/displaySpecies.php?pn=575 
Harpur, B.A., Minaei, S., Kent, C.F. \& Zayed, A. 2012. Management increases genetic diversity of honey bees via admixture. Molecular Ecology, 21: 4414-4421.

Harris, D.R. 1989. An evolutionary continuum of peopleplant interaction. In D.R. Harris \& G.C. Hillman, eds. Foraging and farming: the evolution of plant exploitation, pp. 11-26. London, Unwin Hyman.

Harrison, G.W. \& Rutström, E.E. 2008. Experimental evidence on the existence of hypothetical bias in value elicitation methods. In C.R. Plott \& V.L. Smith, eds. Handbook of experimental economics results, pp. 752-767. Amsterdam, North Holland.

Harrison, S., Gregorio, N. \& Herbohn, J. 2008. A critical overview of forestry seedling production policies and practices in relation to smallholder forestry in developing countries. Small-scale Forestry, 7: 207-223.

Harrison, P.A., Berry, P.M., Simpson, G., Haslett, J.R., Blicharska, M., Bucur, M., Dunford, R. et al. 2014. Linkages between biodiversity attributes and ecosystem services: a systematic review. Ecosystem Services, 9: 191-203.

Hassell, J.M., Begon, M., Ward, M.J. \& Fèvre, E.M. 2017. Urbanization and disease emergence: dynamics at the wildlife-livestock-human interface. Trends in Ecology and Evolution, 32(1): 55-67.

Hauer, F.R., Locke, H., Dreitz, V.J., Hebblewhite, M., Lowe, W.H., Muhlfeld, C.C. \& Rood, S.B. 2016. Gravel-bed river floodplains are the ecological nexus of glaciated mountain landscapes. Science Advances, 2(6): e1600026.

Hawkes, C. 2008. Dietary implications of supermarket development: a global perspective. Development Policy Review, 26(6): 657-692.

Hawkes, C., Chopra, M. \& Friel, S. 2009. Globalization, trade, and the nutrition transition. In R. Labonte, T. Schrecker, C. Packer \& V. Runnels, eds. Globalization and health: pathways, evidence and policy, pp. 235-262. New York, USA, Routledge.

Hayes, B.J., Lewin, H.A. \& Goddard, M.E. 2013. The future of livestock breeding: genomic selection for efficiency, reduced emissions intensity, and adaptation. Trends in Genetics, 29(4): 206-214.

Hazell, P. \& Wood, S. 2008. Drivers of change in global agriculture. Philosophical Transactions of the Royal Society B: Biological Sciences, 363(1491): 495-515.
Heard, T.A. 1999. The role of stingless bees in crop pollination. Annual Review of Entomology, 44(1): 183-206.

Heard, T.A. \& Dollin, A.E. 2000. Stingless bee keeping in Australia: snapshot of an infant industry. Bee World, 81(3): 116-125.

Heck, K.L., Hays, G. \& Orth, R.J. 2003. Critical evaluation of the nursery role hypothesis for seagrass meadows. Marine Ecology Progress Series, 253: 123-136.

Heesterbeek, H., Anderson, R., Andreasen, V., Bansal, S., De Angelis, D., Dye, C., Eames, K. et al. 2015. Modeling infectious disease dynamics in the complex landscape of global health. Science, 13(347): 6227.

Heimpel, G.E. \& Cock, M.J.W. 2018. Shifting paradigms in the history of classical biological control. BioControl, 63(1): 27-37.

Hein, L. 2011. Economic benefits generated by protected areas : the case of the Hoge Veluwe forest, the Netherlands. Ecology And Society, 16(2): 13.

Hemp, A. 2006. The banana forests of Kilimanjaro: biodiversity and conservation of the Chagga homegardens. Biodiversity and Conservation, 15(4): 1193-1217.

Henderson, G., Cox, F., Ganesh, S., Jonker, A., Young, W., Collaborators, G.R. \& Janssen, P.H. 2015. Rumen microbial community composition varies with diet and host, but a core microbiome is found across a wide geographical range. Scientific Reports, 5: 1-13.

Henry, M., Tittonell, P., Manlay, R.J., Bernoux, M., Albrecht, A. \& Vanlauwe, B. 2009. Biodiversity, carbon stocks and sequestration potential in aboveground biomass in smallholder farming systems of western Kenya. Agriculture, Ecosystems and Environment, 129(1-3): 238-252.

Henry, L.M., Nigel, M., Acheampong, S., Gillespie, D.R. \& Roitberg., B.D. 2010. Host-adapted parasitoids in biological control: does source matter? Ecological Applications, 20(1): 242-250.

Heong, K., Manza, A., Catindig, J., Villareal, S. \& Jacobsen, T. 2007. Changes in pesticide use and arthropod biodiversity in the IRRI research farm. Outlooks on Pest Management, 18(5): 229-233.

Heron, S.F., Eakin, C.M. \& Douver, F. 2017. Impacts of climate change on World Heritage coral reefs: a first global scientific assessment. Paris, UNESCO. 
Herrero, M., González-Estrada, E., Thornton, P.K., Quirós, C., Waithaka, M.M., Ruiz, R. \& Hoogenboom, G. 2007. IMPACT: Generic household-level databases and diagnostics tools for integrated crop-livestock systems analysis. Agricultural Systems, 92(1-3): 240-265.

Herrero, M., Thornton, P.K., Notenbaert, A., Msangi, S., Wood, S., Kruska, R., Dixon, J. et al. 2012.

Drivers of change in crop-livestock systems and their potential impacts on agro-ecosystems services and human wellbeing to 2030. A study commissioned by the CGIAR Systemwide Livestock Programme. Nairobi, International Livestock Research Institute.

Herrero, M., Havlik, P., Valin, H., Notenbaert, A., Rufino, M.C., Thornton, P.K., Blummel, M., Weiss, F., Grace, D. \& Obersteiner, M. 2013. Biomass use, production, feed efficiencies, and greenhouse gas emissions from global livestock systems. Proceedings of the National Academy of Sciences, 110(52): 20888-20893.

Herrero, M., Havlik, P., Mclntire, J., Palazzo, A. \& Valin, H. 2014. African livestock futures: realizing the potential of livestock for food security, poverty reduction and the environment in sub-Saharan Africa. Office of the Special Representative of the UN Secretary General for Food Security and Nutrition and the United Nations System.

Hesse, C., Anderson, S., Cotula, L., Skinner, J. \& Toulmin, C. 2013. Managing the boom and bust: supporting climate resilient livelihoods in the sahel. IIED Issue Paper. London, International Institute for Environment and Development.

Heywood, V.H. 2013. Overview of agricultural biodiversity and its contribution to nutrition and health. In J. Fanzo, D. Hunter, T. Borelli \& F. Mattei, eds. Diversifying food and diets: using agricultural biodiversity to improve nutrition and health, pp. 35-67. Oxford, UK, Routledge.

Hickey, G.M., Pouliot, M., Smith-Hall, C., Wunder, S. \& Nielsen, M.R. 2016. Quantifying the economic contribution of wild food harvests to rural livelihoods: a global-comparative analysis. Food Policy, 62: 122-132.

Hicks, C., Woroniecki, S., Fancourt, M., Bieri, M., Garcia Robles, H., Trumper, K. \& Mant, R. 2014. The relationship between biodiversity, carbon storage and the provision of other ecosystem services: critical review for the forestry component of the International Climate Fund. Cambridge, UK, UNEP.

Hilborn, R. 2011. Future directions in ecosystem based fisheries management: a personal perspective. Fisheries Research, 108: 235-239.

HLPE. 2014a. Sustainable fisheries and aquaculture for food security and nutrition. A report by the High Level Panel of Experts on Food Security and Nutrition of the Committee on World Food Security. Rome. (available at http://www.fao.org/3/a-i3844e.pdf).

HLPE. 2014b. Food losses and waste in the context of sustainable food systems. A report by the High Level Panel of Experts on Food Security and Nutrition of the Committee on World Food Security. Rome. (available at http://www.fao.org/3/a-i3901e.pdf).

HLPE. 2016. Sustainable agricultural development for food security and nutrition: what roles for livestock? A report by the High Level Panel of Experts on Food Security and Nutrition of the Committee on World Food Security. Rome. (available at http://www.fao. org/3/a-i5795e.pdf).

HLPE. 2017a. Sustainable forestry for food security and nutrition. A report by the High Level Panel of Experts on Food Security and Nutrition of the Committee on World Food Security. Rome. (available at http://www. fao.org/3/a-i7395e.pdf).

HLPE. 2017b. Nutrition and food systems. A report by the High Level Panel of Experts on Food Security and Nutrition of the Committee on World Food Security. Rome. (available at http://www.fao.org/3/a-i7846e.pdf)

Hocking, D. \& Babbit, K. 2014. Amphibian contributions to ecosystem services. Herpetological Conservation and Biology, 9(1): 1-17.

Hocking, D.J. \& Babbitt, K.J. 2014. Effects of redbacked salamanders on ecosystem functions. PLOS ONE, 9(1).

Hoffmann, M., Hilton-Taylor, C., Angulo, A., Böhm, M., Brooks, T.M., Butchart, S.H.M., Carpenter, K.E. et al. 2010. The impact of conservation on the status of the world's vertebrates. Science, 330(6010): 1503-1509.

Hofstede, R., Segarra, P. \& Mena, P.V. 2003. LoS páramos del mundo. Proyecto atlas mundial de los páramos. Quito, Global Peatland Initiative/NC-IUCN/ EcoCiencia. 
Hogarth, P.J. 2015. The biology of mangroves and seagrasses. Third edition. Oxford, UK, Oxford University Press.

Holding-Anyonge, C. \& Roshetko, J.M. 2003. Farmlevel timber production: orienting farmers towards the market. Unaslyva, 212(54): 48-56.

Holl, K.D. 2017. Restoring tropical forests from the bottom up. Science, 355: 455-456.

Holland, G.J. 2012. Hurricanes and rising global temperatures. PNAS, 109(48): 19513-19514.

Holland, J., Oaten, H., Moreby, S., Birkett, T., Simper, J., Southway, S. \& Smith, B. 2012. Agrienvironment scheme enhancing ecosystem services: a demonstration of improved biological control in cereal crops. Agriculture, Ecosystems \& Environment, 155: 147-152.

Holland, J.M., Smith, B.M., Storkey, J., Lutman, P.J.W. \& Aebischer, N.J. 2015. Managing habitats on English farmland for insect pollinator conservation. Biological Conservation, 182: 215-222.

Holling, C.S. 1973. Resilience and stability of ecological systems. Annual Review of Ecology and Systematics, 4: 1-23.

Holzschuh, A., Steffan-Dewenter, I. \& Tscharntke, T. 2008. Agricultural landscapes with organic crops support higher pollinator diversity. Oikos, 117(3): 354-361.

Holzschuh, A., Steffan-Dewenter, I. \& Tscharntke, T. 2010. How do landscape composition and configuration, organic farming and fallow strips affect the diversity of bees, wasps and their parasitoids? Journal of Animal Ecology, 79(2): 491-500.

Hooper, D.U., Chapin, F.S., Ewel, J.J., Hector, A., Inchausti, P., Lavorel, S., Lawton, J.H. et al. 2005. Effects of biodiversity on ecosystem functioning: a consensus of current knowledge. Ecological Monographs, 75(1): 3-35.

Hopkins, K.B. \& Herr, C. 2010. Factors affecting the successful cryopreservation of honey bee (Apis mellifera) spermatozoa. Apidologie, 41: 548-556.

Hopkins, B.K., Herr, C. \& Sheppard, W.S. 2012. Sequential generations of honey bee (Apis mellifera) queens produced using cryopreserved semen. Reproduction, Fertility and Development, 24(8): 1079-1083.

Hopper, K.R., Roush, R.T. \& Powell, W. 1993. Management of genetics of biological control.
Introductions. Annual Review of Entomology 38: 27-51.

Hosonuma, N., Herold, M., de Sy, V., de Fries, R.S., Brockhaus, M., Verchot, L., Angelsen, A. \& Romijn, E. 2012. An assessment of deforestation and forest degradation drivers in developing countries. Environmental Research Letters, 7(4): 4009.

Howard, P. 2003. The major importance of "minor" resources: women and plant biodiversity. Gatekeeper Series No. 112. London, International Institute for Environment and Development Natural Resources Group and Sustainable Agriculture and Rural Livelihoods Programme.

Huang, Y., Chen, Y., Castro-Izaguirre, N., Baruffol, M., Brezzi, M., Lang, A., Li, Y. et al. 2018. Impacts of species richness on productivity in a large-scale subtropical forest experiment. Science, 362(6410): 80-83.

Huenneke, L.F. 1991. Ecological implications of genetic variation in plant populations. In D.A. Falk \& K.E. Holsinger, eds. Genetics and conservation of rare plants, pp. 31-44. Oxford, UK, Oxford University Press.

Huerta Lwanga, E., Gertsen, H., Gooren, H., Peters, P., Salánki, T., Van Der Ploeg, M., Besseling, E., Koelmans, A.A. \& Geissen, V. 2016. Microplastics in the terrestrial ecosystem: implications for Lumbricus terrestris (Oligochaeta, Lumbricidae). Environmental Science \& Technology. 50(5): 2685-2691.

Huertas, I.E., Rouco, M., López-Rodas, V. \& Costas, E. 2011. Warming will affect phytoplankton differently: evidence through a mechanistic approach. Proceedings of the Royal Society B: Biological Sciences, 278: 3534-3543.

Hughes, T.P., Kerry, J.T., Álvarez-Noriega, M., Álvarez-Romero, J.G., Anderson, K.D., Baird, A.H., Babcock, R.C. et al. 2017. Global warming and recurrent mass bleaching of corals. Nature, 543(7645): 373-377.

Hughes, T.P., Anderson, K.D., Connolly, S.R., Heron, S.F., Kerry, J.T., Lough, J.M., Baird, A.H. et al. 2018. Spatial and temporal patterns of mass bleaching of corals in the Anthropocene. Science, 359(6371): 80-83.

Hungate, R.E. 1966. The rumen and its microbes. New York, USA, Academic Press. 
Hunter, D., Pouono, K. \& Semisi, S. 1998. The impact of taro leaf blight in the Pacific Islands with special reference to Samoa. Journal of South Pacific Agriculture, 5(2): 44-56.

Husch, B. 1987. Guideilines for forest policy formulation. FAO Forestry Paper No. 81. Rome, FAO. (available at http://www.fao.org/docrep/016/ap462e/ ap462e00.pdf).

Hussain, S., Siddique, T., Saleem, M., Arshad, M. \& Khalid, A. 2009. Chapter 5: Impact of pesticides on soil microbial diversity, enzymes, and biochemical reactions. Advances in Agronomy, 102: 159-200.

Hylander, K. \& Nemomissa, S. 2008. Home garden coffee as a repository of epiphyte biodiversity in Ethiopia. Frontiers in Ecology and the Environment, 6(10): 524-528.

IAASTD (International Assessment of Agricultural Knowledge, Science and Technology for Development). 2009. Global report: agriculture at a crossroads. B.D. McIntyre, H.R. Herren, J. Wakhungu \& R.T. Watson, eds. (available at http://www.fao.org/ fileadmin/templates/est/Investment/Agriculture_at_a_ Crossroads_Global_Report_IAASTD.pdf).

Ibrahim, A., Reuter, G.S. \& Spivak, M. 2007. Field trial of honey bee colonies bred for mechanisms of resistance against Varroa destructor. Apidologie, 38: 67-76.

ICCA Consortium. 2018. ICCA Consortium. (available at https://www.iccaconsortium.org/).

ICCA Registry. 2012. ICCA Registry Case Studies: Kawawana, Senegal. [Cited 5 April 2018]. http:// www.iccaregistry.org/en/explore/Senegal/kawawana-

ICES (International Council for the Exploration of the Sea). 2013. Report of the ICES Advisory Committee 2013. Book 1: Introduction, overviews and special requests. Copenaghen.

ICIPE (International Centre of Insect Physiology and Ecology). 2015. The "push-pull" farming system: climate-smart, sustainable agriculture for Africa. Nairobi.

Ickowitz, A., Powell, B., Salim, M.A. \& Sunderland, T.C.H. 2014. Dietary quality and tree cover in Africa. Global Environmental Change, 24(1): 287-294.

IFA (International Forum for Agroecology). 2015. Declaration of the International Forum for Agroecology. Development, 58 (2-3): 163-168.

\section{IFOAM (International Federation of Organic} Agriculture Movements). 2017. The IFOAM norms for organic production and processing. Version 2014. Bonn, Germany, IFOAM-Organics International.

IIASA \& FAO. 2012. Global agro-ecological zones (GAEZ v3.0). Laxenburg, Austria, International Institute for Applied Systems Analysis, and Rome, FAO.

Ilstedt, U., Bargués Tobella, A., Bazié, H.R., Bayala, J., Verbeeten, E., Nyberg, G., Sanou, J. et al. 2016. Intermediate tree cover can maximize groundwater recharge in the seasonally dry tropics. Scientific Reports, 6: 21930.

IPBES (Intergovernmental Science-Policy Platform on Biodiversity and Ecosystem Services). 2014. IPBES-4/1: Work programme of the Platform. Bonn, Germany, Secretariat of the IPBES.

IPBES. 2016a. The assessment report on pollinators, pollination and food production of the Intergovernmental Science-policy Platform on Biodiversity and Ecosystem Services. S.G. Potts, V.L. Imperatriz-Fonseca \& H.T. Ngo, eds. Bonn, Secretariat of the IPBES.

IPBES. 2016b. Summary for policymakers of the assessment report of the Intergovernmental SciencePolicy Platform on Biodiversity and Ecosystem Services on pollinators, pollination and food production. S.G. Potts, V.L. Imperatriz-Fonseca, H.T. Ngo, J.C. Biesmeijer, T.D. Breeze, L.V. Dicks, L.A. Garibaldi et al., eds. Bonn, Secretariat of the IPBES.

IPBES. 2018a. Summary for policymakers of the thematic assessment report on land degradation and restoration of the Intergovernmental Science-Policy Platform on Biodiversity and Ecosystem Services.

R. Scholes, L. Montanarella, A. Brainich, N. Barger, B. ten Brink, M. Cantele, B. Erasmus et al., eds. Bonn, Germany, Secretariat of the IPBES. (available at https://www.ipbes.net/system/tdf/spm_3bi_ldr_ digital. pdf?file=1\&type=node\&id=28335).

IPBES. 2018b. Science and policy for people and nature [online]. Bonn, Germany. [Cited 25 June 2018]. https:// www.ipbes.net/ipbes-science-policy-people-nature

IPBES. 2018c. IPBES/6/INF/3/Rev.1. Chapters of the regional and subregional assessment of biodiversity and ecosystem services for Africa. Bonn, Germany, Secretariat of the Intergovernmental Science-Policy Platform on Biodiversity and Ecosystem Services. 
IPBES. 2018d. IPBES/6/INF/4/Rev. 1. Chapters of the regional and subregional assessment of biodiversity and ecosystem services for the Americas.

Bonn, Germany, Germany, Secretariat of the Intergovernmental Science-Policy Platform on Biodiversity and Ecosystem Services.

IPBES. 2018e. IPBES/6/INF/5/Rev. 1. Chapters of the regional and subregional assessment of biodiversity and ecosystem services for Asia and the Pacific. Bonn, Germany, Secretariat of the Intergovernmental SciencePolicy Platform on Biodiversity and Ecosystem services.

IPBES. forthcoming (a). Global assessment on biodiversity and ecosystem services. Bonn, Germany, Secretariat of the IPBES.

IPBES. forthcoming (b). Thematic assessment on land degradation and restoration. Bonn, Germany, Secretariat of the IPBES.

IPC (International Planning Committee for Food Sovereignty). forthcoming. Biodiversity for food and agriculture: the perspectives of small-scale providers. Thematic study prepared by the IPC Agricultural Biodiversity Working Group for The State of the World's Biodiversity for Food and Agriculture. Rome.

IPCC (Intergovernmental Panel on Climate Change).

2012. Managing the risks of extreme events and disasters to advance climate change adaptation. A Special Report of Working Groups I and II of the Intergovernmental Panel on Climate Change. C.B. Field, V. Barros, T.F. Stocker, D. Qin, D.J. Dokken, K.L. Ebi, M.D. Mastrandrea, K.J. Mach, G.-K. Plattner, S.K. Allen, M. Tignor \& P.M. Midgley, eds. Cambridge, UK, Cambridge University Press.

IPCC. 2014. Climate change 2014: impacts, adaptation, and vulnerability. Part A: Global and sectoral aspects. Contribution of Working Group II to the Fifth Assessment Report of the Intergovernmental Panel on Climate Change. Cambridge, UK, and New York, USA, Cambridge University Press.

IPES-Food. 2017. Too big to feed - Exploring the impacts of mega-mergers, concentration, concentration of power in the agri-food sector. Brussels (available at http://www.ipes-food.org/_img/ upload/files/Concentration_FullReport.pdf).

IPGRI \& FAO. 2001. Broadening the genetic base of crop production. H.D. Cooper, C. Spillane \& T. Hodgkin, eds. Wallingford, UK, CABI.
IPK (Leibniz Institute of Plant Genetics and Crop Plant Research). 2017. Mansfeld's World Database of Agriculture and Horticultural Crops. [Cited 25 June 2018]. http://mansfeld.ipk-gatersleben.de/ apex/f?p=185:3

Isaacs, R. \& Kirk, A.K. 2010. Pollination services provided to small and large highbush blueberry fields by wild and managed bees. Journal of Applied Ecology, 47: 841-849.

Isaacs, R., Tuell, J., Fiedler, A., Gardiner, M. \& Landis, D. 2009. Maximizing arthropod-mediated ecosystem services in agricultural landscapes: the role of native plants. Frontiers in Ecology and the Environment, 7(4): 196-203.

Isaacs, R., Blaauw, B., Williams, N., Kwapong, P., Lee-Mäder, E. \& Vaughan, M. 2016. Farm-tailored measures to sustain and enhance pollination services. In B. Gemmill-Herren, ed. Pollination services to agriculture - Sustaining and enhancing a key ecosystem service, pp. 113-130. London, Routledge.

\section{ISC (International Scientific Committee for Tuna} and Tuna-Like Species in the North Pacific Ocean). 2018. Stock assessment of Pacific bluefin tuna (Thunnus orientalis) in the Pacific Ocean in 2018. 18th Meeting of the International Scientific Committee for Tuna and Tuna-Like Species in the North Pacific Ocean. Yeosu, Republic of Korea, 11-16 July 2018. (available at http://isc.fra.go.jp/ pdf/ISC18/ISC_18_ANNEX_14_Pacific_Bluefin_Tuna_ Stock_Assessment_2018_FINAL.pdf).

Ishaq, S.L. \& Wright, A.D.G. 2014. Design and validation of four new primers for next-generation sequencing to target the $18 \mathrm{~S}$ rRNA genes of gastrointestinal ciliate protozoa. Applied Environmental Microbiology, 80: 5515-5521.

Islam, Z., Heong, K.L., Catling, D. \& Kritani, K. 2012. Invertebrates in rice production systems: status and trends. Commission on Genetic Resources for Food and Agriculture Background Study Paper No. 62. Rome, FAO. (available at http://www.fao.org/ docrep/016/ap630e/ap630e.pdf).

Isomura, N., Iwao, K. \& Fukami, H. 2013. Possible natural hybridization of two morphologically distinct species of Acropora (Cnidaria, Scleractinia) in the Pacific: fertilization and larval survival rates. PLOS ONE, 8: e56701. 
Isomura, N., Iwao, K., Morita, M. \& Fukami, H. 2016. Spawning and fertility of $\mathrm{F} 1$ hybrids of the coral genus Acropora in the Indo-Pacific. Coral Reefs, 35: 851-855.

Israilides, C., Smith, A., Scanlon, B. \& Barnett, C. 1999 Pullulan from agroindustrial wastes. Biotechnology and Genetic Engineering Reviews, 16: 309-324.

ITTO (International Tropical Timber Organization). 2002. ITTO Guidelines for the restoration, management and rehabilitation of degraded and secondary tropical forests. Yokohama, Japan.

IUCN (International Union for Conservation of

Nature). 2008. Defining protected areas: an international conference in Almeria, Spain, May 2007. N. Dudley \& S. Stolton, eds. Gland, Switzerland, IUCN.

IUCN. 2011. The land we graze: a synthesis of case studies about how pastoralists' organizations defend their land rights. Nairobi. (available at http:// www.cmsdata.iucn.org/downloads/land_rights_ publication_english_web.pdf).

IUCN. 2012. IUCN Red List categories and criteria: Version 3.1. Second Edition. Cambridge, UK, and Gland, Switzerland. (available at https://www.iucn. org/km/content/iucn-red-list-categories-and-criteriaversion-31-second-edition).

IUCN. 2016a. Valuing our vultures. [Cited 10 April 2018] https://www.iucn.org/content/valuing-our-vultures

IUCN. 2016b. Restoration of forest ecosystems and landscapes as contribution to the Aichi Biodiversity Targets. Gland, Switzerland.

IUCN. 2016c. A Global Standard for the Identification of Key Biodiversity Areas, Version 1.0. Gland, Switzerland. IUCN. 2017a. The IUCN Red List of Threatened Species. Version 2017-3. [Cited 22 March 2018]. http://www. iucnredlist.org/

IUCN. 2017b. Gender and biodiversity: analysis of women and gender equality considerations in National Biodiversity Strategies and Action Plans (NBSAPS). Washington, DC, IUCN Global Gender Office.

IUCN. undated. Paramos. Enhancing capacities and coordination to cope with climate change effects. Cambridge, UK and Gland, Switzerland.

IUCN \& WCPA. 2017. IUCN Green List of Protected and Conserved Areas: Standard, Version 1.1. Gland, Switzerland, IUCN. (available at https://www. iucn.org/sites/dev/files/iucn_green_list_standard_ version_1.1_nov_2017_3.pdf).
IUCN \& WCPA. 2018. Applying IUCN's Global Conservation Standards to Marine Protected Areas (MPA). Delivering effective conservation action through MPAs, to secure ocean health and sustainable development. Version 1.0. Gland, Switzerland.

IUCN \& WRI. 2014. A guide to the Restoration Opportunities Assessment Methodology (ROAM): assessing forest landscape restoration opportunities at the national or sub-national level. Gland, Switzerland, IUCN.

Jackson, J.B.C., Donovan, M.K., Cramer, K.L. \& Lam, V. V. 2014. Status and trends of Caribbean coral reefs: 1970-2012. Global Coral Reef Monitoring Network. IUCN, Gland, Switzerland.

Jackson, E.L., Rees, S.E., Wilding, C. \& Attrill, M.J. 2015. Use of a seagrass residency index to apportion commercial fishery landing values and recreation fisheries expenditure to seagrass habitat service. Conservation Biology, 29(3): 899-909.

Jaffé, R., Dietemann, V., Allsopp, M.H., Costa, C., Crewe, R.M., Dall'olio, R., De La Rúa, P. et al. 2010. Estimating the density of honeybee colonies across their natural range to fill the gap in pollinator decline censuses. Conservation Biology, 24(2): 583-593.

James, R. \& Pitts-Singer, T.L. 2008. Bee pollination in agricultural ecosystems. Oxford, UK, Oxford University Press.

Jamnadass, R., Dawson, I.K., Anegbeh, P., Asaah, E., Atangana, A., Cordeiro, N.J., Hendrickx, H. et al. 2010. Allanblackia, a new tree crop in Africa for the global food industry: market development, smallholder cultivation and biodiversity management. Forests, Trees and Livelihoods, 19: 251-268.

Jamnadass, R.H., Dawson, I.A.K., liyama, M., Kehlenbeck, K., Malézieux, E., Masters, E., McMullin, S. et al. 2013. The benefits of agroforestry systems for food and nutritional security. Nairobi, ICRAF.

Jansen, T. \& Sirikolo, M.Q. 2010. Petanigaki ta Siniqa ni Lauru - The forest foods of Lauru. Honiara, Kastom Gaden Association

Jaramillo, J., Muchugu, E., Vega, F.E., Davis, A., Borgemeister, C. \& Chabi-Olaye, A. 2011. Some like it hot: the influence and implications of climate change on coffee berry borer (Hypothenemus hampei) and coffee production in East Africa. PLOS ONE, 6(9): e24528. 
Jaronski, S.T. \& Goettel, M.S. 1997. Development of Beauveria bassiana for control of grasshoppers and locusts. Memoirs of the Entomological Society of Canada, 129: 225-237.

Jarvis, A., Upadhyaya, H., Gowda, C.L.L., Aggarwal, P.K., Fujisaka, S. \& Anderson, B. 2008. Climate change and its effect on conservation and use of plant genetic resources for food and agriculture and associated biodiversity for food security. Thematic Background Study. Rome, FAO. (available at http:// www.fao.org/docrep/013/i1500e/i1500e16.pdf).

Jat, R., Sahrawat, K. I. \& Kassam, A.H. 2014.

Conservation agriculture: global prospects and challenges. Wallingford, UK, CABI.

Jepson, P.C., Guzy, M., Blaustein, K., Sow, M., Sarr, M., Mineau, P. \& Kegley, S. 2014. Measuring pesticide ecological and health risks in West African agriculture to establish an enabling environment for sustainable intensification. Philosophical Transactions of the Royal Society of London. Series B, Biological Sciences, 369(1639): 20130491.

Jha, R.K. 2008. An assessment of farm-level use of bio-pesticides in Nepal: a case study based on IPM Farmers' Field Schools of Bhaktapur District. 3rd Annual Meeting of Plant Protection Society of Nepal. Kathmandu, Plant Protection Society of Nepal.

Jin, Y.K., Lundgren, P., Lutz, A., Raina, J.-B., Howells, E.J., Paley, A.S., Willis, B.L. \& van Oppen, M.J.H. 2016. Genetic markers for antioxidant capacity in a reef-building coral. Science Advances, 2(5): e1500842.

Jodha, N.S. 1992. Common property resources: a missing dimension of development strategies. World Bank Discussion Papers No. 169. Washington, DC, World Bank.

Johansen, C.A., Mayer, D.F. \& Eves, J.D. 1978. Biology and management of the alkali bee, Nomia melanderi Cockerell (Hymenoptera, Halictidae). Melanderia, 28: $25-46$

John, R.P., Tyagi, R.D., Prévost, D., Brar, S.K., Pouleur, S. \& Surampalli, R.Y. 2010. Mycoparasitic Trichoderma viride as a biocontrol agent against Fusarium oxysporum f. sp. adzuki and Pythium arrhenomanes and as a growth promoter of soybean. Crop Protection, 29(12): 1452-1459.
Johns, T. \& Eyzaguirre, P.B. 2006. Linking biodiversity, diet and health in policy and practice. The Proceedings of the Nutrition Society, 65(2): 182-189.

Johnson, D.V. \& Nair, P.K.R. 1985. Perennial cropbased agroforestry systems in Northeast Brazil. Agroforestry Systems, 2(4): 281-292.

Johnson, M.D., Kellermann, J.L. \& Stercho, A.M. 2010. Pest reduction services by birds in shade and sun coffee in Jamaica. Animal Conservation, 13(2): 140-147.

Johnson, P.T.J., Ostfeld, R.S. \& Keesing, F. 2015. Frontiers in research on biodiversity and disease. Ecology Letters, 18(10): 1119-1133.

Joint FAO/WHO Codex Alimentarius Commission. 1999. Guidelines for the production, processing, labelling and marketing of organically produced foods. GL 32-1999. Rome, Secretariat of the Joint FAOMHO Food Standards Programme. (available at www.fao.org/input/download/standards/360/ cxg\%7B_\%7D032e.pdf).

Joint Genome Institute. 2017. Approved proposals FY17 gene function in rumen microbes. [Cited 27 April 2018]. https://jgi.doe.gov/gene-functionrumen-microbes/0/

Jones, T.A. \& Monaco, T.A. 2009. A role for assisted evolution in designing native plant materials for domesticated landscapes. Frontiers in Ecology and the Environment, 7: 541-547.

Jones, K.E., Patel, N.G., Levy, M.A., Storeygard, A., Balk, D., Gittleman, J.L. \& Daszak, P. 2008. Global trends in emerging infectious diseases. Nature, 451(7181): 990-993.

Jongema, Y. 2017. Worldwide list of recorded edible insects. Updated 1 April 2017. https://www.wur. nl/upload_mm/8/a/6/0fdfc700-3929-4a74-8b69f02fd35a1696_Worldwide\%20list\%20of\%20 edible\%20insects\%202017.pdf

Jonsson, M., Wratten, S.D., Landis, D.A. \& Gurr, G.M. 2008. Recent advances in conservation biological control of arthropods by arthropods. Biological Control, 45: 172-175.

Joost, S., Bonin, A., Bruford, M.W., Després, L., Conord, C., Erhardt, G. \& Taberlet, P. 2007. A spatial analysis method (SAM) to detect candidate loci for selection: towards a landscape genomics approach to adaptation. Molecular Ecology, 16(18): 3955-3969. 
Jordan, N.R., Aldrich-Wolfe, L., Huerd, S.C., Larson, D.L. \& Muehlbauer, G. 2012. Soiloccupancy effects of invasive and native grassland plant species on composition and diversity of mycorrhizal associations. Invasive Plant Science and Management, 5(4): 494-505.

Kaewchai, S., Soytong, K. \& Hyde, K.D. 2009. Mycofungicides and fungal biofertilizers. Fungal Diversity, 38: 25-50.

Kaewpaitoon, K. 1992. Utilization of septage-raised tilapia (Oreochromis niloticus) as feed for snakehead (Channa striates). Khlong Nueng, Thailand. Asian Institute of Technology.

Kahane, R., Hodgkin, T., Jaenicke, H., Hoogendoorn, C., Hermann, M., Dyno Keatinge, J.D.H., D’Arros Hughes, J., Padulosi, S. \& Looney, N. 2013. Agrobiodiversity for food security, health and income. Agronomy for Sustainable Development, 33(4): 671-693.

Kairis, O., Karavitis, C., Salvati, L., Kounalaki, A. \& Kosmas, K. 2015. Exploring the impact of overgrazing on soil erosion and land degradation in a dry Mediterranean agro-forest landscape (Crete, Greece). Arid Land Research and Management, 29(3): 360-374

Kakuru, O. V, Doreen, M. \& Wilson, M. 2014. Adoption of on-farm tree planting in Kibaale District, Western Uganda. Journal of Sustainable Forestry, 33(1): 87-98.

Kala, C.P. 2009. Aboriginal uses and management of ethnobotanical species in deciduous forests of Chhattisgarh State in India. Journal of Ethnobiology and Ethnomedicine, 5: 20.

Kålås, J.A., Viken, Å., Henriksen, S. \& Skjelseth, S. 2010. The 2010 Norwegian Red List for Species. Trondheim, Norway, Norwegian Biodiversity Information Centre.

Kanbe, Y., Okada, I., Yoneda, M., Goka, K. \& Tsuchida, K. 2008. Interspecific mating of the introduced bumblebee Bombus terrestris and the native Japanese bumblebee Bombus hypocrita sapporoensis results in inviable hybrids. Naturwissenschaften, 10: 1003-1008.

Kang, B.T., Wilson, G.F. \& Sipkens, L. 1981. Alley cropping maize (Zea mays L.) and leucaena (Leucaena leucocephala Lam) in southern Nigeria. Plant and Soil, 63(2): 165-179.
Kapulnik, Y. \& Kushnir, U. 1991. Growth dependency of wild, primitive and modern cultivated wheat lines on vesicular-arbuscular mycorrhiza fungi. Euphytica, 56(1): 27-36.

Karp, D.S., Mendenhall, C.D., Sandí, R.F., Chaumont N., Ehrlich, P.R., Hadly, E.A. \& Daily, G.C. 2013. Forest bolsters bird abundance, pest control and coffee yield. Ecology Letters, 16(11): 1339-1347.

Karr, K., Fujita, R., Halpenin, S., Kapel, C., Crowder, L., Selkoe, K., Alcolado, P. \& Roder, D. 2015. Thresholds in Caribbean coral reefs: implications for ecosystem-based fishery management. Journal of Applied Ecology, 52(2): 402-412.

Karvonen, A., Aalto-Araneda, M., Virtala, A.M., Kortet, R., Koski, P. \& Hyvärinen, P. 2016. Enriched rearing environment and wild genetic background can enhance survival and disease resistance of salmonid fishes during parasite epidemics. Journal of Applied Ecology, 53(1): 213-221.

Kassam, A., Friedrich, T. \& Derpsch, R. 2017. Global spread of conservation agriculture: interim update 2015/16. In M.L.C. Bartz, R. Fuentes \& R. Ralisch, eds. Proceedings of the 7th World Congress on Conservation Agriculture. 1-4 August 2017, Rosario, Argentina, pp. 16-19. Curitiba, Brazil, Positivo University Library.

Kassam, A., Friedrich, T. \& Derpsch, R. 2018. Global spread of conservation agriculture. International Journal of Environmental Studies, DOI: 10.1080/00207233.2018.1494927

Kassam, A., Saidi, M. \& Friedrich, T., eds. 2017. Conservation agriculture for Africa: building resilient farming systems in a changing climate. Wallingford, UK, CABI.

Kassam, A., Friedrich, T., Shaxson, F. \& Pretty, J. 2009. The spread of conservation agriculture: justification, sustainability and uptake. International Journal of Agricultural Sustainability, 7(4): 292-320.

Kassam, A., Basch, G., Friedrich, T., Shaxson, F., Goddard, T., Amado, T., Crabtree, B., Hongwen, L., Mello, I., Pisante, M. \& S., M. 2013. Sustainable soil management is more than what and how crops are grown. In R. Lal \& B.A. Stewart, eds. Principles of soil management in agro-ecosystems, pp. 337-400. Boca Raton, USA, CRC Press. 
Kassam, A., Friedrich, T., Derpsch, R. \& Kienzle, J. 2015. Overview of the worldwide spread of conservation agriculture. Field Actions Science Reports, 8: 1-11.

Kastl, B. 2014. Reducing disaster risks to mangrove forest livelihoods through watershed-based protected area management. In R. Murti \& C. Buvck, eds. Safe havens: protected areas for disaster risk reduction and climate change adaptation, pp. 22-32. Gland, Switzerland, IUCN.

Kaumbutho, P. \& Kienzle., J. 2007. Conservation agriculture as practised in Kenya: two case studies. Nairobi, African Conservation Tillage Network, CIRAD \& FAO

Keesing, F., Belden, L.K., Daszak, P., Dobson, A., Harvell, C.D., Holt, R.D., Hudson, P. et al. 2010. Impacts of biodiversity on the emergence and transmission of infectious diseases. Nature, 468(7324): 647-652.

Kefuss, J., Vanpoucke, J., Bolt, M. \& Kefuss, C. 2015. Selection for resistance to Varroa destructor under commercial beekeeping conditions. Journal of Apicultural Research, 54: 563-576.

Kehlenbeck, K., Kindt, R., Sinclair, F.L., Simons, A.J. \& Jamnadass, R. 2011. Exotic tree species displace indigenous ones on farms at intermediate altitudes around Mount Kenya. Agroforestry Systems, 83: 133-147.

Keleman, A. \& Hellin, J. 2009. Specialty maize varieties in Mexico: a case study in market-driven agrobiodiversity conservation. Journal of Latin American Geography, 8(2): 147-174.

Keller, R.P., Geist, J., Jeschke, J.M. \& Kühn, L. 2011. Invasive species in Europe: ecology, status, and policy. Environmenta/ Sciences Europe, 23(1): 23-40.

Kemp, R., Howard, P., Allcock, L., Carpenter, K., Obura, D., Polidoro, B. \& Rishmont, N. 2012. Marine invertebrate life. In B. Collen, M. Böhm, R. Kemp \& J.E.M. Baillie, eds. Spineless : status and trends of the world's invertebrates, pp. 34-44. London, Zoological Society of London.

Keneni, G., Bekele, E., Imtiaz, M. \& Dagne, K. 2012 Genetic vulnerability of modern crop cultivars: causes, mechanism and remedies. International Journal of Plant Research, 2(3): 69-79.
Kennedy, G., Nantel, G. \& Shetty, P. 2004 Globalization of food systems in developing countries: a synthesis of country case studies. Globalization of food systems in developing countries: impact on food security and nutrition, pp. 1-26. Rome, FAO. (available at http://www.fao. org/3/a-y5736e.pdf).

Kennedy, G.L., Pedro, M.R., Seghieri, C., Nantel, G. \& Brouwer, I. 2007. Dietary diversity score is a useful indicator of micronutrient intake in non-breastfeeding Filipino children. The Journal of Nutrition, 137(2): 472-477.

Kennedy, C.M., Lonsdorf, E., Neel, M.C., Williams, N.M., Ricketts, T.H., Winfree, R., Bommarco, R. et al. 2013. A global quantitative synthesis of local and landscape effects on wild bee pollinators in agroecosystems. Ecology Letters, 16(5): 584-599.

Kennedy, G., Stoian, D., Hunter, D., Kikulwe, E., Termote, C., Alders, R., Burlingame, B., Jamnadass, R., McMullin, S. \& Thilsted, S. 2017. Food biodiversity for healthy, diverse diets. In Bioversity International, ed. Mainstreaming agrobiodiversity in sustainable food systems: Scientific foundations for an agrobiodiversity index Summary, pp. 10-13. Rome, Bioversity International.

Kerr, J.T., Pindar, A., Galpern, P., Packer, L., Potts, S.G., Roberts, S.M., Rasmont, P. et al. 2015. Climate change impacts on bumblebees converge across continents. Science, 349(6244): 177-180.

Kessler, J.J. 1992. The influence of karité (Vitellaria paradoxa) and néré (Parkia biglobosa) trees on sorghum production in Burkina Faso. Agroforestry Systems, 17: 97-118.

Kgosikoma, O.E. \& Mogotsi, K. 2013. Understanding the causes of bush encroachment in Africa: the key to effective management of savanna grasslands. Tropical Grasslands, 1(2): 215-219.

Khoury, C.K., Bjorkman, A.D., Dempewolf, H., RamirezVillegas, J., Guarino, L., Jarvis, A., Rieseberg, L.H. \& Struik, P.C. 2014. Increasing homogeneity in global food supplies and the implications for food security. PNAS, 111(11): 4001-4006.

Khoury, C.K. \& Jarvis, A. 2014. The changing composition of the global diet: implications for CGIAR research. CIAT Policy Brief No.18. Cali, Colombia. Centro Internacional de Agricultura Tropical. 
Kindt, R., Kalinganire, A., Larwanou, M., Belem, M., Dakouo, J.M., Bayala, J. \& Kaire, M. 2008. Species accumulation within land use and tree diameter categories in Burkina Faso, Mali, Niger and Senegal. Biodiversity and Conservation, 17: 1905-1993.

Kindt, R., Ahmad, M., Onkware, B., John, I., Vagen, T.-G., van Breugel, P. \& Lillesø, J.-P. 2017. Africa tree finder. Version 2. World Agroforestry Centre.

King, K.C. \& Lively, C.M. 2012. Does genetic diversity limit disease spread in natural host populations. Heredity (Edinb.), 109(4): 199-203.

Kiptot, E., Franzel, S. \& Degrande, A. 2014. Gender, agroforestry and food security in Africa. Current Opinion in Environmental Sustainability, 6: 104-109.

Kittelmann, S., Devente, S.R., Kirk, M.R., Seedorf, H., Dehority, B.A. \& Janssen, P.H. 2015. Phylogeny of intestinal ciliates, including Charonina ventriculi, and comparison of microscopy and 18S rRNA gene pyrosequencing for rumen ciliate community structure analysis. Applied Environmental Microbiology, 81: 2433-2444.

Kjøhl, M., Nielsen, A. \& Stenseth, N.C. 2011. Potential effects of climate change on crop pollination. Rome, FAO. (available at http://www.fao.org/3/a-i2242e.pdf).

Klein, A.M., Vaissiere, B.E., Cane, J.H., SteffanDewenter, I., Cunningham, S.A., Kremen, C. \& Tscharntke, T. 2007. Importance of pollinators in changing landscapes for world crops. Proceedings of the Royal Society B: Biological Sciences, 274(1608): 303-313.

Klein, A.M., Brittain, C., Hendrix, S.D., Thorp, R., Williams, N. \& Kremen, C. 2012. Wild pollination services to California almond rely on semi-natural habitat. Journal of Applied Ecology, 49(3): 723-732.

Kluger, L.C., Taylor, M.H., Mendo, J., Tam, J. \& Wolff, M. 2016. Carrying capacity simulations as a tool for ecosystem-based management of a scallop aquaculture system. Ecological Modelling, 331: 44-55.

Kneafsey, M., Cox, R., Holloway, L., Dowler, E., Venn, L. \& Tuomainen, T. 2008. Reconnecting consumers, producers and food: exploring alternatives. Oxford, UK, Berg Publishers.

Knutson, A. 1998. The trichogramma manual: a guide to the use of trichogramma for biological control with special reference to augmentative releases for control of bollworm and budworm in cotton.
College Station, USA, College Station: Agricultural Communications, The Texas A\&M University System.

Kobori, C.N. \& Rodriguez Amaya, D.B. 2008.

Uncultivated Brazilian green leaves are richer sources of carotenoids than are commercially produced leafy vegetables. Food and Nutrition Bulletin, 29(4): 320-328.

Koelmans, A.A., Gouin, T., Thompson, R., Wallace, N. \& Arthur, C. 2014. Plastics in the marine environment. Environmental Toxicology and Chemistry, 33(1): 5-10.

Koeniger, N., Koeniger, G., Ellis, J. \& Connor, L. 2014. Mating biology of honey bees (Apis mellifera). Kalamazoo, USA, Wickwas Press LLC.

Koffa, S.N. \& Roshetko, J.M. 1999. Farmer-managed germplasm production-diffusion pathways in Lantapan, Phillipines. In J.M. Roshetko \& D.O. Evans, eds. Domestication of agroforestry trees in southeast Asia: proceedings of a regional workshop, Yogyakarta, Indonesia November 4-7, 1997, pp. 142-150. Nairobi, ICRAF.

Köhler-Rollefson, I., Mathias, E., Singh, H., Vivekanandan, P. \& Wanyama, J. 2010. Livestock keepers' rights: the state of discussion. Animal Genetic Resources, 47: 1-5.

Konnert, M., Maurer, W., Degan, B. \& Kätzel, R. 2011. Genetic monitoring in forests - early warning and controlling system for ecosystemic changes. iForest, 4: 77-81.

Koohafkan, P. \& Altieri, M.A. 2010. Globally Important Agricultural Heritage Systems. A legacy for the future. Rome, FAO. (available at http://www.fao.org/ docrep/014/i2232e/i2232e00.htm).

Koskela, J., Vinceti, B., Dvorak, W., Bush, D., Dawson, I., Loo, J., Kjaer, E.D. et al. 2009. The use and exchange of forest genetic resources for food and agriculture. Commission on Genetic Resources for Food and Agriculture. Background Study Paper No. 44. Rome, FAO. (available at http:// www.fao.org/3/a-ak565e.pdf).

Koskela, J., Lefèvre, F., Schueler, S., Kraigher, H., Olrik, D.C., Hubert, J., Longauer, R. et al. 2013. Translating conservation genetics into management: Pan-European minimum requirements for dynamic conservation units of forest tree genetic diversity. Biological Conservation, 157: 39-49. 
Kovács-Hostyánszki, A., Espíndola, A., Vanbergen, A.J., Settele, J., Kremen, C. \& Dicks, L.V. 2017. Ecological intensification to mitigate impacts of conventional intensive land use on pollinators and pollination. Ecology Letters, 20(5): 673-689.

Krell, R. 1996. Value added products from beekeeping FAO Agricultural Services Bulletin. No. 124. Rome, FAO. (available at http://www.fao.org/docrep/ w0076e/w0076e00.htm\%7B\#\%7Dcon).

Kremen, C. \& Merenlender, A.M. 2018. Landscapes that work for biodiversity and people. Science, 362(6412): eaau6020.

Kremen, C. \& Miles, A. 2012. Ecosystem services in biologically diversified versus conventional farming systems: benefits, externalitites, and trade-offs. Ecology and Society, 17(4): 1-23.

Kremen, C., Williams, N.M. \& Thorp, R.W. 2002. Crop pollination from native bees at risk from agricultural intensification. Proceedings of the National Academy of Sciences, 99(26): 16812-16816.

Kristjansson, K. \& Rasmussen, K. 1991. Pollination of sweet pepper (Capsicum annuum L.) with the solitary bee Osmia cornifrons (Radoszkowski). Acta Horticulturae, 288: 172-179.

Kuczera, G. 1987. Prediction of water yield reductions following a bushfire in ash-mixed species eucalypt forest. Journal of Hydrology, 94(3-4): 215-236.

Kumar, B.M. 2006. Carbon sequestration potential of tropical home gardens. In B.M. Kumar \& P.K.R. Nair, eds. Tropical homegardens: a time-tested example of sustainable agroforestry, pp. 185-204. Dordrecht, Netherlands, Springer.

Kumar, B.M. \& Nair, P.K.R. 2006. Tropical homegardens: a time-tested example of sustainable agroforestry. Vol. 3. Dordrecht, Netherlands, Springer.

Kumar, R., McInnes, R.J., Everard, M., Gardner, R.C., Kulindwa, K.A.A., Wittmer, H. \& Infante Mata, D. 2017. Integrating multiple wetland values into decision-making. Ramsar Policy Brief No. 2. Gland, Switzerland, Ramsar Convention Secretariat.

Kusler, J. 2009. Wetlands and natural hazards. Windham, USA, Association of State Wetlands Managers.

Kuyper, E., Vitta, B. \& Dewey, K. 2013. Novel and underused food sources of key nutrients for complementary feeding. Washington, DC, Alive \& Thrive Technical Brief 6.
Kwapong, P., Aidoo, K., Combey, R. \& Karikari, A. 2010. Stingless bees: importance, management and utilisation: a training manual for stingless bee keeping. Accra North, Ghana, UNIMAX Macmillan.

Läderach, P., Ramirez-Villegas, J., Navarro-Racines, C., Zelaya, C., Martinez-Valle, A. \& Jarvis, A. 2017. Climate change adaptation of coffee production in space and time. Climatic Change, 141(1): 47-62.

Laffoley, D. \& Grimsditch, G. 2009. The management of natural coastal carbon sinks. Cambridge, UK, and Gland, Switzerland, IUCN.

Lagucki, E., Burdine, J.D. \& McCluney, K.E. 2017. Urbanization alters communities of flying arthropods in parks and gardens of a medium-sized city. PeerJ, 5: e3620.

Laidlaw, H.H. 1977. Instrumental insemination of honey bee queens. Hamilton, USA, Dadant Publications.

Lambin, E.F., Gibbs, H.K., Ferreira, L., Grau, R., Mayaux, P., Meyfroidt, P., Morton, D.C., Rudel, T.K., Gasparri, I. \& Munger, J. 2013. Estimating the world's potentially available cropland using a bottom-up approach. Global Environmental Change, 23(5): 892-901.

Lamers, H.A.H., Kruijssen, F., Sthapit, B.R. \& Ramanatha Rao, V. 2016. How can markets contribute to the conservation of agricultural biodiversity on farms? From theory into practice. In B.R. Sthapit, H.A.H. Lamers, R.V. Rao \& A. Bailey, eds. Tropical fruit tree diversity: good practices for in situ and on-farm conservation, pp. 253-284. Abingdon, UK, Routledge.

Lamien, N., Sidibe, A. \& Bayala, J. 1996. Use and commercialization of non-timber forest products in western Burkina Faso. Domestication and commercialization of non-timber forest products in agroforestry systems, Non-Wood Forest Products 9. Rome, FAO.

Lande, R. \& Barrowclough, G. 1987. Effective population size, genetic variation, and their use in population management. In M.E. Soulé, ed. Viable populations for conservation, pp. 87-123. Cambridge, UK, Cambridge University Press.

Landis, D.A. 2017. Designing agricultural landscapes for biodiversity-based ecosystem services. Basic and Applied Ecology, 18: 1-12. 
Landis, D., Wratten, S. \& Gurr, G. 2000. Habitat management to conserve natural enemies of arthropod pests in agriculture. Annual Review of Entomology, 45(1): 175-201.

Landon-Lane, C. 2011. Livelihoods grow in gardens: diversifying rural incomes through home gardens. Rome, FAO. (available at http://www.fao.org/ docrep/015/i2463e/i2463e00.pdf).

Lang, K., Schuldes, J., Klingl, A., Poehlein, A., Daniel, R. \& Brune, A. 2015. New mode of energy metabolism in the seventh order of methanogens as revealed by comparative genome analysis of "Candidatus Methanoplasma termitum". Applied Environmental Microbiology, 81: 1338-1352.

Lang, T., Barling, D. \& Caraher, M. 2009. food policy: integrating health environment and society. Oxford, UK, Oxford University Press.

Lange, M., Eisenhauer, N., Sierra, C.A., Bessler, H., Engels, C., Griffiths, R.I., Mellado-Vázquez, P.G. et al. 2015. Plant diversity increases soil microbial activity and soil carbon storage. Nature Communications, 6: 6707.

Langellotto, G.A. \& Denno, R.F. 2004. Responses of invertebrate natural enemies to complex-structured habitats: a meta-analytical synthesis. Oecologia, 139(1): 1-10.

Larios, C., Casas, A., Vallejo, M., Moreno-Calles, A.I.I. \& Blancas, J. 2013. Plant management and biodiversity conservation in Náhuatl homegardens of the Tehuacán Valley, Mexico. Journal of Ethnobiology and Ethnomedicine, 9(1): 74-90.

Larsen, L.G., Choi, J., Nungesser, M.K. \& Harvey, J.W. 2012. Directional connectivity in hydrology and ecology. Ecological Applications, 22(8): 2204-2220.

Latawiec, A.E., Strassburg, B.B.N., Brancalion, P.H.S., Rodrigues, R.R. \& Gardner, T. 2015. Creating space for large-scale restoration in tropical agricultural landscapes. Frontiers in Ecology and the Environment, 13: 211-218.

Laurance, W.F., Sayer, J. \& Cassman, K.G. 2014. Agricultural expansion and its impacts on tropical nature. Trends in Ecology \& Evolution, 29: 107-116.

Laurans, Y., Ruat, R. \& Barthélemy, P. 2016. Counting on nature: how governments plan to rely on ecosystems for their climate strategies. IDDRI Issue Brief No. 5. Paris, IDDRI.
Laurans, Y., Rankovic, A., Billé, R., Pirard, R. \& Mermet, L. 2013. Use of ecosystem services economic valuation for decision making: questioning a literature blindspot. Journal of Environmental Management, 119: 208-219.

Lautenbach, S., Seppelt, R., Liebscher, J. \& Dormann, C.F. 2012. Spatial and temporal trends of global pollination benefit. PLOS ONE, 7(4): e35954.

Lazard, J. \& Dabbadie, L. 2002. Freshwater aquaculture and polyculture. In P. Safran, ed. Fisheries and aquaculture: towards sustainable aquatic living resources management. Encyclopedia of Life Support Systems (EOLSS). Developed under the auspices of the UNESCO, p. 30. Oxford, UK, EOLSS Publishers.

Lazarovits, G. 2001. Management of soil-borne plant pathogens with organic soil amendments: a disease control. Canadian Journal of Microbiology, 23(1): 1-7.

Lazos-Chavero, E. 2016. Stakeholders and tropical reforestation: challenges, trade-offs, and strategies in dynamic environments. Biotropica, 48: 900-914.

Leadley, P.W., Krug, C.B., Alkemade, R., Pereira, H.M., Sumaila, U.R., Walpole, M., Marques, A. et al. 2014. Progress towards the Aichi Biodiversity Targets: an assessment of biodiversity trends, policy scenarios and key actions. CBD Technical Series No. 78. Montreal, Canada, Secretariat of the Convention on Biological Diversity.

Leahy, S.C., Kelly, W.J., Altermann, E., Ronimus, R.S., Yeoman, C.J., Pacheco, D.M., Li, D. et al. 2010. The genome sequence of the rumen methanogen Methanobrevibacter ruminantium reveals new possibilities for controlling ruminant methane emissions. PLOS ONE, 5(1): e8926.

Leakey, R.R.B. 1996. Definition of agroforestry revisited. Agroforestry Today, 8(1): 5-7.

Leakey, R.R.B. 2010. Agroforestry: a delivery mechanism for multi-functional agriculture. In L.R. Kellimore, ed. Handbook of agroforestry: management practices and environmental impact, pp. 461-471. Hauppage, USA, Nova Science Publishers.

Leaky, R., Caron. P., Craufurd, P., Martin, A., McDonald, A., Abedini, W., Afiff, S. et al. 2009. Impacts of AKST on development and sustainability goals. In B.D. McIntyre, H.R. Herren, J. Wakhungu \& R.T. Watson, eds. International Assessment of Agricultural Knowledge, Science and Technology for Development 
(IAASTD): Agriculture at a crossroads, global report, pp.145-253.Washington, DC, Island Press.

Leakey, R.R.B., Weber, J.C., Page, T., Cornelius, J.P., Akinnifesi, F.K., Roshetko, J.M., Tchoundjeu, Z. \& Jamnadass, R. 2012. Tree domestication in agroforestry: progress in the second decade. In P.K.R. Nair \& D.P. Garrity, eds. The future of agroforestry, pp. 145-173. New York, USA, Springer.

Le Conte, Y., Ellis, M. \& Ritter, W. 2010. Varroa mites and honey bee health: can Varroa explain part of the colony losses? Apidologie, 41: 353-363.

Lee, D.J. \& Gordon, R.M. 2006. Economics of aquaculture and invasive aquatic species - an overview. Aquaculture Economics and Management, 10(2): 83-96.

Lee, S., Iwasaki, Y., Shikina, S. \& Yoshizaki, G. 2013. Generation of functional eggs and sperm from cryopreserved whole testes. Proceedings of the National Academy of Sciences, 110(5): 1640-1645.

Lefèvre, F. 2004. Human impacts on forest genetic resources in the temperate zone: an updated review. Forest Ecology and Management, 197(1-3): 257-271.

Lefèvre, F., Koskela, J., Hubert, J., Kraigher, H., Longauer, R., Olrik, D.C., Schüler, S. et al. 2013. Dynamic conservation of forest genetic resources in 33 European countries. Conservation Biology, 27(2): 373-384.

Lefèvre, F., Boivin, T., Bontemps, A., Courbet, F., Davi, H., Durand-Gillmann, M., Fady, B.J. et al. 2014. Considering evolutionary processes in adaptive forestry. Annals of Forest Science, 71(7): 723-739.

Lehmann, J., Rillig, M.C., Thies, J., Masiello, C.A., Hockaday, W.C. \& Crowley, D. 2011. Biochar effects on soil biota - a review. Soil, 43(9): 1812-1836.

LEI (Landbouw-Economisch Institut). 2015. Agrimatie - informatie over de agrosector. Wageningen, Netherlands, Wageningen University \& Research.

Lemessa, F. \& Wakjira, M. 2015. Cover crops as a means of ecological weed management in agroecosystems. Journal of Crop Science and Biotechnology, 18(2): 133-145.

Lenné, J.M. \& Wood, D. 2011. Agrobiodiversity management for food security: a critical review. Wallingford, UK, CABI.

Leonard, S., Kirkpatrick, J. \& Marsden-Smedley, J. 2010. Variation in the effects of vertebrate grazing on fire potential between grassland structural types. Journal of Applied Ecology, 47(4): 876-883.

Letourneau, D.K., Fitzsimmons, M.I. \& Nieto, D.J. 2017. Approaches in plant protection - science, technology, environment and society. In M. Coll \& E. Wajnberg, eds. Environmental pest management within the environment: challenges for agronomists, ecologists, economists and policy makers, pp. 21-53. Hoboken, USA, John Wiley \& Sons.

Letourneau, D.K., Jedlicka, J.A., Bothwell, S.G. \& Moreno, C.R. 2009. Effects of natural enemy biodiversity on the suppression of arthropod herbivores in terrestrial ecosystems. Annual Review of Ecology, Evolution, and Systematics, 40(1): 573-592.

Lévêque, C., Oberdorff, T., Paugy, D., Stiassny, M.L.J. \& Tedesco, P.A. 2008. Global diversity of fish (Pisces) in freshwater. Hydrobiologia, 595(1): 545-567.

Ley, R.E., Hamady, M., Lozupone, C., Turnbaugh, P.J., Ramey, R.R., Bircher, J.S., Schlegel, M.L. et al. 2008. Evolution of mammals and their gut microbes. Science, 320(5883): 1647-1651.

Li, Y., Leahy, S.C., Jeyanathan, J., Henderson, G., Cox, F., Altermann, E., Kelly, W.J. \& Lambie, S.C. 2016. The complete genome of the methanogenic archaeon ISO4-H5 provides insights into the methylotrophic lifestyle of a ruminal representative of the Methanomassiliicoccales. Standards in Genomic Sciences, 11(1): 59.

Liang, J., Crowther, T.W., Picard, N., Wiser, S., Zhou, M., Alberti, G., Schulze, E.D. et al. 2016. Positive biodiversity-productivity relationship predominant in global forests. Science, 354(6309): 196.

Liang, J., Yu, K., Wang, Y., Huang, X., Huang, W., Qin, Z., Pan, Z., Yao, Q., Wang, W. \& Wu, Z. 2017. Distinct bacterial communities associated with massive and branching scleractinian corals and potential linkages to coral susceptibility to thermal or cold stress. Frontiers in Microbiology, 8: 979.

Liebman, M. \& Davis, A.S. 2000. Integration of soil, crop and weed management in low-external-input farming systems. Weed Research, 40(1): 27-47.

Lightner, D.V. 2011. Status of shrimp diseases and advances in shrimp health management. Diseases in Asian aquaculture VII, pp. 121-134. Selangor, Malaysia, Fish Health Section, Asian Fisheries Society. 
Lillesø, J.B.L., Graudal, L., Moestrup, S., Kjær, E.D., Kindt, R., Mbora, A., Dawson, I., Muriuki, J., Ræbild, A. \& Jamnadass, R. 2011. Innovation in input supply systems in smallholder agroforestry: seed sources, supply chains and support systems. Agroforestry Systems, 83(3): 347-359.

Lillesø, J.P.B., Harwood, C., Derero, A., Graudal, L., Roshetko, J.M., Kindt, R., Moestrup, S. et al. 2018. Why institutional environments for agroforestry seed systems matter. Development Policy Review, 36(September 2015): 089-0112.

Lin, B.B. 2007. Agroforestry management as an adaptive strategy against potential microclimate extremes in coffee agriculture. Agricultural and Forest Meteorology, 144(1-2): 85-94.

Lithgow, D., de la Lanza, G. \& Silva, R. 2017. Ecosystem-based management strategies to improve aquaculture in developing countries: case study of Marismas Nacionales. Ecological Engineering, In press.

Litrico, I. \& Violle, C. 2015. Diversity in plant breeding: a new conceptual framework. Trends in Plant Science, 20(10): 604-613.

Lo, C.C. 2010. Effect of pesticides on soil microbial community. Journal of Environmental Science and Health, 45(5): 348-359.

Locey, K.J. \& Lennon, J.T. 2016. Scaling laws predict global microbial diversity. Proceedings of the National Academy of Sciences of the United States of America, 113(21): 5970-5975.

Locke, B. 2016. Natural Varroa mite-surviving Apis mellifera honeybee populations. Apidologie, 47: 467-482.

Lönnstedt, O.M. \& Eklöv, P. 2016. Environmentally relevant concentrations of microplastic particles in influence larval fish ecology. Science, 352(6290): 1213-1216.

Loo, J., Fady, B., Dawson, I., Vinceti, B. \& Baldinelli, G. 2011. Climate change and forest genetic resources: state of knowledge, risks and opportunities. Commission on Genetic Resources for Food and Agriculture. Background Study Paper No. 56. Rome, FAO. (available at http://www.fao.org/ docrep/meeting/023/mb696e.pdf).

López Raggi, F., Pérez Centeno, M.J. \& Lanari, M.R. 2008. Marketing of goat meat under PDO seal. Marketing niche products from indigenous livestock. Writeshop held by the League for Pastoral Peoples in Kalk Bay, South Africa, December 2008. Kalk Bay, South Africa.

Lovreglio, R., Meddour-Sahar, O. \& Leone, V. 2014 Goat grazing as a wildfire prevention tool: a basic review. IForest, 7(4): 260-268.

Lowder, S.K., Skoet, J. \& Raney, T. 2016. The number, size, and distribution of farms, smallholder farms, and family farms worldwide. World Development, 87: 16-29.

Lowder, S.K., Skoet, J. \& Singh, S. 2014. What do we really know about the number and distribution of farms and family farms worldwide? Background paper for The State of Food and Agriculture 2014. ESA Working Paper No. 14-02. Rome, FAO. (available at http://www.fao.org/3/a-i3729e.pdf).

Lowe, C.N., Butt, K.R. \& Sherman, R.L. 2014. Current and potential benefits of mass earthworm culture. In J. Morales-Ramos, M. Guadalupe-Rojas \& D.I. Shapirollan, eds. Mass production of beneficial organisms, pp. 683-709. Cambridge, USA, Academic Press.

LPP, LIFE Network, IUCN-WISP \& FAO. 2010. Adding value to livestock diversity - Marketing to promote local breeds and improve livelihoods. FAO Animal Production and Health Paper. No. 168. Rome, FAO. (available at http://www.fao.org/docrep/012/i1283e/ i1283e00.htm).

Lucas, R., Blonda, P., Bunting, P., Jones, G., Inglada, J., Arias, M., Kosmidou, V. et al. 2015. The earth observation data for habitat monitoring (EODHaM) system. International Journal of Applied Earth Observation and Geoinformation, 37: 17-28.

Łuczaj, Ł., Pieroni, A., Tardío, J., Pardo-DeSantayana, M., Sõukand, R., Svanberg, I. \& Kalle, R. 2012. Wild food plant use in 21st century Europe: the disappearance of old traditions and the search for new cuisines involving wild edibles. Acta Societatis Botanicorum Poloniae, 81(4): 359-370.

Lund, H.G. 2007. Accounting for the world's rangelands. Rangelands, 29(1): 3-10.

Lundgren, P., Vera, J.C., Peplow, L., Manel, S. \& van Oppen, M.J.H. 2013. Genotype-environment correlations in corals from the Great Barrier Reef. BMC Genetics, 14(9).

Maas, B., Clough, Y. \& Tscharntke, T. 2013. Bats and birds increase crop yield in tropical agroforestry landscapes. Ecology Letters, 16(12). 
Maccagnini, B., Ladurner, E., Santi, F. \& Burgio, G. 2003. Osmia cornuta (Hymenoptera, Megachilidae) as a pollinator of pear (Pyrus communis): fruit- and seed-set. Apidologie, 34: 207-216.

Macedo, M. \& Castello, L. 2015. State of the Amazon: freshwater connectivity and ecosystem health. D. Oliveira, C.C. Maretti \& S. Charity, eds. Brasilia, WWF Living Amazon Initiative.

Macfadyen, S., Tylianakis, J.M., Letourneau, D.K., Benton, T.G., Tittonell, P., Perring, M.P., GómezCreutzberg, C. et al. 2015. The role of food retailers in improving resilience in global food supply. Global Food Security, 7: 1-8.

Mäder, P., Fließbach, A., Dubois, D., Gunst, L., Fried, P., Niggli, U., Series, N. \& May, N. 2008. Soil fertility and biodiversity in organic farming soil fertility and biodiversity in organic farming. Science, 296(5573): 1694-1697.

Malik, K.A. \& Hoffmann, P. 1993. Long-term preservation of yeast cultures by liquid-drying. World Journal of Microbiology \& Biotechnology, 9(3): 372-376.

Malusa, E., Sas-Paszt, L. \& Ciesielska, J. 2012. Technologies for beneficial microorganisms inocula used as biofertilizers. Scientific World Journal, 2012: 491206.

Mandelik, Y., Winfree, R., Neeson, T. \& Kremen, C. 2012. Complementary habitat use by wild bees in agro-natural landscapes. Ecological Applications, 22(5): 1535-1546.

Maoz, Y., Gal, S., Argov, Y., Domeratzky, S., Melamed, E., Gan-Mor, S., Coll, M. \& Palevsky, E. 2014. Efficacy of indigenous predatory mites (Acari: Phytoseiidae) against the citrus rust mite Phyllocoptruta oleivora (Acari: Eriophyidae): augmentation and conservation biological control in Israeli citrus orchards. Experimental and Applied Acarology, 63(3): 295-312.

Maranz, S. 2009. Tree mortality in the African Sahel indicates an anthropogenic ecosystem displaced by climate change. Journal of Biogeography, 36: 1181-1193.

Markandya, A., Taylor, T., Longo, A., Murty, M.N., Murty, S. \& Dhavalad, K. 2008. Counting the cost of vulture decline - An appraisal of the human health and other benefits of vultures in India. Ecological Economics, 67(2): 194-202.
Maron, D.F., Smith, T.J.S. \& Nachman, K.E. 2013. Restrictions on antimicrobial use in food animal production: an international regulatory and economic survey. Globalization and Health, 9(1): 48

Marschner, P., Kandeler, E. \& Marschner, B. 2003. Structure and function of the soil microbial community in a long-term fertilizer experiment. Soil Biology and Biochemistry, 35(3): 453-461.

Marshall, F., Reid, R.E.B., Goldstein, S., Storozum, M., Wreschnig, A., Hu, L., Kiura, P., ShahackGross, R. \& Ambrose, S.H. 2018. Ancient herders enriched and restructured African grasslands. Nature, 561(7723): 387-390.

Martin, E., Reineking, B., Seo, B. \& SteffanDewenter, I. 2013. Natural enemy interactions constrain pest control in complex agricultural landscapes. PNAS, 110(14): 5534-5539.

Martini, E., Roshetko, J.M. \& Paramita, E. 2017. Can farmer-to-farmer communication boost the dissemination of agroforestry innovations? A case study from Sulawesi, Indonesia. Agroforestry Systems, 91(5): 811-824.

Marvier, M., Kareiva, P. \& Neubert, M.G. 2004. Habitat destruction, fragmentation, and disturbance promote invasion by habitat generalists in a multispecies metapopulation. Risk Analysis, 24(4): 869-879.

Mathez-Stiefel, S.L. 2016. Agroforestería para la adaptación al cambio climático en los Andes: Aprendiendo de los conocimientos locales. Policy Brief No. 36, Lima, ICRAF.

Maxwell, S.L., Fuller, R.A., Brooks, T.M. \& Watson, J.E.M. 2016. Biodiversity: the ravages of guns, nets and bulldozers. Nature, 536(7615): 143-145.

Mazoyer, M. \& Roudart, L. 2006. A history of world agriculture: from the Neolithic Age to the current crisis. Abingdon, UK, and New York, USA, Earthscan.

Mba, C., Guimaraes, E.P. \& Ghosh, K. 2012. Reorienting crop improvement for the changing climatic conditions of the 21st century. Agriculture \& Food Security, 1(7).

Mbuthia, L.W., Acosta-Martínez, V., DeBruyn, J., Schaeffer, S., Tyler, D., Odoi, E. \& Eash, N. 2015. Long term tillage, cover crop, and fertilization effects on microbial community structure, activity: implications for soil quality. Soil Biology and Biochemistry, 89: 24-34. 
McDonald, T., Gann, G.D., Jonson, J. \& Dixon, K.W. 2016 International standards for the practice of ecological restoration - including principles and key concepts. Washington, DC, Society for Ecological Restoration.

McGee, J.A., Day, S.D., Wynne, R.H. \& White, M.B. 2012. Using geospatial tools to assess the urban tree canopy: decision support for local governments. Journal of Forestry, 110(5): 275-286.

McGinnity, P., Prodöhl, P., Ferguson, A., Hynes, R., Maoiléidigh, N.Ó., Baker, N., Cotter, D. et al. 2003. Fitness reduction and potential extinction of wild populations of Atlantic salmon, Salmo salar, as a result of interactions with escaped farm salmon. Proceedings of the Royal Society B: Biological Sciences, 270(1532): 2443-2450.

McGowan, P.J.K. 2010. Conservation status of wild relatives of animals used for food. Animal Genetic Resources, 47: 115-118.

McIntire, J., Bourzat, D. \& Pingali, P. 1992. Crop-livestock interaction in Sub-Saharan Africa. Washington, DC, World Bank.

Mclntyre, A.D., ed. 2010. Life in the world's oceans: diversity, distribution, and abundance. Chichester, UK, Blackwell Publishing.

McKenzie, L.J., Yoshida, R.L., Langlois, L., Rau, J., Weatherall, K., Bishop, F., Bain, D., Ferguson, S. \& Lindsay, M. 2017. Long-term seagrass monitoring in Roebuck Bay, Broome: report on the first 10 years. A report for the Broome Community Seagrass Monitoring Project, Environs Kimberley. Centre for Tropical Water \& Aquatic Ecosystem Research (TropWATER) Report 17/35. Cairns, Australia, James Cook University.

McLeod, E., Chmura, G.L., Bouillon, S., Salm, R., Björk, M., Duarte, C.M., Lovelock, C.E., Schlesinger, W.H. \& Silliman, B.R. 2011. A blueprint for blue carbon: toward an improved understanding of the role of vegetated coastal habitats in sequestering $\mathrm{CO}_{2}$. Frontiers in Ecology and the Environment, 9(10): 552-560.

McMahon, D.P., Natsopoulou, M.E., Doublet, V., Fürst, M., Weging, S., Brown, M.J.F., GogolDöring, A. \& Paxton, R.J. 2016. Elevated virulence of an emerging viral genotype as a driver of honeybee loss. Proceedings of the Royal Society B: Biological Sciences, 283: 20160811.
MEA (Millennium Ecosystem Assessment). 2005a. Ecosystem and human well-being - Synthesis. Washington, DC, Island Press.

MEA. 2005b. Ecosystems and human well-being: current state and trends. Washington, DC, Island Press.

Mead, R. \& Willey, R.W. 1980. The concept of a 'land equivalent ratio' and advantages in yields from intercropping. Experimental Agriculture, 16(3): 217-228.

Meals, D.W., Dressing, S.A. \& Davenport, T.E. 2010. Lag time in water quality response to best management practices: a review. Journal of Environmental Quality, 39(1): 85-96.

Mediterranean Wetlands Observatory. 2012. Biodiversity: status and trends of species in Mediterranean wetlands. Thematic collection, Special Issue No. 1. Tour du Valat, France.

Meeus, I., Brown, M.J., De Graaf, D.C. \& Smagghe, G. 2011. Effects of invasive parasites on bumble bee declines. Conservation Biology, 25(4): 662-671.

Mekonnen, M.M. \& Hoekstra, A.Y. 2016. Four billion people facing severe water scarcity. Science Advances, 2(2): e1500323.

Melathopoulos, A.P., Cutler, G.C. \& Tyedmers, P. 2015. Where is the value in valuing pollination ecosystem services to agriculture? Ecological Economics, 109: 59-70.

Melman, T.C.P. \& Van der Heide, C.M. 2011. Ecosysteemdiensten in Nederland: verkenning betekenis en perspectieven. Achtergrondrapport bij Natuurverkenning 2011. WOt-rapport 111. Wettelijke Onderzoekstaken Natuur \& Milieu. Wageningen, Netherlands, Wageningen University \& Research.

Mendoza, T. 2002. An energy-based analysis of organic, low external input sustainable agriculture (LEISA) and conventional rice production in the Philippines. The Philippine Agricultural Scientist, 88(3): 257-267.

Meybeck, M., Helmer, R., Förstner, U. \& Chilton, J. 1989. Global assessment of fresh waters quality - a first assessment. In M. Meybeck, R. Helmer \& U. Förstner, eds. Global freshwater quality: a first assessment. Oxford, UK, Blackwell.

Miccolis, A., Mongeli Peneireiro, F., Rodrigues Marques, H., Mascia Vieira, D.L., Francia ArcoVerde, M., Rigon Hoffmann, M., Rehder, T. \& Barbosa Pereira, A.V. 2016. Restauração ecológica 
com sistemas agroflorestais: como conciliar conservação com produção. Opções para cerrado e caatinga. Brasilia, Instituto Sociedade, População e Natureza (ISPN) and ICRAF.

Michener, C.D. 2007. The bees of the world. Baltimore, USA, The John Hopkins University Press.

Miles, L. \& Kapos, V. 2008. Reducing greenhouse gas emissions from deforestation and forest degradation: global land-use implications. Science, 320: 1454-1455.

Miller, A.J. \& Gross, B.L. 2011. From forest to field: perennial fruit crop domestication. American Journal of Botany, 98(9): 1389-1414.

Miller, R.P. \& Nair, P.K.R. 2006. Indigenous agroforestry systems in Amazonia: from prehistory to today. Agroforestry Systems, 66(2): 151-164.

Miller, D.D. \& Sumaila, U.R. 2014. Flag use behavior and IUU activity within the international fishing fleet: Refining definitions and identifying areas of concern. Marine Policy, 44: 204-211.

Minasny, B., Malone, B.P., McBratney, A.B., Angers, D.A., Arrouays, D., Chambers, A., Chaplot, V. et al. 2017. Soil carbon 4 per mille. Geoderma, 292: 59-86.

Ministry of Health of Brazil. 2016. Dietary guidelines for the Brazilian population. Brasilia, Ministry of Health of Brazil.

Ministry of Natural Resources - Rwanda. 2014. Forest landscape restoration opportunity assessment for Rwanda. MINIRENA (Rwanda), IUCN, WRI.

Mitchell, N., Rössler, M. \& Tricard, P.M., eds. 2009 World heritage cultural landscapes: a handbook for conservation and management. World Heritage Papers 26. Paris, UNESCO.

Mitchell, R.J., Bailey, S., Beaton, J.K., Bellamy, P.E., Brooker, R.W., Broome, A., Chetcuti, J. et al. 2014. The potential ecological impact of ash dieback in the UK. JNCC Report No. 483. Peterborough, UK, Joint Nature Conservation Committee (JNCC).

Mitsch, W.J. \& Gosselink, J.G., eds. 2015. Wetlands. Hoboken, USA, John Wiley \& Sons.

MNRE (Ministy of Natural Resources and Environment). 2015. Vietnam National Biodiversity Strategy to 2020, vision to 2030. Hanoi.

Modernel, P., Astigarraga, L. \& Picasso, V. 2013. Global versus local environmental impacts of grazing and confined beef production systems. Environmental Research Letters, 8(3): 035052.
Modernel, P., Rossing, W.A.H., Corbeels, M., Dogliotti, S., Picasso, V. \& Tittonell, P. 2016. Land use change and ecosystem service provision in Pampas and Campos grasslands of southern South America. Environmental Research Letters, 11(11): 113002.

Mohd, N., Mohd, F., Sajap, A.S., Rosliza, J. \& Suri, R. 2010. Conservation and sustainable utilization of stingless bees for pollination services in agricultural ecosystems in Malaysia. In K. Yasuda, F. Ihara \& T.-Y. $\mathrm{Ku}$, eds. Proceedings of International Seminar on Enhancement of Functional Biodiversity Relevant to Sustainable Food Production in ASPAC - in association with MARCO - November 9-11, 2010 Tsukuba, Japan, pp. 1-11. Tsukuba, Japan, National Institute for Agro-Environmental Sciences, Fujimoto, Japan, National Institute of Fruit Tree Science NARO, and Taipei, Food and Fertilizer Technology Center (FFTC) for the Asian and Pacific Region, National Institute for Agro-Environmental Sciences.

Mohd Fahimee, J. 2012. Manual teknologi penternakan lebah kelulut. Kuala Lumpur, Malaysian Agricultural Research and Development Institute (MARDI).

Mohd Fahimee, J., Madihah, H., Muhamad Radzali, M., Rosliza, J., Mohd Masri, S., Mohd Yusri, Z., Roziah, G. \& Idris, A.G. 2016. The diversity and abundance of stingless bee (Hymenoptera: Meliponini) in Peninsular Malaysia. Advance in Environmental Biology, 10(9): 1-7.

Mohri, H., Lahoti, S., Saito, O., Mahalingam, A., Gunatilleke, N., Hitinayake, G., Takeuchi, K. \& Herath, S. 2013. Assessment of ecosystem services in homegarden systems in Indonesia, Sri Lanka, and Vietnam. Ecosystem Services, 5: 124-136.

Moll, H.A.J. 2005. Costs and benefits of livestock systems and the role of market and nonmarket relationships. Agricultural Economics, 32(2): 181-193.

Molur, S., Smith, K.G., Daniel, B.A. \& Darwall, W.R.T. 2011. The status and distribution of freshwater biodiversity in the Western Ghats, India. Cambridge, UK, and Gland, Switzerland IUCN, and Coimbatore, India, Zoo Outreach Organisation.

Momose, K., Yumoto, T., Nagamitsu, T., Kato, M., Nagamasu, H., Sakai, S., Harrison, R.D., Itioka, T., Hamid, A.A. \& Inoue, T. 1998. Pollination biology in a lowland dipterocarp forest in Sarawak Malaysia. I. Characteristics of the plant pollinator 
community in a lowland dipterocarp forest.

American Journal of Botany, 85: 1477-1501.

Montagnini, F., Ibrahim, M. \& Murgueitio, E. 2013.

Silvopastoral systems and climate change mitigation in Latin America. Bois et Forets des Tropiques, 67(316): 3-16.

Montes, J.M. \& Melchinger, A.E. 2016. Domestication and breeding of Jatropha curcas L. Trends in Plant Science, 21(12): 1045-1057.

Monty, F., Murti, R. \& Furuta, N. 2016. Helping nature help us: transforming disaster risk reduction through ecosystem management. Gland, IUCN.

Moodie, R., Stuckler, D., Monteiro, C., Sheron, N., Neal, B., Thamarangsi, T., Lincoln, P. \& Casswell, S. 2013. Profits and pandemics: prevention of harmful effects of tobacco, alcohol, and ultra-processed food and drink industries. The Lancet, 381(9867): 670-679.

Mora, C., Tittensor, D.P., Adl, S., Simpson, A.G.B. \& Worm, B. 2011. How many species are there on earth and in the ocean? PLoS Biology, 9(8): e1001127.

Morales-Ramos, J., Guadalupe-Rojas, M. \& ShapiroIlan, D. 2014. Mass production of beneficial organisms. Cambridge, USA, Academic Press.

Morand, S. \& Lajaunie, C. 2017. Biodiversity and health. Linking life, ecosystems and societies. London, Elsevier \& ISTE Press.

Morgera, E., Buck, M. \& Tsioumani, E. 2013. Introduction. In E. Morgera, M. Buck \& E. Tsioumani, eds. The 2010 Nagoya Protocol on Access and Benefit-sharing in perspective. Implications for international law and implementation challenges, pp. 1-17. Leiden, Netherlands, Brill.

Moriarty, D.J.W. \& Pullin, R.S.V, eds. 1987. Detritus and microbial ecology in aquaculture. ICLARM Conference Proceedings No. 140. Manila, ICLARM.

Moritz, R.F.A., Hartel, S. \& Neumann, P. 2005. Global invasions of the western honeybee (Apis mellifera) and the consequences for biodiversity. Ecoscience, 12: 289-301.

Mortensen, D.A., Egan, J.F., Maxwell, B.D., Ryan, M.R. \& Smith, R.G. 2012. Navigating a critical juncture for sustainable weed management. BioScience, 62(1): 75-84.

Morton, J. \& Meadows, N. 2000. Pastoralism and sustainable livelihoods: an emerging agenda. Chatham, UK, Natural Resources Institute.
Morton, R.A. \& Barras, J.A. 2011. Hurricane impacts on coastal wetlands: a half-century record of stormgenerated features from Southern Louisiana. Journal of Coastal Research, 27(6A): 27-43.

Moser, C.M. \& Barret, B.B. 2003. The disappointing adoption dynamics of a yield-increasing, low external-input technology: the case of SRI in Madagascar. Agricultural Systems, 76: 1085-1100.

Mosquera-Losada, M.R., Moreno, G., Pardini, A., McAdam, J.H., Papanastasis, V.P., Burgess, P.J., Lamersdorf, N., Castro, M., Liagre, F. \& RigueiroRodríguez, A. 2012. Past, present and future of agroforestry systems in Europe. Agroforestry the future of global land use, pp. 31-67. (available at http://link. springer.com/10.1007/978-94-007-4676-3).

Mottet, A., de Haan, C., Falcucci, A., Tempio, G., Opio, C. \& Gerber, P. 2017. Livestock: on our plates or eating at our table? A new analysis of the feed/ food debate. Global Food Security, 14: 1-8.

Moursi, M.M., Arimond, M., Dewey, K.G., Treche, S., Ruel, M.T. \& Delpeuch, F. 2008. Dietary diversity is a good predictor of the micronutrient density of the diet of 6- to 23-month-old children in Madagascar. Journal of Nutrition, 138(12): 2448-2453.

Mozaffarian, D., Afshin, A., Benowitz, N.L., Bittner, V., Daniels, S.R., Franch, H.A., Jacobs, D.R. et al. 2012. Population approaches to improve diet, physical activity, and smoking habits: a scientific statement from the American Heart Association. Circulation, 126(12): 1514-1563.

Muck, R.E., Filya, I. \& Contreras-Govea, F.E. 2007. Inoculant effects on alfalfa silage: in vitro gas and volatile fatty acid production. Journal of Dairy Science, 90: 5115-5125.

Mullin, C.A., Frazier, M., Frazier, J.L., Ashcraft, S., Simonds, R., van Engelsdorp, D. \& Pettis, J.S. 2010. High levels of miticides and agrochemicals in North American apiaries: implications for honey bee health. PLOS ONE, 5: e9754.

Mulyoutami, E., Roshetko, J.M., Martini, E., Awalina, D. \& Janudianto. 2015. Gender roles and knowledge in plant species selection and domestication: a case study in South and Southeast Sulawesi. International Forestry Review, 17(4): 99-111.

Mumby, P.J., Edwards, A.J., Arias-González, J.E., Lindeman, K.C., Blackwell, P.G., Gall, A., 
Gorczynska, M.I. et al. 2004. Mangroves enhance the biomass of coral reef fish communities in the Caribbean. Nature, 427(6974): 533-536.

Mumby, P.J., Hedley, J.D., Kamila, Z., Harborne, A.R. \& Blackwell, P.G. 2006. Revisiting the catastrophic die-off of the urchin Diadema antillarum on Caribbean coral reefs: fresh insights on resilience from a simulation model. Ecological Modelling, 196(1-2): 131-148.

Murchie, A.K. \& Gordon, A.W. 2013. The impact of the "New Zealand flatworm", Arthurdendyus triangulatus, on earthworm populations in the field. Biological Invasions, 15(3): 569-586.

Murcia, C., Guariguata, M.R., Andrade, A., Andrade, G.I., Aronson, J., Escobar, M.E., Etter, A., Moreno, F.H., Ramírez, W. \& Montes, E. 2015. Challenges and prospects for scaling-up ecological restoration to meet international commitments: Colombia as a case study. Conservation Letters, 9(3): 213-220.

Murdiyarso, D., Purbopuspito, J., Kauffman, J.B., Warren, M.W., Sasmito, S.D., Donato, D.C., Manuri, S., Krisnawati, H., Taberima, S. \& Kurnianto, S. 2015. The potential of Indonesian mangrove forests for global climate change mitigation. Nature Climate Change, 5(12): 1089-1092.

Murray, G.F. \& Bannister, M.E. 2004. Peasants, agroforesters, and anthropologists: a 20-year venture in income-generating trees and hedgerows in Haiti. Agroforestry Systems, 61: 383-397.

Murray, C.J.L., Atkinson, C., Bhalla, K., Birbeck, G., Burstein, R., Chou, D., Dellavalle, R. et al. 2013. The state of US health, 1990-2010: burden of diseases, injuries, and risk factors. Journal of the American Medical Association, 310(6): 591-608.

Mutch, L.A. \& Young, J.P.W. 2004. Diversity and specificity of Rhizobium leguminosarum biovar viciae on wild and cultivated legumes. Molecular Ecology, 13(8): 2435-2444.

Myers, J.H. \& Cory, J.S. 2017. Biological control agents: invasive species or valuable solutions? Impact of biological invasions on ecosystem services, pp. 191-202. Cham, Switzerland, Springer.

Nabhan, G.P. \& Buchmann, S.L. 1997. Services provided by pollinators. In G. Daily, ed. Nature's services, pp. 133-150. Washington, DC, Island Press.
Nagelkerken, I., Blaber, S.J.M., Bouillo, S., Green, P., Haywood, M., Kirton, L.G., Meynecke, J.O. et al. 2008. The habitat function of mangroves for terrestrial and marine fauna: a review. Aquatic Botany, 89: 155-185.

Nair, P.K.R. 2006. Whither homegardens? In B.M. Kumar \& P.K.R. Nair, eds. Tropical homegardens: a timetested example of sustainable agroforestry. Vol. 3, pp. 355-370. Dordrecht, Netherlands, Springer.

Naish, K.A., Taylor, J.E., Levin, P.S., Quinn, T.P., Winton, J.R., Huppert, D. \& Hilborn, R. 2007. An evaluation of the effects of conservation and fishery enhancement hatcheries on wild populations of salmon. Advances in Marine Biology, 53(07): 61-194.

Nakkeeran, S., Fernando, W.G.D. \& Siddiqui, Z.A. 2005. Plant growth promoting rhizobacteria formulations and its scope in commercialization for the management of pests and diseases. In Z.A. Siddiqui, ed. PGPR: biocontrol and biofertilization, pp. 257-296. Dordrecht, Netherlands, Springer.

Namkoong, G., Boyle, T., Gregorious, H.R., Joly, H., Savolainen, O., Ratman, W. \& Young, A. 1996. Testing criteria and indicators for assessing the sustainability of forest management: genetic criteria and indicators. CIFOR Working Paper No. 10. Bogor, Indonesia, Centre for International Forestry Research.

Namkoong, G., Boyle, T., El-Kassaby, Y.A., PalmbergLerche, C., Eriksson, G., Gregorius, H.-R., Joly, H. et al. 2002. Criteria and indicators for sustainable forest management: assessment and monitoring of genetic variation. Forest Genetic Resources Working Papers FGR/37E. Rome, FAO.

Narayan, S., Beck, M.W., Reguero, B.G., Losada, I.J., van Wesenbeeck, B., Pontee, N., Sanchirico, J.N. et al. 2016. The benefits, costs and effectiveness of natural and nature-based coastal defenses. PLoS ONE, 11(5): e0154735.

Nasi, R., Brown, D., Wilkie, D., Bennett, E., Tutin, C., van Tol, G. \& Christophersen, T. 2008. Conservation and use of wildlife-based resources: the bushmeat crisis. Technical Series No. 33. Montreal, Canada, Secretariat of the Convention on Biological Diversity, and Bogor, Indonesia, Center for International Forestry Research. 
Nassar, N.M. 2003. Gene flow between cassava, Manihot esculenta Crantz, and wild relatives. Genetics and Molecular Research, 2(4): 334-347.

Nates-Parra, G. 2001. Las abejas sin aguijón (Hymenoptera: Meliponini) de Colombia. Revista Biota Colombiana, 2(3): 233-248.

Nates-Parra, G. 2004. Abejas corbiculadas de Colombia. Bogota, Universidad Nacional de Colombia.

Natsopoulou, M.E., McMahon, D.P., Doublet, V., Frey, E., Rosenkranz, P. \& Paxton, R.J. 2017. The virulent, emerging genotype $B$ of Deformed wing virus is closely linked to overwinter honeybee worker loss. Scientific Reports, 7: 5242.

Nawy, T. 2013. Single-cell sequencing. Nature Methods, 11(1): 18.

NCBI (National Center for Biotechnology Information) 2018. Home - Genome. Cited 14 December 2018. https://www.ncbi.nlm.nih.gov/genome

Nellemann, C., Corcoran, E., Duarte, C.M., Valdés, L., De Young, C., Fonseca, L. \& Grimsditch, G. 2009. Blue carbon. A rapid response assessment. Arendal, Norway, GRID-Arendal, and Nairobi, UNEP.

Nesbitt, M., McBurney, R.P.H., Broin, M. \& Beentje, H.J. 2010. Linking biodiversity, food and nutrition: the importance of plant identification and nomenclature. Journal of Food Composition and Analysis, 23(6): 486-498.

Neugarten, R.A., Langhammer, P.F., Osipova, E., Bagstad, K.J., Bhagabati, N., Butchart, S.H.M., Dudley, N. et al. 2018. Tools for measuring, modelling, and valuing ecosystem services: guidance for key biodiversity areas, natural World Heritage Sites, and protected areas. Gland, Switzerland, IUCN. (available at https://portals.iucn.org/library/ sites/library/files/documents/PAG-028-En.pdf).

Newton, A., Oldfield, S., Rivers, M., Mark, J., Schatz, G., Tejedor Garavito, N., Cantarello, E., Golicher, D., Cayuela, L. \& Miles, L. 2015a. Towards a global tree assessment. Oryx, 49(3): 410-415.

Newton, J.A., Feely, R.A., Jewett, E.B., Williamson, P. \& Mathis, J. 2015b. Global Ocean Acidification Observing Network (GOA-ON): requirements and governance plan. Global Ocean Acidification Observing Network.

NFPF (The National Forest Programme Facility) \& FAO. 2012. NFPs in practice: Ways to improve the implementation of national forest programmes. Rome, FAO. (available at http://www.fao.org/ docrep/015/i2623e/i2623e00.pdf).

Ng, M., Fleming, T., Robinson, M., Thomson, B., Graetz, N., Margono, C., Mullany, E.C. et al. 2014. Global, regional, and national prevalence of overweight and obesity in children and adults during 1980-2013: a systematic analysis for the Global Burden of Disease Study 2013. The Lancet, 384(9945): 766-781.

Ng, E.-L.L., Huerta Lwanga, E., Eldridge, S.M., Johnston, P., Hu, H.-W.W., Geissen, V. \& Chen, D. 2018. An overview of microplastic and nanoplastic pollution in agroecosystems. Science of The Total Environment, 627: 1377-1388.

Nhan, D.K., Milstein, A., Verdegem, M.C.J. \& Verreth, J.A.V. 2006. Food inputs, water quality and nutrient accumulation in integrated pond systems: a multivariate approach. Aquaculture, 261(1): 160-173.

Nhan, D.K., Phong, L.T., Verdegem, M.C.J., Duong, L., Bosma, R. \& Little, D. 2007. Integrated freshwater aquaculture, crop and livestock production in the Mekong delta, Vietnam: determinants and the role of the pond. Agricultural Systems, 94(2): 445-458.

Nicholls, C.I. \& Altieri, M.A. 2013. Plant biodiversity enhances bees and other insect pollinators in agroecosystems. A review. Agronomy for Sustainable Development, 33(2): 257-274.

Nielsen, U.N., Ayres, E., Wall, D.H. \& Bardgett, R.D. 2011. Soil biodiversity and carbon cycling: a review and synthesis of studies examining diversity-function relationships. European Journal of Soil Science, 62(1): 105-116.

Nijar, G.S. 2013. Developing a common pools strategy for genetic resources for food and agriculture. In G. Winter \& E.C. Kamau, eds. Common pools of genetic resources: equity and innovation in international biodiversity law, pp. 127-149. London, Routledge.

Nikolaki, S. \& Tsiamis, G. 2013. Microbial diversity in the era of omic technologies. BioMed Research International, 2013: 958719.

NMFS (National Marine Fisheries Service). 2016. Central Valley Recovery Domain 5-year status review : summary and evaluation of Sacramento River Winter-Run Chinook Salmon ESU. NMFS West Coast Region. (available at https://repository.library. noaa.gov/view/noaa/17014). 
NOAA (National Oceanic and Atmospheric Administration). 2018. CoRIS: Coral Reef Information System. [Cited 21 March 2018]. https:// www.coris.noaa.gov/

Noble, R. \& Coventry, E. 2005. Suppression of soilborne plant diseases with composts: a review. Biocontrol Science and Technology, 15(1): 3-20.

NordGen. 2015. Plan of Action for the Conservation of the Nordic Brown Bee. Ås, Norway, Nordic Genetic Resources Center.

Nordlund, L.M., Unsworth, R.K.F., Gullström, M. \& Cullen-Unsworth, L.C. 2018. Global significance of seagrass fishery activity. Fish and Fisheries: 19(3): 319-412.

Noriega, J.A., Hortal, J., Azcárate, F.M., Berg, M.P., Bonada, N., Briones, M.J.I., Del Toro, I. et al. 2018. Research trends in ecosystem services provided by insects. Basic and Applied Ecology, 26: 8-23.

Notarnicola, B., Sala, S., Anton, A., McLaren, S.J., Saouter, E. \& Sonesson, U. 2017. The role of life cycle assessment in supporting sustainable agrifood systems: a review of the challenges. Journal of Cleaner Production, 140: 399-409.

Nowak, D.J., Hirabayashi, S., Bodine, A. \& Greenfield, E. 2014. Tree and forest effects on air quality and human health in the United States. Environmental Pollution, 193: 119-129.

NRC (National Research Council). 1993. Managing global genetic resources: agricultural crop issues and policies. Washington, DC, National Academies Press.

NRC. 1972. Genetic vulnerability of major crops. Washington, DC, National Academy of Sciences.

NRC. 2002. Riparian areas: functions and strategies for management. Washington, DC, Committee on Riparian Zone Functioning and Strategies for Management, Water Science and Technology Board, National Research Council, National Academies Press.

NRC. 2007. Status of pollinators in North America. Washington, DC, National Academies Press.

NRC. 2010. The impact of genetically engineered crops on farm sustainability in the United States. Washington, DC, National Academies Press.

Nunes-Silva, P., Hrncir, M., da Silva, C.I., Roldão, Y.S. \& Imperatriz-Fonseca, V.L. 2013. Stingless bees, Melipona fasciculata, as efficient pollinators of eggplant (Solanum melongena) in greenhouses. Apidologie, 44: 537-546.

Ocean Health Index. 2018. Seagrass. [Cited 22 March 2018]. http://www.oceanhealthindex.org/ methodology/components/seagrass

Öckinger, E. \& Smith, H.G. 2007. Semi-natural grasslands as population sources for pollinating insects in agricultural landscapes. Journal of Applied Ecology, 44(1): 50-59.

OECD (Organisation for Economic Co-operation and Development). 2001. Biological resource centres: underpinning the future of life sciences and biotechnology. Paris.

OECD. 2013. OECD compendium of agri-environmental indicators. Paris. (available at https://www.oecdilibrary.org/fr/agriculture-and-food/oecd-compendiumof-agri-environmental-indicators_9789264186217en?_ga=2.134309746.280343264.15474813691593362190.1547307848).

Ogada, D., Kessing, F. \& Virani, M.Z. 2012. Dropping dead: causes and consequences of vulture population declines worldwide. Annals of the New York Academy of Sciences, 1249(1): 57-71.

Okano, J., Shibata, J., Sakai, Y., Yamaguchi, M., Ohishi, M., Goda, Y., Nakano, S. \& Okuda, N. 2018. The effect of human activities on benthic macroinvertebrate diversity in tributary lagoons surrounding Lake Biwa. Limnology, 19(2): 199-207.

Okoth, P., Okoth, S. \& Jefwa, J.M. 2013. The conservation and use of micro-organisms and invertebrates in root crop-based systems: state of knowledge, trends and future prospects. Commission on Genetic Resources for Food and Agriculture. Background Study Paper No. 63. Rome. (available at http://www.fao.org/3/19898EN/i9898en.pdf).

Oldfield, S., Ali, N., Goettsch, B., Hardcastle, J. \& Shi, Y. forthcoming. Study on the linkages between protected areas and the conservation of biodiversity for food and agriculture. Thematic study prepared for The State of the World's Biodiversity for Food and Agriculture. Rome, FAO.

Olesen, I., Bentsen, H., Phillips, M. \& Ponzoni, R. 2015. Can the global adoption of genetically improved farmed fish increase beyond $10 \%$, and how? Journal of Marine Science and Engineering, 3(2): 240-266. 
Ollerton, J., Winfree, R. \& Tarrant, S. 2011. How many flowering plants are pollinated by animals? Oikos, 120(3): 321-326.

Opio, C., Gerber, P., Mottet, A., Falcucci, A., Tempio, G., MacLeod, M., Vellinga, T., Henderson, B. \& Steinfeld, H. 2013. Greenhouse gas emissions from ruminant supply chains - A global life cycle assessment. Rome, FAO. (available at http://www. fao.org/docrep/018/i3460e/i3460e.pdf).

Oregon State University. 2008. Greatest value of forests is sustainable water supply. [Cited 21 March 2018]. https://www.sciencedaily.com/ releases/2008/07/080714162600.htm

Orgiazzi, A., Dunbar, M.B., Panagos, P., de Groot, G.A. \& Lemanceau, P. 2015. Soil biodiversity and DNA barcodes: opportunities and challenges. Soil Biology and Biochemistry, 80: 244-250.

Orgiazzi, A., Bardgett, R.D., Barrios, E., BehanPelletier, V., Briones, M.J.I., Chotte, J.-L., De Deyn, G.B. et al., eds. 2016. Global soil biodiversity atlas. Luxembourg, European Commission, Publications Office of the European Union.

Orr, D. 2009. Biological control and integrated pest management. In R. Peshin \& A. Dhawan, eds. Integrated pest management: innovationdevelopment process, pp. 207-339. Dordrecht, Netherlands, Springer.

Orr, B.J., Cowie, A.L., Castillo Sanchez, V.M., Chasek, P., Crossman, N.D., Erlewein, A., Louwagie, G. et al. 2017. Scientific conceptual framework for land degradation neutrality. A report of the SciencePolicy Interface. Bonn, Germany, United Nations Convention to Combat Desertification (UNCCD).

Orsini, F., Kahane, R., Nono-Womdim, R. \& Gianquinto, G. 2013. Urban agriculture in the developing world: a review. Agronomy for Sustainable Development, 33(4): 695-720.

Orth, R.J., Carrunthers, T.J.B., Dennison, W.C., Duarte, C.M., Fourqurean, J.W., Heck Jr., K.L., Randall Hughes, A. et al. 2006. A global crisis for seagrass ecosystems. BioScience, 56(12): 987-996.

Osemeobo, G.J. 1987. Smallholder farmers and forestry development: a study of rural land use in Bendel, Nigeria. Agricultural Systems, 24: 32-52.

Ostroumov, S.A. 2002. Polyfunctional role of biodiversity in processes leading to water purification: current conceptualizations and concluding remarks. Hydrobiologia, 469: 203-204.

Ostroumov, S.A. 2005. On the multifunctional role of the biota on the self-purification of aquatic ecosystems. Russian Journal of Ecology, 36(6): 414-420.

Ostroumov, S.A. 2010. Biocontrol of water quality: multifunctional role of biota in water selfpurification. Russian Journal of General Chemistry, 80(13): 2754-2761.

Otte, J., Costales, A., Dijkman, J., Pica-Ciamara, U., Robinson, T., Ahuja, V., Ly, C. \& Roland-Holst, D. 2012. Livestock sector for poverty reduction: an economic and policy perspective - Livestock's many virtues. Rome, FAO. (available at http://www.fao.org/ docrep/015/i2744e/i2744e00.pdf).

Ottesen, O., Treasurer, J., Fitzgerald, R., D’Arcy, J., Maguire, J., O’Neill, D., Rebours, C. \& Dunavyeska, E. 2011. Rearing ballan wrasse for sea lice control. Fish Farmer, November/D: 12-15.

Ouedraogo, I., Runge, J., Eisenberg, J., Barron, J. \& Sawadogo-Kaboré, S. 2014. The re-greening of the Sahel: natural cyclicity or human-induced change? Land, 3(3): 1075-1090.

Ouwehand, A.C., Salminen, S. \& Isolauri, E. 2002. Probiotics: an overview of beneficial effects. $\ln \mathrm{W}$. Konings, O.P. Kuipers \& J.H.J Huis in 't Veld, eds. Lactic acid bacteria: genetics, metabolism and applications, pp. 279-289. Dordrecht, Netherlands, Springer.

Oxfam Novib, ANDES, SEARICE \& CGN-WUR. 2016. Women's roles in biodiversity management. From lessons to practice and impact: scaling up pathways in people's biodiversity management. Case study. The Hague, Netherlands, Oxfam Novib.

Ozlu, E. \& Kumar, S. 2018. Response of soil organic carbon, $\mathrm{pH}$, electrical conductivity, and water stable aggregates to long-term annual manure and inorganic fertilizer. Soil Science Society of America Journal, 82(5): 1243-1251.

Packer, L., Ali, E., Dumesh, S. \& Walker, K. 2016. Identification of pollinators - where are we and where should we go? In B. Gemhill-Herren, ed. Pollination services to agriculture: sustaining and enhancing key ecosystem services, pp. 283-299. London, Routledge.

Padoch, C. \& de Jong, W. 1991. The house gardens of Santa Rosa: diversity and variability in an Amazonian agricultural system. Economic Botany, 45(2): 166-175. 
Page, R.E. 2013. The spirit of the hive. The mechanisms of social evolution. Cambridge, USA, Harvard University Press.

Page, T., Murphy, M.E., Mizrahi, M., Cornelius, J.P. \& Venter, M. 2016. Sustainability of wood-use in remote forest-dependent communities of Papua New Guinea. Forest Ecology and Management, 382: 88-99.

Pagiola, S. 2006. Payments for environmental services in Costa Rica. MPRA Paper No. 2010. Munich, Germany, The Munich Personal RePEc Archive (MPRA).

Palmer, A.R. \& Bennett, J.E. 2013. Degradation of communal rangelands in South Africa: towards an improved understanding to inform policy. African Journal of Range \& Forage Science, 30(1-2): 57-63.

Palmer, M.A., Covich, A.P., Lake, S., Biro, P., Brooks, J.J., Cole, J. \& Van De Bund, W.J. 2000. Linkages between aquatic sediment biota and life above sediments as potential drivers of biodiversity and ecological processes. BioScience, 60: 820-832.

Palmgren, M.G., Edenbrandt, A.K., Vedel, S.E., Andersen, M.M., Landes, X., Østerberg, J.T., Falhof, J. et al. 2015. Are we ready for back-tonature crop breeding? Trends in Plant Science, 20(3): 155-164.

Pardo, D., Forcada, J., Wood, A.G., Tuck, G.N., Ireland, L., Pradel, R., Croxall, J.P. \& Phillips, R.A. 2017. Additive effects of climate and fisheries drive ongoing declines in multiple albatross species. Proceedings of the National Academy of Sciences, 114(50): E10829-E10837.

Parfitt, J., Barthel, M. \& Macnaughton, S. 2010. Food waste within food supply chains: quantification and potential for change to 2050. Philosophical Transactions of the Royal Society B: Biological Sciences, 365(1554): 3065-3081.

Parlesak, A., Geelhoed, D. \& Robertson, A. 2014. Toward the prevention of childhood undernutrition: diet diversity strategies using locally produced food can overcome gaps in nutrient supply. Food and Nutrition Bulletin, 35(2): 191-199.

Parr, J.F., Papendick, R.I., Youngberg, I.G. \& Meyer, R.E. 1990. Sustainable agriculture in the United States. In C.A. Edwards, R. Lal, P. Madden, R.H. Miller \& G. House, eds. Sustainable agricultural systems, pp. 50-67. Ankeny, USA, Soil and Water Conservation Society.
Parry, L., Barlow, J. \& Peres, C.A. 2009. Hunting for sustainability in tropical secondary forests. Conservation Biology, 23(5): 1270-1280.

Paterson, R. \& Lima, N., eds. 2017. Bioprospecting. Success, potential and constraints. Cham, Switzerland, Springer International Publishing.

Pattanayak, S.K. \& Sills, E.O. 2001. Do tropical forests provide natural insurance? The microeconomics of non-timber forest product collection in the Brazilian Amazon. Land Economics, 77(4): 595-612.

Pauly, D., Christensen, V., Dalsgaard, J., Froese, R. \& Torres, F. 1998. Fishing down marine food webs. Science, 279(5352): 860-863.

Pearce, D. 1993. Economic values and the natural world. London, Earthscan.

Pearce, D. \& Moran, D. 1994. The economic value of biodiversity. London, Earthscan.

Pecora, G., Musto, M., D'adamo, C., Adduci, F., Freschi, P. \& Cosentino, C. 2015. GIS system and livestock field survey as tools to manage the potential reducing of fuel load for fire prevention. Journal of Agricultural Informatics, 6(3): 57-66.

PEFC. 2018. Programme for the Endorsement of Forest Certification. [Cited 23 April 2018]. https://www. pefc.org

Pelosi, C., Toutous, L., Chiron, F., Dubs, F., Hedde, M., Muratet, A., Ponge, J.F., Salmon, S. \&

Makowski, D. 2013. Reduction of pesticide use can increase earthworm populations in wheat crops in a European temperate region. Agriculture, Ecosystems and Environment, 181: 223-230.

Pendleton, L., Donato, D.C., Murray, B.C., Crooks, S., Jenkins, W.A., Sifleet, S., Craft, C. et al. 2012. Estimating global "blue carbon" emissions from conversion and degradation of vegetated coastal ecosystems. PLOS ONE, 7(9): e43542.

Peng, S. \& Khushg, G. 2003. Four decades of breeding for varietal improvement of irrigated lowland rice in the International Rice Research Institute. Plant Production Science, 6(3): 157-164.

Perdana, A., Roshetko, J.M. \& Kurniawan, I. 2012. Forces of competition: smallholding teak producers in Indonesia. International Forestry Review, 14(2): 238-248.

Pérez-Jaramillo, J.E., Mendes, R. \& Raaijmakers, J.M. 2016. Impact of plant domestication on rhizosphere 
microbiome assembly and functions. Plant Molecular Biology, 90(6): 635-644.

Peters, C.M., Nepstad, D.C. \& Schwartzman, S. 1992. The ecology and economics of oligarchic forests. In D. Nepstad \& S. Schwartzman, eds. Non-timber products from tropical forests. Evaluation of a conservation and development strategy, pp. 15-22. New York, USA, New York Botanical Garden.

Pham, T.T., Bennet, K., Brunner, J., Le, N.D. \& Nguyen, D.T. 2013. Payment for forest environmental services in Viet Nam: from policy to practice. Occasional Paper 93. Bogor, Indonesia, Centre for International Forestry Research.

Piaggio, A.J., Segelbacher, G., Seddon, P.J., Alphey, L., Bennett, E.L., Carlson, R.H., Friedman, R.M. et al. 2017. Is it time for synthetic biodiversity conservation? Trends in Ecology \& Evolution, 32: 97-107.

Pica-Ciamarra, U., Baker, D., Bedane, B., Emwanu, T. \& Morgan, N. 2010. Integrating livestock into agricultural statistics. The AU-IBAR, FAO, ILRI, WB Data Innovation Project. (available at http://www. fao.org/3/a-as291e.pdf).

Piccini, I., Arnieri, F., Caprio, E., Nervo, B., Pelissetti, S., Palestrini, C., Roslin, T. \& Rolando, A. 2017. Greenhouse gas emissions from dung pats vary with dung beetle species and with assemblage composition. PLOS ONE, 12(7): e0178077.

Pilling, D. \& Hoffmann, I. 2011. Climate change and animal genetic resources for food and agriculture: state of knowledge, risks and opportunities. Commission on Genetic Resources for Food and Agriculture. Background Study Paper No. 53. Rome, FAO. (available at http://www.fao.org/docrep/ meeting/022/mb386e.pdf).

Pimentel, D., Zuniga, R. \& Morrison, D. 2005. Update on the environmental and economic costs associated with alien-invasive species in the United States. Ecological Economics, 52(3 SPEC. ISS.): 273-288.

Pingali, P. 2015. Agricultural policy and nutrition outcomes - getting beyond the preoccupation with staple grains. Food Security, 7(3): 583-591.

Pingali, P.L. \& Roger, P.A., eds. 1995. Impact of pesticides on farmer health and the rice environment. Norwell, USA, Kluwer Academic Publishers.
Pinstrup-Andersen, P. 2013. Can agriculture meet future nutrition challenges? European Journal of Development Research, 25(1): 5-12.

Pitcher, T.J., Kalikoski, D., Short, K., Varkey, D. \& Pramod, G. 2009. An evaluation of progress in implementing ecosystem-based management of fisheries in 33 countries. Marine Policy, 33: 223-232.

Pitman, M.G. \& Läuchli, A. 2002. Global impact of salinity and agricultural ecosystems. In A. Läuchl \& U. Lüttge, eds. Salinity: environment - plants - molecules, pp. 3-20. Dordrecht, Netherlands, Kluwer Academic Publishers.

Pitts-Singer, T.L. \& Cane, J.H. 2011. The alfalfa leafcutting bee, Megachile rotundata: the world's most intensively managed solitary bee. Annual Review of Entomology, 56: 221-237.

Pivari, D., Pacca, H.M. \& Sebrian, T. 2017. Occurrence of Boto-do-Araguaia (Inia araguaiaensis) in a Region of the Araguaia River, Brazil, documented for an environmental impact study for a hydroelectric dam. Aquatic Mammals, 43(5): 530-536.

Polidoro, B.A., Carpenter, K.E., Collins, L., Duke, N.C., Ellison, A.M., Ellison, J.C., Farnsworth, E.J. et al. 2010. The loss of species: mangrove extinction risk and geographic areas of global concern. PLOS ONE, 4: e10095.

Pollinator Health Task Force. 2015. National strategy to promote the health of honey bees and other pollinators. Washington, DC.

Popkin, B. 2017. Relationship between shifts in food system dynamics and acceleration of the global nutrition transition. Nutrition Reviews, 75(2): 73-82.

Popkin, B.M., Adair, L.S. \& Ng, S.W. 2012. Global nutrition transition and the pandemic of obesity in developing countries. Nutrition Reviews, 70(1): 3-21.

Porro, R. 2009. Expectativas e desafios para a adoção da alternativa agroflorestal na Amazônia em transformação. In R. Porro, ed. Alternativa agroflorestal na Amazônia em transformação, pp. 34-51. Brasilia, Embrapa.

Postel, S.L. \& Thompson, B.H. 2005. Watershed protection: capturing the benefits of nature's water supply services. Natural Resources Forum, 29(2): 98-108.

Postollec, F., Falentin, H., Pavan, S., Combrisson, J. \& Sohier, D. 2011. Recent advances in quantitative 
PCR (qPCR) applications in food microbiology. Food Microbiology, 28(5): 848-861.

Potkanski, T. 1999. Mutual assistance among the Ngorongoro Maasai. In D.M. Anderson \& V. Broch-Due, eds. The poor are not us: poverty and pastoralism in Eastern Africa, pp. 199-217. Athens, USA, Ohio University Press.

Potts, S.G., Vulliamy, B., Roberts, S., O'Toole, C., Dafni, A., Ne'eman, G. \& Willmer, P. 2005. Role of nesting resources in organising diverse bee communities in a Mediterranean landscape. Ecological Entomology, 30(1): 78-85.

Potts, S.G., Biesmeijer, J.C., Kremen, C., Neumann, P., Schweiger, O. \& Kunin, W.E. 2010. Global pollinator declines: trends, impacts and drivers. Trends in Ecology and Evolution, 25(6): 345-353.

Potts, S.G., Imperatriz-Fonseca, V., Ngo, H.T., Aizen, M.A., Biesmeijer, J.C., Breeze, T.D., Dicks, L.V. et al. 2016. Safeguarding pollinators and their values to human well-being. Nature, 540(7632): 220-229.

Potts, J., Voora, V., Lynch, M. \& Mammadova, A. 2017. Standards and biodiversity. Thematic Review. Winnipeg, Canada, International Institute for Sustainable Development. (available at https://www. iisd.org/sites/default/files/publications/standardsbiodiversity-ssi-report.pdf).

Poux, X. 2008. Low input farming systems in Europe: what is at stake? In K. Biala, J.-M. Terres, P. Pointereau \& M.L. Paracchini, eds. Low input farming systems: an opportunity to develop sustainable agriculture. Proceedings of the JRC Summer University Ranco, 2-5 July 2007, pp. 1-11. Luxembourg, European Commission, Publications Office of the European Union.

Powell, B., Maundu, P., Kuhnlein, H.V \& Johns, T. 2013. Wild foods from farm and forest in the East Usambara Mountains, Tanzania. Ecology of Food and Nutrition, 52(6): 451-478.

Powell, B., Ouarghidi, A., Johns, T., Tattou, M.I. \& Eyzaguirre, P. 2014. Wild leafy vegetable use and knowledge across multiple sites in Morocco: a case study for transmission of local knowledge? Journal of Ethnobiology and Ethnomedicine, 10(34).

Powell, B., Thilsted, S.H., Ickowitz, A., Termote, C., Sunderland, T. \& Herforth, A. 2015. Improving diets with wild and cultivated biodiversity from across the landscape. Food Security, 7(3): 535-554.
Powell, A., Treasurer, J.W., Pooley, C.L., Keay, A.J., Lloyd, R., Imsland, A.K., \& Garcia de Leaniz, C. 2018. Use of lumpfish for sea-lice control in salmon farming: challenges and opportunities. Reviews in aquaculture, 10(3): 68-702.

Power, A.G. 2010. Ecosystem services and agriculture: tradeoffs and synergies. Philosophical Transactions of the Royal Society B: Biological Sciences, 365: 2959-2971.

Prabhu, R., Barrios, E., Bayala, J., Diby, L., Donovan, J., Gyau, A., Graudal, L. et al. 2015. Agroforestry: realizing the promise of an agroecological approach. In FAO, ed. Agroecology for food security and nutrition: Proceedings of the FAO International Symposium, 18-19 September 2014, Rome, pp. 201-224. Rome, FAO. (available at http://www.fao.org/3/a-i4729e.pdf).

Prakash, V., Green, R.E., Pain, D.J., Ranade, S.P., Saravanan, S. \& Prakash, N. 2007. Recent changes in populations of resident Gyps vultures in India. Journal of the Bombay Natural History Society, 104(2): 127-133.

Prakash, V., Bishwakarma, M.C., Chaudhary, A., Cuthbert, R., Dave, R., Kulkarni, M., Kumar, S. et al. 2012. The population decline of Gyps vultures in India and Nepal has slowed since veterinary use of Diclofenac was banned. PLOS ONE, 7(11): e49118.

Pretty, J. \& Bharucha, Z.P. 2015. Integrated pest management for sustainable intensification of agriculture in Asia and Africa. Insects, 6(1): 152-182.

Pretty, J., Toulmin, C. \& Williams, S. 2011. Sustainable intensification in African agriculture. International Journal of Agricultural Sustainability, 9(1): 5-24.

Pretty, J., Benton, T.G., Bharucha, Z.P., Dicks, L.V., Flora, C.B., Godfray, H.C.J., Goulson, D. et al. 2018. Global assessment of agricultural system redesign for sustainable intensification. Nature Sustainability, 1(8): 441-446.

Pullin, R. \& White, P. 2011. Climate change and aquatic genetic resources for food and agriculture: state of knowledge, risks and opportunities. Commission on Genetic Resource for Food and Agriculture. Background Study Paper No. 55. Rome, FAO. (available at http://www.fao.org/docrep/ meeting/022/mb507e.pdf).

Putnam, H.M. \& Gates, R.D. 2015. Preconditioning in the reef-building coral Pocillopora damicornis and the 
potential for trans-generational acclimatization in coral larvae under future climate change conditions. The Journal of Experimental Biology, 218: 2365-2372.

Pywell, R.F., Warman, E.A., Carvell, C., Sparks, T.H., Dicks, L.V, Bennett, D., Wright, A., Critchley, C.N.R., \& Sherwood, A. 2005. Providing foraging resources for bumblebees in intensively farmed landscapes. Biological Conservation, 121: 479-494.

Queensland Government. 2017. Impacts of nutrient and pesticide run-off from cane farming. [Cited 18 July 2018]. https://www.qld.gov.au/environment/ agriculture/sustainable-farming/canefarming-impacts

Quemada, M., Baranski, M., Nobel-de Lange, M.N.J., Vallejo, A. \& Cooper, J.M. 2013. Meta-analysis of strategies to control nitrate leaching in irrigated agricultural systems and their effects on crop yield. Agriculture, Ecosystems \& Environment, 174: 1-10.

Quigley, K.M., Baker, A.C., Coffroth, M.A., Willis, B.L. \& van Oppen, M.J.H. 2018. Bleaching resistance and the role of algal endosymbionts. In M.J.H. van Oppen \& J.M. Lough, eds. Coral bleaching: patterns, processes, causes and consequences, pp. 111-151. Berlin, Springer.

Rafikov, M., Balthazar, J. \& von Bremen, H. 2008. Mathematical modeling and control of population systems: applications in biological pest control. Applied Mathematics and Computation, 200(2): 557-573.

Rah, J.H., Akhter, N., Semba, R.D., Pee, S.D., Bloem, M.W., Campbell, A.A., Moench-Pfanner, R., Sun, K., Badham, J. \& Kraemer, K. 2010. Low dietary diversity is a predictor of child stunting in rural Bangladesh. European Journal of Clinical Nutrition, 64(12): 1393-1398.

Rahman, M., Varga, I. \& Chowdhury, S., eds. 1992. Manual on polyculture and integrated fish farming in Bangladesh. Project: FAO-FI—BGD/87/045/91/11. Institutional Strengthening in the Fisheries Sector. Dhaka, Department of Fisheries, Government of Bangladesh, Washington, DC, UNDP, and Rome, FAO. (available at http://www.fao.org/docrep/ field/003/ac375e/AC375E00.htm).

Ramsar Convention. 1990. Recommendation 4.1: Wetland restoration. Fourth meeting of the Conference of the Contracting Parties, Montreux, Switzerland, 27 June-4 July 1990. Gland, Switzerland, Ramsar Convention Secretariat.
Ramsar Convention. 2002. "Wetlands: water, life, and culture". Principles and guidelines for wetland restoration. Adopted by Resolution VIII. 16 (2002) of the Ramsar Convention. Eighth meeting of the Conference of the Contracting Parties to the Convention on Wetlands, Valencia, Spain, 18-26 November 2002. Gland, Switzerland, Ramsar Convention Secretariat.

Ramsar Convention. 2010. Designating Ramsar Sites: Strategic Framework and guidelines for the future development of the List of Wetlands of International Importance. 4th edition. Gland, Switzerland.

Ramsar Convention. 2011a. Water purification. Wetland ecosystem services factsheet 5. Gland, Switzerland, Ramsar Convention Secretariat.

Ramsar Convention. 2011b. Flood control. Wetland ecosystem services factsheet 1. Gland, Switzerland, Ramsar Convention Secretariat.

Ramsar Convention. 2011c. Shoreline stabilization and storm protection. Wetland ecosystem services factsheet 3. Gland, Switzerland, Ramsar Convention Secretariat.

Ramsar Convention. 2015a. State of the world's wetlands and their services to people: a compilation of recent analyses. Briefing Note 7. Gland, Switzerland, Ramsar Convention Secretariat.

Ramsar Convention. 2015b. Wetlands: source of sustainable livelihoods. Fact Sheet 7. Gland, Switzerland, Ramsar Convention Secretariat.

Ramsar Convention. 2015c. Keep peatlands wet for a better future. Fact Sheet 8 . Gland, Switzerland, Ramsar Convention Secretariat.

Ramsar Convention. 2016. An introduction to the Convention on Wetlands. Gland, Switzerland, Ramsar Convention Secretariat.

Ramsar Convention. 2018. Global Wetland Outlook: State of the World's Wetlands and their Services to People. Gland, Switzerland, Ramsar Convention Secretariat. (available at https://www.ramsar.org/sites/ default/files/flipbooks/ramsar_gwo_english_web.pdf).

Ran, Y., Deutsch, L., Lannerstad, M. \& Heinke, J. 2013. Rapidly intensified beef production in Uruguay: Impacts on water related ecosystem services. Aquatic Procedia, 1: 77-87.

Randazzo, C.L., Caggia, C. \& Neviani, E. 2009. Application of molecular approaches to study 
lactic acid bacteria in artisanal cheeses. Journal of Microbiological Methods, 78(1): 1-9.

Randolph, T.F., Schelling, E., Grace, D., Nicholson, C.F., Leroy, J.L., Cole, D.C., Demment, M.W., Omore, A., Zinsstag, J. \& Ruel, M. 2007. Invited review: Role of livestock in human nutrition and health for poverty reduction in developing countries. Journal of Animal Science, 85(11): 2788-2800.

RBG Kew (Royal Botanic Gardens Kew). 2017. The State of the World's Plants 2017. Kew, UK.

Reckling, M., Hecker, J.M., Bergkvist, G., Watson, C.A., Zander, P., Schläfke, N., Stoddard, F.L. et al. 2016.

A cropping system assessment framework - Evaluating effects of introducing legumes into crop rotations. European Journal of Agronomy, 76: 186-197.

Redo, D.J., Grau, H.R., Aide, T.M. \& Clark, M.L. 2012. Asymmetric forest transition driven by the interaction of socioeconomic development and environmental heterogeneity in Central America. PNAS, 109(23): 8839-8844

Reed, J. 2014. James Reed on integrated landscape approaches - YouTube. [Cited 14 May 2018]. https:// www.youtube.com/watch?v=vyvqpLrtOLs

Reed, J., Deakin, L. \& Sunderland, T. 2015. What are 'Integrated Landscape Approaches' and how effectively have they been implemented in the tropics: a systematic map protocol. Environmental Evidence, 4(1): 2.

Reed, J., van Vianen, J., Foli, S., Clendenning, J., Yang, K., MacDonald, M., Petrokofsky, G., Padoch, C. \& Sunderland, T. 2017. Trees for life: the ecosystem service contribution of trees to food production and livelihoods in the tropics. Forest Policy and Economics, 84: 62-71.

Regan, E.C., Santini, L., Ingwall-King, L., Hoffmann, M., Rondinini, C., Symes, A., Taylor, J. \& Butchart, S.H.M. 2015. Global trends in the status of bird and mammal pollinators. Conservation Letters, 8(6): 397-403.

Reganold, J. \& Wachter, J. 2016. Organic agriculture in the twenty-first century. Nature Plants, 2(2): 15221.

Reid, R. 2017. Developing farmer and community capacity in Agroforestry: is the Australian Master TreeGrower program transferable to other countries? Agroforestry Systems, 91(5): 847-865.

Reid, S., Chan, L. \& van Oers, M.M. 2014. Production of entomopathogenic viruses. In J., Morales-Ramos,
M. Guadalupe Rojas \& D. Shapiro-llan, eds. Mass production of beneficial organisms, pp. 437-482. Cambridge, USA, Academic Press.

Reij, C. \& Garrity, D. 2016. Scaling up farmer-managed natural regeneration in Africa to restore degraded landscapes. Biotropica, 48(6): 834-843.

Reij, C., Tappan, G. \& Smale, M. 2009a. Re-greening the Sahel: farmer-led innovation in Burkina Faso and Niger. In D.J. Spielman \& R. Pandya-Lorch, eds. Millions fed: proven successes in agricultural development, pp. 53-58. Washington, DC, International Food Policy Research Institute (IFPRI).

Reij, C., Tappan, G. \& Smale, M. 2009b.

Agroenvironmental transformation in the Sahel. Another kind of "Green Revolution". IFPRI Discussion Paper 00914. Washington, DC, International Food Policy Research Institute (IFPRI).

Renaud, F. \& Murti, R. 2013. Ecosystems and disaster risk reduction in the context of the Great East Japan Earthquake and Tsunami - a scoping study. Report to the Keindanren Nature Conservation Fund. Cambridge, UK and Gland, IUCN.

Renaud, F.G., Sudmeier-Rieux, K. \& Estrella, M., eds. 2013. The role of ecosystems in disaster risk reduction. Tokyo, UNU Press.

Research Council of Norway. 2010. New approach to combatting sea lice: wrasse to the rescue. [Cited 26 June 2018]. https://www.sciencedaily.com/ releases/2010/04/100423215021.htm

Reyes-Garcia, V., Menendez-Baceta, G., AceitunoMata, L., Acosta-Naranjo, R., Calvet-Mir, L., Dominguez, P., Garnatje, T. et al. 2015. From famine foods to delicatessen: interpreting trends in the use of wild edible plants through cultural ecosystem services. Ecological Economics, 120: 303-311.

Ricketts, T.H., Regetz, J., Steffan-Dewenter, I., Cunningham, S.A., Kremen, C., Bogdanski, A., Gemmill-Herren, B. et al. 2008. Landscape effects on crop pollination services: are there general patterns? Ecology Letters, 11(5): 499-515.

Riesenfeld, C.S., Schloss, P.D. \& Handelsman, J. 2004. Metagenomics: genomic analysis of microbial communities. Annual Review of Genetics, 38(1): 525-552

Rinderer, T.E., ed. 1986. Bee genetics and breeding. New York, USA, Academic Press. 
Rinderer, T.E., Harris, J.W., Hunt, G.J. \& de Guzman, L.I. 2010. Breeding for resistance to Varroa destructor in North America. Apidologie, 41: 409-424.

Robiglio, V. \& Reyes, M. 2016. Restoration through formalization? Assessing the potential of Peru's Agroforestry Concessions scheme to contribute to restoration in agricultural frontiers in the Amazon region. World Development Perspectives, 3: 42-46.

Robinson, T.P., Thornton, P., Franceschini, G., Kruska, R., Chiozza, F., Notenbaert, A., Cecchi, G. et al. 2011. Global livestock production systems. Rome, FAO and ILRI.

Robinson, T.P., William Wint, G.R., Conchedda, G., Van Boeckel, T.P., Ercoli, V., Palamara, E., Cinardi, G. et al. 2014. Mapping the global distribution of livestock. PLOS ONE, 9(5): e96084.

Robinson, T.P., Thornton, P., Franceschini, G., Kruska, R., Chiozza, F., Notenbaert, A., Cecchi, G. et al. 2018. Global distribution of ruminant livestock production systems V5 (5 minutes of arc). Harvard Dataverse. https://doi.org/10.7910/DVN/WPDSZE

Rocca, M. \& Messelink, G.J. 2017. Combining lacewings and parasitoids for biological control of foxglove aphids in sweet pepper. Journal of Applied Entomology, 141(5): 402-410.

Rochman, C.M. 2018. Microplastics research - from sink to source. Science, 360(6384): 28-29.

Rockström, J., Steffen, W., Noone, K., Persson, Å., Chapin, F.S., Lambin, E.F., Lenton, T.M. et al. 2009. A safe operating space for humanity. Nature, 461(7263): 472-475.

Rockström, J., Williams, J., Daily, G., Noble, A., Matthews, N., Gordon, L., Wetterstrand, H. et al. 2017. Sustainable intensification of agriculture for human prosperity and global sustainability. Ambio, 46(1): 4-17.

Rodrigues, A.S.L., Akcakaya, H.R., Andelman, S.J., Bakarr, M.I., Boitani, L., Brooks, T.M., Chanson, J.S. et al. 2004. Global gap analysis: priority regions for expanding the Global Protected-Area Network. BioScience, 54(12): 1092.

Rodríguez-Eugenio, N., McLaughlin, M. \& Pennock, D. 2018. Soil pollution: a hidden reality. Rome, FAO.

Rogers, S., Tarpy, D. \& Burrack, H. 2014. Bee species diversity enhances productivity and stability in a perennial crop. PLoS ONE, 9(5): e97307.
Rollin, O., Bretagnolle, V., Decourtye, A., Aptel, J., Michel, N., Vaissière, B.E. \& Henry, M. 2013 Differences of floral resource use between honey bees and wild bees in an intensive farming system. Agriculture, Ecosystems and Environment, 179: 76-78.

Rosenkranz, P., Aumeier, P. \& Ziegelmann, B. 2010. Biology and control of Varroa destructor. Journal of Invertebrate Pathology, 103: S96-S119.

Roshetko, J.M. \& Evans, D.O. 1999. Domestication of agroforestry trees in southeast Asia: proceedings of a regional workshop, Yogyakarta, Indonesia November 4-7, 1997. Nairobi, ICRAF.

Roshetko, J.M., Mulawarman \& Dianarto, A. 2008.

Tree seed procurement-diffusion pathways in Wonogiri and Ponorogo, Java. Small-scale Forestry, 7(3-4): 333-352.

Ross, E.M., Petrovski, S., Moate, P.J. \& Hayes, B.J. 2013. Metagenomics of rumen bacteriophage from thirteen lactating dairy cattle. BMC Microbiology, 13(242).

Rothenbuhler, W.C. 1964. Behaviour genetics of nest cleaning in honey bees. I. Responses of four inbred lines to disease-killed brood. Animal Behaviour, 12: $578-583$

Roulston, T.H. \& Goodell, K. 2011. The role of resources and risks in regulating wild bee populations. Annual Review of Entomology, 56(1): 293-312.

Rowland, D., Ickowitz, A., Powell, B., Nasi, R. \& Sunderland, T. 2017. Forest foods and healthy diets: quantifying the contributions. Environmental Conservation, 44(2): 102-114.

Roy, H. \& Migeon, A. 2010. Ladybeetles (Coccinellidae). Chapter 8.4. BioRisk, 4(1): 293-313.

Rundlöf, M., Bengtsson, J. \& Smith, H.G. 2008. Local and landscape effects of organic farming on butterfly species richness and abundance. Journal of Applied Ecology, 45: 813-820.

Runyan, C. \& D'Odorico, P. 2016. Global deforestation. New York, USA, Cambridge University Press.

Russi, D., ten Brink, P., Farmer, A., Badura, T., Coates, D., Förster, J., Kumar, R. et al. 2013. The economics of ecosystems and biodiversity for water and wetlands. London, IEEP, and Gland, Switzerland, Ramsar Convention Secretariat.

Rutgers, M., Schouten, A.J., Bloem, J., Van Eekeren, N., De Goede, R.G.M., Jagers op Akkerhuis, G.A.J.M., Van der Wal, A., Mulder, C., Brussaard, 
L. \& Breure, M. 2009. Biological measurements in a nationwide soil monitoring network. European Journal of Soil Science, 60: 820-832.

Rutgers, M., Schouten, A.J., Bloem, B.E., Dimmers, W.J., Van Eekeren, N., De Goede, R.G.M., Jagers op Akkerhuis, G.A.J.M. et al. 2014. Een indicatorsysteem voor ecosysteemdiensten van de bodem. Life support functions revisited. RIVM Rapport 2014-0145. Bilthoven, Netherlands, Rijksinstituut voor Volksgezondheid en Milieu (RIVM).

Ruthenberg, H. 1980. Farming systems in the tropics. Oxford, UK, Clarendon Press.

Saad, N., Delattre, C., Urdaci, M., Schmitter, J.M. \& Bressollier, P. 2013. An overview of the last advances in probiotic and prebiotic field. LWT - Food Science and Technology, 50(1): 1-16.

Sacandé, M., Jøker, D., Dulloo, M.E. \& Thomsen, K.A. 2004. Comparative storage biology of tropical tree seeds. Rome, International Plant Genetic Resources Institute (IPGRI).

Saenger, P., Gartside, D. \& Funge-Smith, S. 2013. A review of mangrove and seagrass ecosystems and their linkage to fisheries and fisheries management. RAP Publication 2013/09. Bangkok, FAO Regional Office for Asia and the Pacific. (available at http:// www.fao.org/docrep/018/i3355e/i3355e.pdf).

Sala, O.E., Yahdjian, L., Havstad, K. \& Aguiar, M.R. 2017. Rangeland ecosystem services: nature's supply and humans' demand. In D.D. Briske, ed. Rangeland systems: processes, management and challenges, pp. 467-489. Cham, Switzerland, Springer Nature.

Salmon Health Consortium \& PMRA. 2003.

Integrated pest management of sea lice in salmon aquaculture. Ottawa, Minister of Public Works and Government Services Canada.

Salton, J.C., Mercante, F.M., Tomazi, M., Zanatta, J.A., Concenço, G., Silva, W.M. \& Retore, M. 2014. Integrated crop-livestock system in tropical Brazil: toward a sustainable production system. Agriculture, Ecosystems and Environment, 190: 70-79.

Salvat, B. \& Allemand, D. 2009. Acidification and coral reefs. Scientific review. Noumea Cedex, New Caledonia, Coral Reef Initiatives for the Pacific.

Sambuichi, R.H.R., Vidal, D.B., Piasentin, F.B., Jardim, J.G., Viana, T.G., Menezes, A.A., Mello, D.L.N., Ahnert, D. \& Baligar, V.C. 2012. Cabruca agroforests in southern Bahia, Brazil: tree component, management practices and tree species conservation. Biodiversity and Conservation, 21(4): 1055-1077.

Sanchez, P.A. 2000. Delivering on the promise of agroforestry. Environment, Development and Sustainability, 1(3): 275-284.

Sanchez-Moreno, S., Castro, J., Alonso-Prados, E., Alonso-Prados, J.L., Garcia-Baudin, J.M., Talavera, M. \& Duran-Zuazo, V.H. 2015. Tillage and herbicide decrease soil biodiversity in olive orchards. Agronomy for Sustainable Development, 35(2): 691-700.

Sanderson, M.A., Goslee, S.C., Soder, K.J., Skinner, R.H., Tracy, B.F. \& Deak, A. 2007. Plant species diversity, ecosystem function, and pasture management - a perspective. Canadian Journal of Plant Science, 87(3): 479-487.

Sankaran, K.V. 2004. Giant African snail. Pest Fact Sheet. Asia-Pacific Forest Invasive Species Network. (available at http://www.fao.org/forestry/22071-0a7 14b2449327eb9db0f552d36311fdd7.pdf).

Sans, M. \& Meixner, T. 2016. The role of biodiversity in the hydrological cycle. In F. Poupeau, H. Gupta, A. Serrat-Capdevila, M.A. Sans-Fuentes, S. Harris \& L.G. Hayde, eds. Water bankruptcy in the land of plenty, pp. 249-288. Delft, Netherlands, UNESCO-IHE Institute for Water Education.

Sayer, J., Sunderland, T., Ghazoul, J., Pfund, J.-L., Sheil, D., Meijaard, E., Venter, M. et al. 2013. Ten principles for a landscape approach to reconciling agriculture, conservation, and other competing land uses. Proceedings of the National Academy of Sciences of the United States of America, 110(21): 8349-8356.

Sayre, N.F., Davis, D.K., Bestelmeyer, B. \& Williamson, J.C. 2017. Rangelands: where anthromes meet their limits. Land, 6(2): 31.

Scarcelli, N., Tostain, S., Mariac, C., Agbangla, C., Da, O., Berthaud, J. \& Pham, J.L. 2006. Genetic nature of yams (Dioscorea sp.) domesticated by farmers in Benin (West Africa). Genetic Resources and Crop Evolution, 53(1): 121-130.

Schaffelke, B., Collier, C., Kroon, F., Lough, J., McKenzie, L., Ronan, M., Uthicke, S. \& Brodie, J. 2017. Scientific Consensus Statement 2017. A synthesis of the science of land-based water quality impacts on the Great Barrier Reef, Chapter 1: The condition of coastal and marine ecosystems of the 
Great Barrier Reef. Brisbane, Australia, Government of Queensland.

Scherr, S.J., Shames, S. \& Friedman, R. 2013. Defining integrated landscape management for policy makers. Ecoagriculture Policy Focus, 10.

Schipper, J., Chanson, J.S., Chiozza, F., Cox, N.A., Hoffmann, M. Katariya, V., Lamoreau, J. et al. 2008. The status of the world's land and marine mammals: diversity, threat, and knowledge. Science, 322: 225-230.

Schippmann, U., Leaman, D.J. \& Cunningham, A.B. 2002. Impact of cultivation and gathering of medicinal plants on biodiversity: global trends and issues. In FAO, ed. Biodiversity and the ecosystem approach in agriculture, forestry and fisheries. Satellite event on the occasion of the Ninth Regular Session of the Commission on Genetic Resources for Food and Agriculture. Rome, 12-13 October 2002. Inter-Departmental Working Group on Biological Diversity for Food and Agriculture. Rome, FAO. (available at http://www.fao.org/docrep/005/ AA010E/AA010E00.HTM).

Schlatter, D., Kinkel, L., Thomashow, L., Weller, D. \& Paulitz, T. 2017. Disease suppressive soils: new insights from the soil microbiome. Phytopathology, 107(11): 1284-1297.

Schlüter, S., Weller, U. \& Vogel, H.J. 2011. Soilstructure development including seasonal dynamics in a long-term fertilization experiment. Journal of Plant Nutrition and Soil Science, 174(3): 395-403.

Schmithüsen, F. 2013. Three hundred years of applied sustainability in forestry. Unasylva, 64(240): 3-11.

Schramm, H.L.J. 1995. Uses and effects of cultured fishes in aquatic ecosystems. Bethesda, USA, American Fisheries Society.

Schulp, C.J.E., Thuiller, W. \& Verburg, P.H. 2014. Wild food in Europe: a synthesis of knowledge and data of terrestrial wild food as an ecosystem service. Ecological Economics, 105: 292-305.

Schulz, S., Brankatschk, R., Dumig, A., KogelKnabner, I., Schloter, M. \& Zeyer, J. 2013. The role of microorganisms at different stages of ecosystem development for soil formation. Biogeosciences, 10(6): 3983-3996.

Schutte, G., Eckerstorfer, M., Rastelli, V., Reichenbecher, W., Restrepo-Vassalli, S.,
Ruohonen-Lehto, M., Saucy, A.G.W. \& Mertens, M. 2017. Herbicide resistance and biodiversity: agronomic and environmental aspects of genetically modified herbicide-resistant plants. Environmental Sciences Europe, 29(1): 5.

Scoones, I. 1998. Sustainable rural livelihoods: a framework for analysis. IDS Working Paper 72. Brighton, UK, Institute of Development Studies.

Sears, R.R., Cronkleton, P., Polo Villanueva, F., Miranda Ruiz, M. \& Pérez-Ojeda del Arco, M. 2018. Farm-forestry in the Peruvian Amazon and the feasibility of its regulation through forest policy reform. Forest Policy and Economics, 87(November 2017): 49-58.

Sebiomo, A., Ogundero, V.W. \& Bankole, S.A. 2011. Effect of four herbicides on microbial population, organic matter and dehydrogenase activity. African Journal of Biotechnology, 10: 770-778.

Sedbrook, J.C., Phippen, W.B. \& Marks, M.D. 2014. New approaches to facilitate rapid domestication of a wild plant to an oilseed crop: example pennycress (Thlaspi arvense L.). Plant Science, 227: 122-132.

Seedorf, H., Kittelmann, S. \& Janssen, P.H. 2015. Few highly abundant operational taxonomic units dominate within rumen methanogenic archaeal species in New Zealand sheep and cattle. Applied Environmental Microbiology, 81: 986-995.

Seeley, T.D. 1985. Honeybee ecology. A study of adaptation in social life. Princeton, USA, Princeton University Press.

Sekercioglu, C.H. 2006. Increasing awareness of avian ecological function. Trends in Ecology and Evolution, 21(8): 464-471.

Sengonca, C., Kranz, J. \& Blaeser, P. 2002. Attractiveness of three weed species to polyphagous predators and their influence on aphid populations in adjacent lettuce cultivations. Journal of Pest Science, 75(6): 161-165.

SEPSA (Secretaría Ejecutiva de Planificación Sectorial Agropecuaria). 2017. Política nacional de semillas de Costa Rica 2017-2030. San José.

Serna-Chavez, H.M., Fierer, N. \& Van Bodegom, P.M. 2013. Global drivers and patterns of microbial abundance in soil. Global Ecology and Biogeography, 22(10): 1162-1172.

Seshadri, R., Leahy, S.C., Attwood, G.T., Teh, K.H., Lambie, S.C., Cookson, A.L., Eloe-Fadrosh, E.A. 
et al. 2018. Cultivation and sequencing of rumen microbiome members from the Hungate 1000 Collection. Nature Biotechnology, 36(4): 359-367.

Seto, K.C. \& Ramankutty, N. 2016. Hidden linkages between urbanization and food systems. Science, 352(6288): 943-945.

Settle, W.H., Ariawan, H., Astuti, E.T., Cahyana, W., Hakim, A.L., Hindayana, D. \& Lestari, A.S. 1996. Managing tropical rice pests through conservation of generalist natural enemies and alternate prey. Ecology, 77(7): 1975-1988.

Sevilla Guzmán, E. 2002. A perspectiva sociológica em agroecologia: uma sistematização de seus métodos e técnicas. Agroecologia e Desenvolvimento Rural Sustentável, 3: 18-28.

Shackelford, G., Steward, P.R., Benton, T.G., Kunin, W.E., Potts, S.G., Biesmeijer, J.C. \& Sait, S.M. 2013. Comparison of pollinators and natural enemies: a meta-analysis of landscape and local effects on abundance and richness in crops. Biological Reviews, 88(4): 1002-1021.

Shackleton, C.M. \& Shackleton, S.E. 2006. Household wealth status and natural resource use in the Kat River valley, South Africa. Ecological Economics, 57(2): 306-317.

Sharpley, A., Jarvie, H.P., Buda, A., May, L., Spears, B. \& Kleinman, P. 2013. Phosphorus legacy: overcoming the effects of past management practices to mitigate future water quality impairment. Journal of Environmental Quality, 42(5): 1308-1326.

Shi, W., Moon, C.D., Leahy, S.C., Kang, D., Froula, J., Kittelmann, S., Fan, C. et al. 2014. Methane yield phenotypes linked to differential gene expression in the sheep rumen microbiome. Genome Research, 24(9): 1517-1525.

Shiferaw, B.A., Okello, J. \& Reddy, R. V. 2009. Adoption and adaptation of natural resource management innovations in smallholder agriculture: reflections on key lessons and best practices. Environment, Development and Sustainability, 11(3): 601-619.

Shiferaw, B., Prasanna, B.M., Hellin, J. \& Bänziger, M. 2011. Crops that feed the world 6. Past successes and future challenges to the role played by maize in global food security. Food Security, 3: 307-327.

Short, F.T., Polidoro, B., Livingstone, S.R., Carpenter, K.E., Bandeira, S., Bujang, J.S., Calumpong, H.P. et al. 2011. Extinction risk assessment of the world's seagrass species. Biological Conservation, 144: 1961-1971.

Sileshi, G., Akinnifesi, F.K., Ajayi, O.C. \& Place, F. 2008. Meta-analysis of maize yield response to woody and herbaceous legumes in sub-Saharan Africa. Plant and Soil, 307(1-2): 1-19.

Simões, M.F., Pereira, L., Santos, C. \& Lima, N. 2013. Polyphasic identification and preservation of fungal diversity: concepts and applications. In A. Malik, E. Grohmann \& M. Alves, eds. Management of microbial resources in the environment, pp. 91-117. Dordrecht, Netherlands, Springer.

Simon, D. \& Benhamou, J.F. 2009. Rice-fish farming in Guinée Forestière - outcome of a rural development project. Field Actions Science Reports, 2: 49-56.

SINAC-MINAE. 2014. Quinto Informe Nacional al Convenio sobre Diversidad Biológica, Costa Rica. San José, Sistema Nacional de Áreas de Conservación, Ministerio de Ambiente y Energía, Washington, DC, GEF, and Washington, DC, UNDP.

Singh, V.P., Sinha, R.B., Nayak, D., Neufeldt, H., van Noordwijk, M. \& Rizvi, J. 2016. The national agroforestry policy of India: experiential learning in development and delivery phases. ICRAF Working Paper No. 240. New Delhi, ICRAF.

Sist, P., Dykstra, D. \& Fimbel, R. 1998. Reduced impact logging guidelines for lowland and hill dipterocarp forests in Indonesia. Bulungan Research Report Series No. 1, September 1998, Center for International Forestry Research, Bogor, Indonesia.

Six, J., Feller, C., Denef, K., Ogle, S.M., de Moraes, J.C. \& Albrecht, A. 2002. Soil organic matter, biota and aggregation in temperateand tropical soils Effects of no-tillage. Agronomie, 22(7-8): 755-775.

Six, J., Bossuyt, H., Degryze, S. \& Denef, K. 2004. A history of research on the link between (micro) aggregates, soil biota, and soil organic matter dynamics. Soil \& Tillage Research, 79(1): 7-31.

Skiftesvik, A.B., Blom, G., Agnalt, A.L., Durif, C.M.F., Browman, H.I., Bjelland, R.M., Harkestad, L.S., Farestveit, E., Paulsen, O.I., Fauske, M., Havelin, T., Johnsen, K. \& Mortensen, S. 2014. Wrasse (Labridae) as cleaner fish in salmonid aquaculture the Hardangerfjord as a case study. Marine Biology Research, 10(3): 289-300. 
Slaa, E.J., Sánchez Chaves, L.A., Malagodi-Braga, K. \& Hofstede, F.E. 2006. Stingless bees in applied pollination: practice and perspectives. Apidologie, 37: 293-315.

Slade, E.M., Riutta, T., Roslin, T. \& Tuomisto, H.L. 2016. The role of dung beetles in reducing greenhouse gas emissions from cattle farming. Scientific Reports, 6: 18140

Smaal, A.C., Kater, B.J. \& Wijsman, J. 2009. Introduction, establishment and expansion of the Pacific oyster Crassostrea gigas in the Oosterschelde (SW Netherlands). Helgoland Marine Research, 63: 75-83.

Smith, A., Snapp, S., Chikowo, R., Thorne, P., Bekunda, M. \& Glover, J. 2017. Measuring sustainable intensification in smallholder agroecosystems: a review. Global Food Security, 12: 127-138.

Smith, D. 2012. Culture Collections. In S. Saraslani and G.M. Gadd, eds. Advances in Applied Microbiology, 79: 73-118, Academic, Burlington.

Smith, D. \& Ryan, M.J. 2012. Implementing best practices and validation of cryopreservation techniques for microorganisms. Scientific World Journal, 2012: 805659.

Smith, D., Ryan, M. \& Day, J.G., eds. 2001. The UK National Culture Collection (UKNCC) biological resource: properties, maintenance and management. Egham, UK, The United Kingdom National Culture Collection.

Smith, G.C., Dueker, S.R., Clifford, A.J. \& Grivetti,

L.E. 1996. Carotenoid values of selected plant foods common to Southern Burkina Faso, West Africa. Ecology of Food and Nutrition, 35(1): 43-58.

Smith, J. 2012. Urban air quality. Grantham, UK, The Woodland Trust.

Smith, J., van de Kop, P., Reategui, K., Lombardi, I., Sabogal, C. \& Diaz, A. 1999. Dynamics of secondary forests in slash-and- burn farming: interactions among land use types in the Peruvian Amazon. Agriculture, Ecosystems \& Environment, 76(2-3): 85-98.

Smith, K.M., Loh, E.H., Rostal, M.K., ZambranaTorrelio, C.M., Mendiola, L. \& Daszak, P. 2014. Pathogens, pests, and economics: drivers of honey bee colony declines and losses. Ecohealth, 10(4): 434-445.

Snyder, C.S., Bruulsema, T.W., Jensen, T.L. \& Fixen, P.E. 2009. Review of greenhouse gas emissions from crop production systems and fertilizer management effects. Agriculture, Ecosystems \& Environment, 133(3): 247-266

Society for Range Management. 1998. Glossary of terms used in range management. A definition of terms commonly used in range management. Glossary Update Task Group, ed. Wheat Ridge, USA.

Solden, L.M., Hoyt, D.W., Collins, W.B., Plank, J.E., Daly, R.A., Hildebrand, E., Beavers, T.J. et al. 2017. New roles in hemicellulosic sugar fermentation for the uncultivated Bacteroidetes family BS11. The ISME Journal, 11(3): 691-703.

Somarriba, E., Suárez-Islas, A., Calero-Borge, W., Villota, A., Castillo, C., Vílchez, S., Deheuvels, O. \& Cerda, R. 2014. Cocoa-timber agroforestry systems: Theobroma cacao-Cordia alliodora in Central America. Agroforestry Systems, 88(6): 1001-1019.

Somerville, C., Cohen, M., Pantanella, E., Stankus, A. \& Lovatelli, A. 2014. Small-scale aquaponic food production. Integrated fish and plant farming. FAO Fisheries and Aquaculture Technical Paper No. 589. Rome, FAO. (available at http://www.fao.org/3/ai4021e.pdf).

Soo Bae, J., Won Joo, R. \& Kim, Y. 2012. Forest transition in South Korea: reality, path and drivers. Land Use Policy, 29: 198-207.

Sorrenti, S. 2017. Non-wood forest products in international statistical systems. Rome, FAO. (available at http://www.fao.org/3/a-i6731e.pdf).

Soto, D., White, P., Dempster, T., Silva, S.D., Flores, A., Karakassis, Y., Knapp, G. et al. 2012. Addressing aquaculture-fisheries interactions through the implementation of the ecosystem approach to aquaculture (EAA). In R.P. Subasinghe, J.R. Arthur, D.M. Bartley, S.S. De Silva, M. Halwart, N. Hishamunda, C.V. Mohan \& P. Sorgeloos, eds. Farming the waters for people and food, pp. 385-436. Proceedings of the Global Conference on Aquaculture 2010. Phuket, Thailand, 2225 September 2010. Rome, FAO, and Bangkok, Network of Aquaculture Centres in Asia-Pacific (available at http://www.fao.org/docrep/015/i2734e/ i2734e.pdf).

Spalding, M.D., Blasco, F. \& Field, C.D., eds. 1997 World mangrove atlas. Okinawa, Japan, The International Society for Mangrove Ecosystems. 
Spalding, M.D. Kainuma, M. \& Collins, L. 2010. World atlas of mangroves. London and Washington, DC, Earthscan.

Spalding, M.D., Brumbaugh, R.D. \& Landis, E. 2016. Atlas of ocean wealth - Breaking waves. Arlington, USA, The Nature Conservancy.

Spalding, M.D., Ravilious, C.A. \& Green, E.P. 2001. World atlas of coral reefs. Berkeley, USA, University of California Press.

SPC (Secretariat of the Pacific Community). 2015. A new song for coastal fisheries pathways to change: the Noumea Strategy. Noumea, New Caledonia.

Speed, R., Li, Y., Tickner, D., Huang, H., Naiman, R., Cao, J., Lei, G. et al. 2016. River restoration: a strategic approach to planning and management. Paris, UNESCO.

Spötter, A., Gupta, P., Mayer, M., Reinsch, N. \& Bienefeld, K. 2016. Genome-wide association study of a varroa-specific defense behavior in honeybees (Apis mellifera). Journal of Heredity, 107: 220-227.

Spracklen, D.V., Arnold, S.R. \& Taylor, C.M. 2012. Observations of increased tropical rainfall preceded by air passage over forests. Nature, 489(7415): 282-285.

Sradnick, A., Murugan, R., Oltmanns, M., Raupp, J. \& Joergensen, R.G. 2013. Changes in functional diversity of the soil microbial community in a heterogeneous sandy soil after long-term fertilization with cattle manure and mineral fertilizer. Applied Soil Ecology, 63: 23-28.

St-Pierre, B., Cersosimo, L.M., Ishaq, S.L. \&

Wright, A.D.G. 2015. Toward the identification of methanogenic archaeal groups as targets of methane mitigation in livestock animals. Frontiers in Microbiology, 6(776).

Stackebrandt, E., Smith, D., Casaregola, S., Varese, G., Verkleij, G., Lima, N. \& Bridge, P. 2014. Deposit of microbial strains in public service collections as part of the publication process to underpin good practice in science. SpringerPlus, 3: 1-4.

Stadlmayr, B., Charrondière, U.R., Eisenwagen, S., Jamnadass, R. \& Kehlenbeck, K. 2013. Nutrient composition of selected indigenous fruits from subSaharan Africa. Journal of the Science of Food and Agriculture, 93(11): 2627-2636.

Stapleton, J.J. \& DeVay, J.E. 1986. Soil solarization: a non-chemical approach for management of plant pathogens and pests. Crop Protection, 5(3): 190-198.

Stattersfield, A.J., Crosby, M.J., Long, A.J. \& Wege, D.C. 1998. Endemic Bird Areas of the World. Priorities for biodiversity conservation. BirdLife Conservation Series 7. Cambridge, UK, BirdLife International.

Steffen, W., Richardson, K., Rockström, J., Cornell, S.E., Fetzer, I., Bennett, E.M., Biggs, R. et al. 2015. Planetary boundaries: guiding human development on a changing planet. Science, 347(6223): 736-746.

Steinbeiss, S., Bessler, H., Engels, C., Temperton, V.M., Buchmann, N., Roscher, C., Kreutziger, Y., Baade, J., Habekost, M. \& Gleixner, G. 2008. Plant diversity positively affects short-term soil carbon storage in experimental grasslands. Global Change Biology, 14(12): 2937-2949.

Steinfeld, H., Mooney, H.A., Schneider, F. \& Neville, L.E., eds. 2010. Livestock in a changing landscape. Volume 1. Drivers, consequences, and responses. Washington, DC, Island Press.

Steinhauer, N., Rennich, K., Lee, K., Pettis, J., Tarpy, D.R., Rangel, J., Caron, D. et al. 2015. Colony Loss 2014-2015: Preliminary results. [Cited 11 April 2018]. https://beeinformed.org/results/colony-loss2014-2015-preliminary-results/

Stephen, W.P. 1960. Studies in the alkali bee (Nomia melanderi CKII.). Technical bulletin. Corvallis, USA, Agricultural Experiment Station, Oregon State College.

Stewart, J.B. 1977. Evaporation from the wet canopy of a pine forest. Water Resources Research, 13(6): 915-921.

Straub, C., Finke, D. \& Snyder, W. 2008. Are the conservation of natural enemy biodiversity and biological control compatible goals? Biological Control, 45(2): 225-237.

Strayer, D.L. \& Dudgeon, D. 2010. Freshwater biodiversity conservation: recent progress and future challenges. Journal of the North American Benthological Society, 29: 344-358.

Stritar, M.L., Schweitzer, J.A., Hart, S.C. \& Bailey, J.K. 2010. Introduced ungulate herbivore alters soil processes after fire. Biological Invasions, 12(2): 313-324.

Strohmaier, R., Rioux, J., Seggel, A., Meybeck, A., Bernoux, M., Salvatore, M., Miranda, J. \& Agostini, A. 2016. The agriculture sectors in the 
Intended Nationally Determined Contributions: analysis. Environment and Natural Resources Management Working Paper No. 62. Rome, FAO. (available at http://www.fao.org/3/a-i5687e.pdf).

Strong, A. \& Minnemeyer, S. 2015. Satellite data reveals state of the world's mangrove forests. Washington, DC, World Resources Institute. (available at https:// www.wri.org/blog/2015/02/satellite-data-revealsstate-world-s-mangrove-forests).

Struik, P.C., Kuyper, T.W., Brussaard, L. \& Leeuwis, C. 2014. Deconstructing and unpacking scientific controversies in intensification and sustainability: why the tensions in concepts and values? Current Opinion in Environmental Sustainability, 8: 80-88.

Stryamets, N.N., Elbakidze, M.M., Ceuterick, M.M., Angelstam, P.P. \& Axelsson, R.R. 2015. From economic survival to recreation: contemporary uses of wild food and medicine in rural Sweden, Ukraine and NW Russia. Journal of Ethnobiology and Ethnomedicine, 11: 53-71.

Stuart, T. 2009. Waste: uncovering the global food scandal. London, Penguin Books.

Stuart, S., Wilson, E., Mittermeier, R. \& Rodríguez, J. 2010. The barometer of life. Science, 328: 177-178.

Sudmeier-Rieux, K. 2013. Ecosystem approach to disaster risk reduction: basic concepts and recommendations to governments, with a special focus on Europe. Strasbourg, France, European and Mediterranean Major Hazards Agreement (EUR-OPA), Council of Europe.

Sudmeier-Rieux, K., Fernández, M., Gaillard, J., Guadagno, L. \& Jaboyedoff, M. 2017. Introduction: exploring linkages between disaster risk reduction, climate change adaptation, migration and sustainable development. In K. SudmeierRieux, M. Fernández, I. Penna, M. Jaboyedoff \& J. Gaillard, eds. Identifying emerging issues in disaster risk reduction, migration, climate change and sustainable development, pp. 1-11. Cham, Switzerland, Springer International Publishing.

Sumner, D.A. \& Boriss, H. 2006. Bee-conomics and the leap in pollination fees. Agricultural and Resource Economics Update, 9: 9-11.

Sunderland, T.C.H. 2011. Food security: why is biodiversity important? International Forestry Review, 13(3): 265-274.
Sundt, P., Schulze, P.-E. \& Syversen, F. 2014. Sources of microplastic-pollution to the marine environment. Report No. M-321|2015. Norwegian Environment Agency (Miljødirektoratet).

Sutcliffe, L.M.E., Batáry, P., Kormann, U., Báldi, A., Dicks, L.V., Herzon, I., Kleijn, D. et al. 2015. Harnessing the biodiversity value of Central and Eastern European farmland. Diversity and Distributions, 21(6): 722-730.

Swift, M.J. 1999. Towards the second paradigm: Integrated biological management of soil. In J.O. Siqueira, F.M.S. Moreira, A.S. Lopes, L.R.G. Guiherme, V. Faquin, A.E. Furtani Neto \& J.G. Cavalho, eds. Inter-relacao fertilidade, biologia do solo e nutricao de plantas, pp. 11-24. Lavras, Brazil, Sociedade Brasileira de Ciência do Solo, UFLA.

Szabó, N.D., Colla, S.R., Wagner, D.L., Gall, L.F. \& Kerr, J.T. 2012. Do pathogen spillover, pesticide use, or habitat loss explain recent North American bumblebee declines? Conservation Letters, 5(3): 232-239.

Tabacco, E., Piano, S., Revello-Chion, A. \& Borreani, G. 2011. Effect of Lactobacillus buchneri LN4637 and Lactobacillus buchneri LN40177 on the aerobic stability, fermentation products, and microbial populations of corn silage under farm conditions. Journal of Dairy Science, 94: 5589-5598.

Tamang, J.P. 2010. Diversity of fermented beverages and alcoholic drinks. In J.P. Tamang \& K. Kailasapathy, eds. Fermented foods and beverages of the world, pp. 97-138. Boca Raton, USA, CRC Press.

Tamang, J.P., Watanabe, K. \& Holzapfel, W.H. 2016. Review: diversity of microorganisms in global fermented foods and beverages. Frontiers in Microbiology, 7: 377.

Taylor, R., Herms, D., Cardina, J. \& Moore, R. 2018. Climate change and pest management: unanticipated consequences of trophic dislocation. Agronomy, 8(1): 7

Teasdale, J.R. 2003. Principles and practices of using cover crops in weed management systems. In $\mathrm{R}$. Labrada, ed. Weed management in developing countries, pp. 169-178. FAO Plant Production and Protection Paper 120, Add. 1. Rome, FAO.

TEEB (The Economics of Ecosystems and Biodiversity). 2010. The economics of ecosystems and biodiversity: ecological and economic foundations. P. Kumar, ed. London, Earthscan. 
TEEB. 2015. TEEB for agriculture \& food: an interim report. Geneva, Switzerland, UNEP.

TEEB. 2018. TEEB for agriculture \& food. Scientific and economic foundations. Geneva, UN Environment. (available at http://teebweb.org/agrifood/wp-content/ uploads/2018/10/TEEB_Foundations_October13.pdf).

Teetes, G. 1994. Adjusting crop management recommendations for insect-resistant crop varieties. Journal of Agricultural Entomology, 11(3): 191-200.

Teichroew, J.L., Xu, J., Ahrends, A., Huang, Z.Y., Tan, K. \& Xie, Z. 2017. Is China's unparalleled and understudied bee diversity at risk? Biological Conservation, 210: 19-28.

Teletchea, F. \& Fontaine, P. 2014. Levels of domestication in fish: implications for the sustainable future of aquaculture. Fish and Fisheries, 15(2): 181-195.

Tendall, D.M., Hellweg, S., Pfister, S., Huijbregts, M.A. \& Gaillard, G. 2014. Impacts of river water consumption on aquatic biodiversity in life cycle assessment - a proposed method, and a case study for Europe. Environmental Science \& Technology, 48(6): 3236-3244.

Teo, S.S. 2001. Evaluation of different duck varieties for the control of the golden apple snail (Pomacea canaliculata) in transplanted and direct seeded rice. Crop Protection, 20(7): 599-604.

Ter Hofstede, R. \& Rijnsdorp, A.D. 2011. Comparing demersal fish assemblages between periods of contrasting climate and fishing pressure. ICES Journal of Marine Science, 68: 1189-1198.

Thaman, R.R., Elevitch, C.R. \& Kennedy, J. 2006. Urban and homegarden agroforestry in the Pacific islands: current status and future prospects. In B.M. Kumar \& P.K.R. Nair, eds. Tropical homegardens: a time-tested example of sustainable agroforestry, pp. 25-41. Dordrecht, Netherlands, Springer.

Thapa, R.B. 2013. Field research report on food and nutrition security of the forest dependent households from the forests of Nepal. Bhaktapur, Nepal, Renaissance Society Nepal (RSN).

Thiele-Bruhn, S., Bloem, J., de Vries, F.T., Kalbitz, K. \& Wagg, C. 2012. Linking soil biodiversity and agricultural soil management. Current Opinion in Environmental Sustainability, 4(5): 523-528.

Thierfelder, C., Baudron, F., Setimela, P., Nyagumbo, I., Mupangwa, W., Mhlanga, B., Lee, N. \&
Gérard, B. 2018. Complementary practices supporting conservation agriculture in southern Africa. A review. Agronomy for Sustainable Development, 38(16).

Thilsted, S.H. 2012. The potential of nutrient-rich small fish species in aquaculture to improve human nutrition and health. In R.P. Subasinghe, J.R. Arthur, D.M. Bartley, S.S. De Silva, M. Halwart, N. Hishamunda, C. V Mohan \& P. Sorgeloos, eds. Proceedings of the Global Conference on Aquaculture 2010. Farming the Waters for People and Food, pp. 57-73. Rome, FAO, and Bangkok, Network of Aquaculture Centres in Asia-Pacific. (available at http://www.fao.org/docrep/015/i2734e/i2734e.pdf).

Thilsted, S.H., Thorne-Lyman, A., Webb, P., Bogard, J.R., Subasinghe, R., Phillips, M.J. \& Allison, E.H. 2016. Sustaining healthy diets: the role of capture fisheries and aquaculture for improving nutrition in the post-2015 era. Food Policy, 61: 126-131.

Thomas, P.A. 2016. Biological flora of the British Isles. Journal of Ecology, 104(4): 1158-1209.

Thondhlana, G. \& Muchapondwa, E. 2014 Dependence on environmental resources and implications for household welfare: evidence from the Kalahari drylands, South Africa. Ecological Economics, 108: 59-67.

Thornton, P.K. \& Herrero, M. 2001. Integrated croplivestock simulation models for scenario analysis and impact assessment. Agricultural Systems, 70(2-3): 581-602.

Thornton, P.K. \& Herrero, M. 2015. Adapting to climate change in the mixed crop and livestock farming systems in sub-Saharan Africa. Nature Climate Change, 5(9): 830-836.

Tiemann, L.K., Grandy, A.S., Atkinson, E.E., Marin-Spiotta, E. \& McDaniel, M.D. 2015 Crop rotational diversity enhances belowground communities and functions in an agroecosystem. Ecology Letters, 18: 761-771.

Tikhonovich, I.A. \& Provorov, N.A. 2011. Microbiology is the basis of sustainable agriculture: an opinion. Annals of Applied Biology, 159(2): 155-168.

Timmermann, C., Félix, G.F. \& Tittonell, P. 2018. Food sovereignty and consumer sovereignty: two antagonistic goals? Agroecology and Sustainable Food Systems, 42(3): 274-298. 
Tittonell, P. 2014. Ecological intensification of agriculture - sustainable by nature. Current Opinion in Environmental Sustainability, 8: 53-61.

Tittonell, P. \& Giller, K. 2013. When yield gaps are poverty traps: the paradigm of ecological intensification in African smallholder agriculture. Field Crops Research, 143: 76-90.

Tittonell, P., Klerkx, L., Baudron, F., Félix, G.F., Ruggia, A., van Apeldoorn, D., Dogliotti, S., Mapfumo, P. \& Rossing, W.A.H. 2016. Ecological intensification: local innovation to address global challenges. Sustainable Agriculture Reviews, 19: 1-34.

Titus, K.T., Haynes, T.L. \& Paragi., T.F. 2009. The importance of moose, caribou, deer and small game in the diet of Alaskans. In R.T. Watson, M. Fuller, M. Pokras \& W.G. Hunt, eds. Ingestion of lead from spent ammunition: implications for wildlife and humans, pp. 137-143. Boise, USA, The Peregrine Fund.

Toledo, Á. \& Burlingame, B. 2006. Biodiversity and nutrition: a common path toward global food security and sustainable development. Journal of Food Composition and Analysis, 19(6-7): 477-483.

Tomich, T.P., Brodt, S., Ferris, H., Galt, R., Horwath, W.R., Kebreab, E., Leveau, J.H.J. et al. 2011. Agroecology: a review from a global-change perspective. Annual Review of Environment and Resources, 36: 193-222.

Torchio, P.F. 1984. Field experiments with the pollinator species, Osmia lignaria propinqua Cresson (Hymenoptera: Megachilidae) in apple orchards. Journal of Kansas Entomological Society, 57(3): 517-521.

Torda, G., Donelson, J.M., Aranda, M., Barshis, D.J., Bay, L., Berumen, M.L., Bourne, D.G. et al. 2017. Rapid adaptive responses to climate change in corals. Nature Climate Change, 7: 627-636.

Tóth, G., Hermann, T., Da Silva, M.R. \& Montanarella, L. 2016. Heavy metals in agricultural soils of the European Union with implications for food safety. Environment International, 88: 299-309.

Treweek, J.R., Brown, C. \& Bubb, P. 2006. Assessing biodiversity impacts of trade: a review of challenges in the agriculture sector. Impact Assessment and Project Appraisal, 24(4): 299-309.

Tripp, R. 2005. The performance of low external input technology in agricultural development: a summary of three case studies. International Journal of Agricultural Sustainability, 3(3): 143-153.

Tripp, R. 2006. Is low external input technology contributing to sustainable agricultural development? Natural Resource Perspectives, 102: 1-4.

Troell, M. 2009. Integrated marine and brackishwater aquaculture in tropical regions: research, implementation and prospects. In D. Soto, ed. Integrated mariculture: a global review, pp. 47-131. FAO Fisheries and Aquaculture Technical Paper No. 529. Rome, FAO. (available at http://www.fao.org/ docrep/012/i1092e/i1092e00.htm).

Tscharntke, T., Klein, A.M., Kruess, A., SteffanDewenter, I. \& Thies, C. 2005. Landscape perspectives on agricultural intensification and biodiversity - ecosystem service management. Ecology Letters, 8: 857-874.

Tscharntke, T., Clough, Y., Wanger, T.C., Jackson, L., Motzke, I., Perfecto, I., Vandermeer, J. \& Whitbread, A. 2012. Global food security, biodiversity conservation and the future of agricultural intensification. Biological Conservation, 151(1): 53-59.

Tsegay, Z., Gizaw, B. \& Tefera, G. 2016. Isolation, identification and characterization of yeast species from Kocho and Bulla collected from Gedeo Zone, South Nation Nationality People Regional States. International Journal of Current Trends in Pharmacobiology and Medical Sciences Journal, 1(2): 37-44.

Tsiafouli, M.A., Thébault, E., Sgardelis, S.P., de Ruiter, P.C., van der Putten, W.H., Birkhofer, K., Hemerik, L. et al. 2015. Intensive agriculture reduces soil biodiversity across Europe. Global Change Biology, 21: 973-985.

Tugel, A.J., Lewandowski, A.M. \& Happe-vonArb, D., eds. 2000. Soil biology primer. Ankeny, USA, Soil and Water Conservation Society.

Turbé, A., De Toni, A., Benito, P., Lavelle, P., Lavelle, P., Ruiz, N., Van der Putten, W.H., Labouze, E. \& Mudgal, S. 2010. Soil biodiversity: functions, threats and tools for policy makers. Technical Report - 2010 - 049. European Commission DG ENV. Luxembourg, European Commission, Publications Office of the European Union.

Ugwuanyi, J.O., McNeil, B. \& Harvey, L.M. 2009 Production of protein-enriched feed using 
agroindustrial residues as substrates. In P. Singhnee'-Nigam \& A. Pandey, eds. Biotechnology for agroindustrial residues utilisation, pp. 77-103.

Dordrecht, Netherlands, Springer \& Business Media B.V.

UN Environment (United Nations Environment Programme). 2008. Water quality for ecosystems and human health. Second edition. Burlington, USA, United Nations Environment Programme Global Environment Monitoring System/Water Programme.

UN Environment. 2010. How ecosystems protect communities against natural hazards. [Cited 21 March 2018]. https://reliefweb.int/report/haiti/how-ecosystemsprotect-communities-against-natural-hazards

UN Environment. 2016a. Global gender and environment outlook. Nairobi, United Nations Environment Programme.

UN Environment. 2016b. Marine plastic debris and microplastics: global lessons and research to inspire action and guide policy chance. Nairobi, United Nations Environment Programme.

UN Environment. 2016c. A snapshot of the world's water quality: towards a global assessment. Nairobi, United Nations Environment Programme.

UN Environment \& Natural Justice. 2009. Bio-cultural community protocols - a community approach to ensuring the integrity of environmental law and policy. K. Bavikatte \& H. Jonas, eds. Nairobi, UNEP.

UNCCD (United Nations Convention to Combat Desertification). 2017. Global land outlook. Bonn, Germany, Secretariat of the UNCCD.

UNCED (United Nations Conference on Environment and Development). 1992. Rio Declaration of the United Nations Conference on Environment and Development. Report of the United Nations Conference on Environment and Development reprinted in 31 ILM 876). Annex 1. Rio de Janeiro, 3-14 June 1992. (available at http://www.un.org/ documents/ga/conf151/aconf15126-1annex1.htm).

UNCTAD (United Nations Conference on Trade and Development). 2012. Economic Development in Africa, Report 2012. Structural transformation and sustainable development in Africa. Geneva, Switzerland.

UNDP (United Nations Development Programme). 2013. Pescado Azul Women's Association of Isabela. Equator Initiative Case Study Series. New York, USA.
UNEP-WCMC (UN Environment World Conservation Monitoring Centre). 2006. In the front line: shoreline protection and other ecosystem services from mangroves and coral reefs. Cambridge, UK.

UNEP-WCMC. 2010. Global distribution of coral reefs. [Cited 22 March 2018]. http://data.unep-wcmc.org/ datasets/1

UNEP-WCMC. 2014. The importance of mangroves to people: a call to action. J. van Bochove, E. Sullivan \& T. Nakamura, eds. Cambridge, UK.

UNEP-WCMC. 2018. 2018 United Nations list of protected areas. Supplement on protected area management effectiveness. Cambridge, UK.

UNEP-WCMC \& IUCN. 2018. World Database on Protected Areas (WDPA). [Cited 8 December 2018]. https://www.protectedplanet.net/

UNEP-WCMC, IUCN \& NGS. 2018. Protected Planet Report 2018. Cambridge, UK, Gland, Switzerland, and Washington, DC.

UNEP-WCMC \& Short, F.T. 2017. Global distribution of seagrasses (version 5.0). Fourth update to the data layer used in Green and Short (2003). Cambridge, UK, UNEP-WCMC.

UNESCO (United Nations Educational, Scientific and Cultural Organization). 2016. A new roadmap for the Man and the Biosphere (MAB) Programme and its World Network of Biosphere Reserves. Paris.

UNESCO, WHO \& UN Environment. 1996. Water quality assessments - A guide to use of biota, sediments and water in environmental monitoring. D. Chapman, ed. Cambridge, UK, Cambridge University Press

UNESCO World Heritage Centre. 2015. The Operational Guidelines for the Implementation of the World Heritage Convention. Paris.

UN, European Commission, FAO, IMF, OECD \& World Bank. 2014a. System of environmental-economic accounting 2012 - central framework. New York, USA, UN.

UN, European Commission, FAO, IMF, OECD \& World Bank. 2014b. System of environmental-economic accounting 2012 - experimental ecosystem accounting. New York, USA, UN.

UNFCCC (United Nations Framework Convention on Climate Change). 2015. The Paris Agreement. Bonn, Germany (available at https://unfccc.int/sites/ default/files/english_paris_agreement.pdf). 
UNFCCC. 2017a. Glossary of climate change acronyms and terms. [Cited 21 March 2018]. https://unfccc.int/ process-and-meetings/the-convention/glossary-ofclimate-change-acronyms-and-terms

UNFCCC. 2017b. National Adaptation Programmes of Action. [Cited 6 April 2018]. http://unfccc.int/ national\%7B_\%7Dreports/napa/items/2719.php

UNFCCC. 2017c. FOCUS: Mitigation - NAMAs, Nationally Appropriate Mitigation Actions. [Cited 5 April 2018]. http://unfccc.int/focus/mitigation/items/7172.php

UNFCCC. 2017d. High level engagement day on resilience. Resilience-based climate solutions. 14 November 2017. Marrakech Partnership for Global Climate Action. Twenty-third Session of the Conference of the Parties to the United Nations Framework Convention on Climate Change, Bonn, Germany, 6-17 November 2017. (available at https:// unfccc.int/sites/default/files/cop_23_outcomeresilience_final.pdf)

UNFCCC. 2018. Intended Nationally Determined Contributions (INDCS). [Cited 6 April 2018]. http:// unfccc.int/focus/indc\%7B_\%7Dportal/items/8766.php

UNISDR (United Nations International Strategy for Disaster Reduction). 2009. UNISDR terminology on disaster risk reduction. Geneva, Switzerland.

United Nations. 2007. Non-legally binding instrument on all types of forests. Resolution adopted by the General Assembly on 17 December 2007. A/RES/62/98. New York, USA. (available at http:// www.fao.org/forestry/14717-03d86aa8c1a7426cf69 bf9e2f5023bb12.pdf).

United Nations. 2014a. World urbanization prospects the 2014 revision. Highlights. ST/ESA/SER.A/352. New York, USA, United Nations, Department of Economic and Social Affairs, Population Division.

United Nations. 2014b. New York Declaration on Forests. Declaration and action agenda. New York, USA.

United Nations. 2015a. Sendai Framework for Disaster Risk Reduction 2015-2030. New York, USA.

United Nations. 2015b. International arrangement on forests beyond 2015. Resolution adopted by the Economic and Social Council on 22 July 2015. E/RES/2015/33. New York, USA.

United Nations. 2016. Report of the open-ended intergovernmental expert working group on indicators and terminology relating to disaster risk reduction. Seventy-first Session, New York, USA, 1 December 2016. A/71/644.

United Nations. 2017a. World urbanization prospects: the 2017 revision. ESA/P/WP/248. New York, USA, UN, Department of Economic and Social Affairs, Population Division.

United Nations. 2017b. The First Global Integrated Marine Assessment: World Ocean Assessment I. Cambridge University Press.

United Nations. 2017c. United Nations Strategic Plan for Forests 2017-2030. Resolution adopted by the General Assembly on 27 April 2017. A/RES/71/285. New York, USA.

United Nations. 2018. World urbanization prospects: the 2018 revision. Key facts. New York, USA, United Nations, Department of Economic and Social Affairs Population Division. (available at https://population. un.org/wup/Publications/Files/WUP2018-KeyFacts.pdf).

UN-REDD Programme. 2018. UN-REDD How We Work. [Cited 6 April 2018]. http://www.un-redd.org/howwe-work

Unwin, M. 2011. The atlas of birds. Princeton, USA, Princeton University Press.

UPOV (International Union for the Protection of New Varieties of Plants). 1991. International Convention for the Protection of New Varieties of Plants. Geneva, Switzerland.

UPOV. 2017. Members of the International Union for the Protection of New Varieties of Plants. Geneva. [Cited 6 April 2018]. http://www.upov.int/export/sites/upov/ members/en/pdf/pub423.pdf

USDA (United States Department of Agriculture).

2012. Report on the National Stakeholders Conference on Honey Bee Health. National Honey Bee Health Stakeholder Conference Steering Committee, Alexandria, USA, 15-17 October 2012. Washington, DC.

\section{USFWS (United States Fish and Wildlife Service).} 2011. 2011 National survey of fishing, hunting, and wildlife-associated recreation. Washington, DC, US Department of the Interior, US Fish and Wildlife Service.

Uzunova-Doneva, T. \& Donev, T. 2005. Anabiosis and conservation of microorganisms. Journal of Culture Collections, 4: 17-28.

Vaessen, J. \& De Groot, J. 2003. Measuring outcome and impact of small development projects: lessons from 
the evaluation of a training project on low external input agriculture in Guatemala. IOB Discussion Papers 2003.04. Antwerp, Belgium, Universiteit Antwerpen, Institute of Development Policy (IOB).

Valette, D. 2014. Invisible helpers: women's views on the contributions of working donkeys and mules to their lives. London, The Brooke \& Voices for Women.

Valiela, I., Bowen, J. \& York, J. 2001. Mangrove forest: one of world's threatened major tropical environments. Bioscience, 51(10): 807-815.

Van Bruggen, A.H.C., He, M.M., Shin, K., Mai, V., Jeong, K.C., Finckh, M.R. \& Morris, J.G. 2018. Environmental and health effects of the herbicide glyphosate. Science of The Total Environment, 616-617: 255-268.

Vandecandelaere, E., Teyssier, C., Barjolle, D., Jeanneaux, P., Fournier, S. \& Beucherie, O. 2018. Strengthening sustainable food systems through geographical indications. Rome, Nutrition and Food Systems Division and the Investment Centre Division, under the FAO/EBRD cooperation. (available at http://www.fao.org/3//8737EN/i8737en.pdf).

Vandermeer, J.H. 2011. The ecology of agroecosystems Sudbury, USA, Jones \& Bartlett.

van der Zijpp, A.J., Verreth, J.A.J., Le Quang, T., van Mensvoort, M.E.F., Bosma, R.H. \& Beveridge, M.C.M., eds. 2007. Fishponds in farming systems. Wageningen, Netherlands, Wageningen Academic Publishers.

van Dijk, K.C., Lesschen, J.P. \& Oenema, O. 2016. Phosphorus flows and balances of the European Union Member States. Science of the Total Environment, 542: 1078-1093.

Van Dijk, T.C., Van Staalduinen, M.A., Van der Sluijs, J.P., Maxim, L., der Sluijs, J.P. Van, Krupke, C.H., Hunt, G.J. et al. 2013. Macro-invertebrate decline in surface water polluted with imidacloprid. PLOS ONE, 8(5): e62374.

Van Engelsdorp, D. \& Meixner, M.D. 2010. A historical review of managed honey bee populations in Europe and the United States and the factors that may affect them. Journal of Invertebrate Pathology, 103: 80-95.

van Hijum, S.A.F.T., Vaughan, E.E. \& Vogel, R.F. 2013. Application of state-of-art sequencing technologies to indigenous food fermentations. Current Opinion in Biotechnology, 24(2): 178-186. van Hintum, T.J.L., Brown, A.H.D., Spillane, C. \& Hodgkin, T. 2000. Core collections of plant genetic resources. IPGRI Technical Bulletin No. 3. Rome, International Plant Genetic Resources Institute (IPGRI).

van Hoof, L. 2015. Fisheries management, the ecosystem approach, regionalisation and the elephants in the room. Marine Policy, 60: 20-26.

van Huis, A., Van Itterbeeck, J., Klunder, H., Mertens, E., Halloran, A., Muir, G. \& Vantomme, P. 2013. Edible insects: future prospects for food and feed security. FAO Forestry Paper No. 171. Rome, FAO. (available at http://www.fao.org/docrep/018/ i3253e/i3253e.pdf).

Van Lavieren, H., Spalding, M., Alongi, D.M., Kainuma, M., Clüsener-Godt, M. \& Adeel, Z. 2012. Securing the future of mangroves. A policy brief. Hamilton, USA, United Nations University - Institute for Water, Environment and Health (UNU-INWEH).

Van Lenteren, J.C., Bolckmans, K., Köhl, J., Ravensberg, W.J. \& Urbaneja, A. 2018. Biological control using invertebrates and microorganisms: plenty of new opportunities. BioControl, 63(1): 39-59.

Van Noordwijk, M., Coe, R. \& Sinclair, F. 2016. Central hypotheses for the third agroforestry paradigm within a common definition. ICRAF Working Paper No. 233. Nairobi, ICRAF.

van Noordwijk, M., Bizard, V., Wangpakapattanawong, P., Tata, H.L., Villamor, G.B. \& Leimona, B. 2014. Tree cover transitions and food security in Southeast Asia. Global Food Security, 3(3-4): 200-208.

van Oosten, C. 2015. The landscape puzzle: an introduction to the landscape approach - YouTube. [Cited 15 May 2018]. https://www.youtube.com/ watch?v=fB5BiKCerF0

van Oppen, M.J.H., Puill-Stephan, E., Lundgren, P., De'ath, G. \& Bay, L.K. 2014. First generation fitness consequences of interpopulational hybridisation in a Great Barrier Reef coral and its implications for assisted migration management. Coral Reefs, 33: 607-611.

van Oppen, M.J.H., Oliver, J.K., Putnam, H.M. \& Gates, R.D. 2015. Building coral reef resilience through assisted evolution. PNAS, 112: 2307-2313.

van Oppen, M.J.H., Gates, R.D., Blackall, L.L., Cantin, N., Chakravarti, L.J., Chan, W.Y., Cormick, C. et al. 2017. Shifting paradigms in restoration of the 
world's coral reefs. Global Change Biology, 23(9): 3437-3448.

Van Tussenbroek, B.I., Villamil, N., MárquezGuzmán, J., Wong, R., Monroy-Velázquez, L.V. \& Solis-Weiss, V. 2016. Experimental evidence of pollination in marine flowers by invertebrate fauna. Nature Communications, 7: 12980.

Vanni, M.J. 2002. Nutrient recycling by animals in freshwater ecosystems. Annual Review of Ecology and Systematics, 33: 341-370.

Velarde, E., Ezcurra, E. \& Anderson, D.W. 2013. Seabird diets provide early warning of sardine fishery declines in the Gulf of California. Scientific Reports, 3: 1332.

Velasco, D., García-Llorente, M., Alonso, B., Dolera, A., Palomo, I., Iniesta-Arandia, I. \& Martín-López, B. 2015. Biodiversity conservation research challenges in the 21st century: a review of publishing trends in 2000 and 2011. Environmental Science \& Policy, 54: 90-96.

Veldman, J.W., Overbeck, G., Negreiros, D., Mahy, G., Le Stradic, S., Fernandes, G.W., Durigan, G., Buisson, E., Putz, F.E. \& Bond, W.J. 2015. Tyranny of trees in grassy biomes. Science, 347(6221): 484-485.

Veldman, J.W., Silveira, F.A.O., Fleischman, F.D., Ascarrunz, N.L. \& Durigan, G. 2017. Grassy biomes: an inconvenient reality for large-scale forest restoration? American Journal of Botany, 104: 649-651.

Velthuis, H.H.W. \& van Doorn, A. 2006. A century of advances in bumblebee domestication and the economic and environmental aspects of its commercialization for pollination. Apidologie, 37: 421-451.

Verdonschot, P.F.M., Spears, B.M., Feld, C.K., Brucet, S., Heizer-Vlek, H., Borja, A., Elliot, M., Kernan, M. \& Johnson, R.K. 2013. A comparative review of recovery processes in rivers, lakes, estuarine and coastal waters. Hydrobiologia, 704(1): 453-474.

Verones, F., Bartl, K., Pfisterl, S., Jiménez Vílchez, R. \& Hellweg, S. 2012. Modeling the local biodiversity impacts of agricultural water use: case study of a wetland in the coastal arid area of Peru. Environmental Science \& Technology, 46(9): 4966-4974.

Viana, B.F., da Encarnacao Coutinho, J.G., Garibaldi, L.A., Braganca Gastagnino, G.L., Peres
Gramacho, K. \& da Silva, F.O. 2014. Stingless bees further improve apple pollination and production. Journal of Pollination Ecology, 14: 261-269.

Vicens, N. \& Bosch, J. 2000. Pollinating efficacy of Osmia cornuta and Apis mellifera (Hymenoptera: Megachilidae, Apidae) on 'Red Delicious' apple. Environmental Entomology, 29(2): 235-240.

Vigne, J.D. 2011. The origins of animal domestication and husbandry: a major change in the history of humanity and the biosphere. Comptes rendus biologies, 334(3): 171-181.

Vilela, C.L.S., Bassin, J.P. \& Peixoto, R.S. 2018. Water contamination by endocrine disruptors: impacts, microbiological aspects and trends for environmental protection. Environmental Pollution, 235: 546-559.

Villanueva, A.B., Halewood, M. \& Noriega, I.L. 2017. Agricultural biodiversity in climate change adaptation planning. European Journal of Sustainable Development, 6(2).

Vinceti, B., Ickowitz, A., Powell, B., Kehlenbeck, K., Termote, C., Cogill, B. \& Hunter, D. 2013. The contributions of forest foods to sustainable diets. Unasylva, 64(241): 54-64.

Vira, B. \& Kontoleon, A. 2012. Dependence of the poor on biodiversity: which poor, what biodiversity? In D. Roe, J. Elliott, C. Sandbrook \& M. Walpole, eds. Biodiversity conservation and poverty alleviation: exploring the evidence for a link, pp. 52-84. Hoboken, USA, Wiley-Blackwell.

Vogel, S. 1969. Chiropterophilie in der neotropischen Flora. Neue Mitteilungen III. Flora, Abt. B., 158: 289-323.

Vorley, B. 2003. Food, Inc. Corporate concentration from farm to consumer. London, IIED and UK Food Group.

Waage, J. 2007. The sustainable management of biodiversity for biological control in food and agriculture: status and needs. Commission on Genetic Resources for Food and Agriculture. Background Study Paper No. 38. Rome, FAO. (available at http://www.fao.org/tempref/docrep/fao/ meeting/014/k0150e.pdf).

Wagg, C., Bender, S.F., Widmer, F. \& van der Heijden, M.G.A. 2014. Soil biodiversity and soil community composition determine ecosystem multifunctionality. PNAS, 111(14): 5266-5270.

Wagner, B., de Leeuw, J., Liyama, M. \& Jamnadass, R. 2013. Towards greater resilience in the drylands: 
trees are the key. Policy Brief No. 18. Nairobi, World Agroforestry Centre (ICRAF).

Waliyar, F., Collette, L. \& Kenmore, P.E. 2002. Beyond the gene horizon: sustaining agricultural productivity and enhancing livelihoods through optimization of crop and crop-associated biodiversity with emphasis on semi-arid tropical agroecosystems. Patencheru, India, International Crops Research Institute for the Semi-Arid Tropics.

Wallberg, A., Han, F., Wellhagen, G., Dahle, B., Kawata, M., Haddad, N., Simoes, Z.L.P. et al. 2014. A worldwide survey of genome sequence variation provides insight into the evolutionary history of the honeybee Apis mellifera. Nature Genetics, 46: 1081-1088.

Walters, B.B., Sabogal, C., Snook, L.K. \& De Almeida, E. 2005. Constraints and opportunities for better silvicultural practice in tropical forestry: an interdisciplinary approach. Forest Ecology and Management, 209(1-2): 3-18.

Wang, Q., Cheng, L., Liu, J., Li, Z., Xie, S., \& De Silva, S.S. 2015. Freshwater aquaculture in PR China: trends and prospects. Reviews in Aquaculture, 7(4): 283-302.

Wang, J., Guleria, S., Koffas, M.A.G. \& Yan, Y. 2016. Microbial production of value-added nutraceuticals. Current Opinion in Biotechnology, 37: 97-104.

Warner, K.D. 2005. Extending agroecology: grower participation in partnerships is key social learning. Renewable Agriculture and Food Systems, 21: 84-94.

Warren-Thomas, E., Dolman, P.M. \& Edwards, D.P. 2015. Increasing demand for natural rubber necessitates a robust sustainability initiative to mitigate impacts on tropical biodiversity. Conservation Letters, 8(4): 230-241.

Watson, J., Dudley, N., Segan, D. \& Hockings, M. 2014. The performance and potential of protected areas. Nature, 515: 67-73.

Waycott, M., Duarte, C., Carruthers, T.J.B., Orth, R.J., Dennison, W.C., Olyarnik, S., Calladine, A. et al. 2009. Accelerating loss of seagrasses across the globe threatens coastal ecosystems. PNAS, 106(30): 12377-12381.

Weatherdon, L.V., Fletcher, R., Jones, M.C., Kaschner, K., Sullivan, E., Tittensor, D.P., Mcowen, C. et al. 2017. Manual of marine and coastal datasets of biodiversity importance. December 2015 edition. 2017 extract. Cambridge, UK, UNEP-WCMC.

Webb, E.L. \& Kabir, M.E. 2009. Home gardening for tropical biodiversity conservation. Conservation Biology, 23(6): 1641-1644.

Welcomme, R.L. 1999. A review of a model for qualitative evaluation of exploitation levels in multispecies fisheries. Fisheries Management and Ecology, 6: 1-19.

Wenny, D.G., DeVault, T.L., Johnson, M.D., Kelly, D. \& Sekercioglu, C.H. 2011. The need to quantify ecosystem services provided by birds. The Auk, 128(1): 1-14.

Westwood, J.H., Charudattan, R., Duke, S.O., Fennimore, S.A., Marrone, P., Slaughter, D.C., Swanton, C. \& Zollinger, R. 2018. Weed management in 2050: perspectives on the future of weed science. Weed Science, 66(3): 275-285.

Wezel, A., Bellon, S., Dore, T., Francis, C., Vallod, D. \& David, C. 2009. Agroecology as a science, a movement and a practice: a review. Agronomy for Sustainable Development, 29: 503-515.

Wezel, A., Soboska, G., McClelland, S., Delespesse, F. \& Boisseau, A. 2015. The blurred boundaries of ecological, sustainable, and agroecological intensification: a review. Agronomy for Sustainable Development, 35: 1283-1295.

White, P. 2017. Aquaculture pollution: an overview of issues with a focus on China, Vietnam, and the Philippines. World Bank Regional Agricultural Pollution Study. Washington, DC, World Bank Group

White, R., Murray, S. \& Rohweder, M. 2000. Pilot analysis of global ecosystems: grassland ecosystems. Washington, DC, World Resources Institute.

White, S.L., Miller, W.L., Dowell, S.A., Bartron, M.L. \& Wagner, T. 2018. Limited hatchery introgressions into wild brook trout (Salvelinus fontinalis) populations despite reocurring stocking. Evolutionary Applications, 11(9): 1567-1581.

WHO (World Health Organization). 1994. Environmental health criteria 159: glyphosate. International Programme of Chemical Safety (IPCS). Geneva, Switzerland.

WHO. 2016. Frequently asked questions. Third WHO Urban Ambient Air Pollution Database. Updated May 2016. Geneva, Switzerland. 
WHO. 2018. Obesity and overweight. World Health Organization Fact Sheets. (available at http://www. who.int/news-room/fact-sheets/detail/obesity-andoverweight).

WHO \& CBD. 2015. Connecting global priorities: biodiversity and human health. A state of knowledge review. Geneva, Switzerland, World Health Organization, and Montreal, Canada, Secretariat of the Convention on Biological Diversity.

Wickneswari, R., Rajora, O.P., Finkeldey, R., Aravanopoulos, F., Bouvet, J.M., Vaillancourt, R.E., Kanashiro, M., Fady, B., Tomita, M. \& Vinson, C. 2014. Genetic effects of forest management practices: global synthesis and perspectives. Forest Ecology and Management, 333: 52-65.

Wijkström, U.N. 2012. Is feeding fish with fish a viable practice? In R.P. Subasinghe, J.R. Arthur, D.M. Bartley, S.S. De Silva, M. Halwart, N. Hishamunda, C.V. Mohan \& P. Sorgeloos, eds. Farming the waters for people and food, pp. 33-55. Proceedings of the Global Conference on Aquaculture 2010. Phuket, Thailand, 2225 September 2010. Rome, FAO, and Bangkok, Network of Aquaculture Centres in AsiaPacific. (available at http://www.fao.org/docrep/015/ i2734e/i2734e.pdf)

Wilkaniec, Z. \& Radajewska, B. 1997. Solitary bee Osmia rufa L. (Apoidea, Megachilidae) as pollinator of strawberry cultivated in an unheated plastic tunnel. Acta Horticulturae, 439: 489-493.

Wilkie, M.L., Holmgren, P. \& Castañeda, F., eds. 2003. Sustainable forest management and the ecosystem approach: two concepts, one goal. Forest Management Working Papers, Working Paper FM 25. Forest Resources Development Service, Forest Resources Division. Rome, FAO. (available at http:// www.fao.org/forestry/6417-0905522127db12a324c 6991d0a53571fa.pdf).

Wilkinson, C. 2008. Status of coral reefs of the world: 2008. Global Coral Reef Monitoring Network, and Townsville, Australia, Reef and Rainforest Research Centre.

Willer, H. \& Lernoud, J. 2018. The world of organic agriculture, statistics \& emerging trends 2018. Frick, Switzerland, Research Institute of Organic Agriculture (FiBL), and Bonn, Germany, IFOAMOrganics International.
Williams, A.G. \& Coleman, G.S. 1992. The rumen protozoa. Berlin, Springer Verlag

Williams, N.M., Crone, E.E., Roulston, T.H., Minckley، R.L., Packer, L. \& Potts, S.G. 2010. Ecological and life-history traits predict bee species responses to environmental disturbances. Biological Conservation, 143(10): 2280-2291.

Willis, B.L., Babcock, R.C., Harrison, P.L. \& Wallace, C.C. 1997. Experimental hybridisation and breeding incompatibilities within the mating systems of mass spawning reef corals. Coral Reefs, 16(Suppl.): 553-565.

Willis, B.L., van Oppen, M.J.H., Miller, D.J., Vollmer, S.V. \& Ayre, D.J. 2006. The role of hybridization in the evolution of reef corals. Annual Review of Ecology, Evolution \& Systematics, 37: 489-517.

Willmer, P. 2011. Pollination and floral ecology. Princeton, USA, Princeton University Press.

Winfree, R., Williams, N.M., Gaines, H., Ascher, J.S. \& Kremen, C. 2008. Wild bee pollinators provide the majority of crop visitation across land-use gradients in New Jersey and Pennsylvania, USA. Journal of Applied Ecology, 45(3): 793-802.

Winfree, R., Reilly, J.R., Bartomeus, I., Cariveau, D.P., Williams, N.M. \& Gibbs, J. 2018. Species turnover promotes the importance of bee diversity for crop pollination at regional scales. Science, 359(6377): 791-793.

Winston, M.L. 1987. The biology of the honey bee. Cambridge, USA, Harvard University Press.

WIPO (World Intellectual Property Organization). 2017. Geographical Indications: An introduction. Geneva, Switzerland.

Wittenberg, R. \& Cock, M.J.W. 2001. How to address one of the greatest threats to biodiversity: a toolkit of best prevention and management practices. Wallingford, UK, CABI.

Wolmarans, K. \& Swart, W.J. 2014. Influence of glyphosate, other herbicides and genetically modified herbicide-resistant crops on soil microbiota: a review. South African Journal of Plant and Soil, 31(4): 177-186.

Woodland Trust. 2012. Woodwise: conservation grazing in woodland management. Grantham, UK, The Woodland Trust

Woodward, G., Gessner, M.O., Giller, P.S., Gulis, V., Hladyz, S., Lecerf, A., Malmqvist, B. et al. 2012. 
Continental-scale effects of nutrient pollution on stream ecosystem functioning. Science, 336(6087): $1438-1440$

Worku, B.B., Woldegiorgis, A.Z. \& Gemeda, H.F. 2016. Indigenous processing methods of cheka: a traditional fermented beverage in Southwestern Ethiopia. Journal of Food Processing \& Technology, 7: 540.

World Air Quality. 2018. World-wide air quality monitoring data coverage. [Cited 29 October 2018]. http://aqicn.org/sources/

World Bank. 2008. World Development Report 2008: Agriculture for development. Washington, DC. (available at https://siteresources.worldbank.org/ INTWDR2008/Resources/WDR_00_book.pdf).

World Bank. 2010. Valuing protected areas. Washington, DC.

World Bank. 2012a. Landscapes : Frequently Asked Questions (FAQ) (English). Rio+20: a framework for action for sustainable development. Washington, DC. (available at http://documents.worldbank.org/ curated/en/468091468153281587/LandscapesFrequently-Asked-Questions-FAQ).

World Bank. 2012b. Hidden harvest: The global contribution of capture fisheries. World Bank, FAO, World Fish Center. 92 pp.

World Bank. 2018. Personal remittances, received (\% of GDP). [Cited 16 May 2018]. https://data.worldbank. org/indicator/BX.TRF.PWKR.DT.GD.ZS

World Bank, FAO \& IFAD. 2009. Gender in agriculture sourcebook. Washington, DC.

WoRMS. 2018. World Register of Marine Species. [Cited 8 May 2018]. http://www.marinespecies.org at VLIZ

Wortley, L., Hero, J.-M. \& Howes, M. 2013. Evaluating ecological restoration success: a review of the literature. Restoration Ecology, 21(5): 537-543.

Wraight, S. \& Ramos, M. 2002. Application parameters affecting field efficacy of Beauveria bassiana foliar treatments against Colorado potato beetle Leptinotarsa decemlineata. Biological Control, 23(2): 164-178.

WRI (World Resources Institute). 2014. Atlas of forest and landscape restoration opportunities. Washington, DC.

WRI, UNDP, UN Environment \& World Bank. 2000. World Resources 2000-2001, People and Ecosystems: The Fraying Web of Life. Washington, DC.
Wright, J.S., Fu, R., Worden, J.R., Chakraborty, S., Clinton, N.E., Risi, C., Sun, Y. \& Yin, L. 2017. Rainforest-initiated wet season onset over the southern Amazon. Proceedings of the National Academy of Sciences, 114(32): 8481-8486.

Wrona, F.J., Prowse, T.D., Reist, J.D., Hobbie, J.E., Lévesque, L.M. \& Vincent, W.F. 2006. Climate change effects on aquatic biota, ecosystem structure and function. Ambio, 35(7): 359-369.

Wu, X.M., Long, Y.H., Li, Y.R., Liu, R.X. \& Li, M. 2014. Effects of napropamide on microbiological characteristics of tobacco rhizosphere soil and its dissipation. Journal of Soil Science and Plant Nutrition, 14(1): 151-159.

Wuana, R.A. \& Okieimen, F.E. 2011. Heavy metals in contaminated soils: a review of sources, chemistry, risks and best available strategies for remediation. ISRN Ecology, 2011: 1-20.

WWAP (United Nations World Water Assessment Programme). 2017. The United Nations World Water Development Report 2017. Wastewater: the untapped resource. Paris, UNESCO.

WWAP \& UN-Water. 2018. The United Nations World Water Development Report 2018: nature-based solutions for water. Paris, UNESCO.

WWF. 2004. Rivers at risk - Dams and the future of freshwater ecosystems. Surrey, UK, WWF Dams Initiative.

WWF. 2015. Illegal fishing. Which fish species are at highest risk from illegal and unreported fishing? Washington, DC.

WWF International \& Institute for Environmental Studies. 2004. Living waters. Conserving the source of life. The economic values of the world's wetlands. Gland, Switzerland, WWF International, and Amsterdam, Institute for Environmental Studies.

Yang, R. \& Keding, G.B. 2009. Nutritional contributions of important African indigenous vegetables. In C.M Shackleton, M.W. Pasquini \& A.W. Drescher, eds. African indigenous vegetables in African agriculture, pp. 105-135. London, Earthscan.

Yang, J., McBride, J., Zhou, J. \& Sun, Z. 2005. The urban forest in Beijing and its role in air pollution reduction. Urban Forestry \& Urban Greening, 3: 65-78.

Yaninek, S. \& Hanna, R. 2003. Cassave green mite in Africa - a unique example of successful classical 
biological control of a mite pest on a continental scale. Biological control in IPM systems in Africa, pp. 61-75. Wallingford, UK, CABI.

Yates, K.K., Rogers, C.S., Herlan, J.J., Brooks, J.R., Smiley, N.A. \& Larson, R.A. 2014. Diverse coral communities in mangrove habitats suggest a novel refuge from climate change. Biogeosciences, 11: 4321-4337.

Yengoh, G.T. \& Svensson, M.G.E. 2008. Low external input strategies for sustainable small-scale farming in Kenya: a systems dynamic approach. In B.C. Dangerfield, ed. Proceedings of the 26th International Conference. July 20 - July 24, 2008 Athens, Greece. Albany, USA, System Dynamics Society.

Yu, Y., Stomph, T.J., Makowski, D. \& van der Werf, W. 2015. Temporal niche differentiation increases the land equivalent ratio of annual intercrops: a meta-analysis. Field Crops Research, 184: 133-144.

Zander, S. V, Jacobs, K. \& Hawkins, H.-J. 2016. The impact of crop rotation on soil microbial diversity: a meta-analysis. Pedobiologia, 59(4): 215-223.

Zeder, M. 2012. Pathways to animal domestication. In P. Gepts, T.R. Famula, R.L. Bettinger, S.B. Brush, A.B. Damania, P.E. McGuire \& C.O. Qualset, eds. Biodiversity in agriculture: domestication, evolution, and sustainability, pp. 227-259. Cambridge, UK, Cambridge University Press.

Zehnder, G., Gurr, G., Kühne, S., Wade, M., Wratten, S. \& Wyss, E. 2007. Arthropod pest management in organic crops. Annual Review of Entomology, 52(1): $57-80$

Zeilinger, S., Gruber, S., Bansal, R. \& Mukherjee, P.K. 2016. Secondary metabolism in Trichoderma Chemistry meets genomics. Fungal Biology Reviews, 30(2): 74-90.
Zhang, Y., Ma, Y., Wan, P., Mu, L. \& Li, G. 2013. Bacillus thuringiensis insecticidal crystal proteins affect lifespan and reproductive performance of Helicoverpa armigera and Spodoptera exigua adults. Journal of Economical Entomology, 106(2): 614-662.

Zhang, Y., Cao, C., Guo, L., Wu, Q. \& Cui, Z. 2015. Soil properties, bacterial community composition, and metabolic diversity responses to soil salinization of a semiarid grassland in northeast China. Journal of Soil and Water Conservation, 70(2): 110-120.

Ziegler, M., Seneca, F.O., Yum, L.K., Palumbi, S.R. \& Voolstra, C.R. 2017. Bacterial community dynamics are linked to patterns of coral heat tolerance. Nature Communications, 8: 14213.

Zimmermann, H.G., Moran, V.C. \& Hoffmann, J.F. 2000. The renowned cactus moth, Cactoblastis cactorum: its natural history and threat to native Opuntia floras in Mexico and the United States of America. Diversity and Distributions, 6: 259-269.

Zomer, R.J., Trabucco, A., Coe, R., Place, F., van Noorwijk, M. \& Xu, J. 2014. Trees on farms: an update and reanalysis of agroforestry's global extent and socio-ecological characteristics. ICRAF Working Paper No. 179. Nairobi, ICRAF.

Zongo, S. 2011. Analyse de la contribution de l'opération «fosses fumières» à l'amélioration des rendements des cultures cerealieres dans les Regions du Nord, du Centre-Ouest et du Sud-Ouest du Burkina Faso. Bobo-Dioulasso, Burkina Faso, Département de Vulgarisation Agricole, Université technique de Bobo-Dioulasso.

ZSL (Zoological Society of London). 2017. International Zoo Yearbook. Volume 51. D. Field, C. Lees, K. Leus, R. Miller, P. Pullen \& A. Rubel, eds. London. 




\section{The State of the World's Biodiversity for Food and Agriculture presents}

the first global assessment of biodiversity for food and agriculture worldwide. Biodiversity for food and agriculture is the diversity of plants, animals and micro-organisms at genetic, species and ecosystem levels, present in and around crop, livestock, forest and aquatic production systems. It is essential to the structure, functions and processes of these systems, to livelihoods and food security, and to the supply of a wide range of ecosystem services. It has been managed or influenced by farmers, livestock keepers, forest dwellers, fish farmers and fisherfolk for hundreds of generations.

Prepared through a participatory, country-driven process, the report draws on information from 91 country reports to provide a description of the roles and importance of biodiversity for food and agriculture, the drivers of change affecting it and its current status and trends. It describes the state of efforts to promote the sustainable use and conservation of biodiversity for food and agriculture, including through the development of supporting policies, legal frameworks, institutions and capacities. It concludes with a discussion of needs and challenges in the future management of biodiversity for food and agriculture.

The report complements other global assessments prepared under the auspices of the Commission on Genetic Resources for Food and Agriculture, which have focused on the state of genetic resources within particular sectors of food and agriculture. 